\title{
On the development of multipurpose skeletal core combustion chemical kinetic
}

\section{mechanisms}

Quan-De Wang a,*, Snehasish Panigrahy, ${ }^{\mathrm{b}, *}$, Shiyou Yang ${ }^{\mathrm{c}}$, Sergio Martinez ${ }^{\mathrm{b}}$, Jinhu Liang ${ }^{\mathrm{d}}$, Henry J.

\section{Curran ${ }^{\mathrm{b}}$}

${ }^{a}$ Low Carbon Energy Institute and School of Chemical Engineering, China University of Mining and

Technology, Xuzhou, 221008, People's Republic of China

${ }^{\mathrm{b}}$ Combustion Chemistry Centre, School of Chemistry, Ryan Institute, MaREI, National University of Ireland Galway, University Road, Galway, H91 TK33, Ireland

${ }^{\mathrm{c}}$ Research and Advanced Engineering, Ford Motor Company, 2101 Village Road, Dearborn, MI 48124, USA

d School of Environmental and Safety Engineering, North University of China, Taiyuan, 030051, People's

Republic of China

\section{Table of Contents}

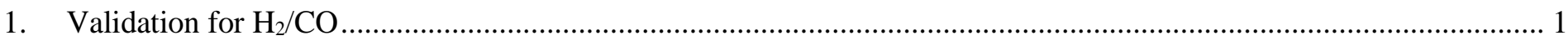

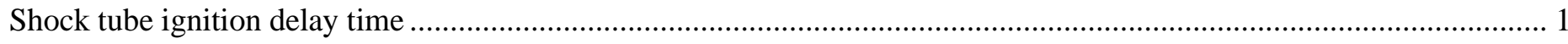

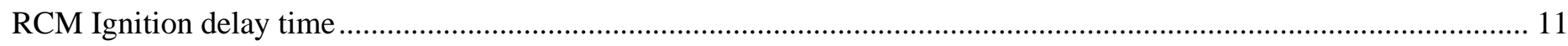

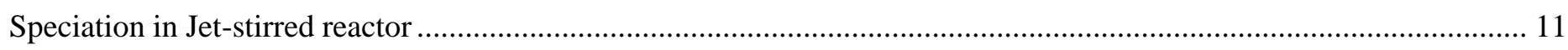

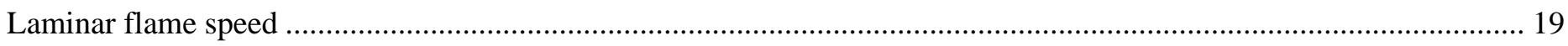

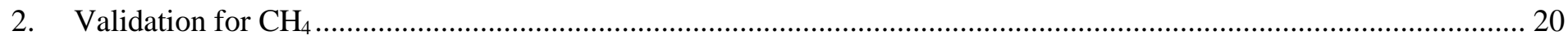

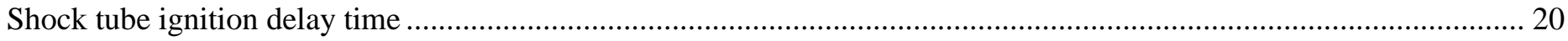

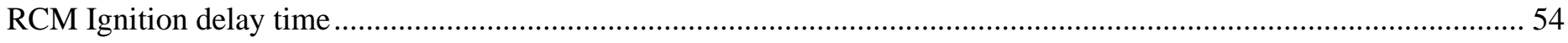

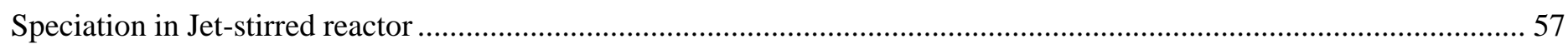

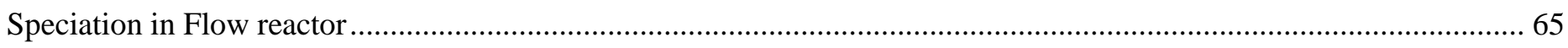

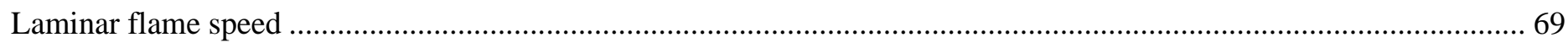

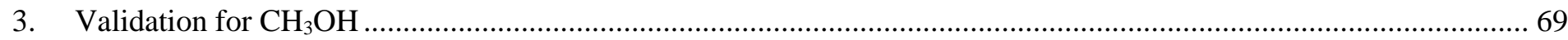

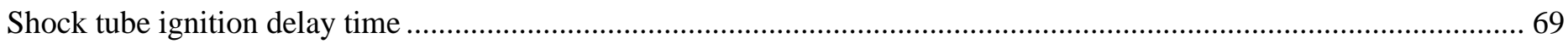

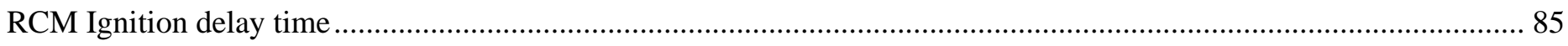

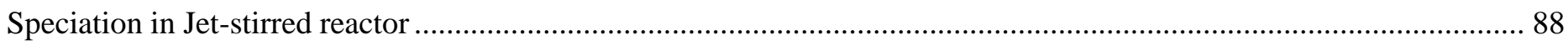

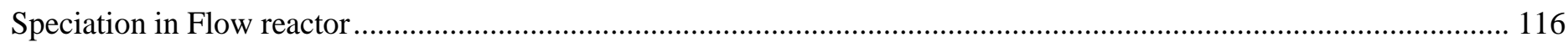

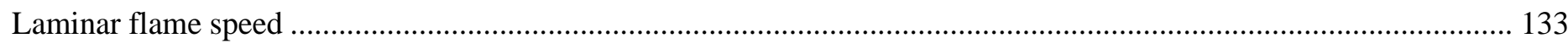




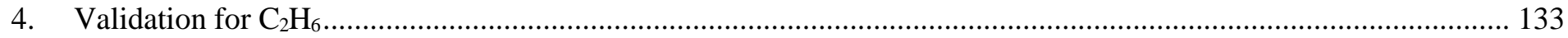

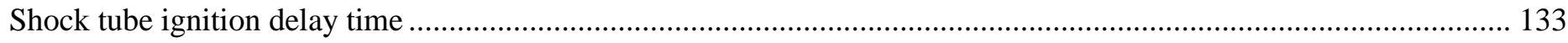

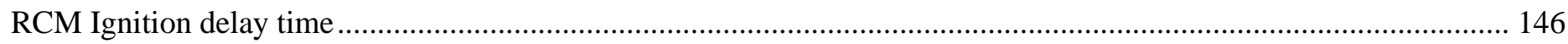

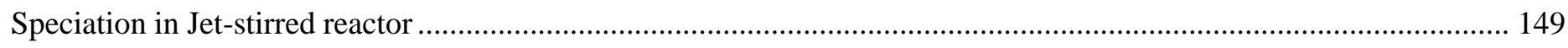

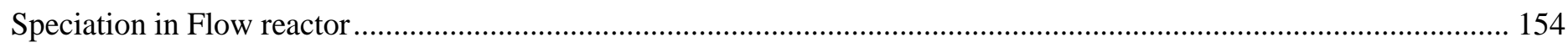

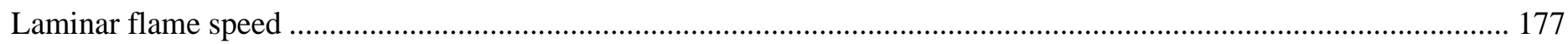

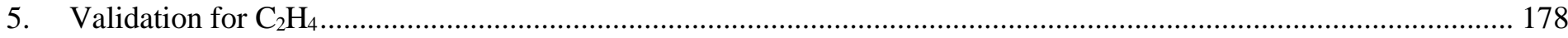

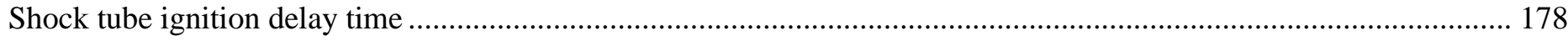

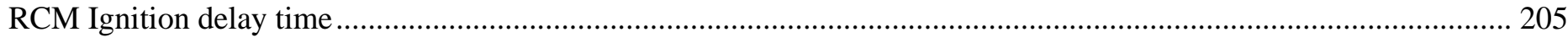

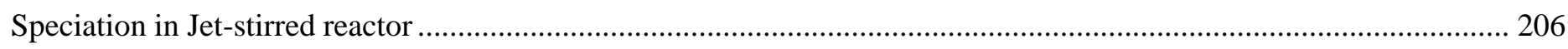

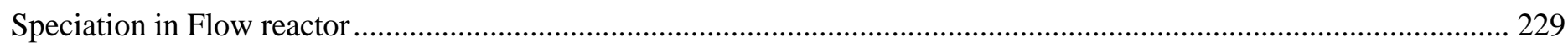

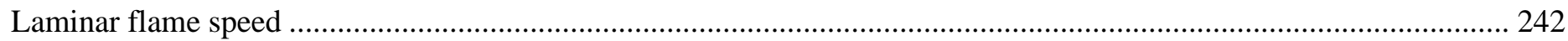

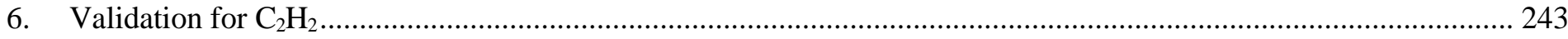

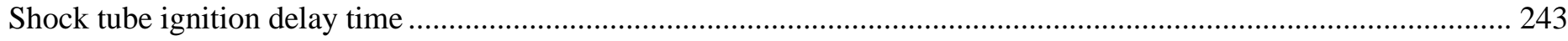

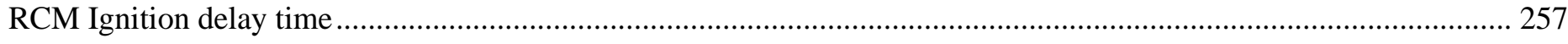

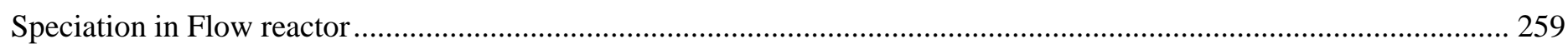

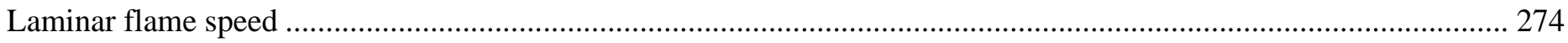

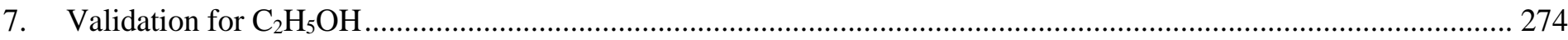

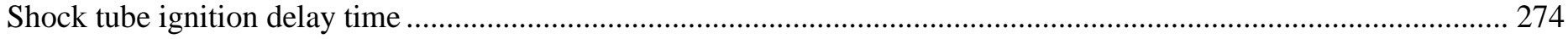

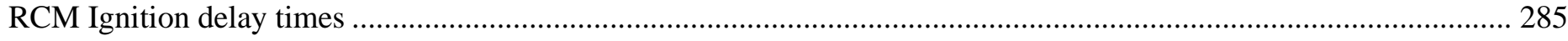

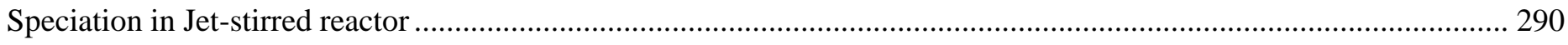

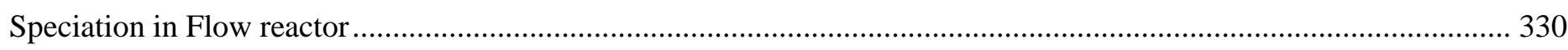

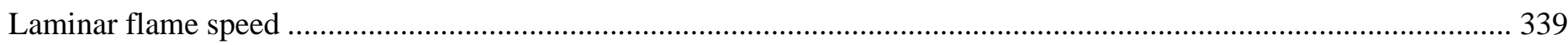

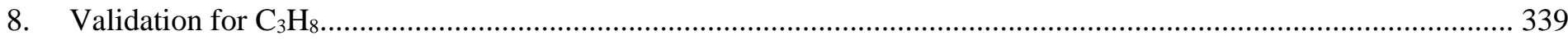

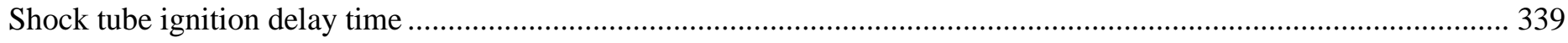

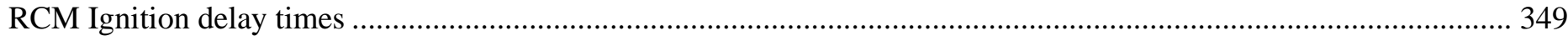

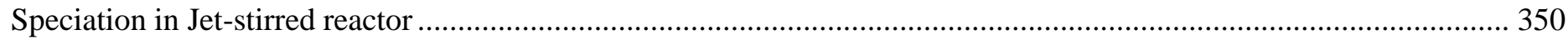

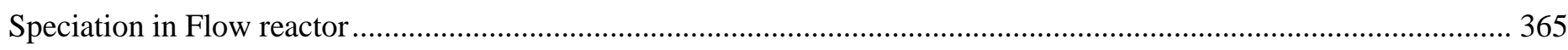

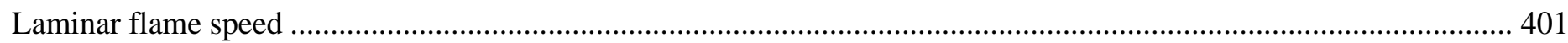

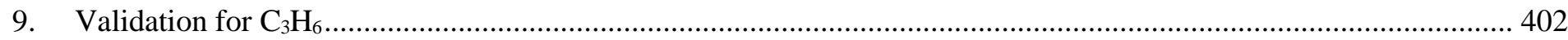

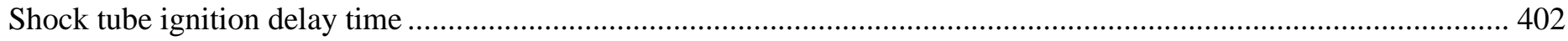




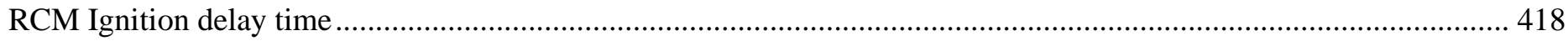

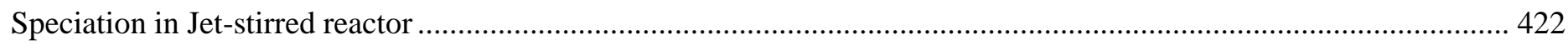

Speciation in Flow reactor

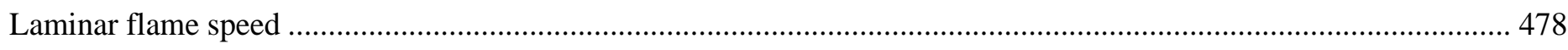

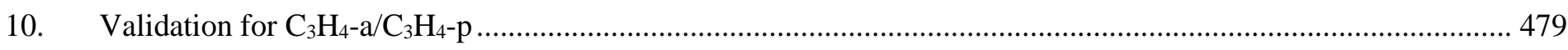

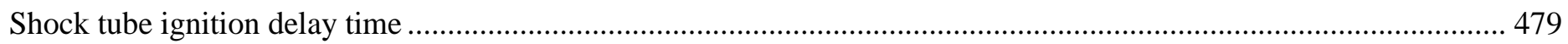

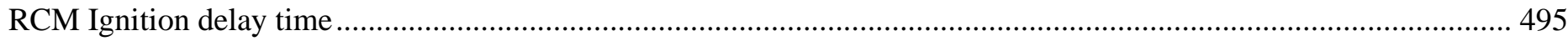

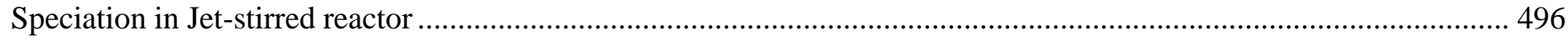

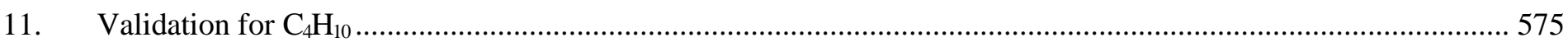

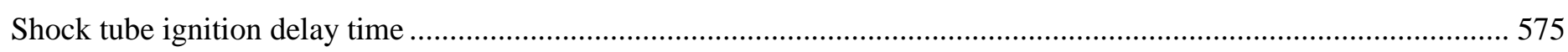

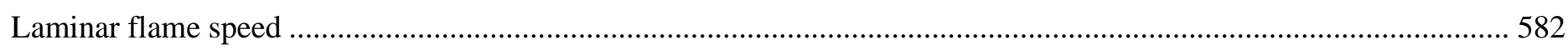

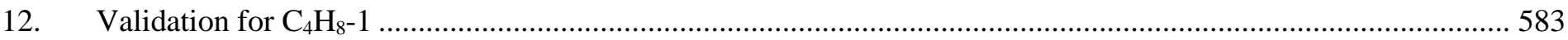

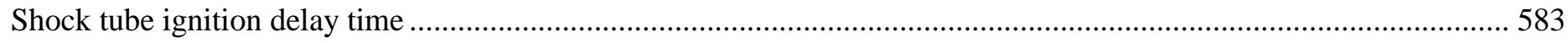

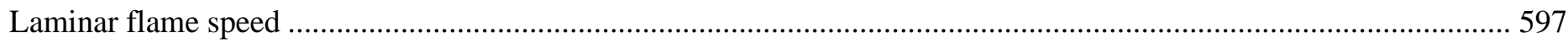

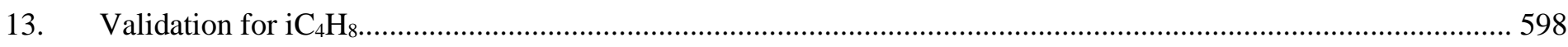

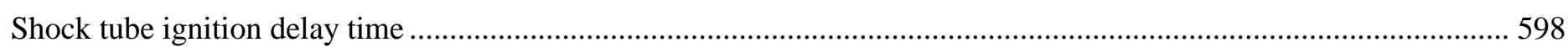

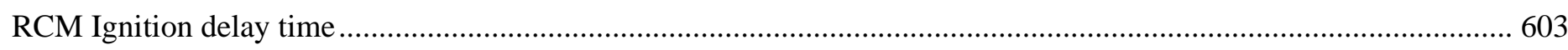

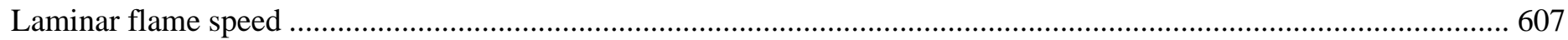

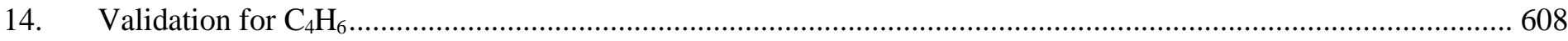

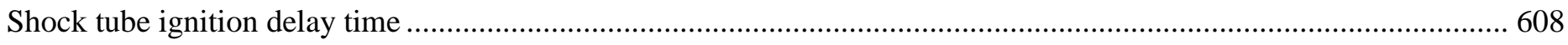

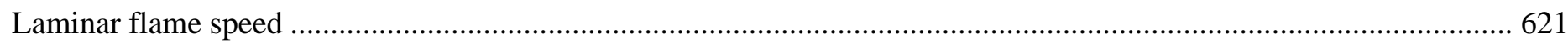




\section{Validation for $\mathrm{H}_{2} / \mathrm{CO}$ :}

\section{Shock tube ignition delay time}

1.1) Shao, J., Choudhary, R., Davidson, D. F., Hanson, R. K., Barak, S., \& Vasu, S. Proceedings of the Combustion Institute, 37(4) (2019) 4555-4562.

$85.0 \% \mathrm{CO}_{2}$

$5.0 \% \mathrm{O}_{2}, 85.0 \% \mathrm{CO}_{2}, 85.0 \% \mathrm{Ar}$

$\phi=1.0,270.57 \mathrm{~atm}$

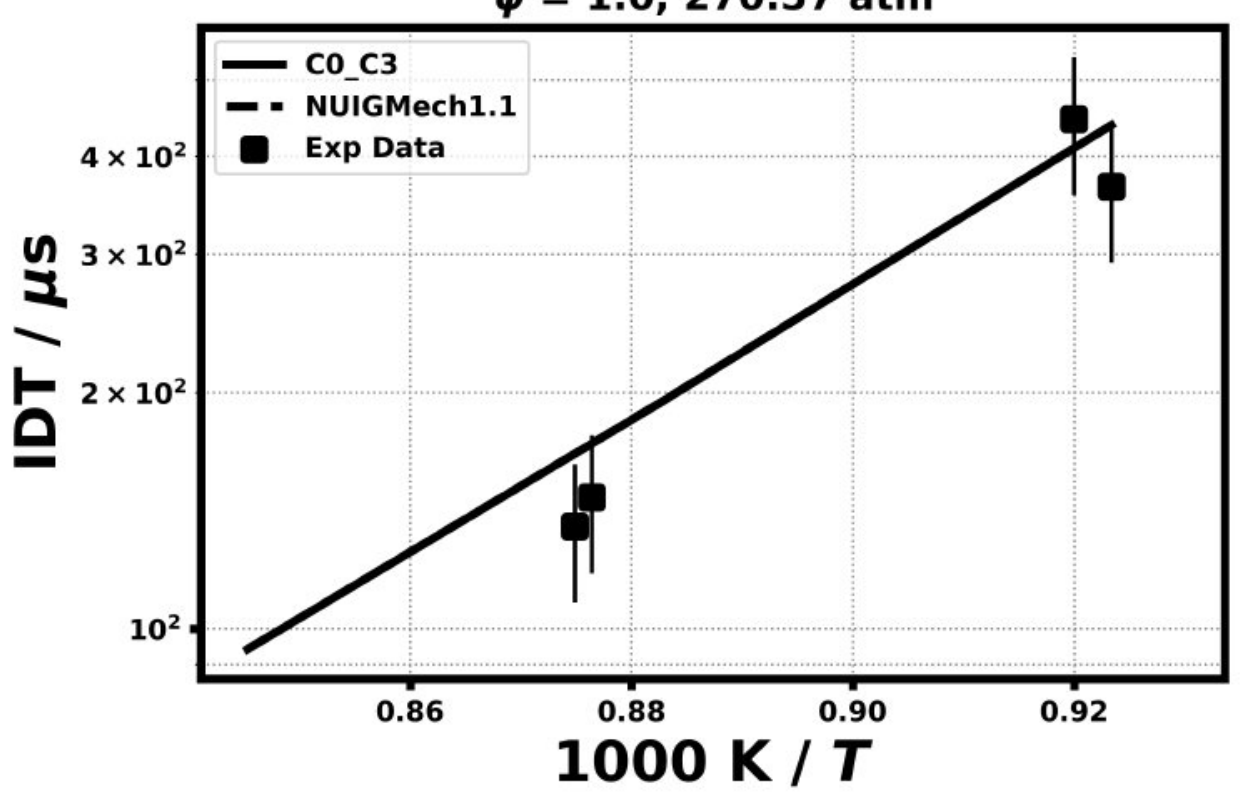

1.2) Hidaka, Y., Sato, K., Henmi, Y., Tanaka, H., \& Inami, K., Combustion and flame, 118(3) (1999) 340-358.

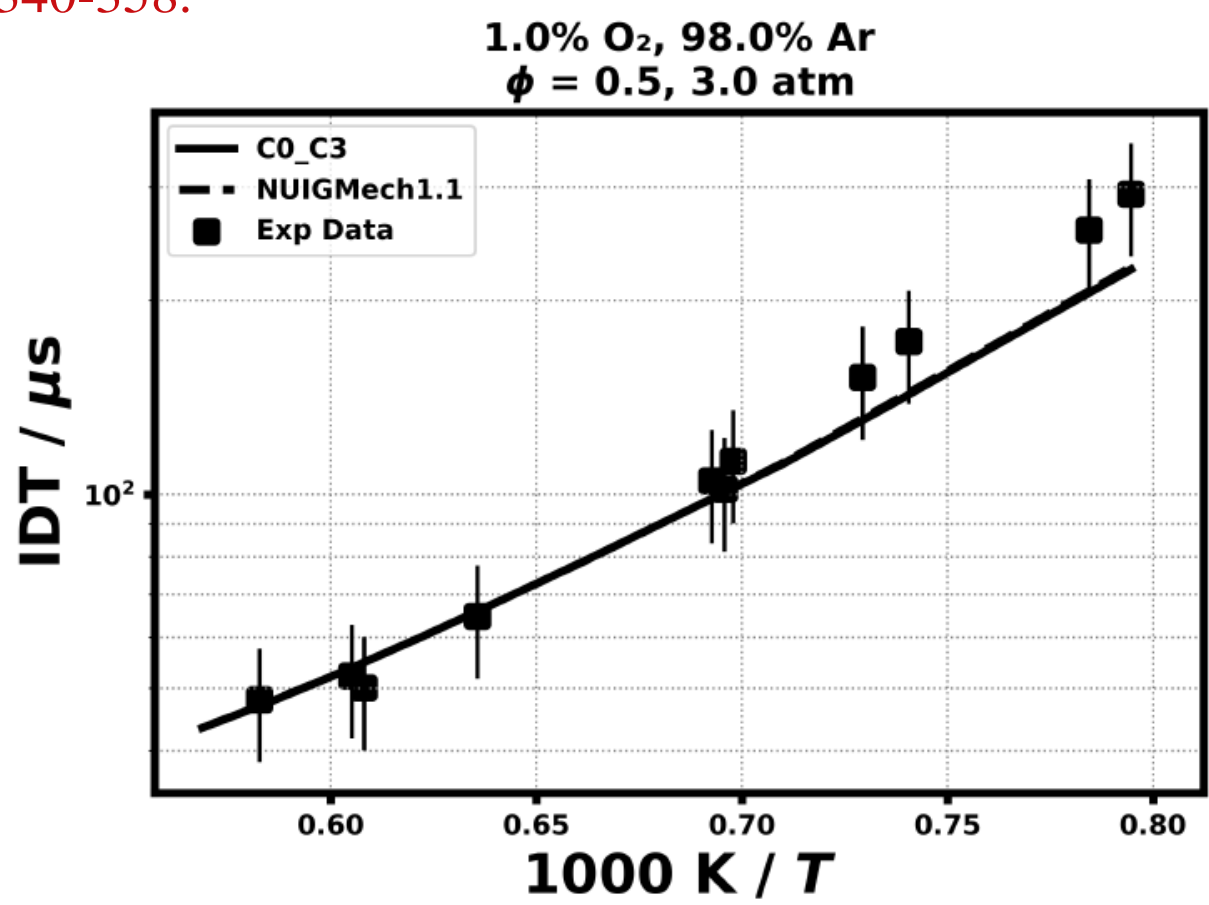


1.3) Bhaskaran, K. A., Gupta, M. C., \& Just, T., Combustion and Flame, 21(1) (1973) 45-48.

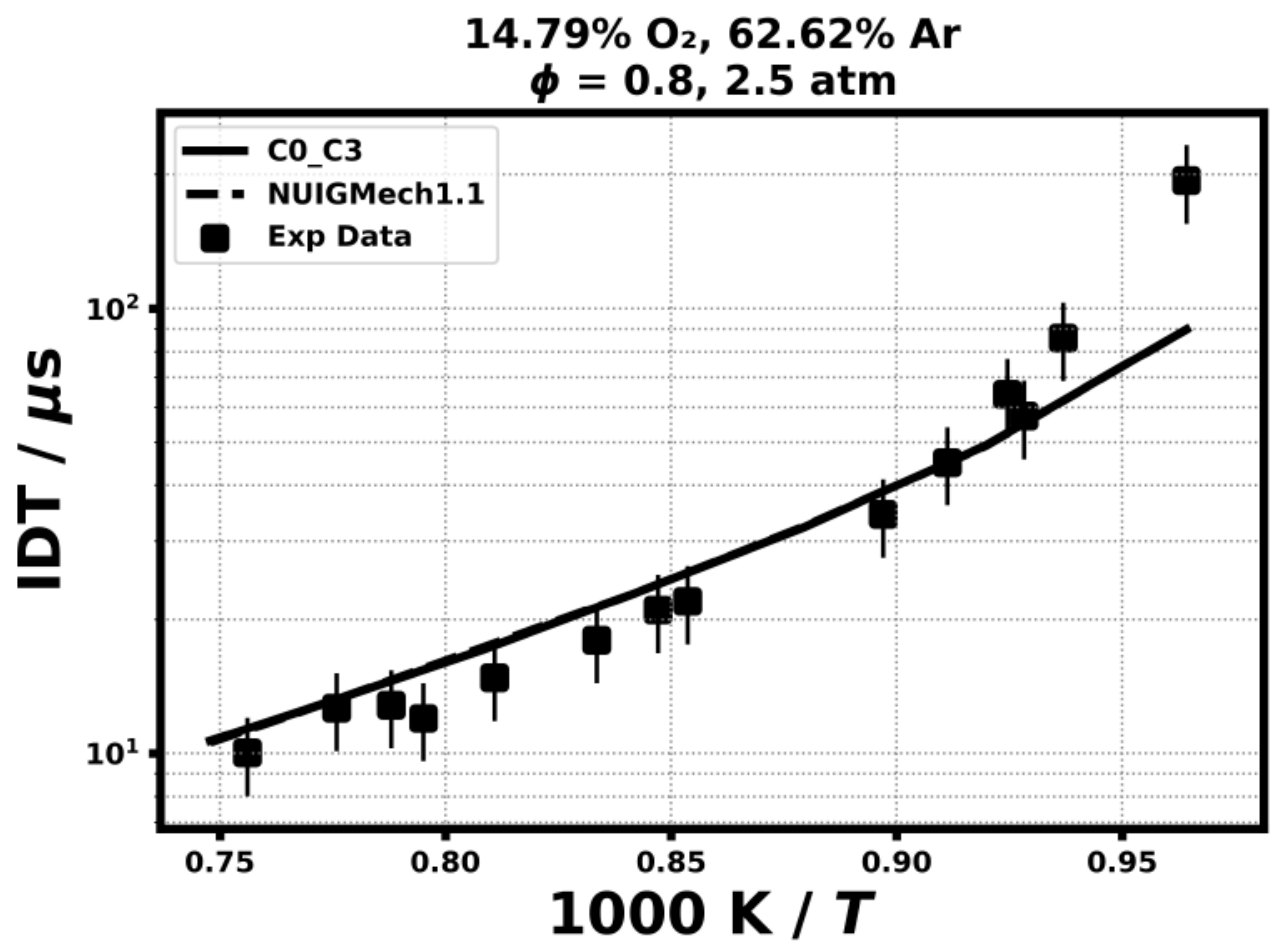

1.4) Cheng, R. K., \& Oppenheim, A. K., Combustion and flame 58(2) (1984) 125-139.

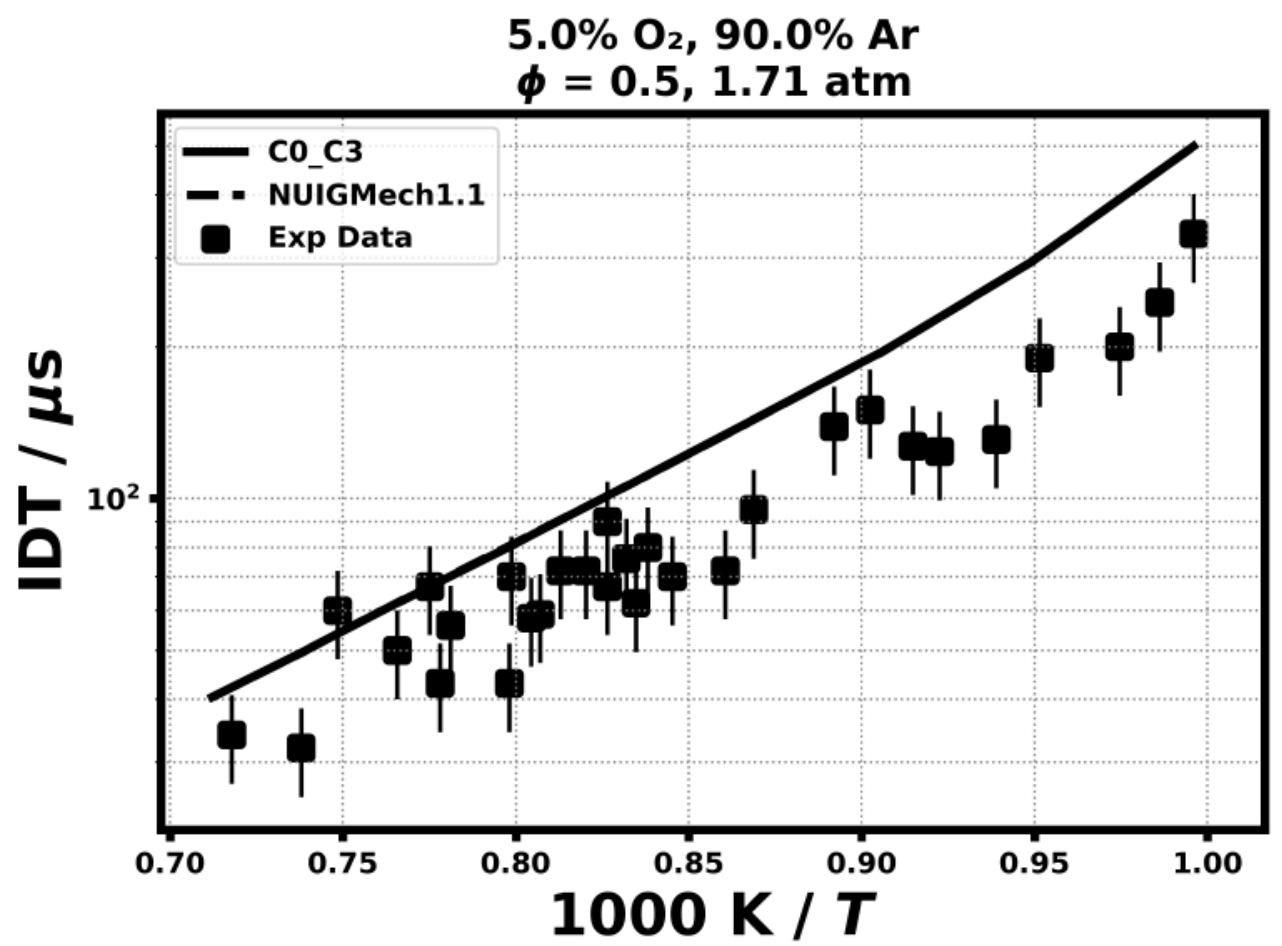


1.5) Herzler, J., \& Naumann, C., Proceedings of the combustion institute, 32(1) (2009) 213-220.

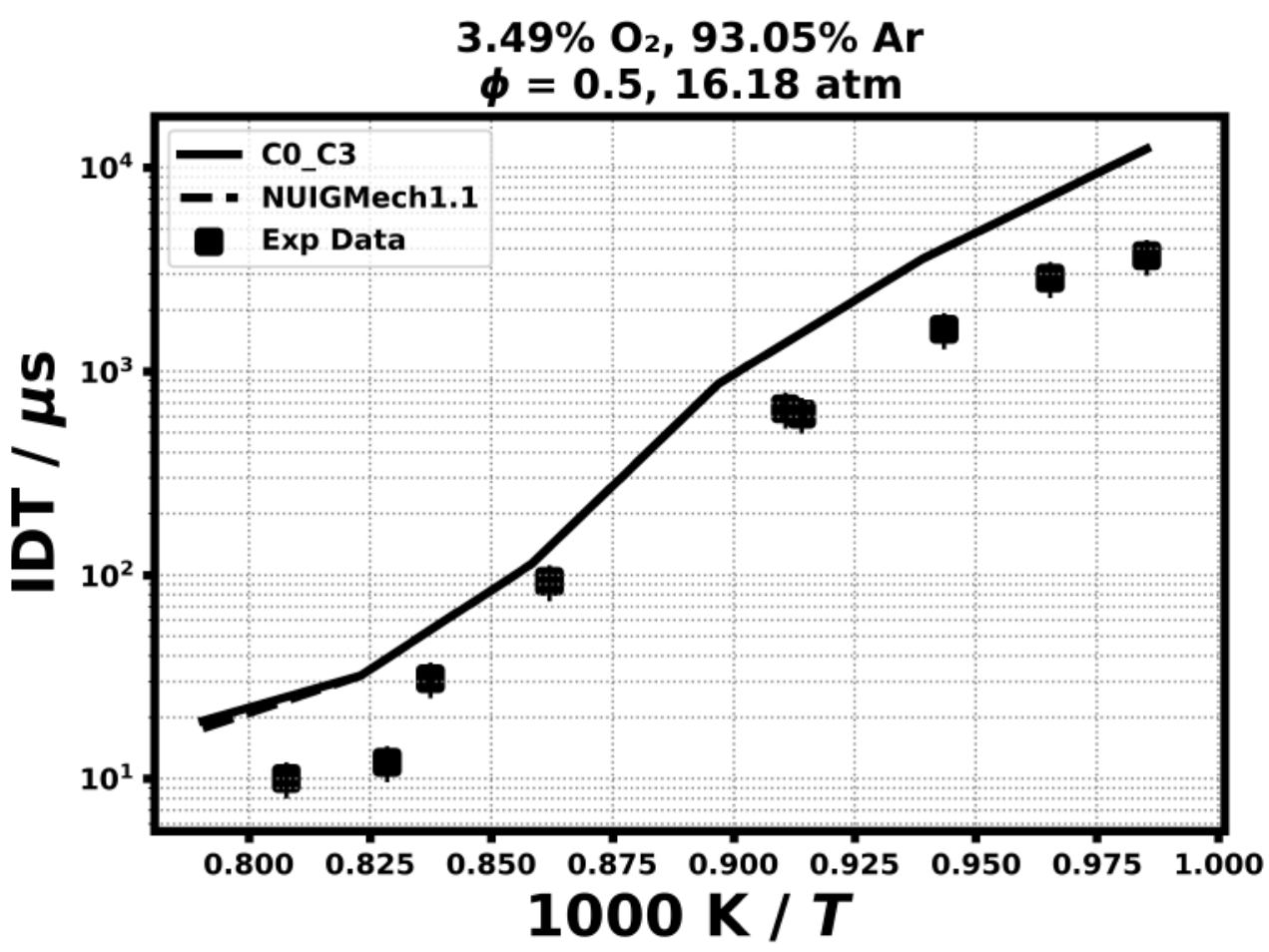

1.6) Slack, M. W., Combustion and Flame, 28 (1977) 241-249.

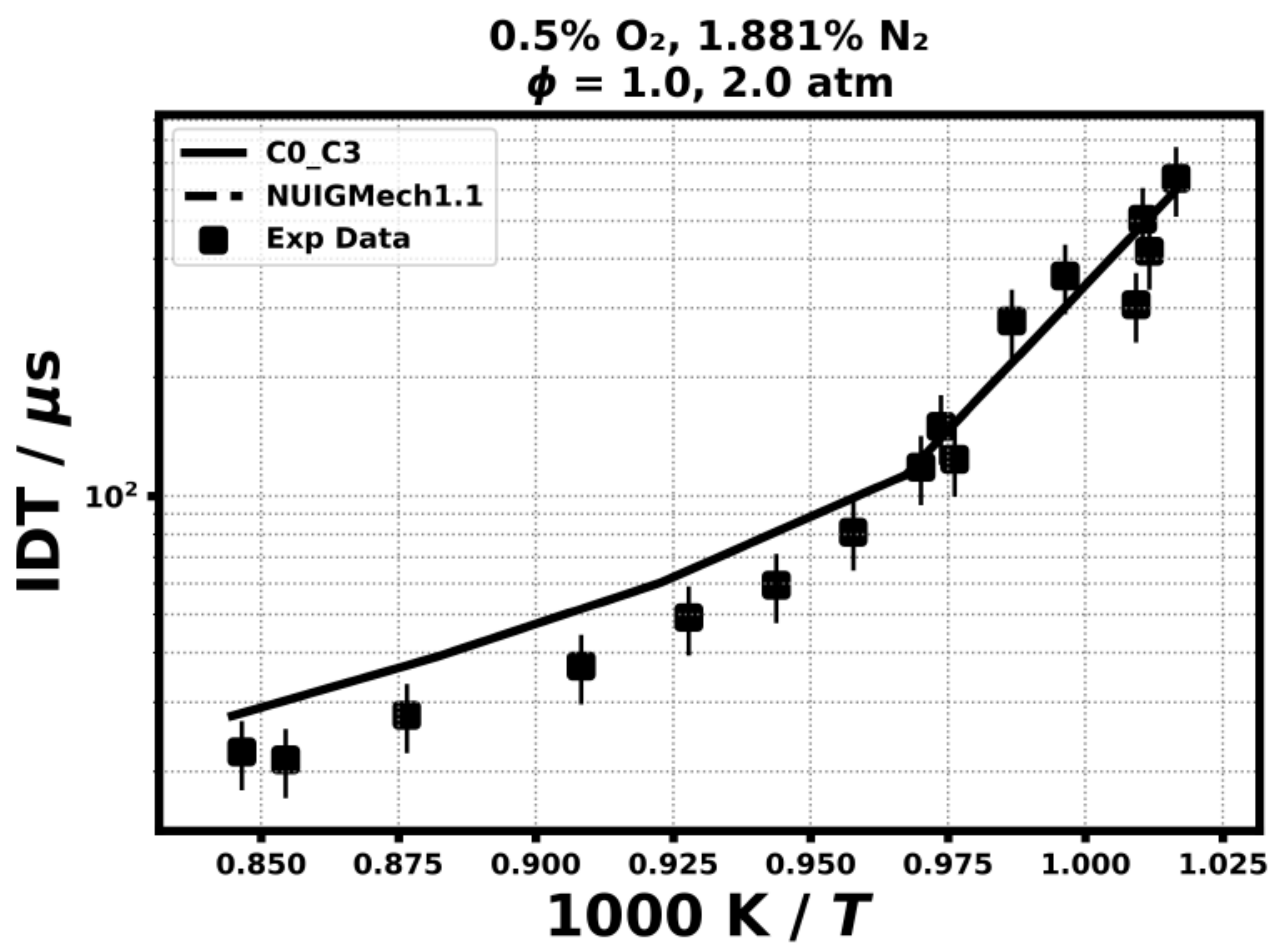


1.7) Kalitan, D. M., Mertens, J. D., Crofton, M. W., \& Petersen, E. L., Journal of propulsion and power, 23(6) (2007) 1291-1301.
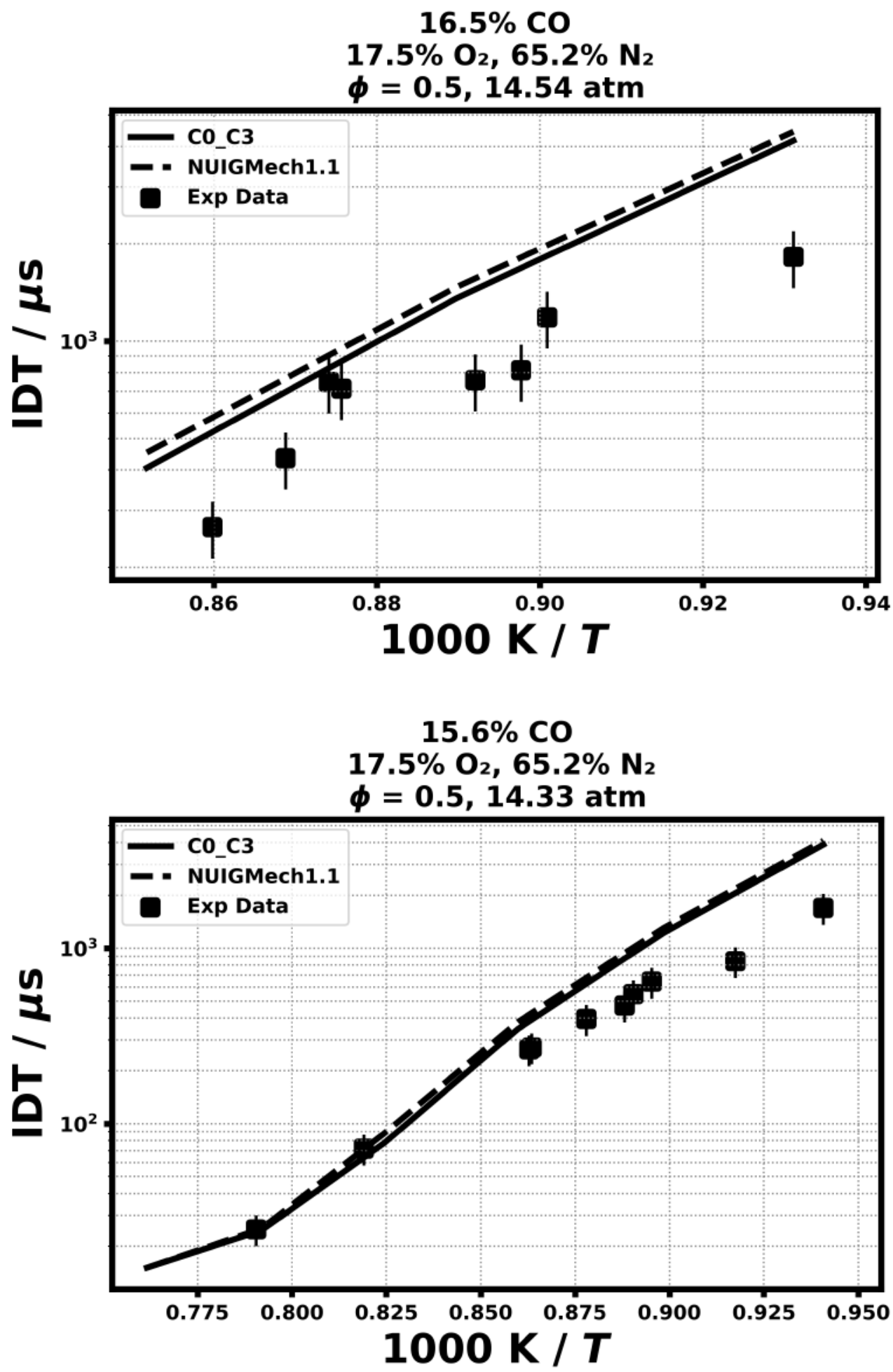

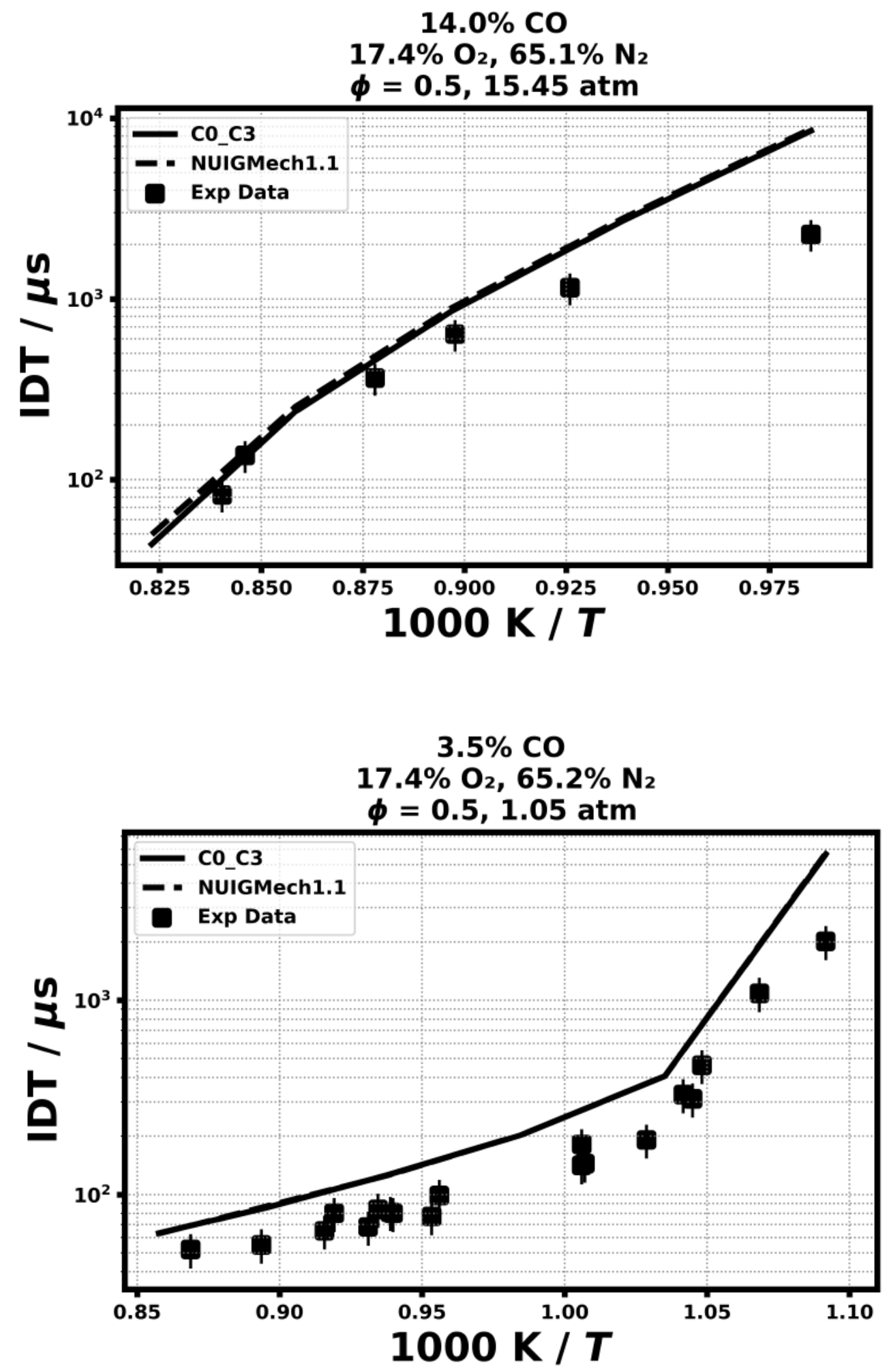


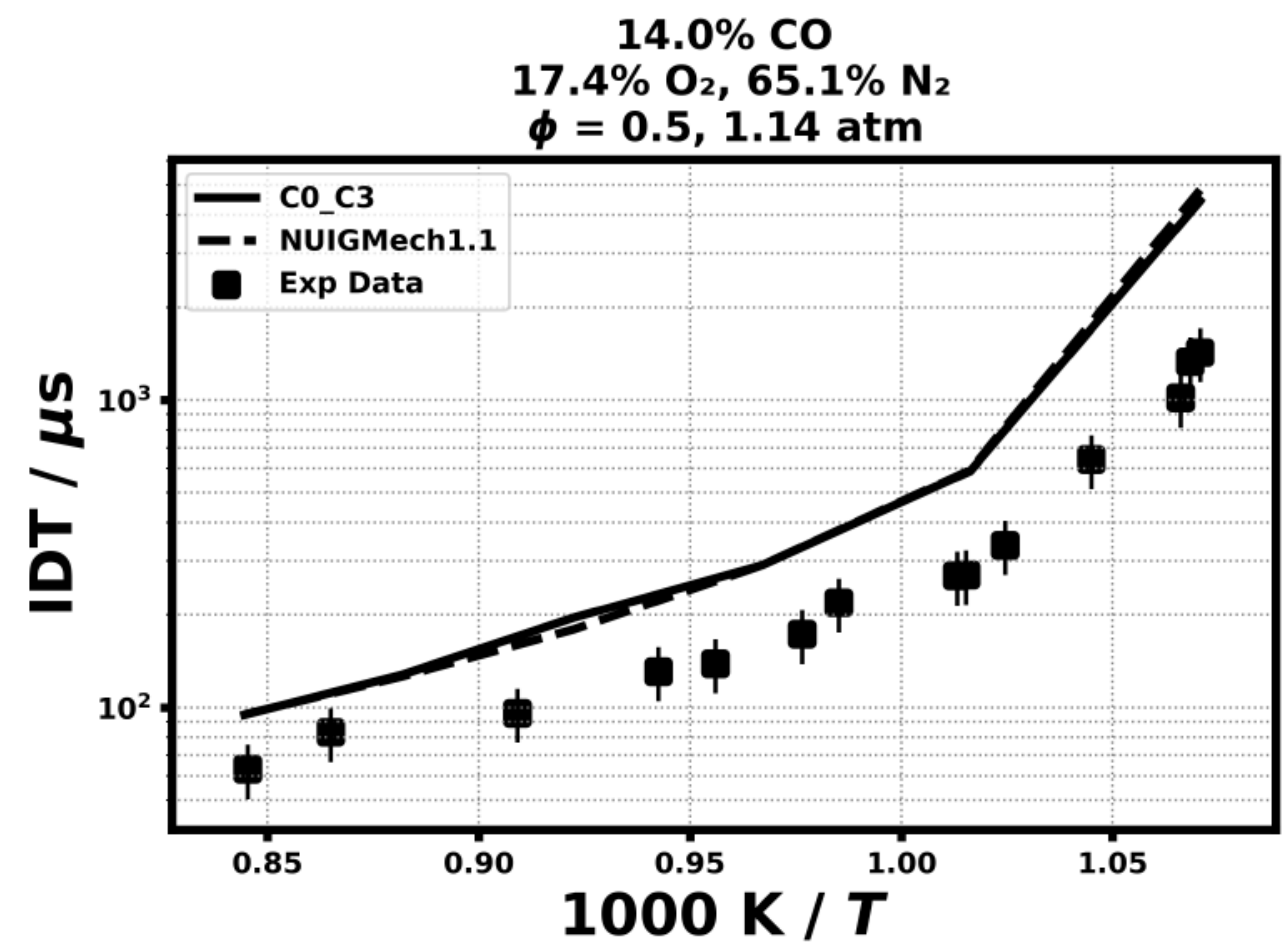

1.8) Kéromnès, A., Metcalfe, W. K., Heufer, K. A., Donohoe, N., Das, A. K., Sung, C. J., \& Krejci, M. C., Combustion and Flame, 160(6), (2013) 995-1011.

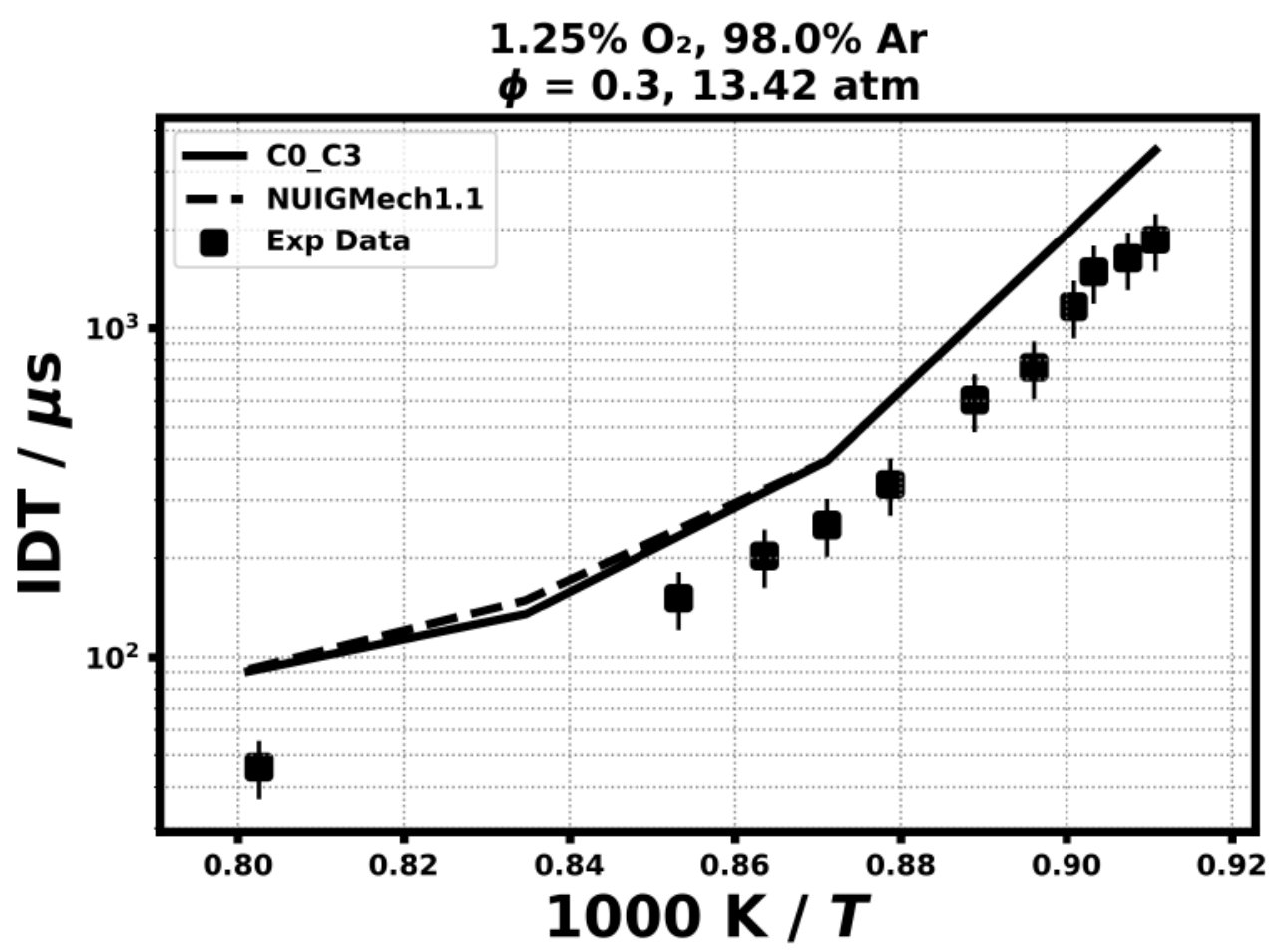



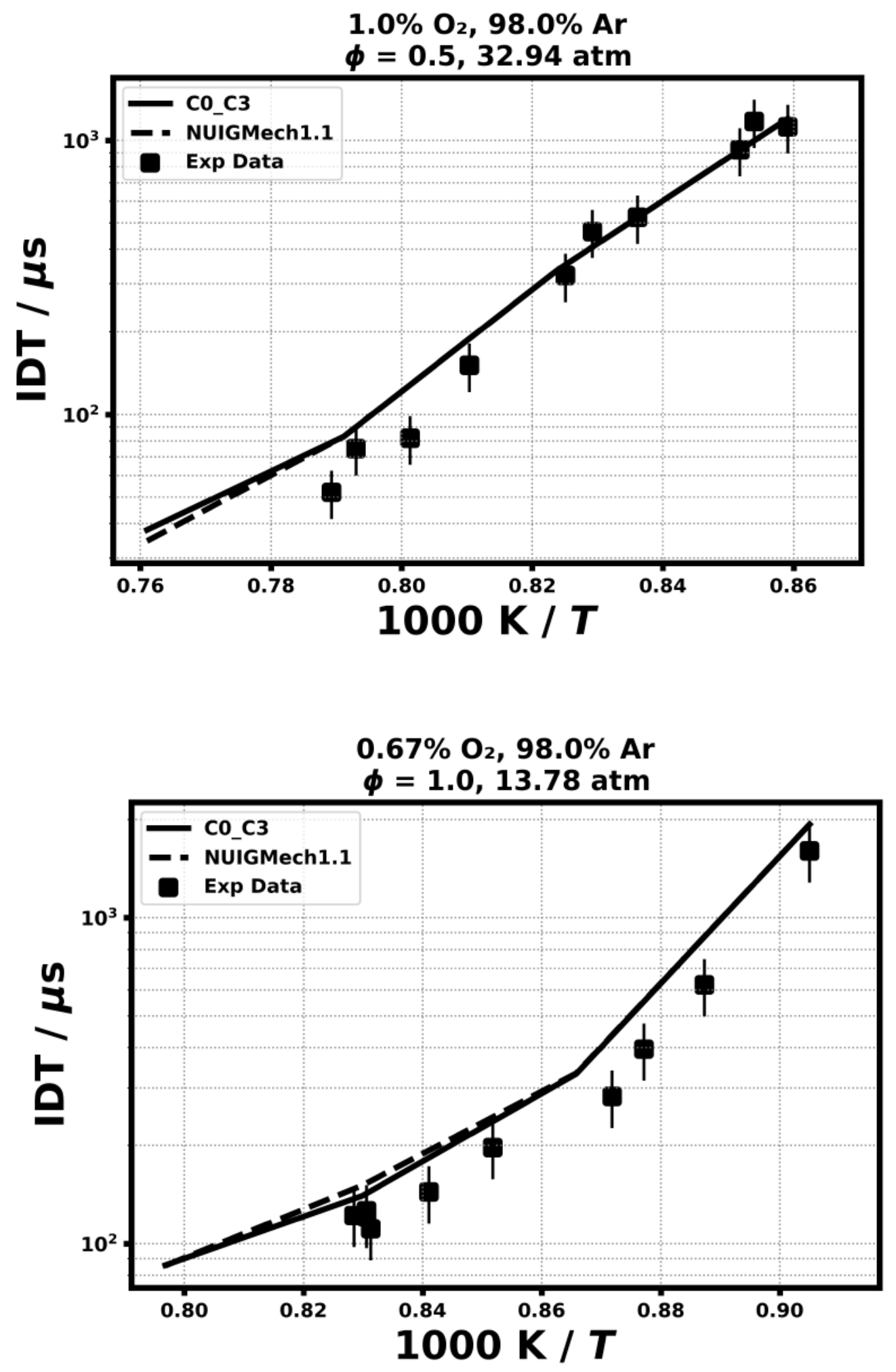

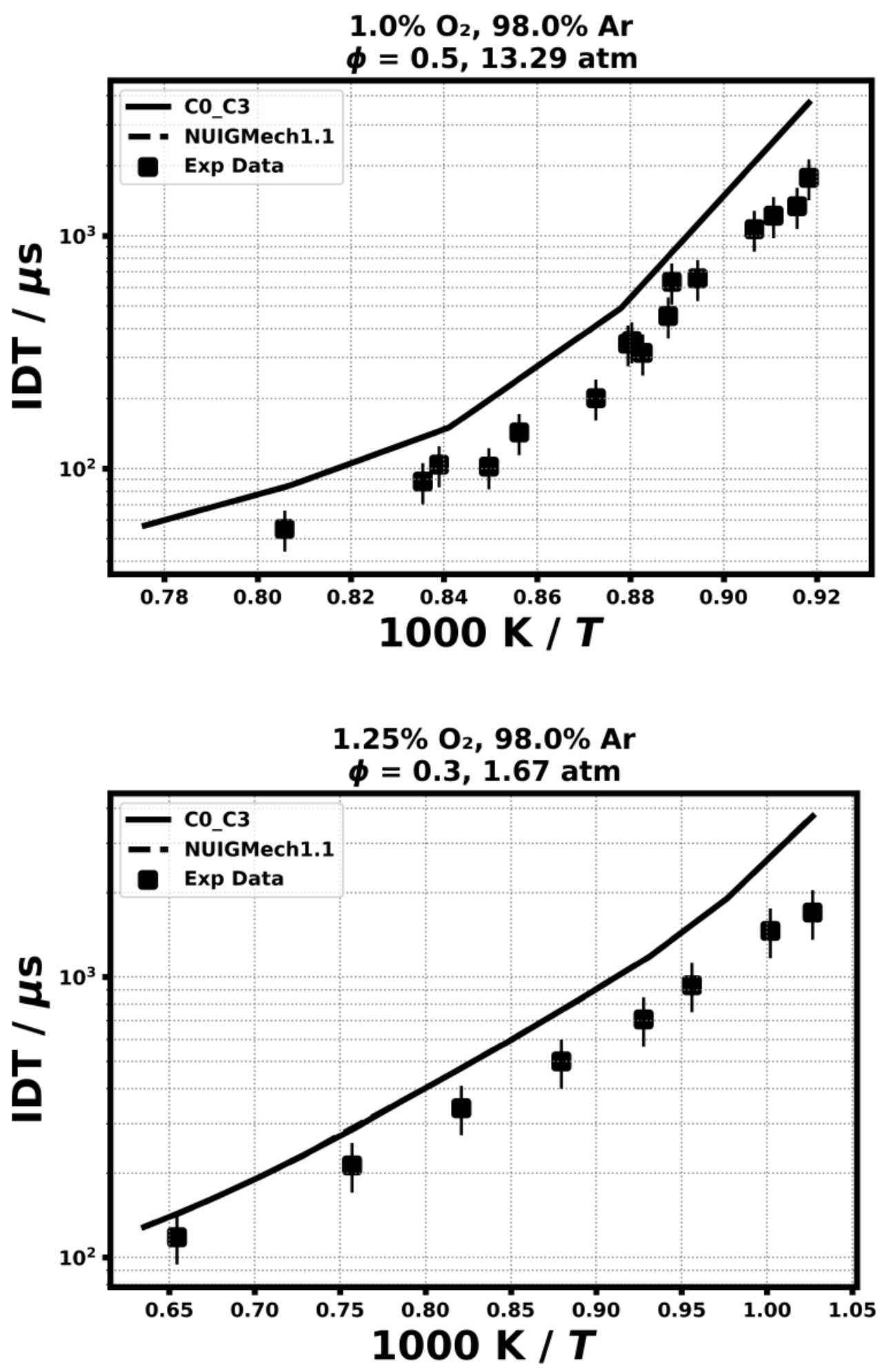

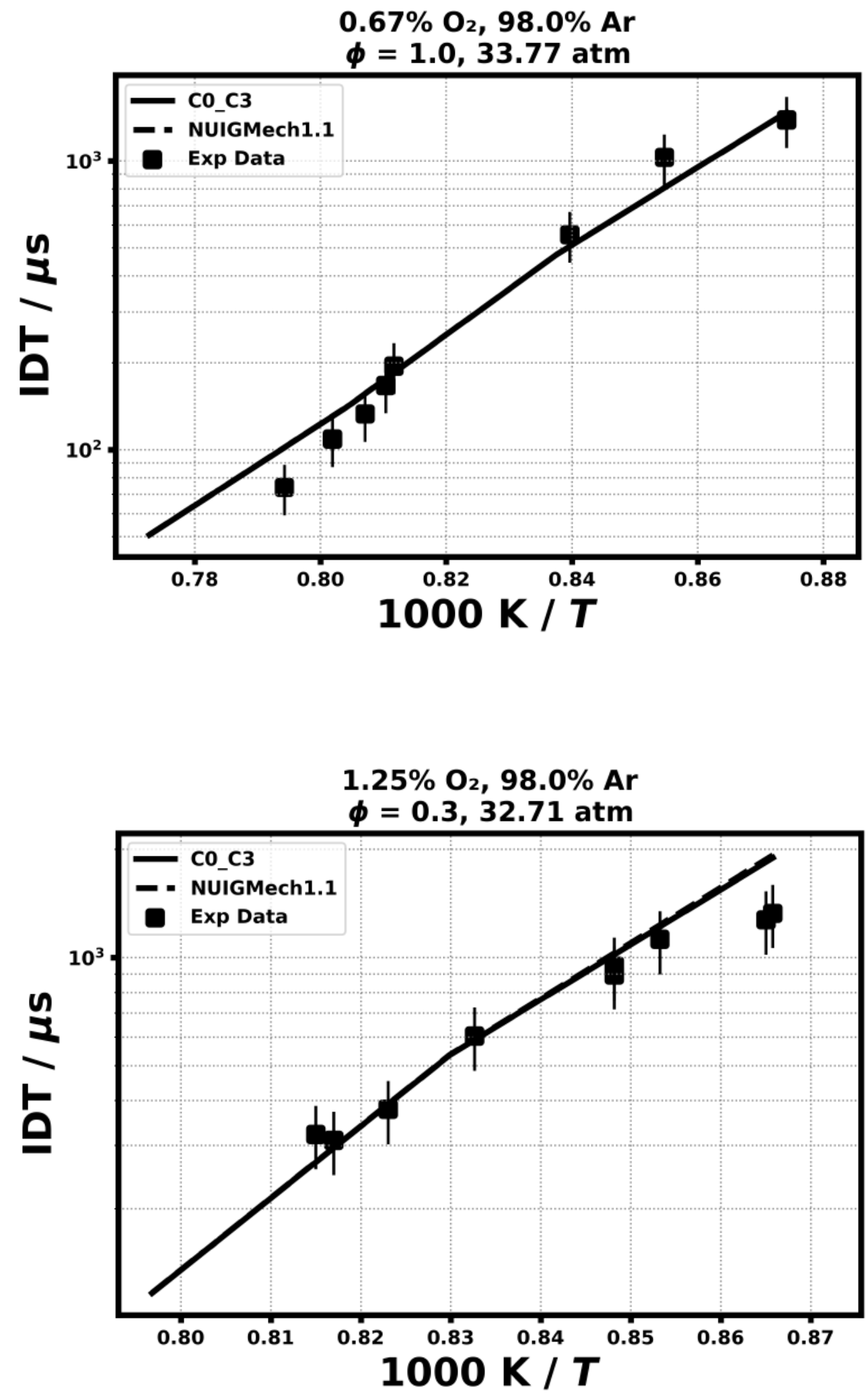


\section{RCM Ignition delay time}

1.8) Kéromnès, A., Metcalfe, W. K., Heufer, K. A., Donohoe, N., Das, A. K., Sung, C. J., \& Krejci, M. C., Combustion and Flame, 160(6), (2013) 995-1011.

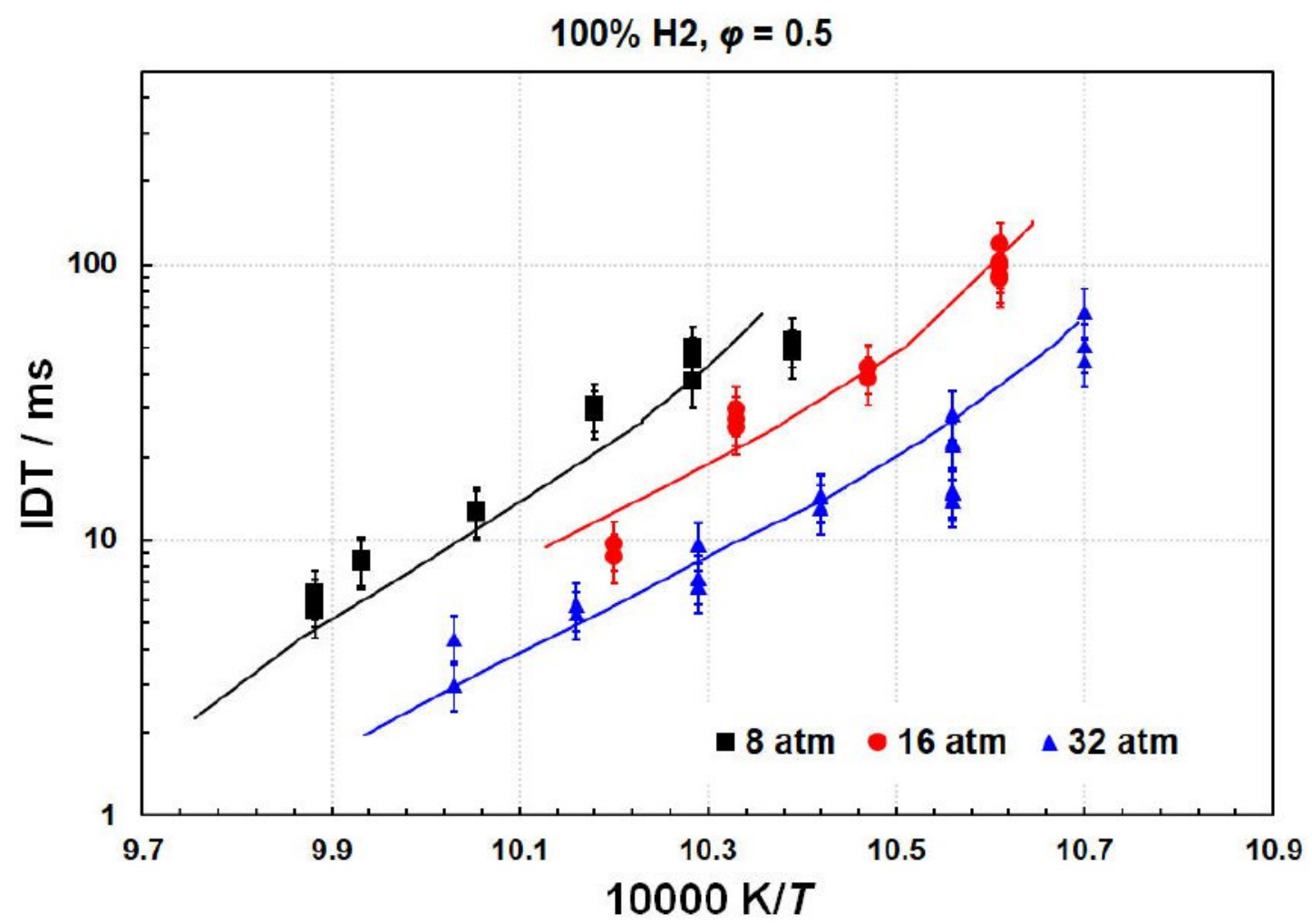

Speciation in Jet-stirred reactor

1.9) Le Cong, T., \& Dagaut, P., Energy \& Fuels, 23(2) (2009) 725-734.

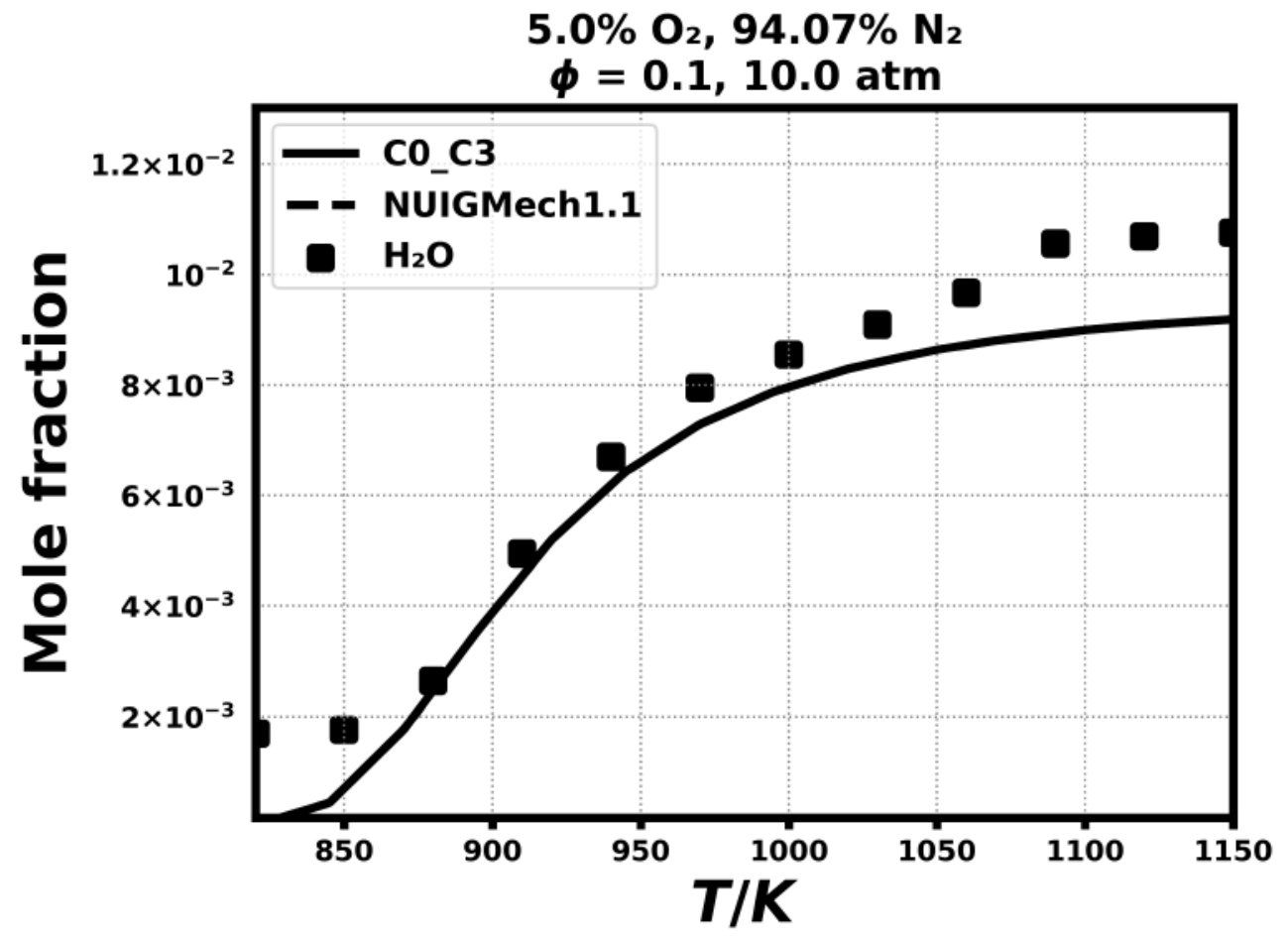



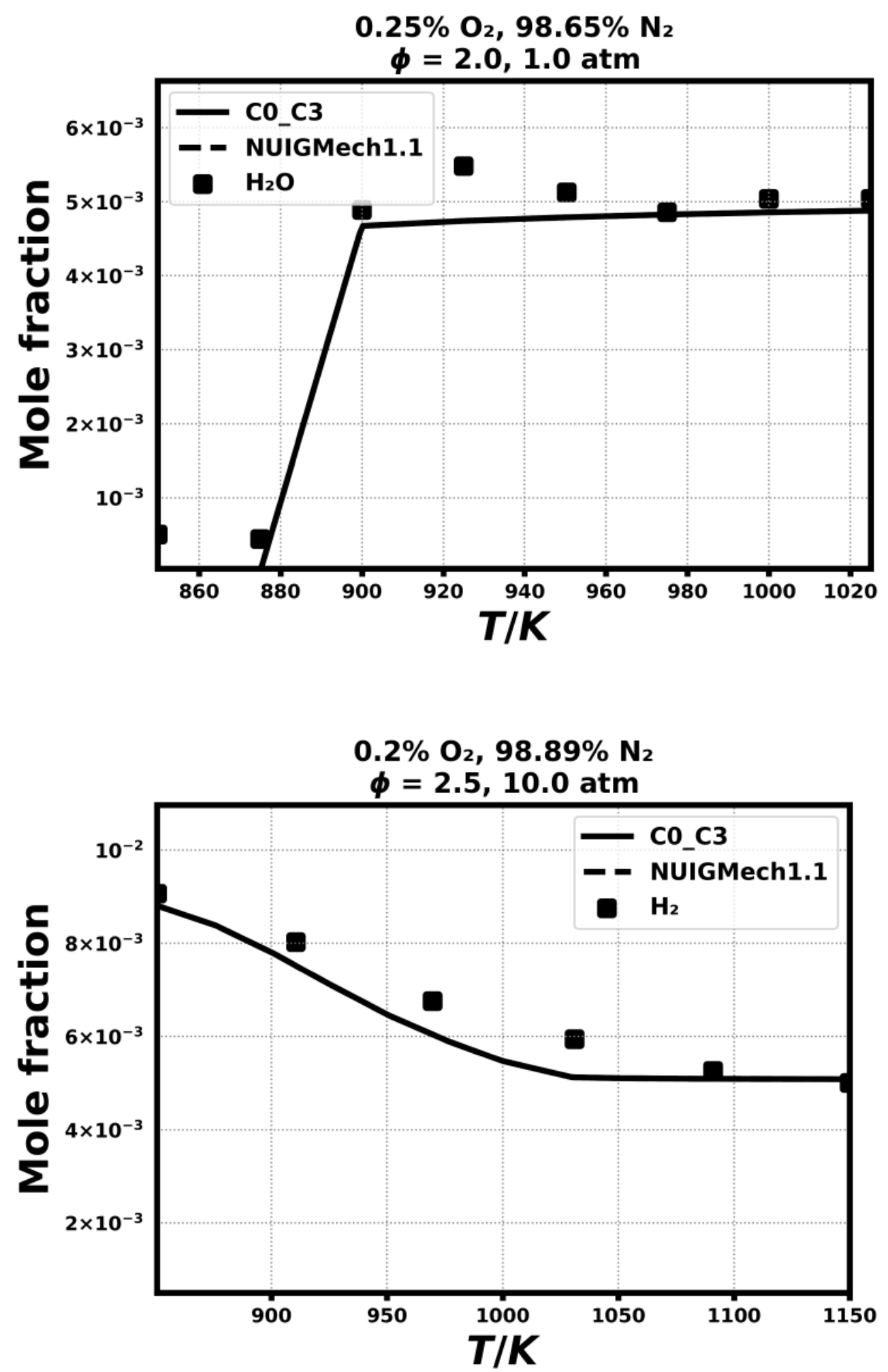

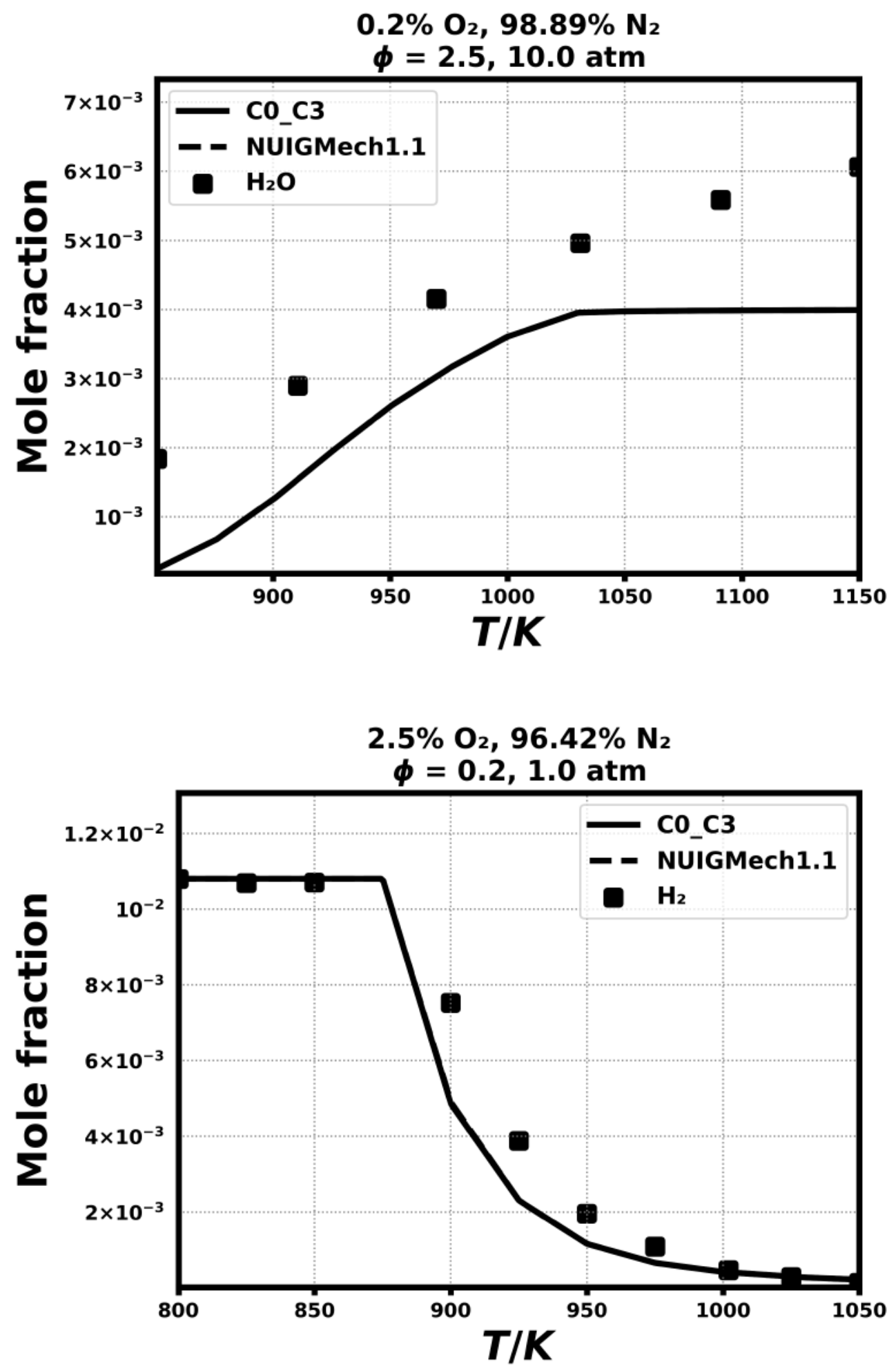

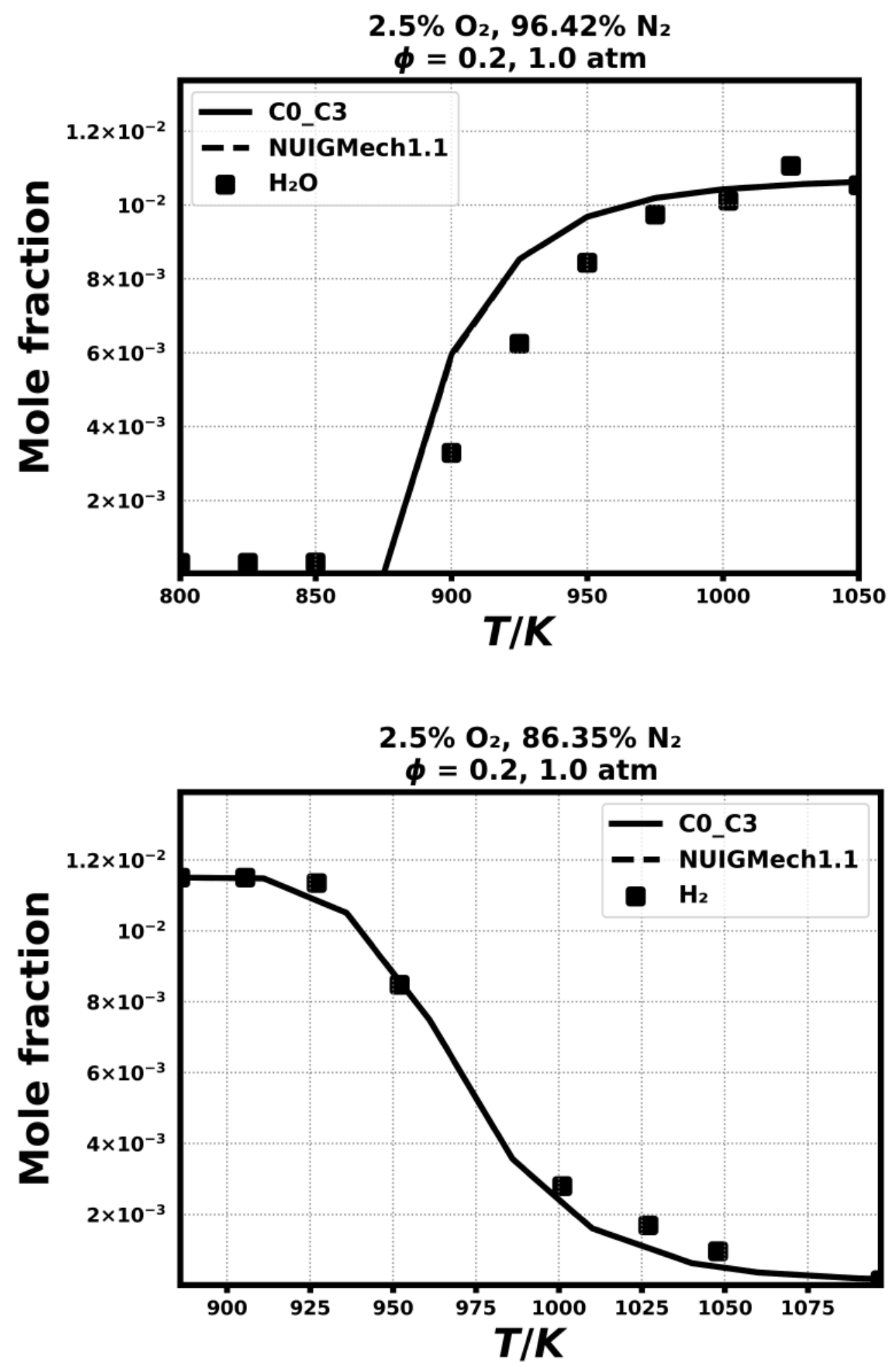

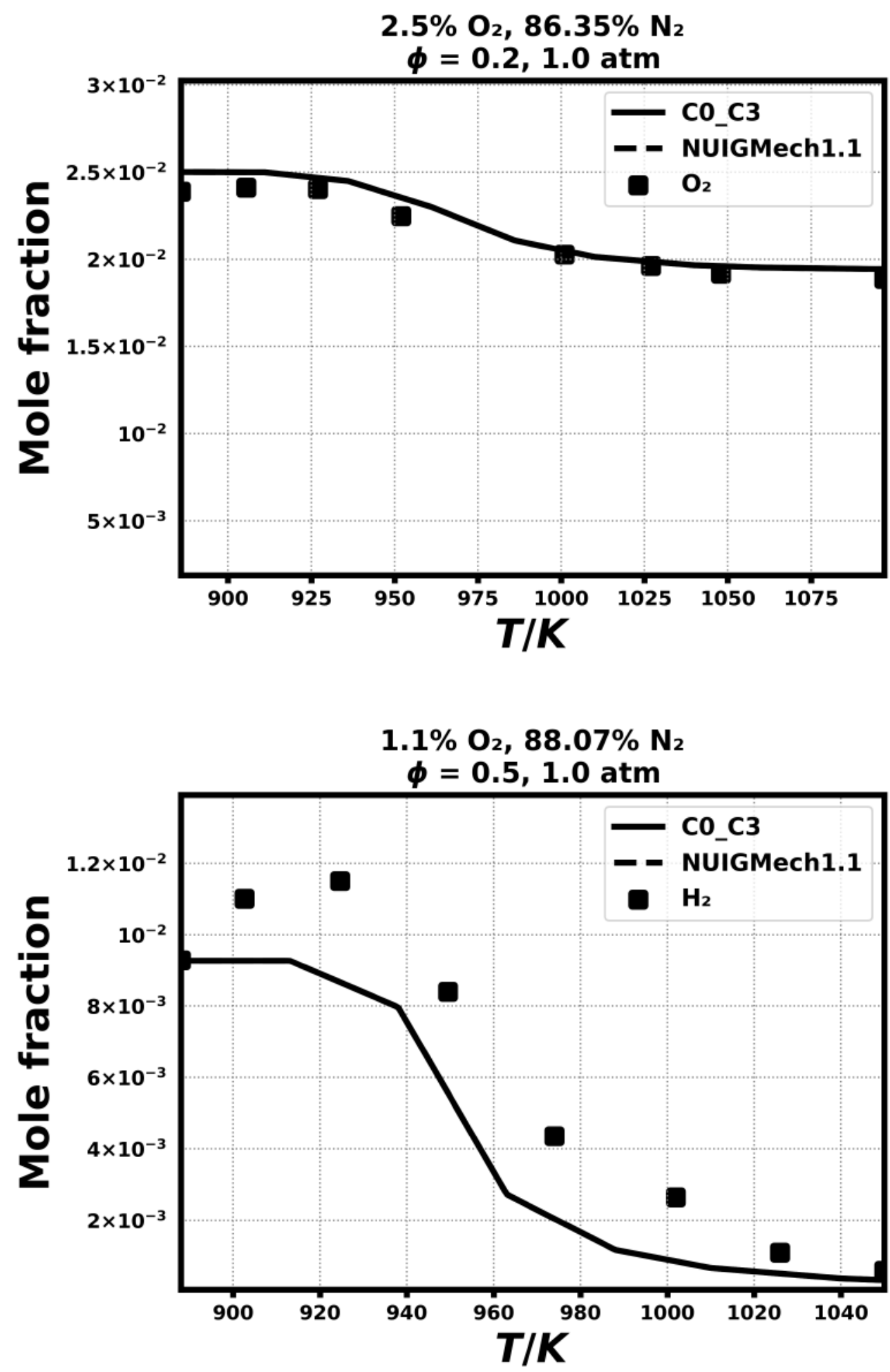

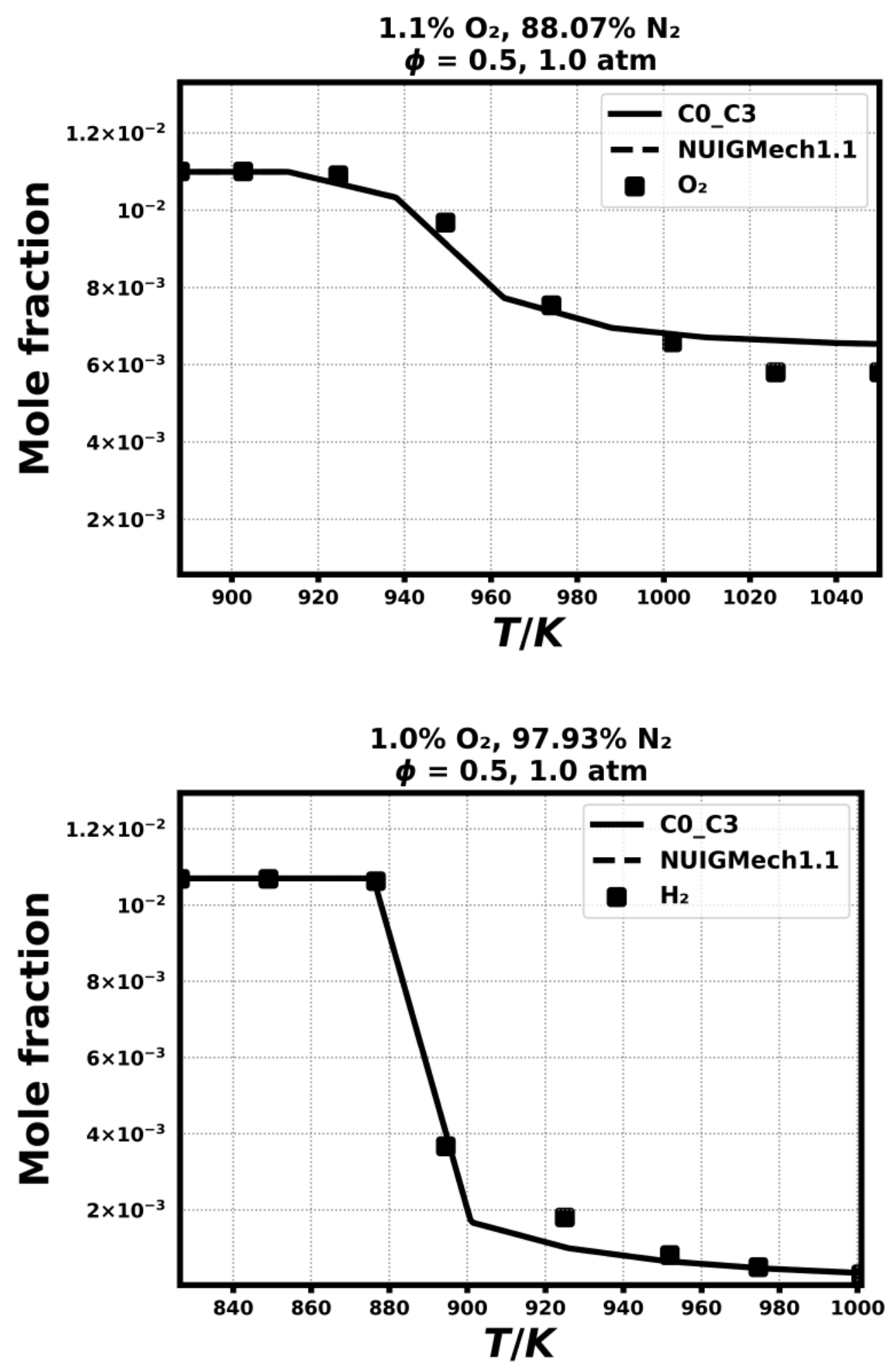

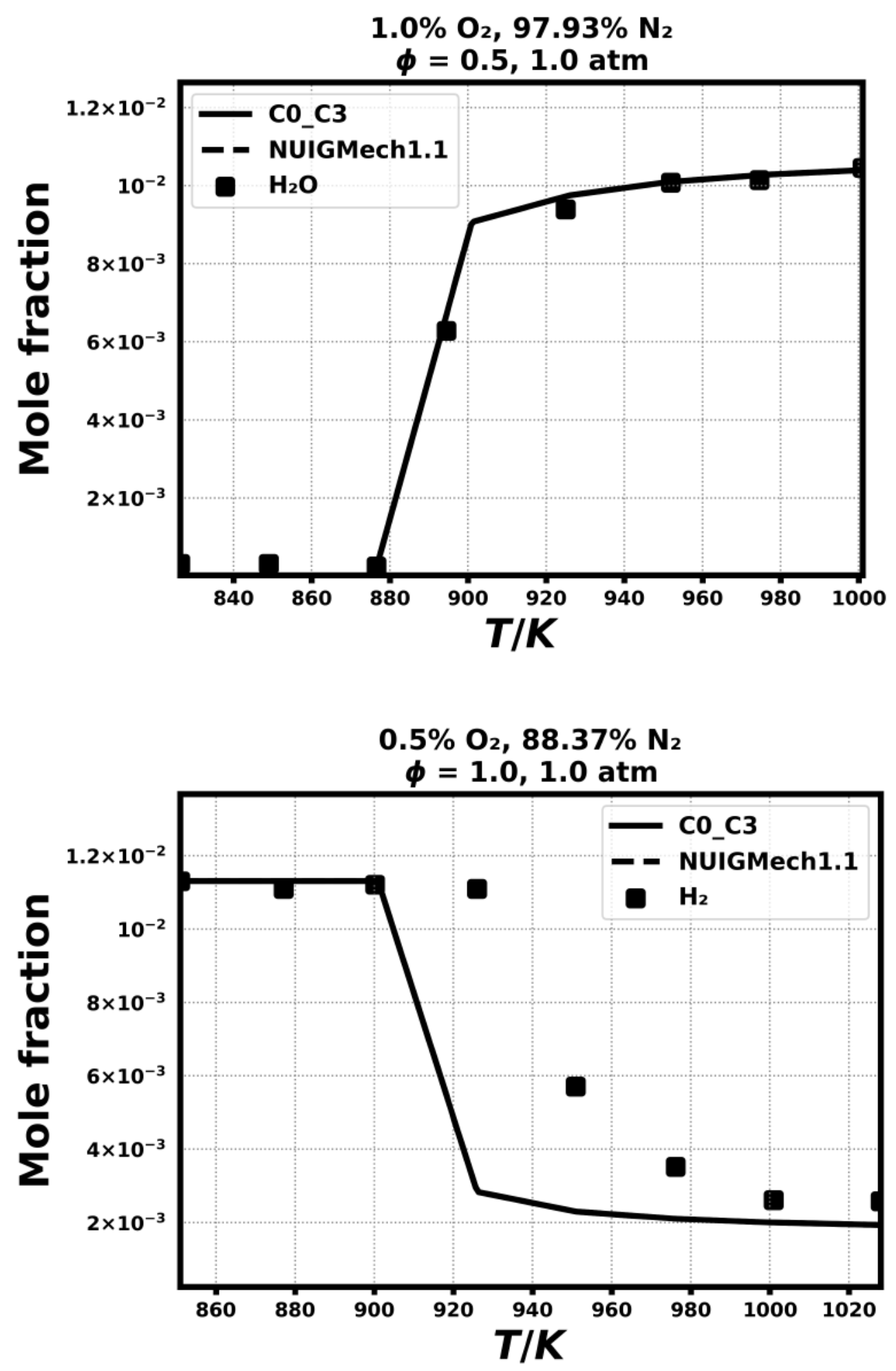

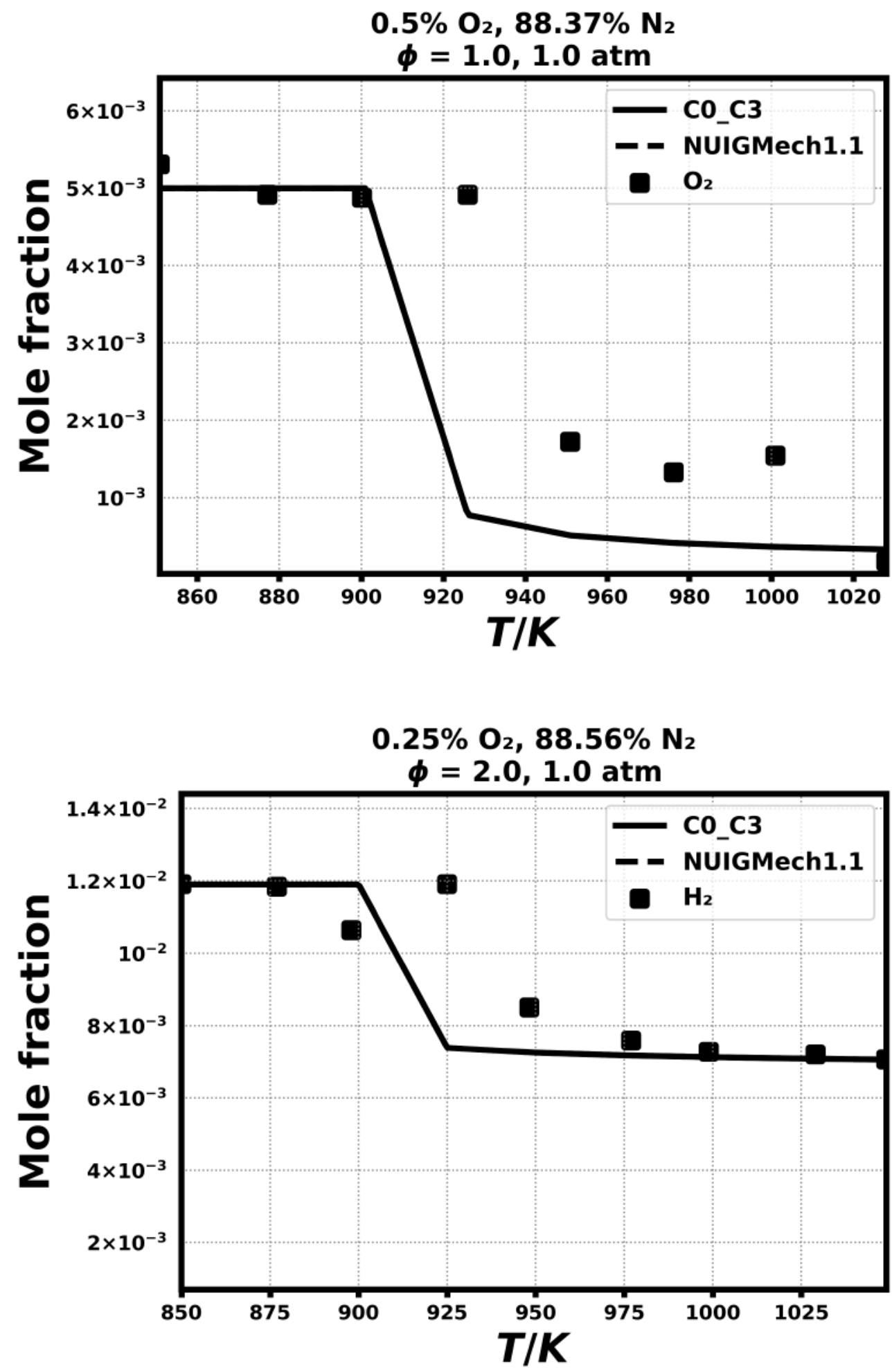

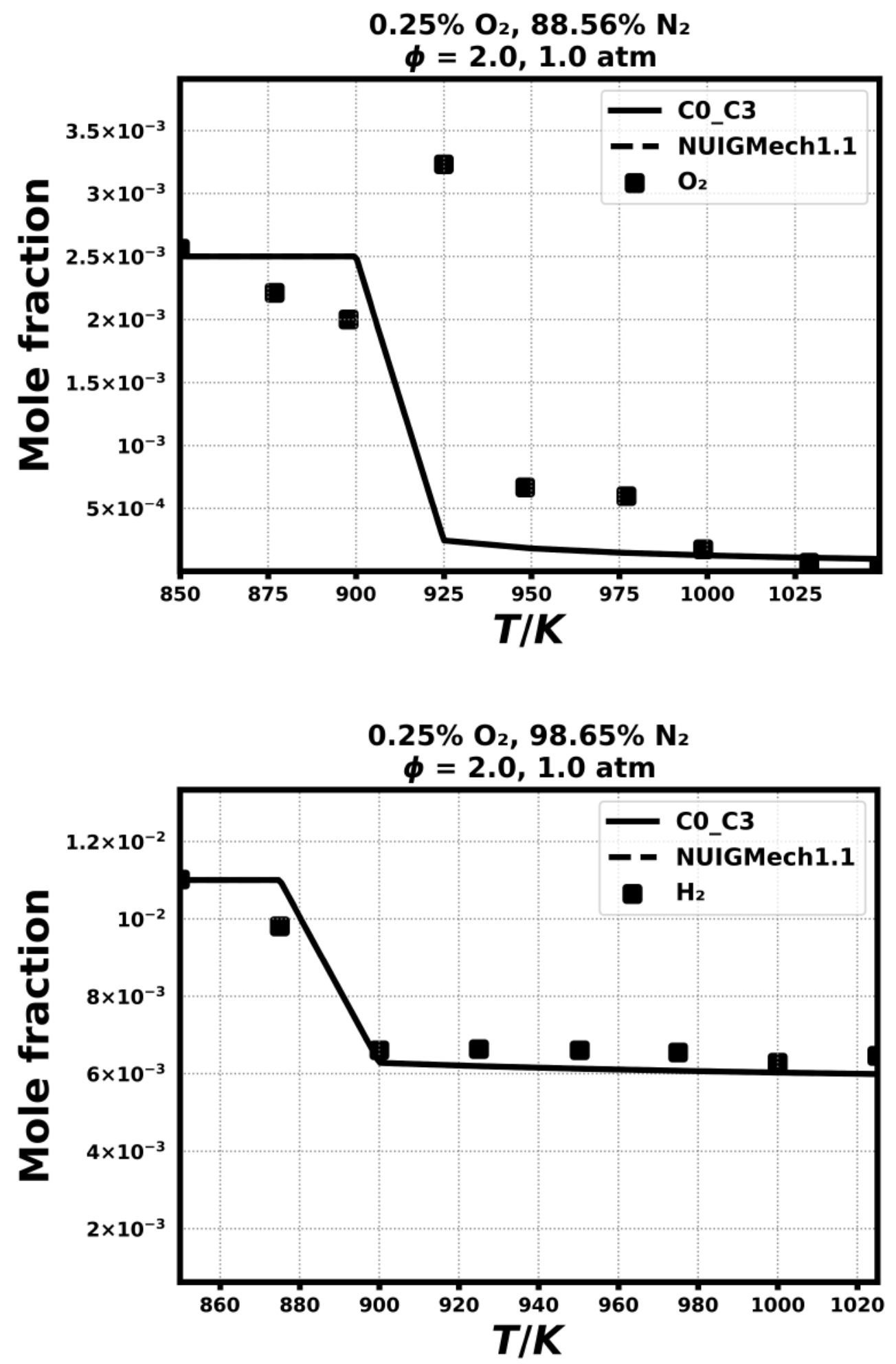


\section{Laminar flame speed}

1.10) Tse, S. D., Zhu, D. L., \& Law, C. K., Proceedings of the combustion institute, 28 (2) (2000) 1793-1800.

1.11) Wu, C., \& Law, C. K., Symposium (International) on Combustion, 20 (1985, January) 1941-1949

1.12) Dowdy, D. R., Smith, D. B., Taylor, S. C., \& Williams, A., In Symposium (International) on Combustion, 23 (1991, January) 325-332

1.13)Egolfopoulos, F. N., \& Law, C. K., In Symposium (international) on combustion, 23, (1991, January) 333-340

1.14)Vagelopoulos, C. M., Egolfopoulos, F. N., \& Law, C. K., In Symposium (international) on combustion, 25 (1994, January) 1341-1347

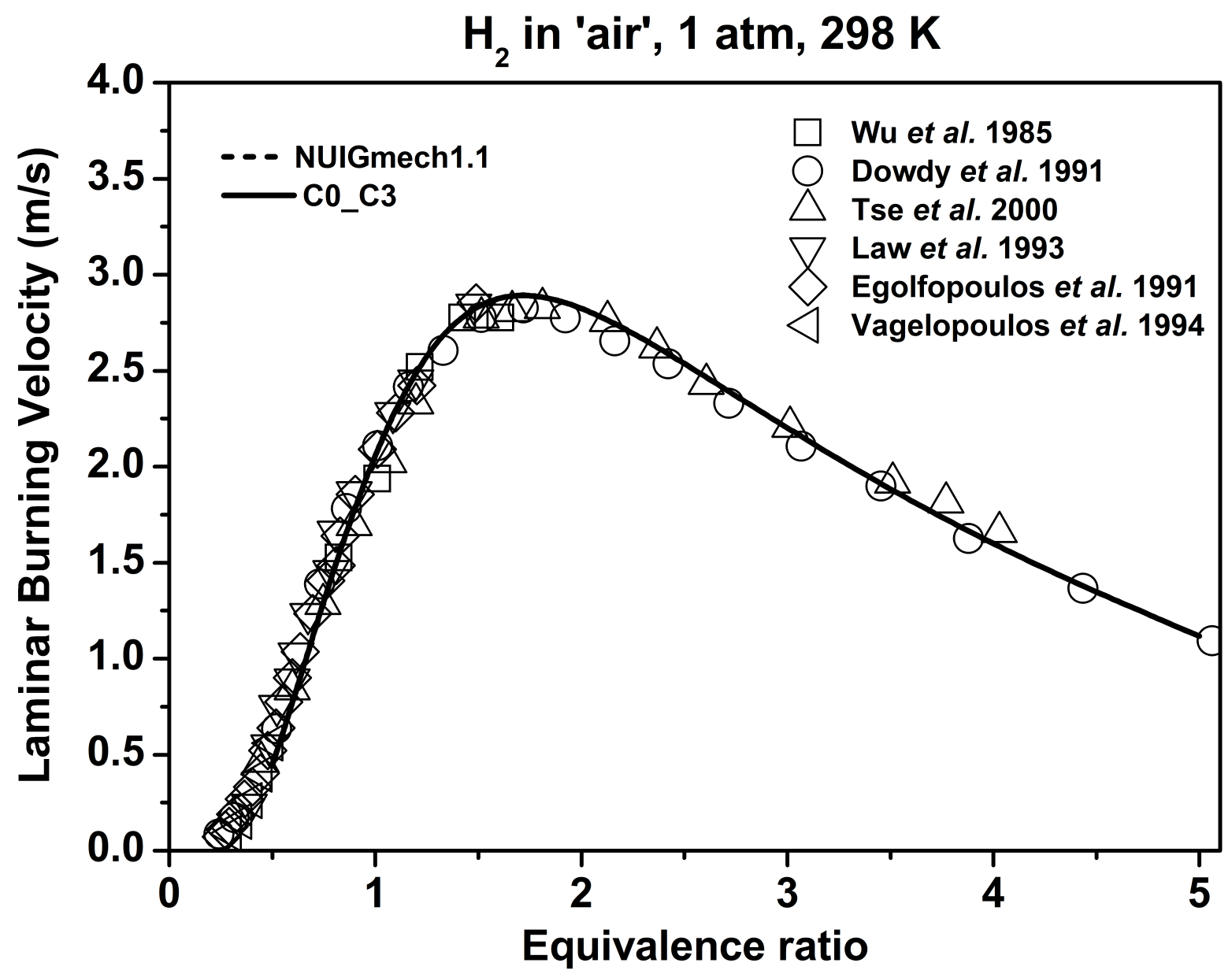




\section{Validation for $\mathrm{CH}_{4}$}

\section{Shock tube ignition delay time}

2.1) Seery, Daniel J., and Craig T. Bowman., Combustion and Flame, 141 (1970) 37-47.
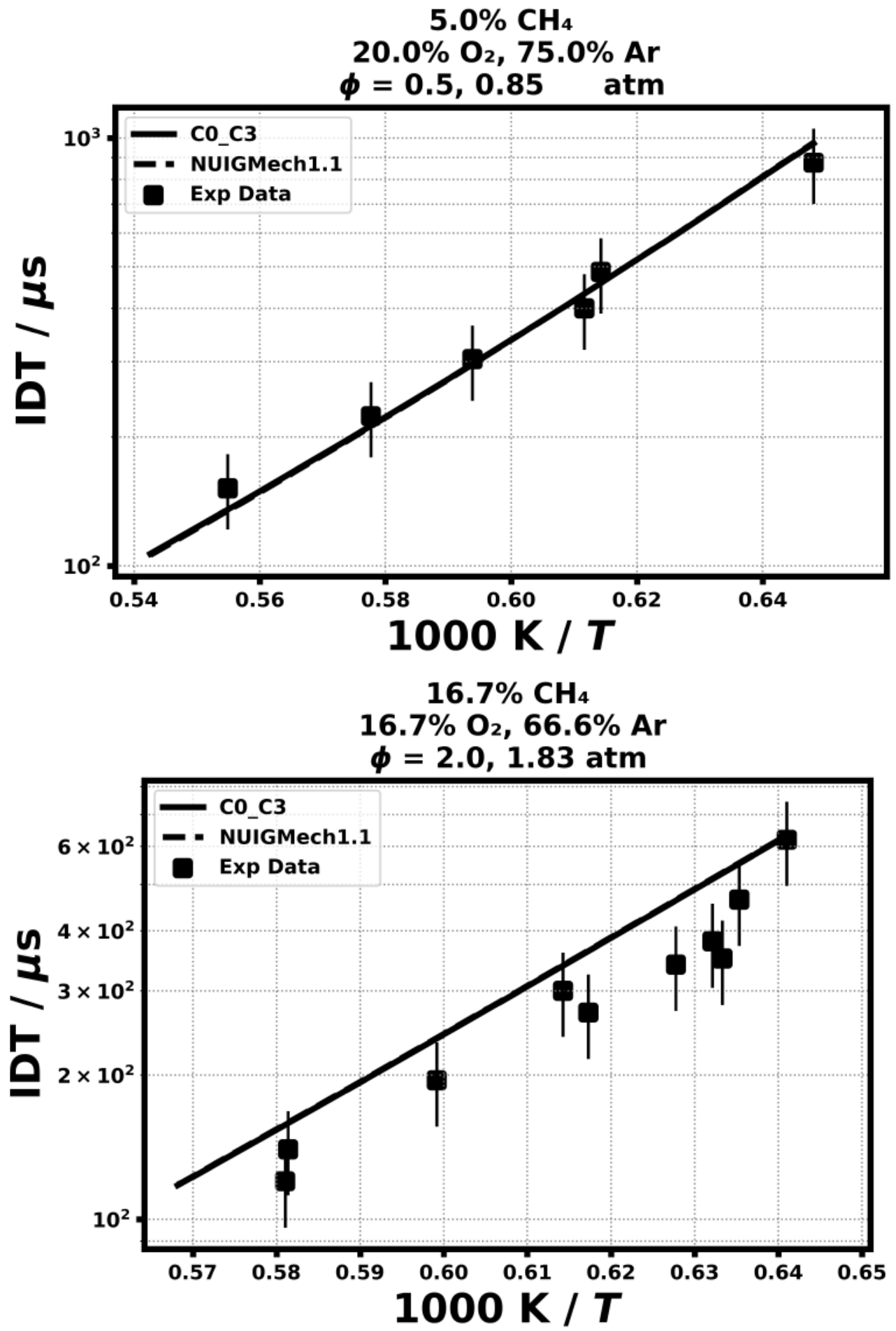

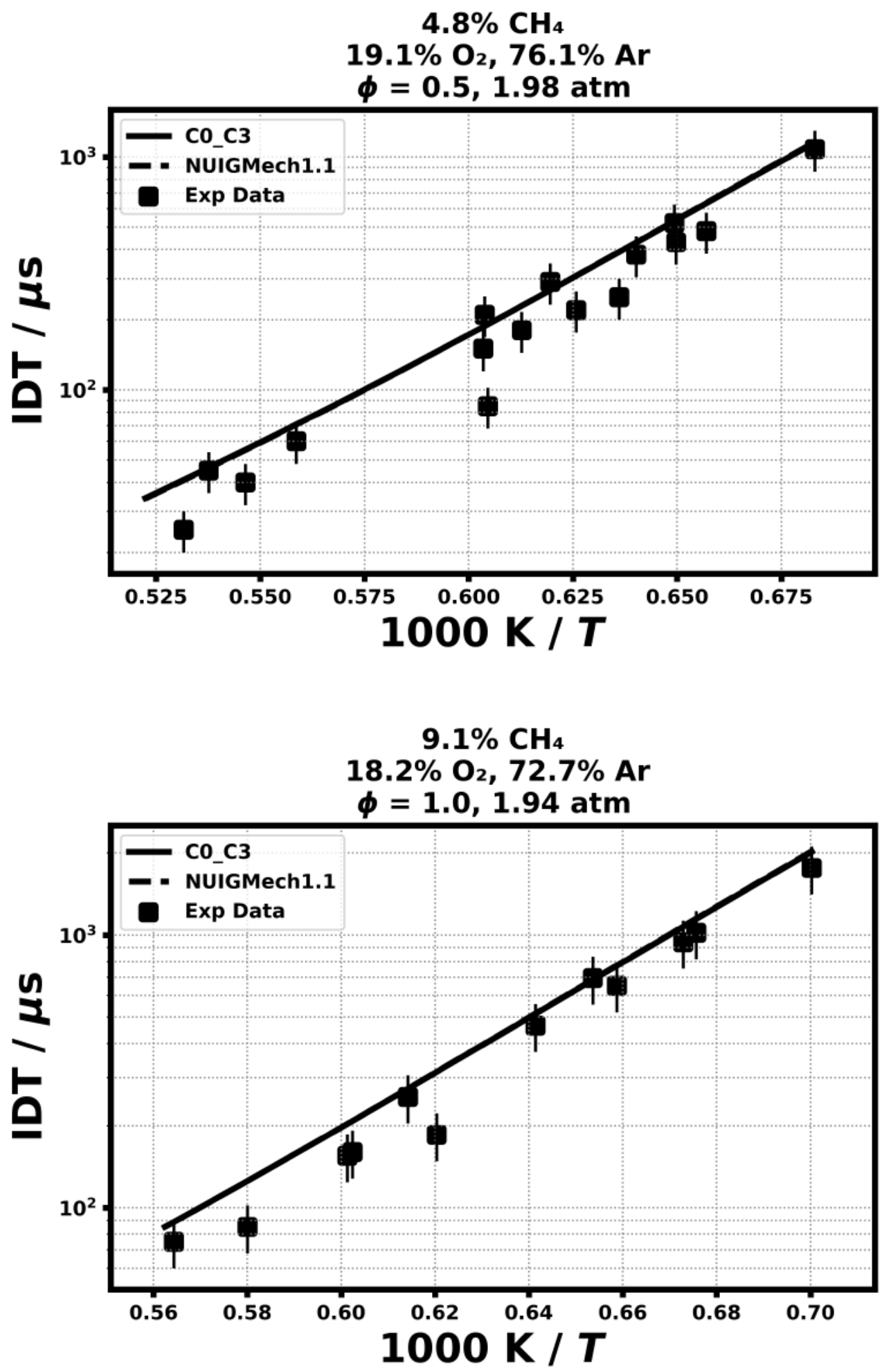


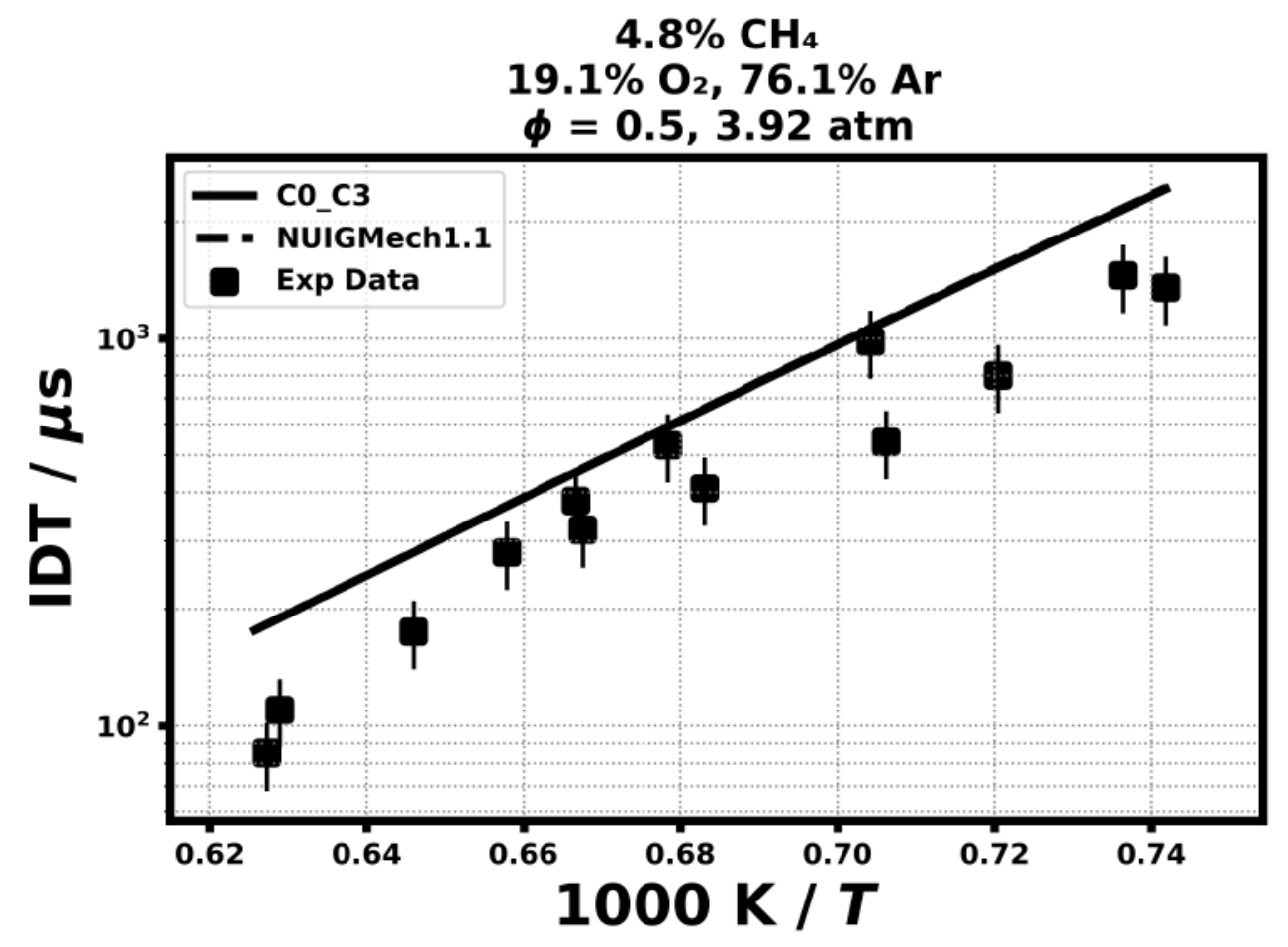

2.2) Burke, U., Somers, K. P., O’Toole, P., Zinner, C. M., Marquet, N., Bourque, G., ... \& Curran, H. J., Combustion and flame, 162(2) (2015) 315-330.

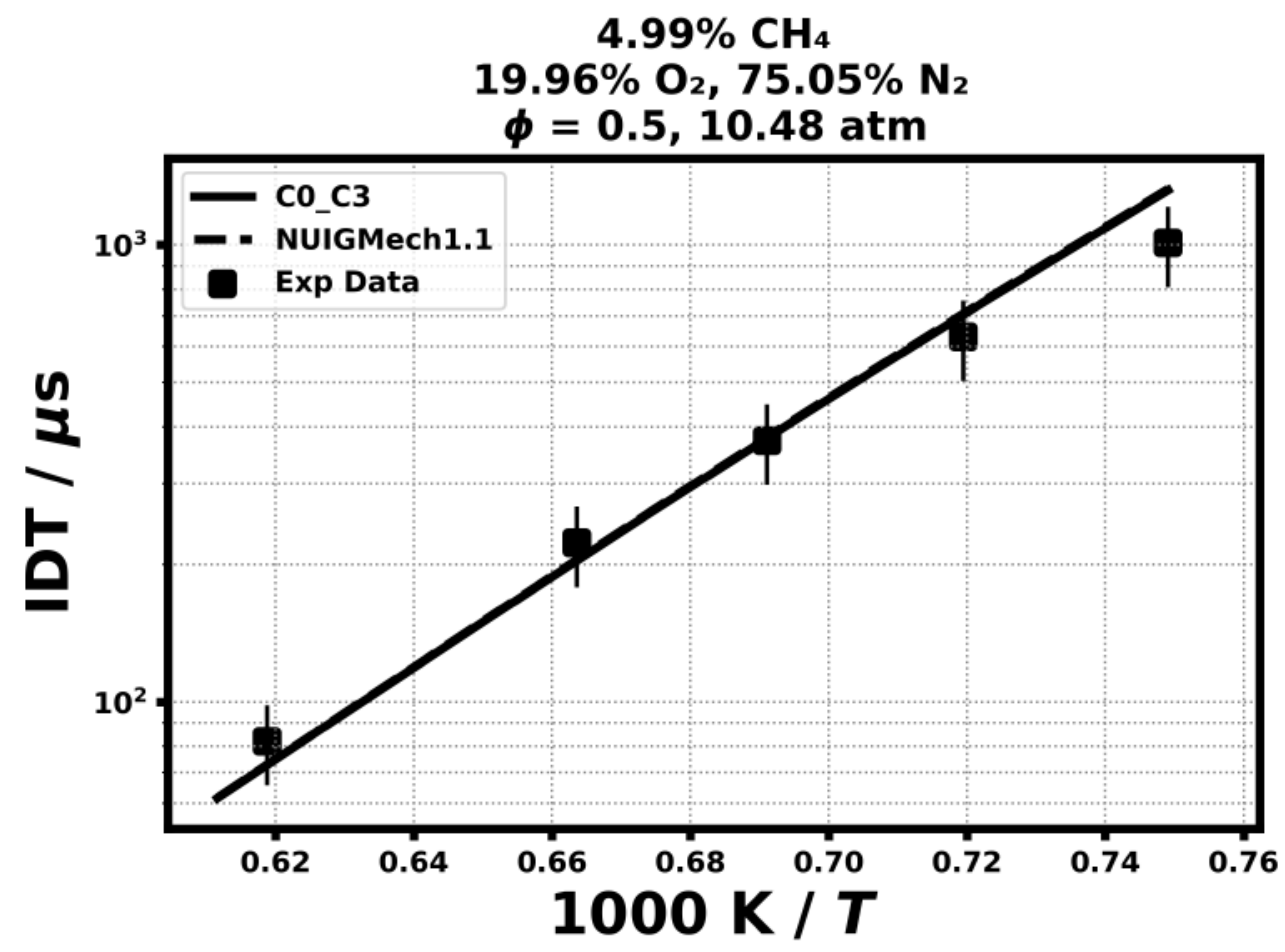



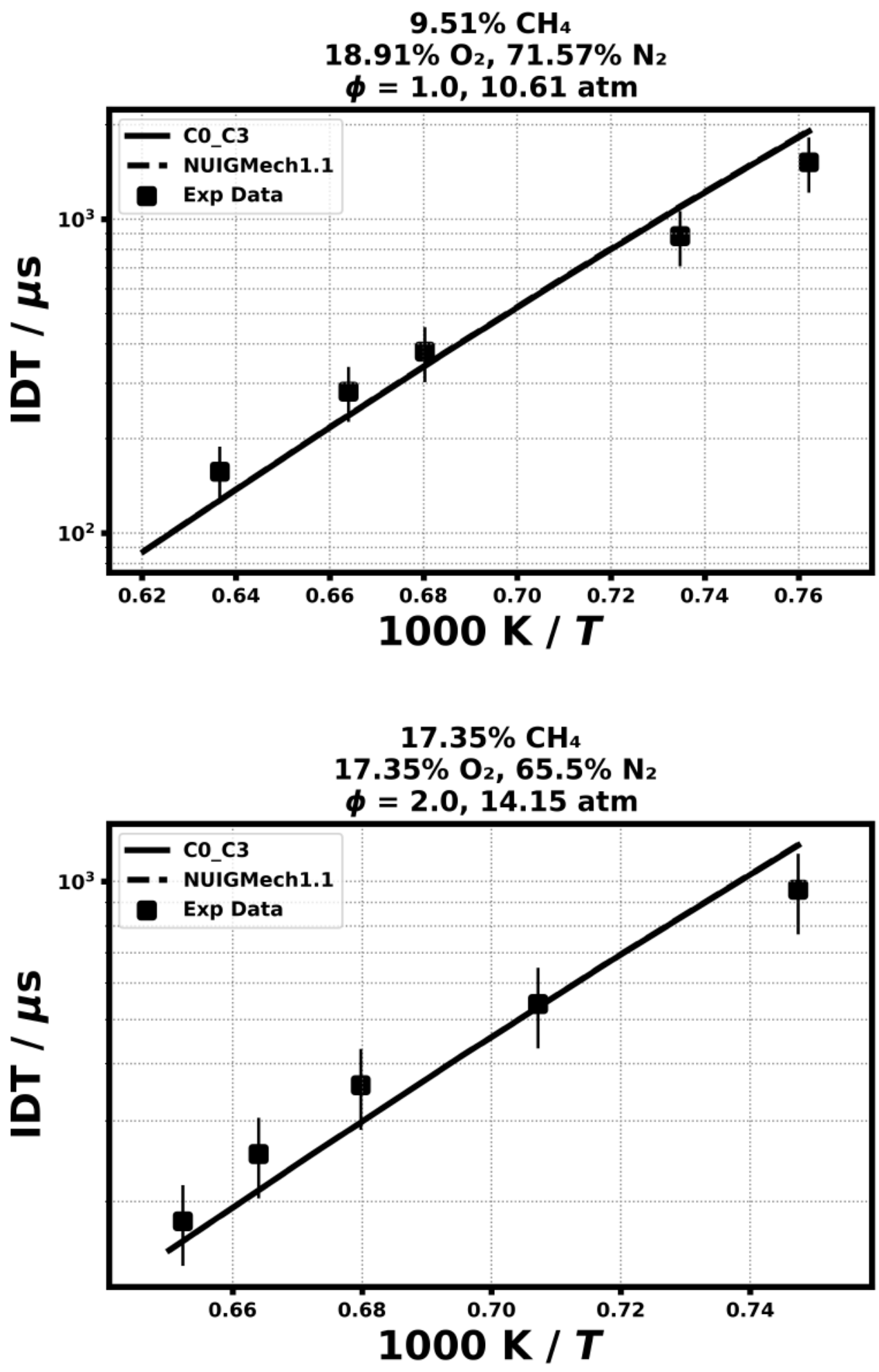

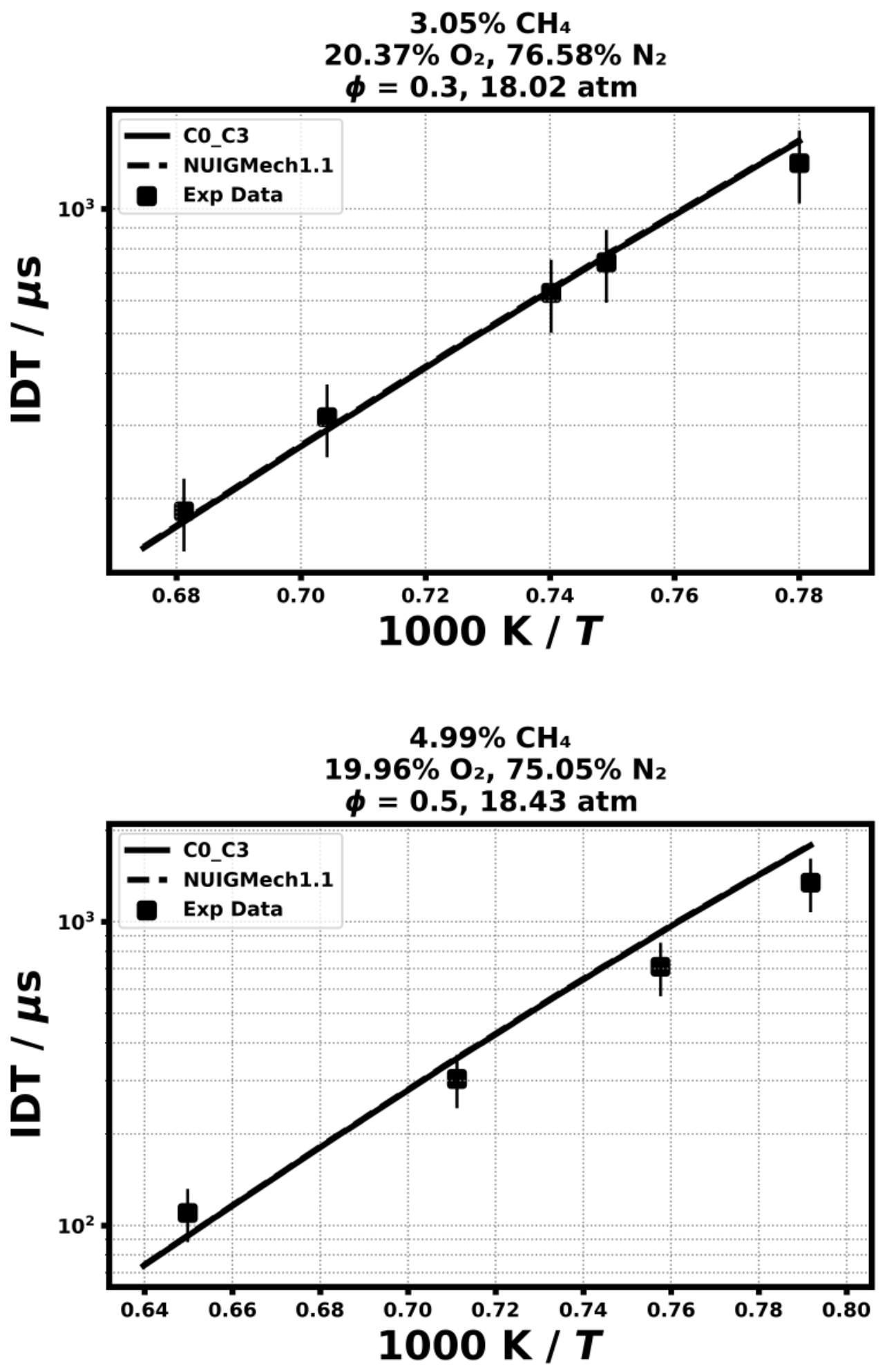

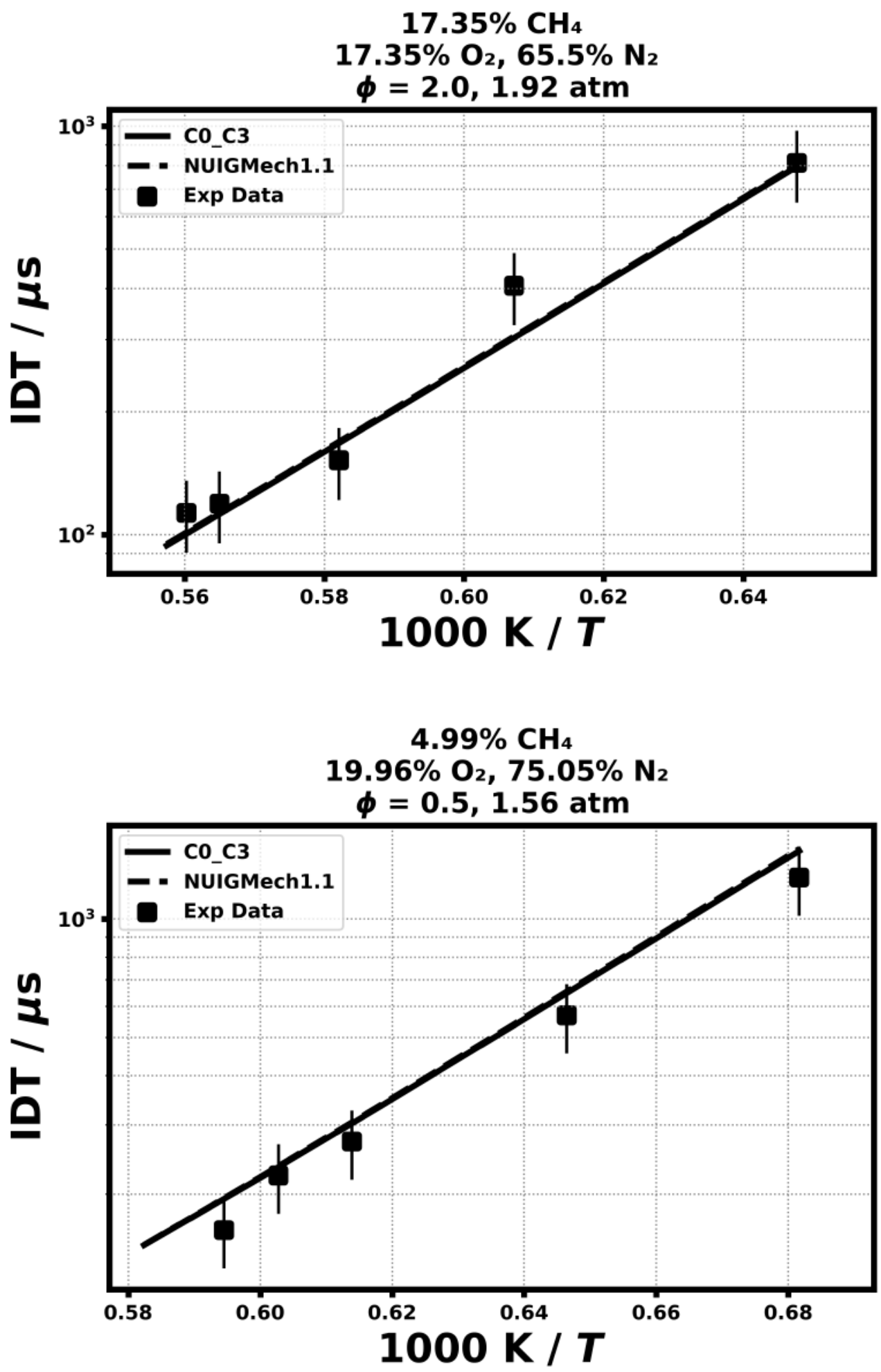

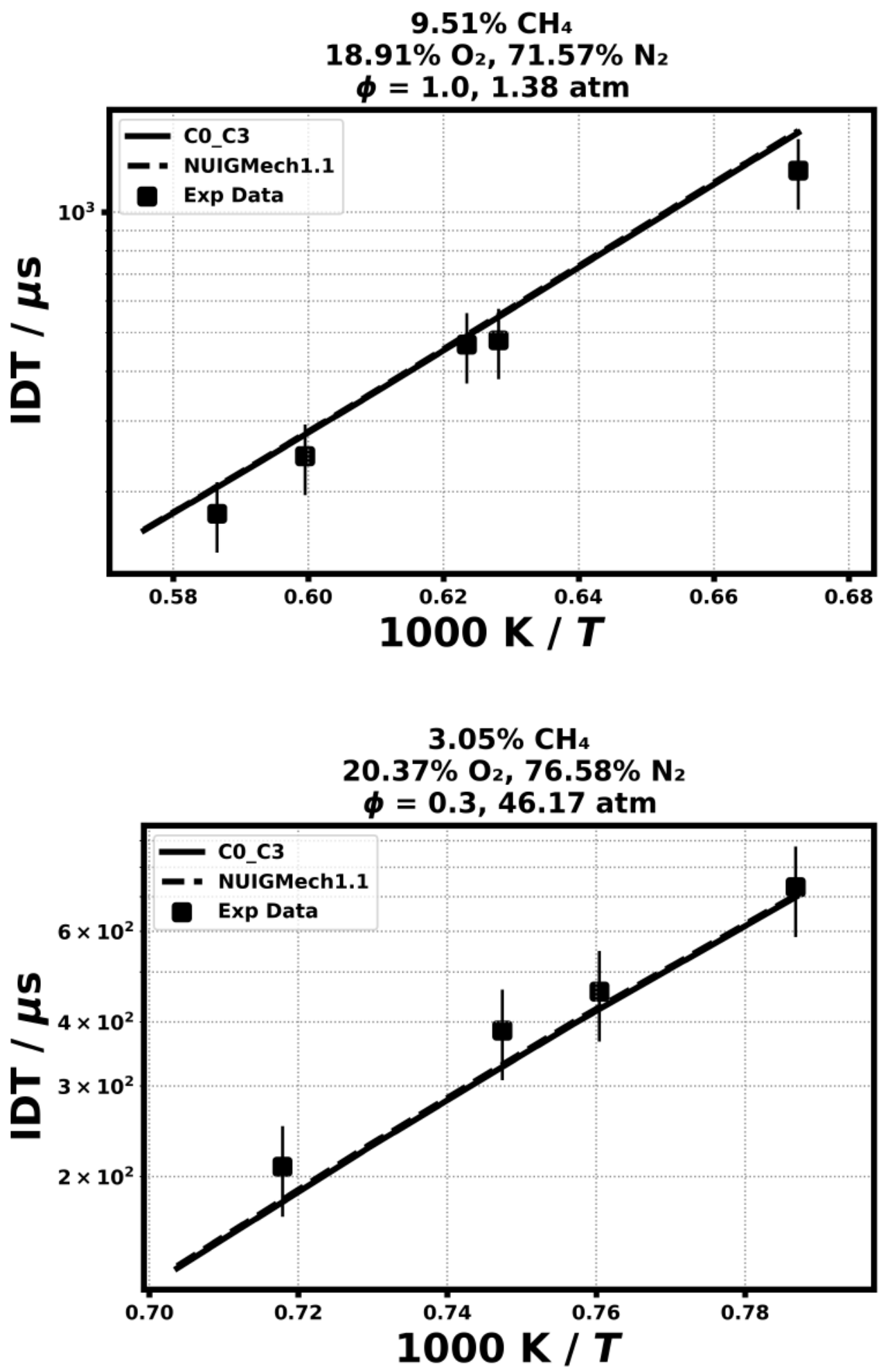

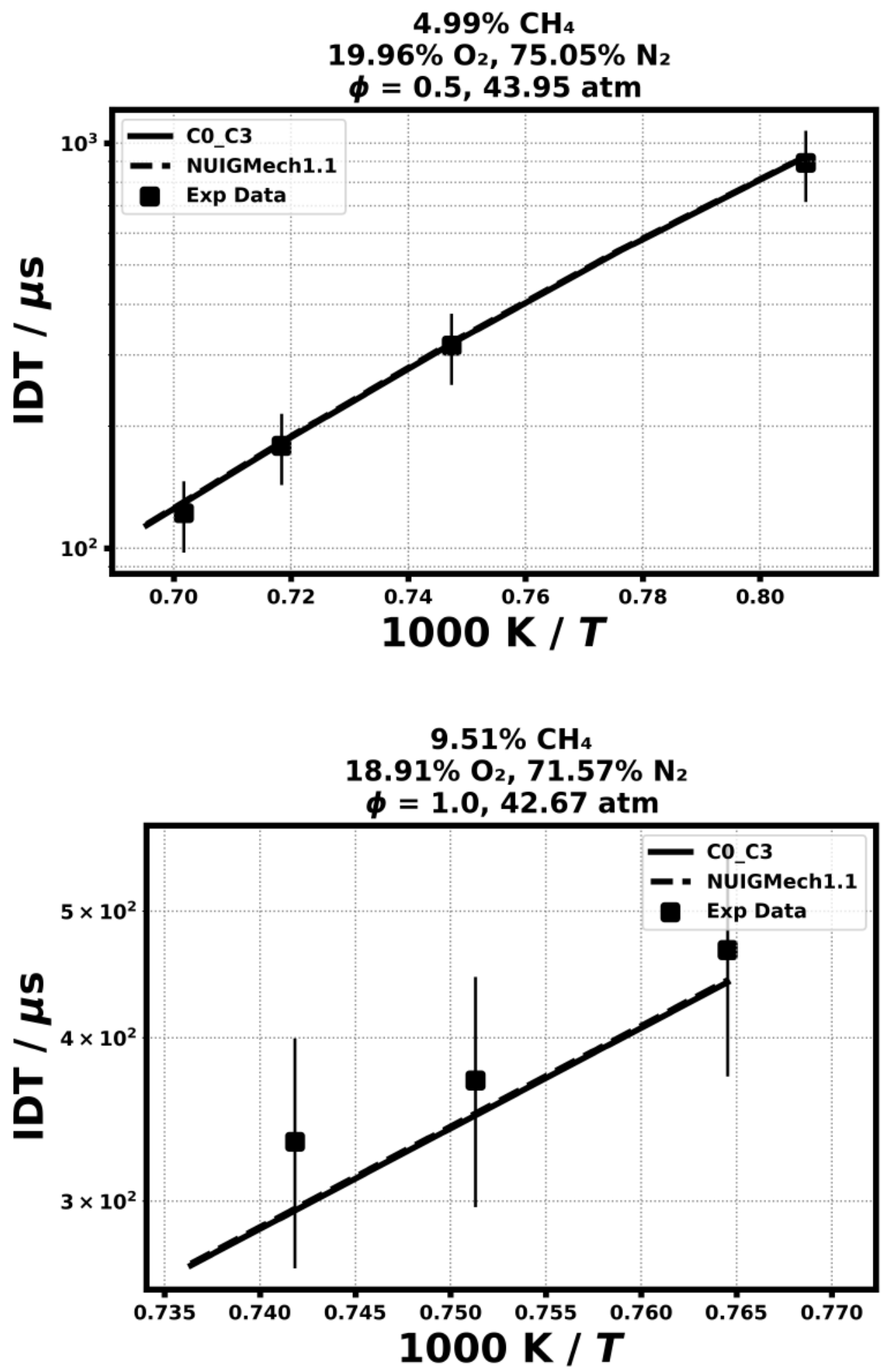


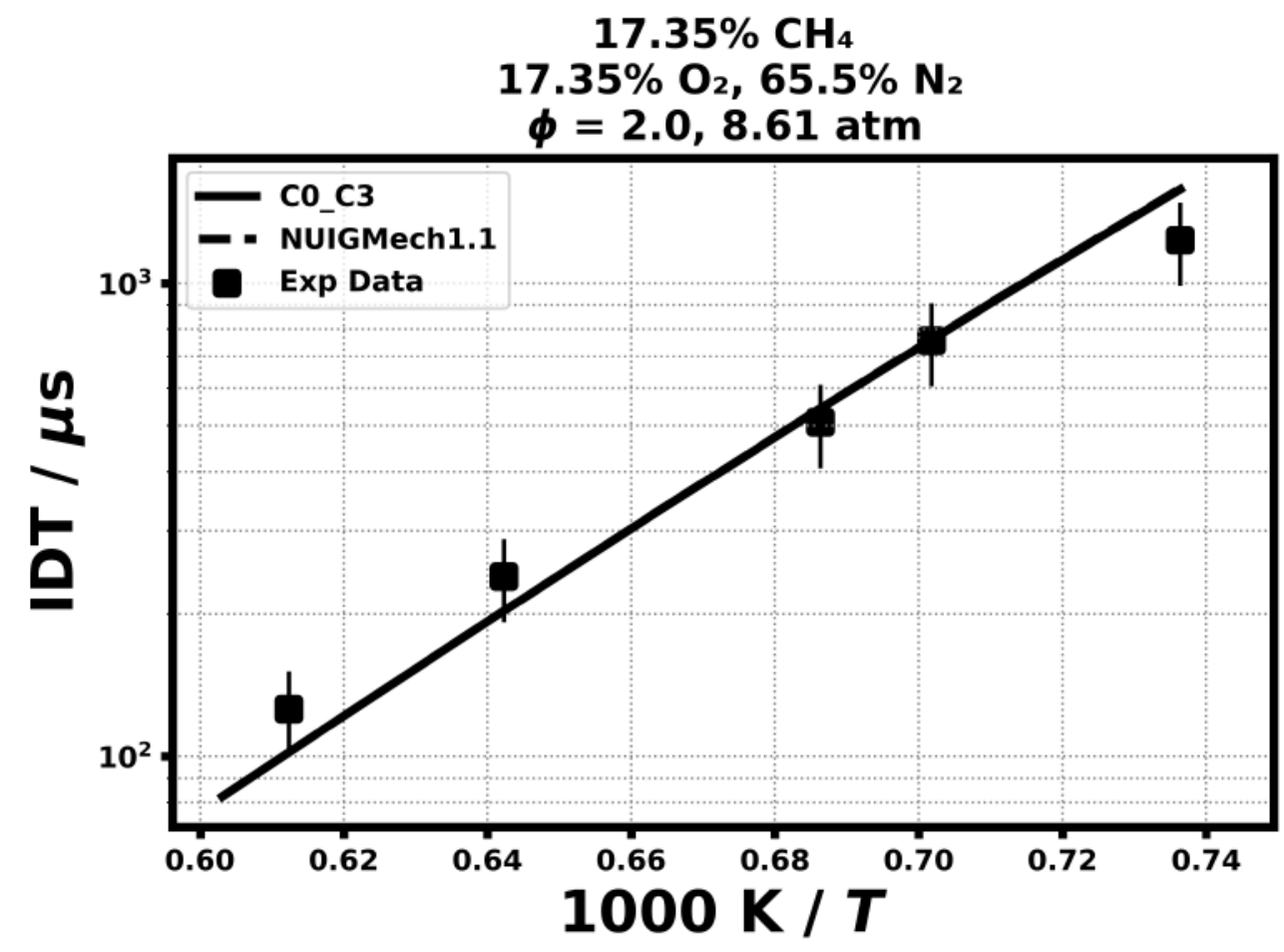

2.3) Eubank, C. S., M. J. Rabinowitz, W. C. Gardiner Jr, and R. E. Zellner, In Symposium (International) on Combustion, 18 (1981) 1767-1774.

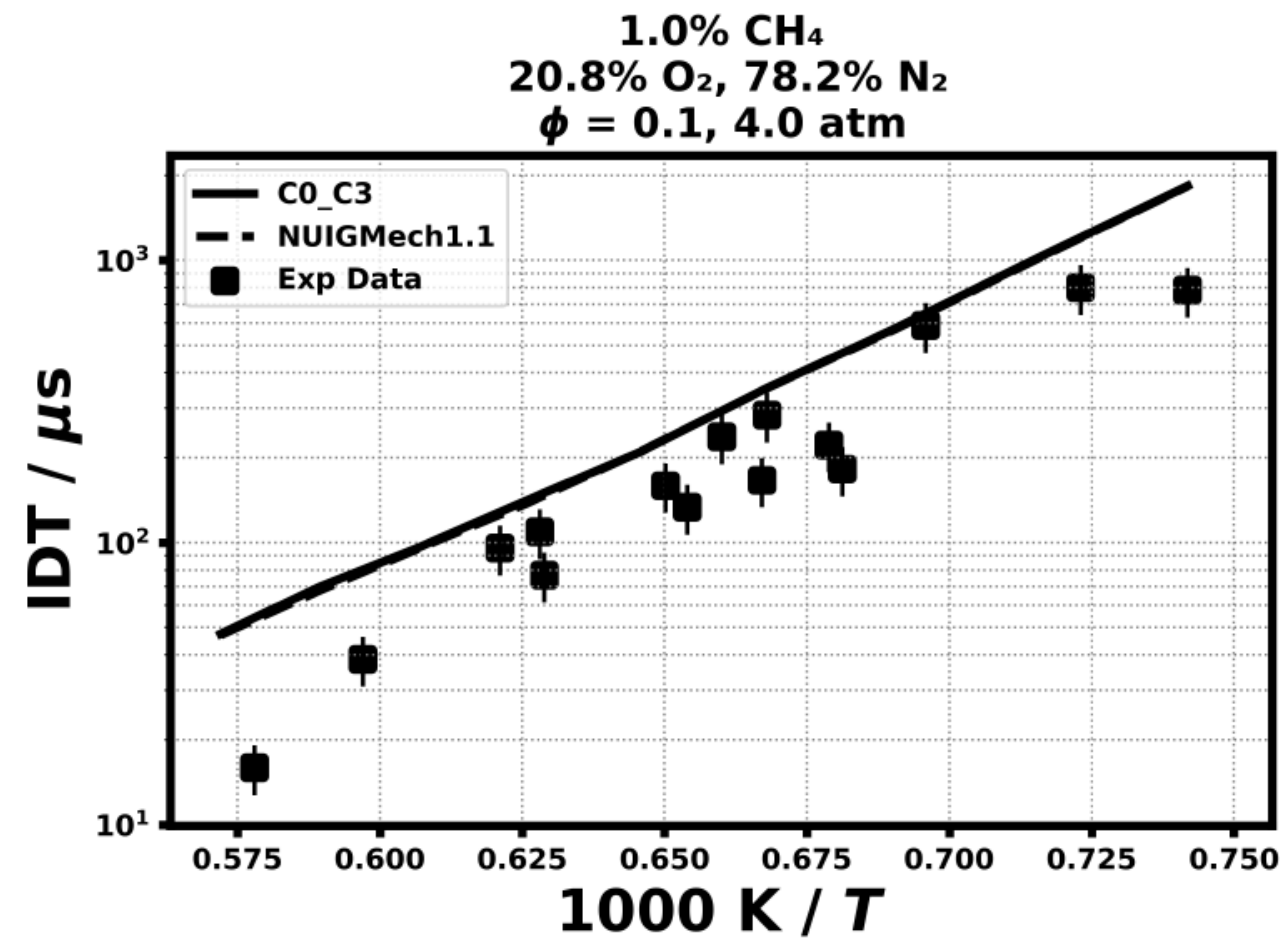



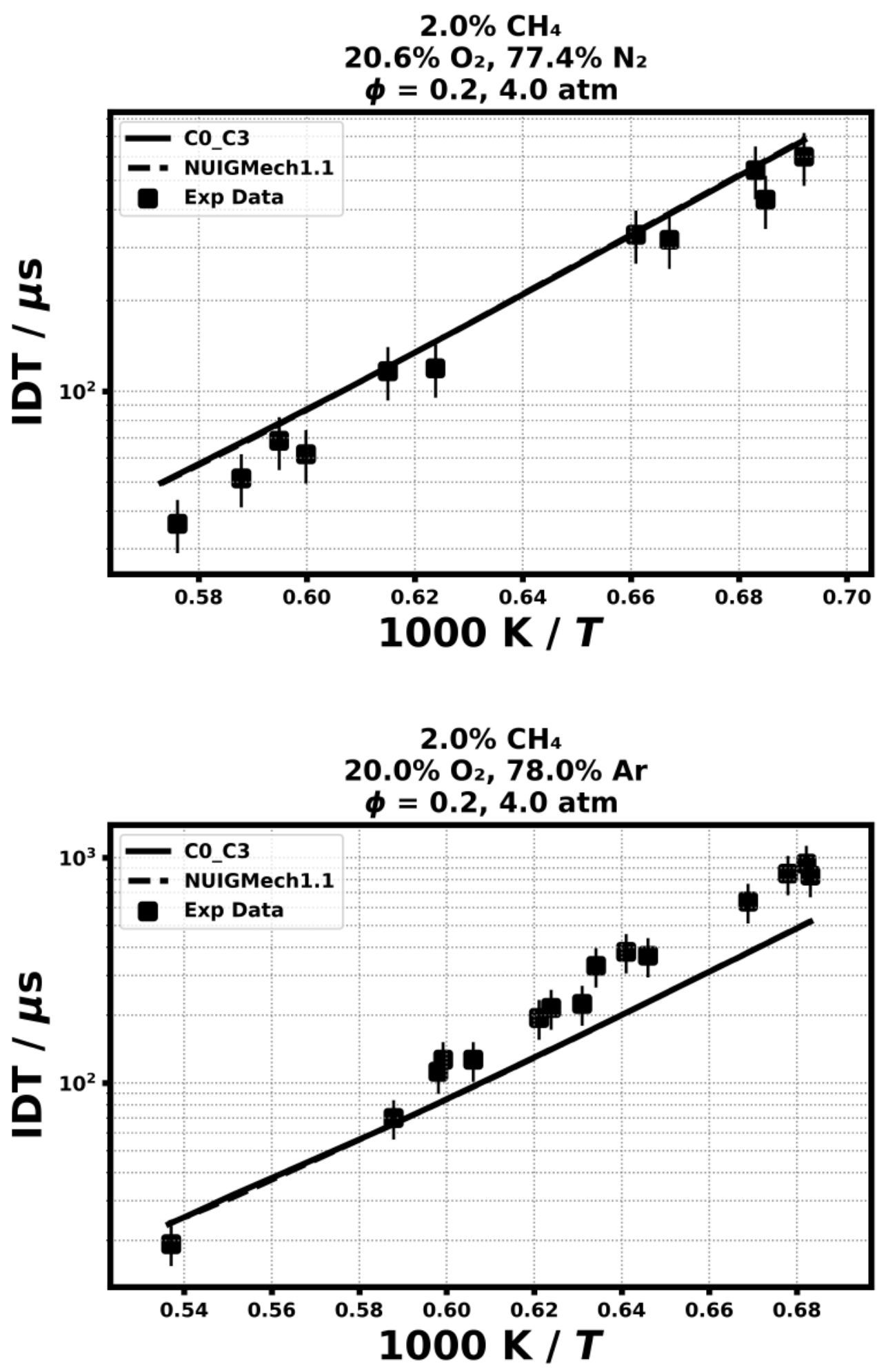

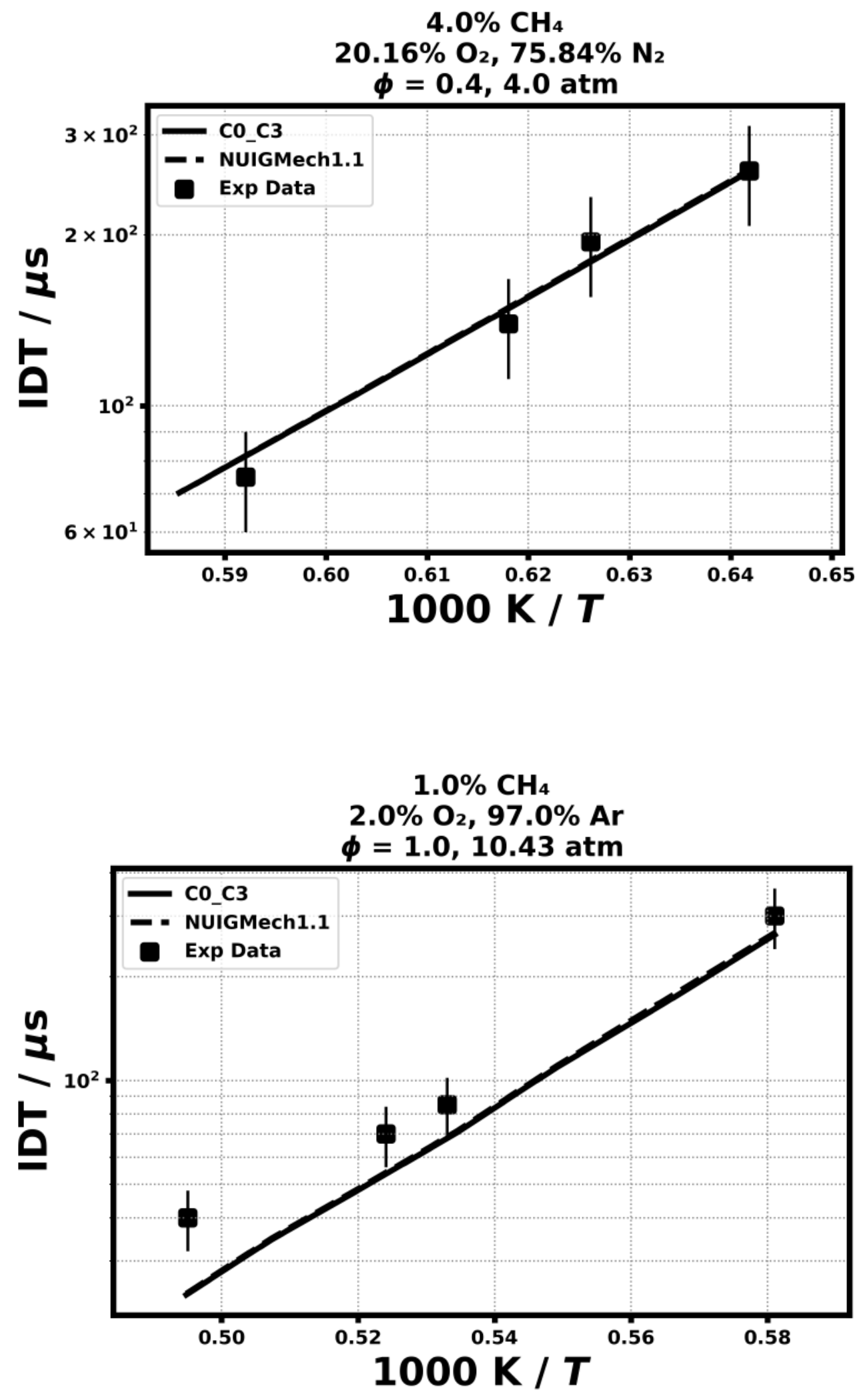


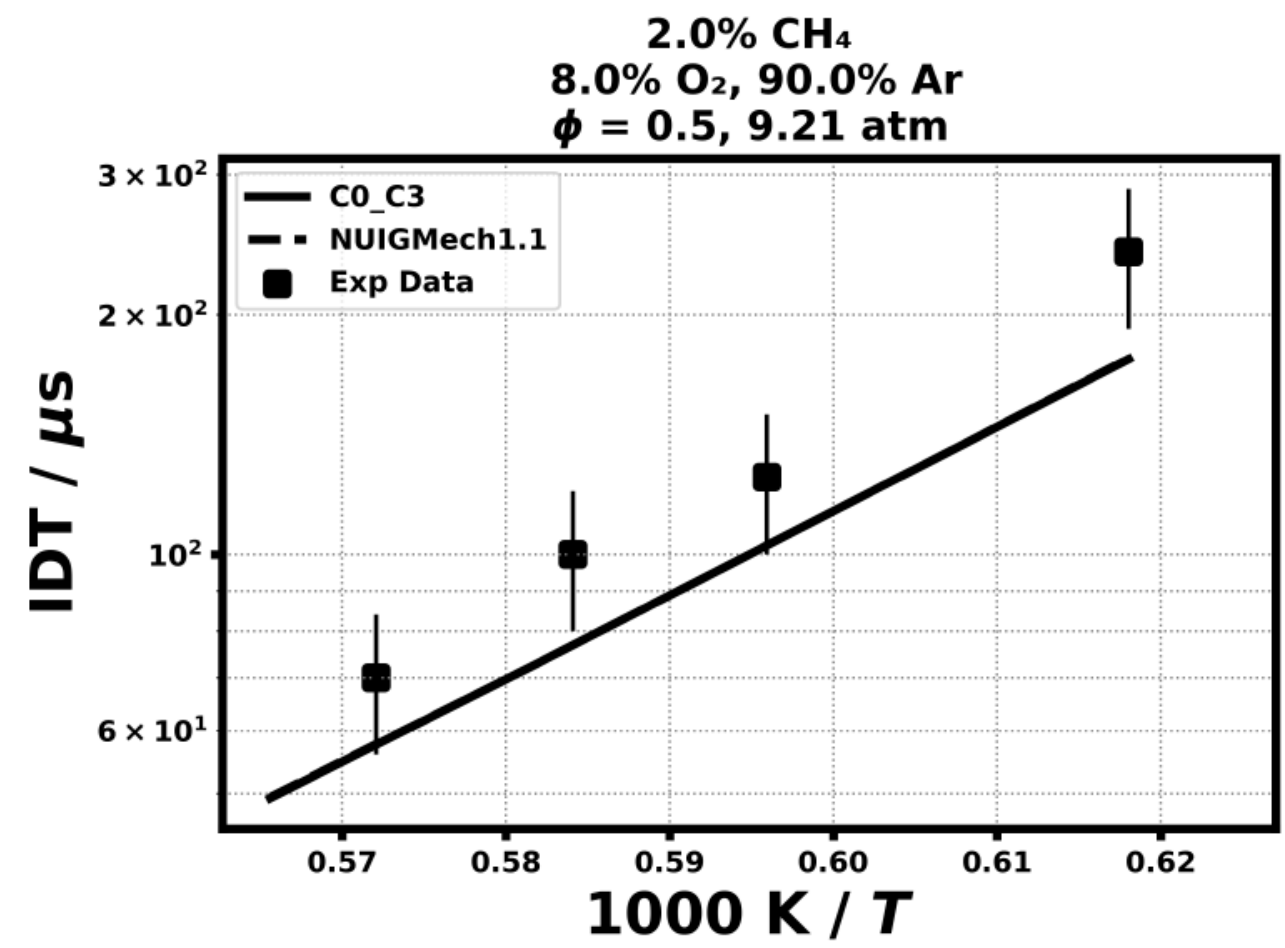

2.4) Lifshitz, A., Scheller, K., Burcat, A., \& Skinner, G. B. Combustion and Flame, 16(3) (1971) 311-321.

\section{$2.1 \% \mathrm{CH}_{4}$}

$2.1 \% \mathrm{O}_{2}, 95.8 \% \mathrm{Ar}$

$\phi=2.0,9.42 \mathrm{~atm}$

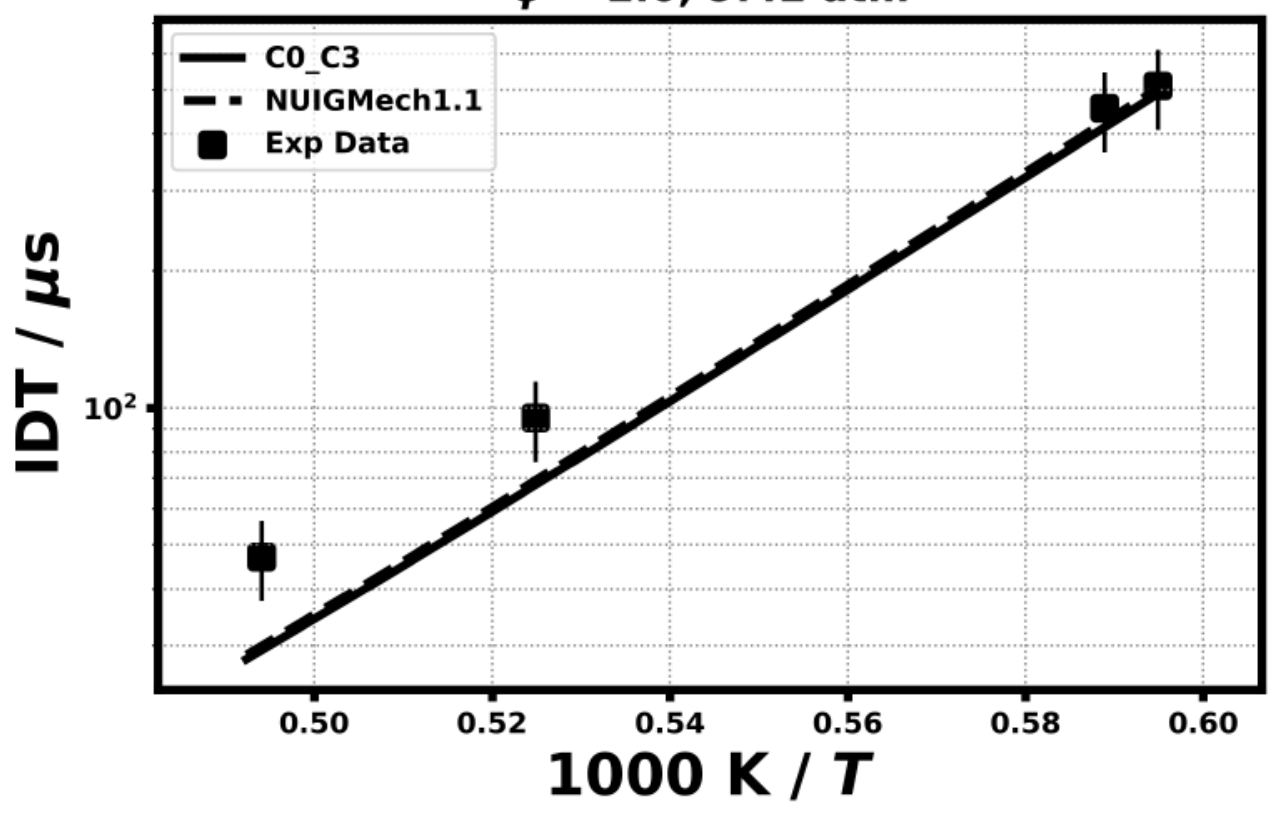



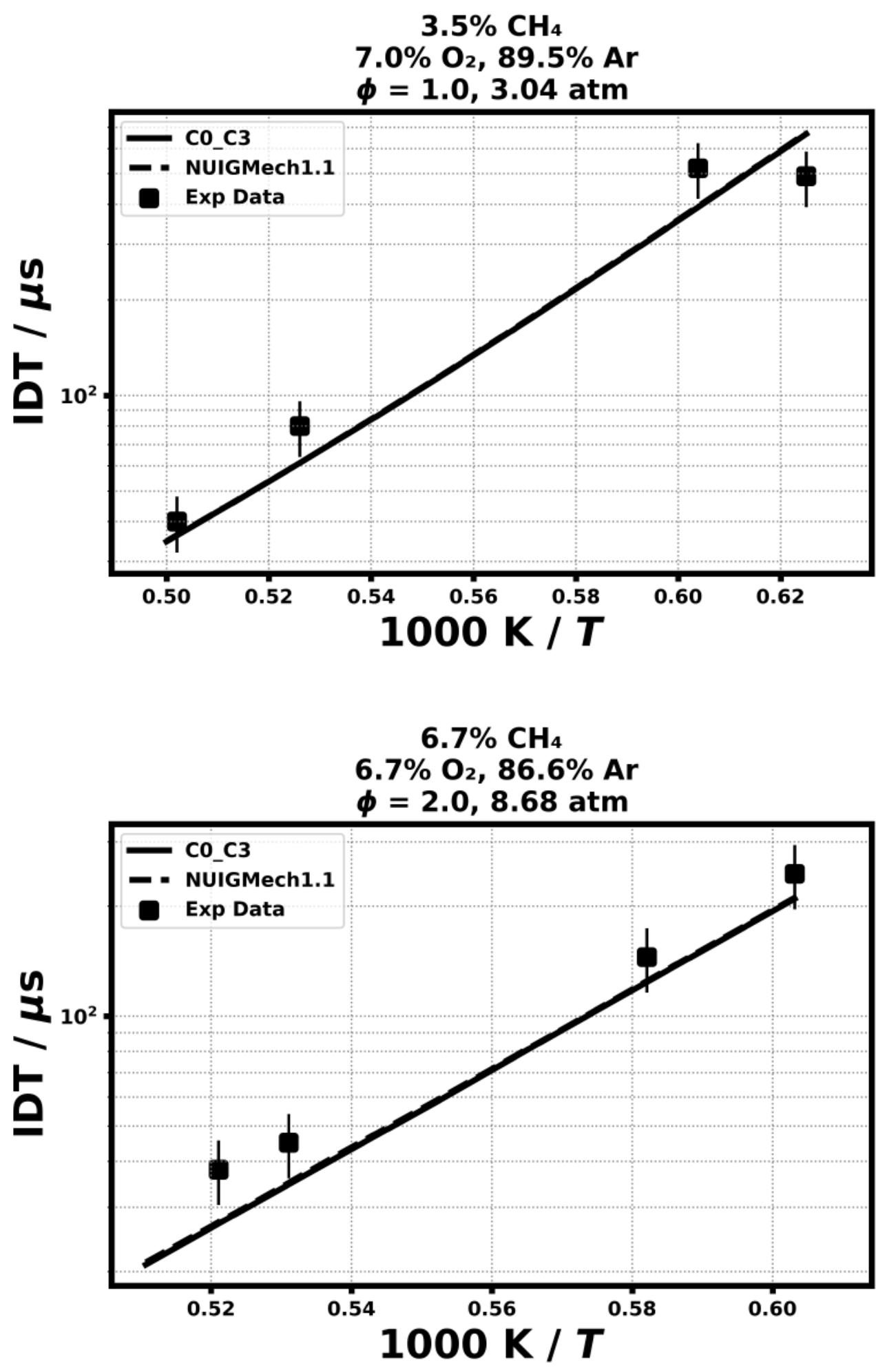

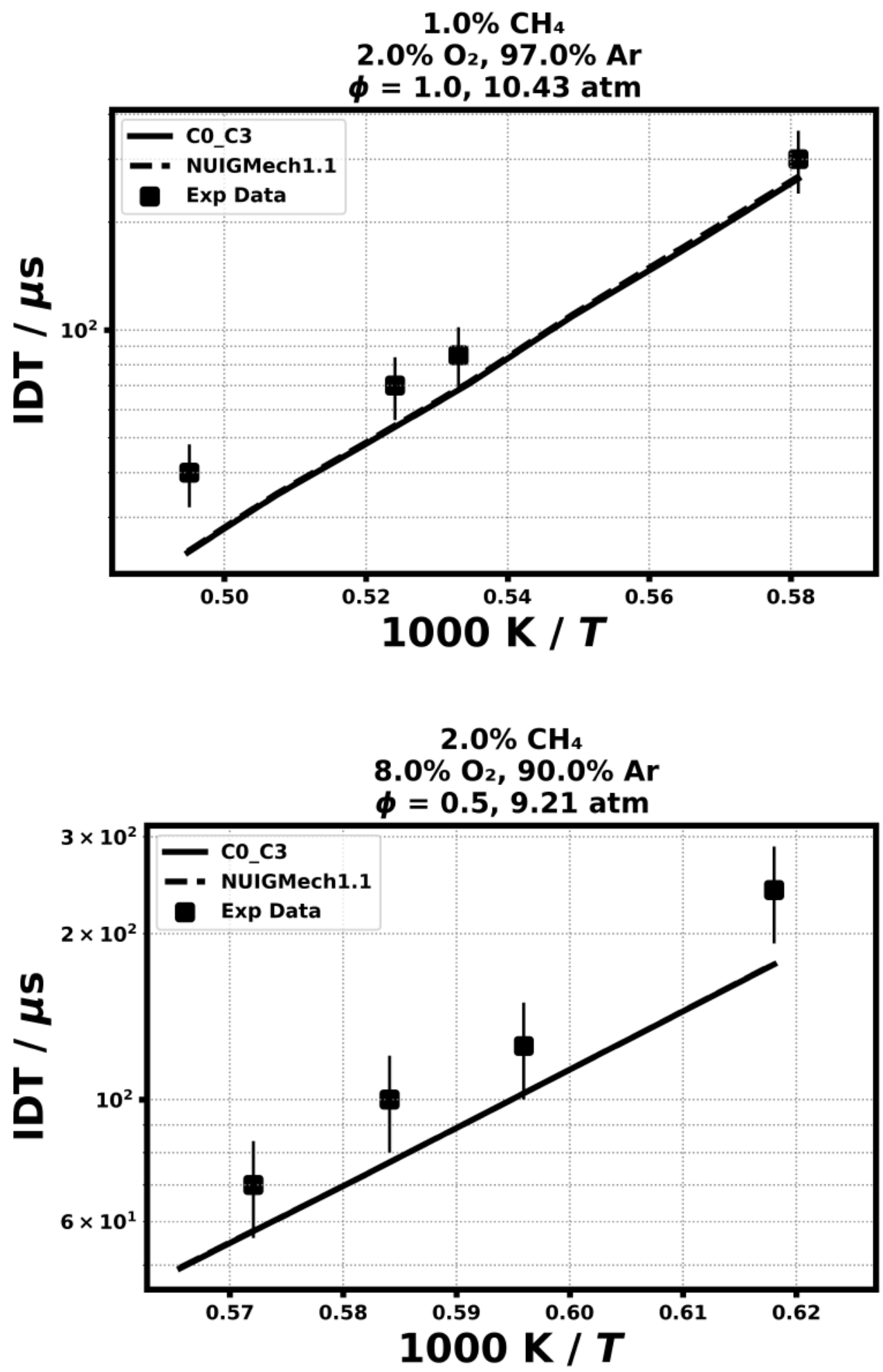

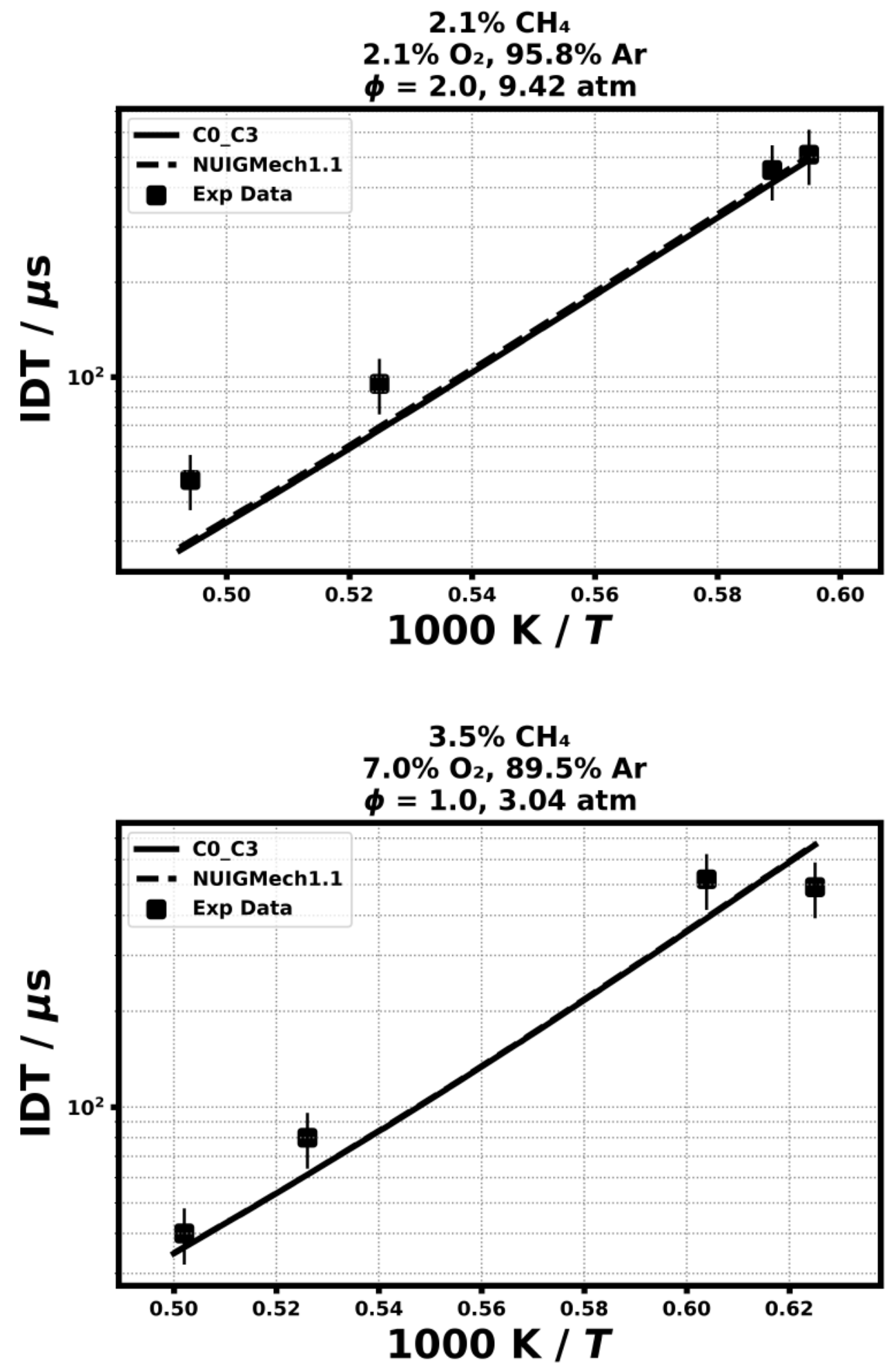


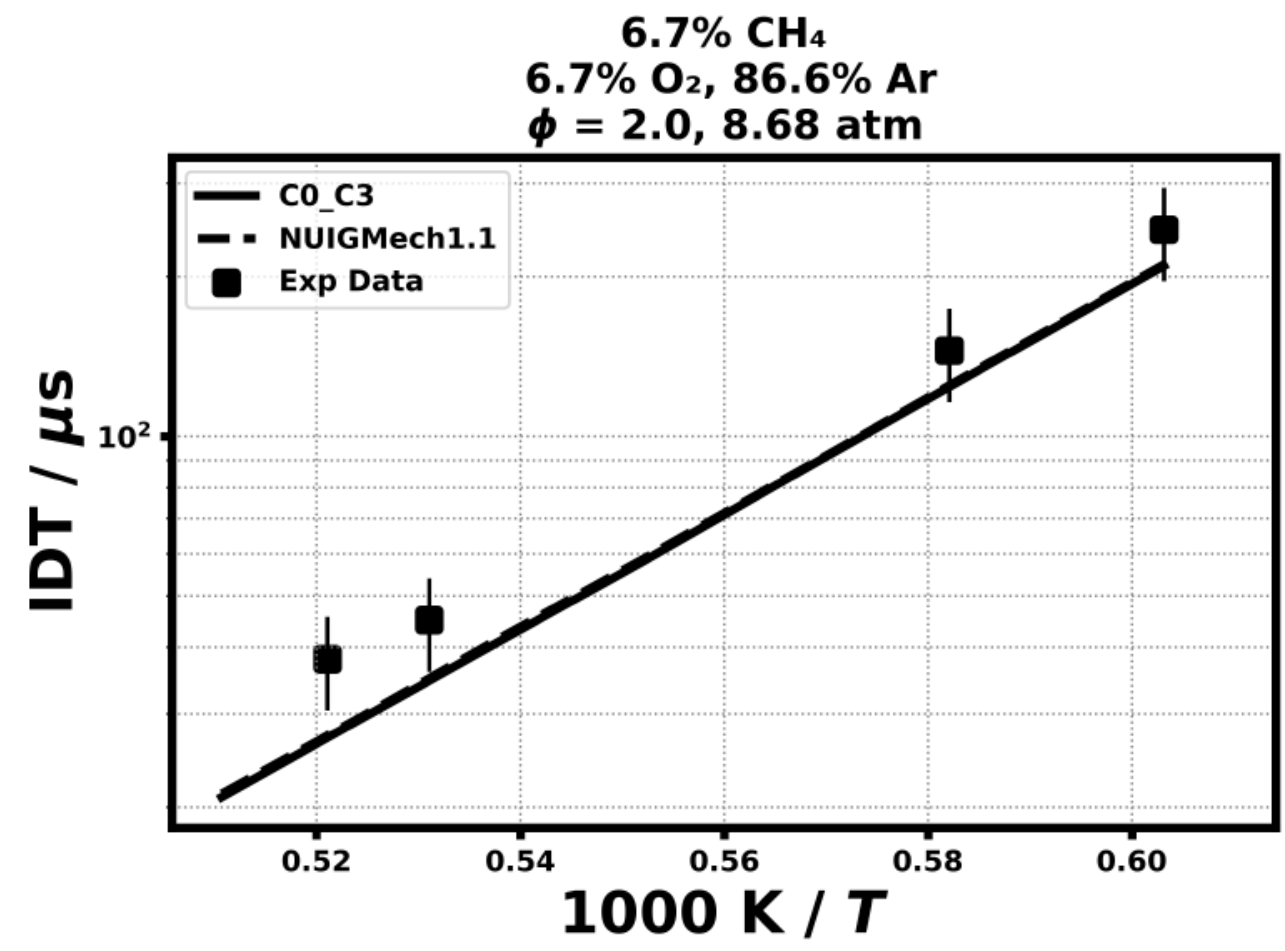

2.5) Mathieu, O., Goulier, J., Gourmel, F., Mannan, M. S., Chaumeix, N., \& Petersen, E. L., Proceedings of the Combustion Institute, 35(3) (2015) 2731-2739.

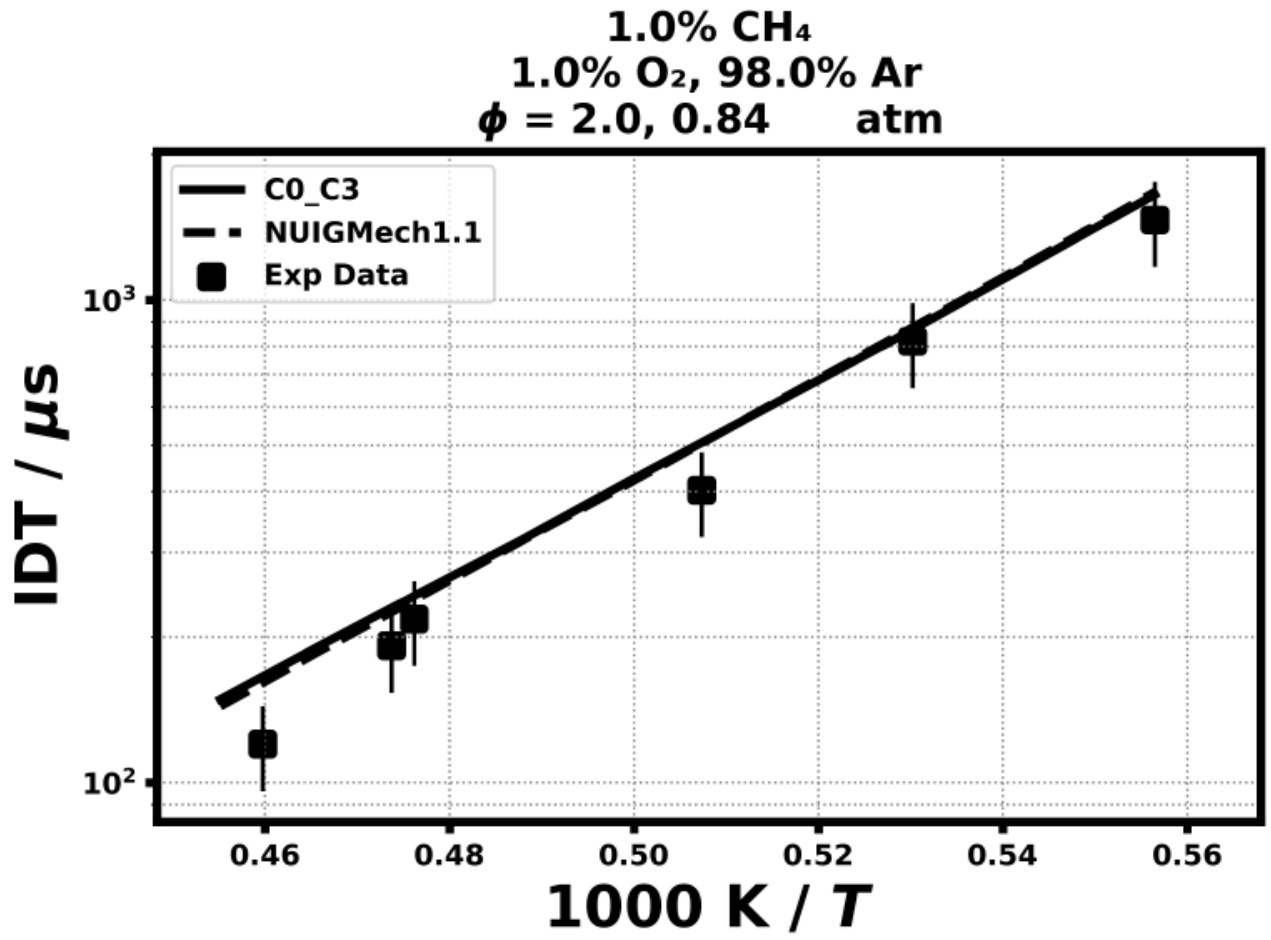



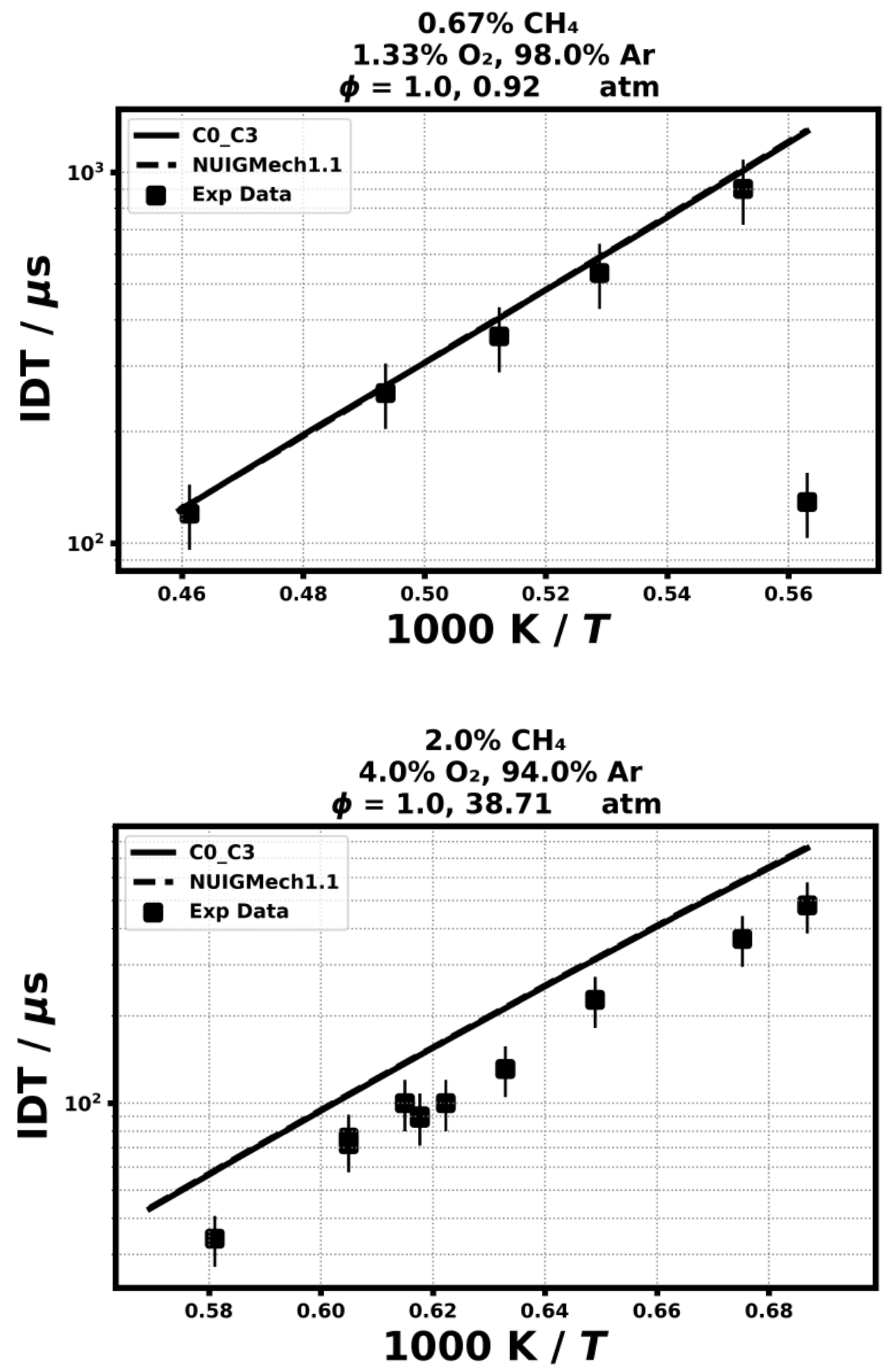
2.6) Petersen, E. L., Davidson, D. F., \& Hanson, R. K. Journal of Propulsion and Power, 15(1) (1999) 82-91.
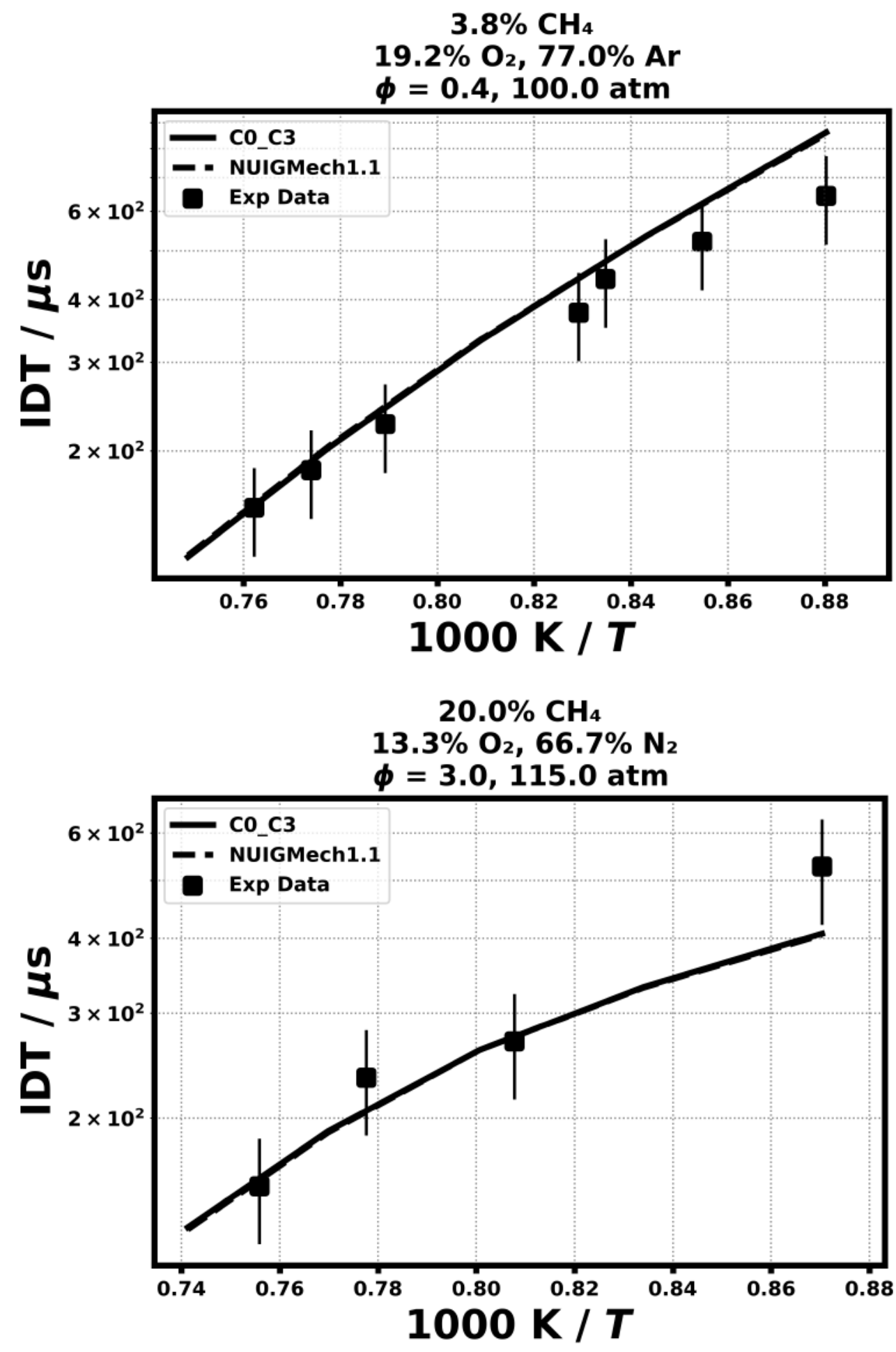

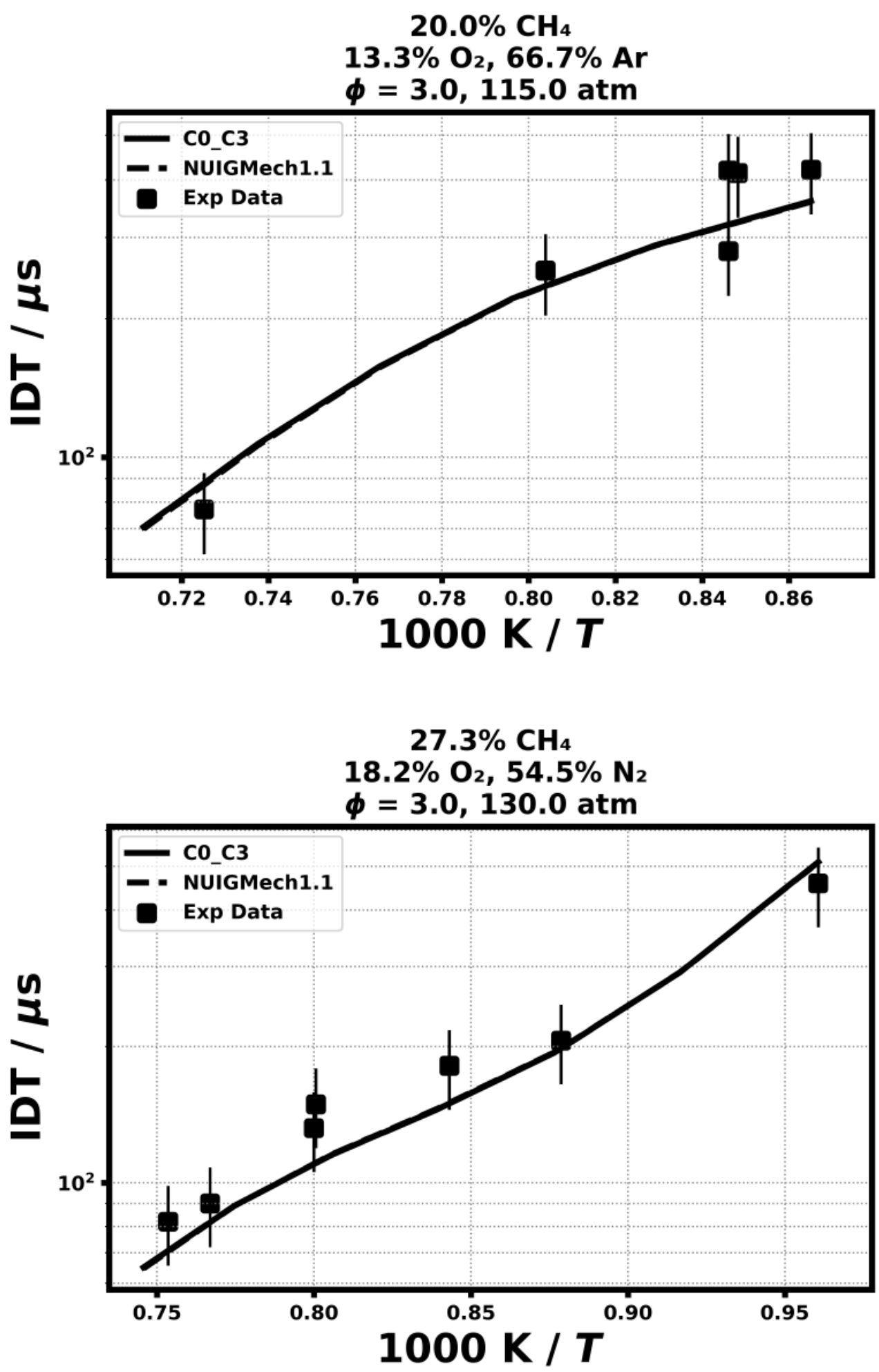

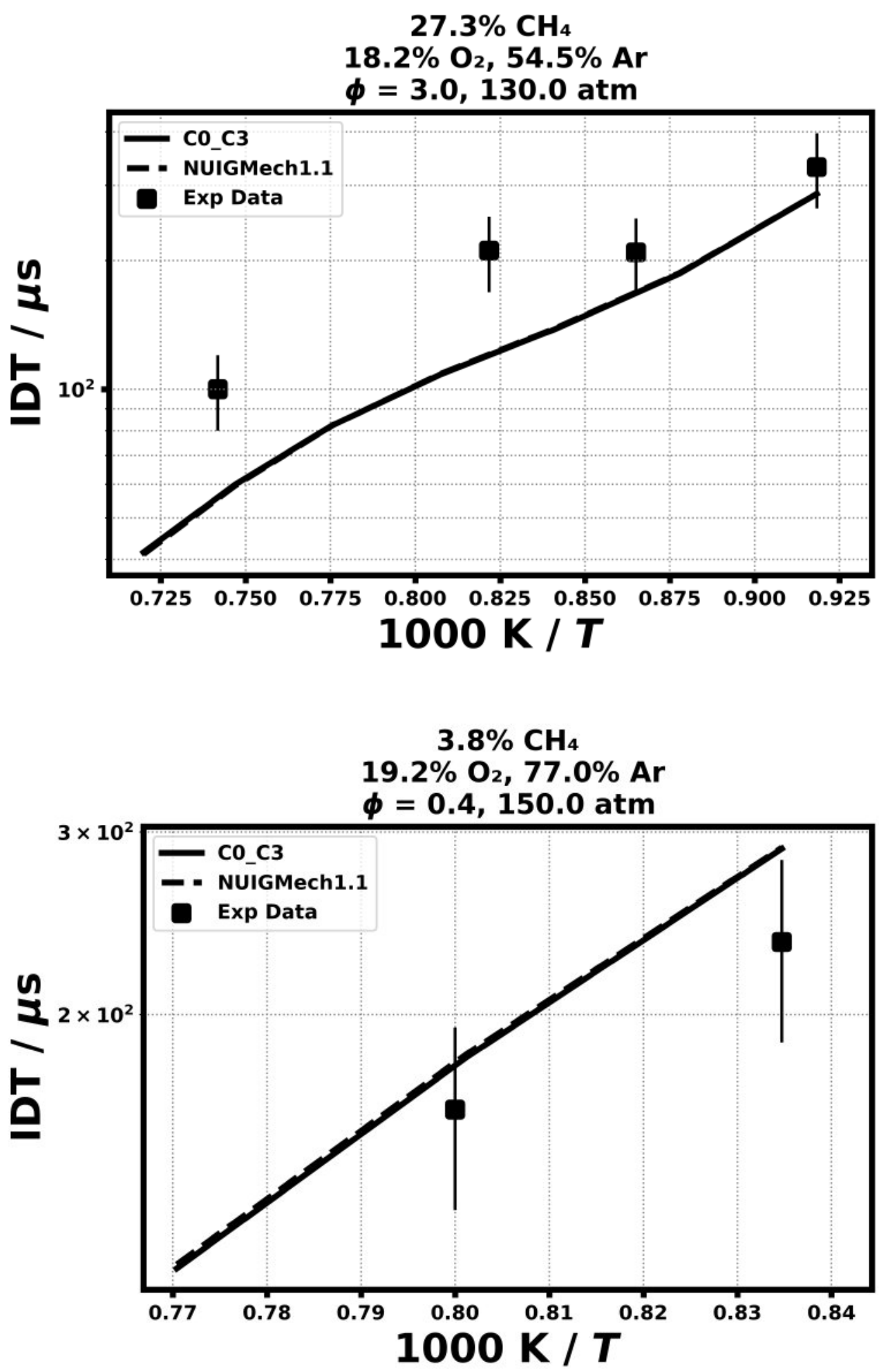

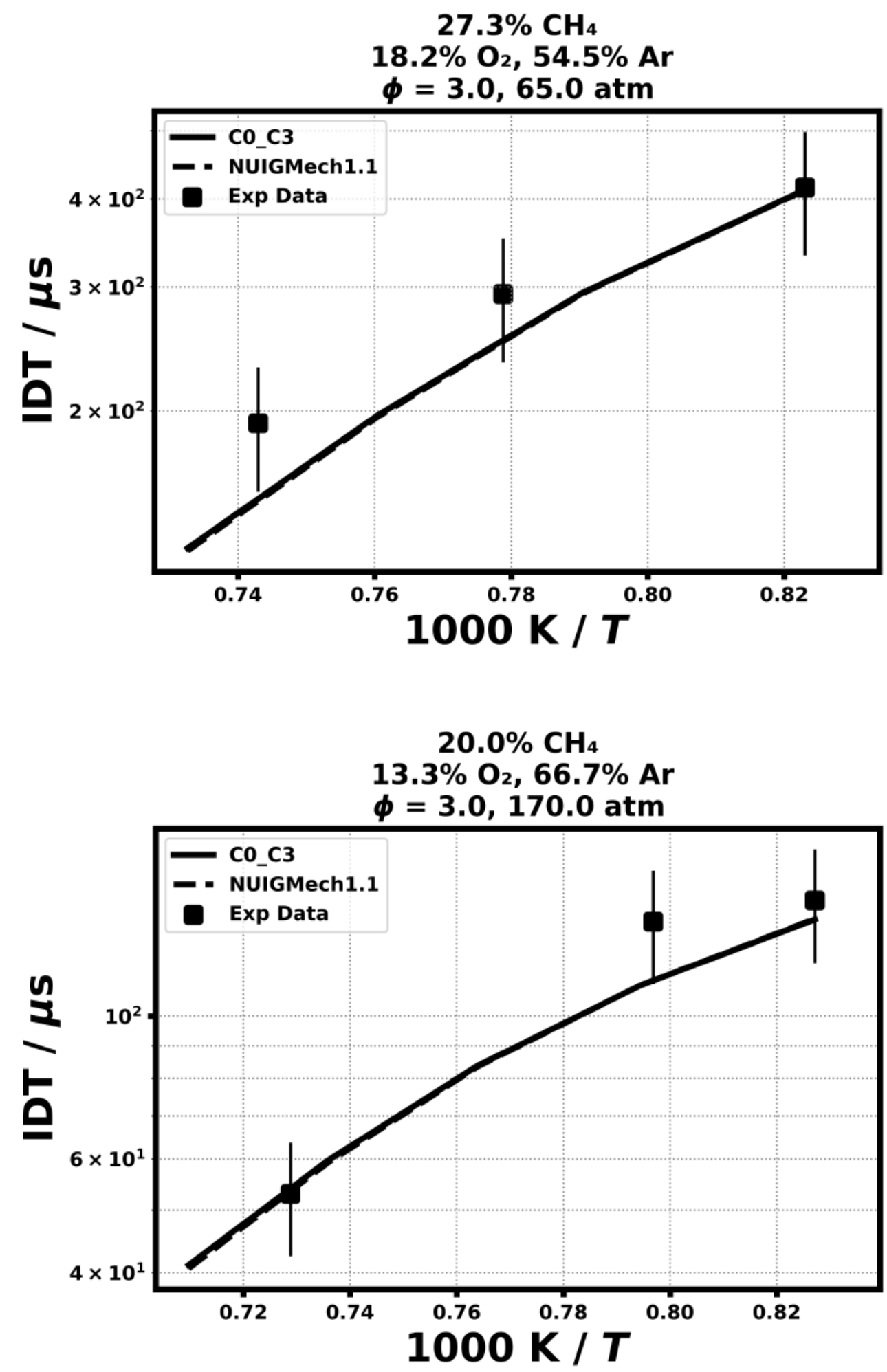

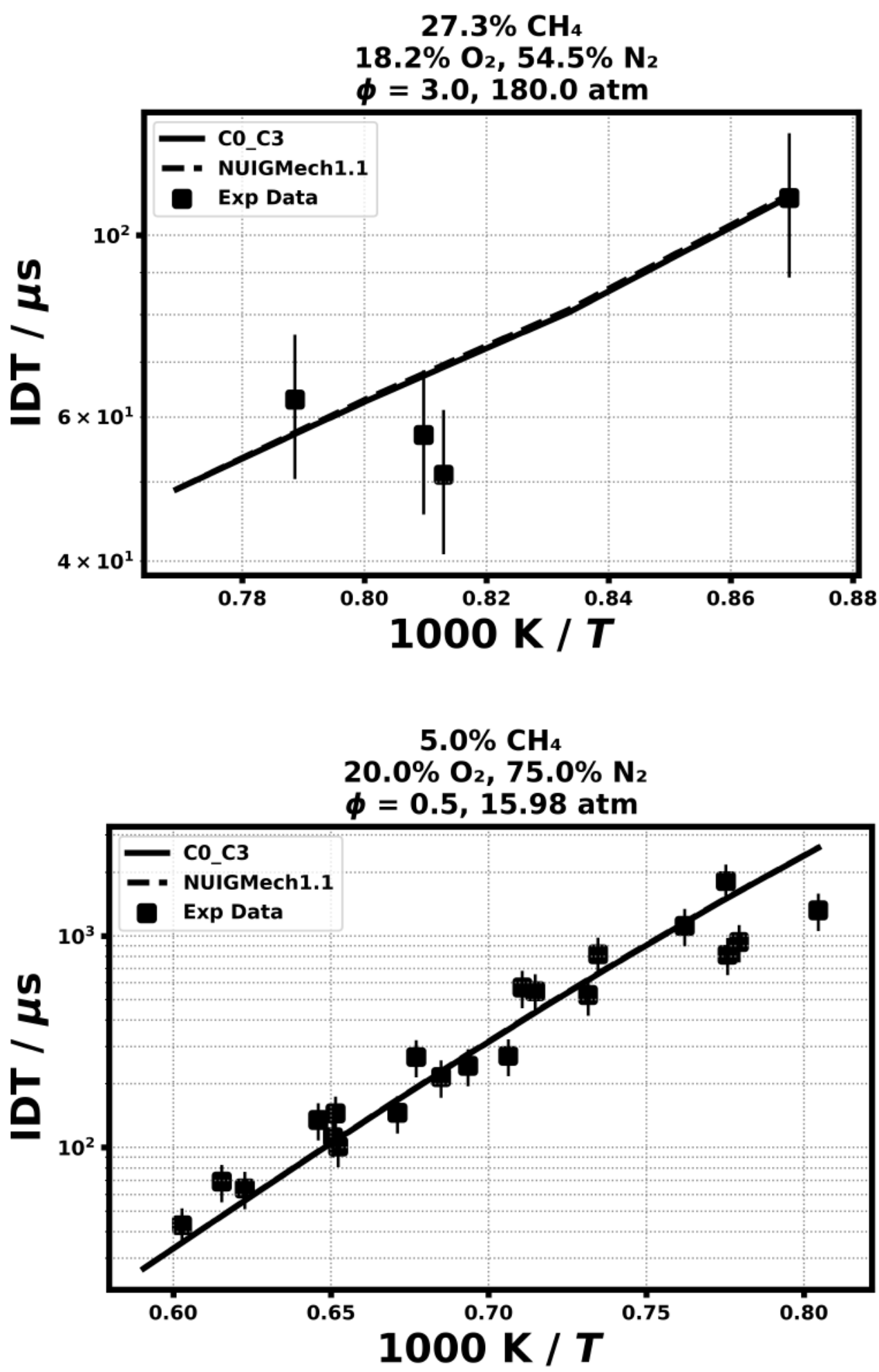

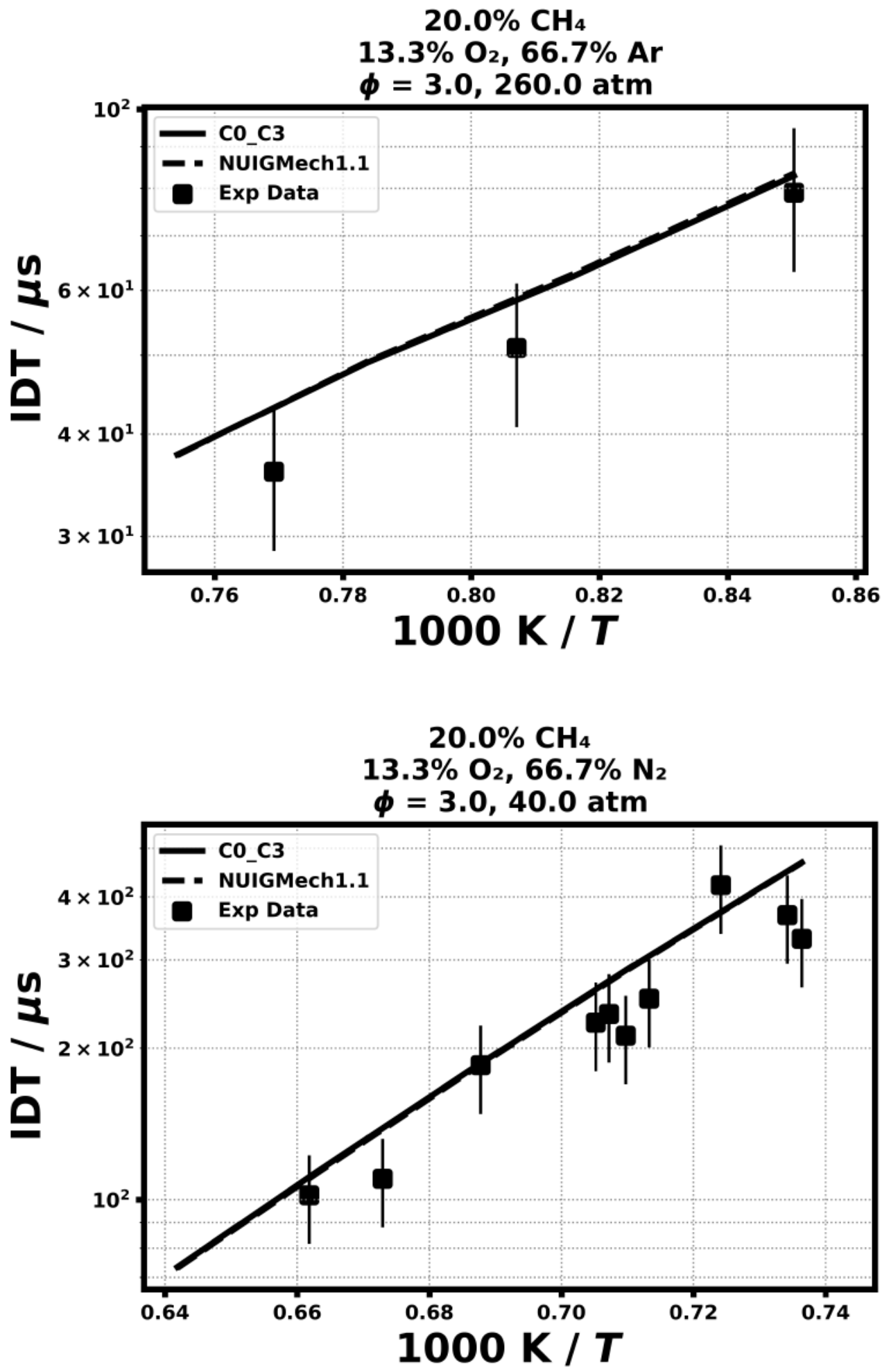

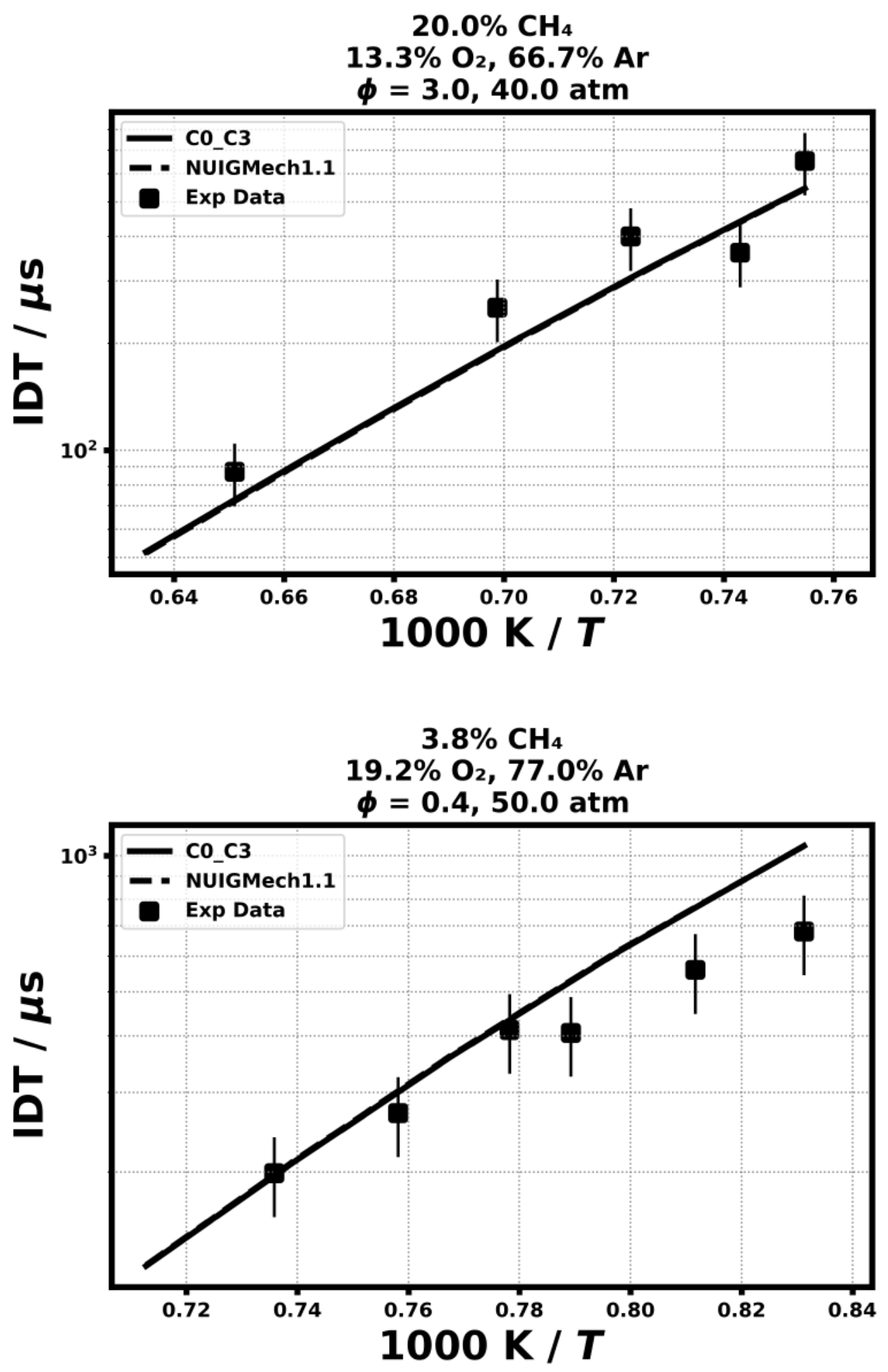

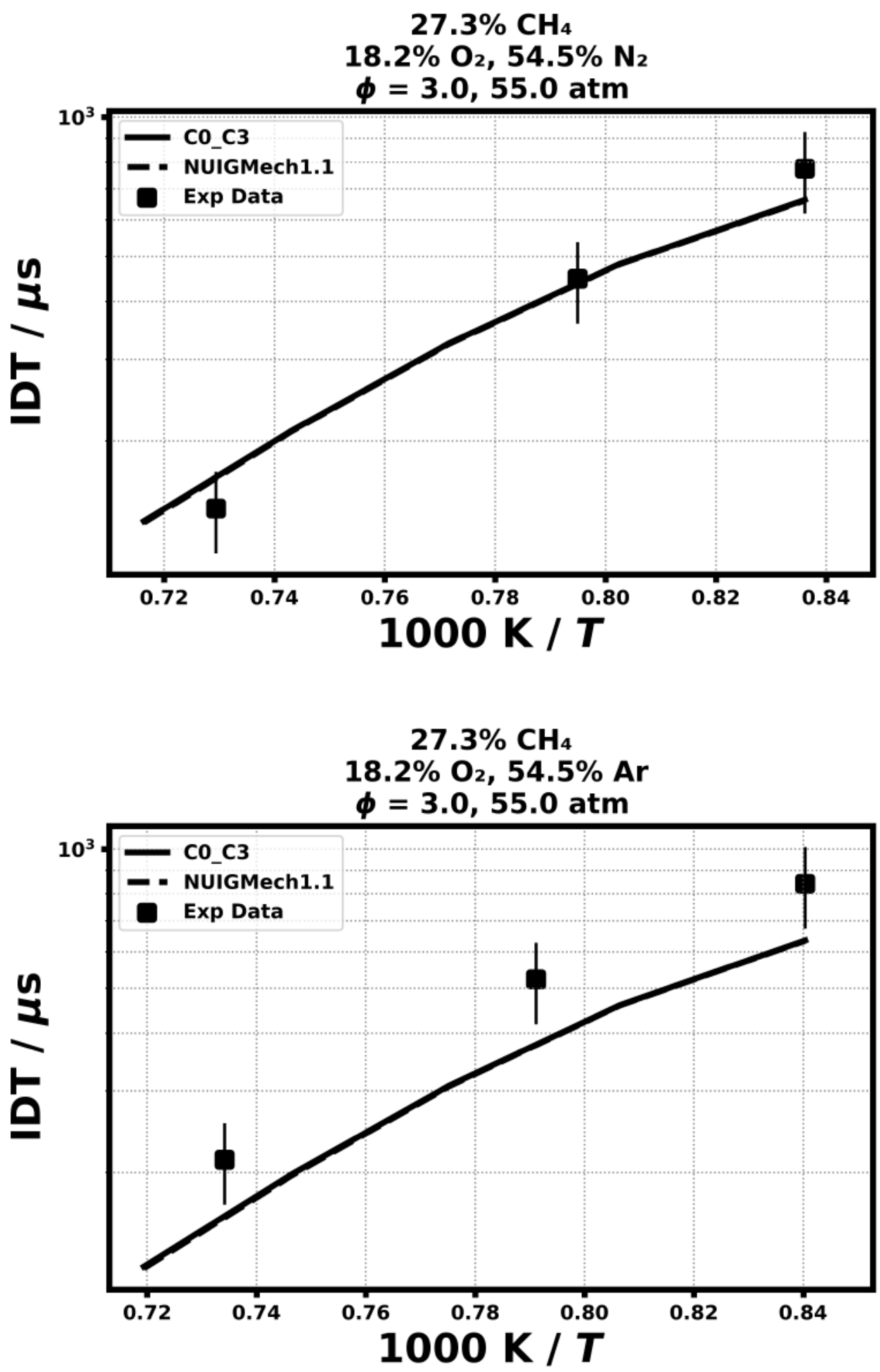

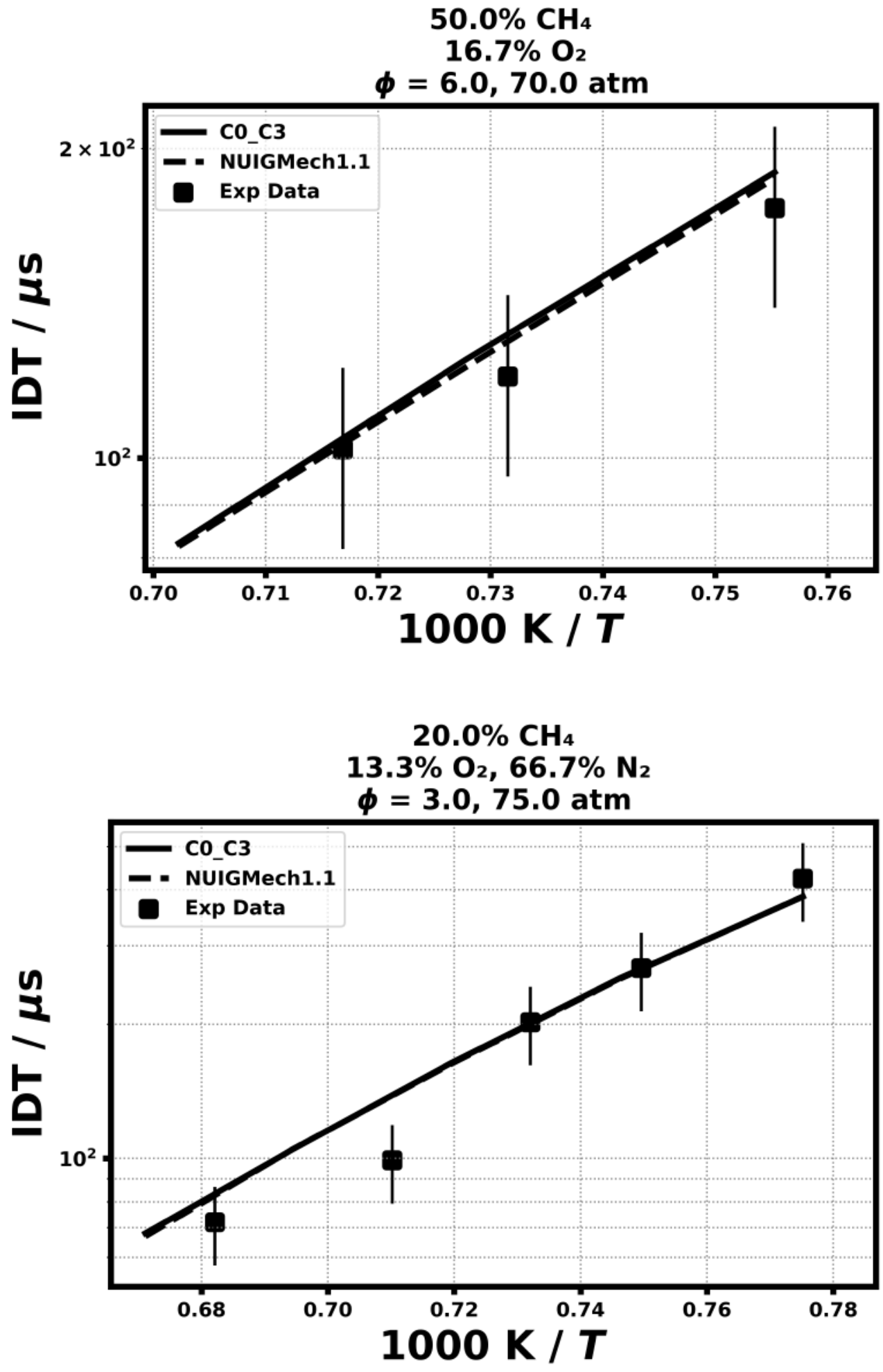

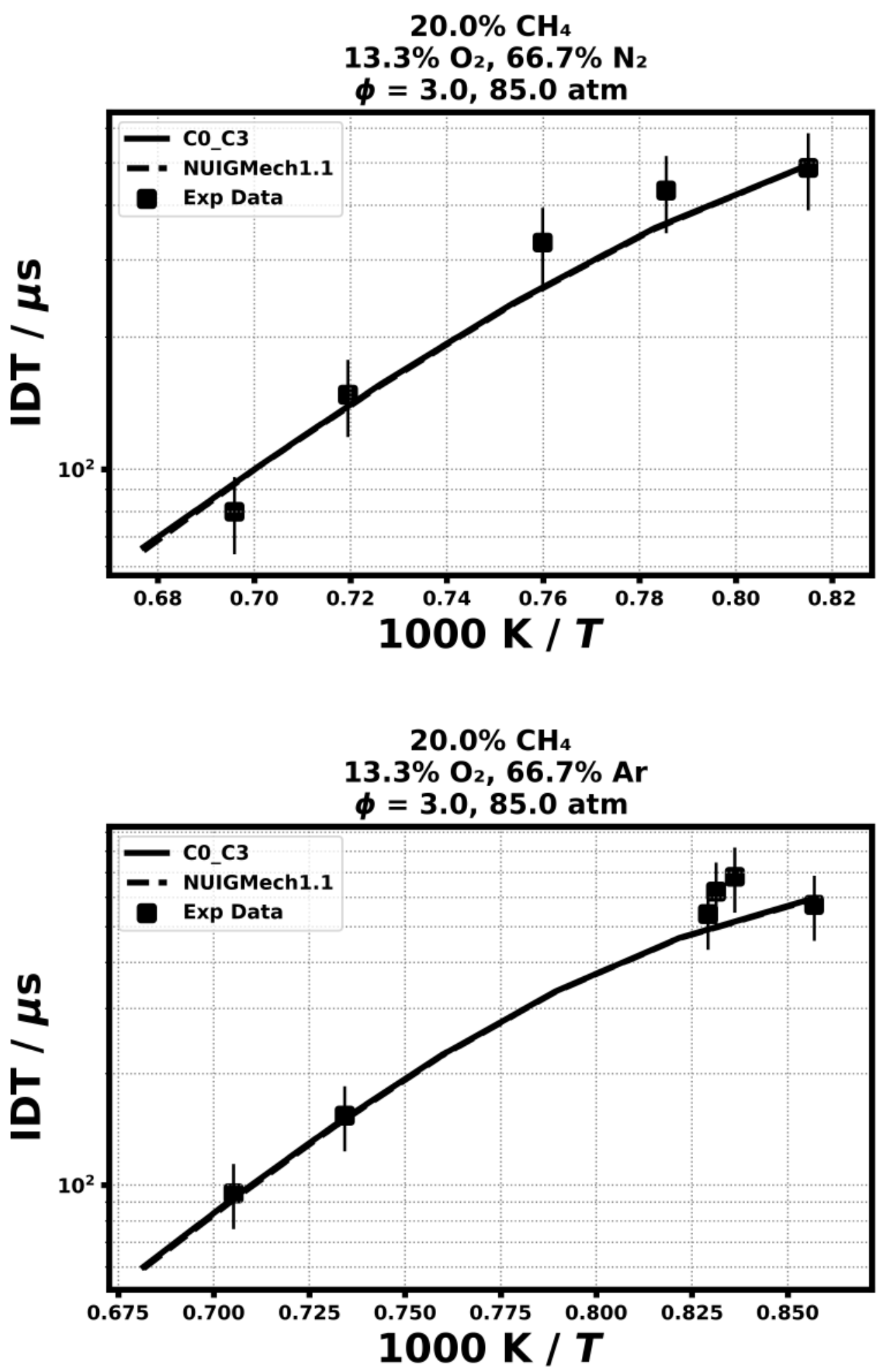

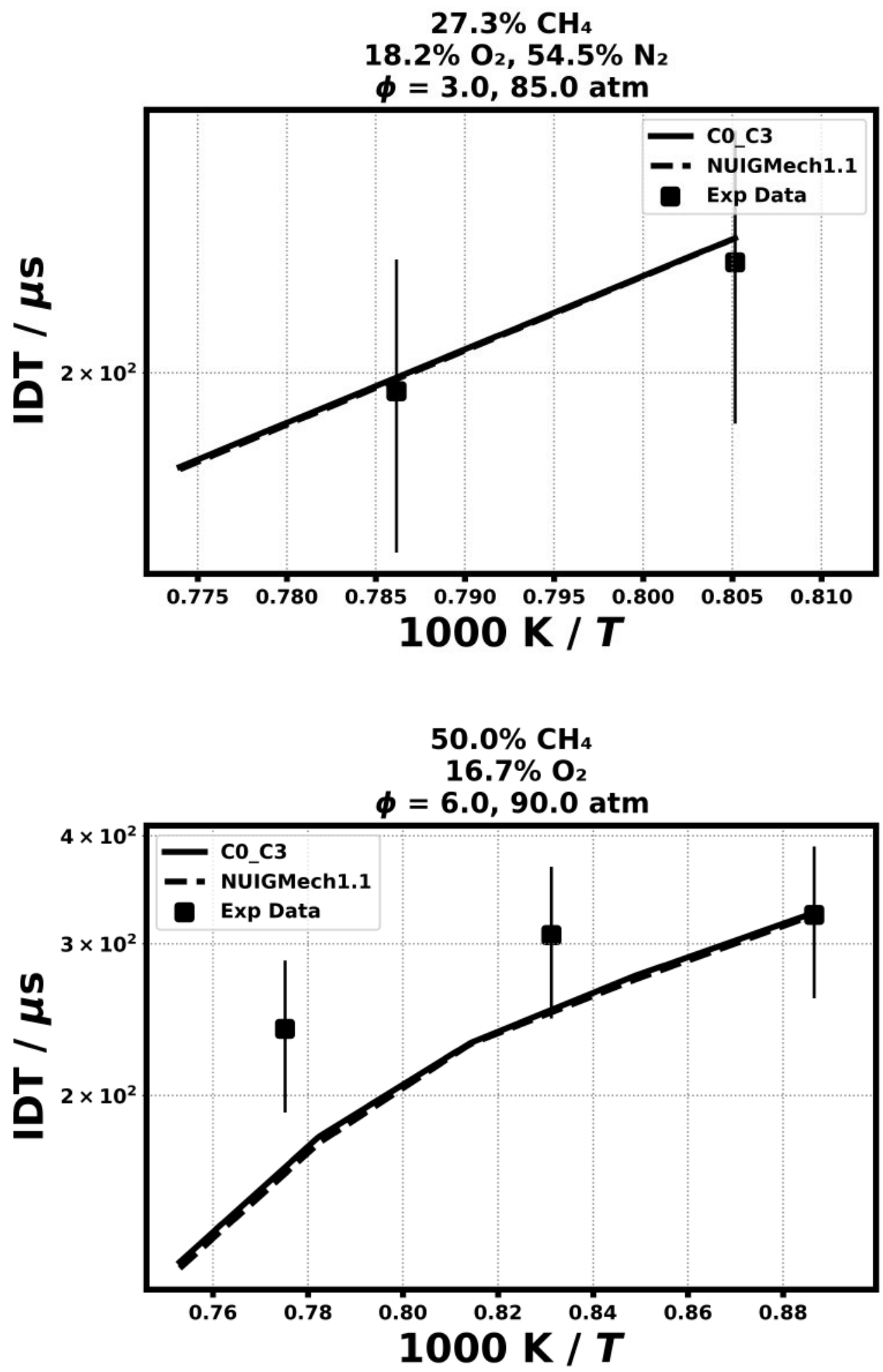
2.7) Shao, J., Choudhary, R., Davidson, D. F., Hanson, R. K., Barak, S., \& Vasu, S. Proceedings of the Combustion Institute, 37(4) (2019) 4555-4562.

\section{$7.5 \% \mathrm{CH}_{4}, 77.5 \% \mathrm{CO}_{2}$}

$15.0 \% \mathrm{O}_{2}, 77.5 \% \mathrm{CO}_{2}, 77.5 \% \mathrm{Ar}$

$\phi=1.0,106.33$ atm

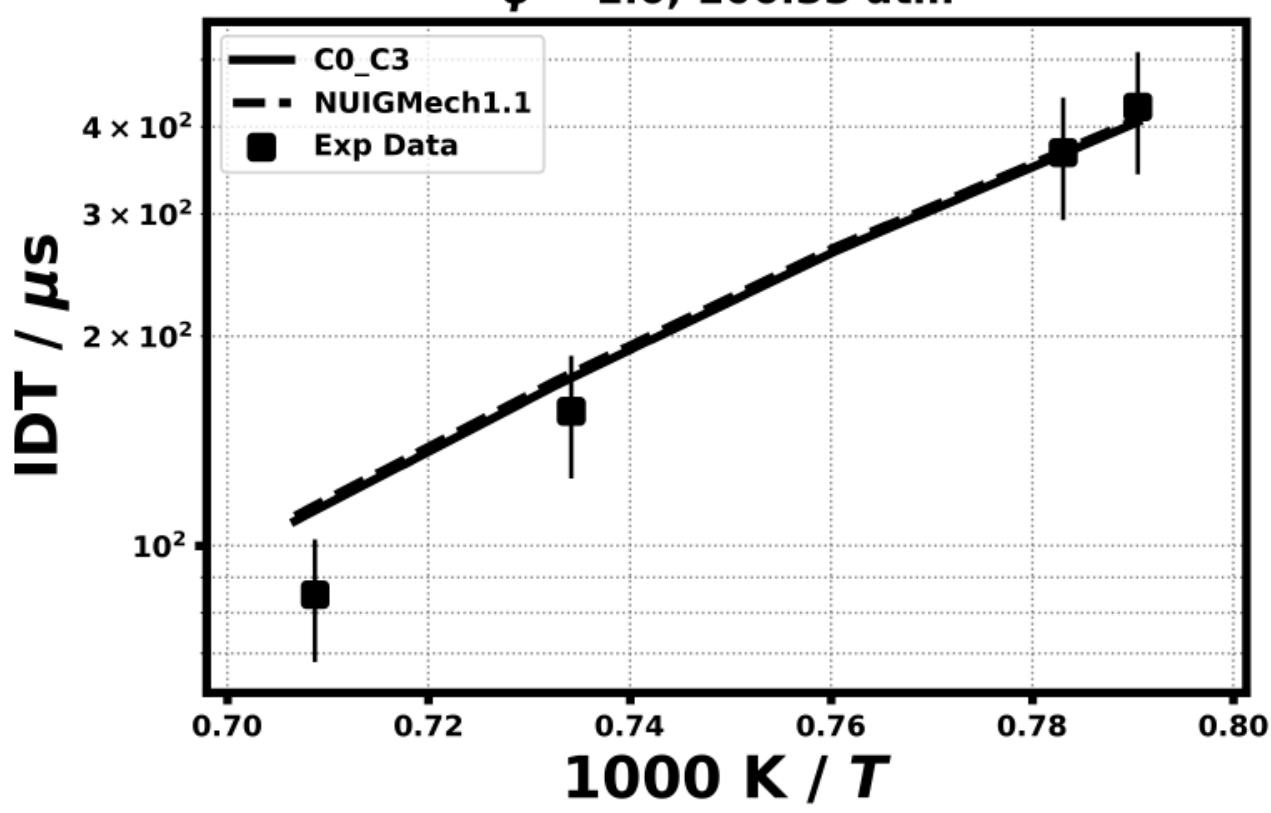

$7.5 \% \mathrm{CH}_{4}, 77.5 \% \mathrm{CO}_{2}$

$15.0 \% \mathrm{O}_{2}, 77.5 \% \mathrm{CO}_{2}, 77.5 \% \mathrm{Ar}$

$\phi=1.0,259.95$ atm

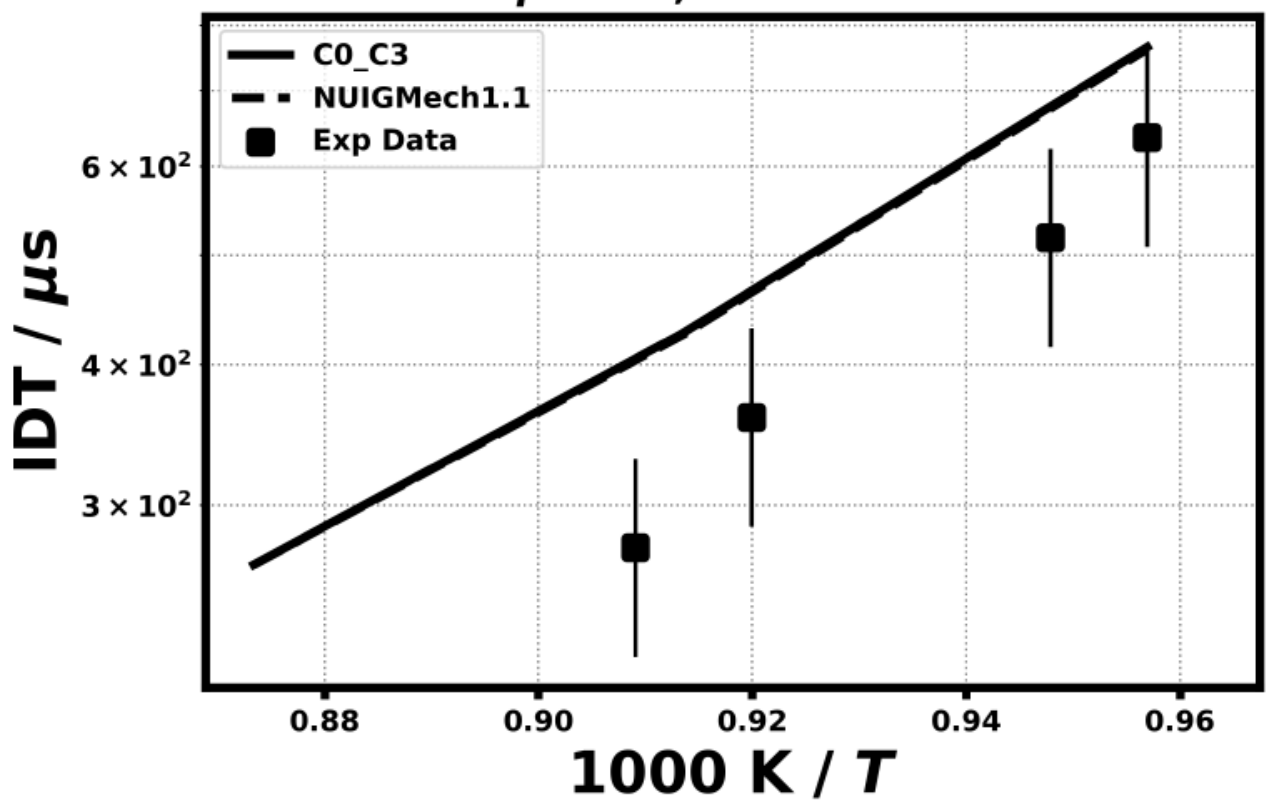



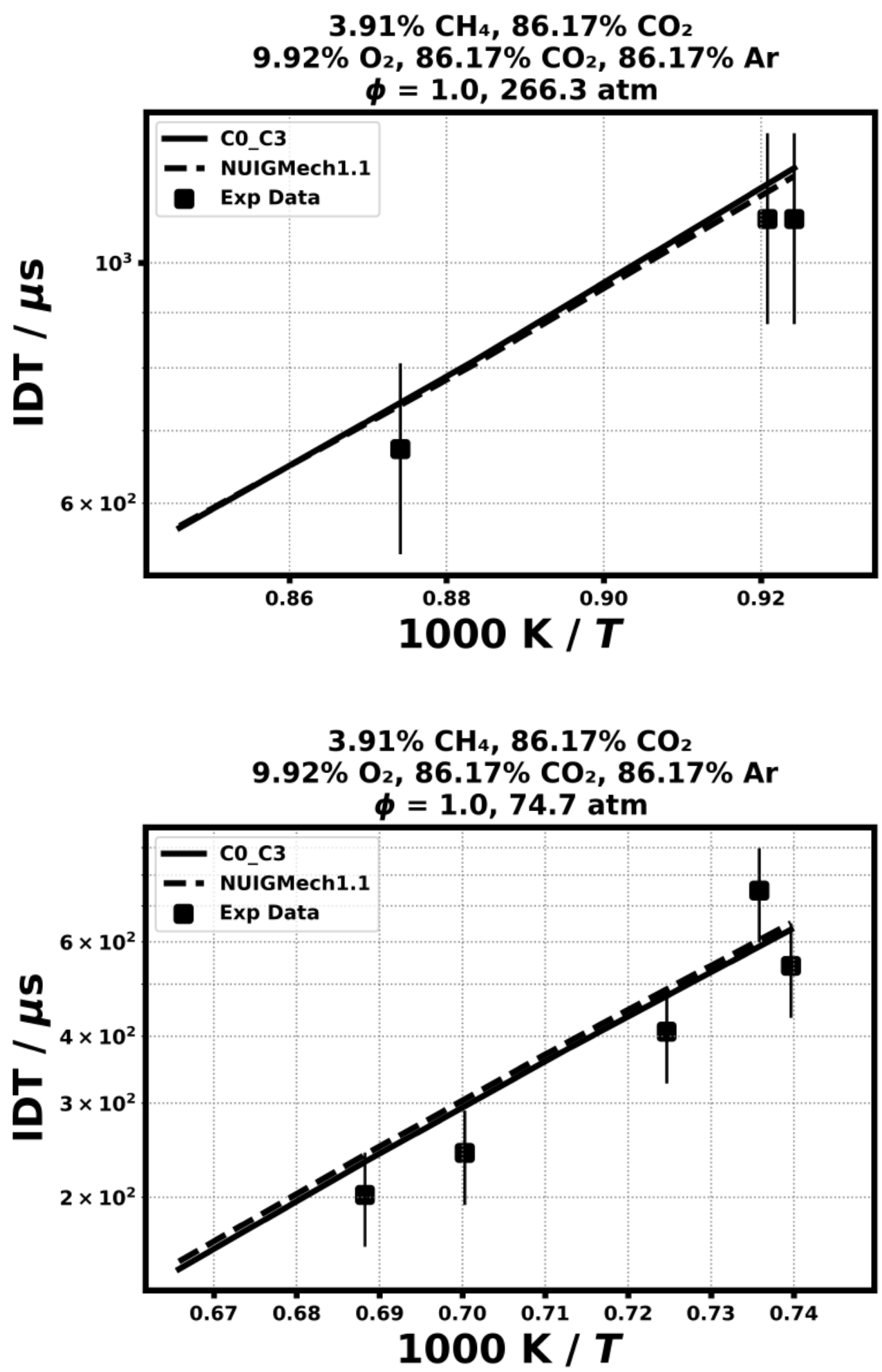
2.8) Spadaccini, L. J., \& Colket Iii, M. B., Progress in energy and combustion science, 20 (5) (1994) 431-460.
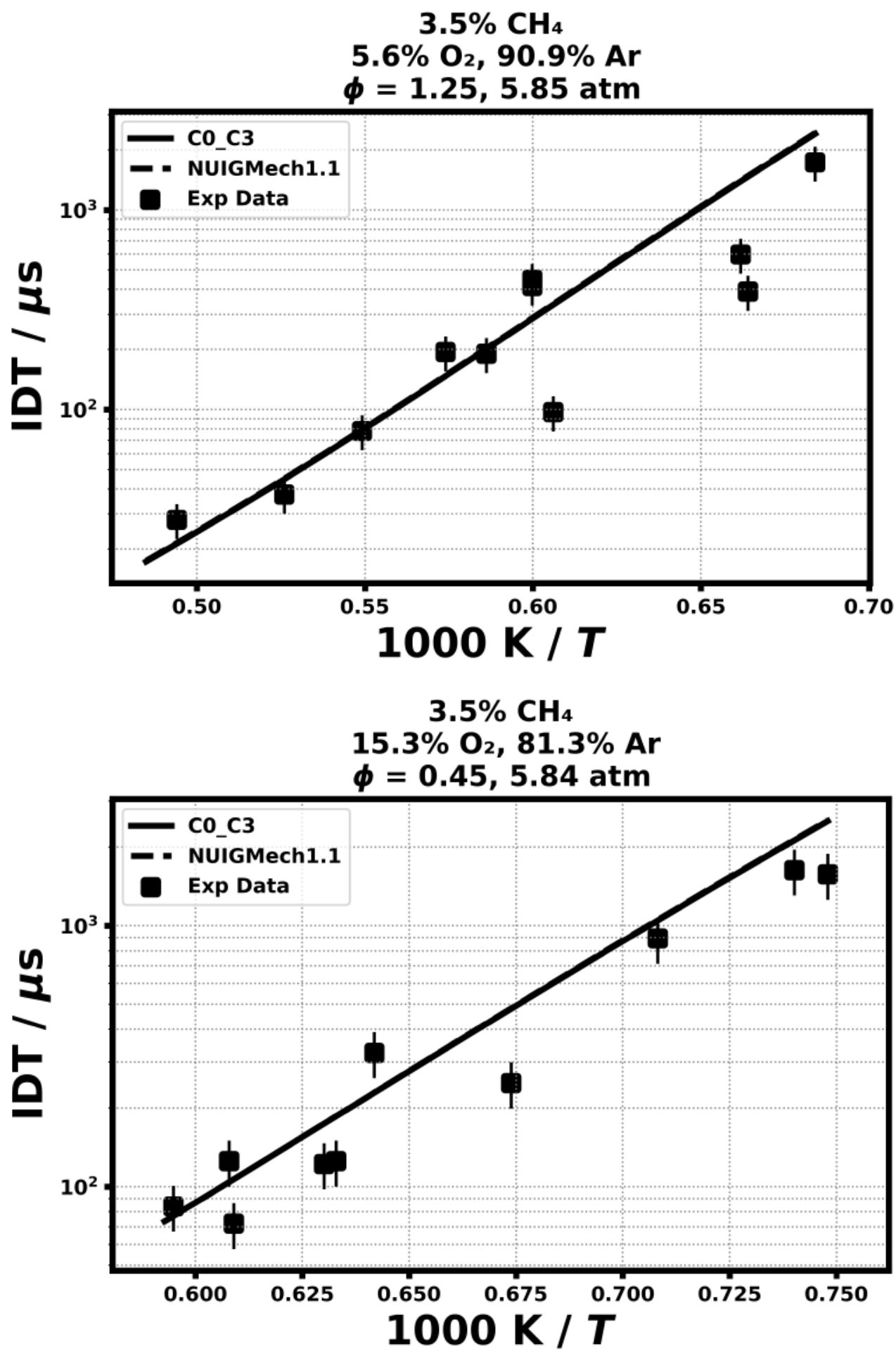

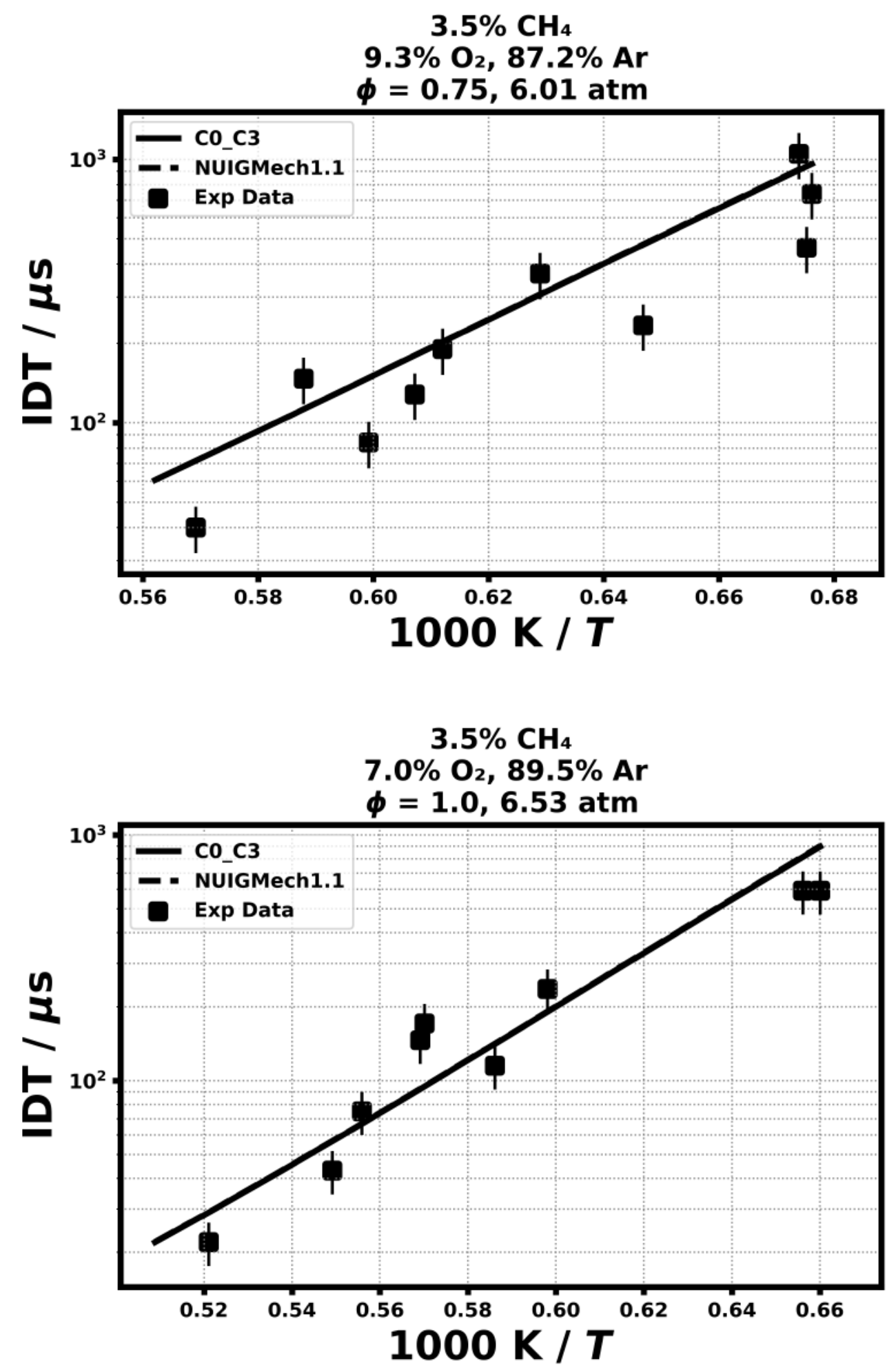
2.9) Petersen, E. L., Davidson, D. F., \& Hanson, R. K. Journal of Propulsion and Power, 15(1) (1999) 82-91.
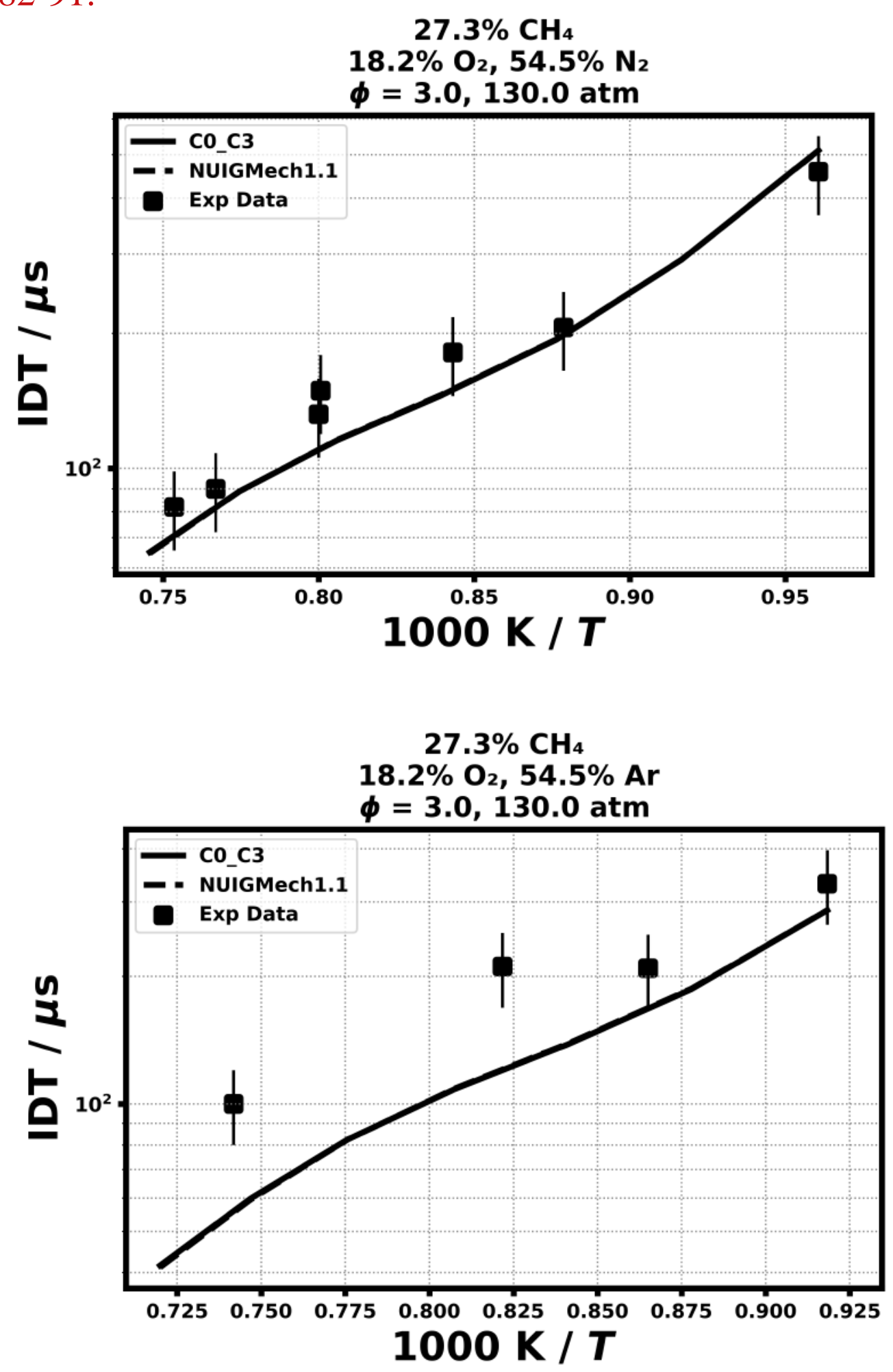


\section{RCM Ignition delay time}

2.10) Burke, U., Somers, K. P., O'Toole, P., Zinner, C. M., Marquet, N., Bourque, G., \& Curran, H. J., Combustion and flame, 162(2) (2015) 315-330.
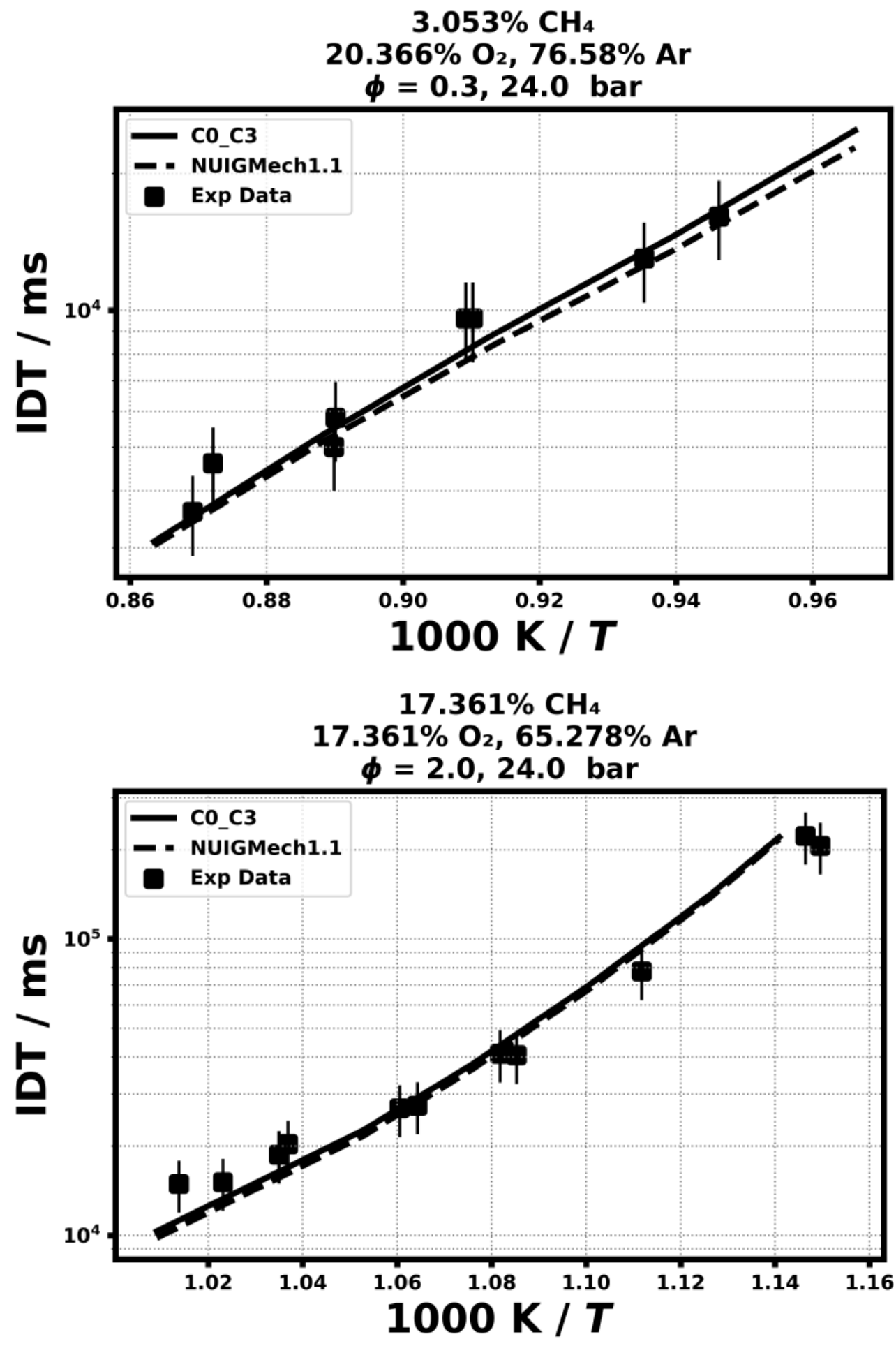

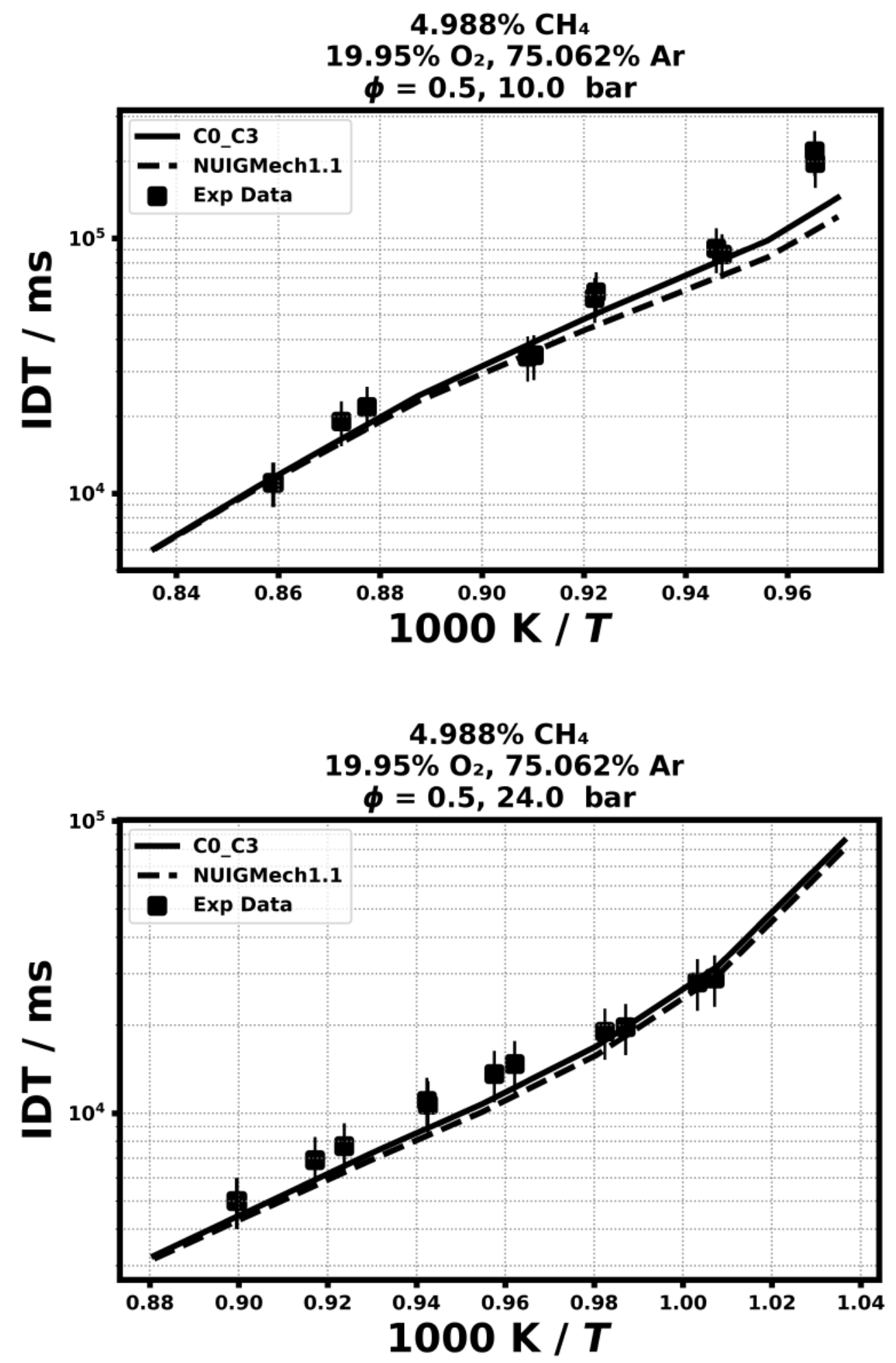

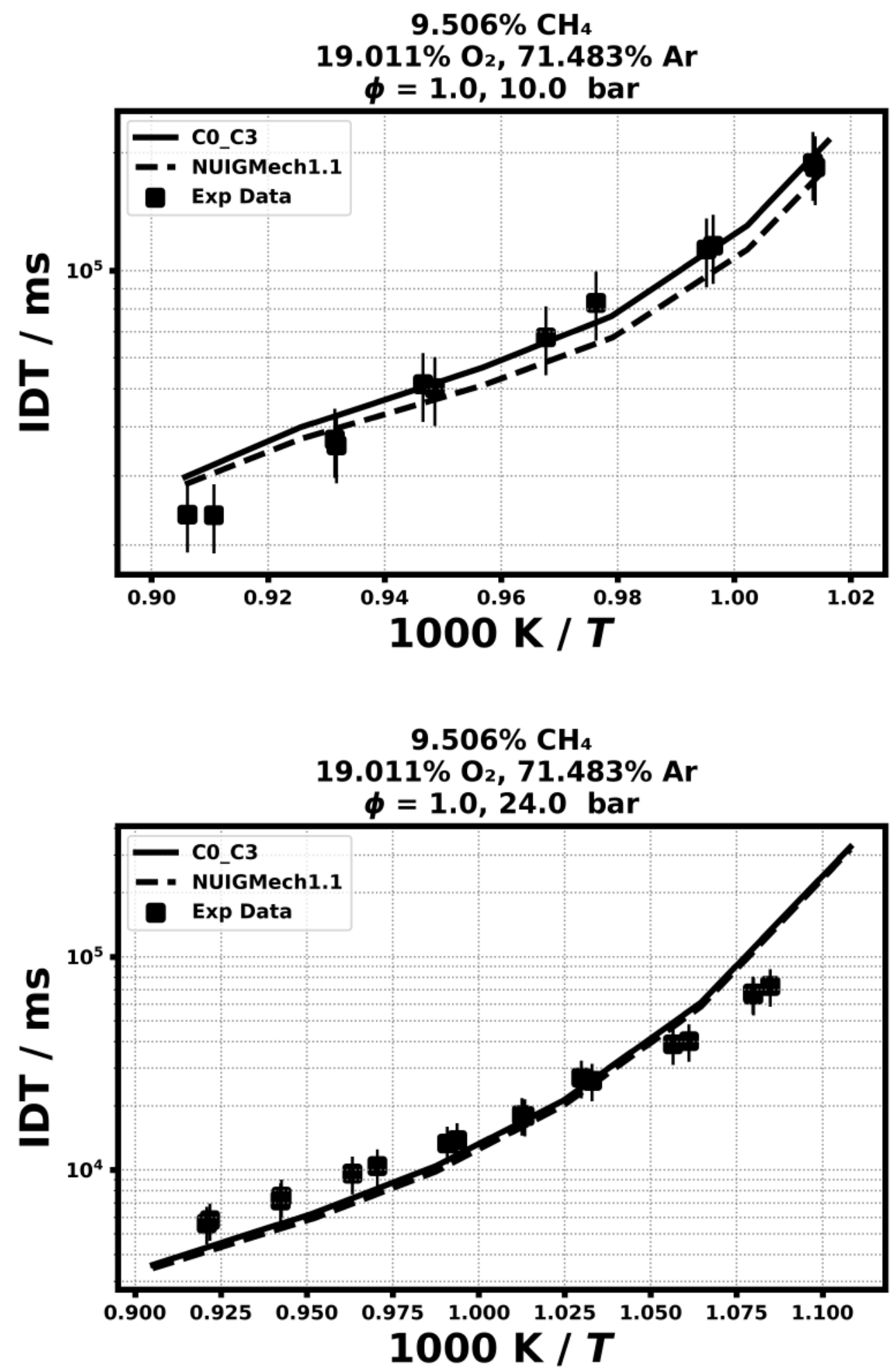


\section{Speciation in Jet-stirred reactor}

2.11) Dagaut, P., Boettner, J. C., \& Cathonnet, M., Combustion science and technology, 77(1-3) (1991) 127-148.
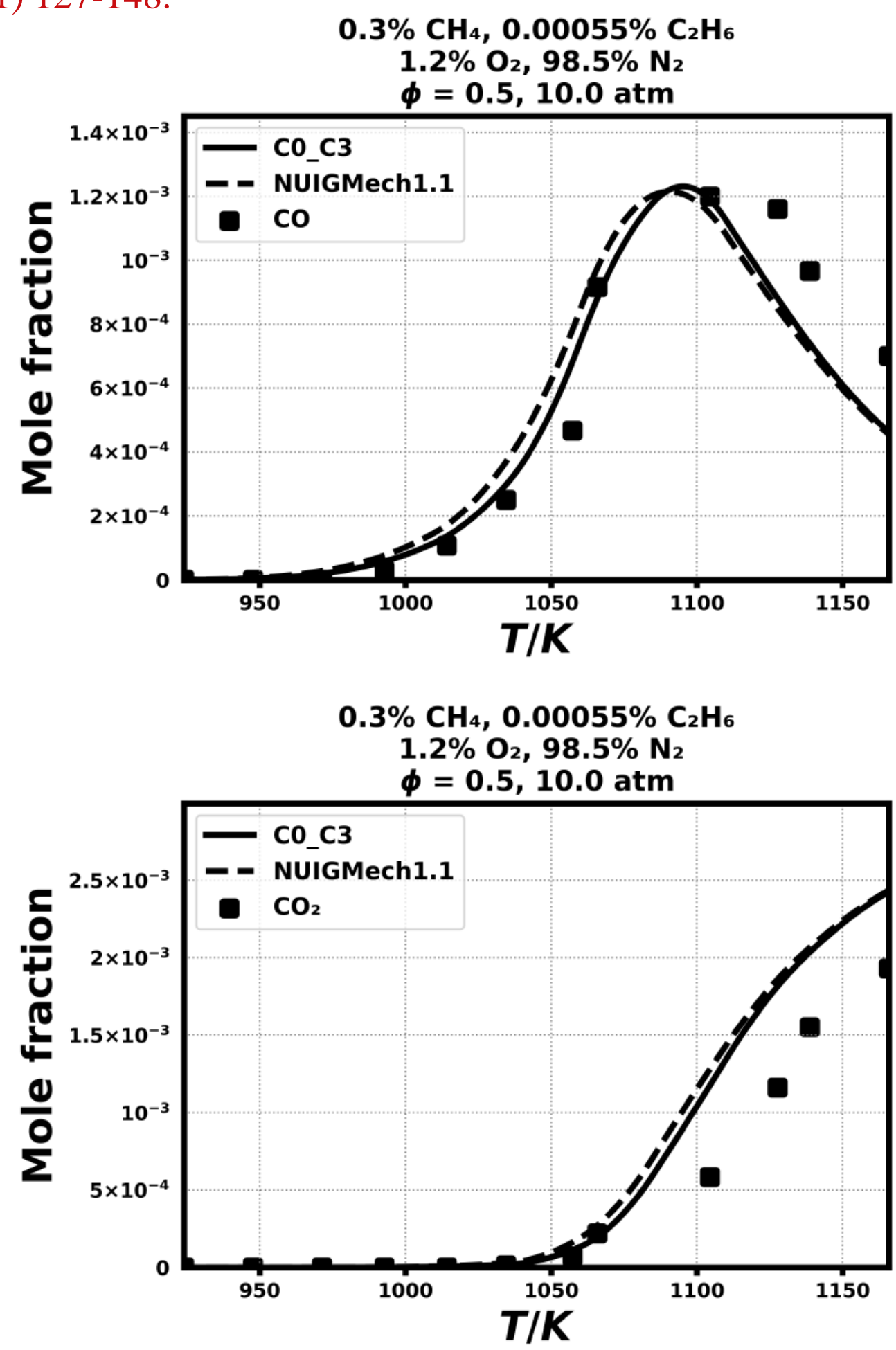

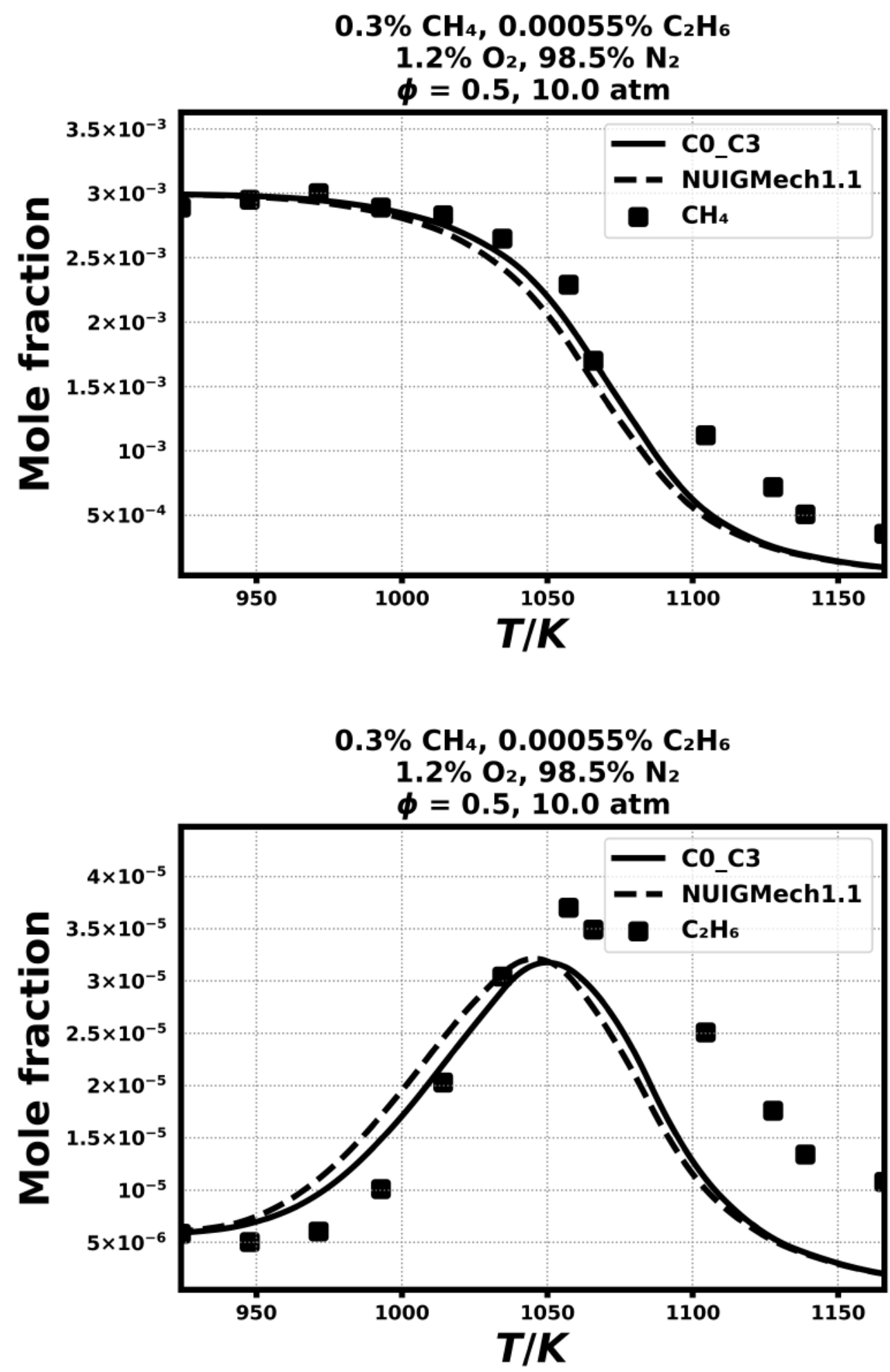

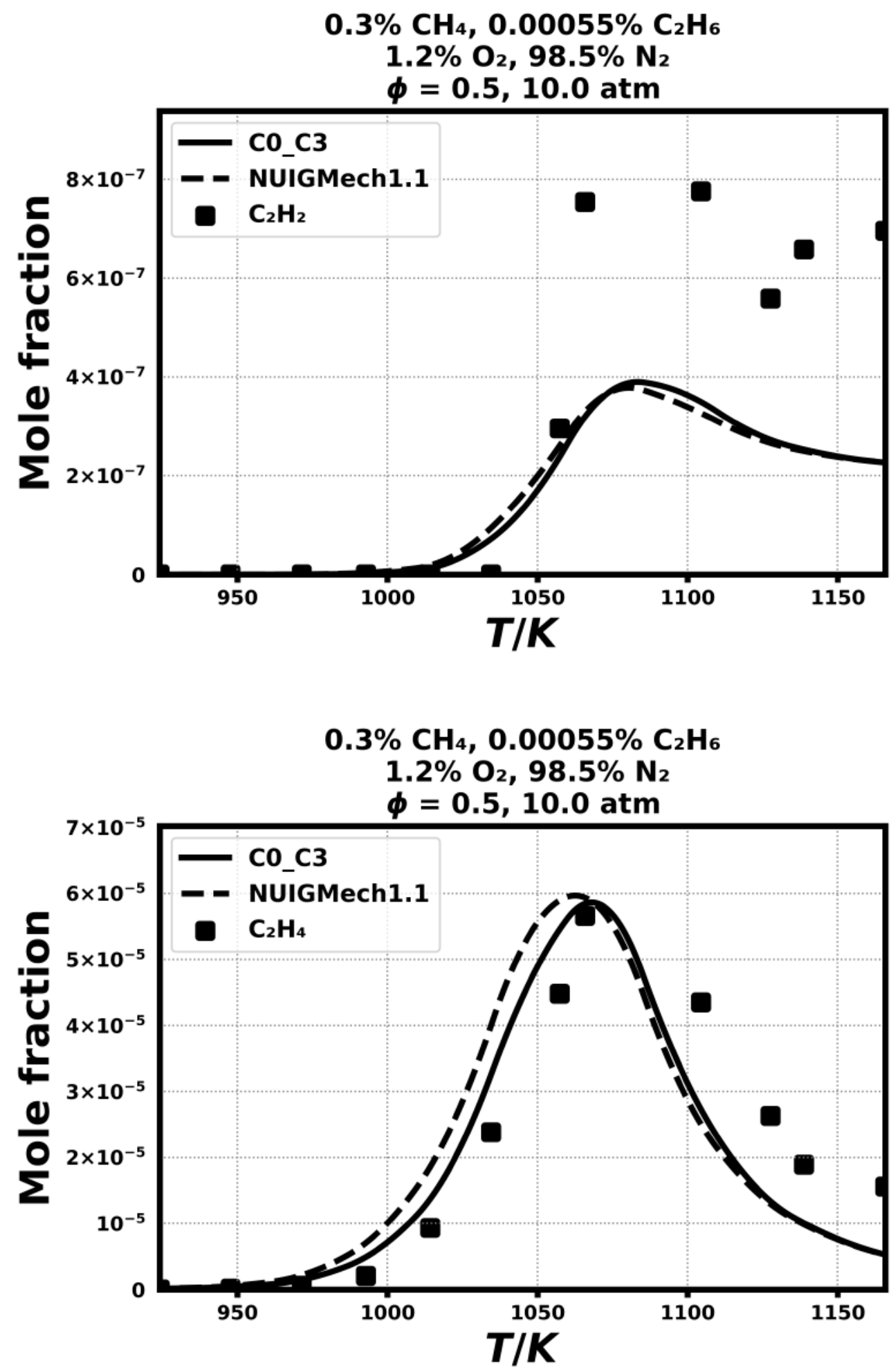

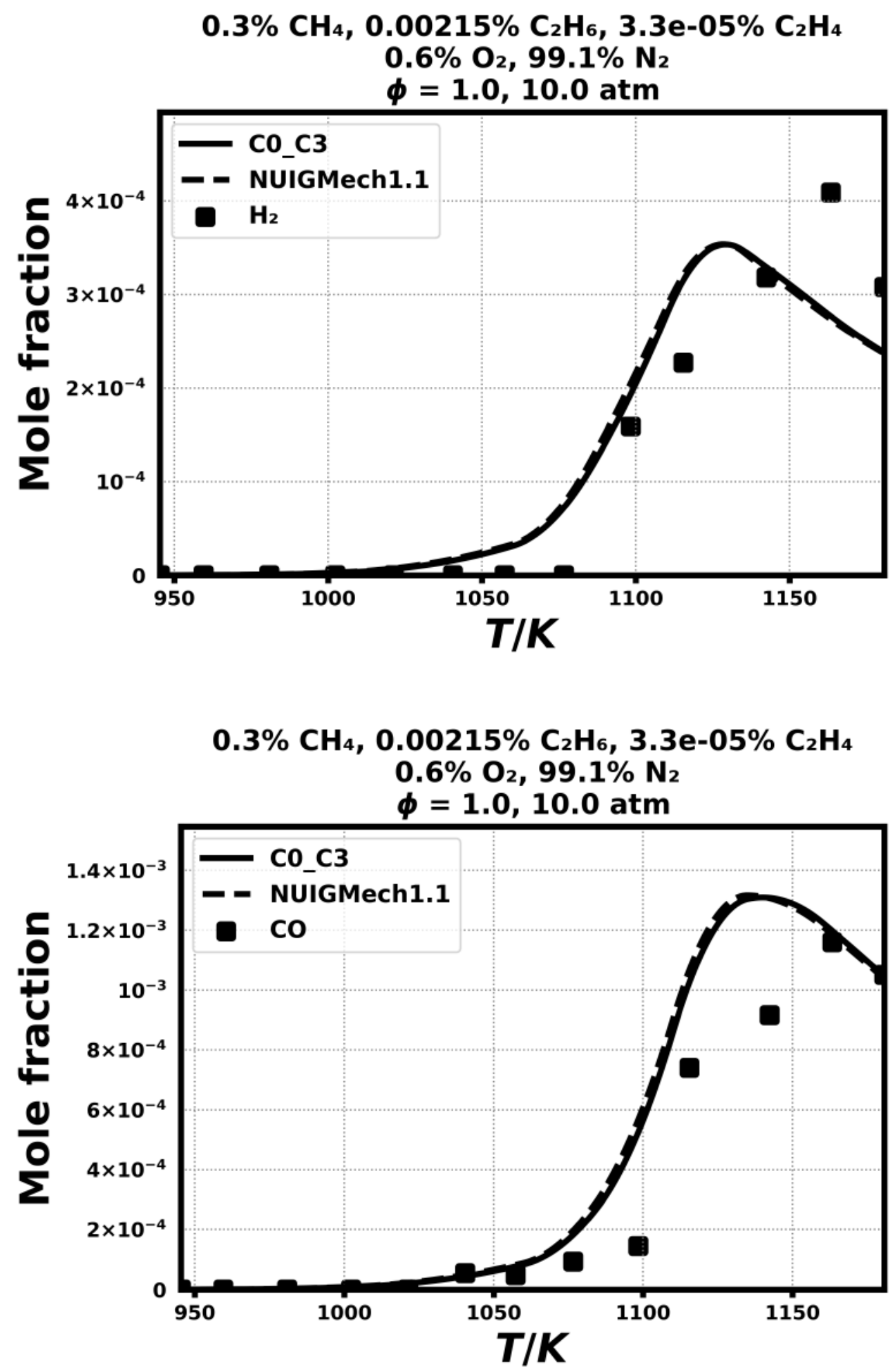

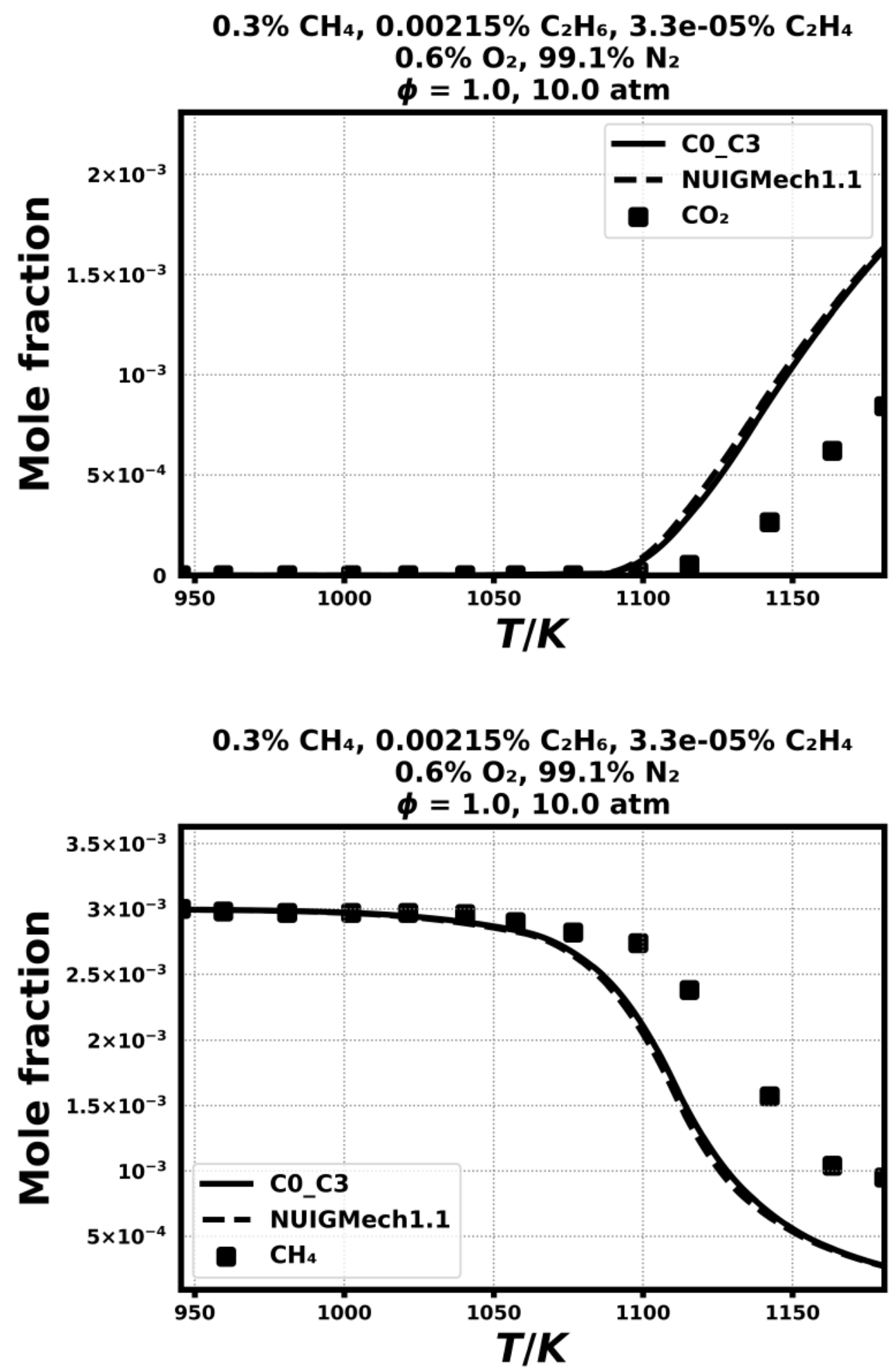

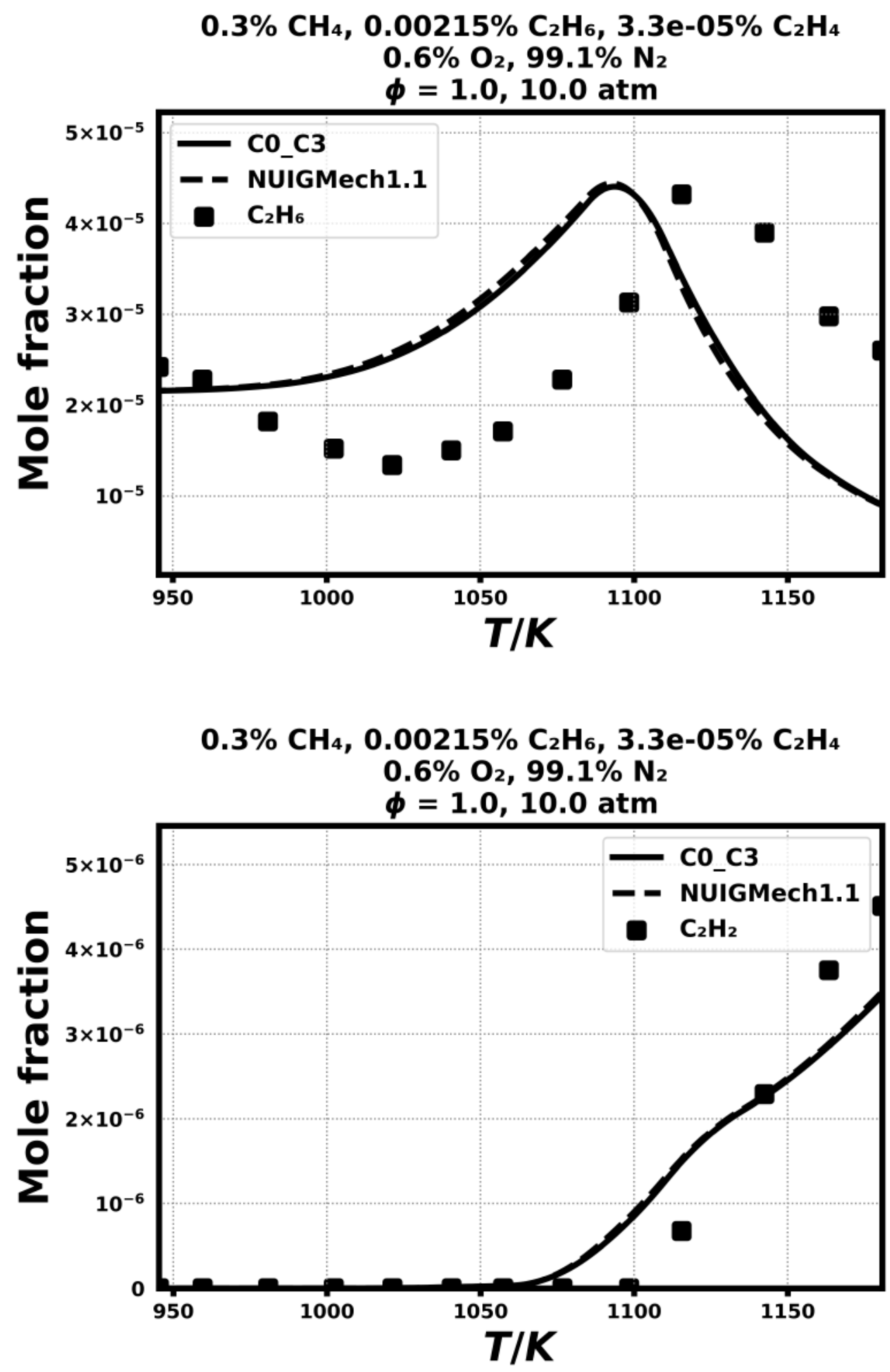

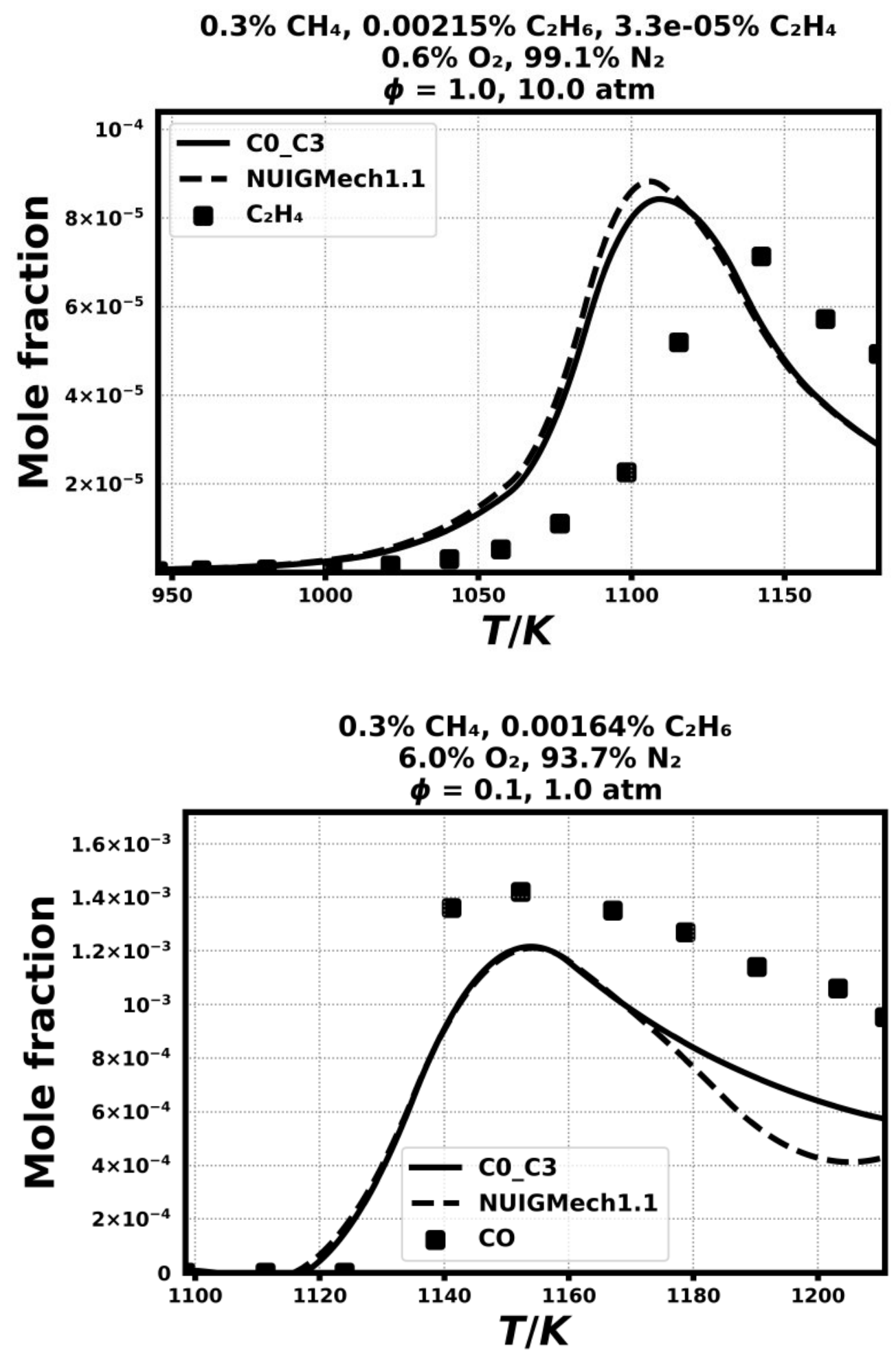

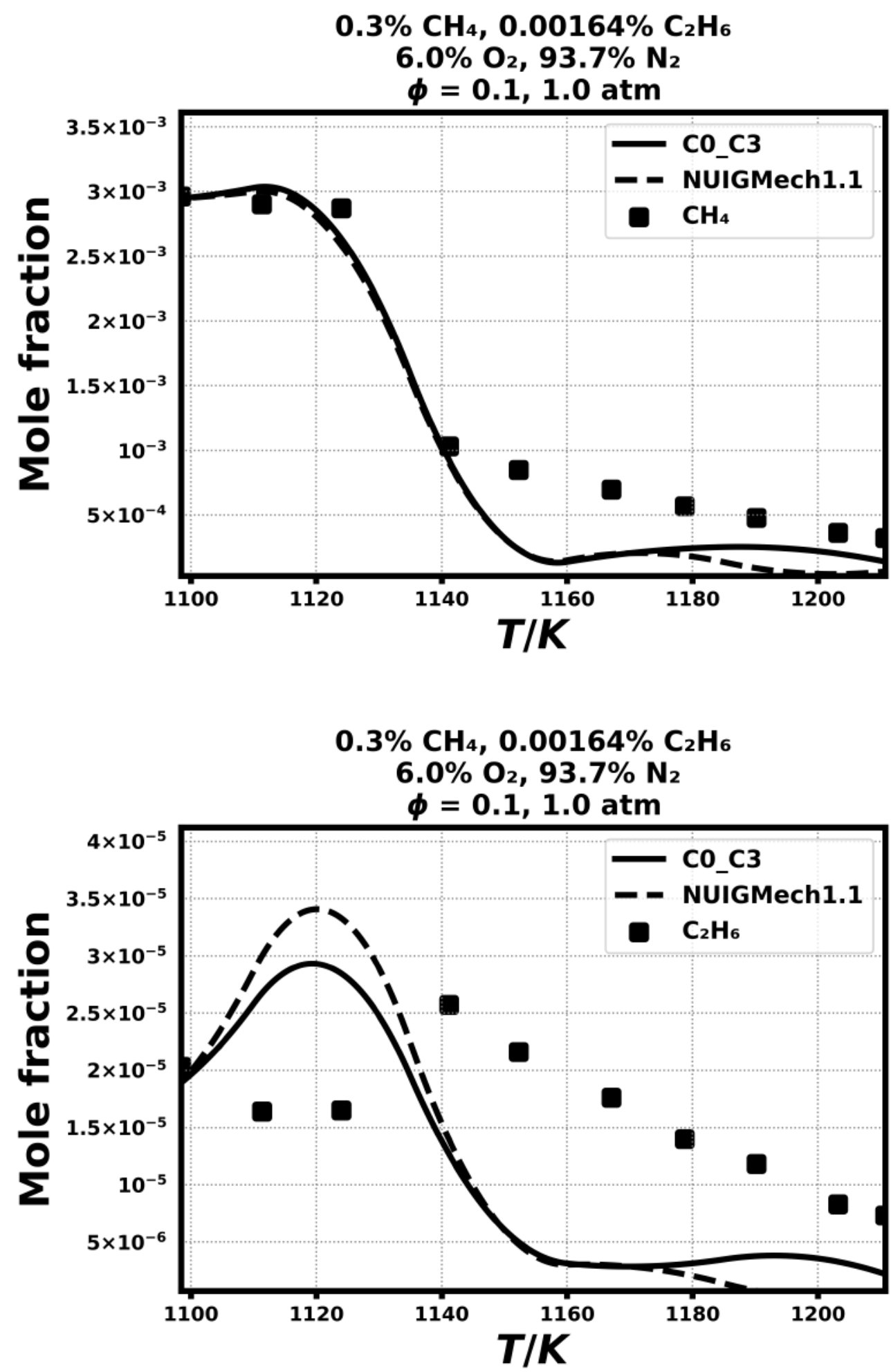


\section{Speciation in Flow reactor}

2.12) E.J.Chang, M. ENG. Thesis, Mechanical Engineering Department, Stanford University. Stanford CA (1995)
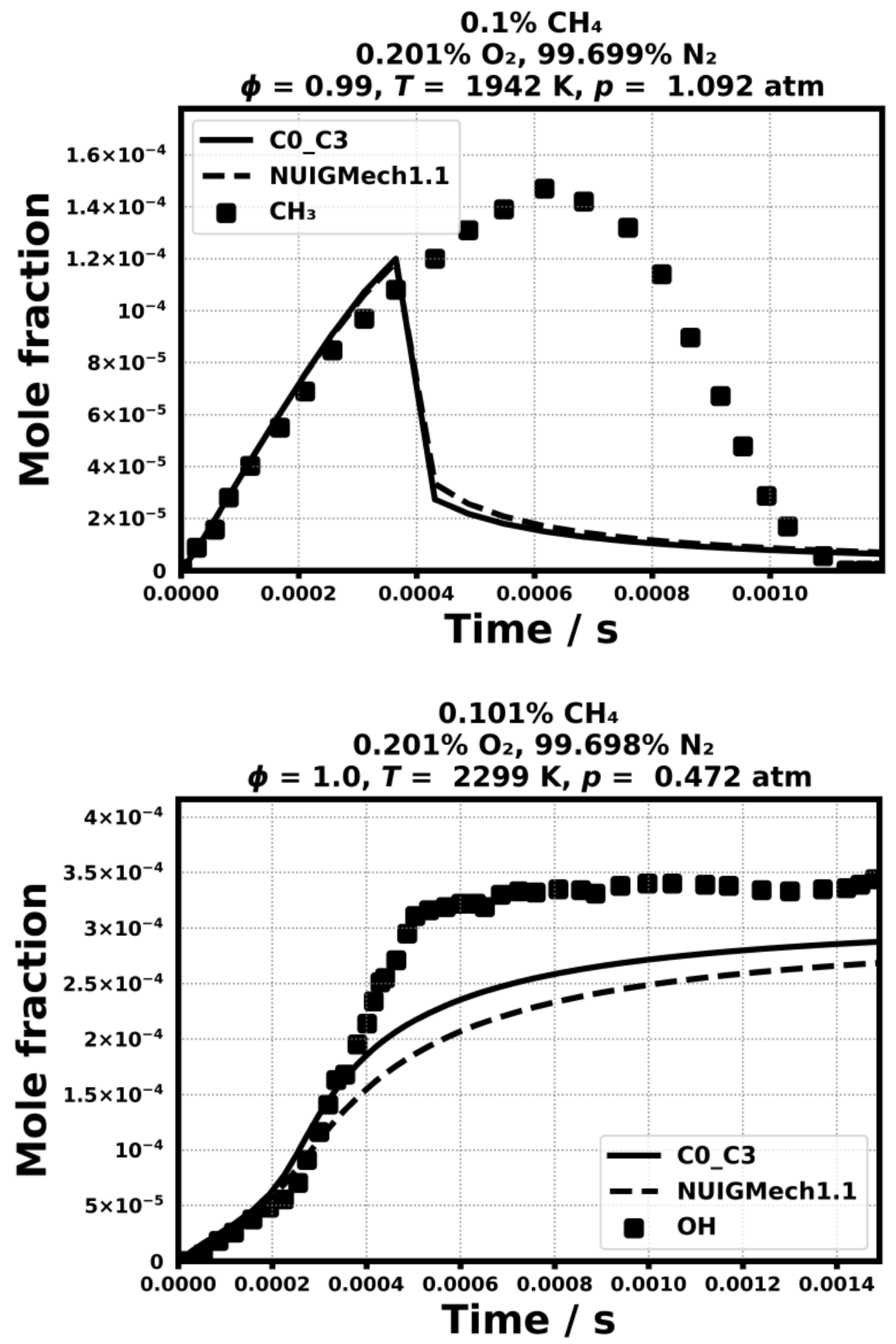

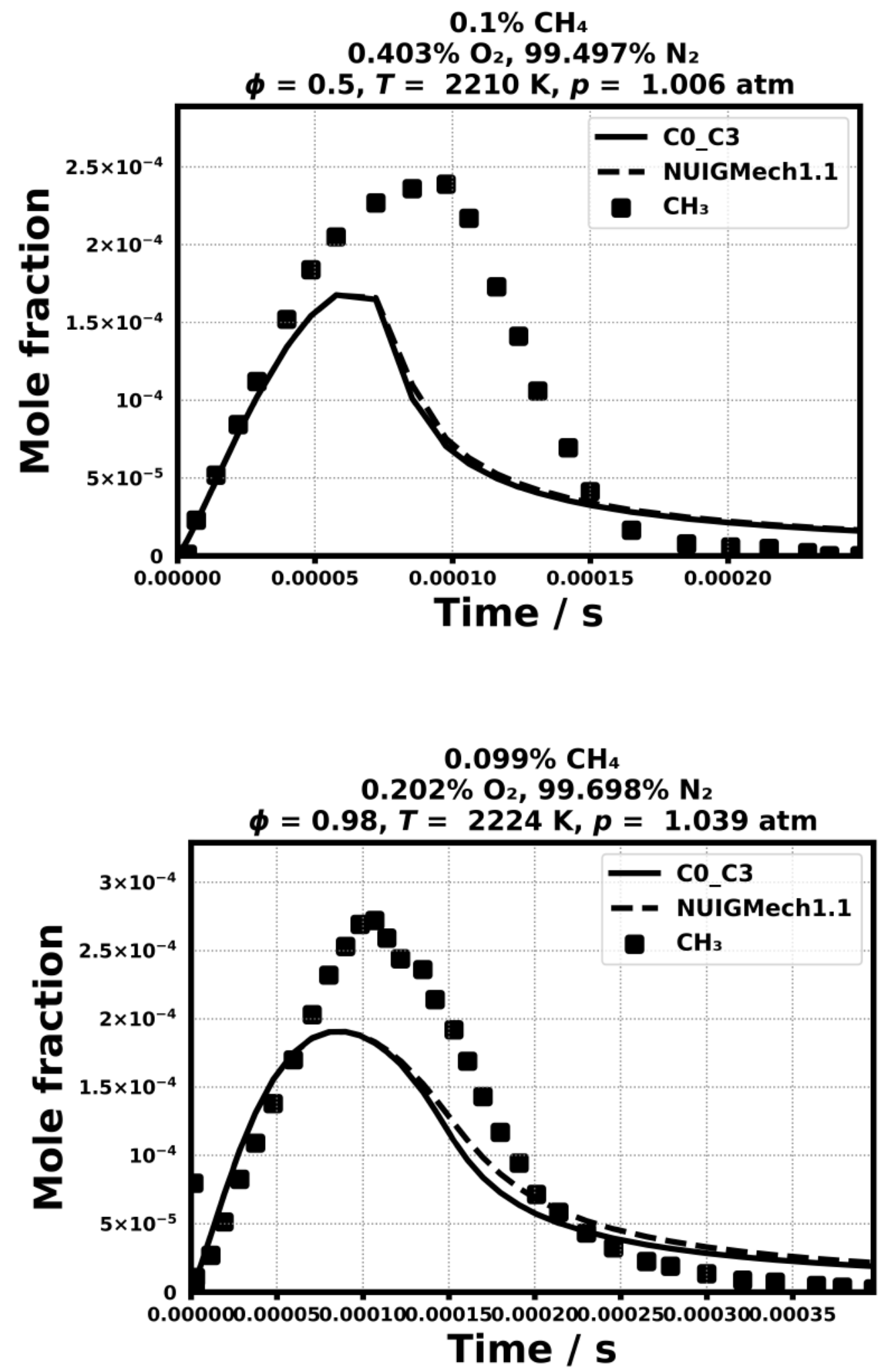


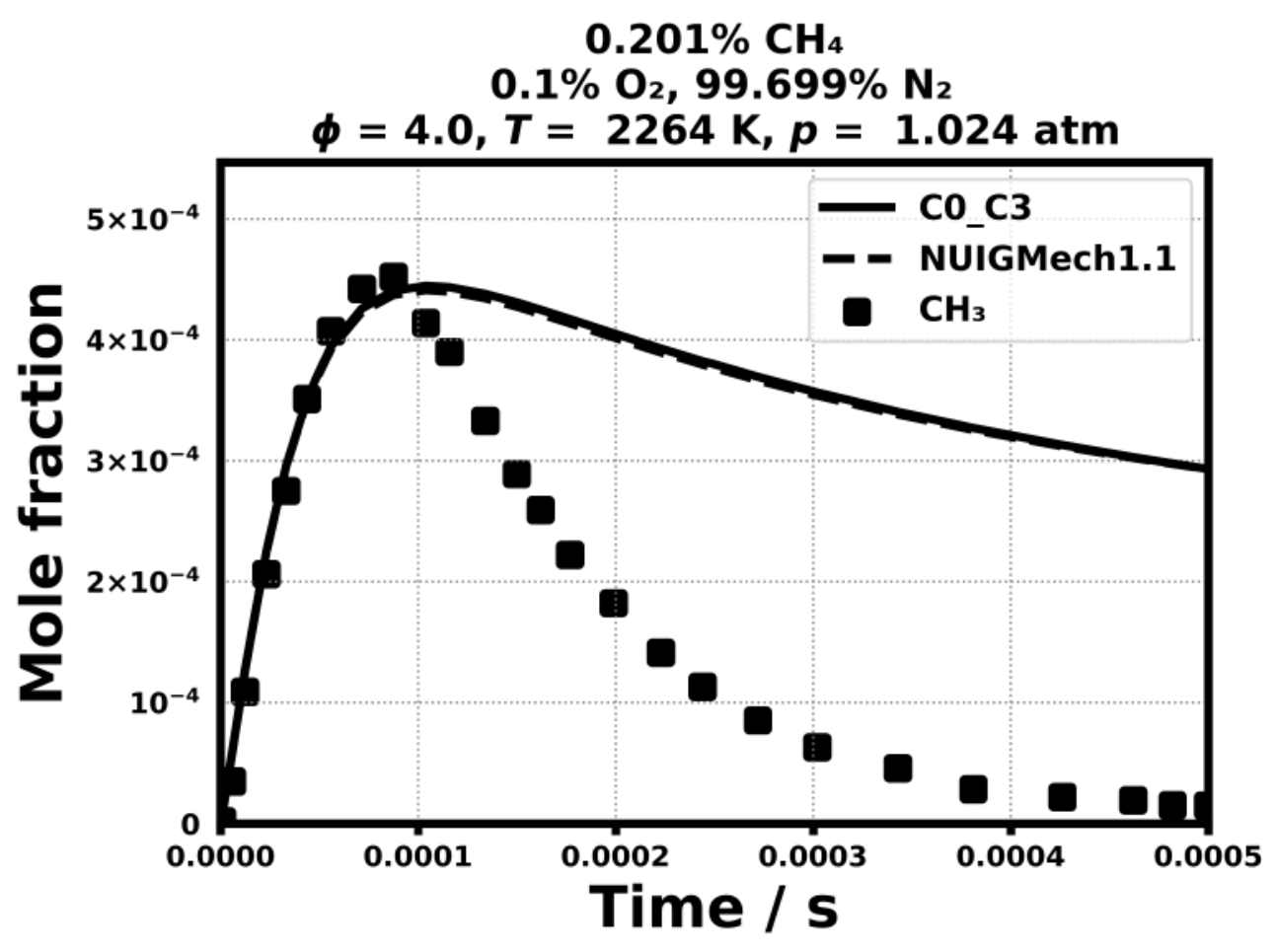

2.13) Petersen, E. L., Röhrig, M., Davidson, D. F., Hanson, R. K., \& Bowman, C. T., In Symposium (International) on Combustion, 26 (1996, January) 799-806

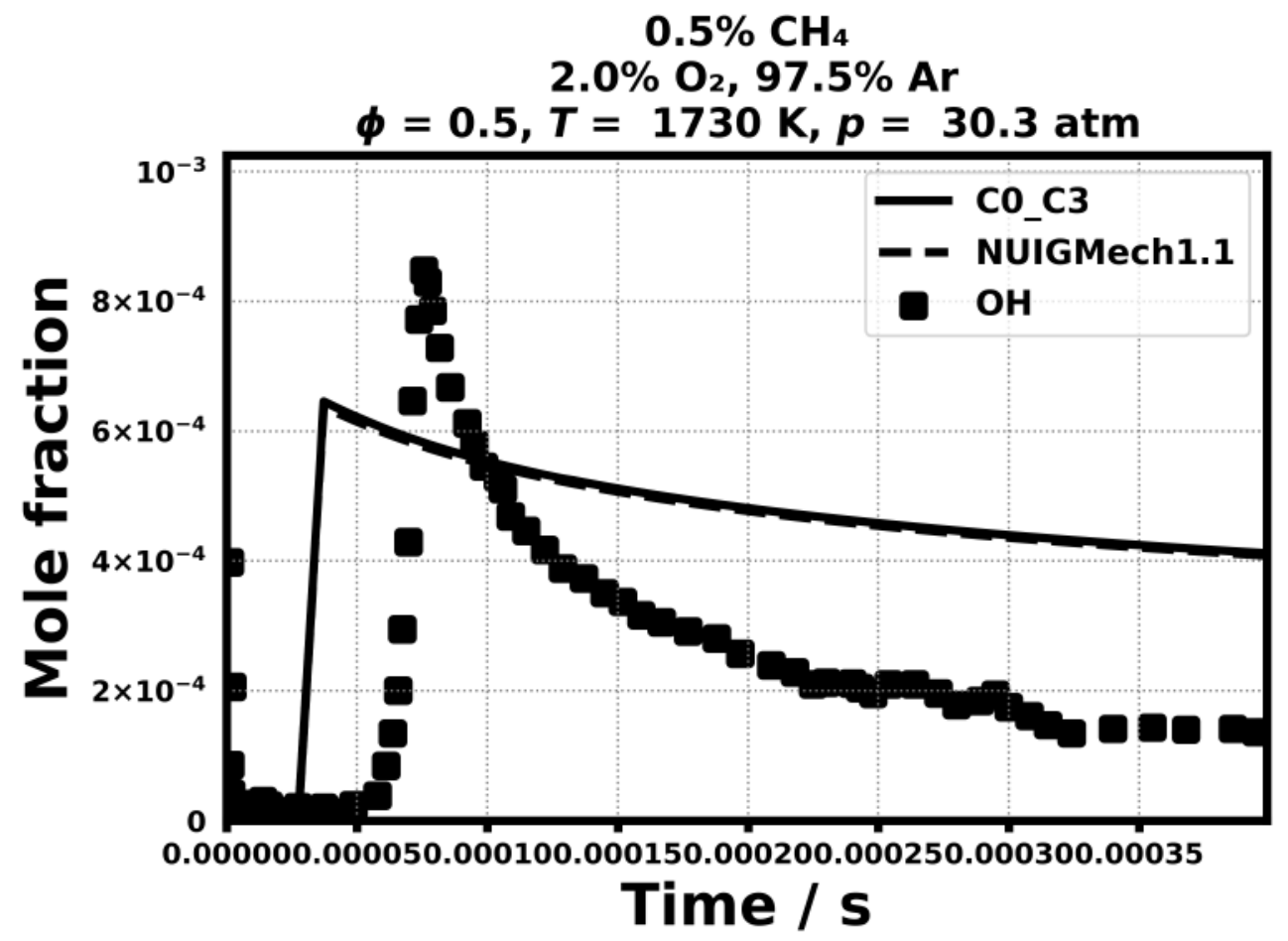




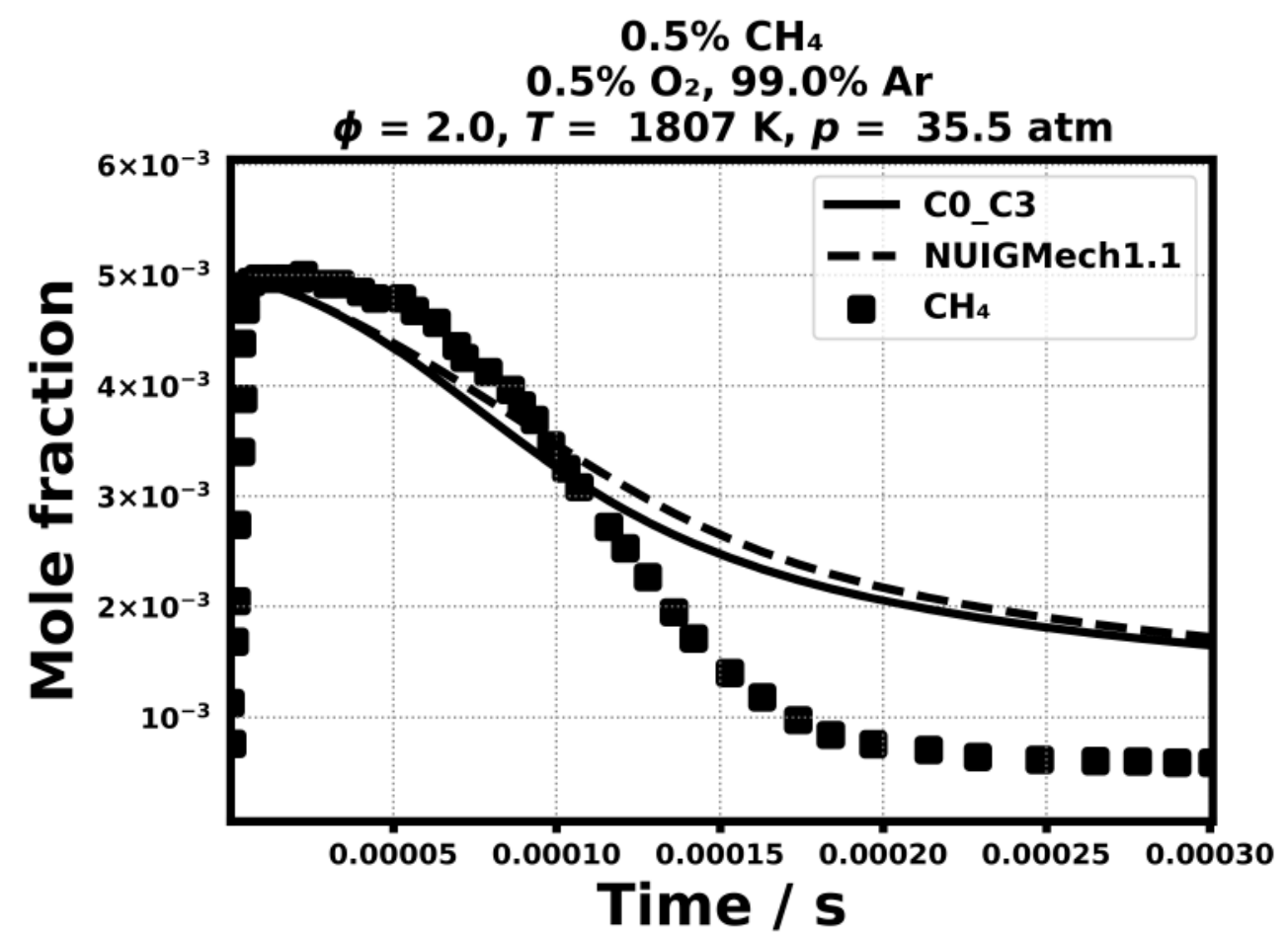




\section{Laminar flame speed}

2.14) Gu, X. J., Haq, M. Z., Lawes, M., \& Woolley, R., Combustion and flame, 121(1-2) (2000) 41-58.

2.15) Rozenchan, G., Zhu, D. L., Law, C. K., \& Tse, S. D., Proceedings of the Combustion Institute, 29(2) (2002) 1461-1470.

2.16) Hassan, M. I., Aung, K. T., \& Faeth, G. M., Combustion and flame, 115(4) (1998) 539-550..

2.17) Zhu, D. L., Egolfopoulos, F. N., \& Law, C. K., In Symposium (International) on Combustion,22, (1989, January) 1537-1545

2.18) Lowry, W., de Vries, J., Krejci, M., Petersen, E., Serinyel, Z., Metcalfe, W., Bourque, G., Jornal of Engineering for Gas Turbines and Power, 133(9) (2011).

2.19) Egolfopoulos, F. N., Zhu, D. L., \& Law, C. K., In Symposium (International) on Combustion, 23 (1991, January) 471-478.

2.20) S. Taylor, PhD diss., University of Leeds, 1991.

2.21) Vagelopoulos, C. M., Egolfopoulos, F. N., \& Law, C. K., In Symposium (international) on combustion, 25 (1994, January) 1341-1347

2.22) Van Maaren, A., Thung, D. S., \& DE GOEY, L. R. H., Combustion Science and Technology, 96(4-6) (1994) 327-344.

2.23) U. Kochar, Turbo Expo: Power for Land, Sea, and Air (Vol. 54624 (2011) 129-140.

\section{$\mathrm{CH}_{4}$ in 'air', $T_{u}=298 \mathrm{~K}, p=1 / 2 / 5 / 10 / 20 \mathrm{~atm}$}

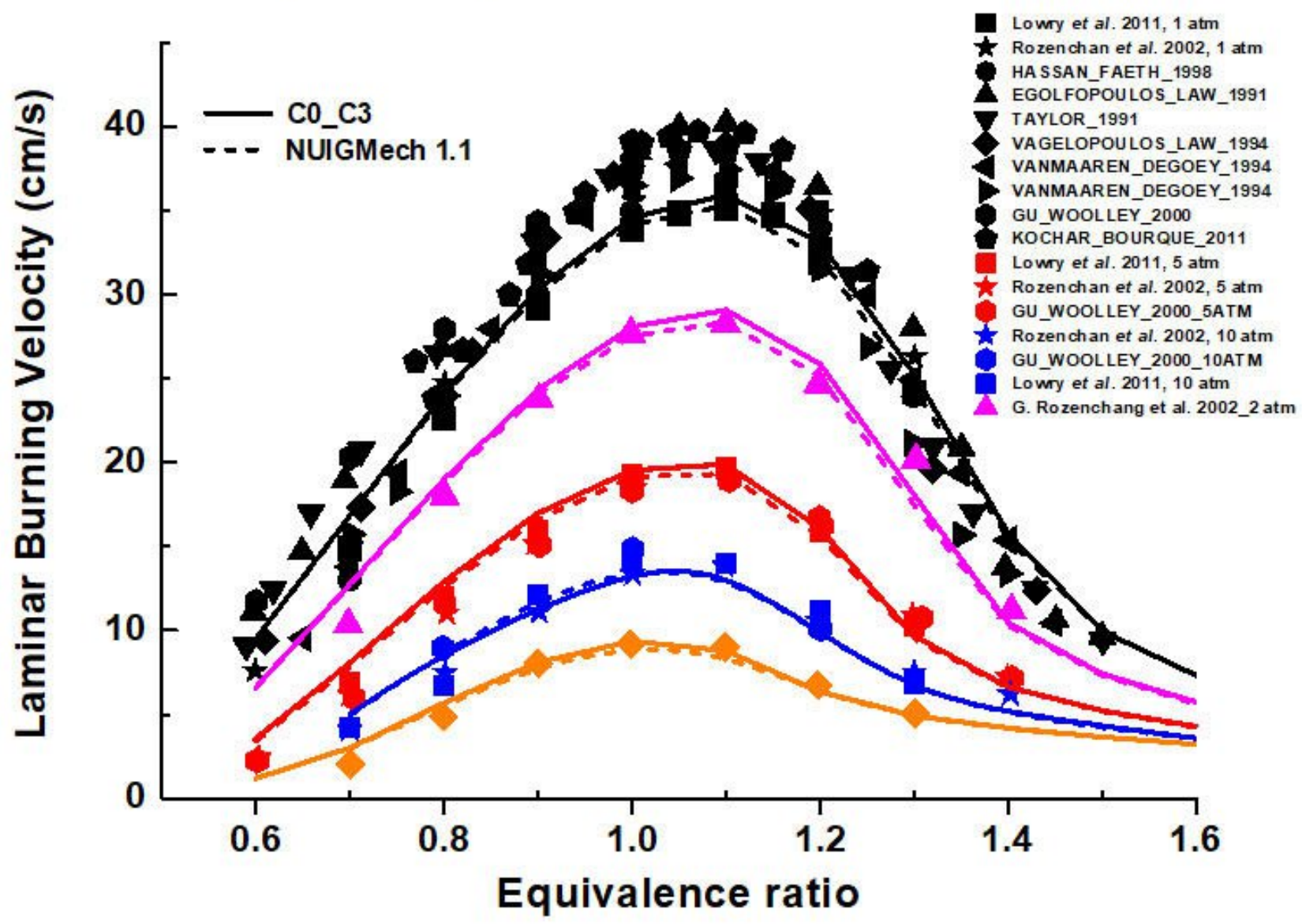




\section{Validation for $\mathrm{CH}_{3} \mathrm{OH}$}

\section{Shock tube ignition delay time}

3.1) Bowman, C. T., Combustion and Flame 25 (1975) 343-354.
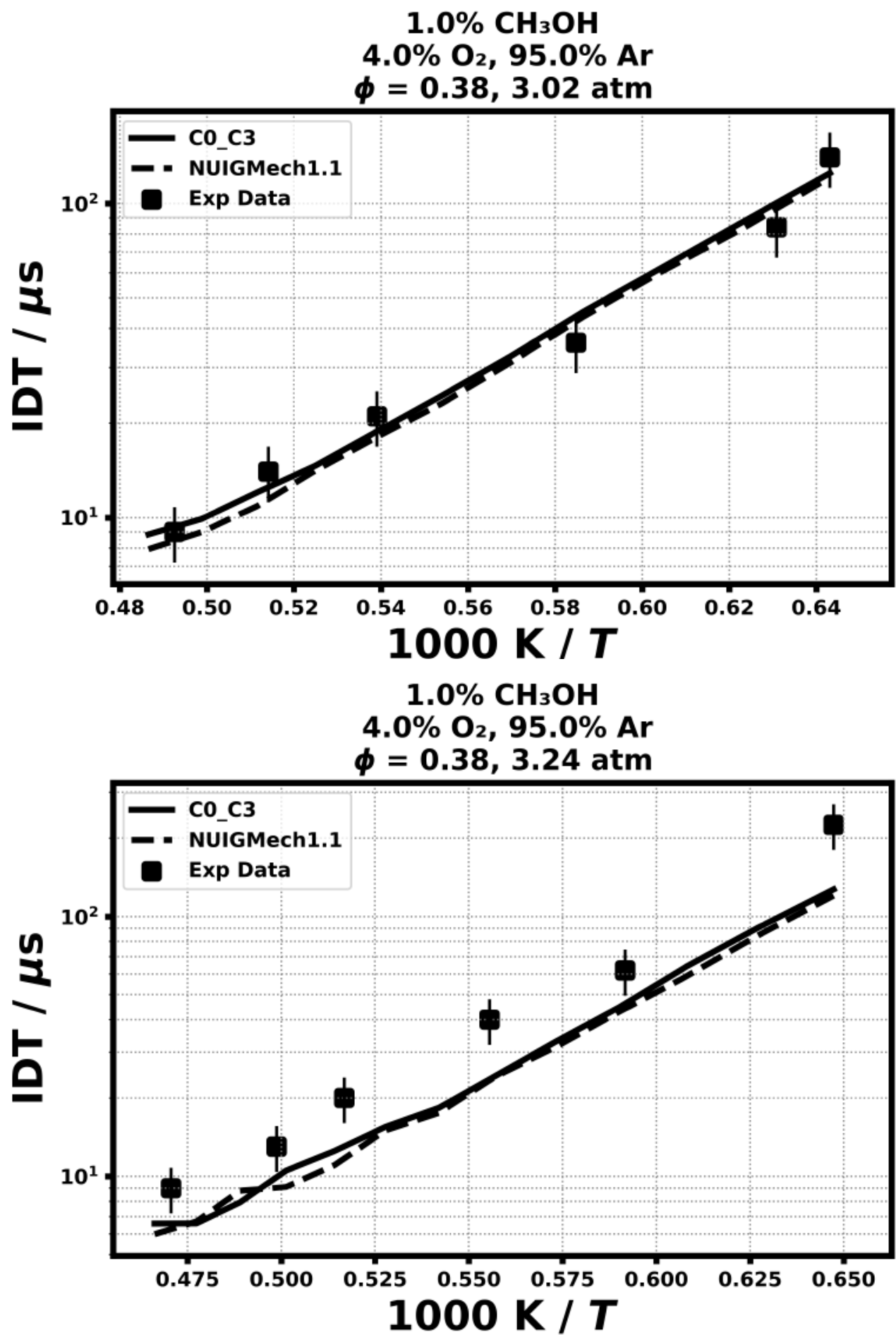

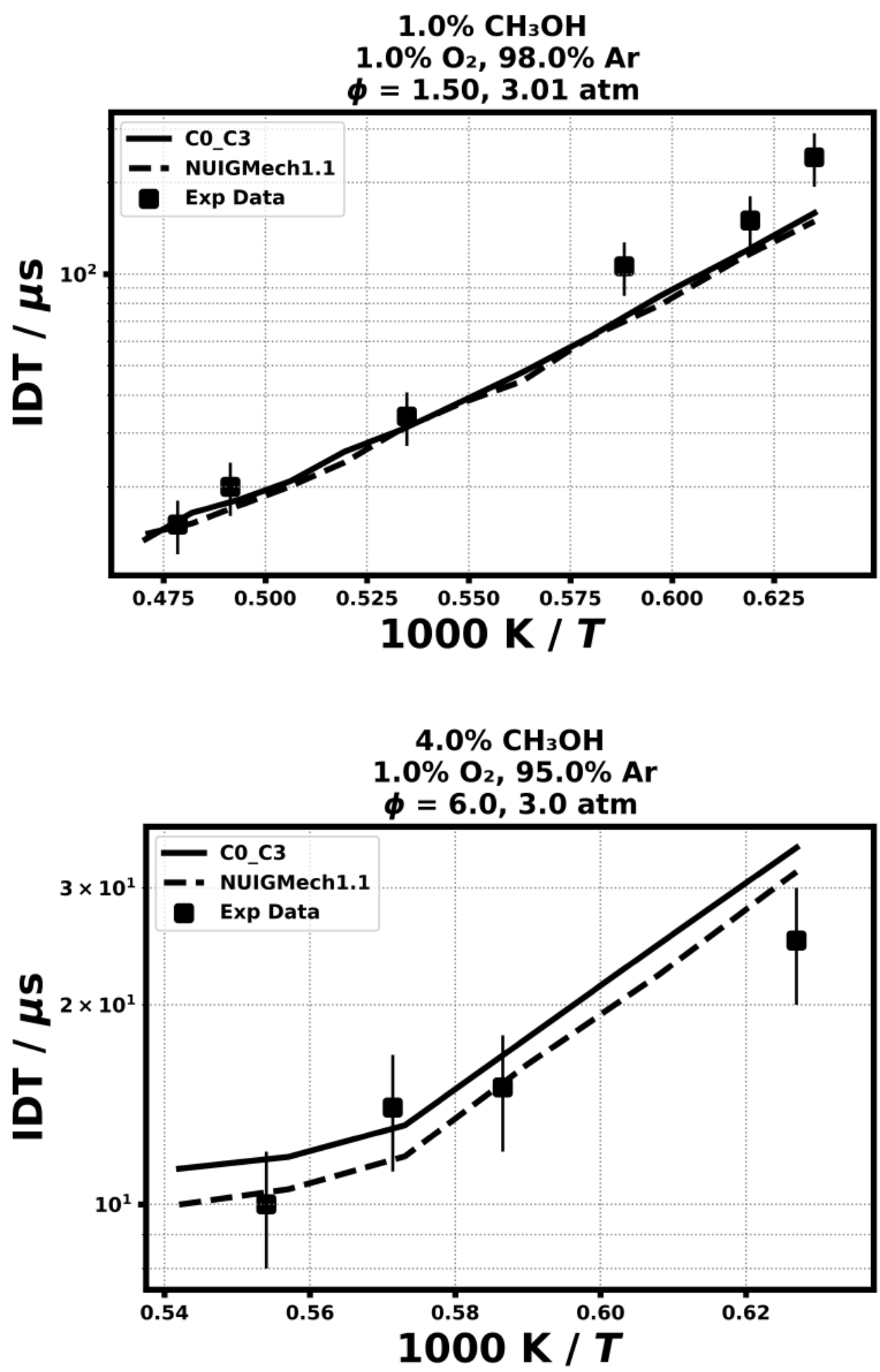

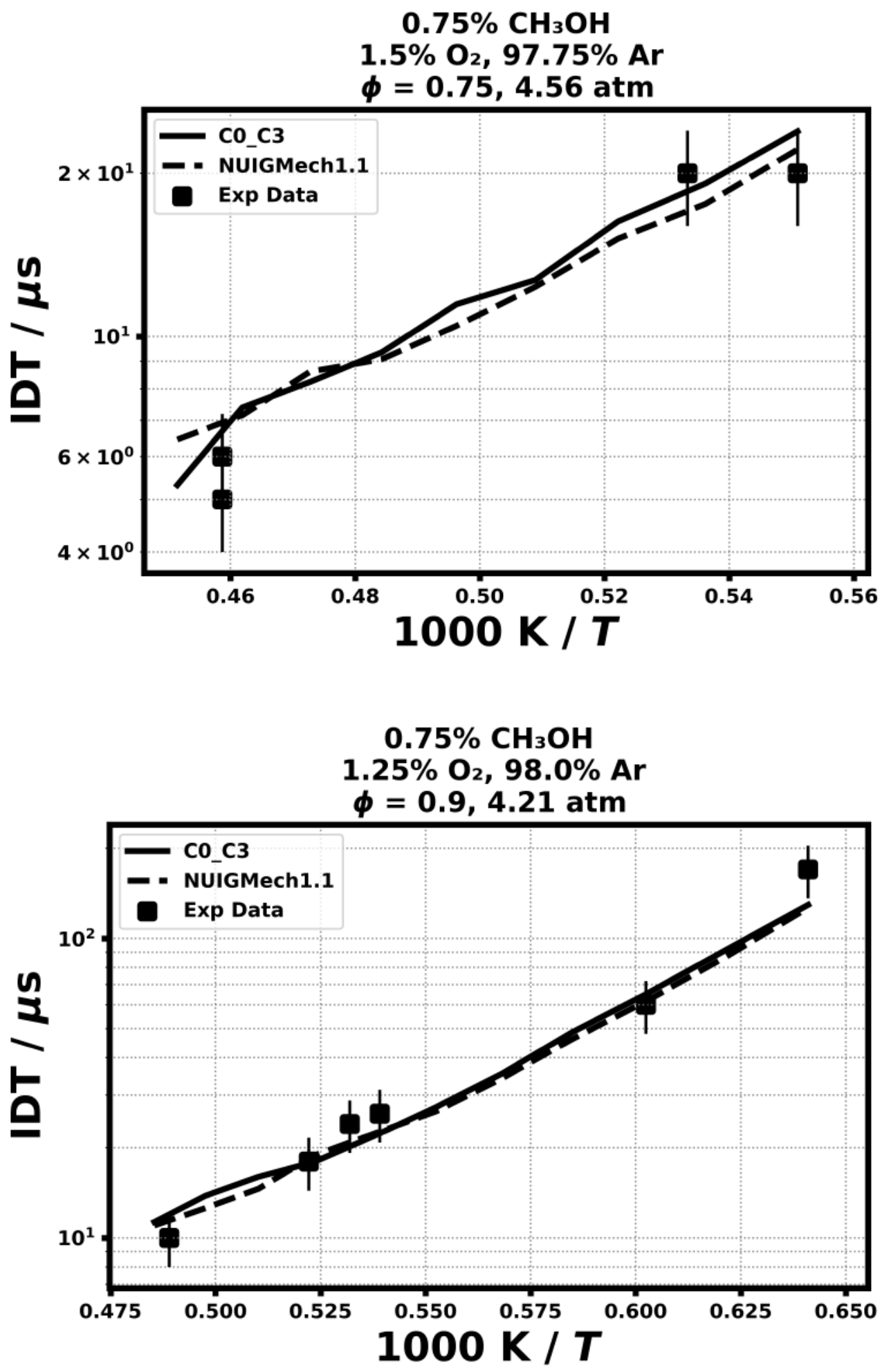
3.2) Burke, U., Metcalfe, W. K., Burke, S. M., Heufer, K. A., Dagaut, P., \& Curran, H. J. Combustion and Flame, 165 (2016) 125-136.
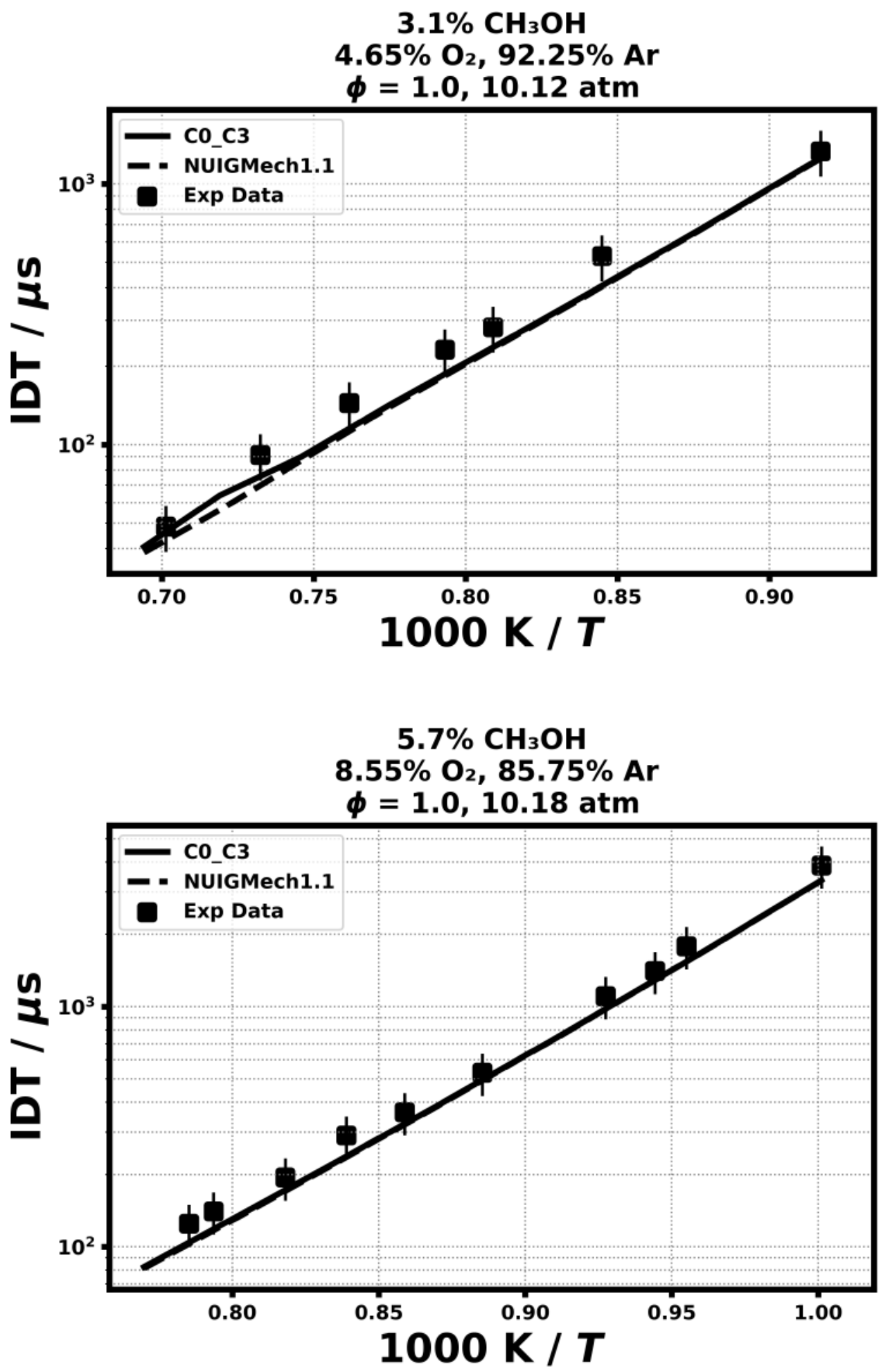

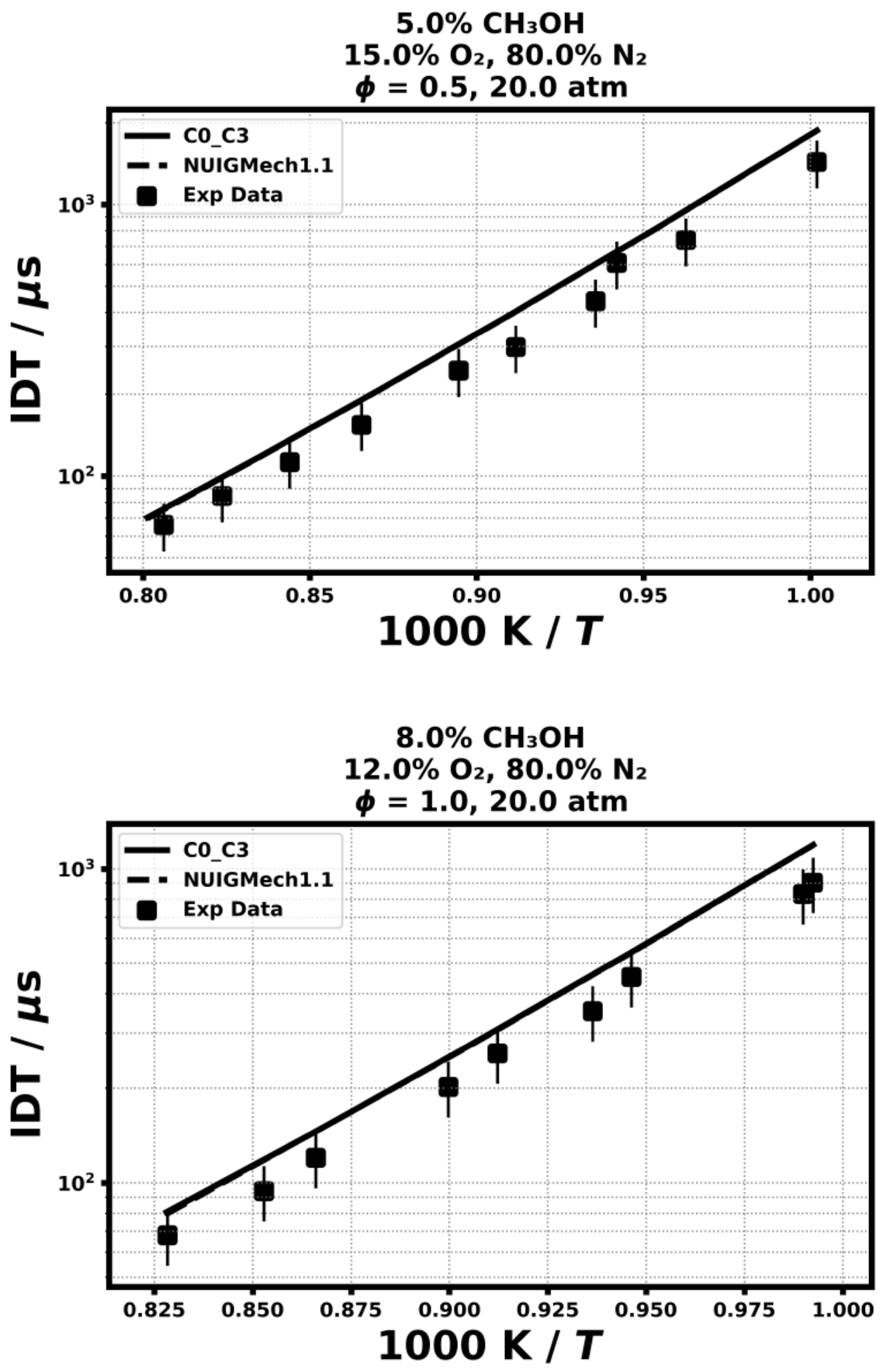

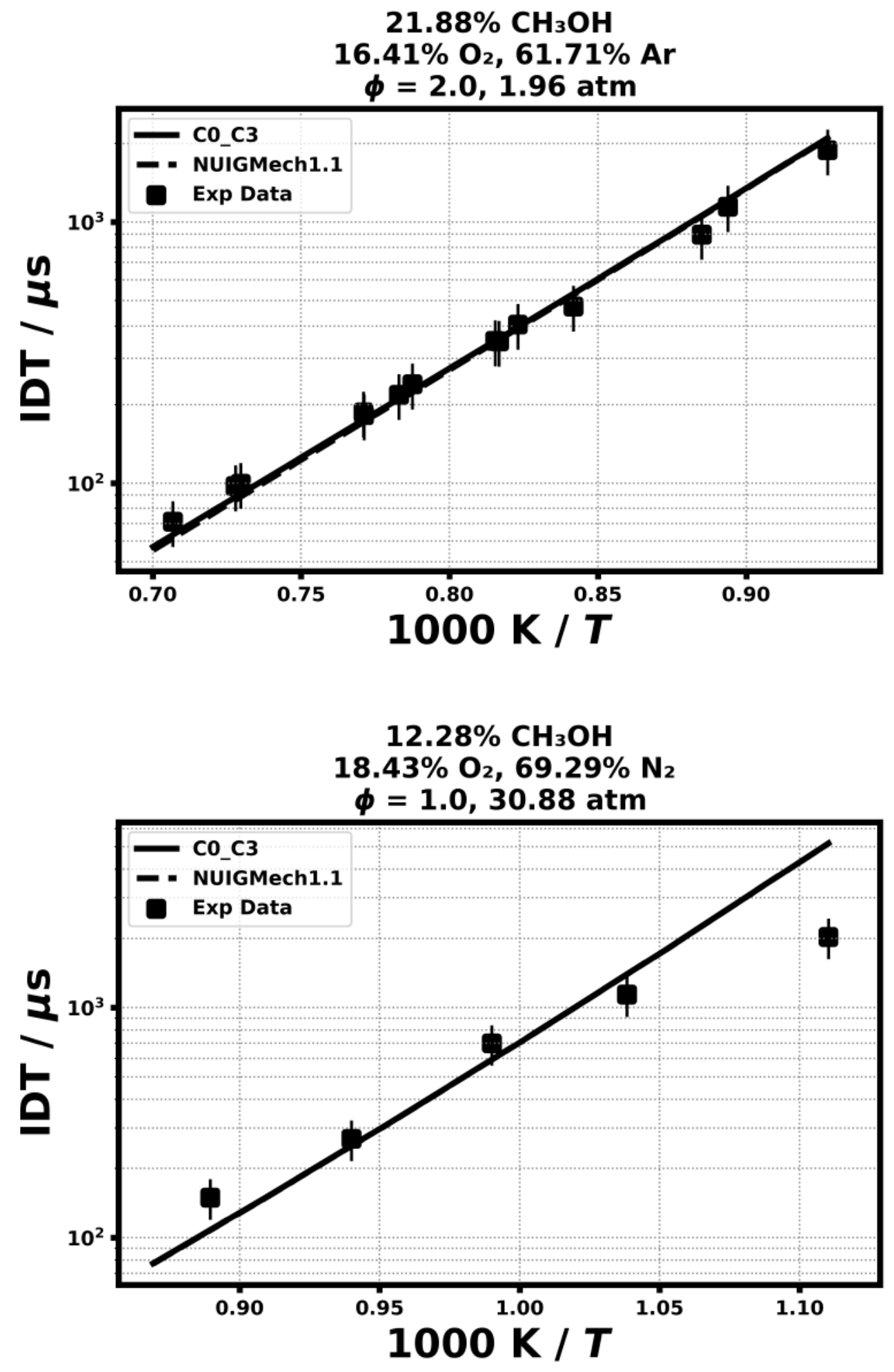

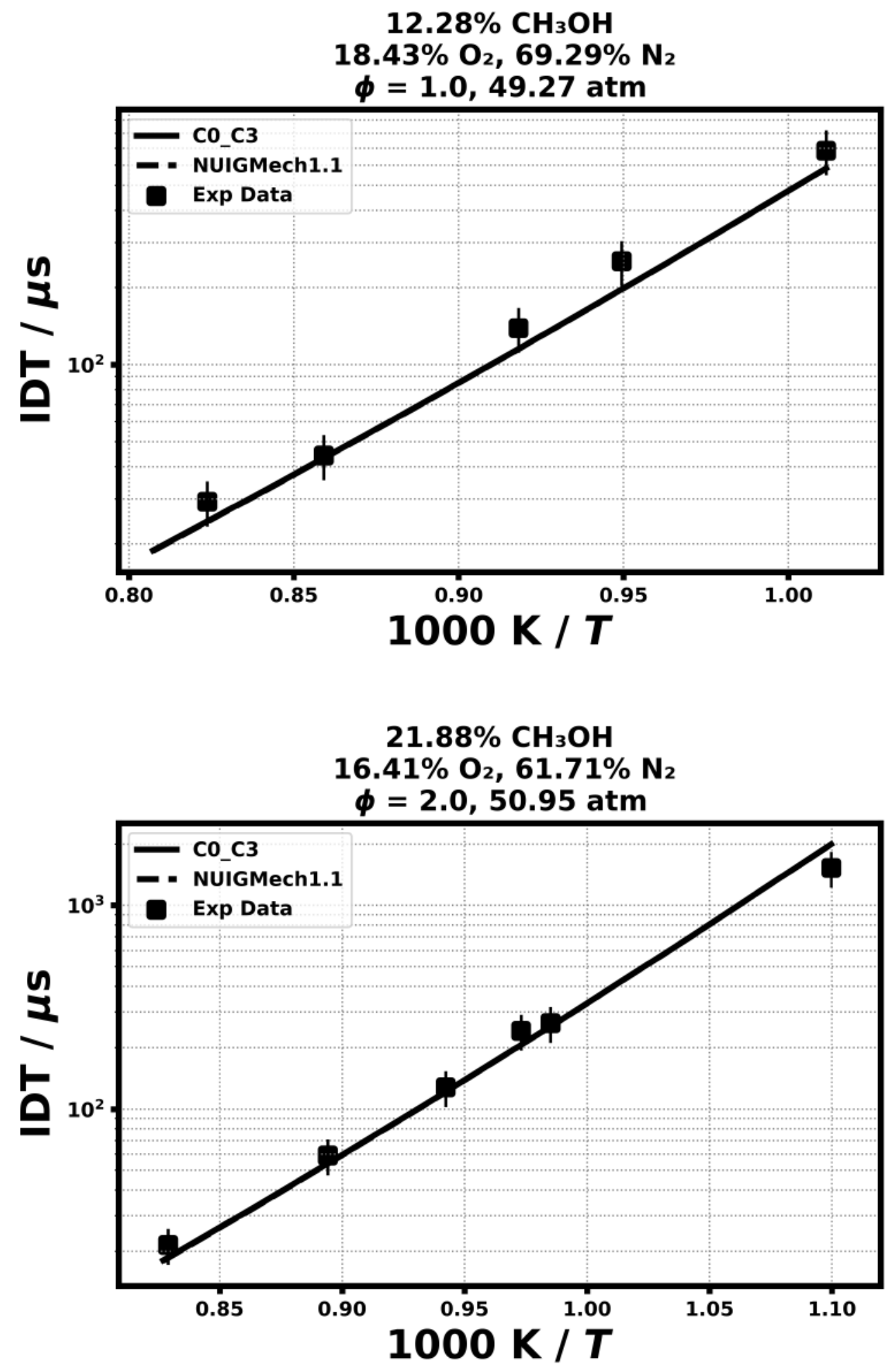

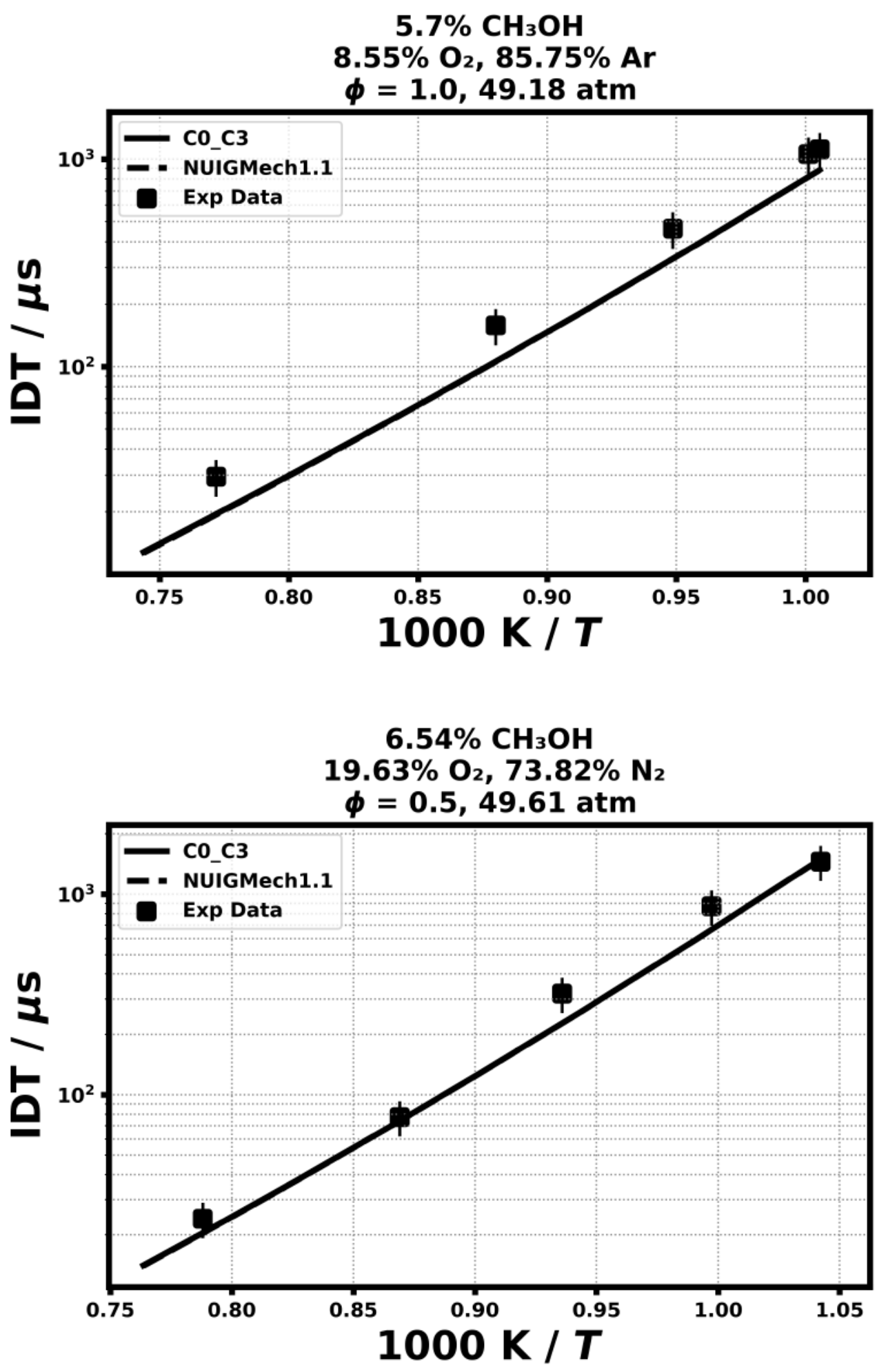
3.3) Fieweger, K., Blumenthal, R., \& Adomeit, G., Combustion and Flame, 109(4) (1997) 599-619.
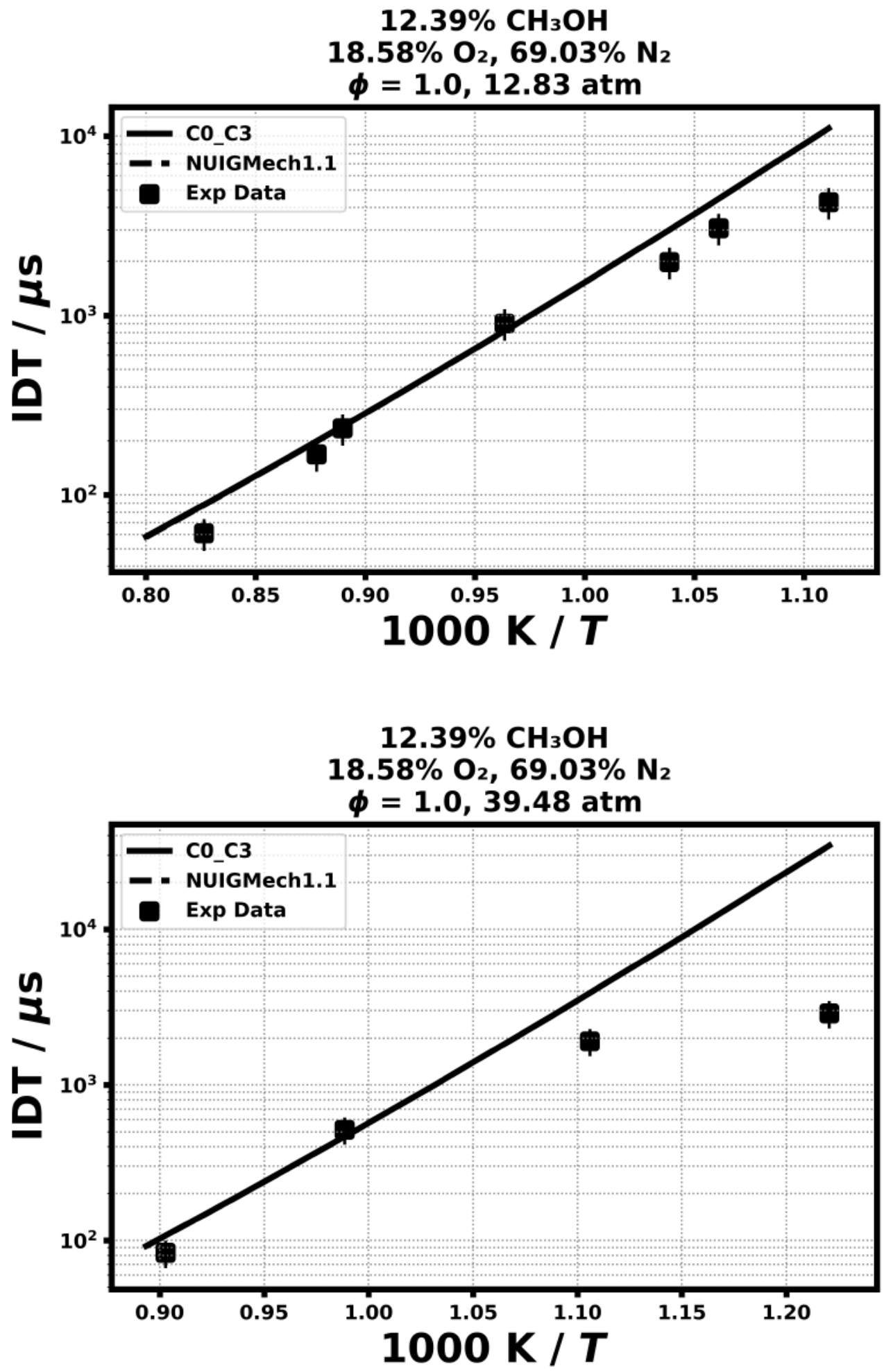
3.4) J. Herzler, European Combust. Meeting, Lund Sweden, 2013
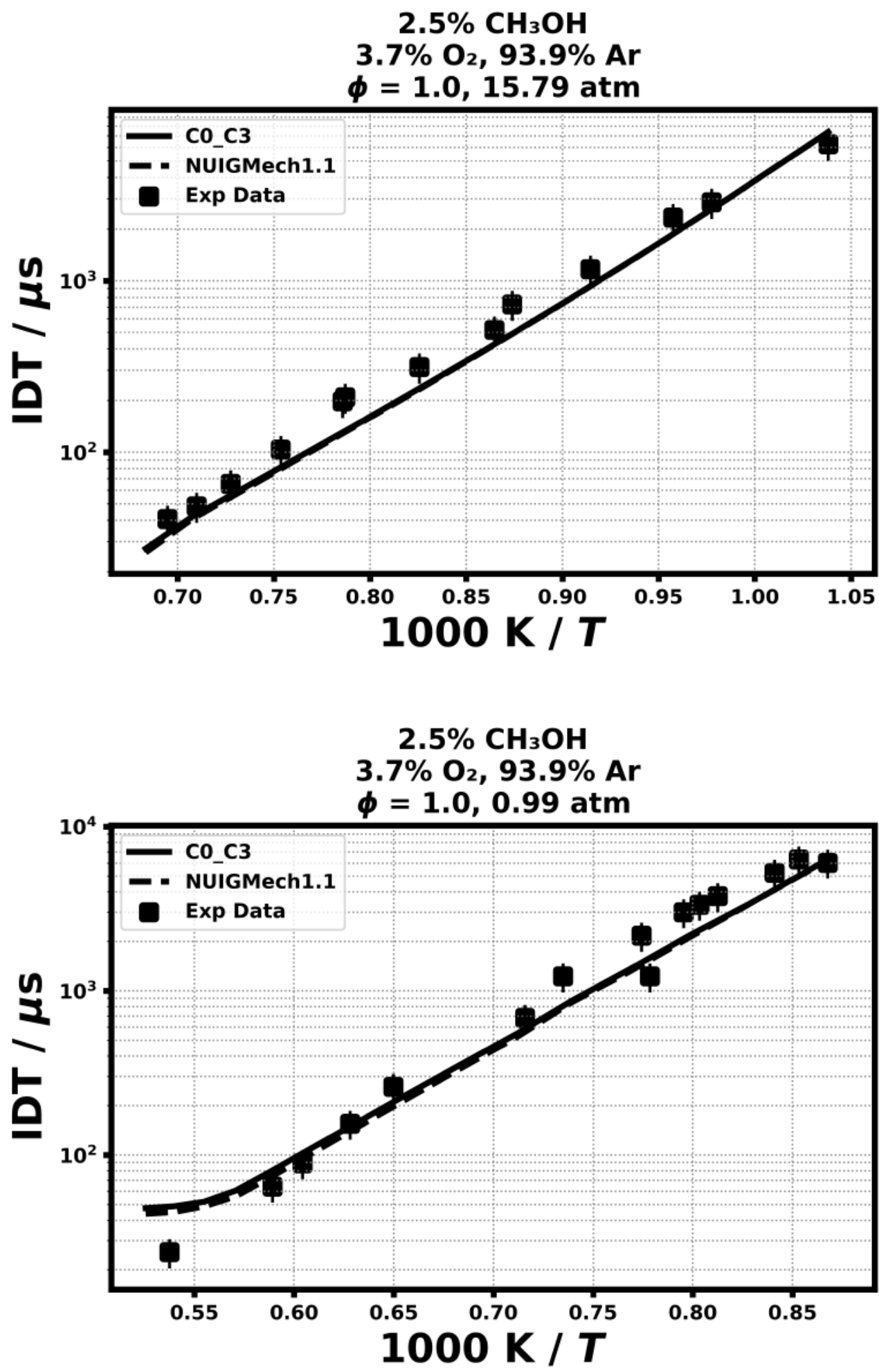


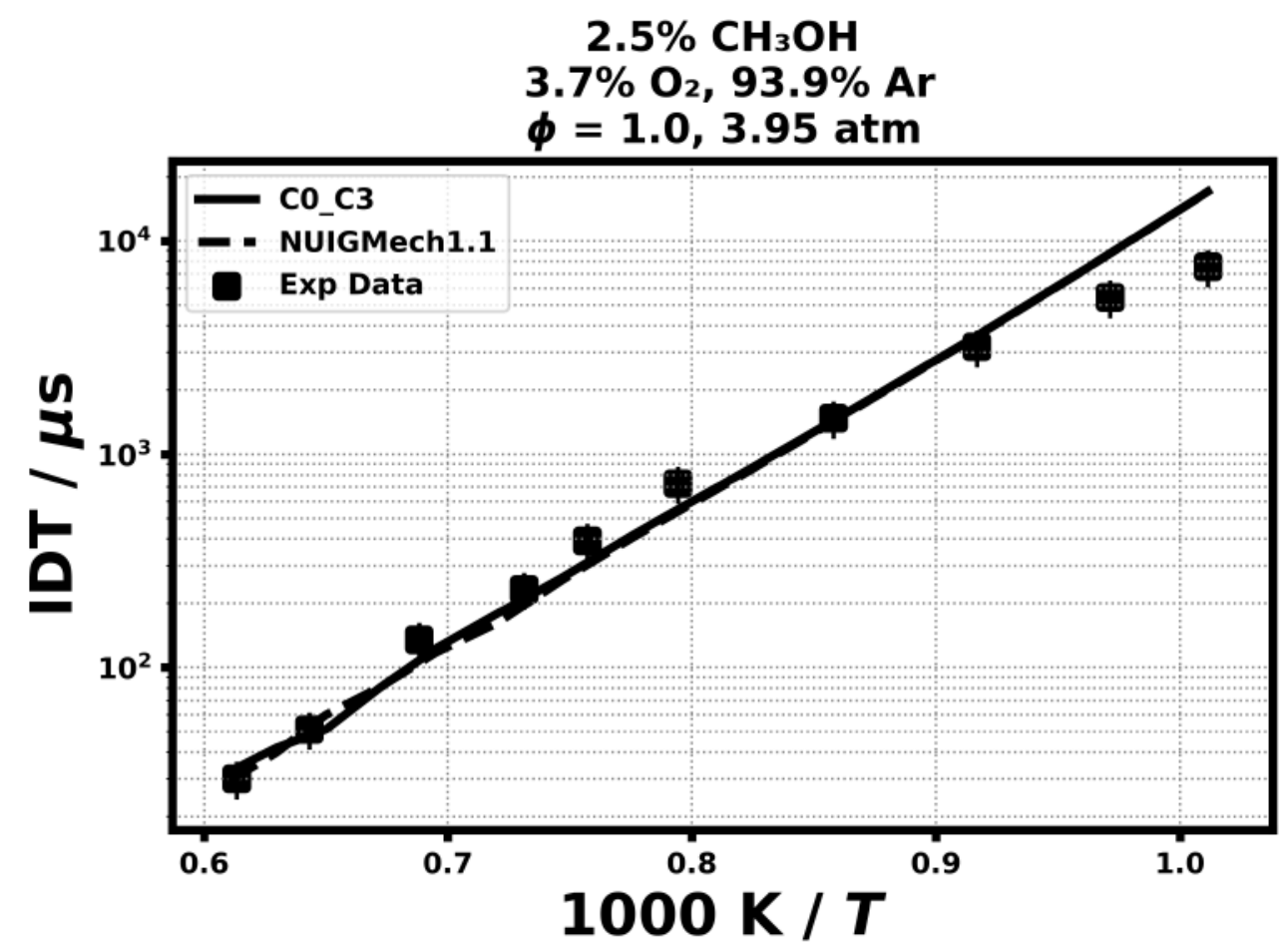

3.5) Natarajan, K., \& Bhaskaran, K. A., Combustion and Flame, 43 (1981) 35-49.

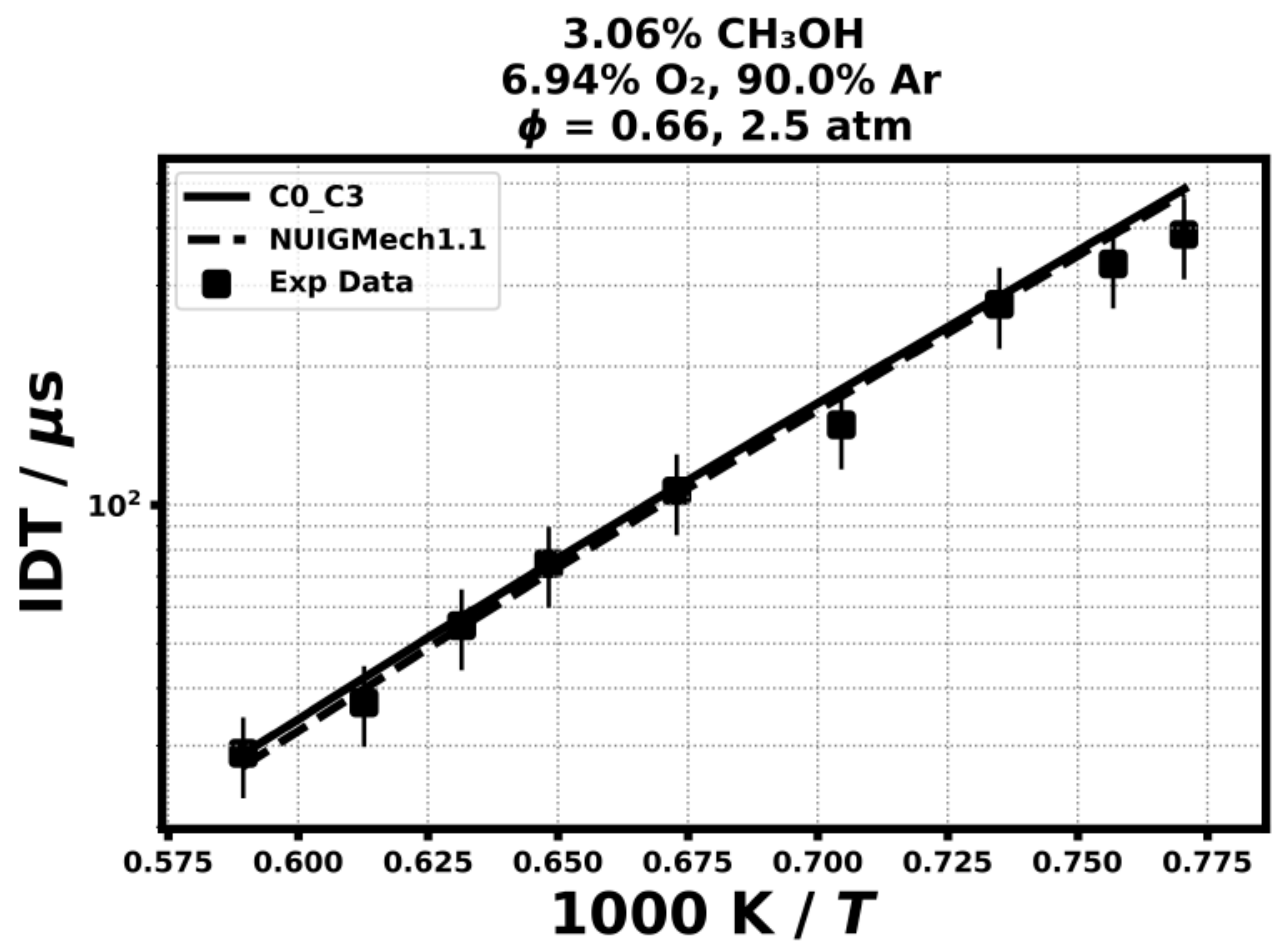



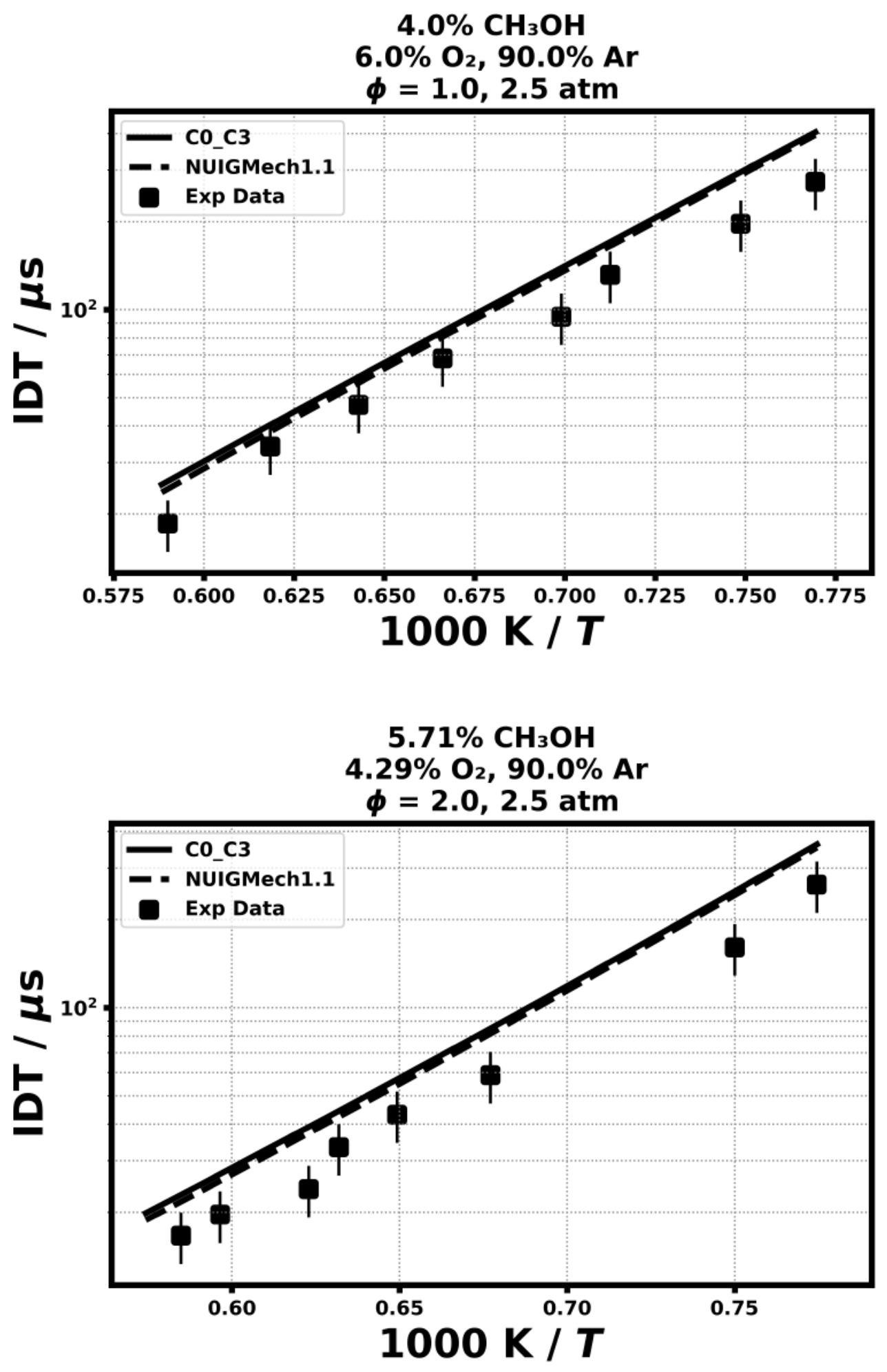
3.6) Noorani, K. E., Akih-Kumgeh, B., \& Bergthorson, J. M., Energy \& fuels, 24(11) (2010) 5834-5843.
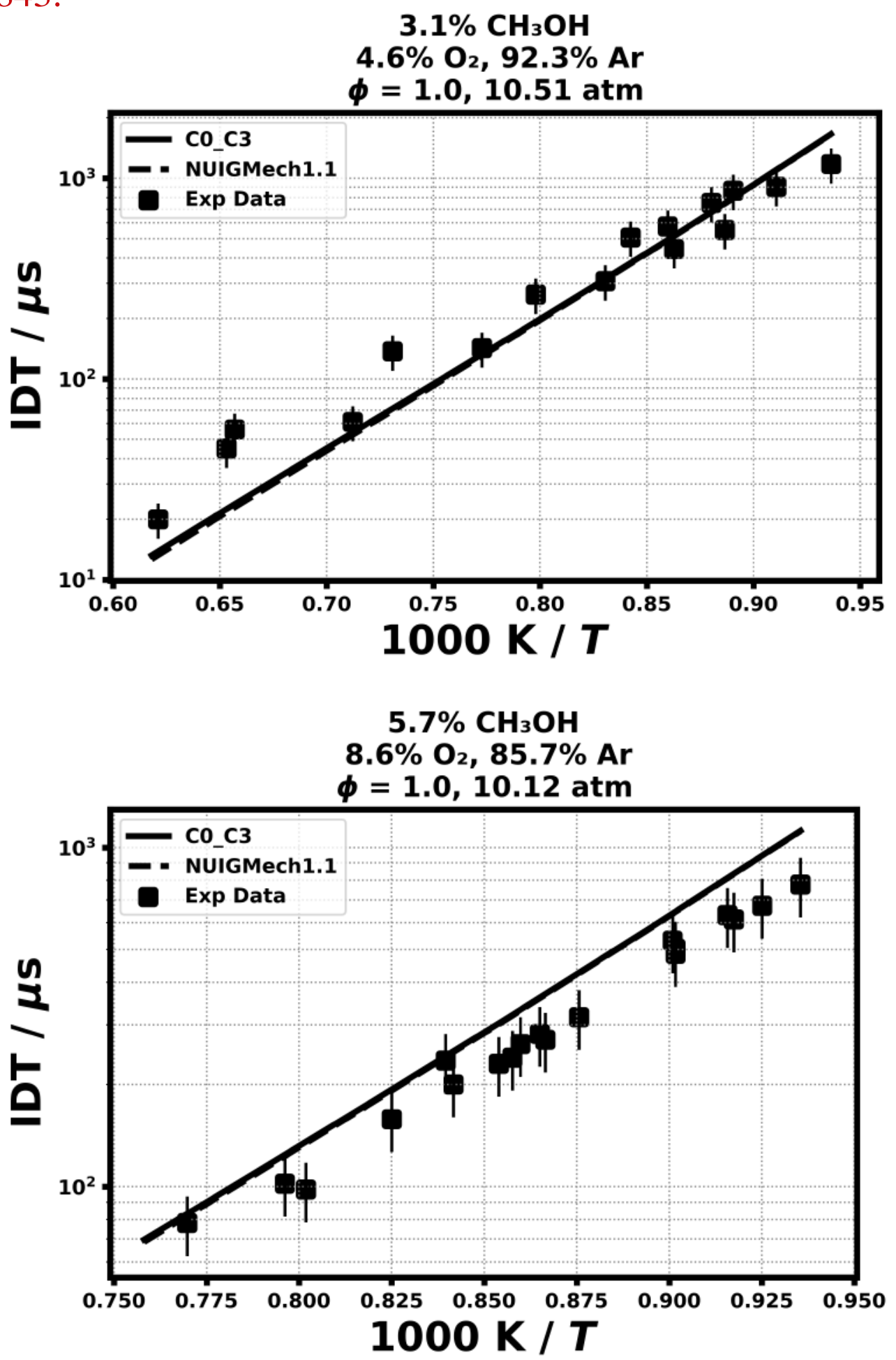

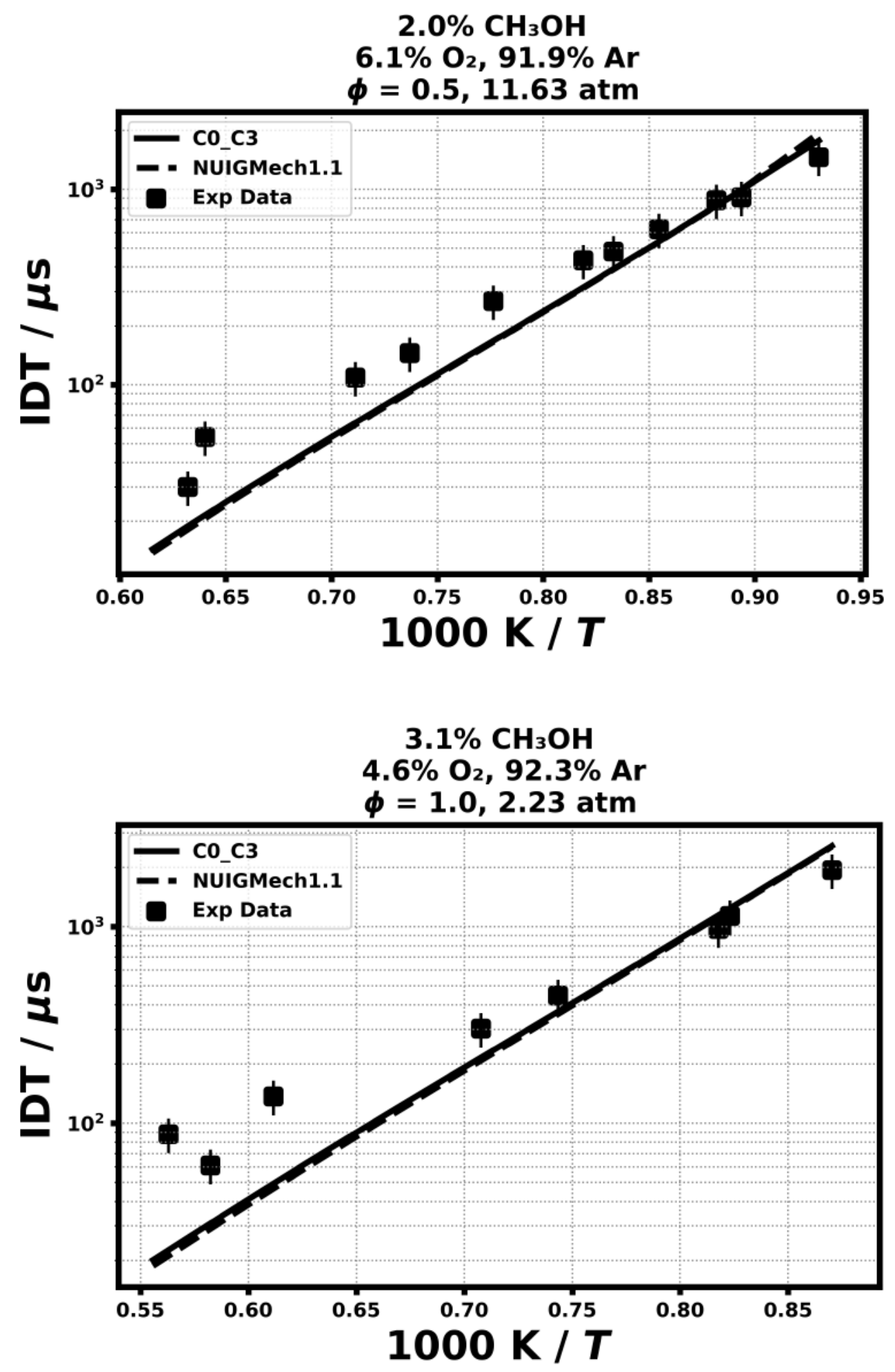

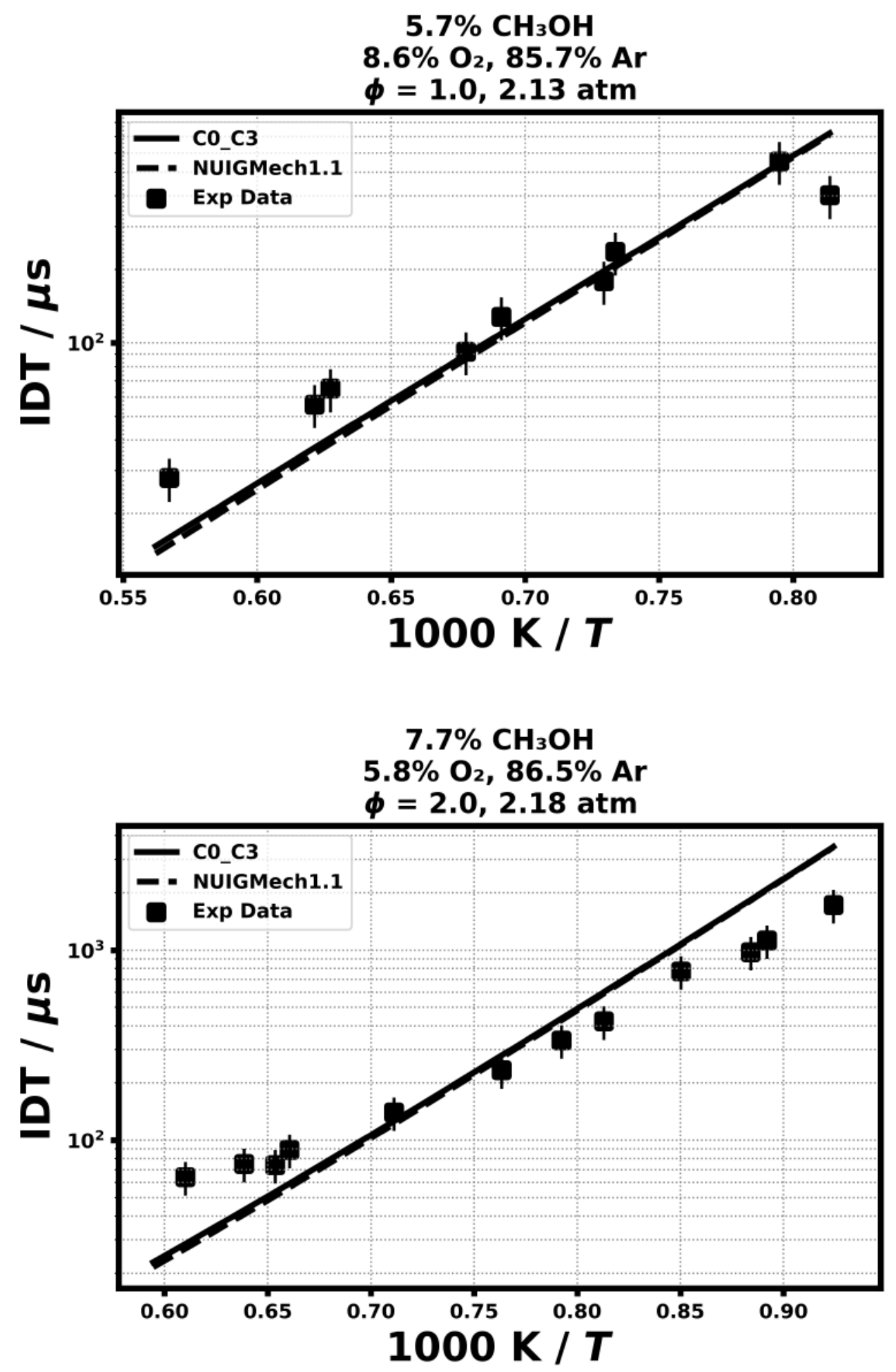


\section{RCM Ignition delay time}

3.7) Burke, U., Metcalfe, W. K., Burke, S. M., Heufer, K. A., Dagaut, P., \& Curran, H. J., Combustion and Flame, 165 (2016) 125-136.
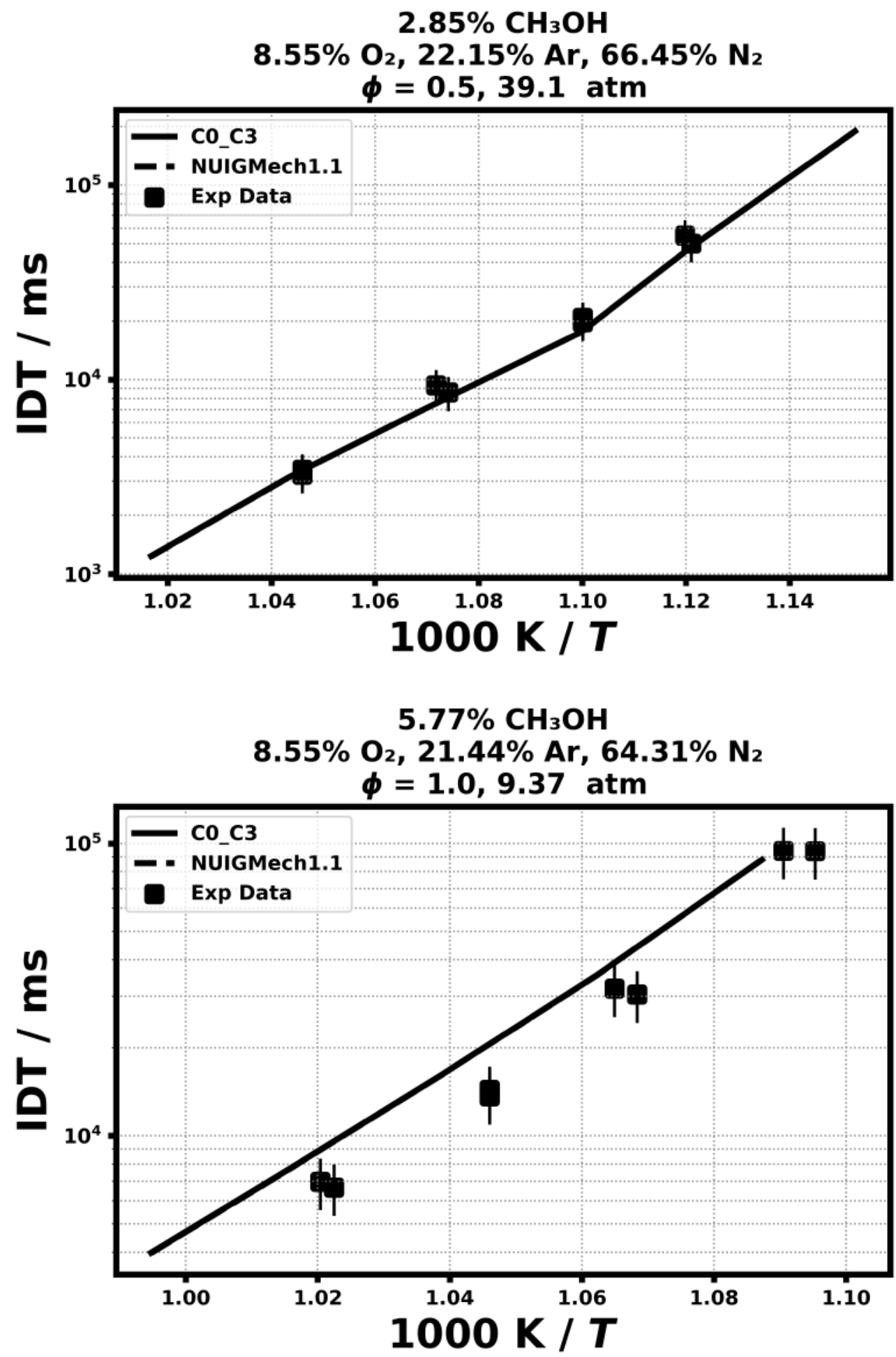

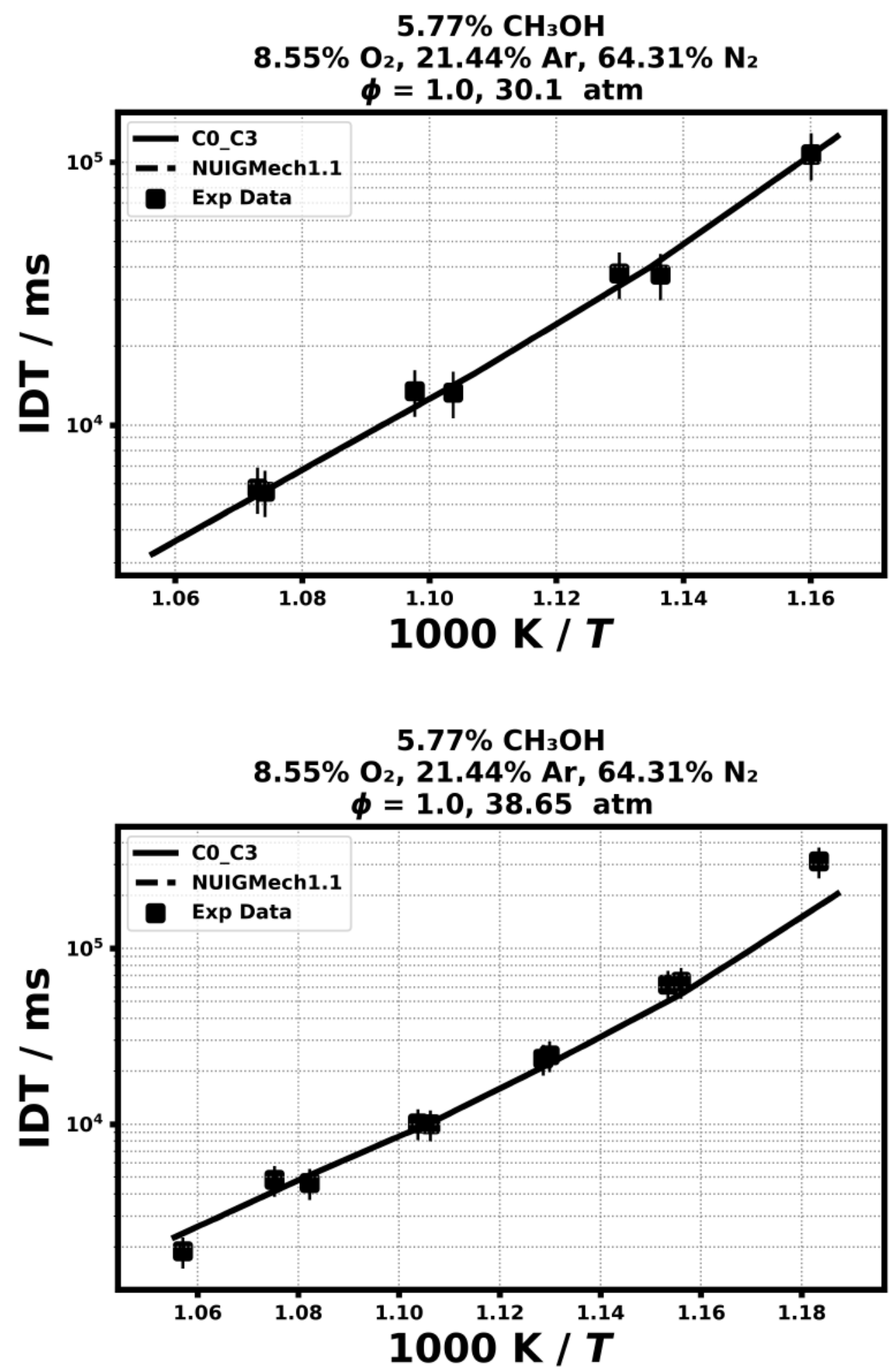

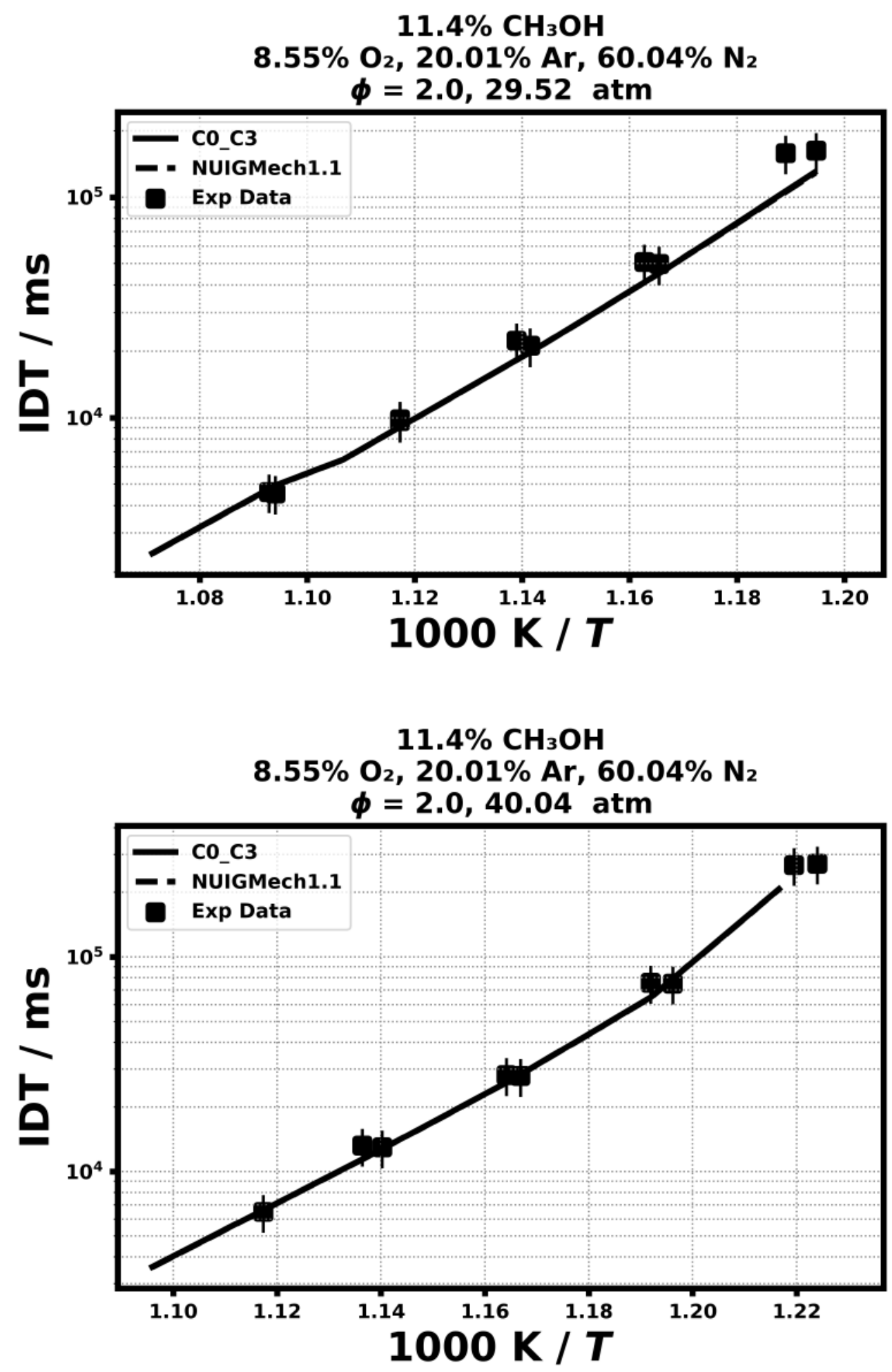


\section{Speciation in Jet-stirred reactor}

3.8) Burke, U., Metcalfe, W. K., Burke, S. M., Heufer, K. A., Dagaut, P., \& Curran, H. J., Combustion and Flame, 165 (2016) 125-136.
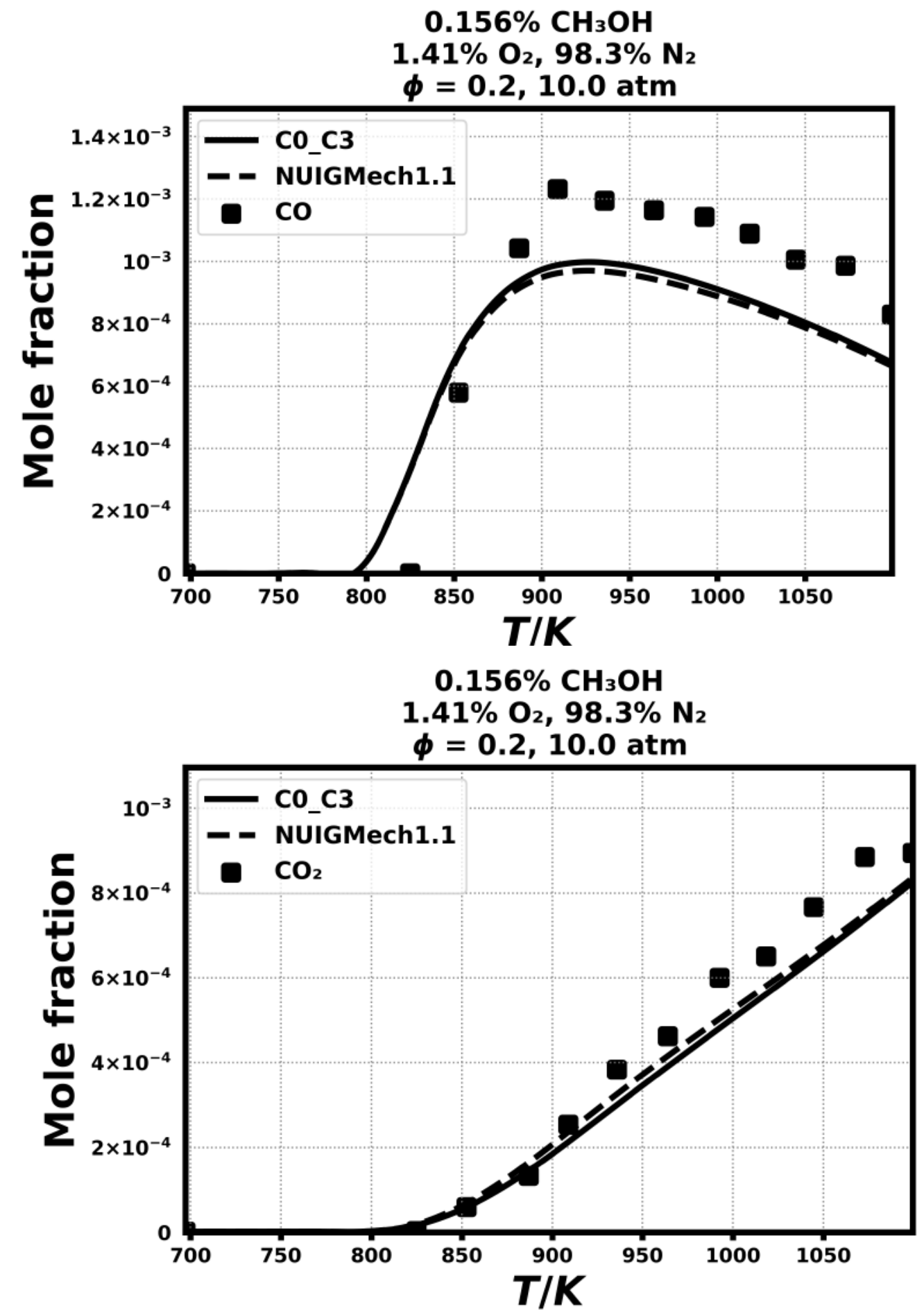

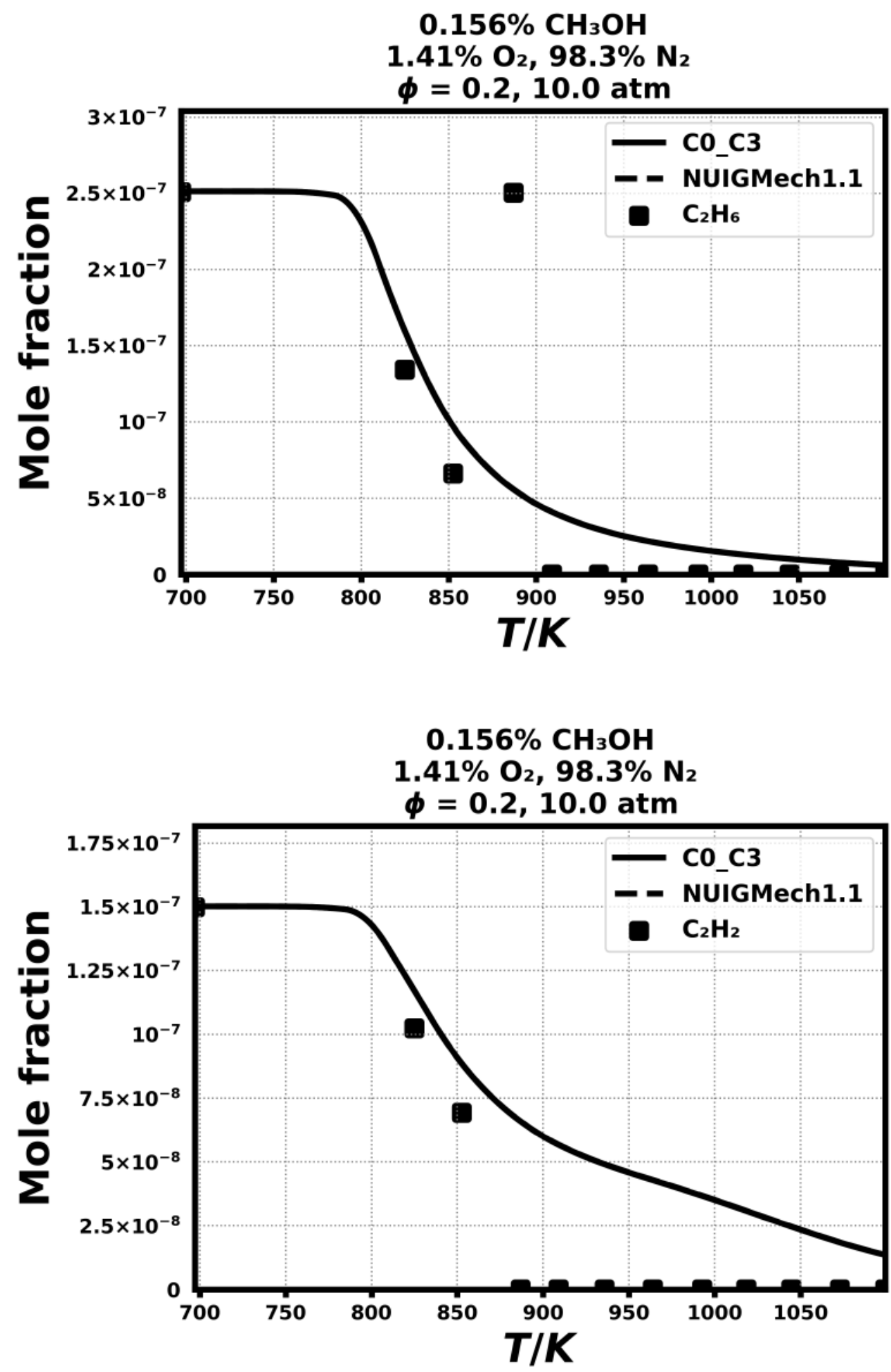

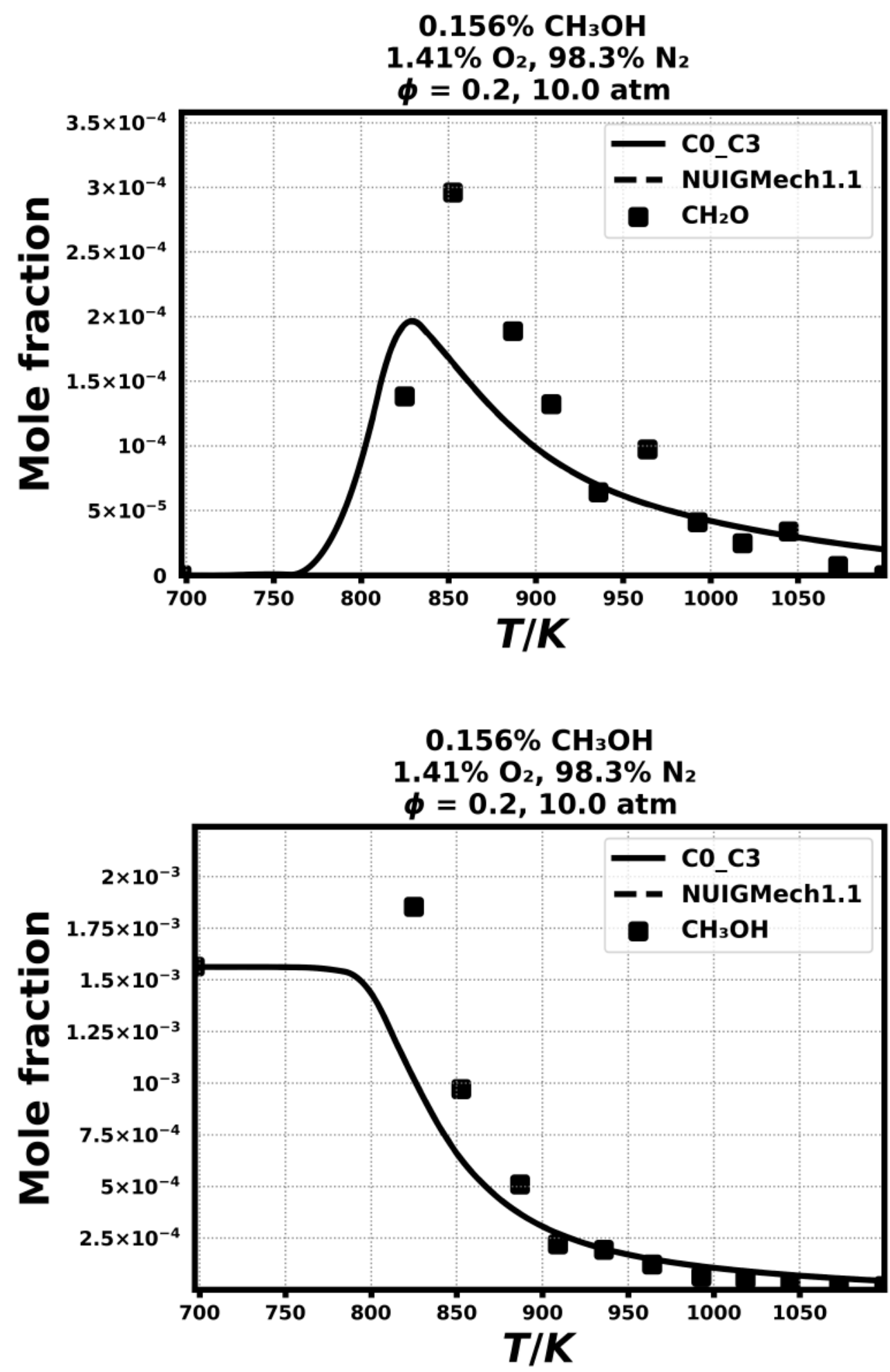

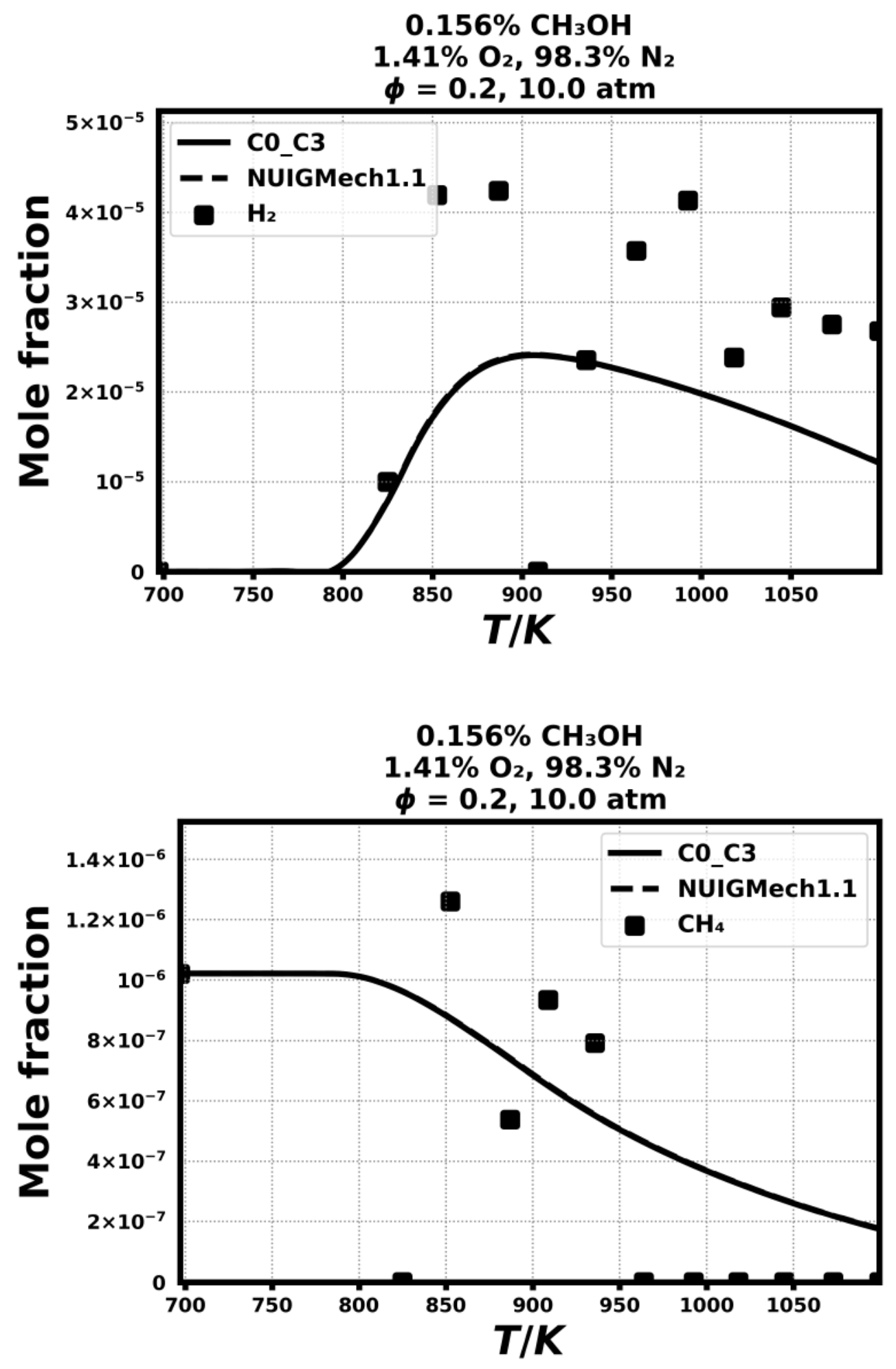

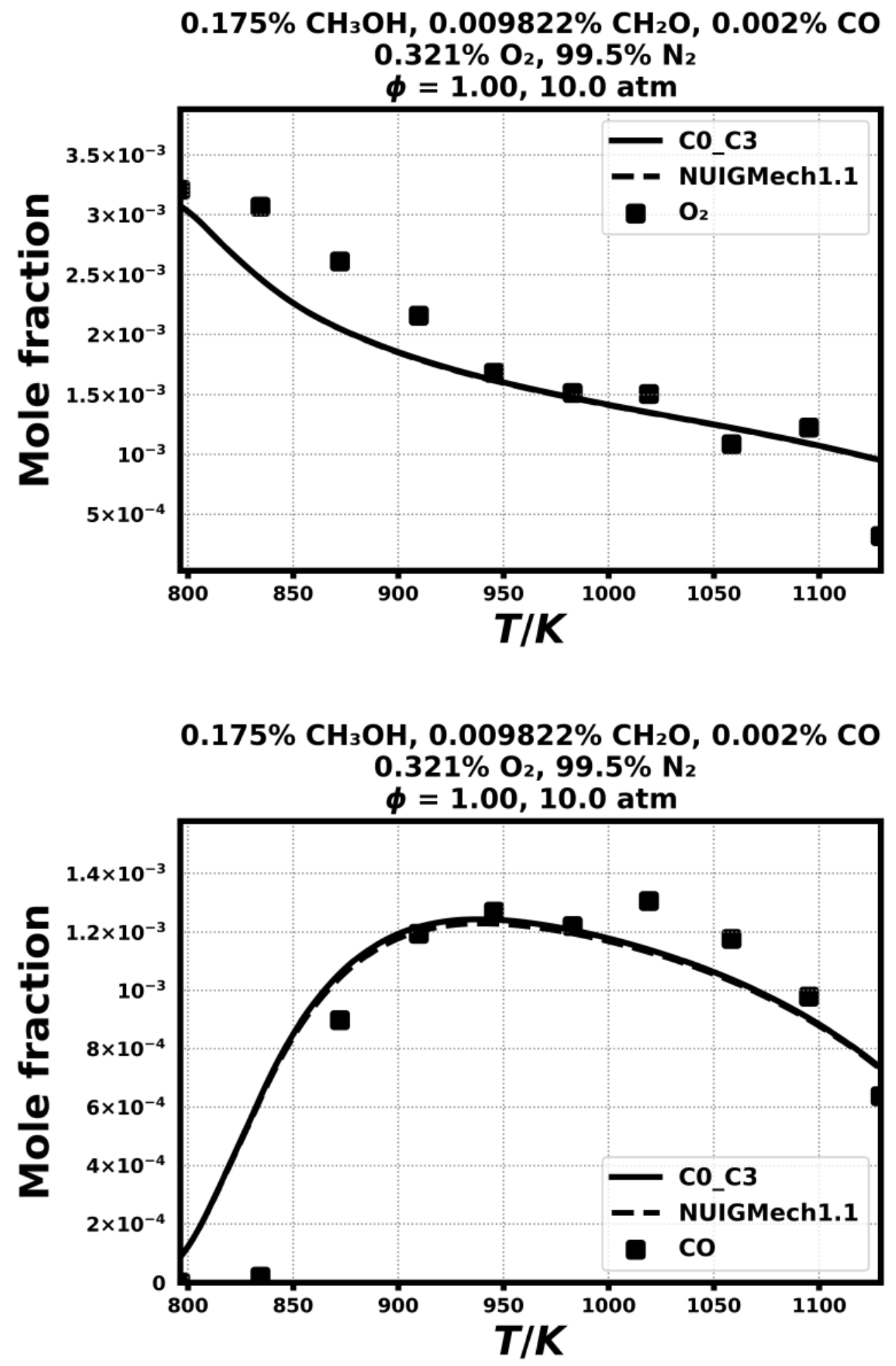

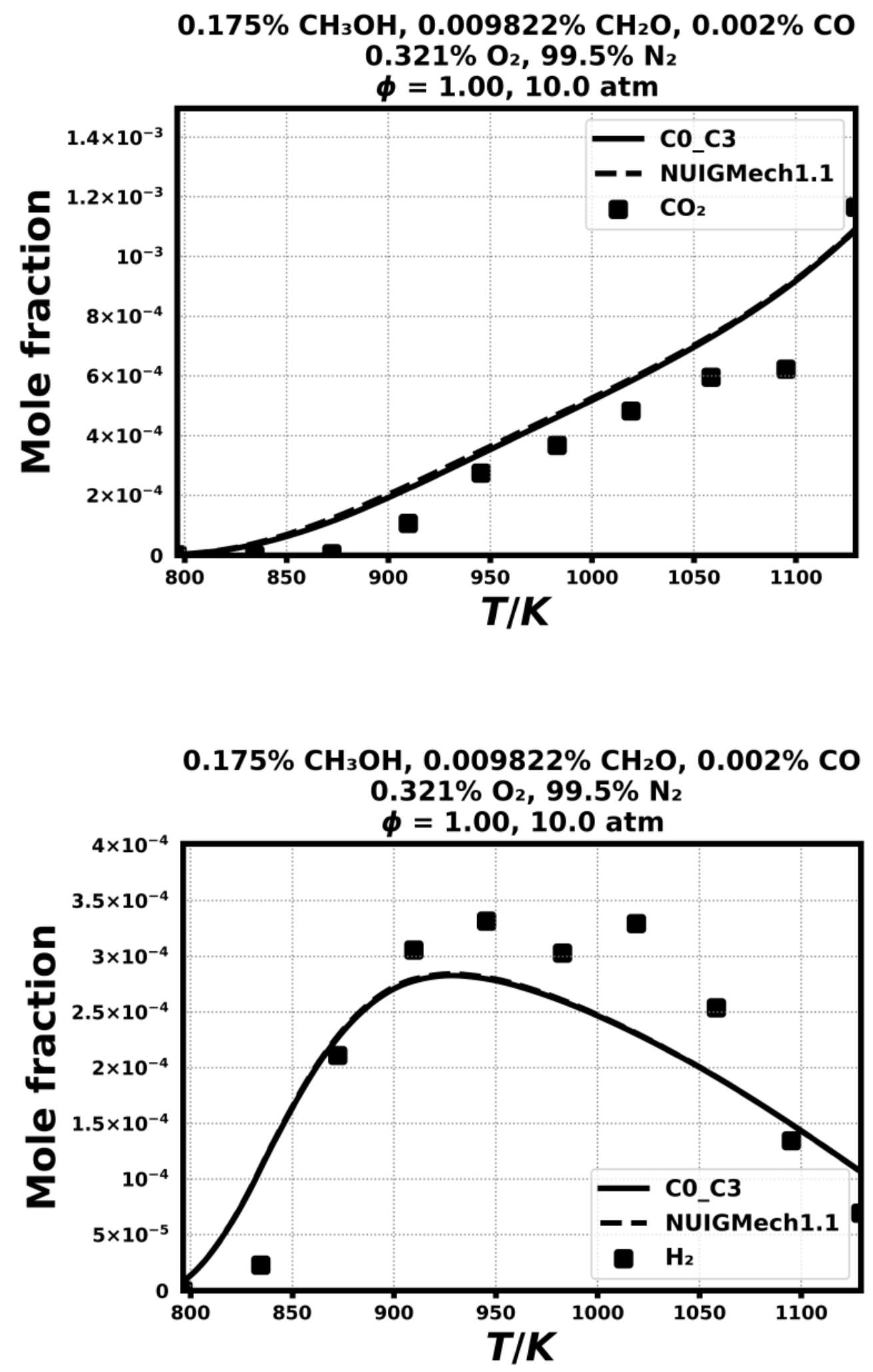

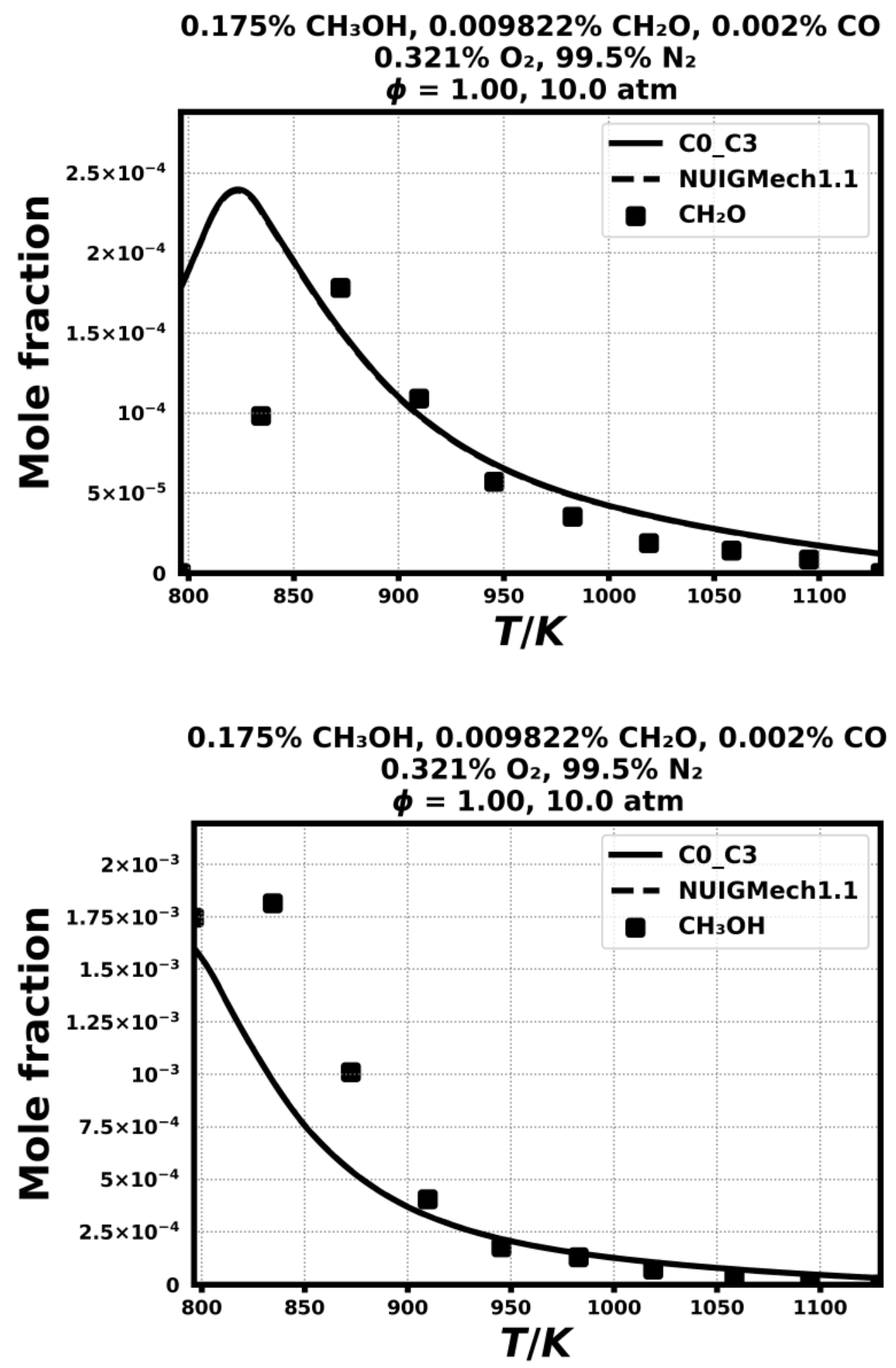

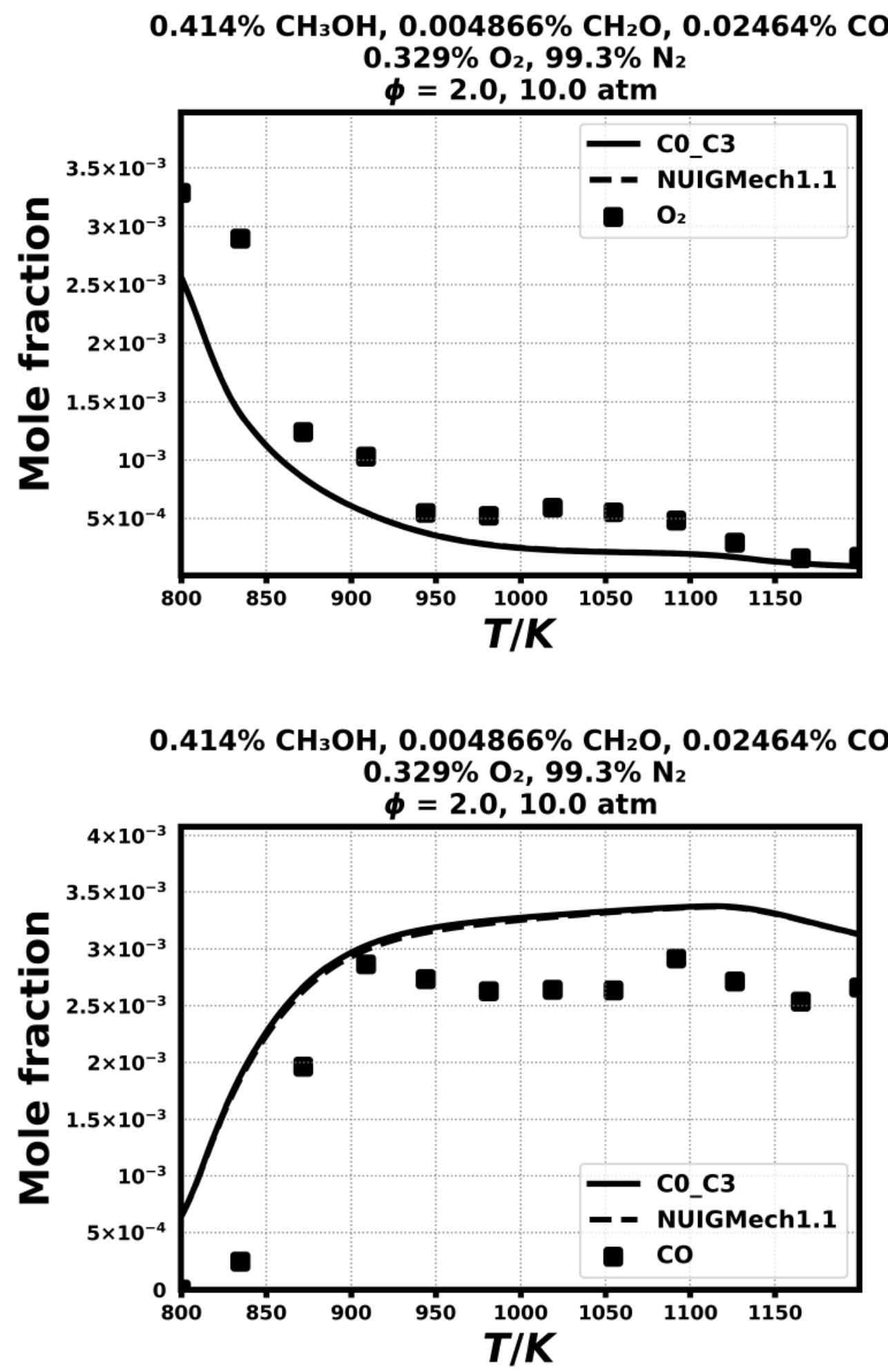

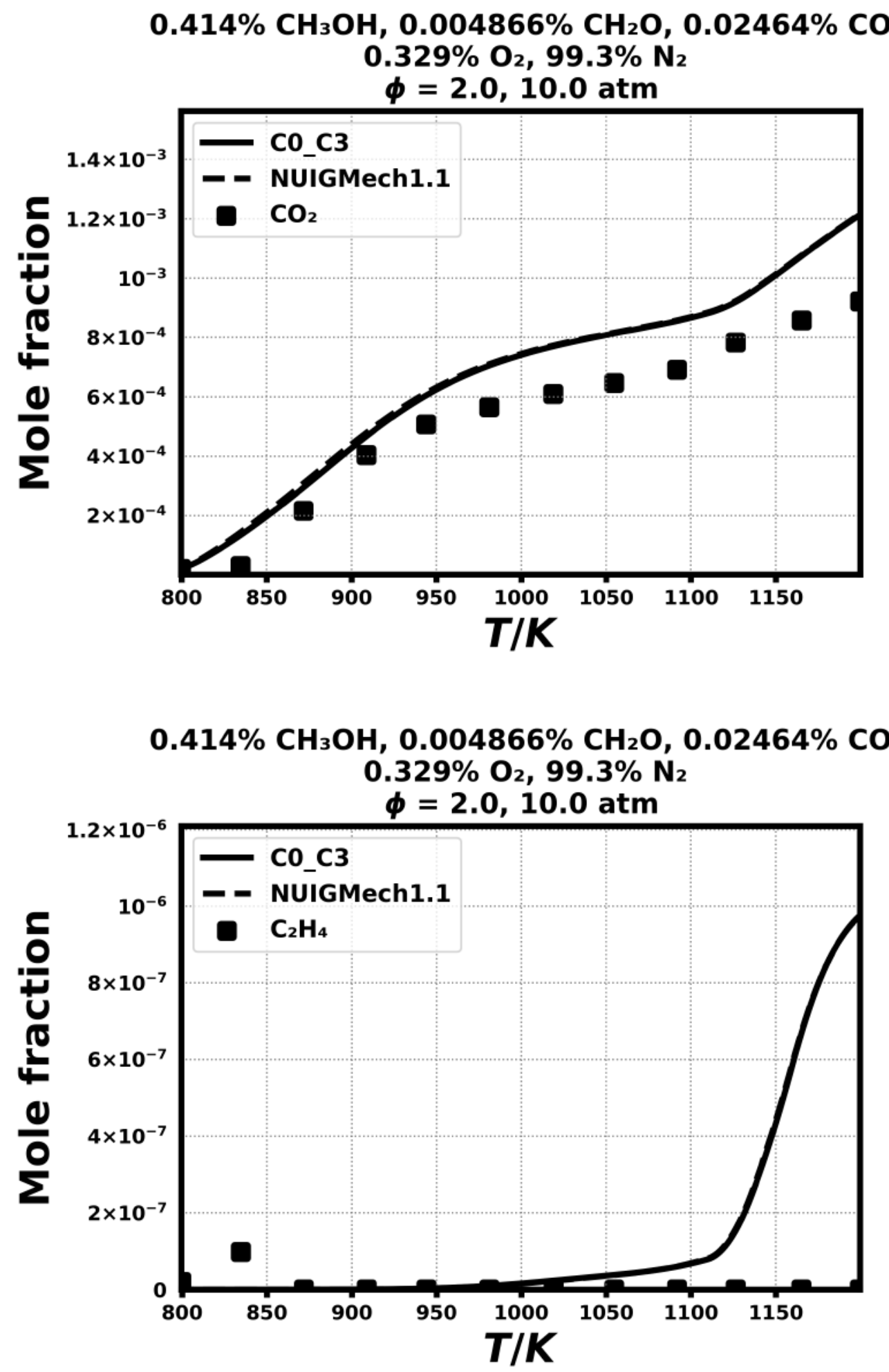

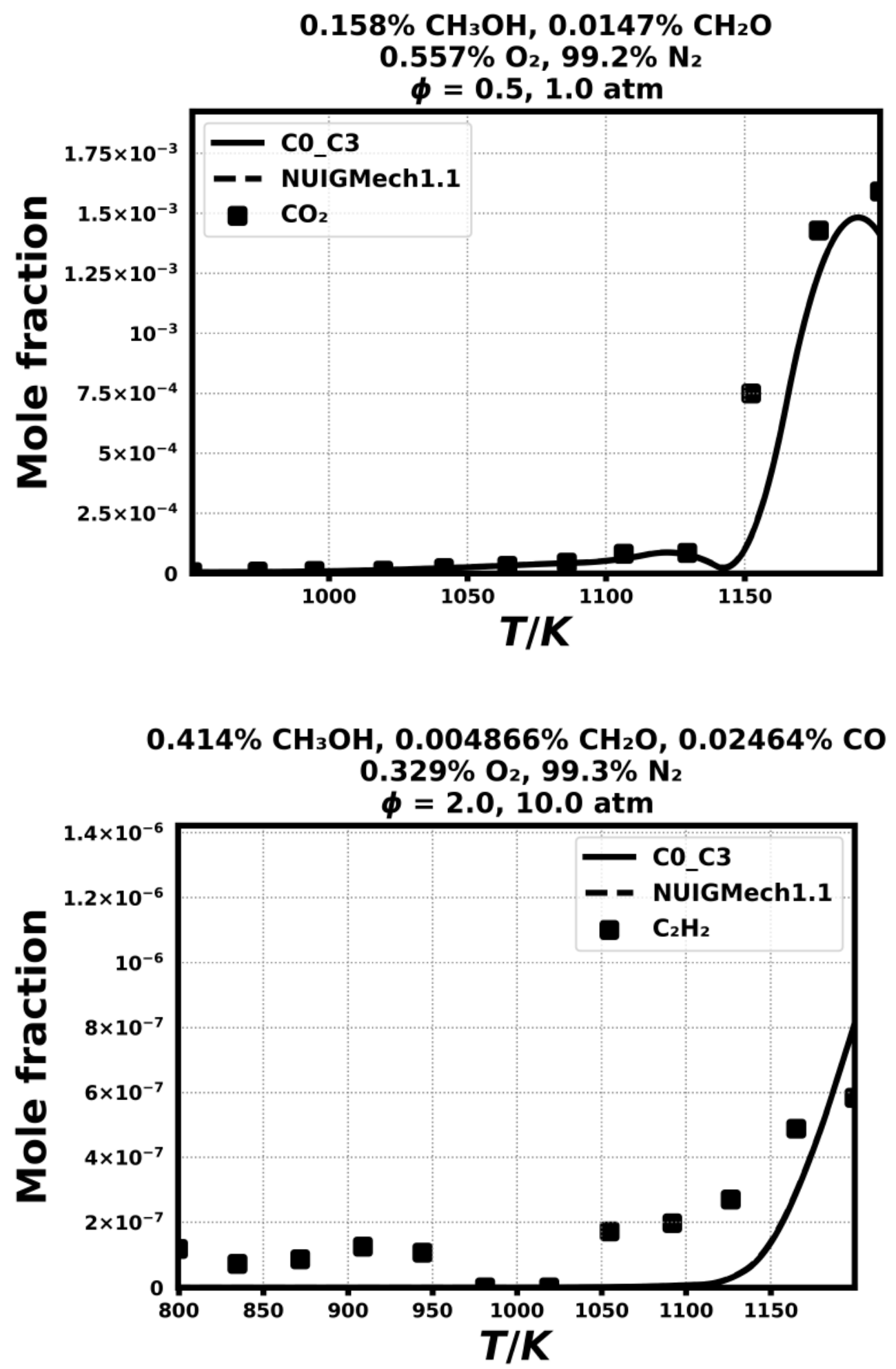

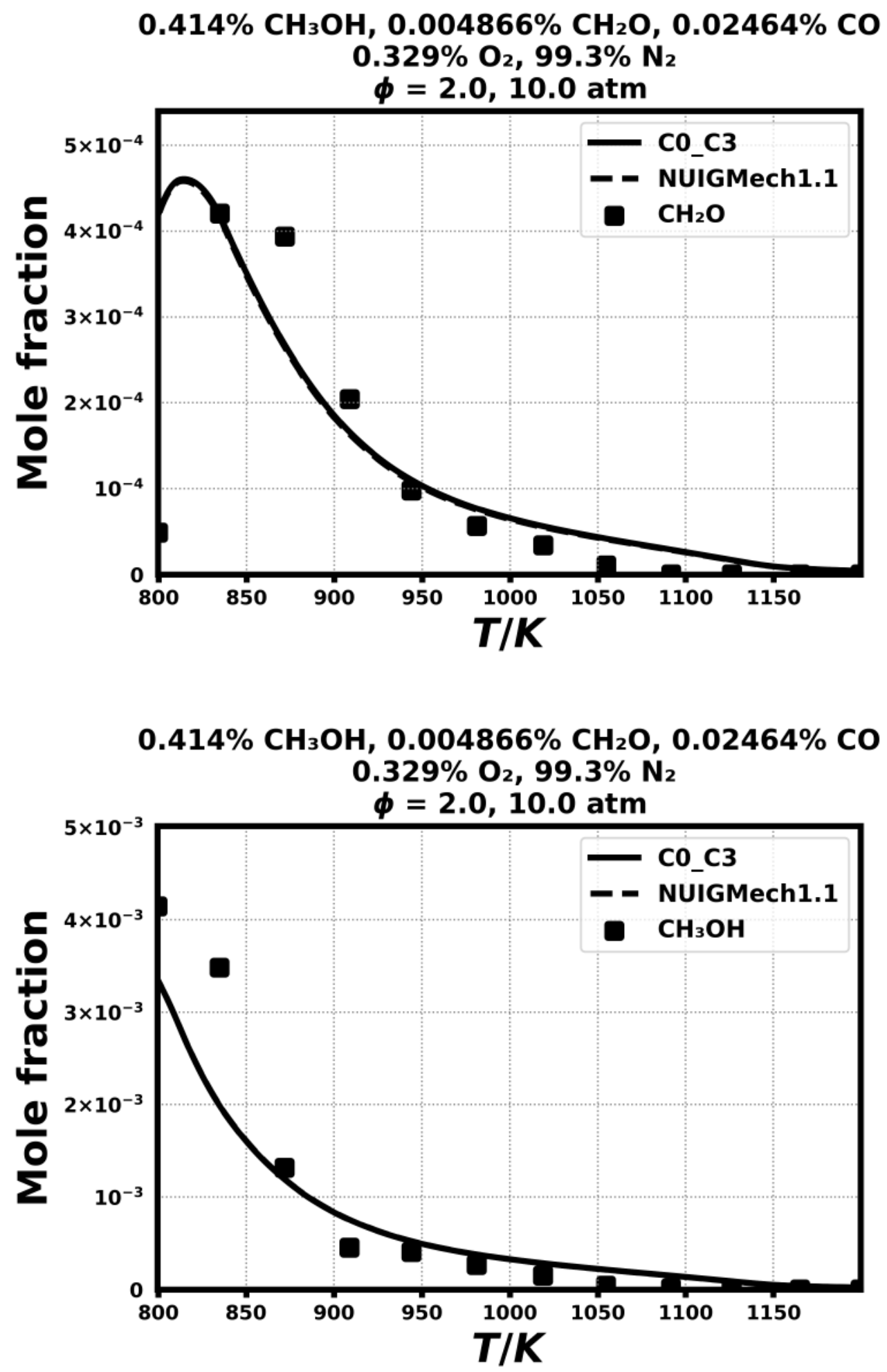

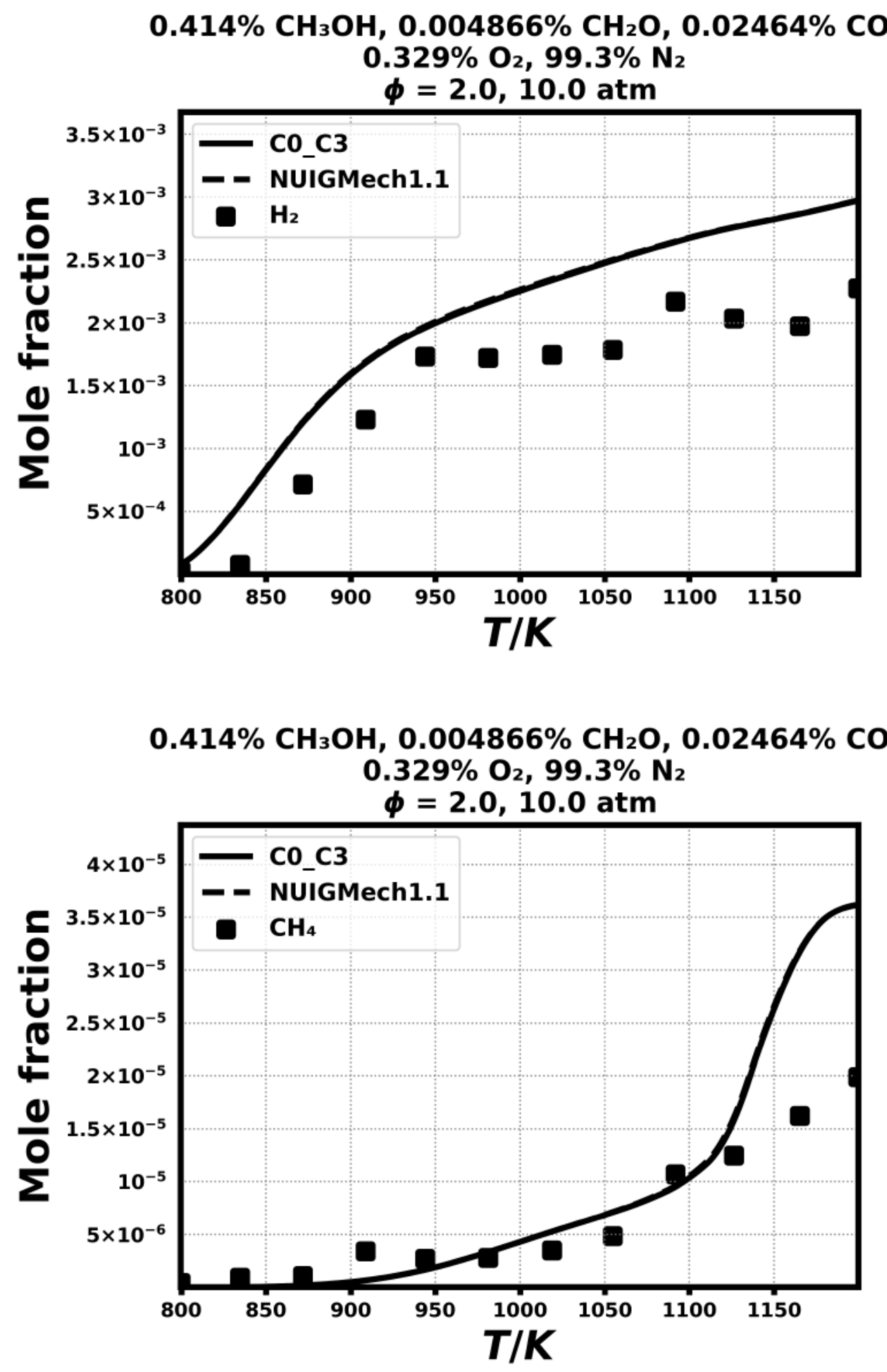

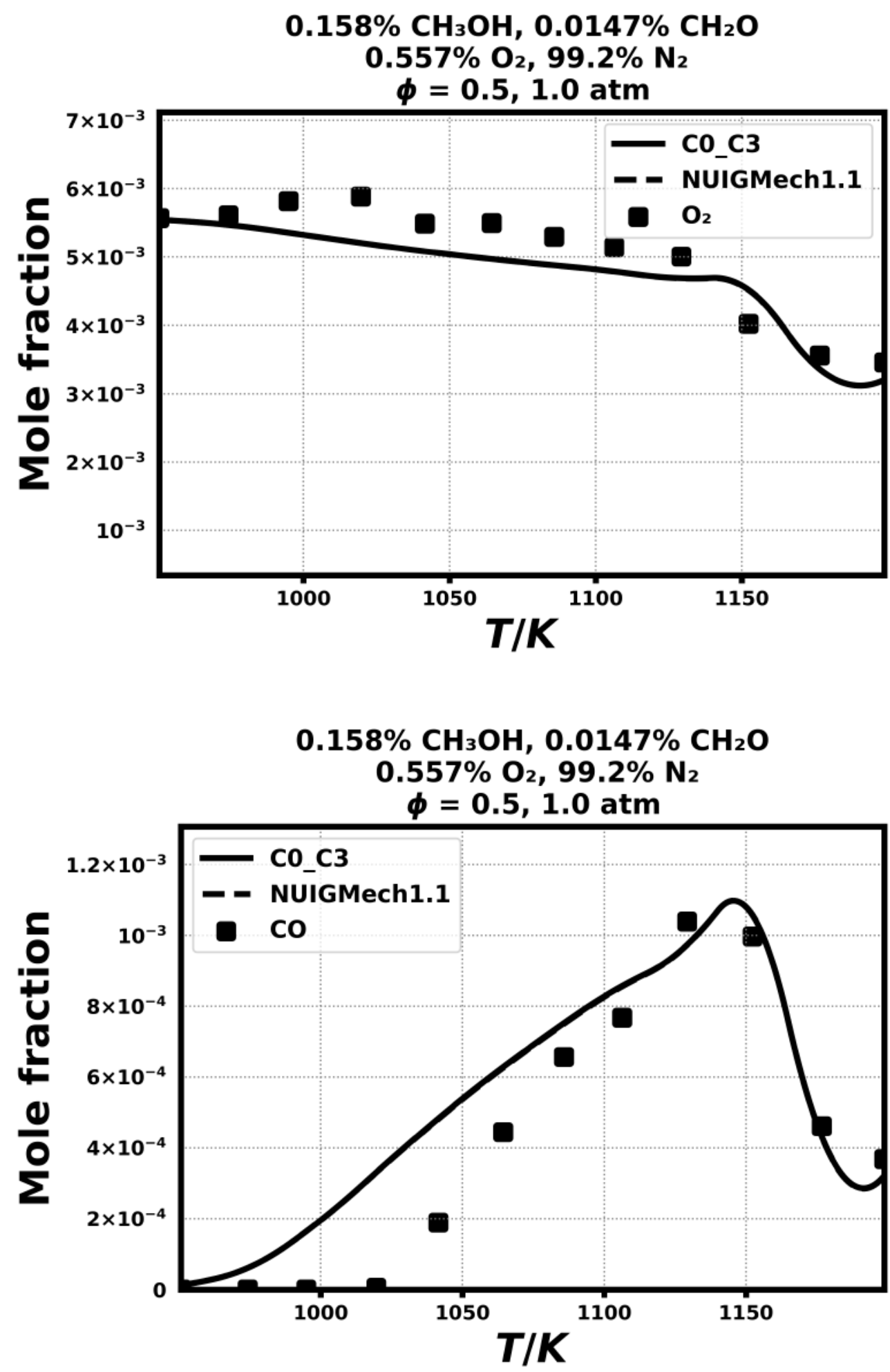

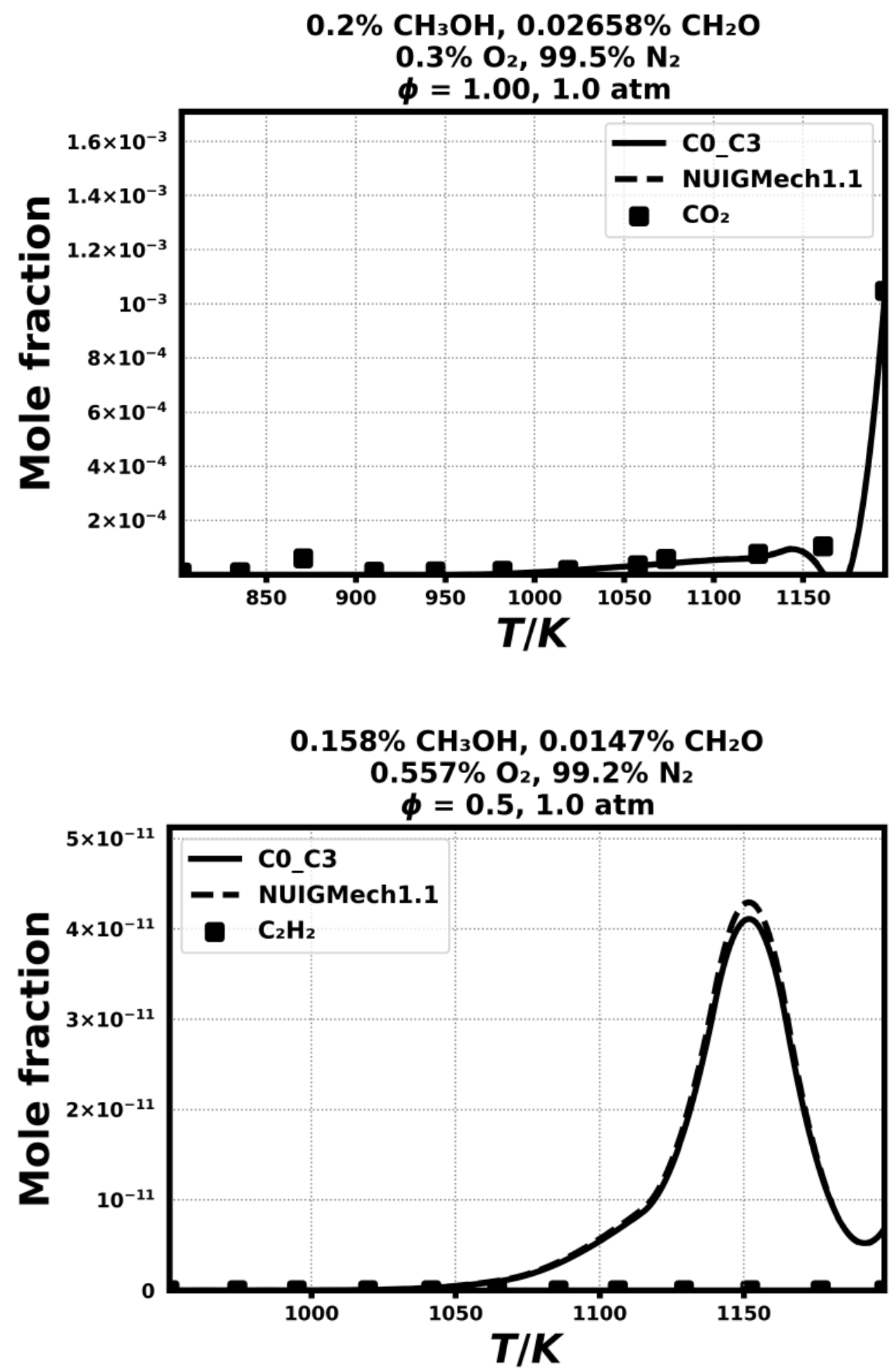

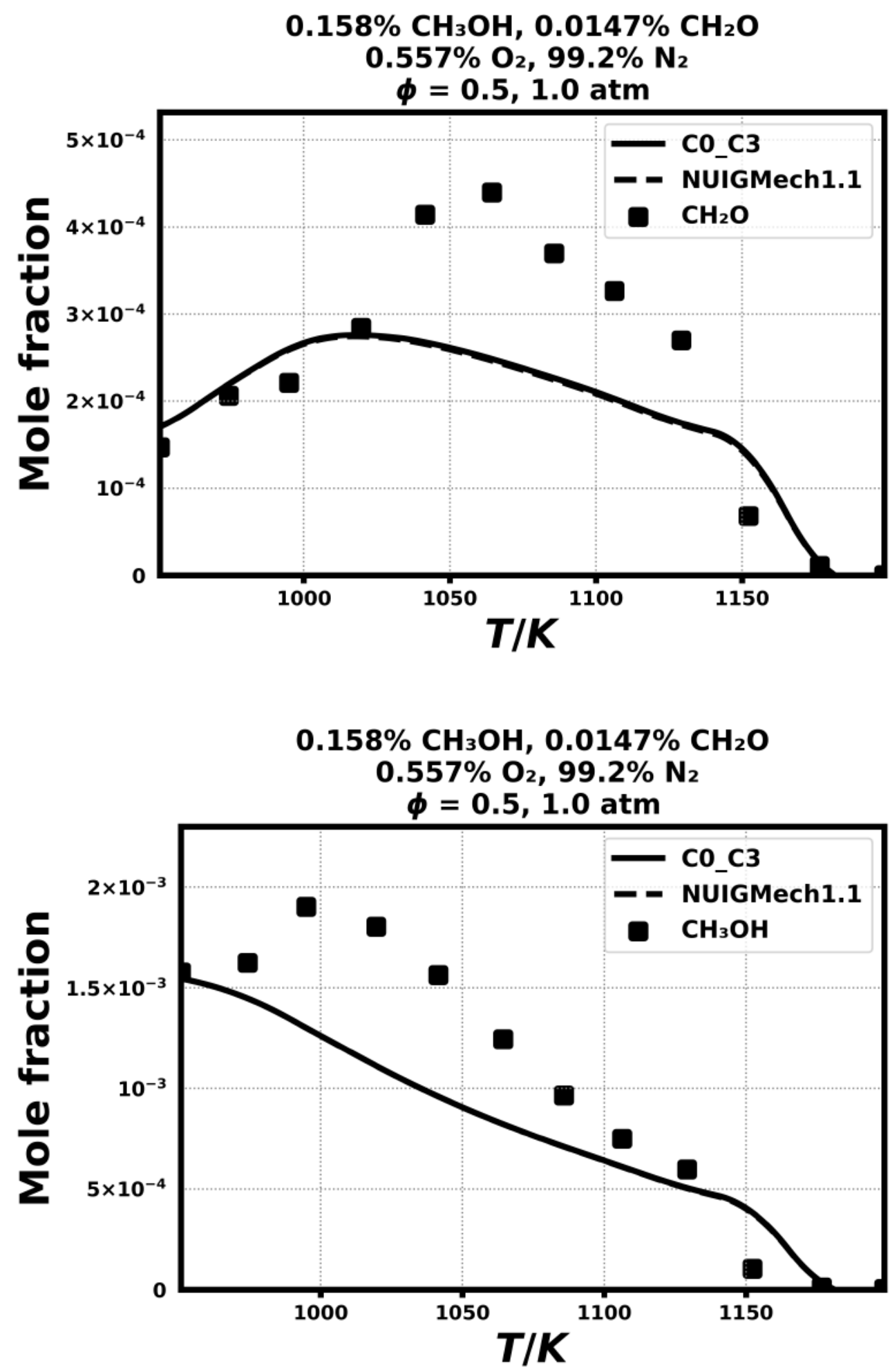

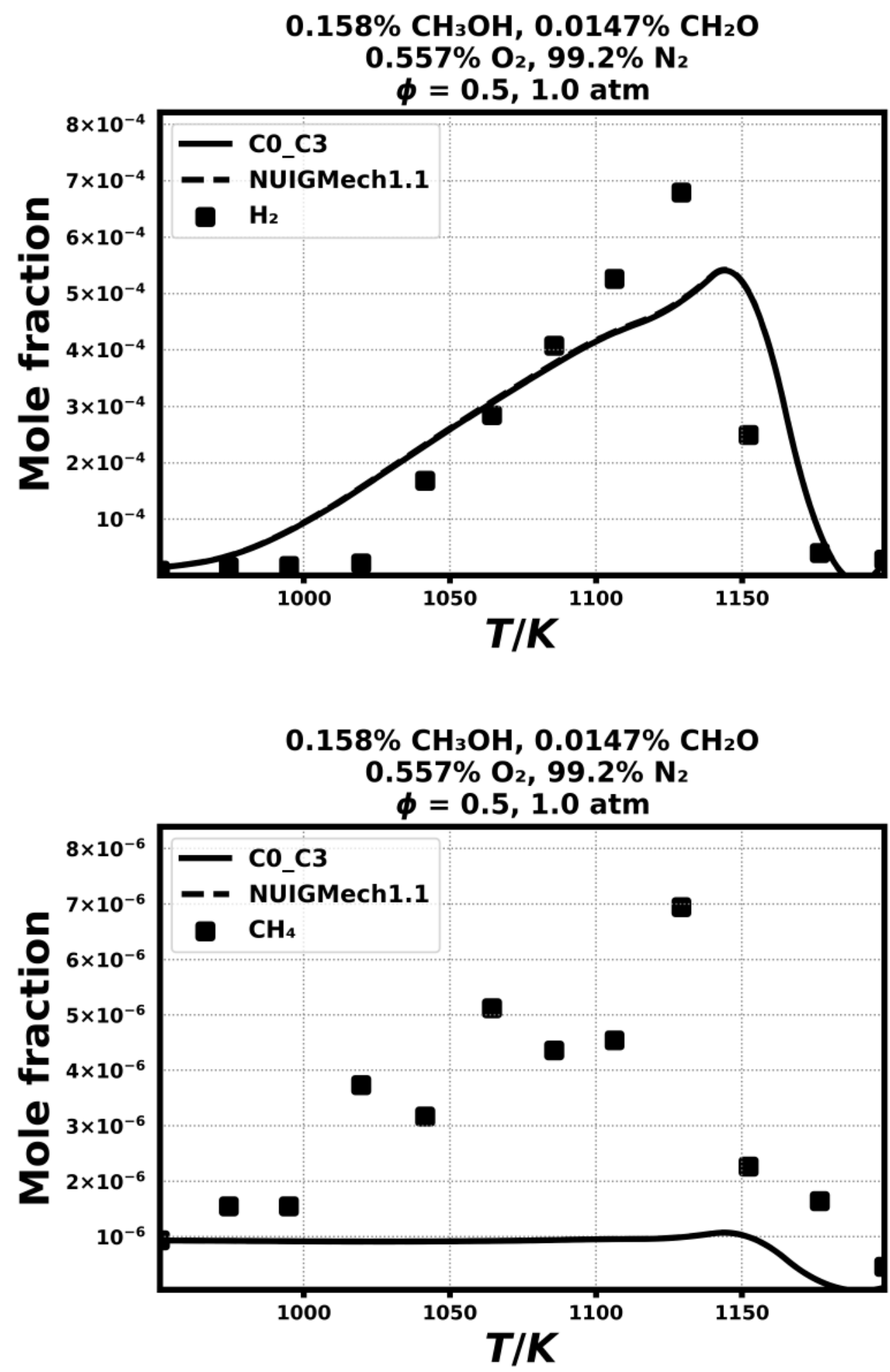

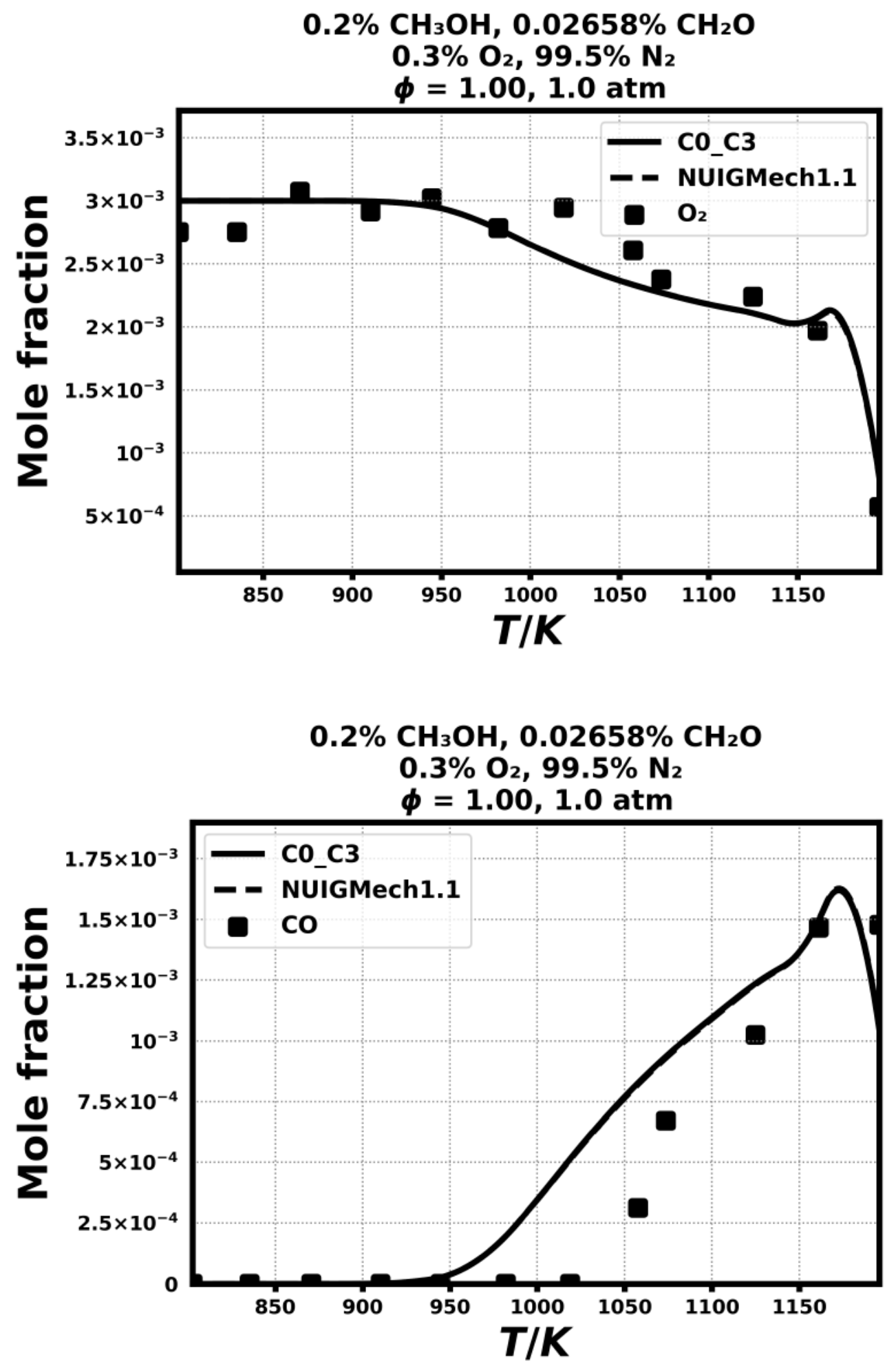

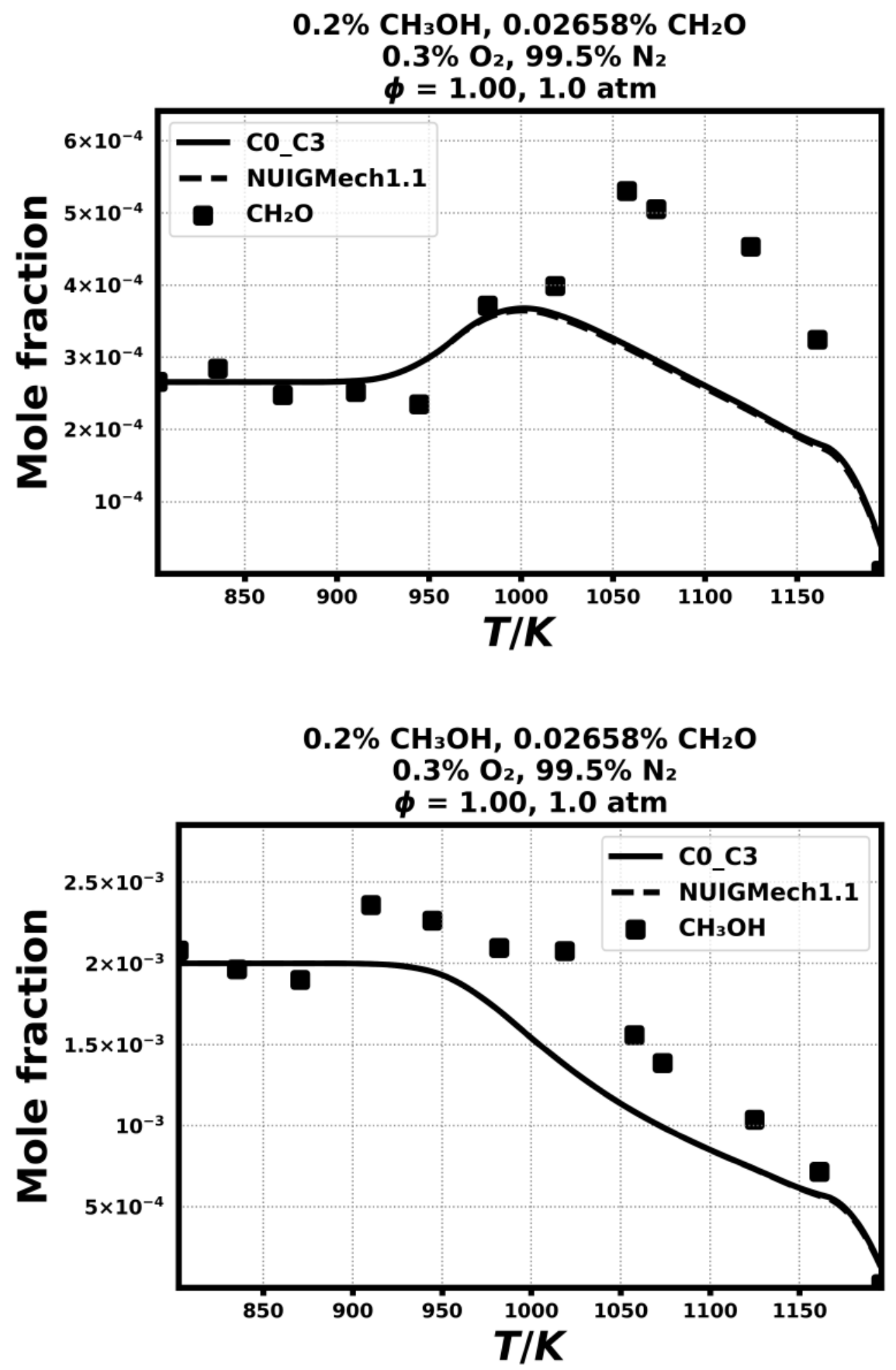

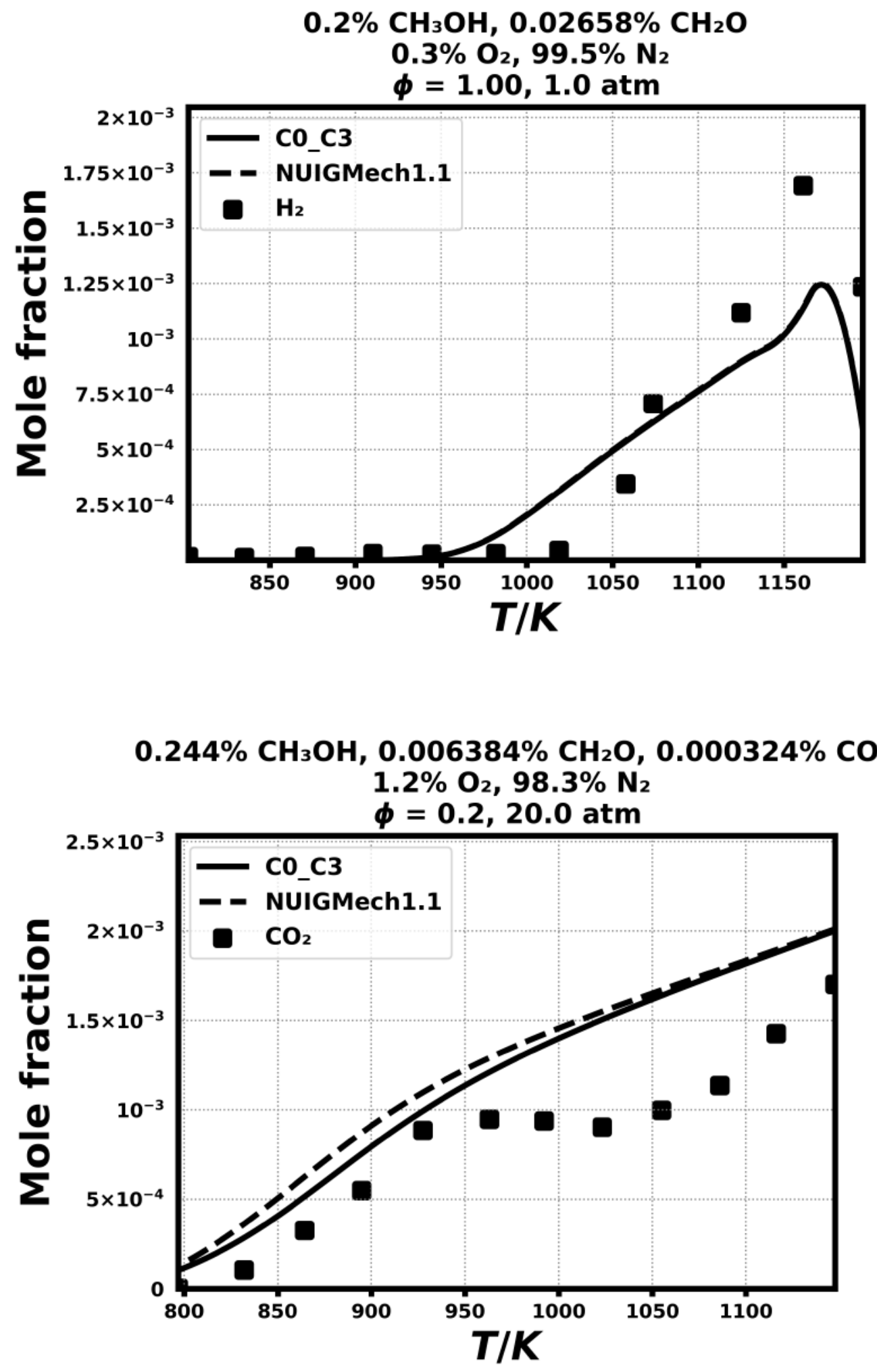

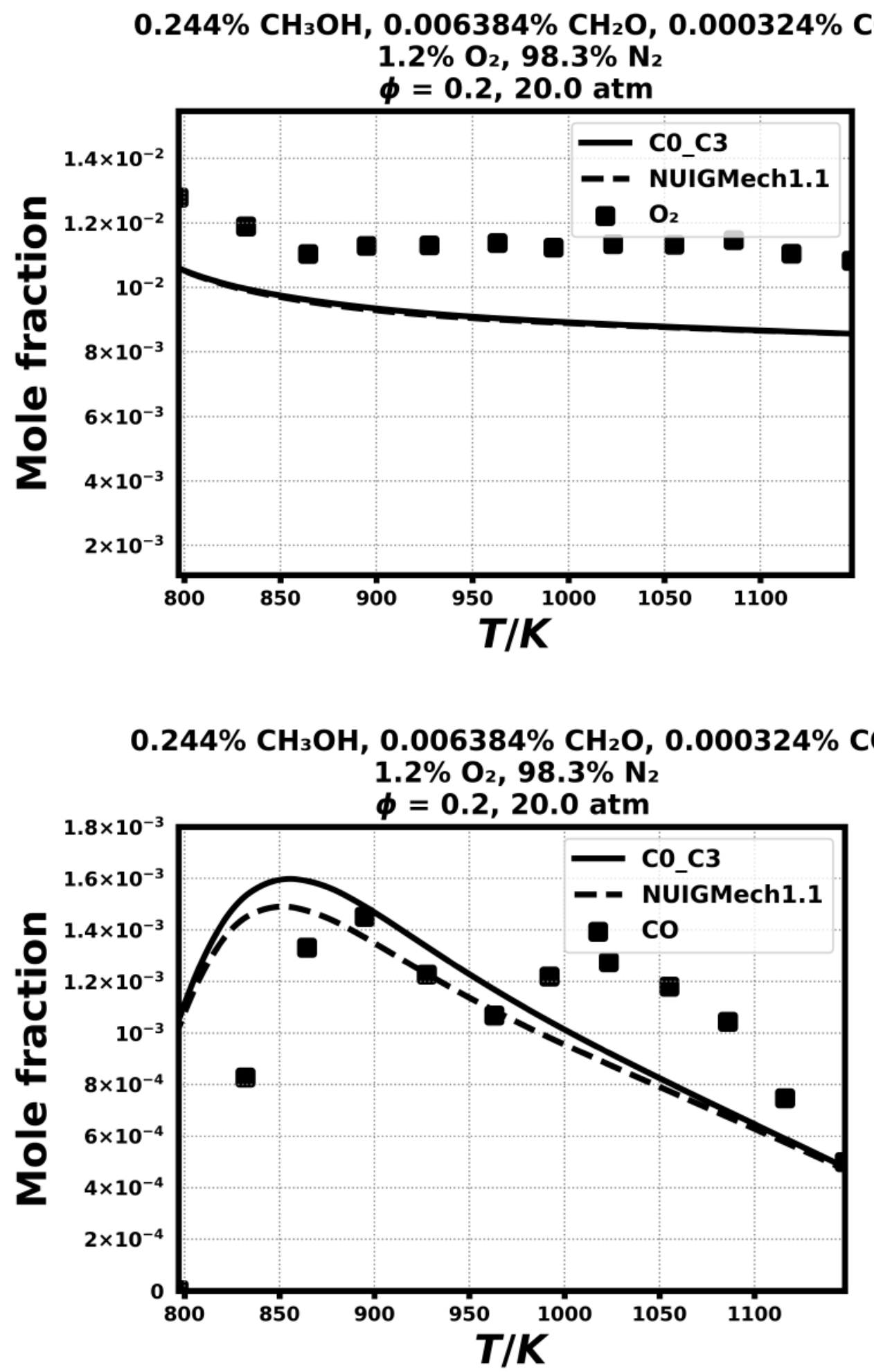

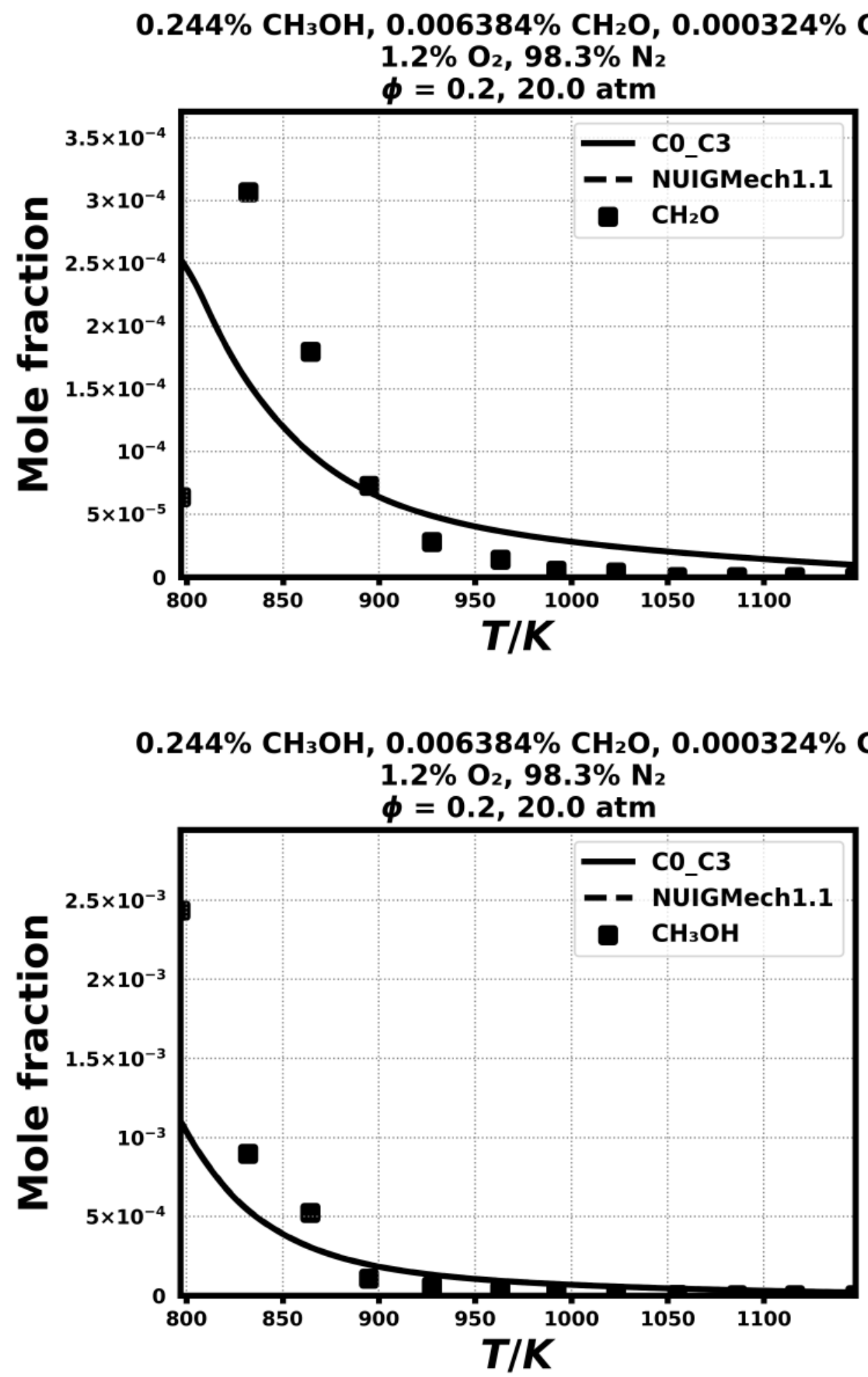
$0.178 \% \mathrm{CH}_{3} \mathrm{OH}, 0.0305 \% \mathrm{CH}_{2} \mathrm{O}, 0.02959 \% \mathrm{CO}$ $0.506 \% \mathrm{O}_{2}, 99.2 \% \mathrm{~N}_{2}$

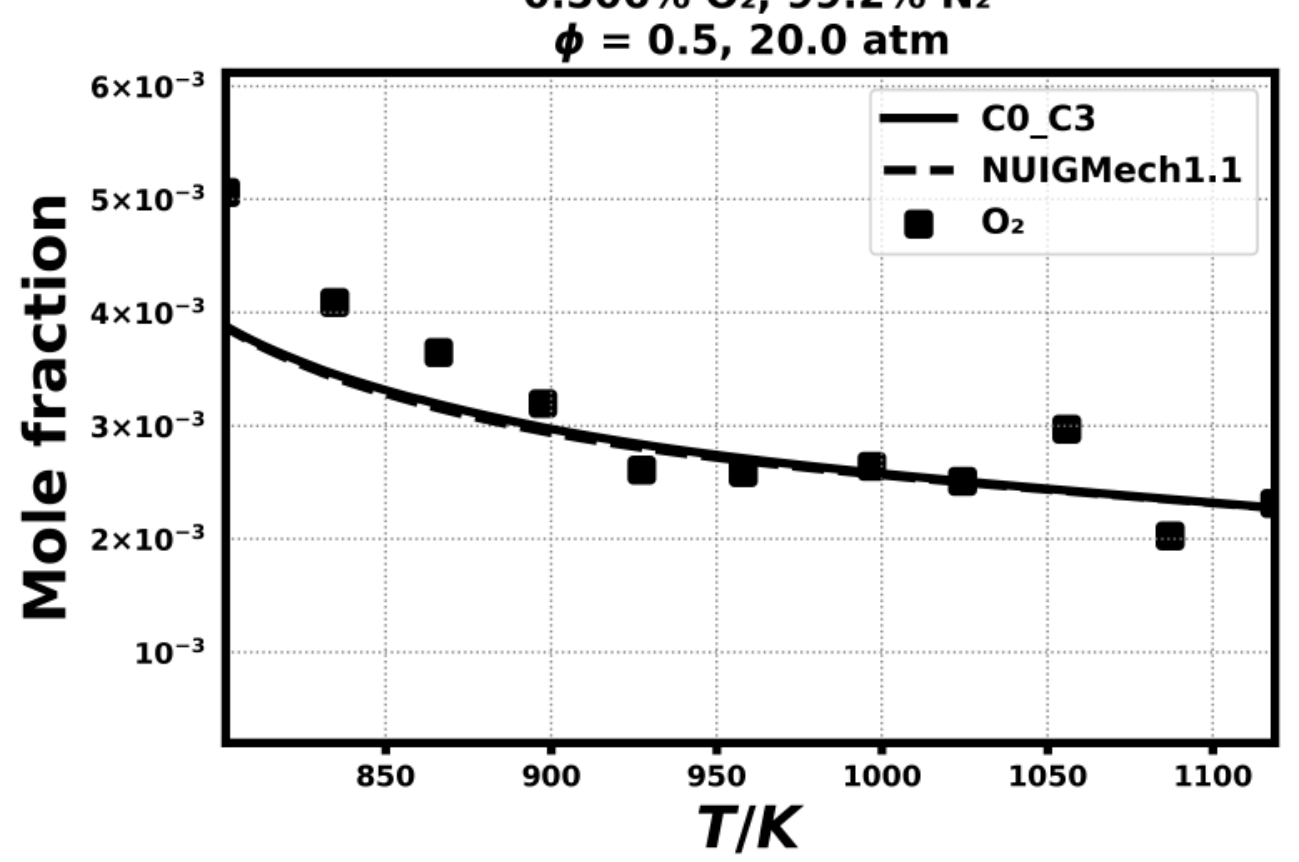

$0.178 \% \mathrm{CH}_{3} \mathrm{OH}, 0.0305 \% \mathrm{CH}_{2} \mathrm{O}, 0.02959 \% \mathrm{CO}$ $0.506 \% \mathrm{O}_{2}, 99.2 \% \mathrm{~N}_{2}$

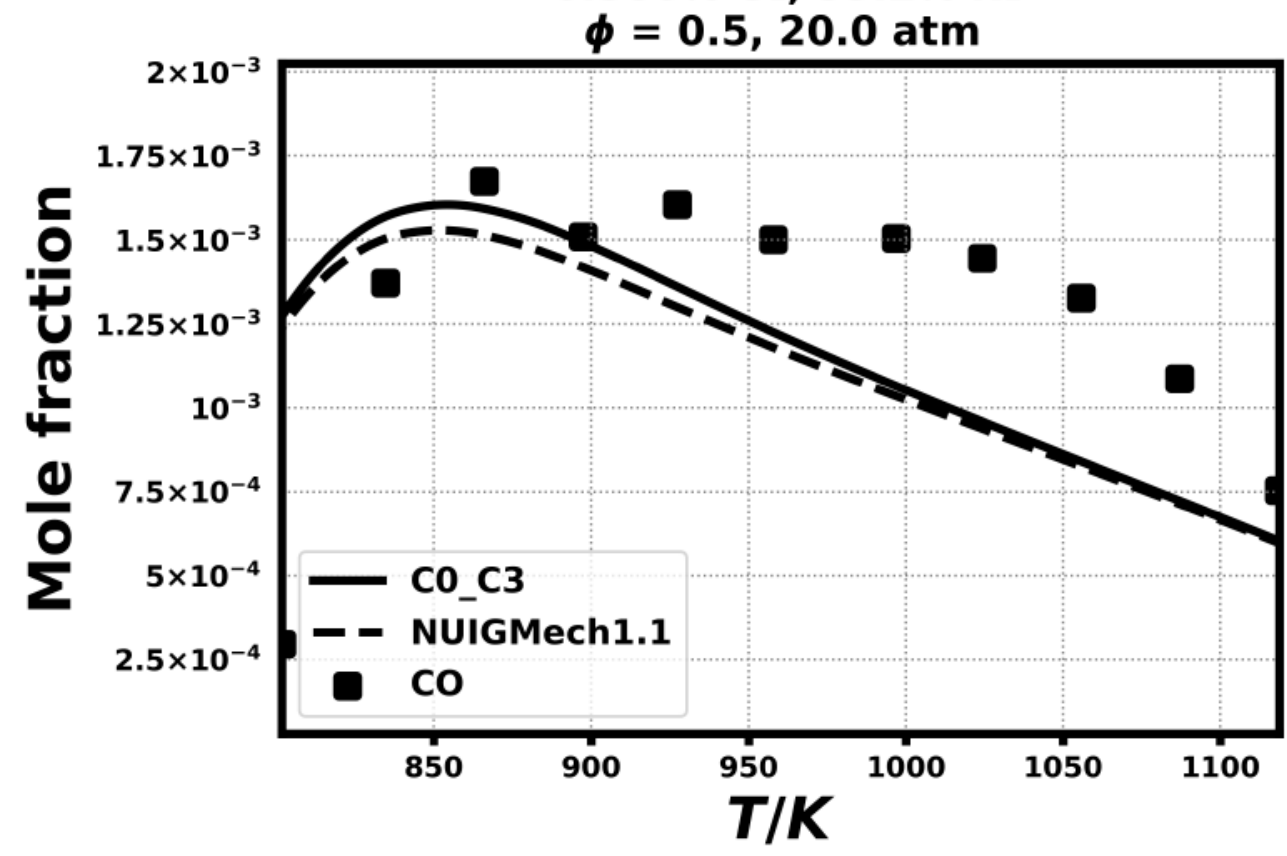




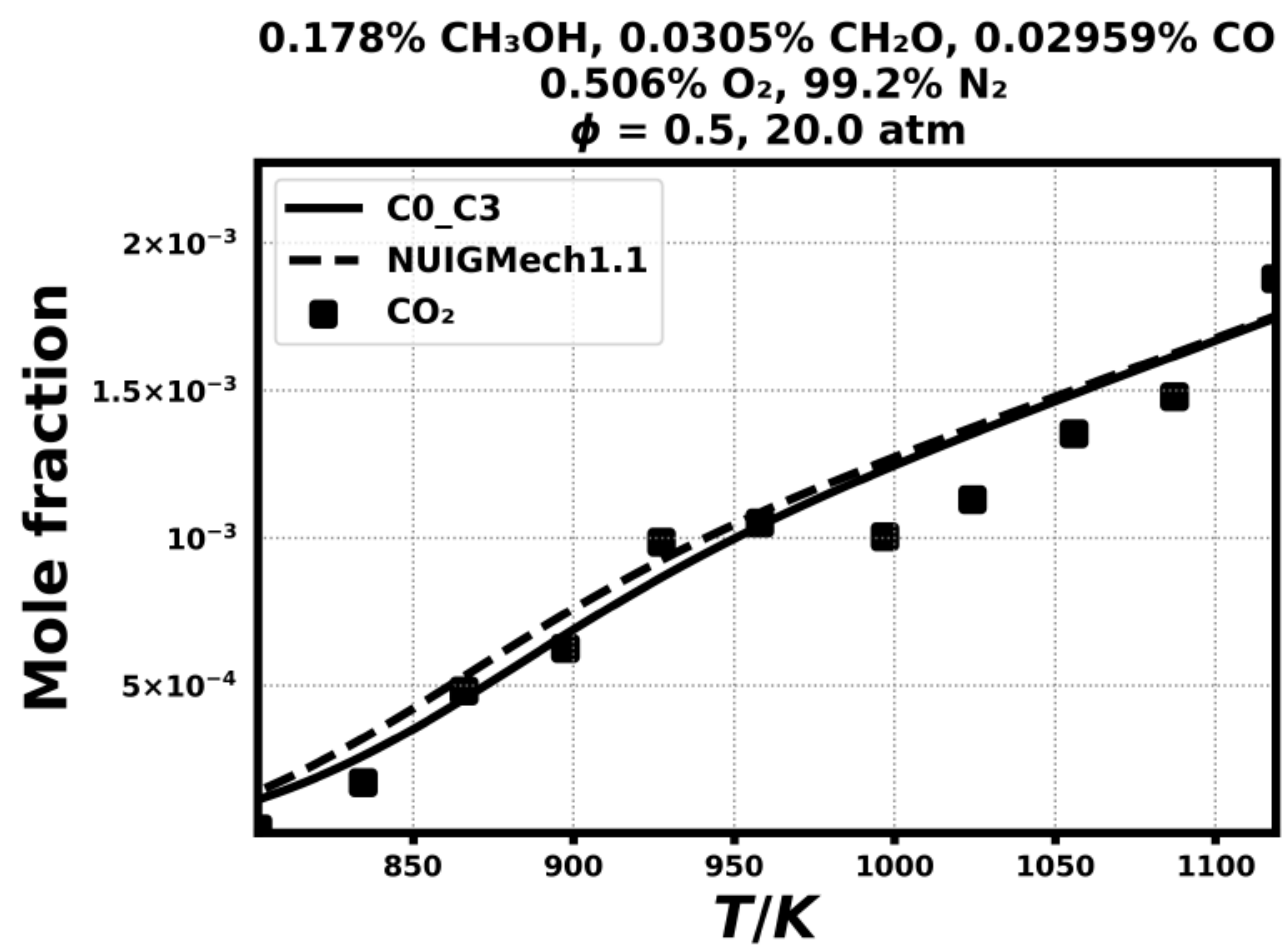

$0.178 \% \mathrm{CH}_{3} \mathrm{OH}, 0.0305 \% \mathrm{CH}_{2} \mathrm{O}, 0.02959 \% \mathrm{CO}$ $0.506 \% \mathrm{O}_{2}, 99.2 \% \mathrm{~N}_{2}$ $\phi=0.5,20.0$ atm

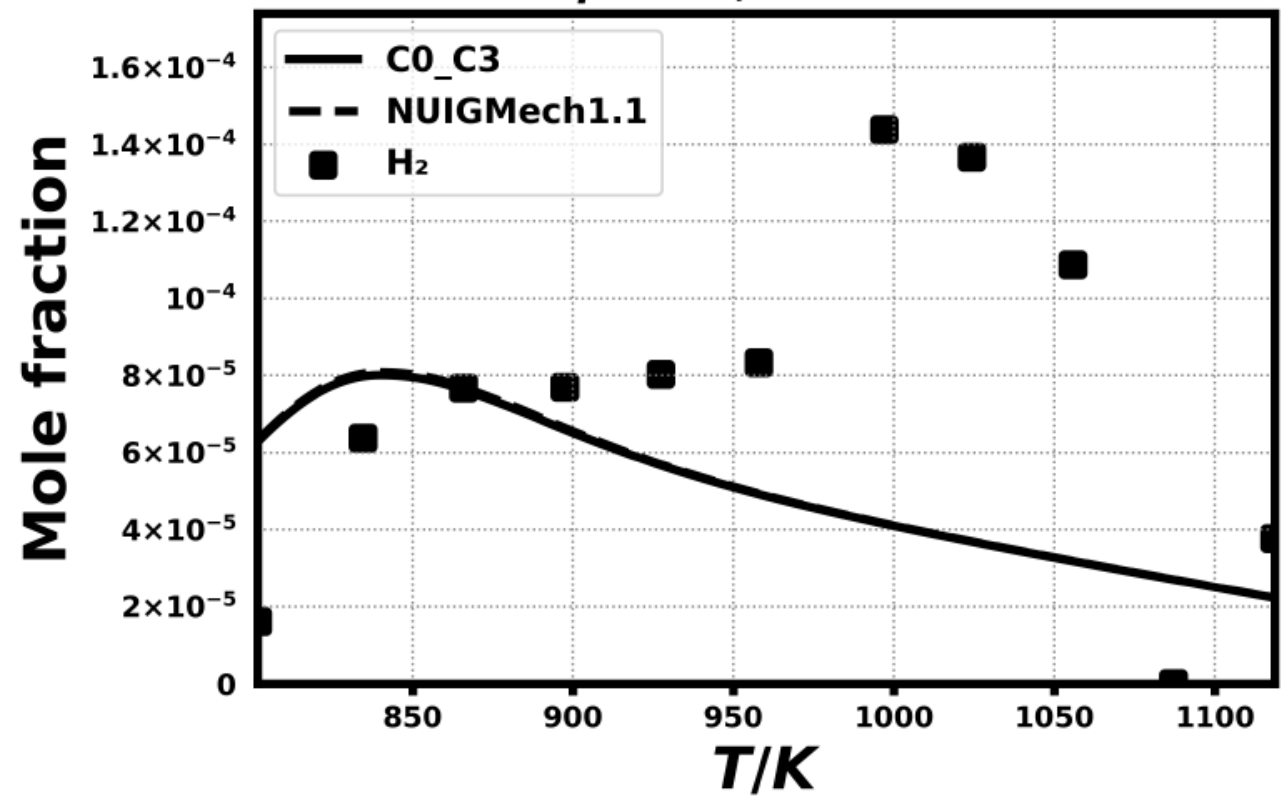



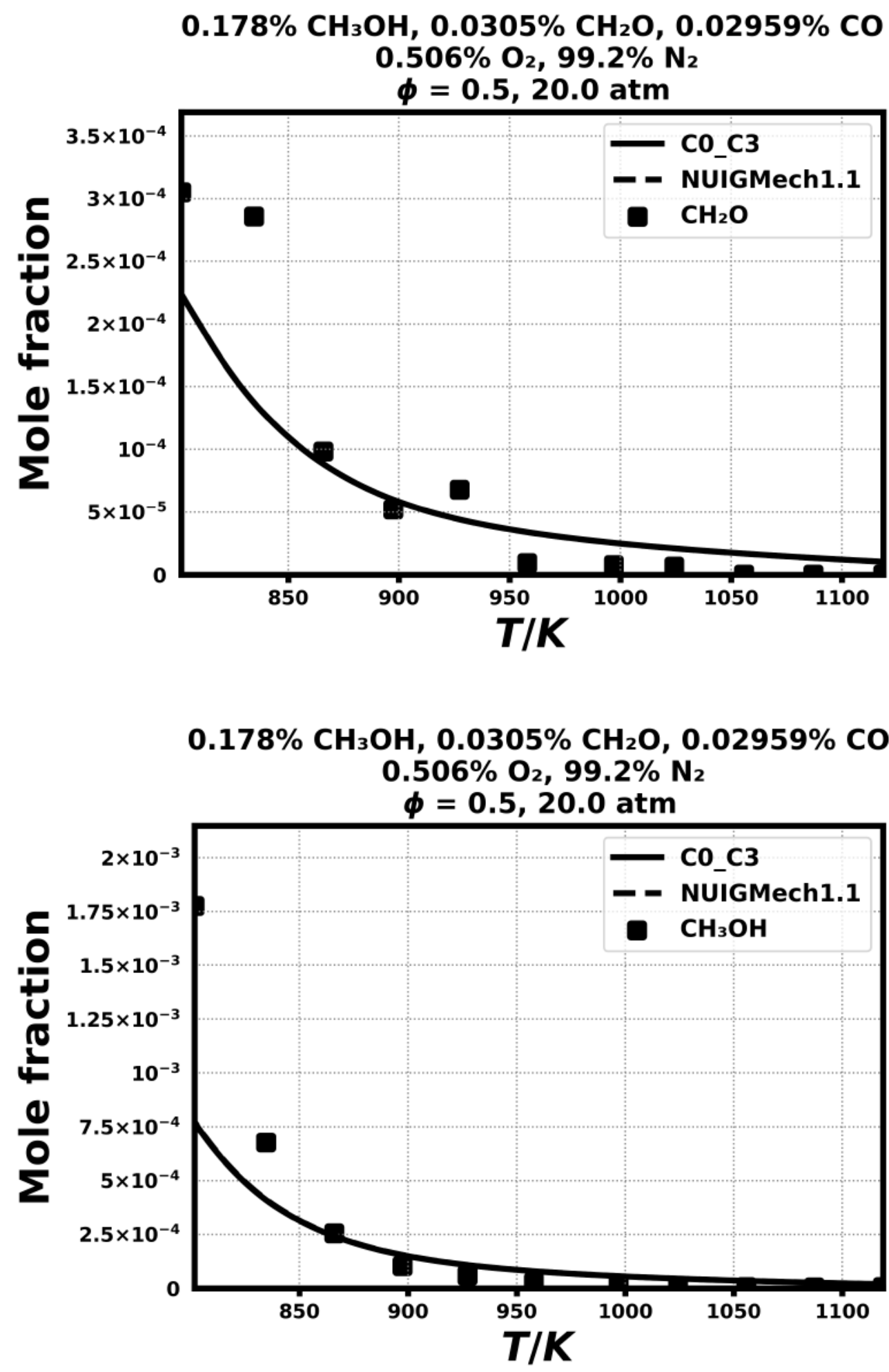

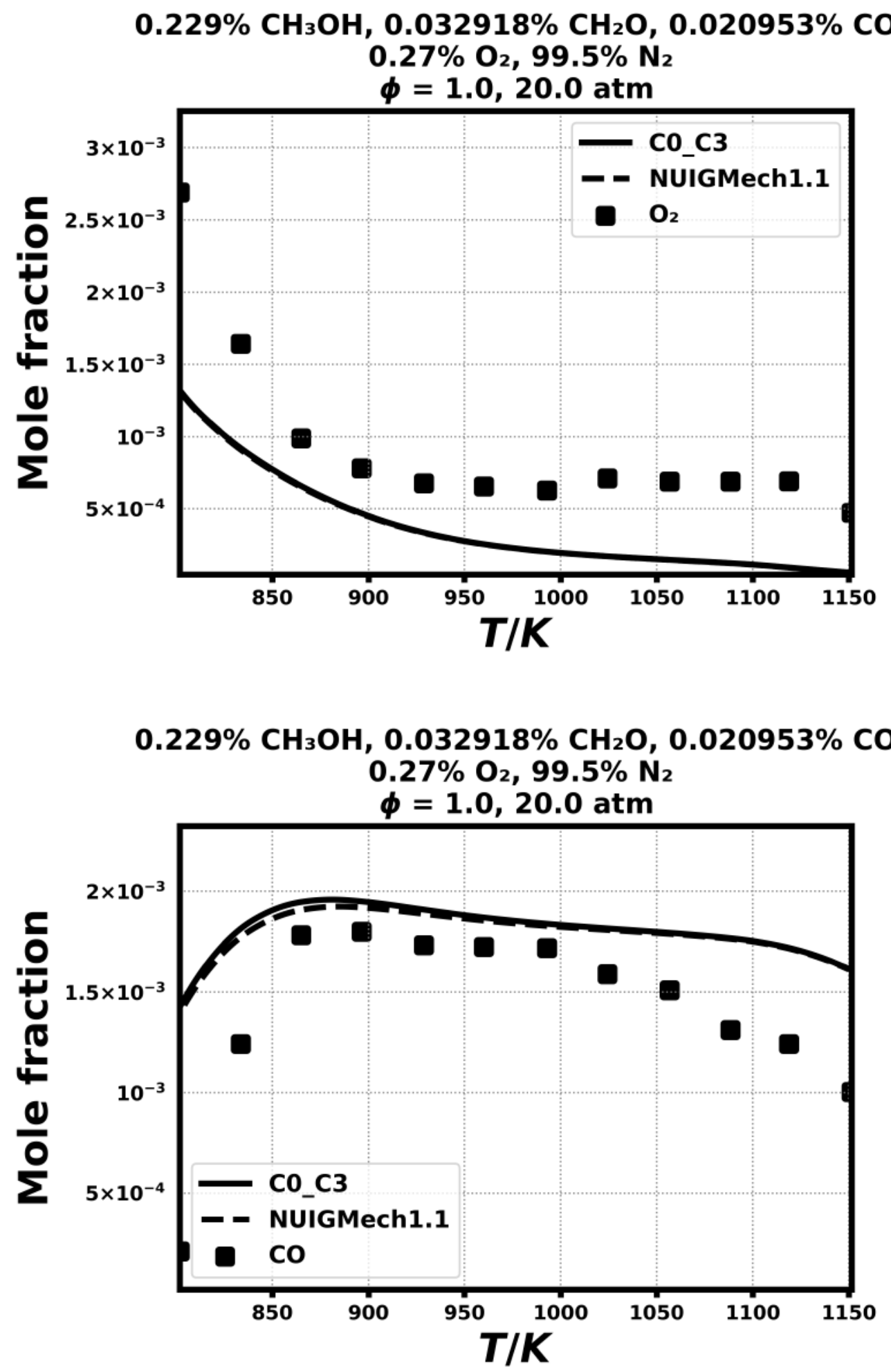

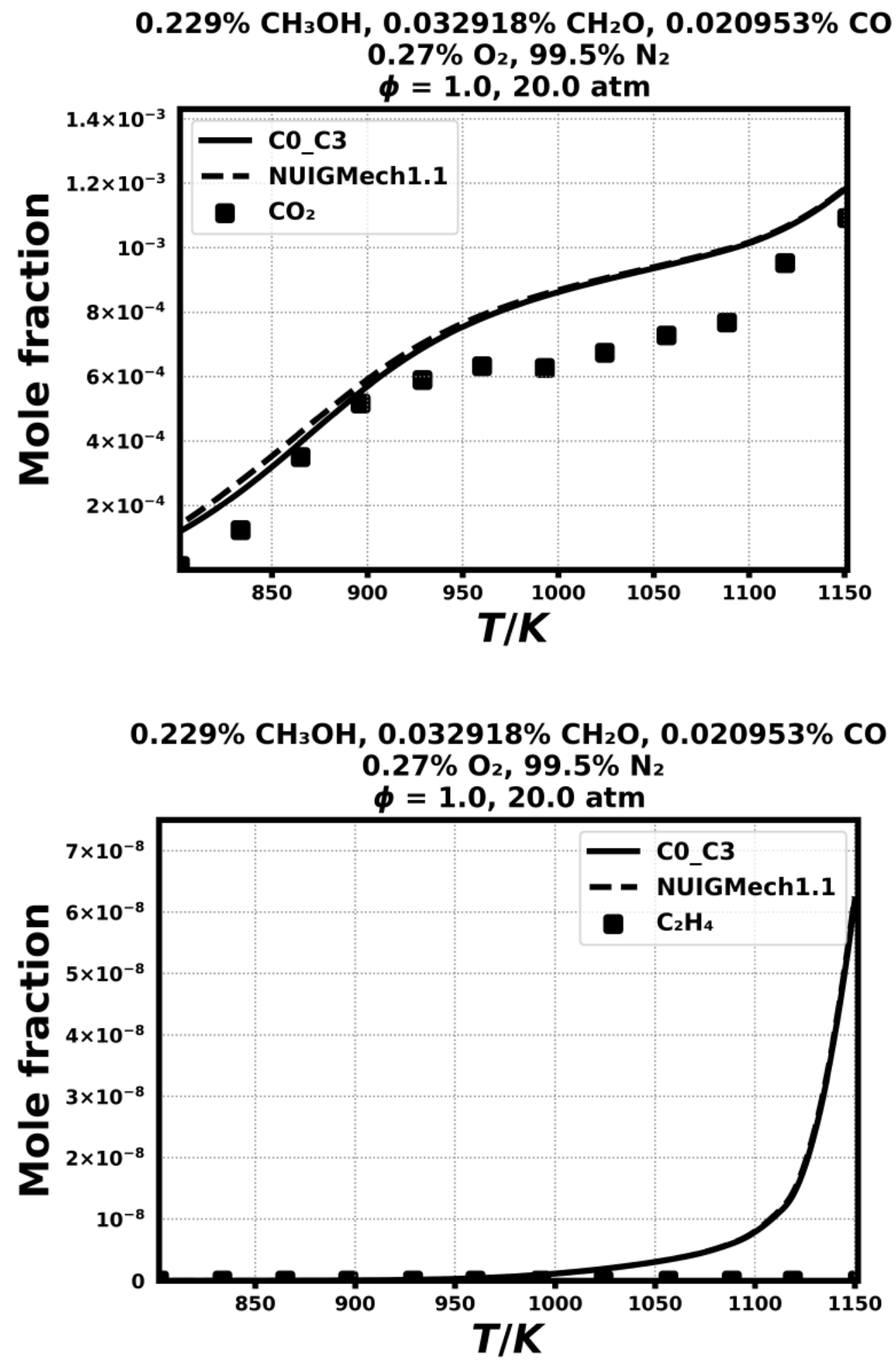

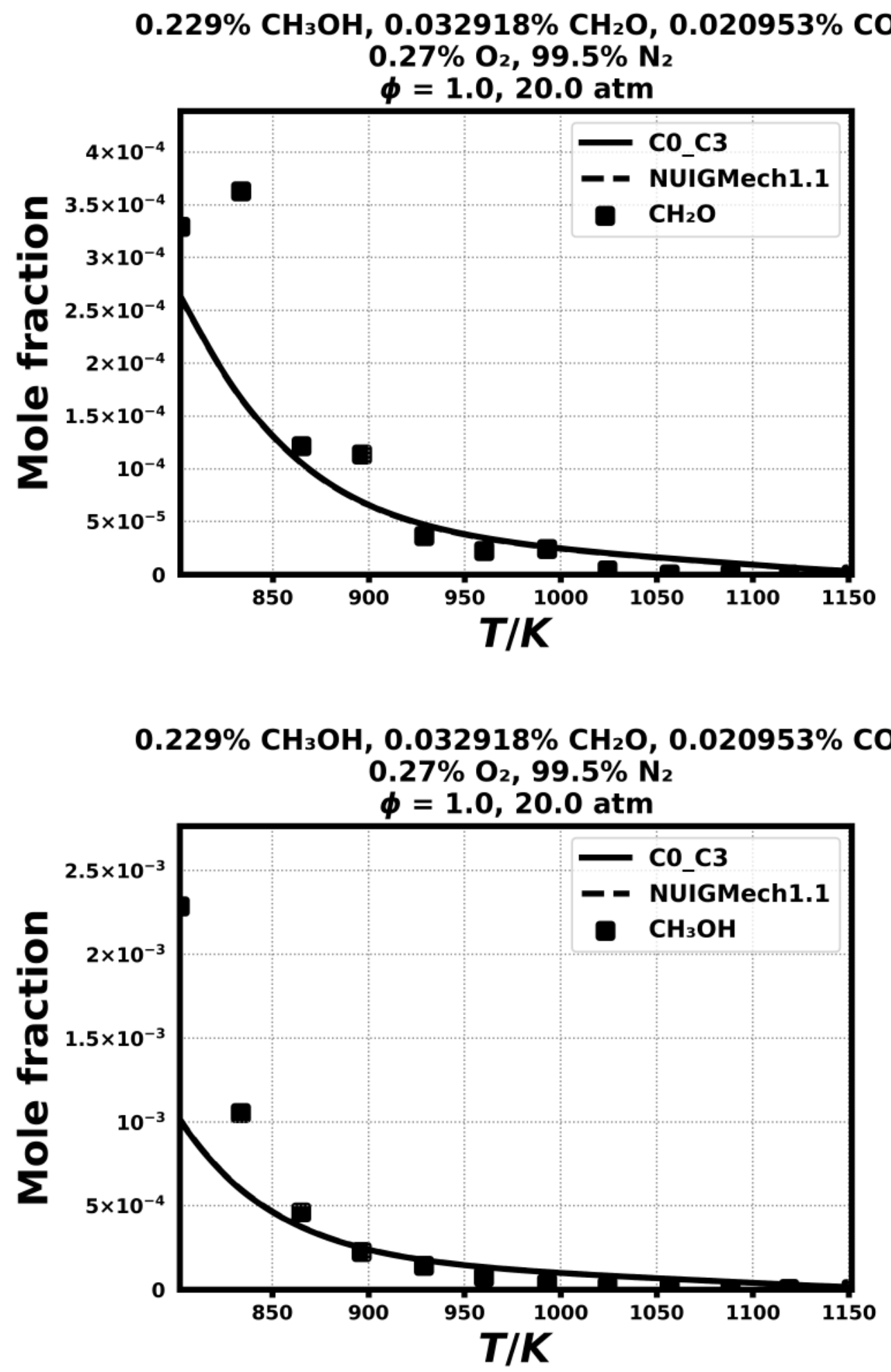

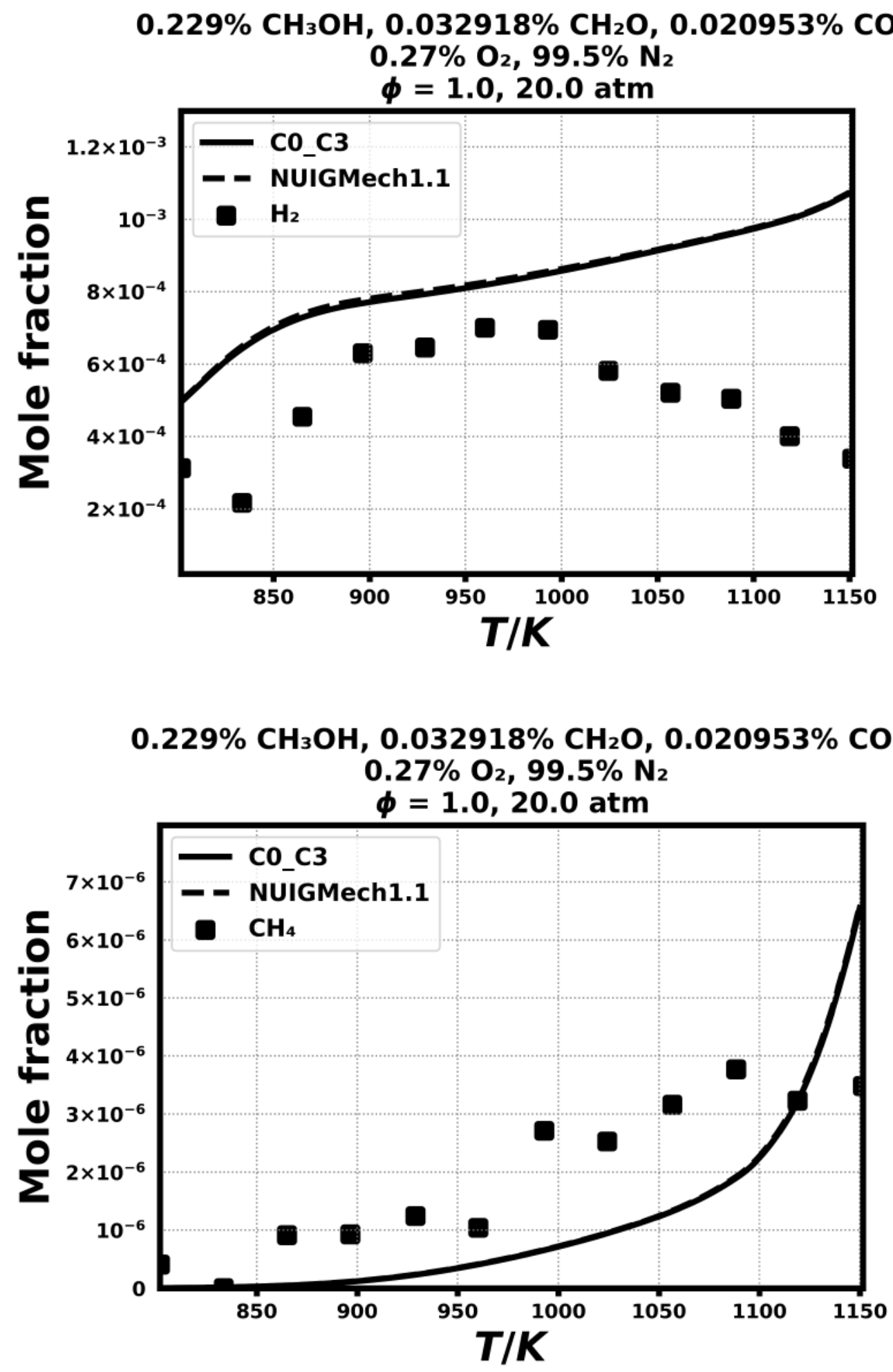


\section{Speciation in Flow reactor}

3.9) Held, T. J., \& Dryer, F. L., International Journal of Chemical Kinetics, 30(11) (1998) 805-830.
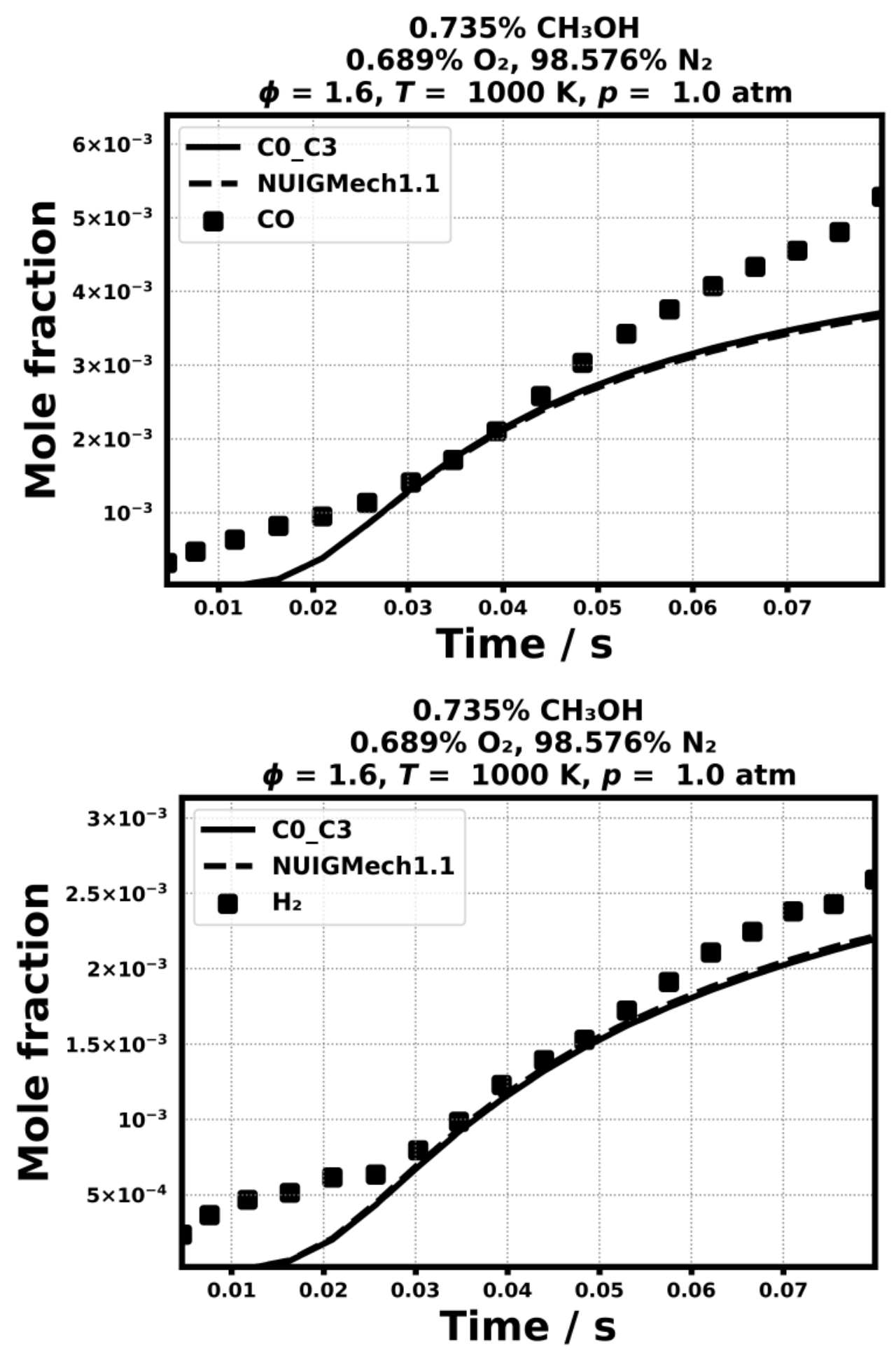

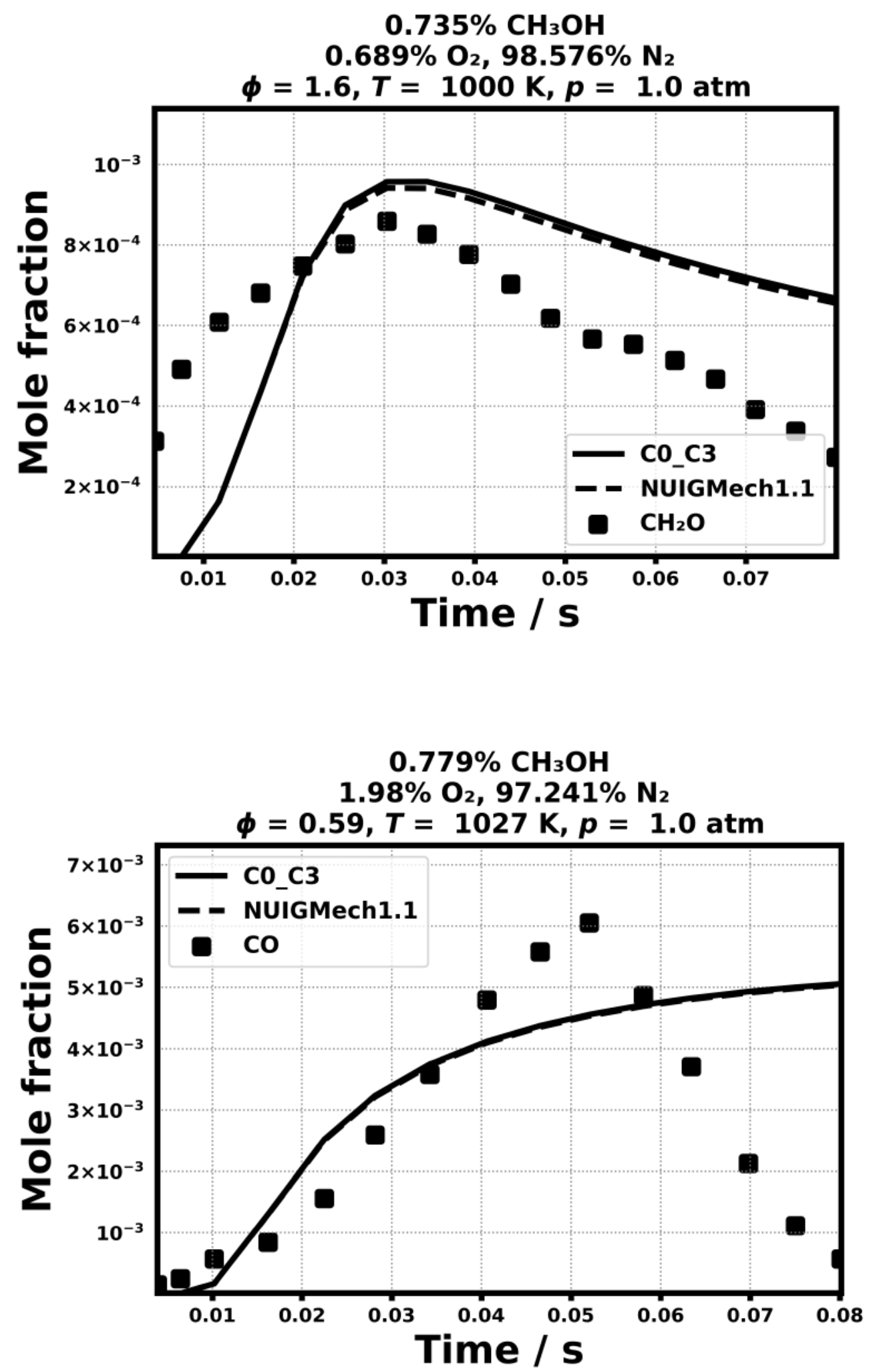

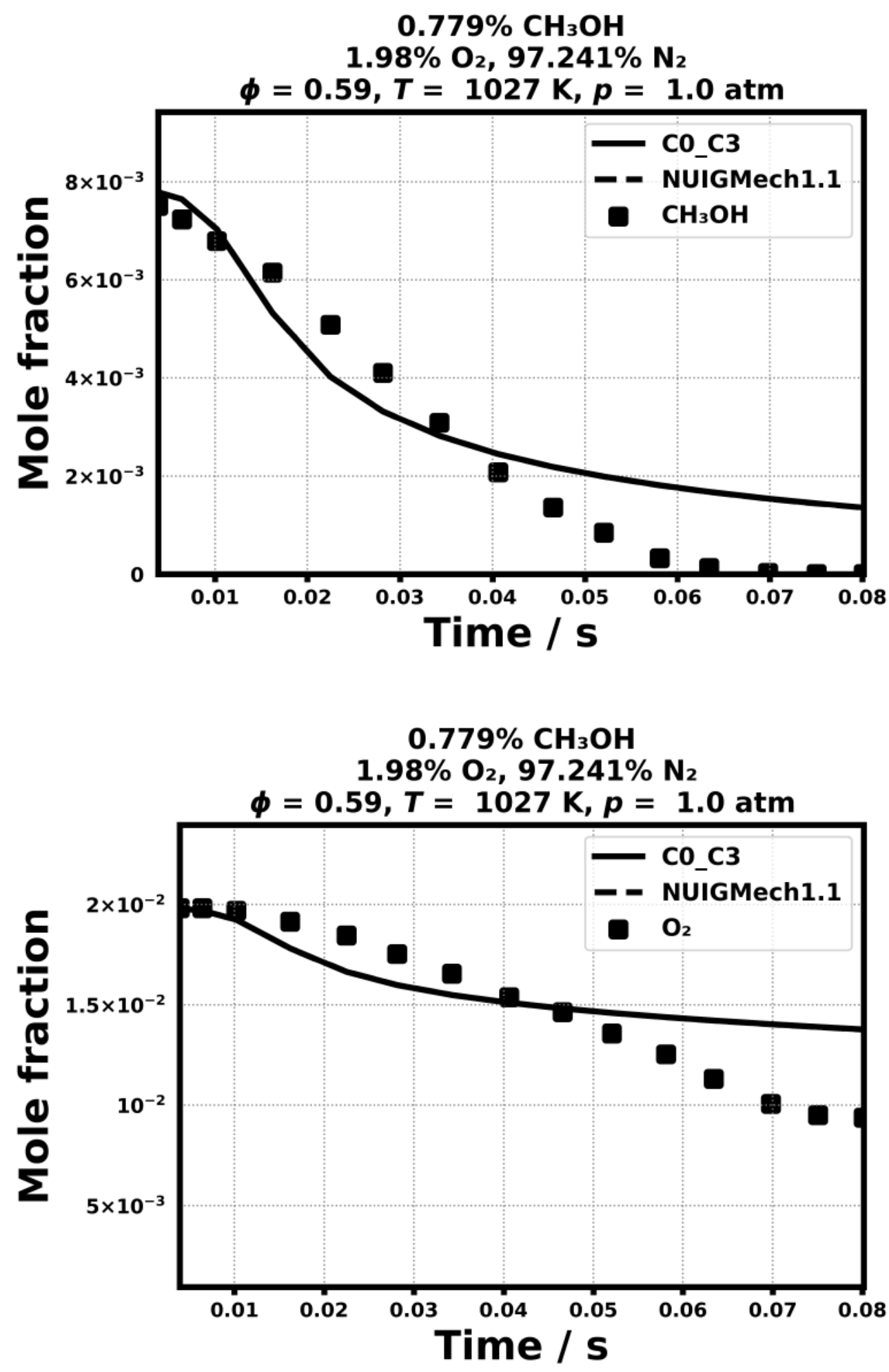

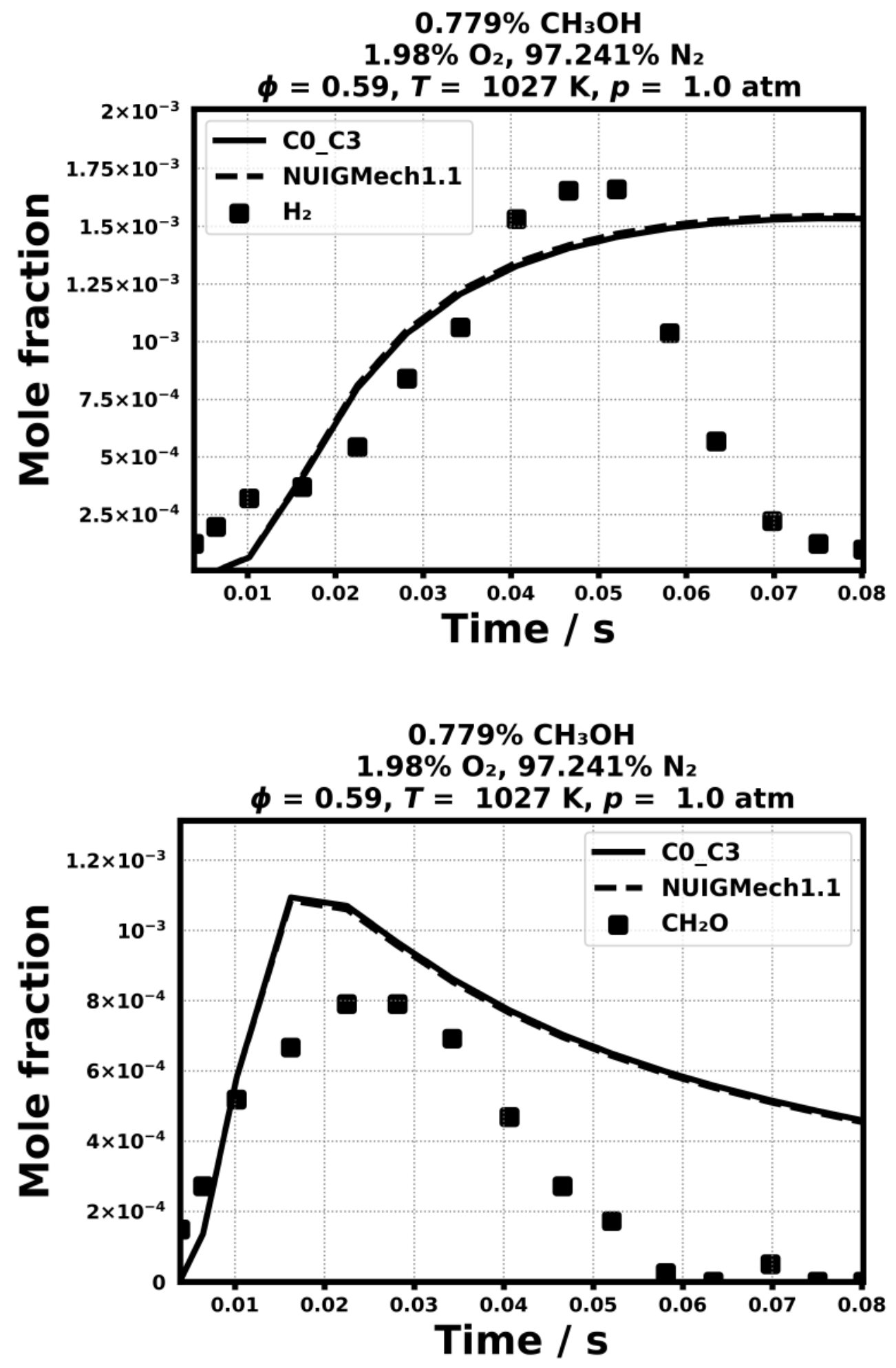

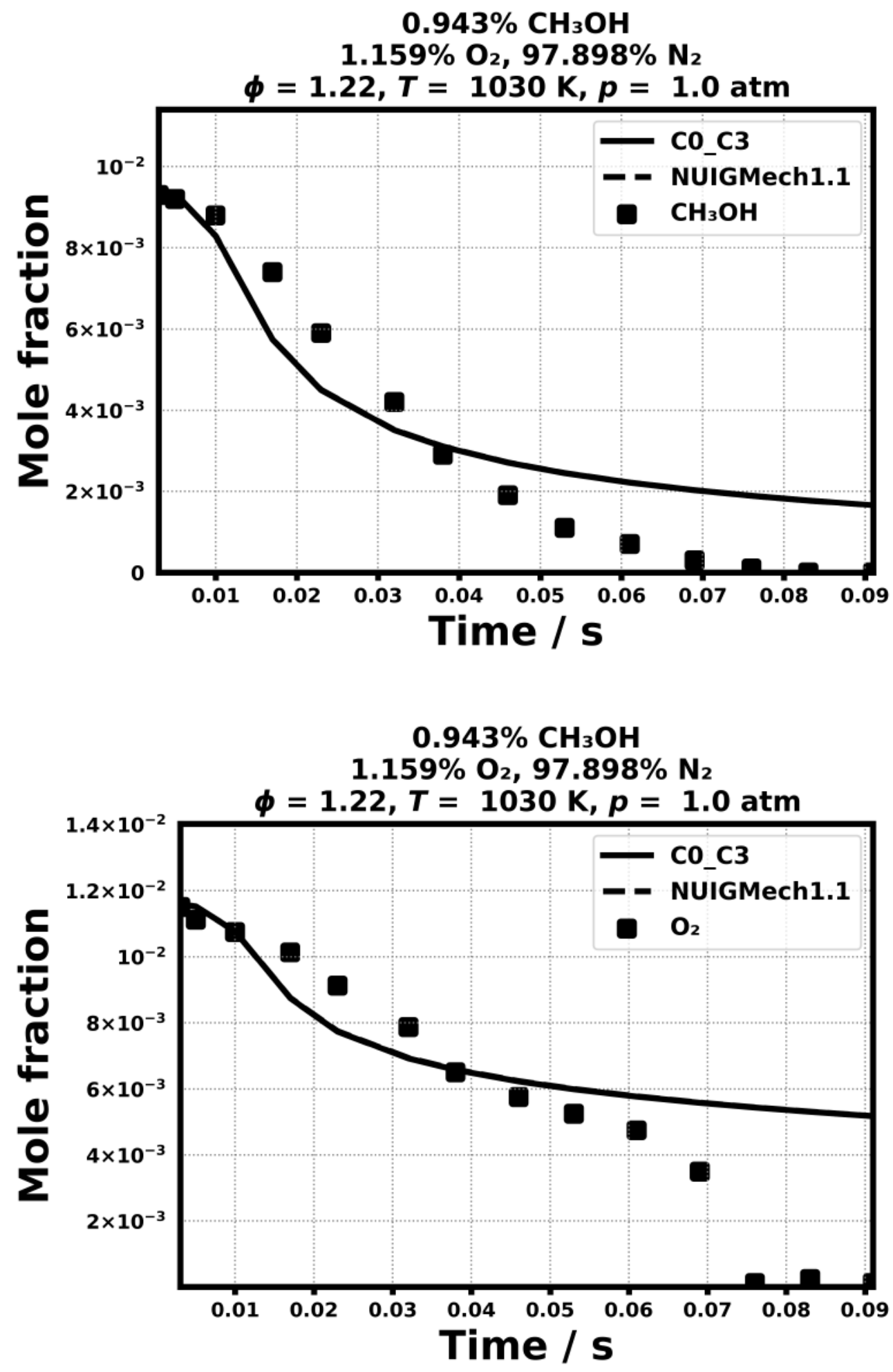

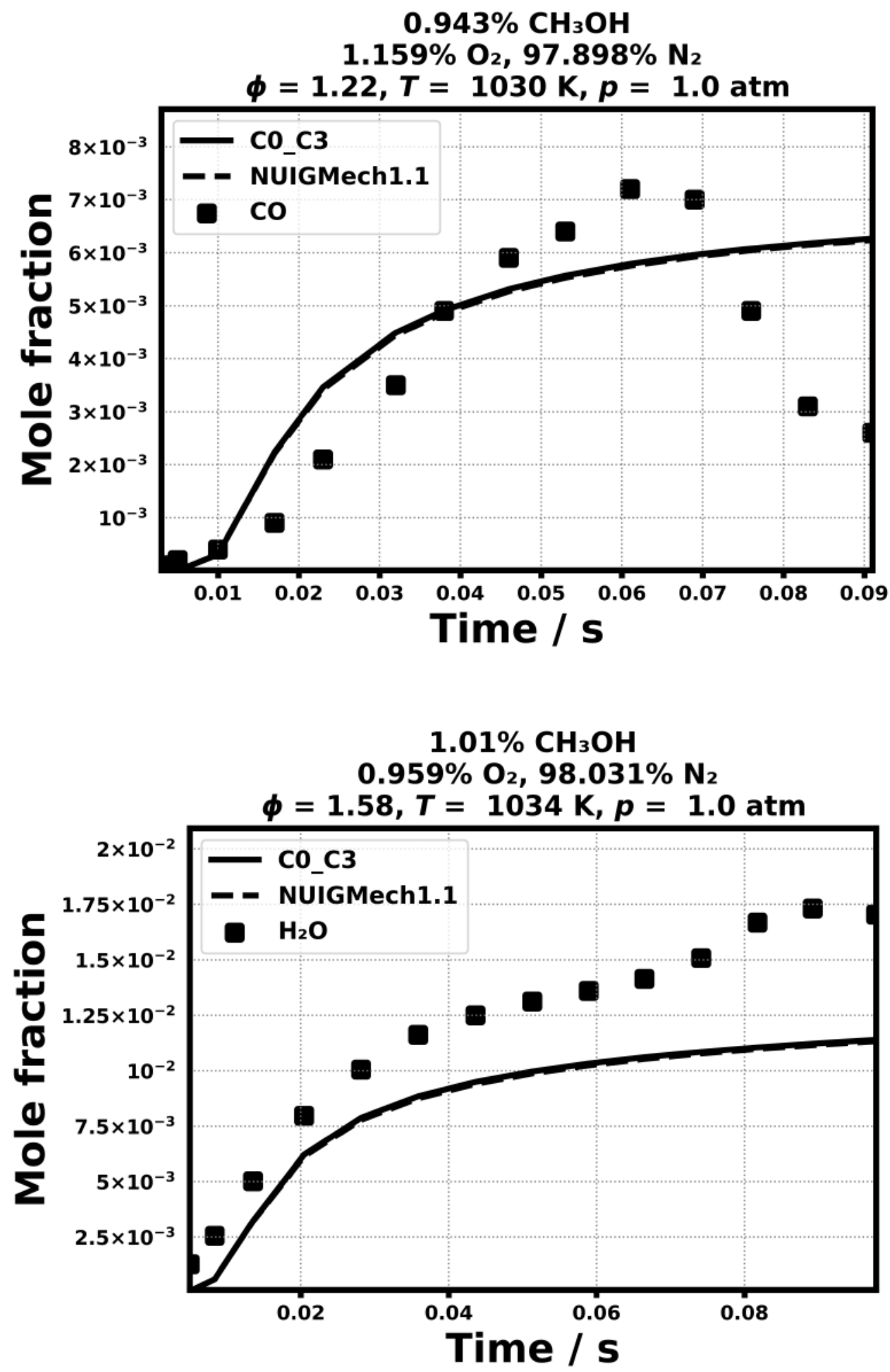

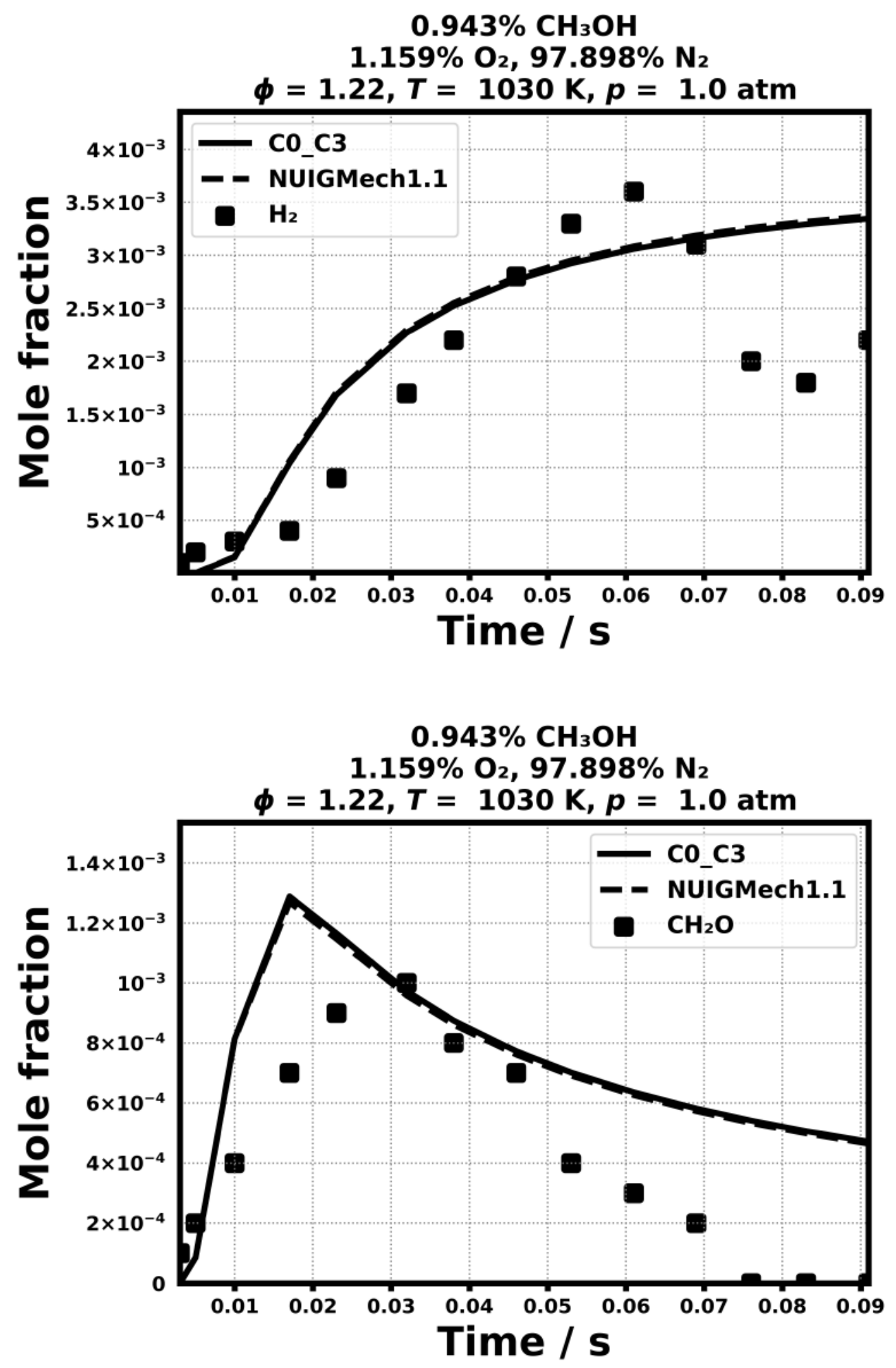

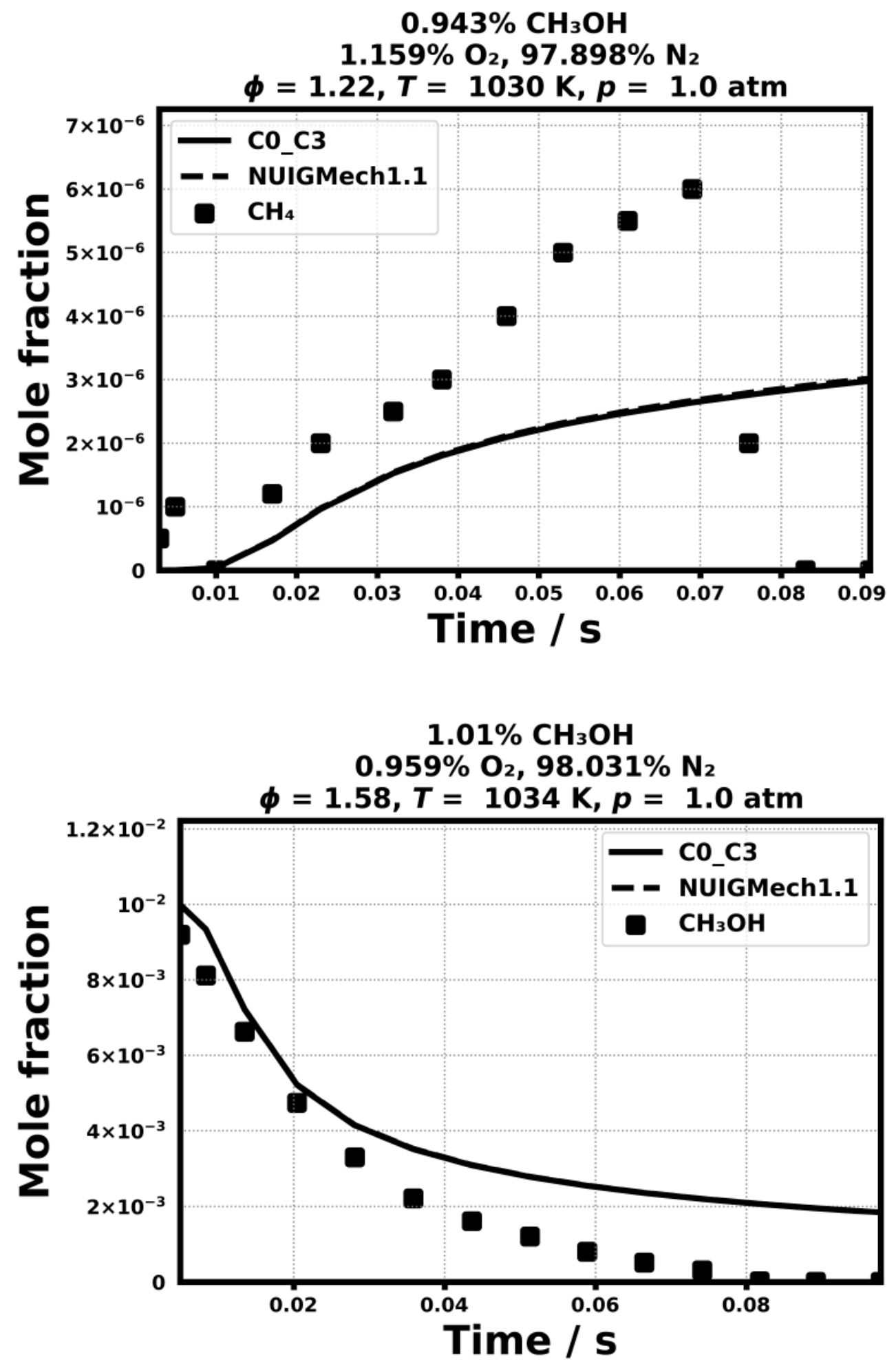

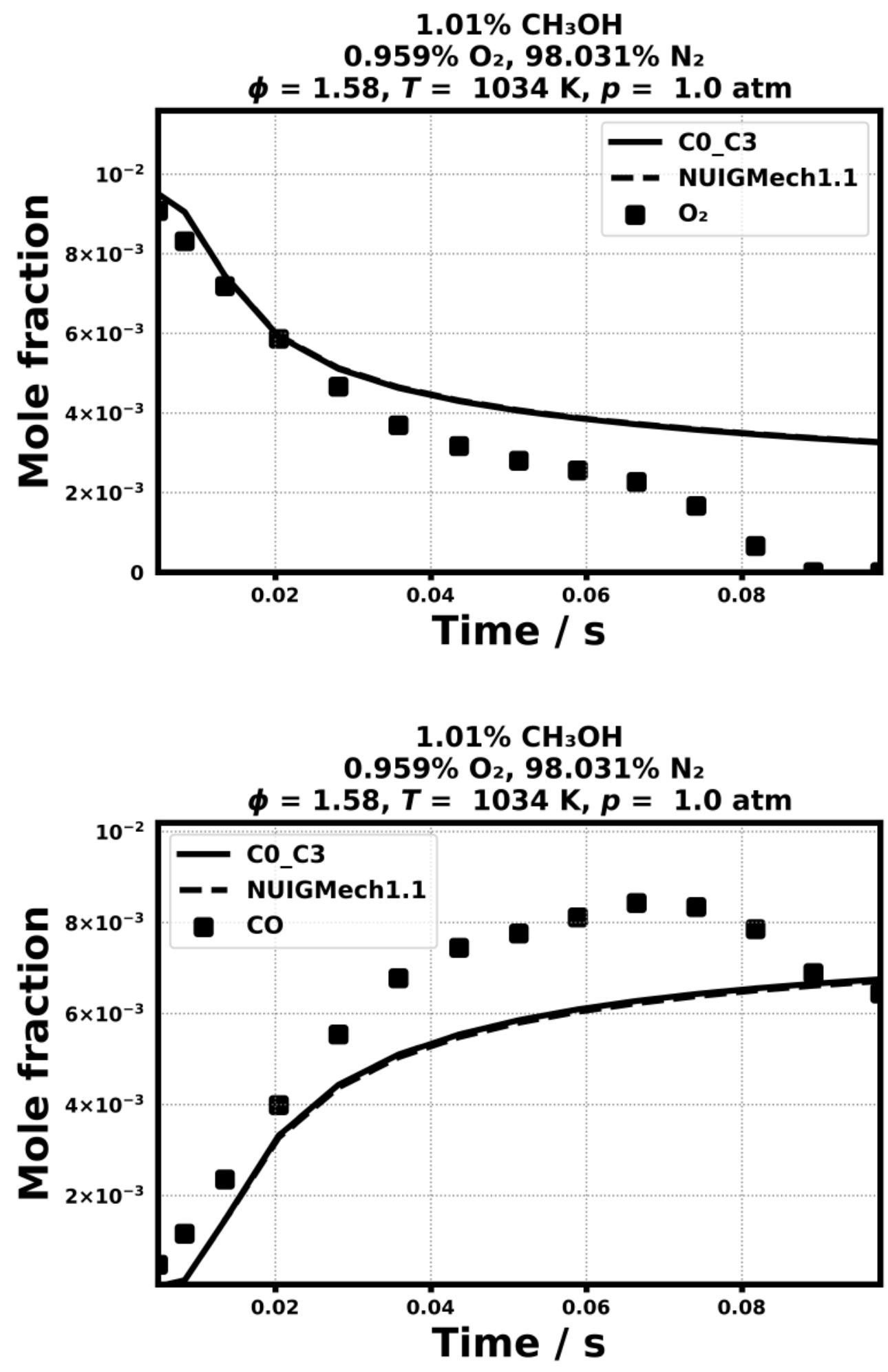

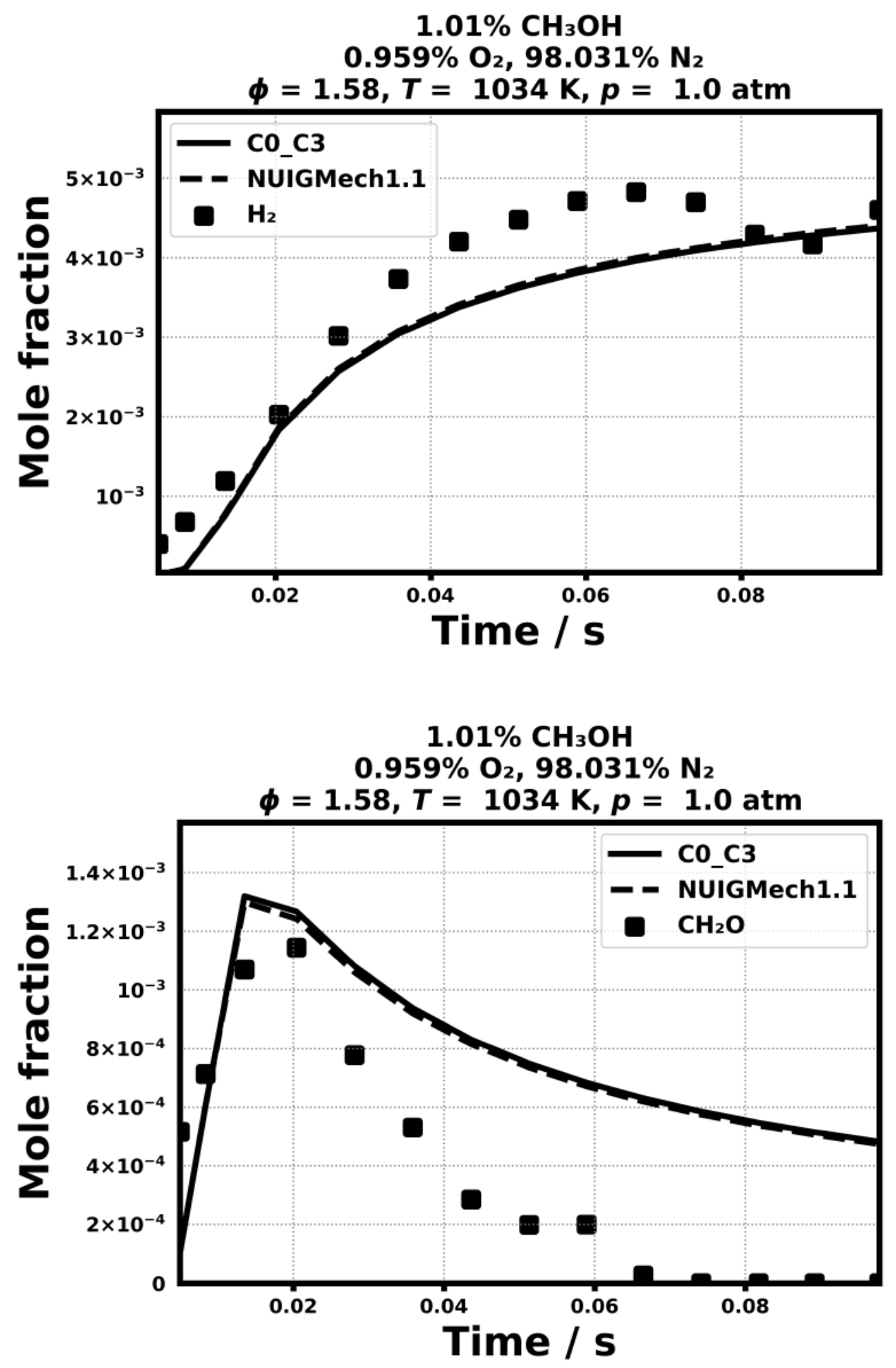

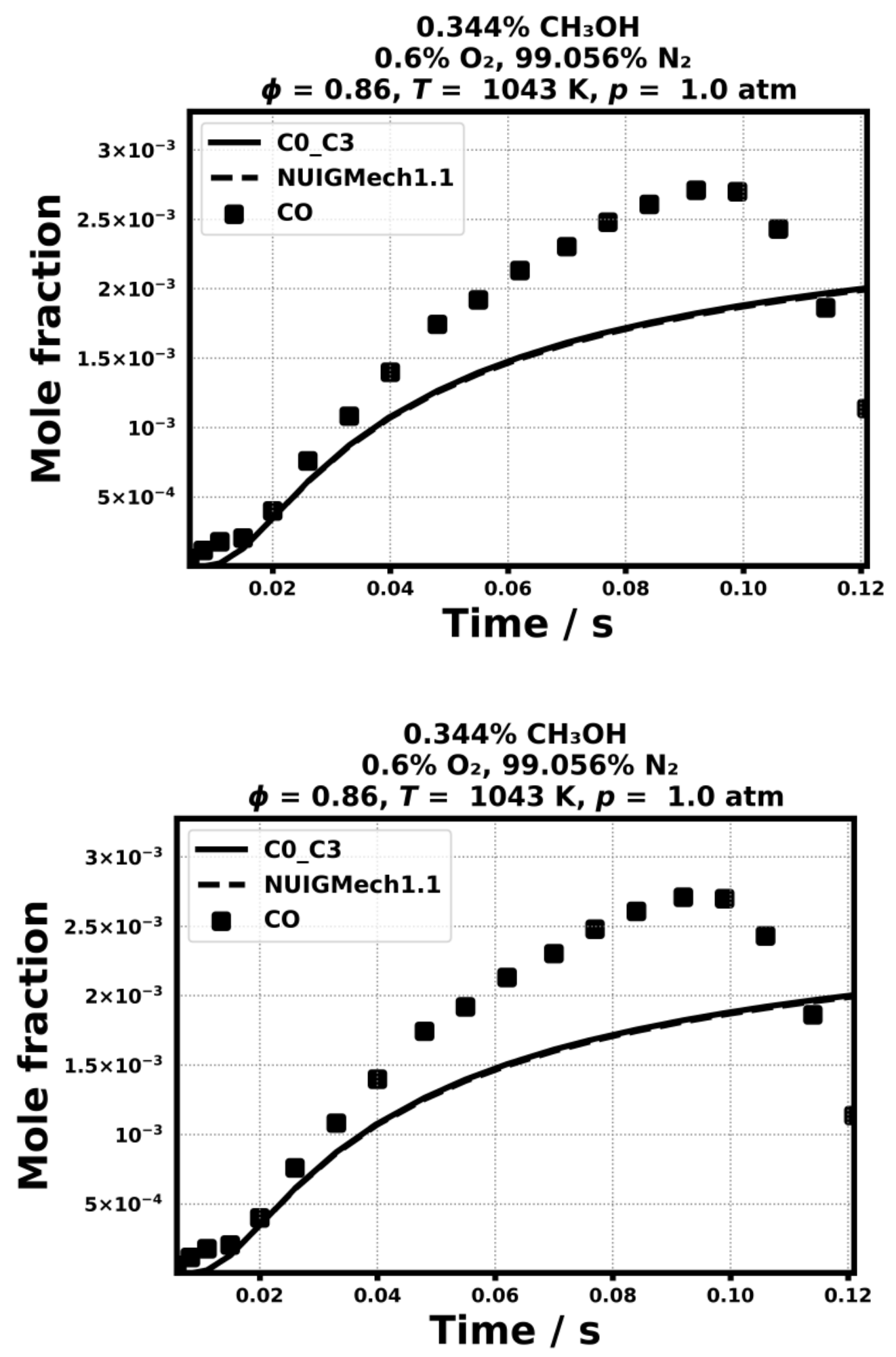

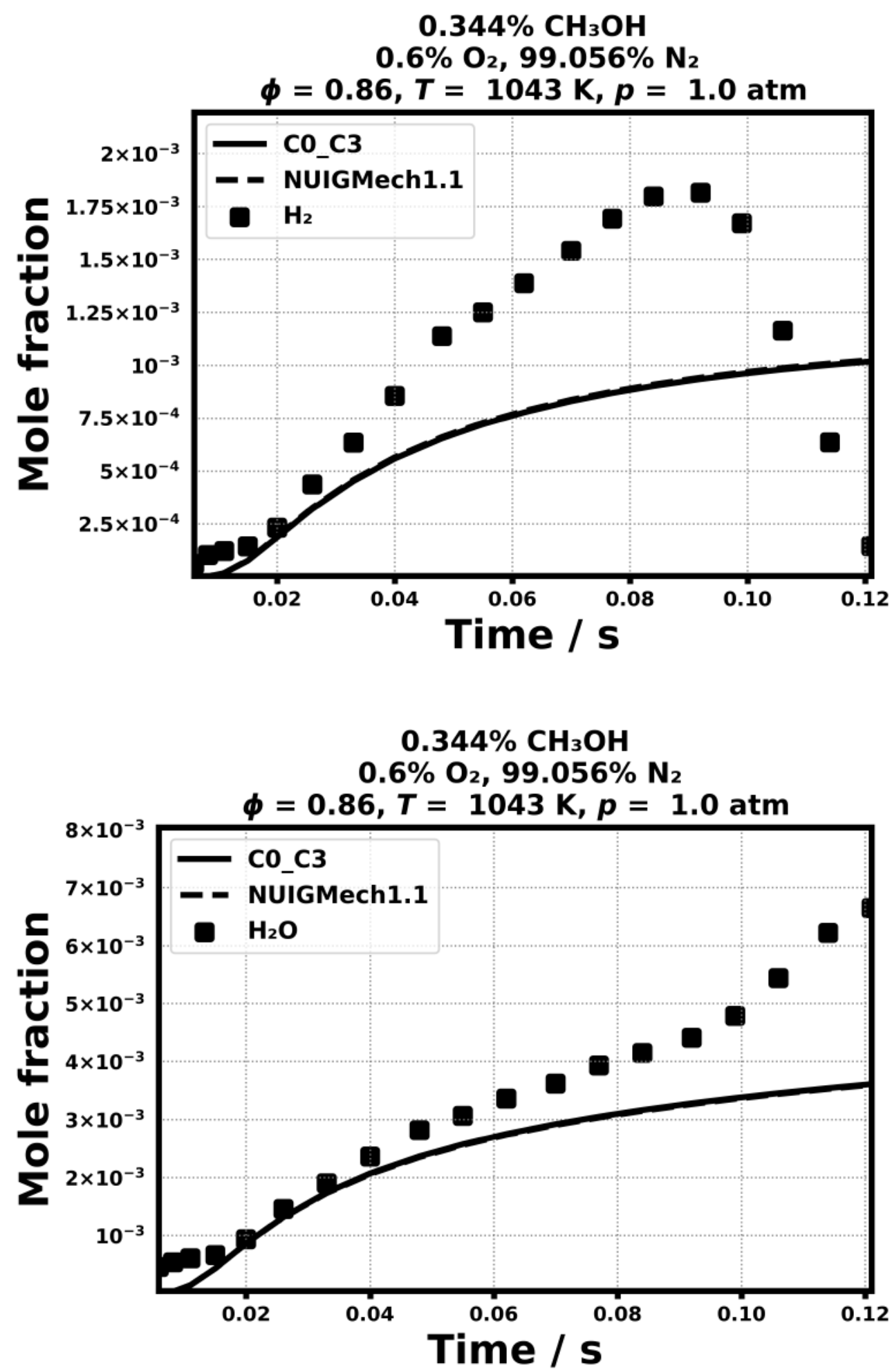

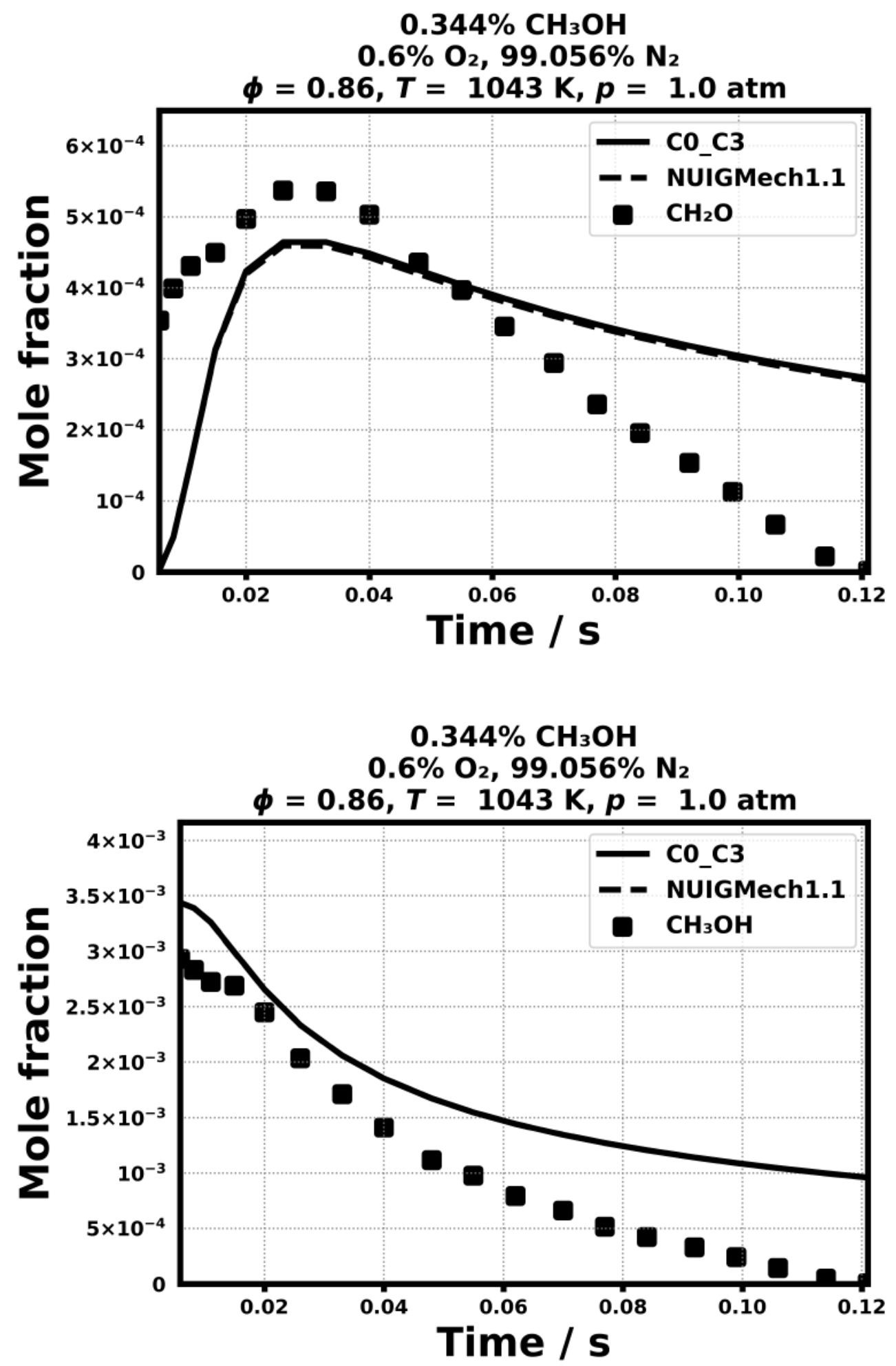

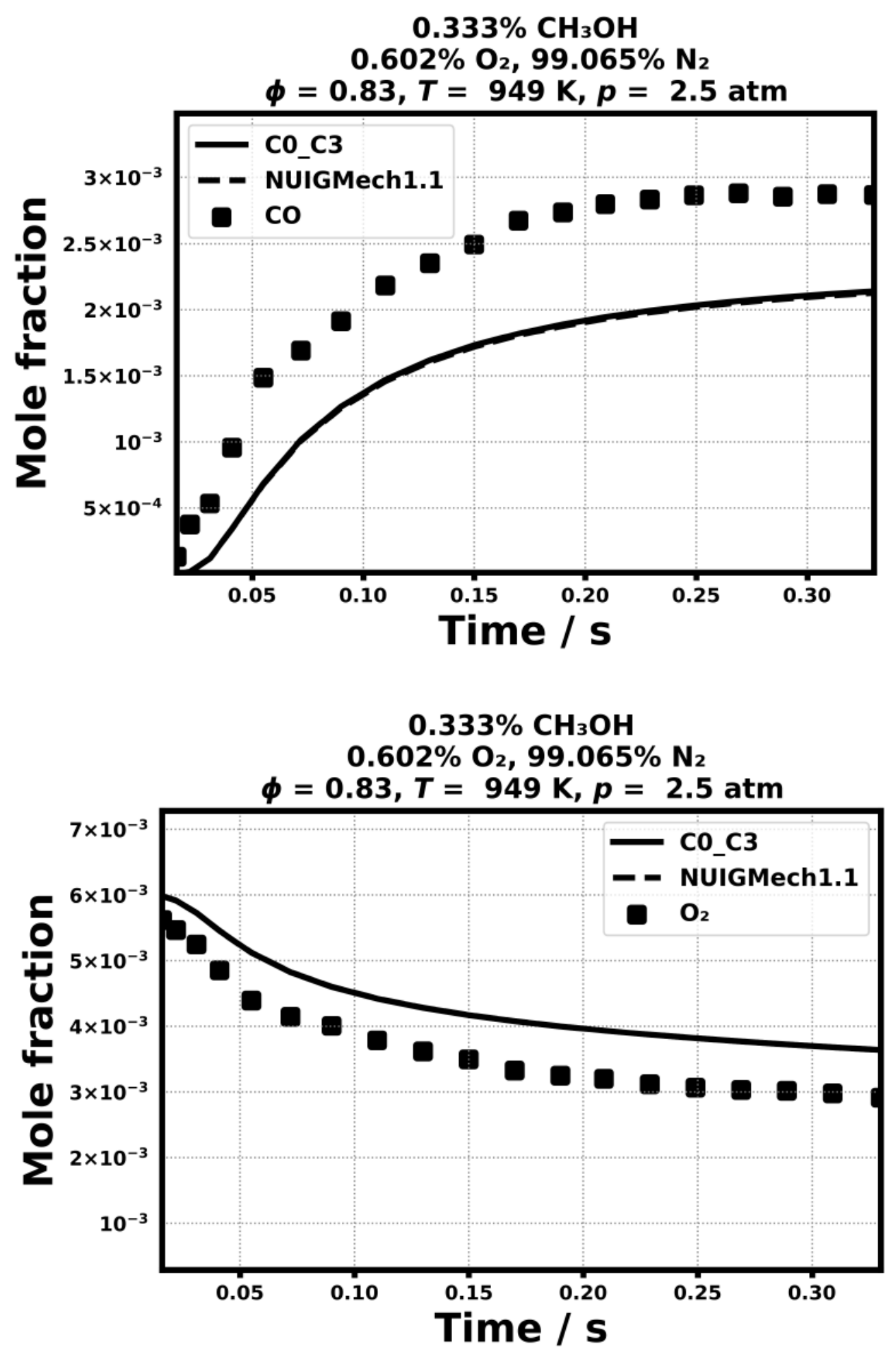

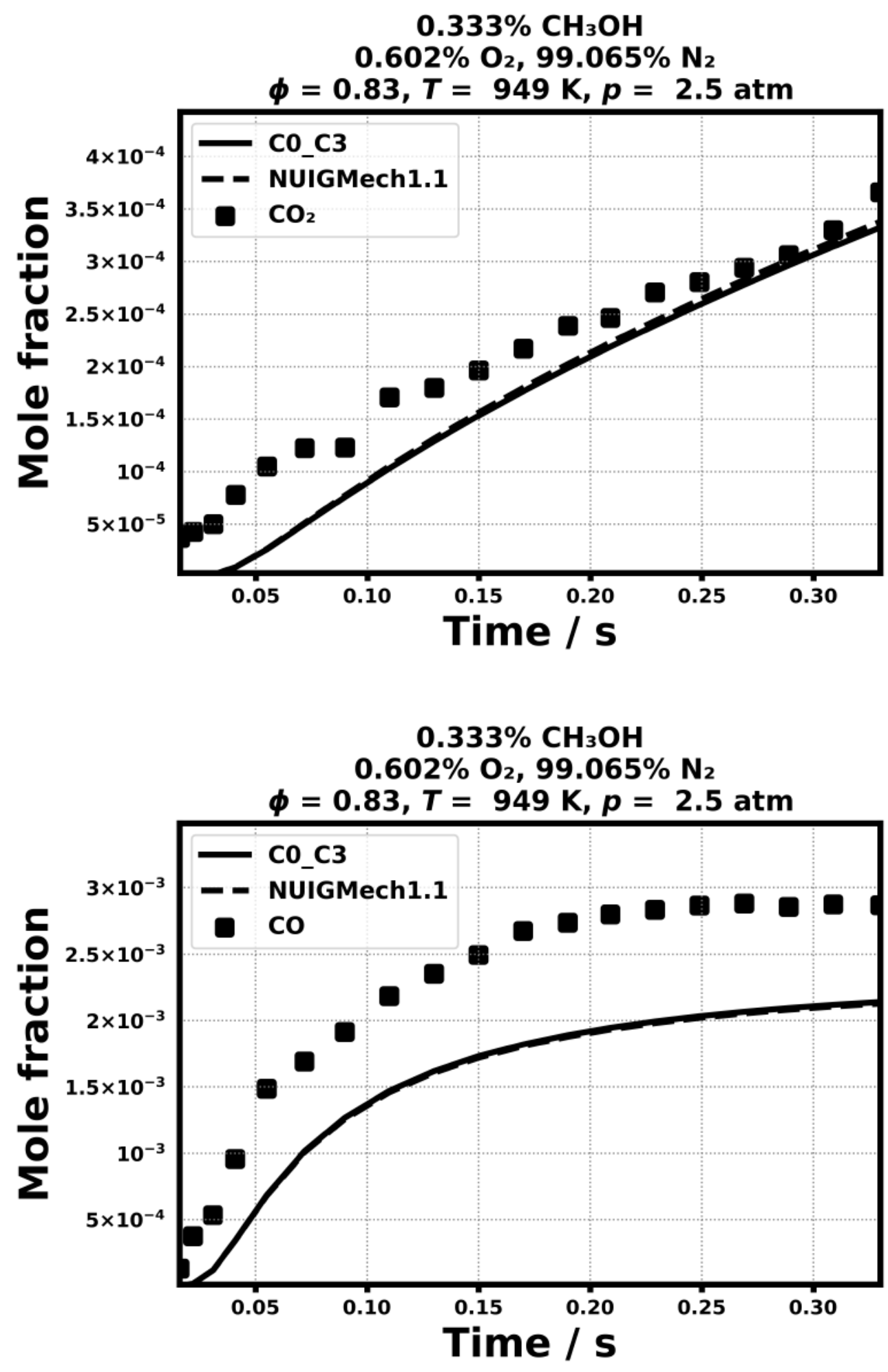

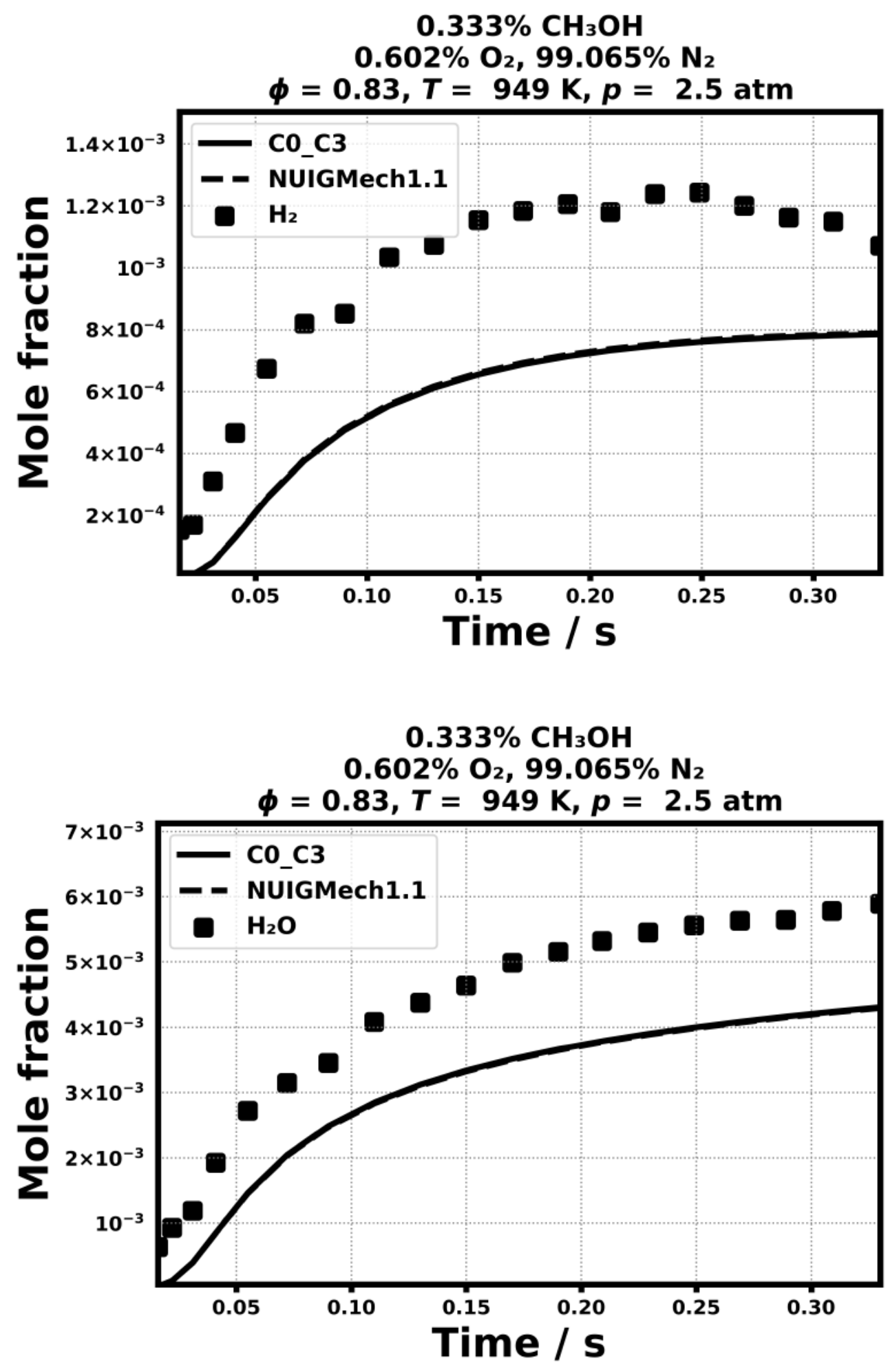

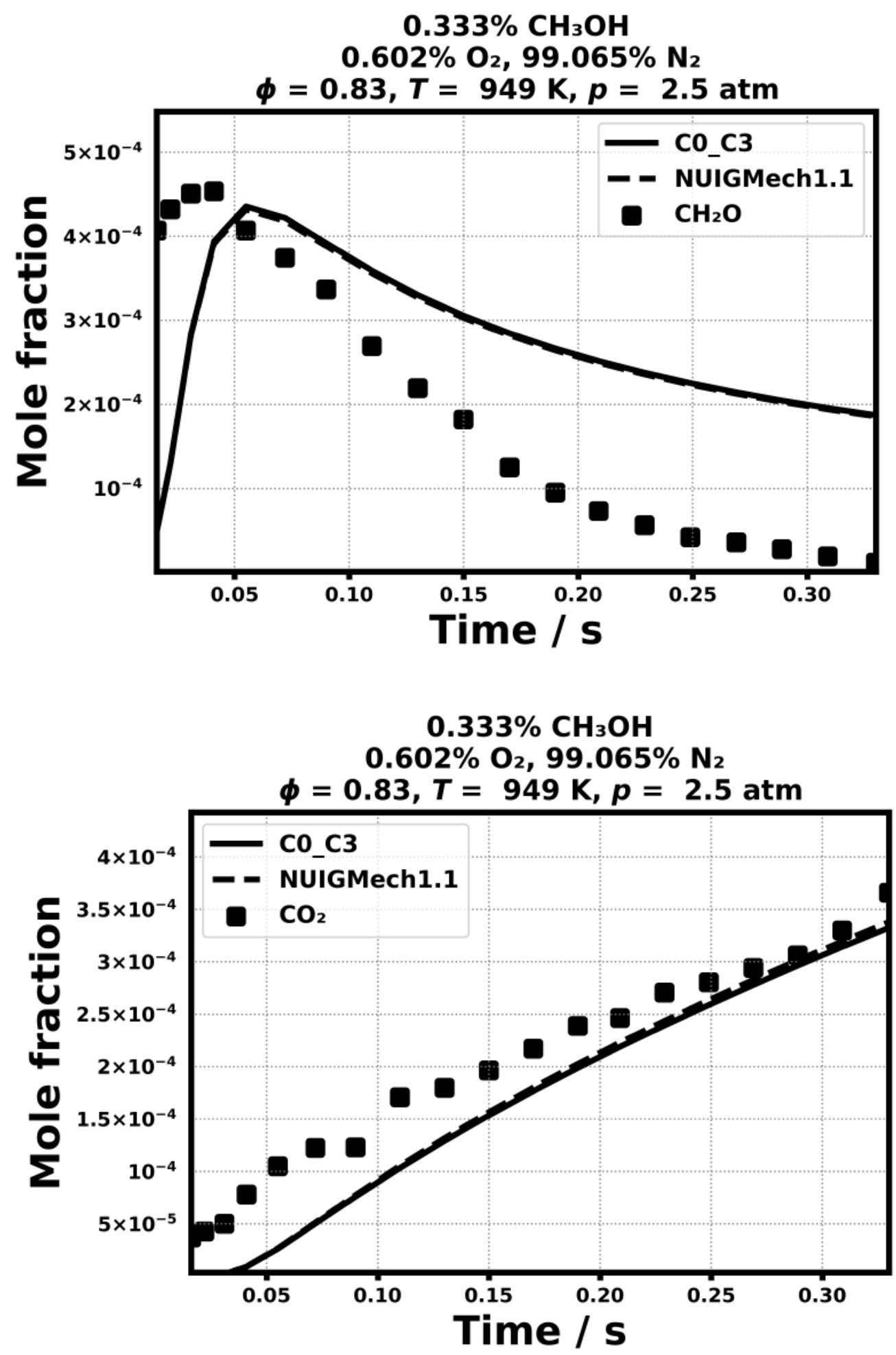


\section{Laminar flame speed}

3.10) Veloo, P. S., Wang, Y. L., Egolfopoulos, F. N., \& Westbrook, C. K., Combustion and Flame, 157(10), (2010) 1989-2004.

3.11) Vancoillie, J., Christensen, M., Nilsson, E. J. K., Verhelst, S., \& Konnov, A. A., Energy \& fuels, 26 (2012) 1557-1564.

3.12) Sileghem, L., Alekseev, V.A., Vancoillie, J., Nilsson, E.J.K., Verhelst, S. and Konnov, A.A., Fuel, 115 (2014) 32-40.
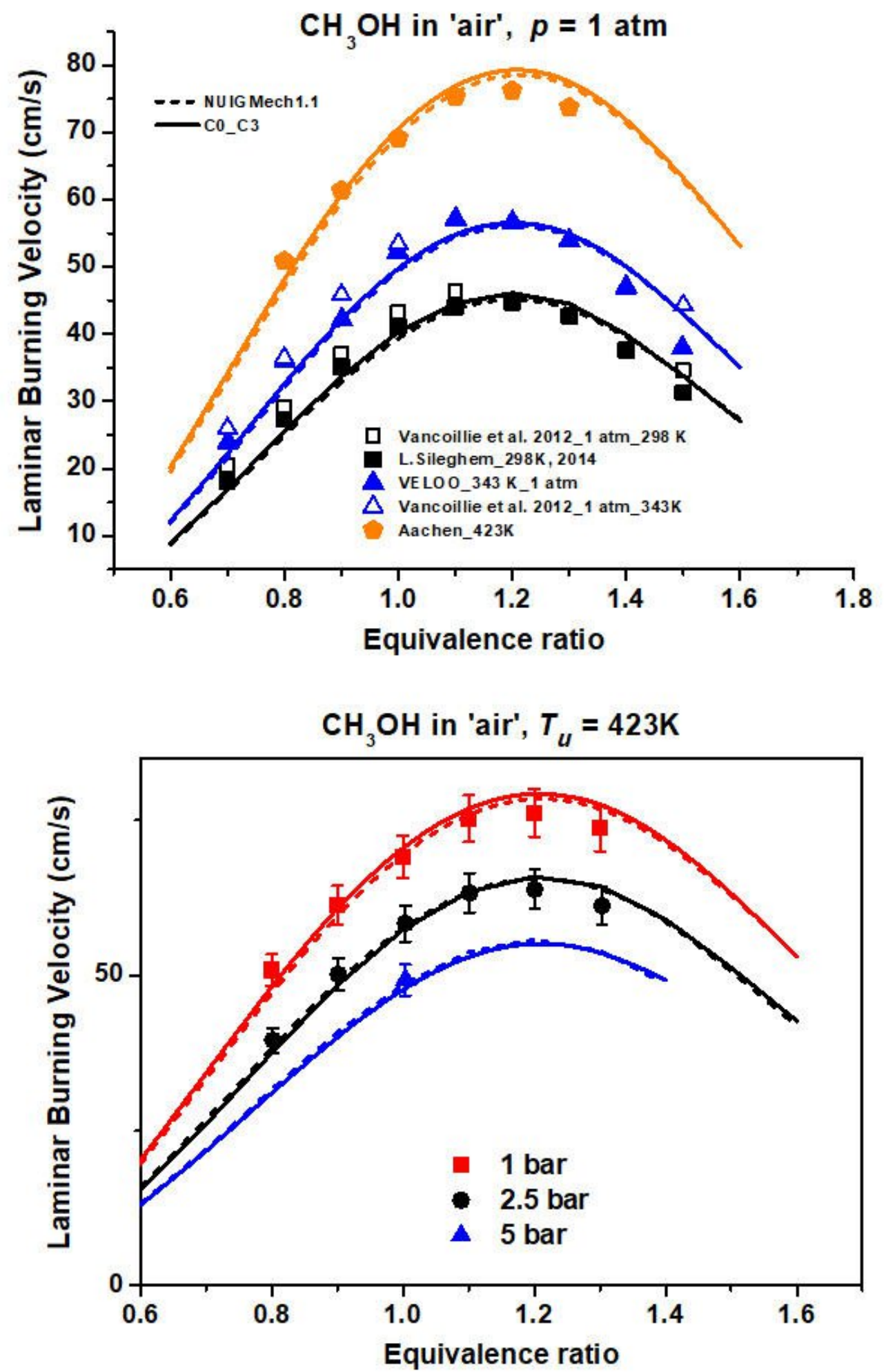


\section{Validation for $\mathrm{C}_{2} \mathrm{H}_{6}$}

\section{Shock tube ignition delay time}

4.1) Baigmohammadi, M., Patel, V., Martinez, S., Panigrahy, S., Ramalingam, A., Burke, U. \& Curran, H. J., Energy \& Fuels, 34(3) (2020) 3755-3771.
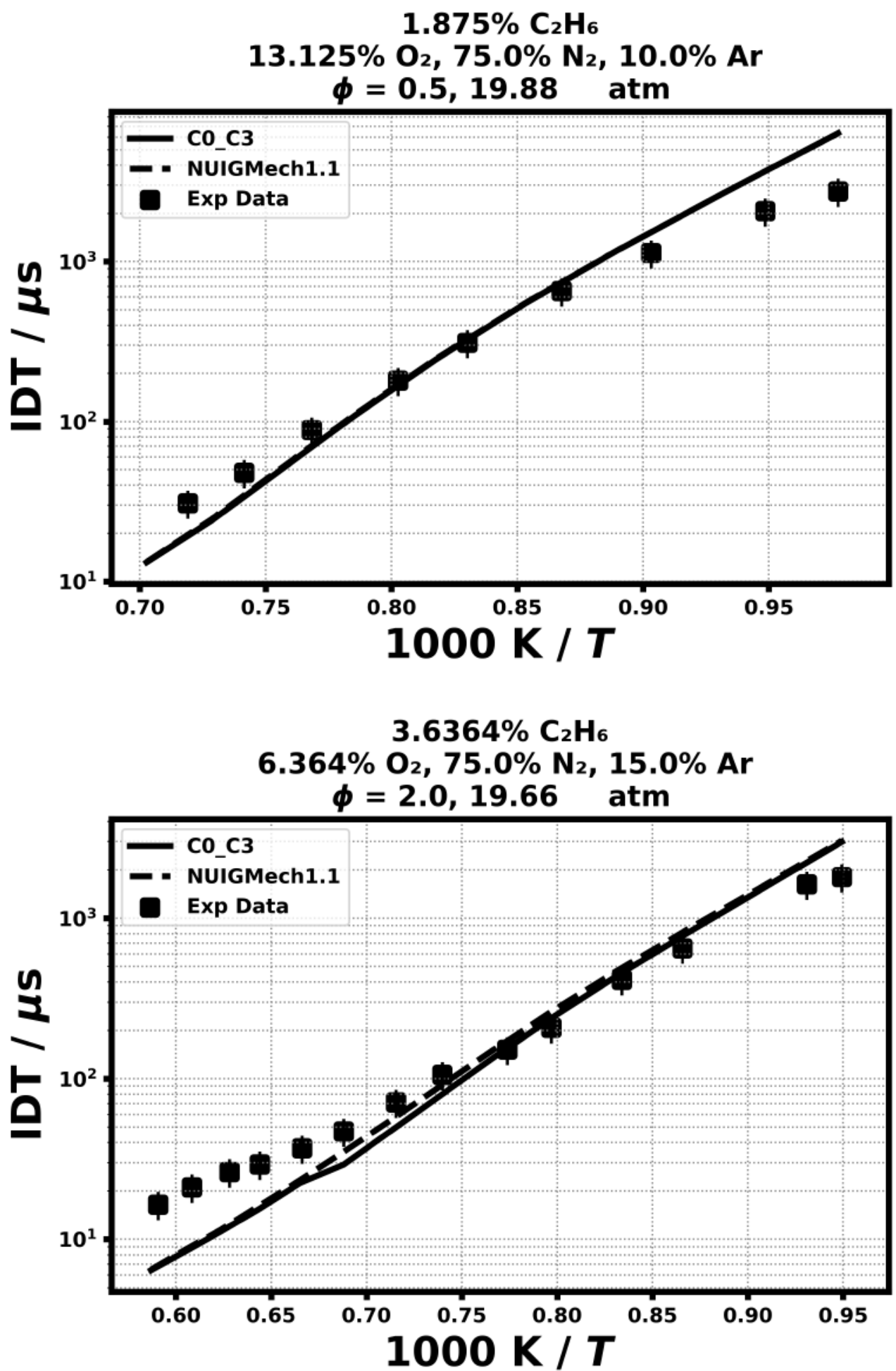

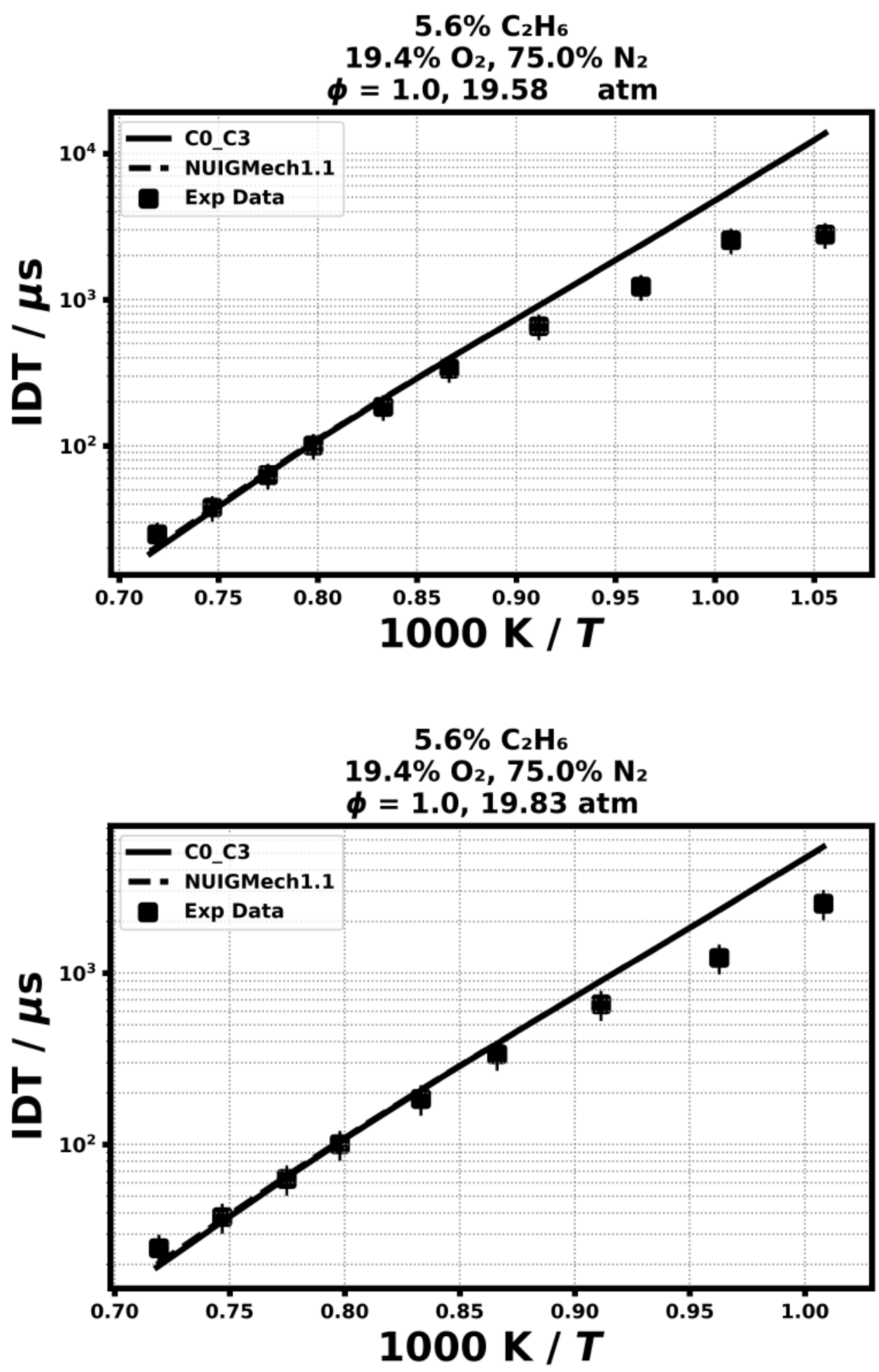

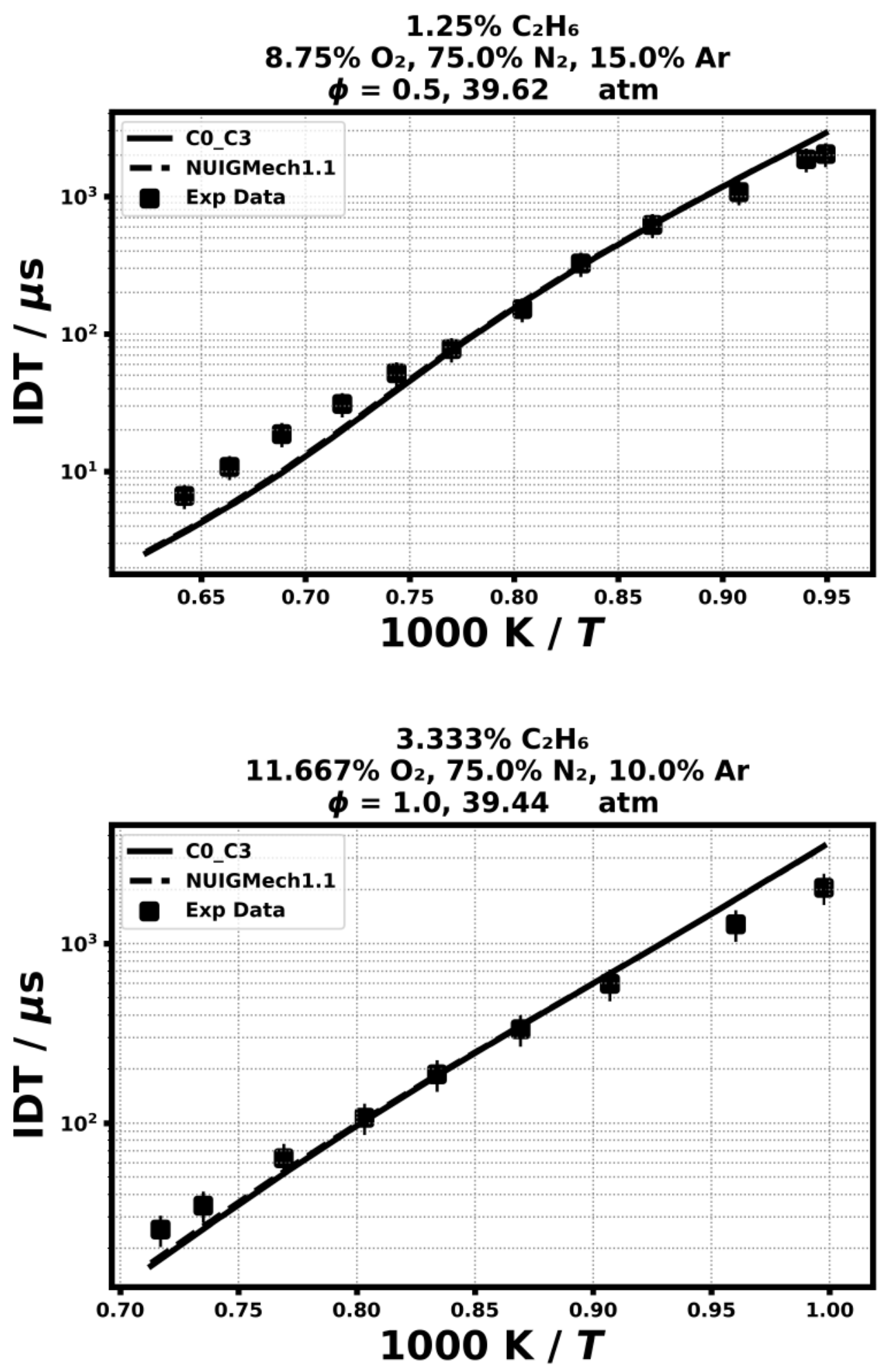

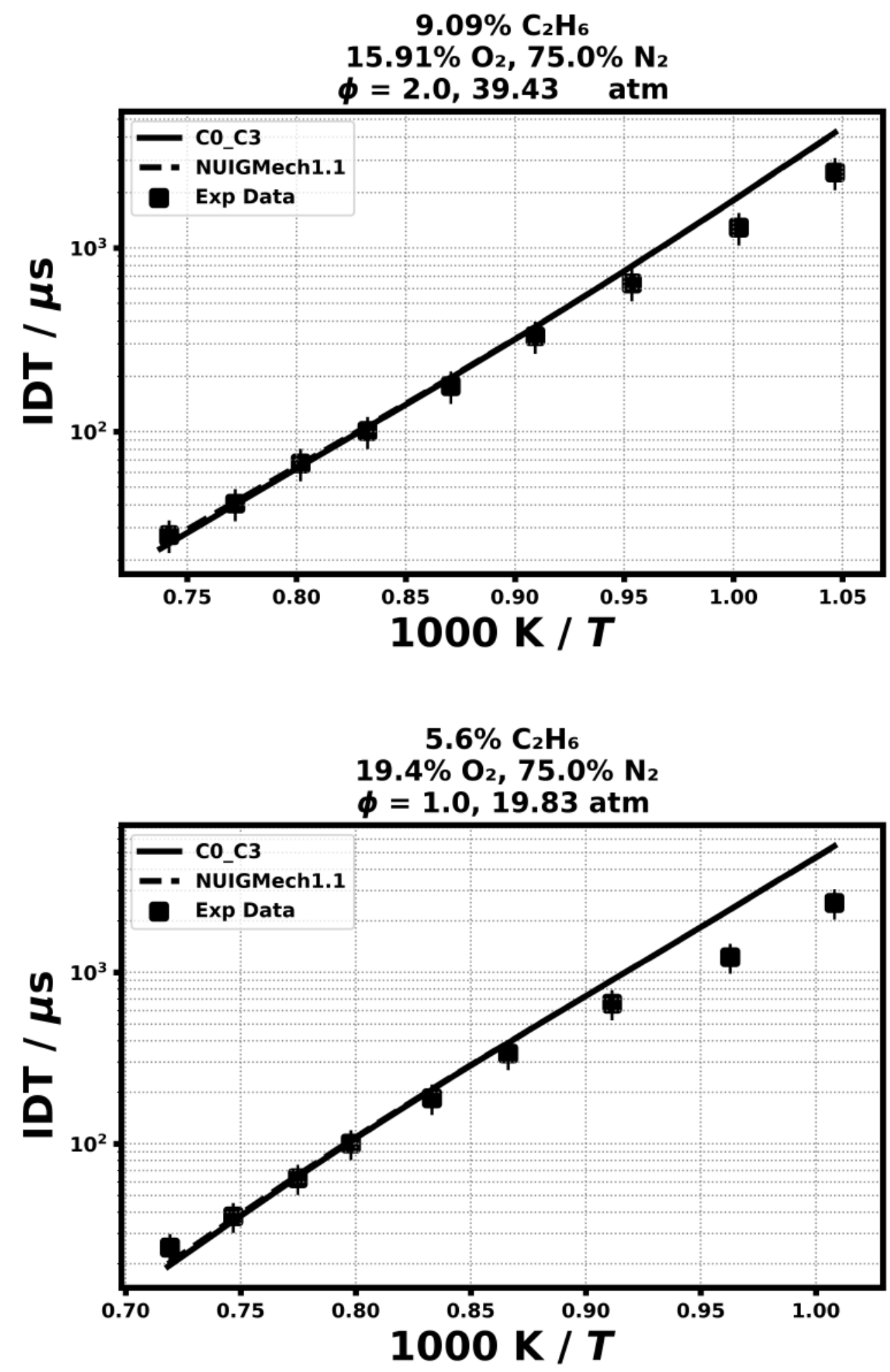


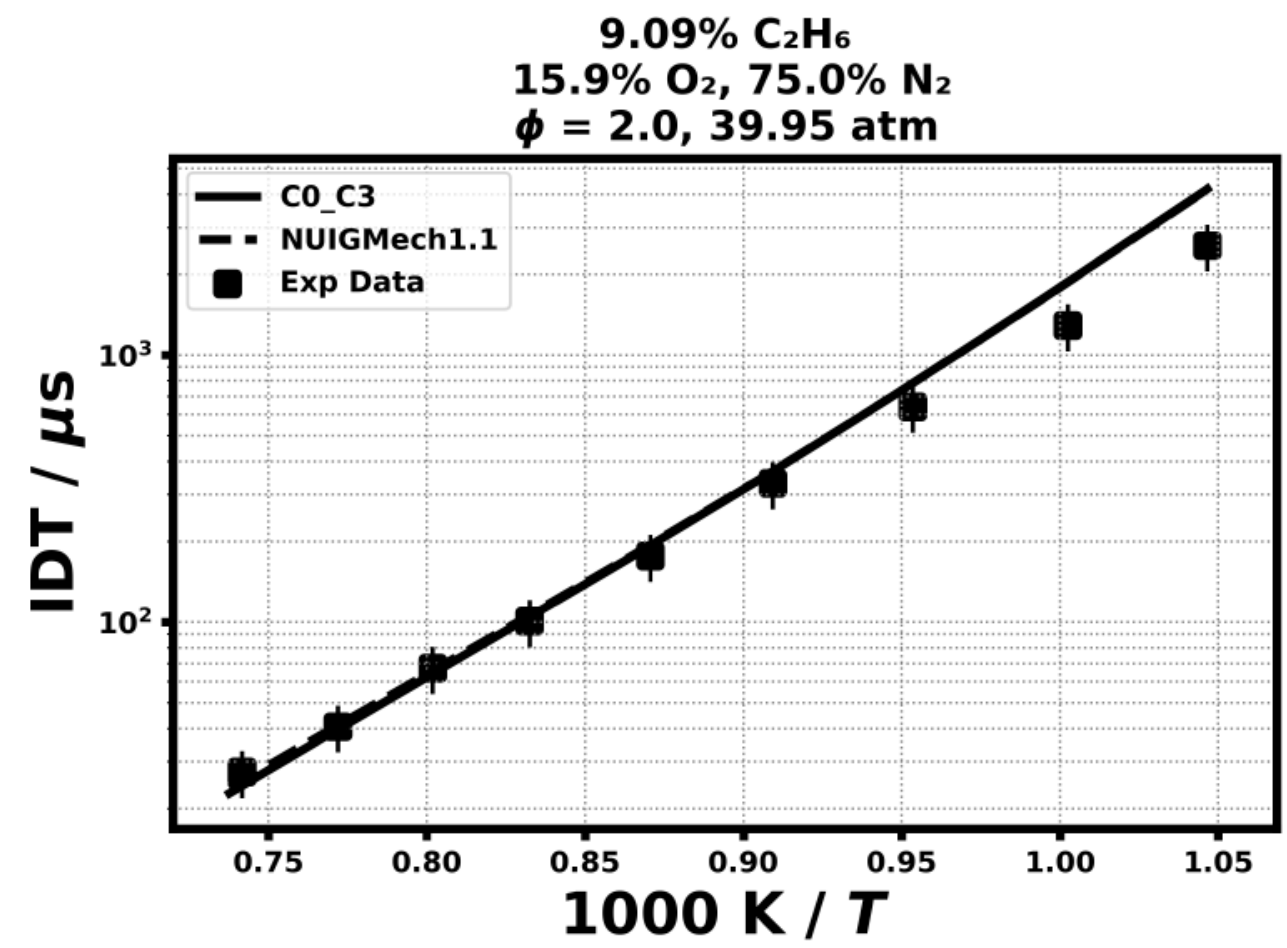

4.2) Burcat, A., Scheller, K., \& Lifshitz, A., Combustion and Flame, 16(1) (1971) 29-33.

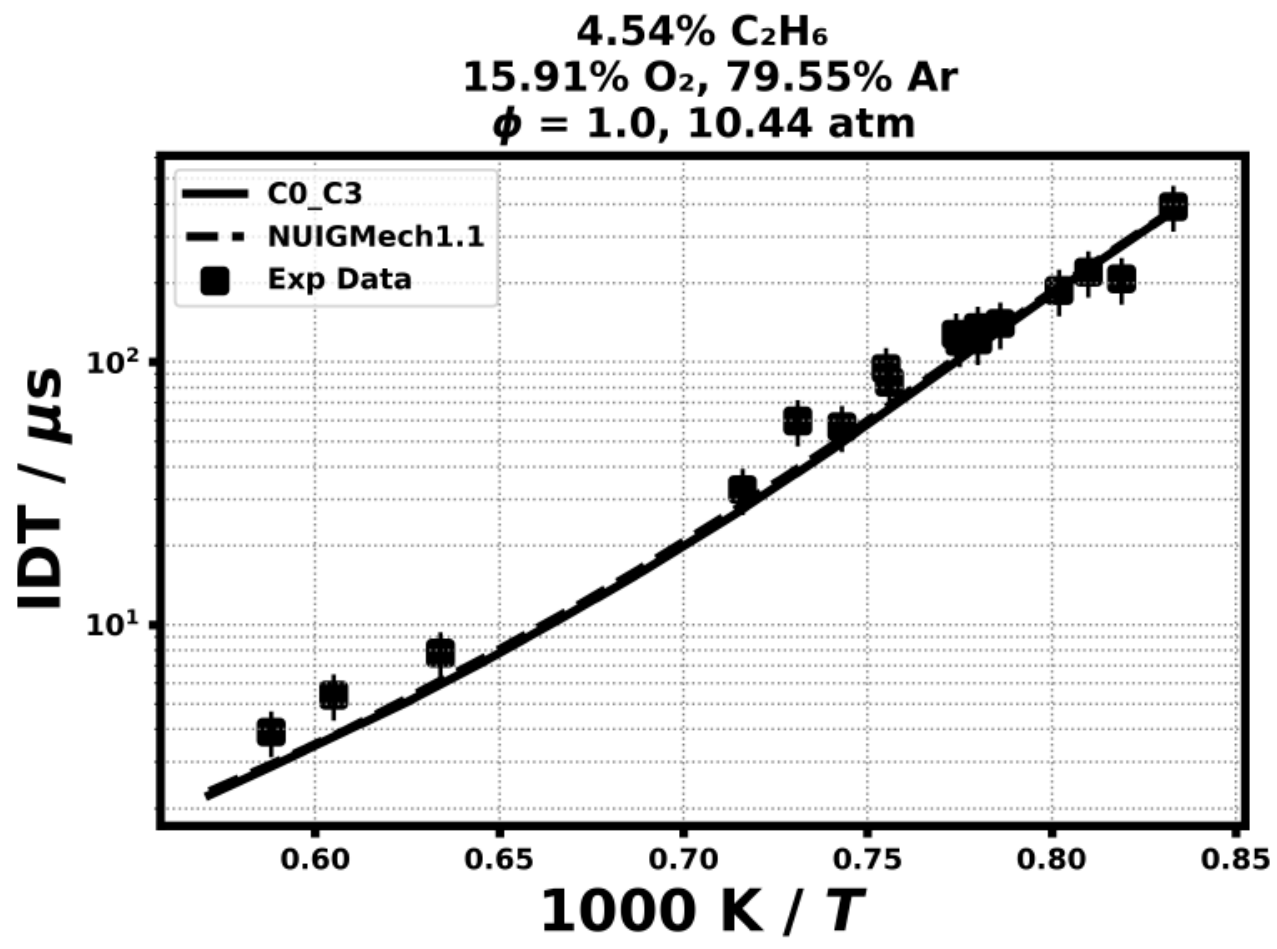



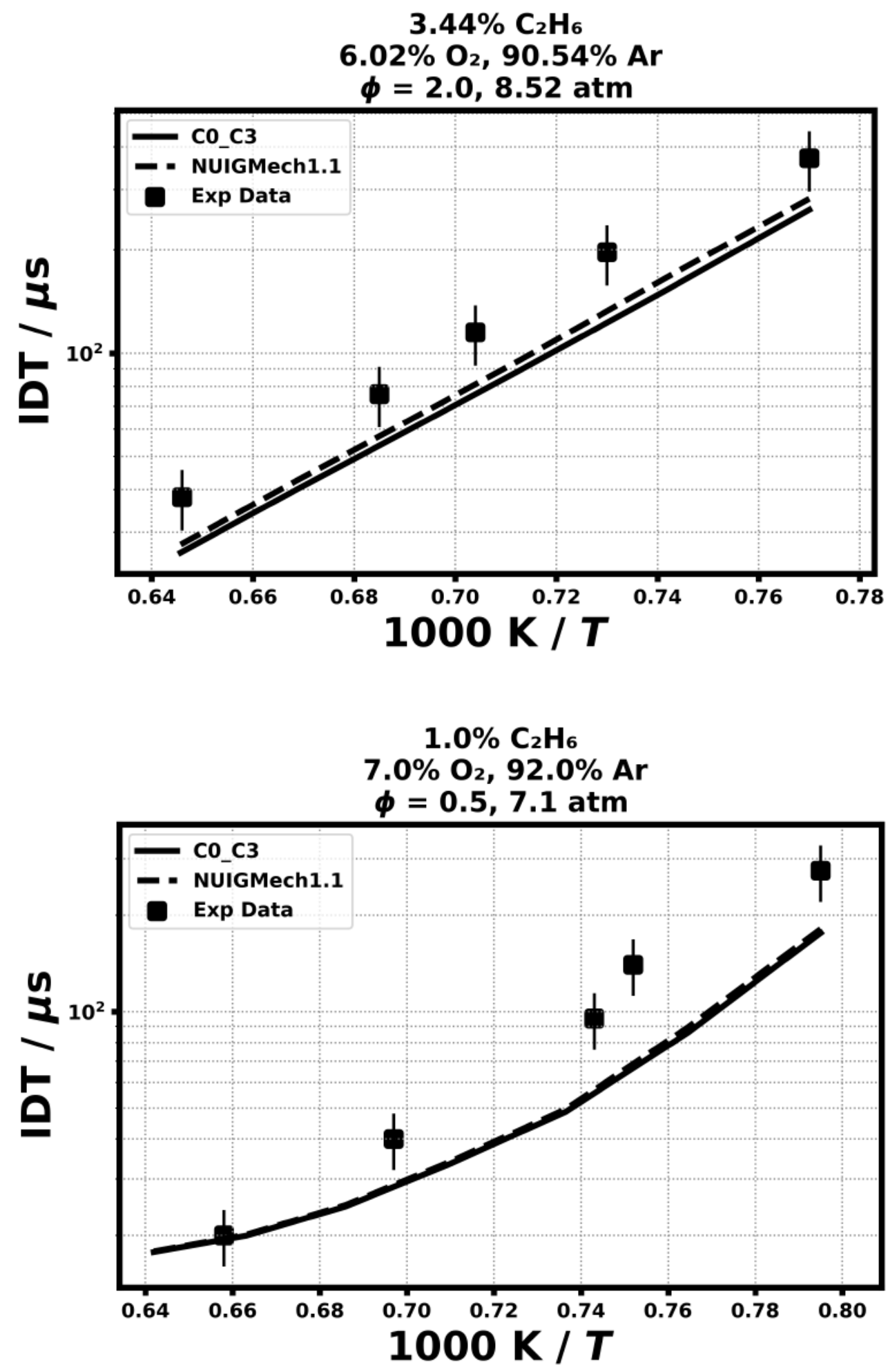


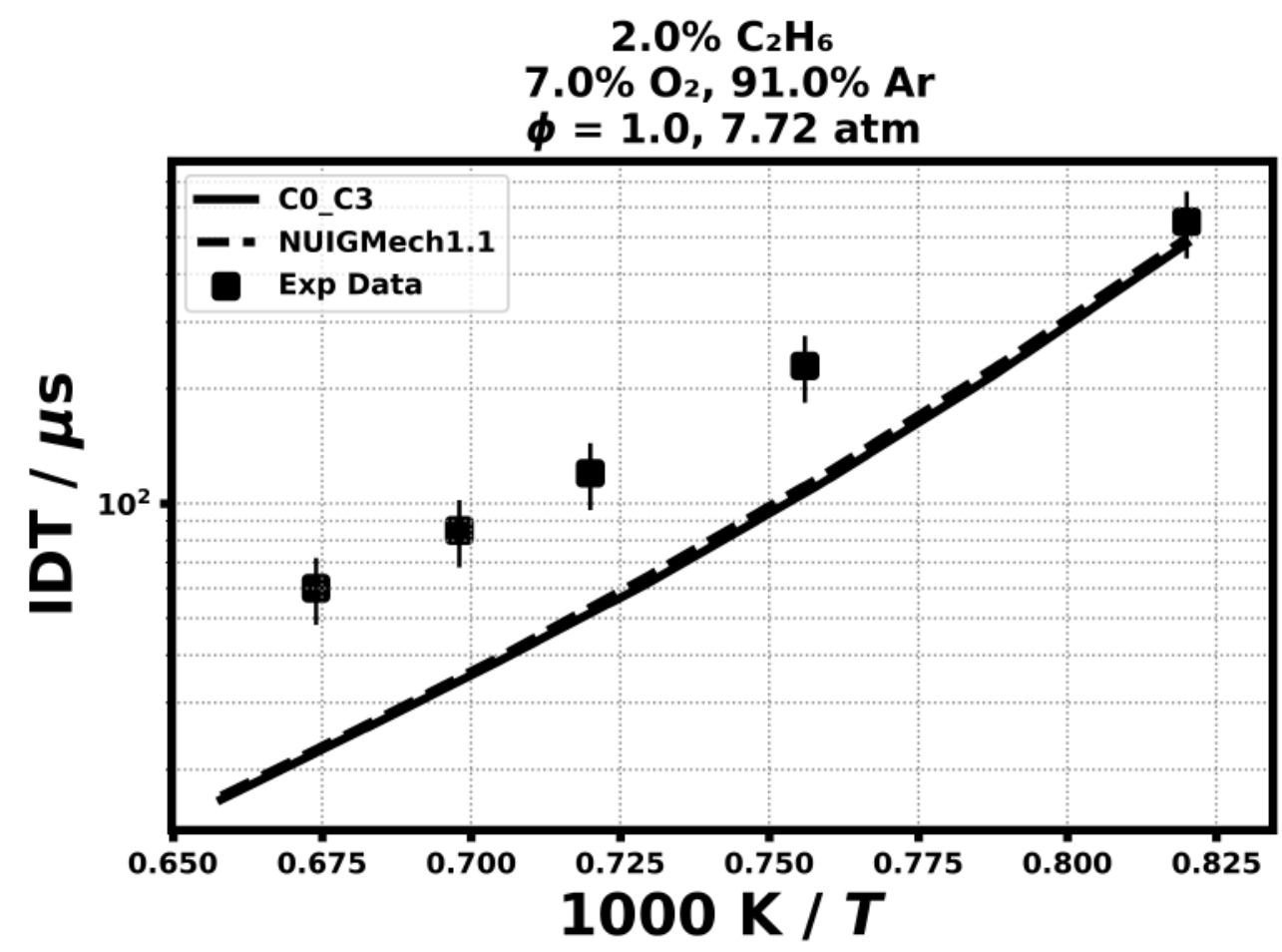

4.3) Hidaka, Y., Sato, K., Henmi, Y., Tanaka, H., \& Inami, K. Combustion and flame, 118 (3) (1999) 340-358.

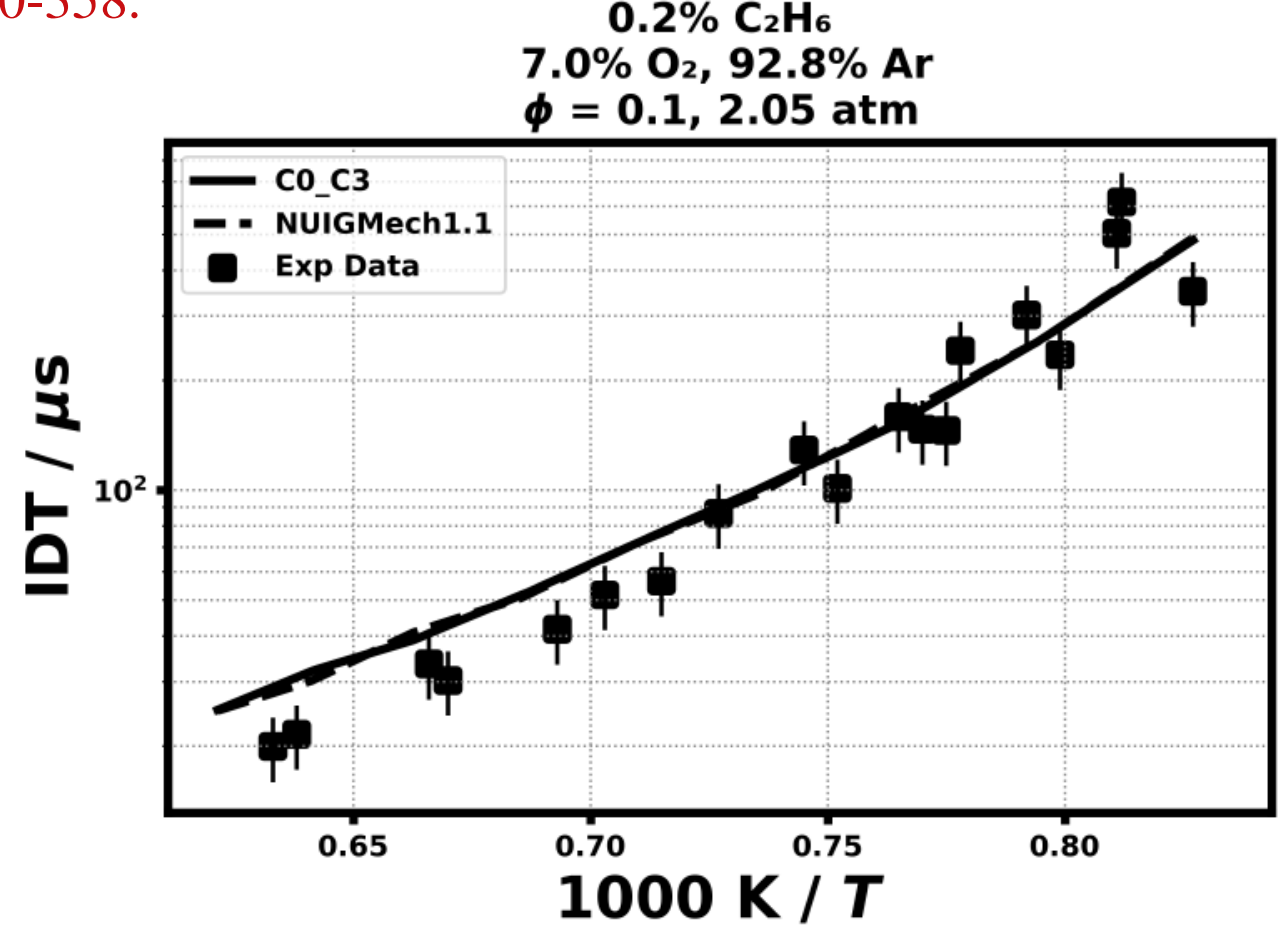



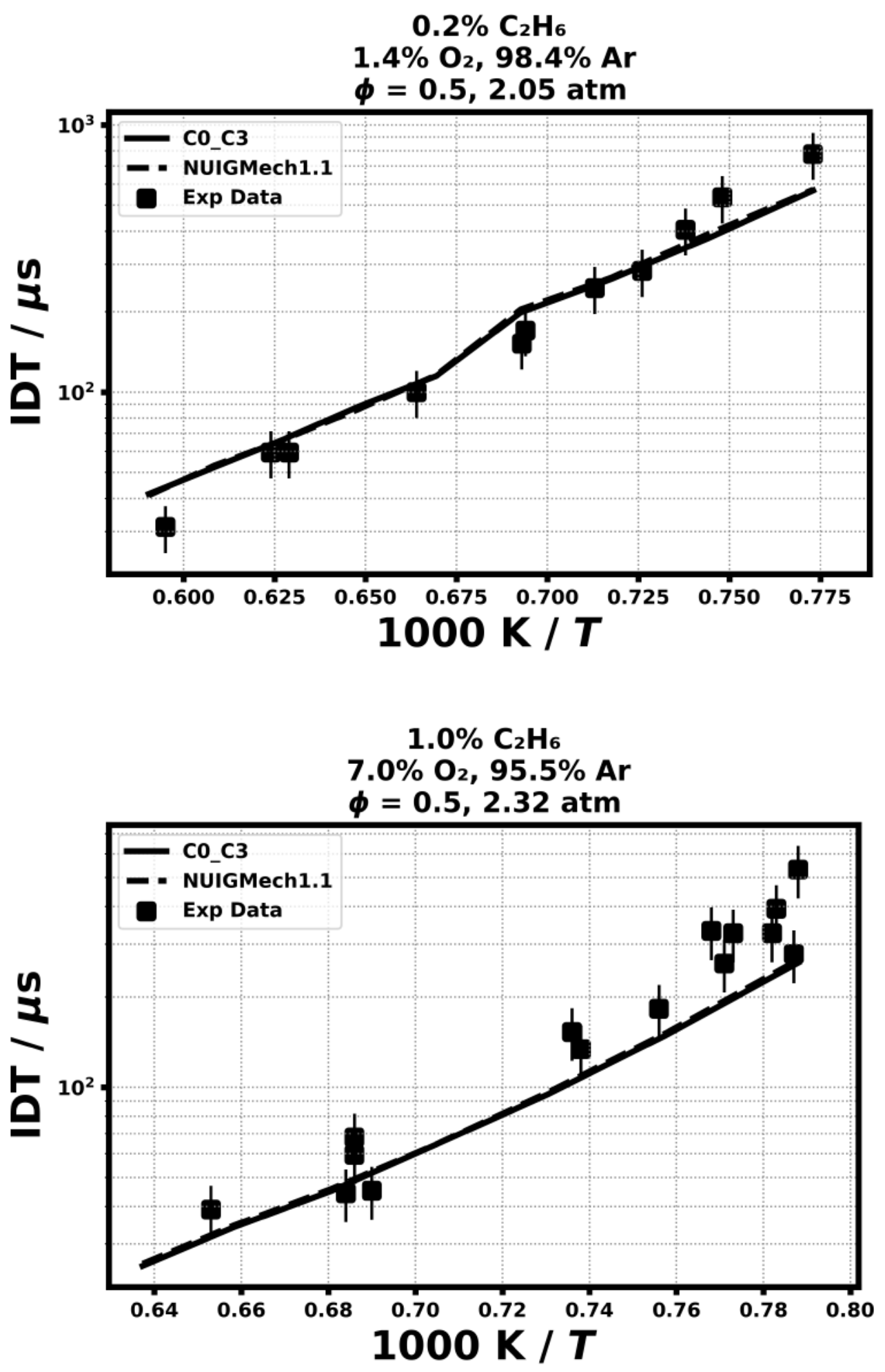

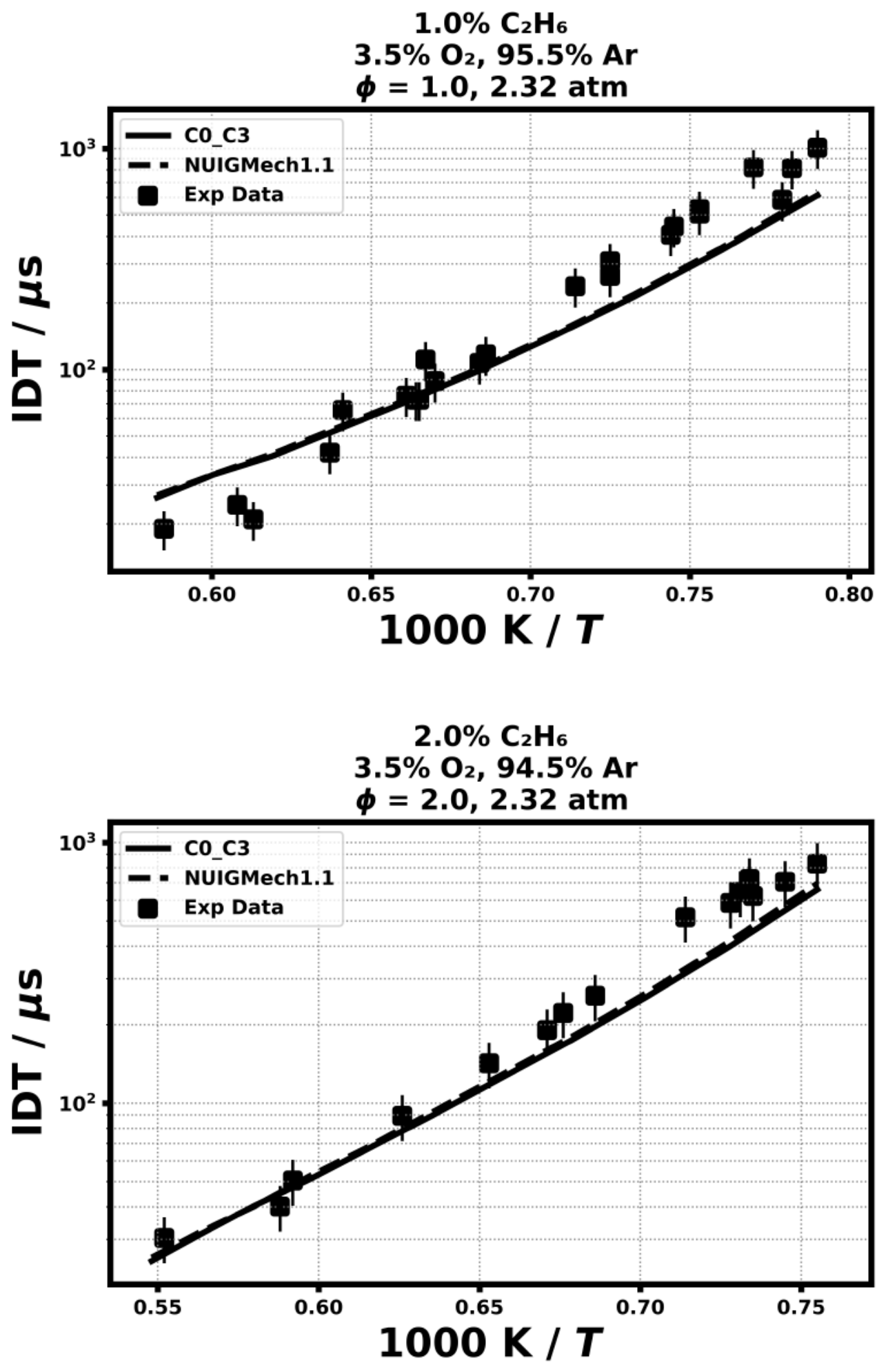
4.4) de Vries, J., Hall, J. M., Simmons, S. L., Rickard, M. J., Kalitan, D. M., \& Petersen, E. L., Combustion and flame, 150(1-2) (2007) 137-150.
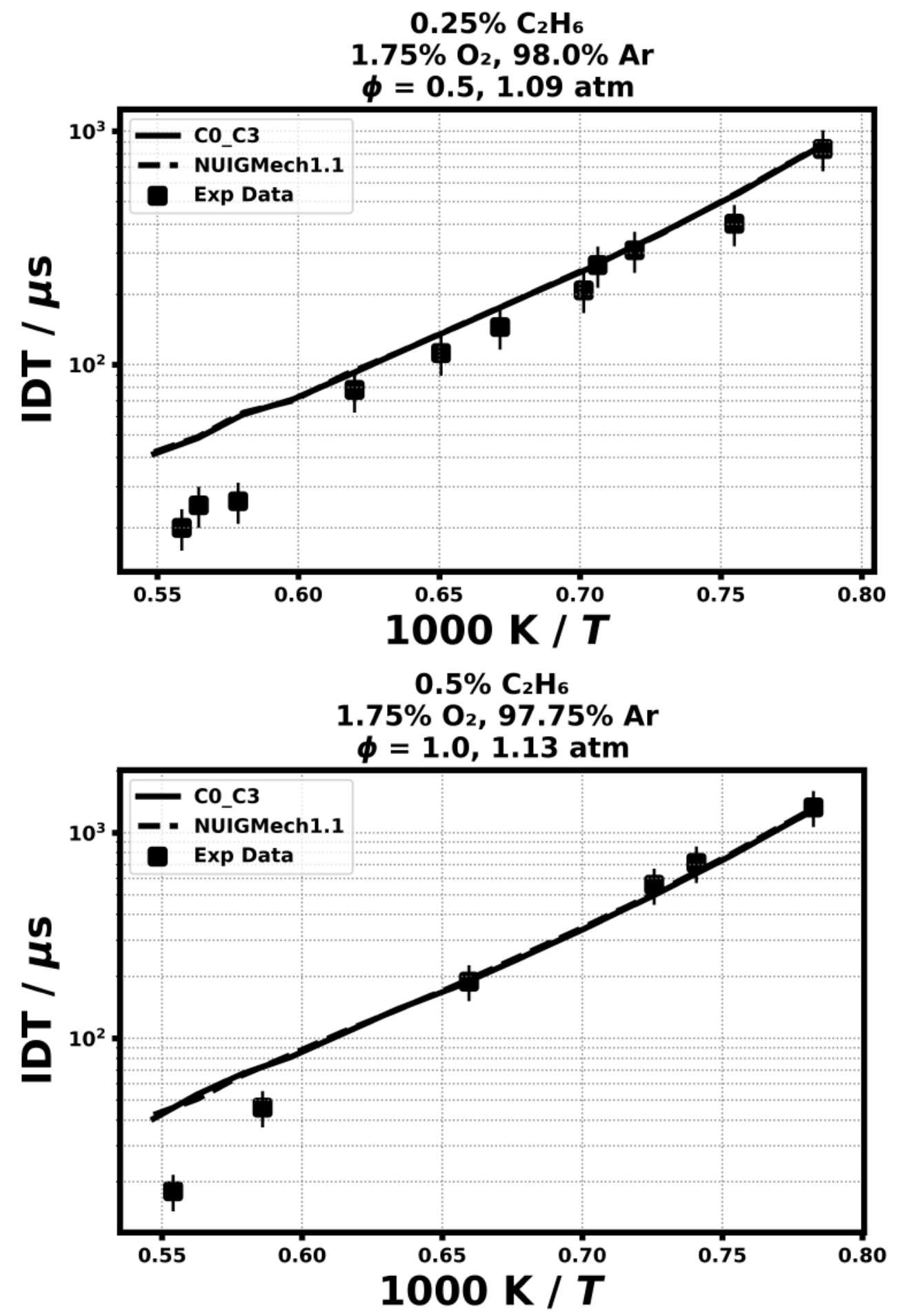

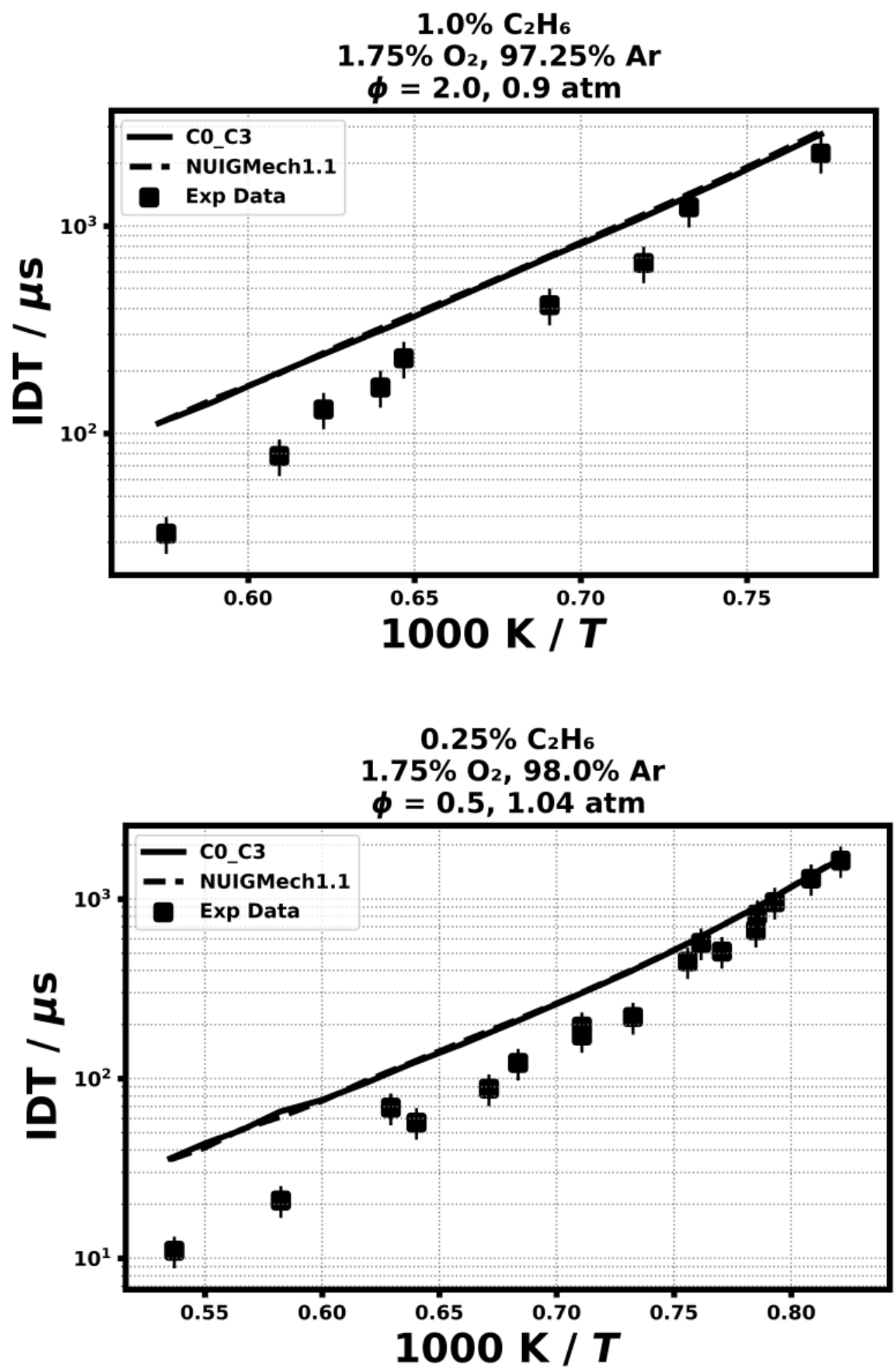

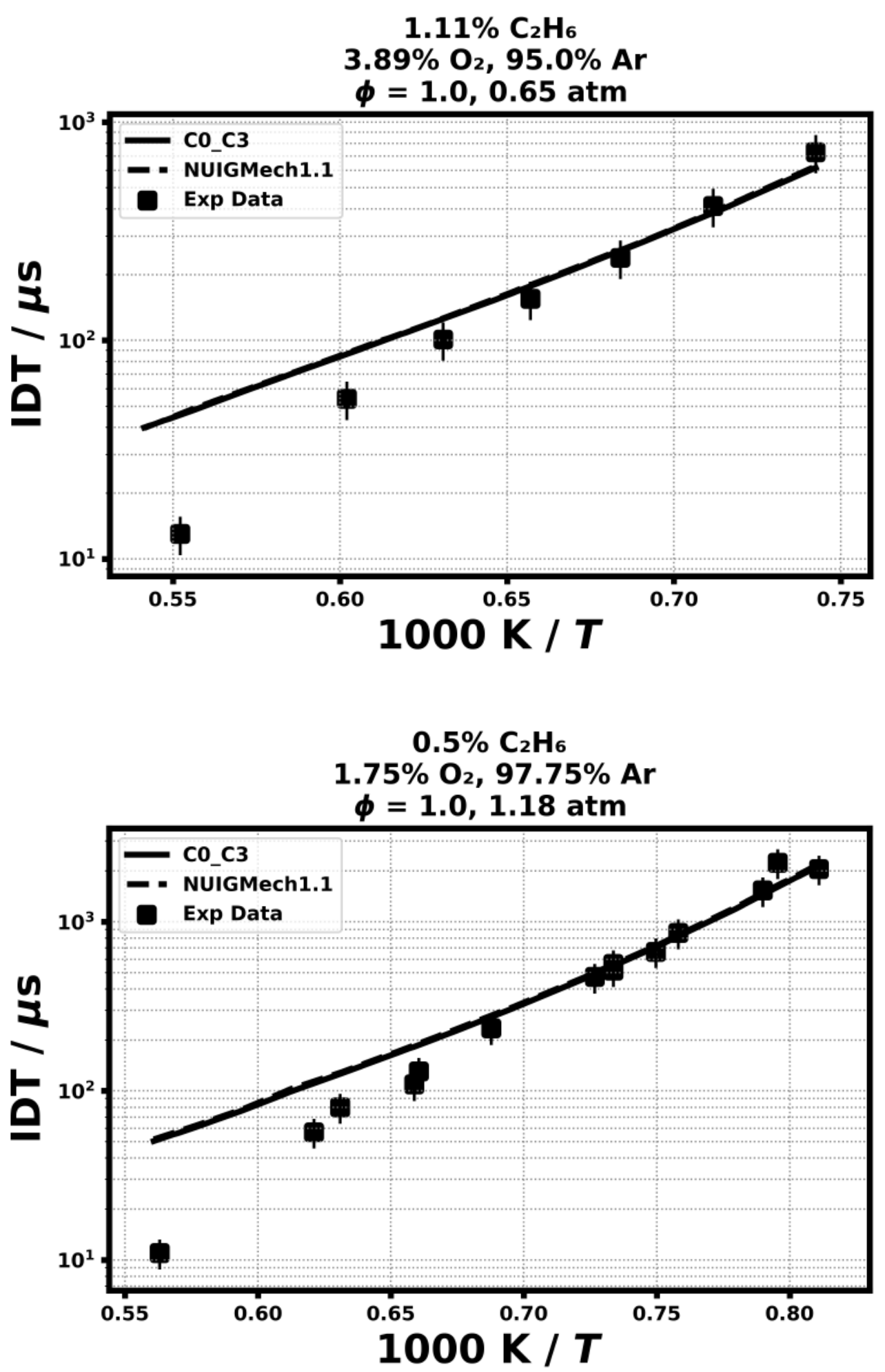

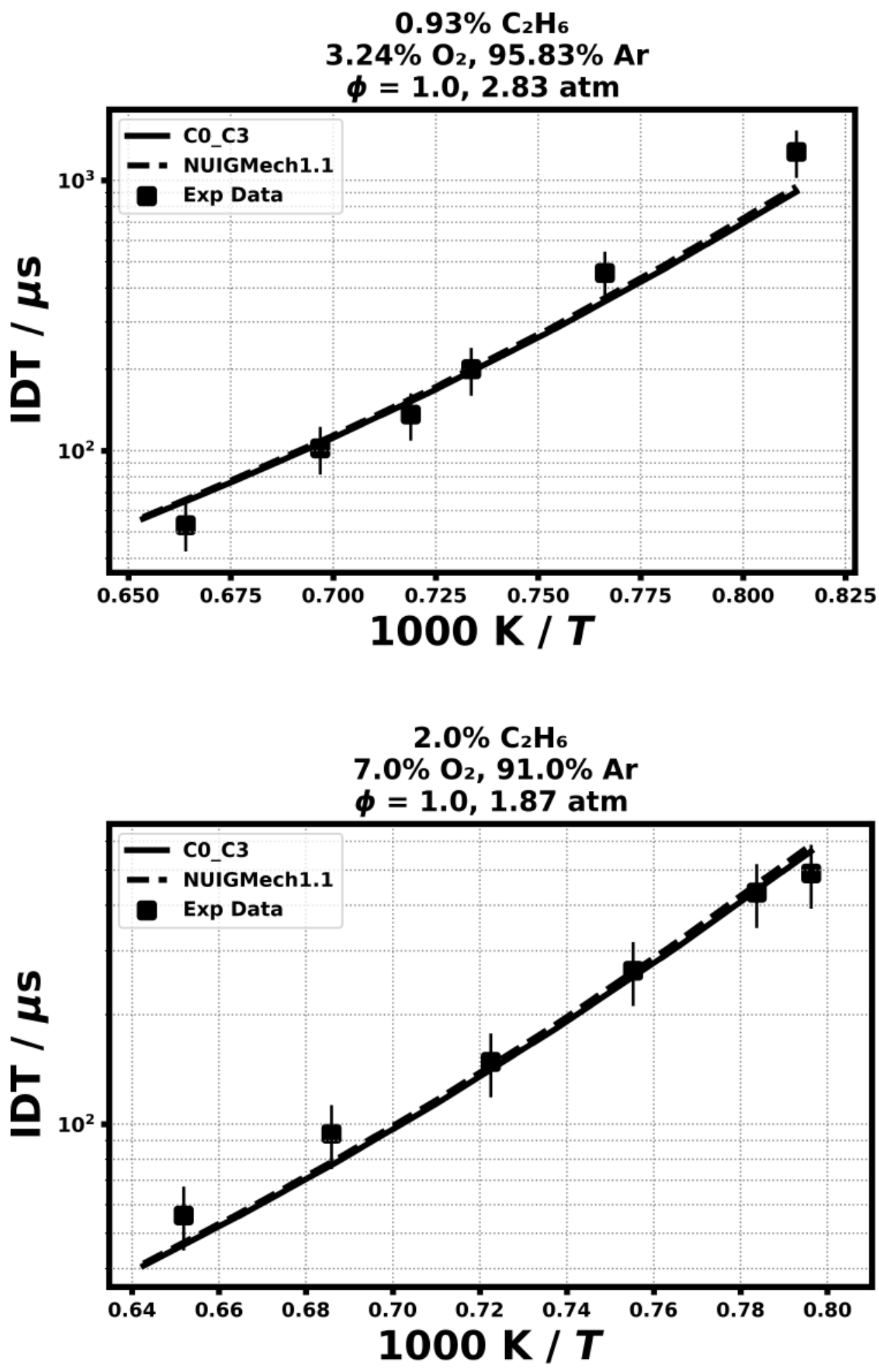


\section{RCM Ignition delay time}

4.6) Baigmohammadi, M., Patel, V., Martinez, S., Panigrahy, S., Ramalingam, A., Burke, U. \& Curran, H. J., Energy \& Fuels, 34(3) (2020) 3755-3771.
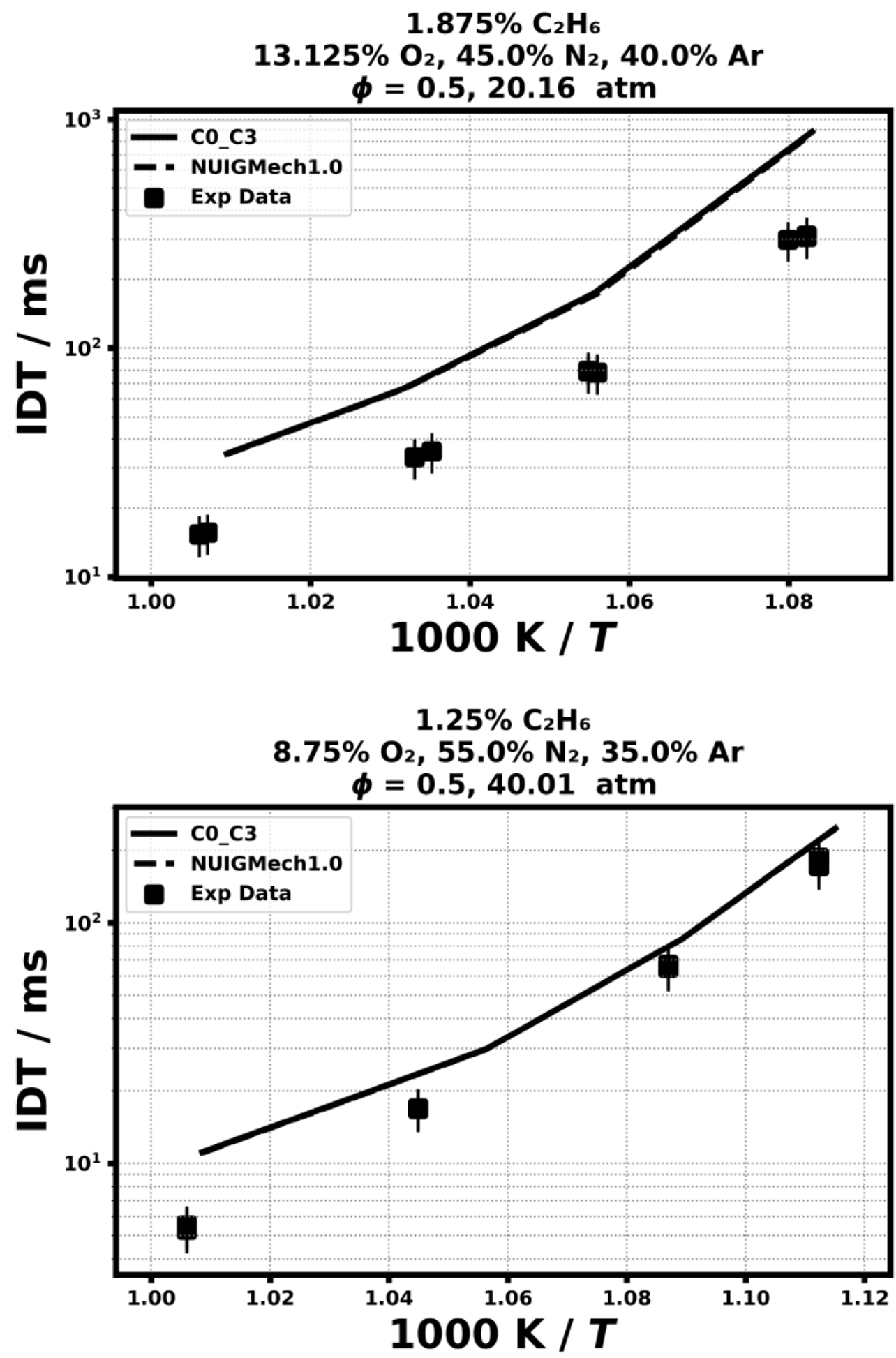

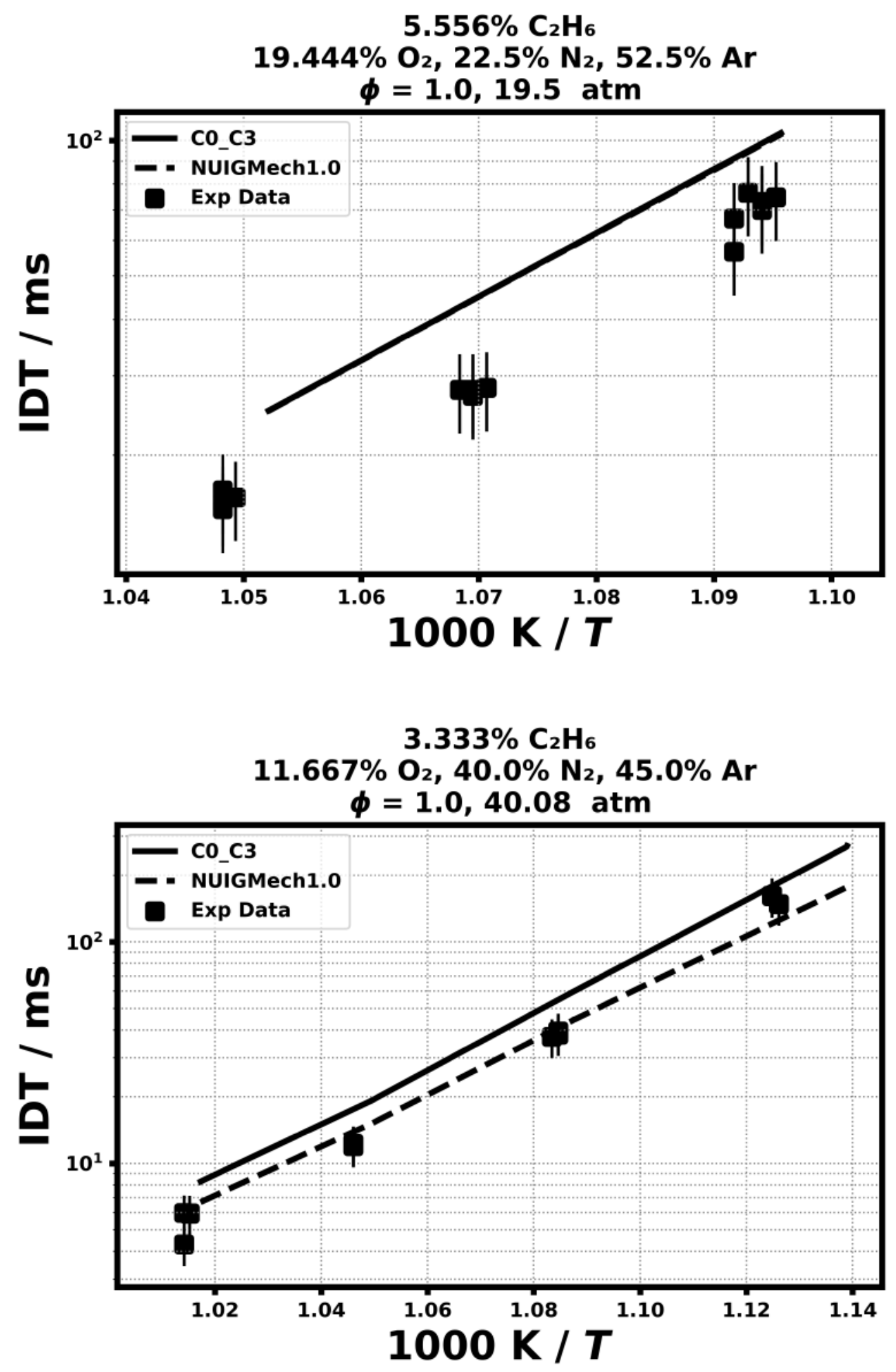

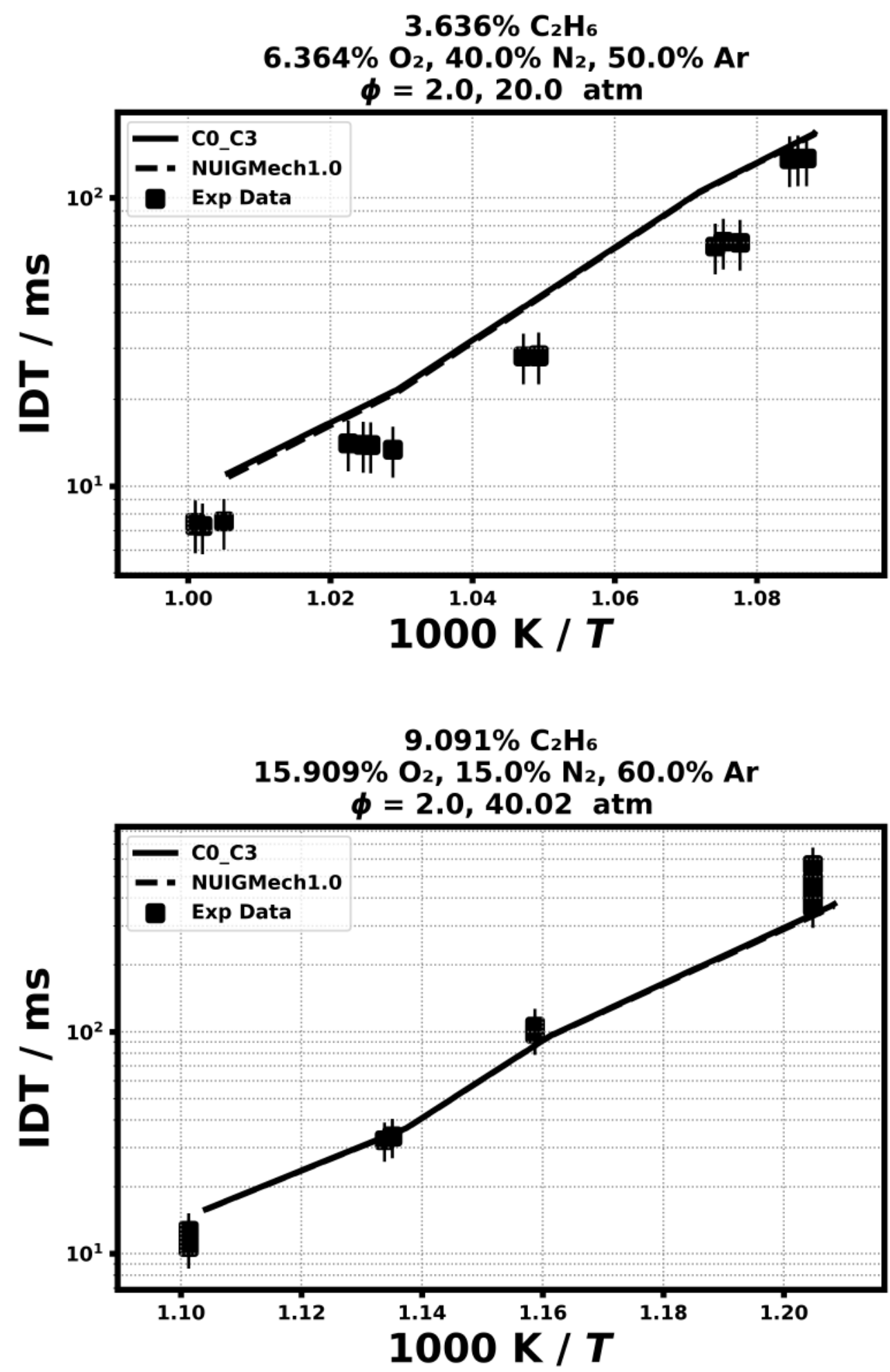


\section{Speciation in Jet-stirred reactor}

4.7) Dagaut, P., Cathonnet, M., \& Boettner, J. C. International journal of chemical kinetics, 23(5) (1991) 437-455.

\section{$0.15 \% \mathrm{C}_{2} \mathrm{H}_{6}$}

$5.25 \% \mathrm{O}_{2}, 94.6 \% \mathrm{~N}_{2}$

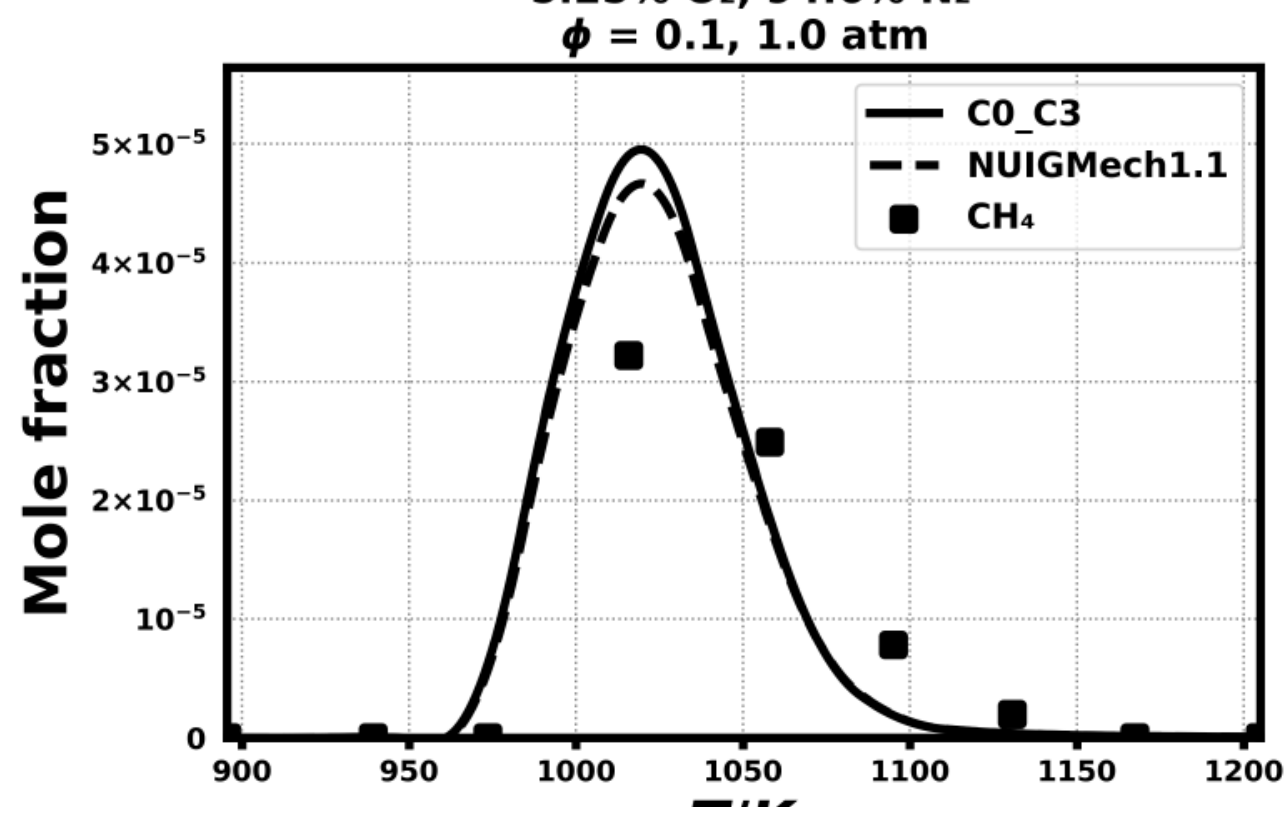

$0.15 \% \mathrm{C}_{2} \mathrm{H}_{6}$

$5.25 \% \mathrm{O}_{2}, 94.6 \% \mathrm{~N}_{2}$

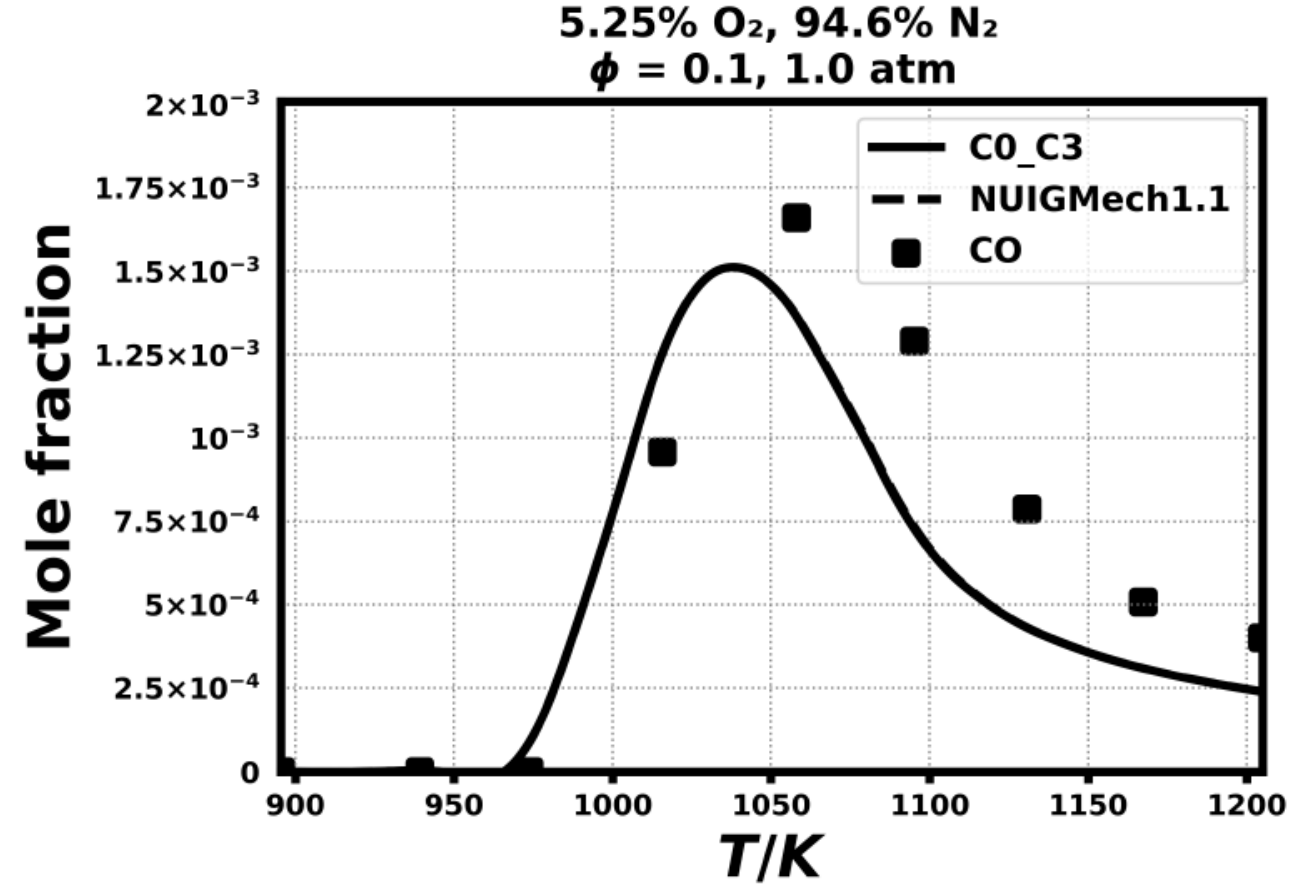



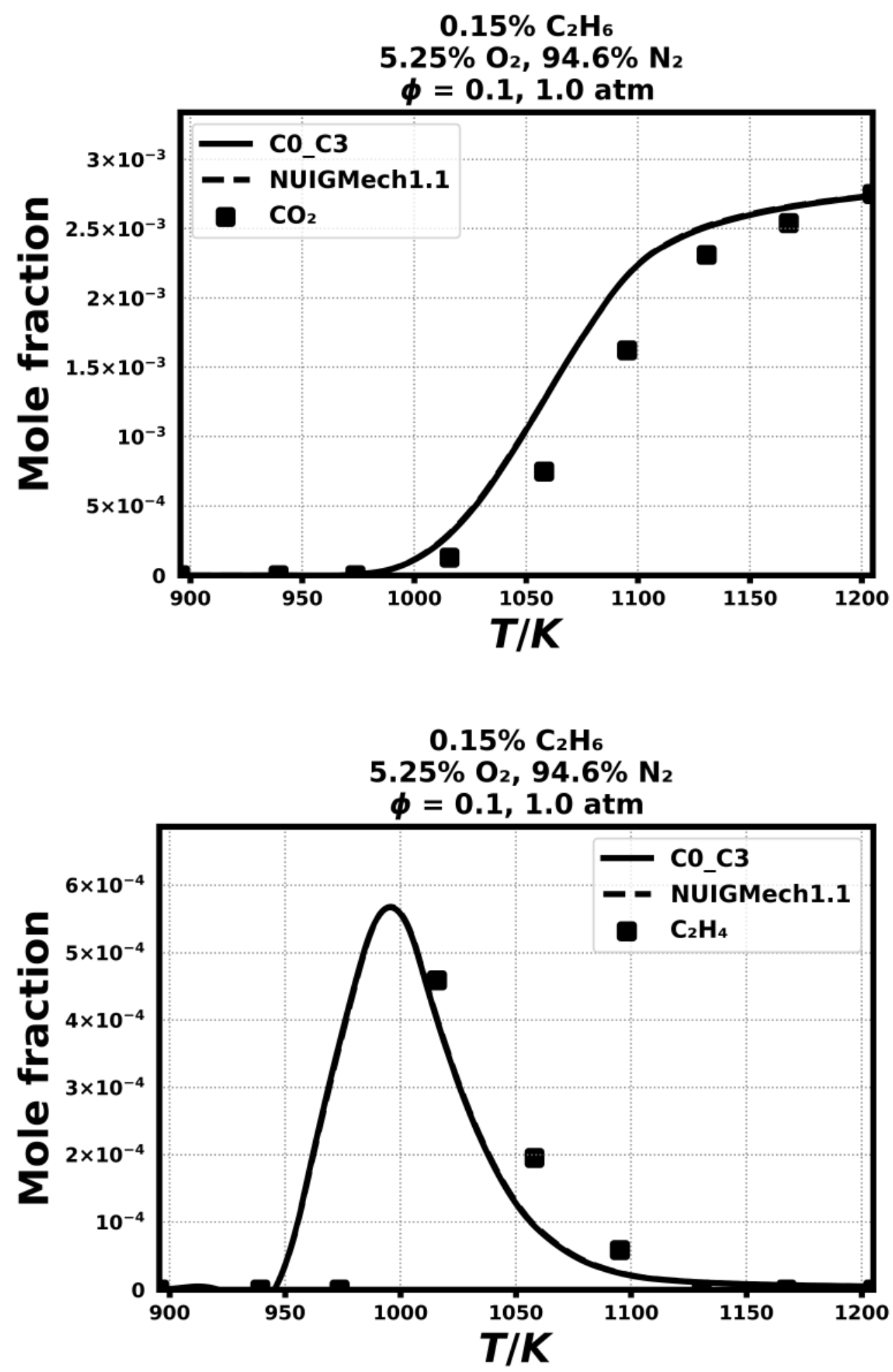

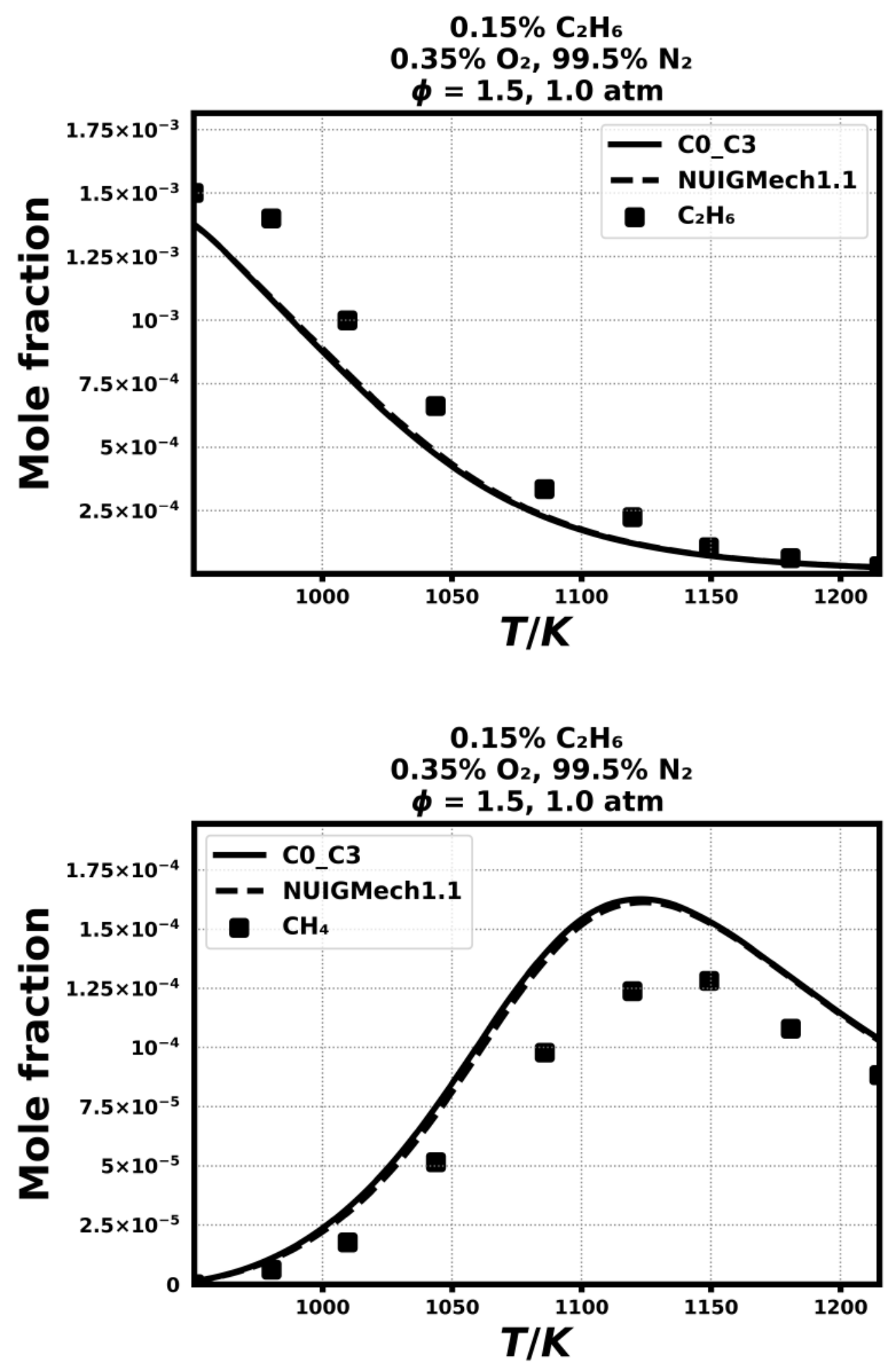

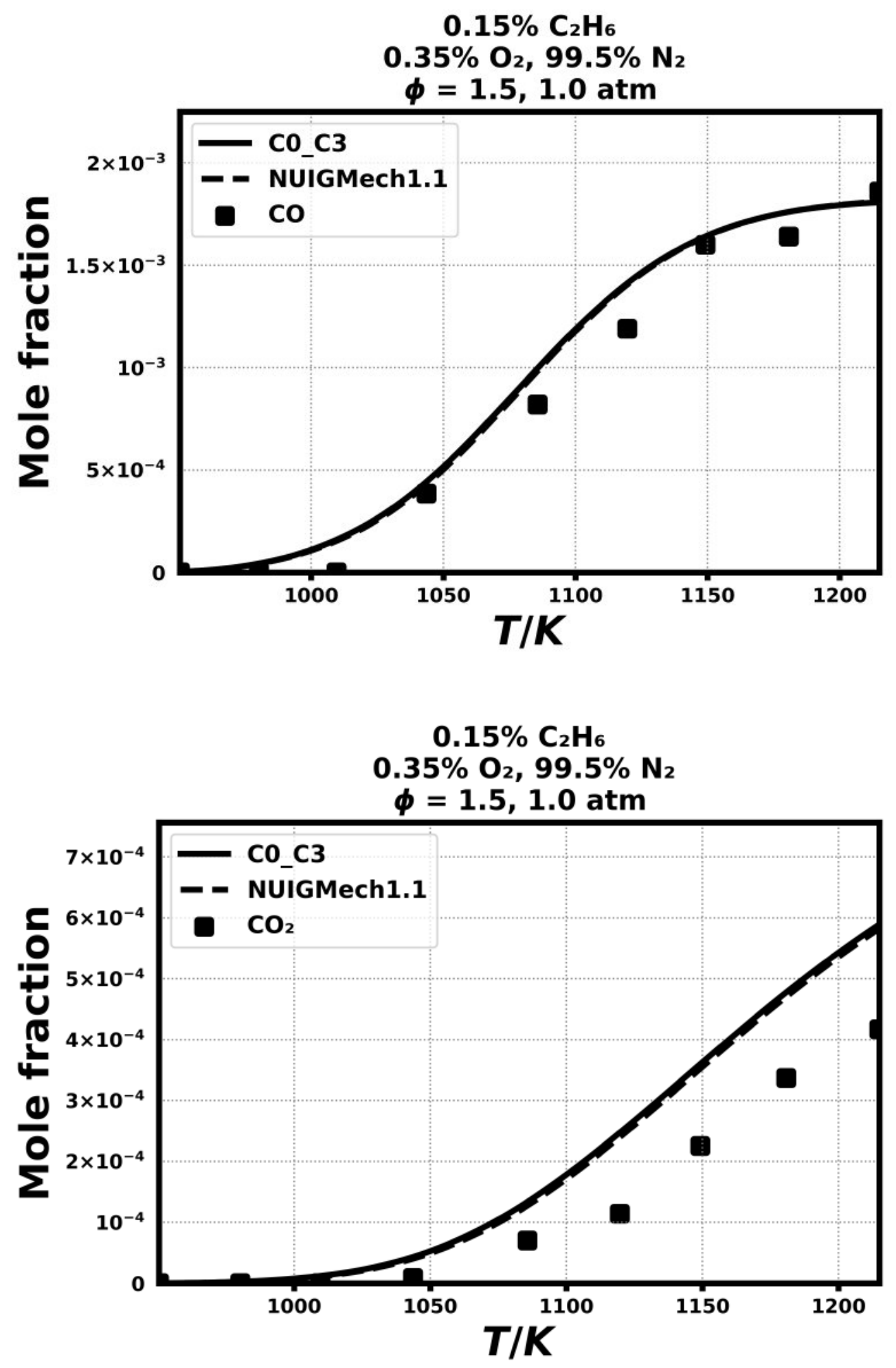

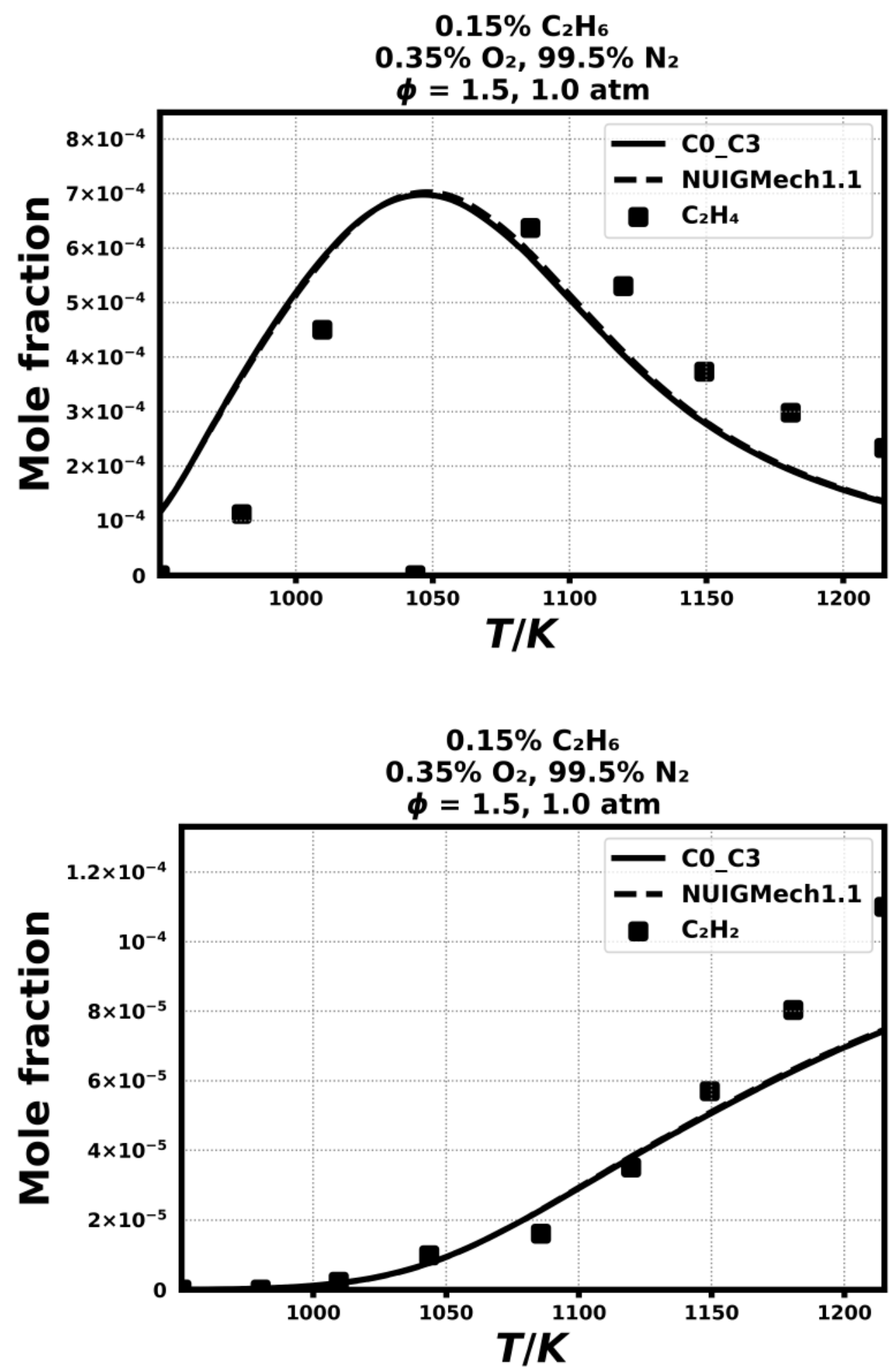


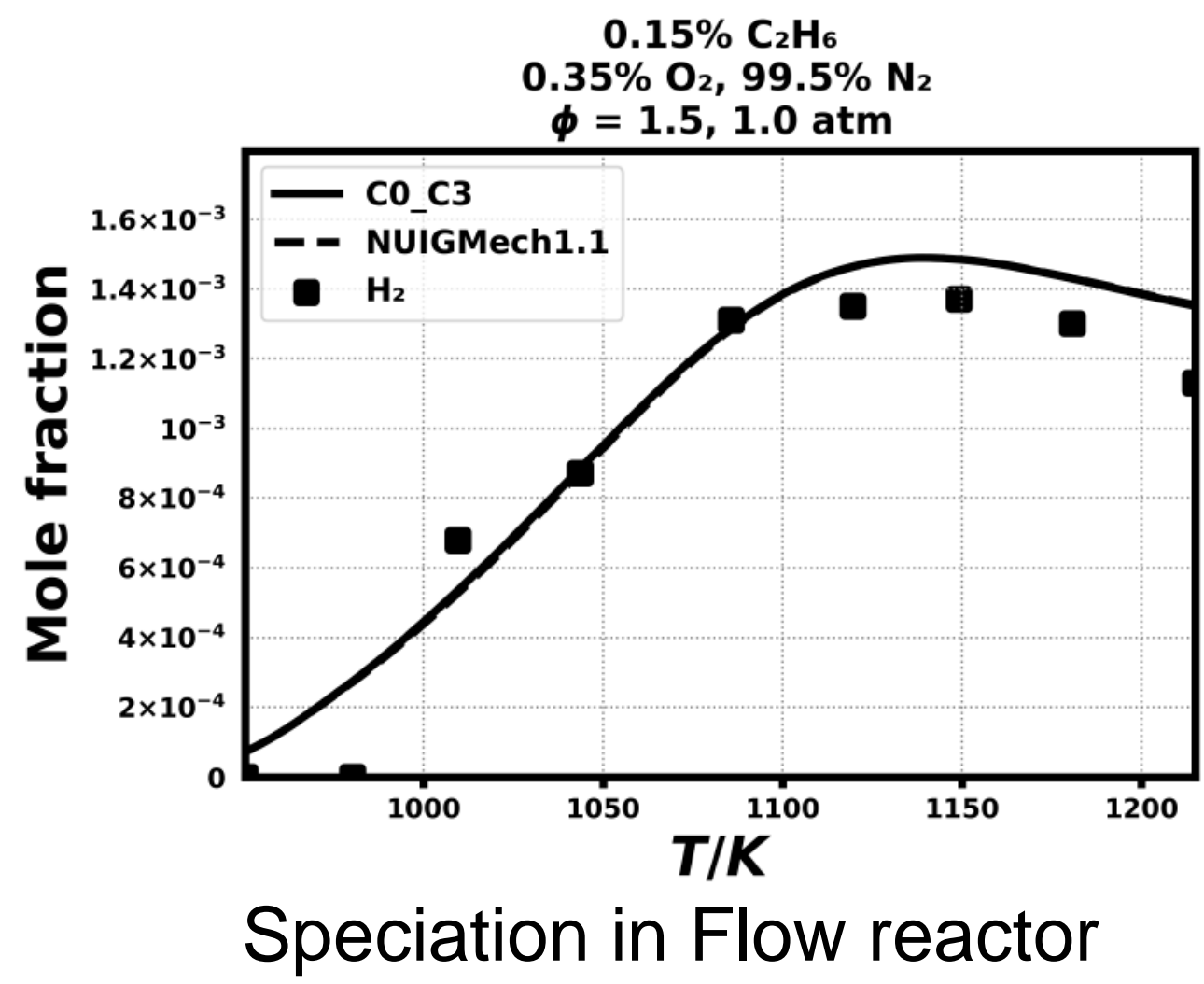

4.8) Hashemi, H., Jacobsen, J. G., Rasmussen, C. T., Christensen, J. M., Glarborg, P., Gersen, S \& Klippenstein, S. J., Combustion and Flame, 182 (2017) 150-166.

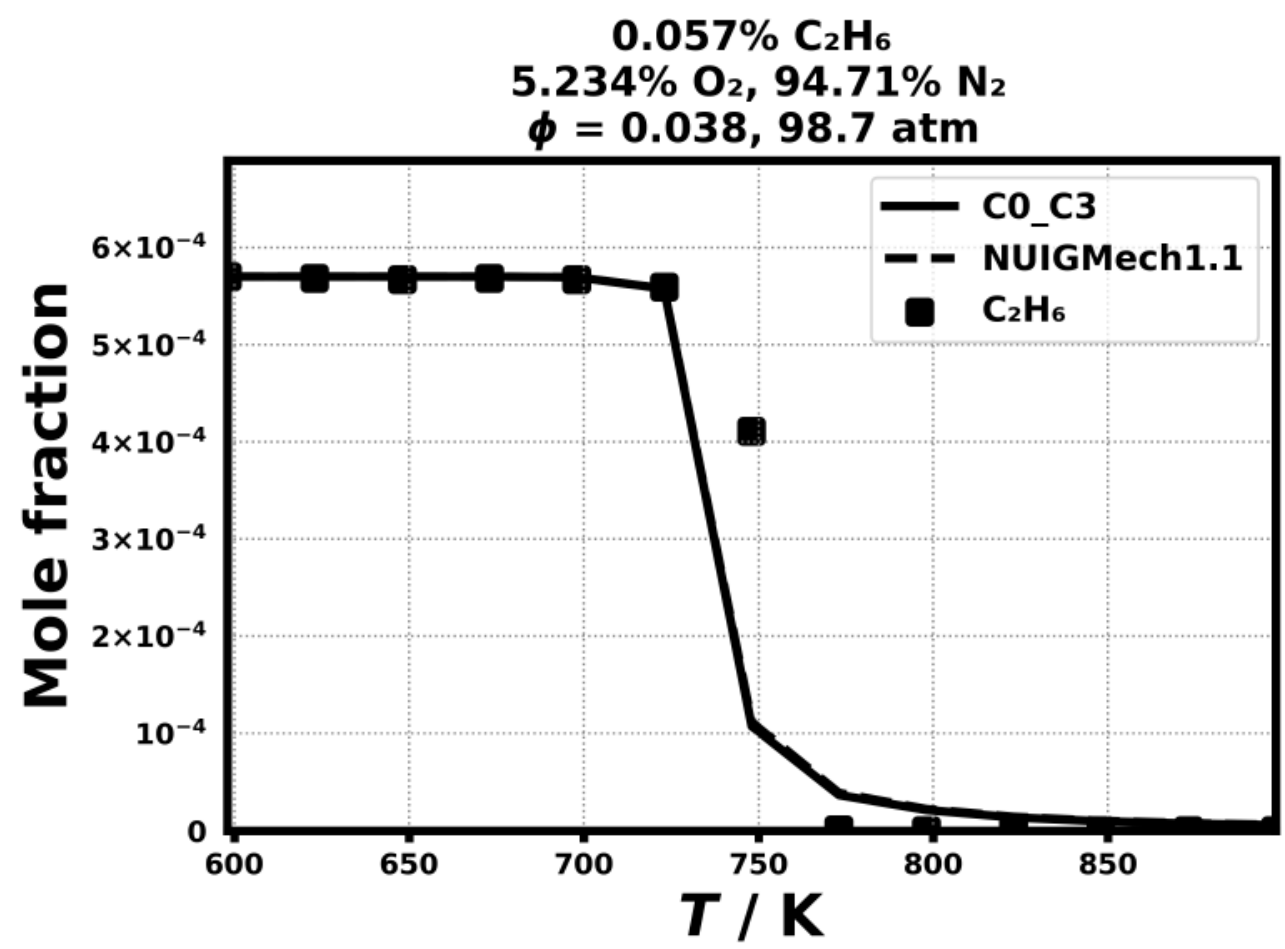



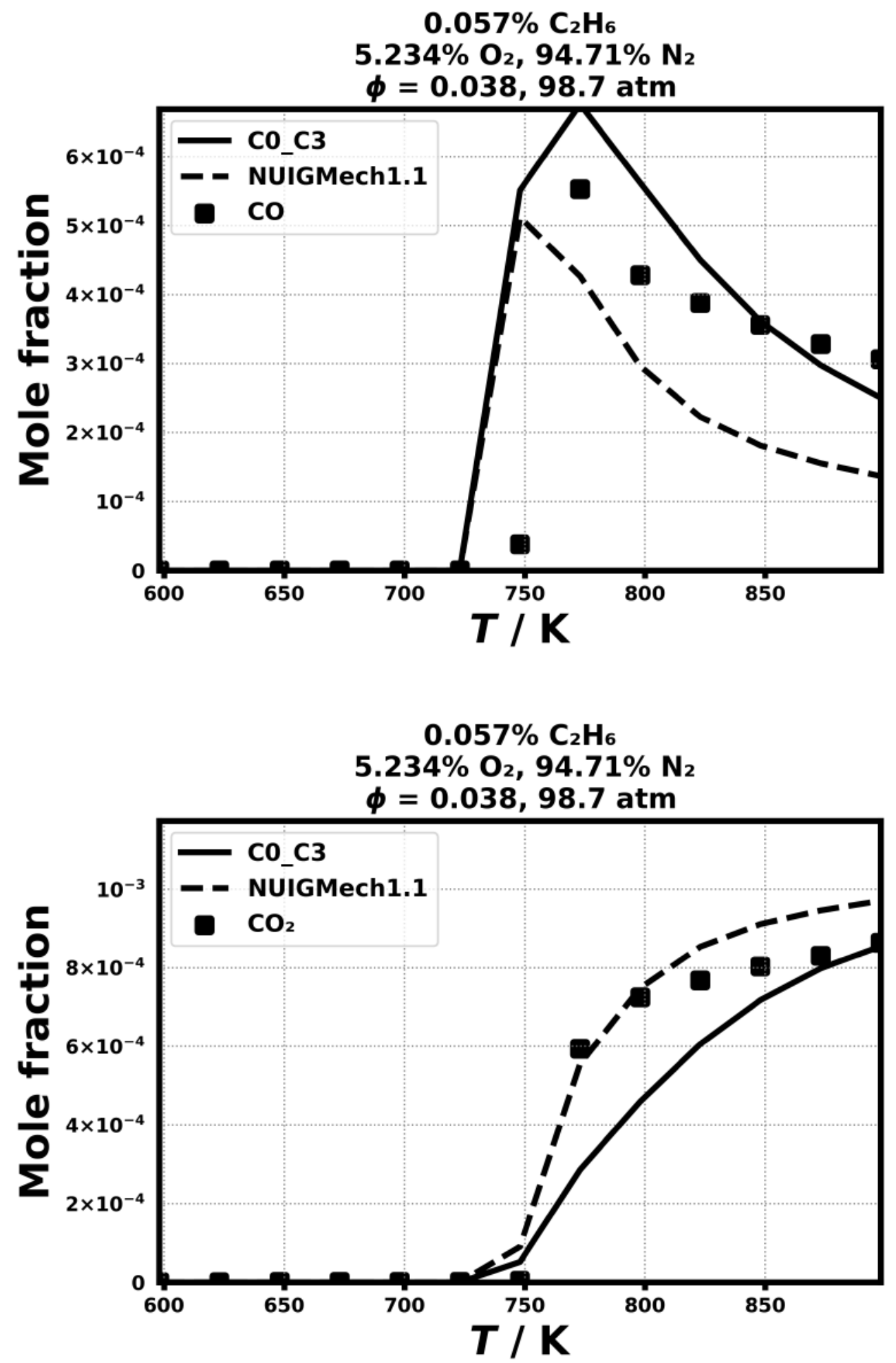

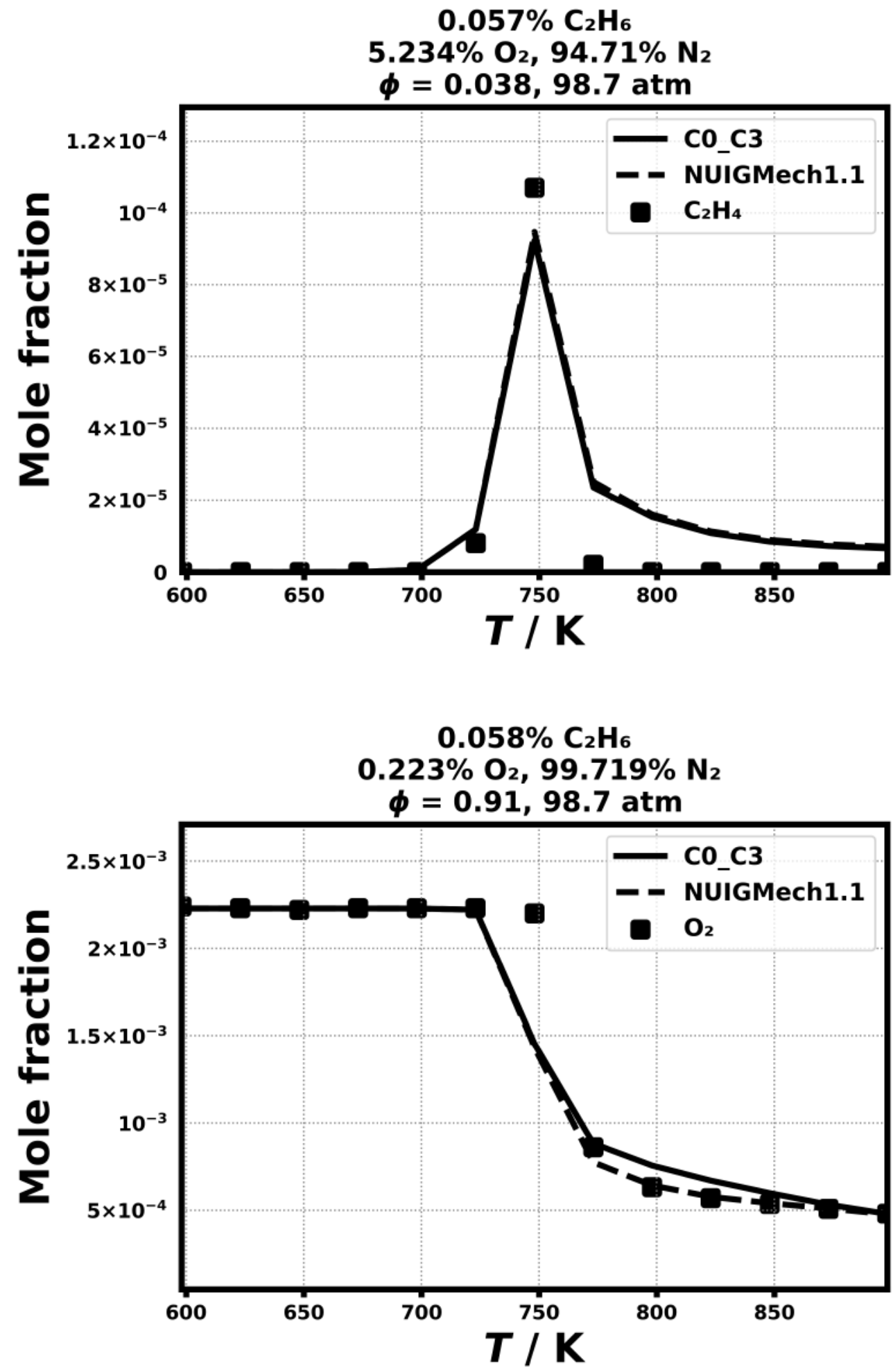

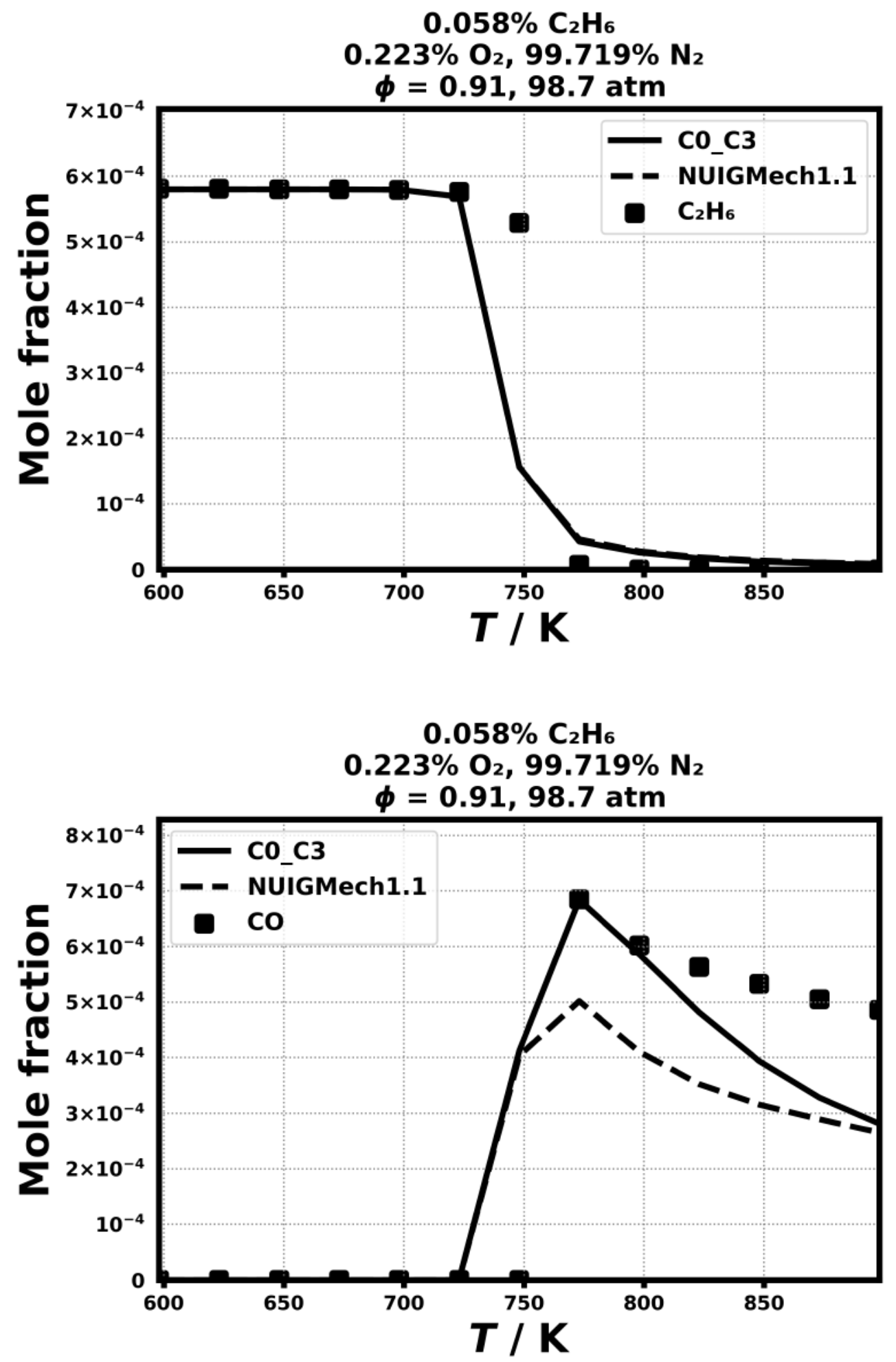

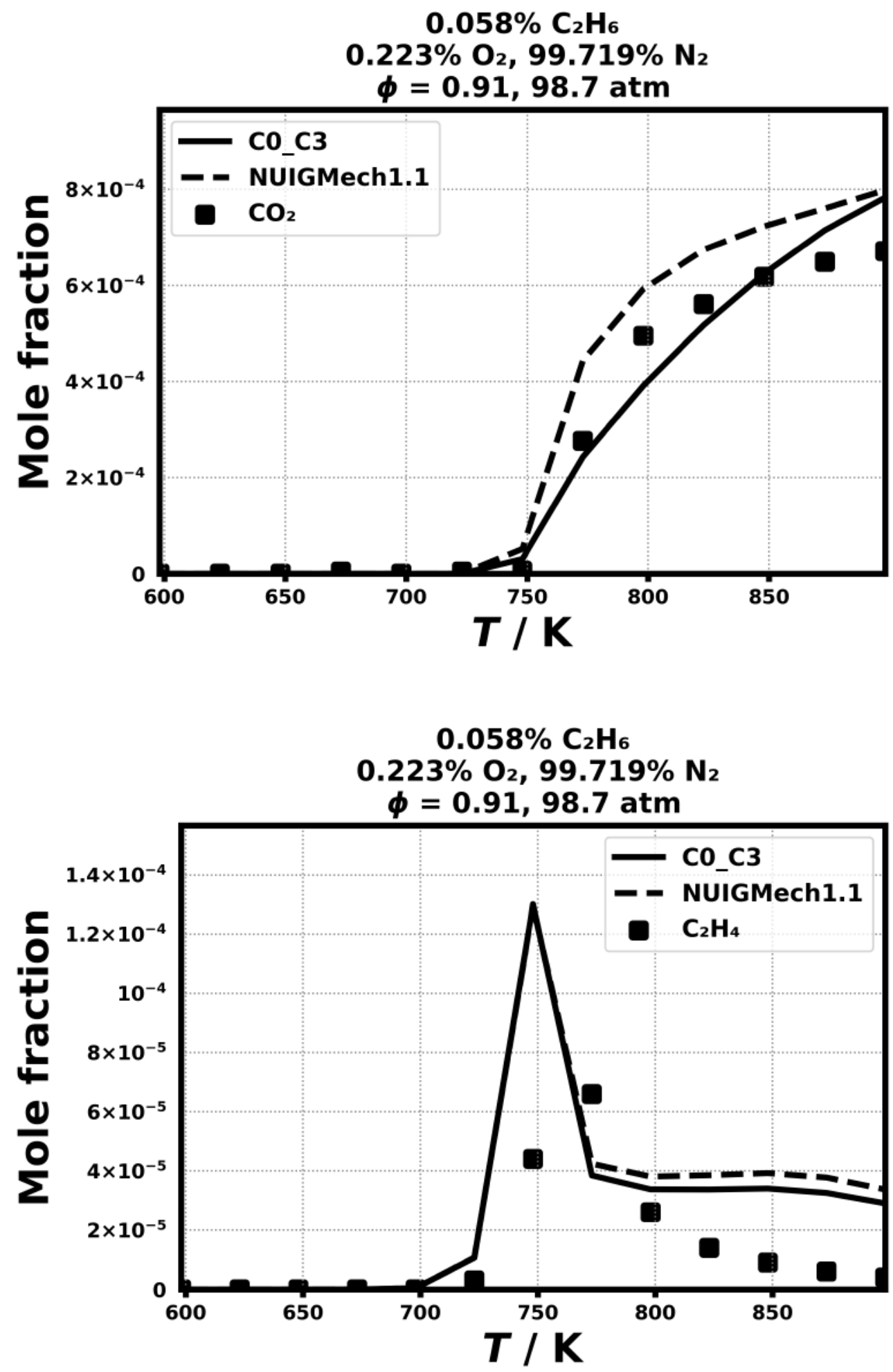

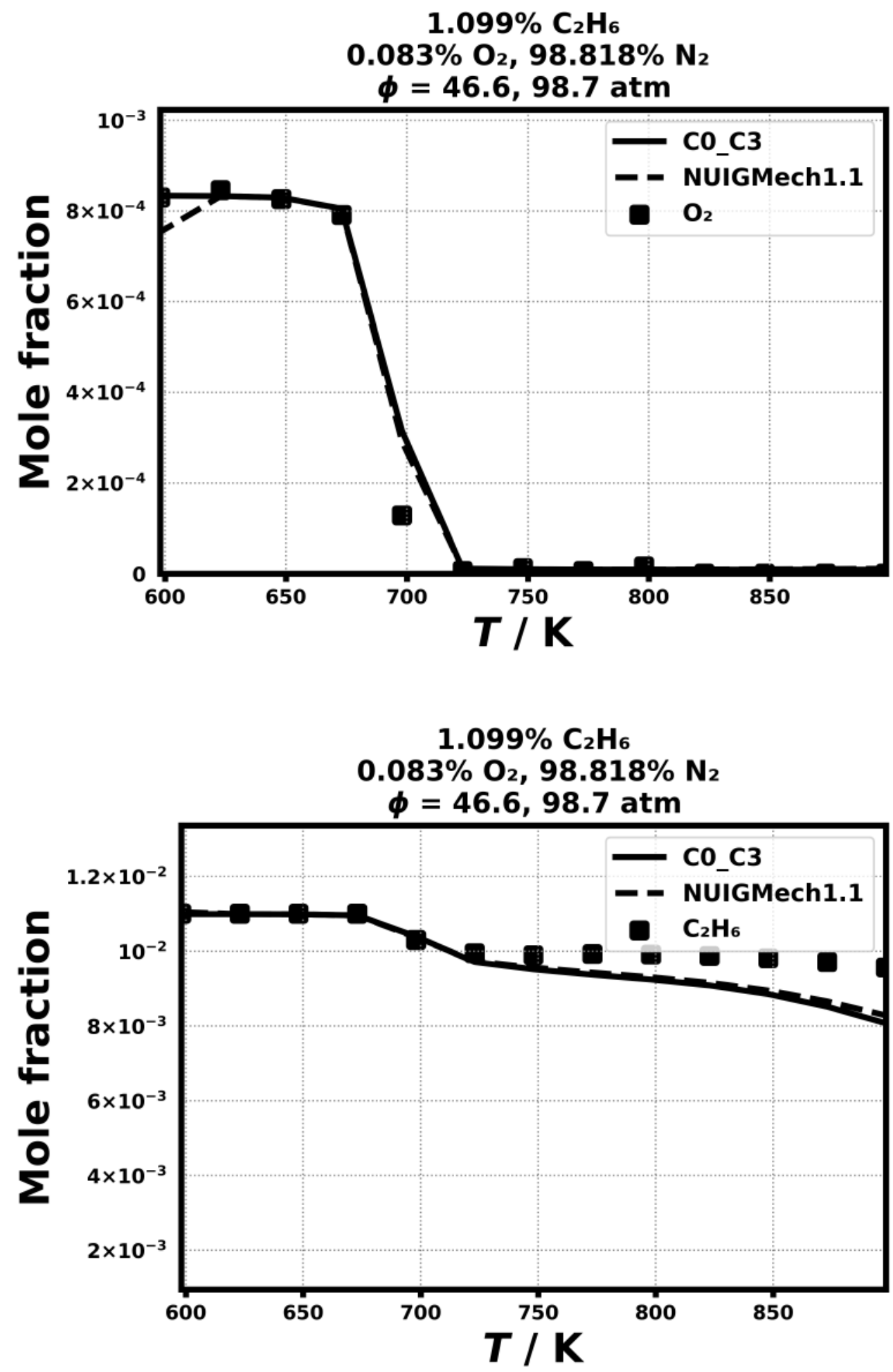

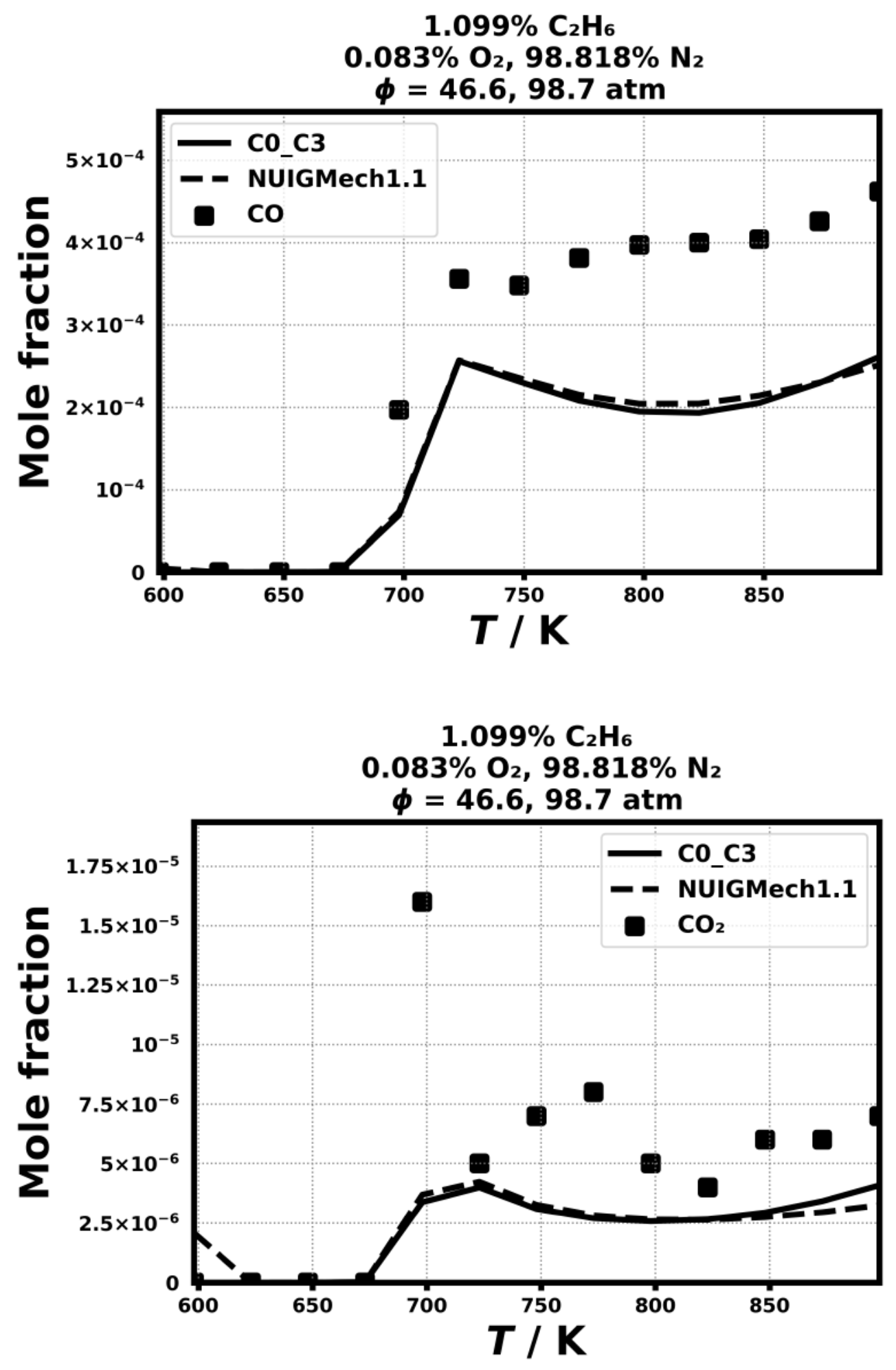

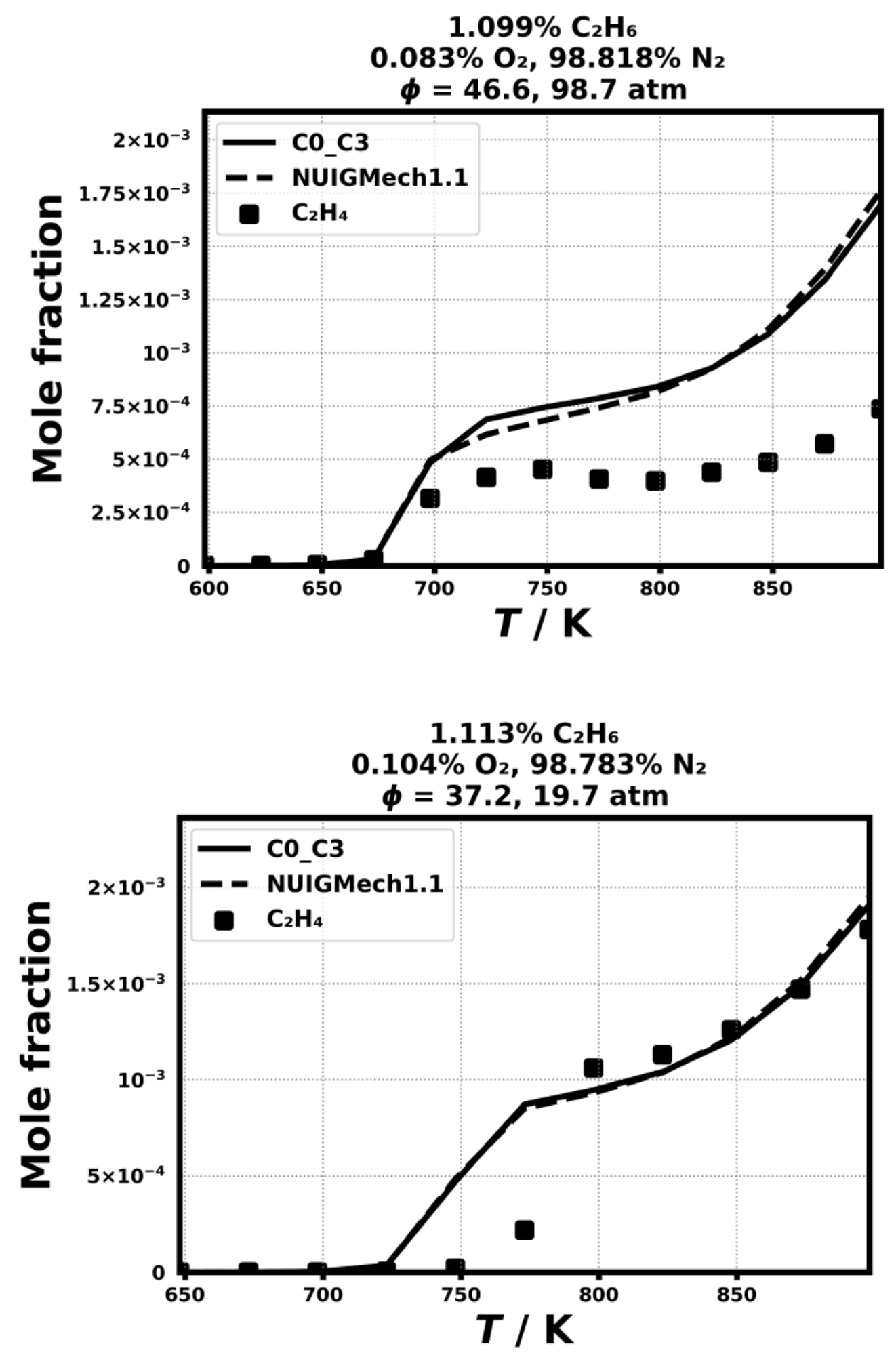

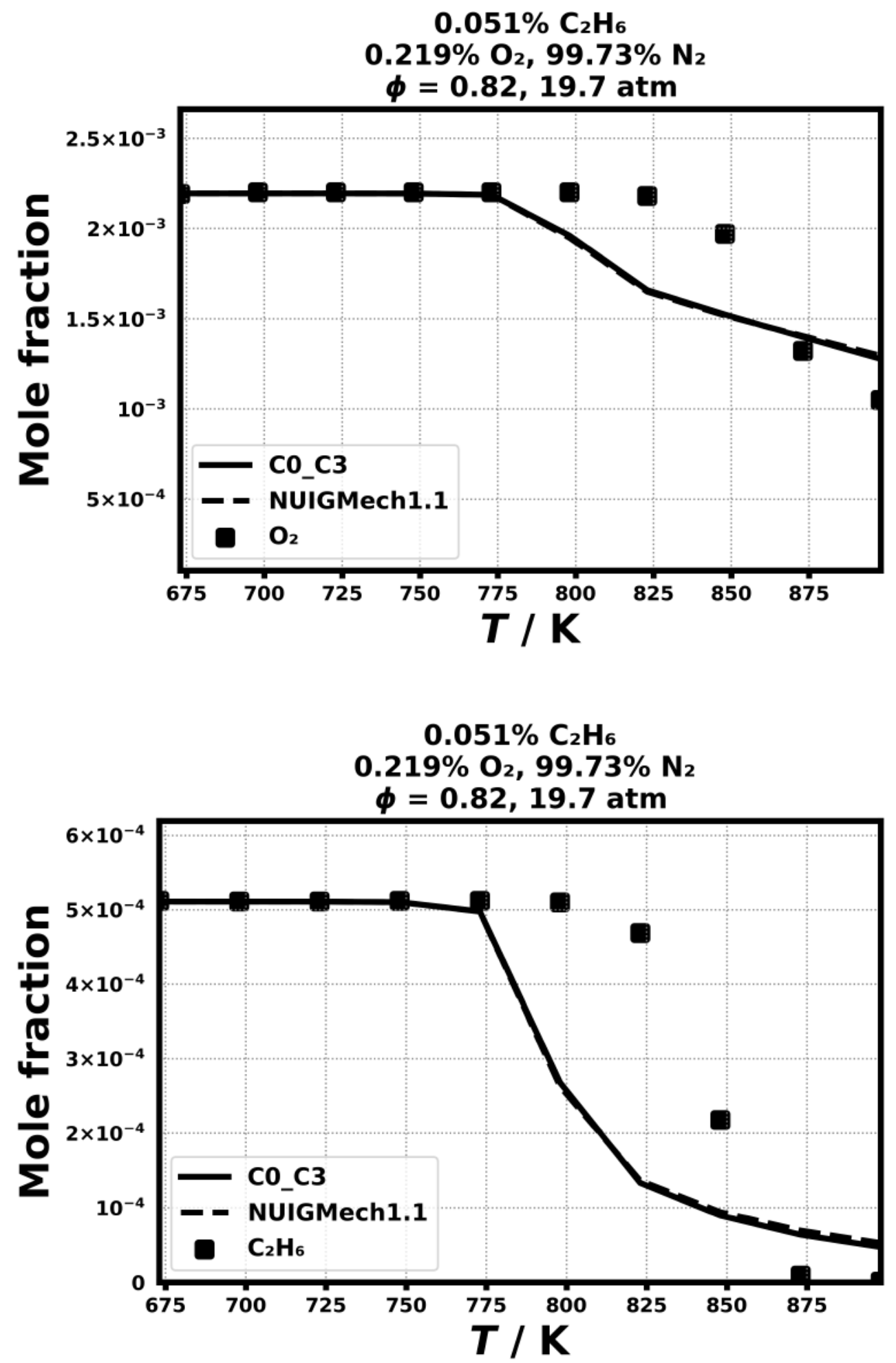

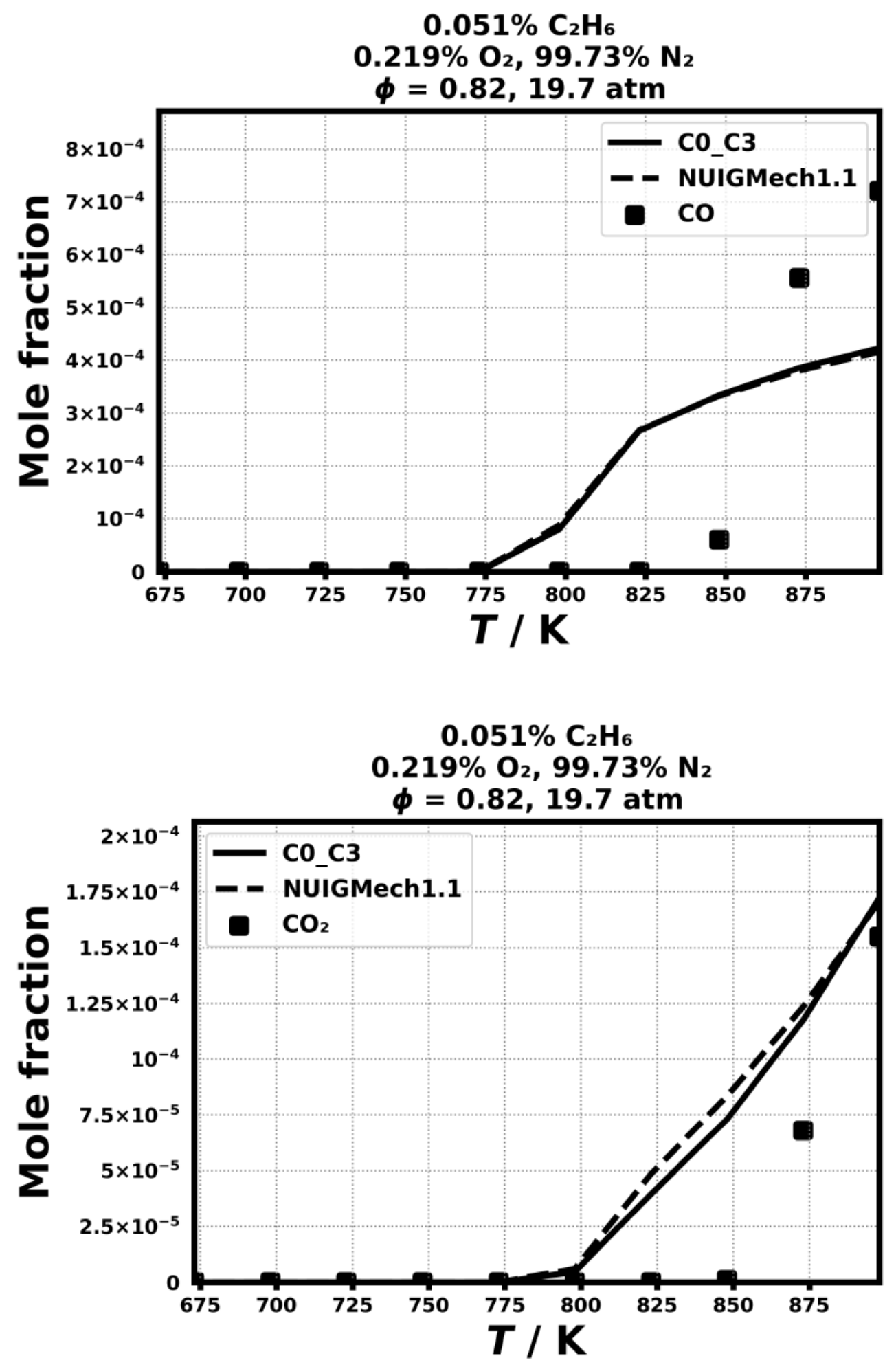

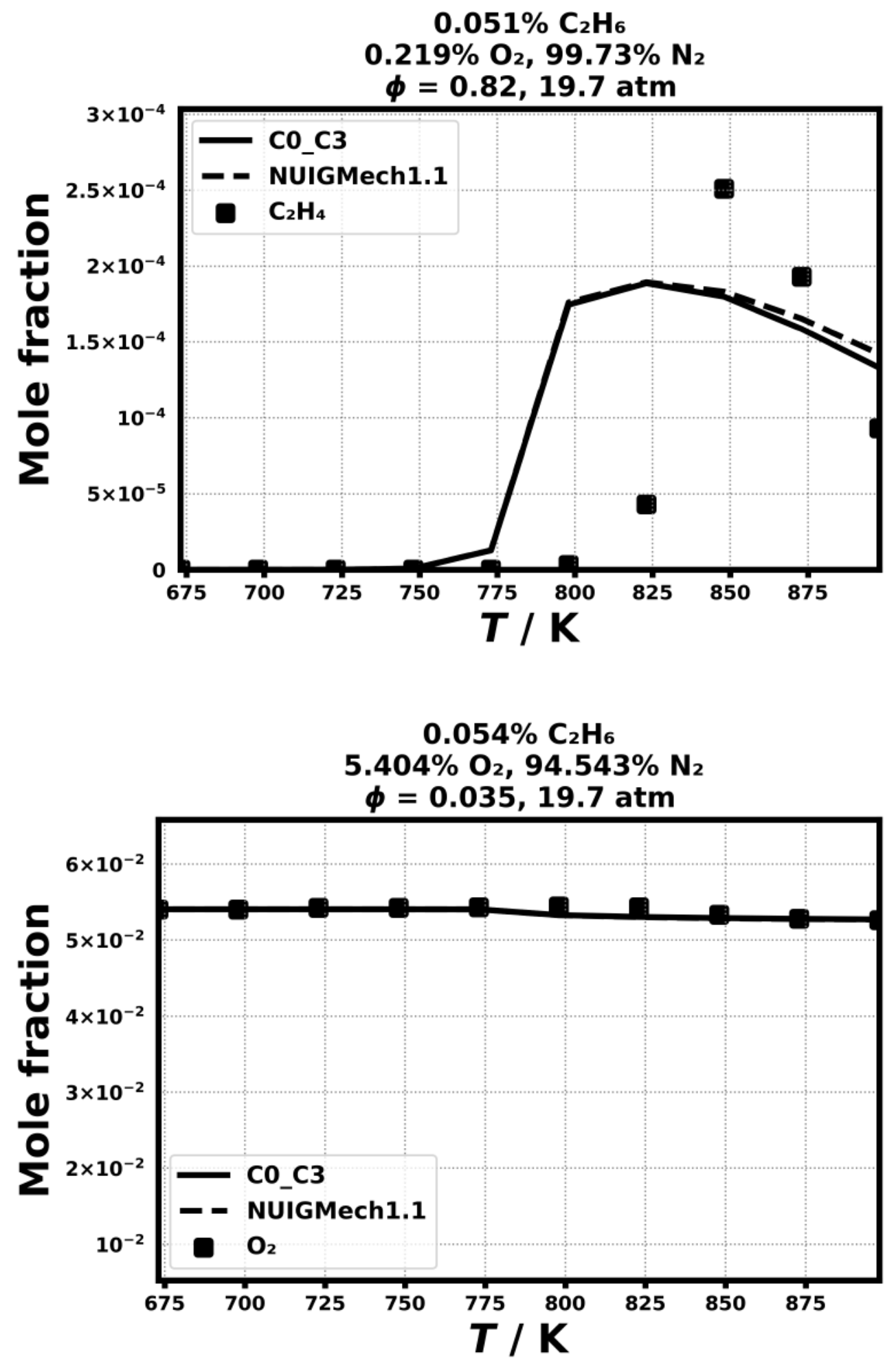

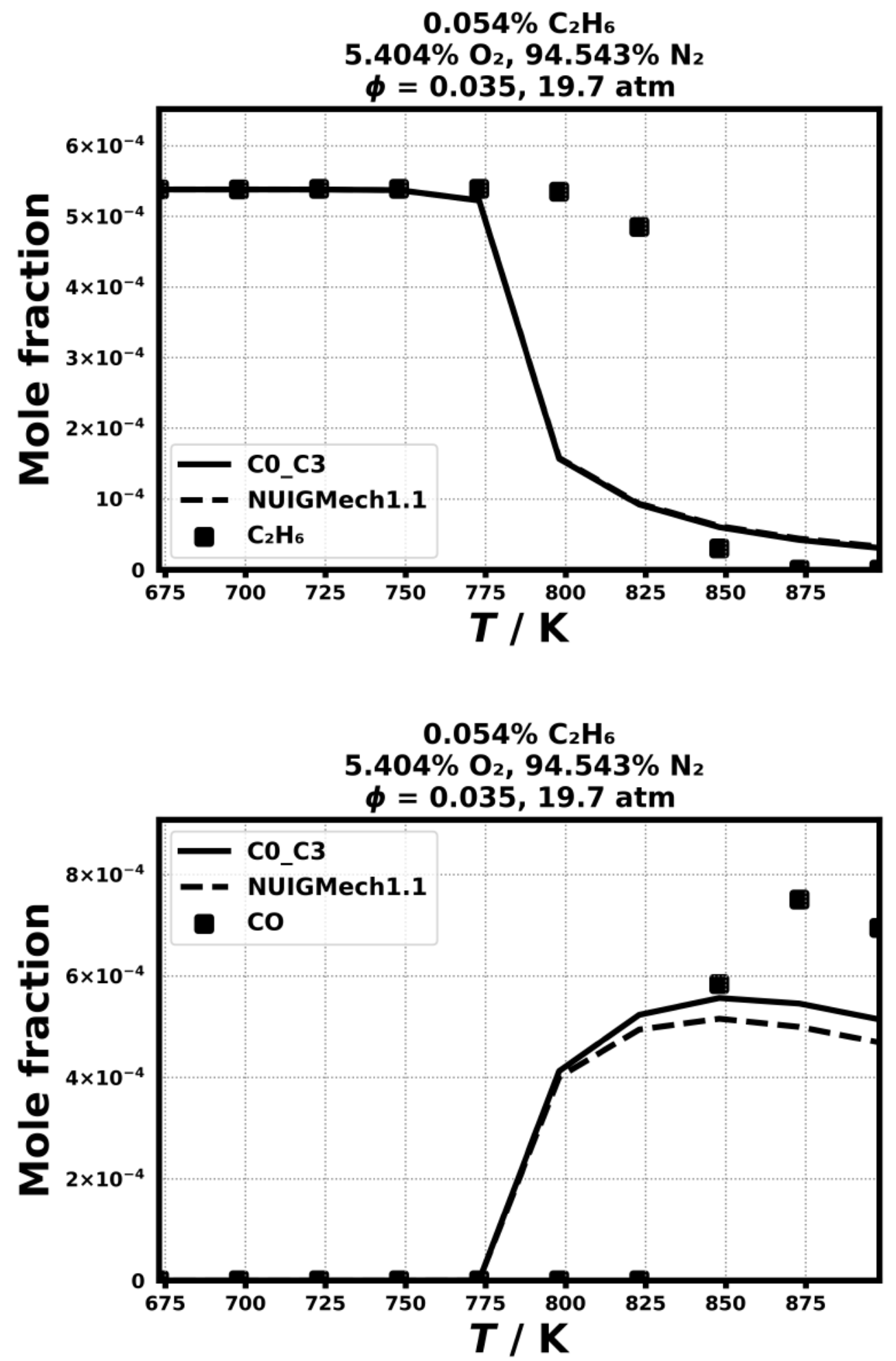

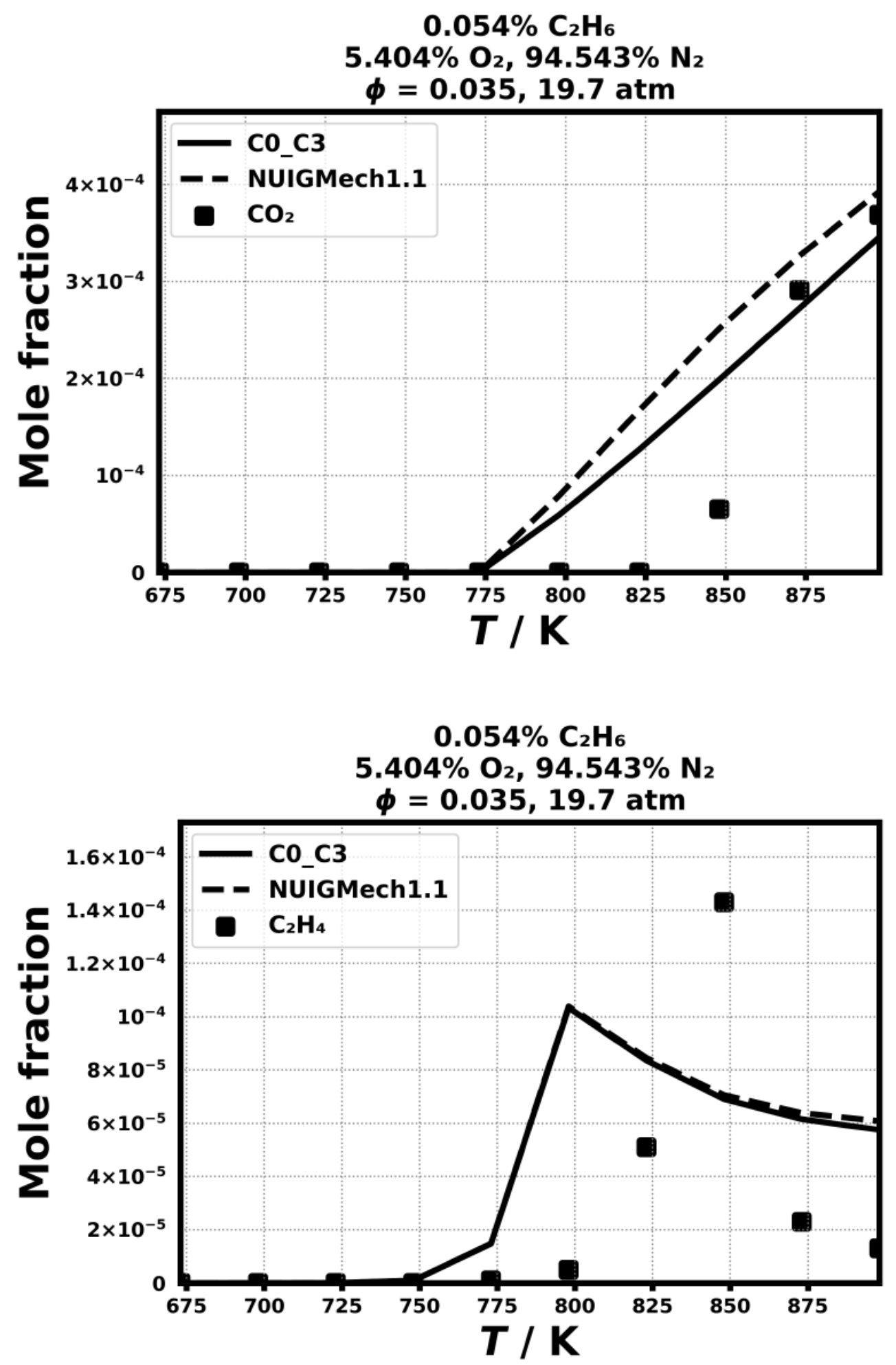

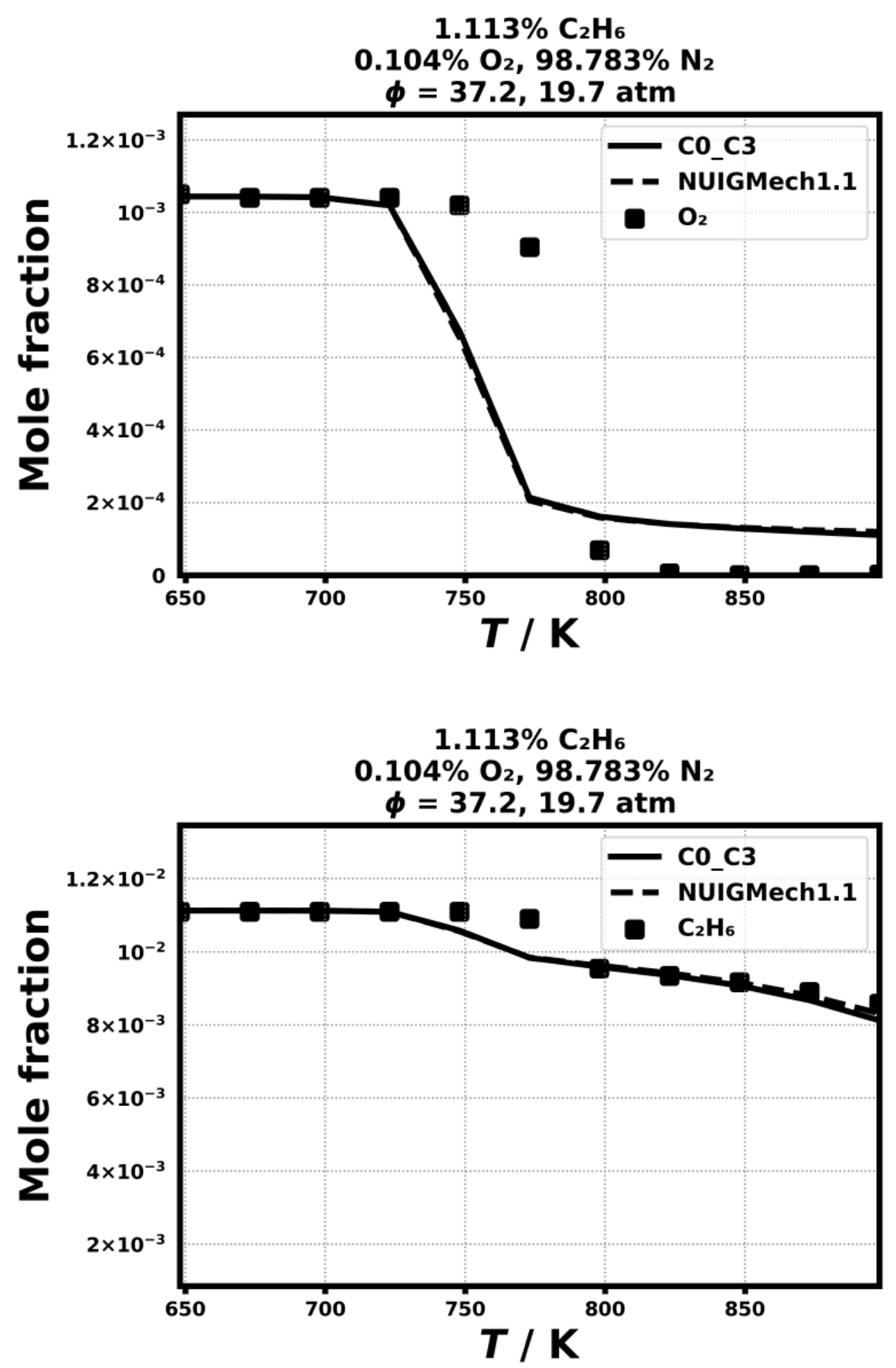

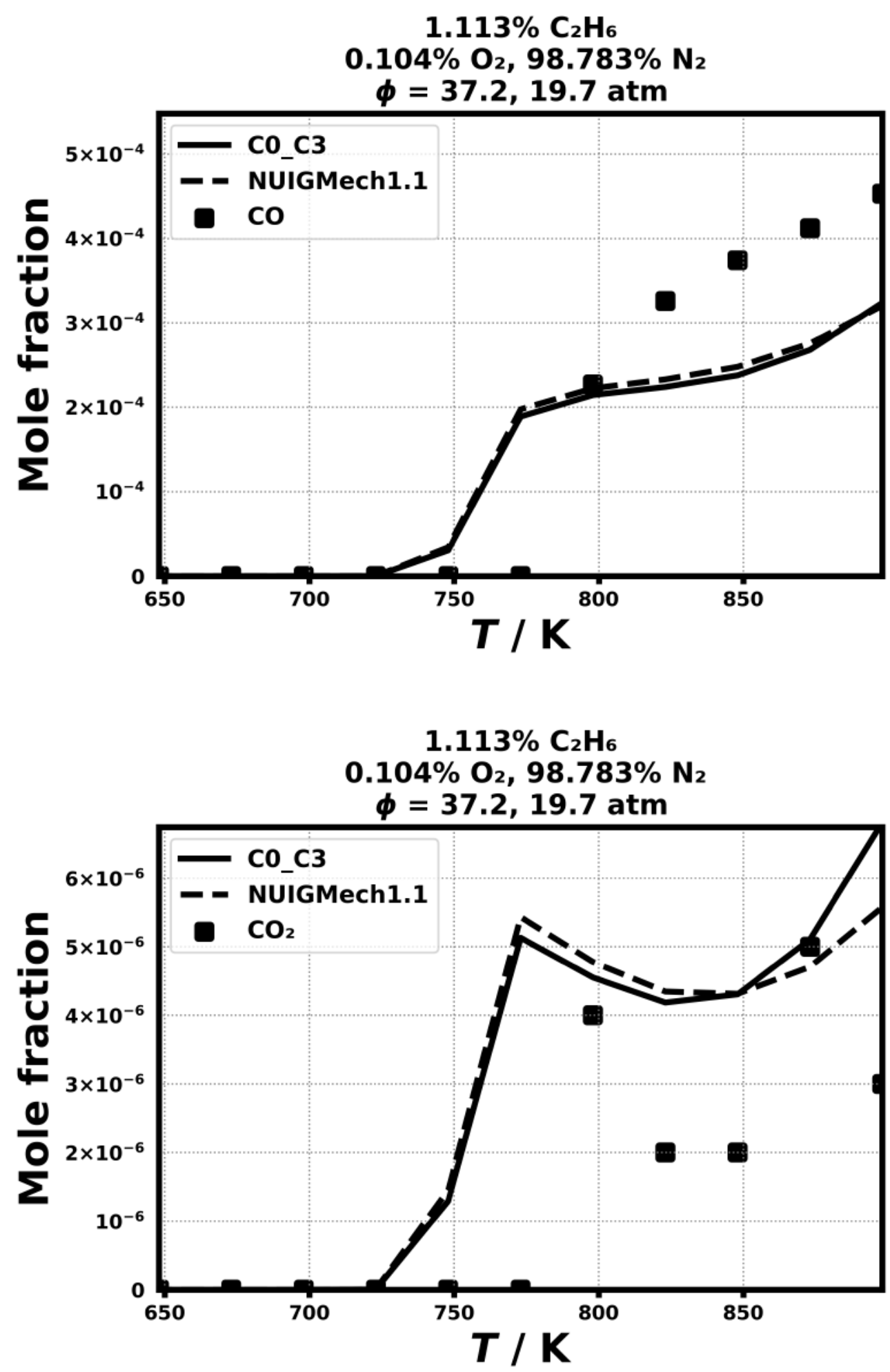

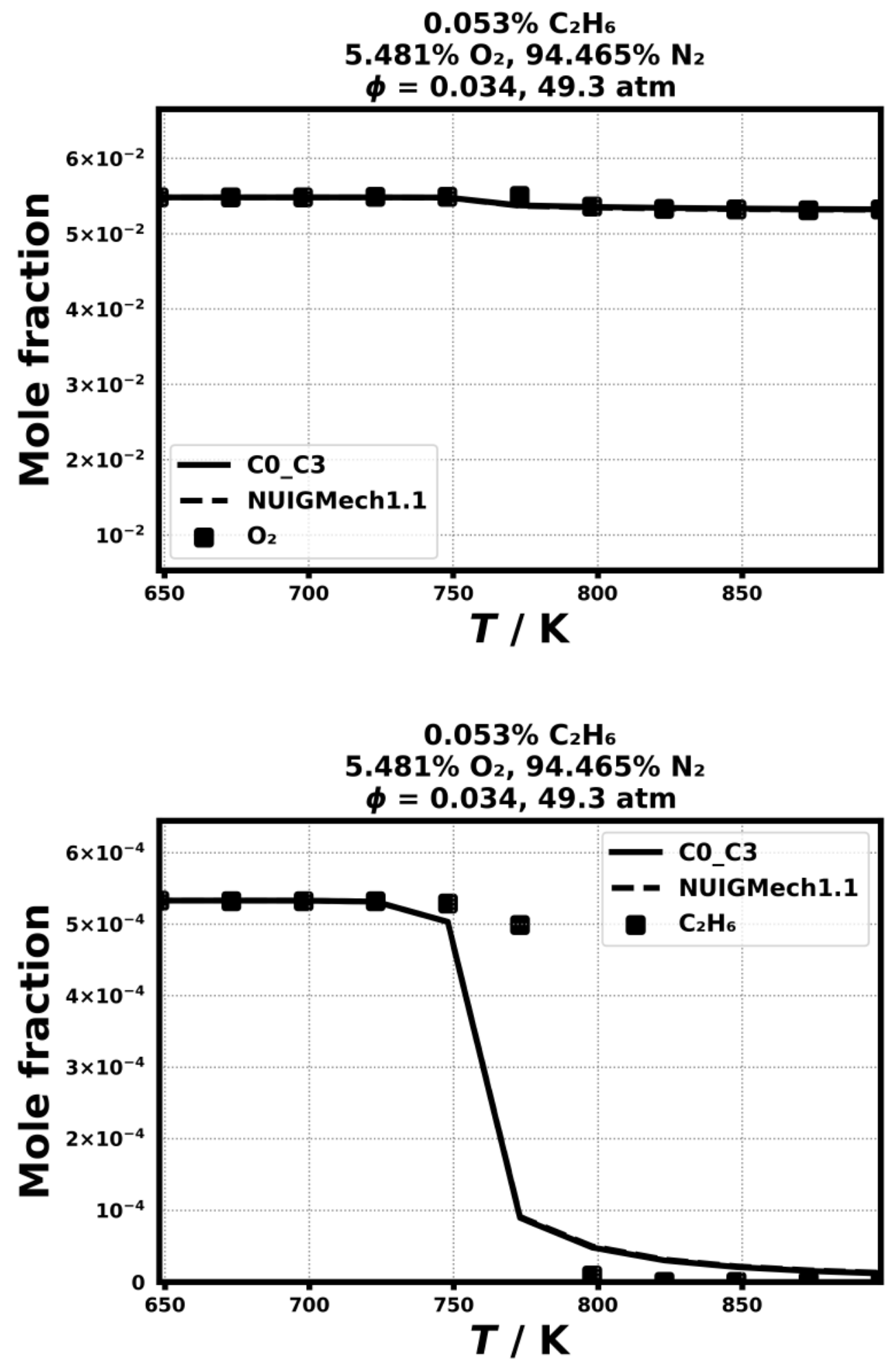

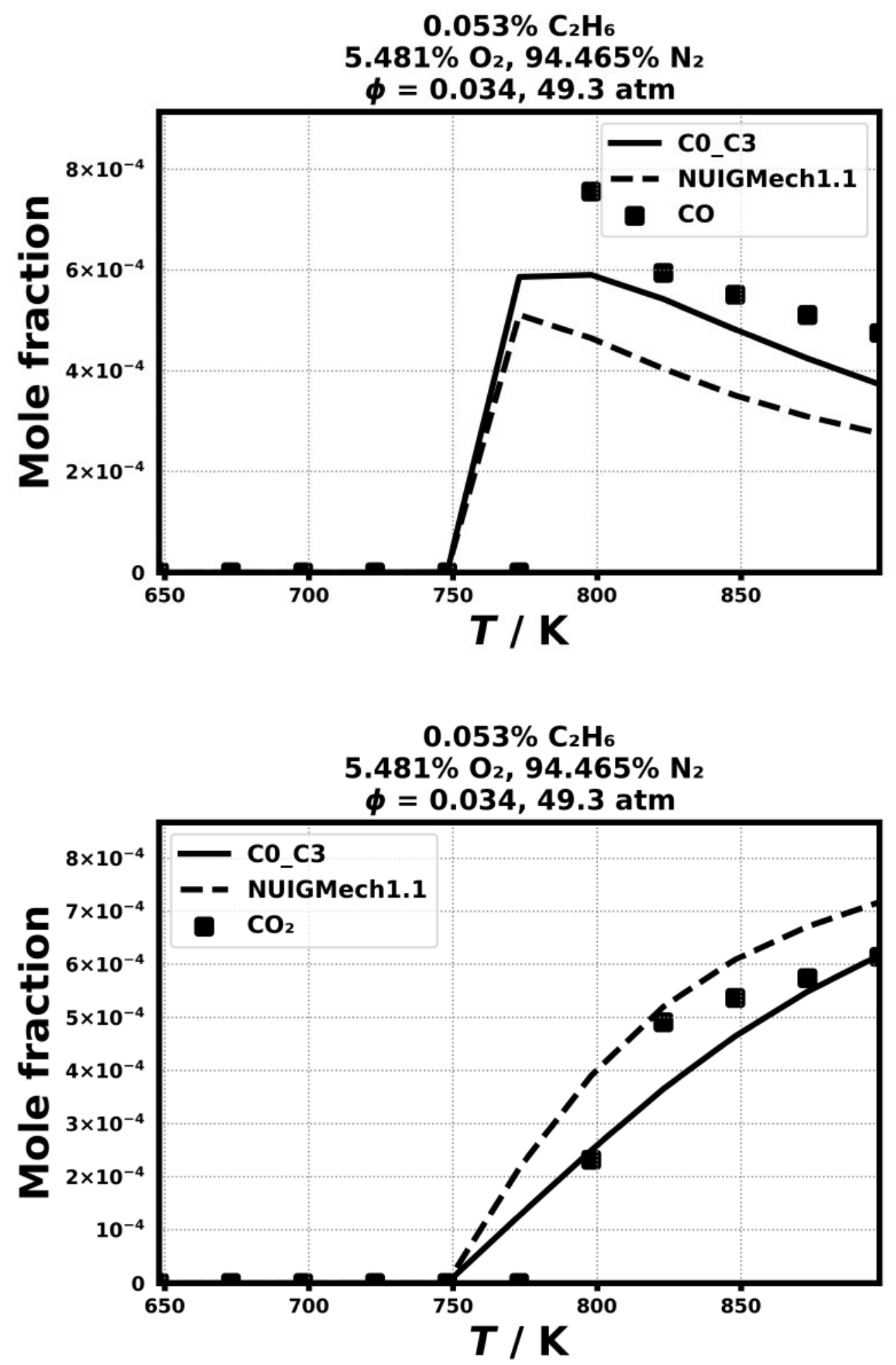

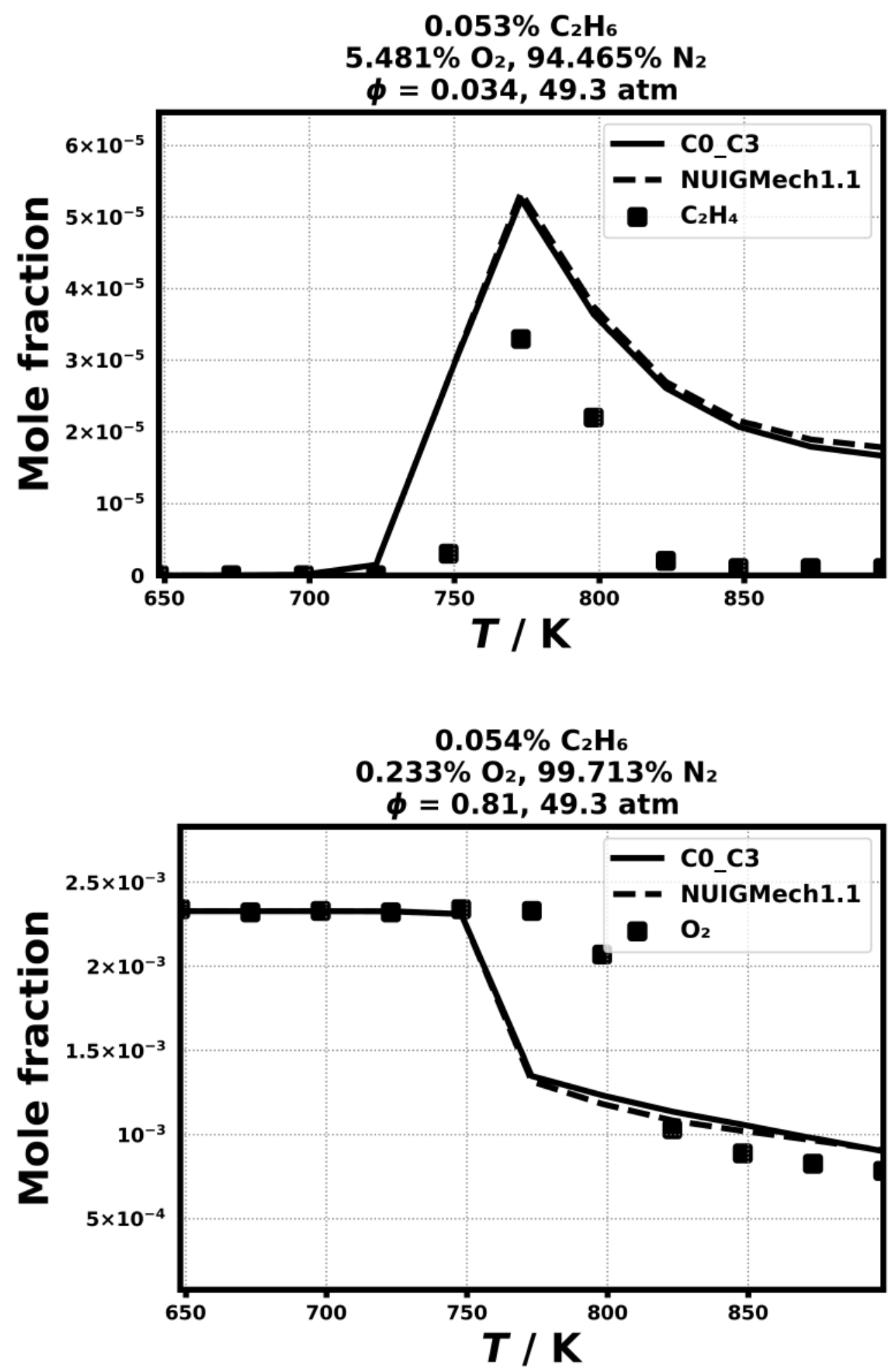

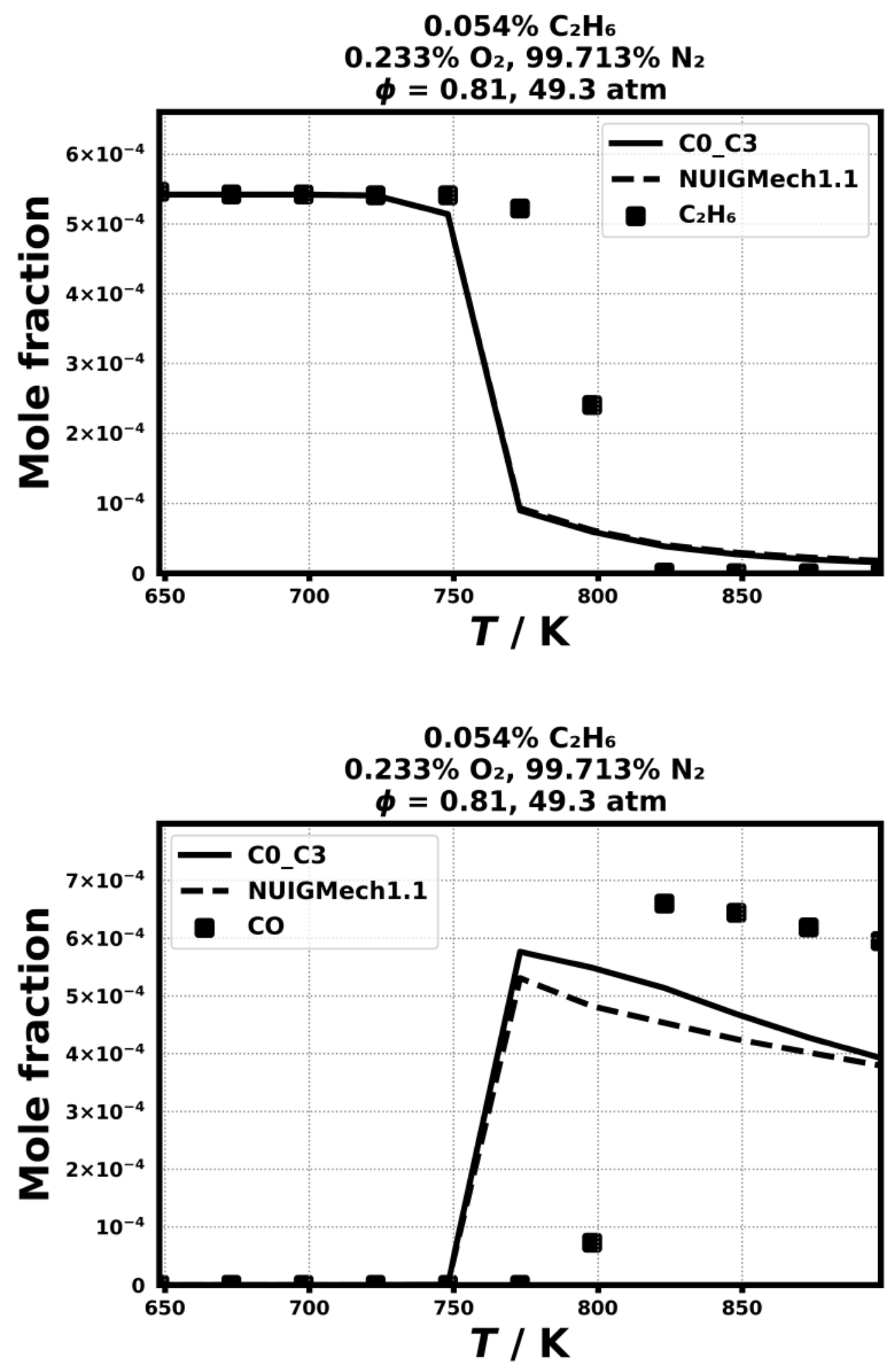

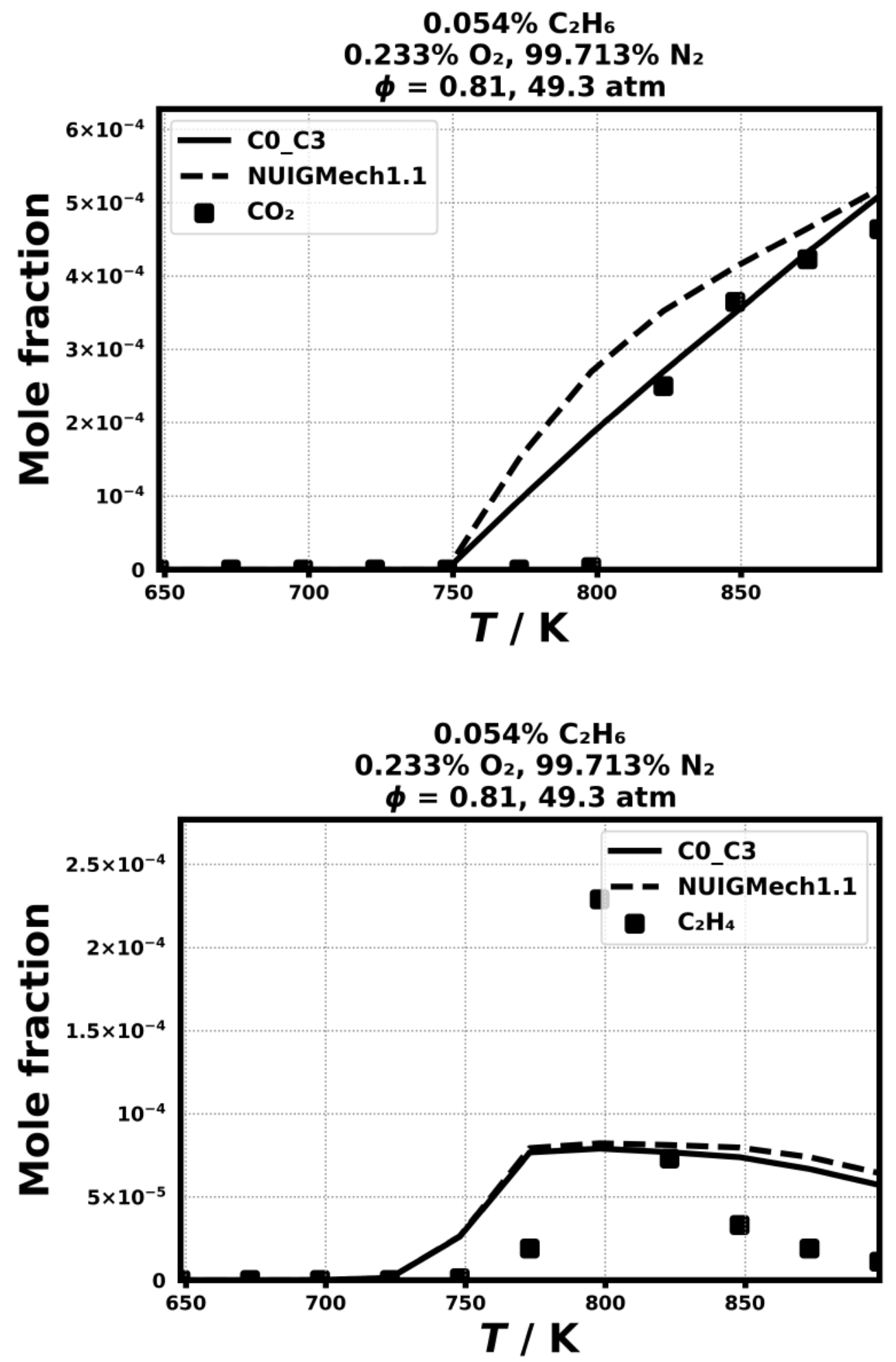

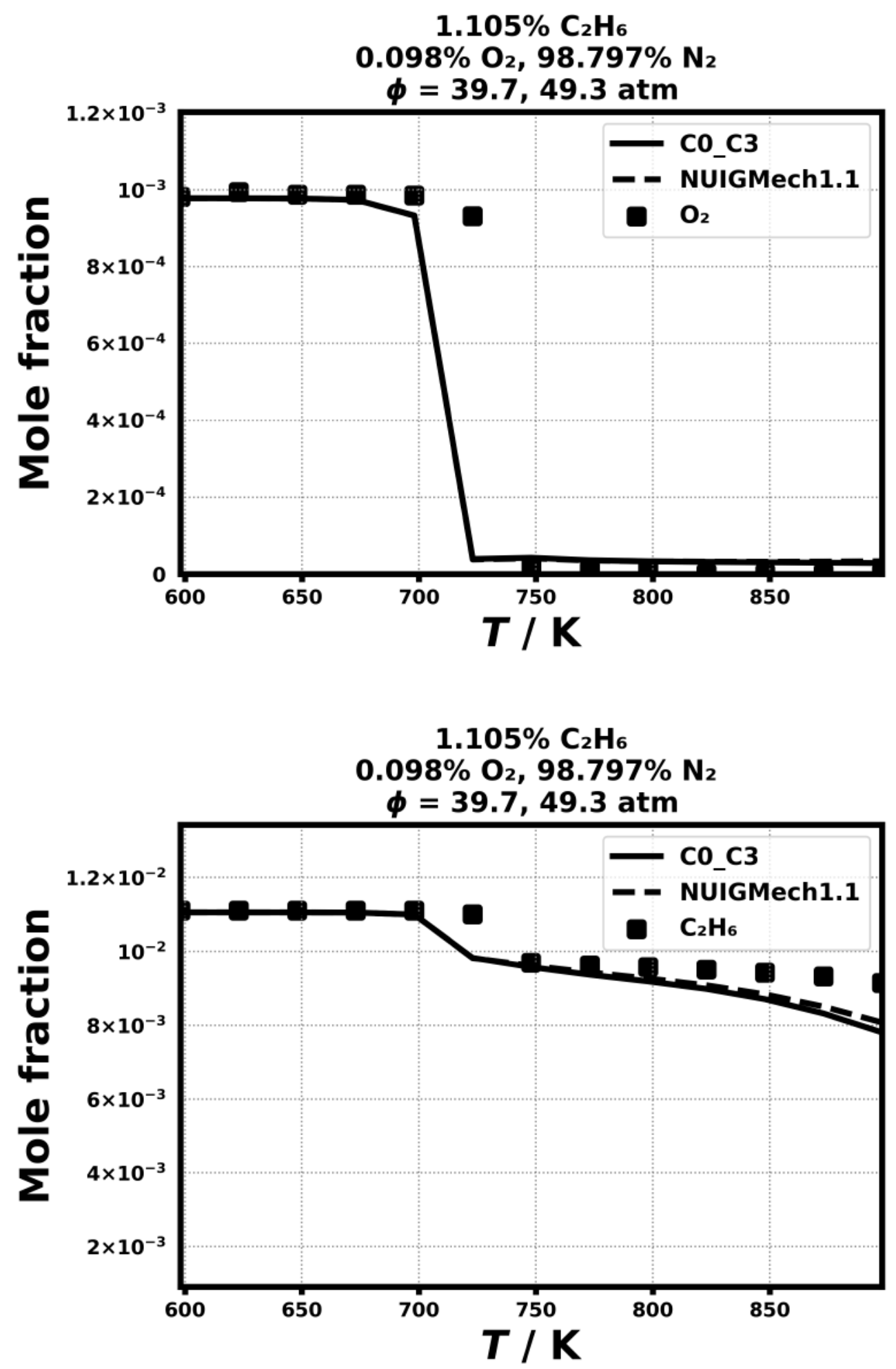

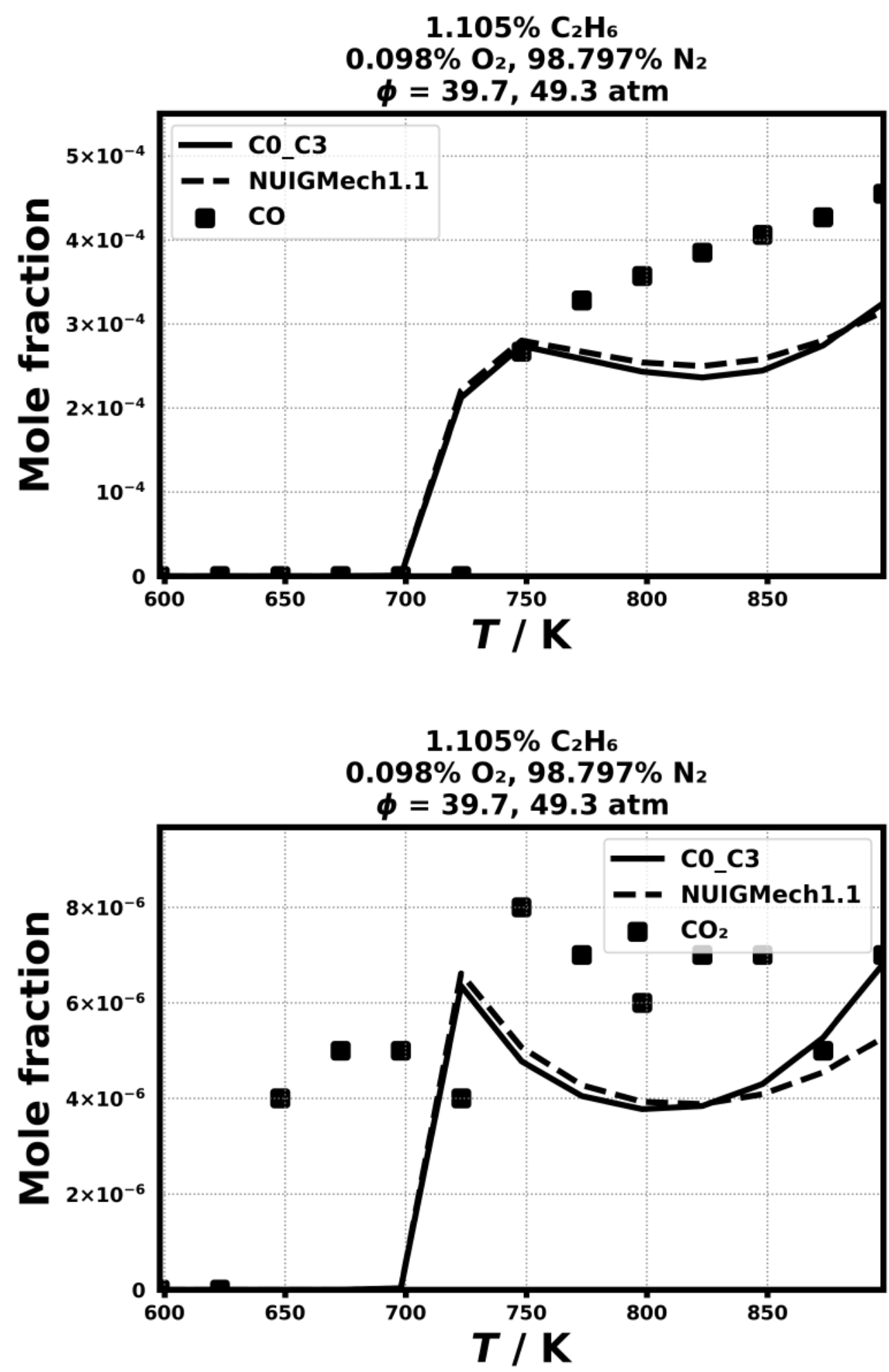

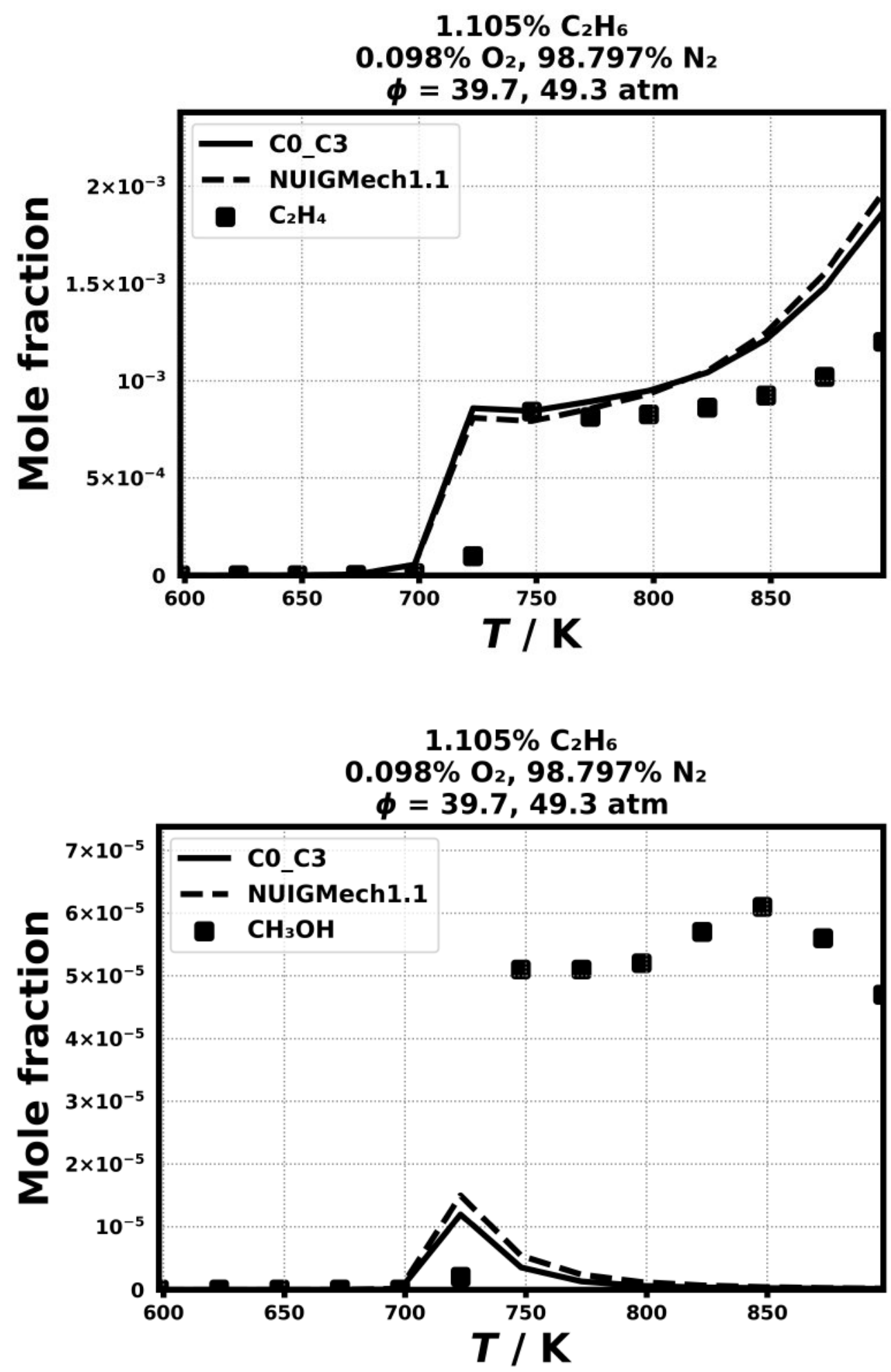


\section{Laminar flame speed}

4.8) F. N. Egolfopoulos, D. L. Zhu, C. K. Law, Proceedings of the Combustion Institute 23 (1990) 471-478.

4.9) K.J. Bosschaart, L.P.H. de Goey, Combustion and Flame 136 (2004) 261-269.

4.10)G. Jomaas, X. L. Zheng, D. L. Zhu, C. K. Law, Proceedings of the Combustion Institute 30 (2005) 193-200.

4.11) C. M. Vagelopoulos, F. N. Egolfopoulos, Proceedings of the Combustion Institute 27 (1998) 513-519.

4.12) Konnov, A. A., Dyakov, I. V., \& De Ruyck, J. Experimental thermal and fluid science, 27(4) (2003)

379-384.

4.13) Kochar, Y., Seitzman, J., Lieuwen, T., Metcalfe, W., Burke, S. A., Curran, H., \& Bourque, G, In Turbo Expo: Power for Land, Sea, and Air, 54624 (2011, January) 129-140.

4.14) Lowry, W., de Vries, J., Krejci, M., Petersen, E., Serinyel, Z., Metcalfe, W., ... \& Bourque, G., Journal of

Engineering for Gas Turbines and Power, 133(9) (2011).

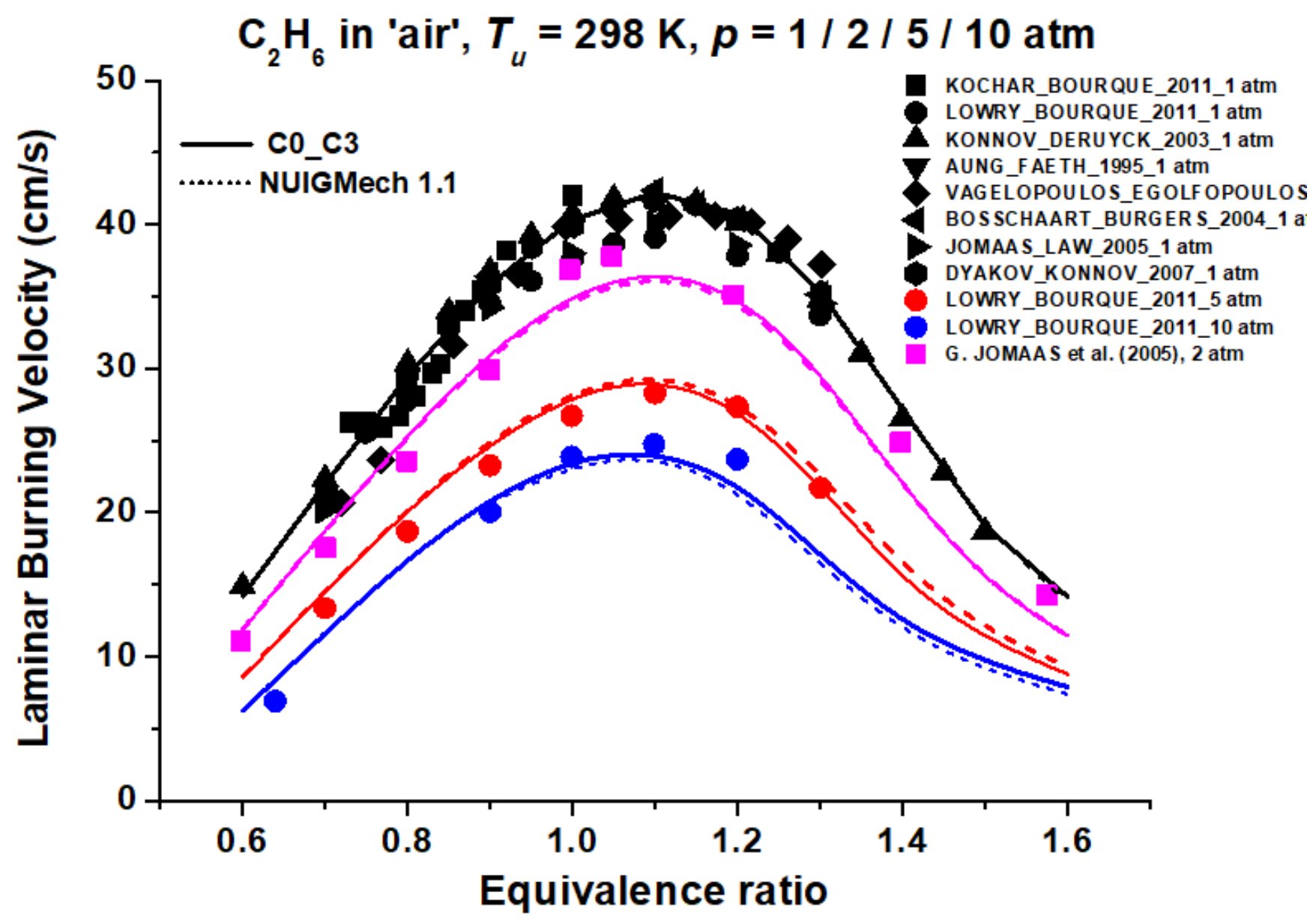




\section{Validation for $\mathrm{C}_{2} \mathrm{H}_{4}$}

\section{Shock tube ignition delay time}

5.1) Baigmohammadi, M., Patel, V., Martinez, S., Panigrahy, S., Ramalingam, A., Burke, U., .. \& Curran, H. J., Energy \& Fuels, 34(3) (2020) 3755-3771.
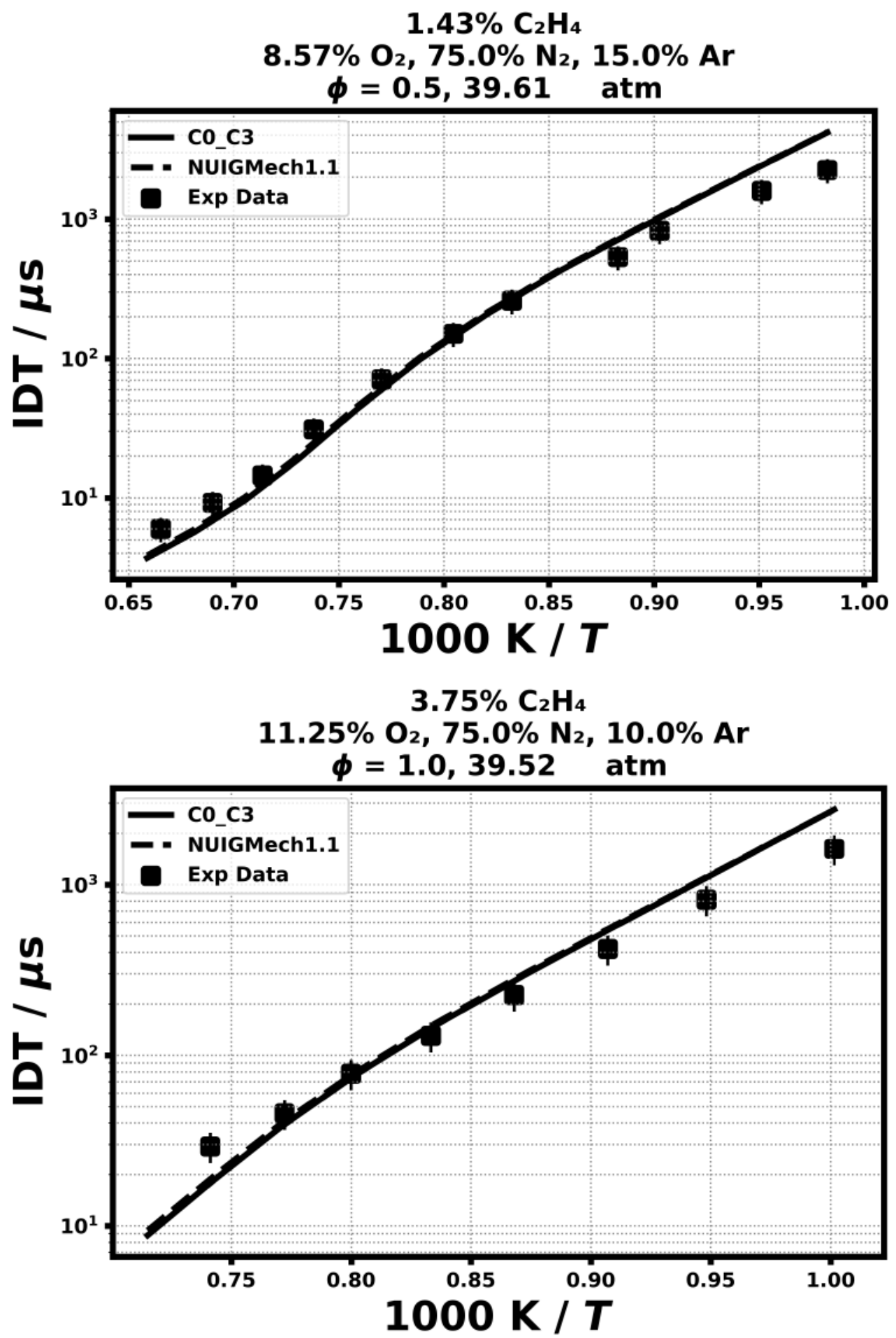

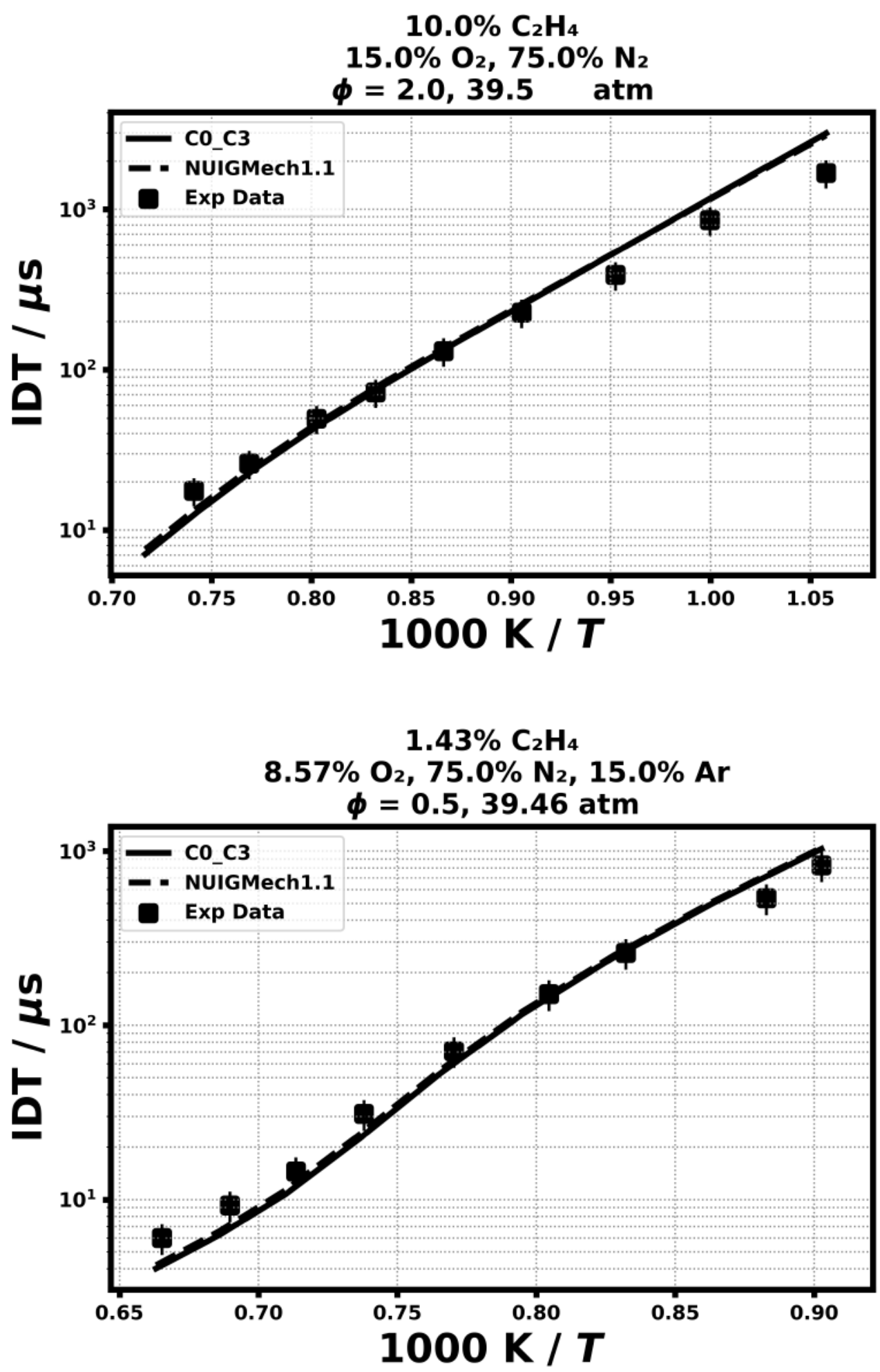

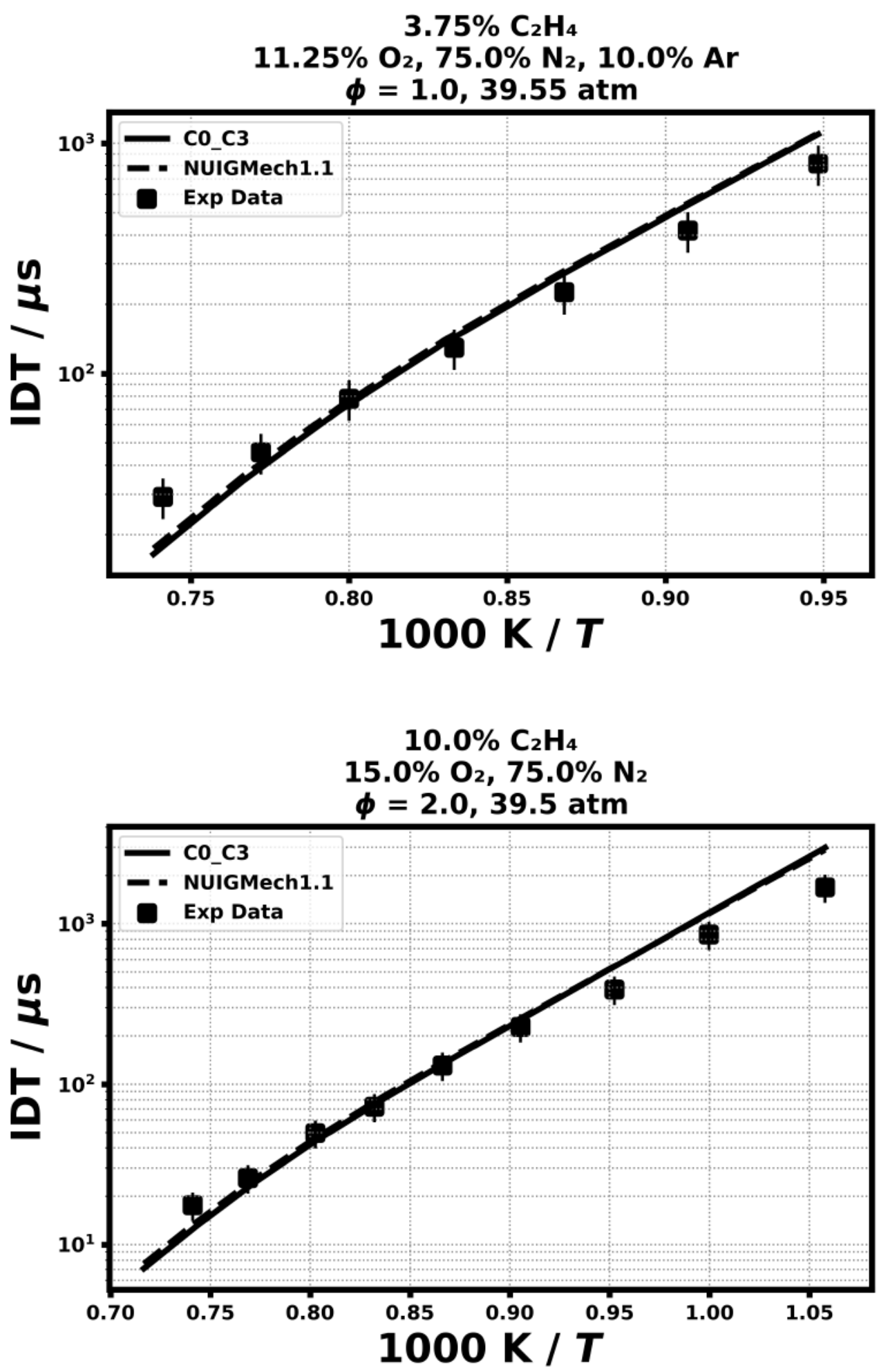

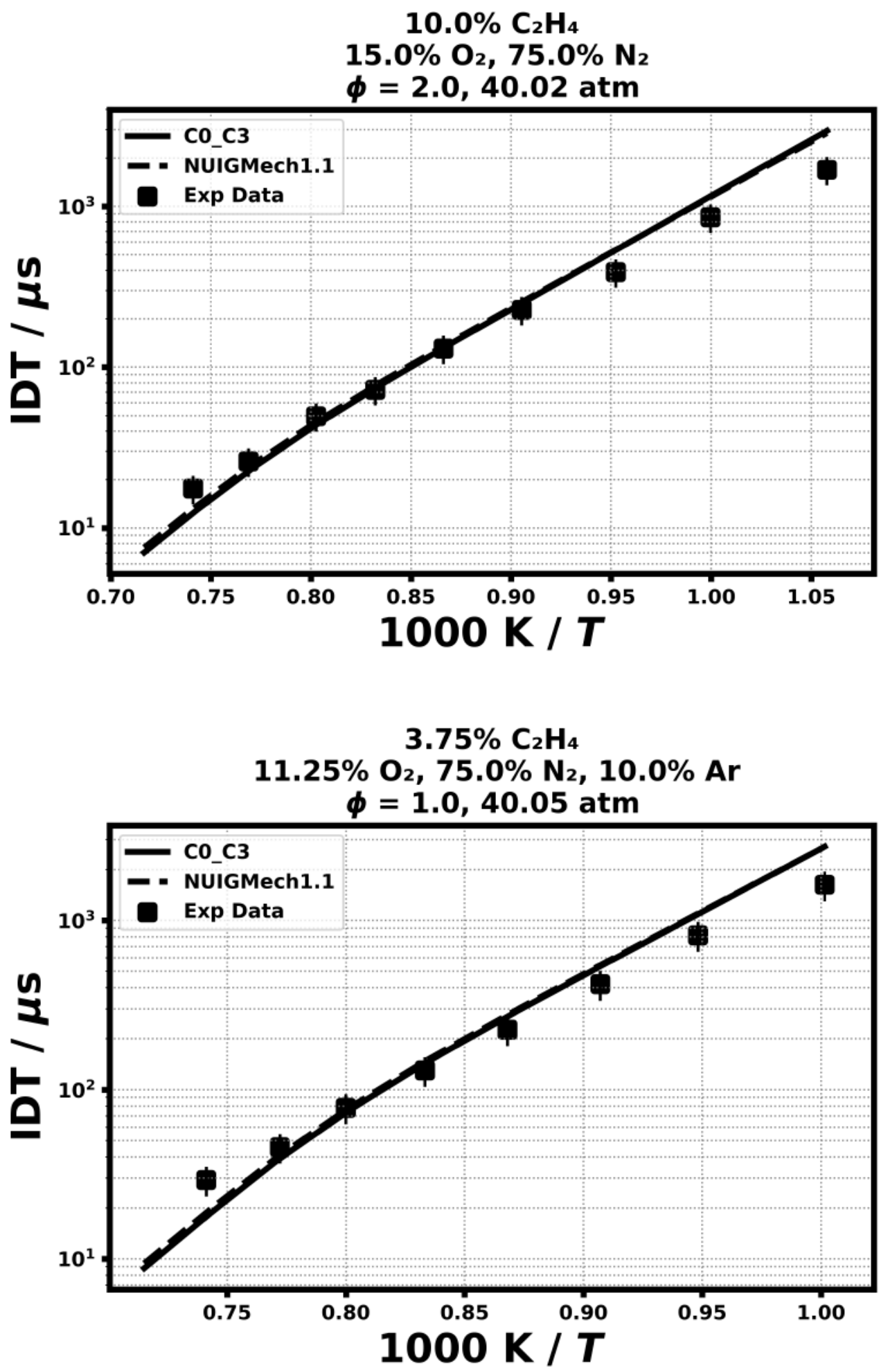
5.2) Brown, C. J., \& Thomas, G. O., Combustion and Flame, 117(4) (1999) 861-870.
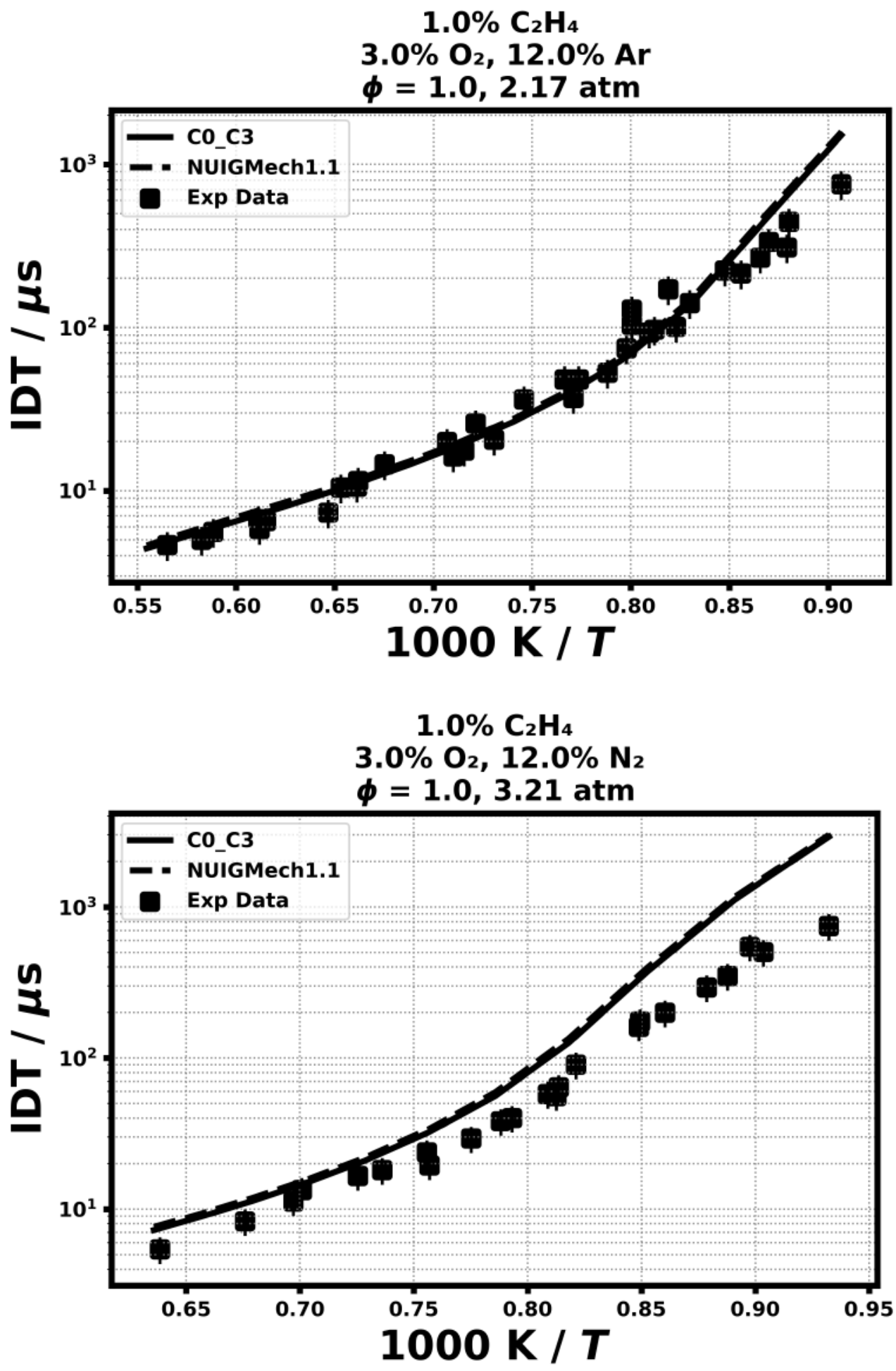


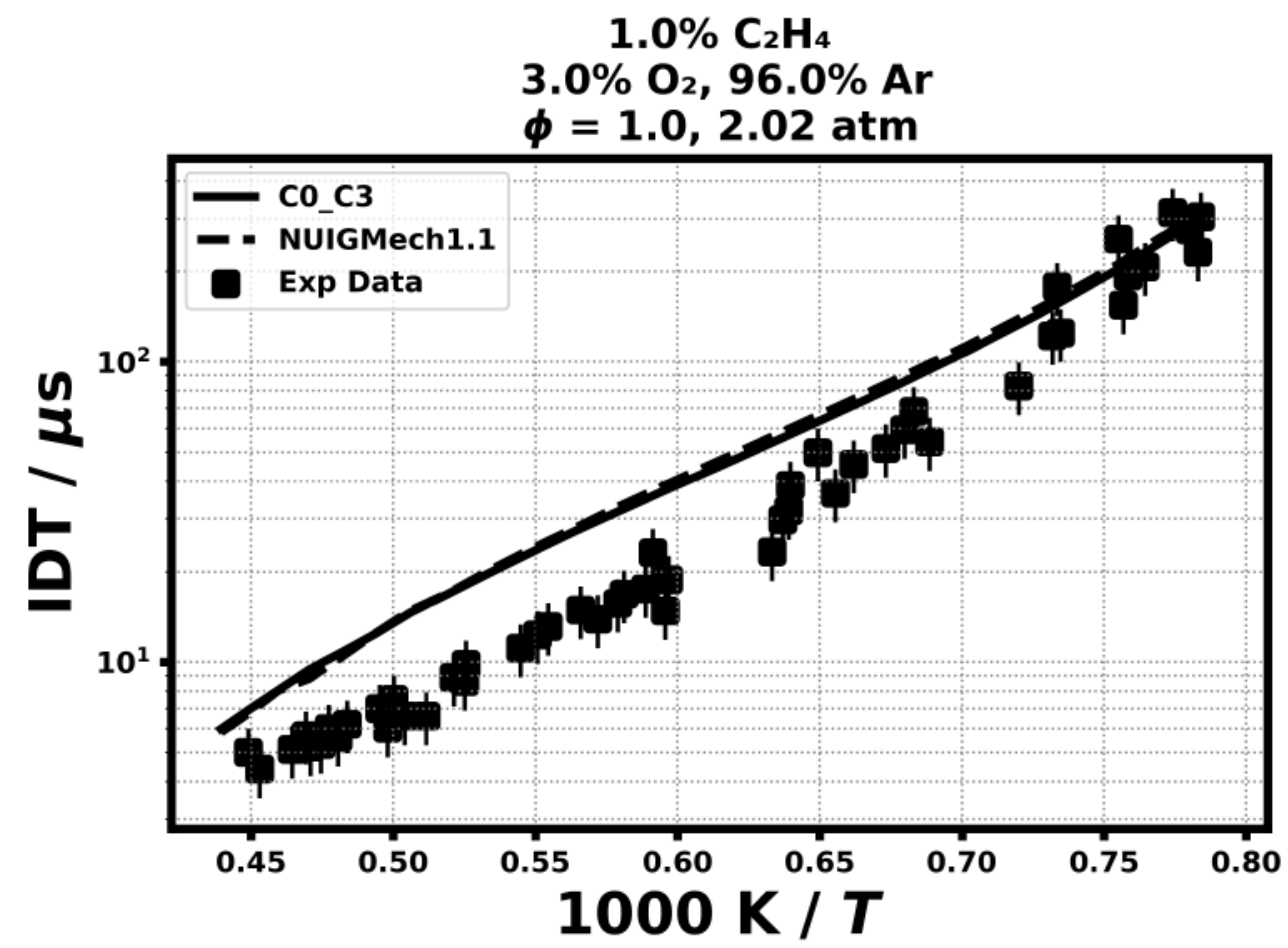

5.3) D.F.Davidson et al., 50th AIAA Aerospace Sciences Meeting, January 2012

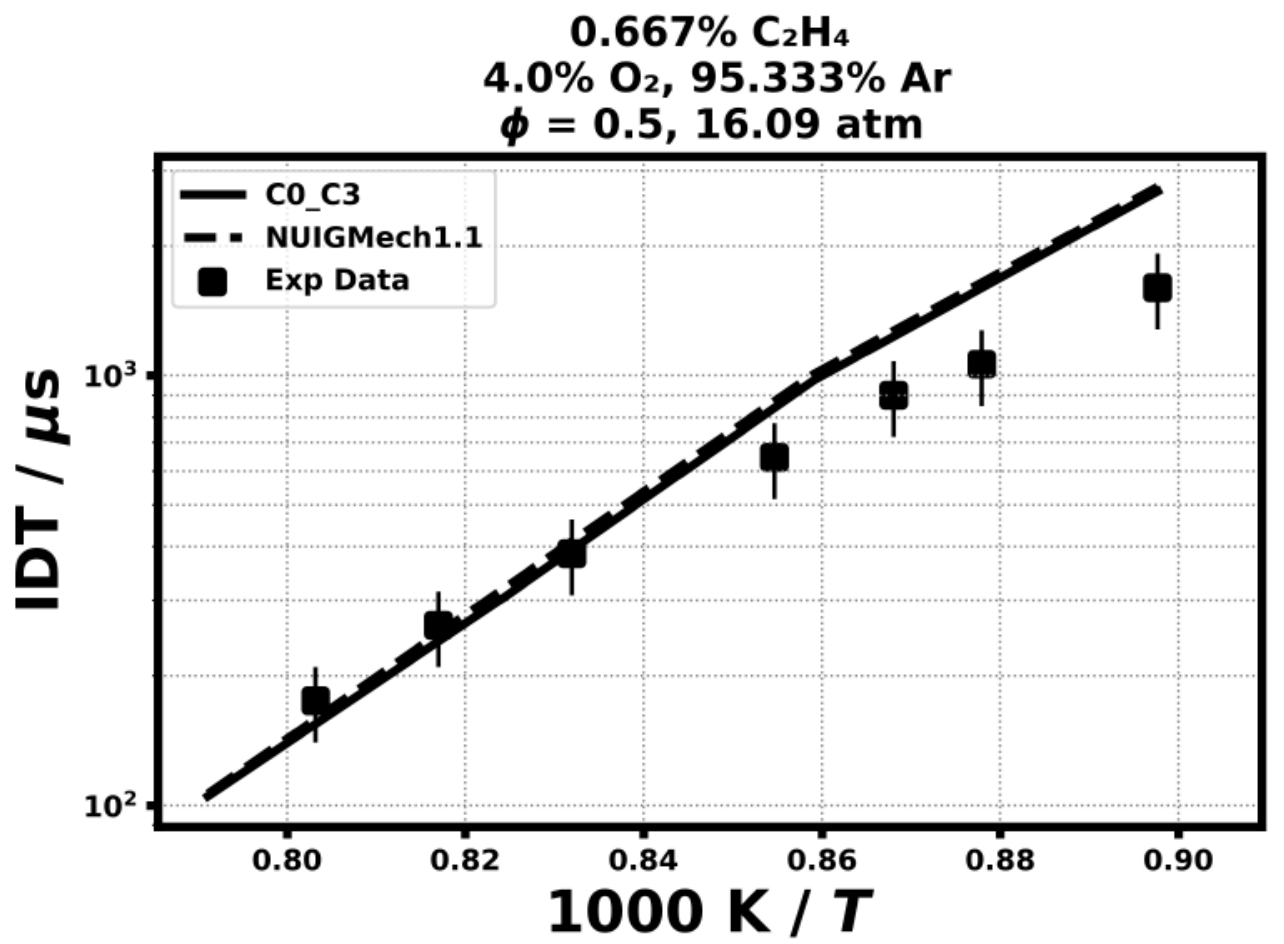



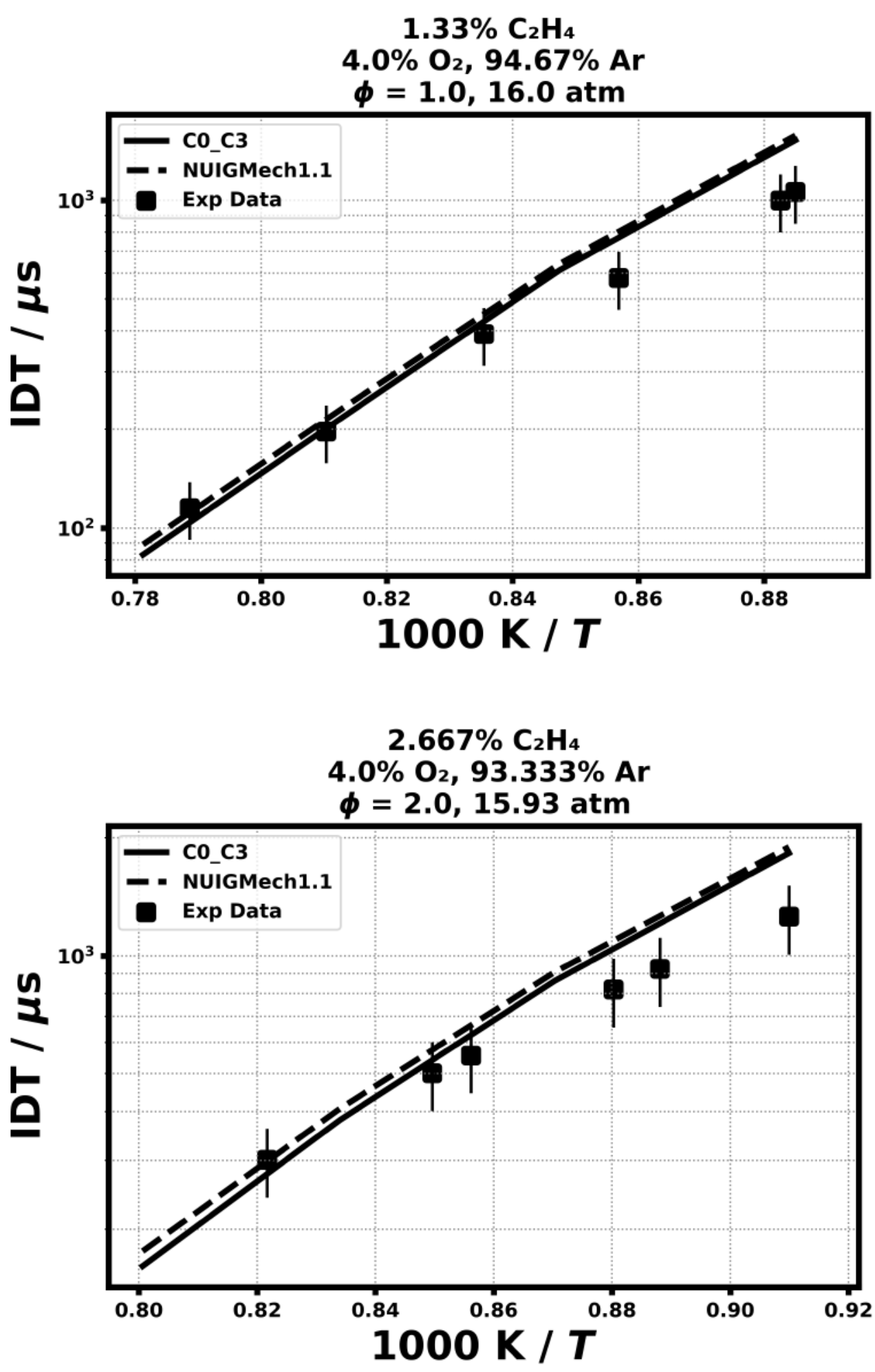


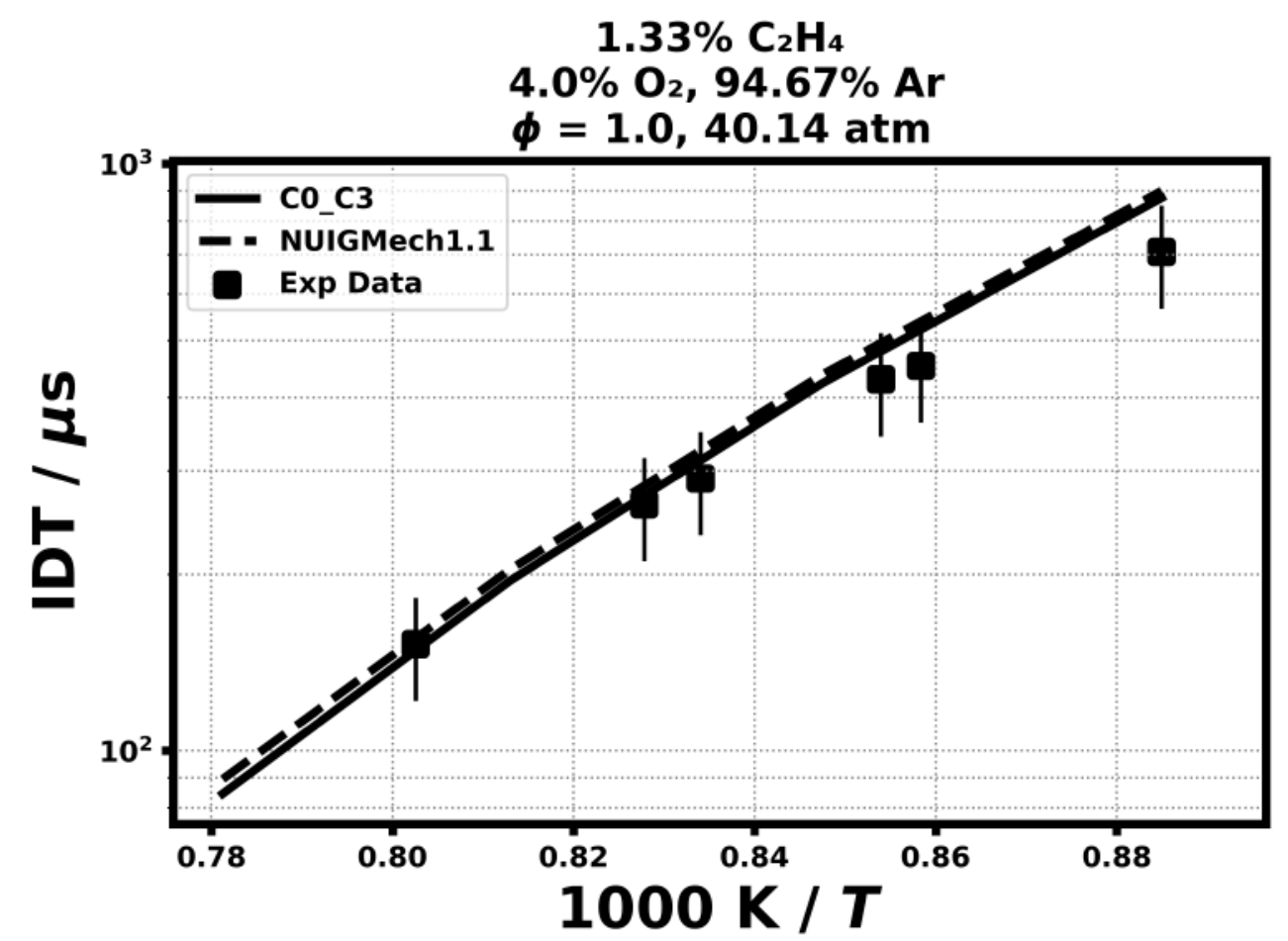

5.4) F.R. Gillespie et al., Phd Thesis, National Univ. Ire. Galway, 2010

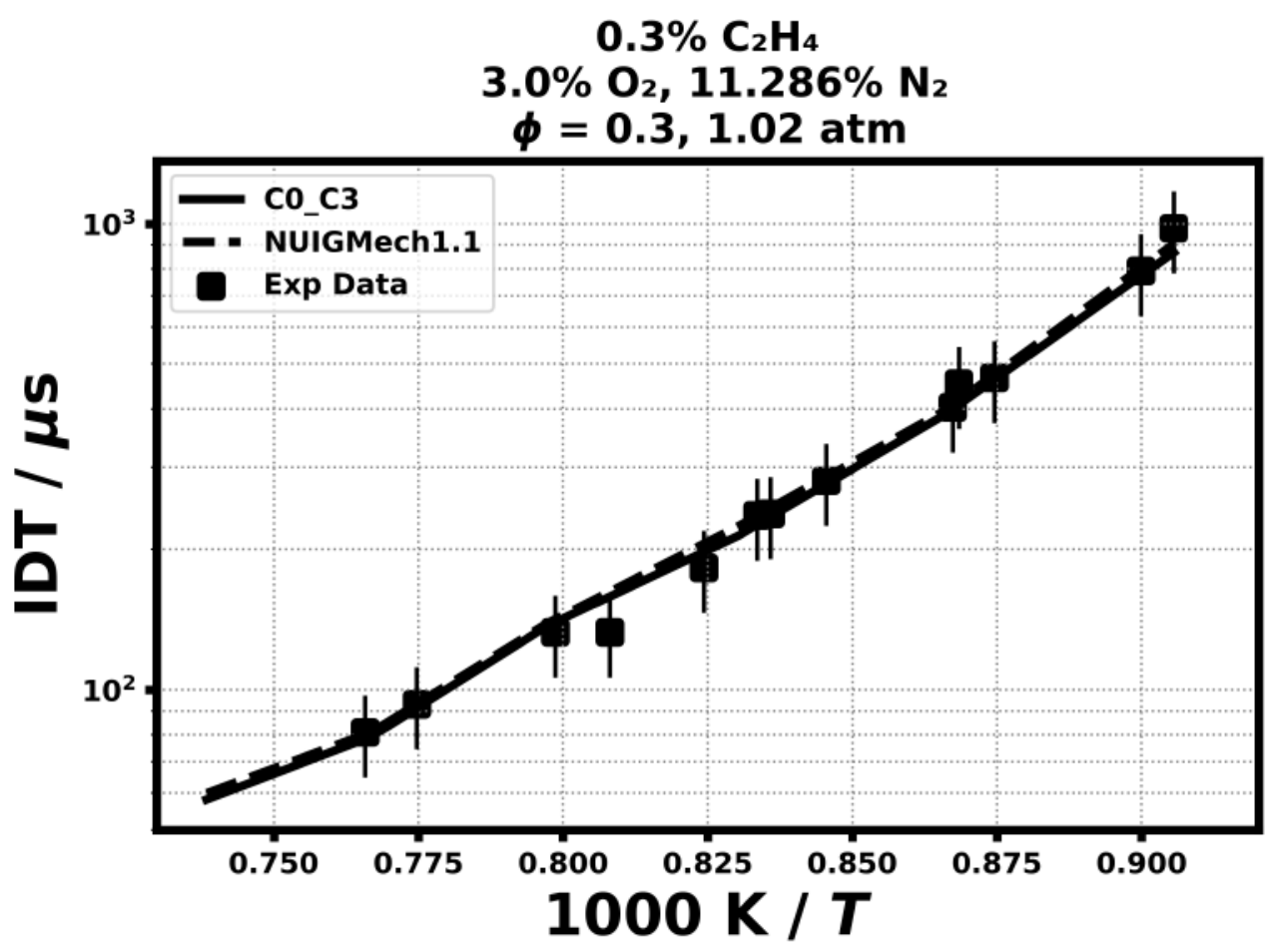



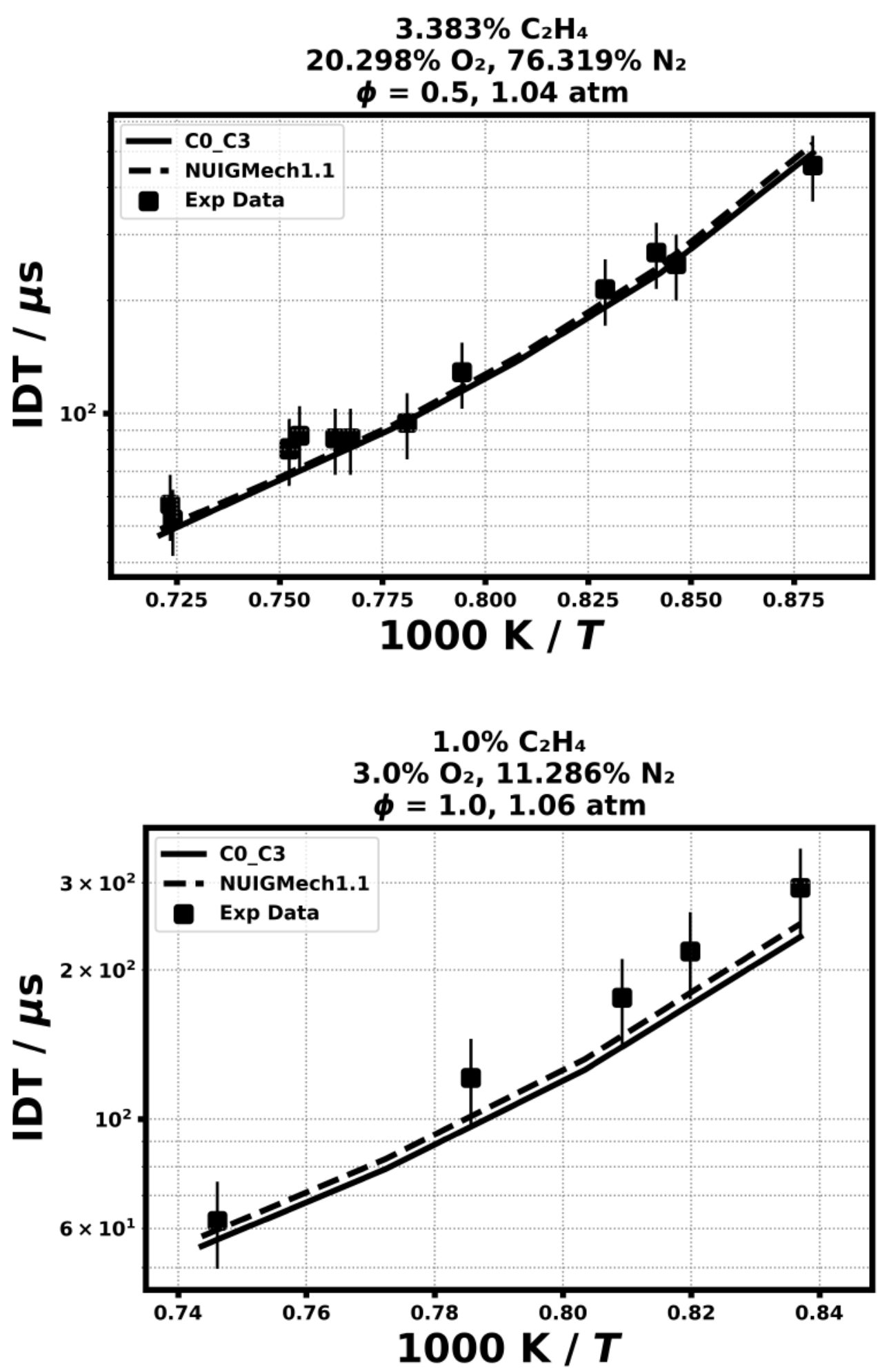
5.5) D.C. Horning et al., Phd Thesis, Mech. Eng. Dept. Stanford, Report No. tsd-135, 2001
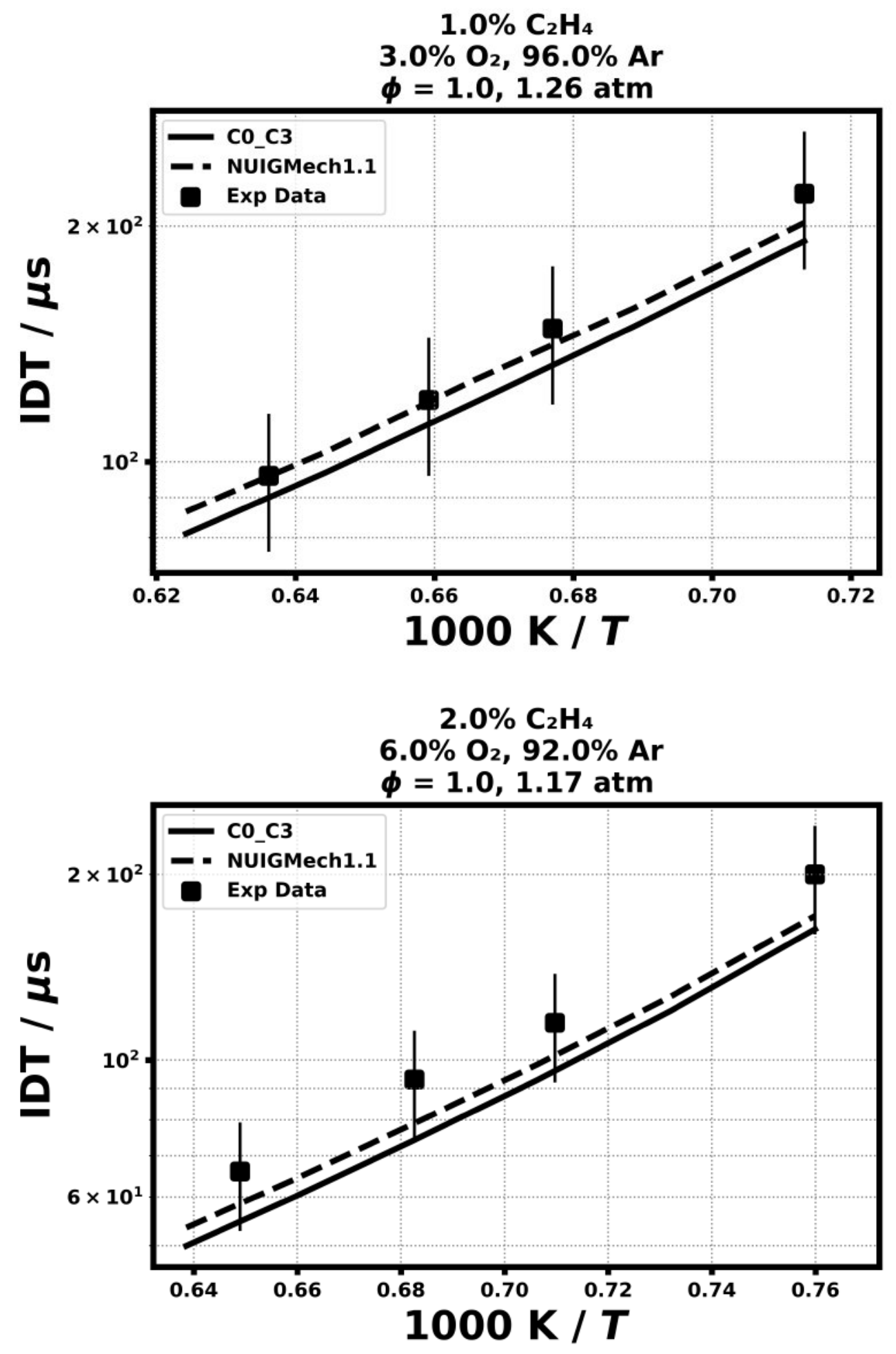

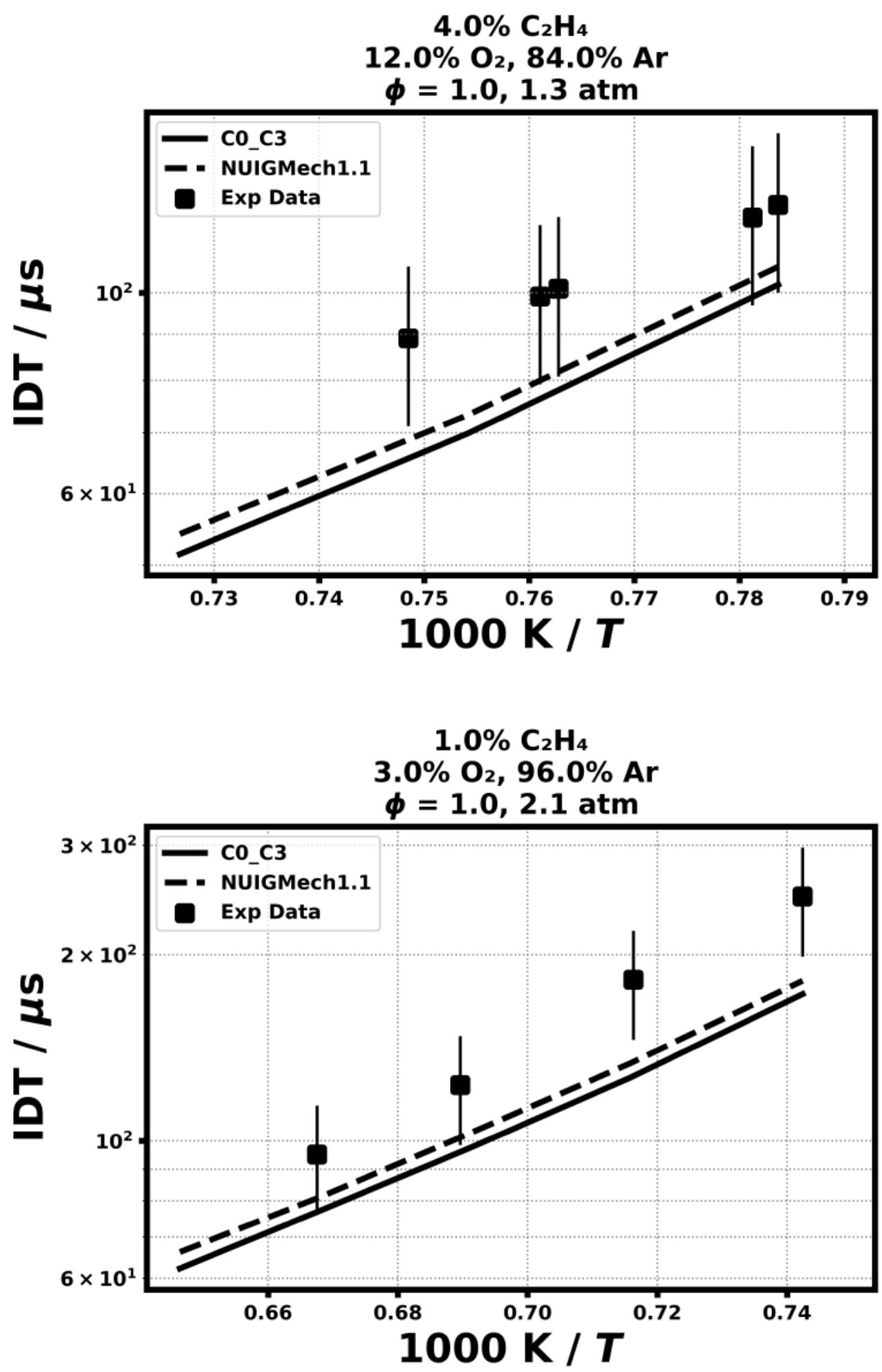

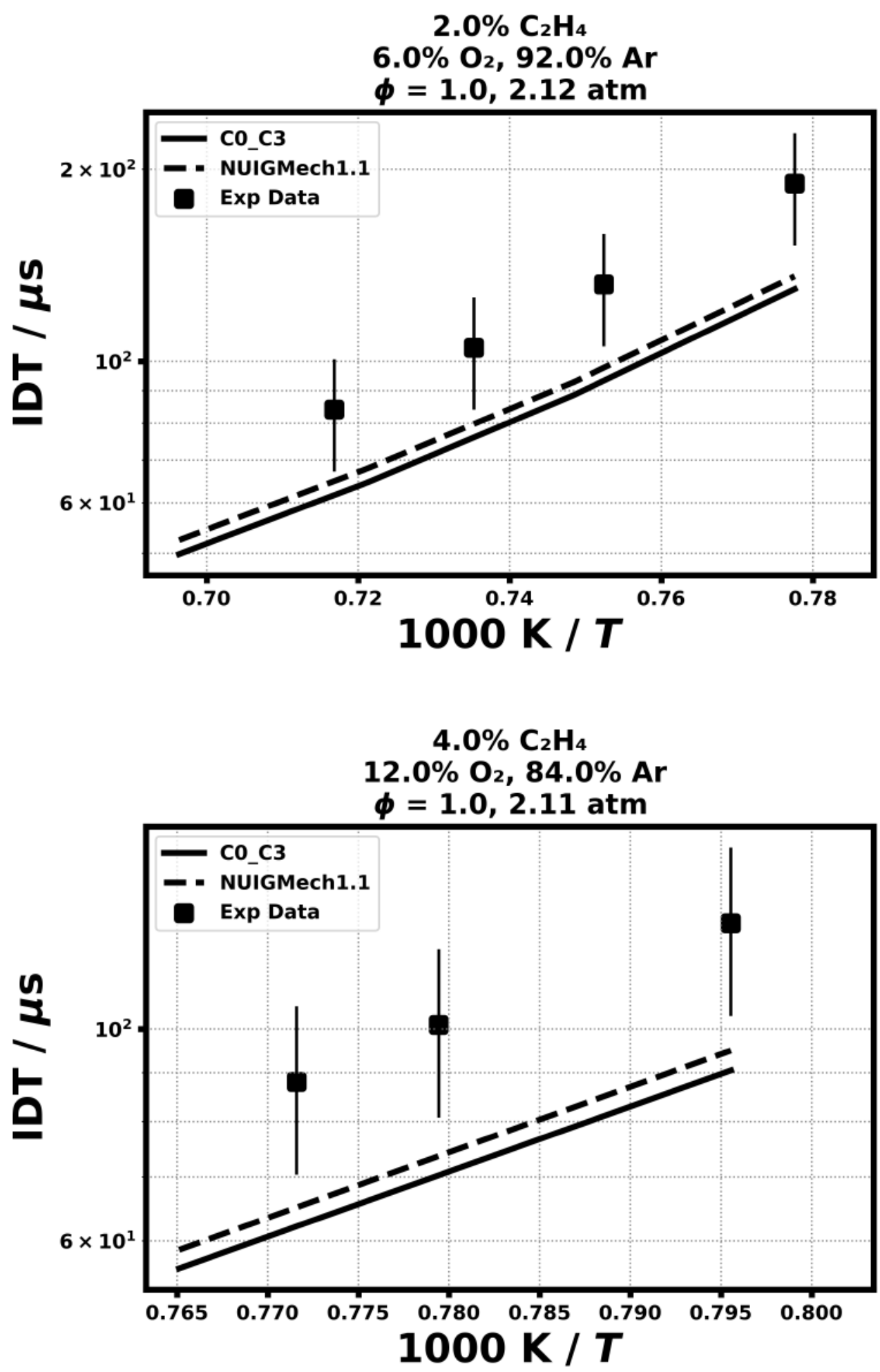


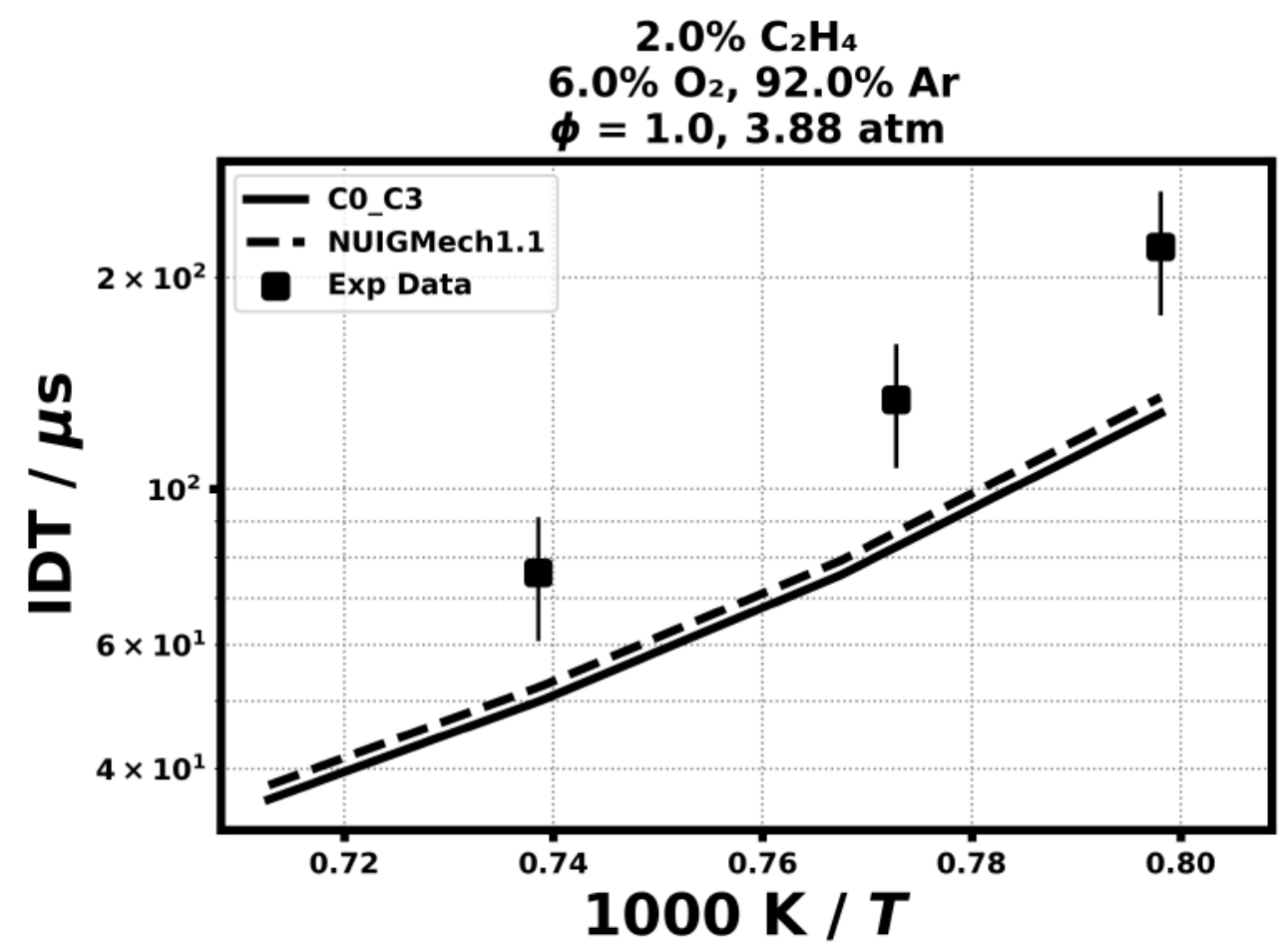

5.6) Kopp, M. M., Donato, N. S., Petersen, E. L., Metcalfe, W. K., Burke, S. M., \& Curran, H. J. Journal of Propulsion and Power, 30(3) (2014) 790-798.

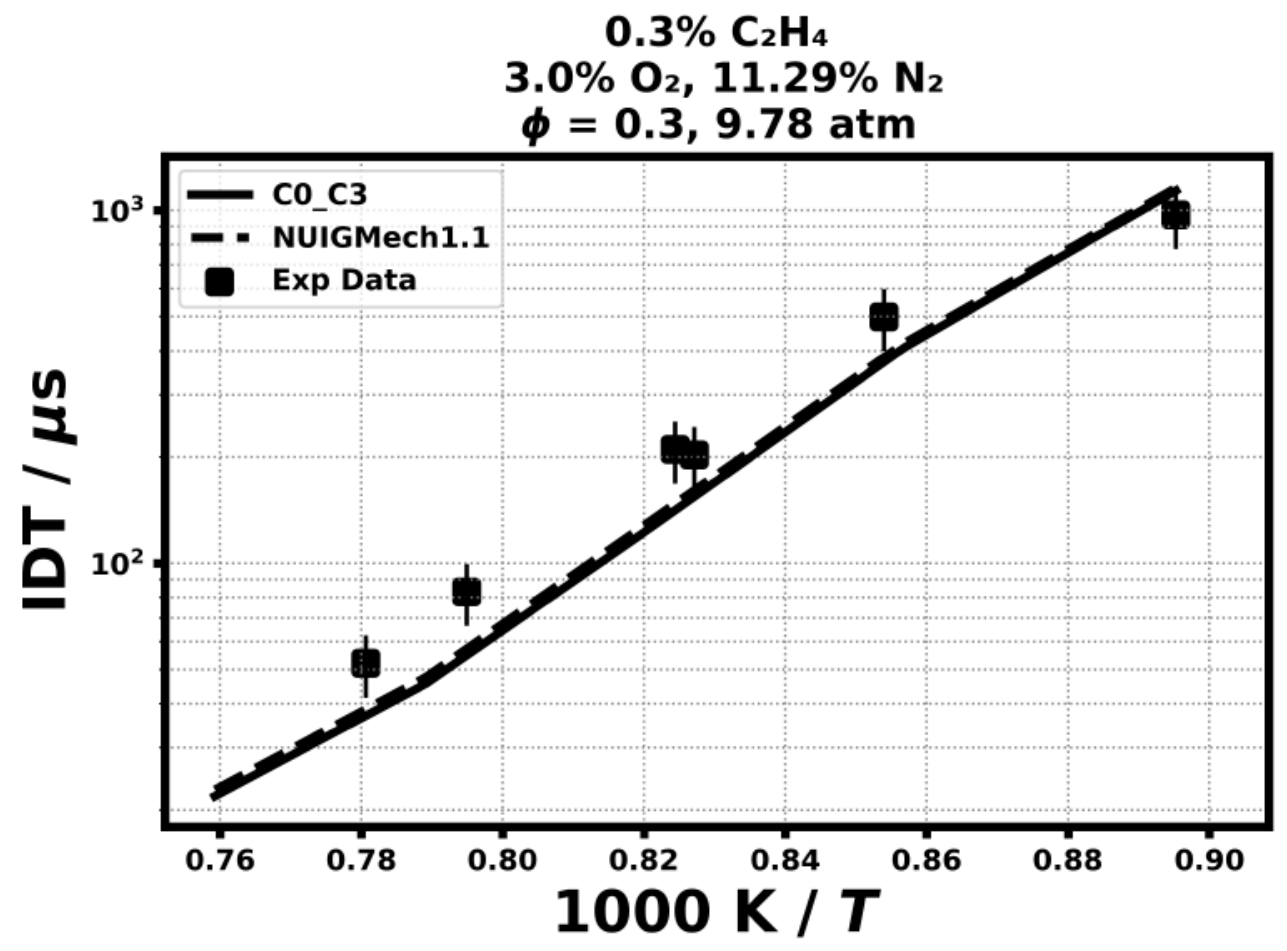



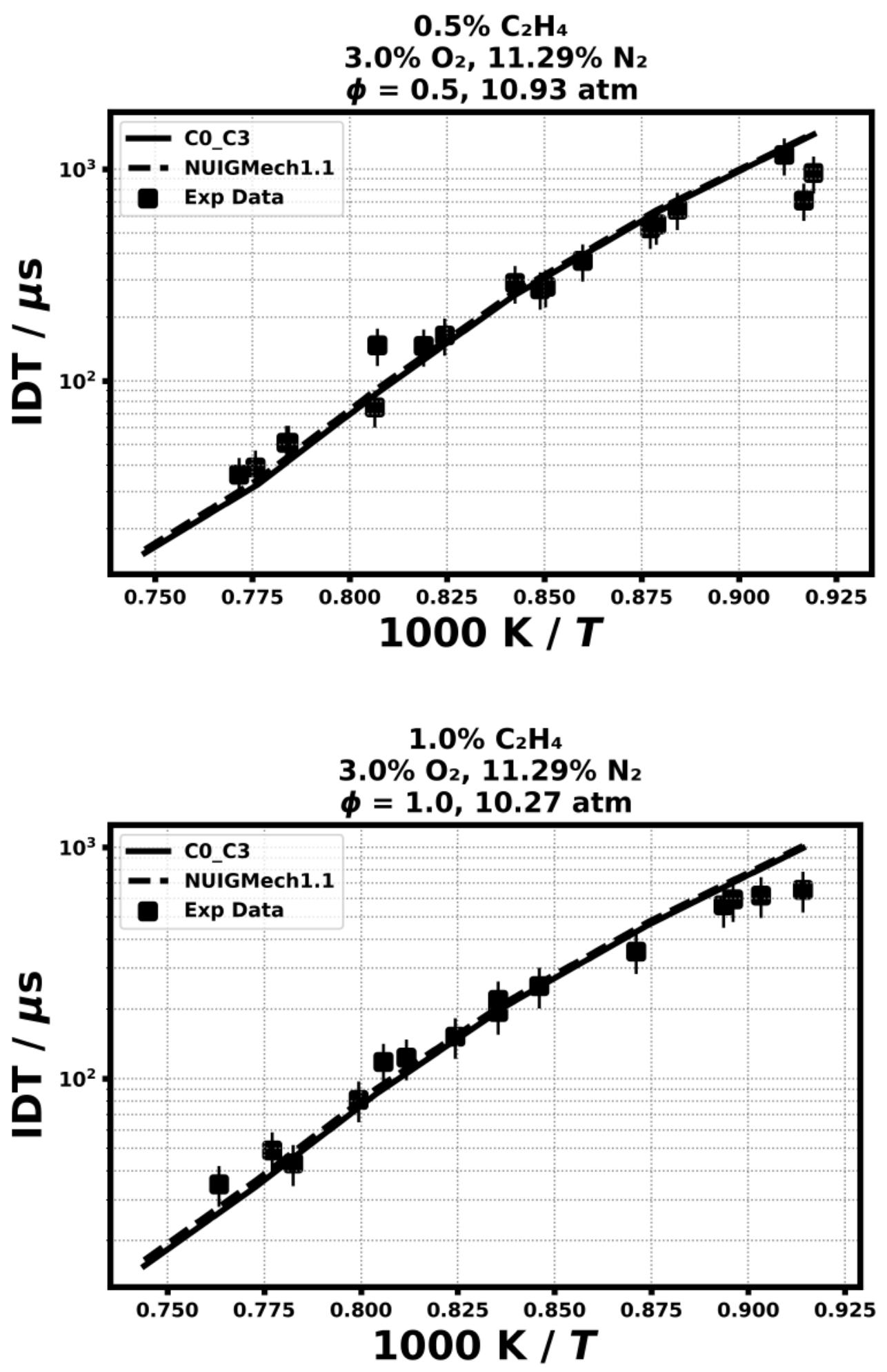

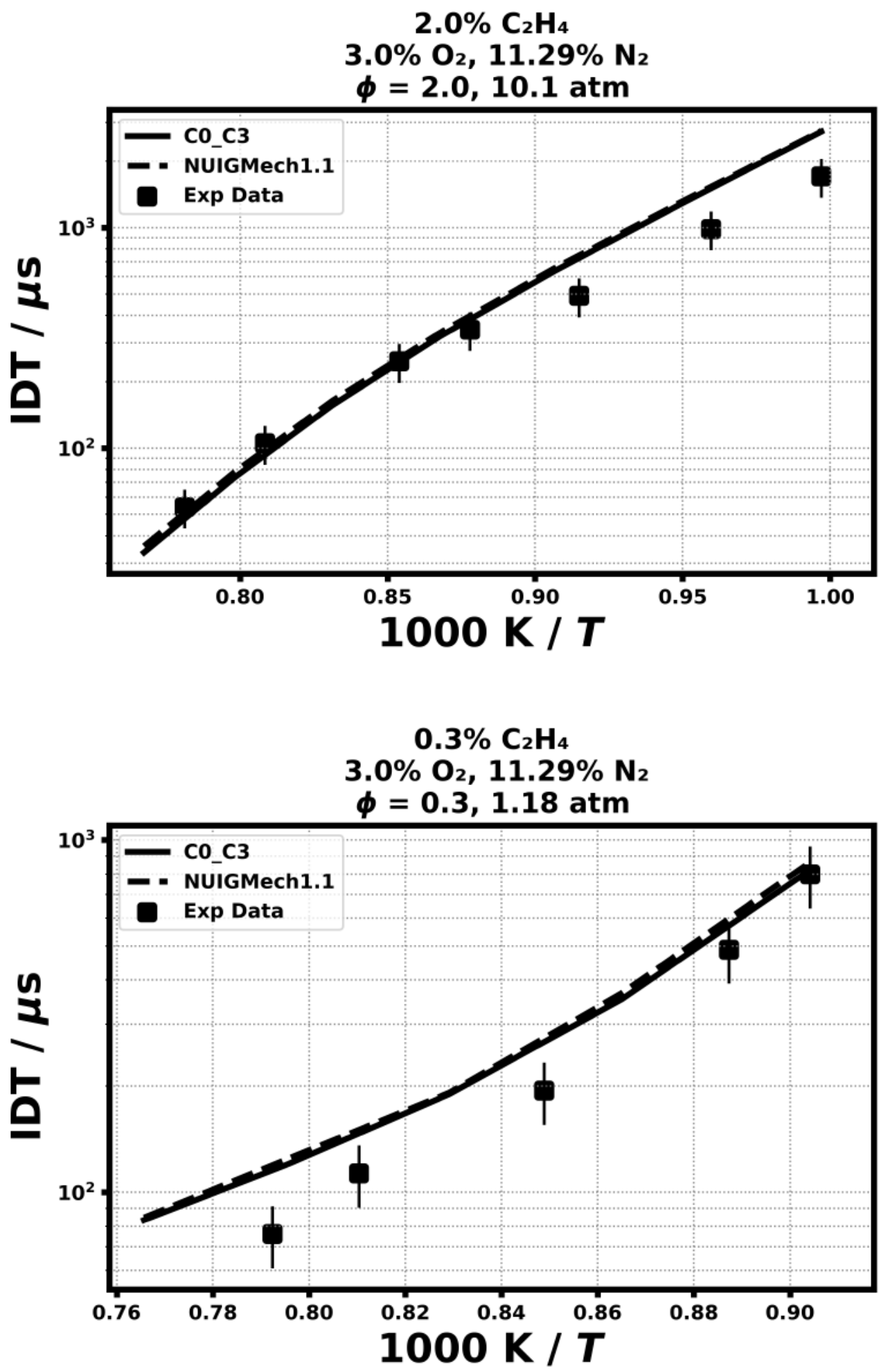

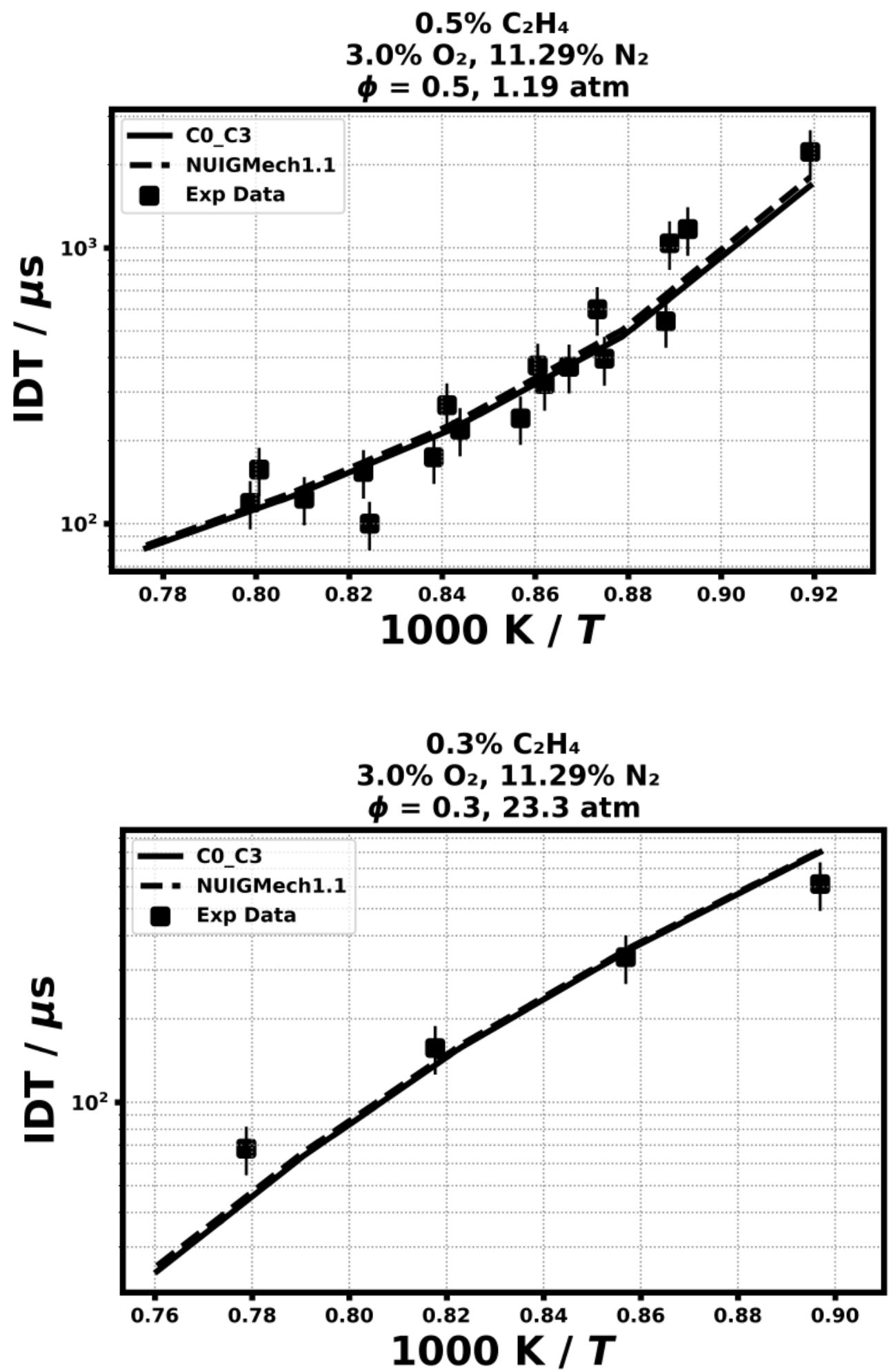

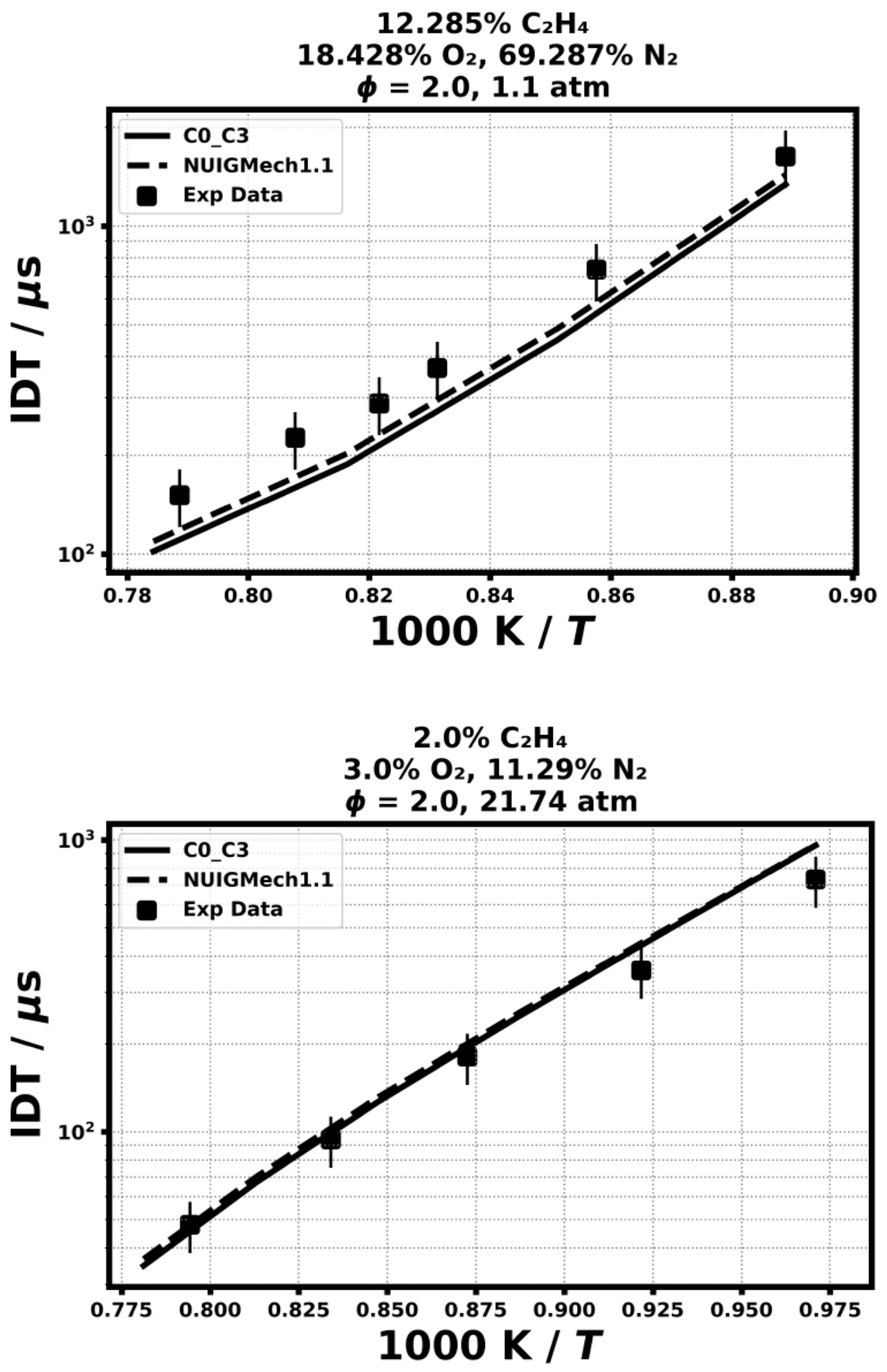
5.7) Penyazkov, O. G., Sevrouk, K. L., Tangirala, V., \& Joshi, N., Proceedings of the Combustion Institute, 32(2) (2009) 2421-2428.
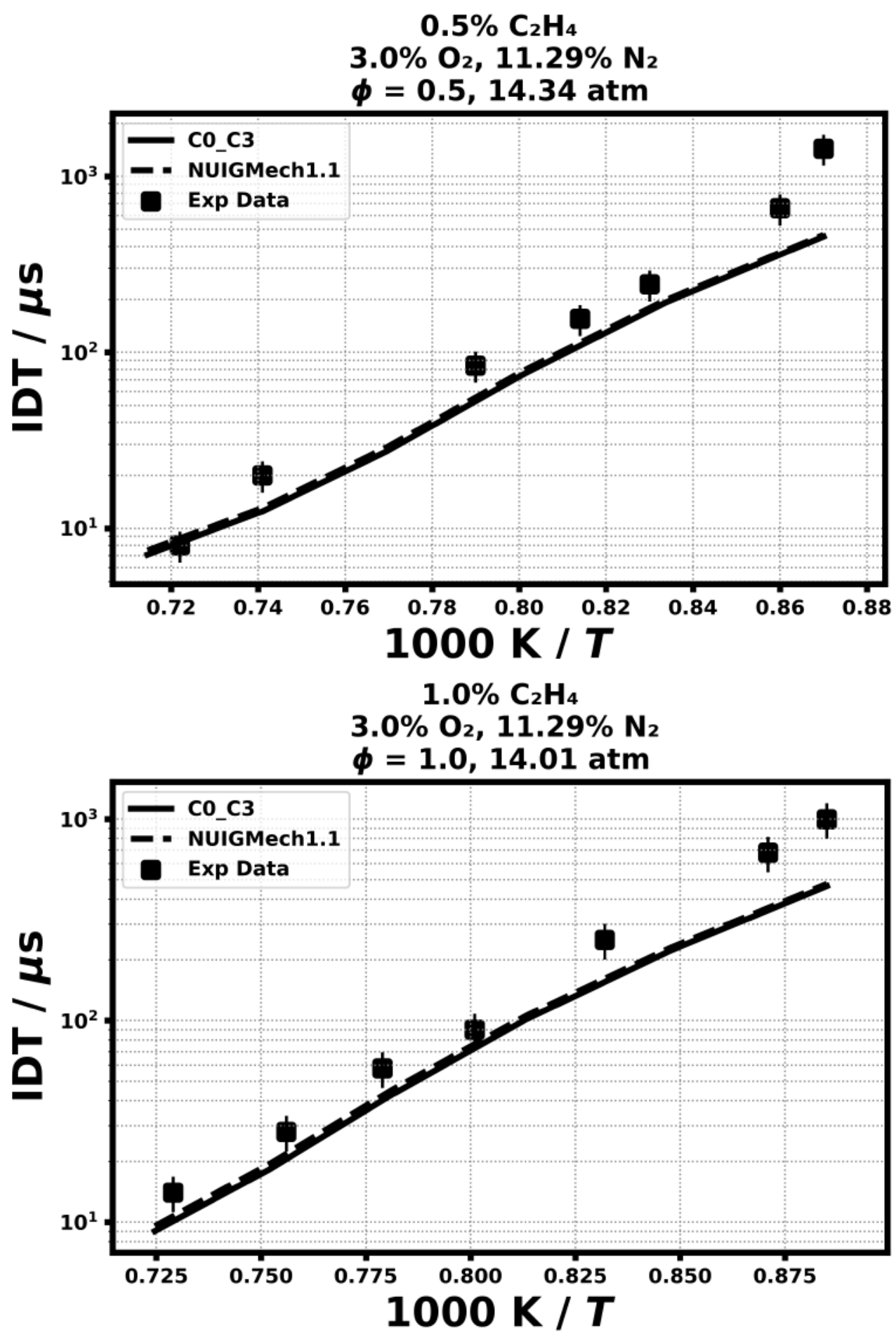

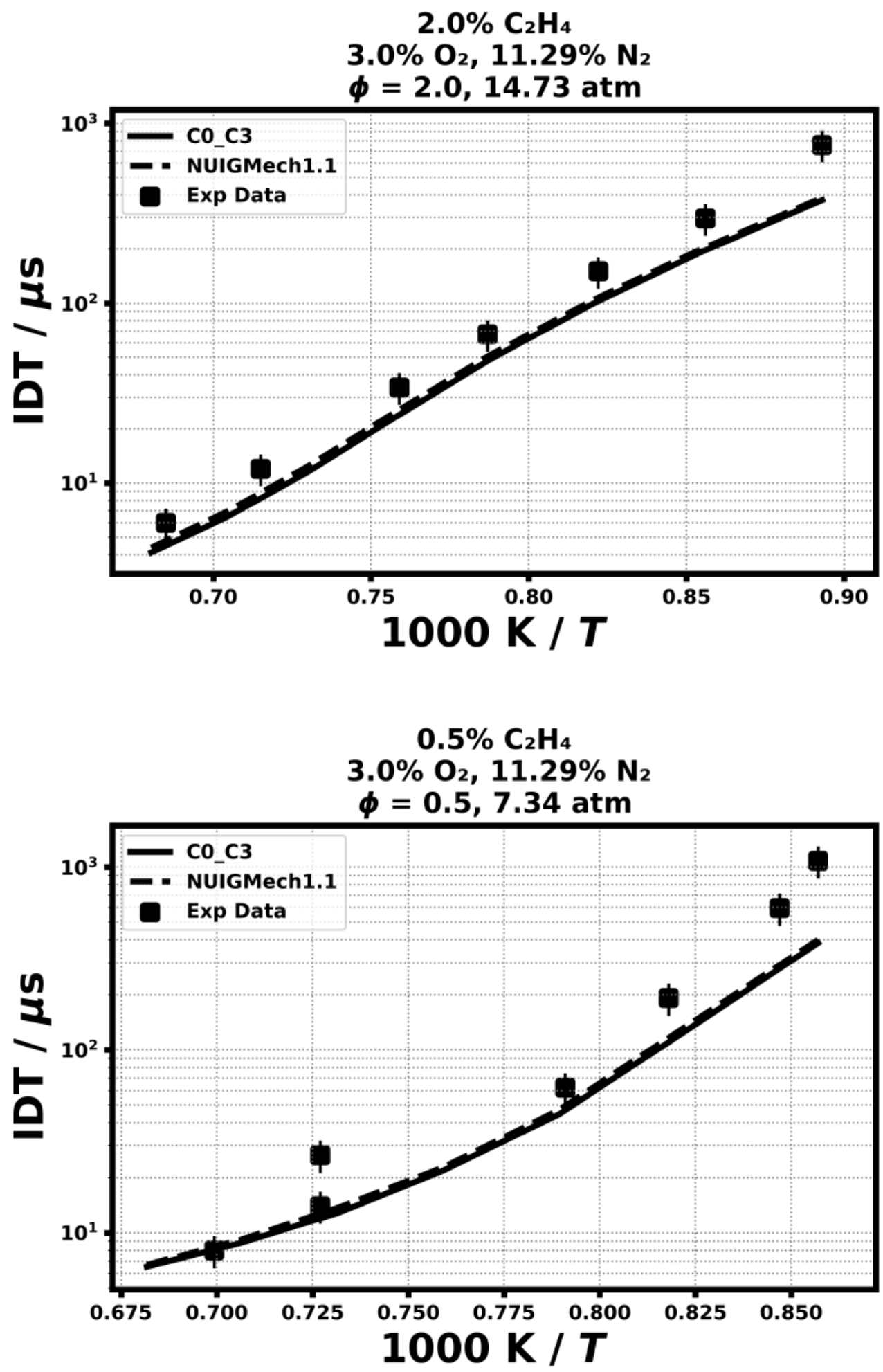

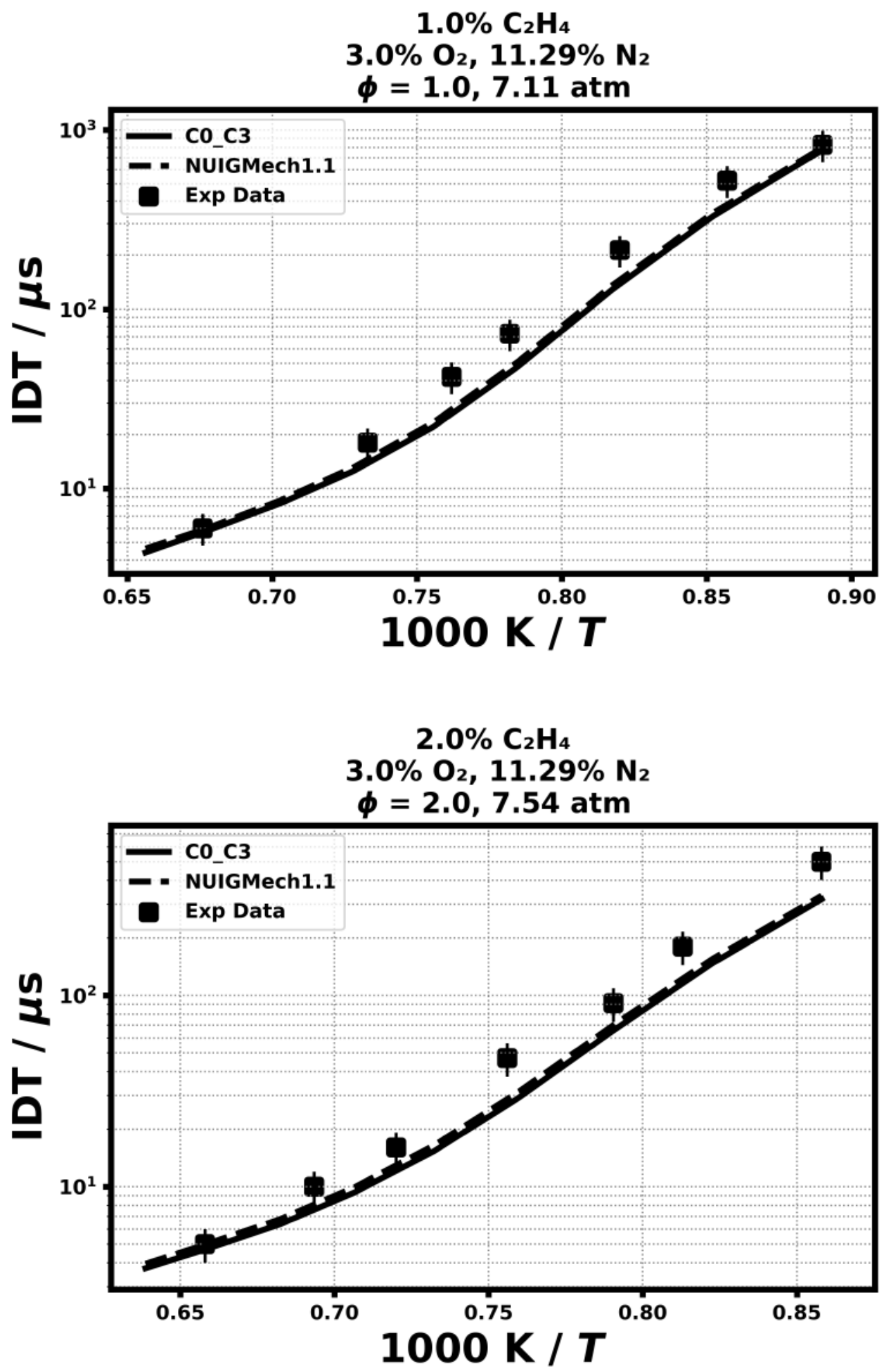
5.8) Ren, W., Davidson, D. F., \& Hanson, R. K. International Journal of Chemical Kinetics, 44(6) (2012) 423-432.
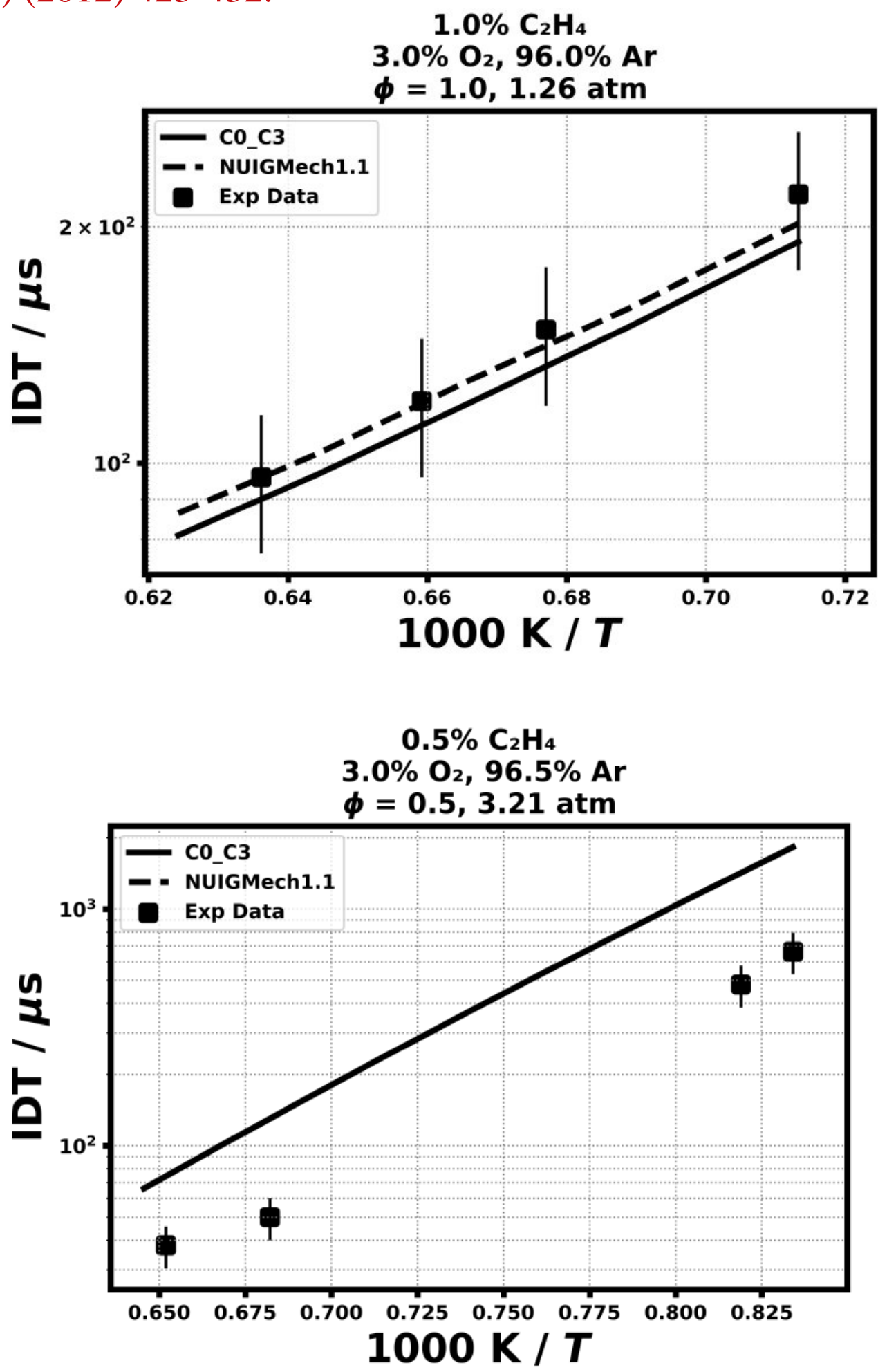


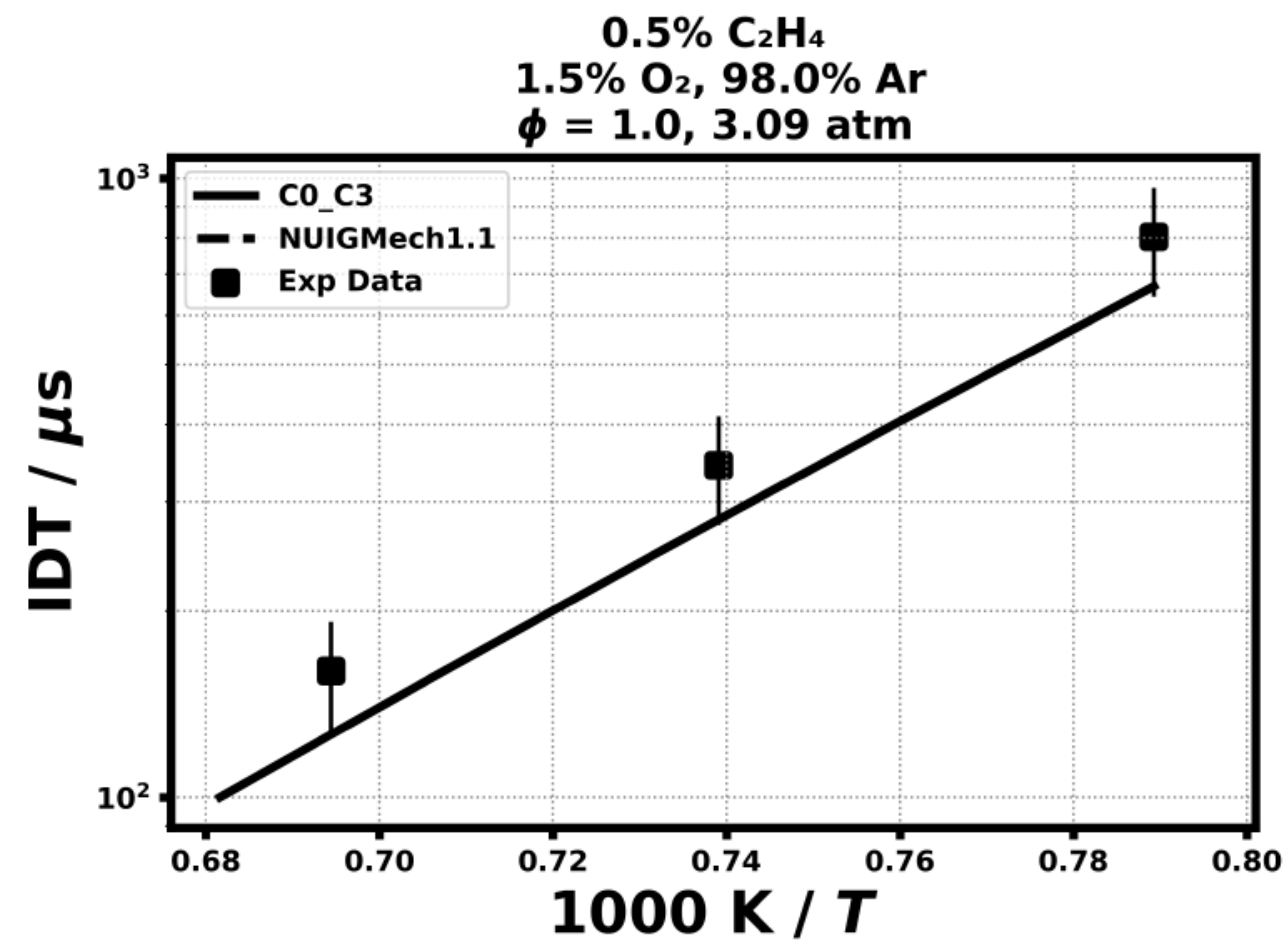

5.9) Saxena, S., Kahandawala, M. S. P., \& Sidhu, S. S. Combustion and flame, 158(6) (2011) 1019-1031.

$0.5 \% \mathrm{C}_{2} \mathrm{H}_{4}$

$1.5 \% \mathrm{O}_{2}, 98.0 \% \mathrm{Ar}$

$\phi=1.0,9.8 \mathrm{~atm}$

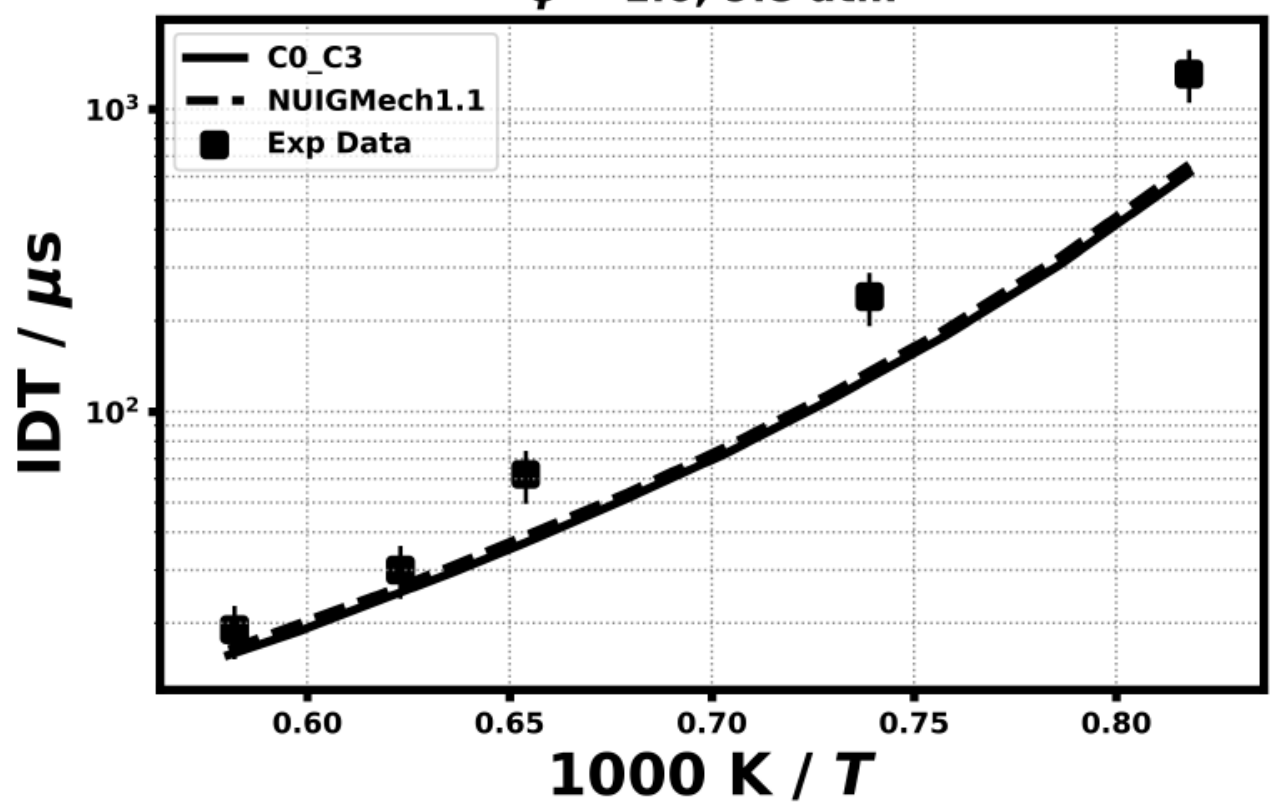




\section{$1.75 \% \mathrm{C}_{2} \mathrm{H}_{4}$}
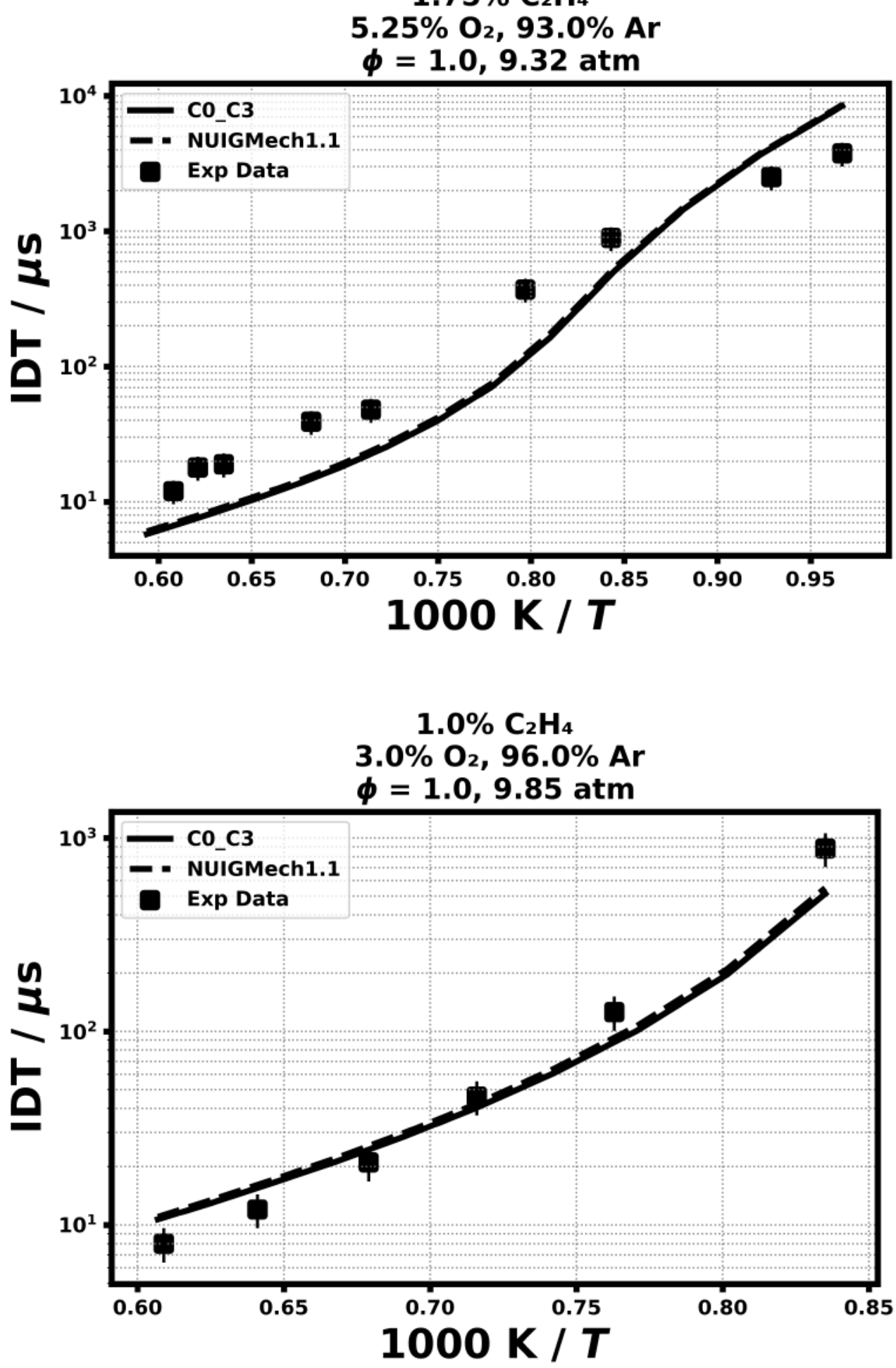

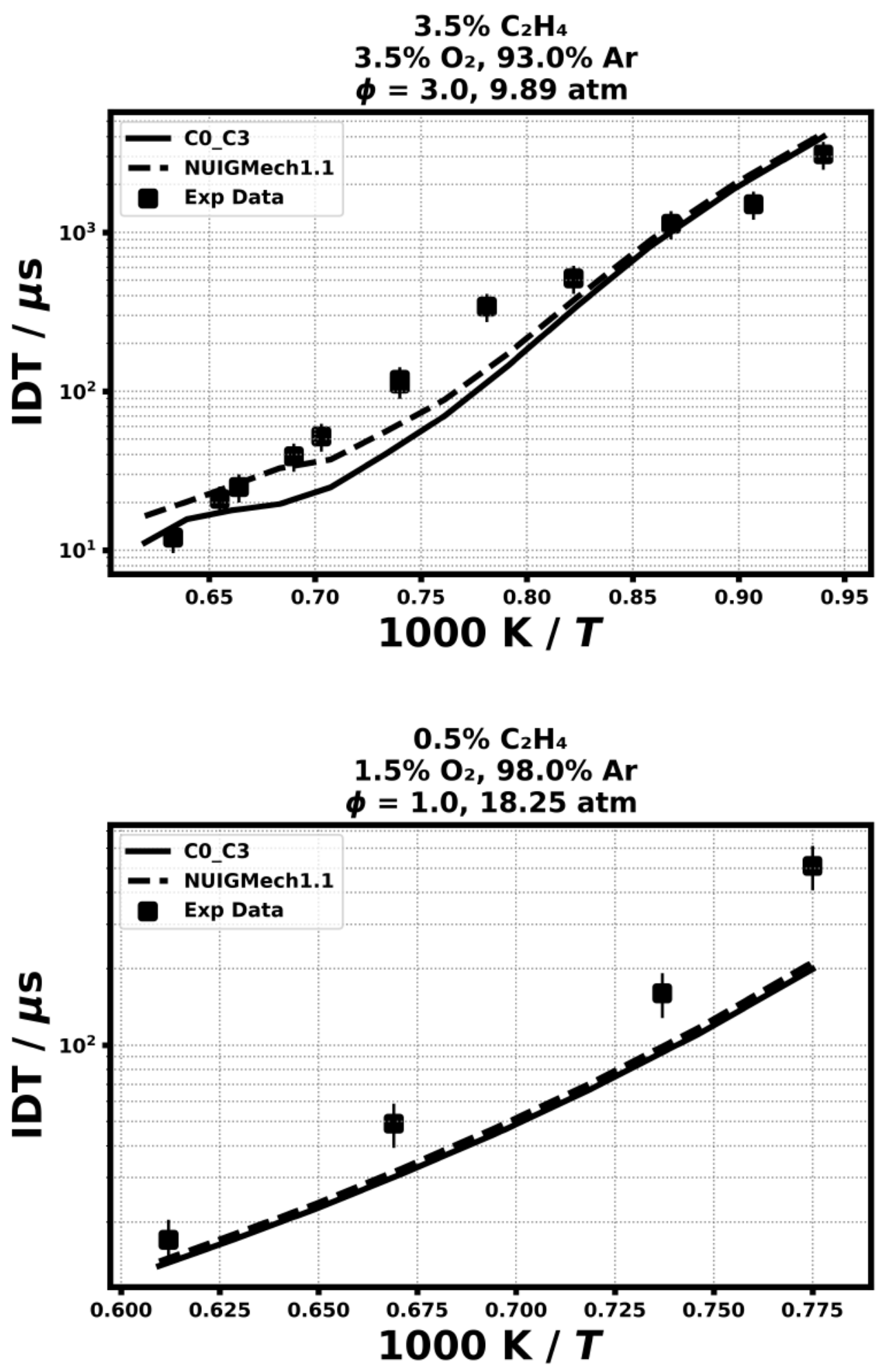

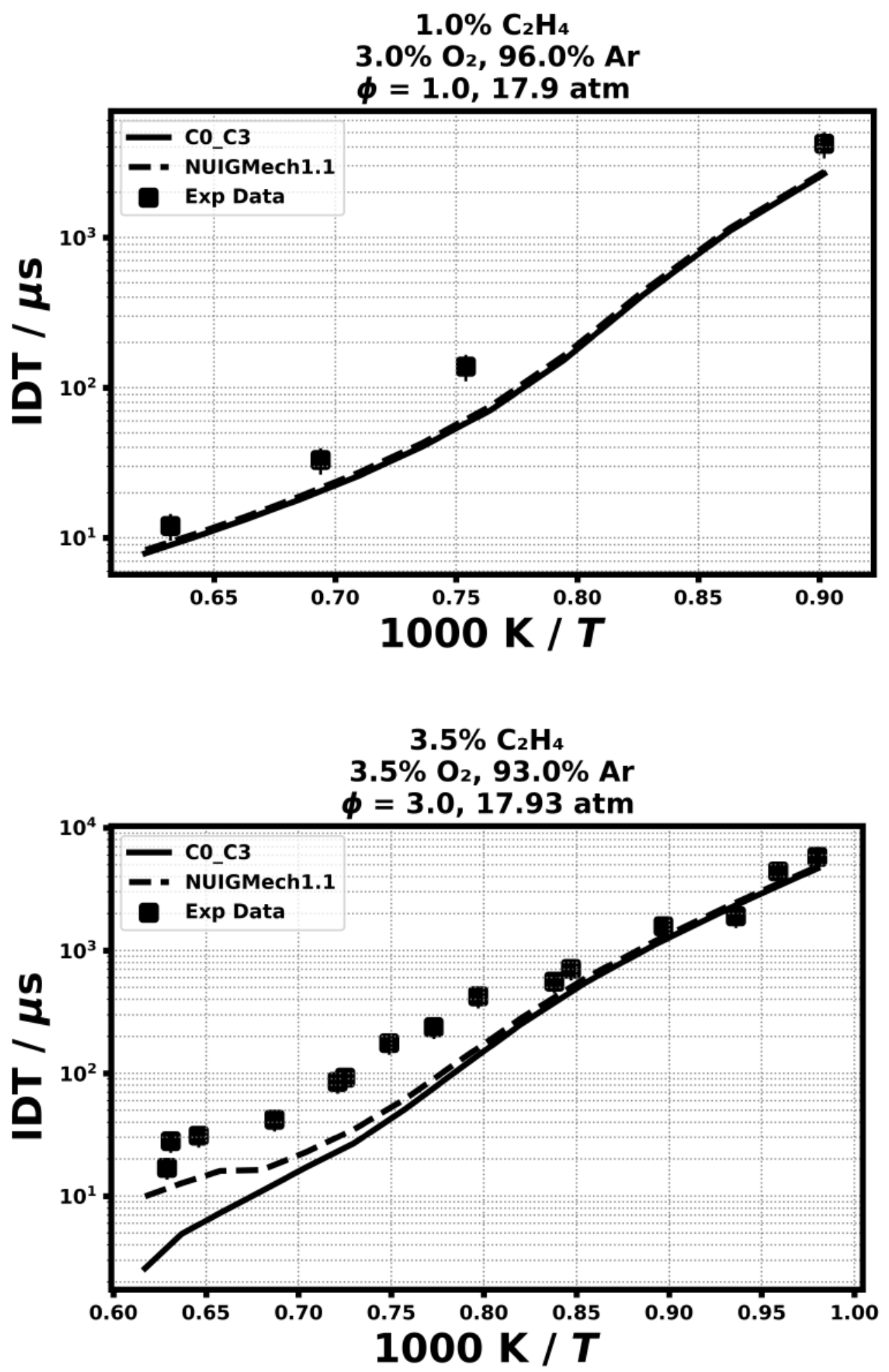

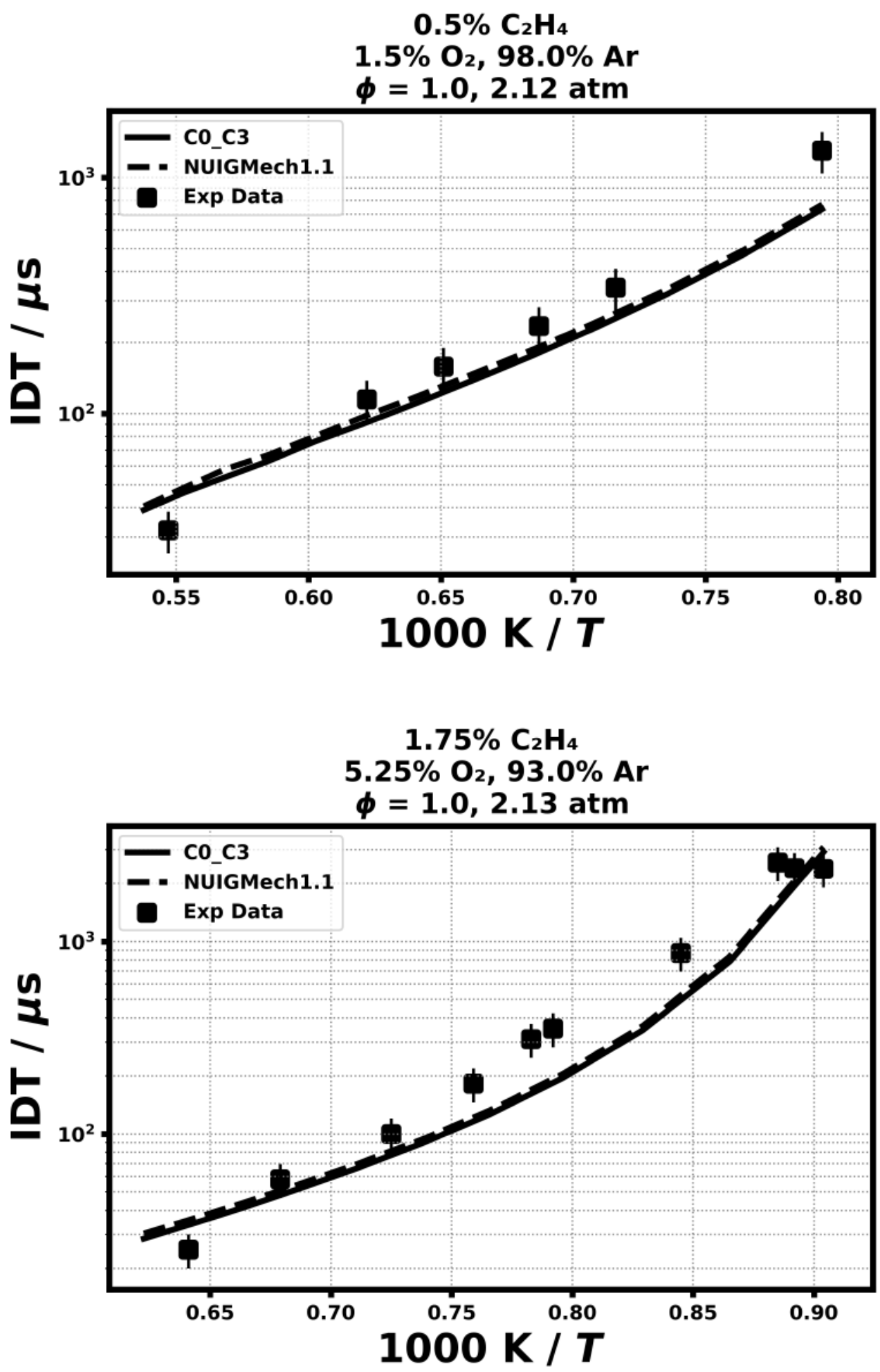

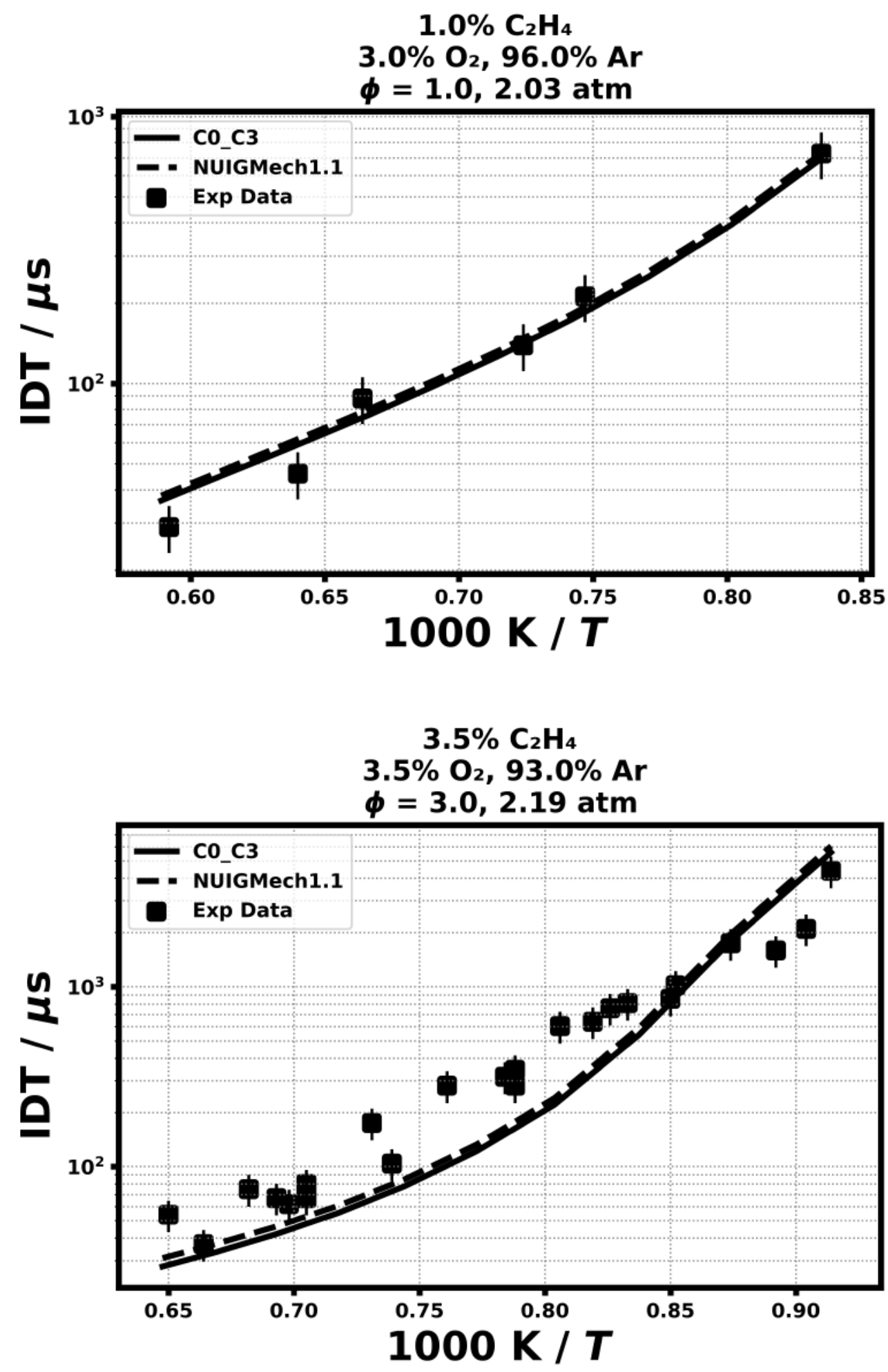


\section{RCM Ignition delay time}

5.10) Baigmohammadi, M., Patel, V., Martinez, S., Panigrahy, S., Ramalingam, A., Burke, U., ... \& Curran, H. J., Energy \& Fuels, 34(3) (2020) 3755-3771.
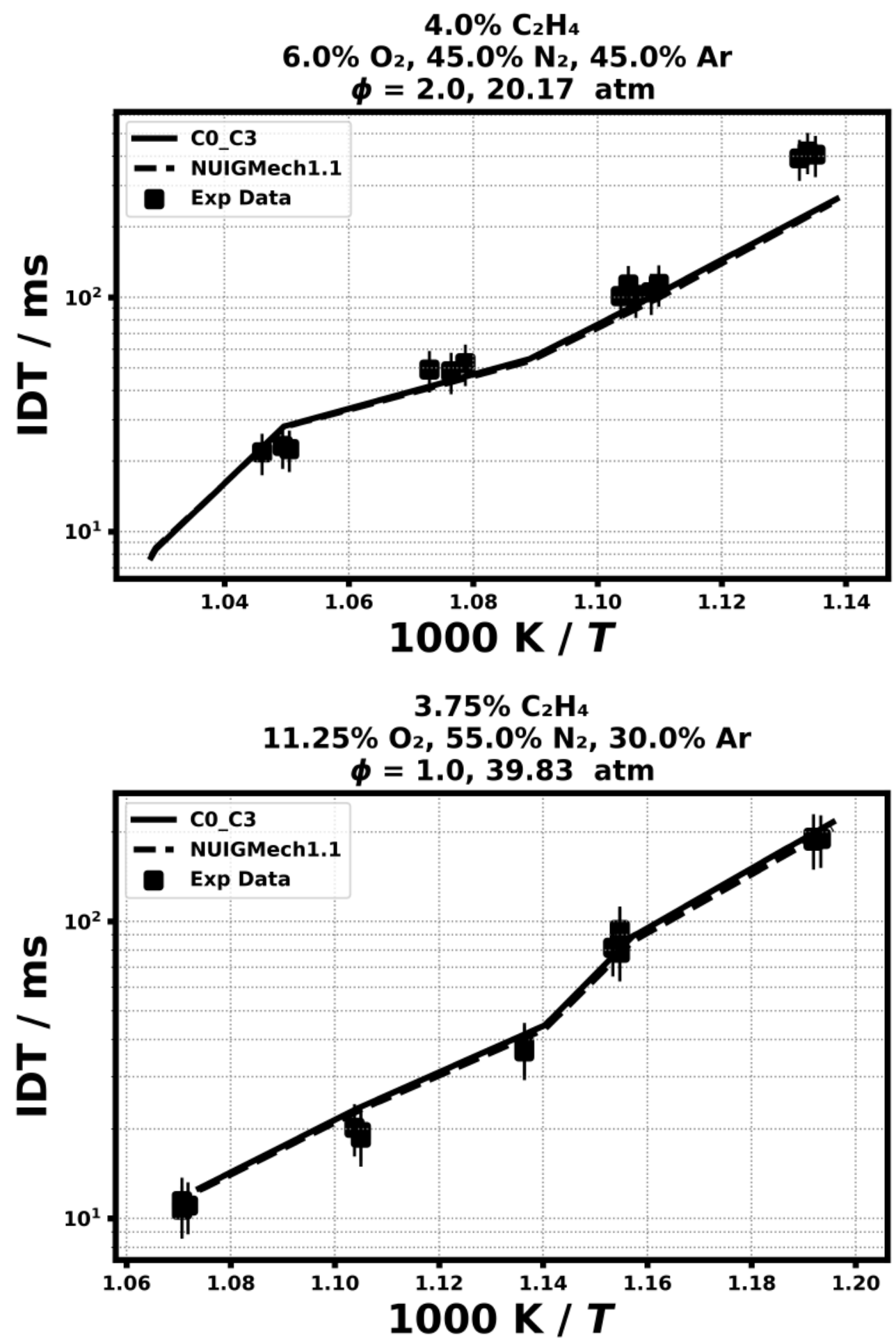


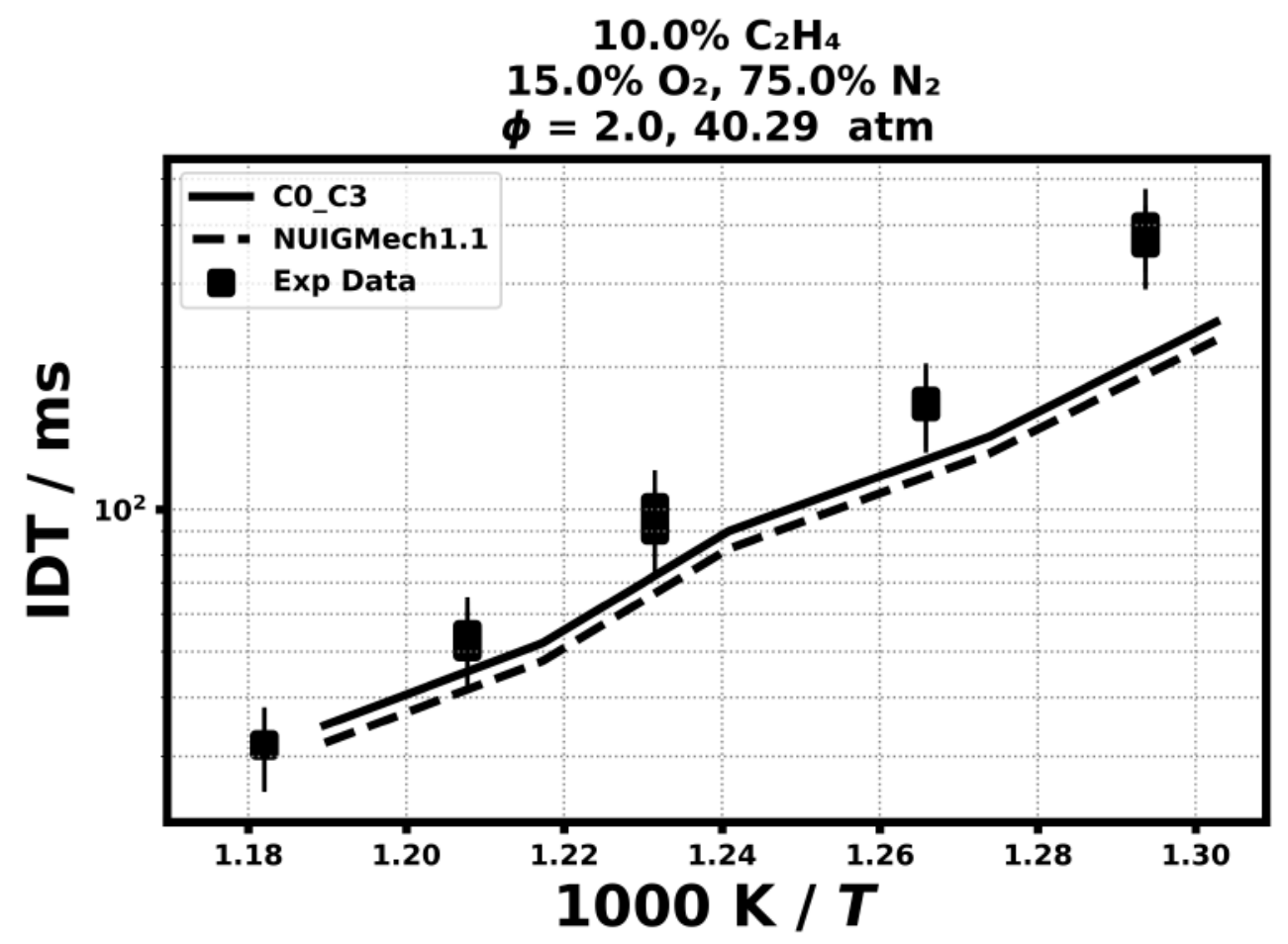

Speciation in Jet-stirred reactor

5.11) Lopez, J. G., Rasmussen, C. L., Alzueta, M. U., Gao, Y., Marshall, P., \& Glarborg, P. Proceedings of the Combustion Institute, 32(1) (2009) 367-375.

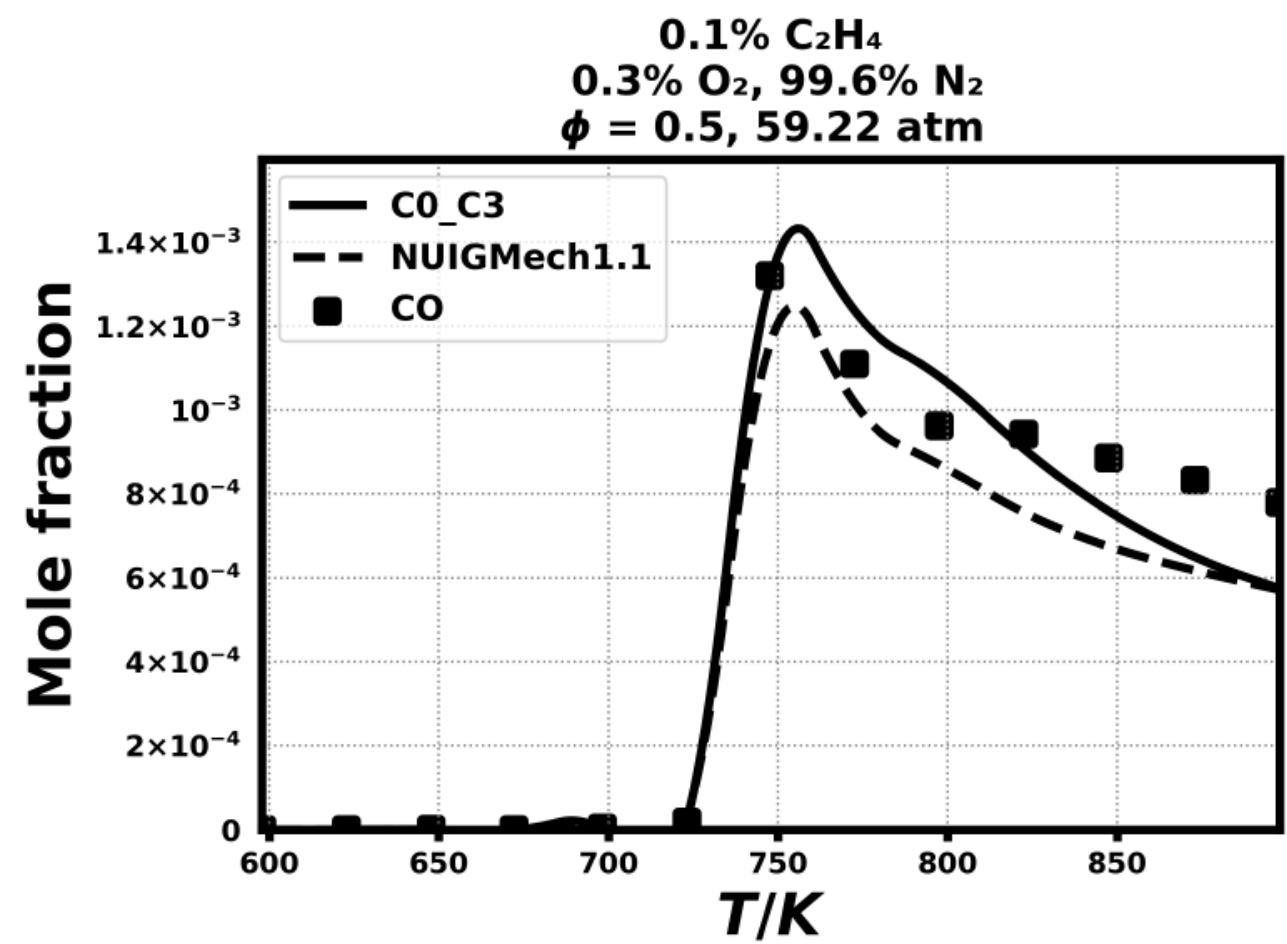



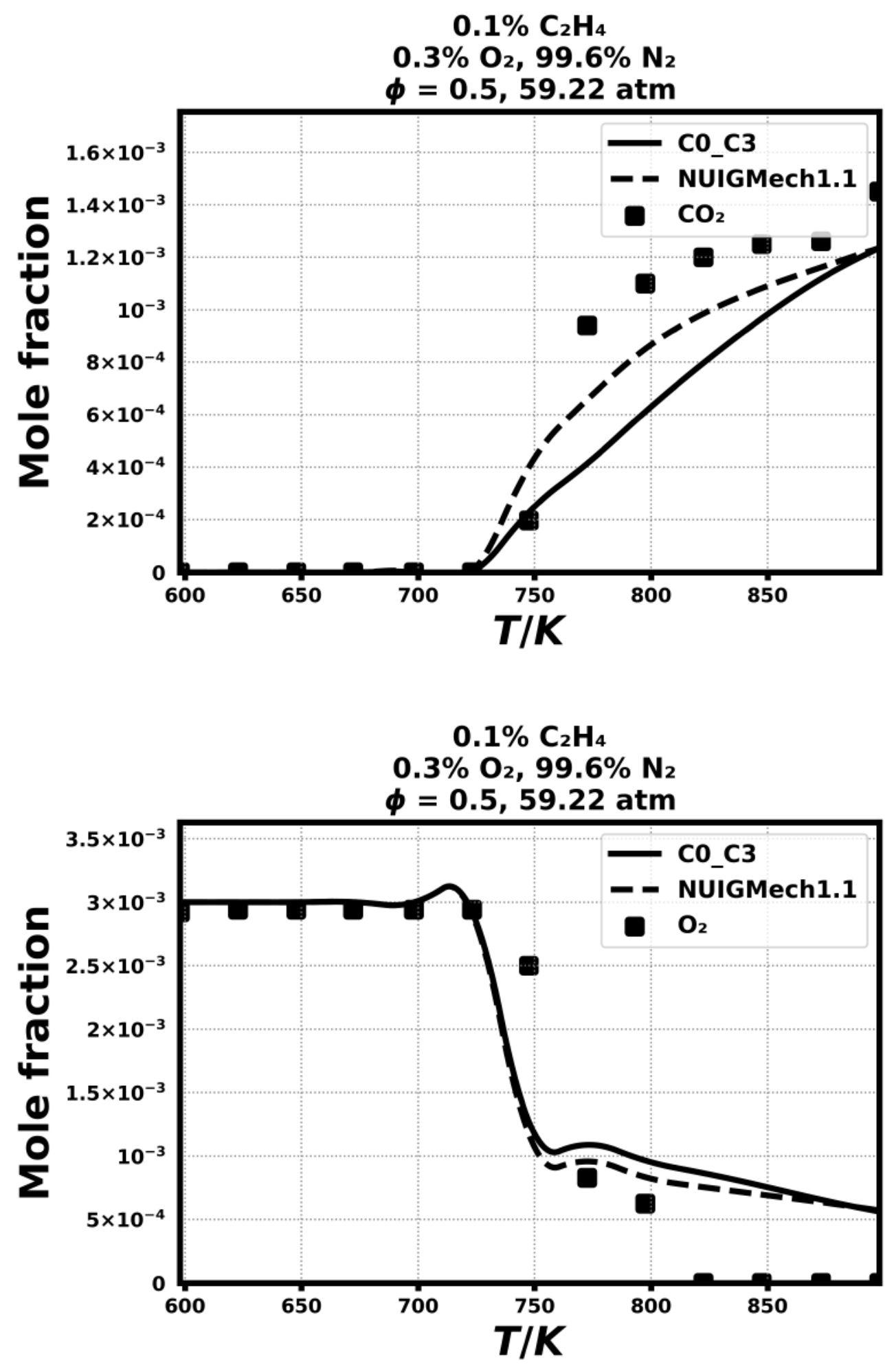

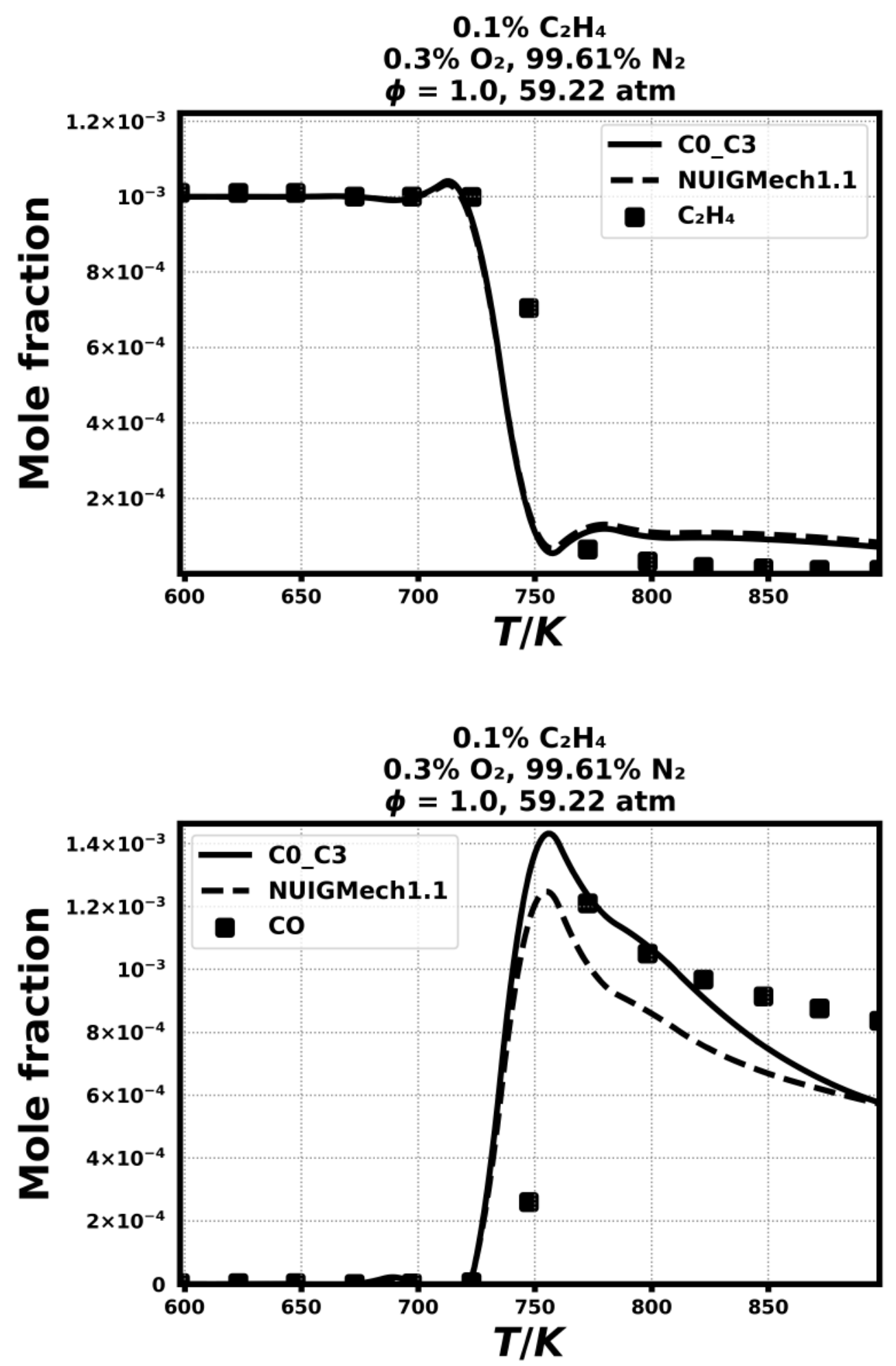

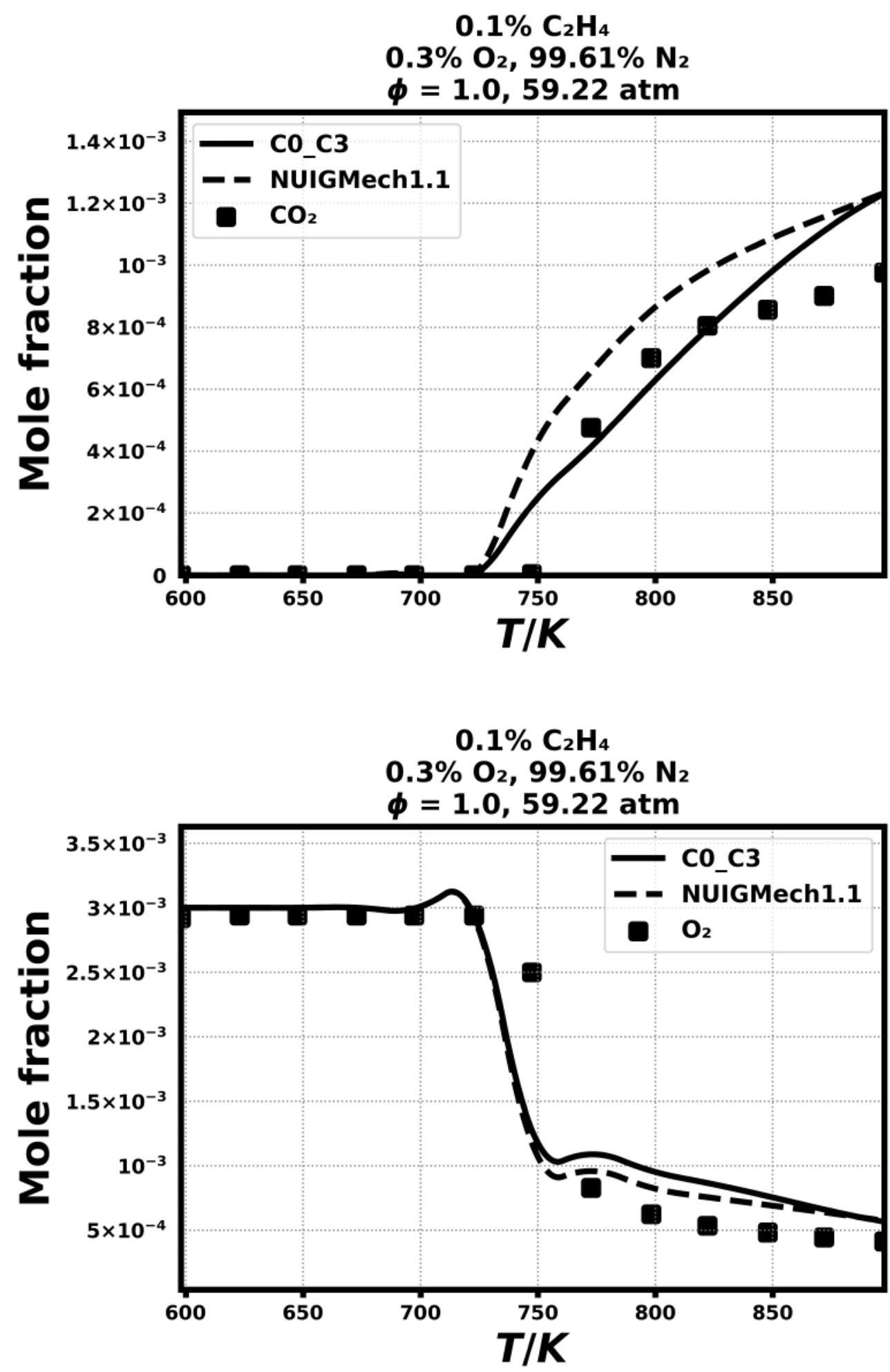

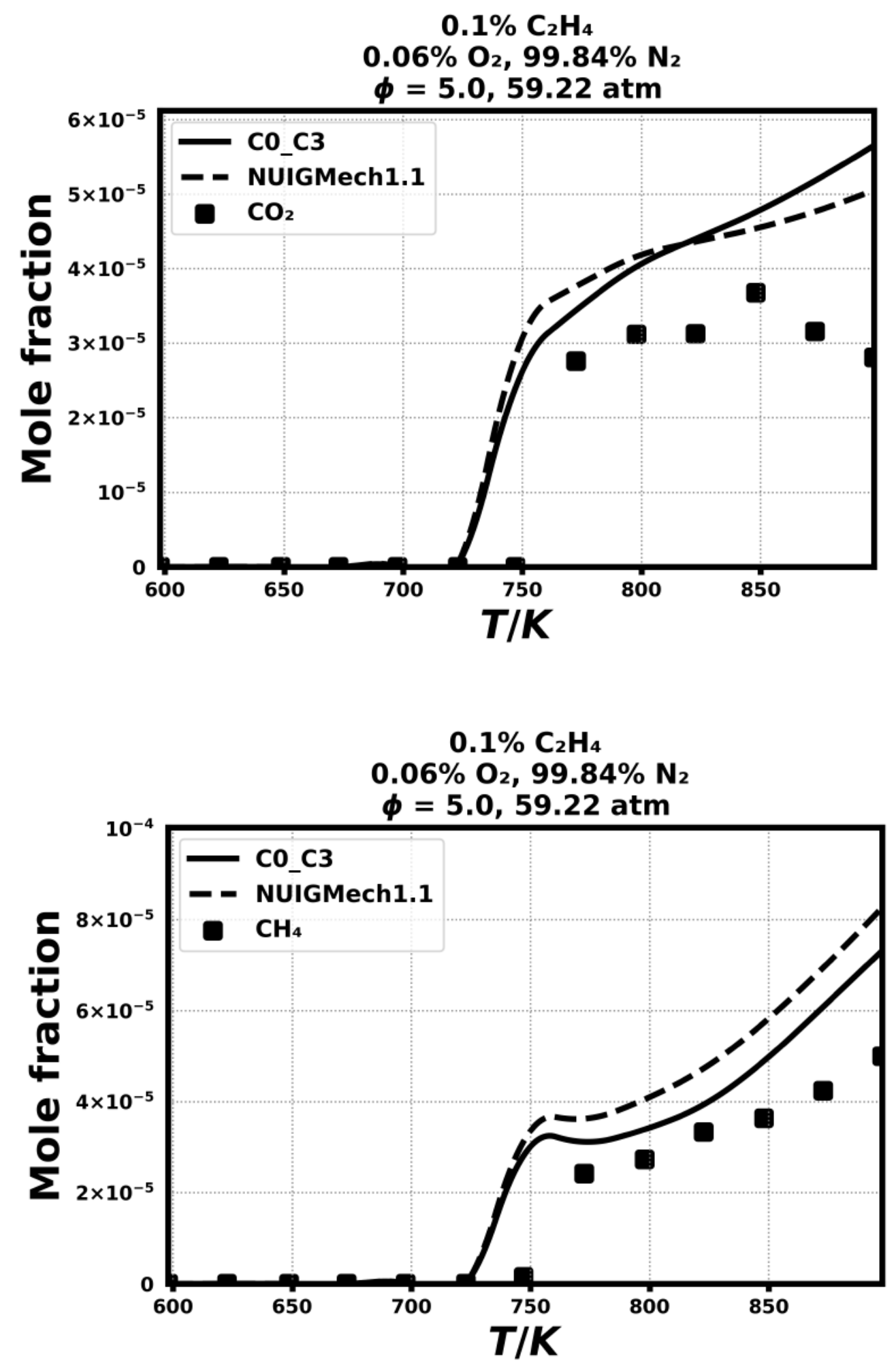
5.12) Jallais, S., Bonneau, L., Auzanneau, M., Naudet, V., \& Bockel-Macal, S, Industrial $\&$ engineering chemistry research, 41(23) (2002) 5659-5667.
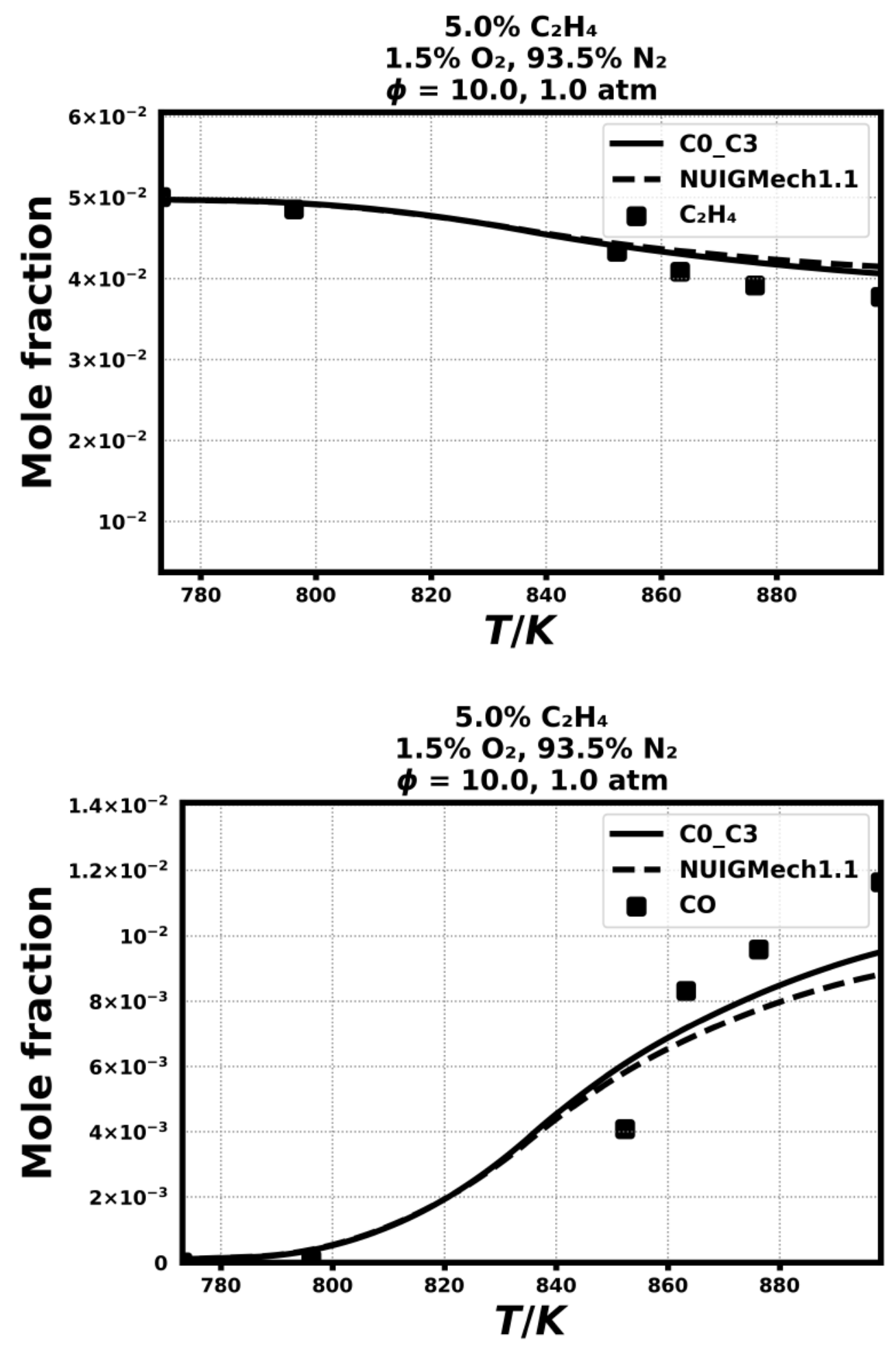

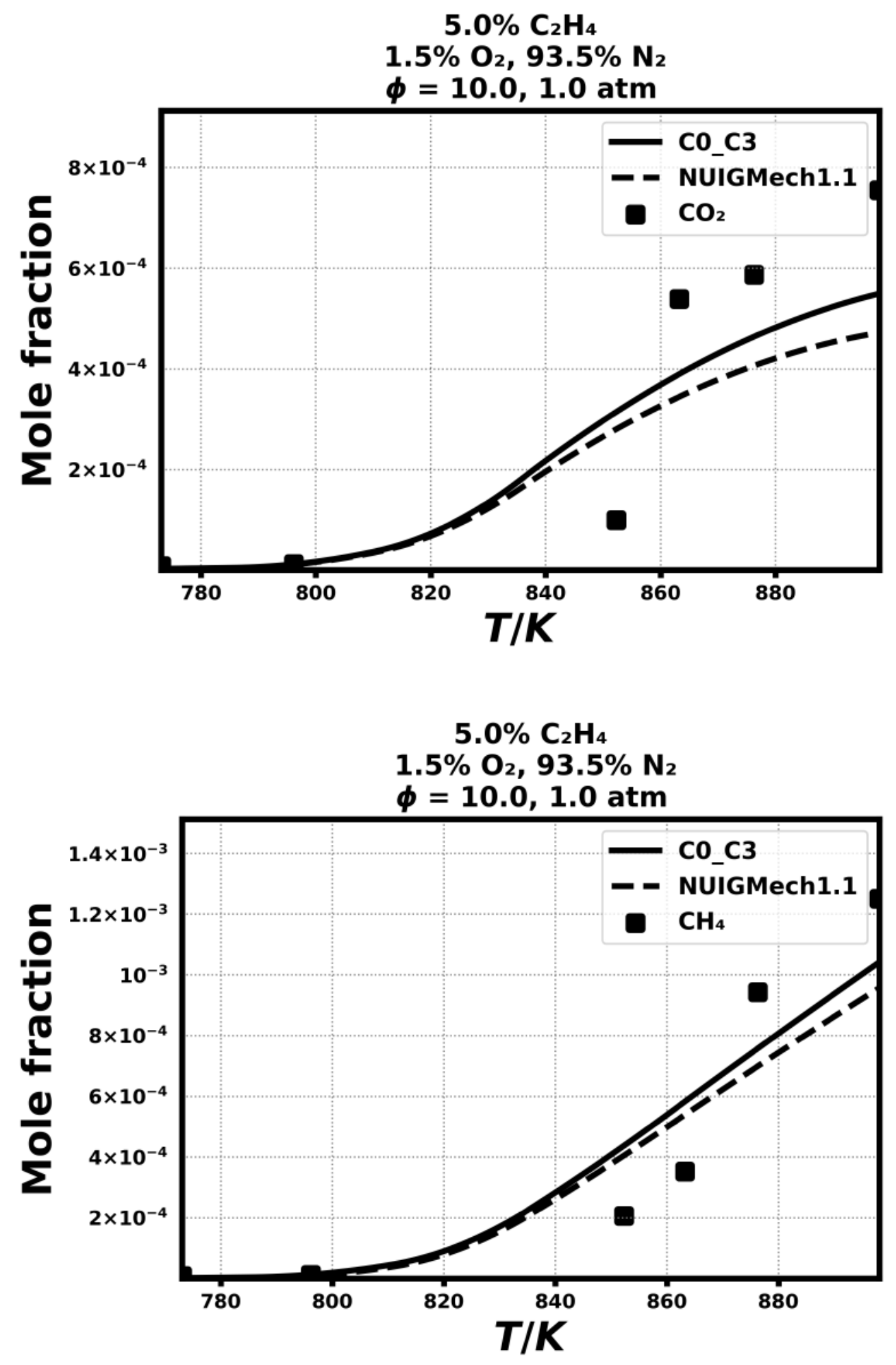

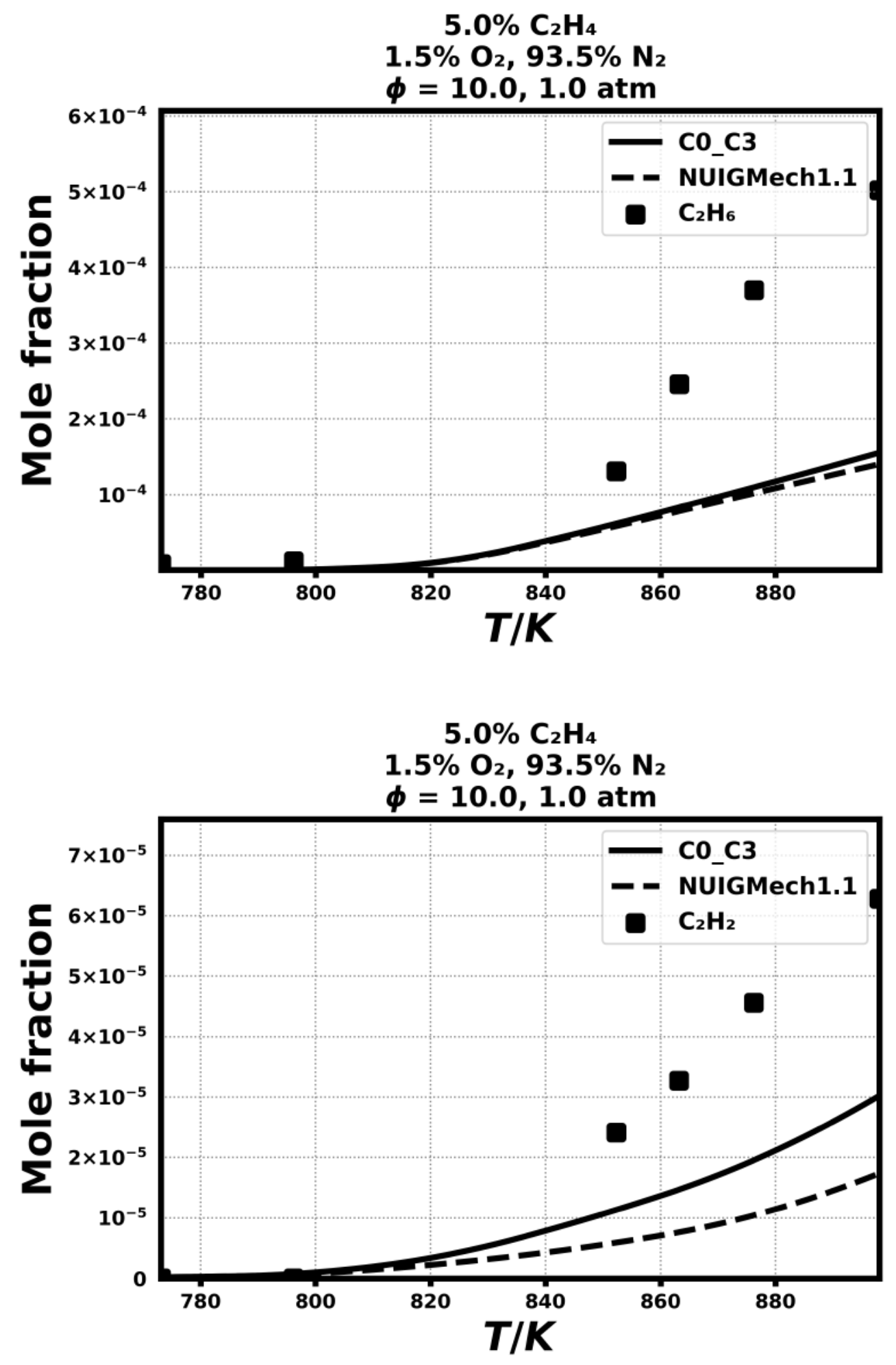

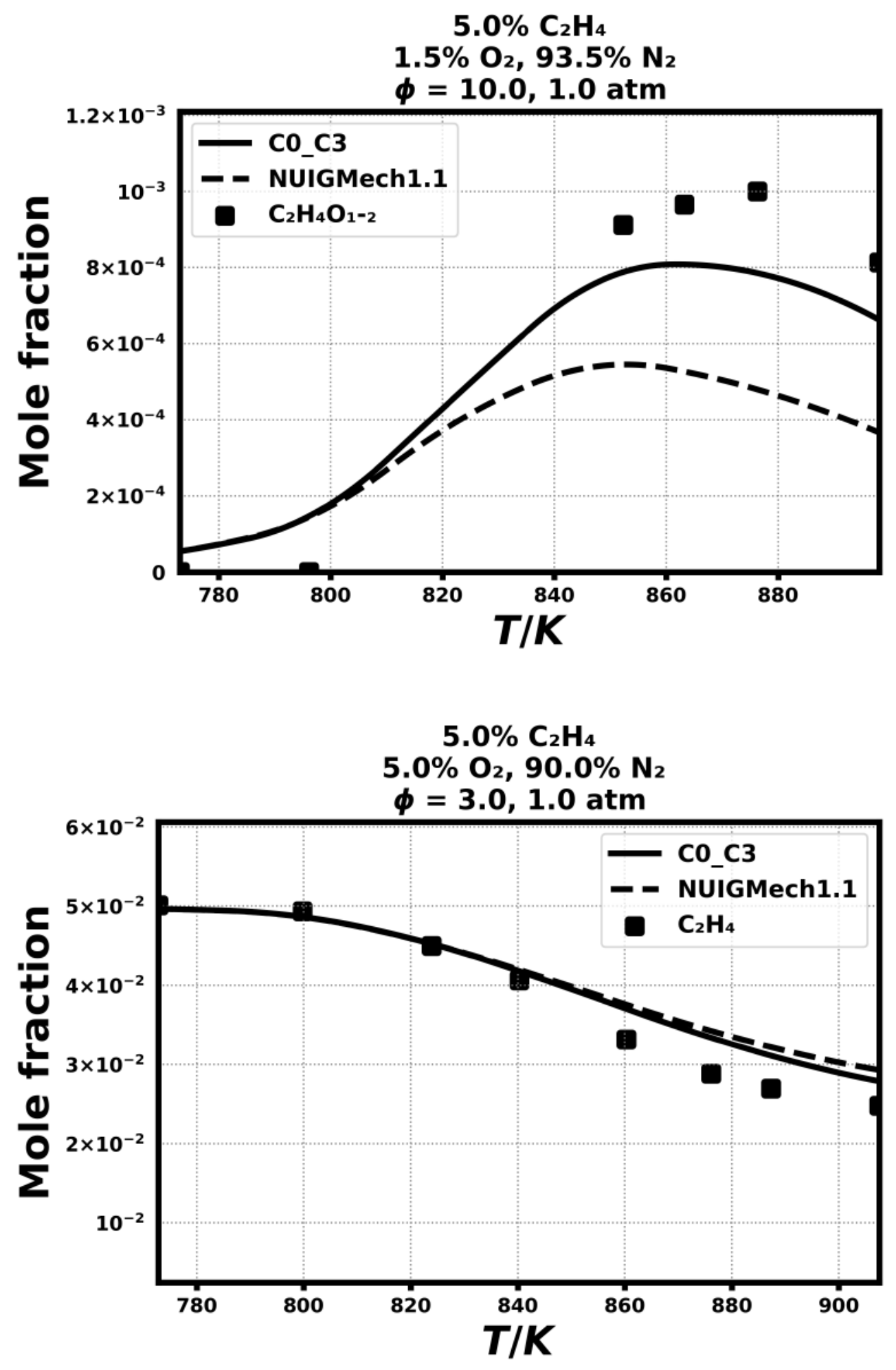

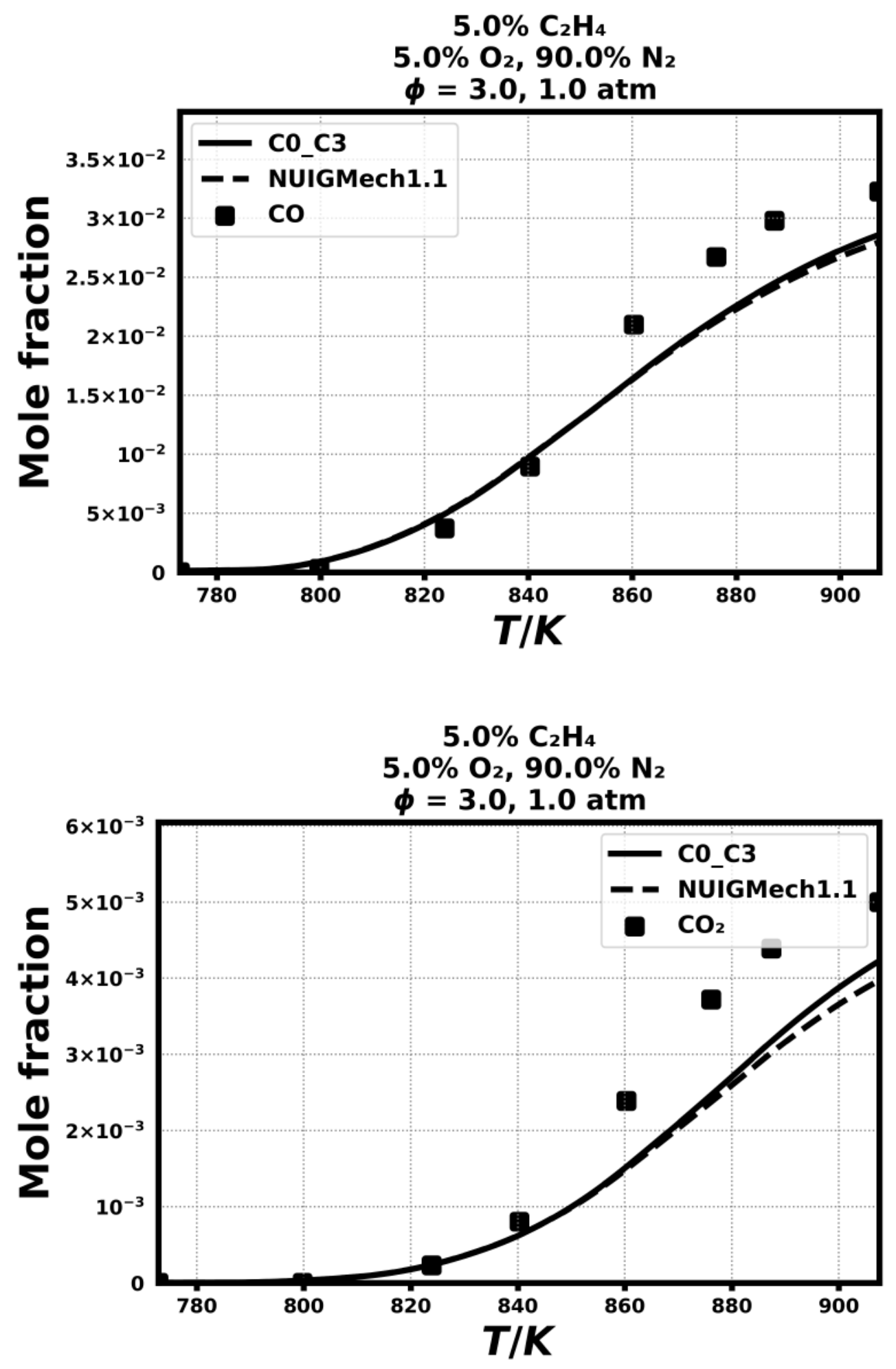

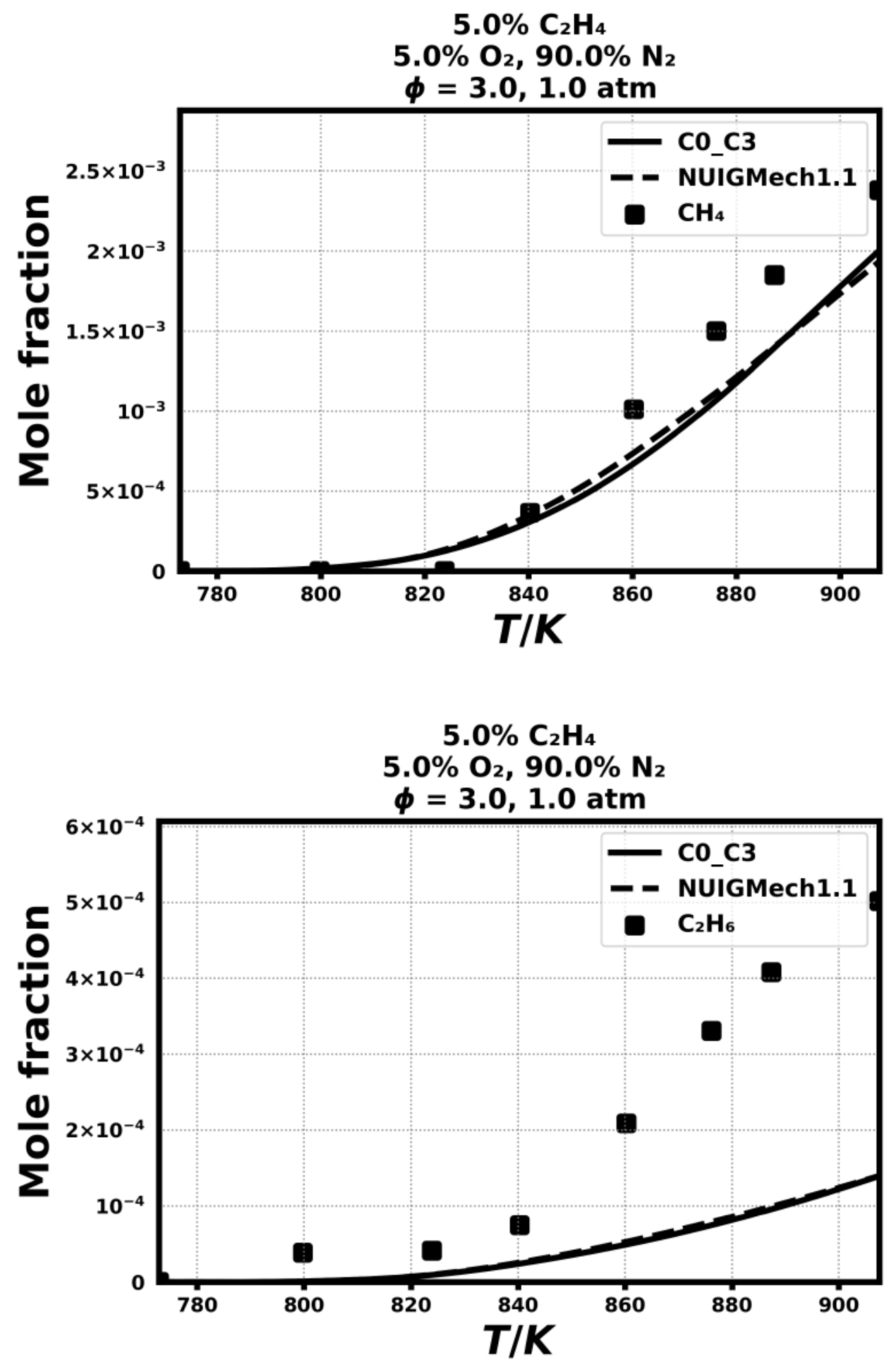

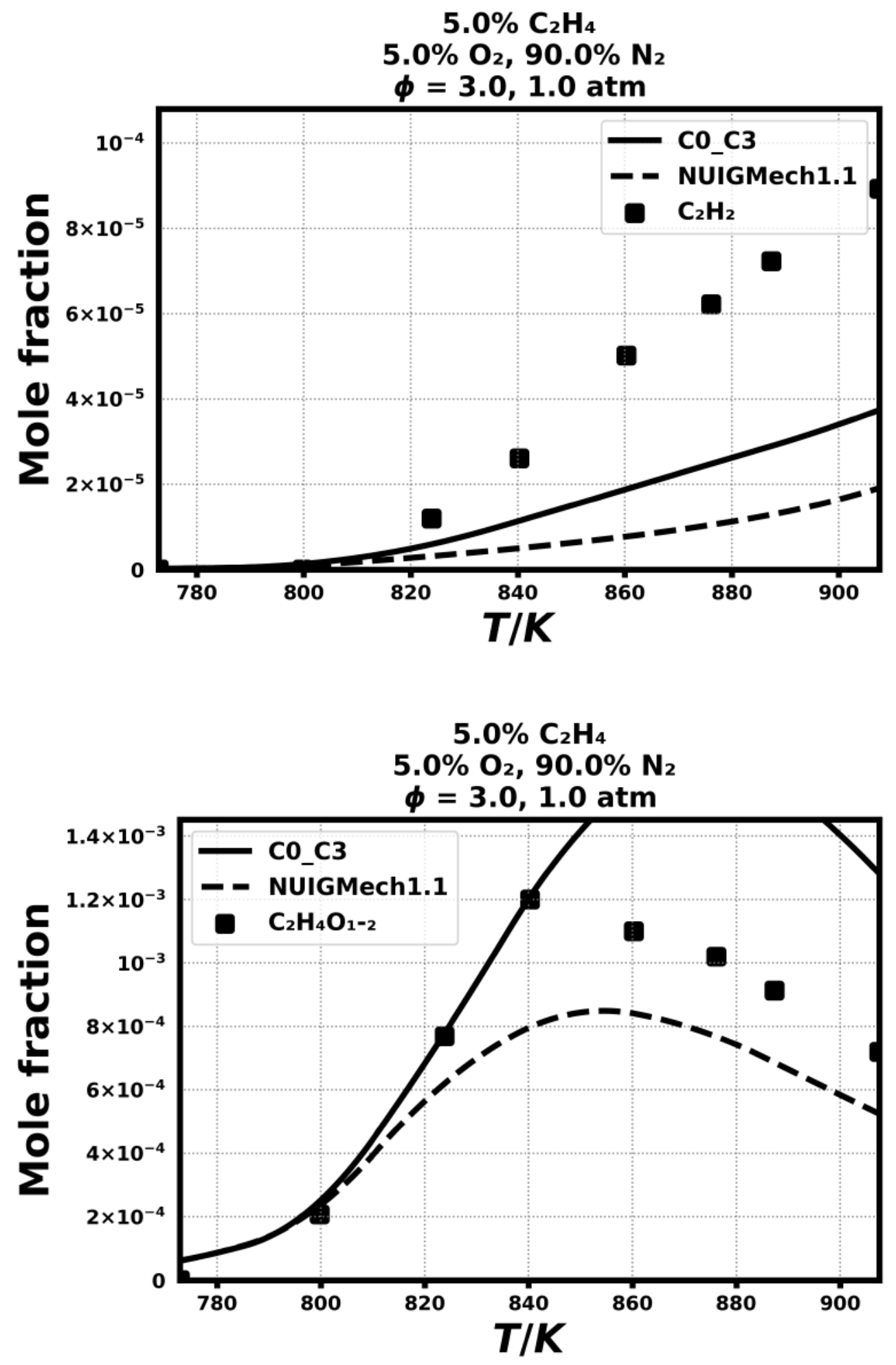

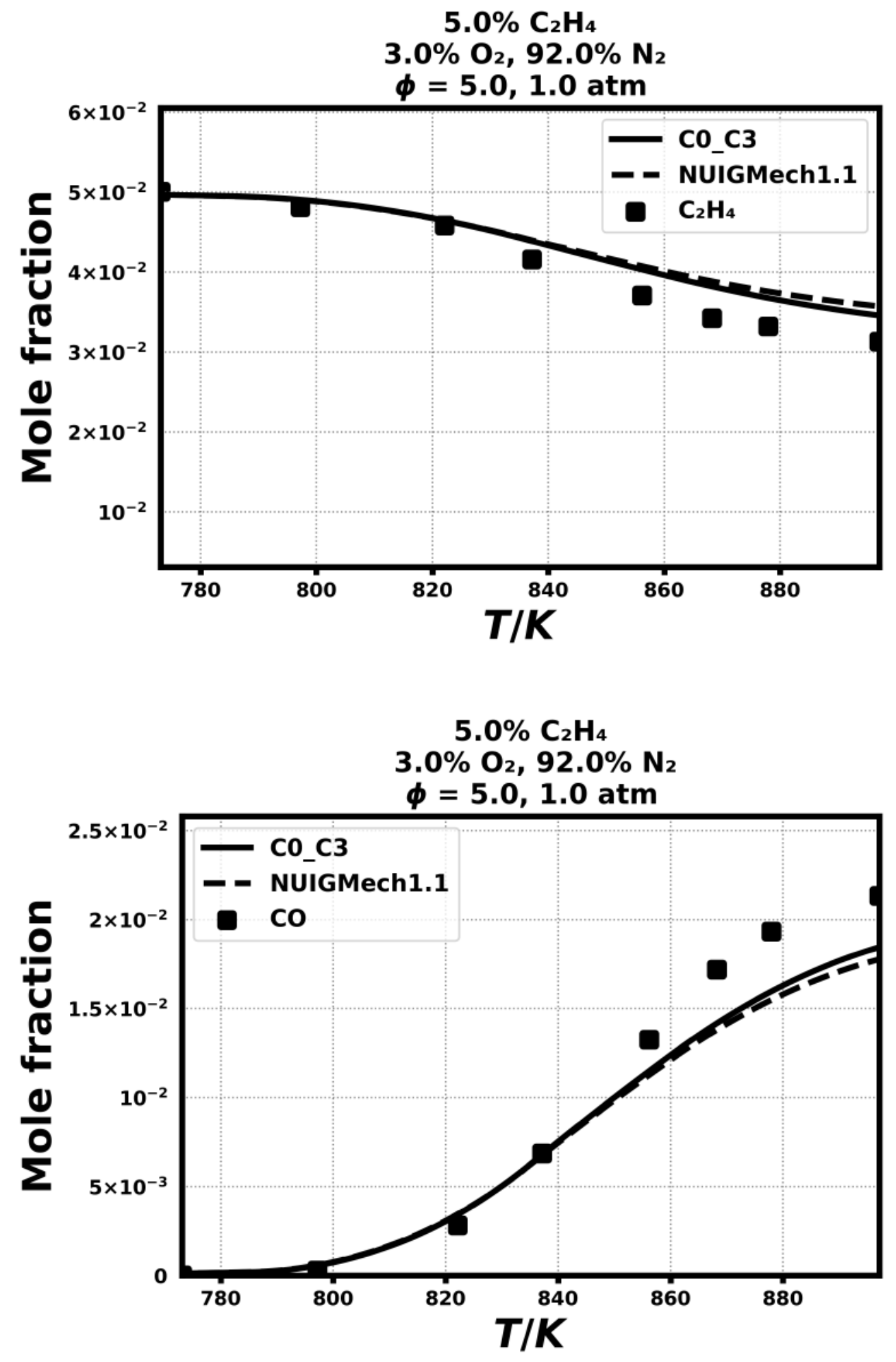

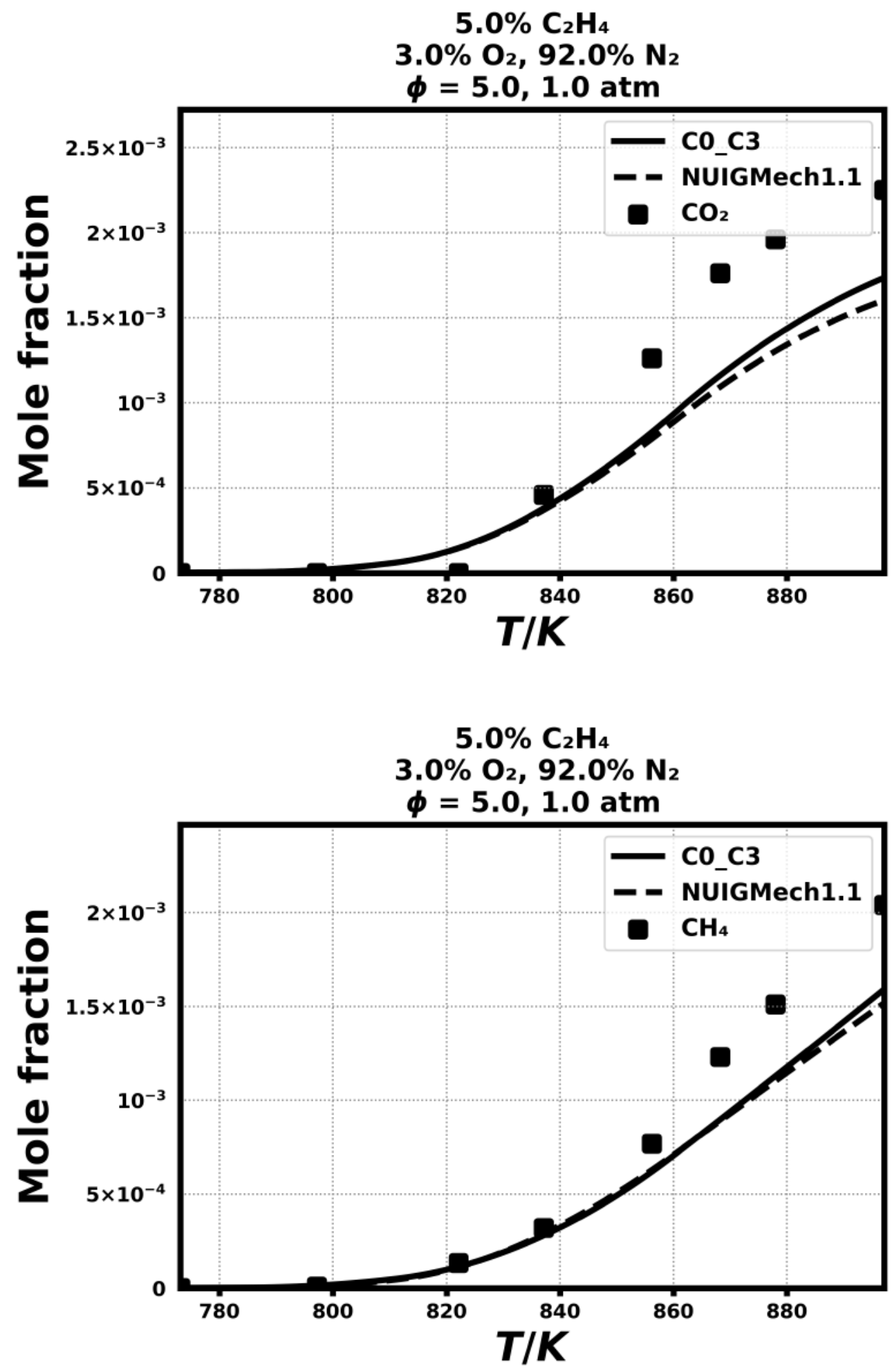

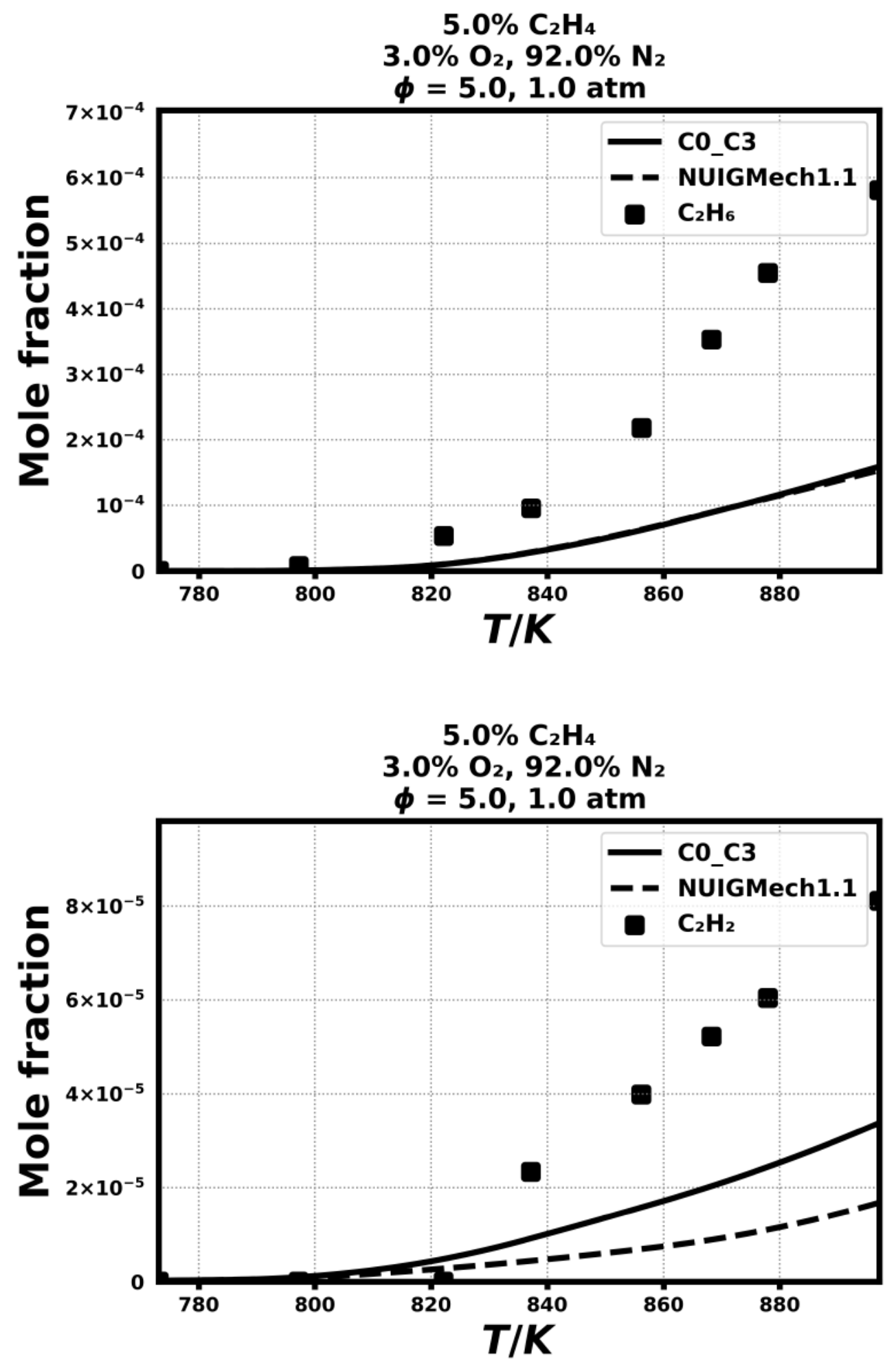


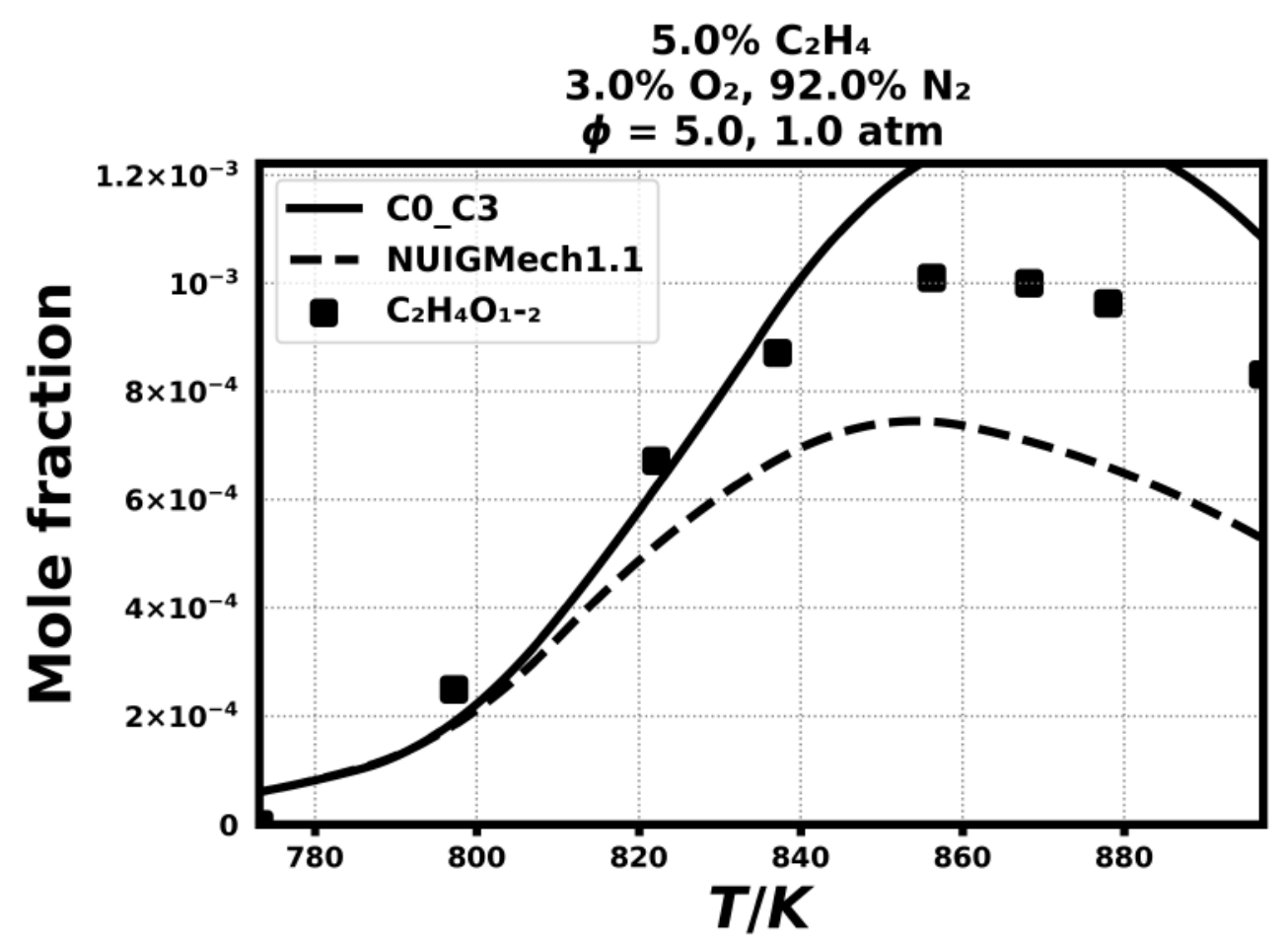

5.13) Cong, T. L., Bedjanian, E., \& Dagaut, P., Combustion science and technology, 182 (4-6) (2010) 333-349.

$0.17 \% \mathrm{C}_{2} \mathrm{H}_{4}$

$1.02 \% \mathrm{O}_{2}, 98.81 \% \mathrm{~N}_{2}$ $\phi=0.5,1.0 \mathrm{~atm}$

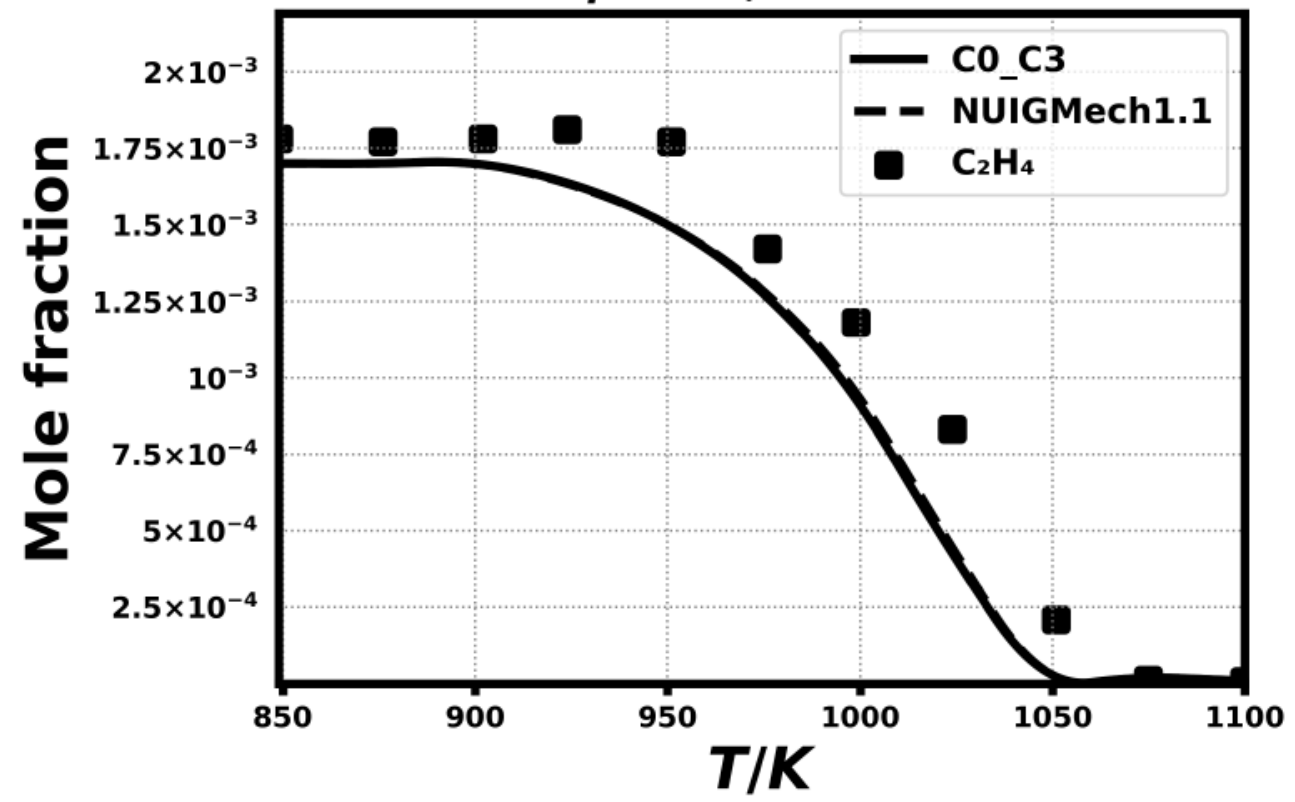



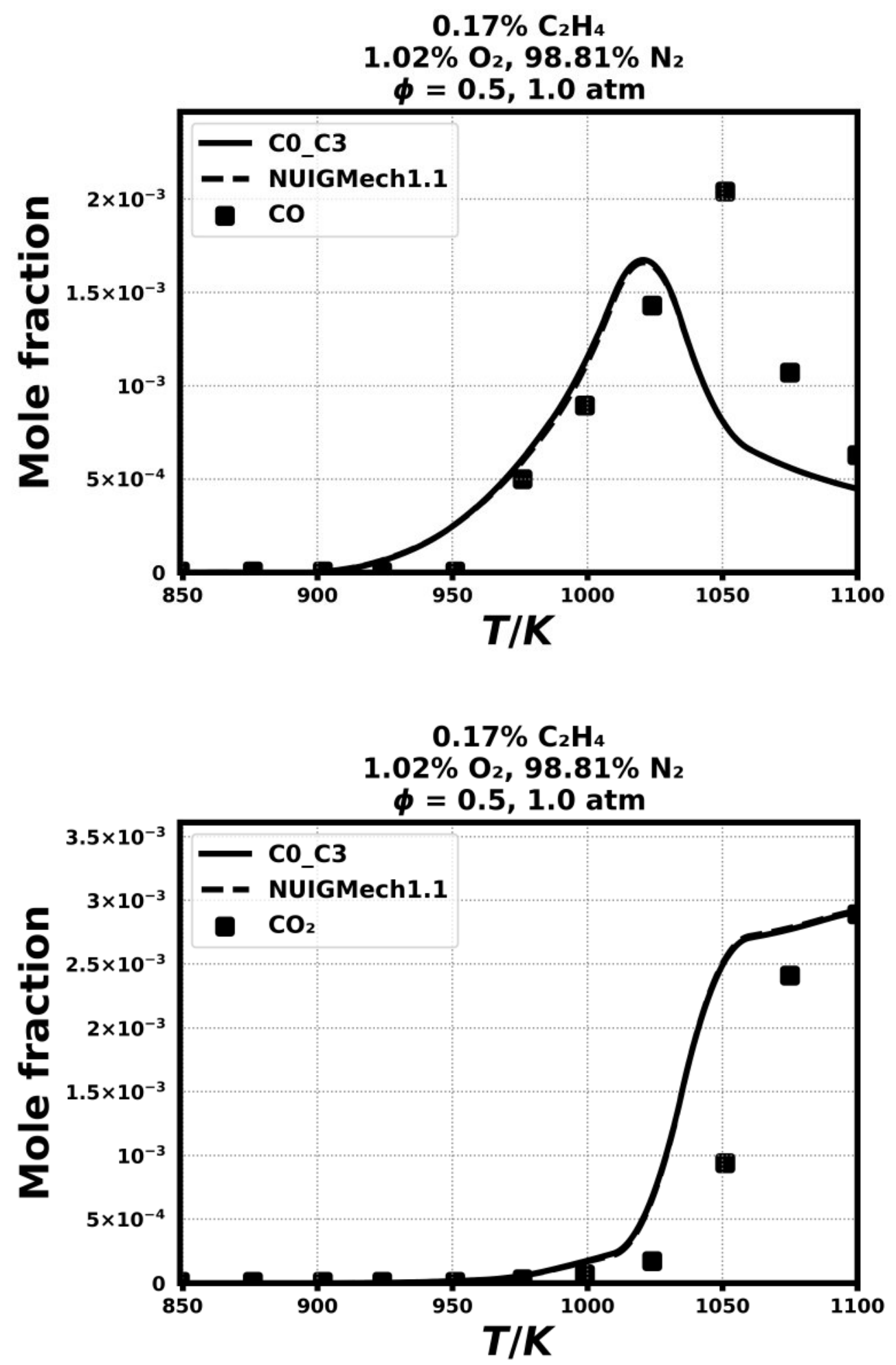

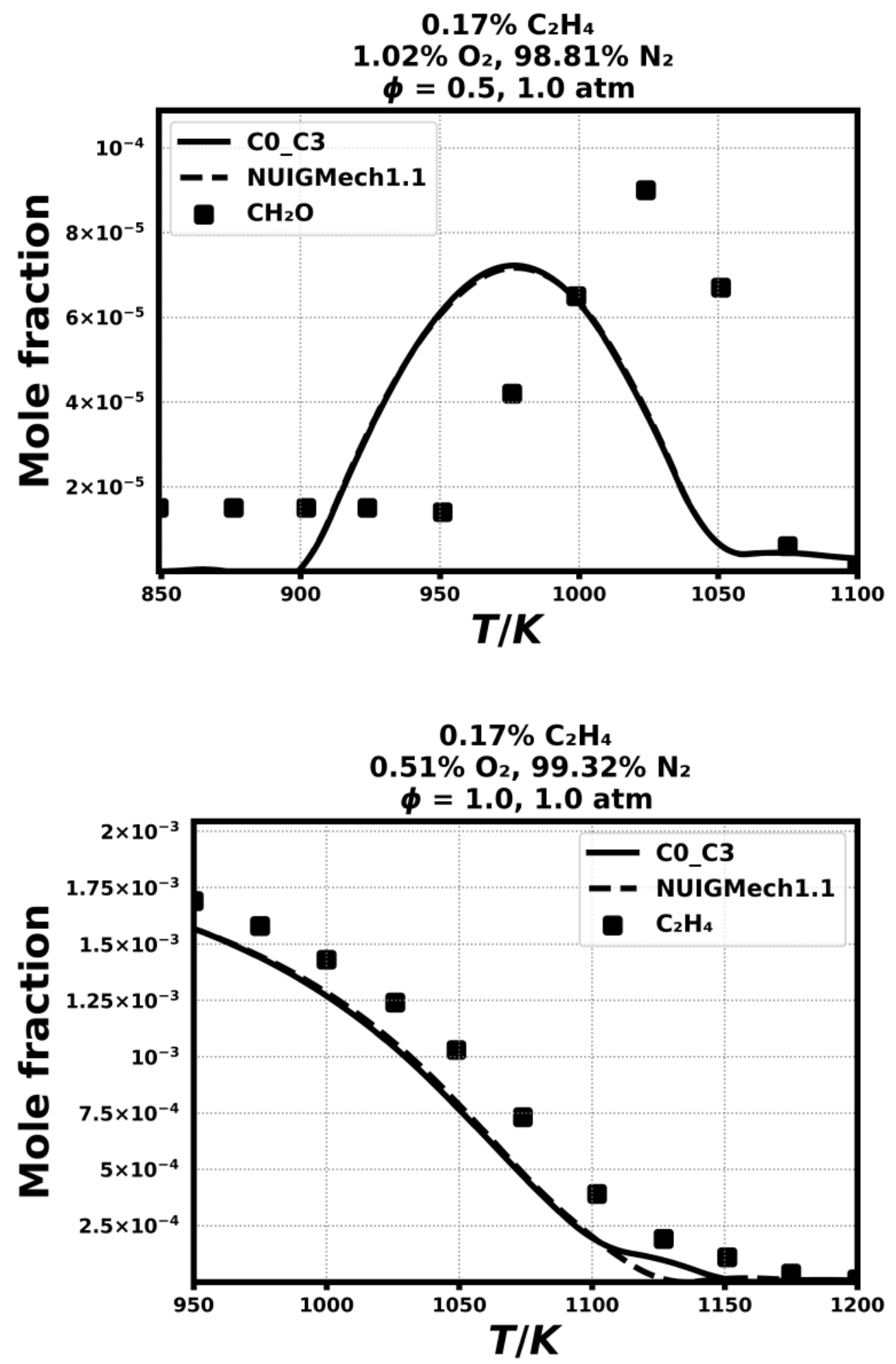

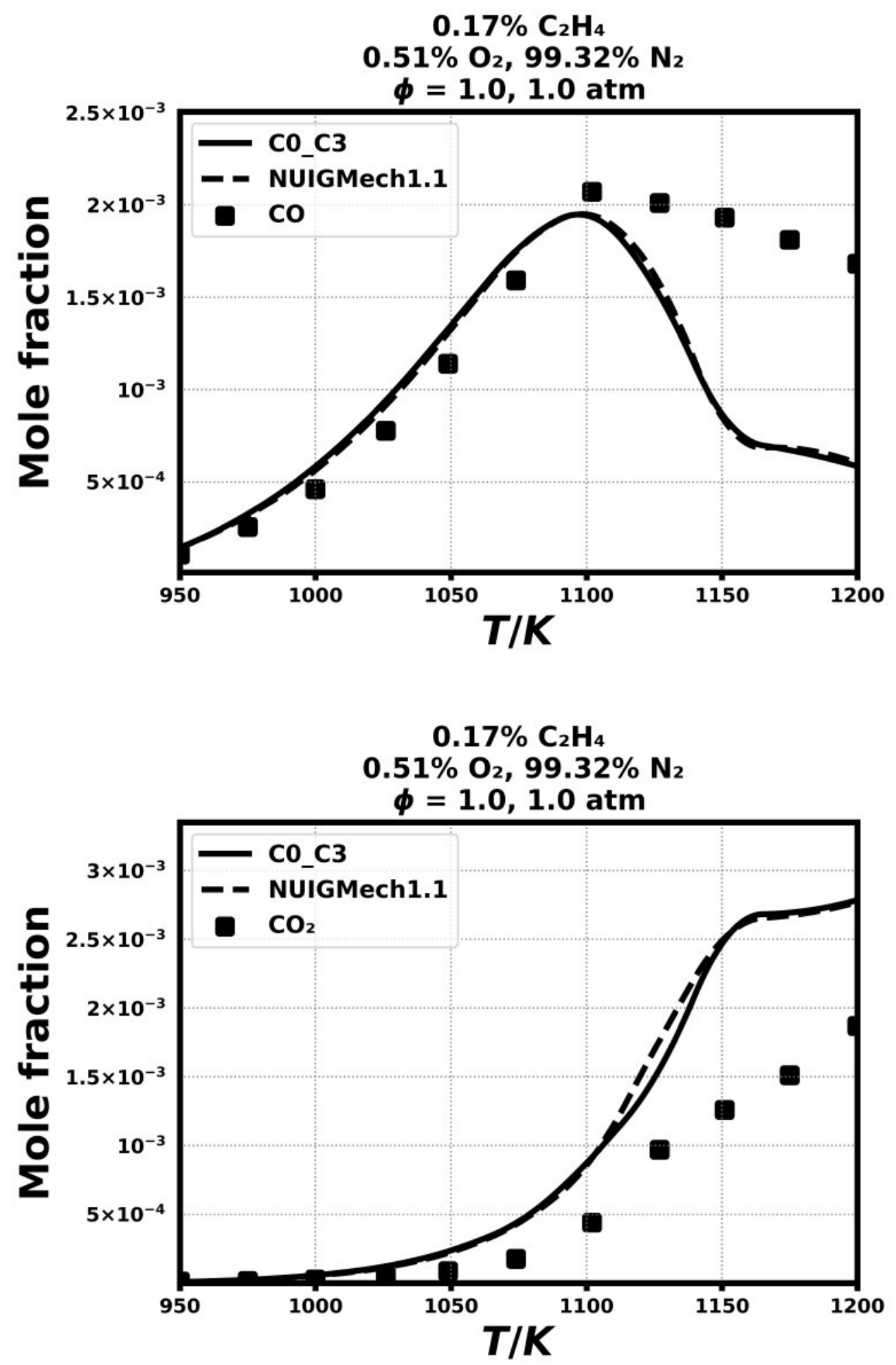

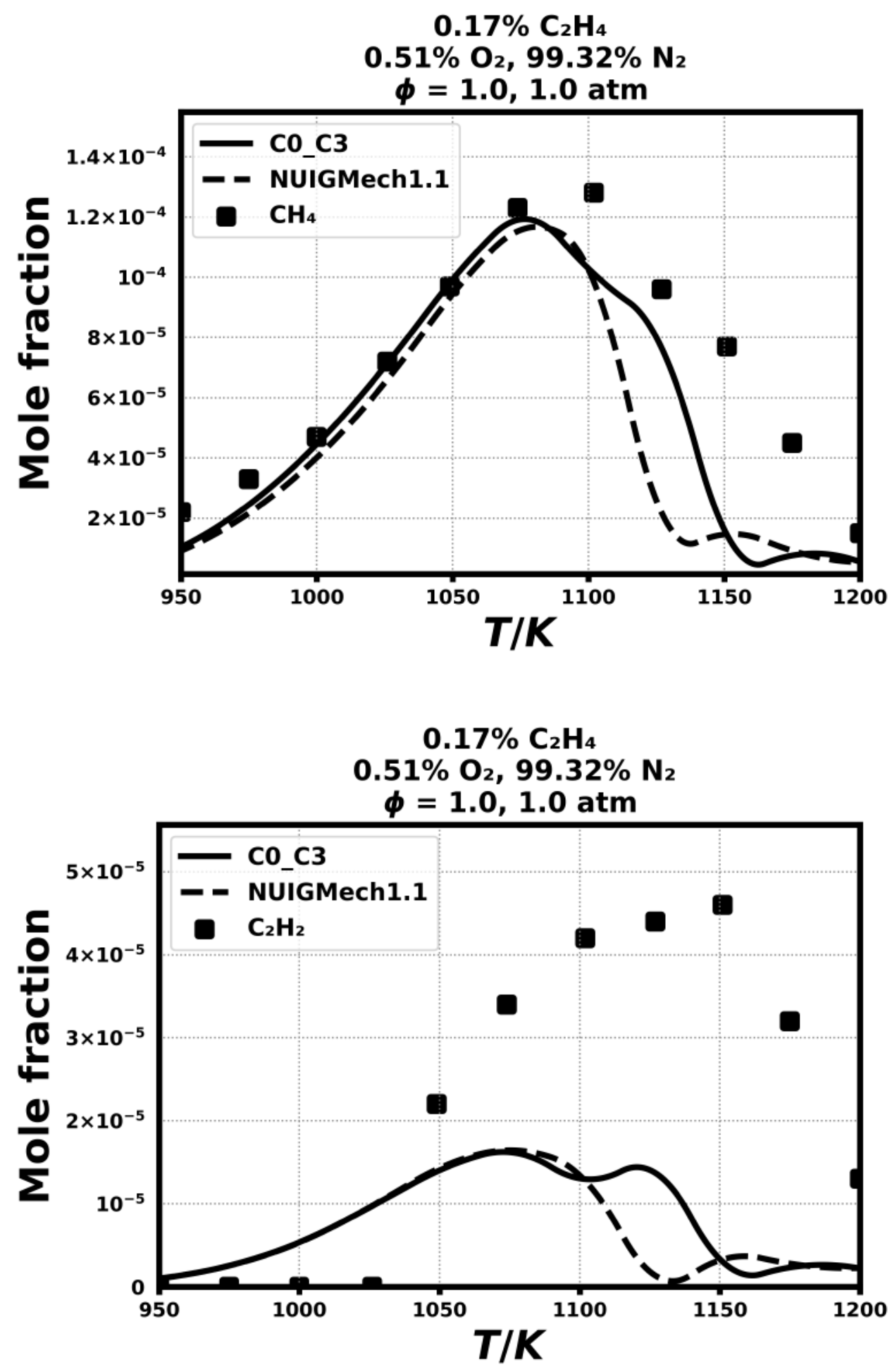

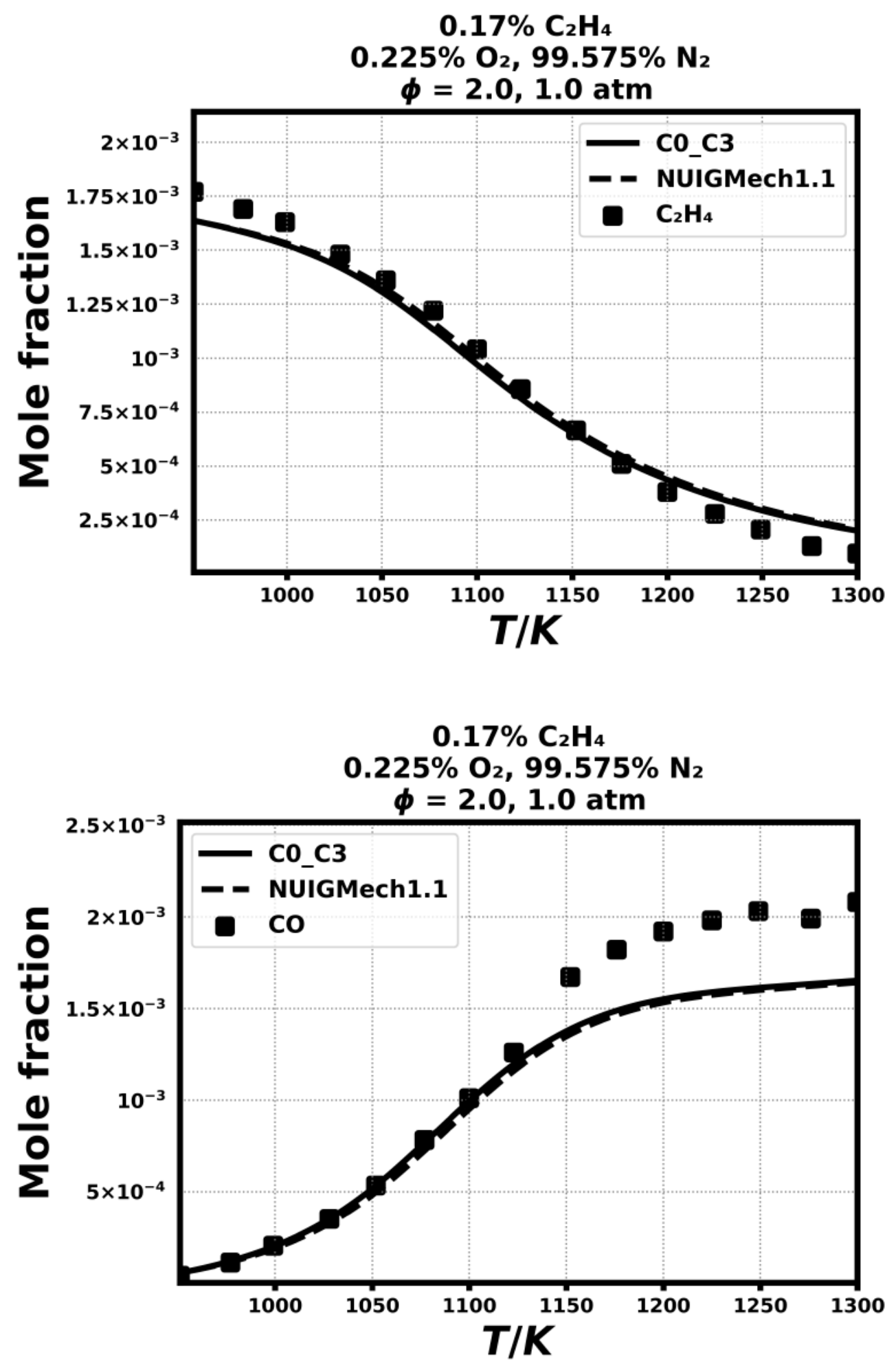

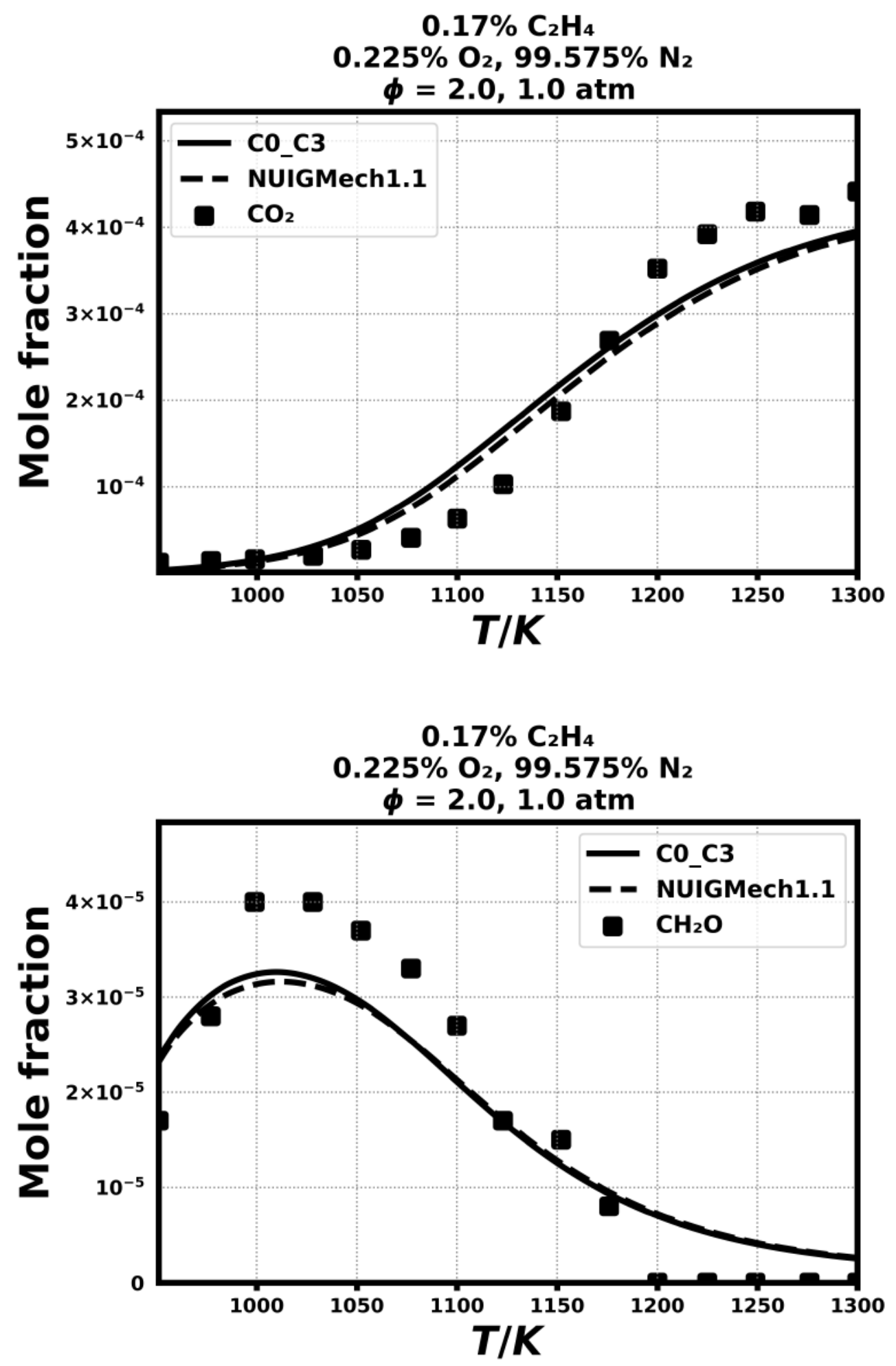

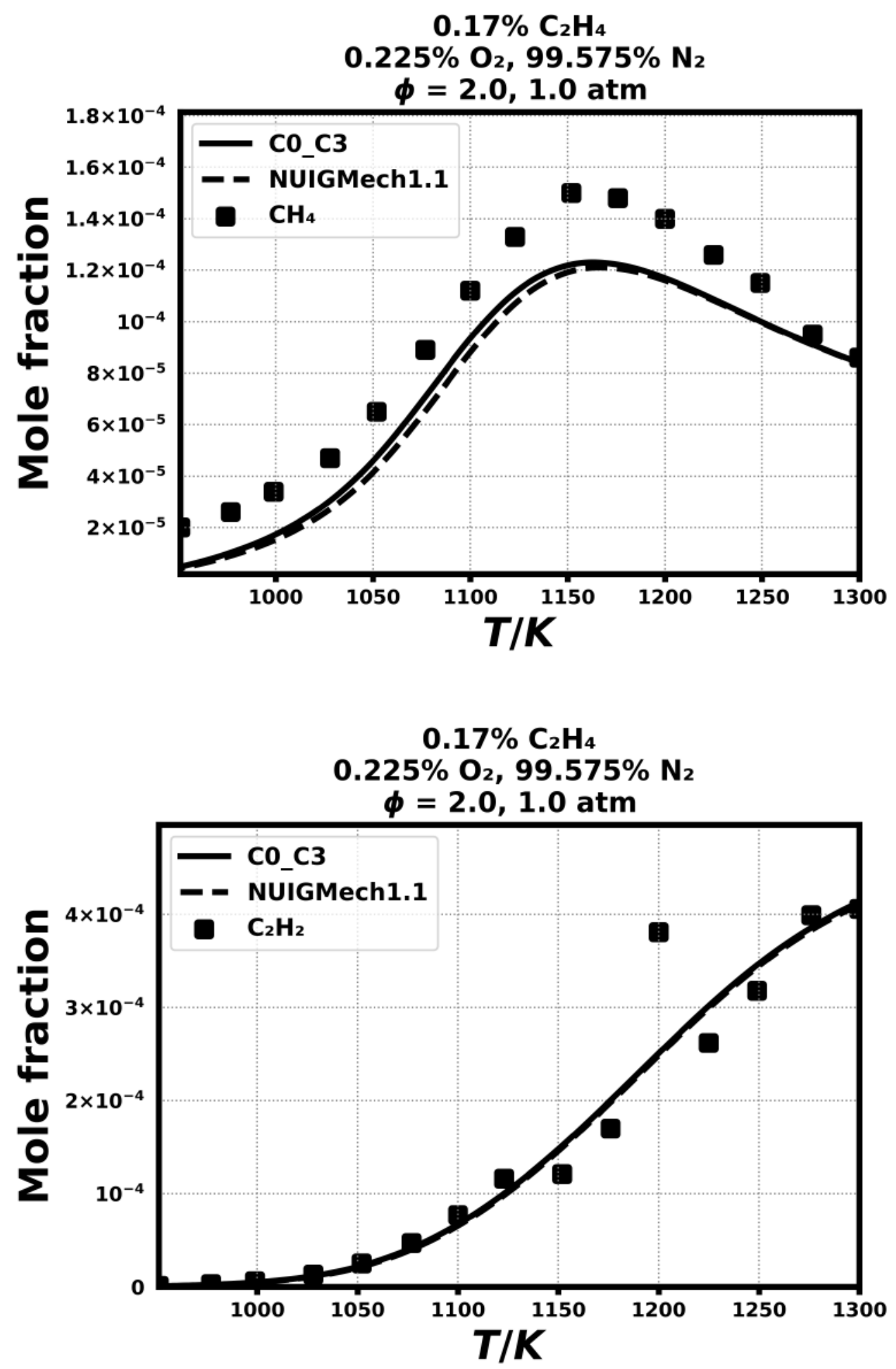


\section{Speciation in Flow reactor}

5.14) Carriere, T., Westmoreland, P. R., Kazakov, A., Stein, Y. S., \& Dryer, F. L., Proceedings of the Combustion Institute, 29(1) (2002) 1257-1266.
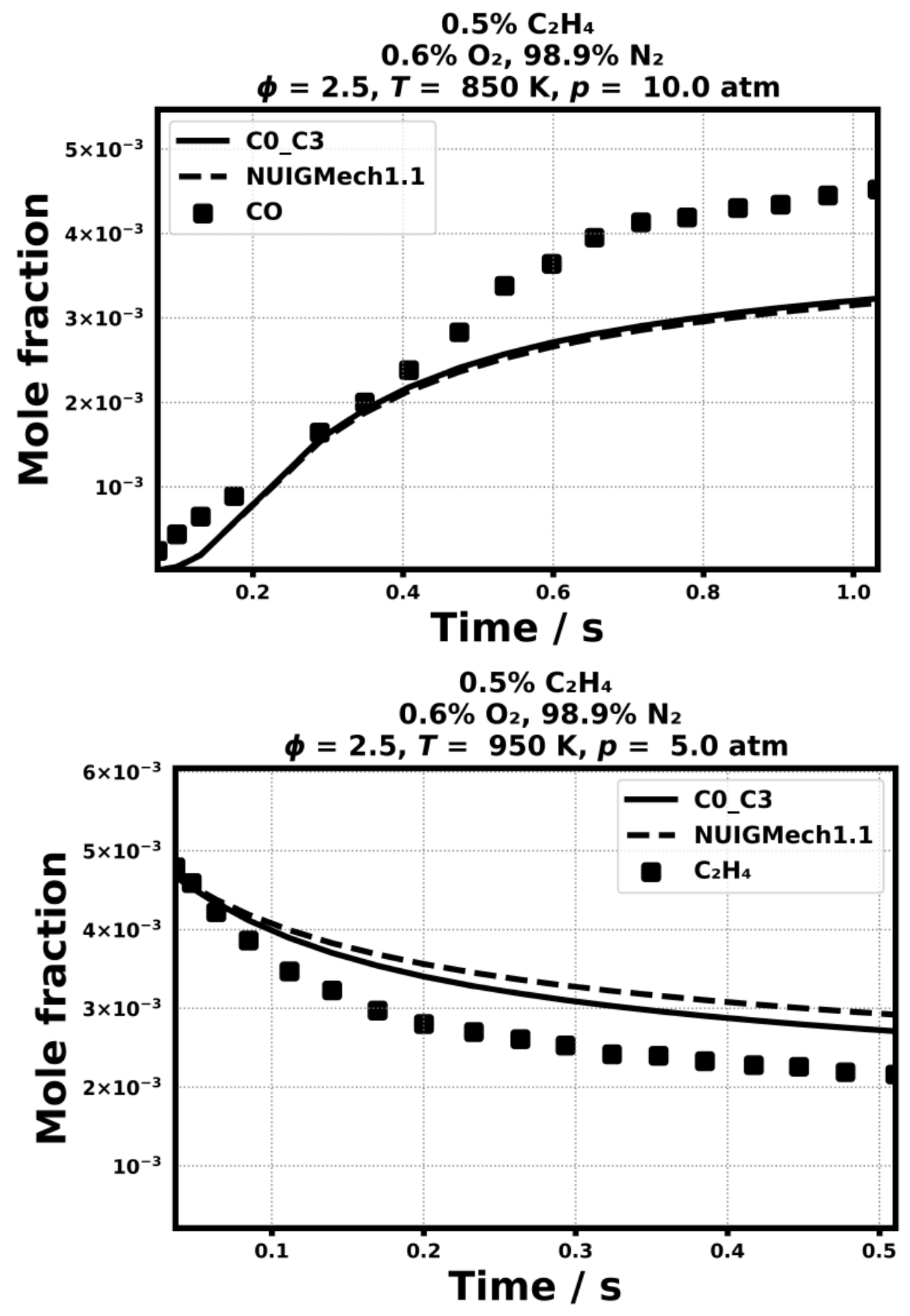

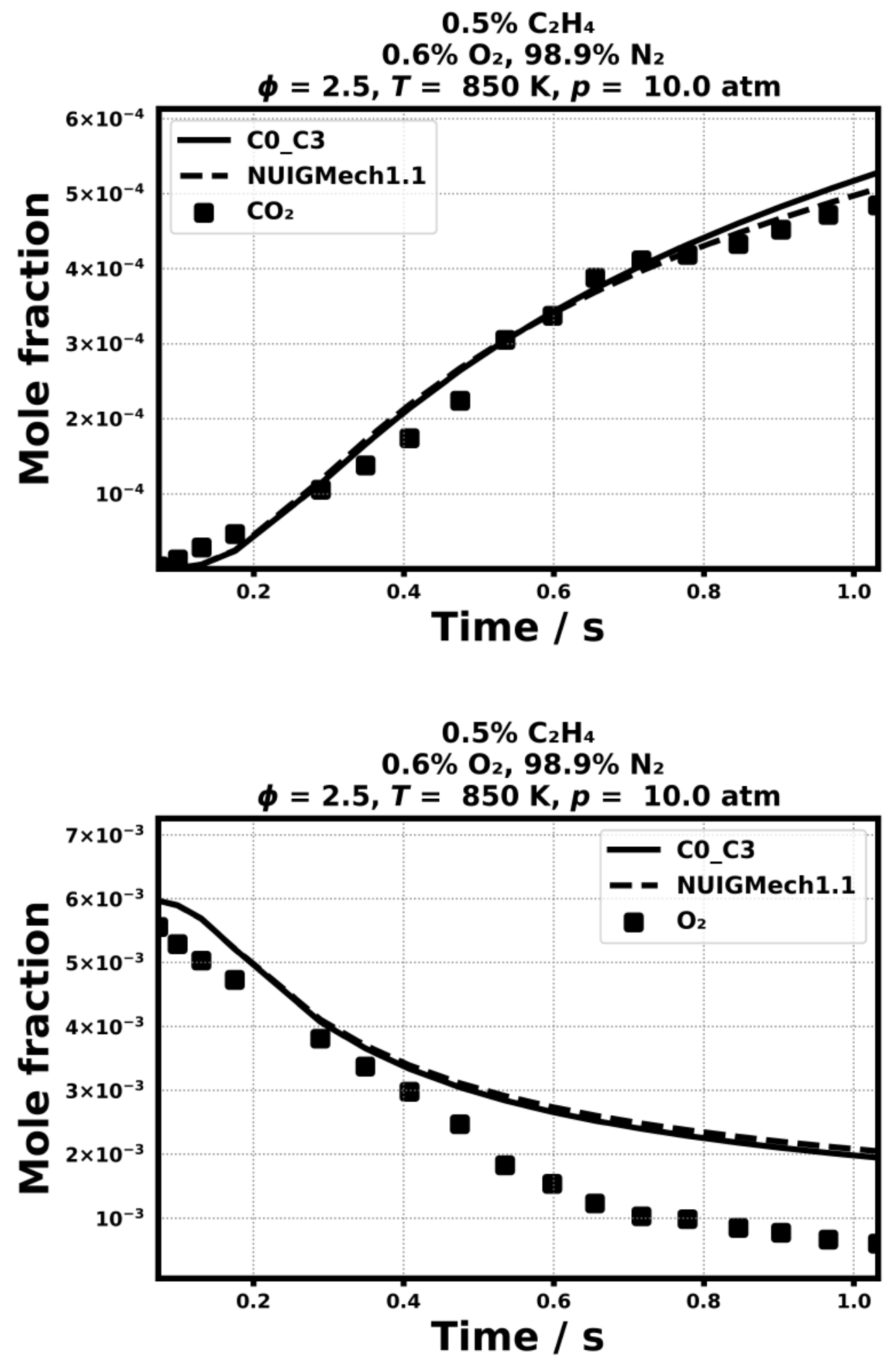

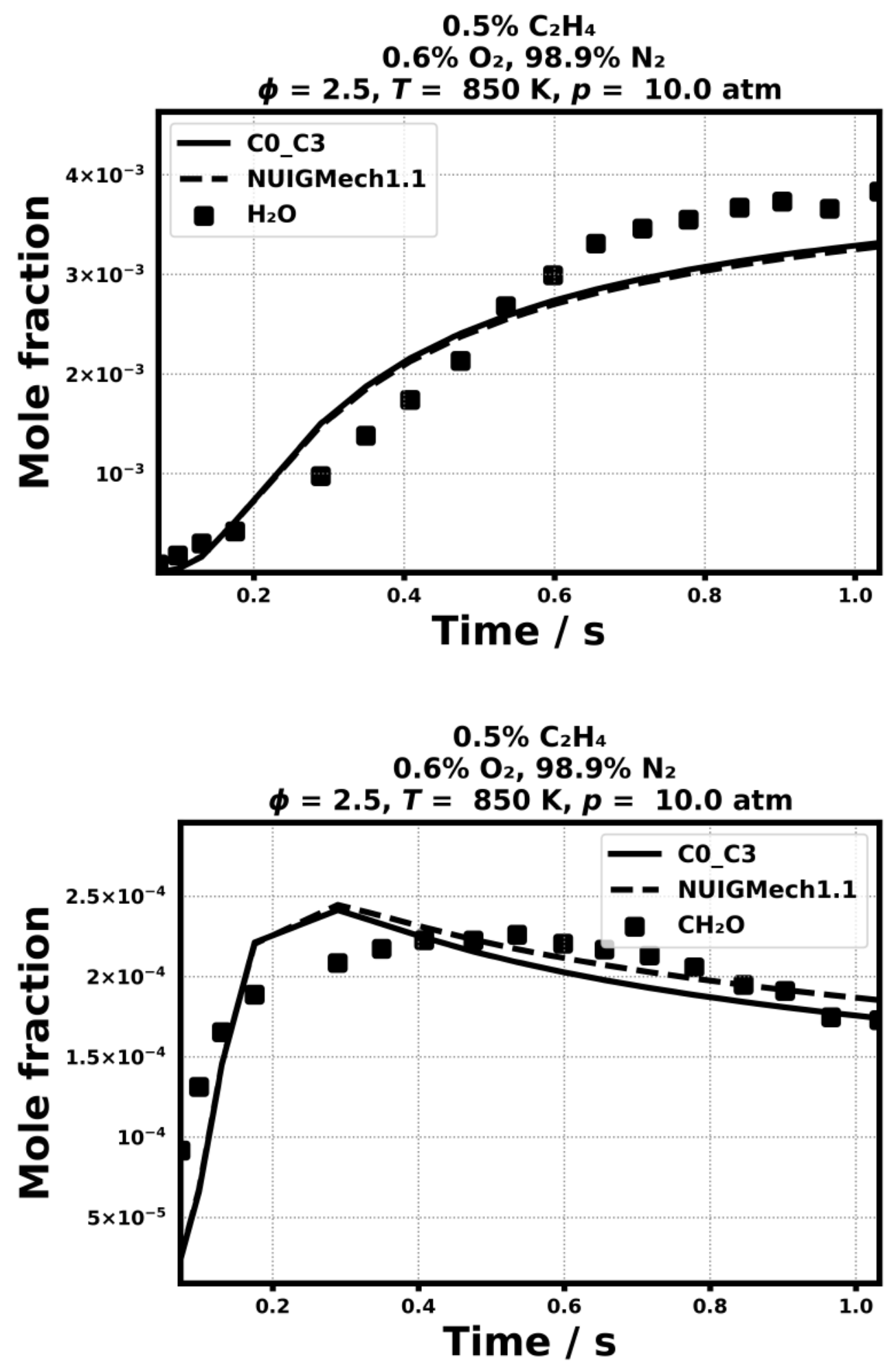

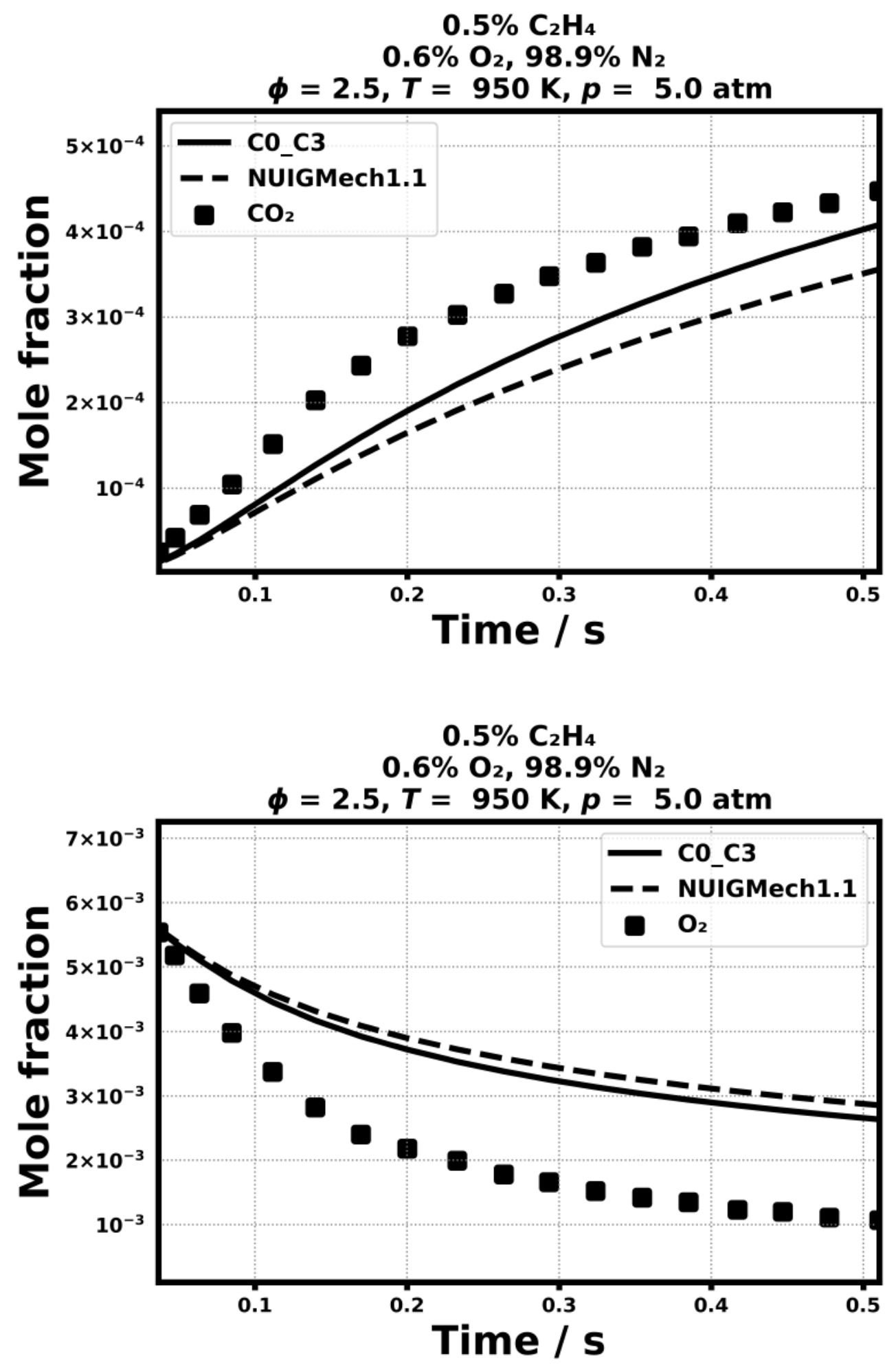

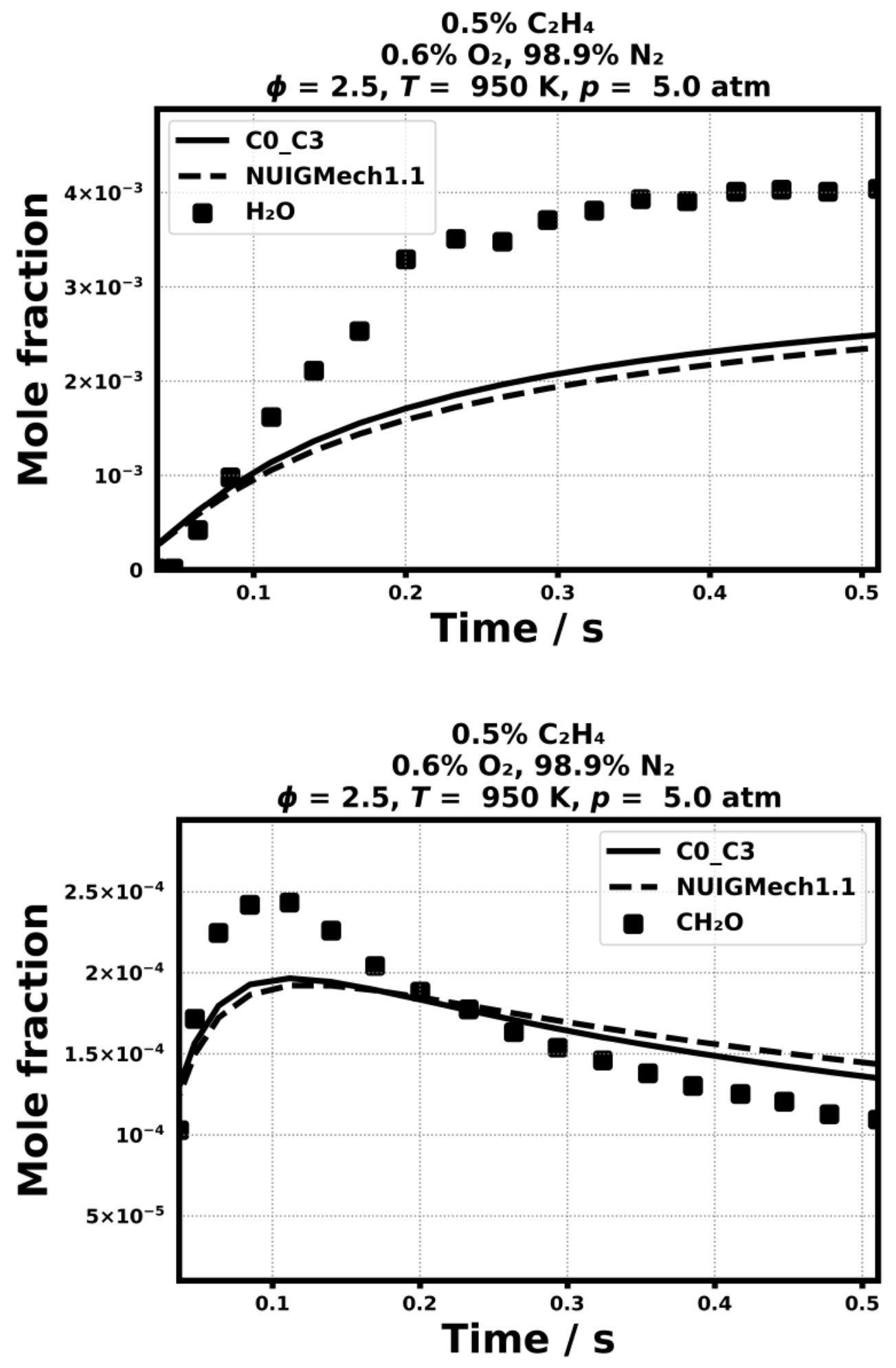
5.15) Dagaut, P., Boettner, J. C., \& Cathonnet, M. (1991). Combustion science and technology, 77(1-3), 127-148.

\section{$0.15 \% \mathrm{C}_{2} \mathrm{H}_{4}$}

$0.6 \% \mathrm{O}_{2}, 99.25 \% \mathrm{~N}_{2}$
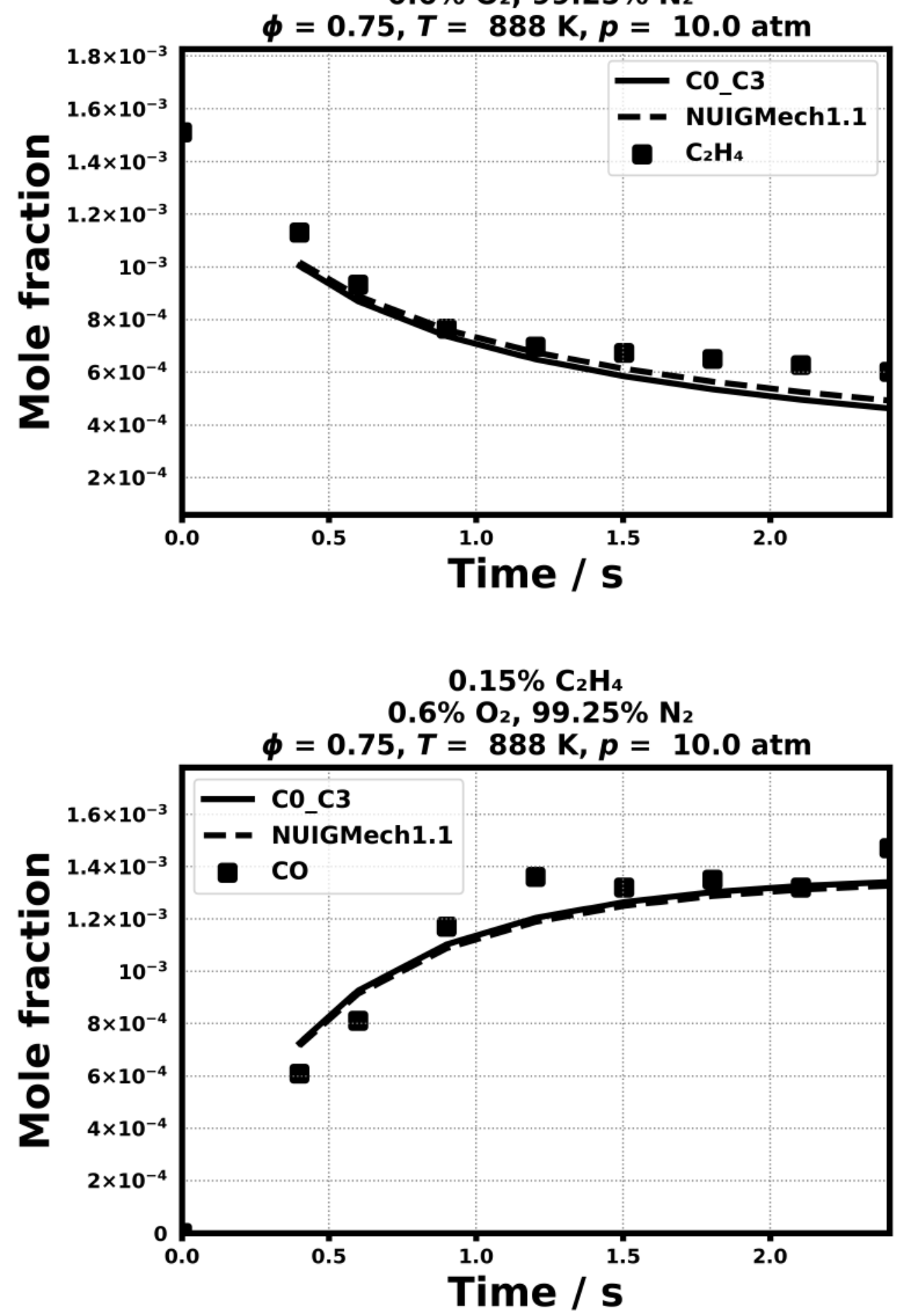

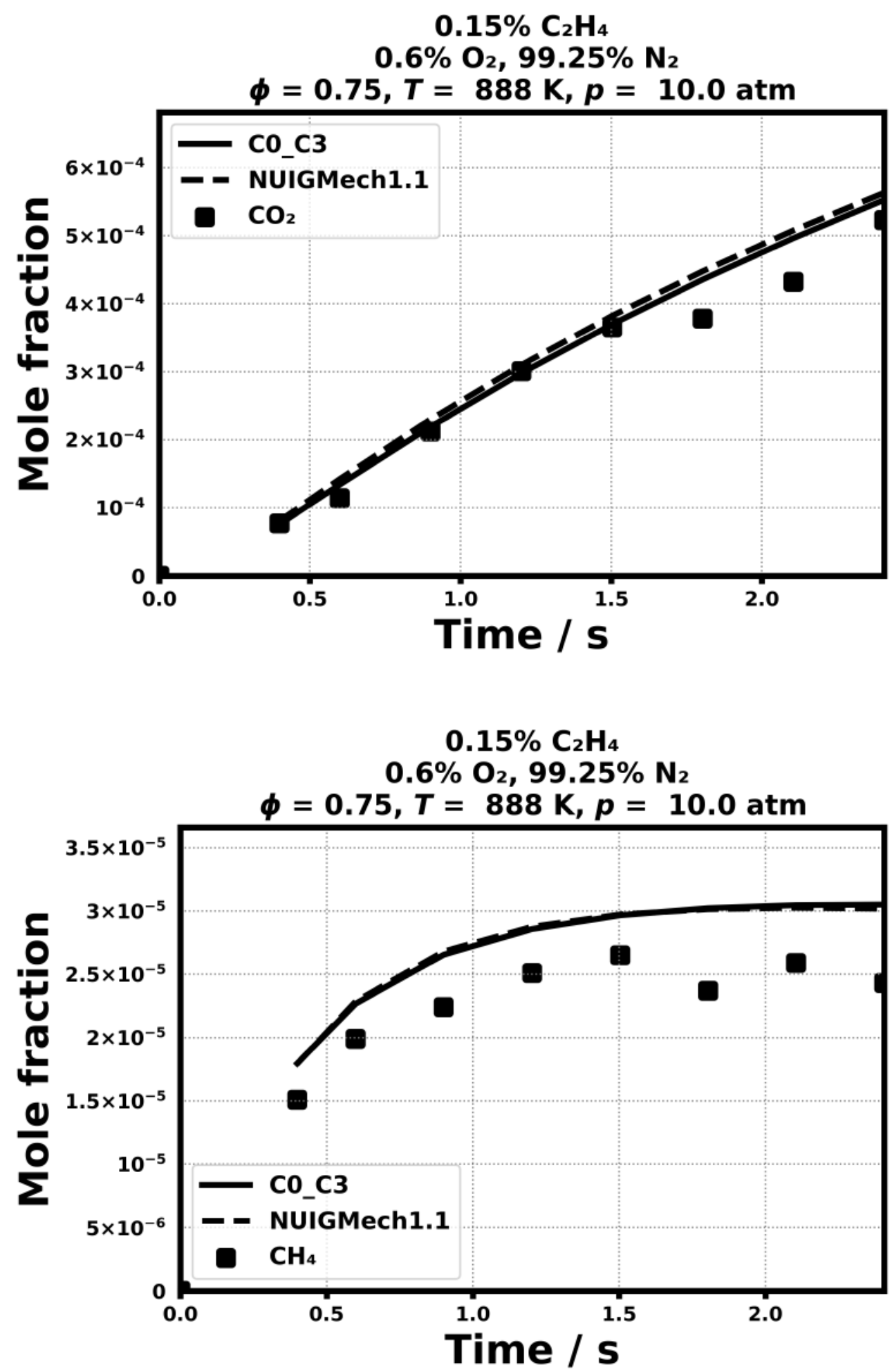

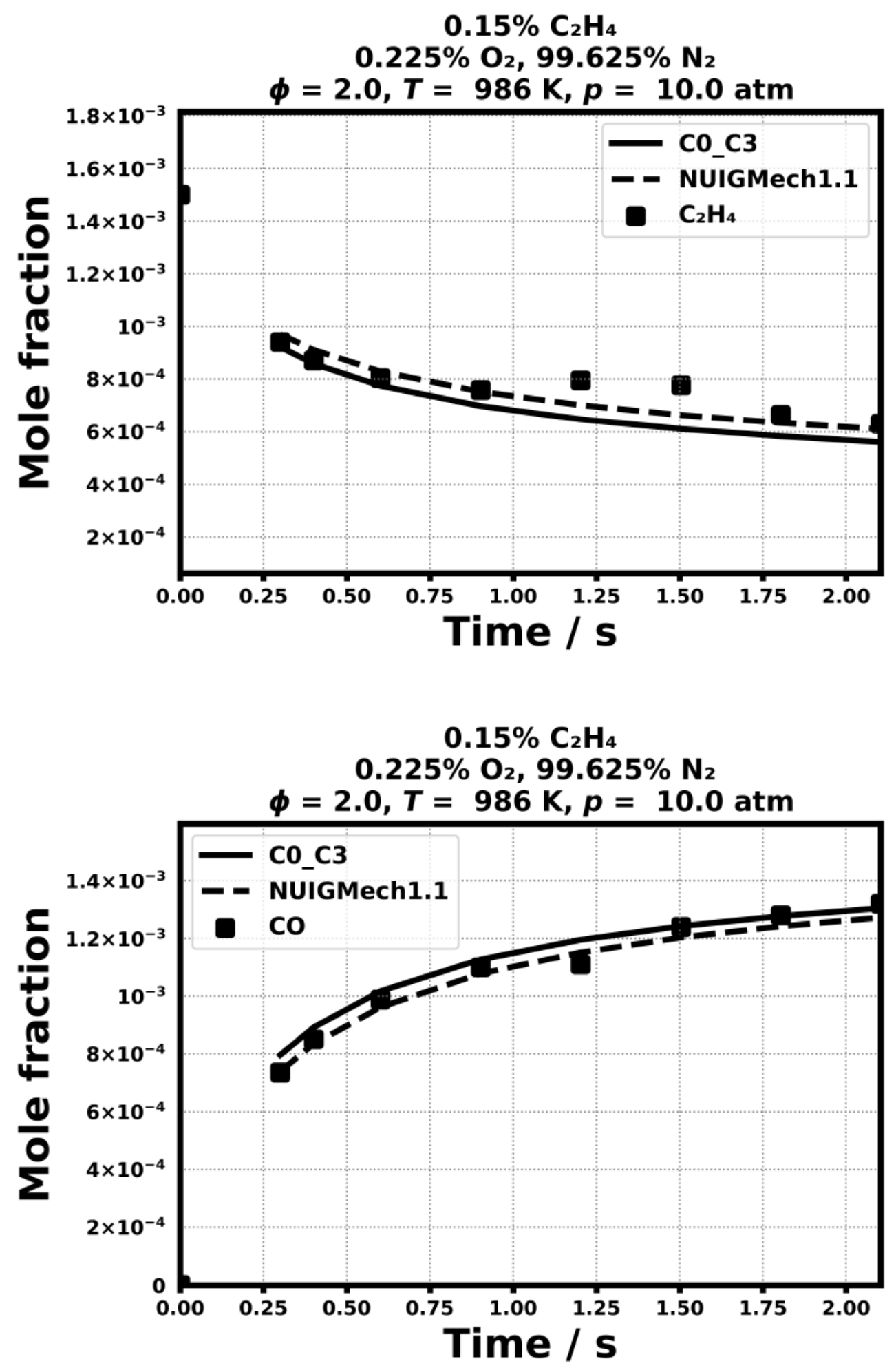

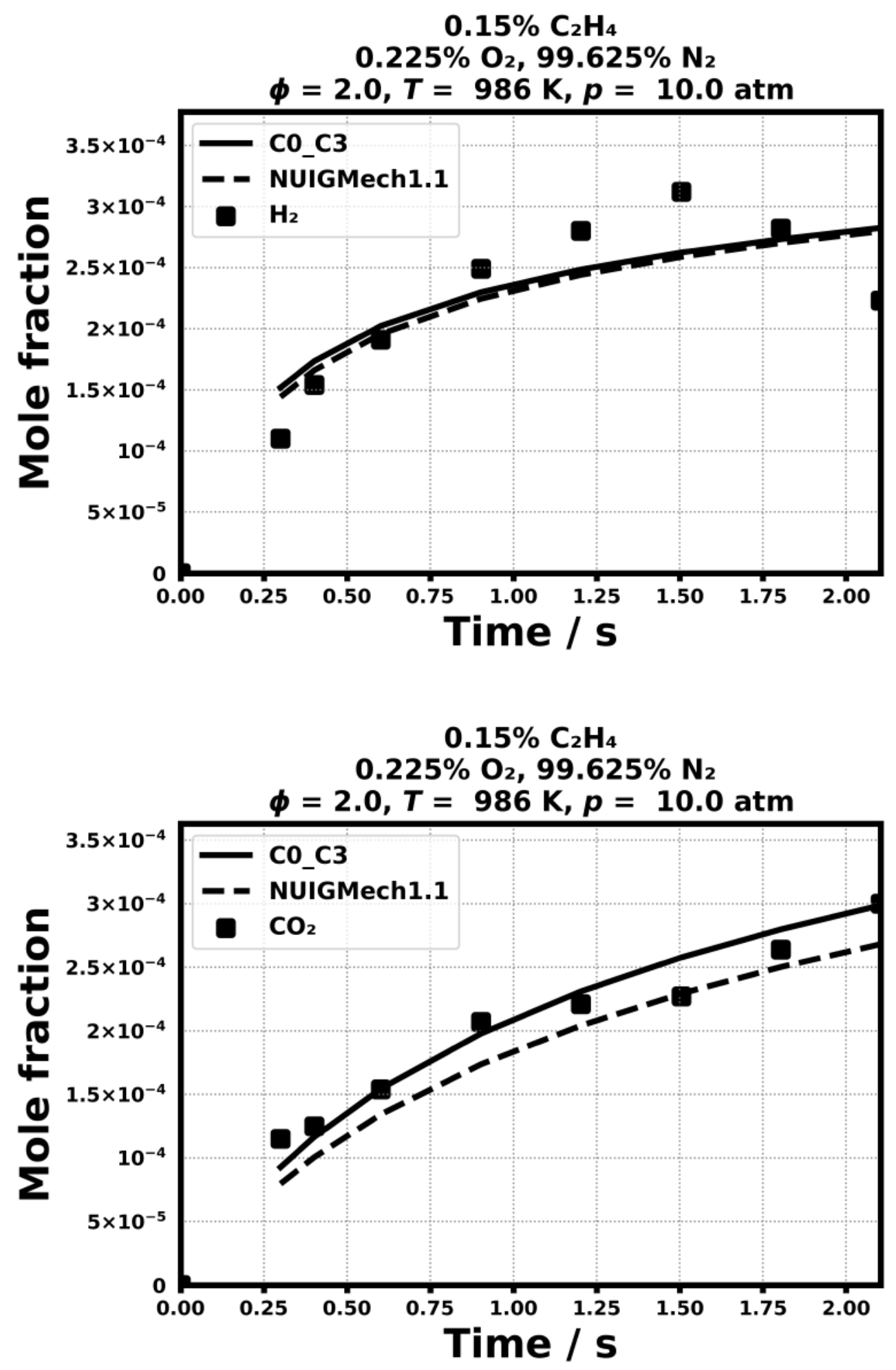

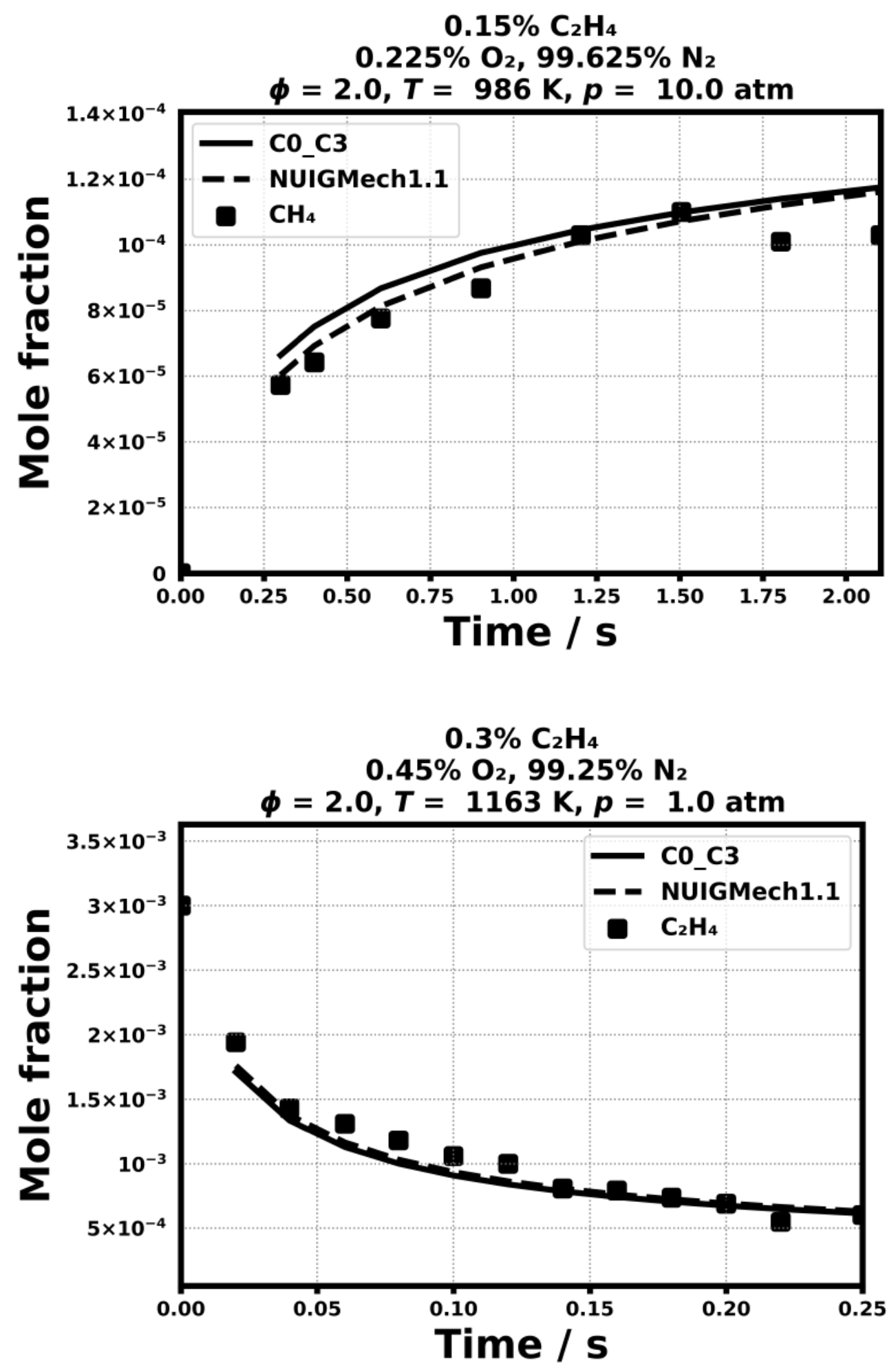

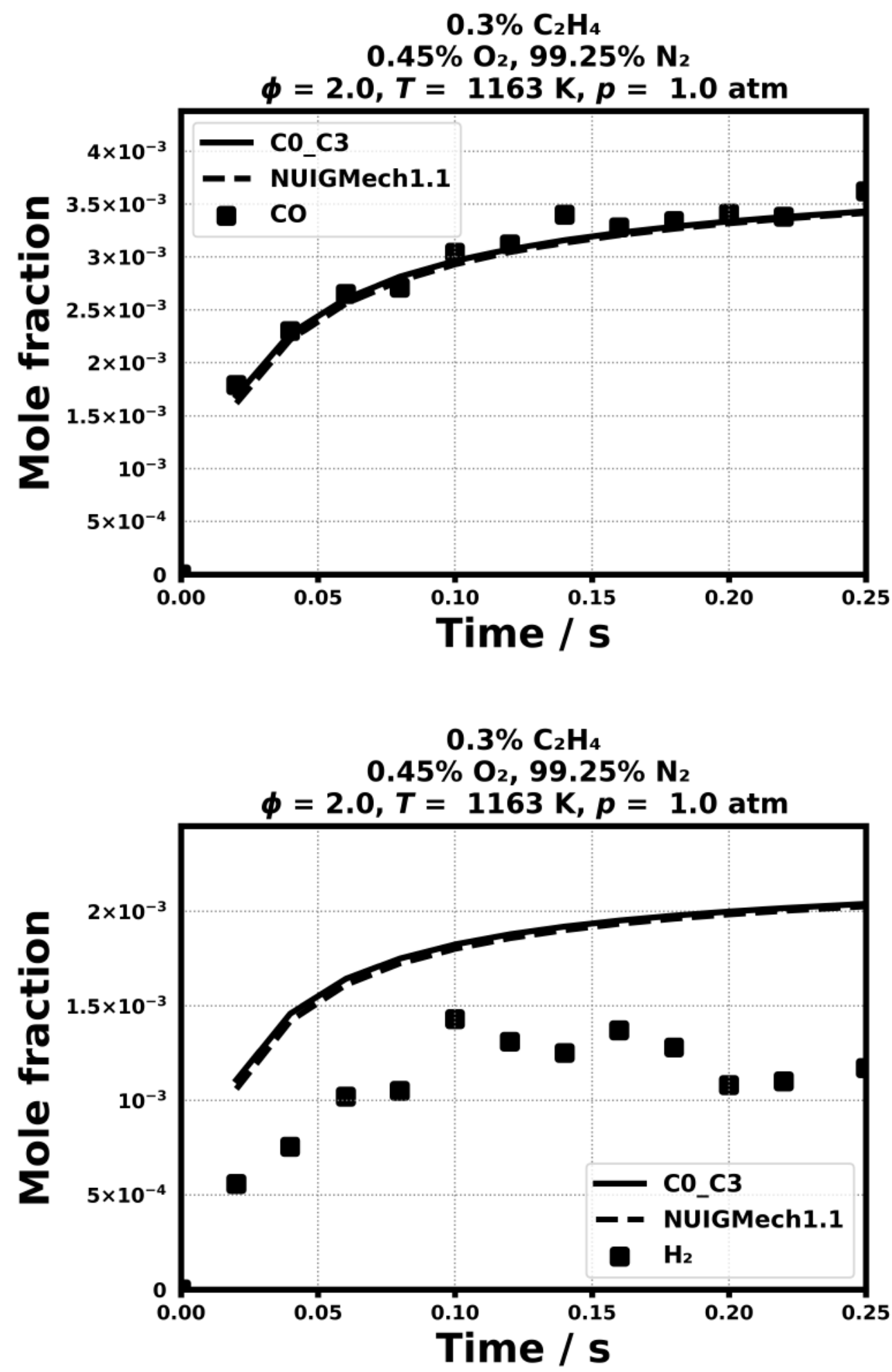

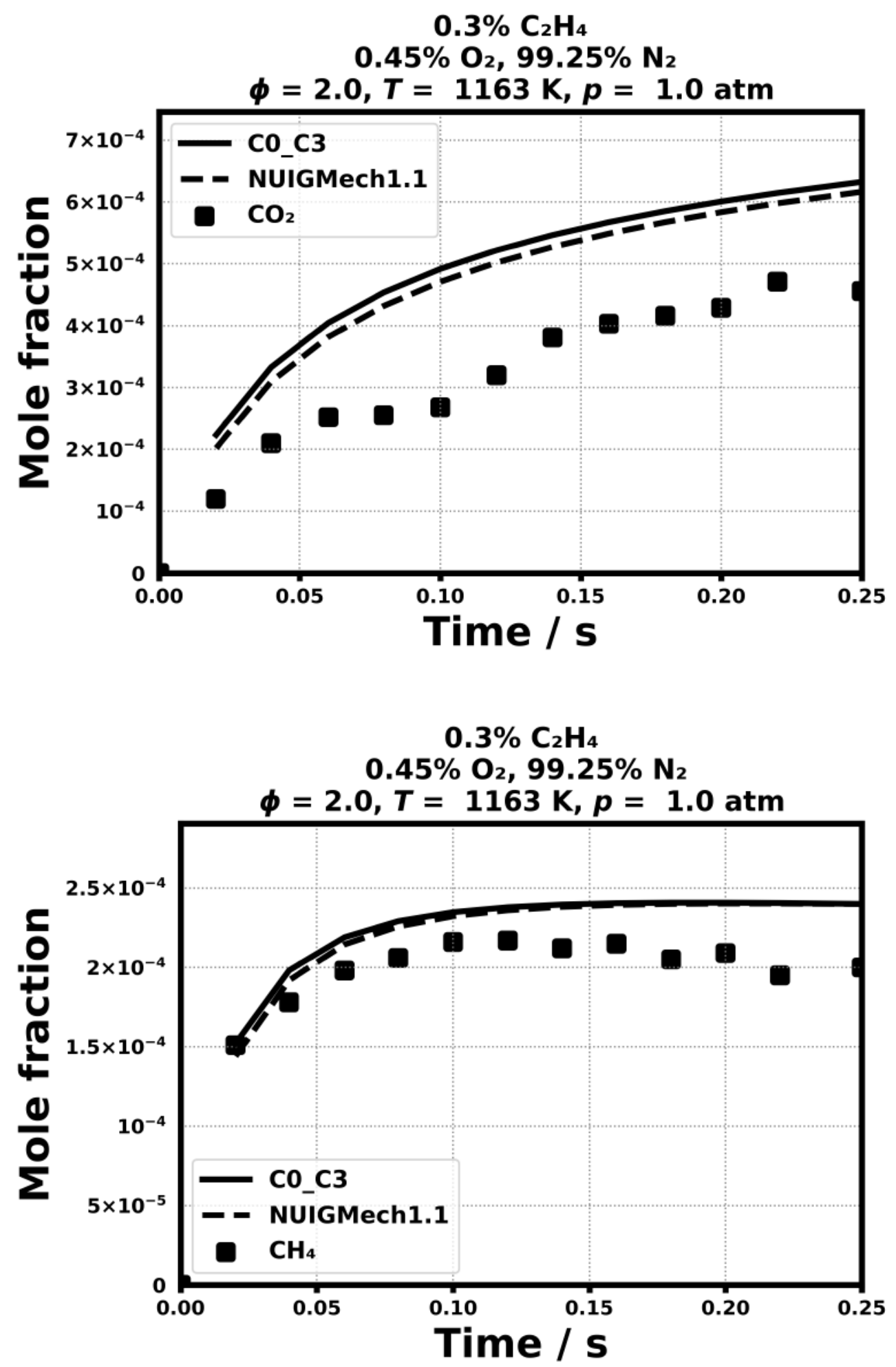

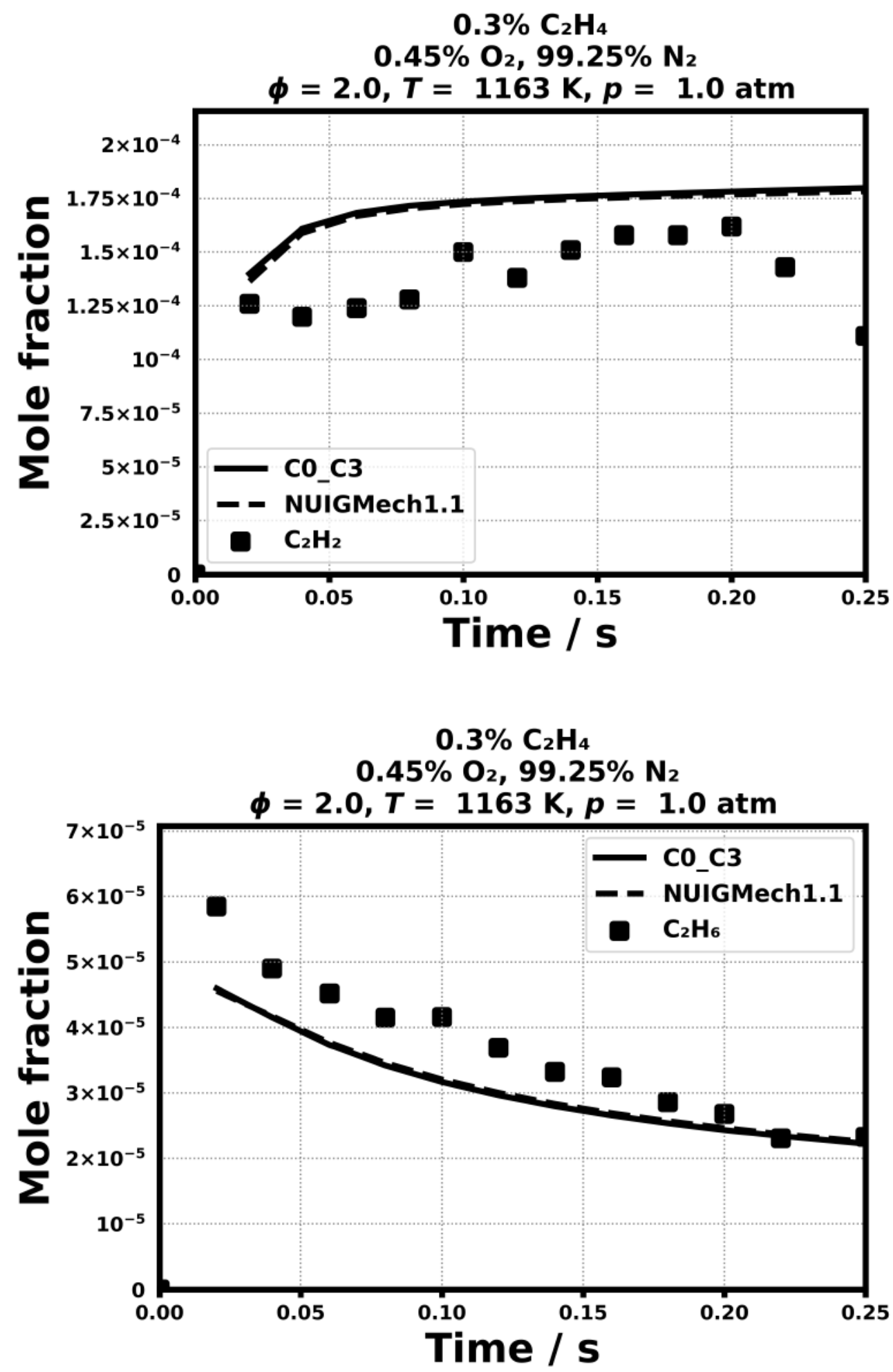


\section{Laminar flame speed}

5.16) F. N. Egolfopoulos, D. L. Zhu, C. K. Law, Proceedings of the Combustion Institute 23 (1990) 471-478.

5.17) G. Jomaas, X. L. Zheng, D. L. Zhu, C. K. Law, Proceedings of the Combustion Institute 30 (2005) 193-200.

5.18) M. I. Hassan, K. T. Aung, O. C. Kwon,G. M. Faeth, Journal of Propulsion and Power 14 (1998) 479-488.

5.19) K. Kumar, G. Mittal, C. J. Sung, C. K. Law, Combustion and Flame 153 (2008) 343-361

5.20) Ravi, S., Sikes, T. G., Morones, A., Keesee, C. L., \& Petersen, E. L., Proceedings of the Combustion Institute, 35(1) (2015) 679-686.

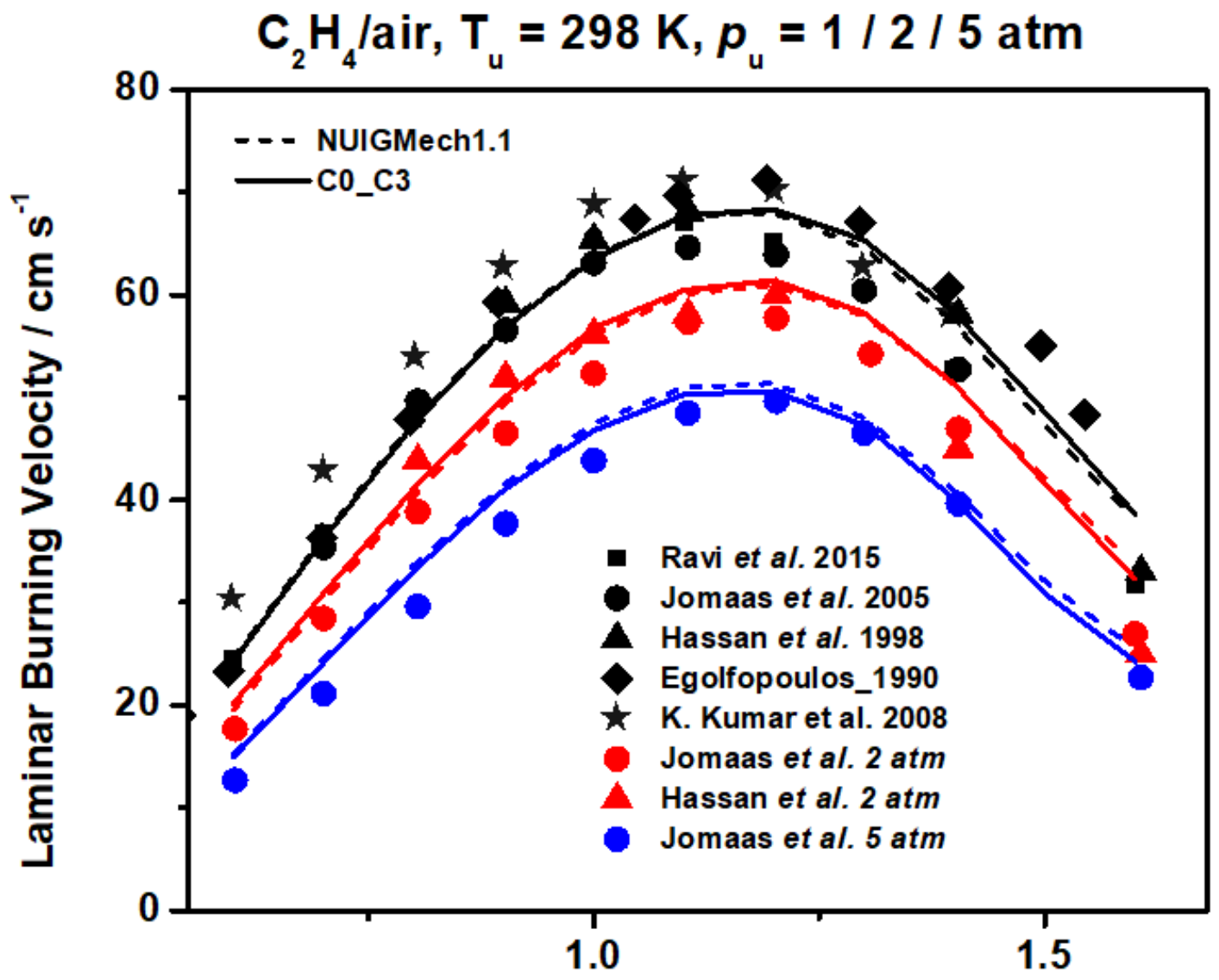

Equivalence Ratio 


\section{Validation for $\mathrm{C}_{2} \mathrm{H}_{2}$}

\section{Shock tube ignition delay time}

6.1) Eiteneer, B., \& Frenklach, M., International Journal of Chemical Kinetics, 35(9) (2003) 391-414.
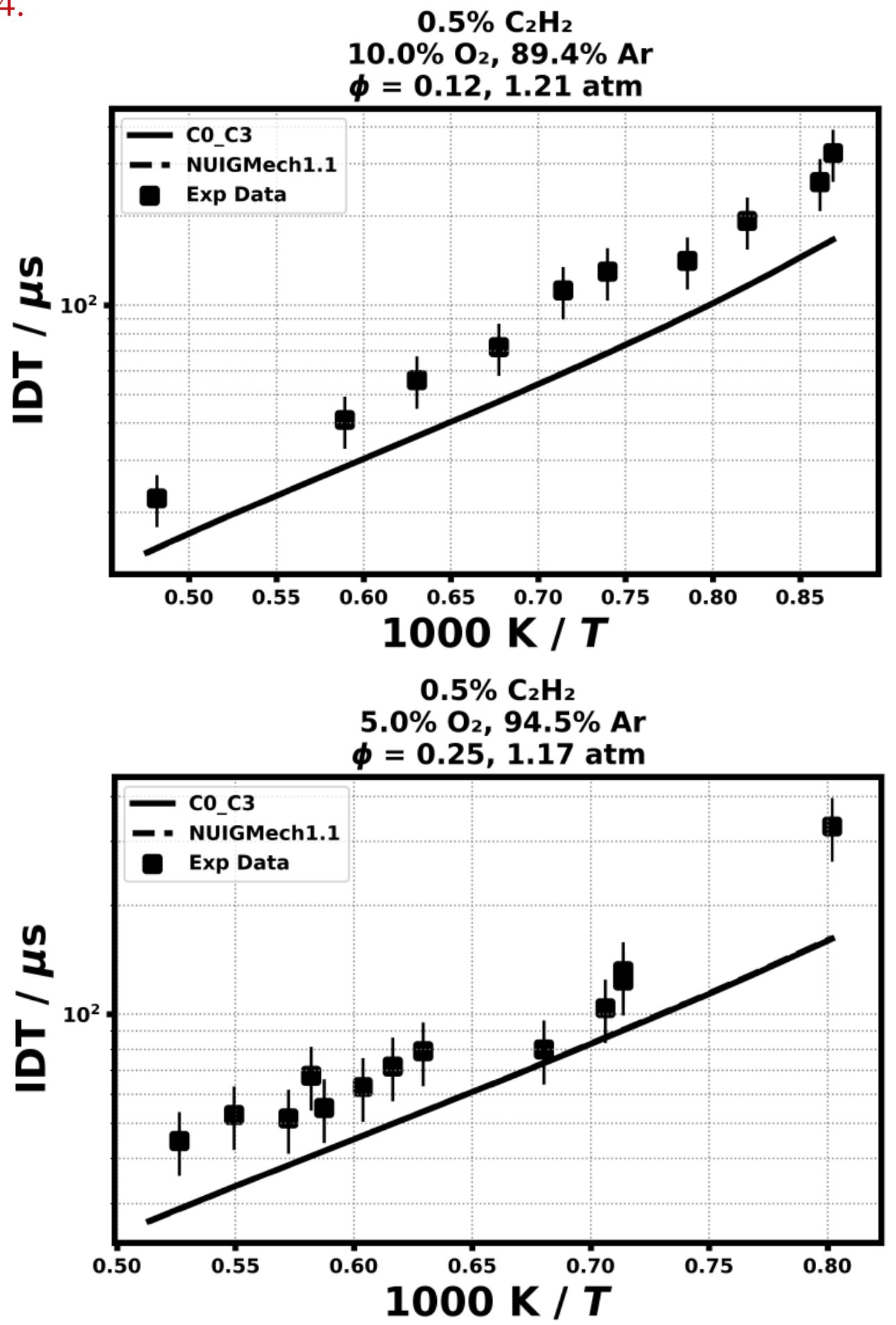

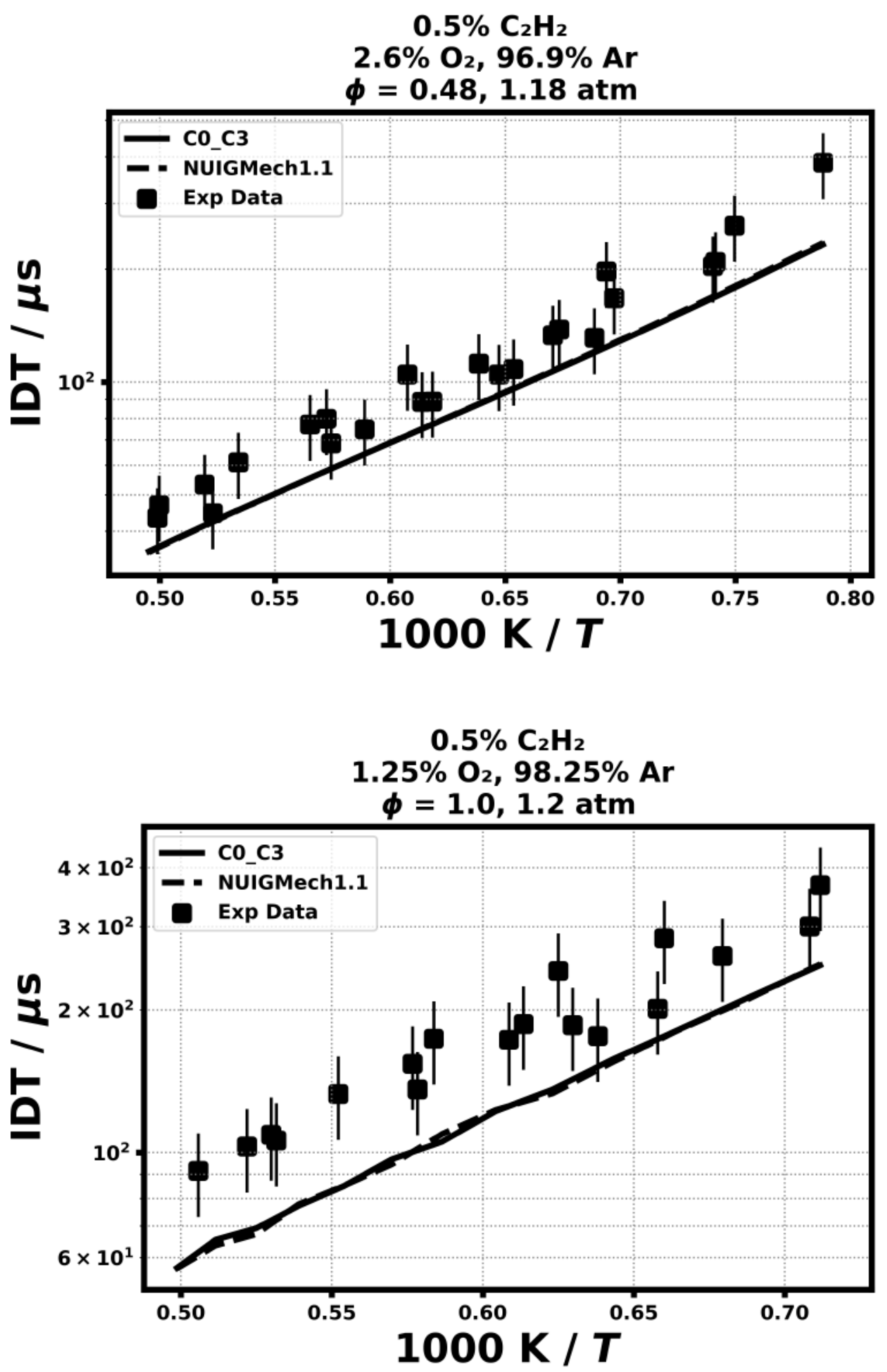
6.2) Fournet, R., Bauge, J. C., \& Battin Leclerc, F. International journal of chemical kinetics, 31(5) (1999) 361-379.
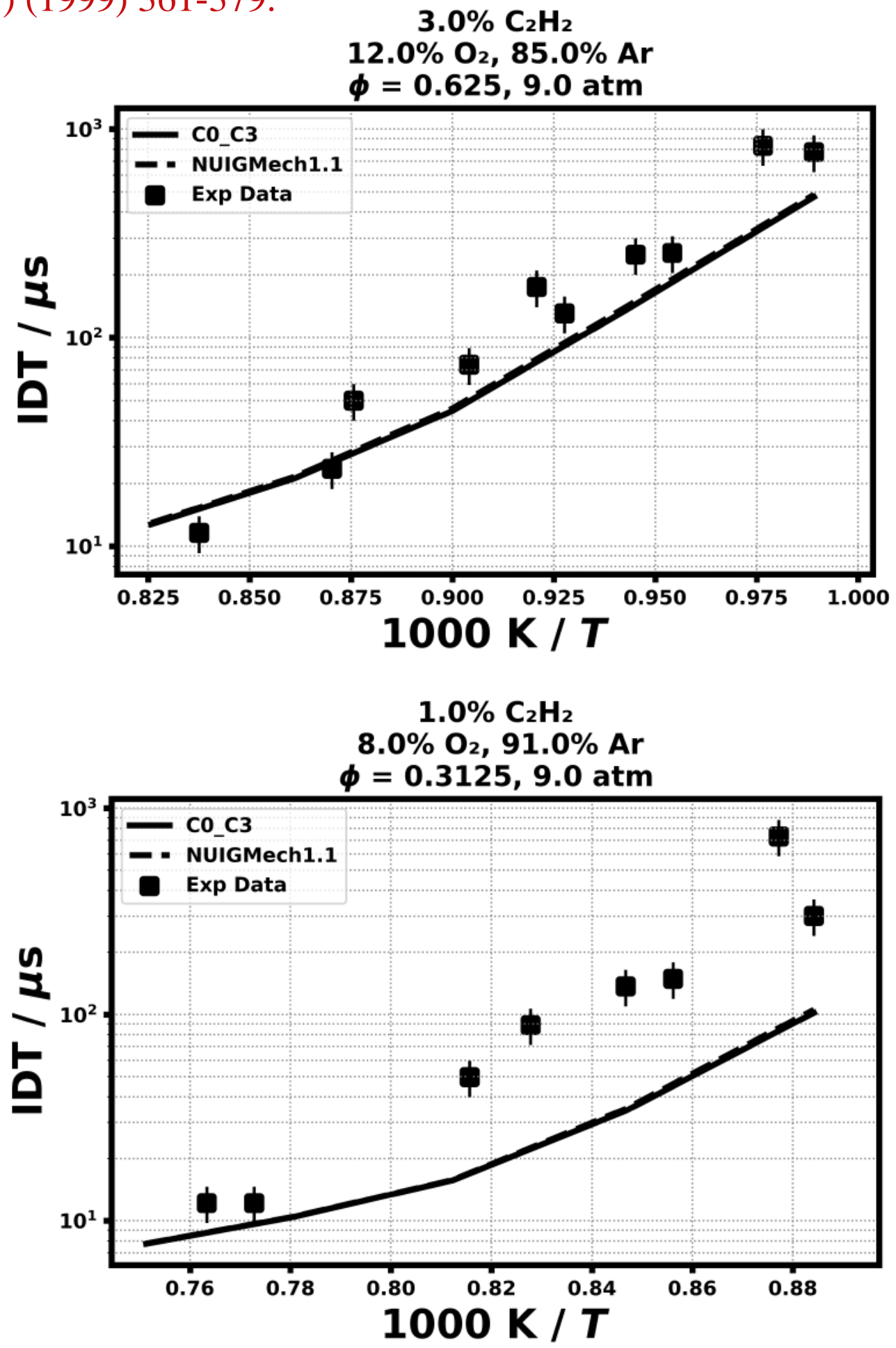
6.3) Hidaka, Y., Hattori, K., Okuno, T., Inami, K., Abe, T., \& Koike, T. Combustion and Flame, 107(4) (1996) 401-417.
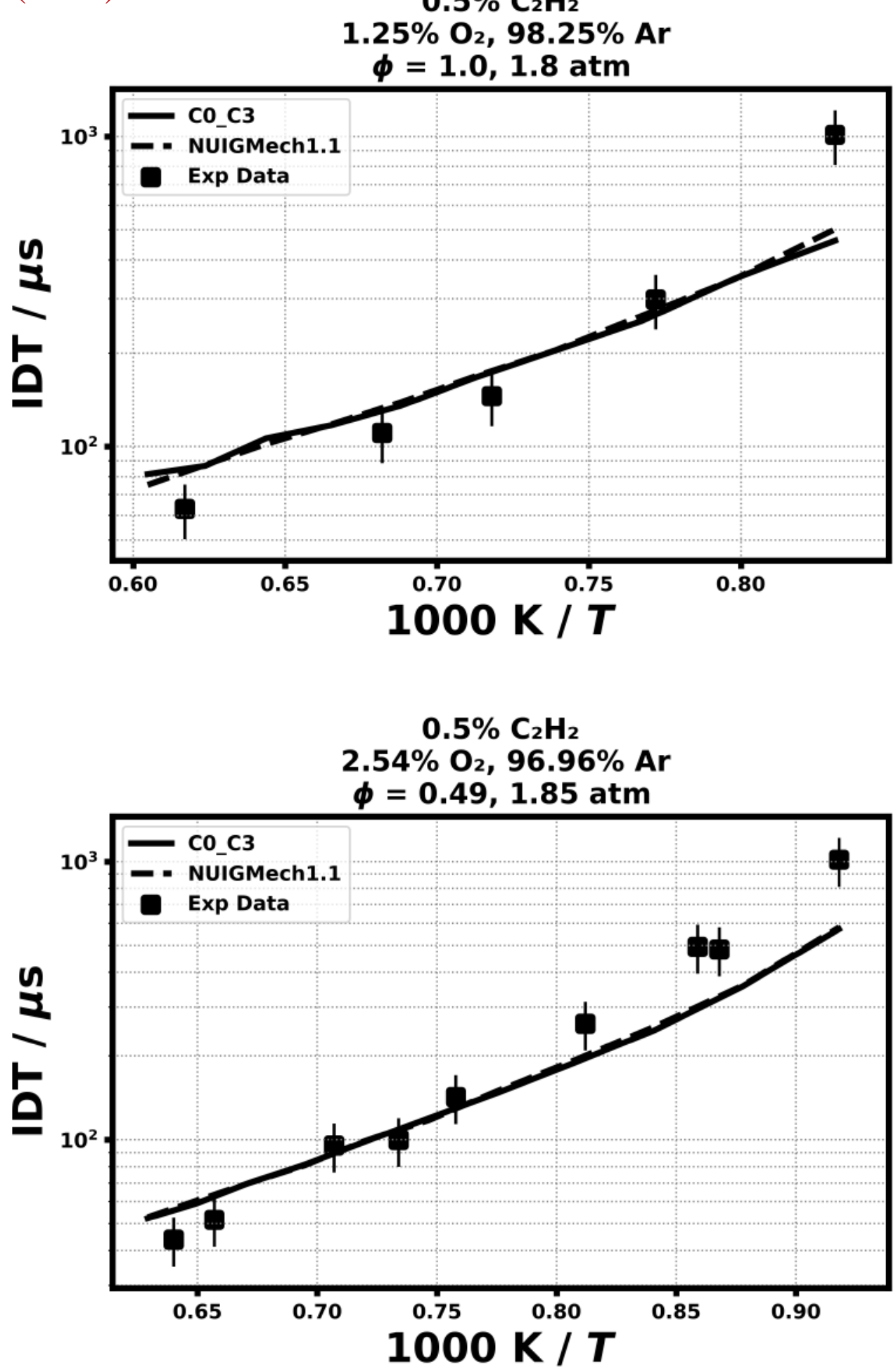

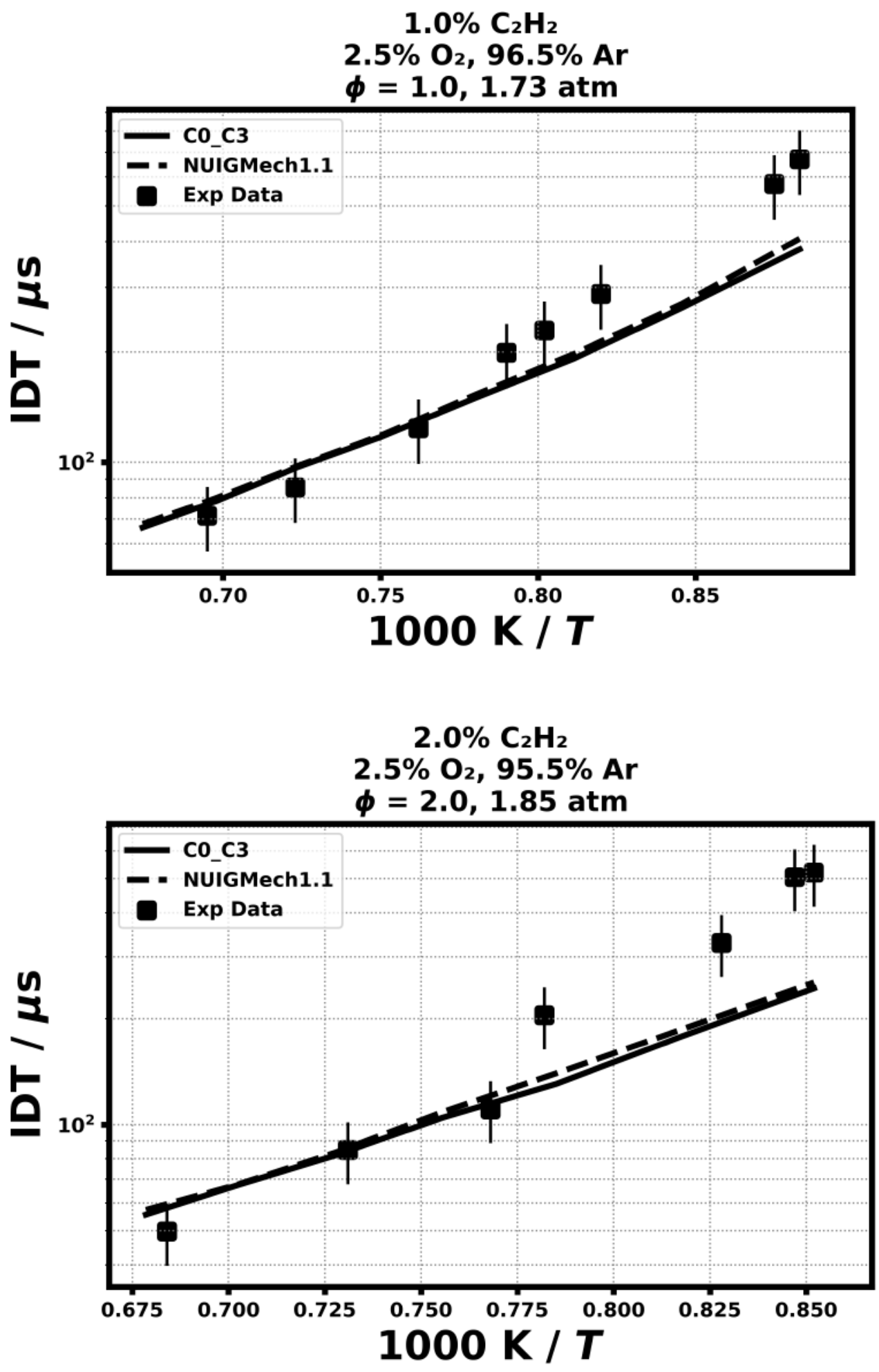
6.4) Lokachari, N., Burke, U., Ramalingam, A., Turner, M., Hesse, R., Somers, K. P., ... \& Curran, H. J., Proceedings of the Combustion Institute, 37(1) (2019) 583-591.
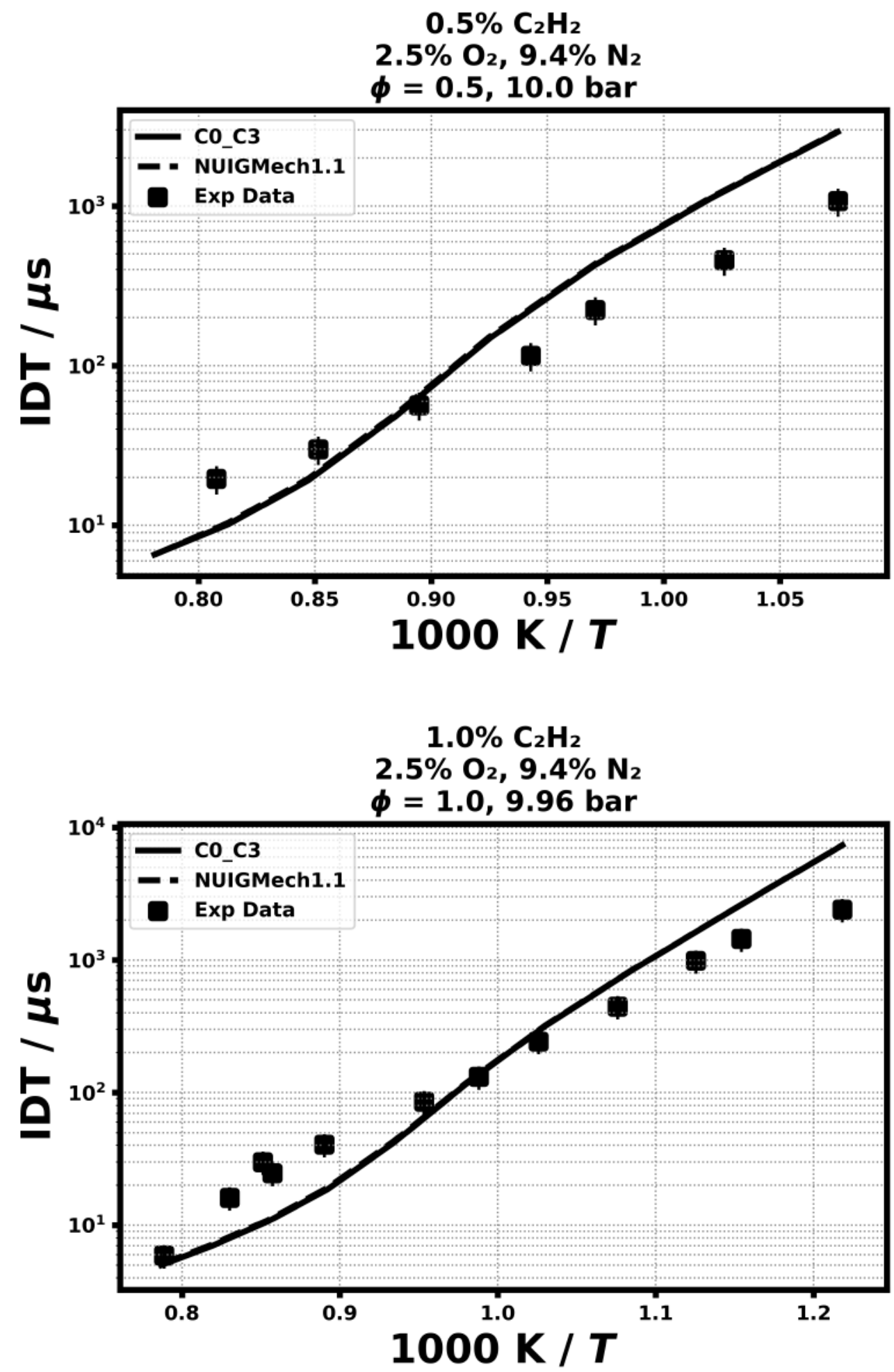

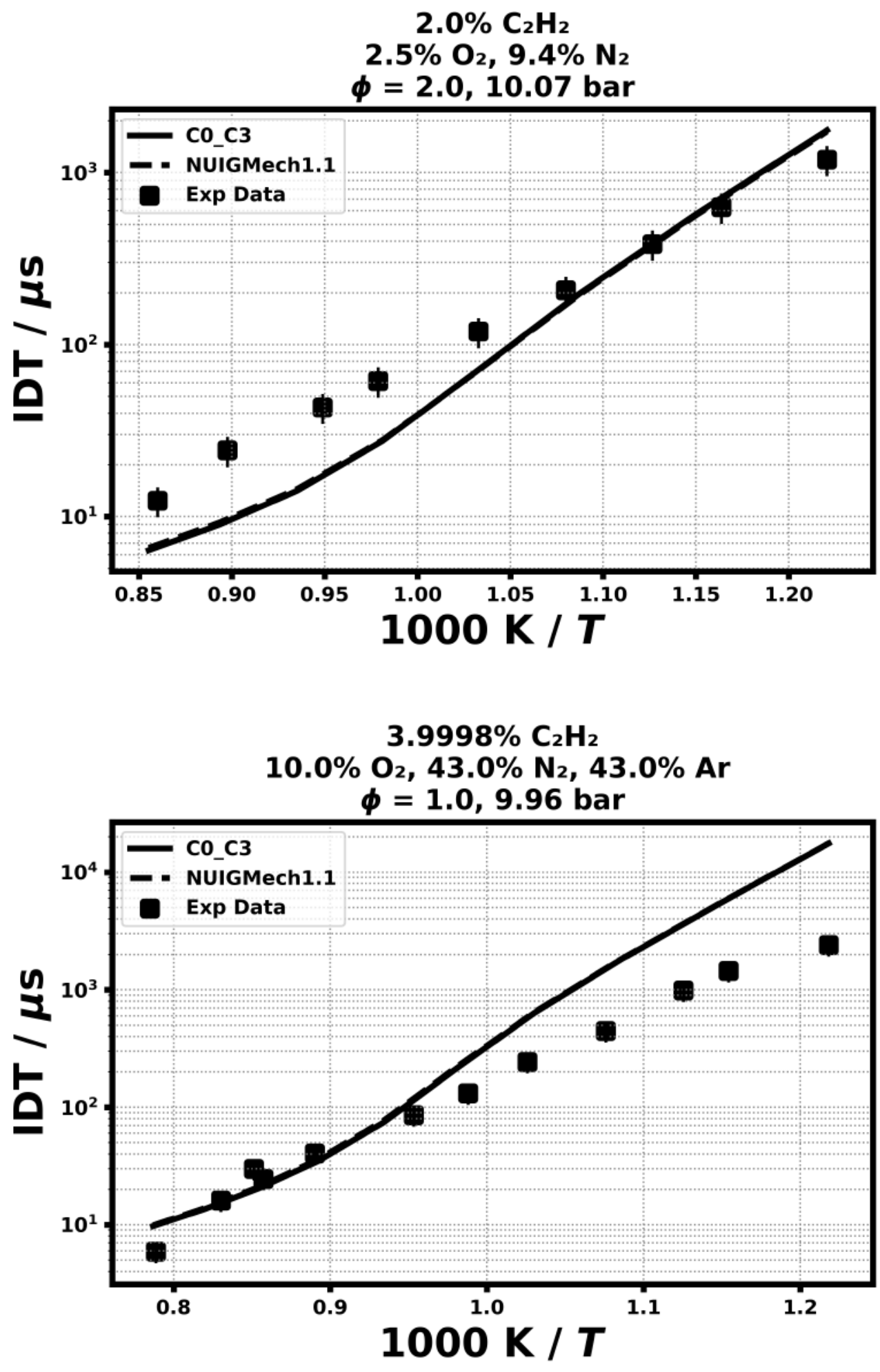

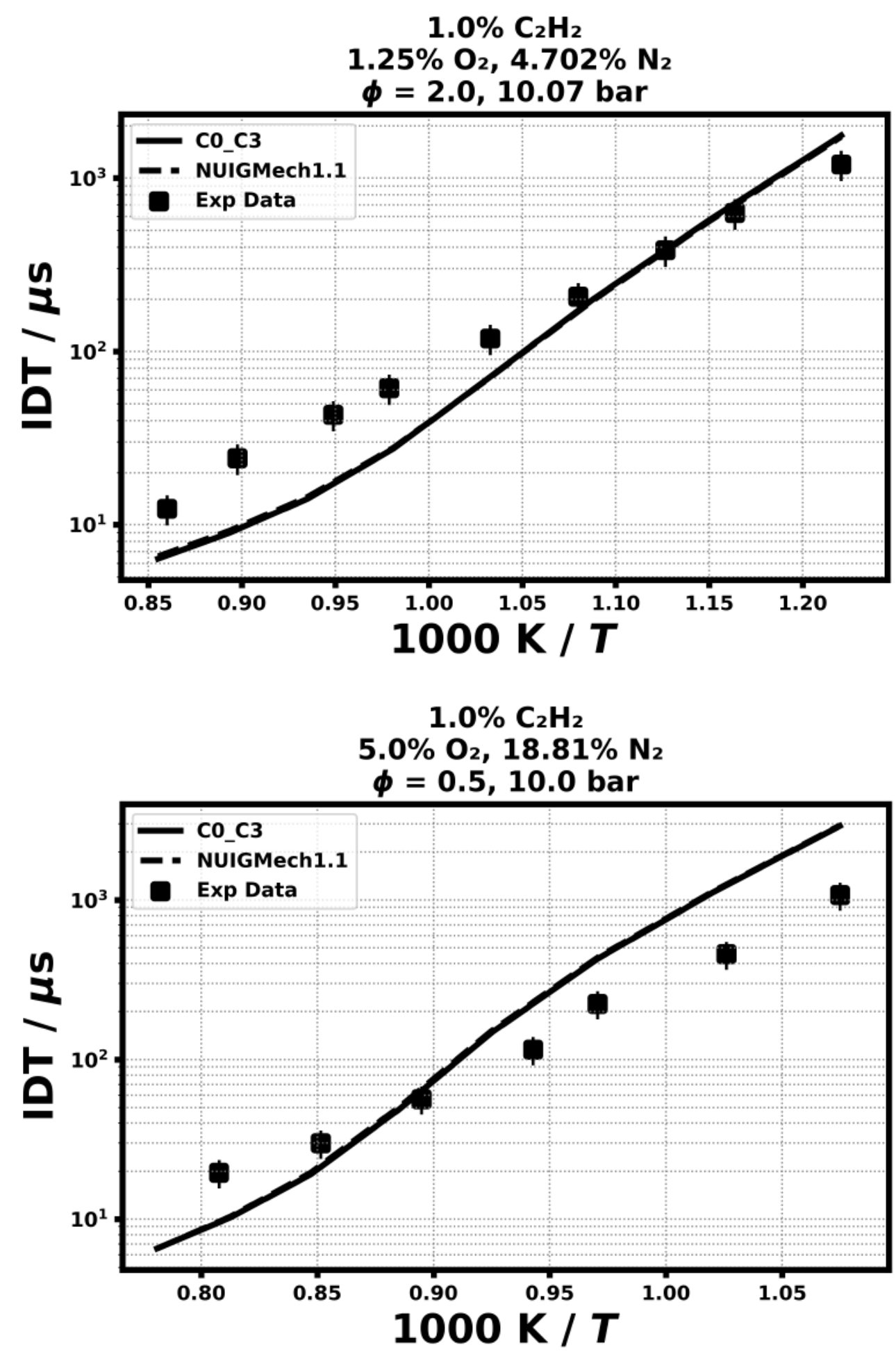

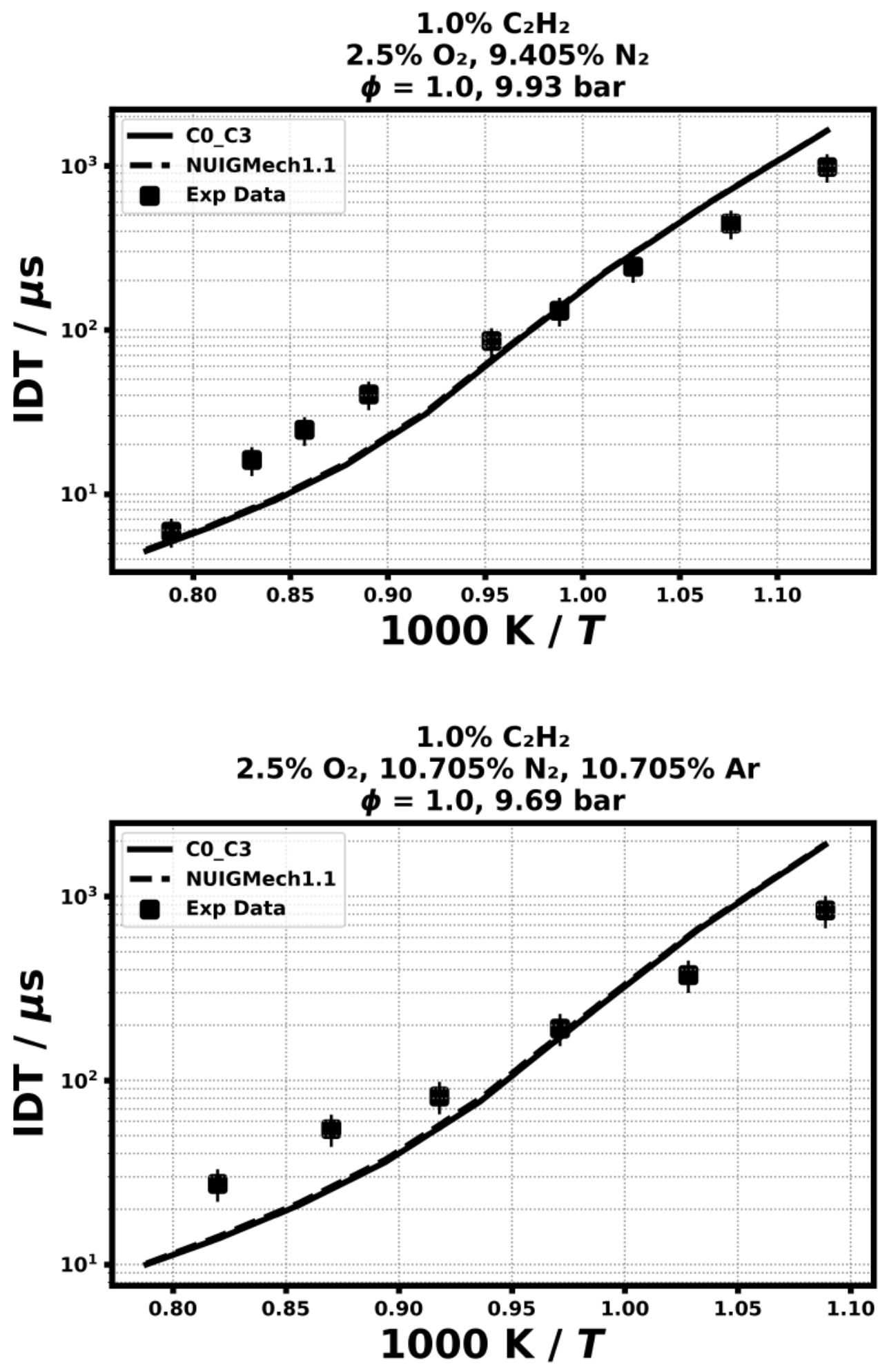

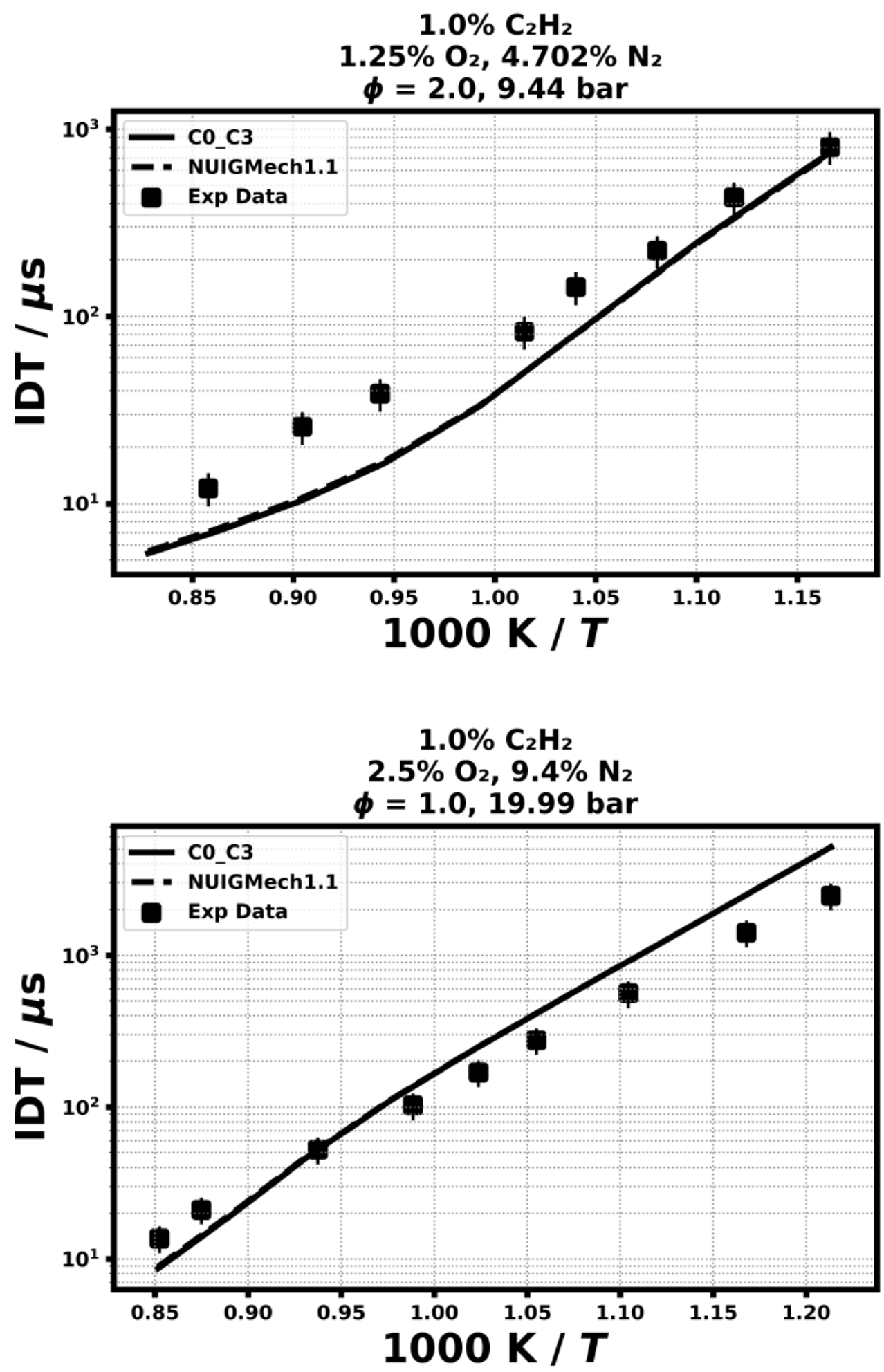

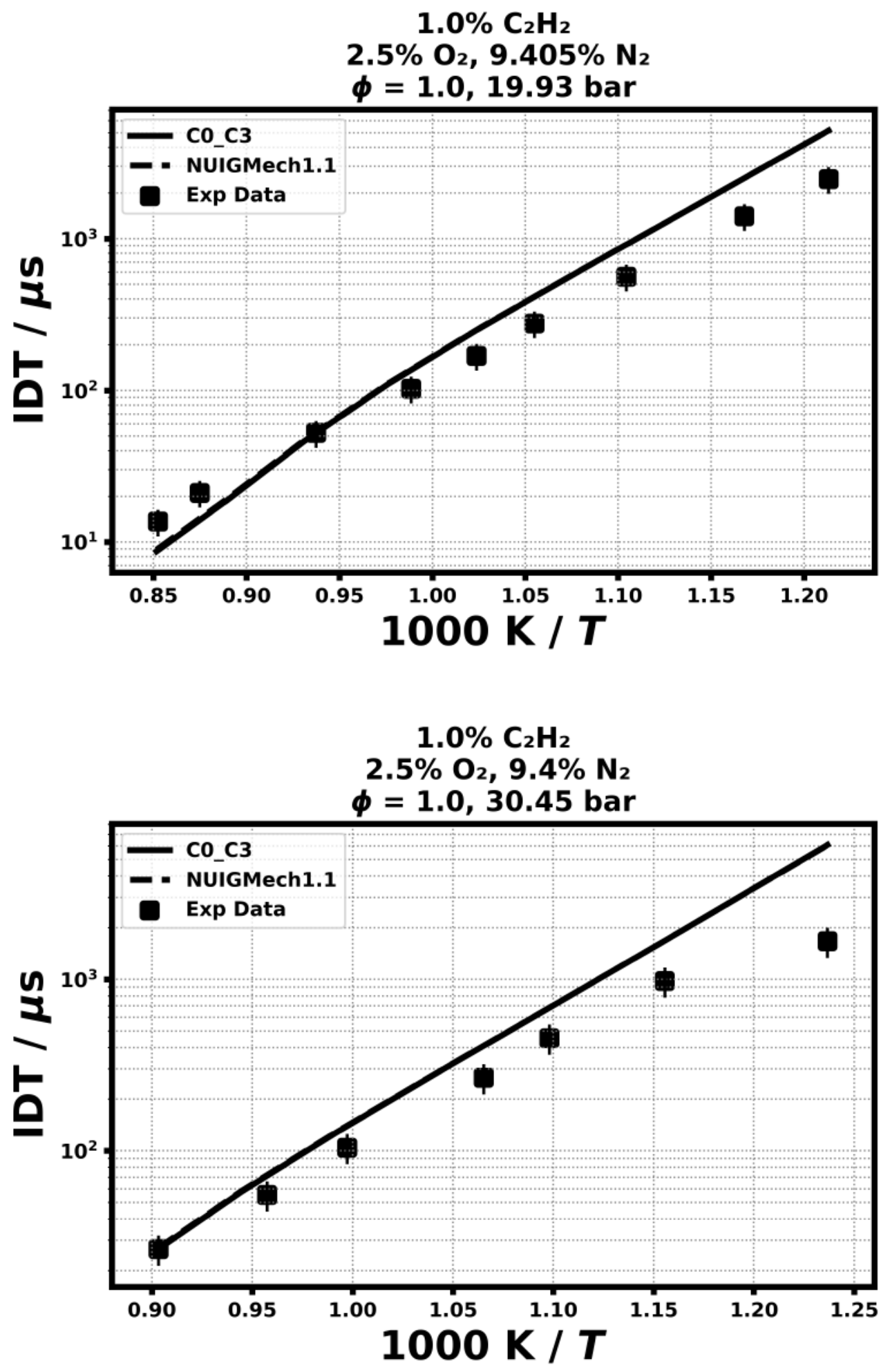


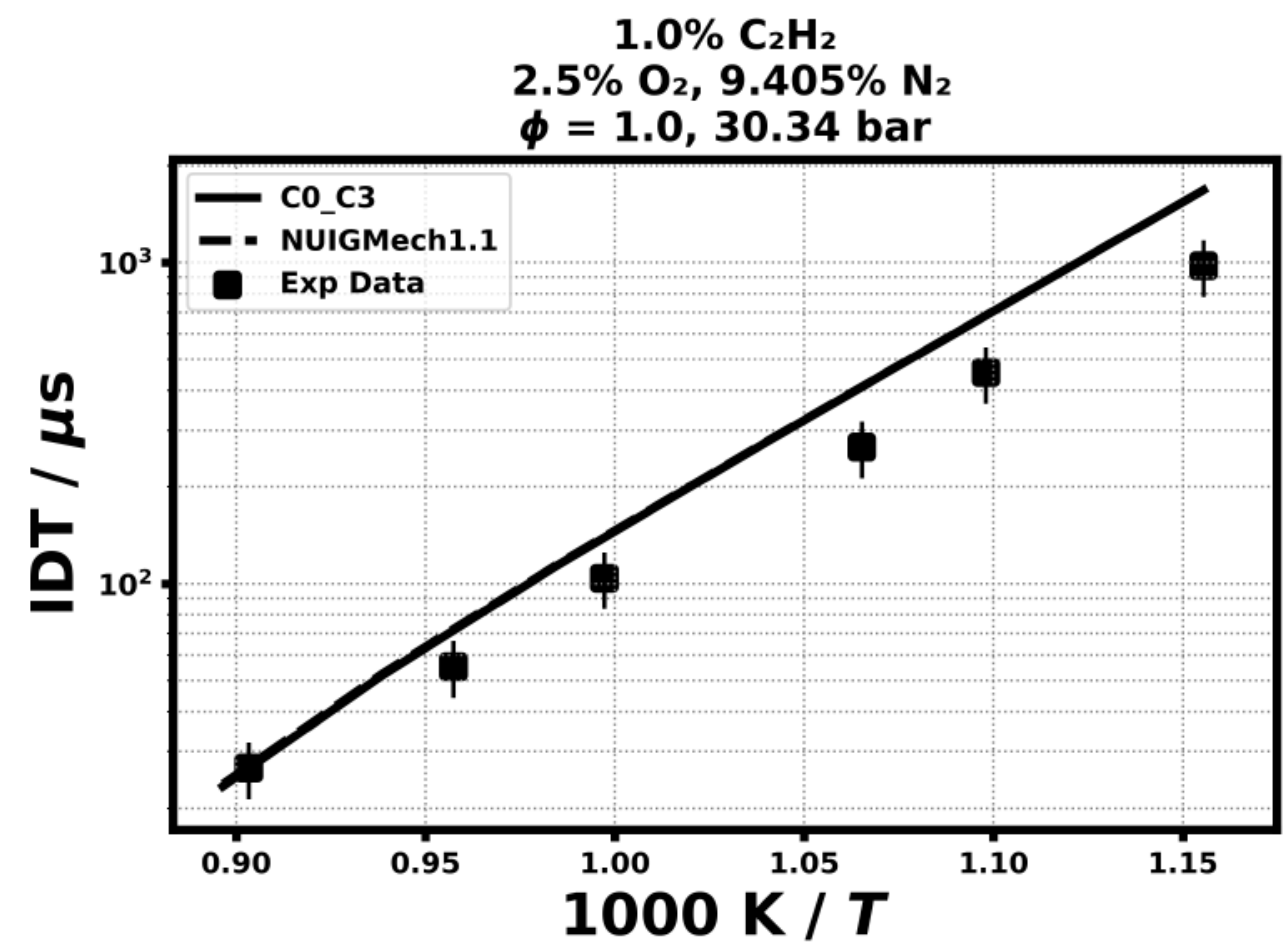

6.5) Rickard, M. J. A., Hall, J. M., \& Petersen, E. L., Proceedings of the Combustion Institute, 30(2) (2005) 1915-1923.

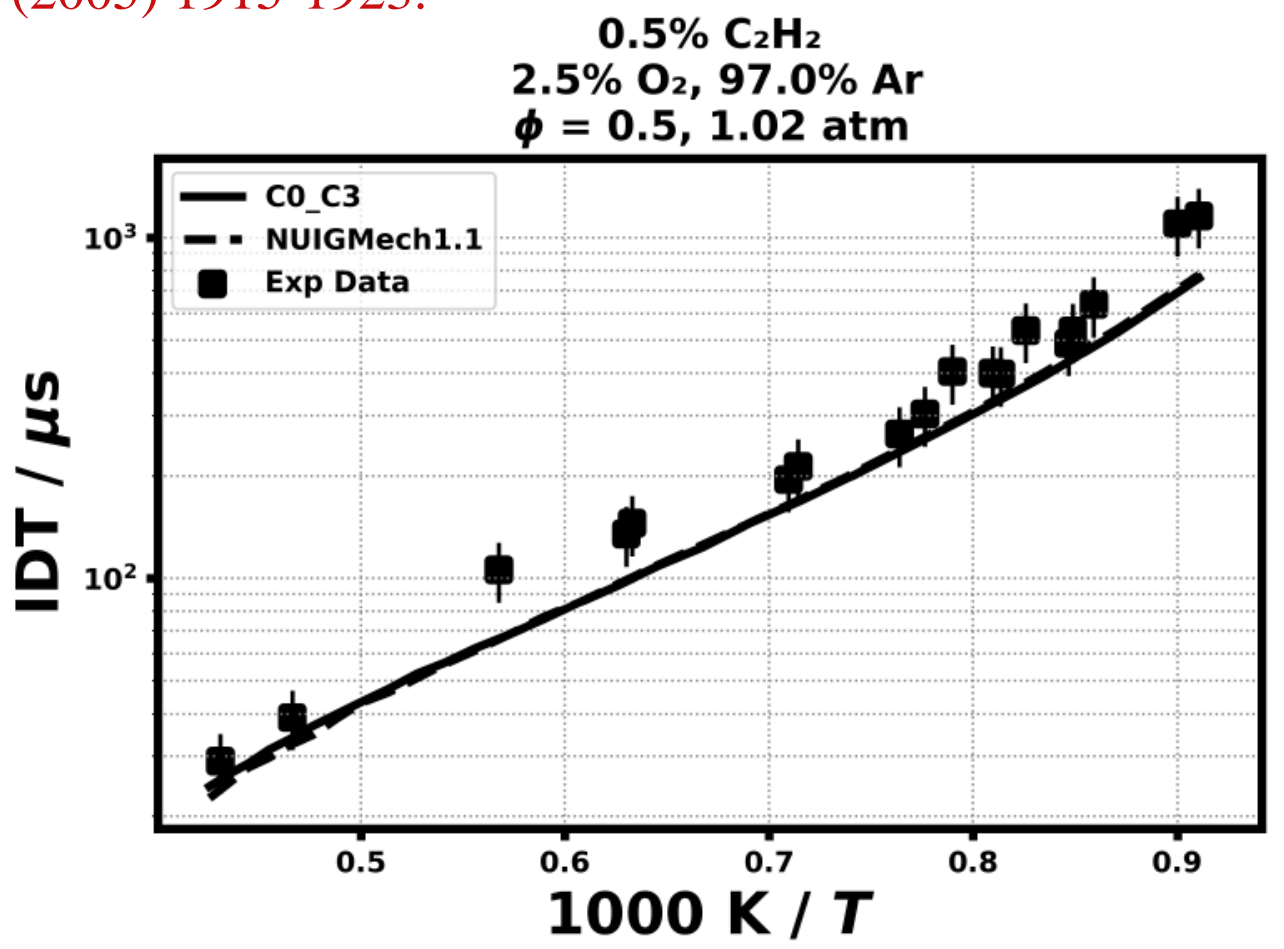



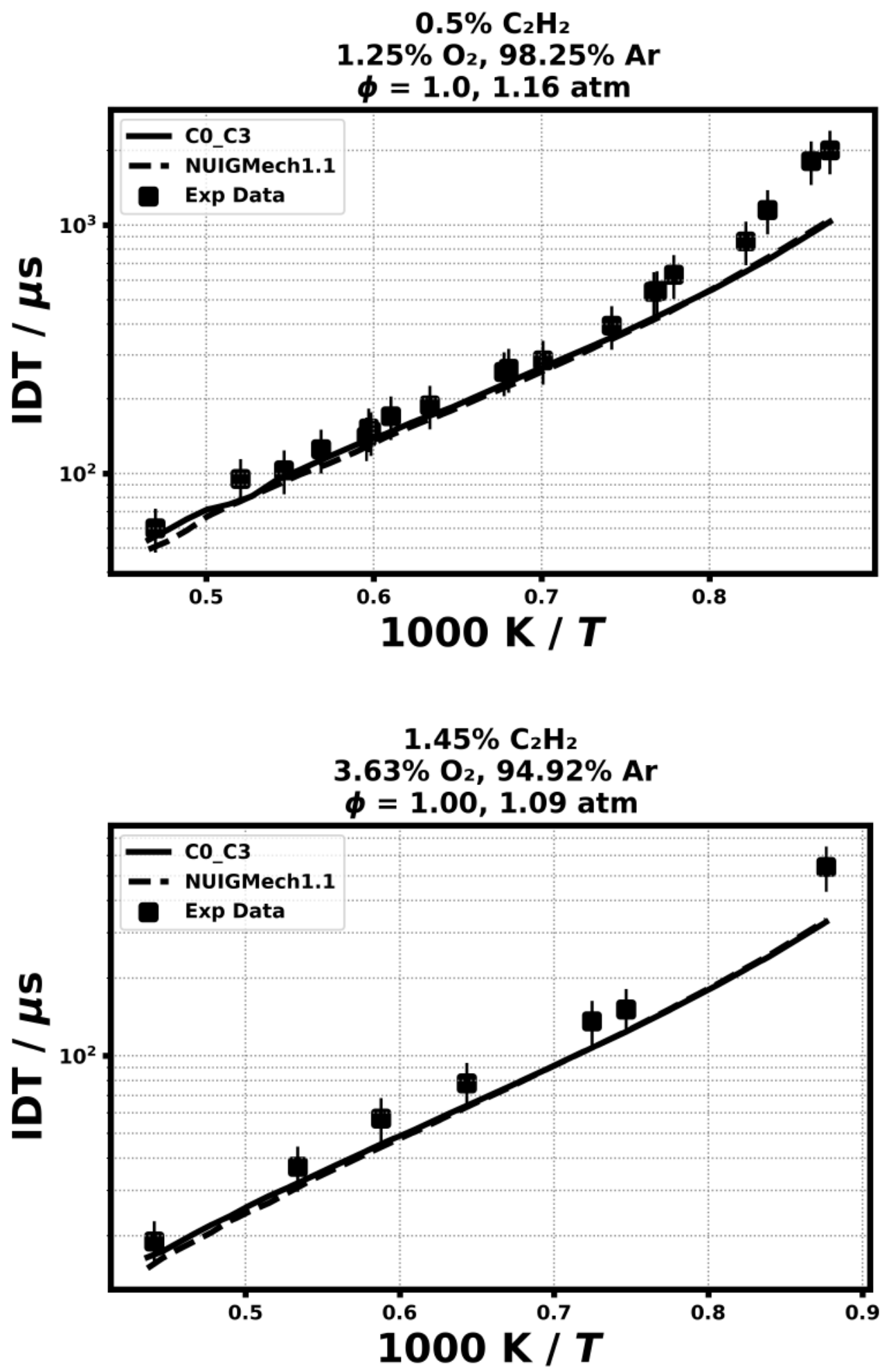


\section{RCM Ignition delay time}

6.6) Lokachari, N., Burke, U., Ramalingam, A., Turner, M., Hesse, R., Somers, K. P., ... \& Curran, H. J., Proceedings of the Combustion Institute, 37(1) (2019) 583-591.
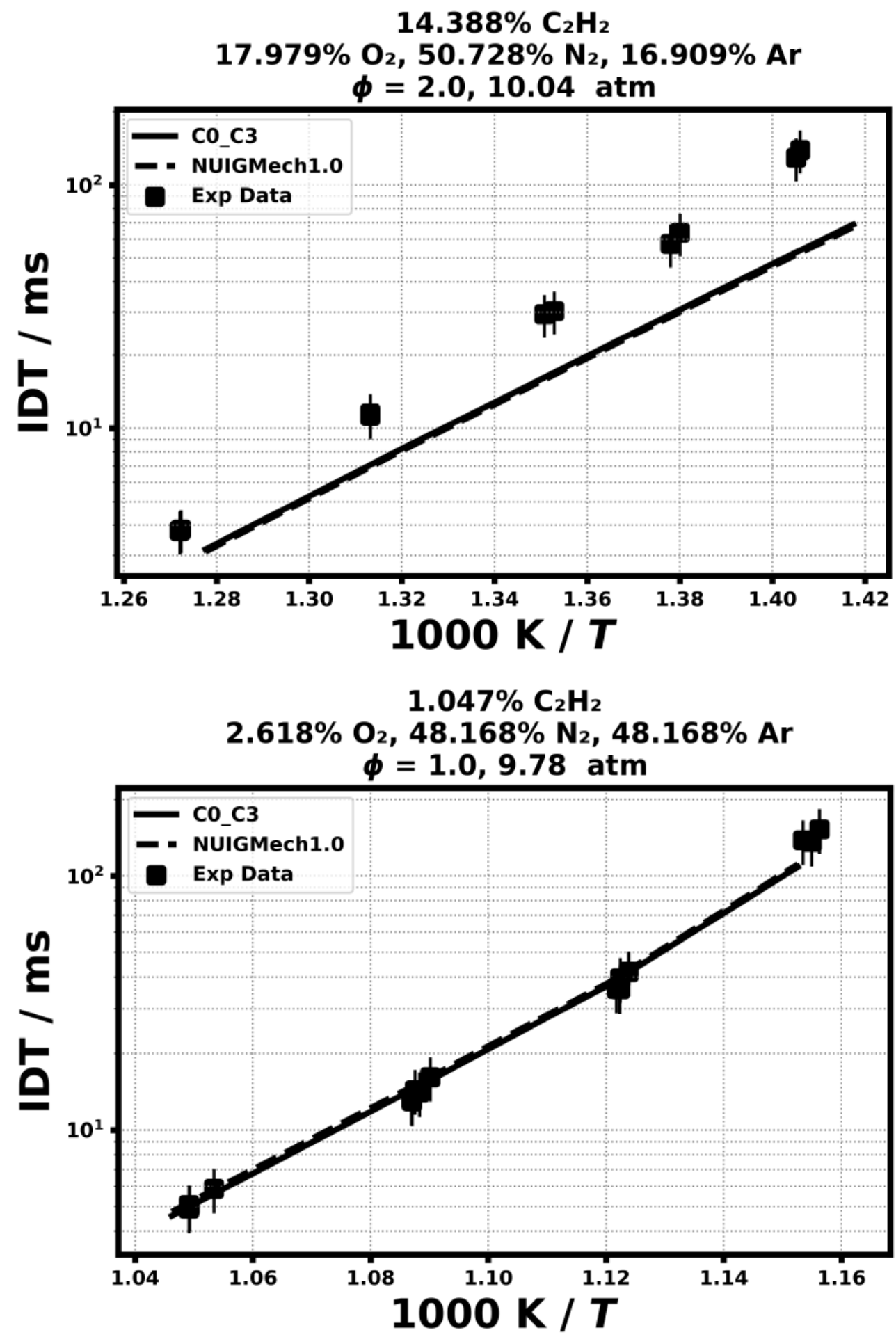

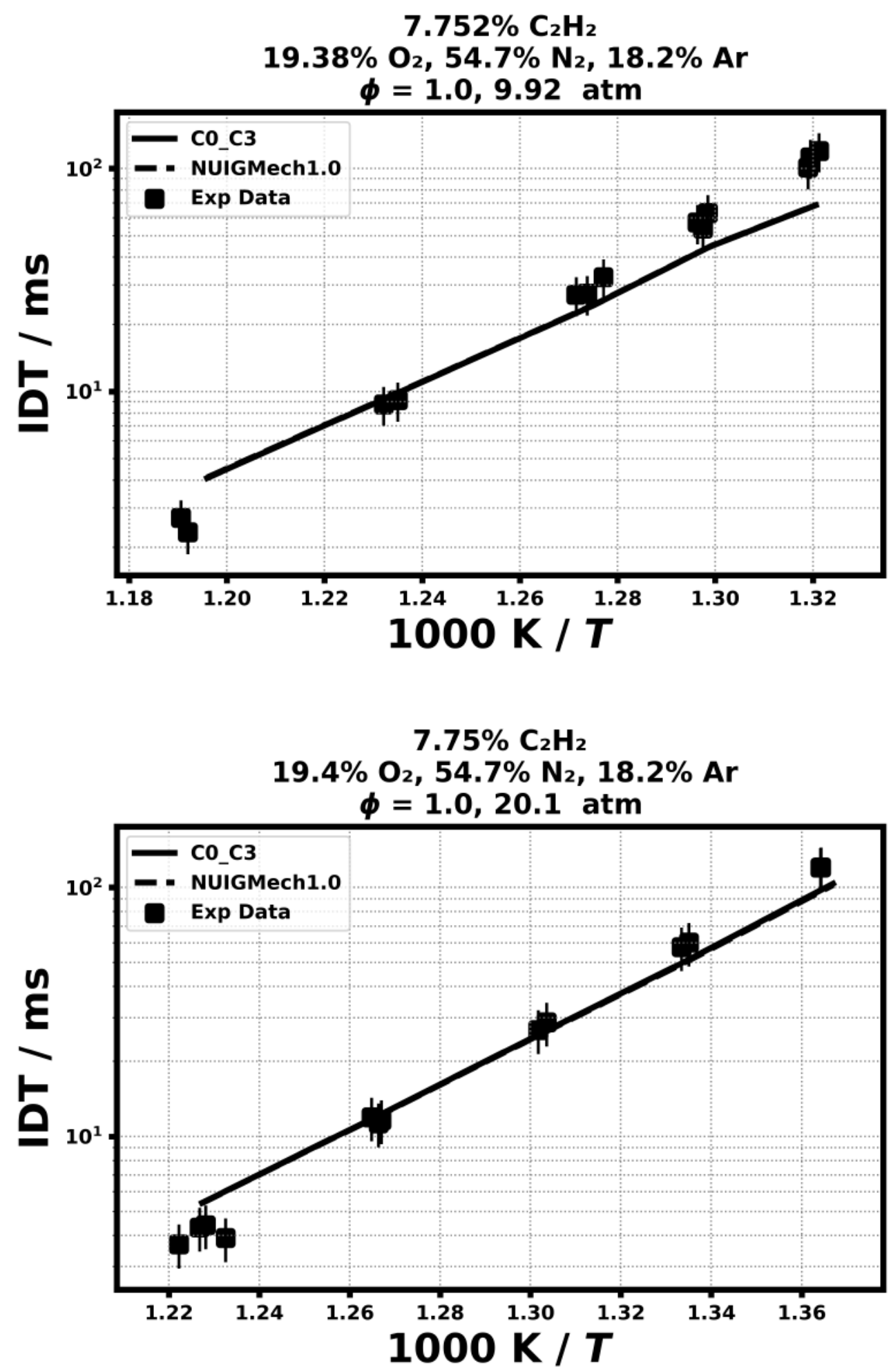


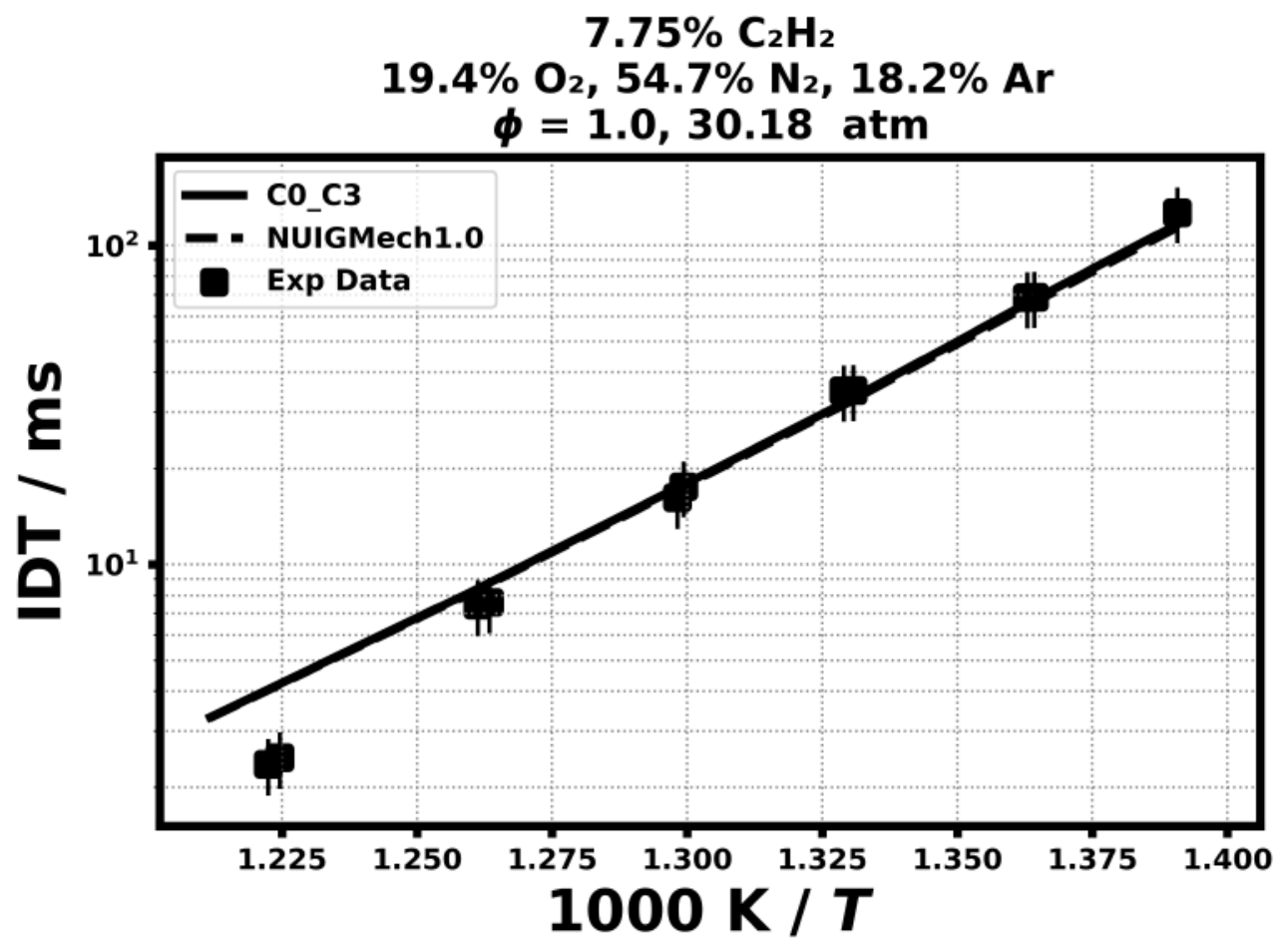

\section{Speciation in Flow reactor}

6.7) Alzueta, M. U., Borruey, M., Callejas, A., Millera, A., \& Bilbao, R. Combustion and flame, 152(3) (2008) 377-386.

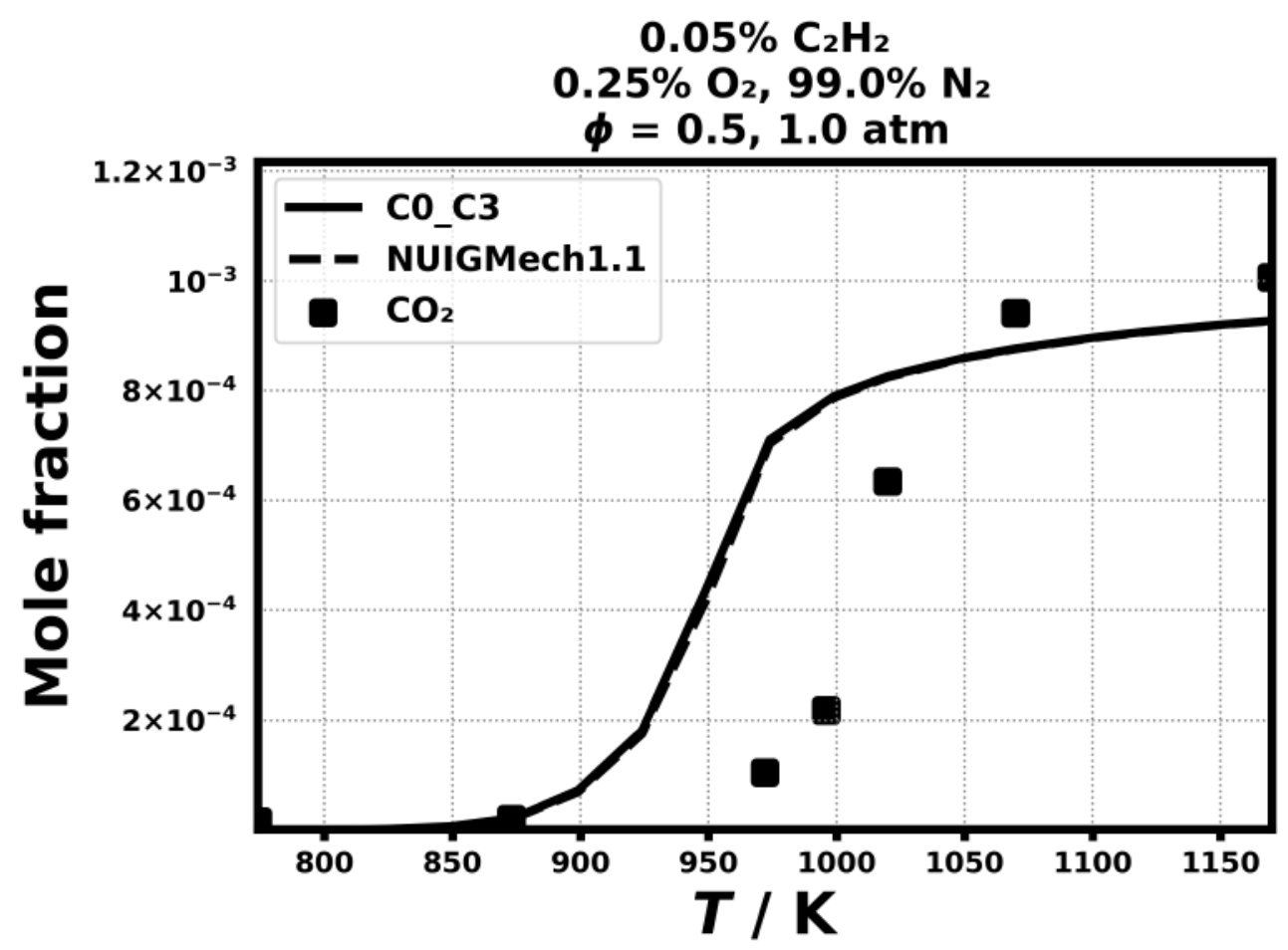



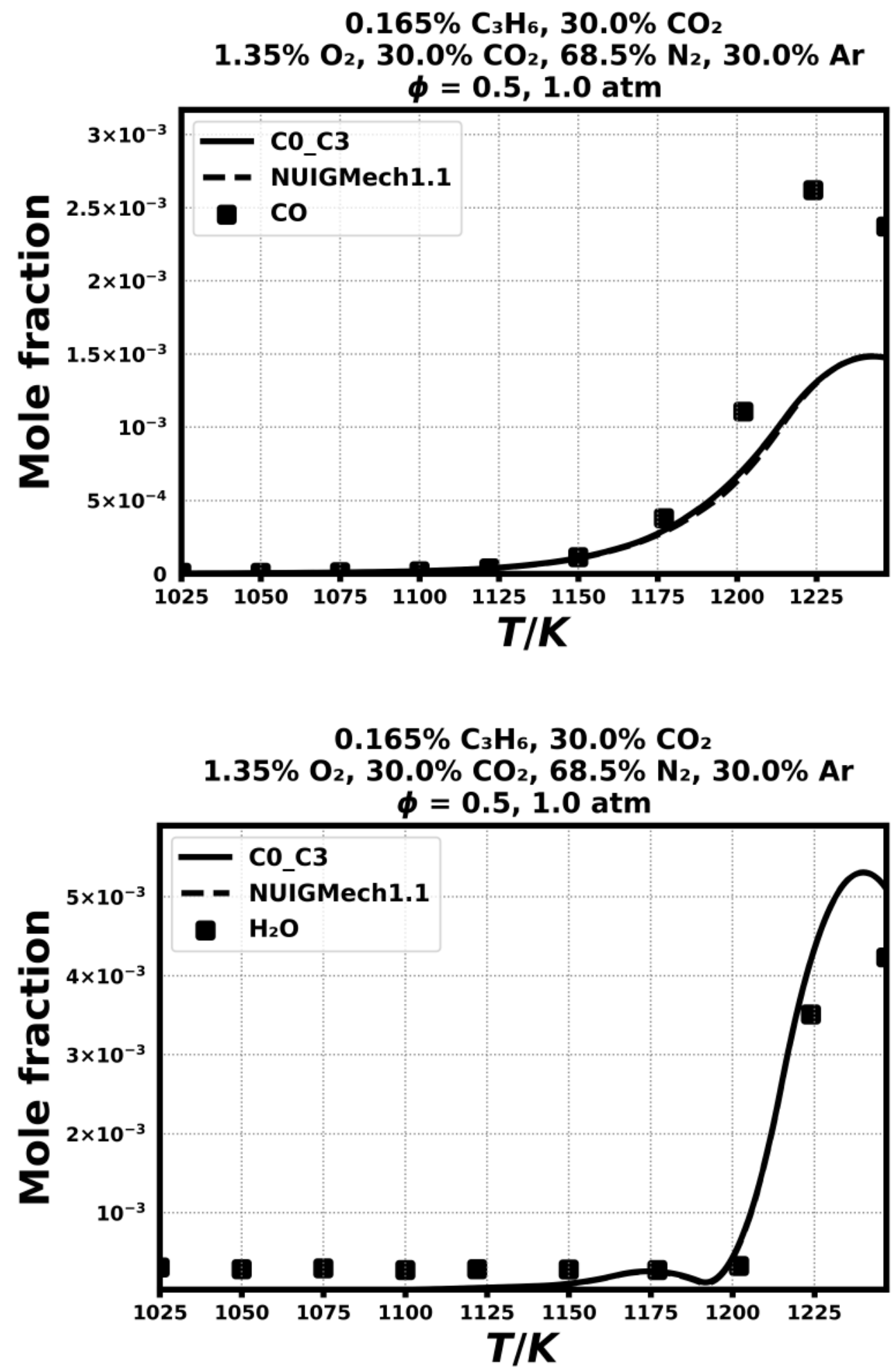

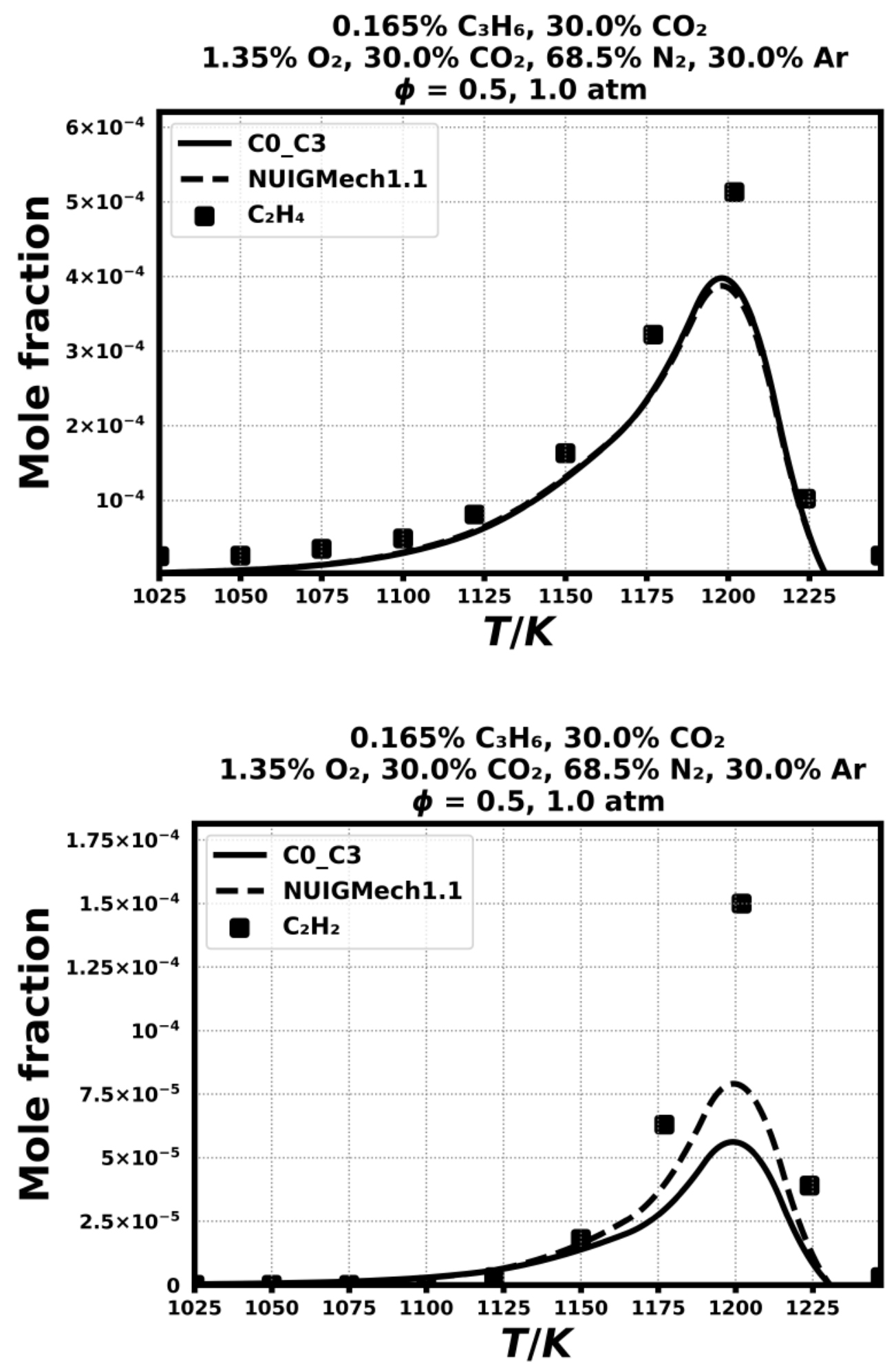

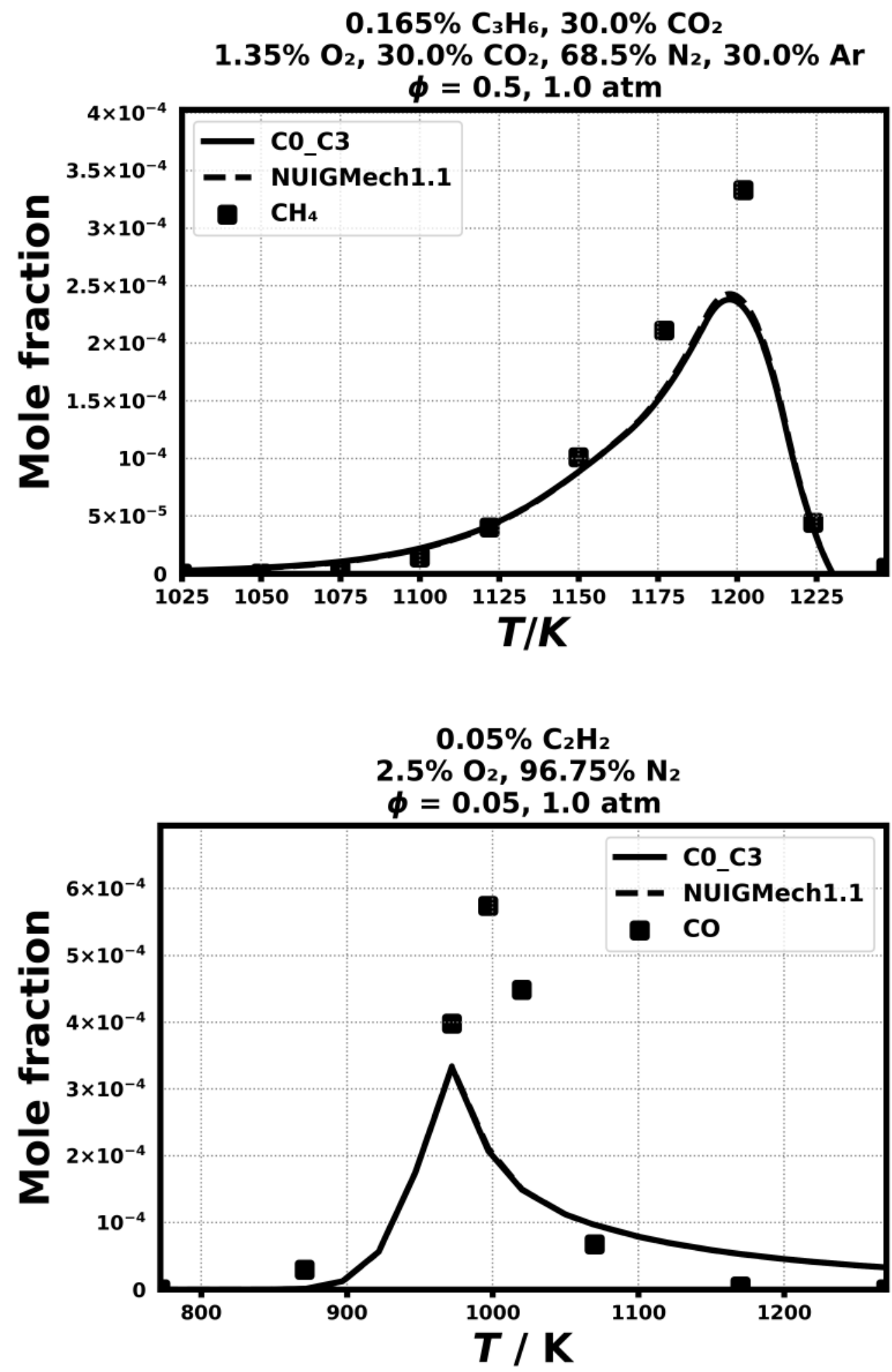

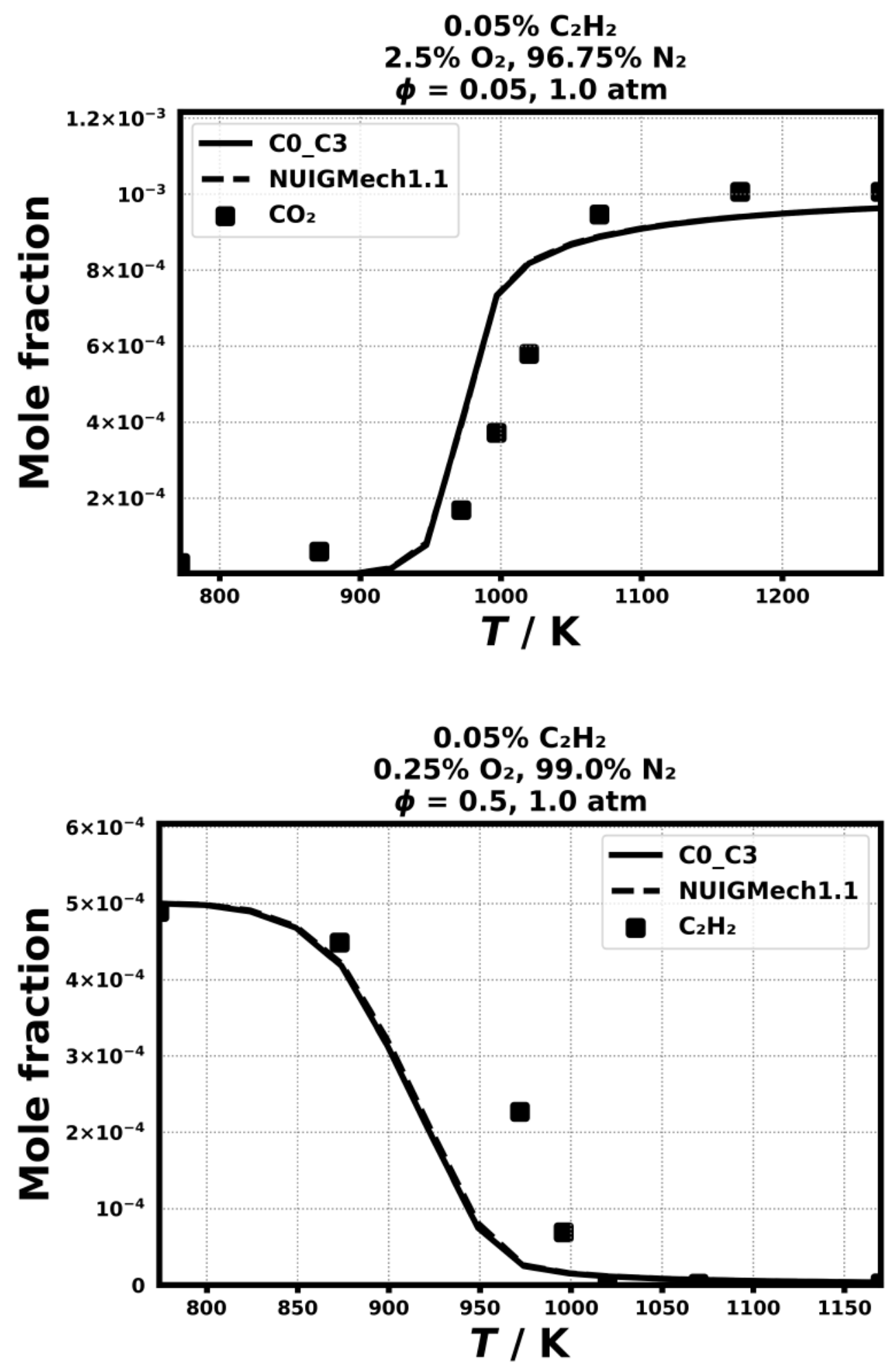

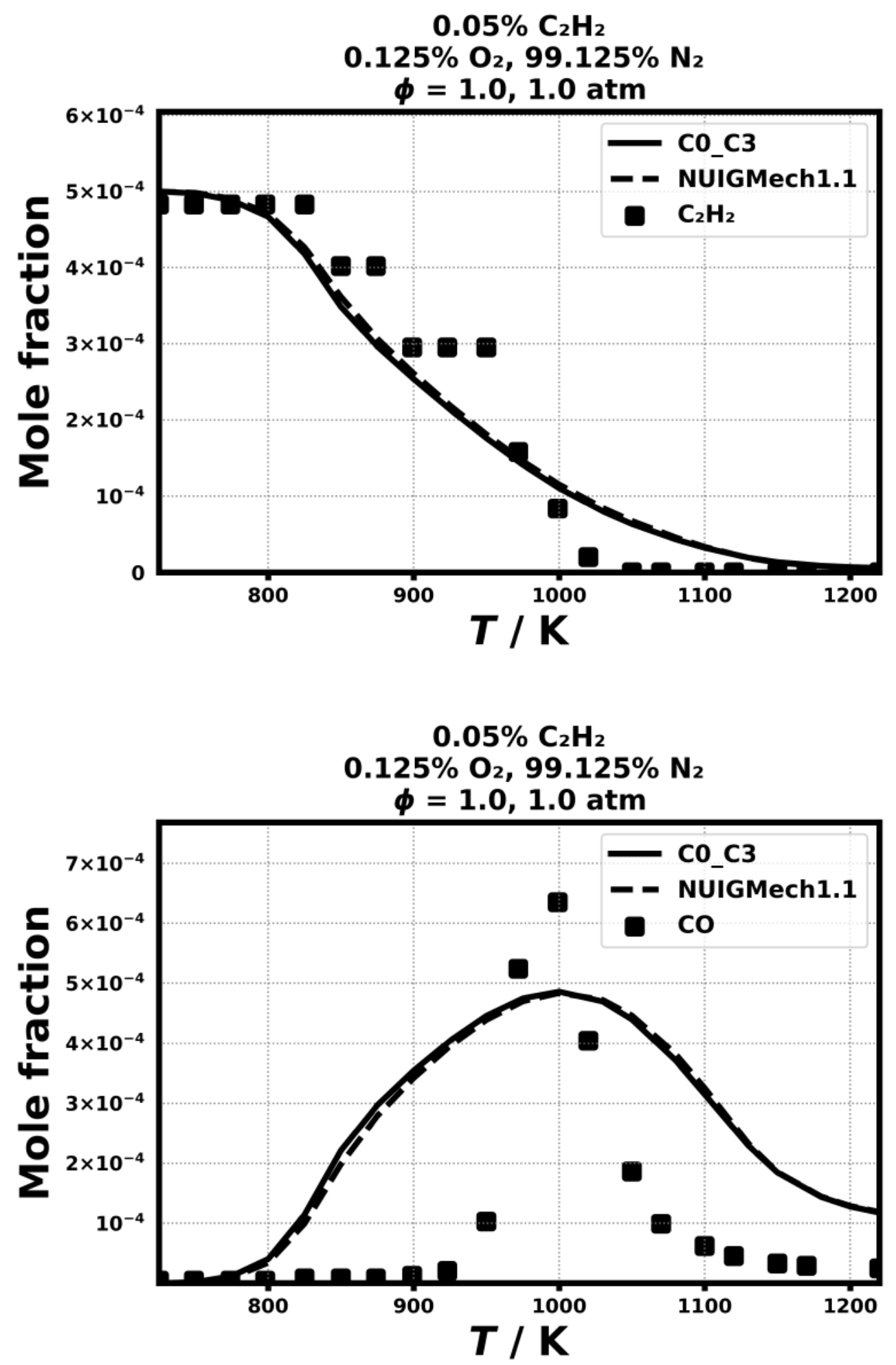

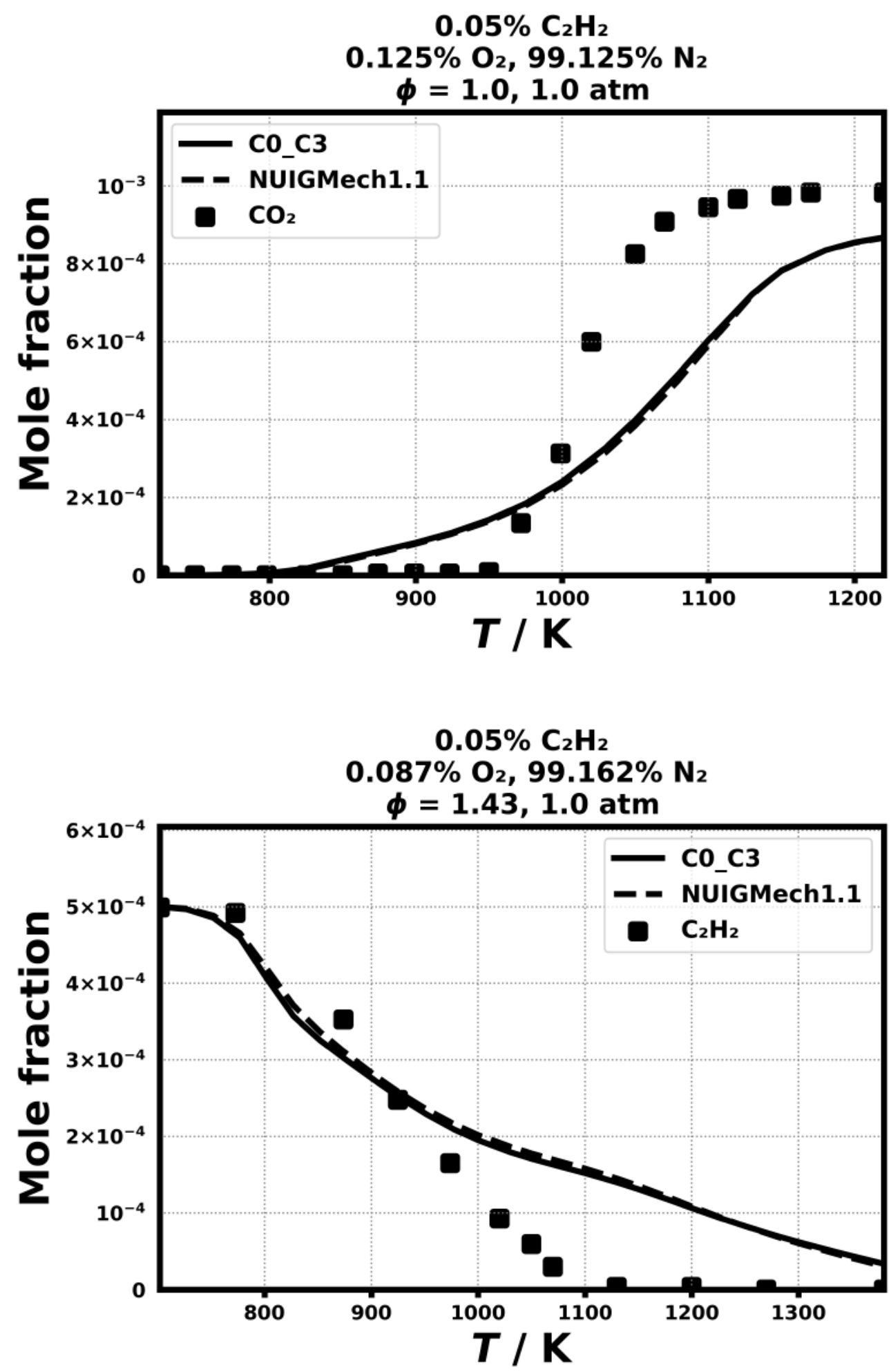

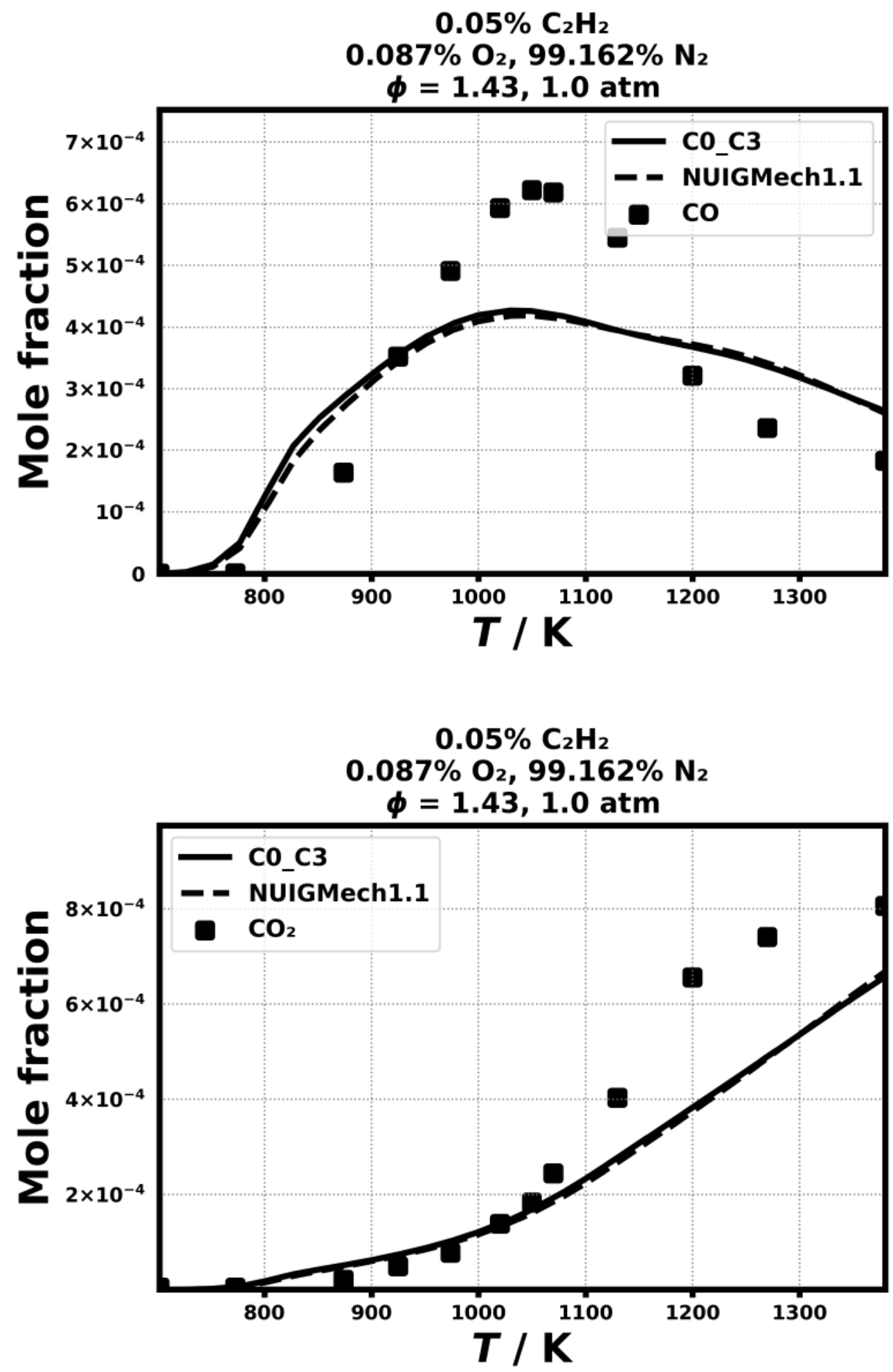
6.8) Lopez, J. G., Rasmussen, C. L., Alzueta, M. U., Gao, Y., Marshall, P., \& Glarborg, P. Proceedings of the Combustion Institute, 32(1) (2009) 367-375.
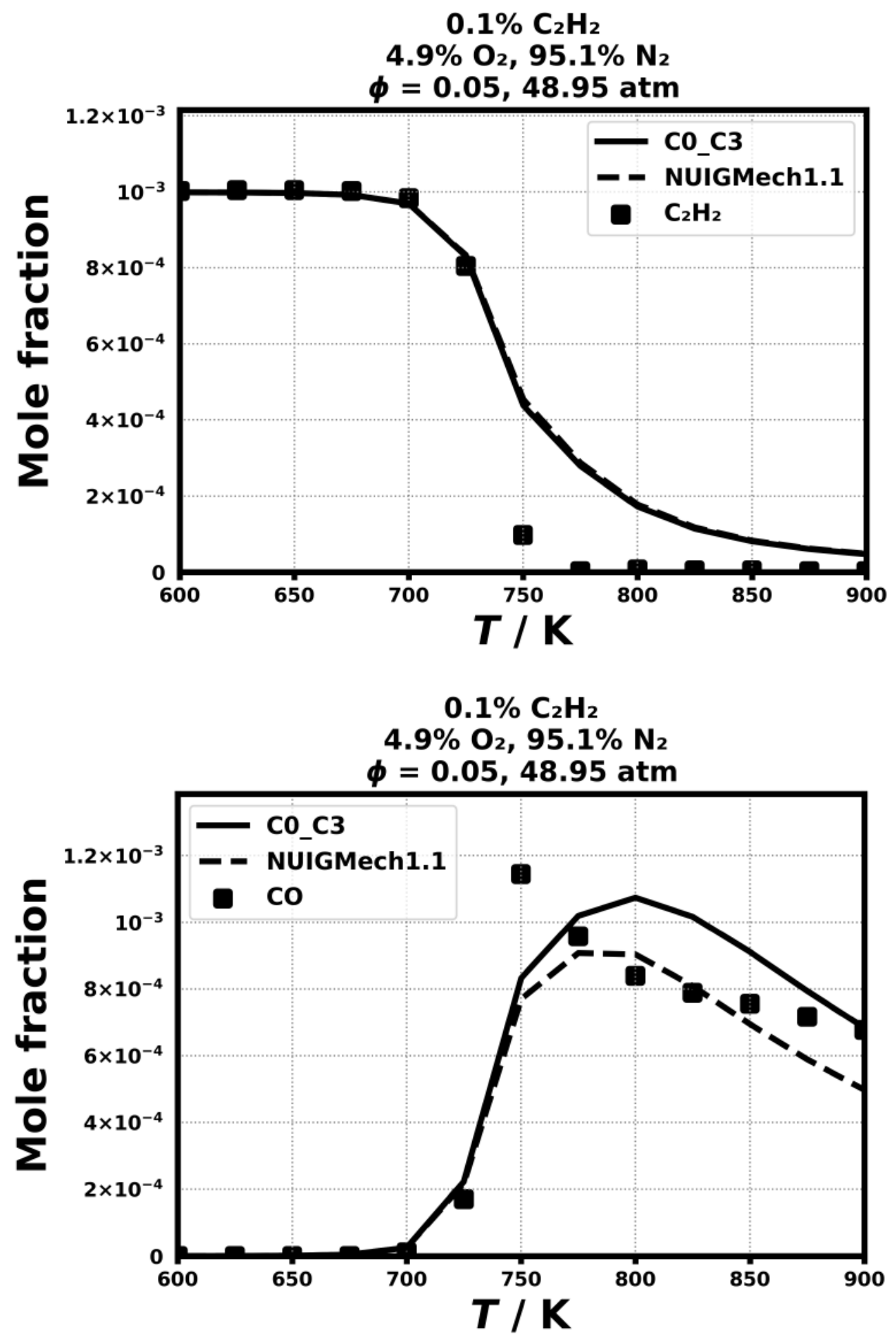

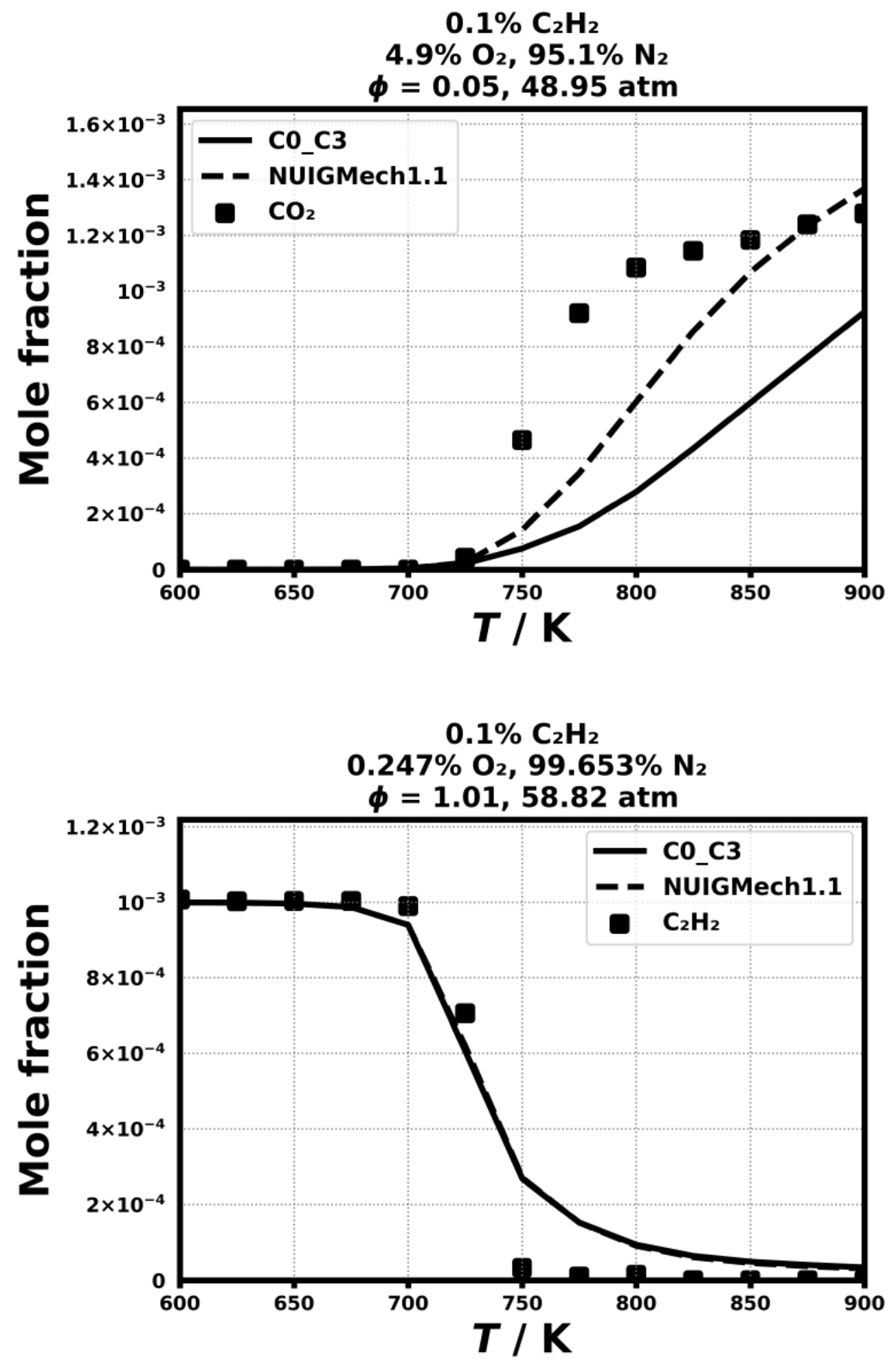

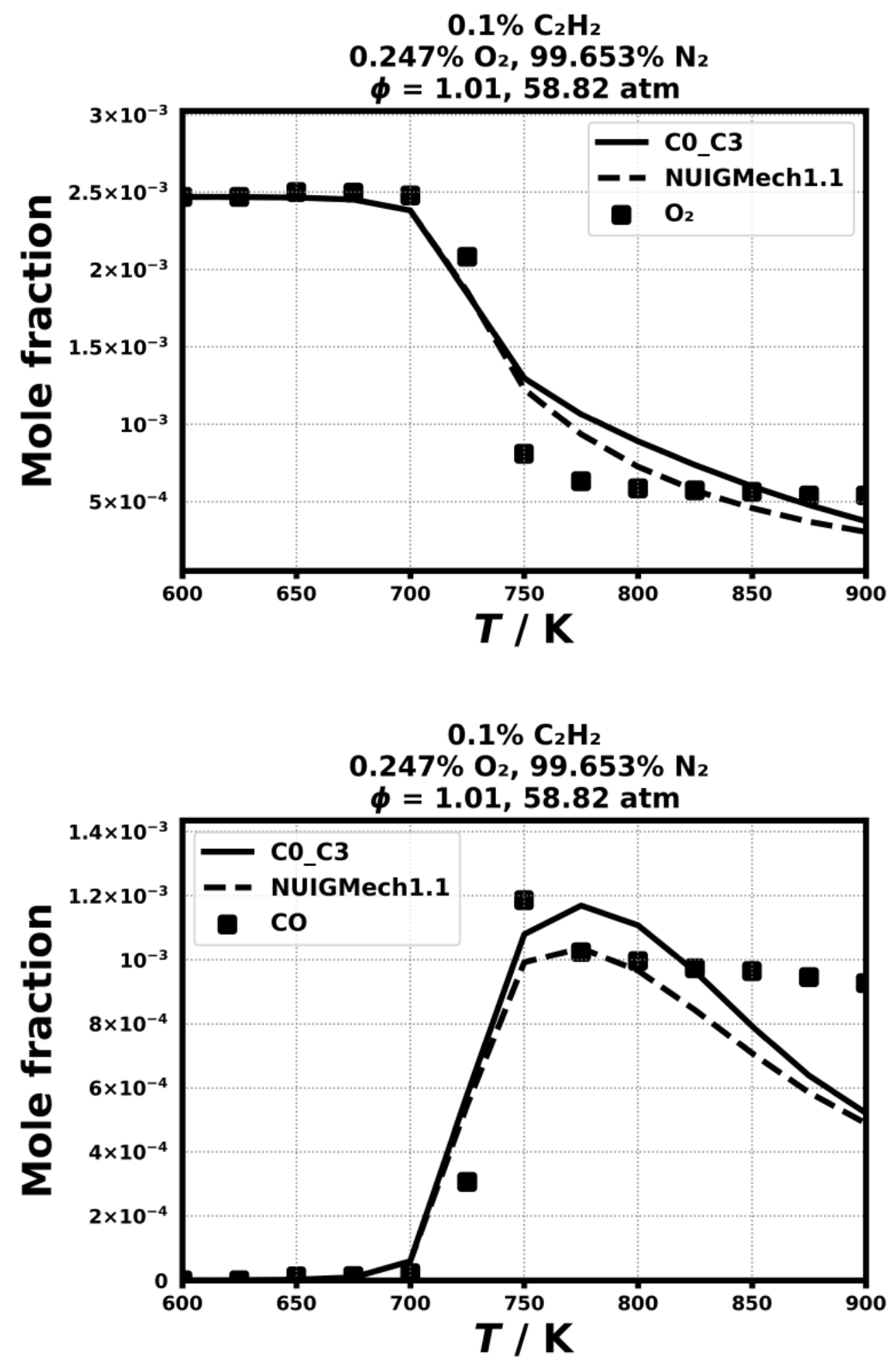

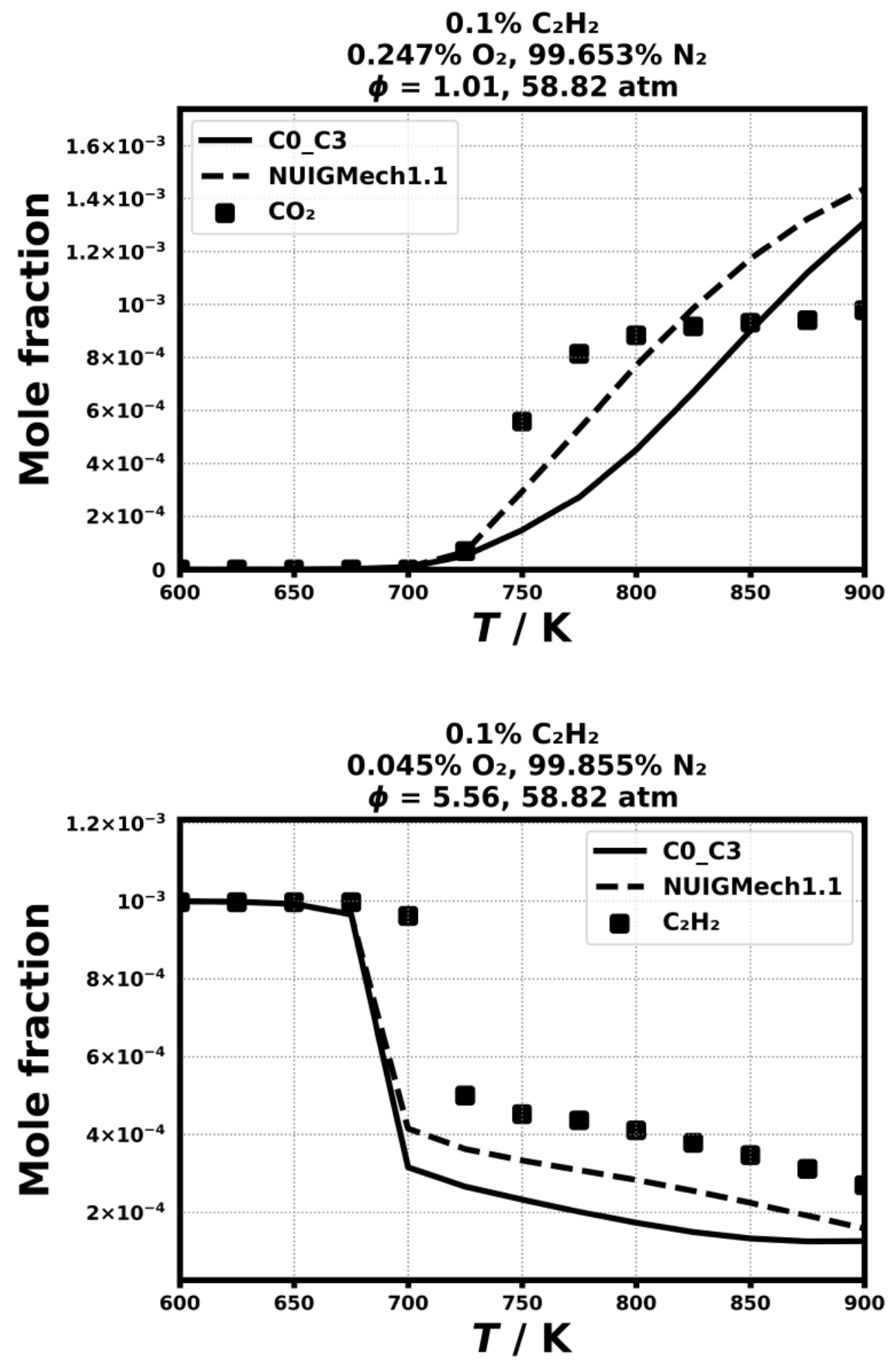

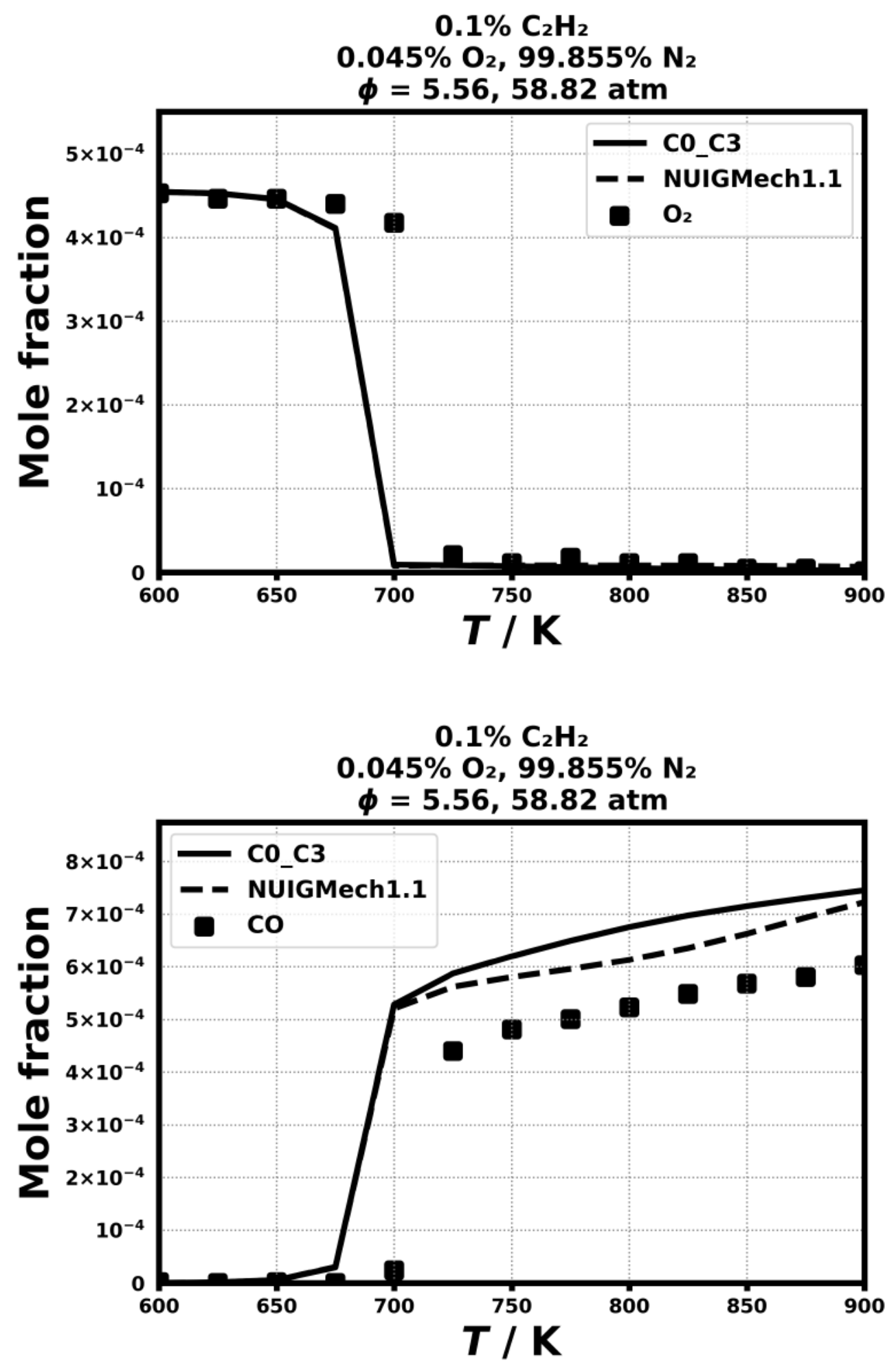

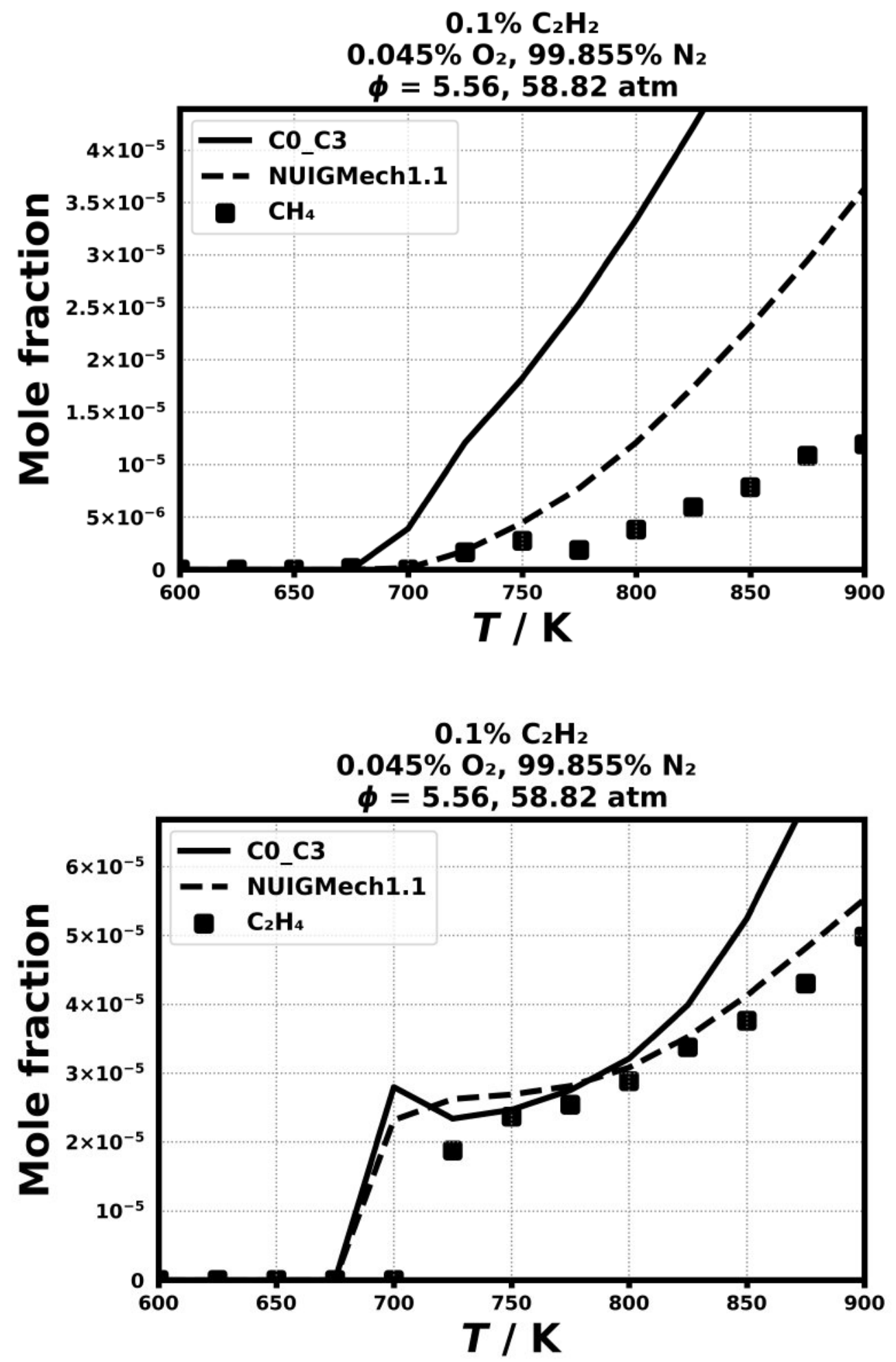


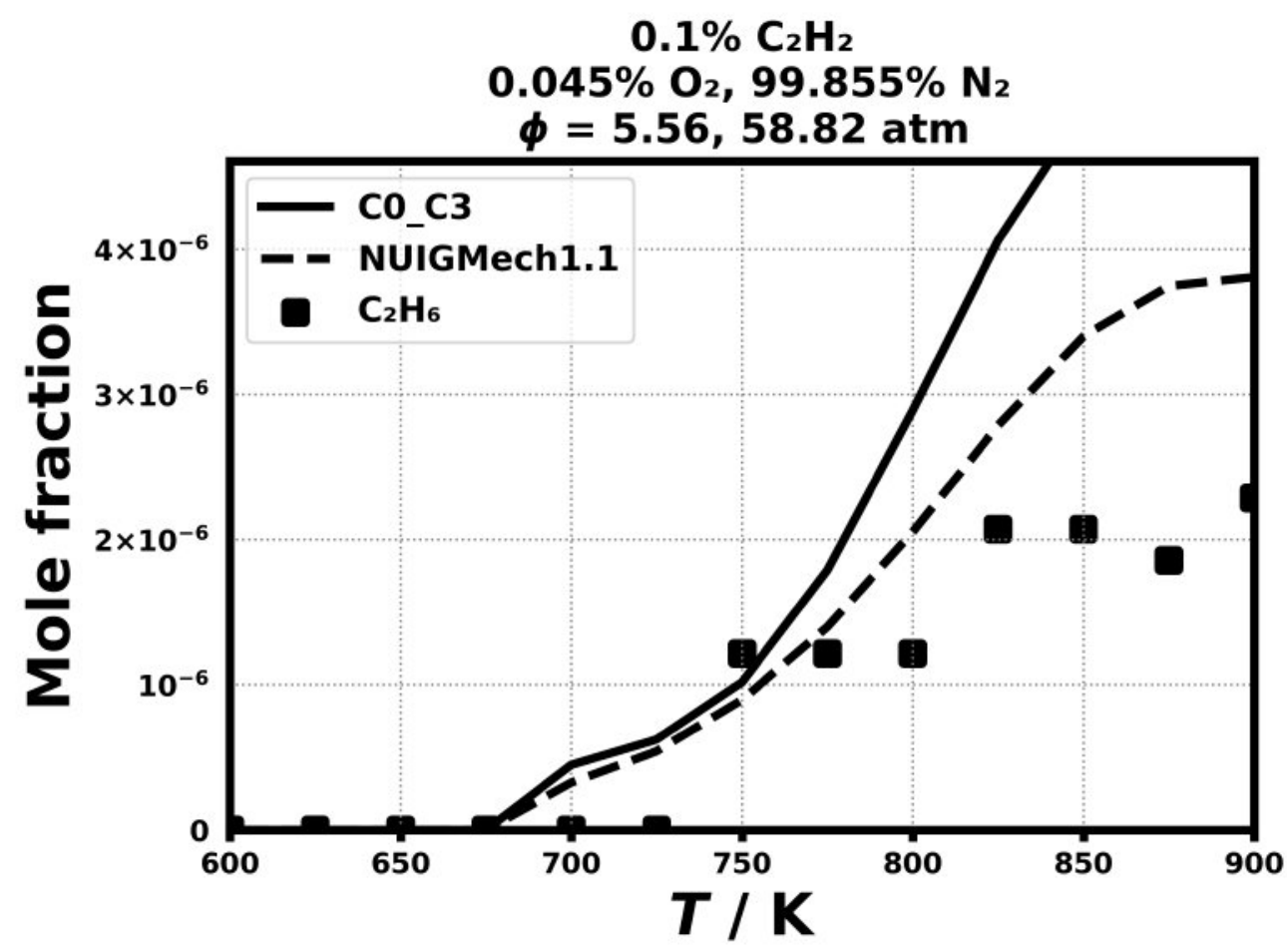




\section{Laminar flame speed}

6.9) F. N. Egolfopoulos, D. L. Zhu, C. K. Law, Proceedings of the Combustion Institute 23 (1990) 471-478.

6.10) G. Jomaas, X. L. Zheng, D. L. Zhu, C. K. Law, Proceedings of the Combustion Institute 30 (2005) 193-200.

6.11) Lokachari, N., Burke, U., Ramalingam, A., Turner, M., Hesse, R., Somers, K. P., ... \& Curran, H. J., Proceedings of the Combustion Institute, 37(1) (2019) 583-591.

6.12) Shen, X., Yang, X., Santner, J., Sun, J., \& Ju, Y. Proceedings of the Combustion Institute, 35(1) (2015) 721-728.

6.13) Rokni, E., Moghaddas, A., Askari, O., \& Metghalchi, H., Journal of Energy Resources Technology, 137(1).(2015)

6.14) Ravi, S., Sikes, T. G., Morones, A., Keesee, C. L., \& Petersen, E. L., Proceedings of the Combustion Institute, 35(1) (2015) 679-686.

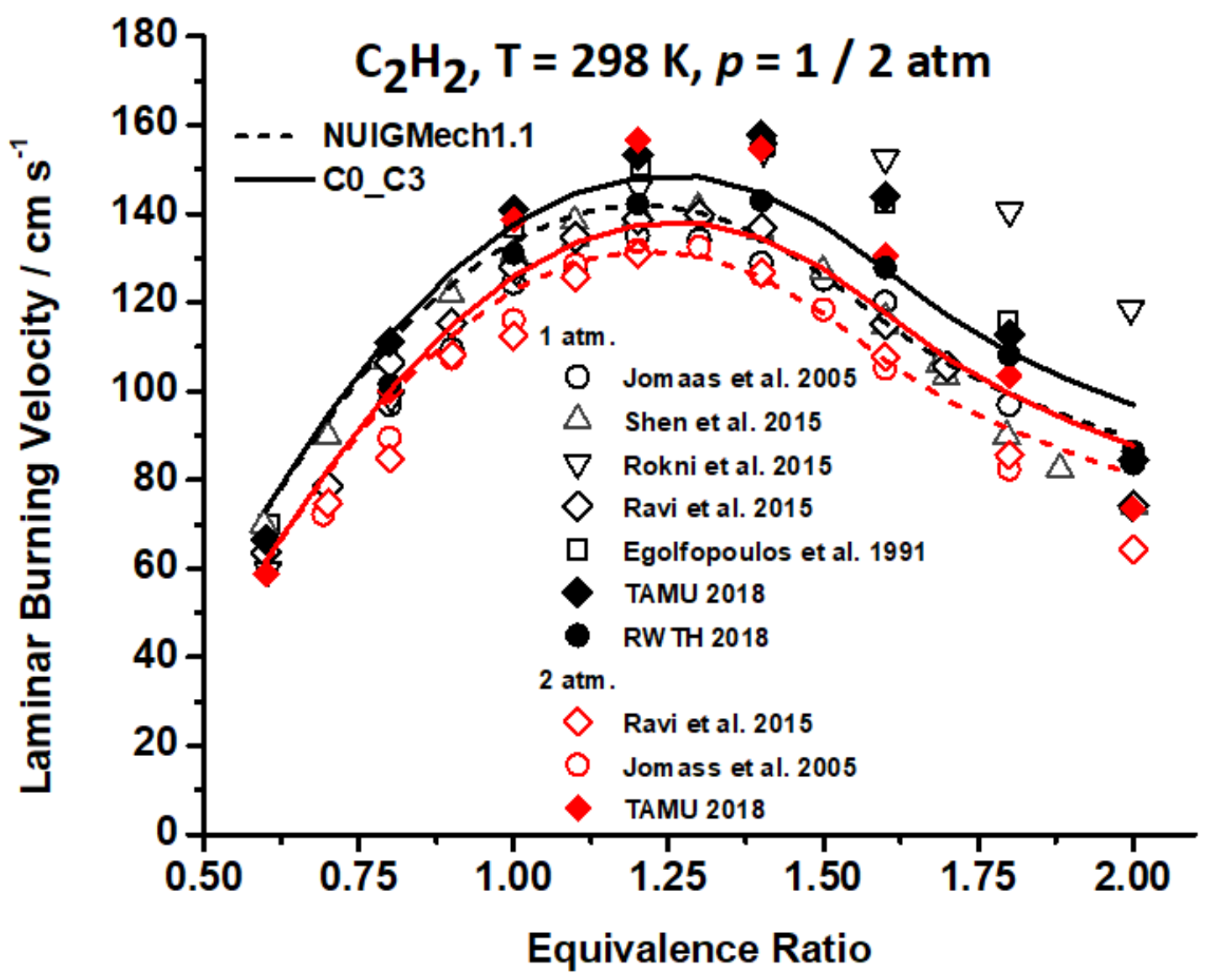




\section{Validation for $\mathrm{C}_{2} \mathrm{H}_{5} \mathrm{OH}$}

\section{Shock tube ignition delay time}

7.1) F.R. Gillespie, Phd Thesis, National Univ. Ire. Galway, 2010
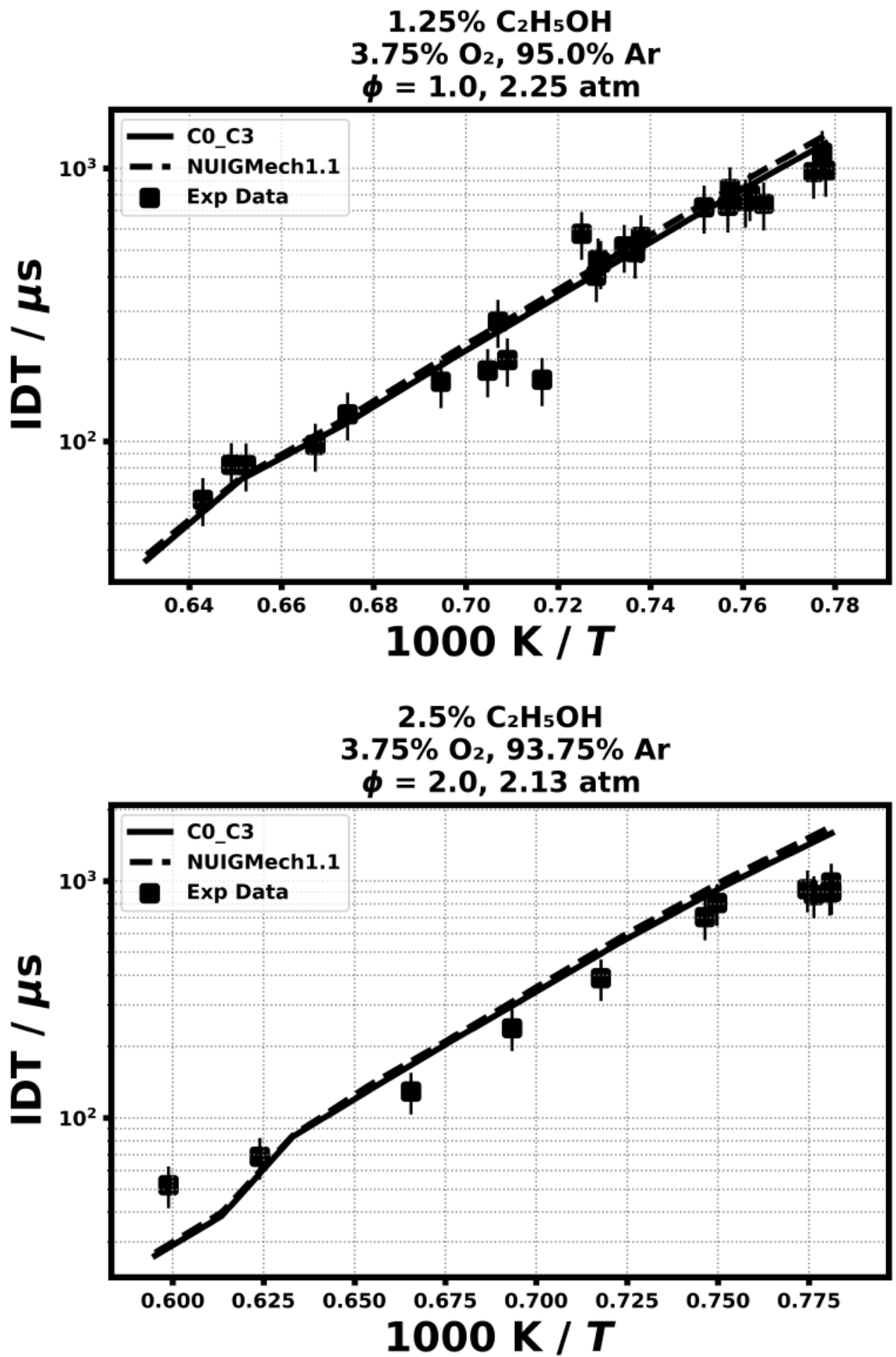

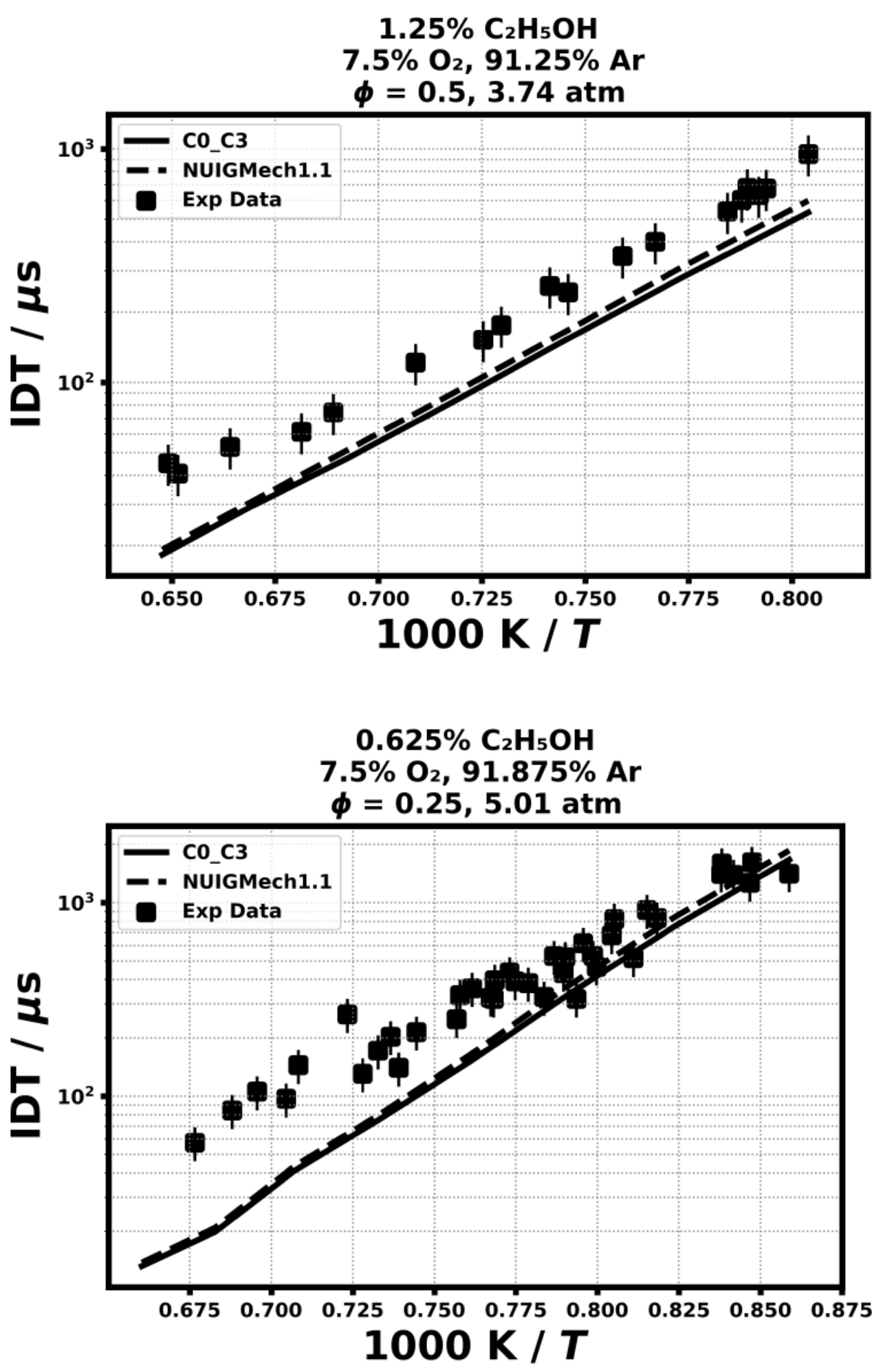
7.2) Heufer, K. A., \& Olivier, H. J. S. W., Shock Waves, 20(4) (2010) 307-316.
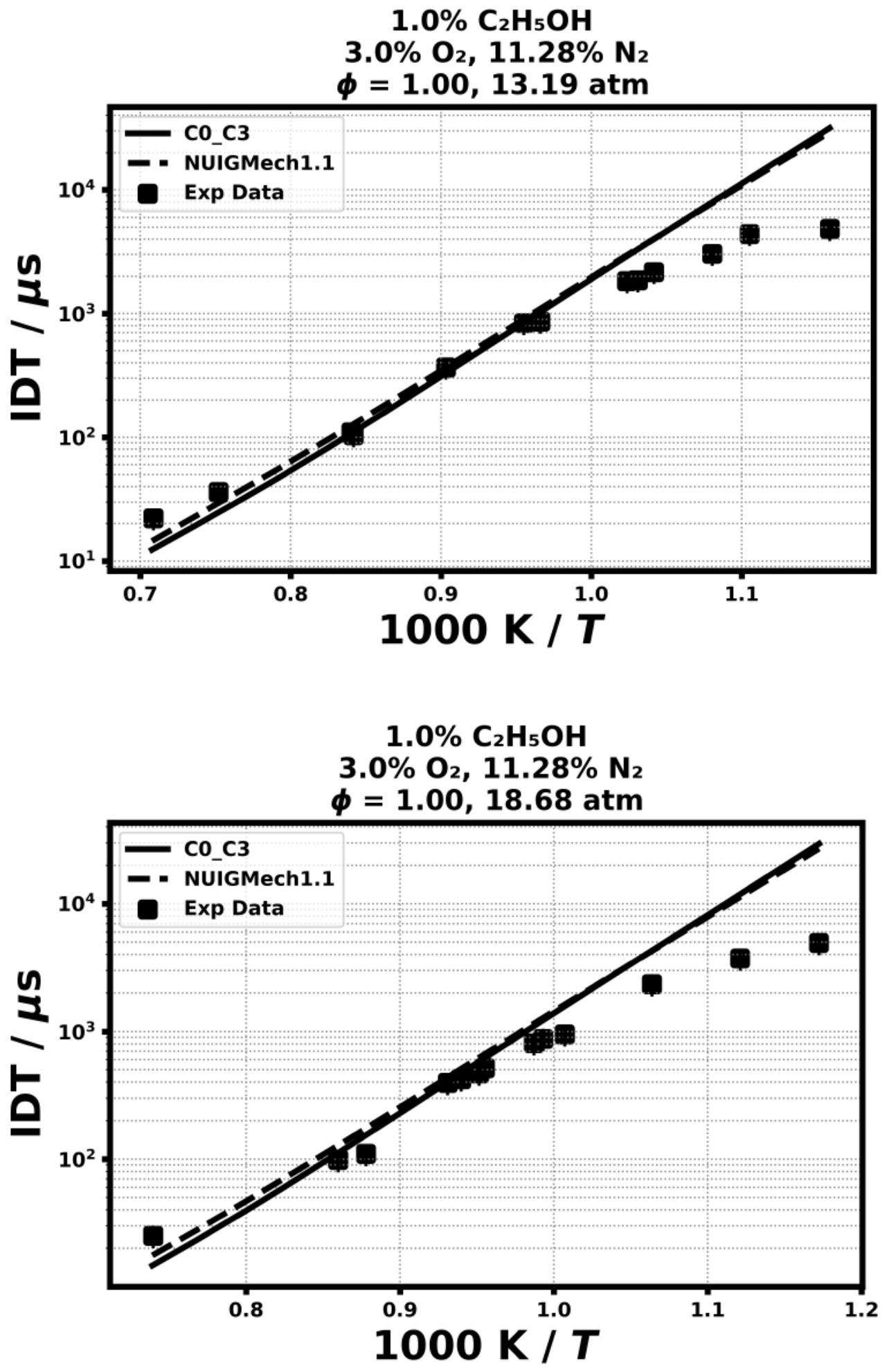

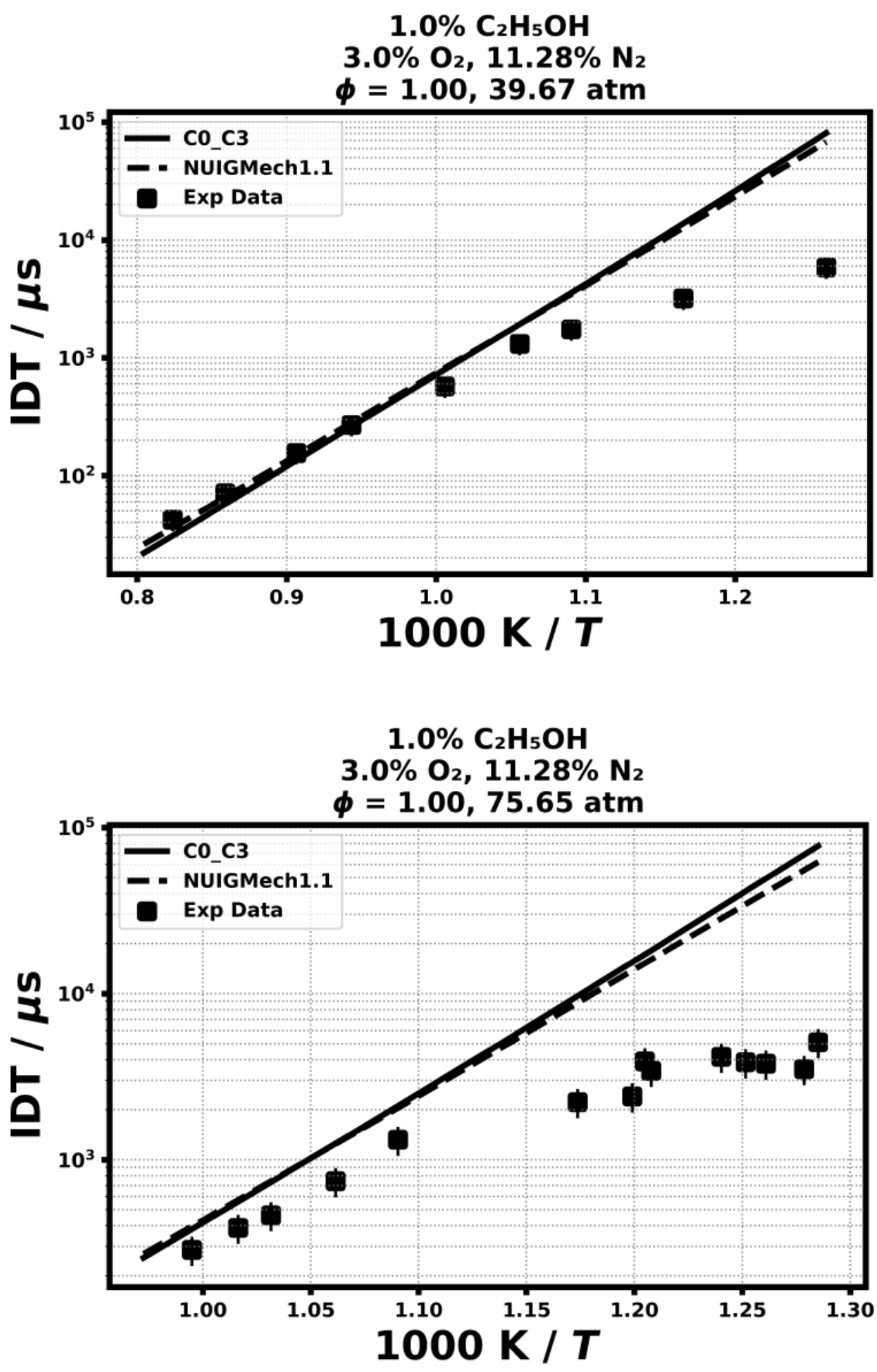
7.3) Noorani, K. E., Akih-Kumgeh, B., \& Bergthorson, J. M., Energy \& fuels, 24(11) (2010) 5834-5843.
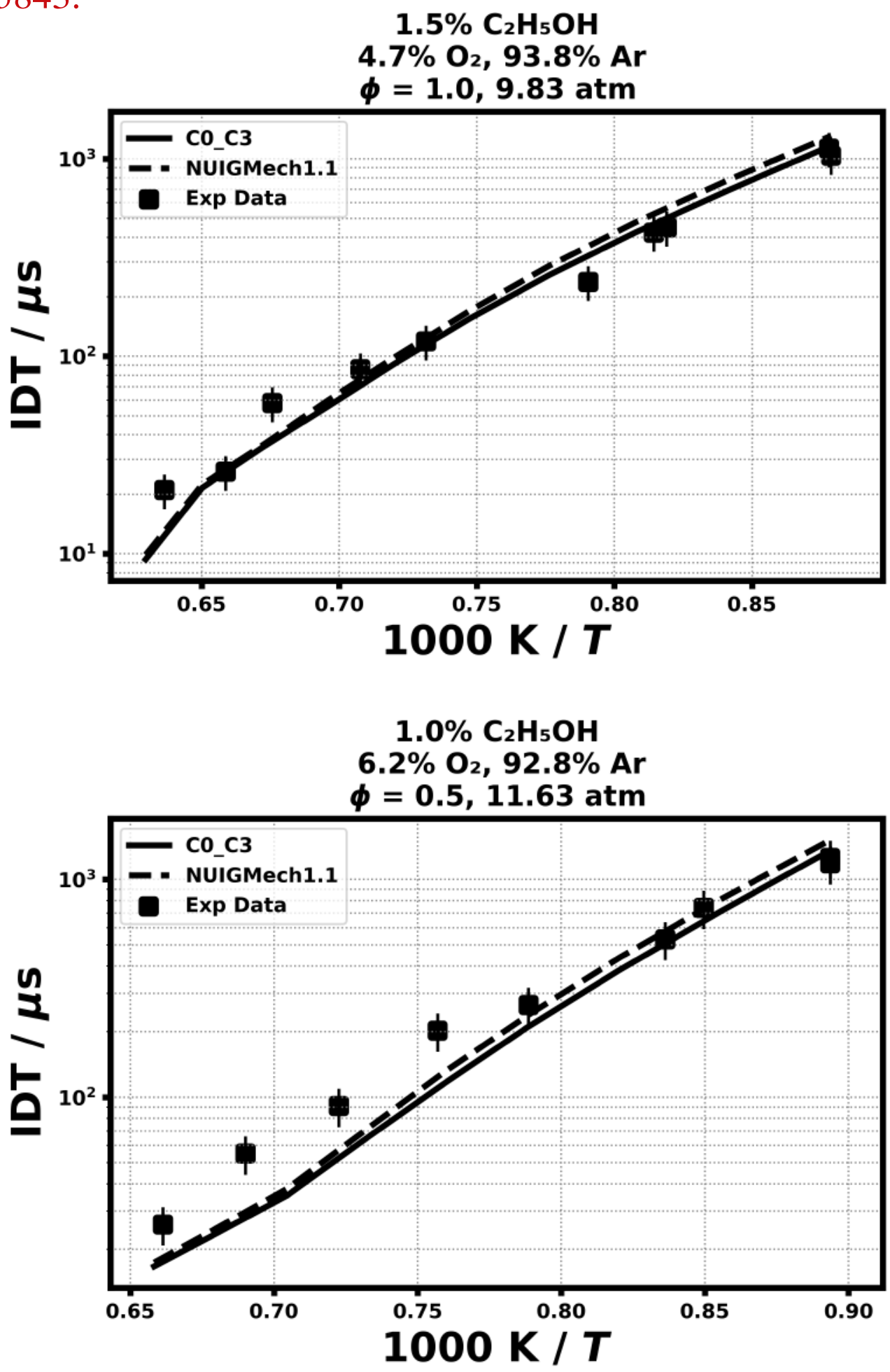

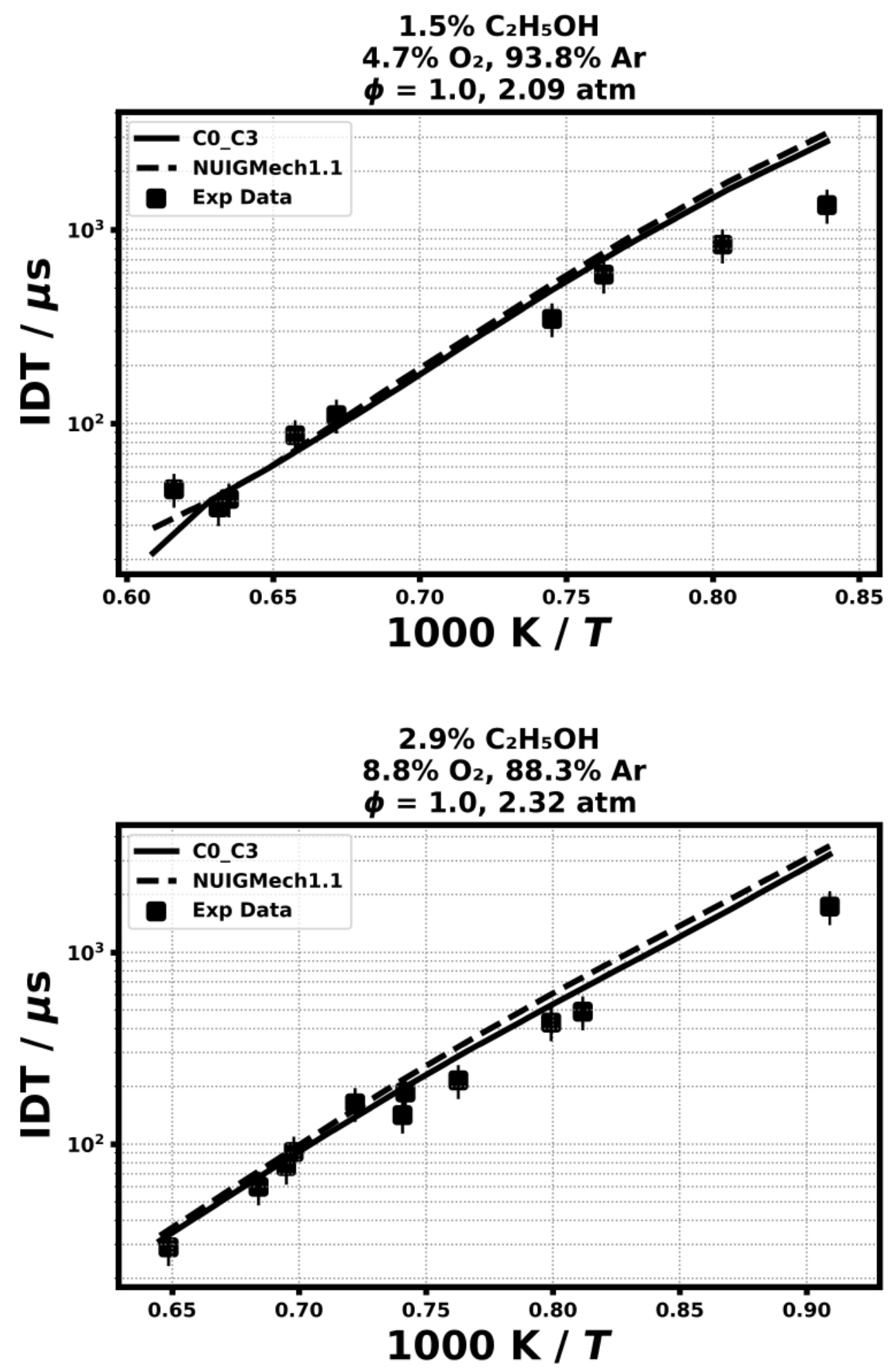


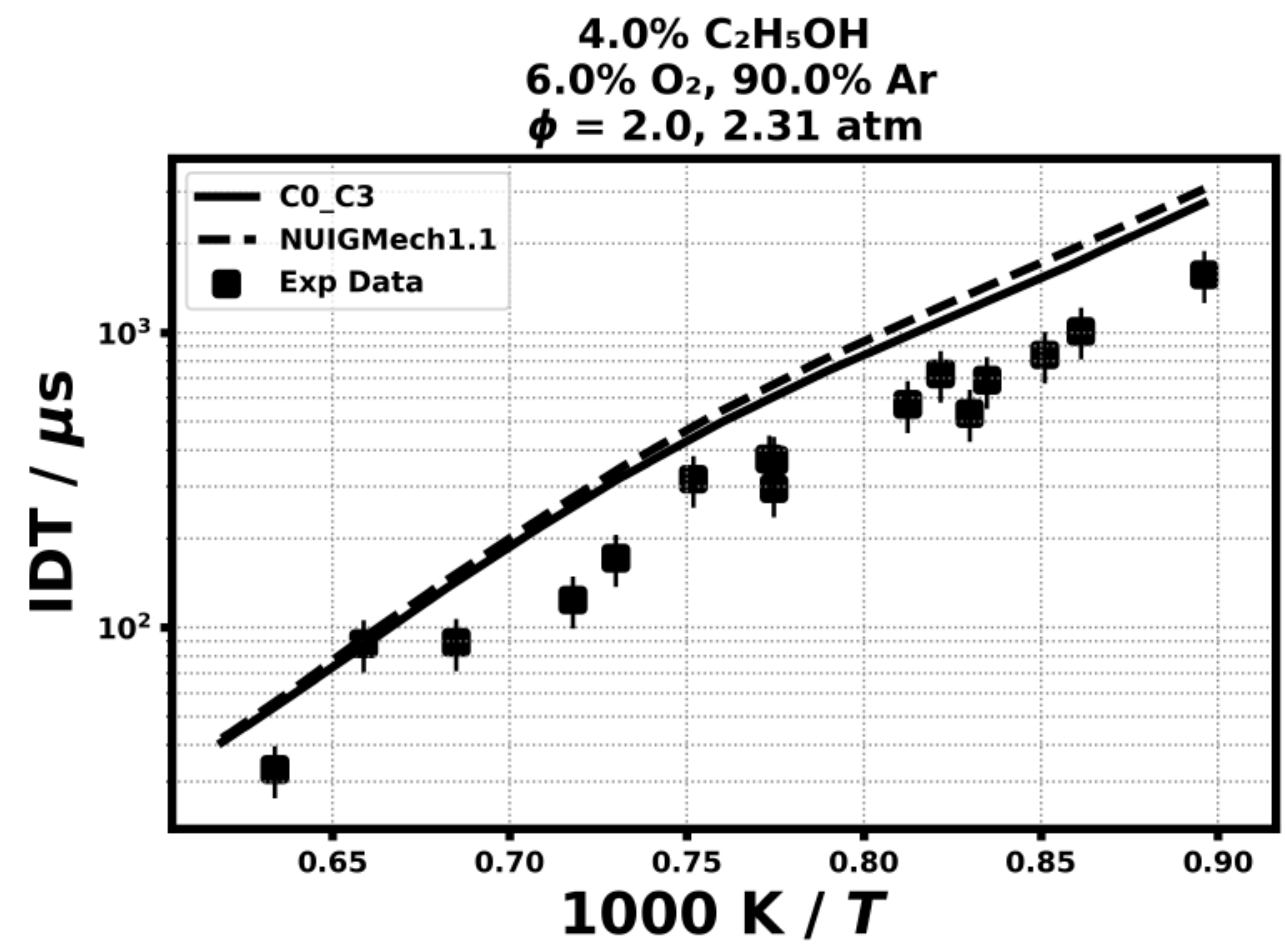

7.4) Zhang, Y., El-Merhubi, H., Lefort, B., Le Moyne, L., Curran, H. J., \& Kéromnès, A., Combustion and Flame, 190 (2018) 74-86.

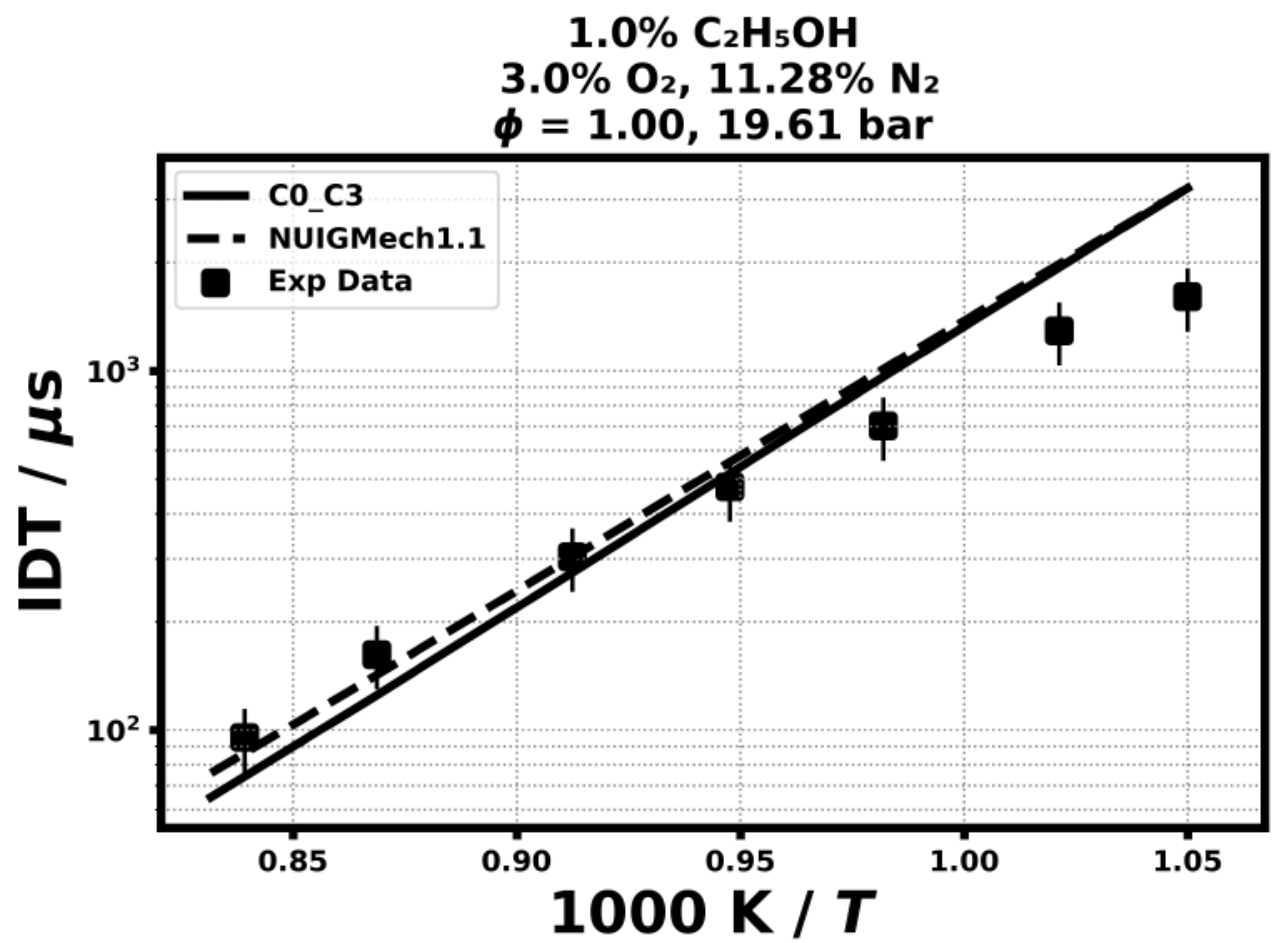



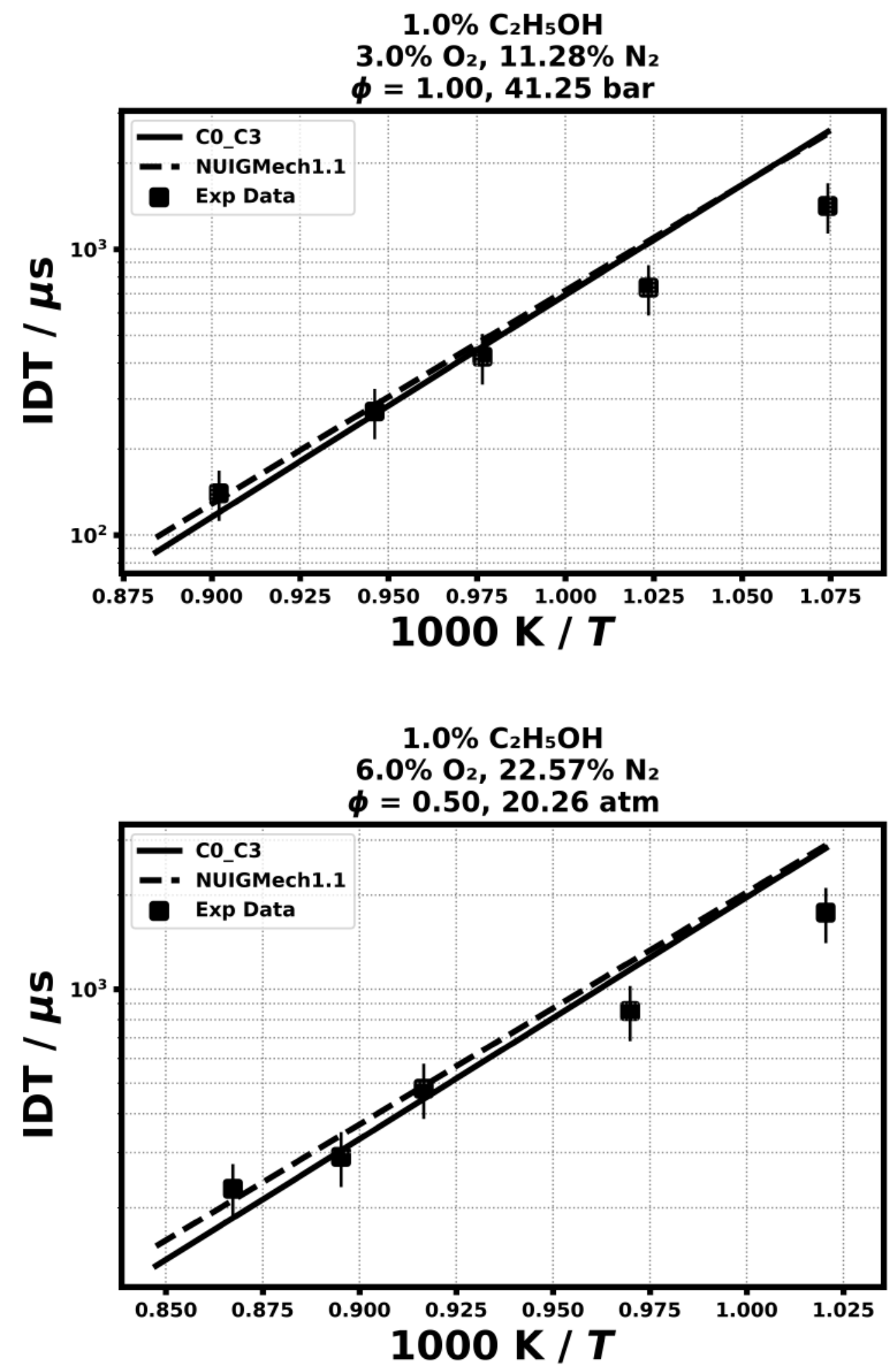

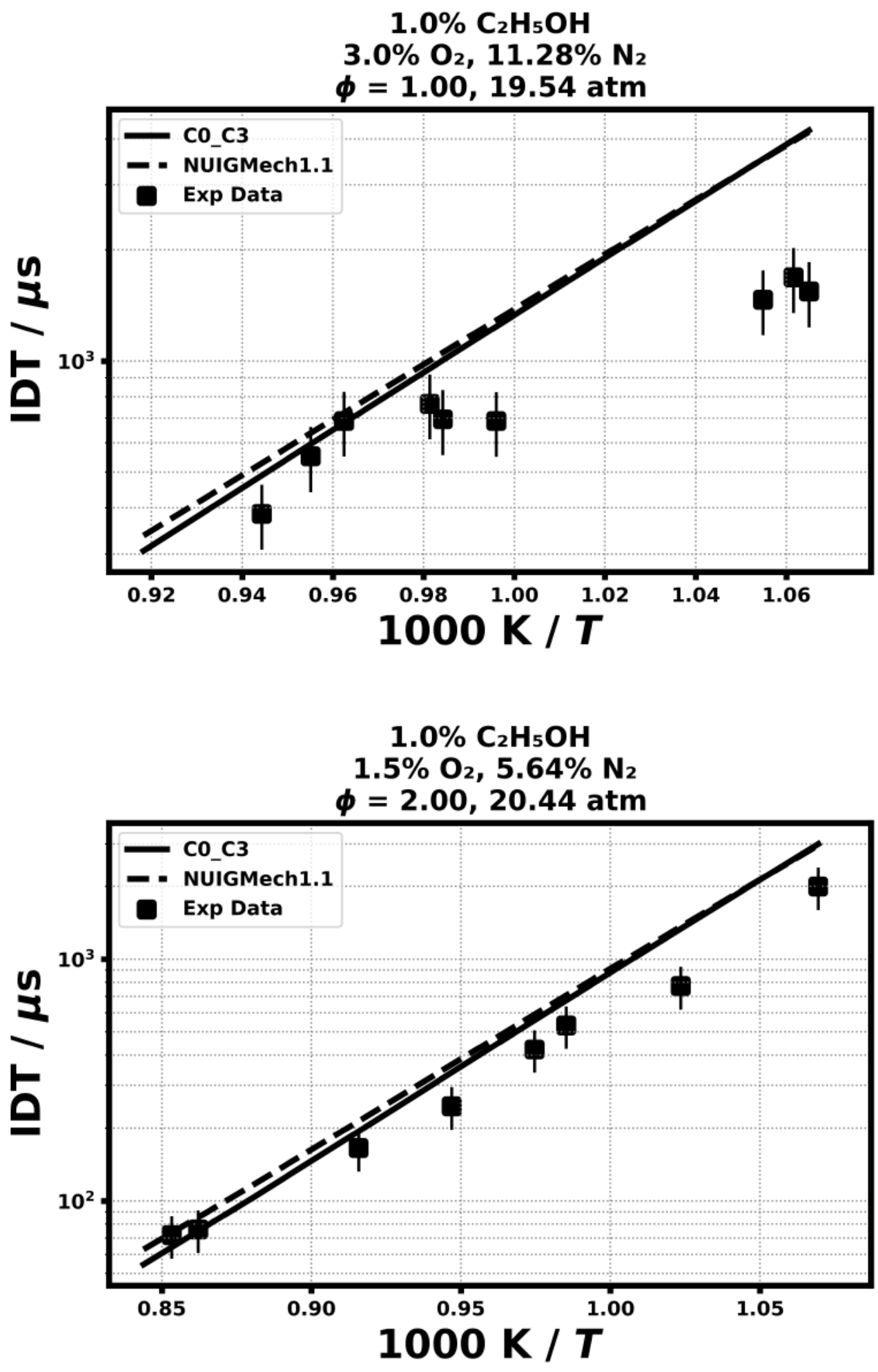

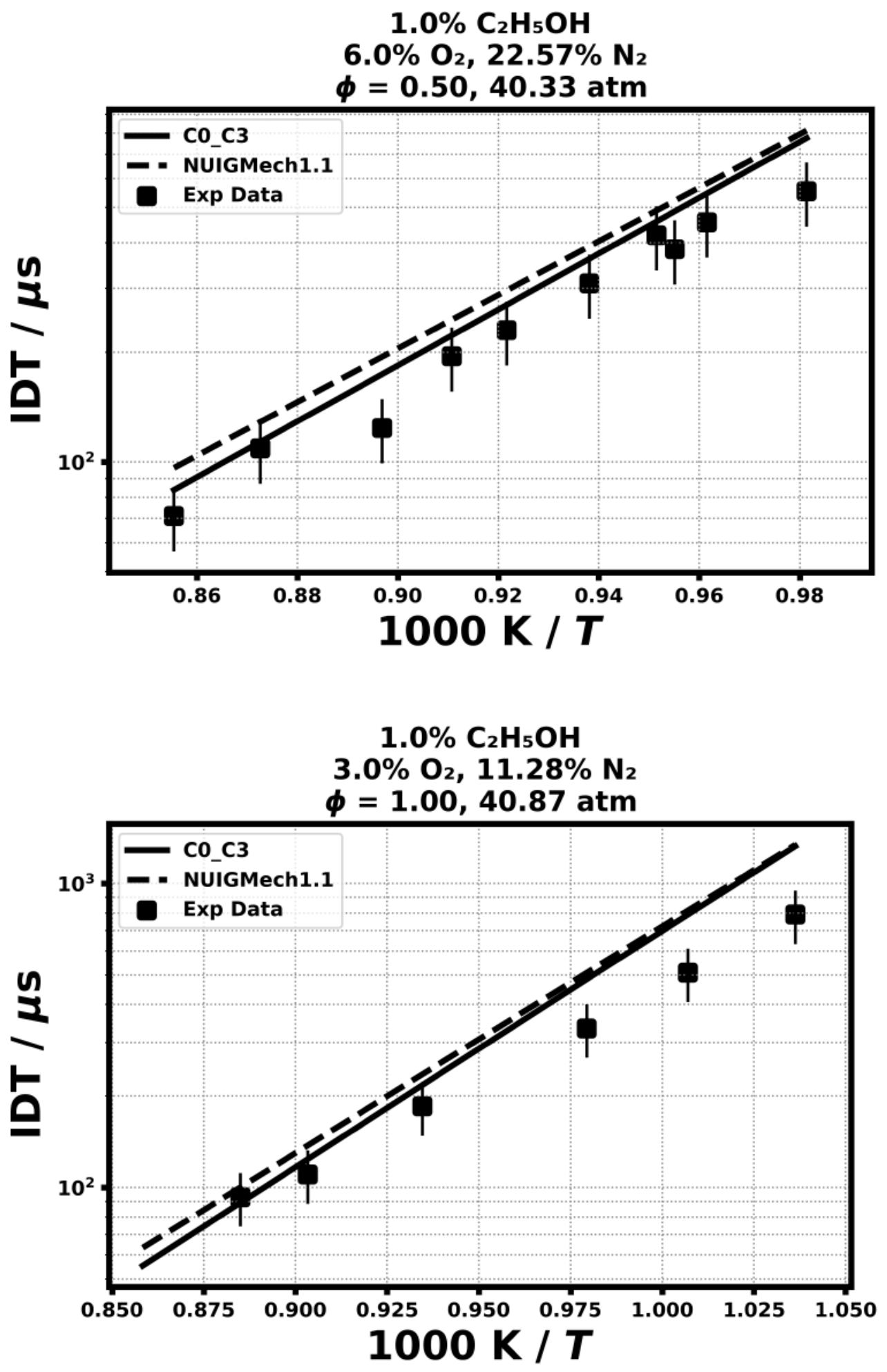


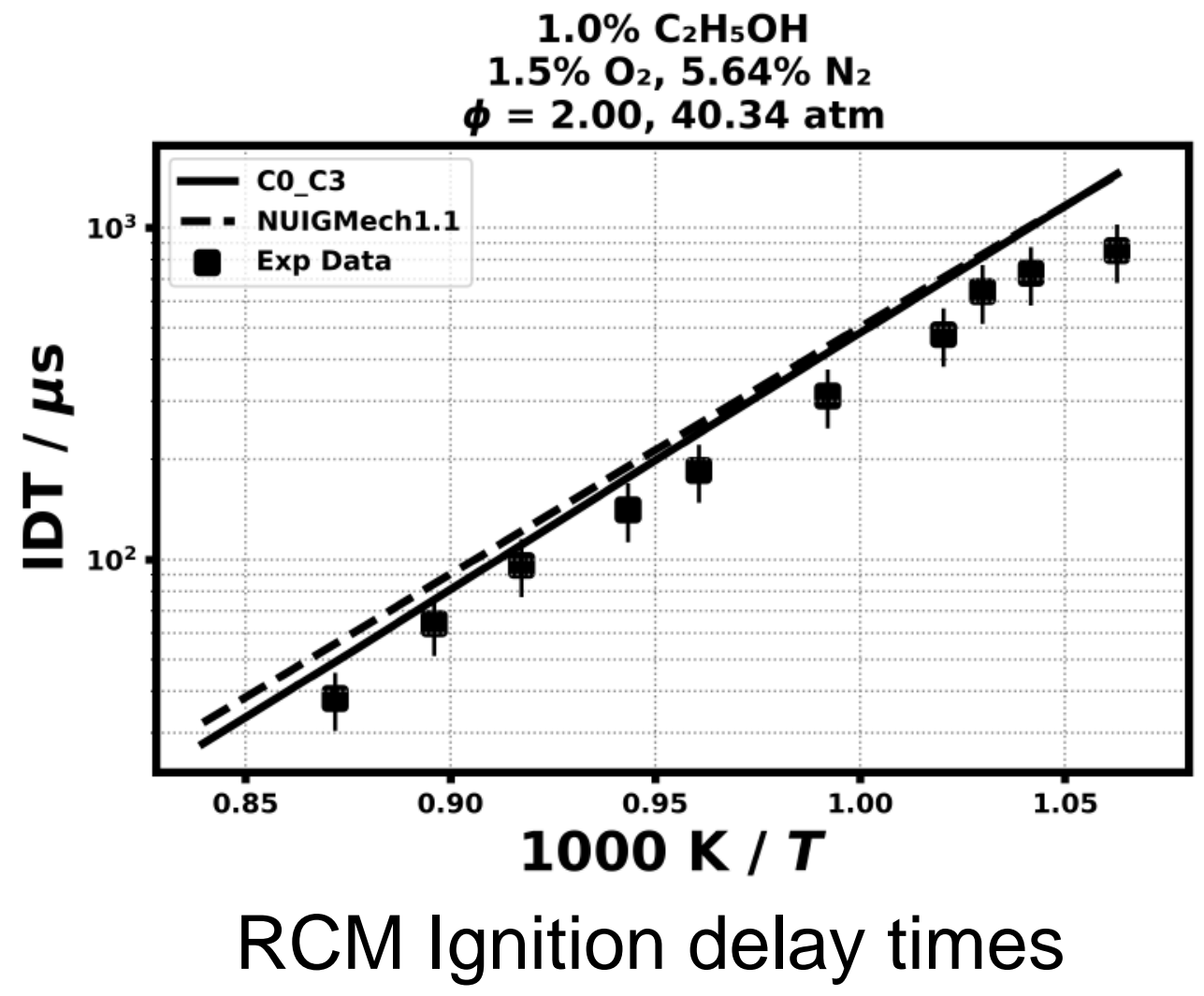

7.5) Mittal, G., Burke, S. M., Davies, V. A., Parajuli, B., Metcalfe, W. K., \& Curran, H. J., Combustion and Flame, 161(5) (2014) 1164-1171.

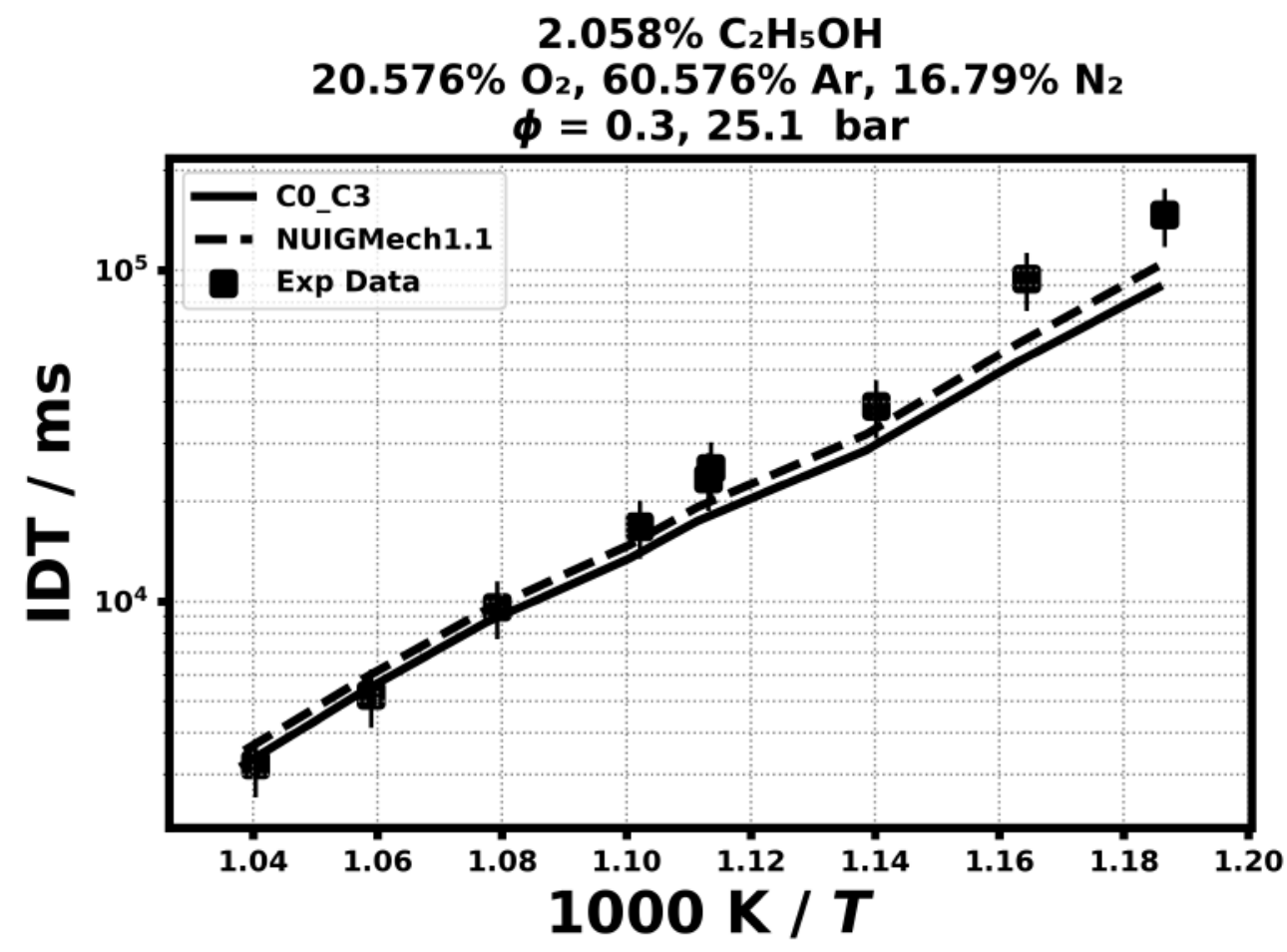



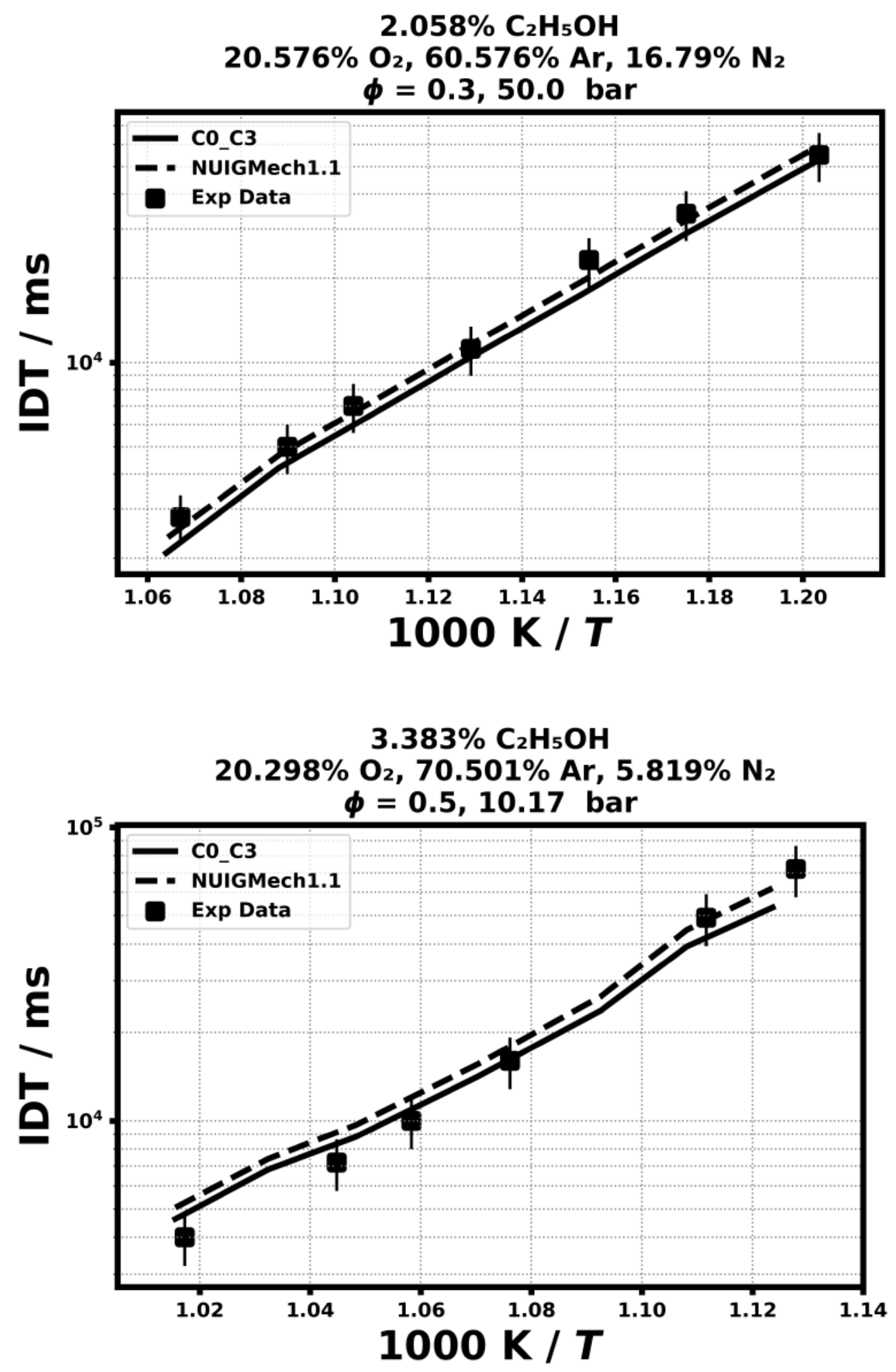

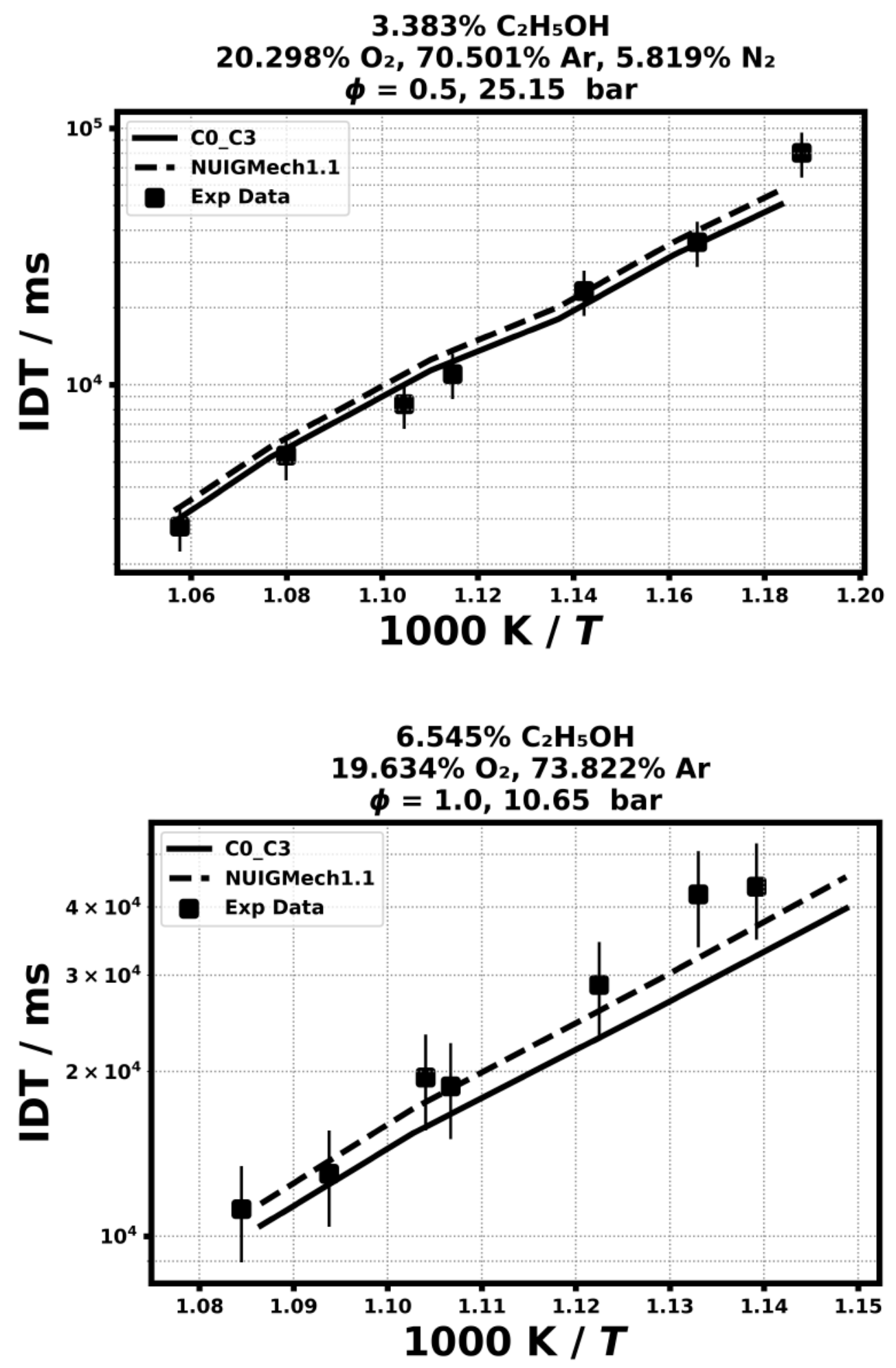
7.6) Zhang, Y., El-Merhubi, H., Lefort, B., Le Moyne, L., Curran, H. J., \& Kéromnès, A. Combustion and Flame, 190 (2018) 74-86.
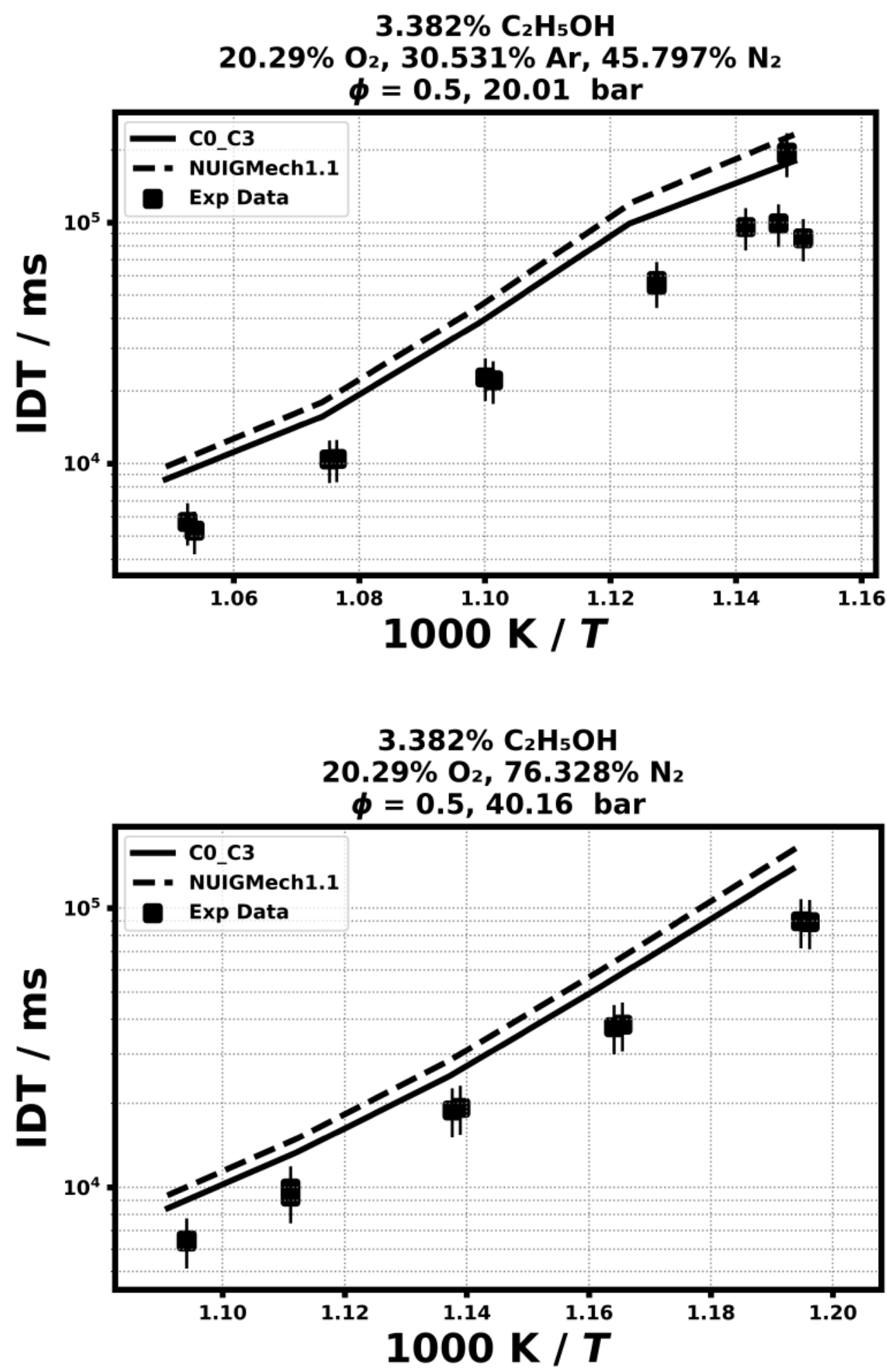

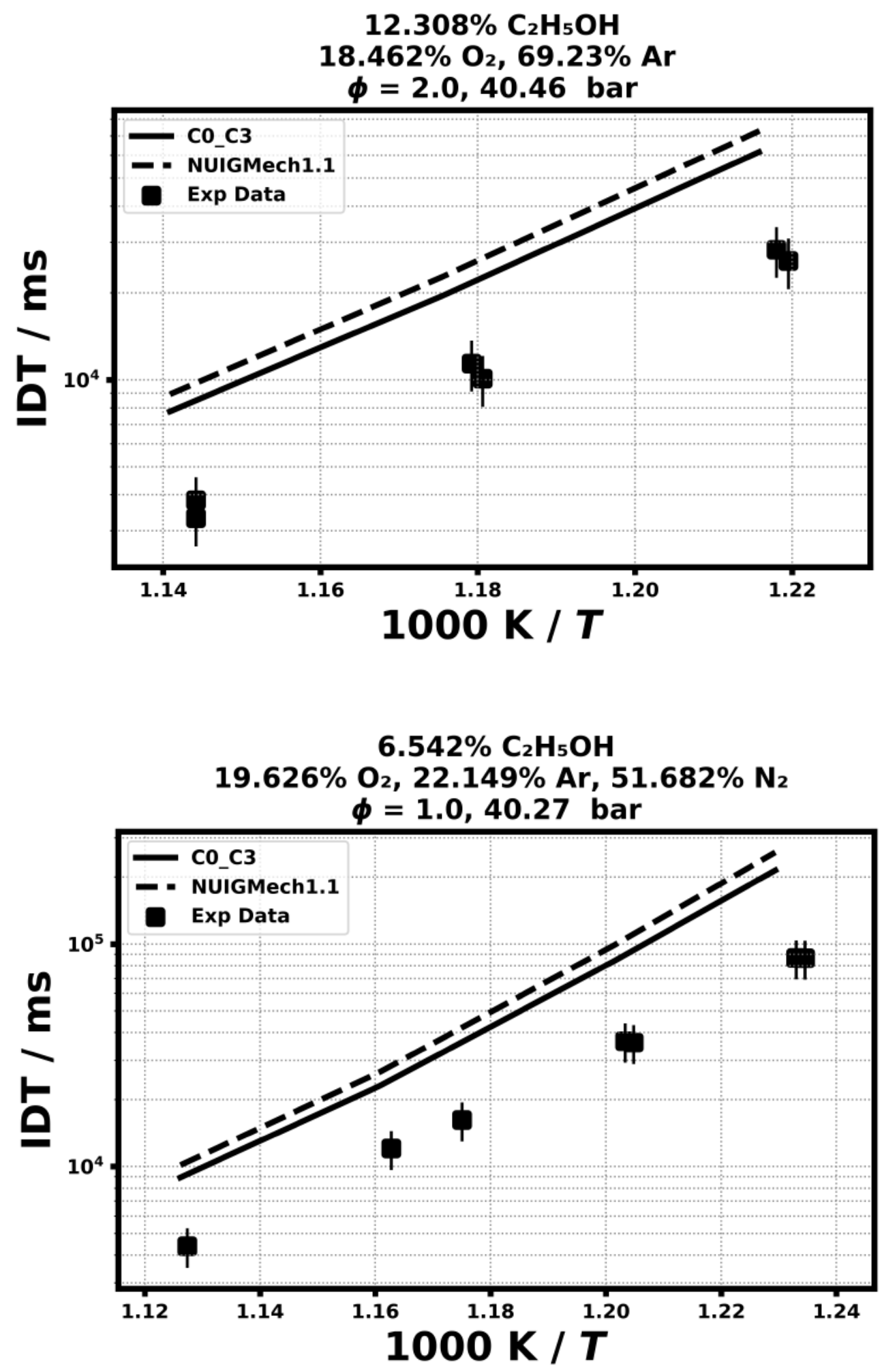


\section{Speciation in Jet-stirred reactor}

7.8) Leplat, N., Dagaut, P., Togbé, C., \& Vandooren, J., Combustion and Flame, 158 (4) (2011) 705-725.
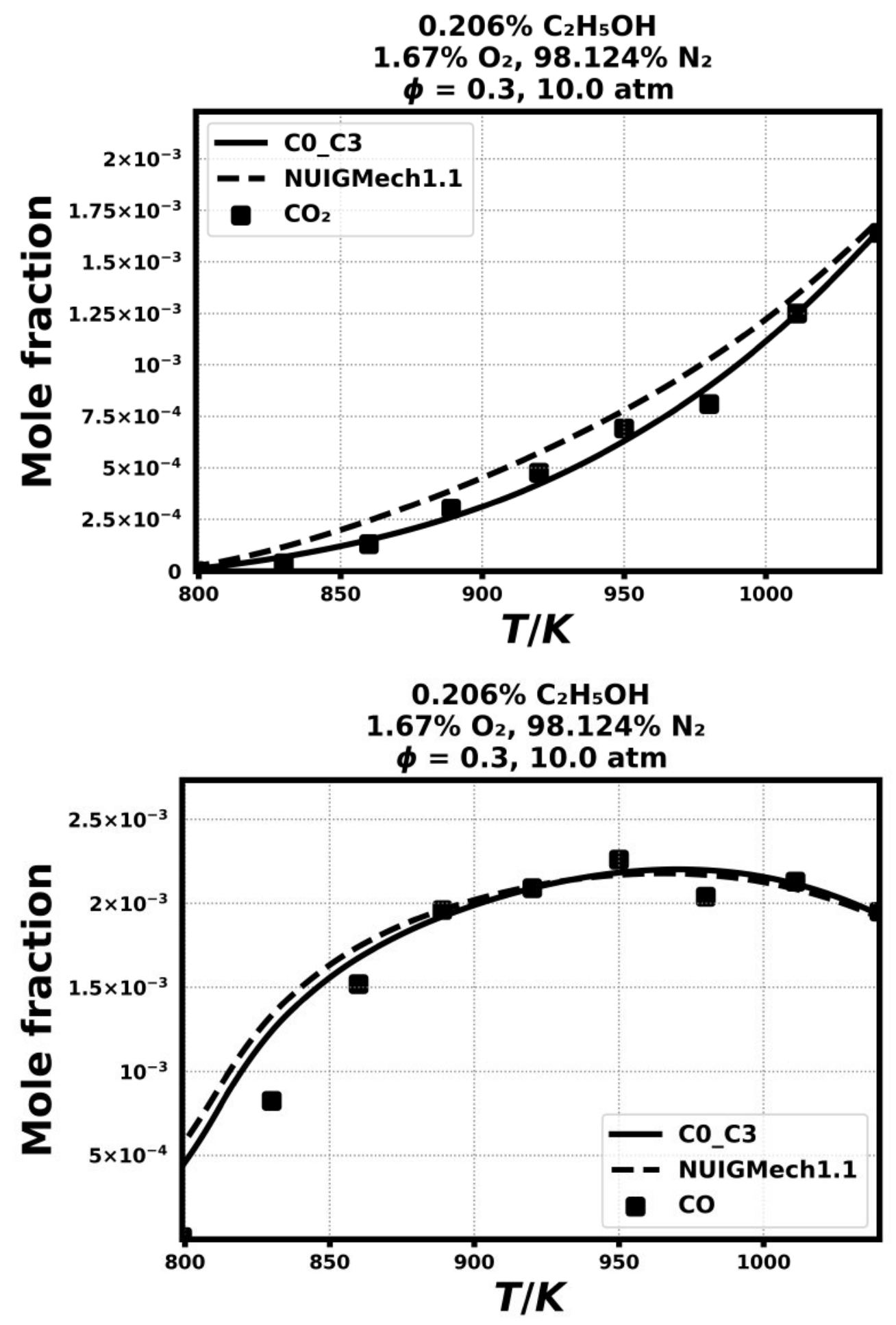

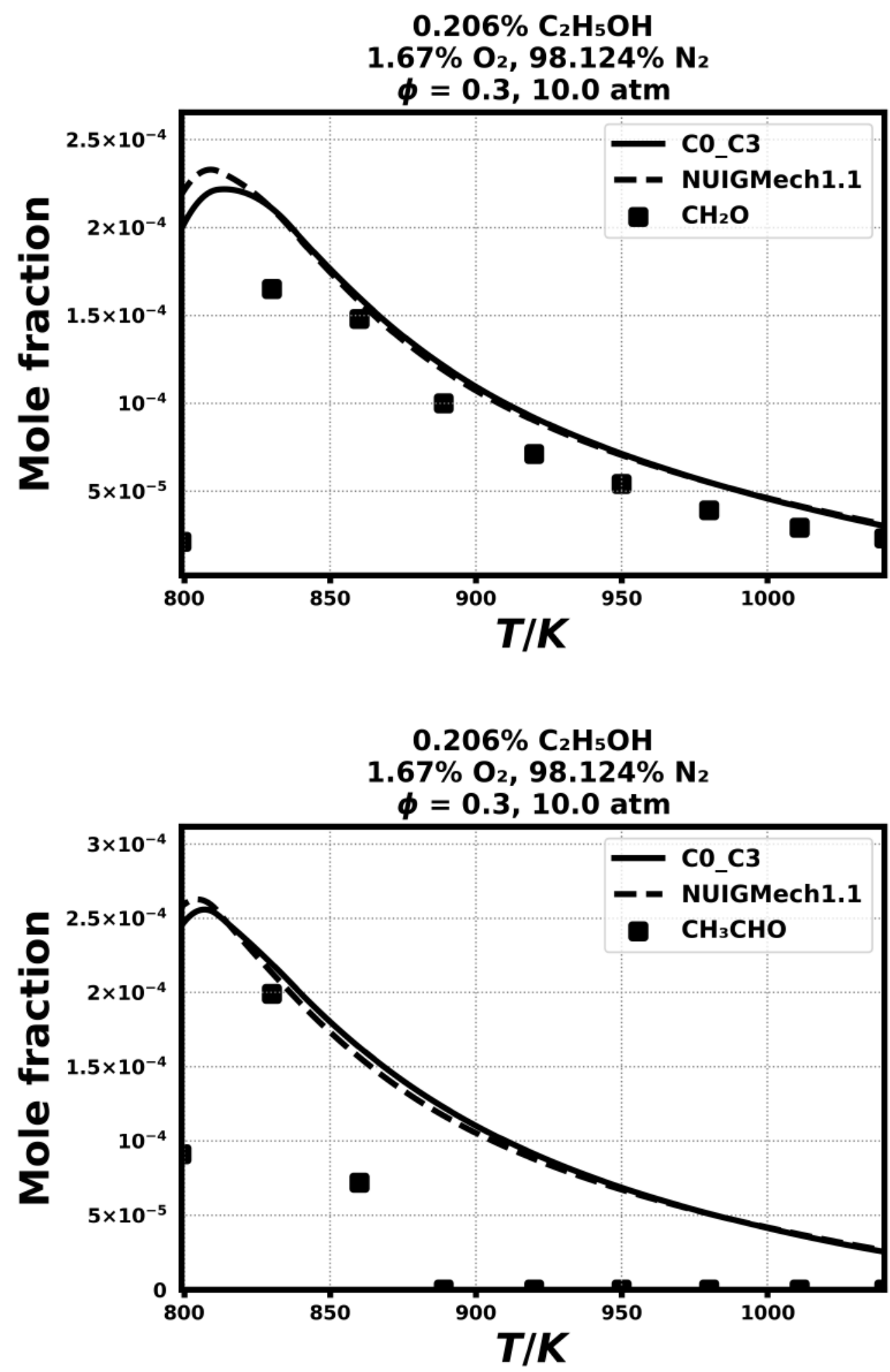

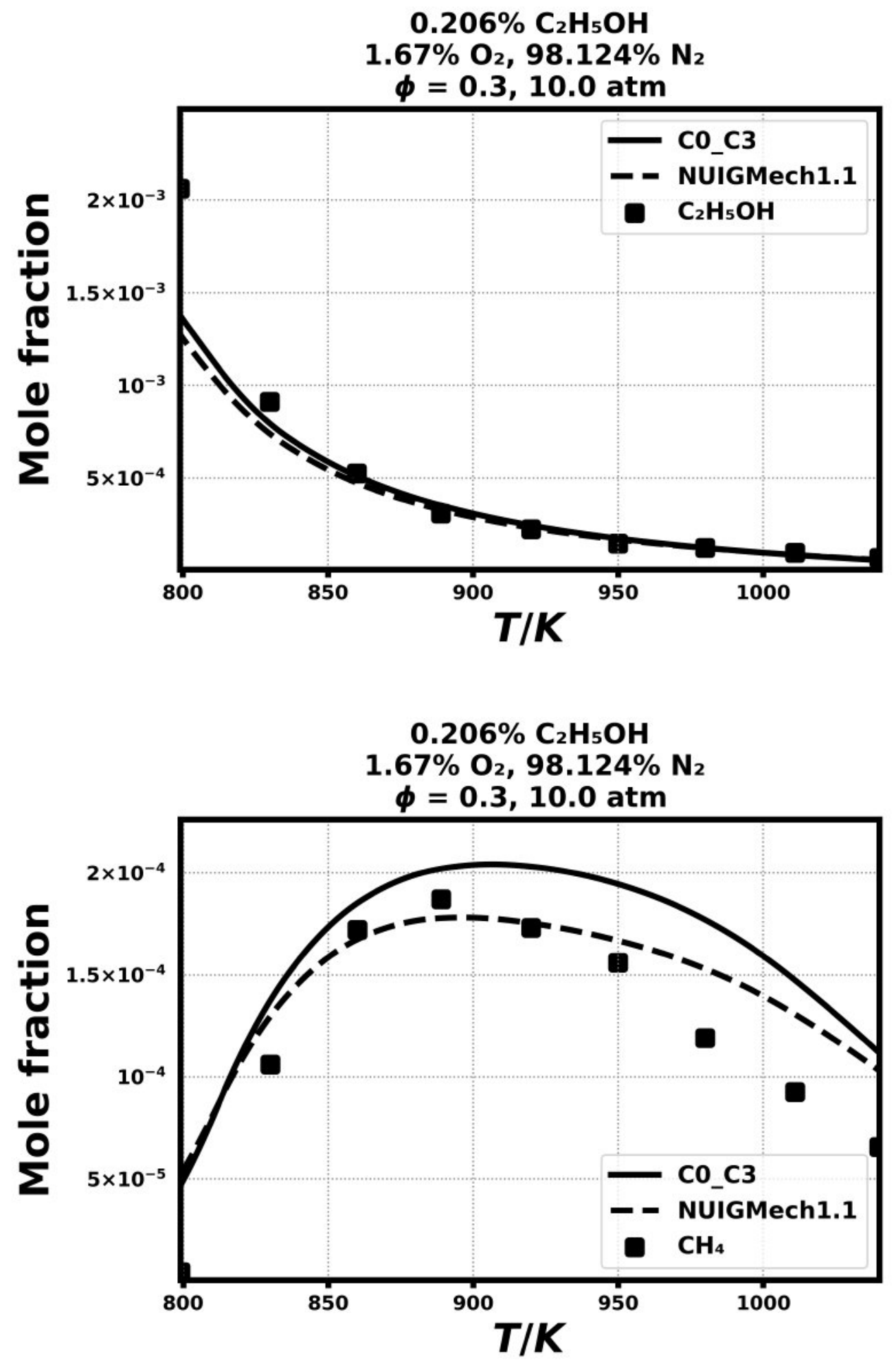

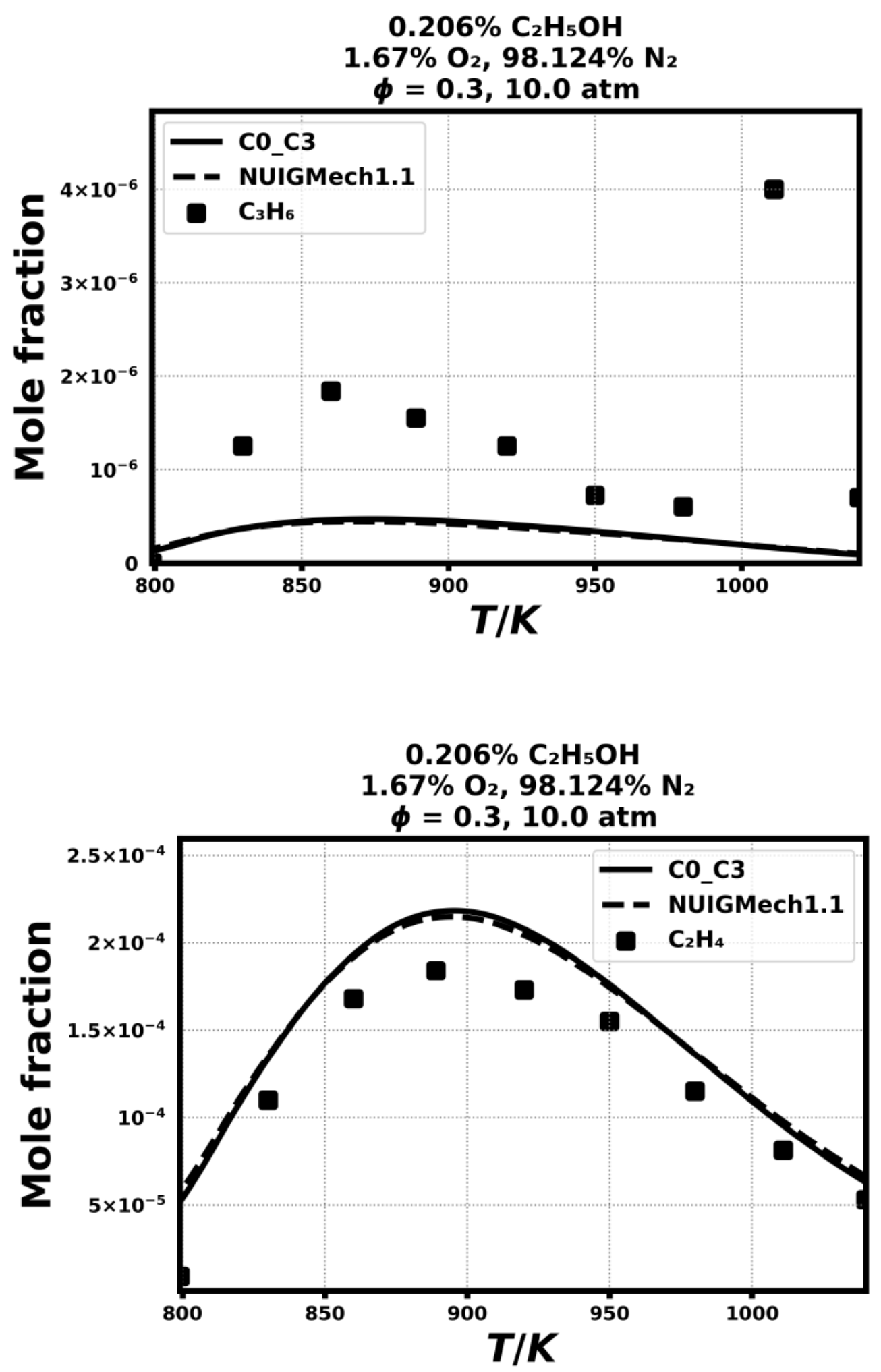

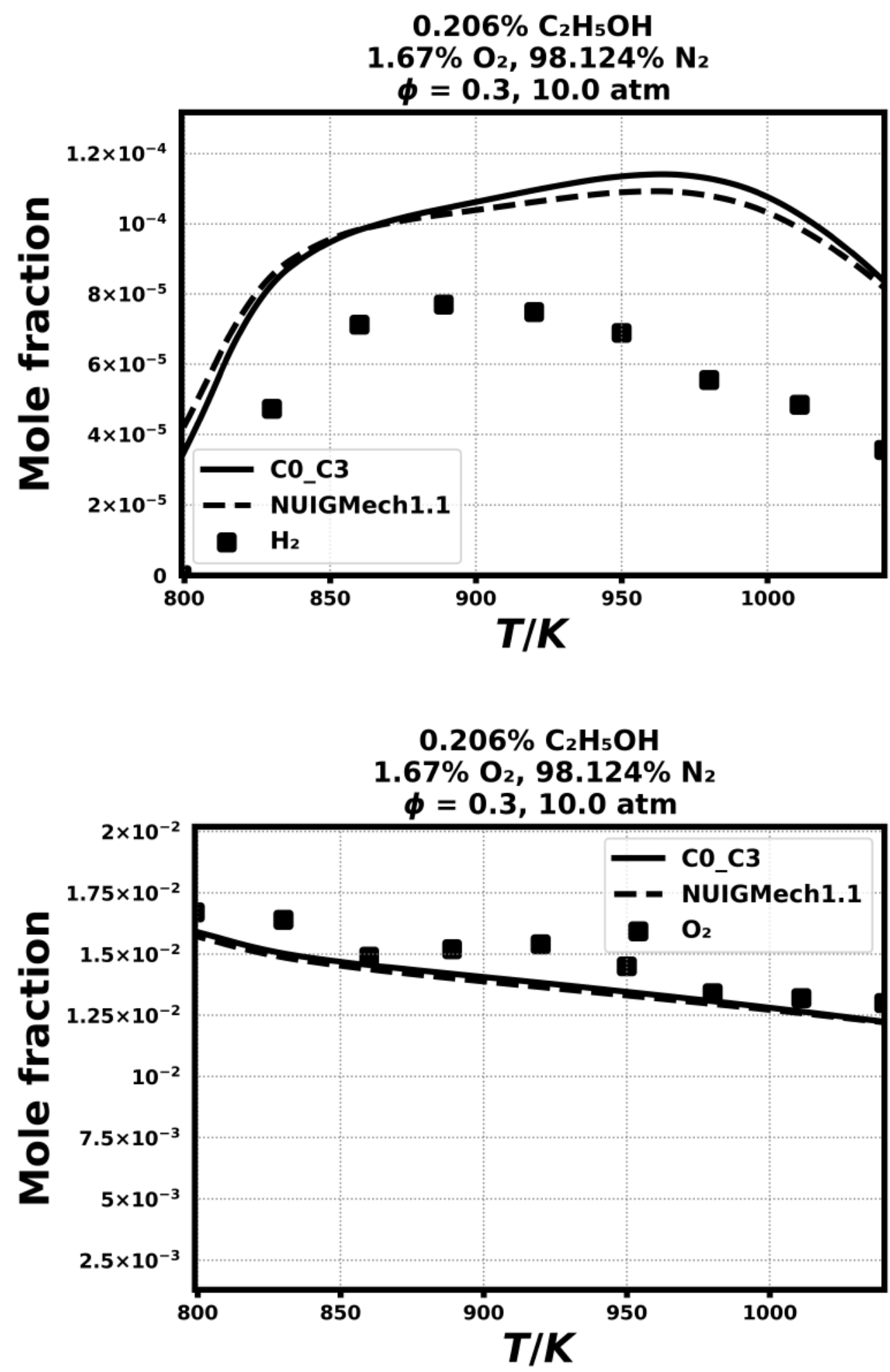

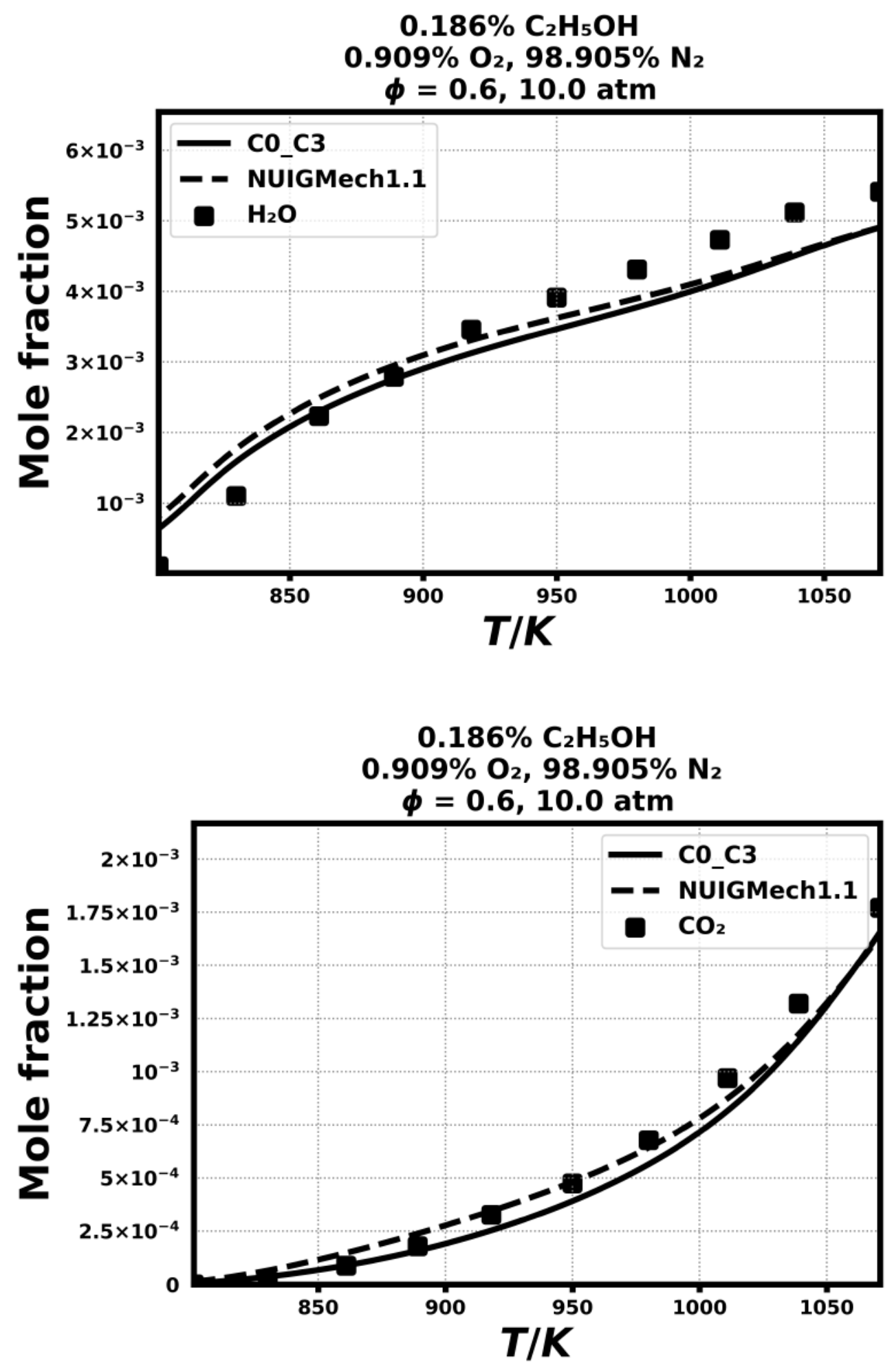

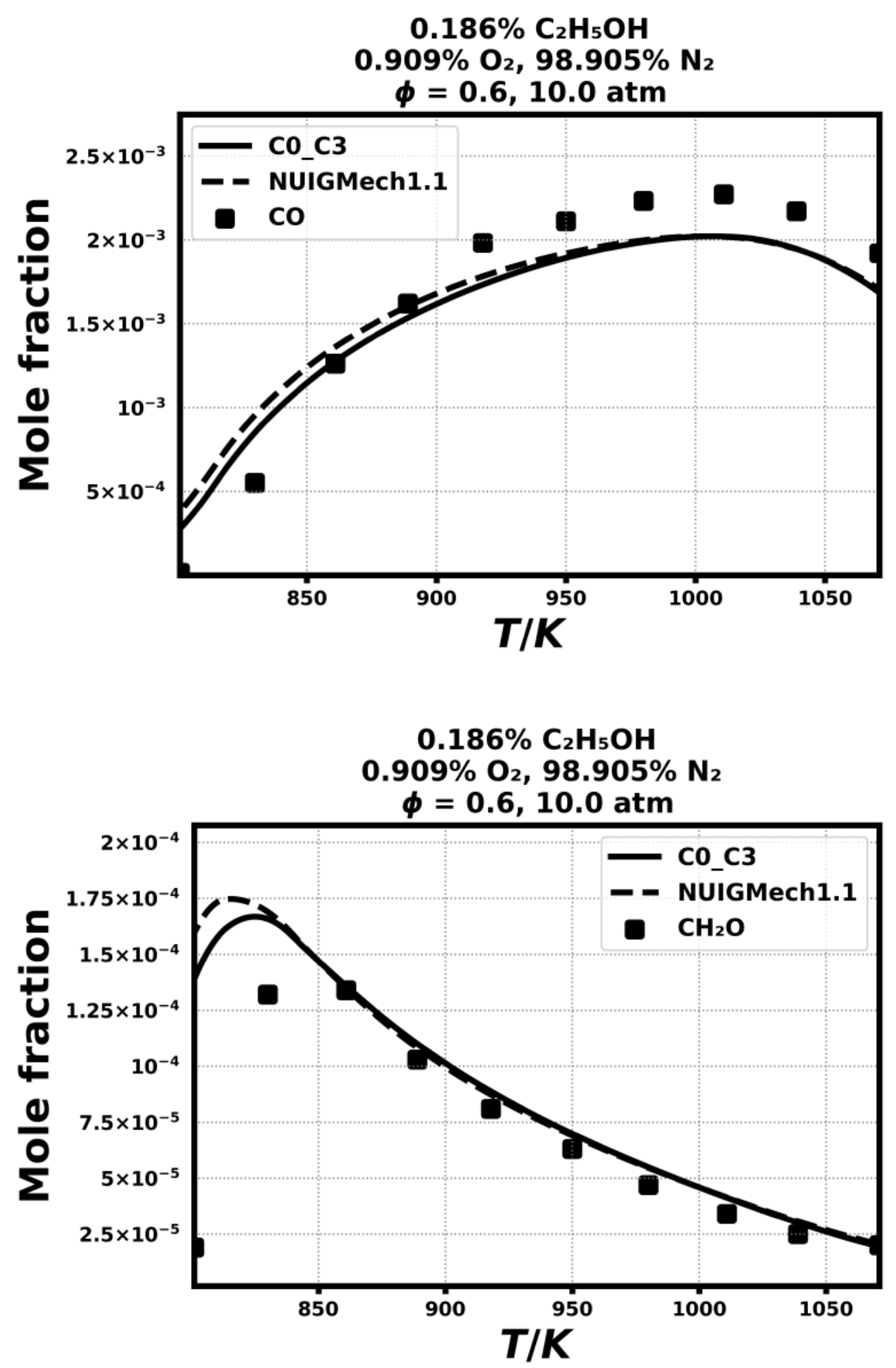

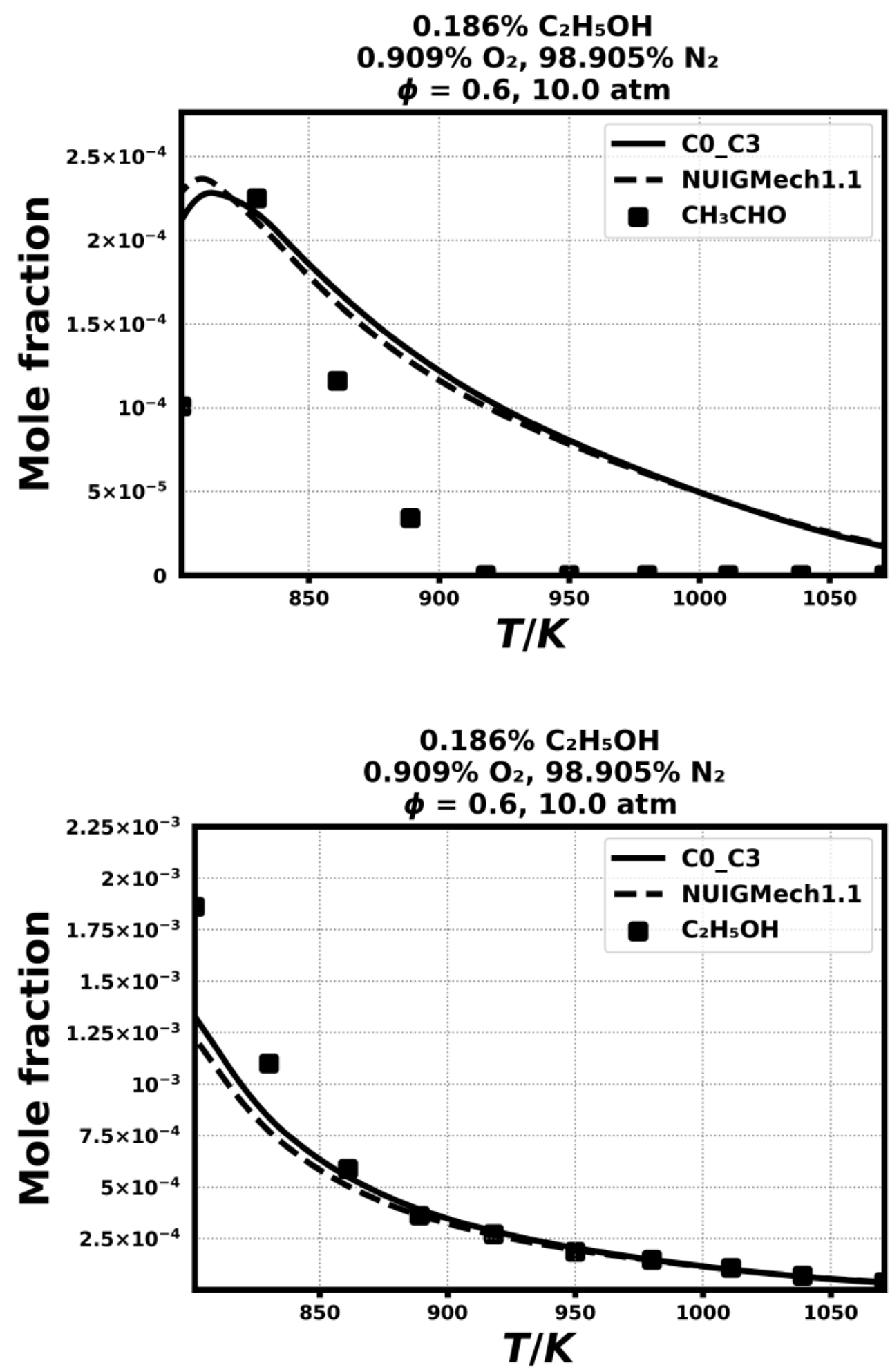

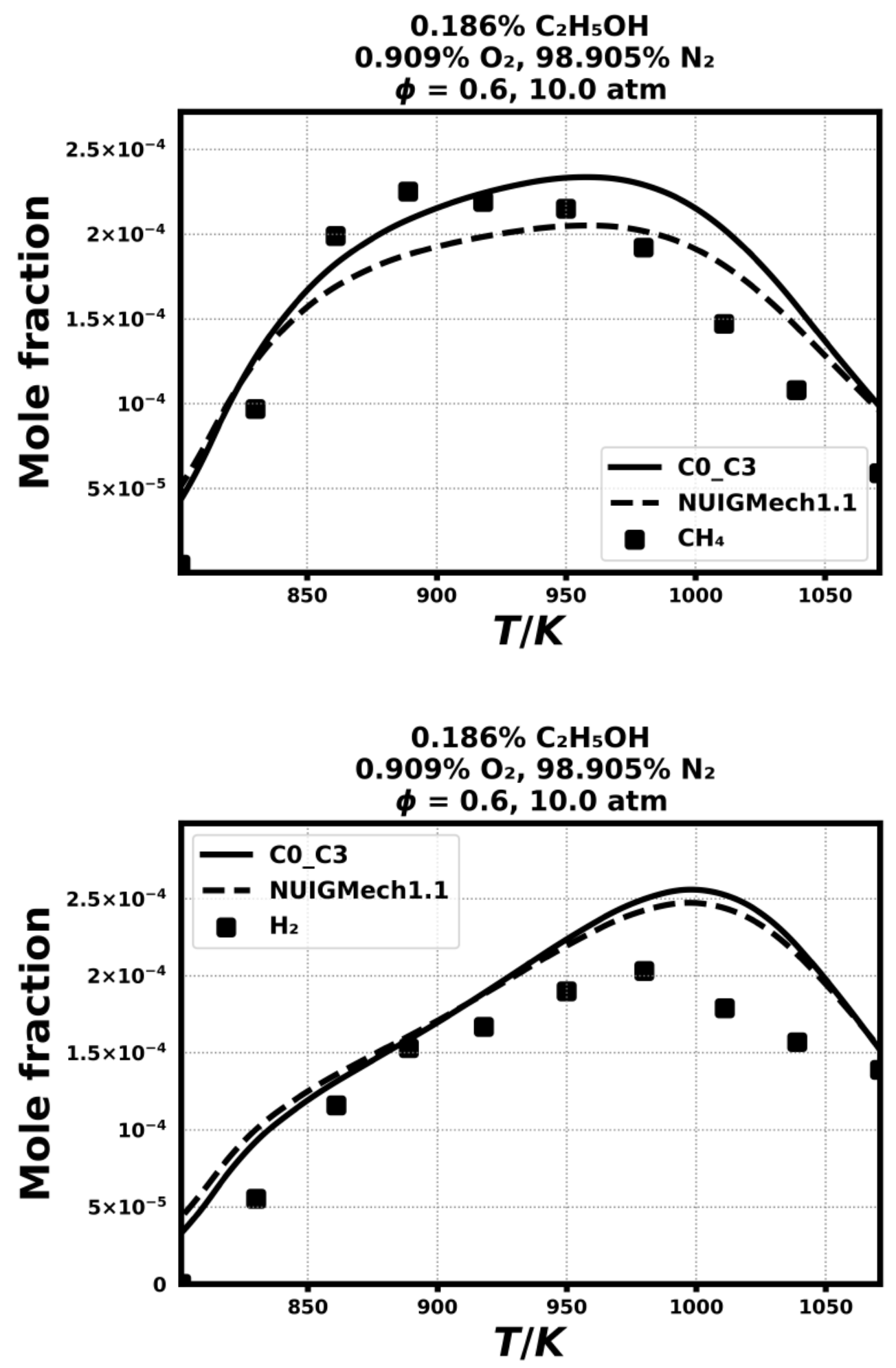

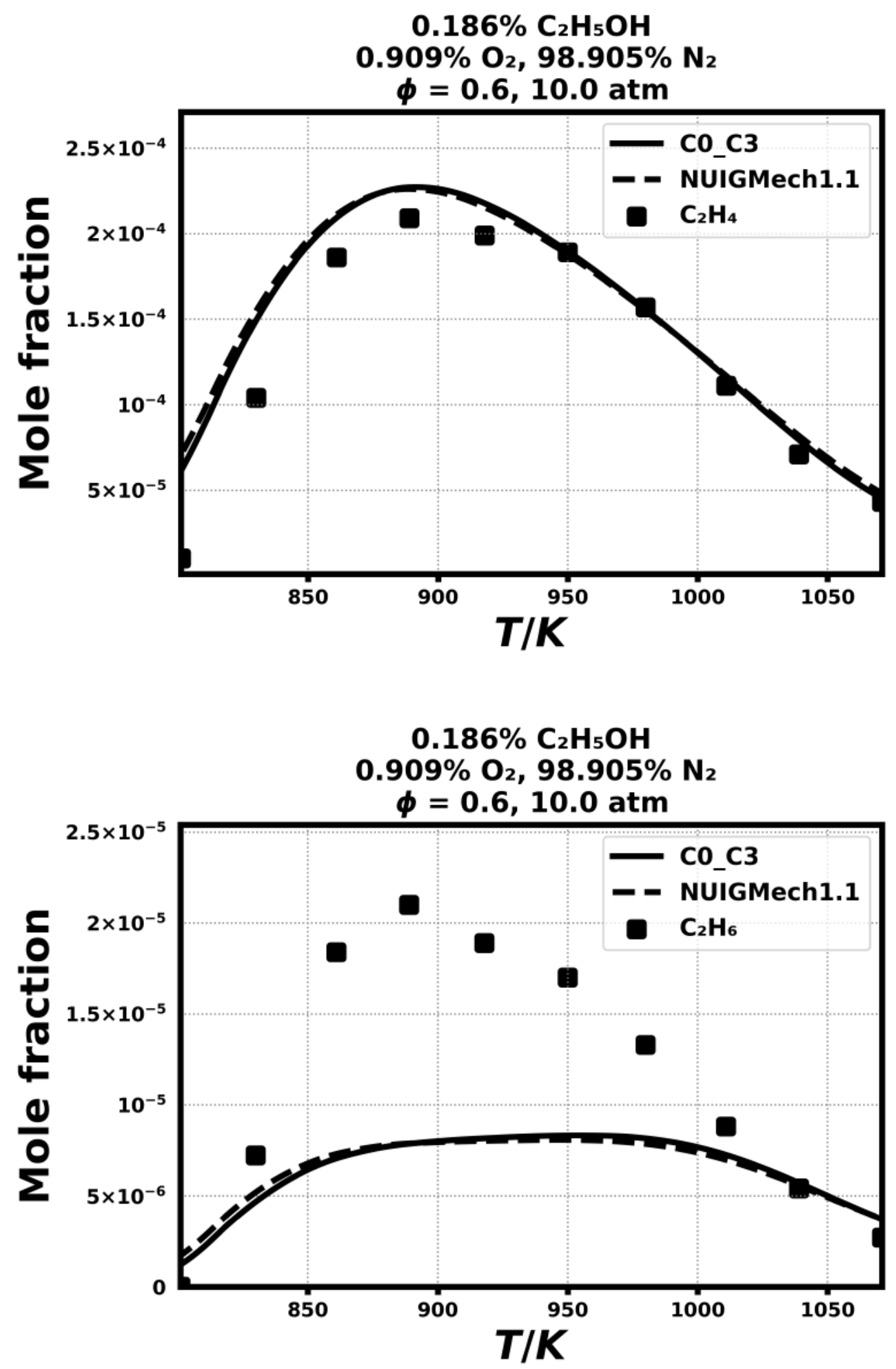

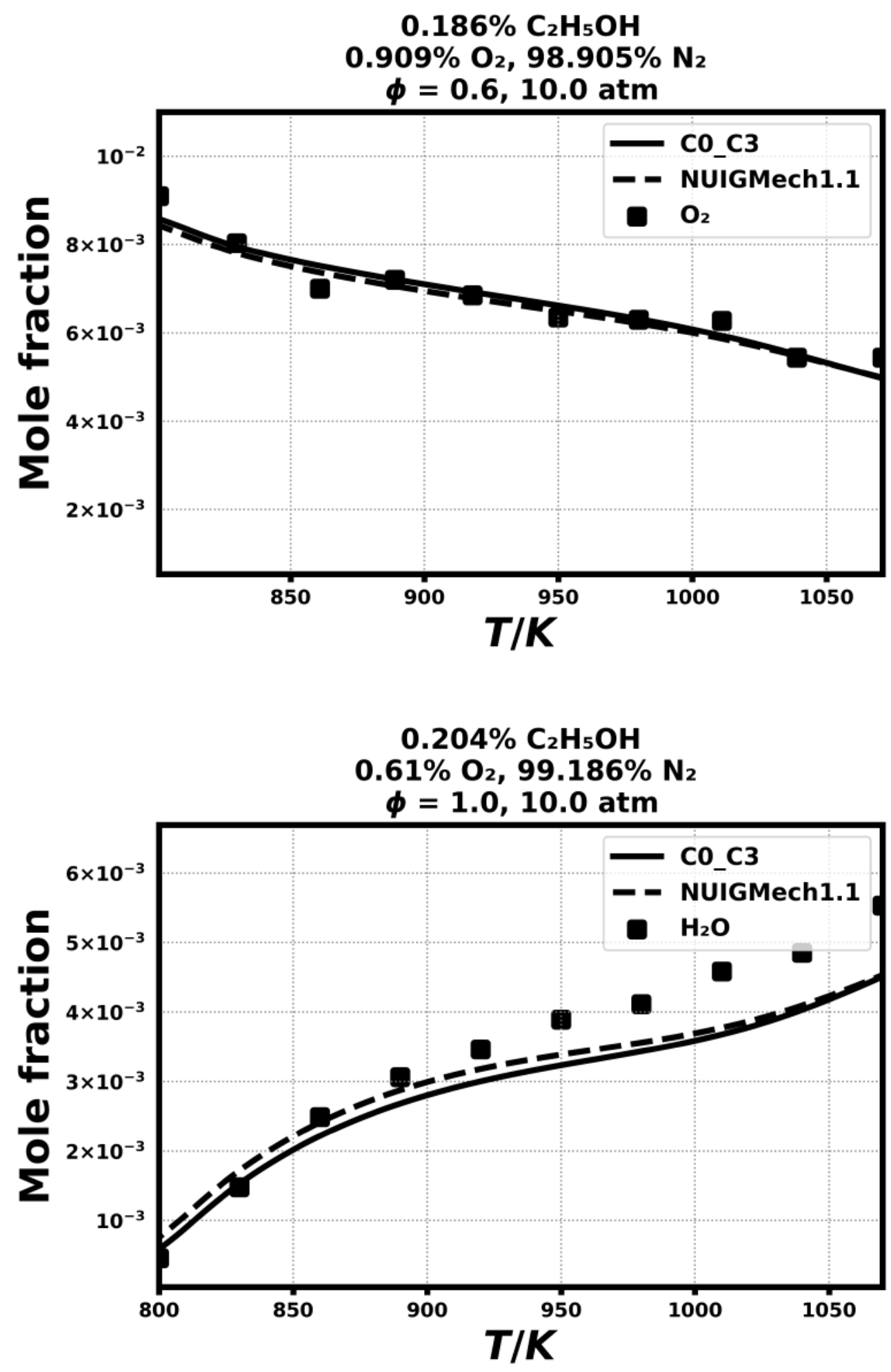

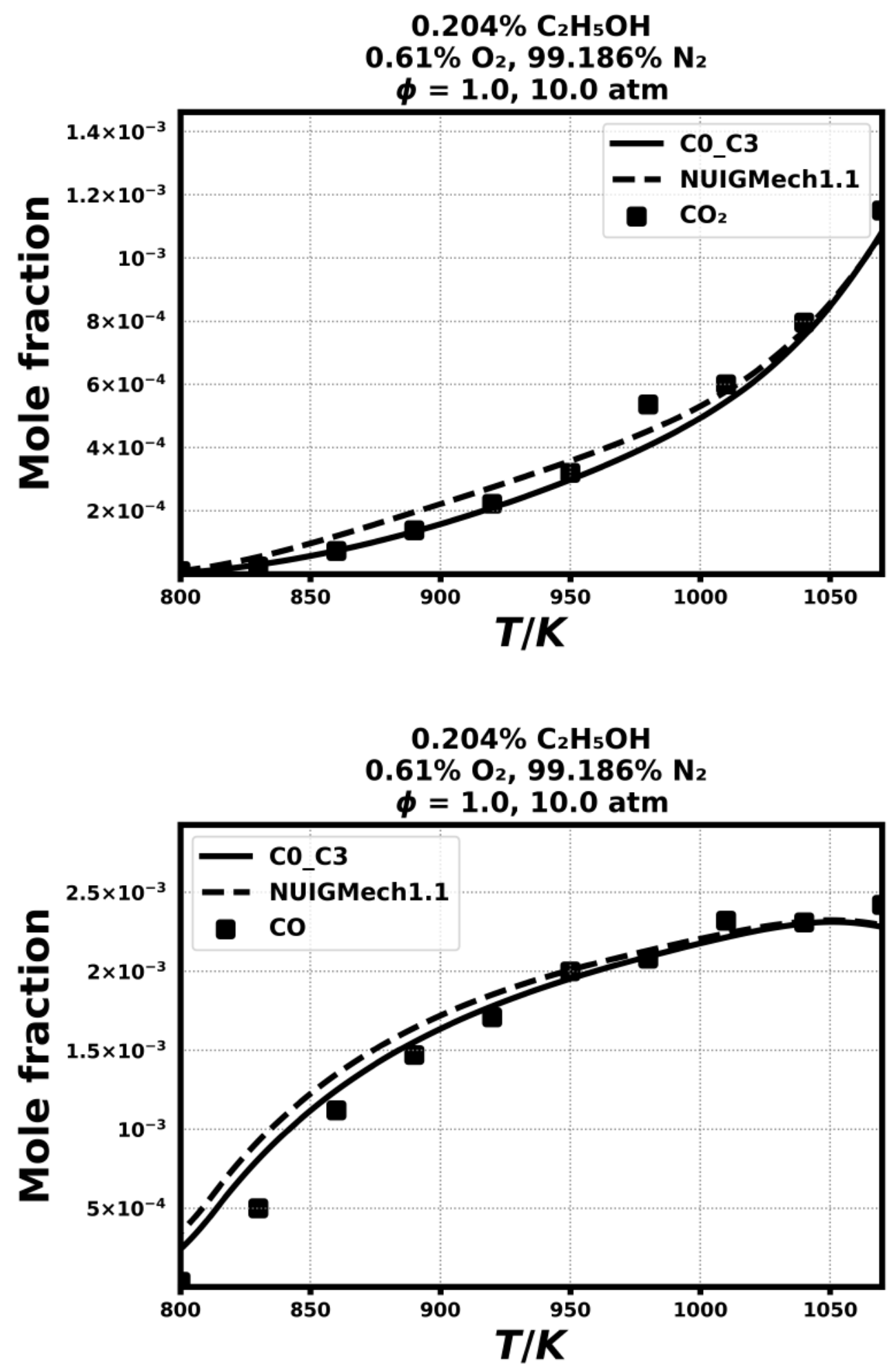

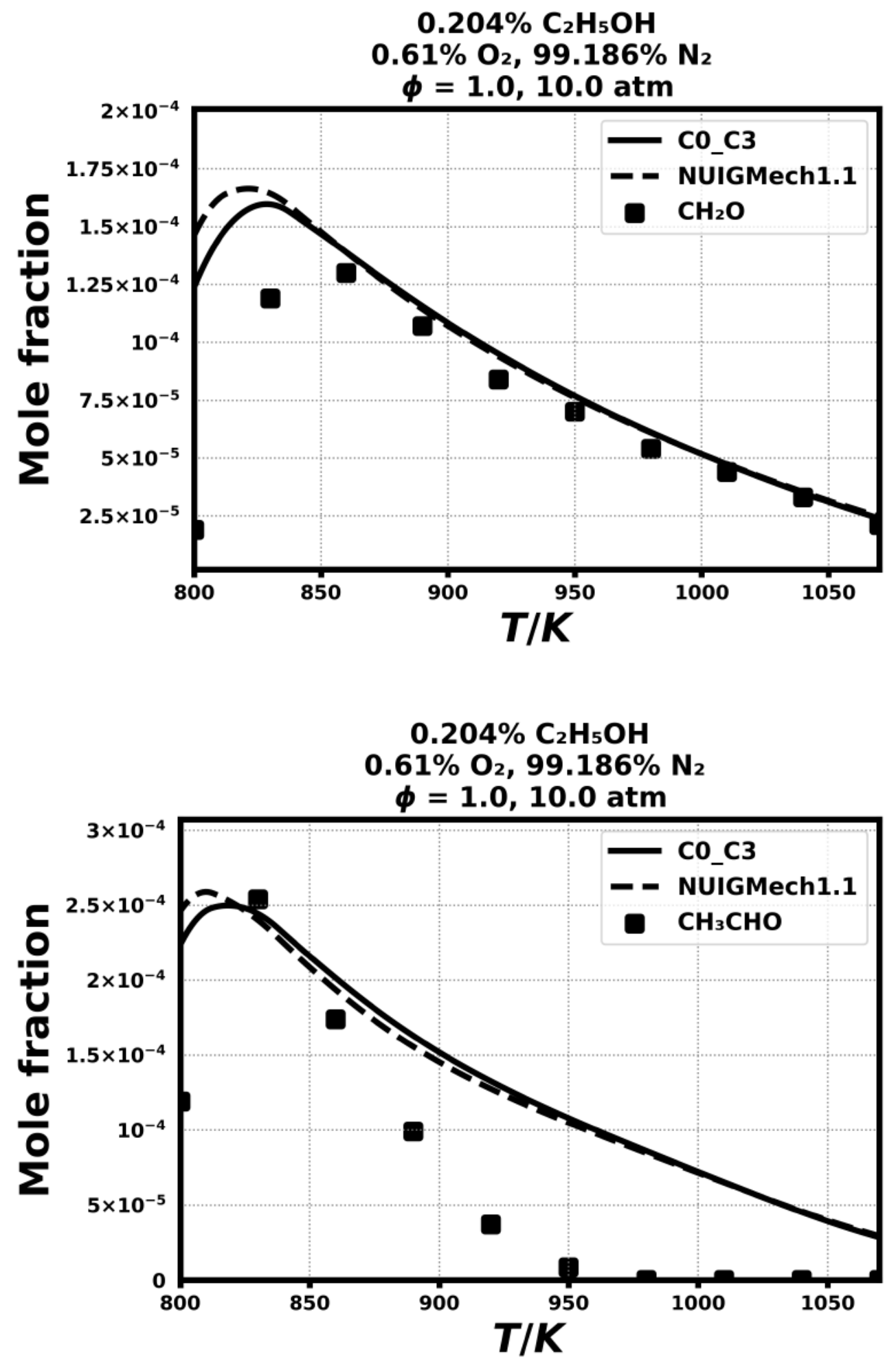

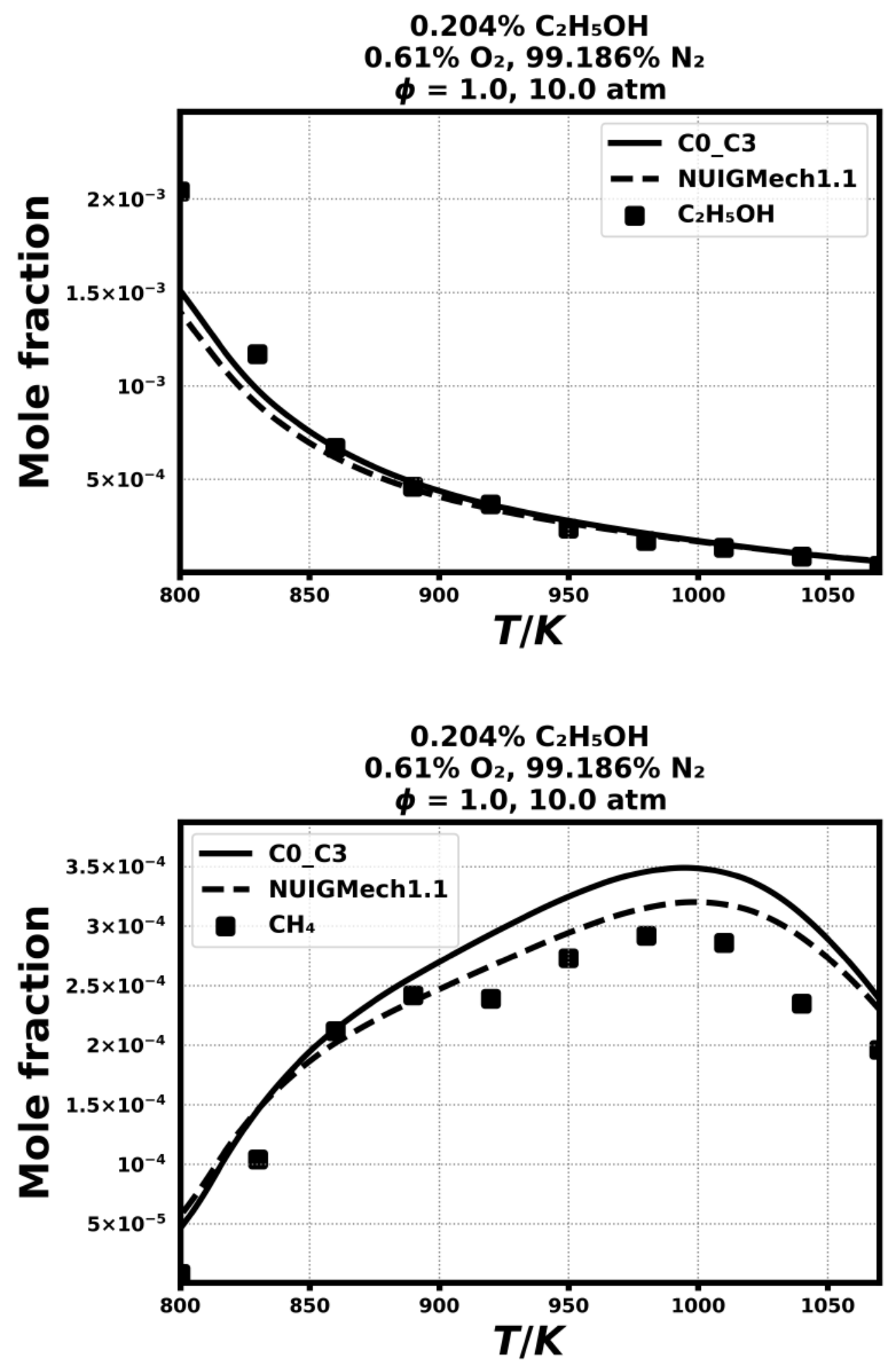

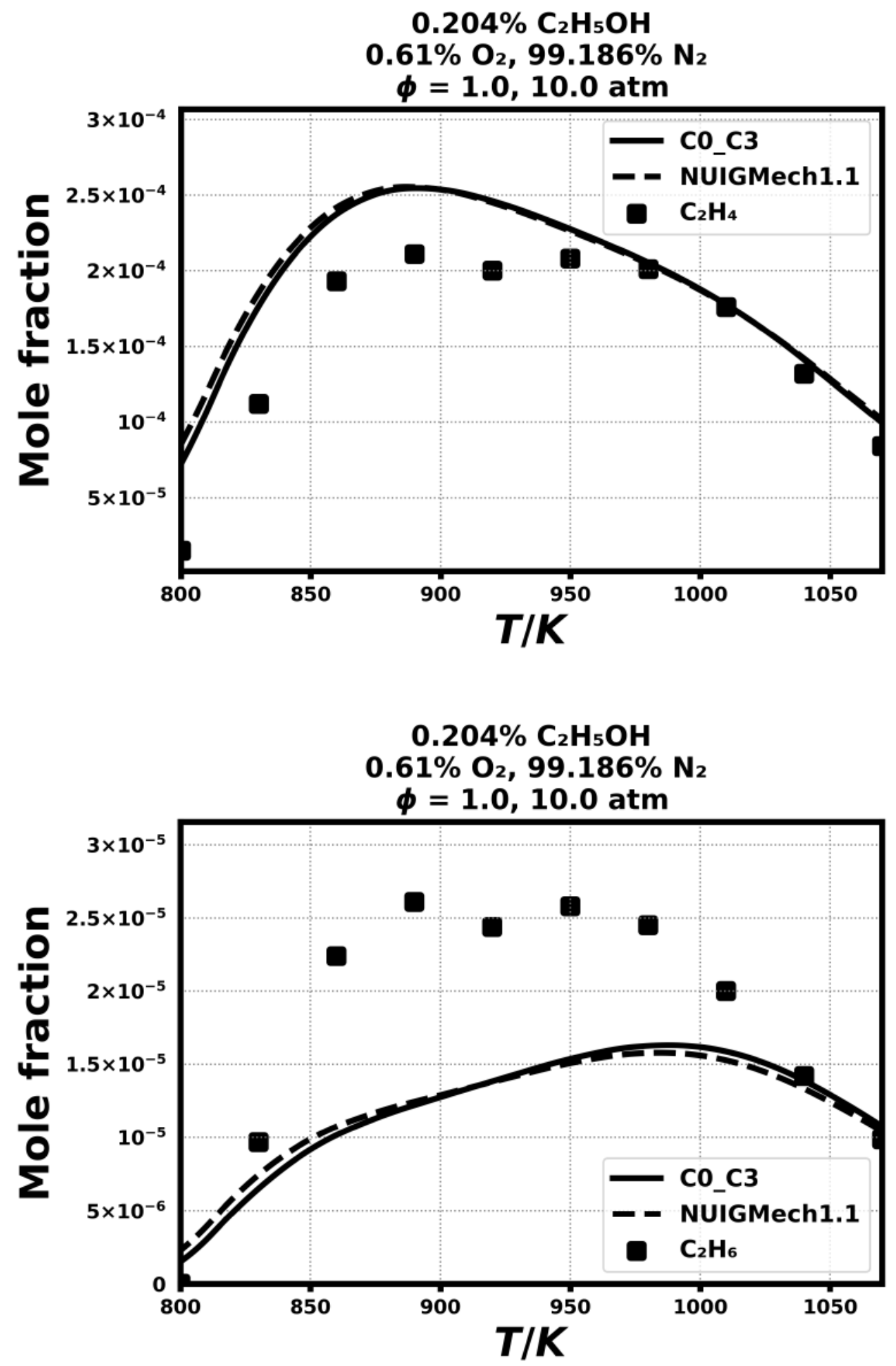

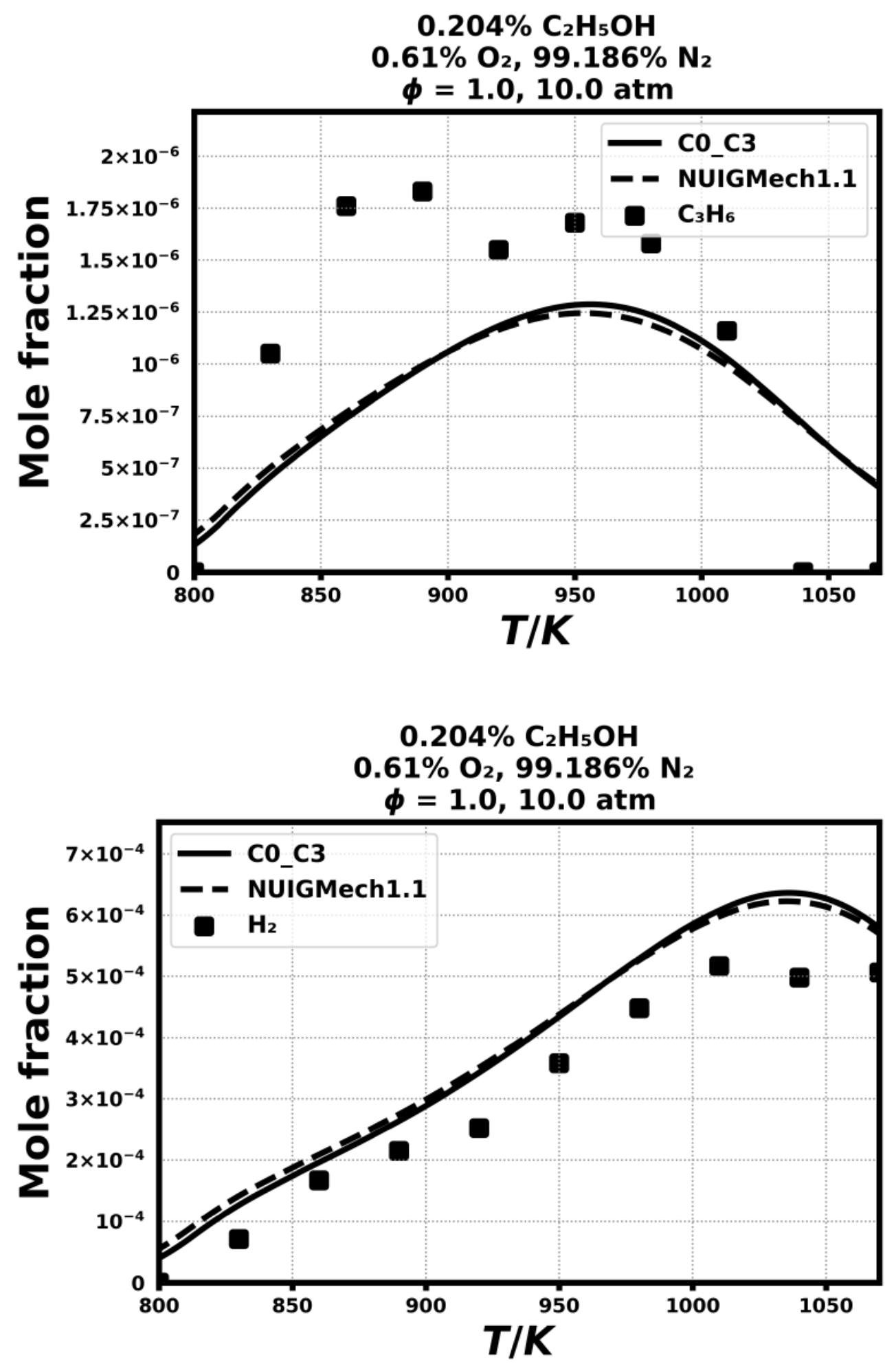

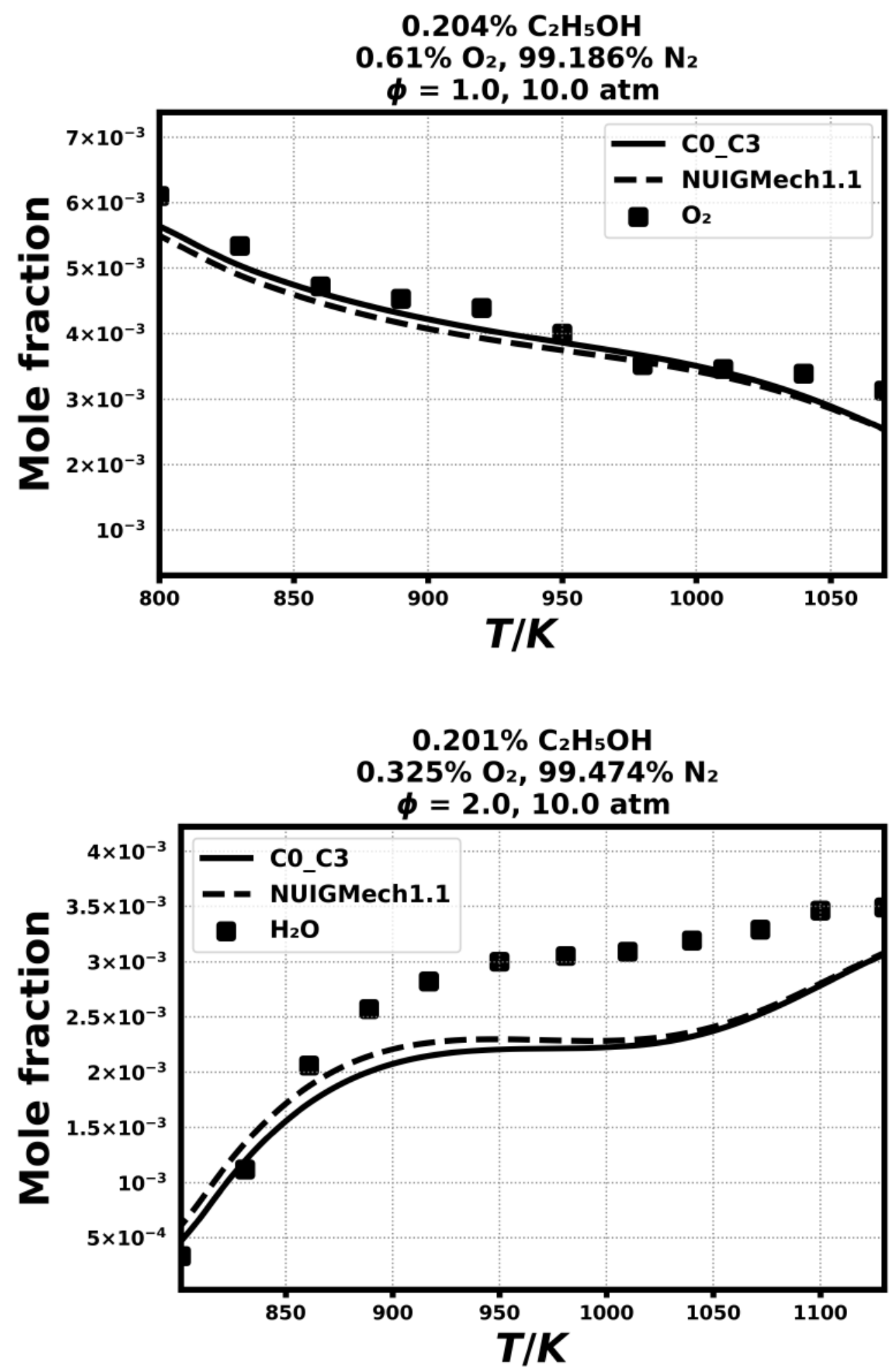

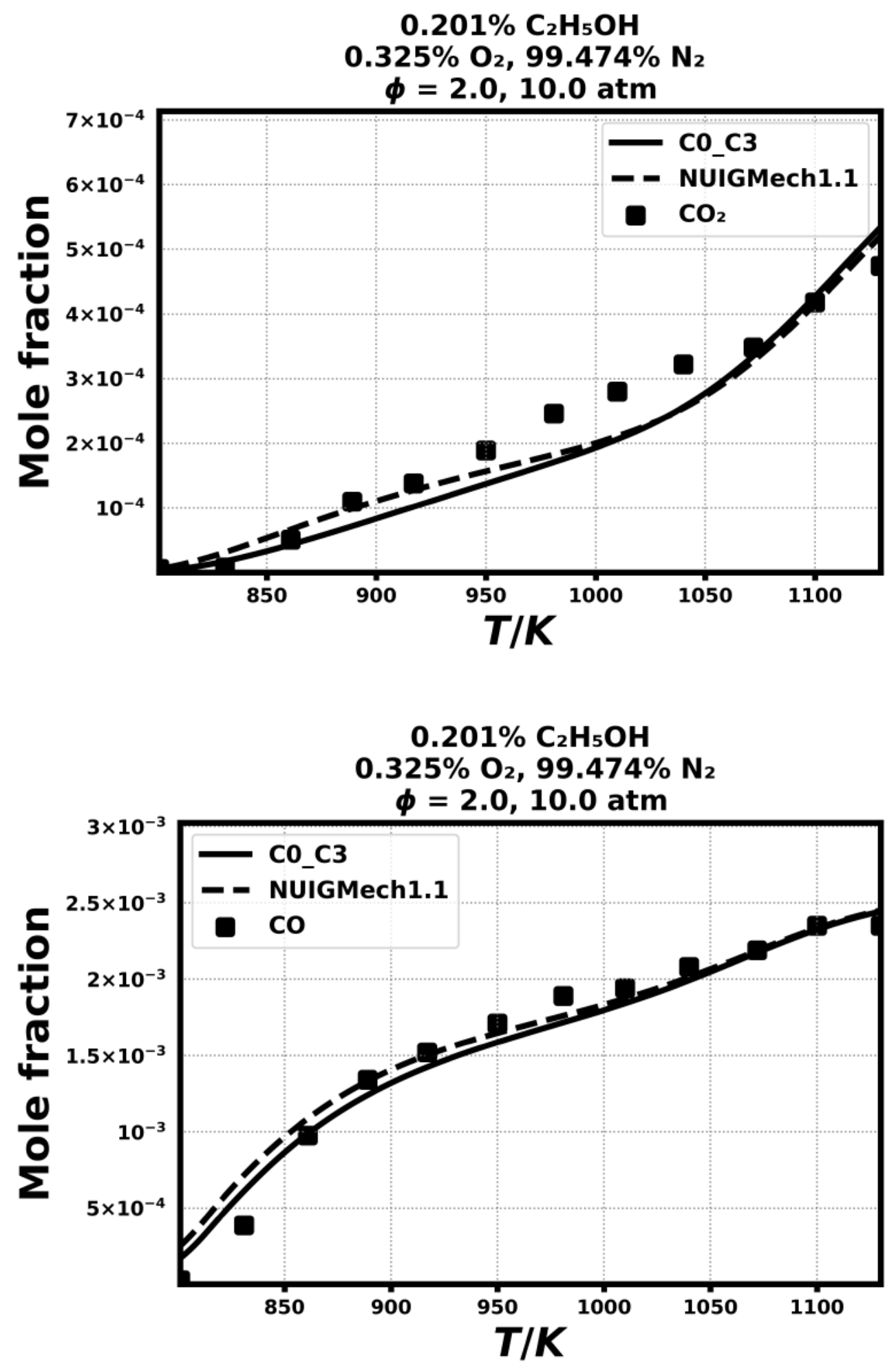

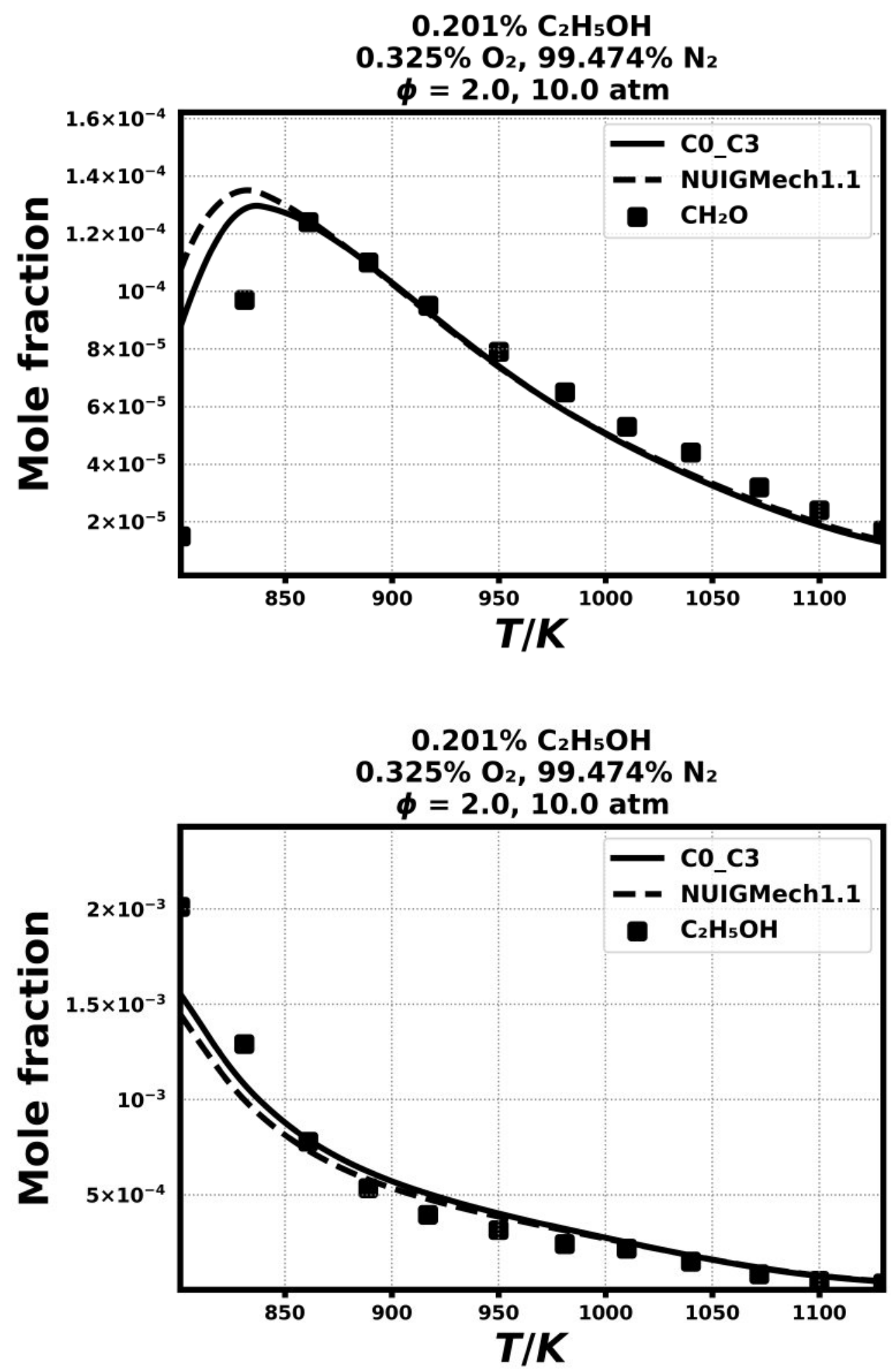

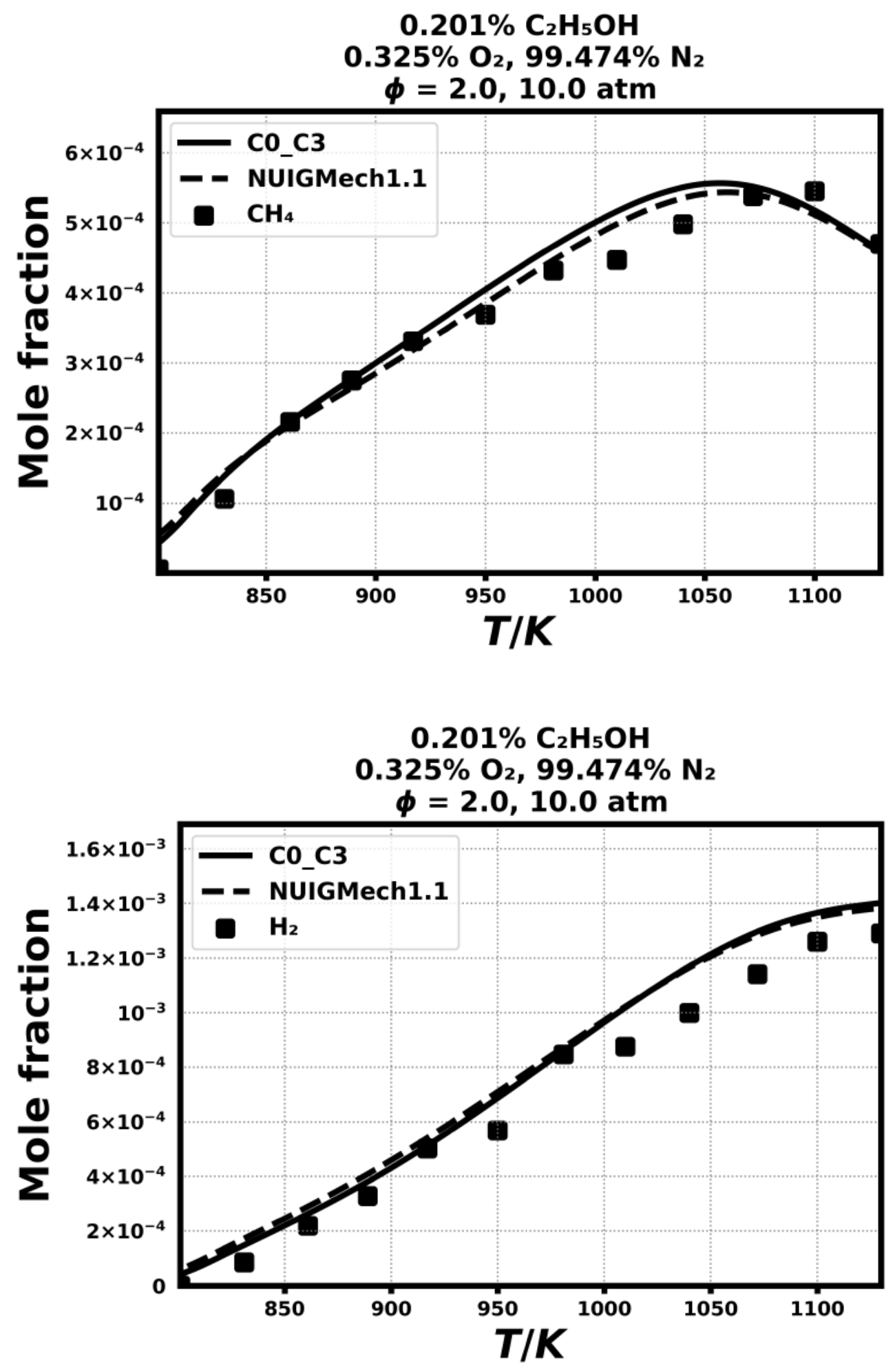

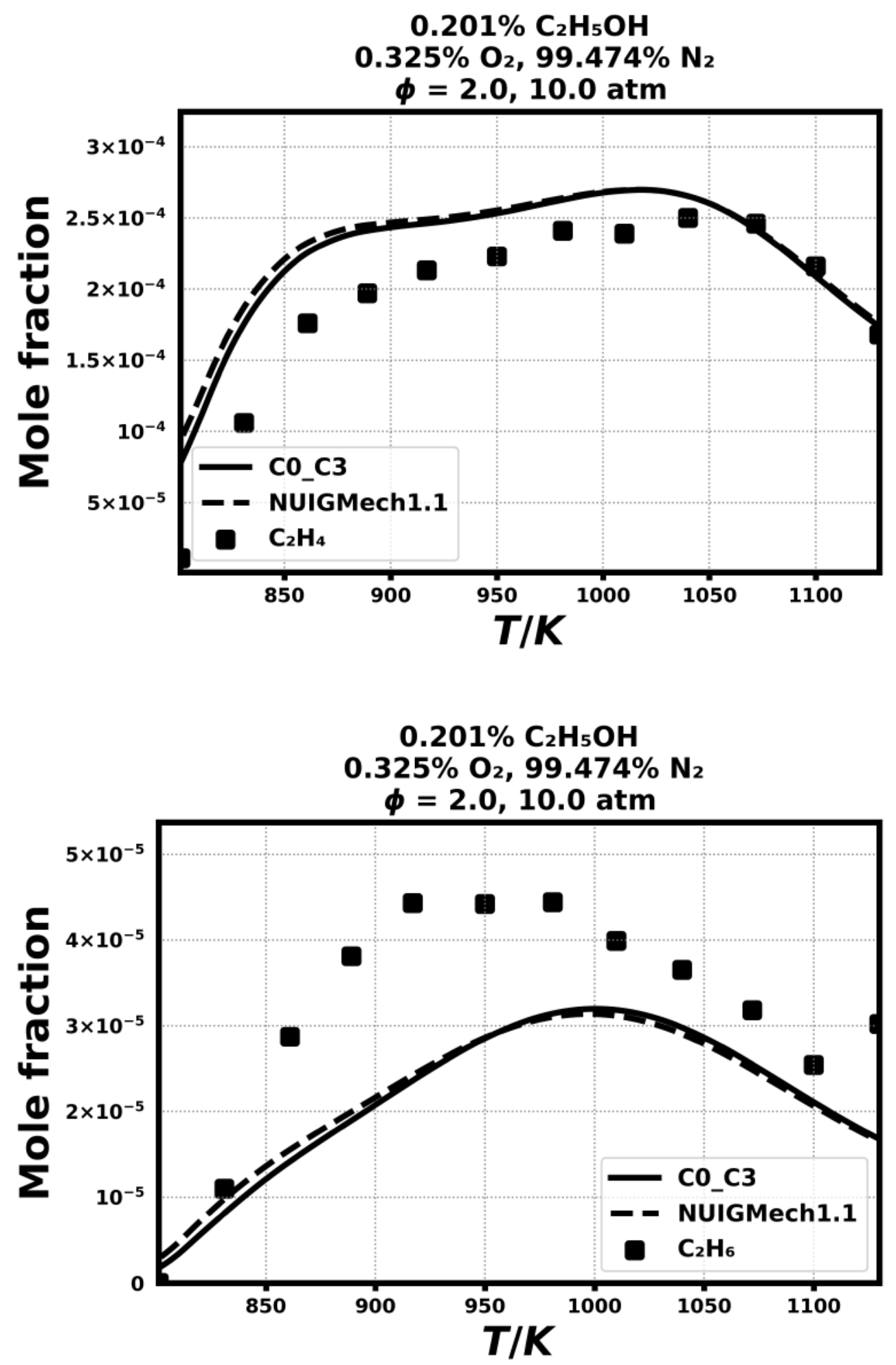

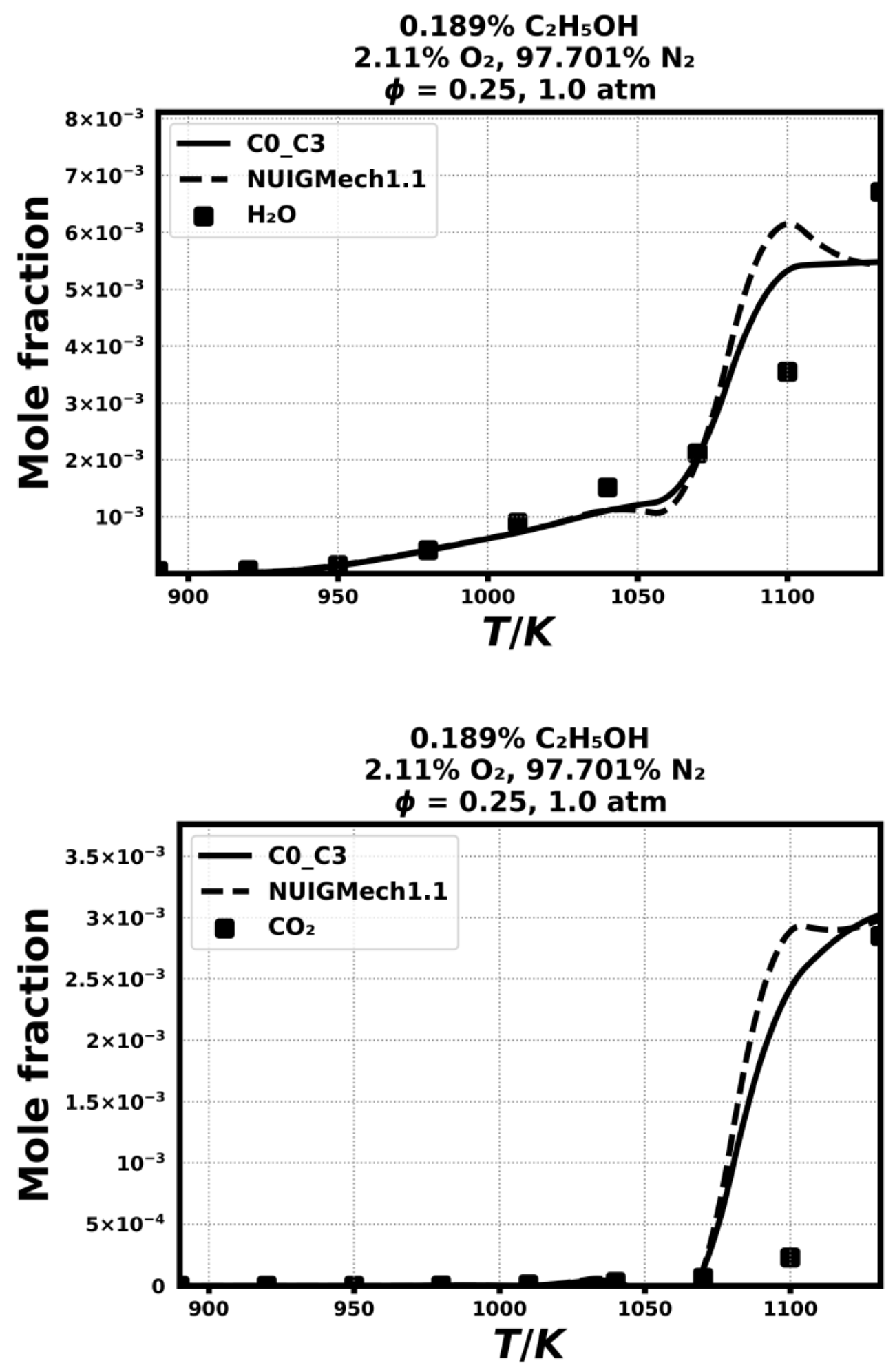

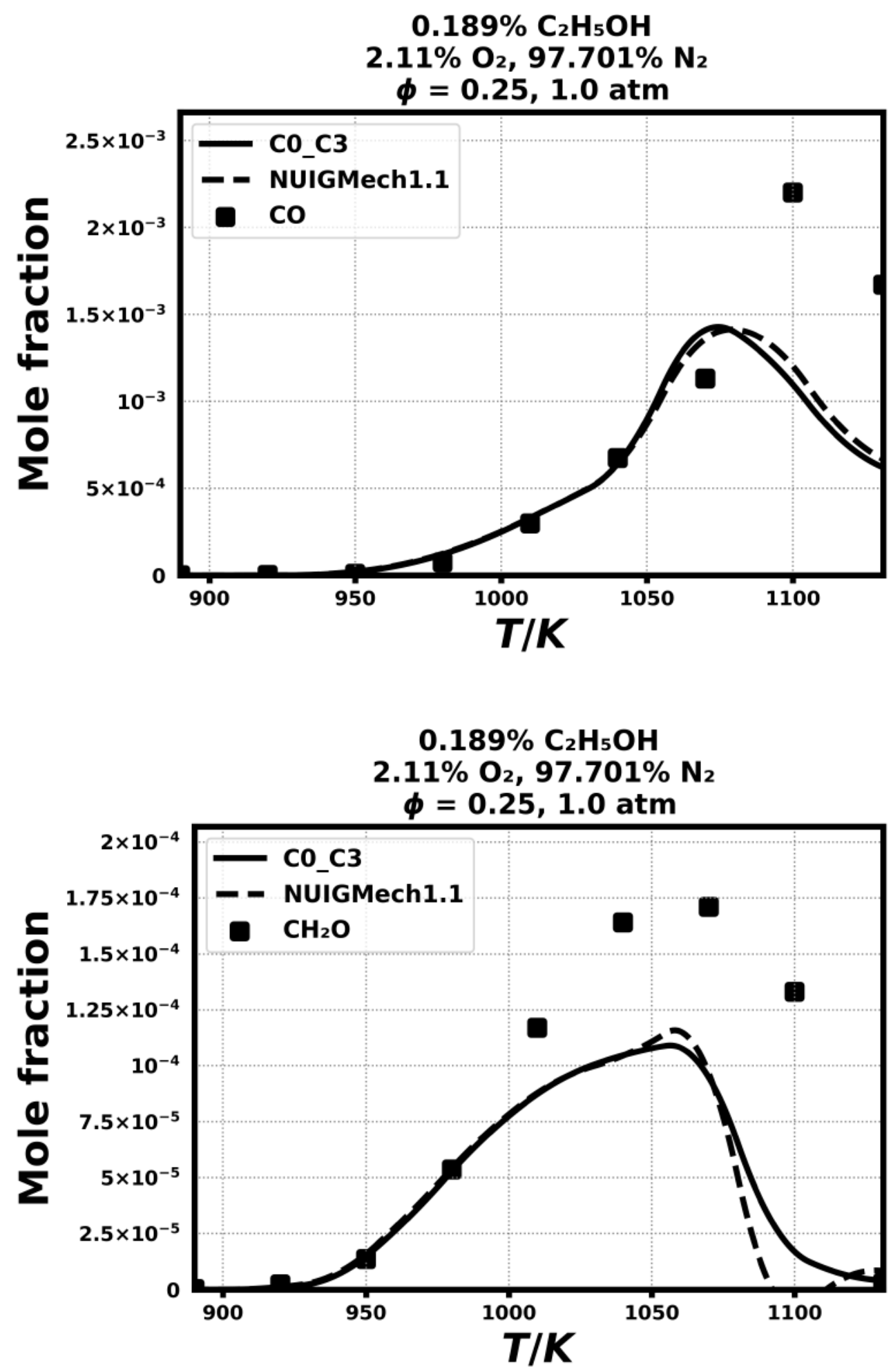

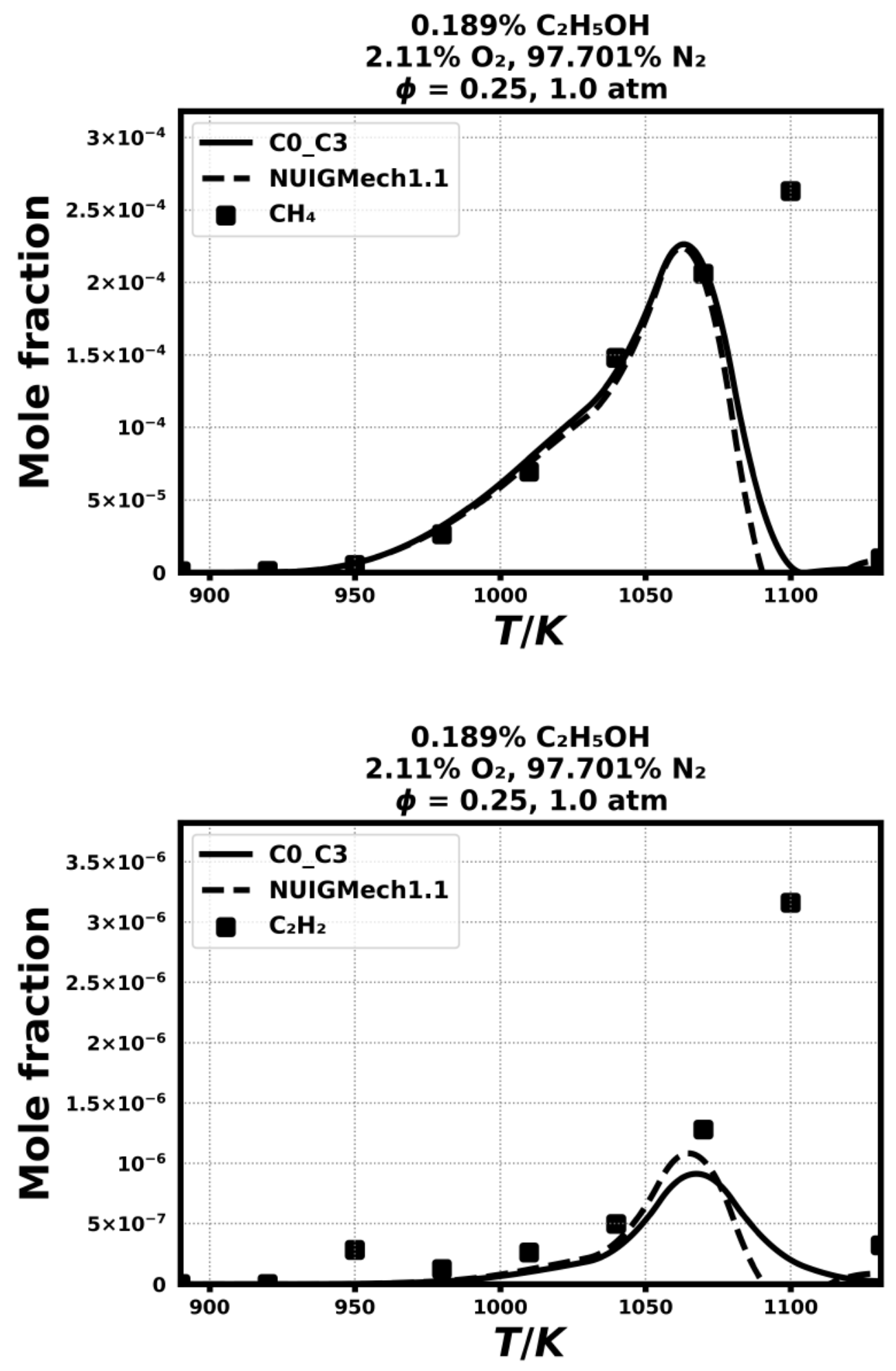

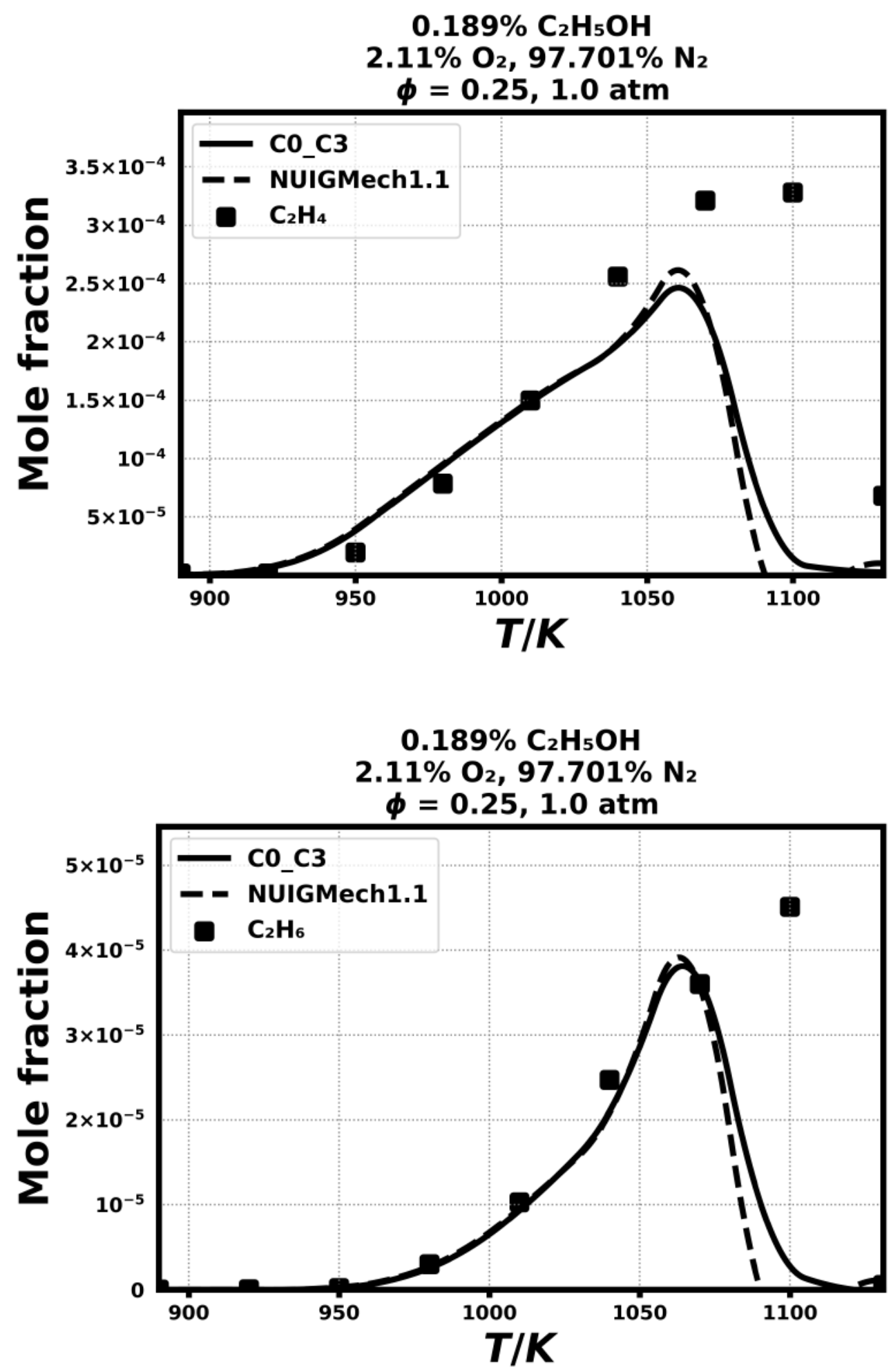

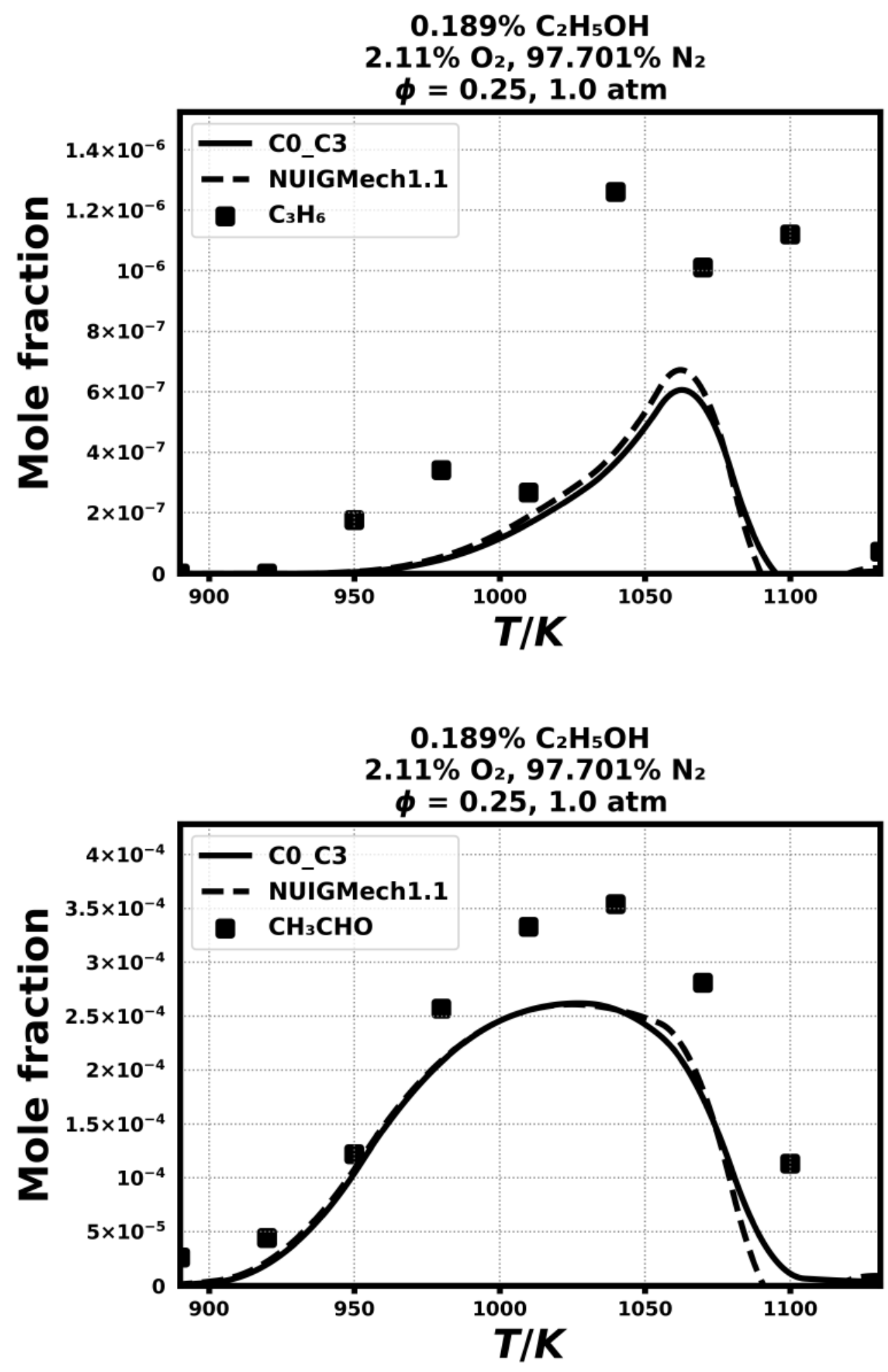

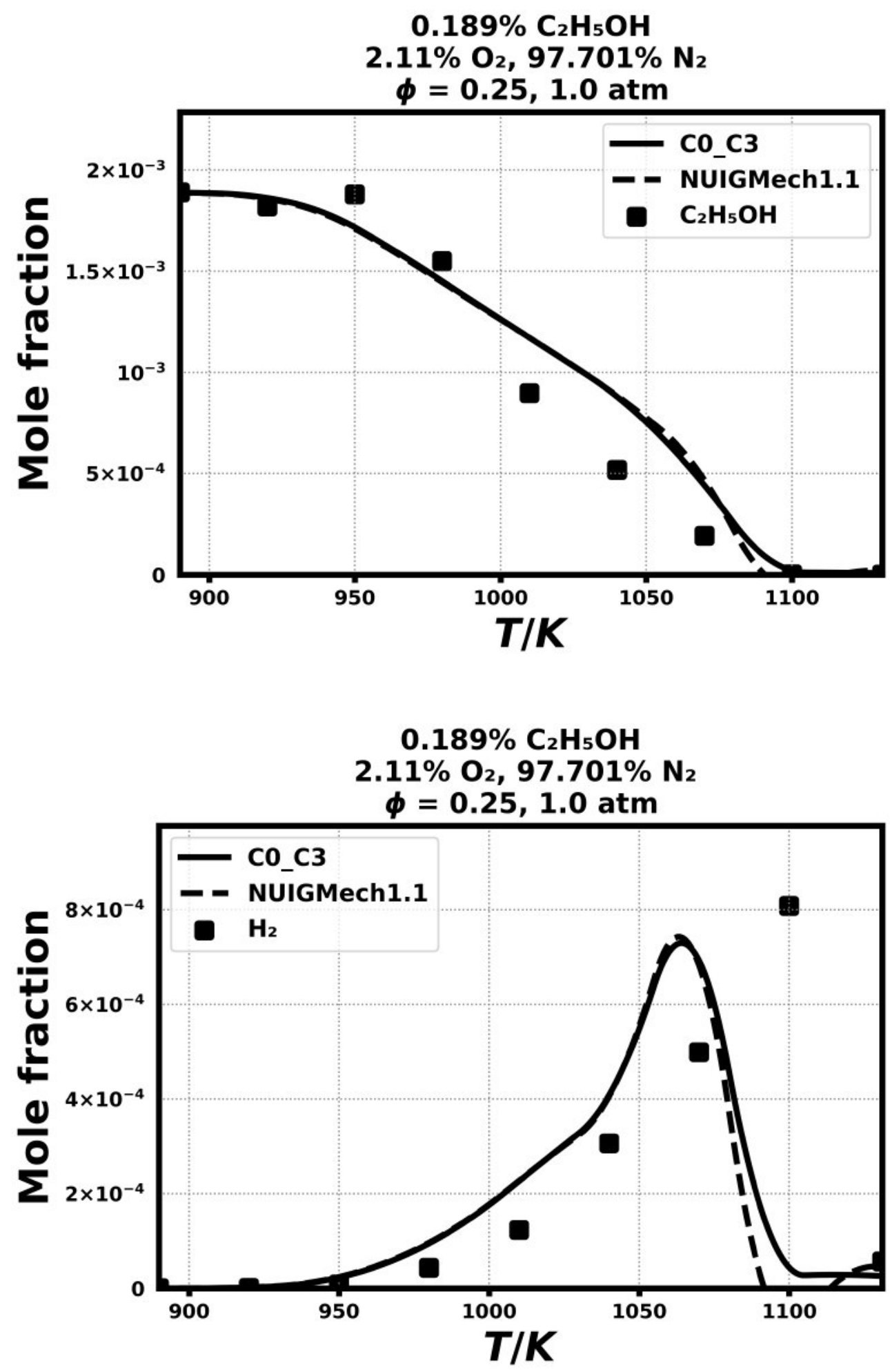

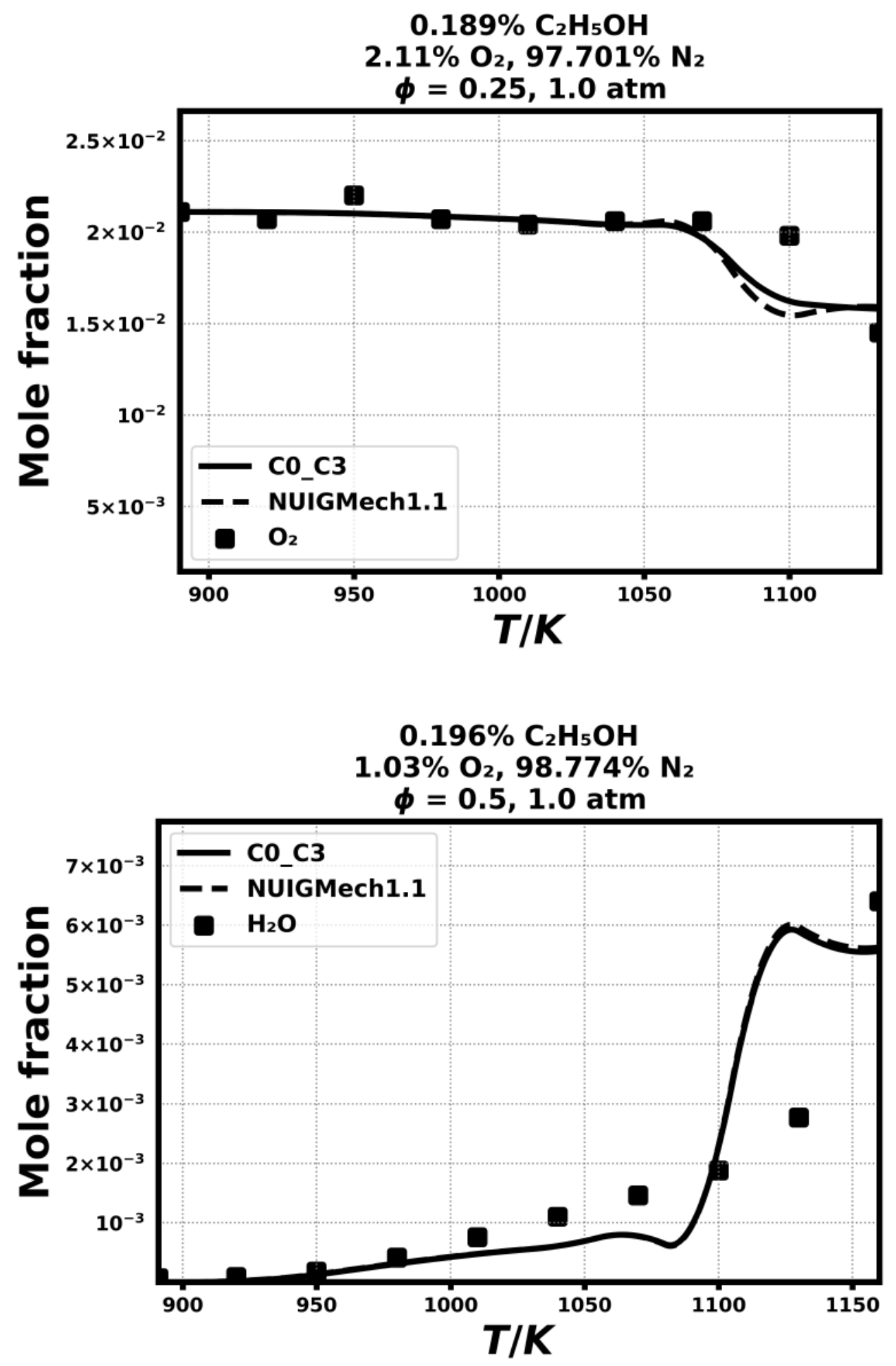

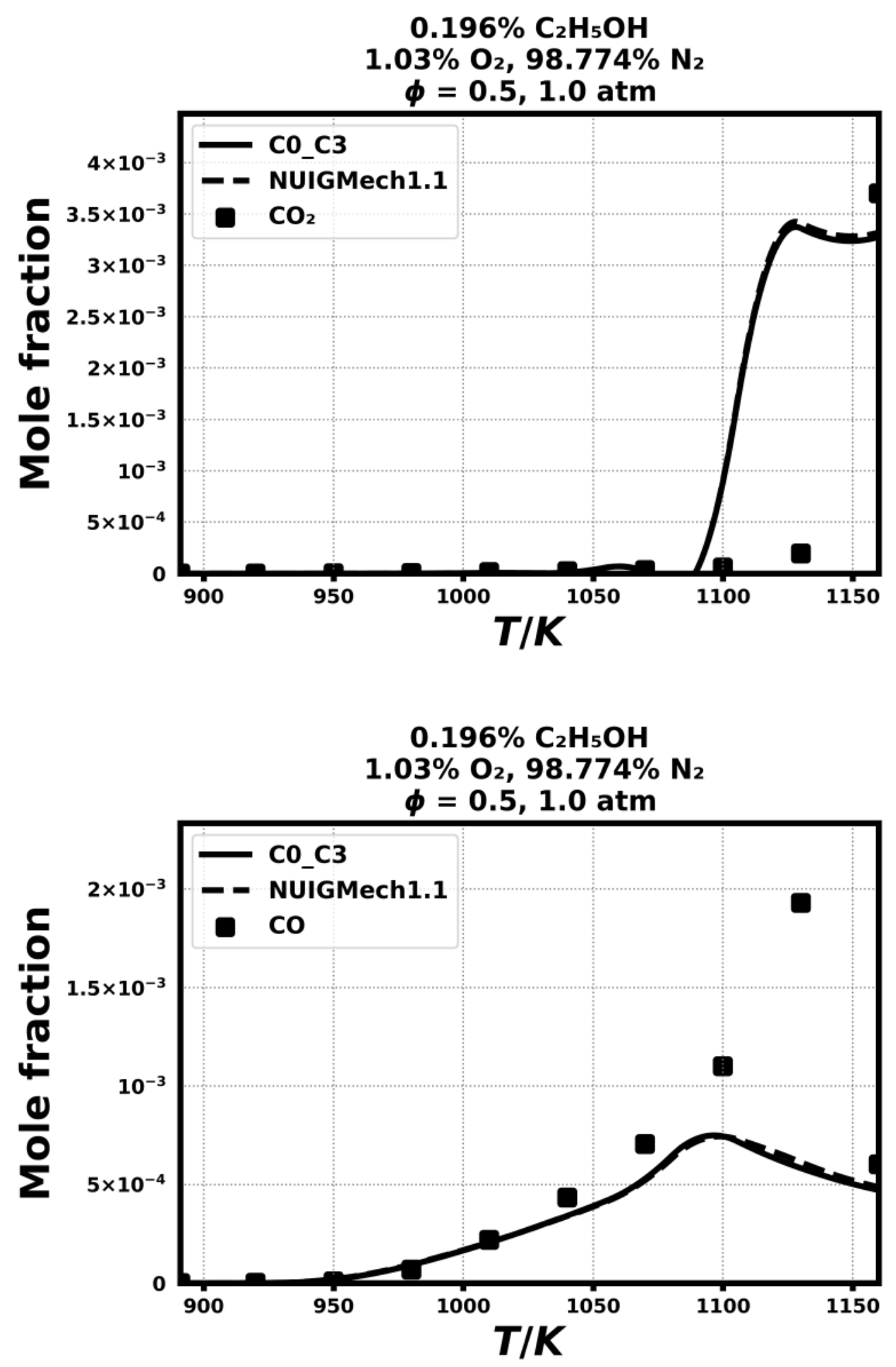

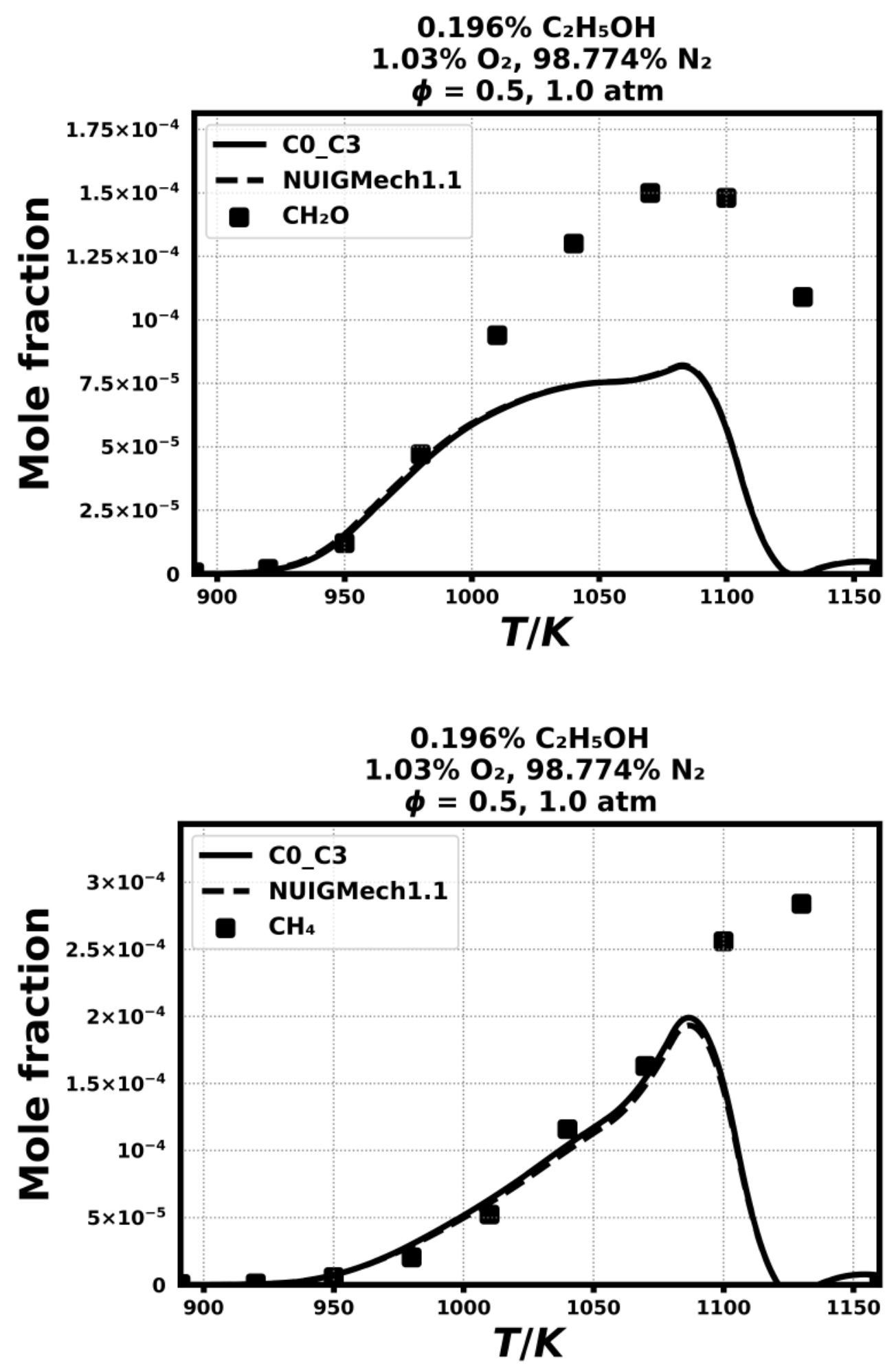

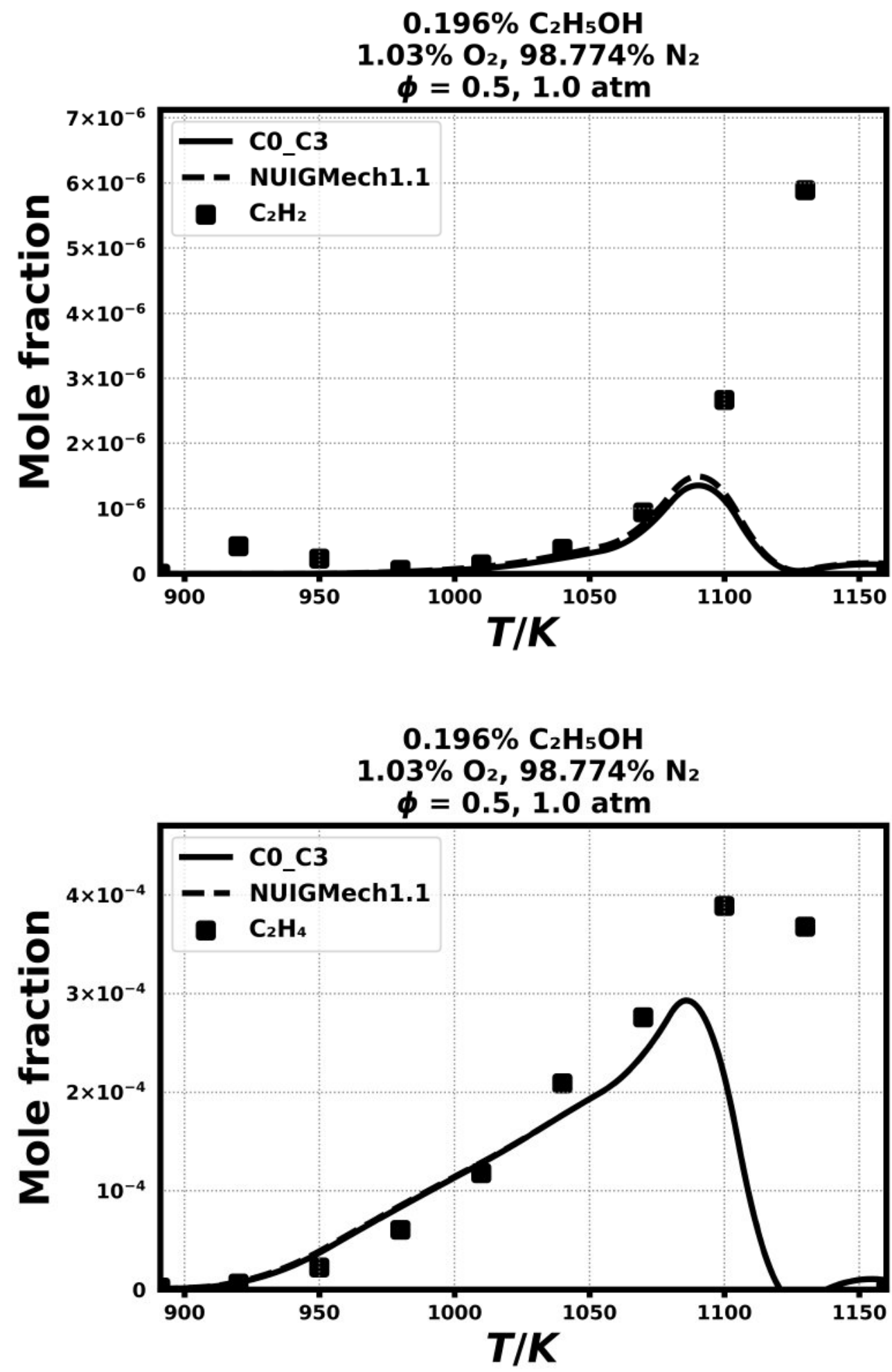

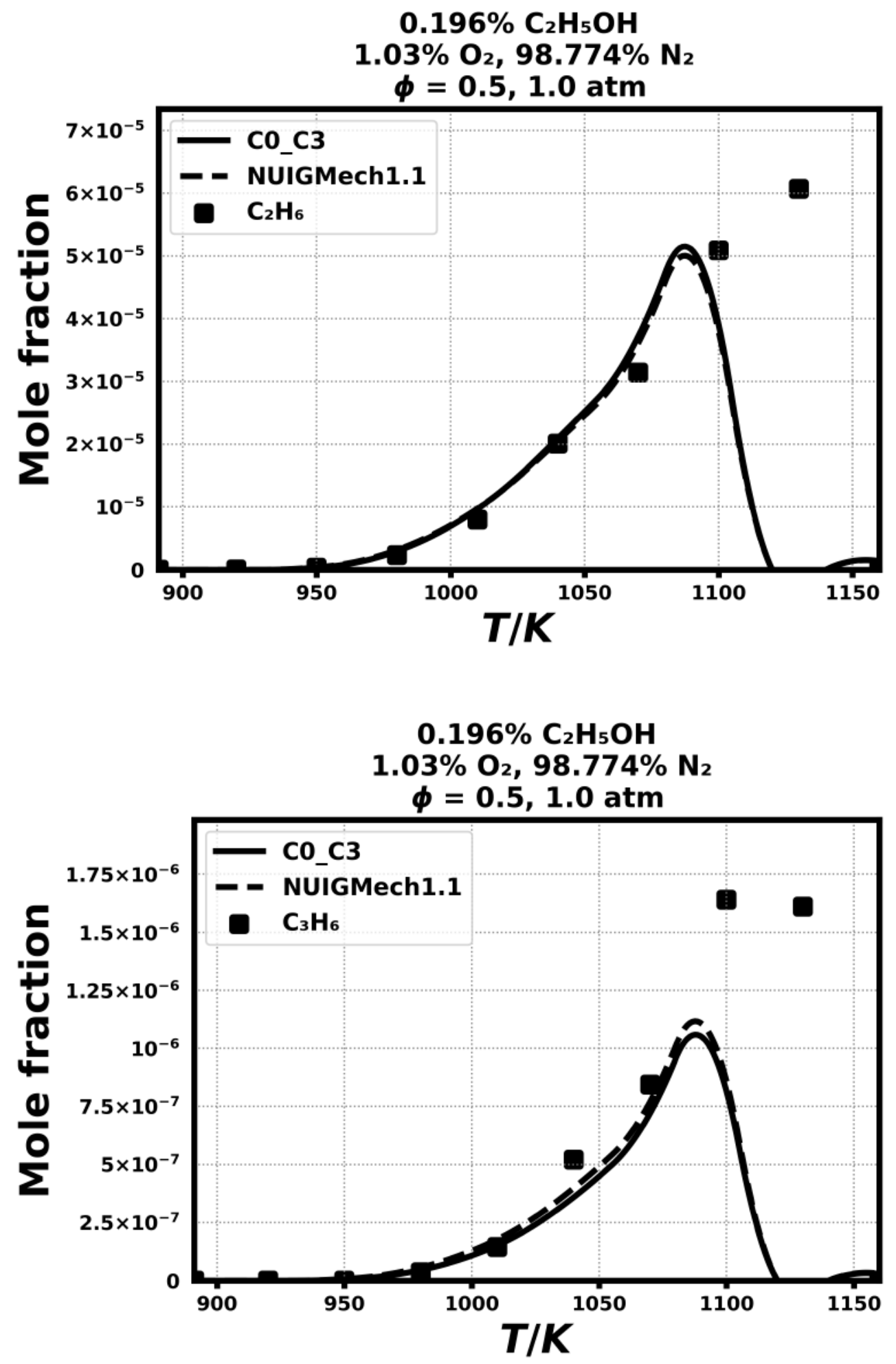

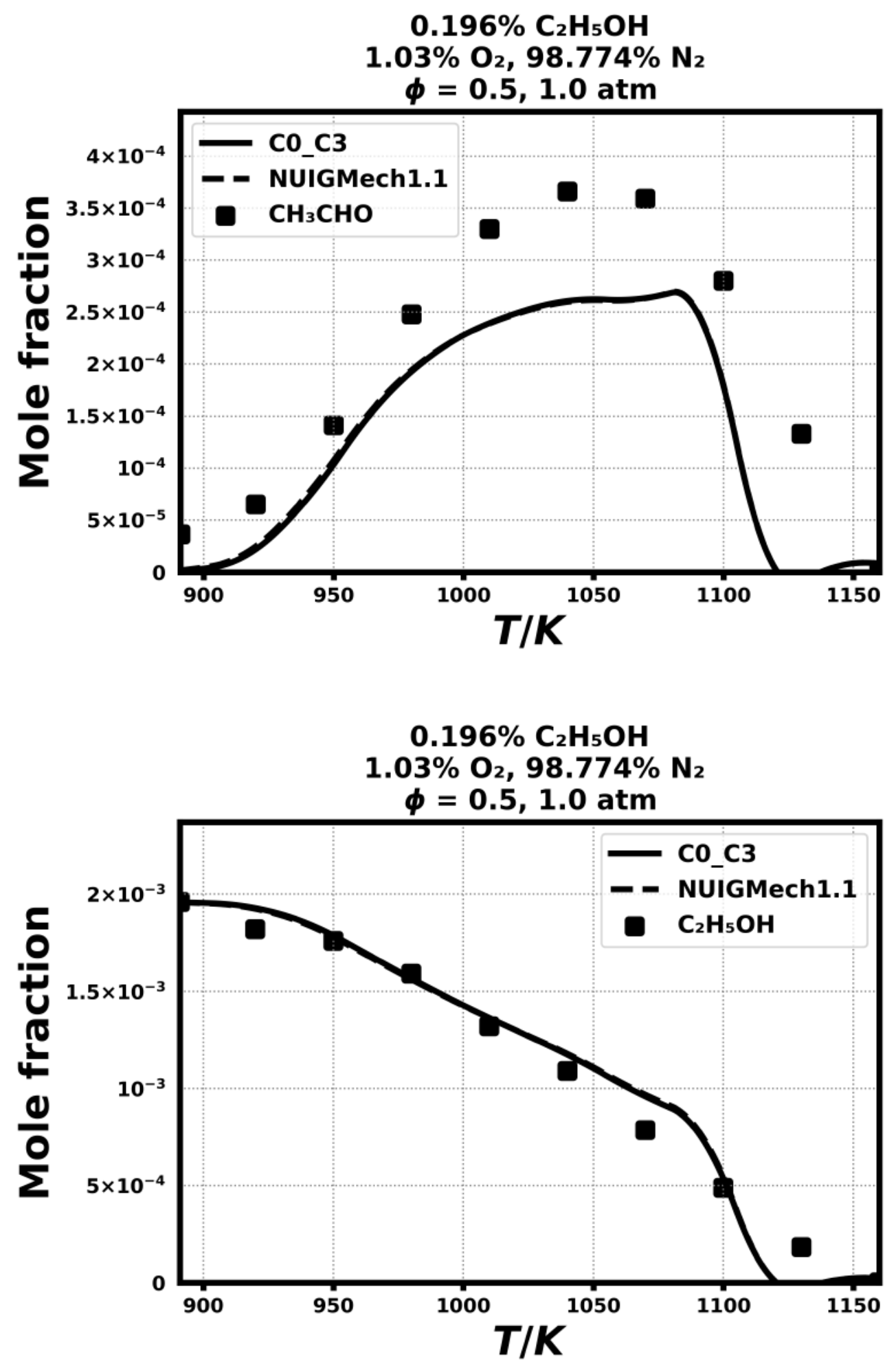

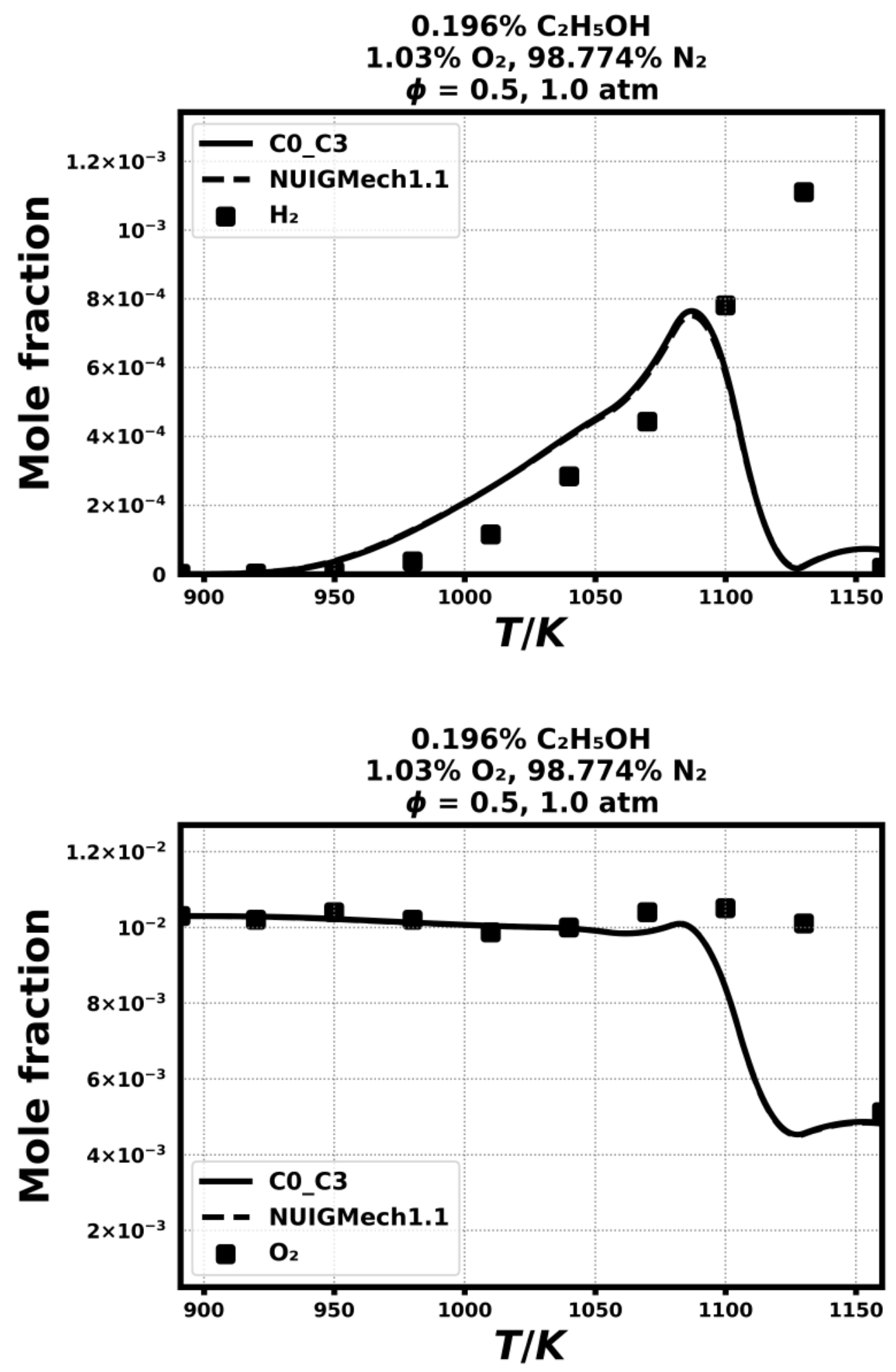

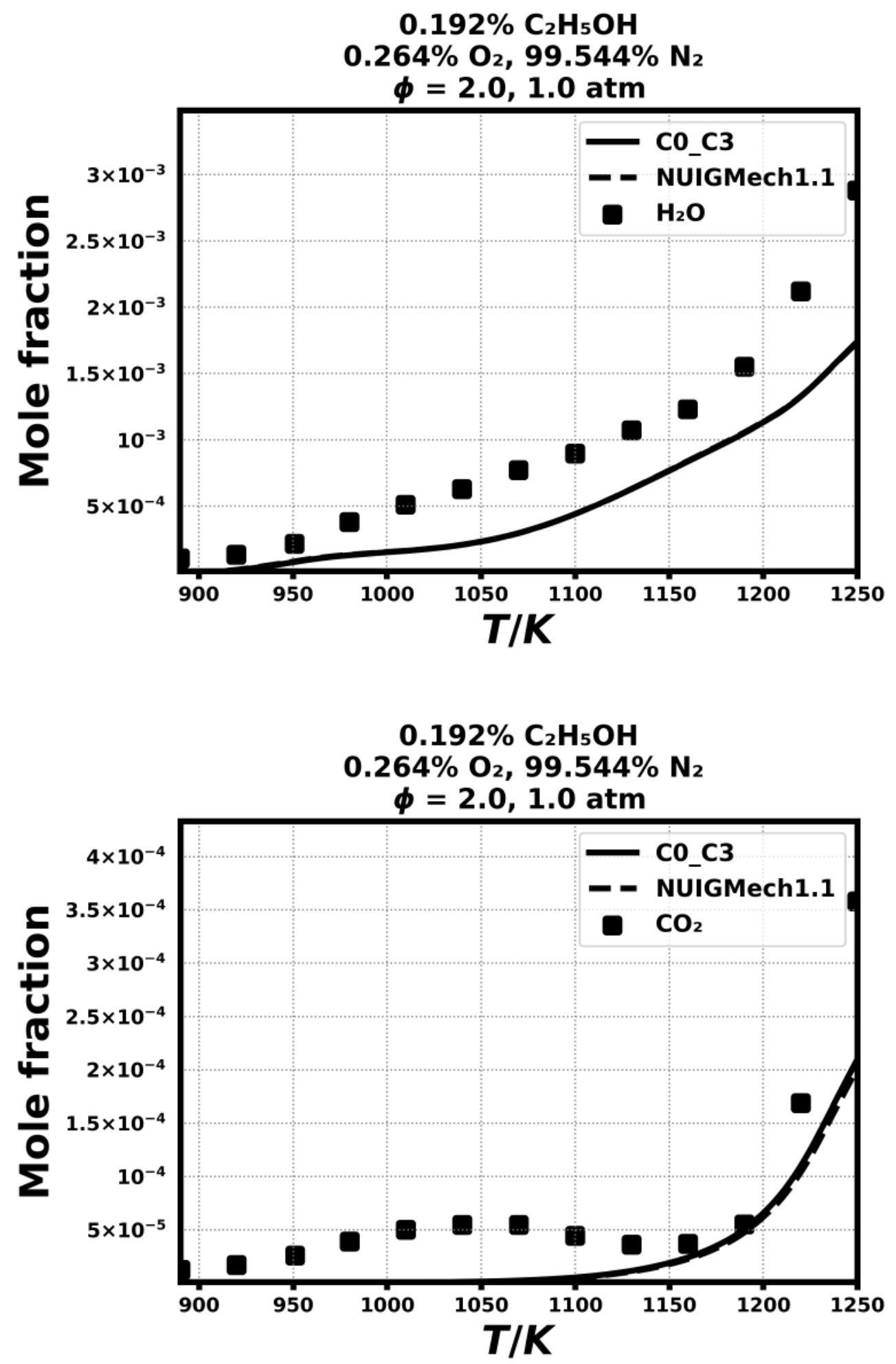

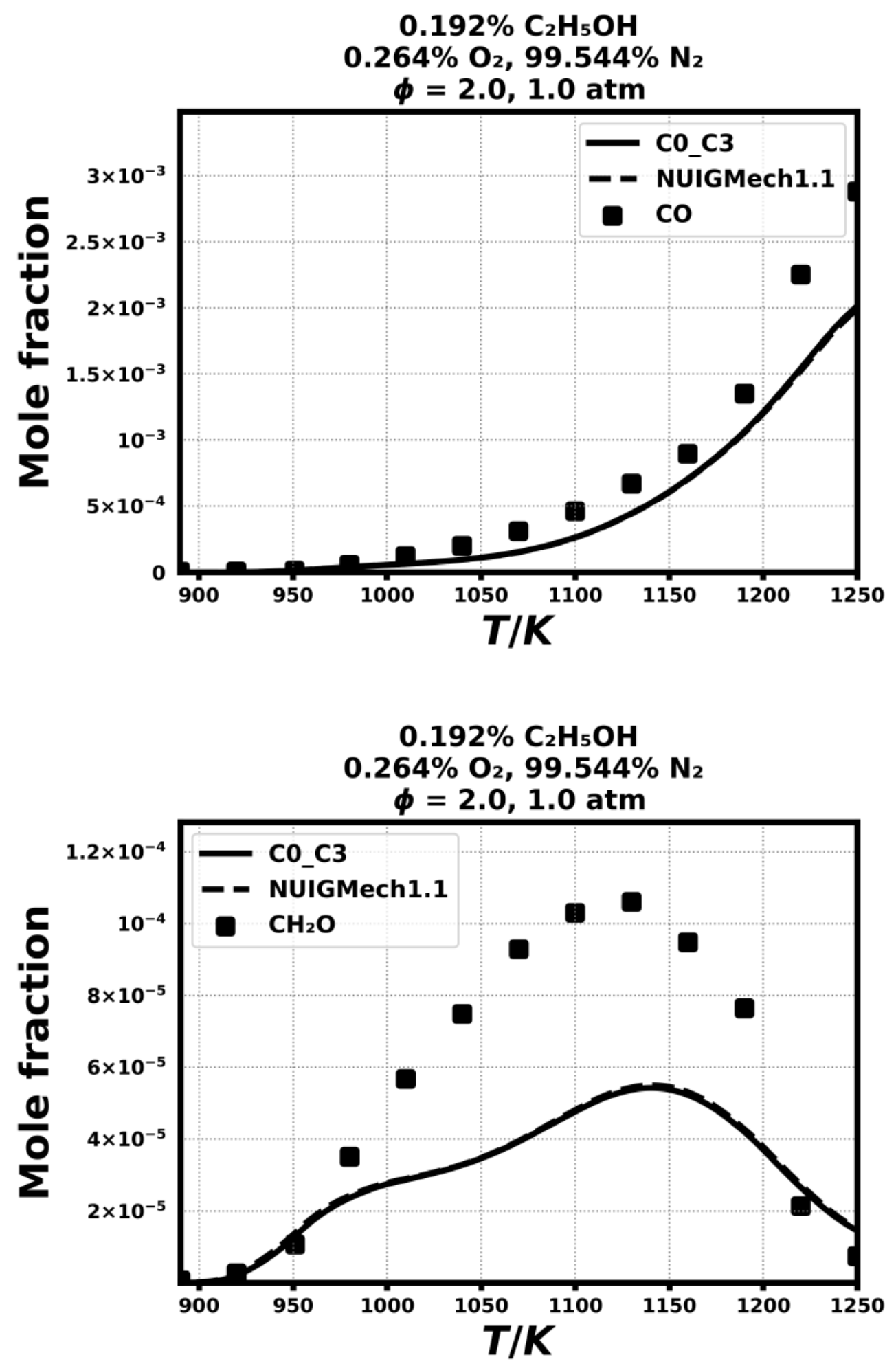

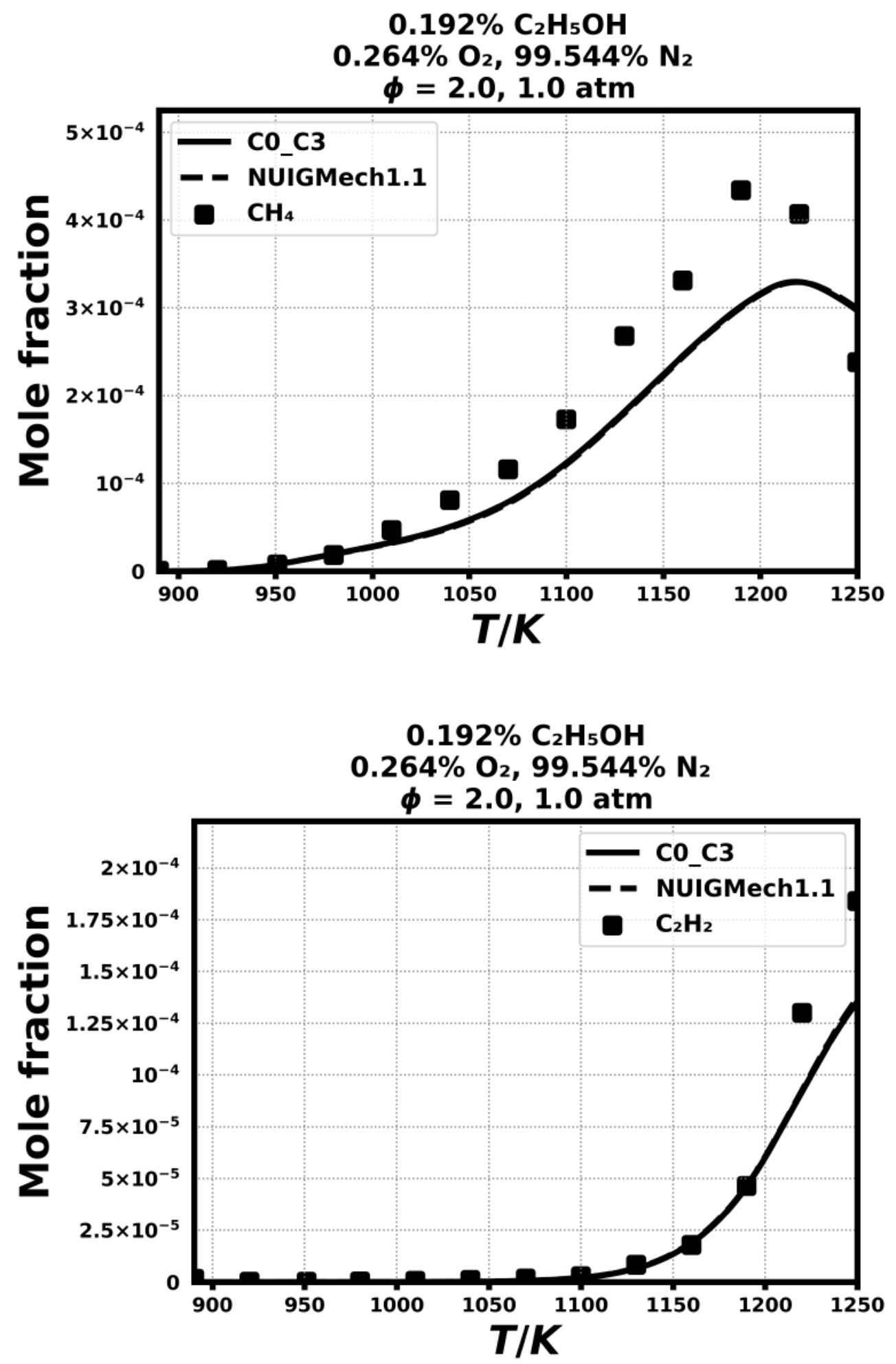

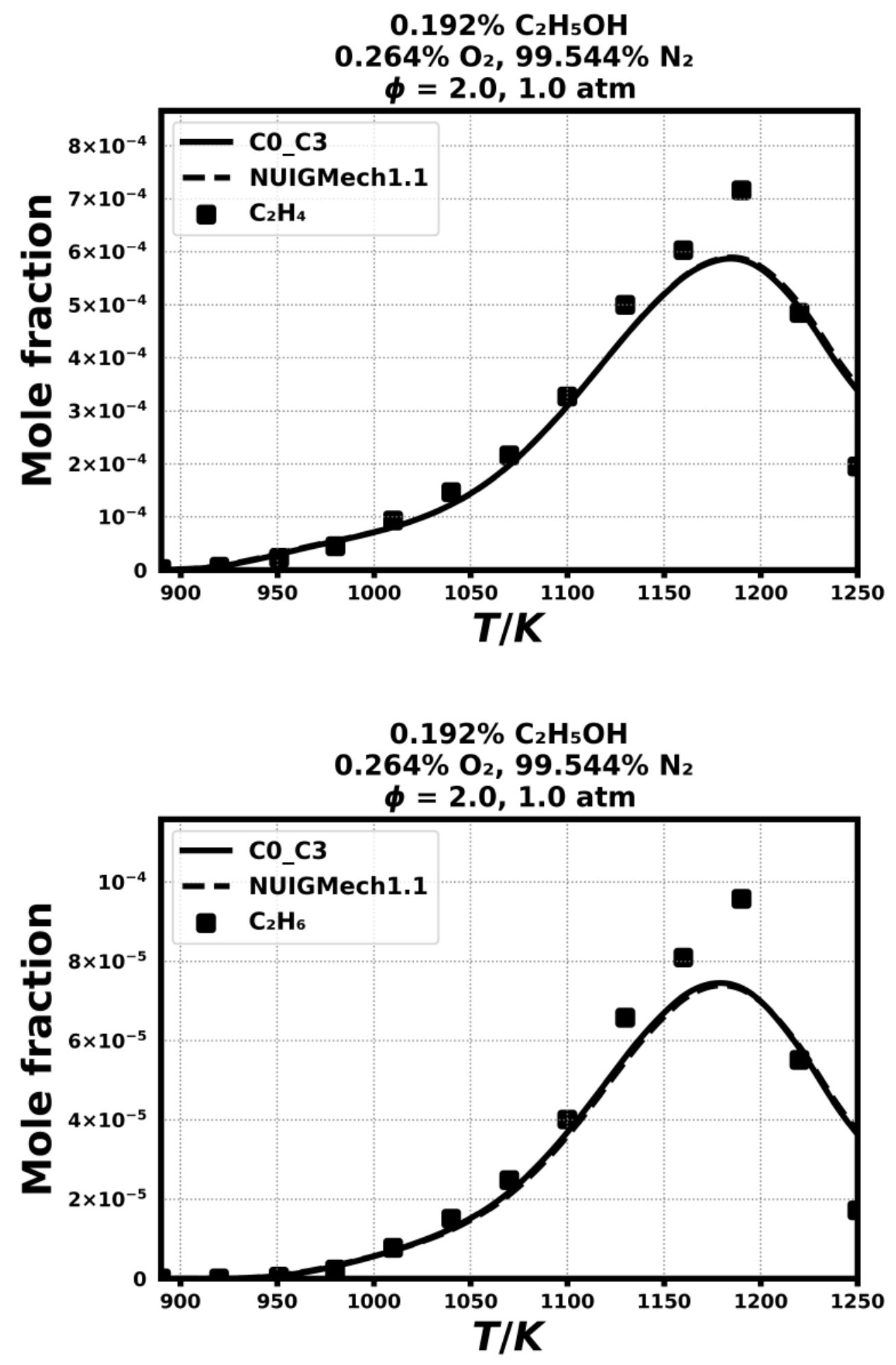

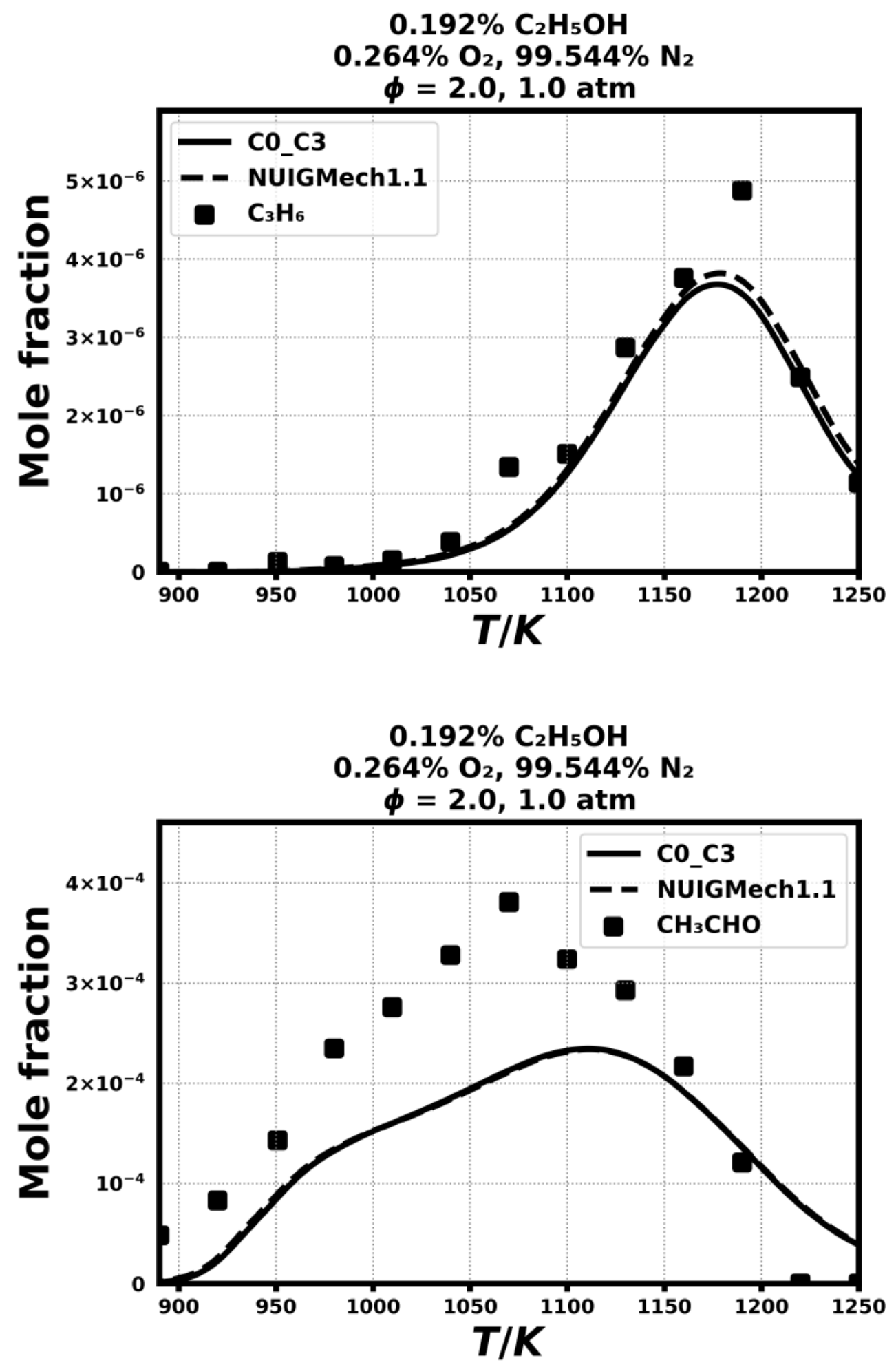

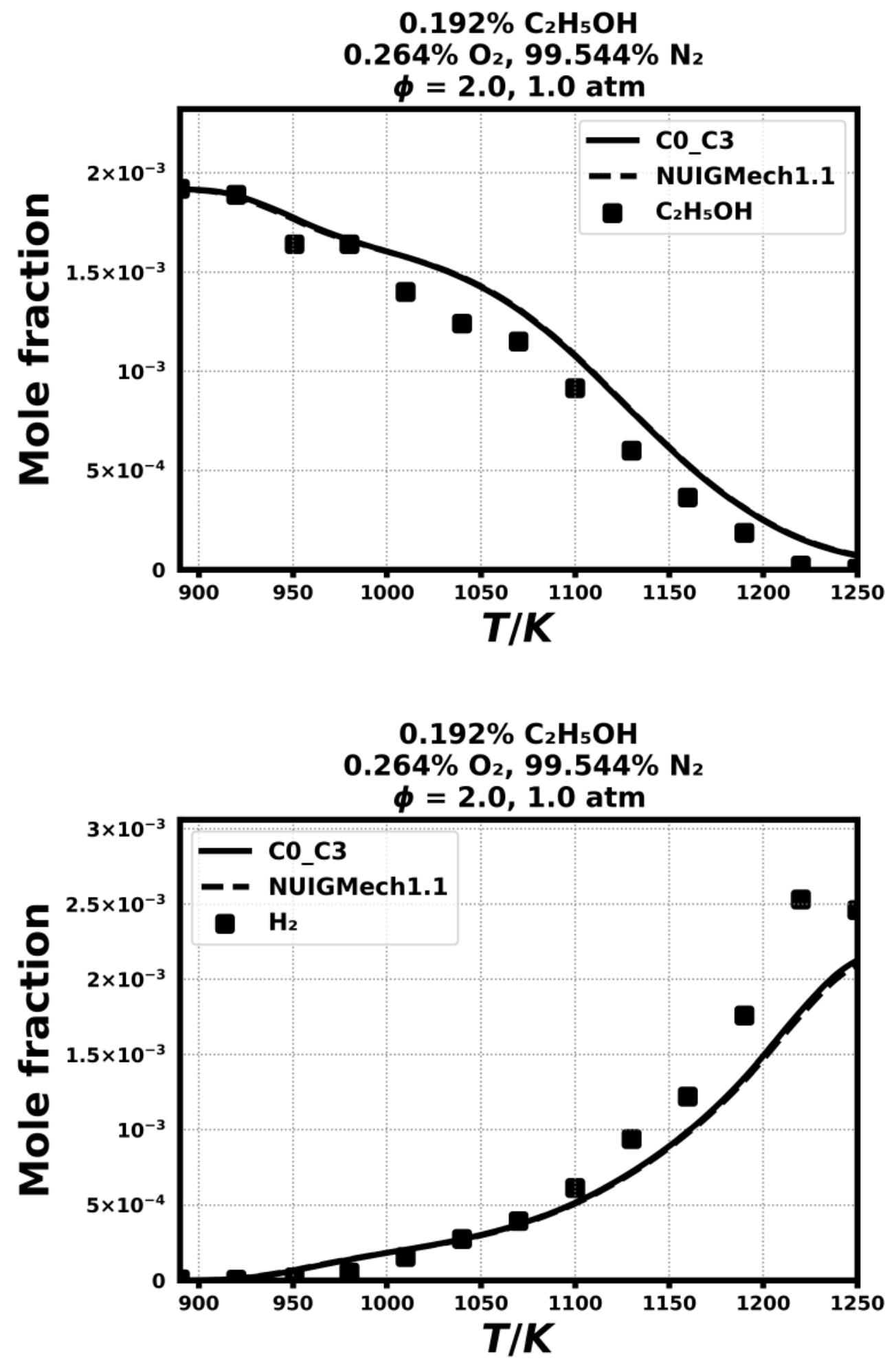


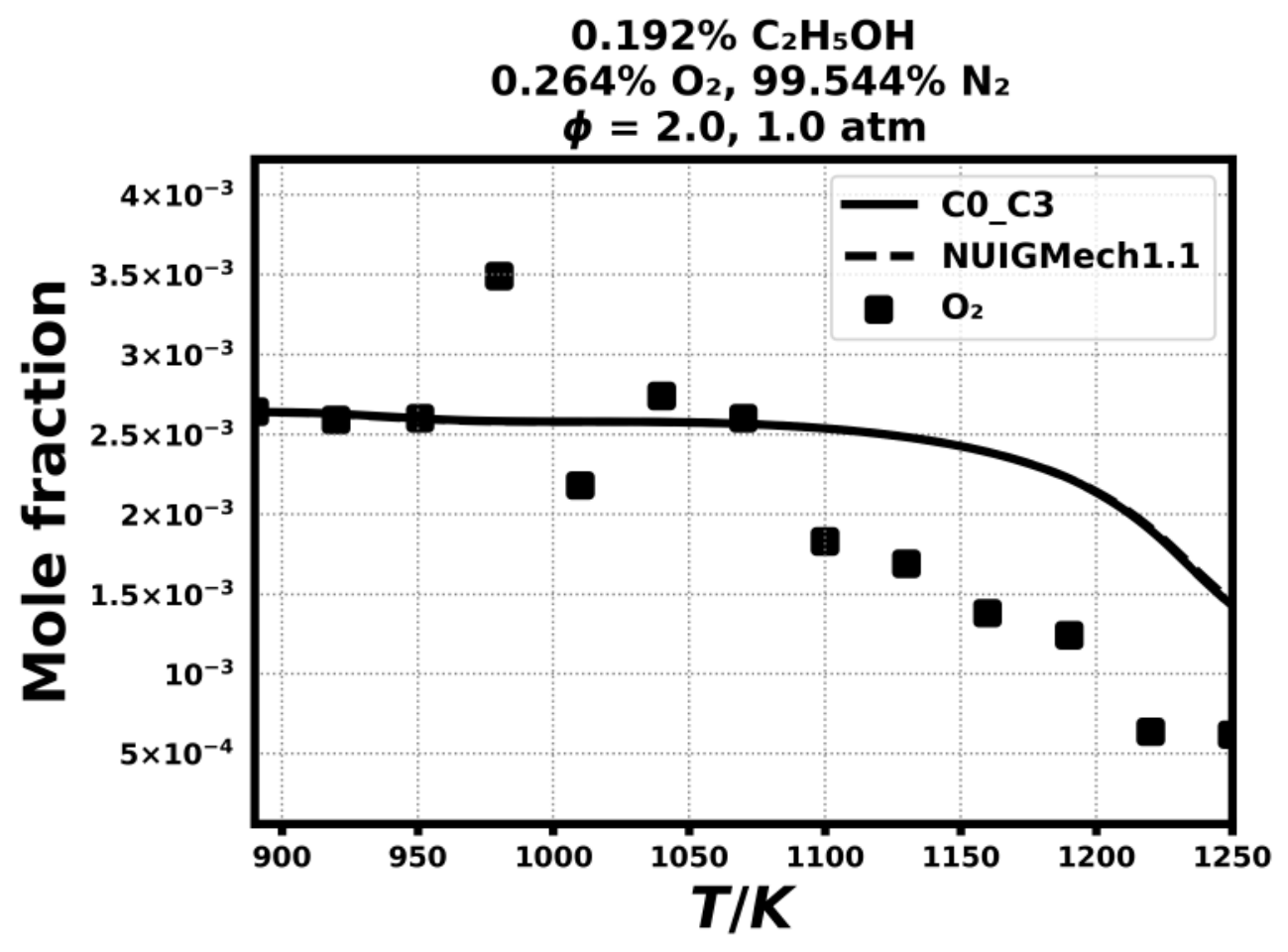

\section{Speciation in Flow reactor}

7.9) Alzueta, M. U., \& Hernández, J. M., Energy \& fuels, 16(1) (2002) 166-171.

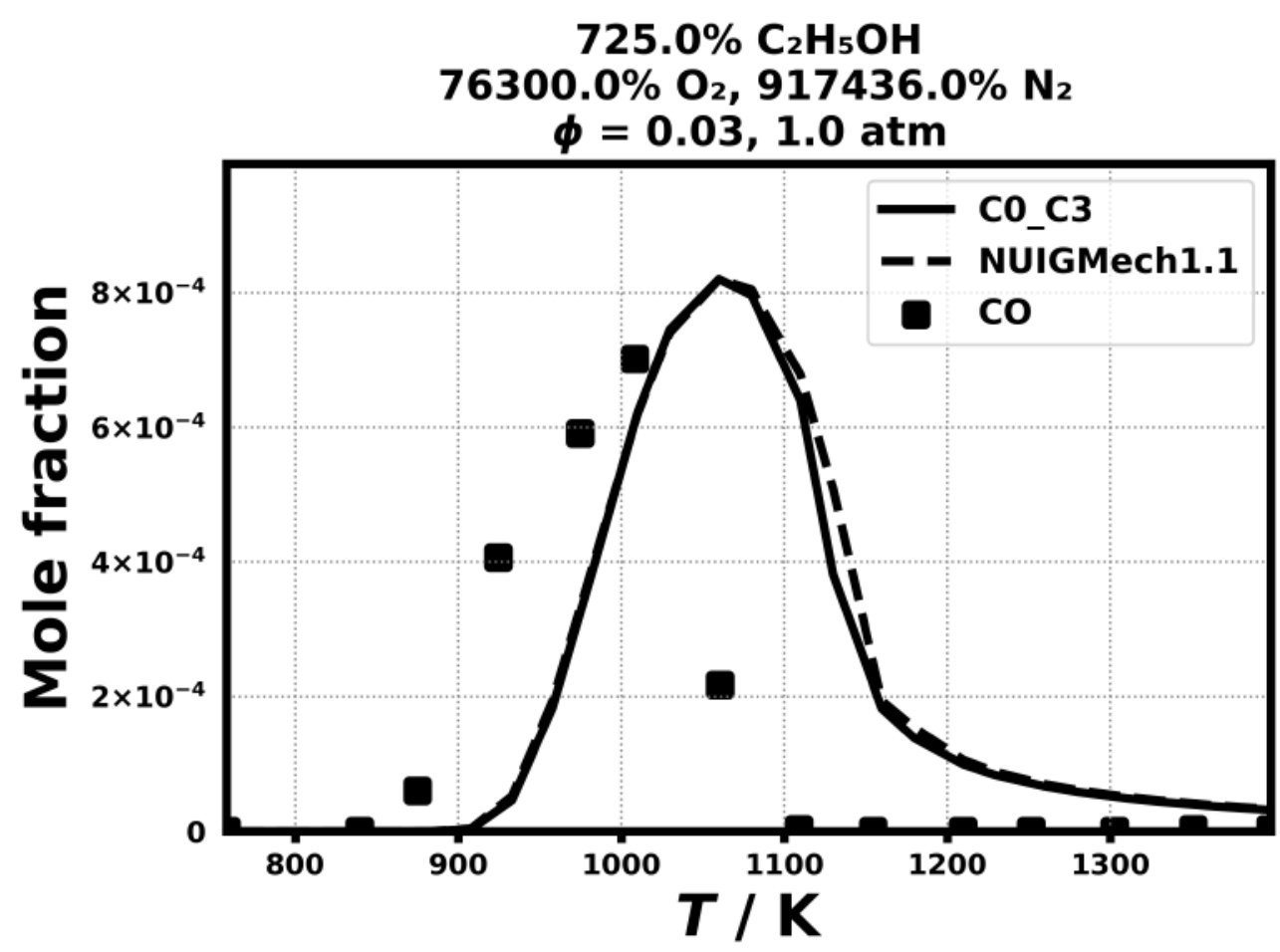



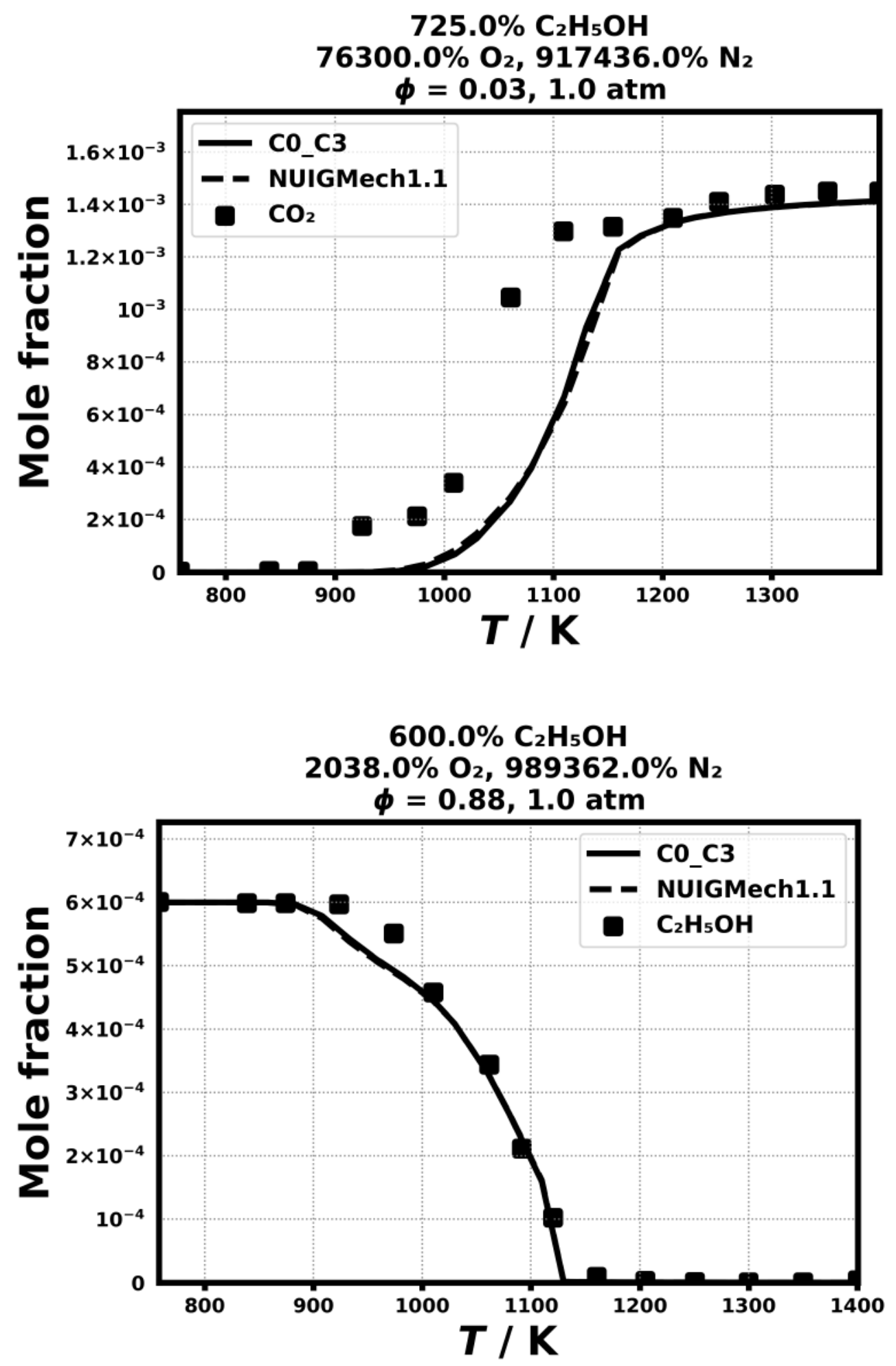

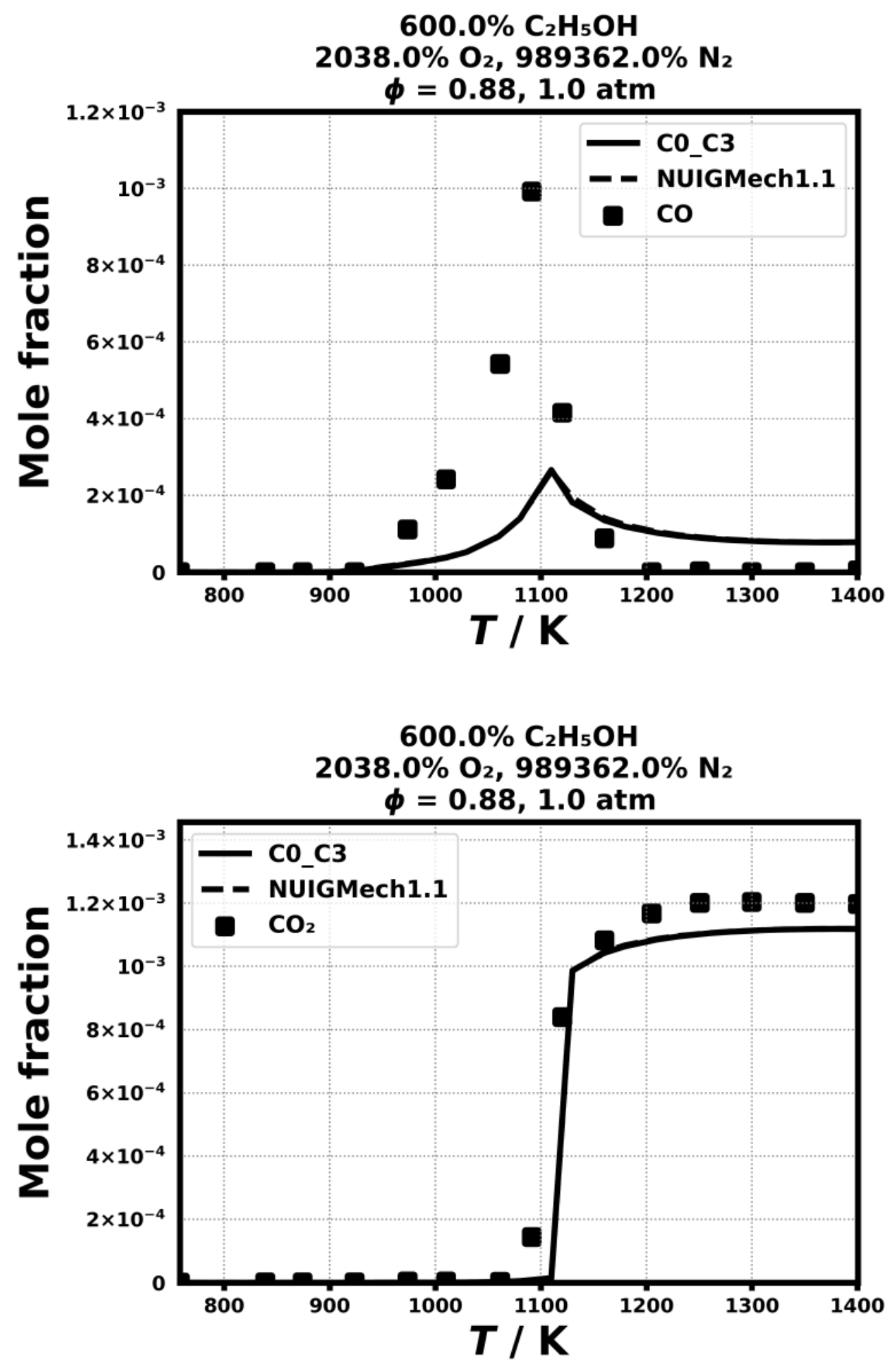

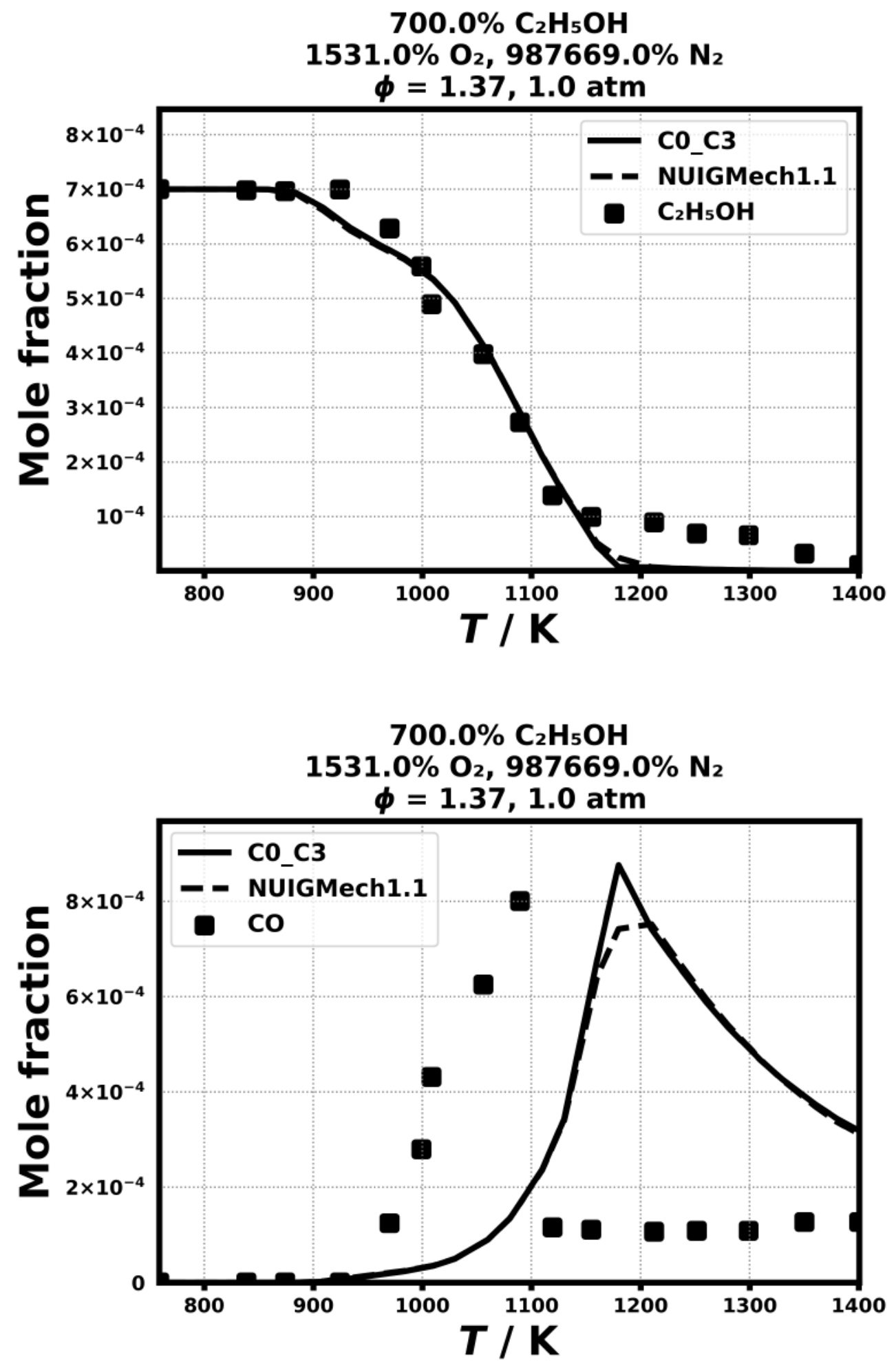


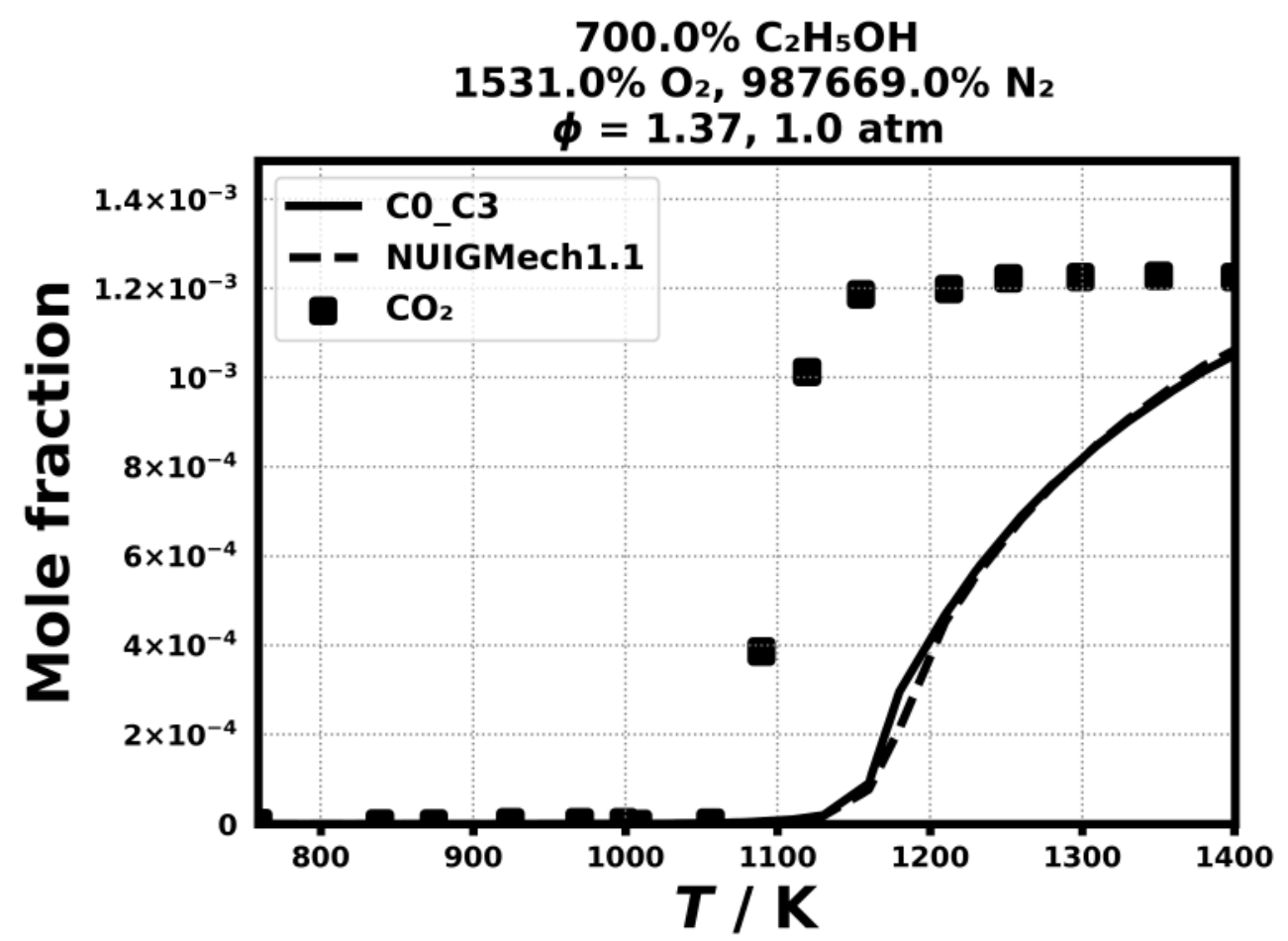



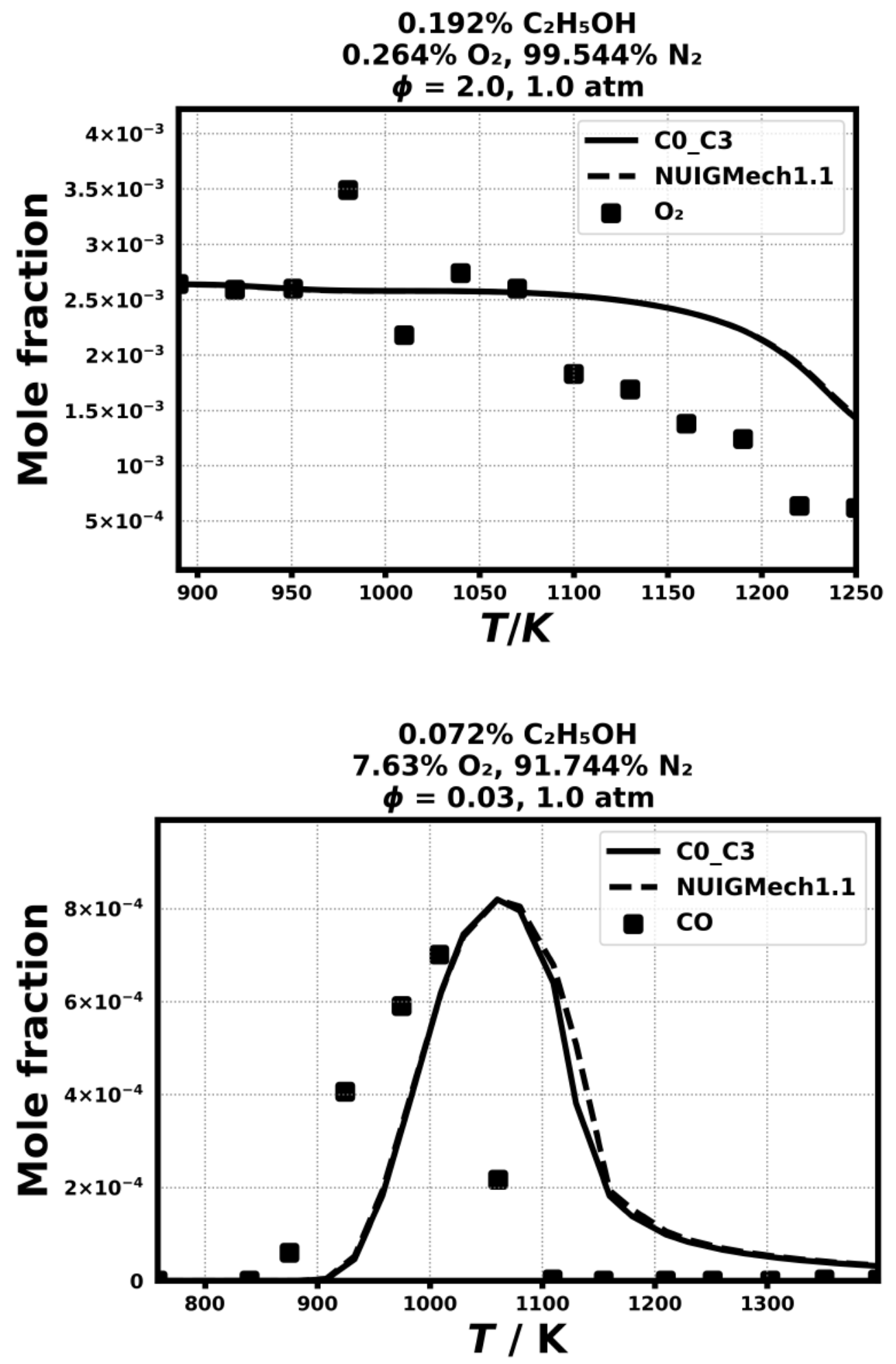

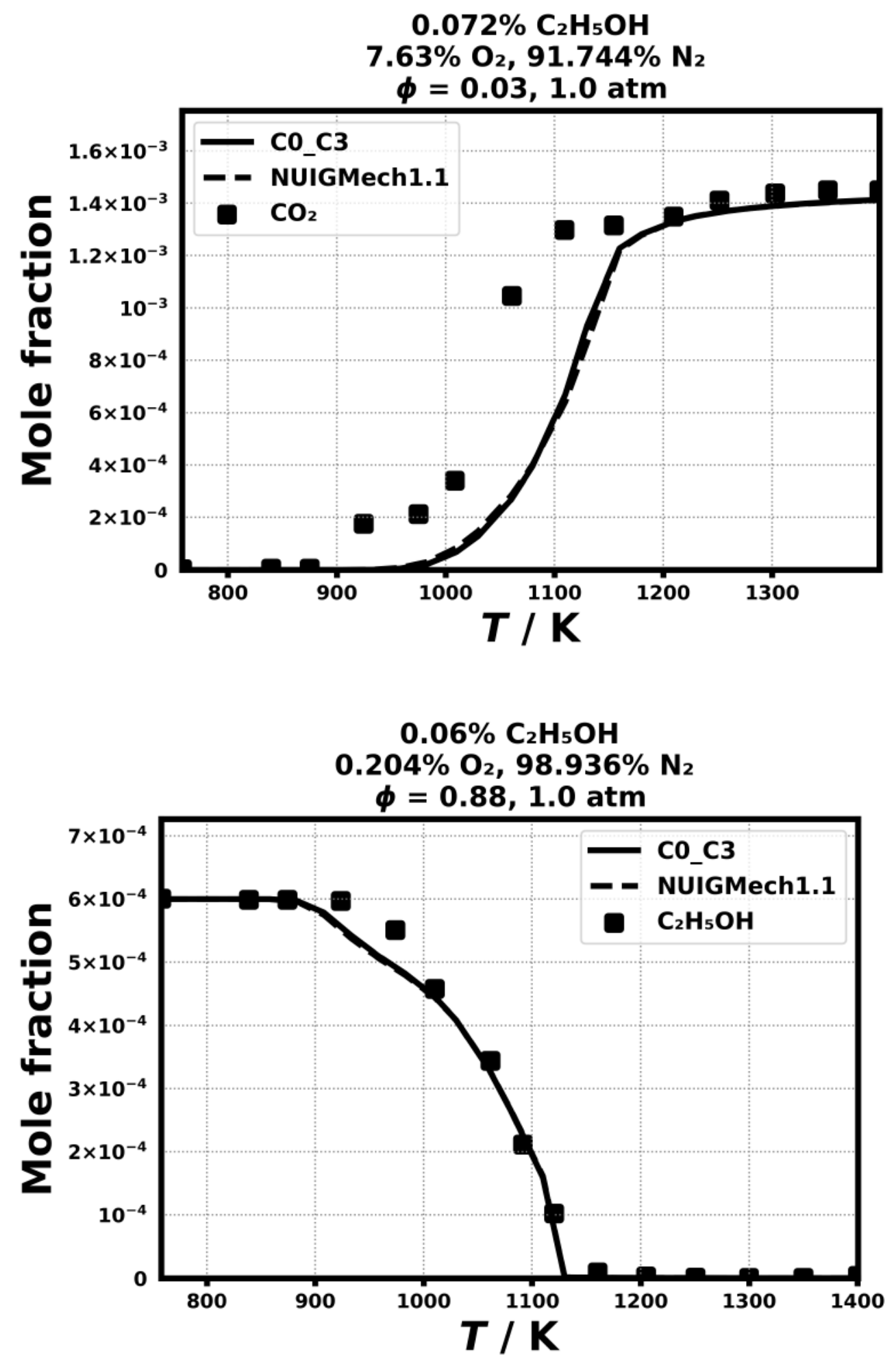

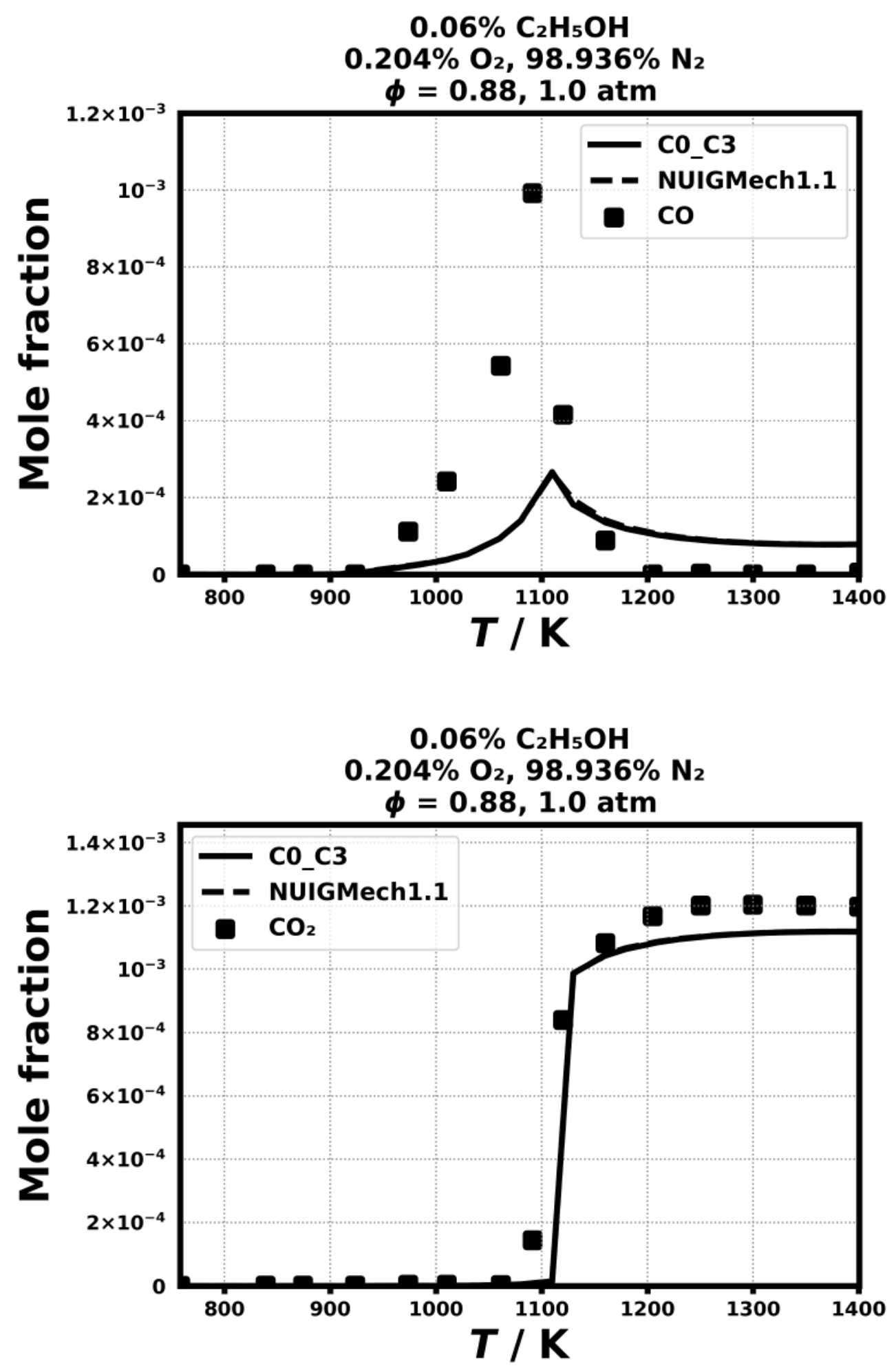

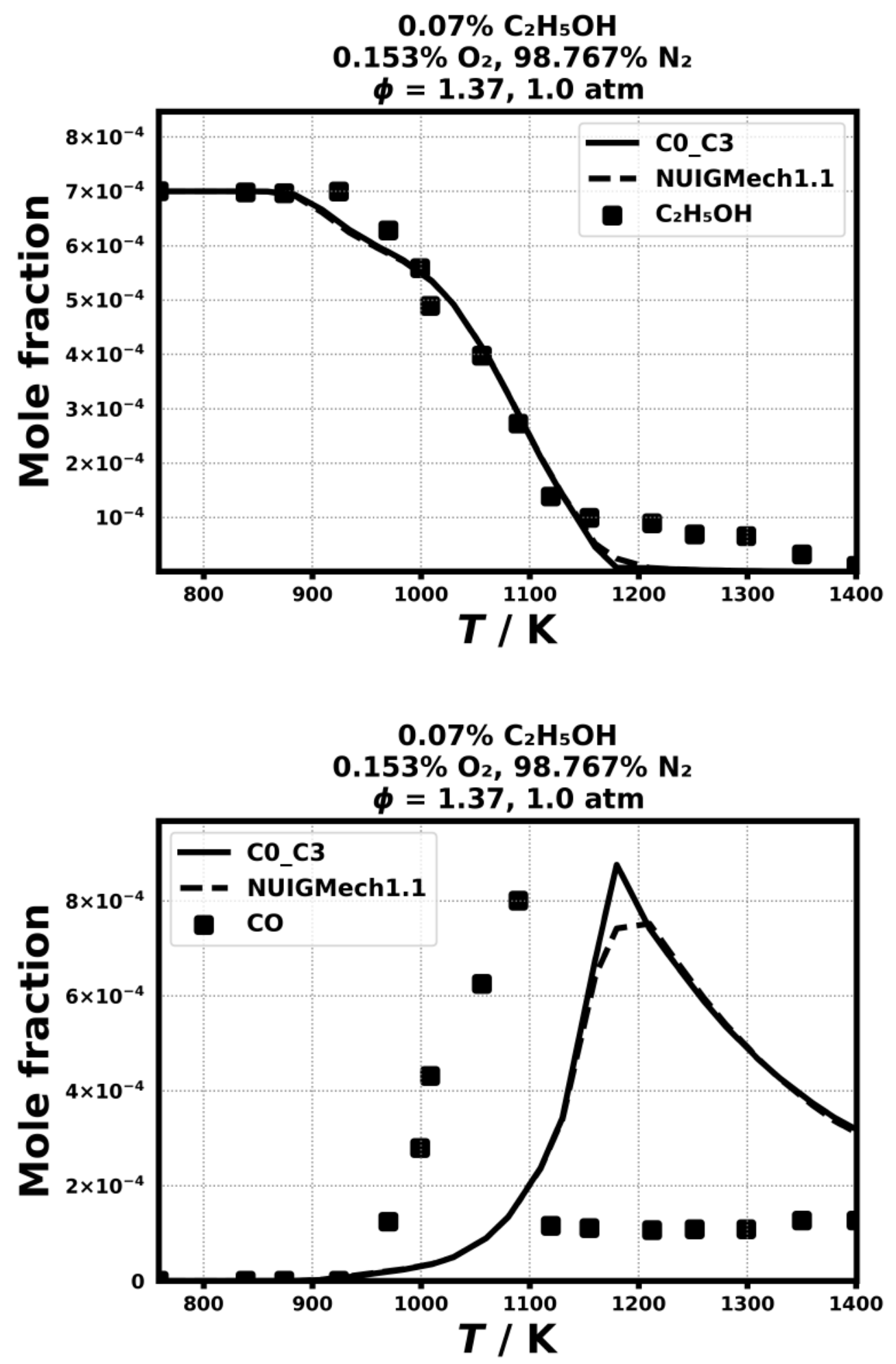


\section{Laminar flame speed}

7.10) P. S. Veloo, Y. L. Wang, F. N. Egolfopoulos, C. K. Westbrook, Combustion and Flame 157 (2010) 1989-2004.

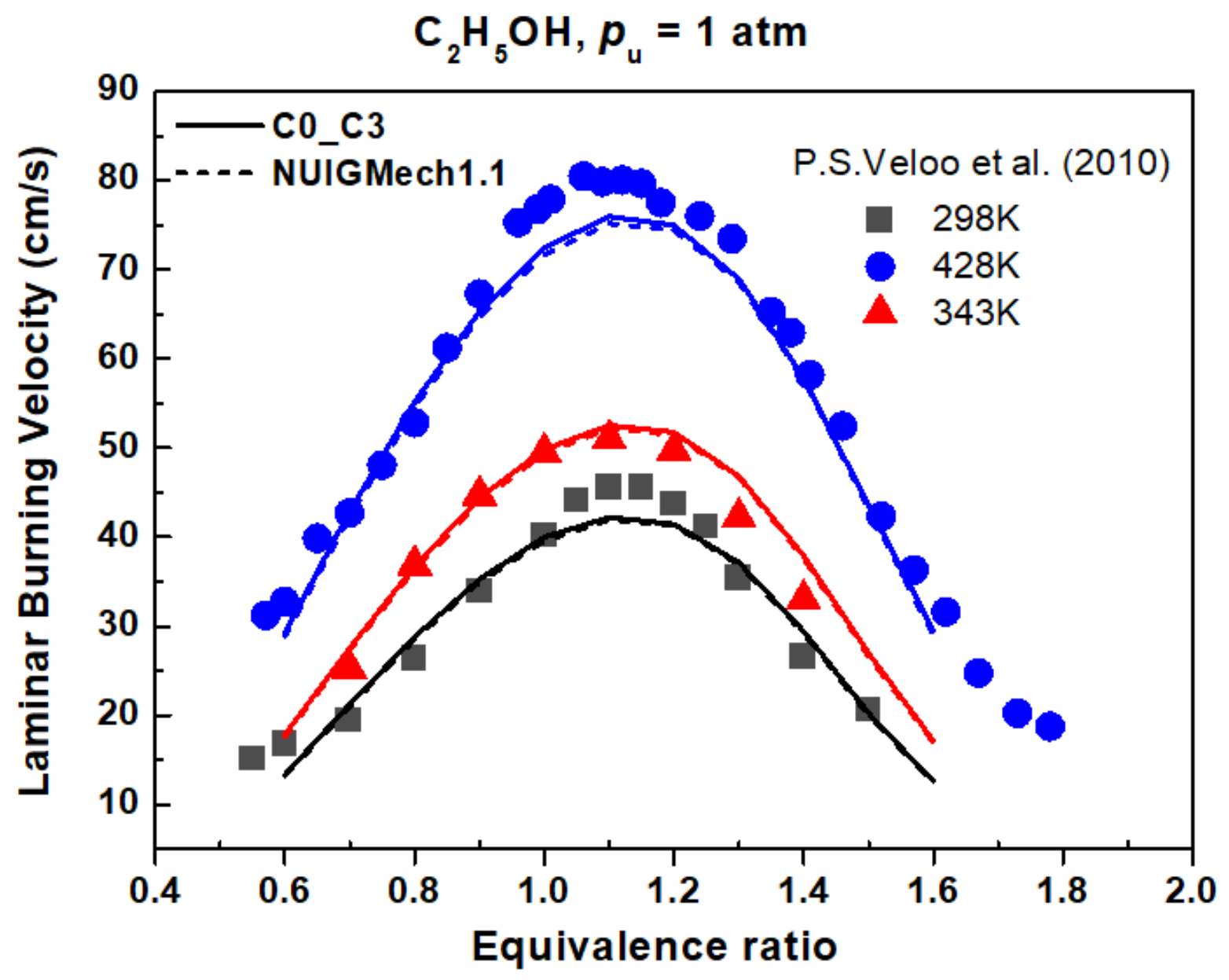




\section{Validation for $\mathrm{C}_{3} \mathrm{H}_{8}$}

\section{Shock tube ignition delay time}

8.1) Burcat, A., Lifshitz, A., Scheller, K., \& Skinner, G. B. In Symposium (International) on Combustion, 13 (1971, January) 745-755
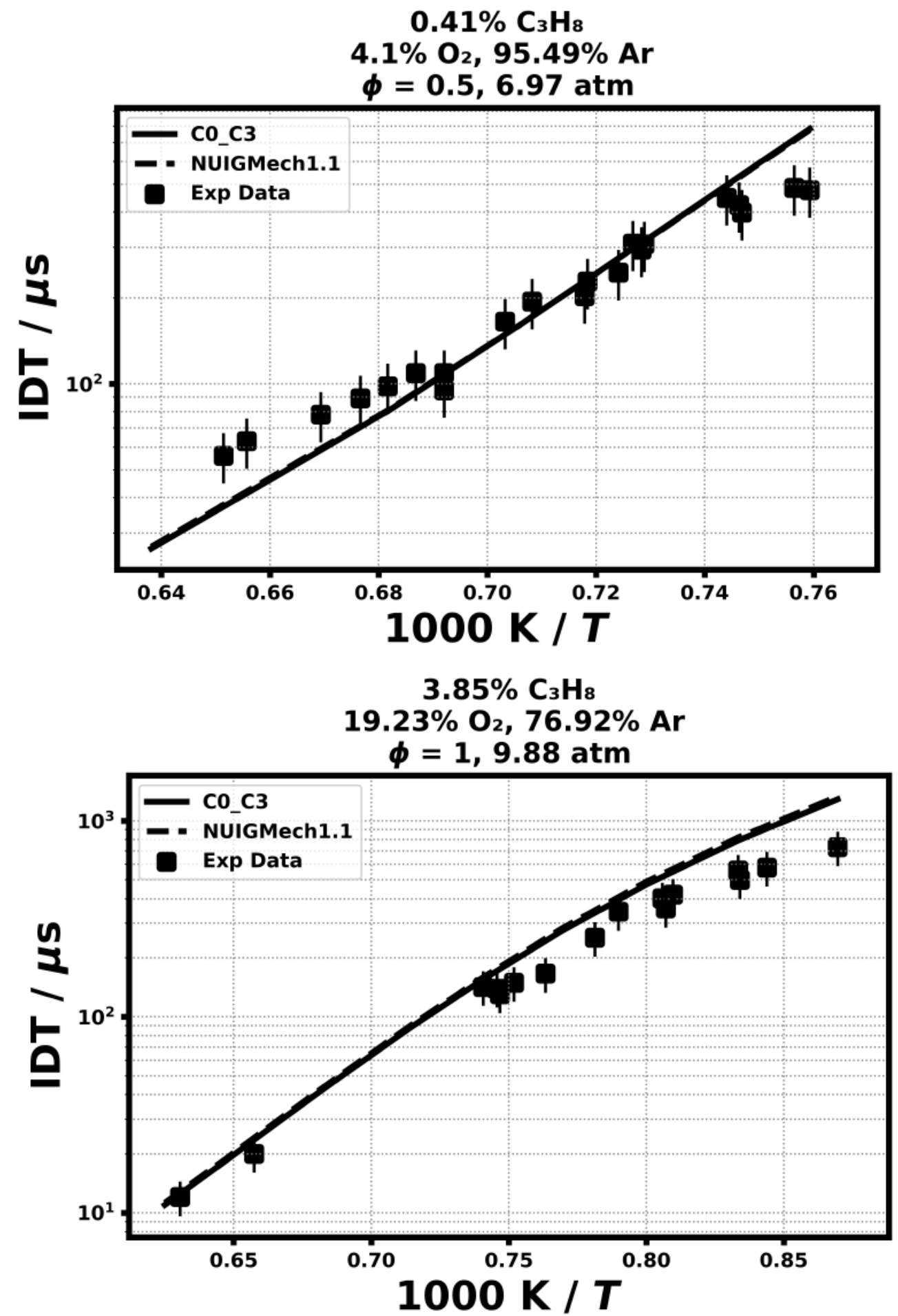

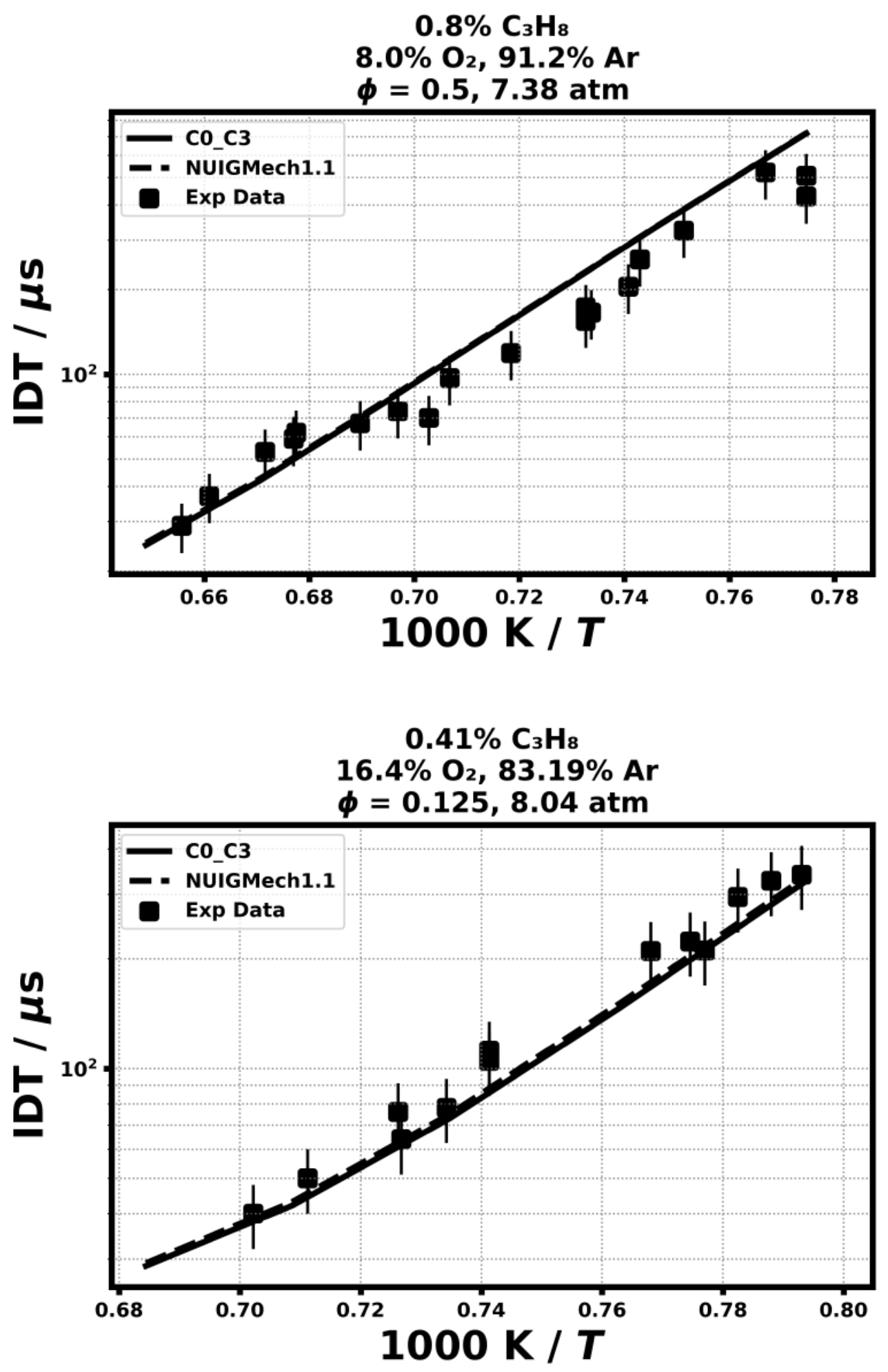

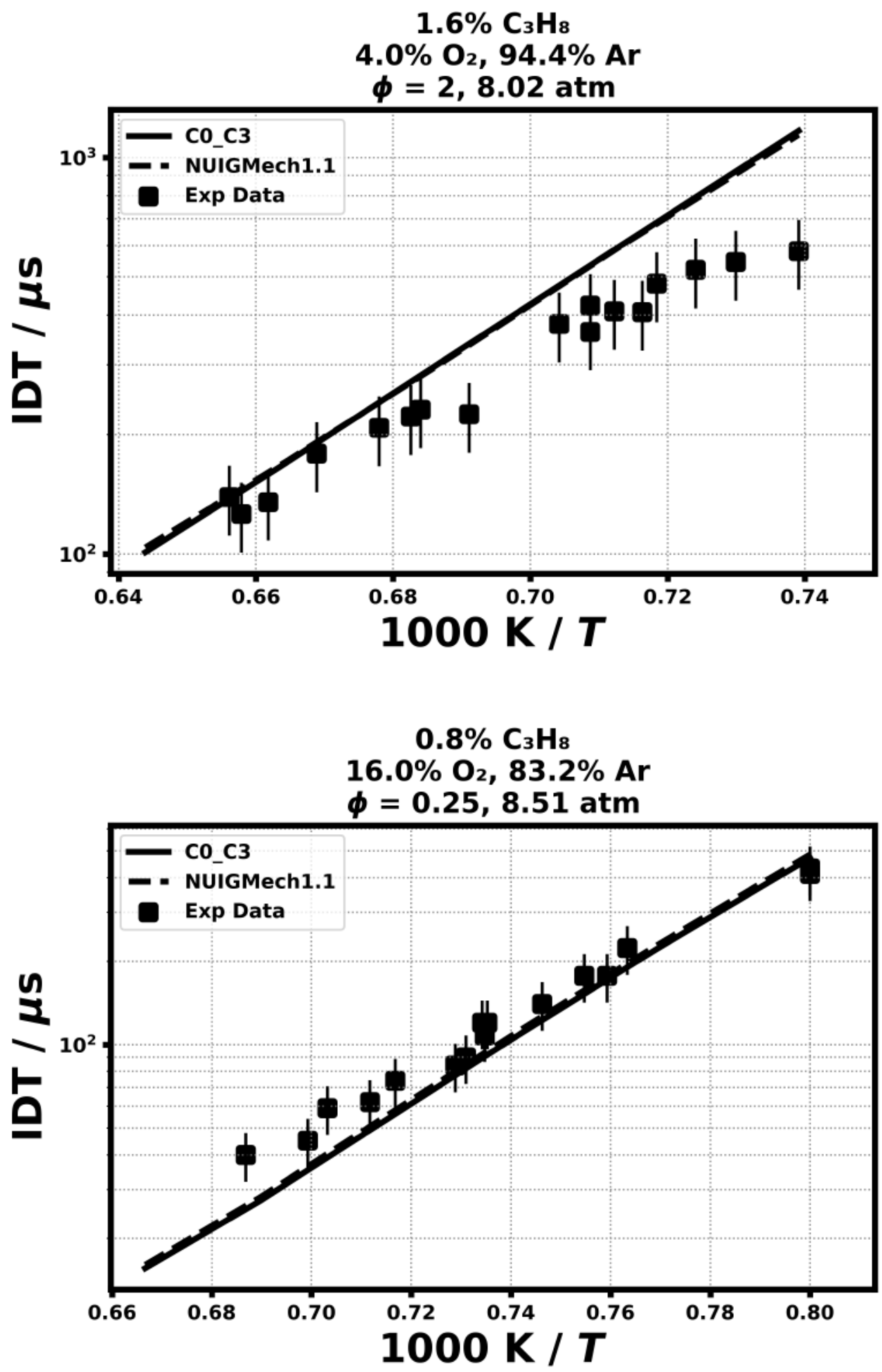


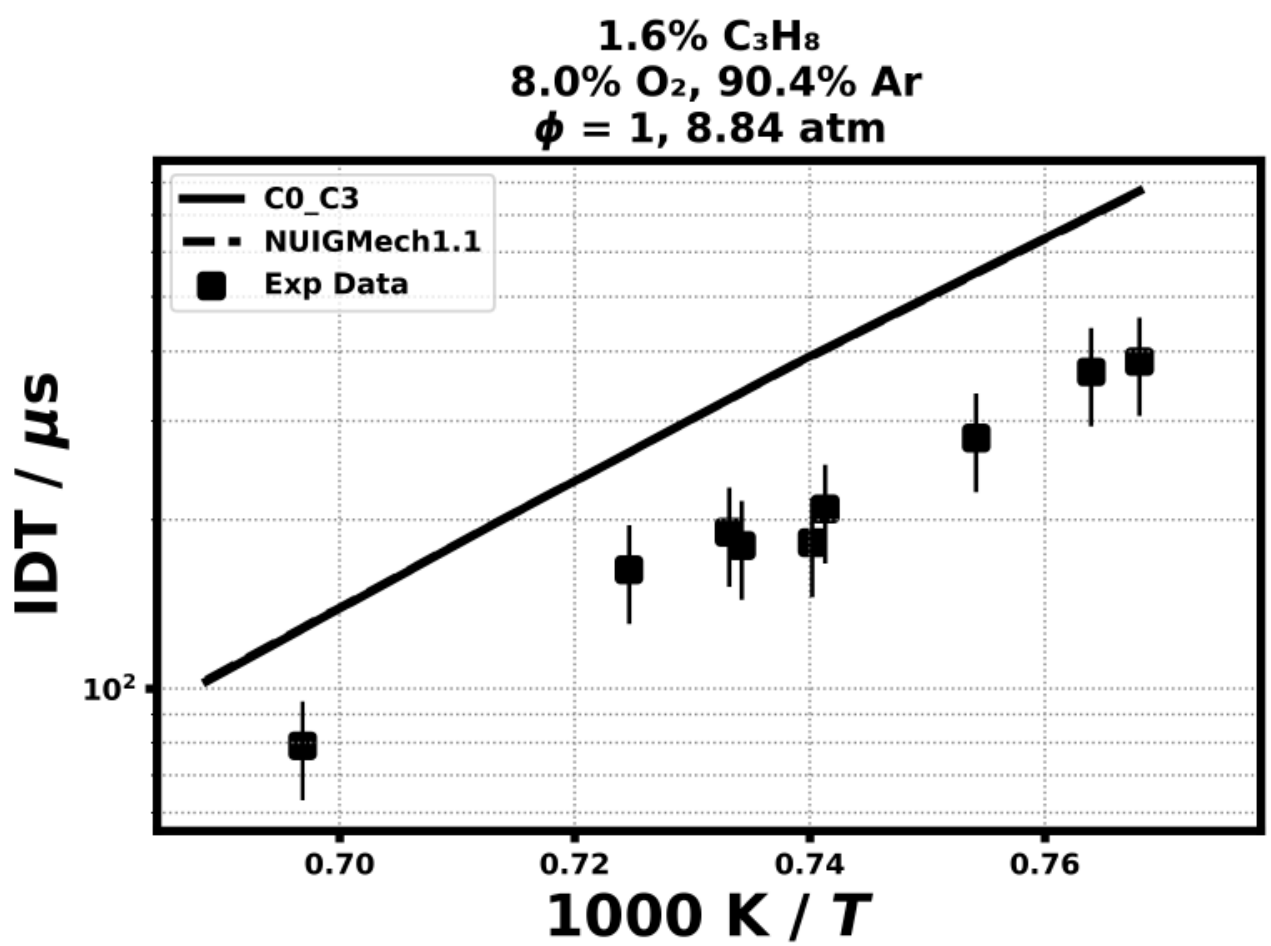

8.2) Herzler, J., Jerig, L., \& Roth, P. Combustion science and technology, 176(10) (2004) $1627-1637$.

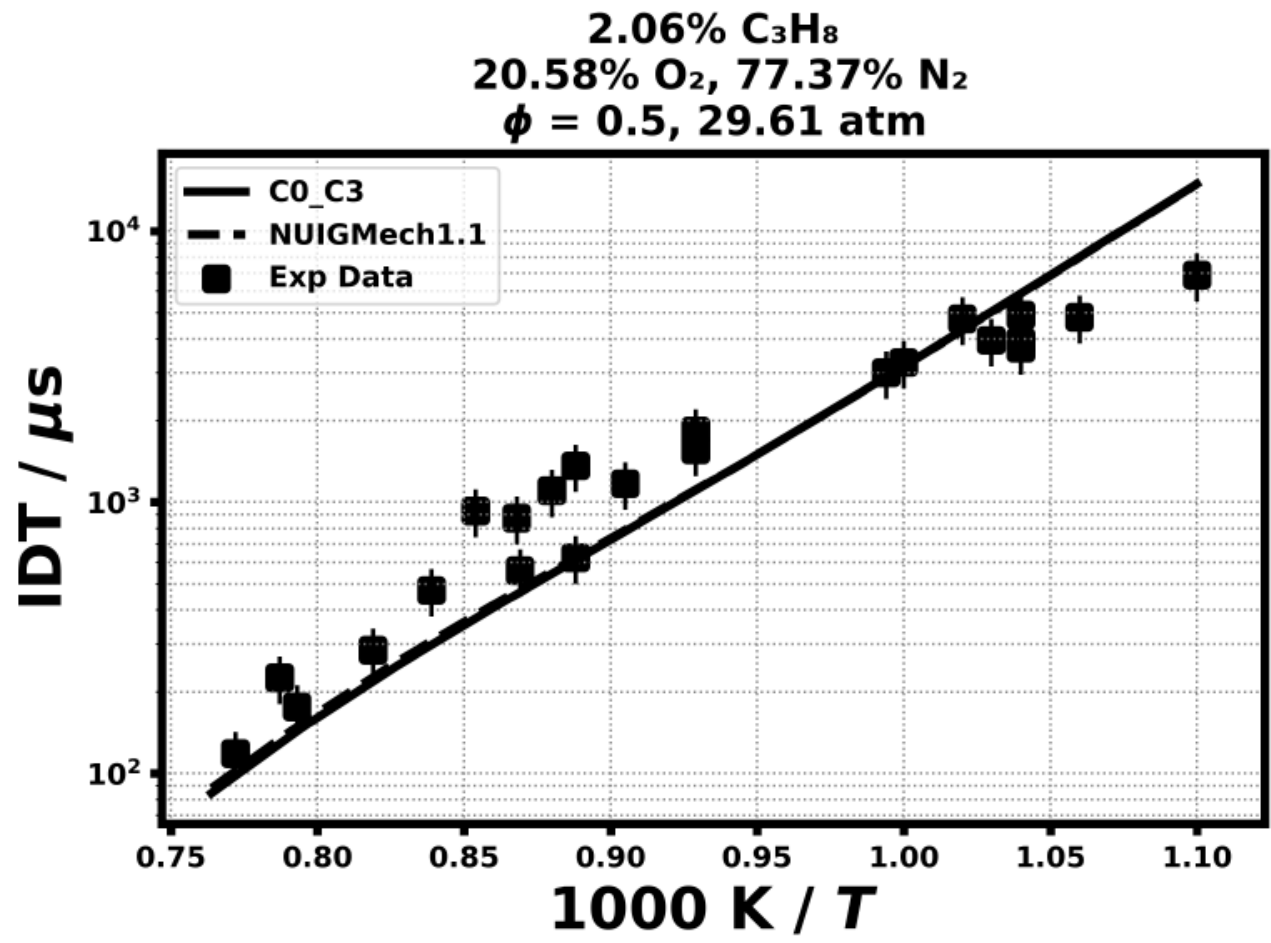


8.4) Hu, E., Zhang, Z., Pan, L., Zhang, J., \& Huang, Z., Energy \& fuels, 27(7), (2013) 4007-4013.

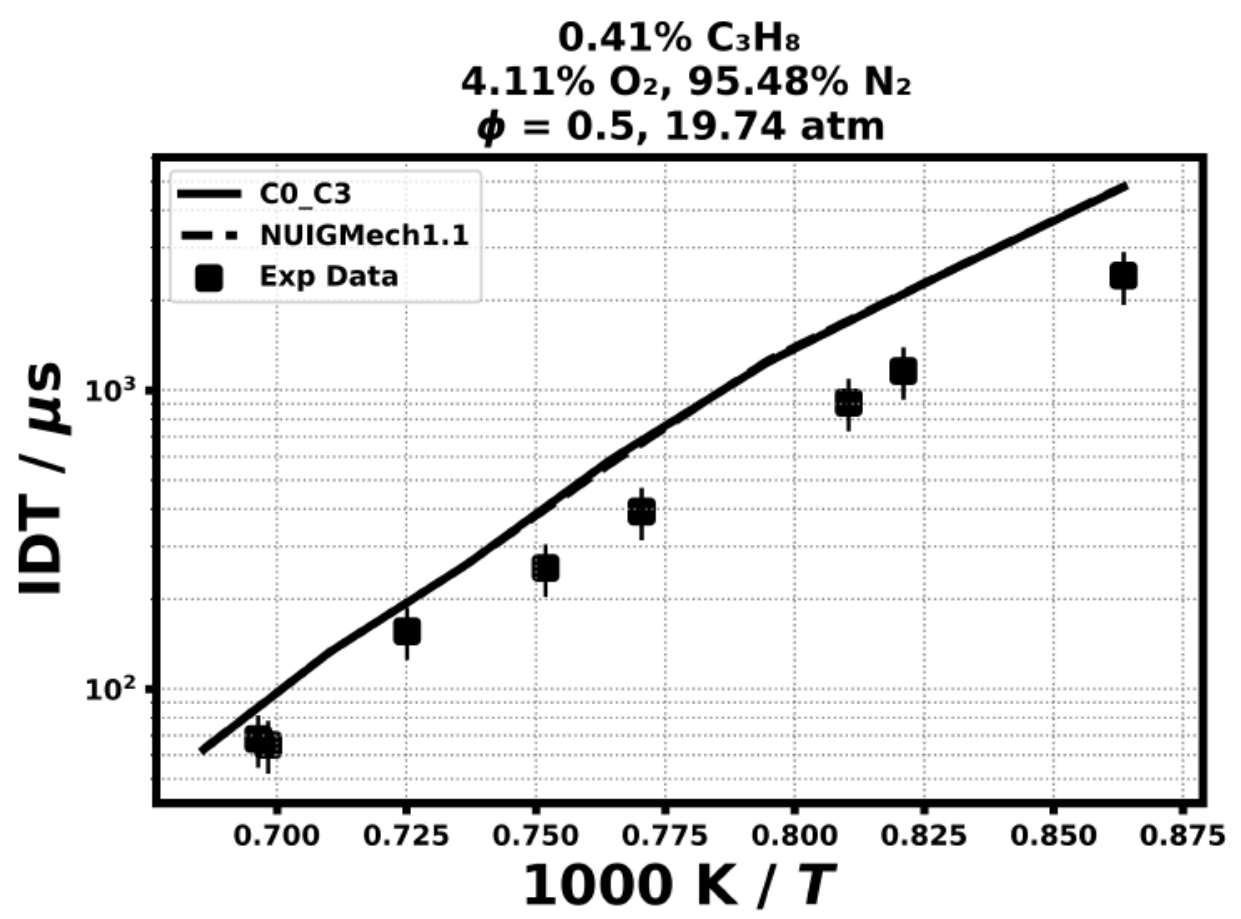

8.5) Kim, G. Y., \& Sin, G. S., Bulletin of the Korean Chemical Society, 22 (2001) 303-307.

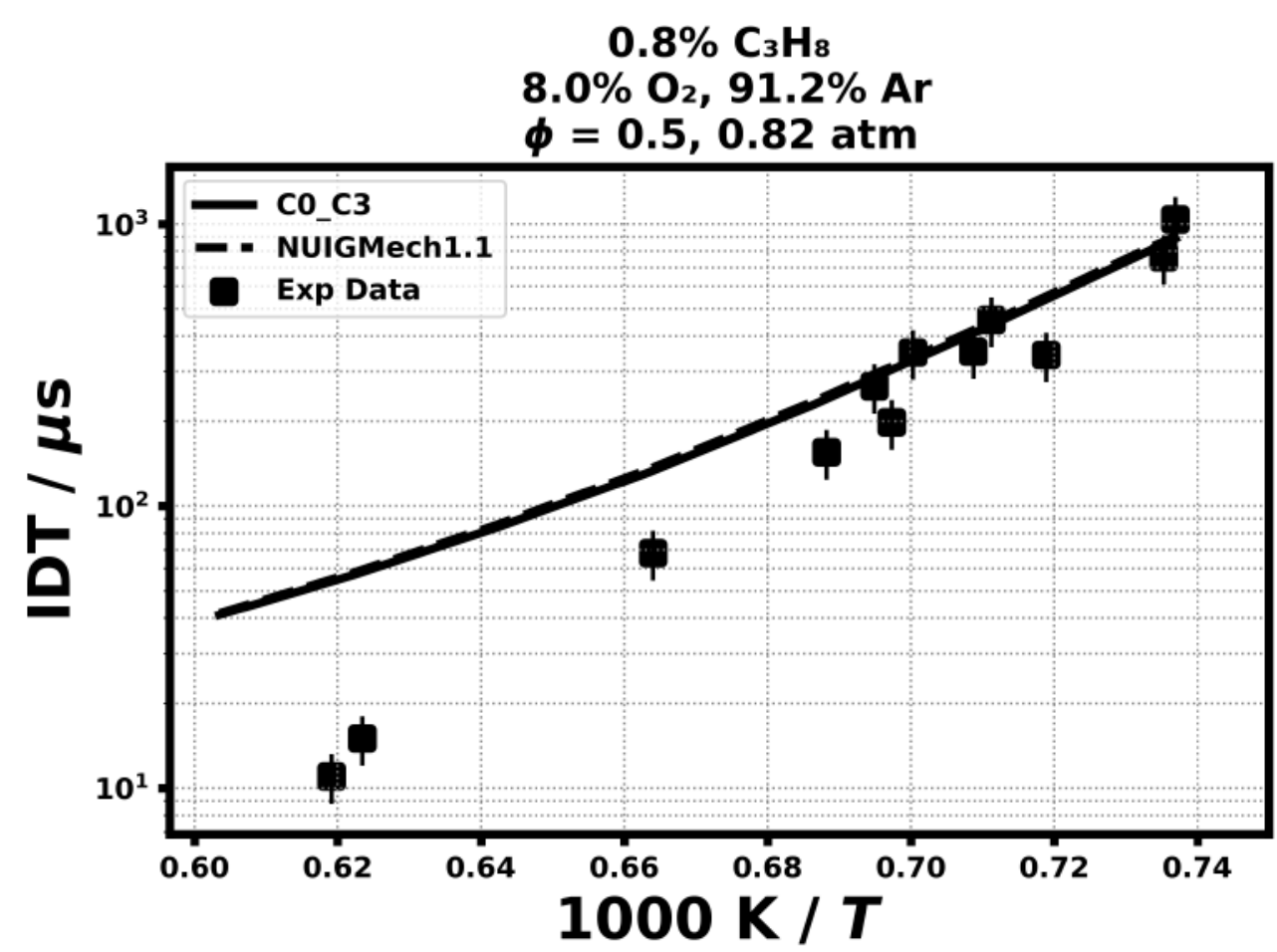



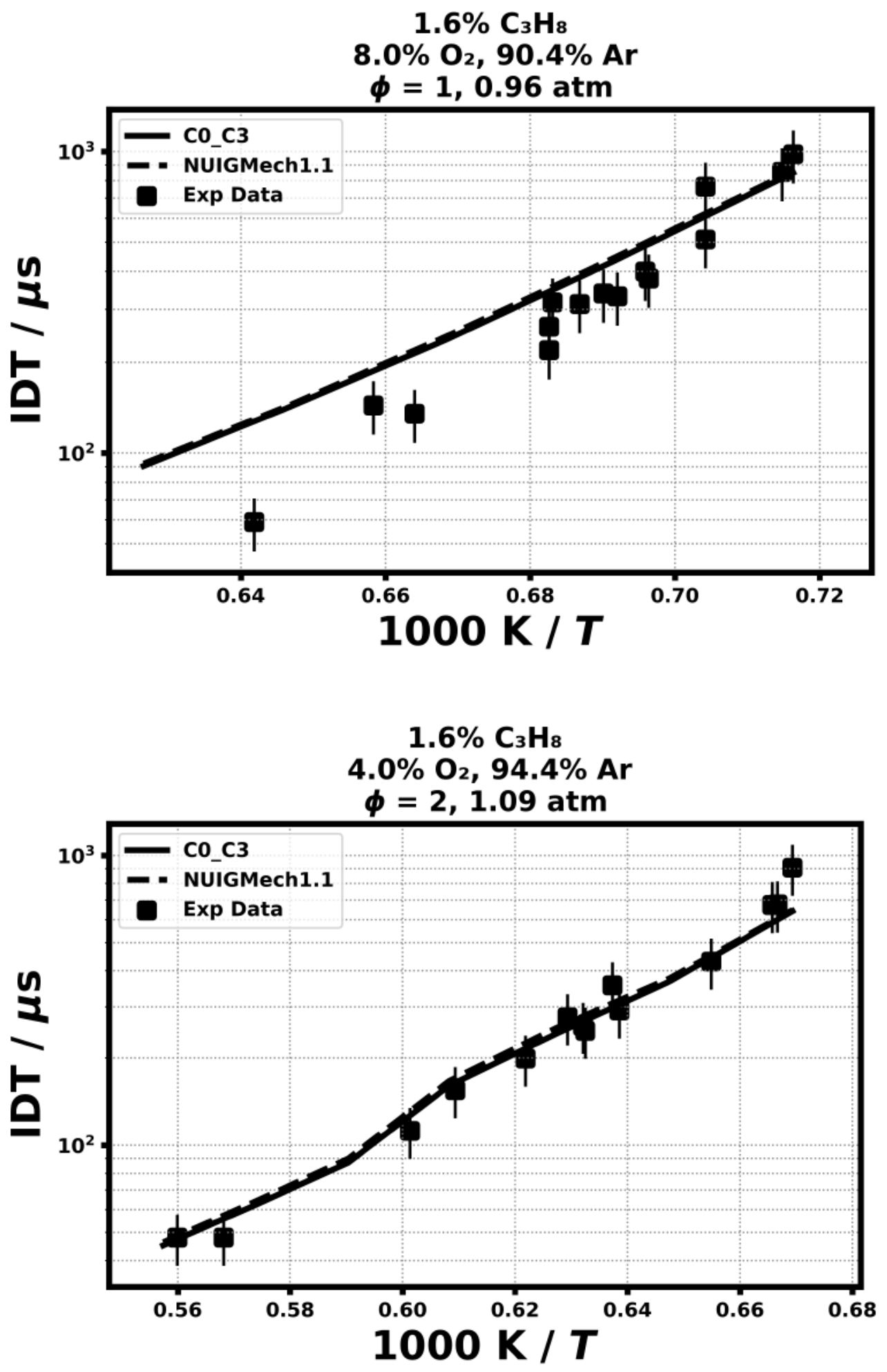

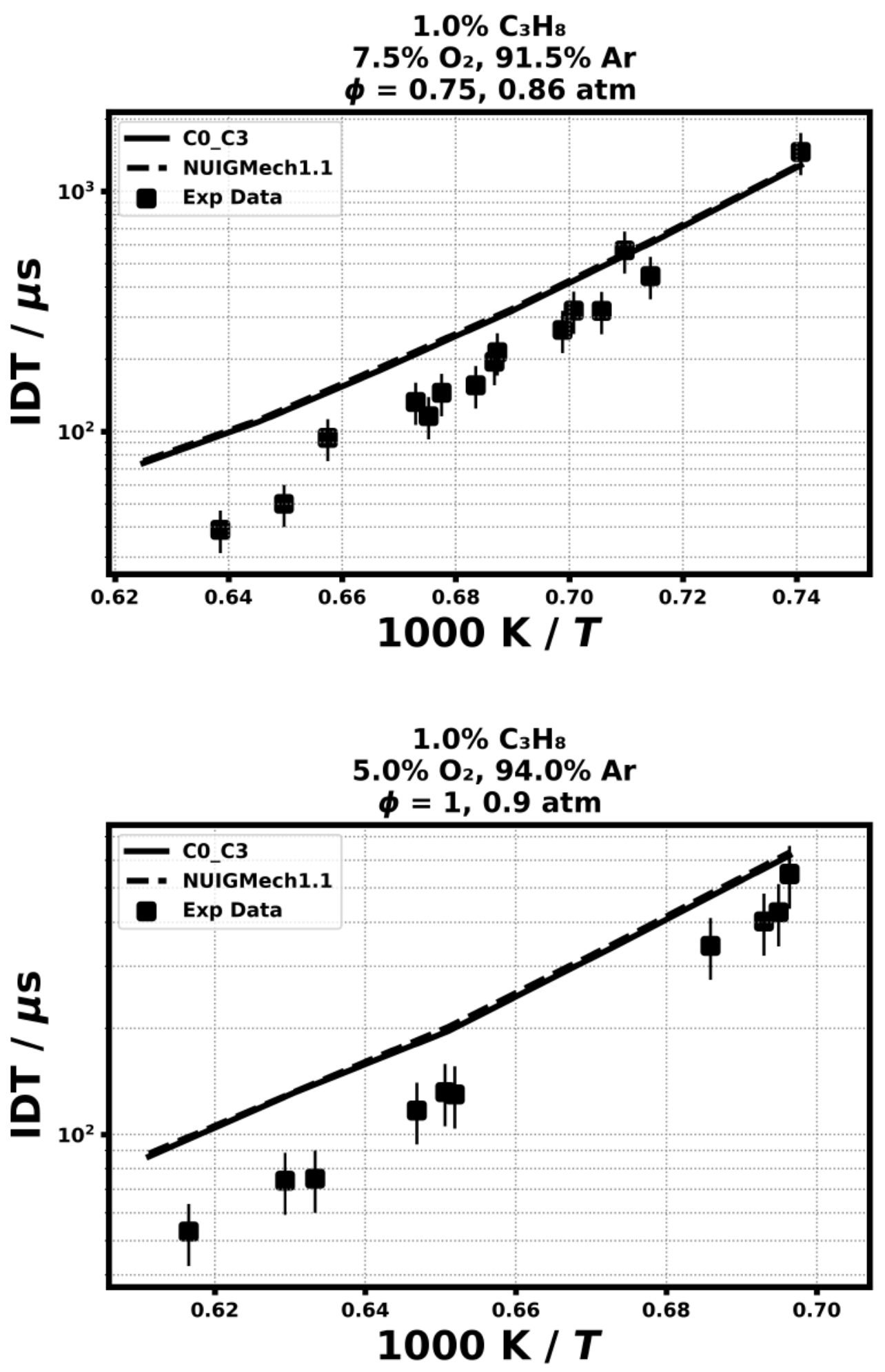

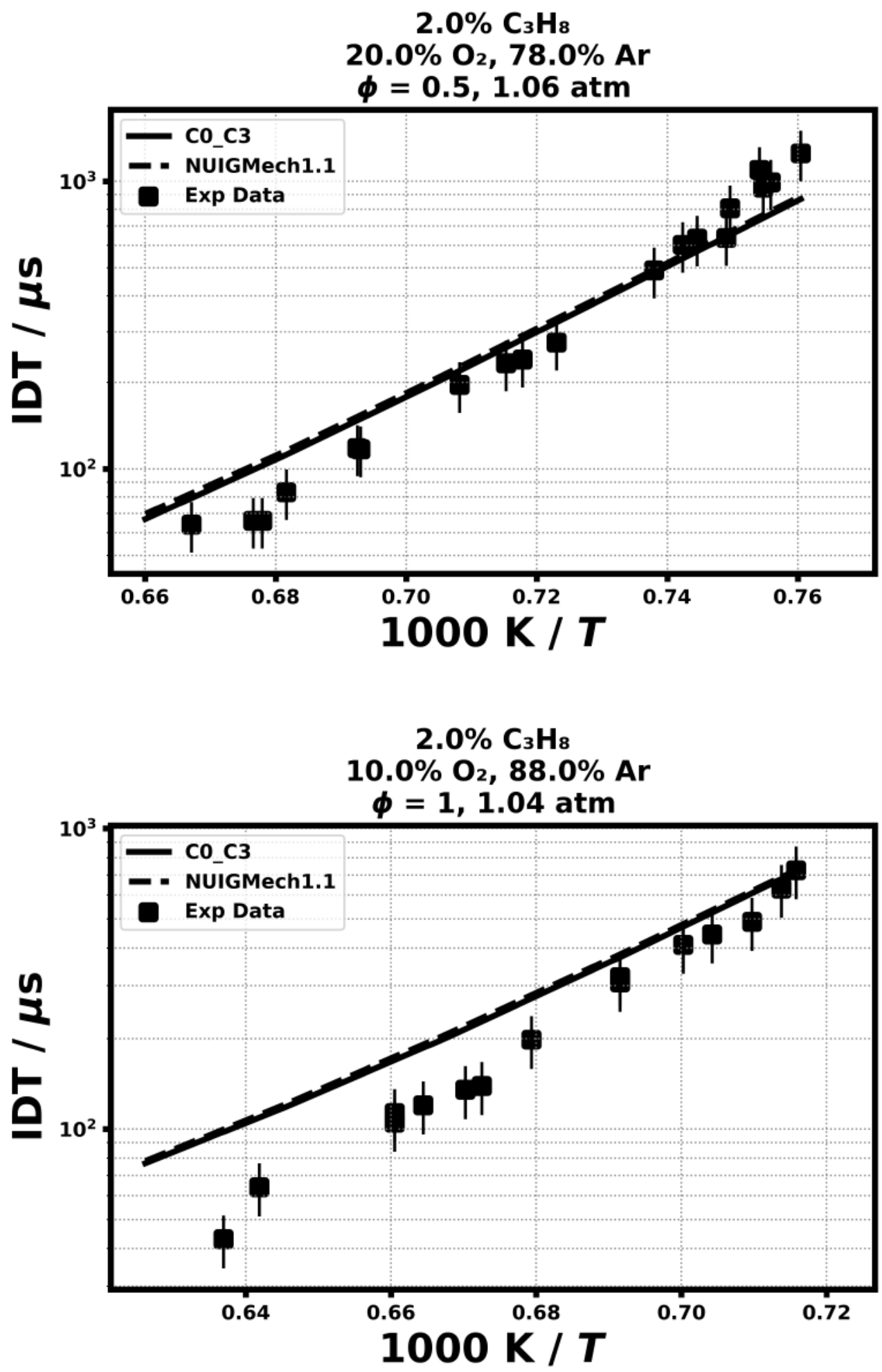

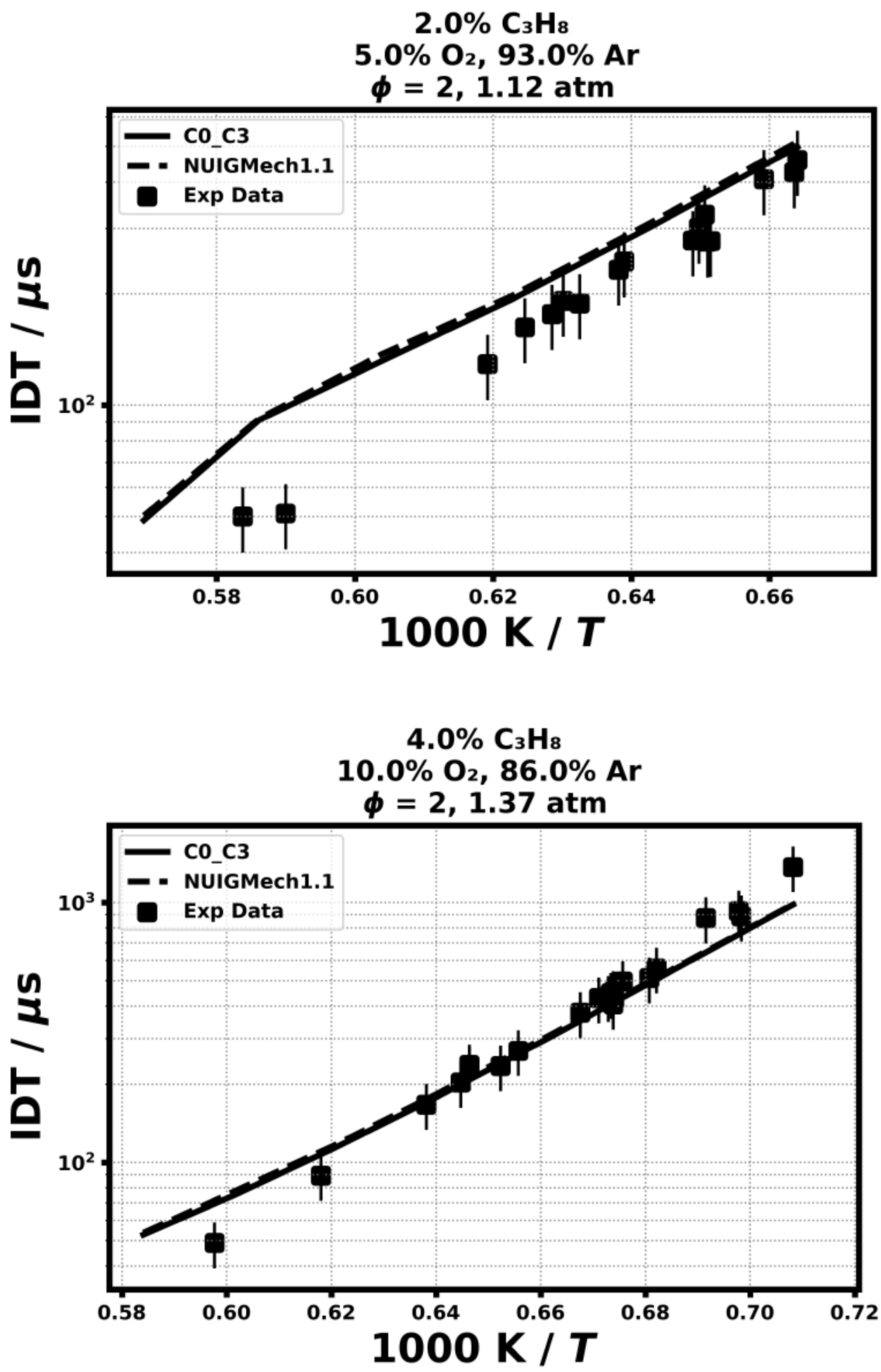
8.6) Qin, Z., Lissianski, V. V., Yang, H., Gardiner, W. C., Davis, S. G., \& Wang, H., Proceedings of the Combustion Institute, 28(2) (2000) 1663-1669.
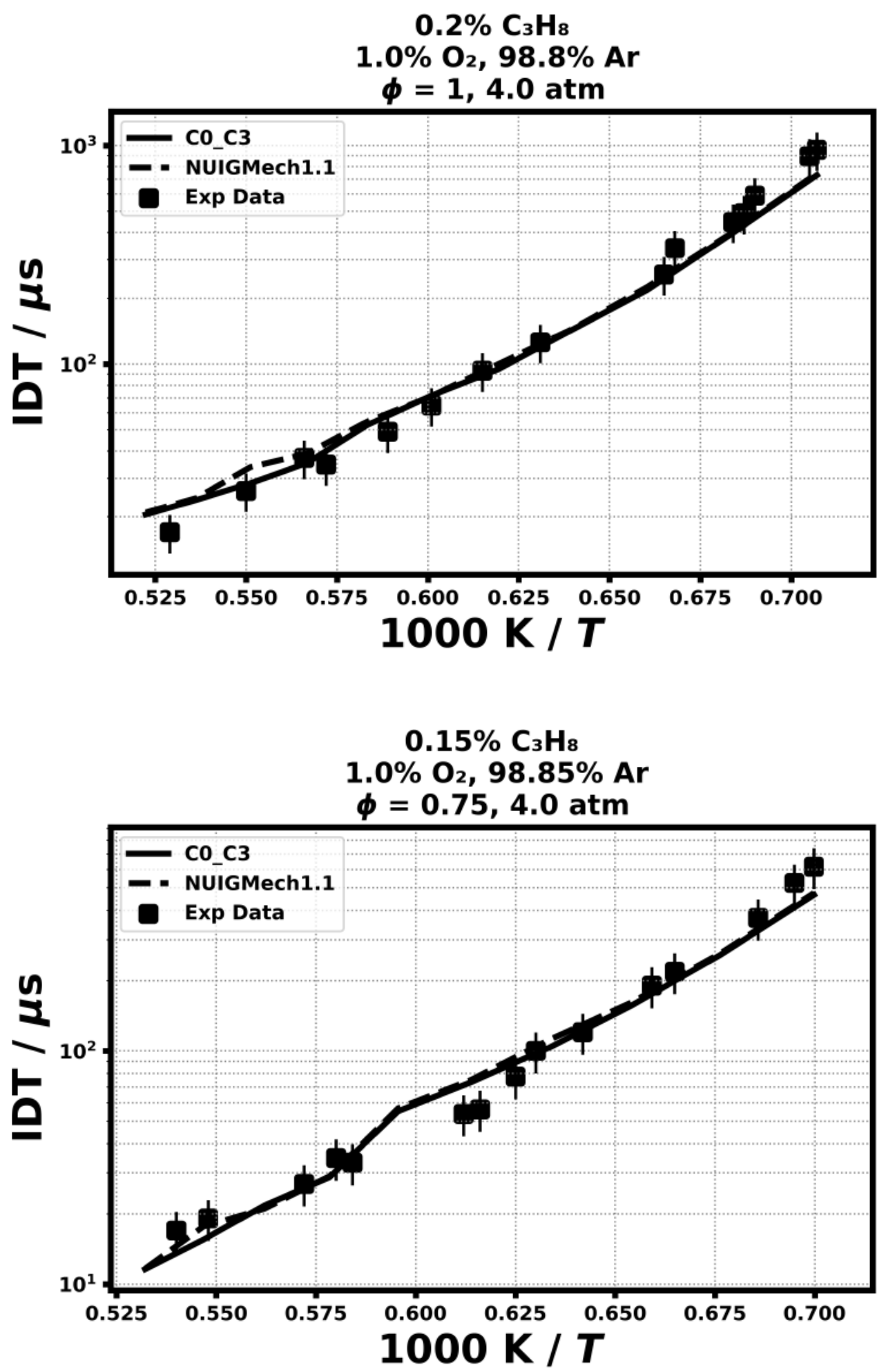


\section{RCM Ignition delay times}

8.7) Ramalingam, A., Panigrahy, S., Fenard, Y., Curran, H., \& Heufer, K. A. Combustion and Flame, 223 (2021) 361-375.

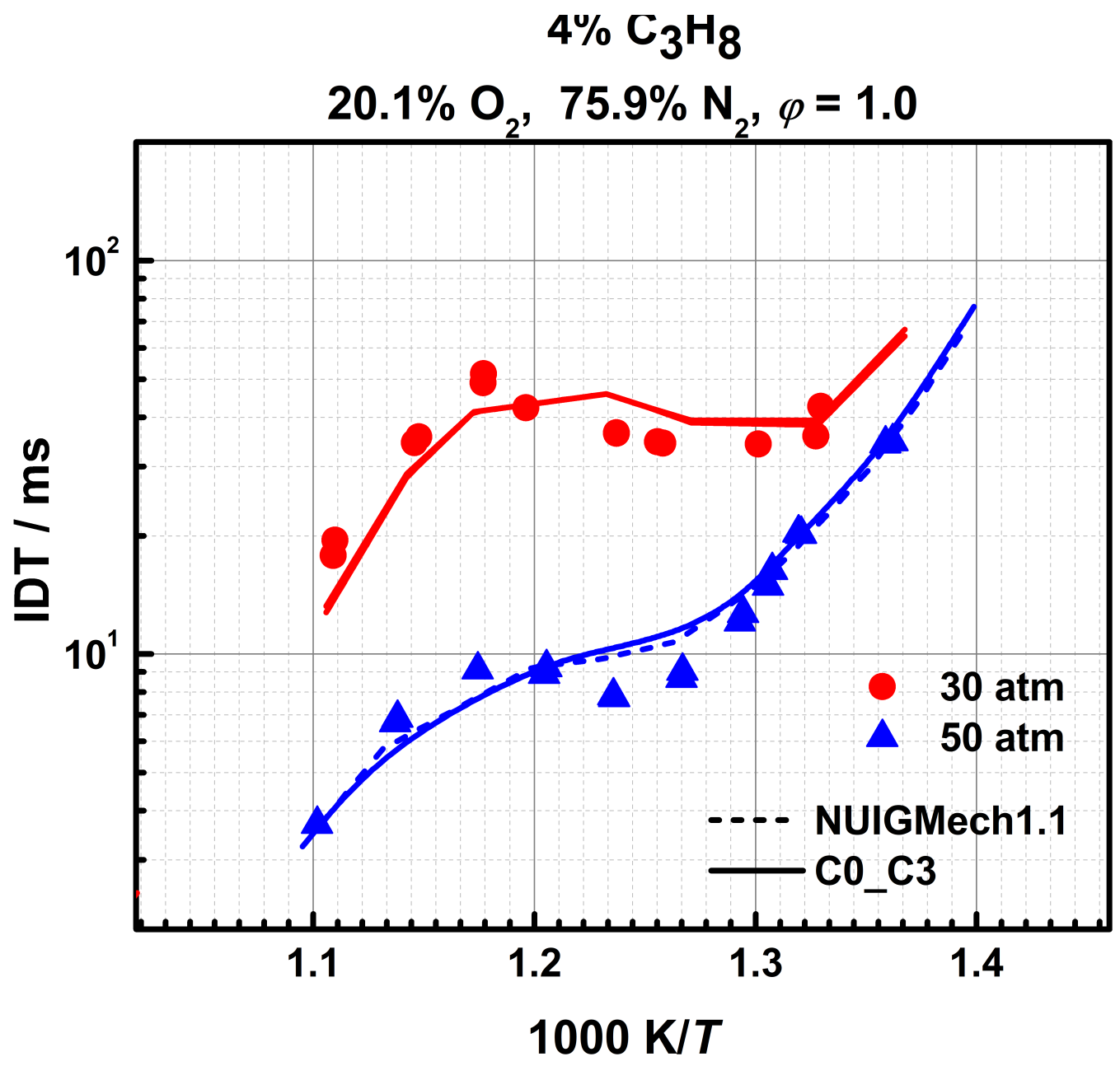




\section{Speciation in Jet-stirred reactor}

8.7) Dagaut, P., Luche, J., \& Cathonnet, M., Fuel, 80(7) (2001) 979-986.
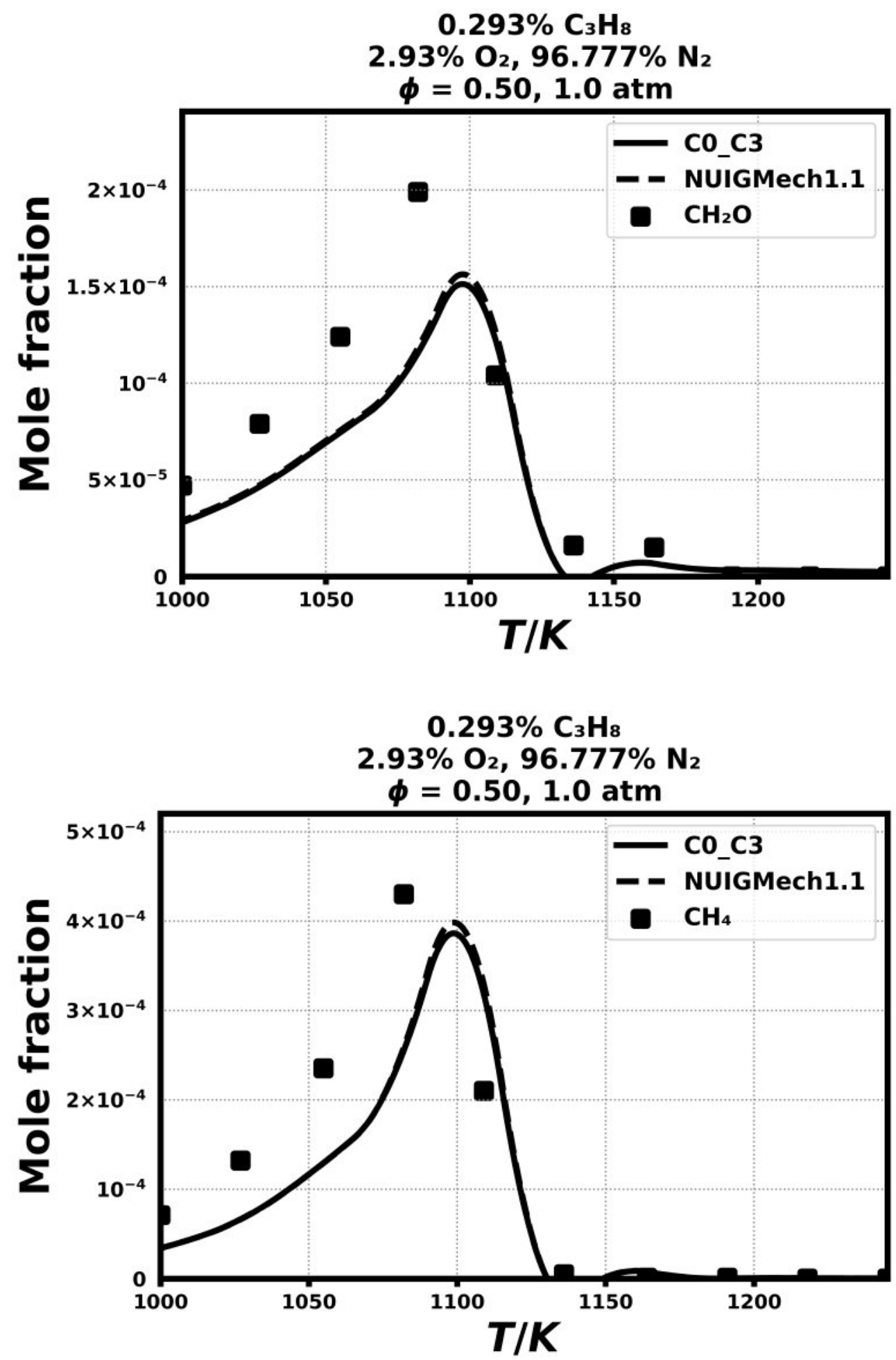

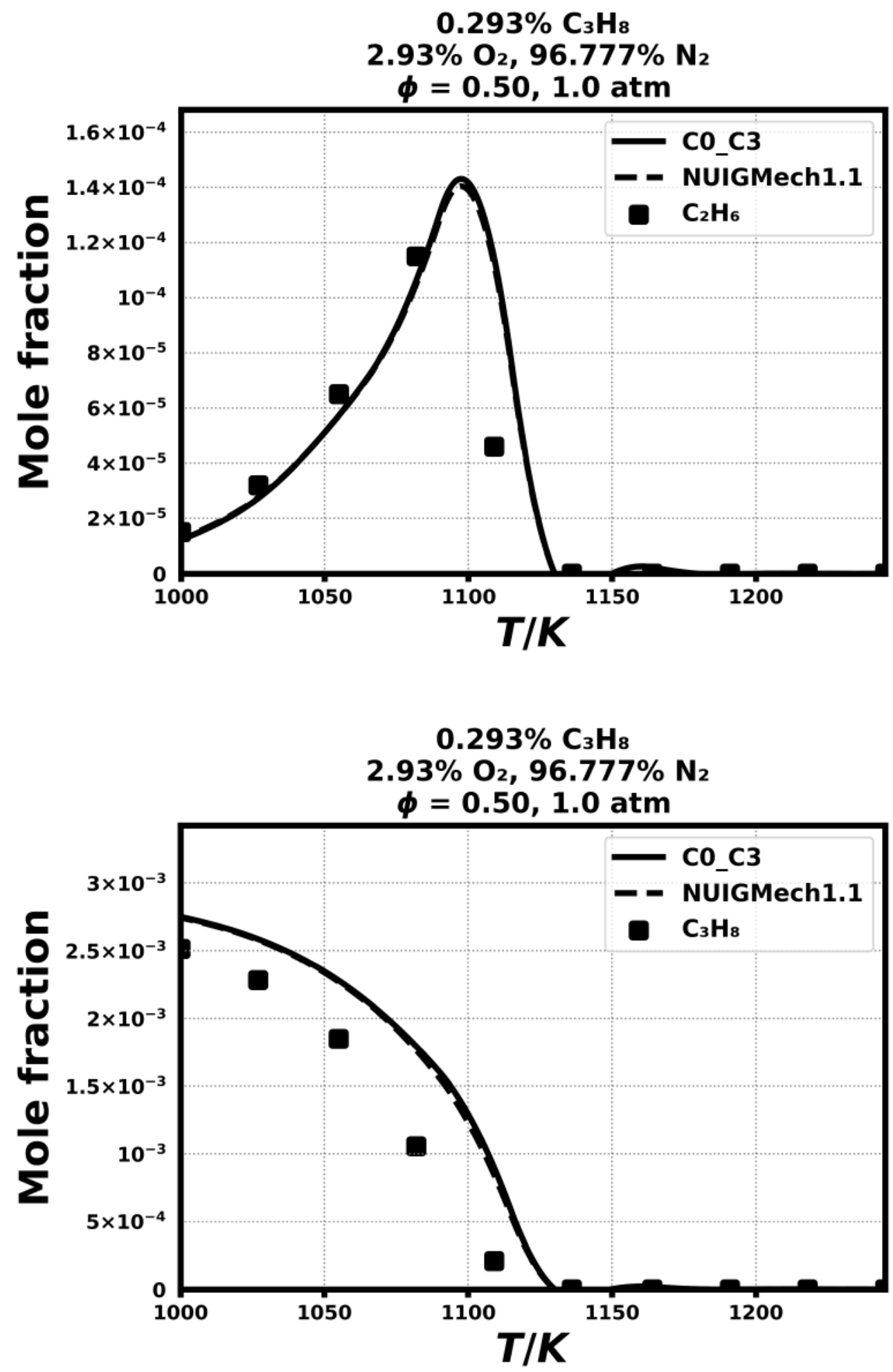

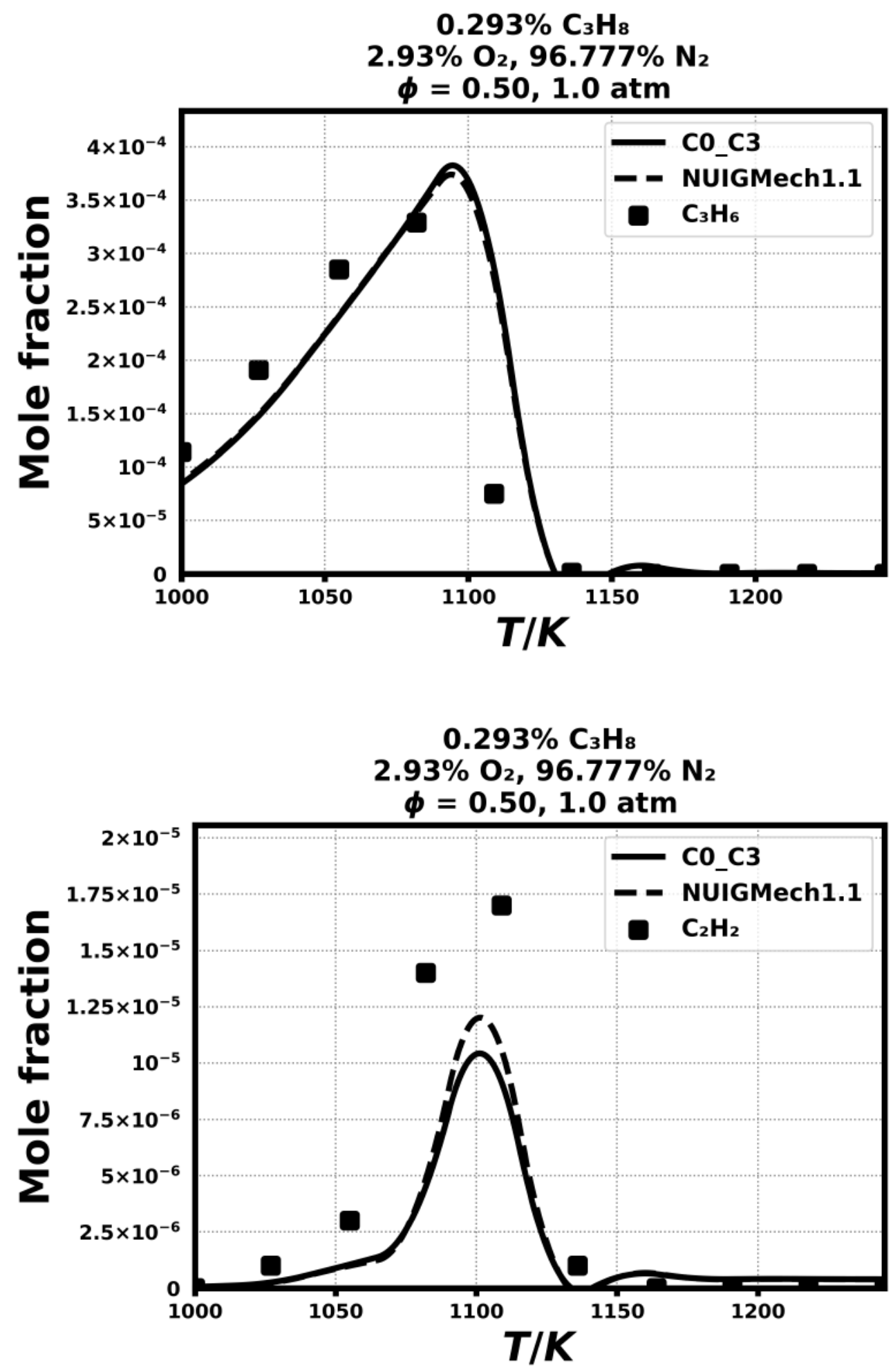

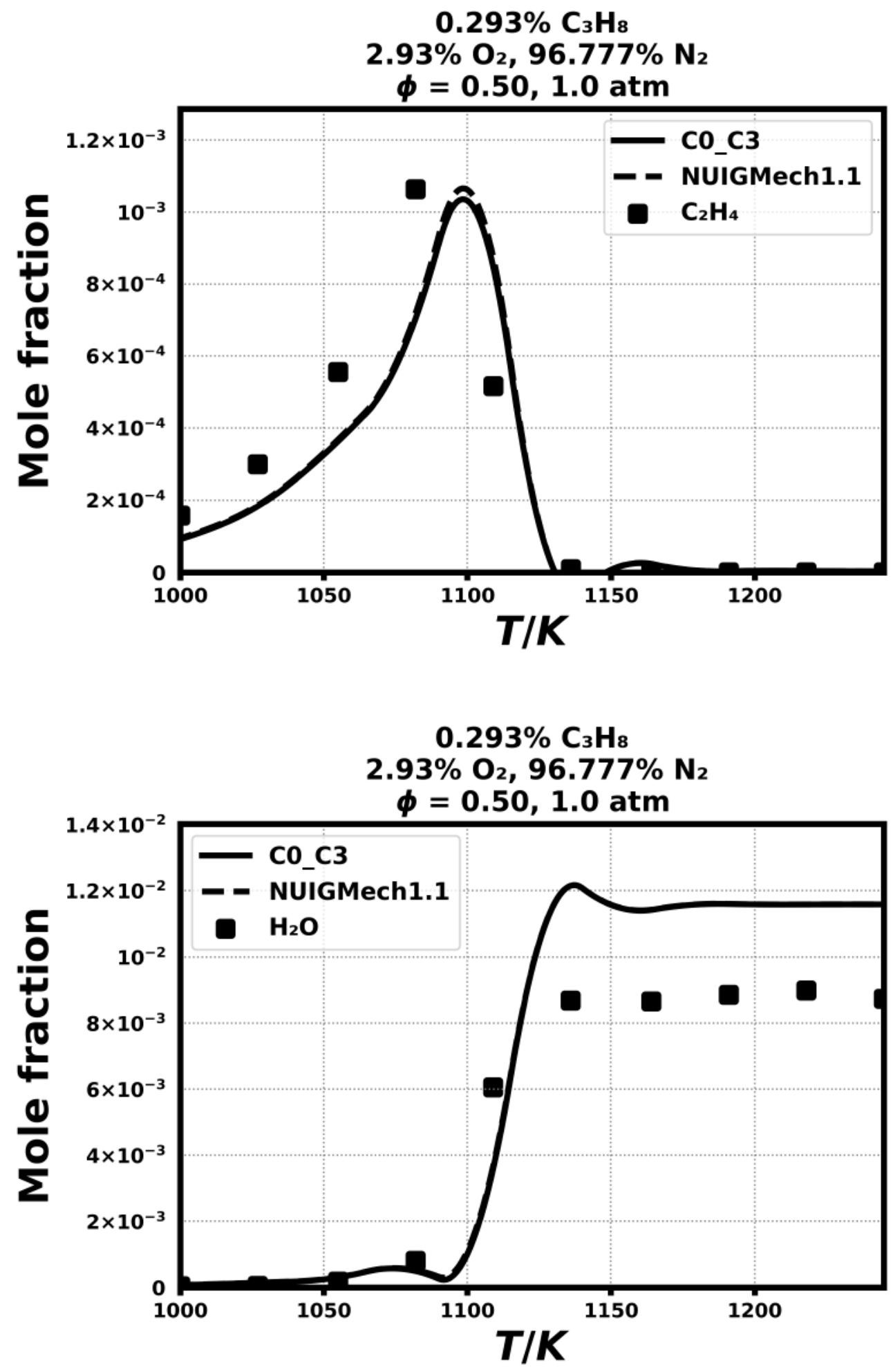

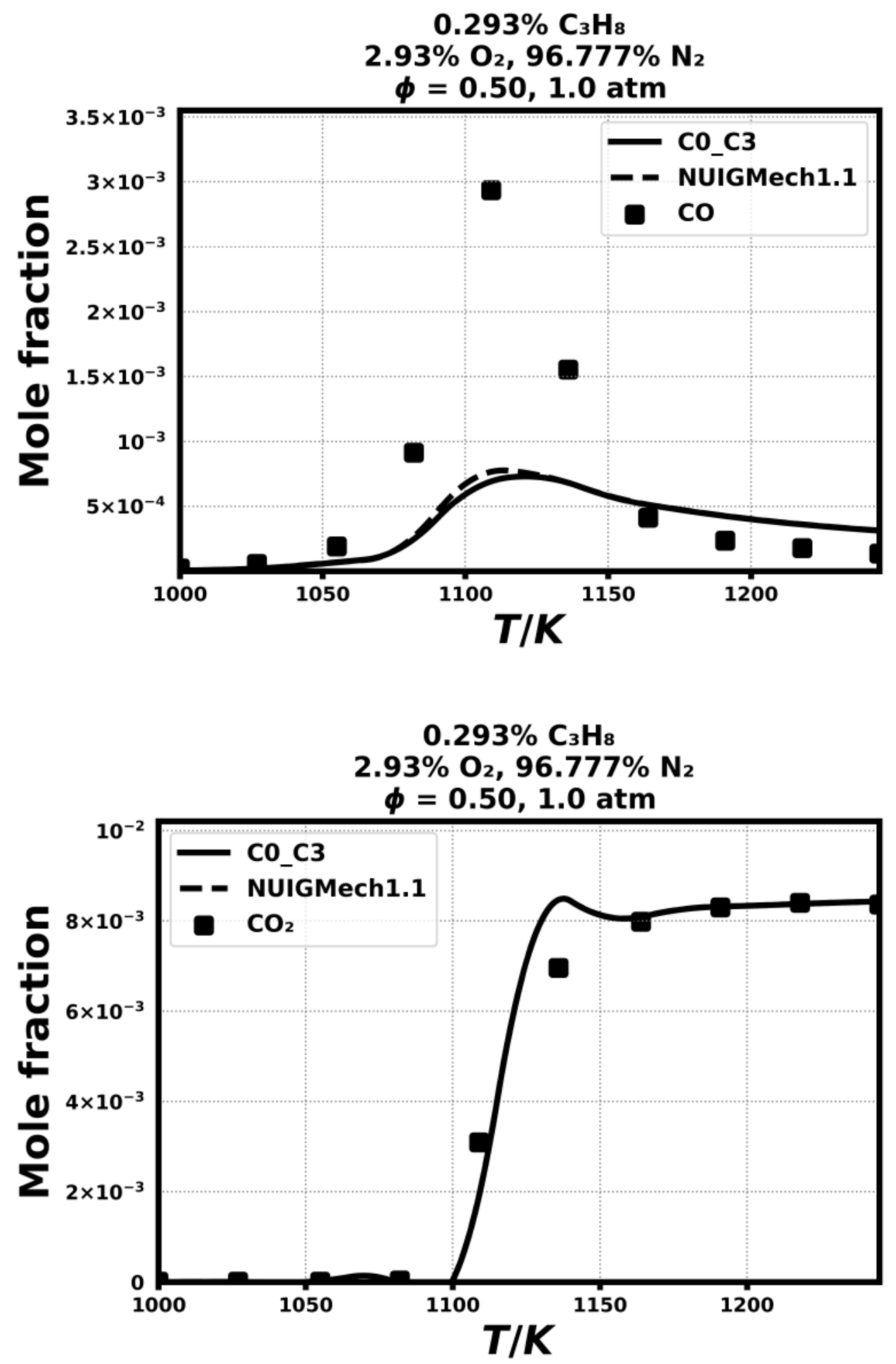

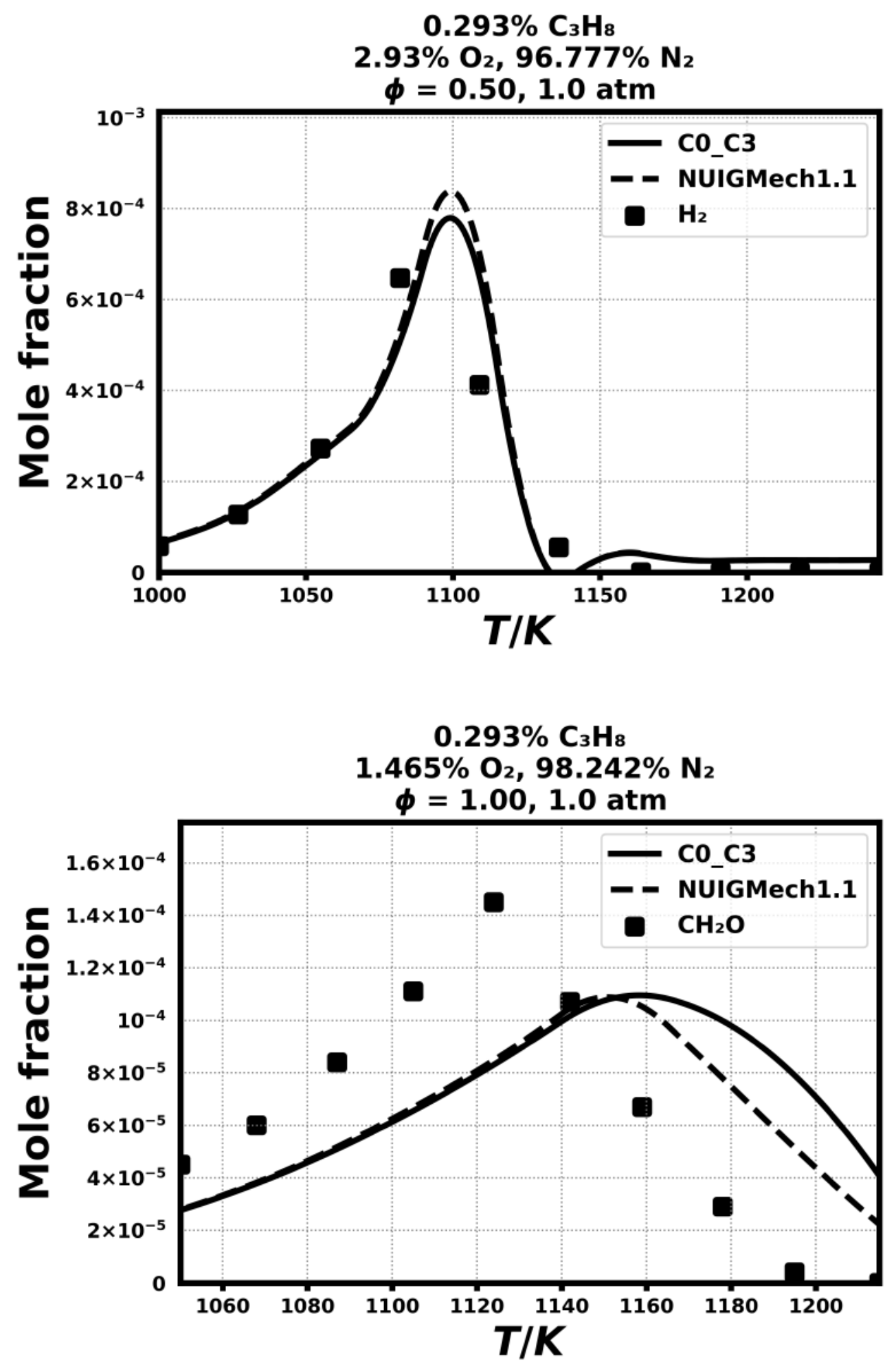

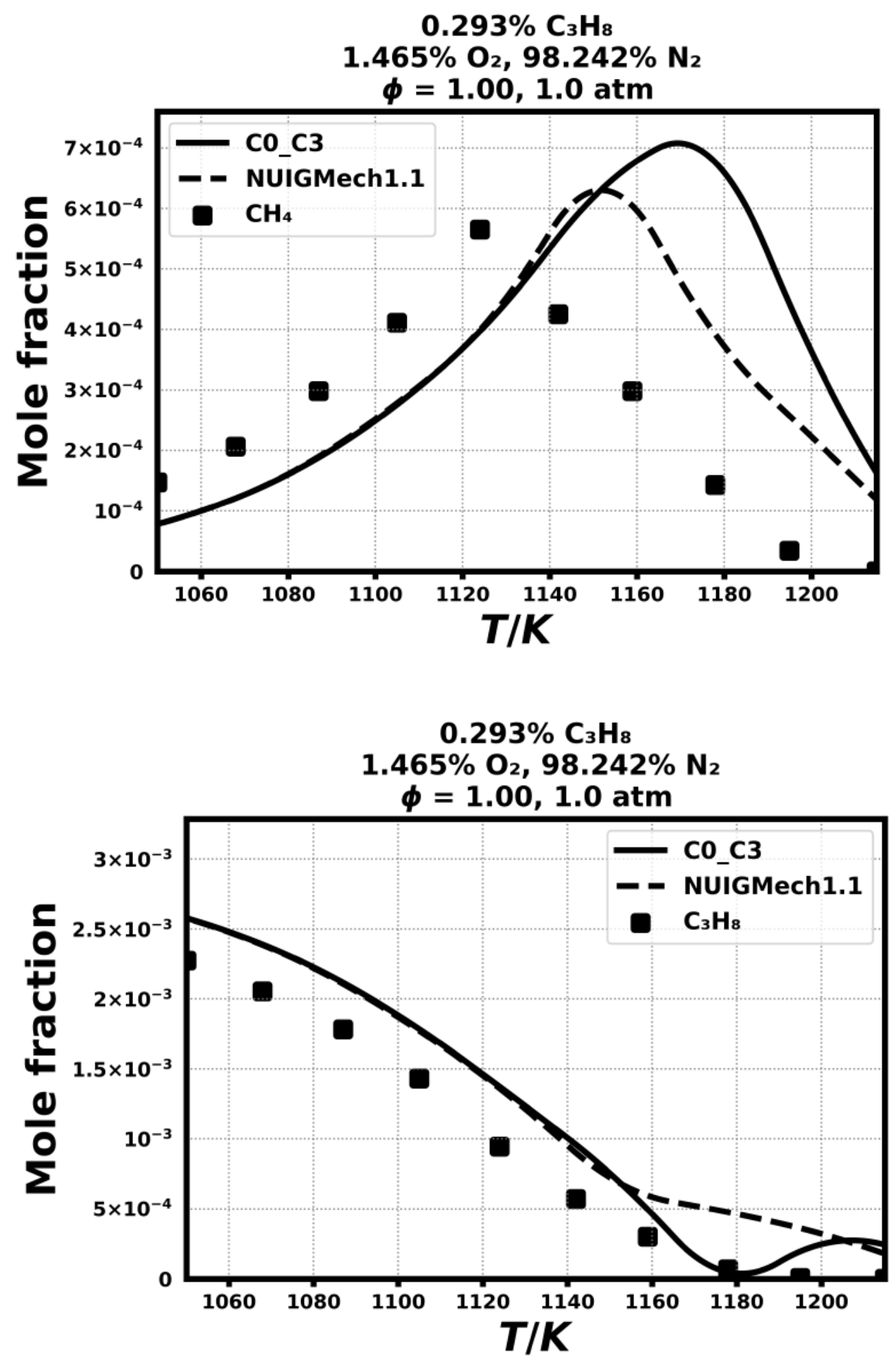

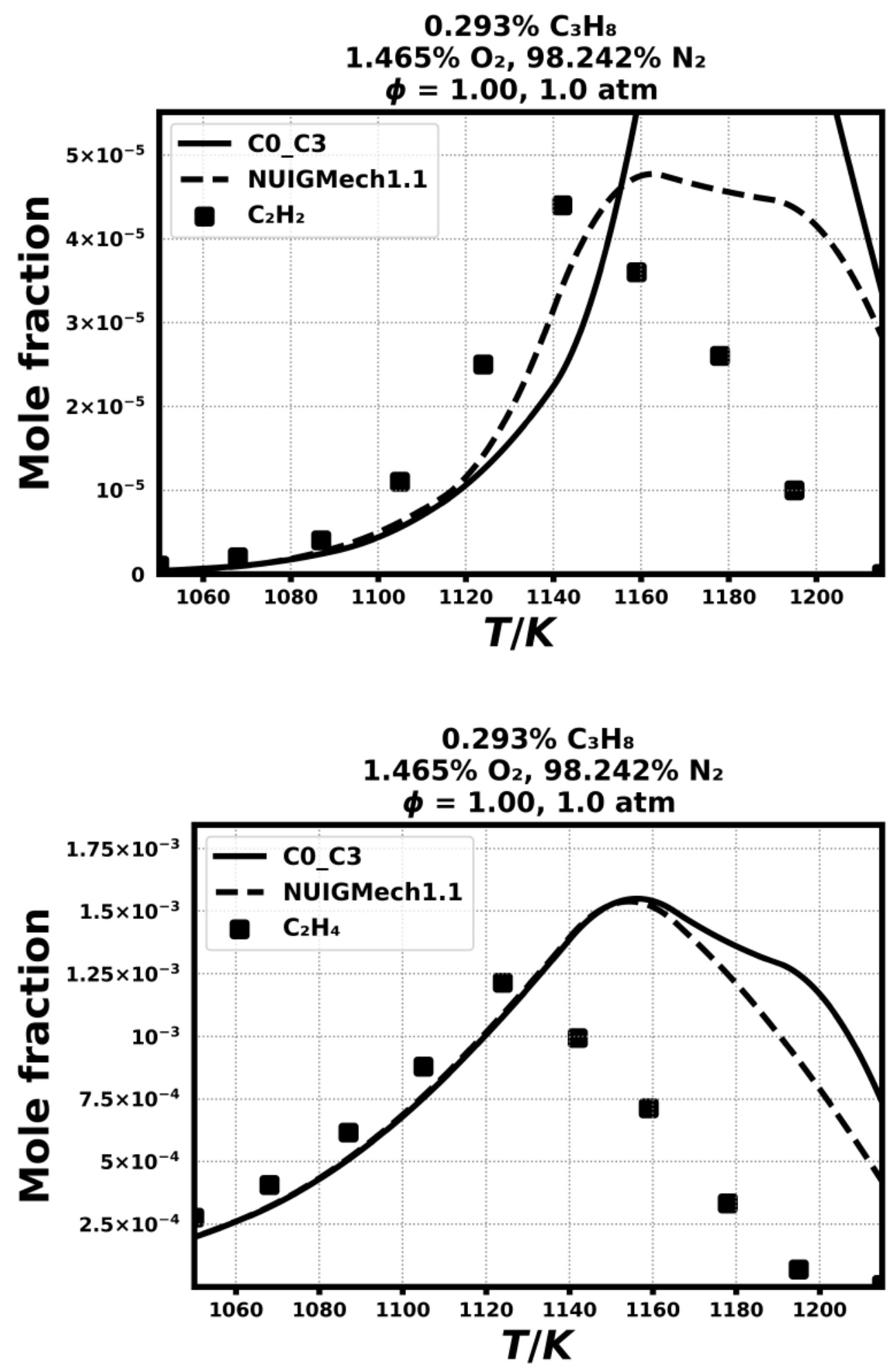

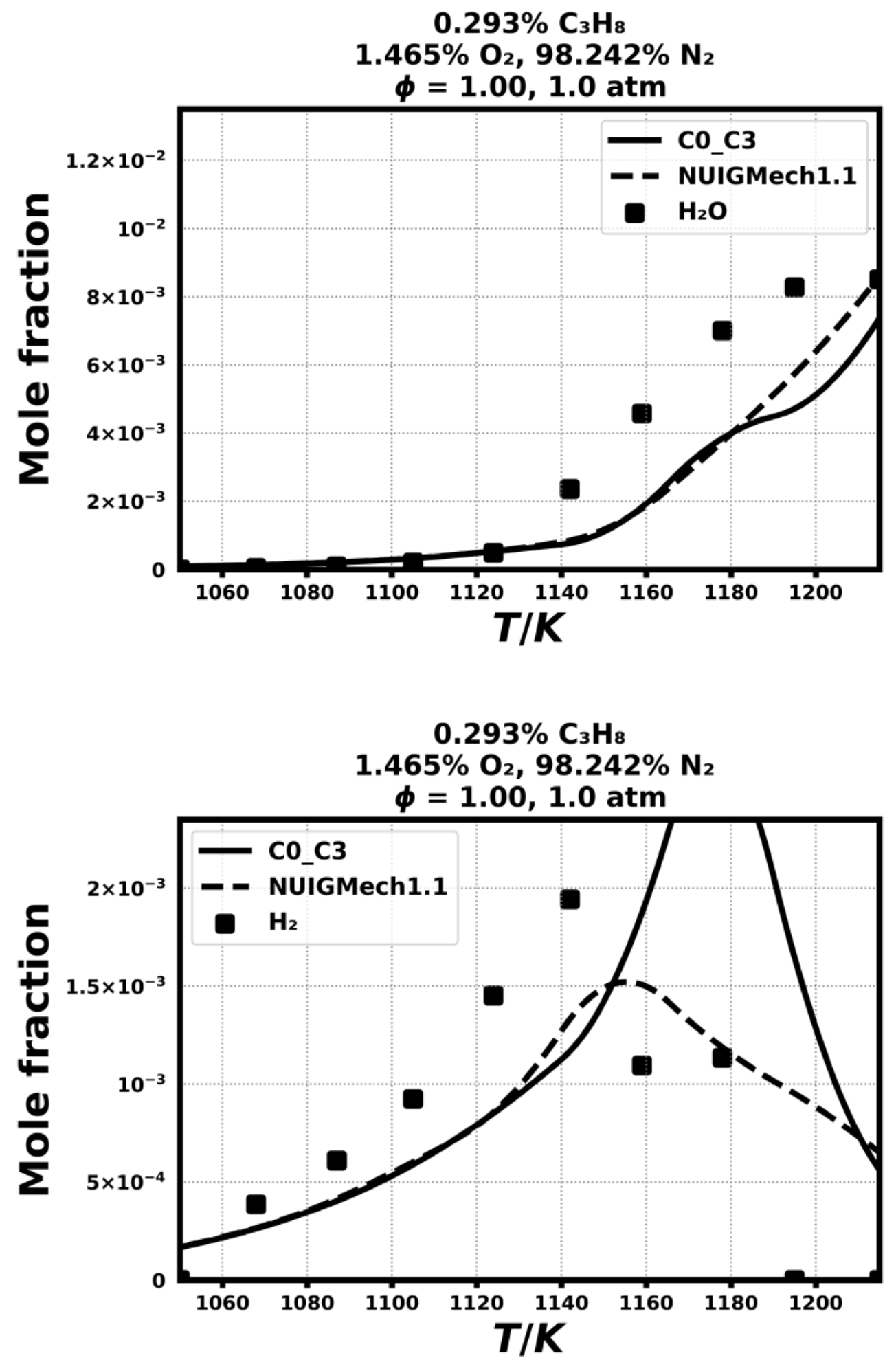

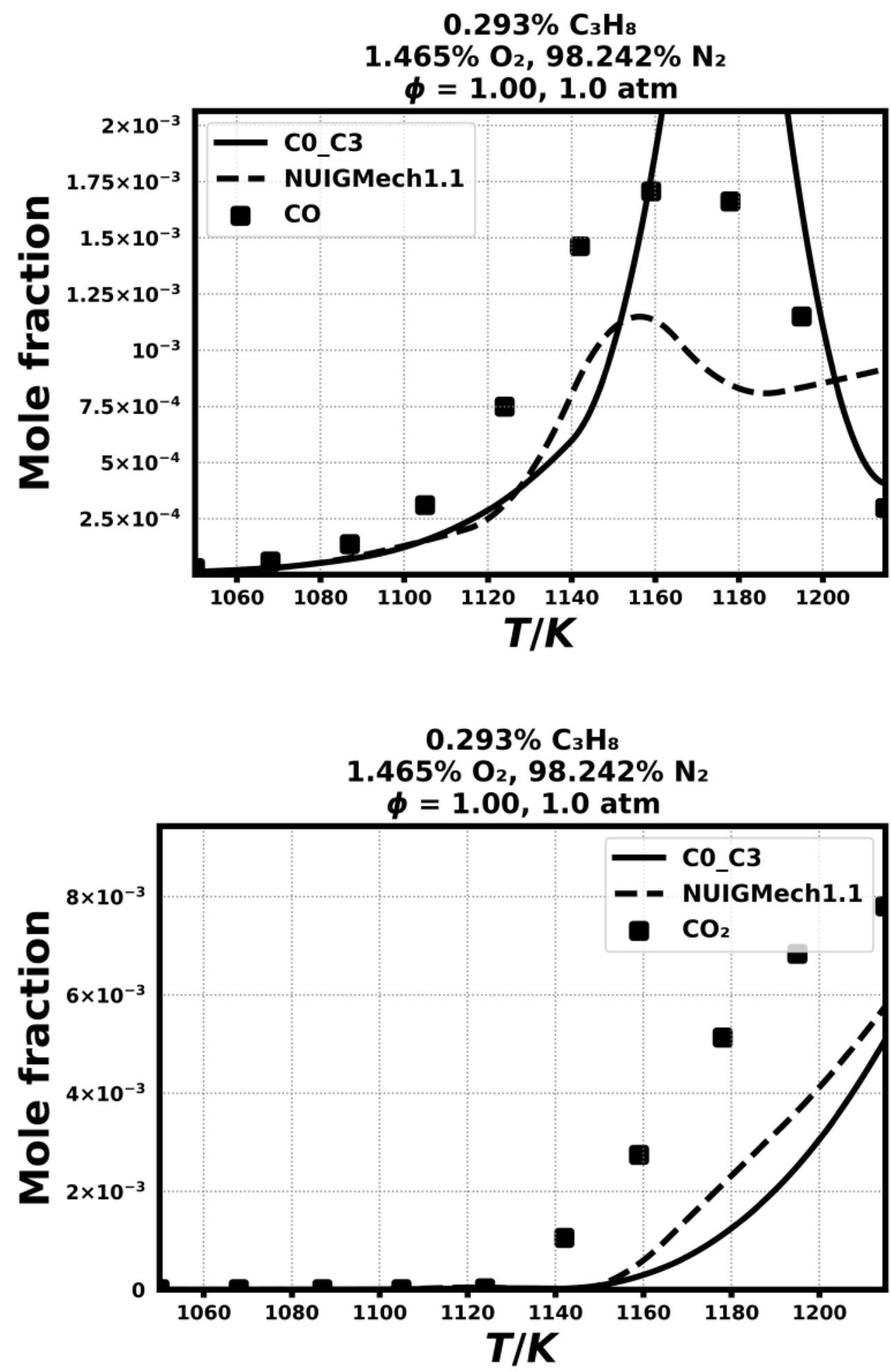

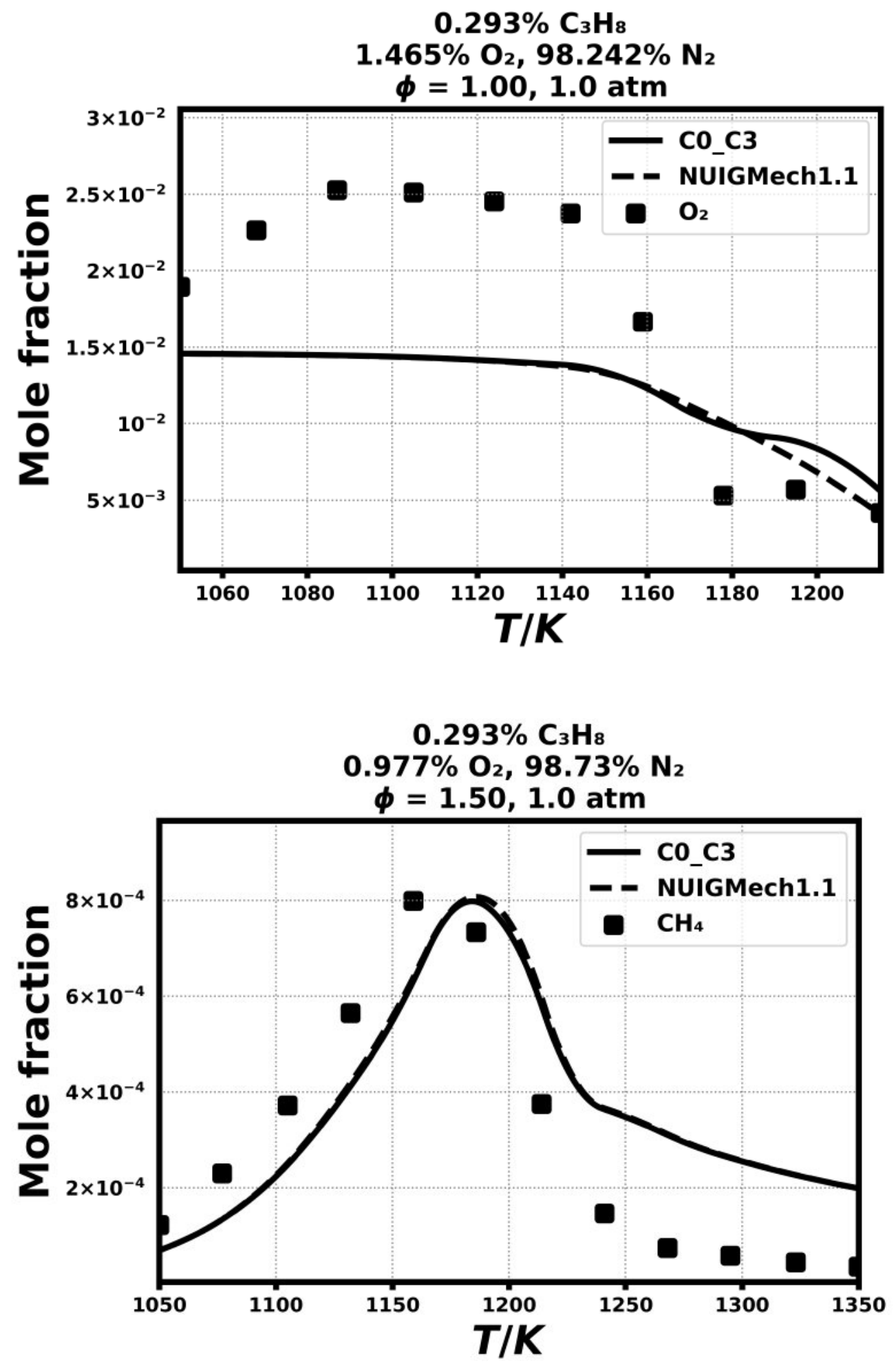

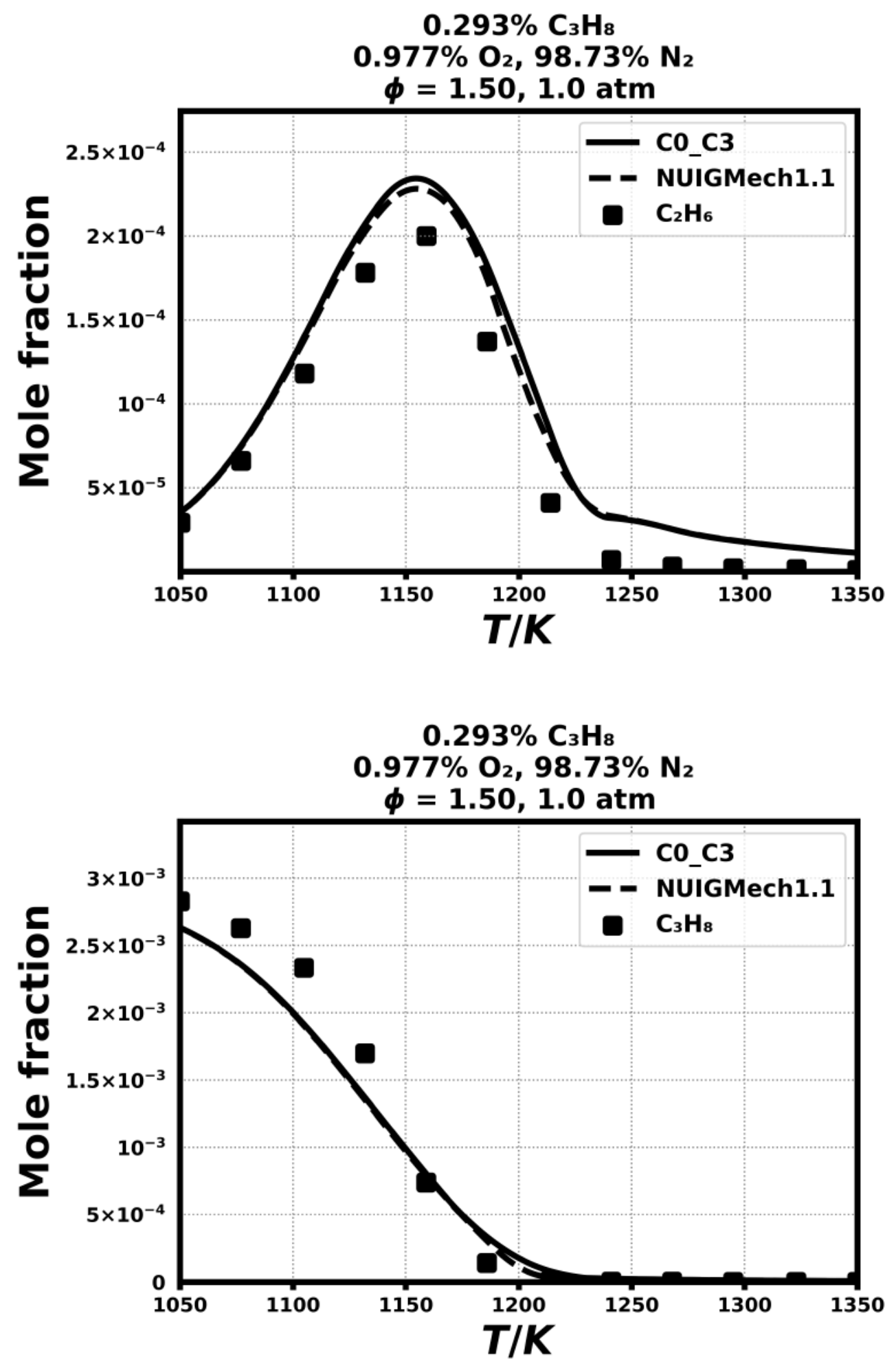

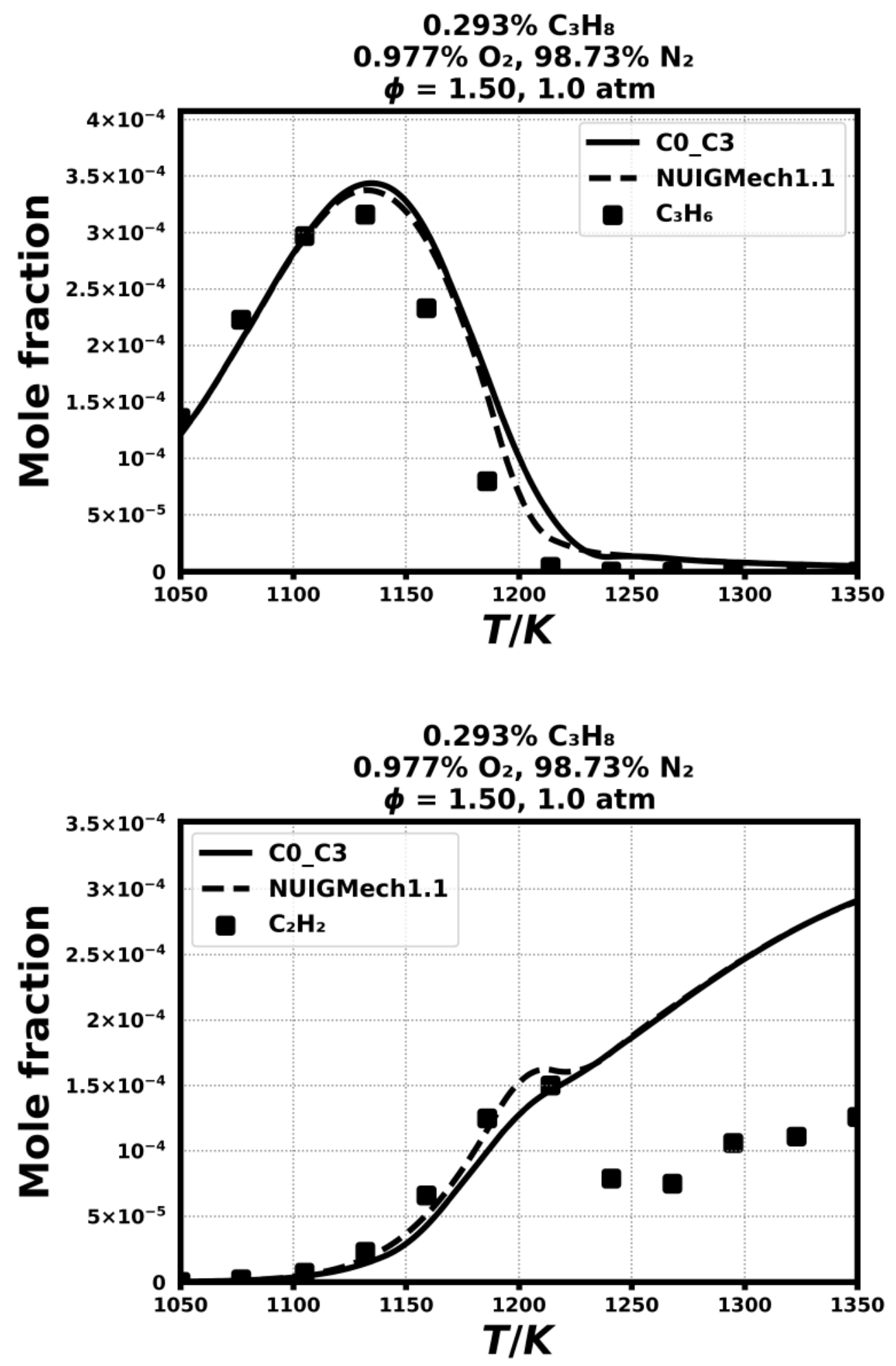

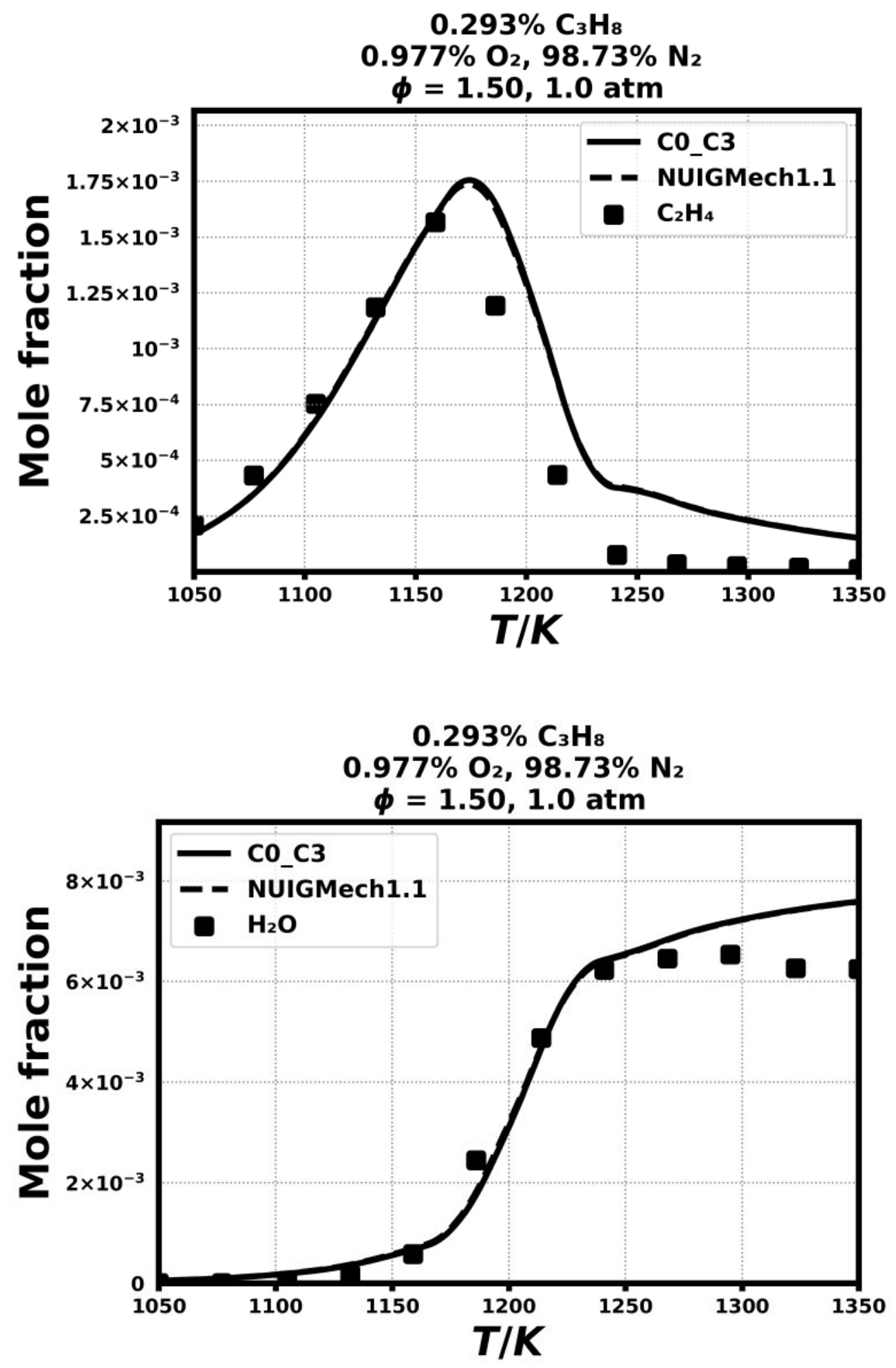

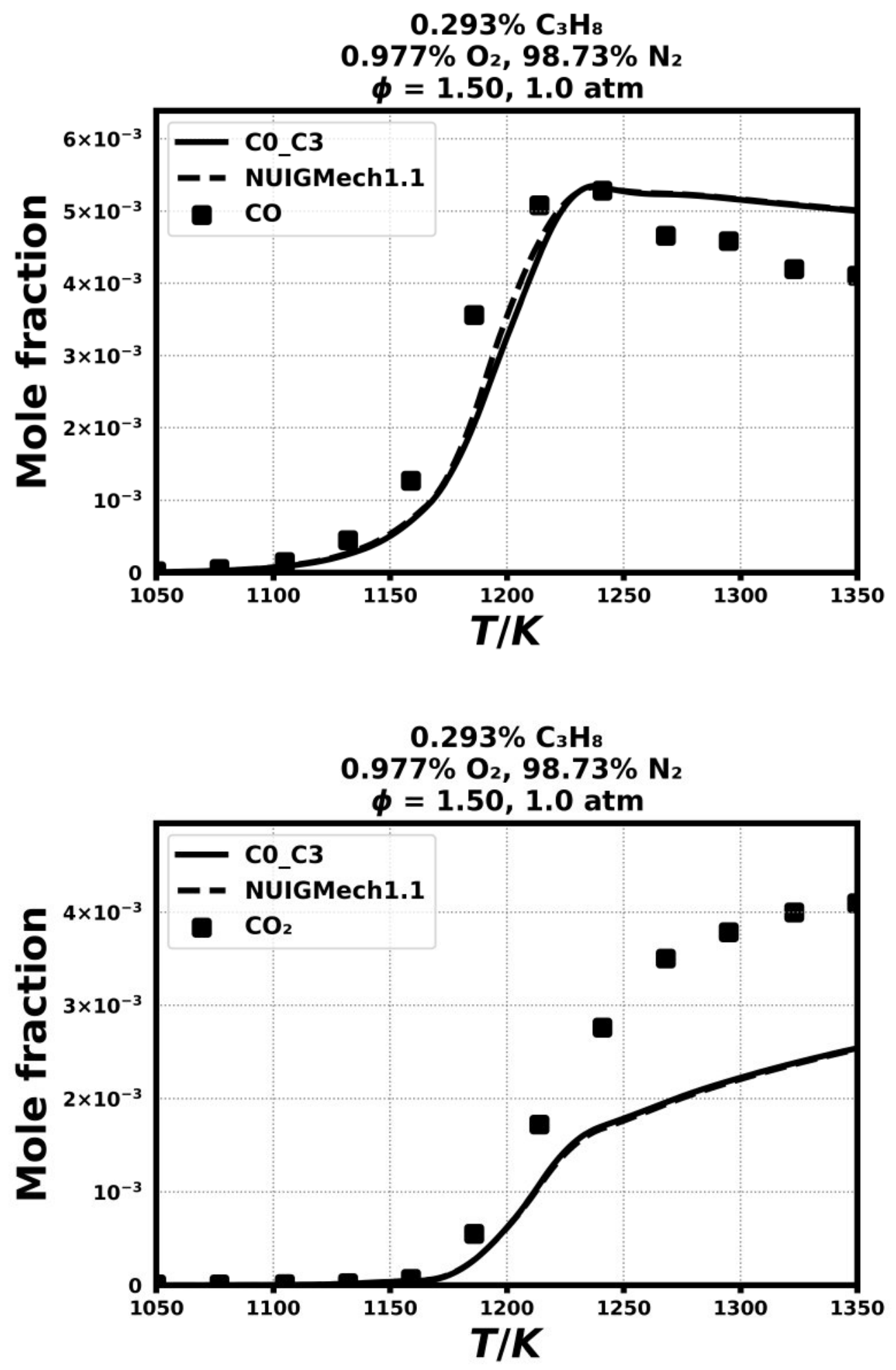


\section{Speciation in Flow reactor}

8.8) Hashemi, H., Christensen, J. M., Harding, L. B., Klippenstein, S. J., \& Glarborg, P., Proceedings of the Combustion Institute, 37(1) (2019) 461-468.
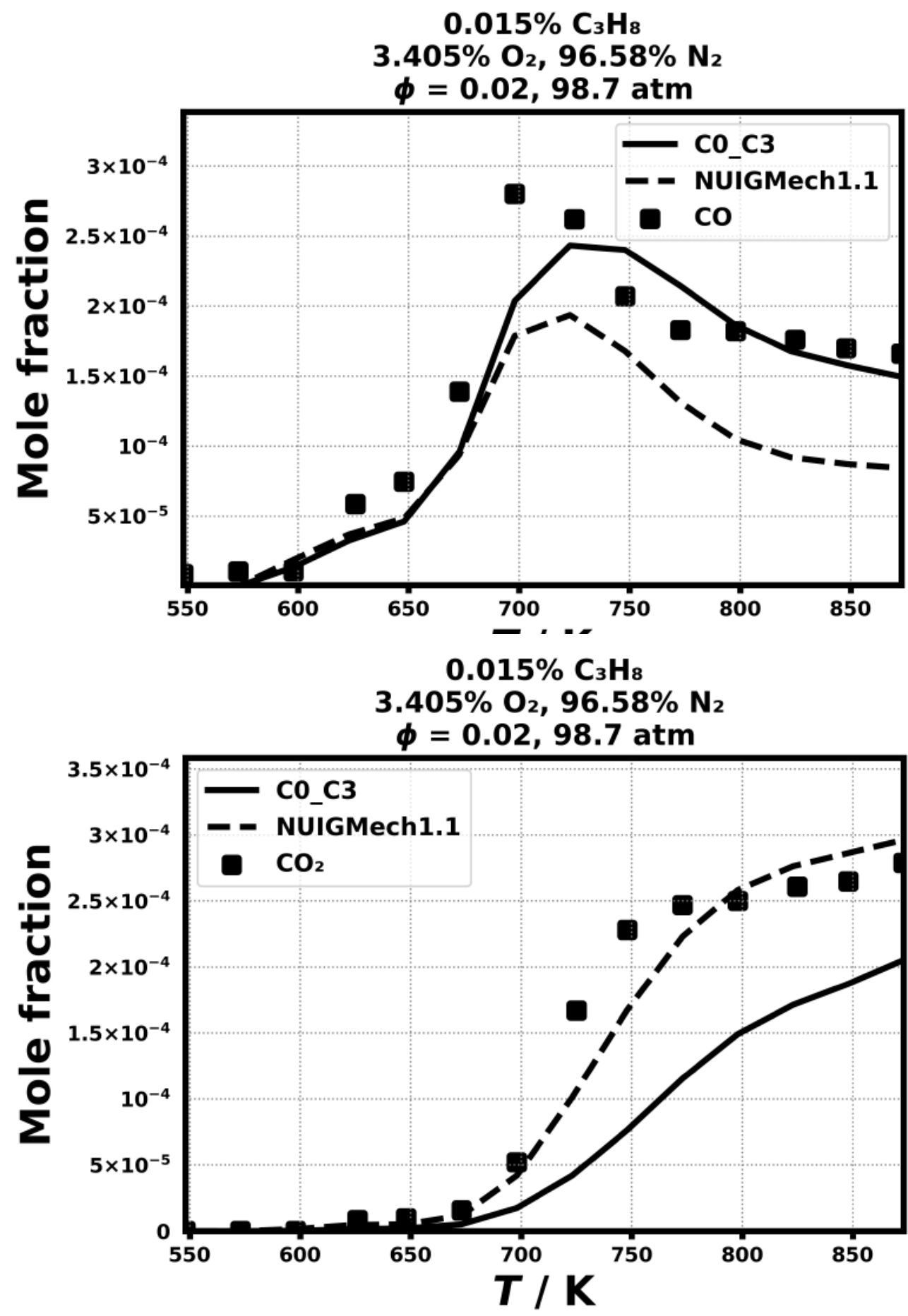

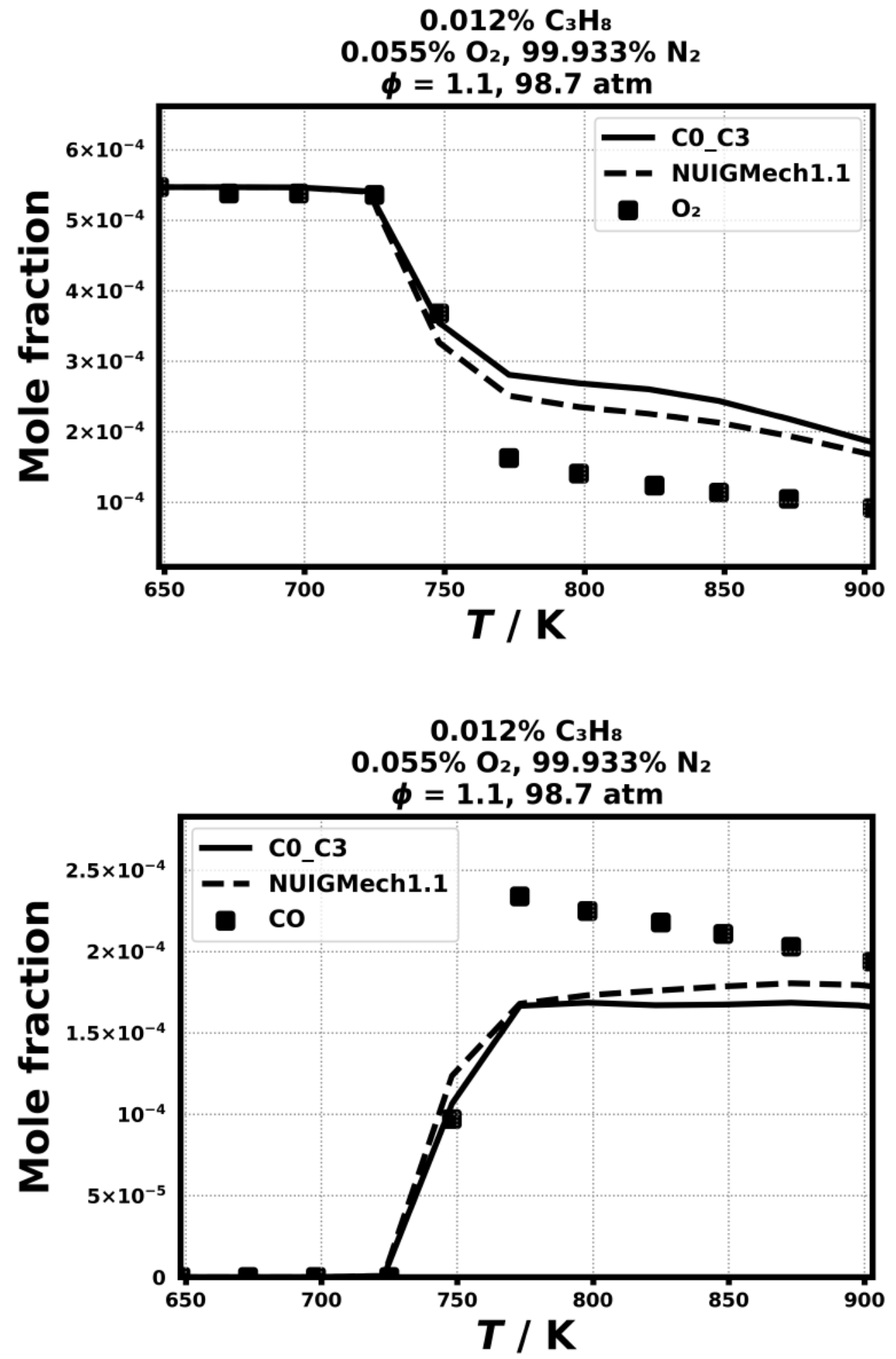

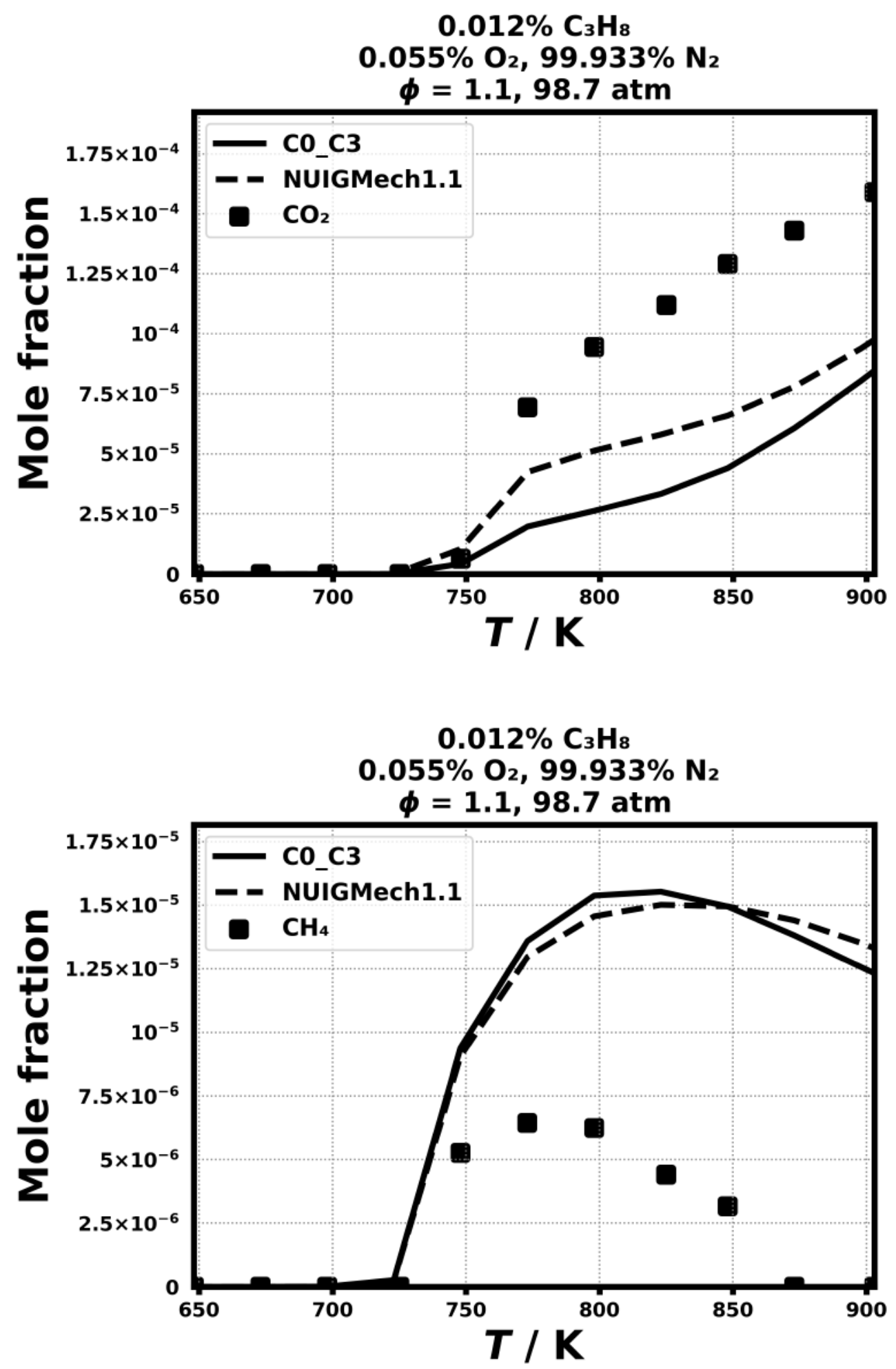

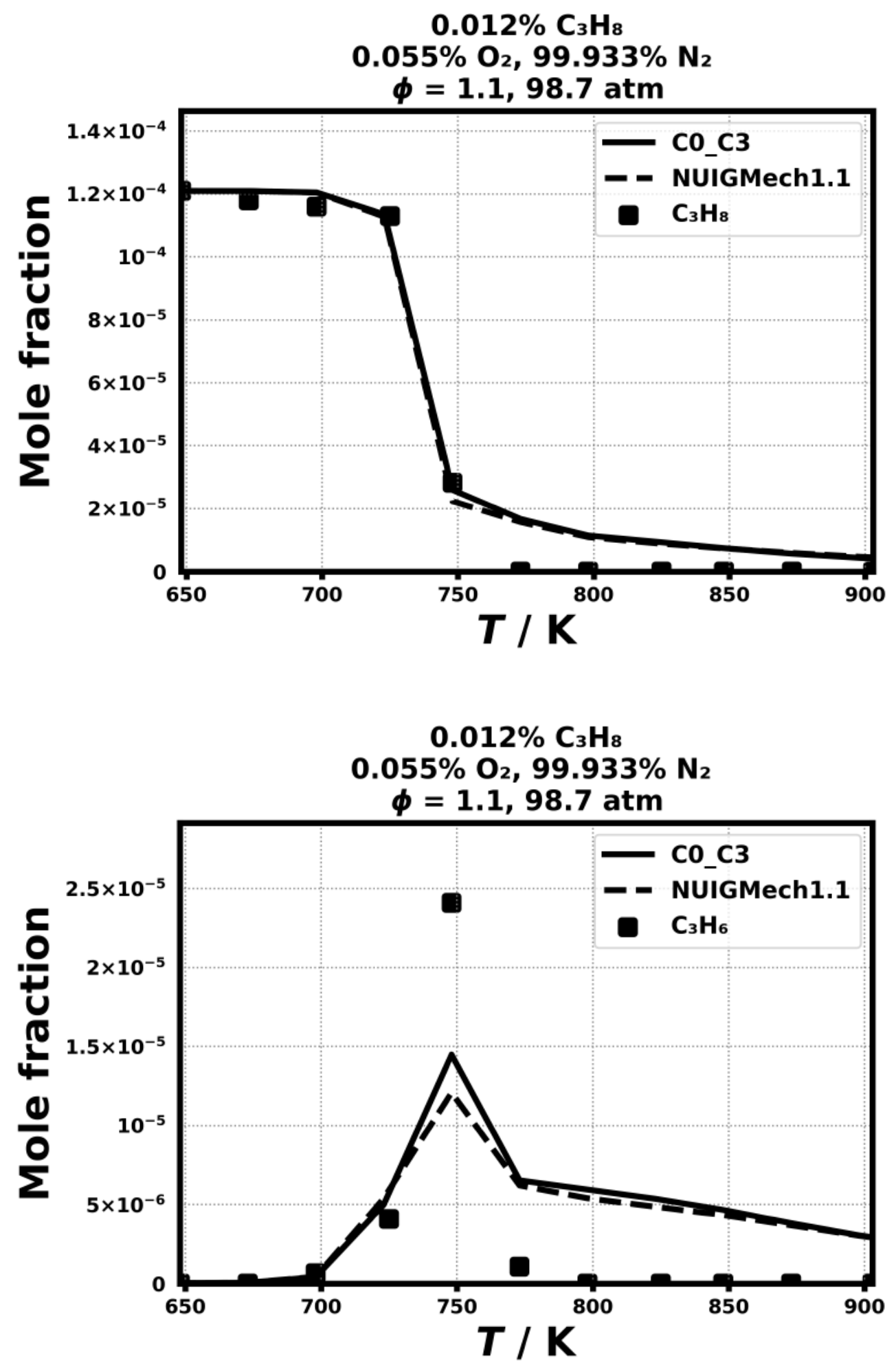
8.9) Dagaut, P., Cathonnet, M., Boetiner, J. C., \& Gaillard, F., Combustion science and technology, 56(1-3) (1987) 23-63.
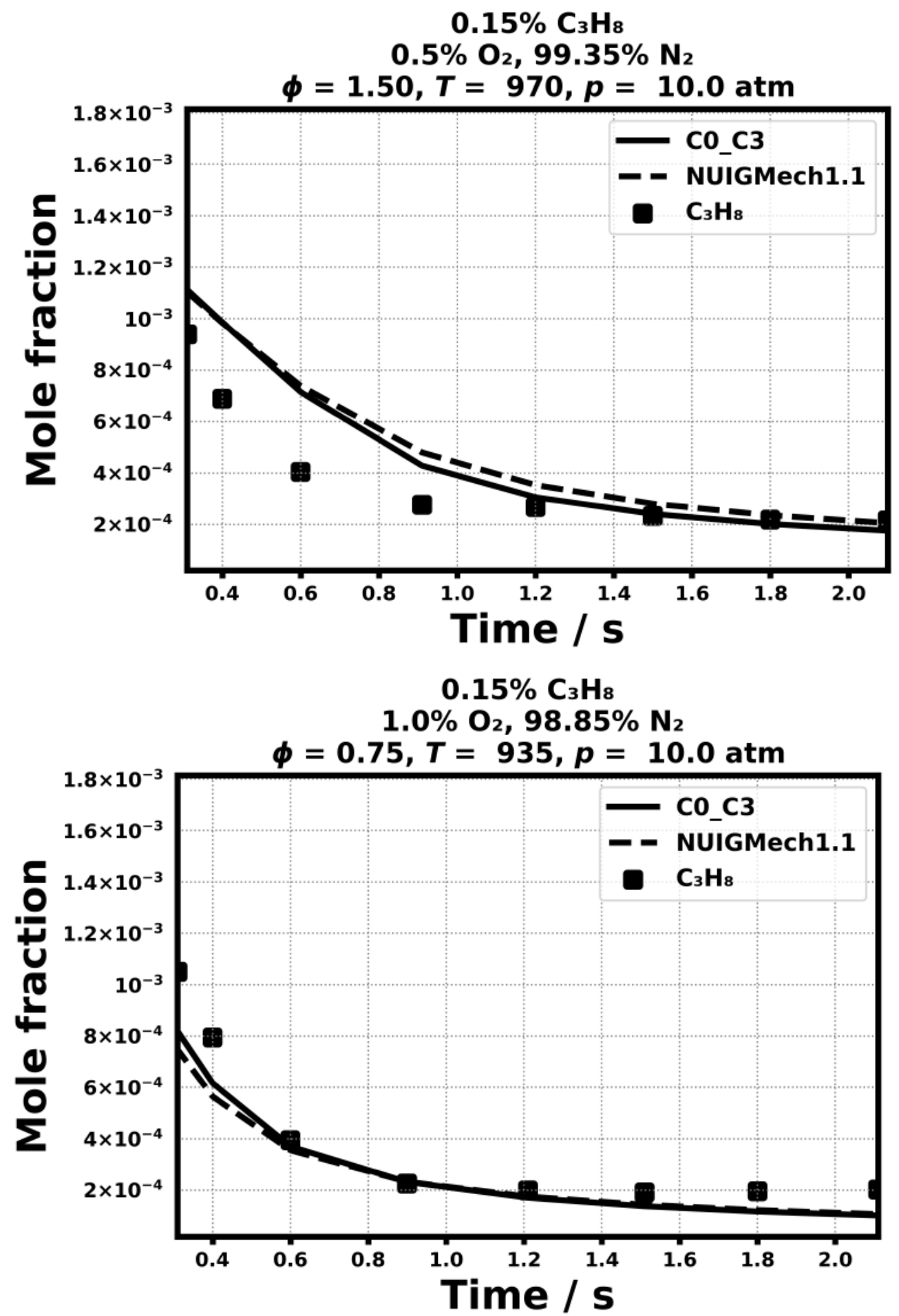

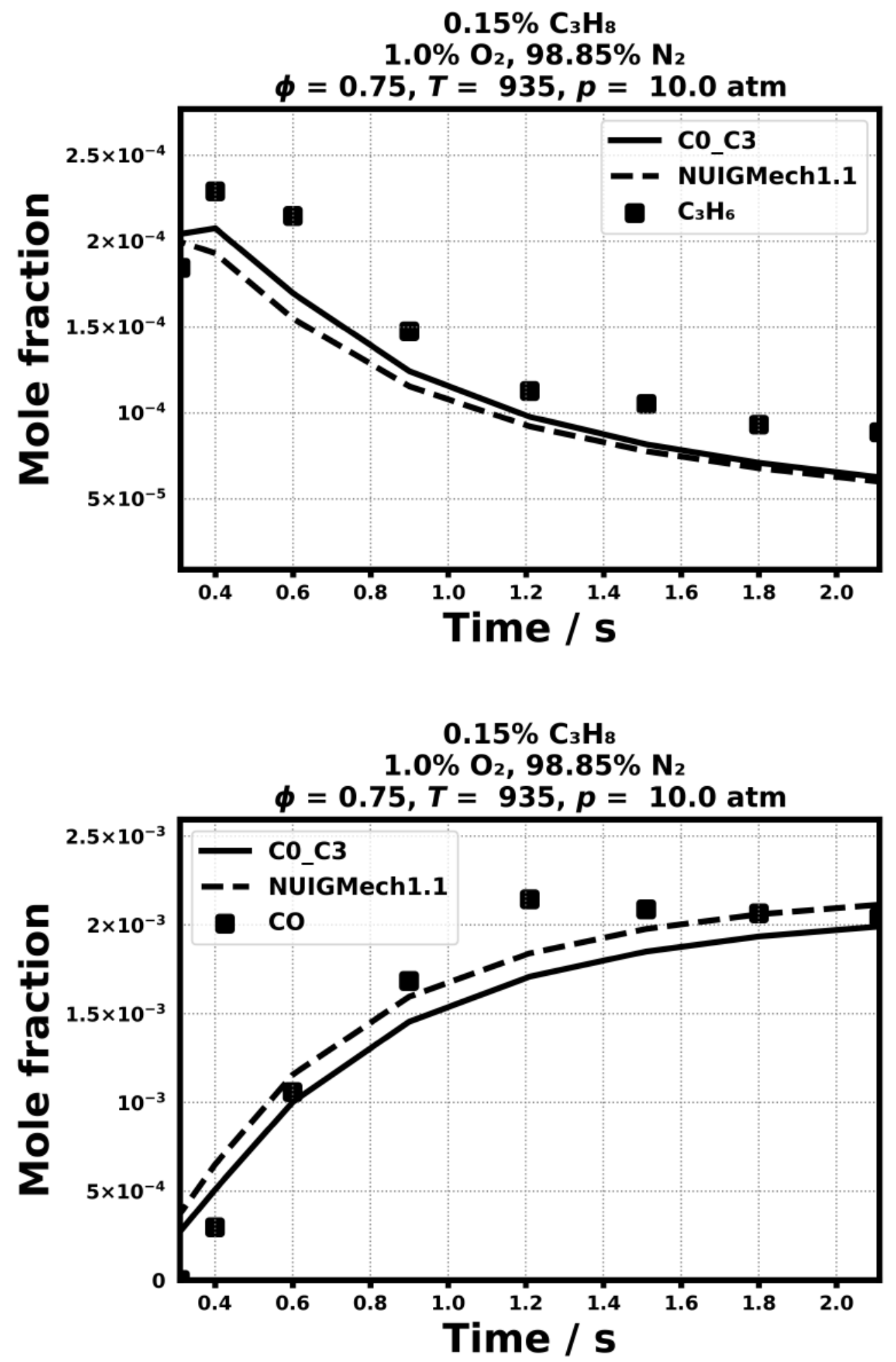

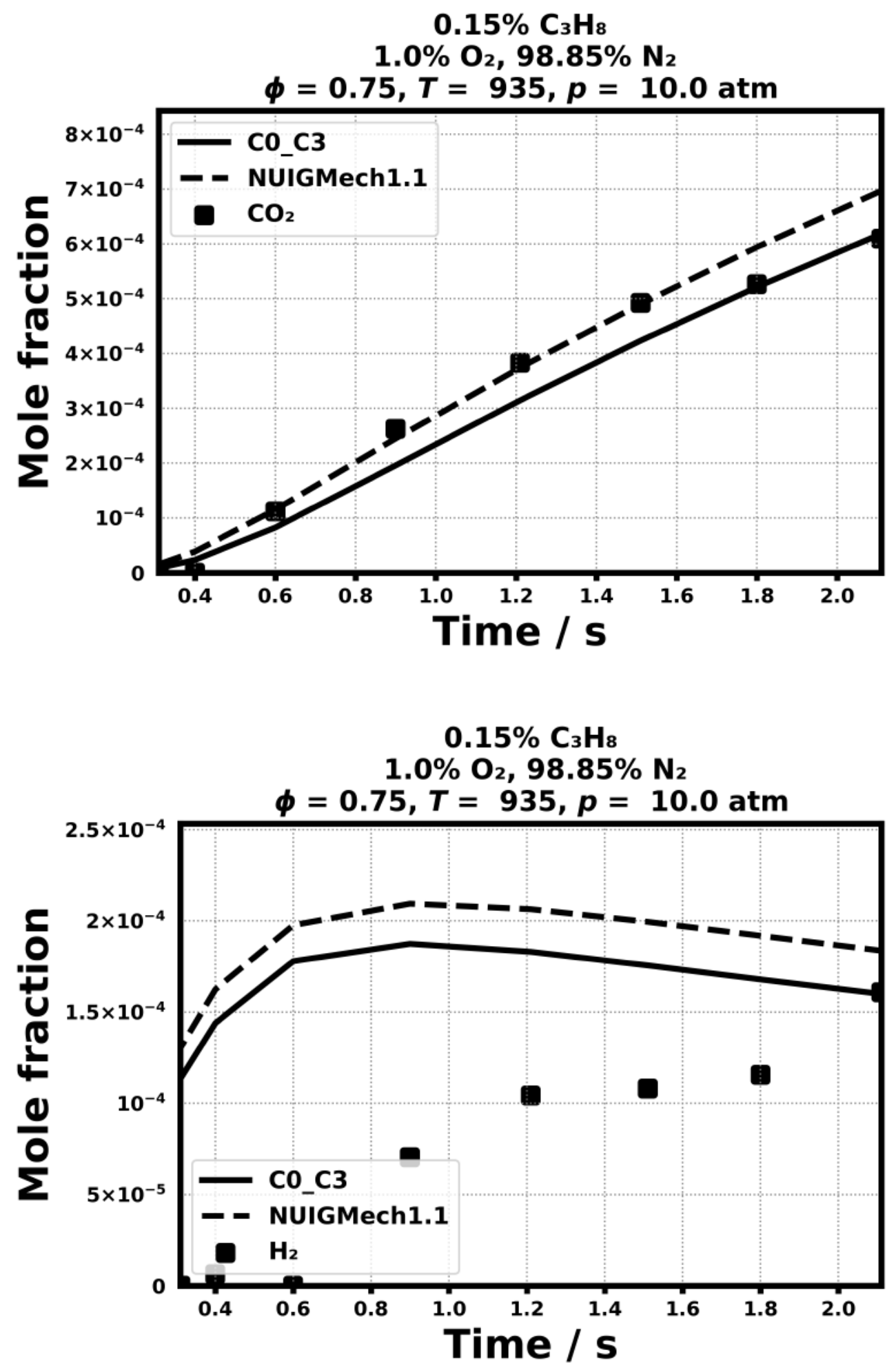

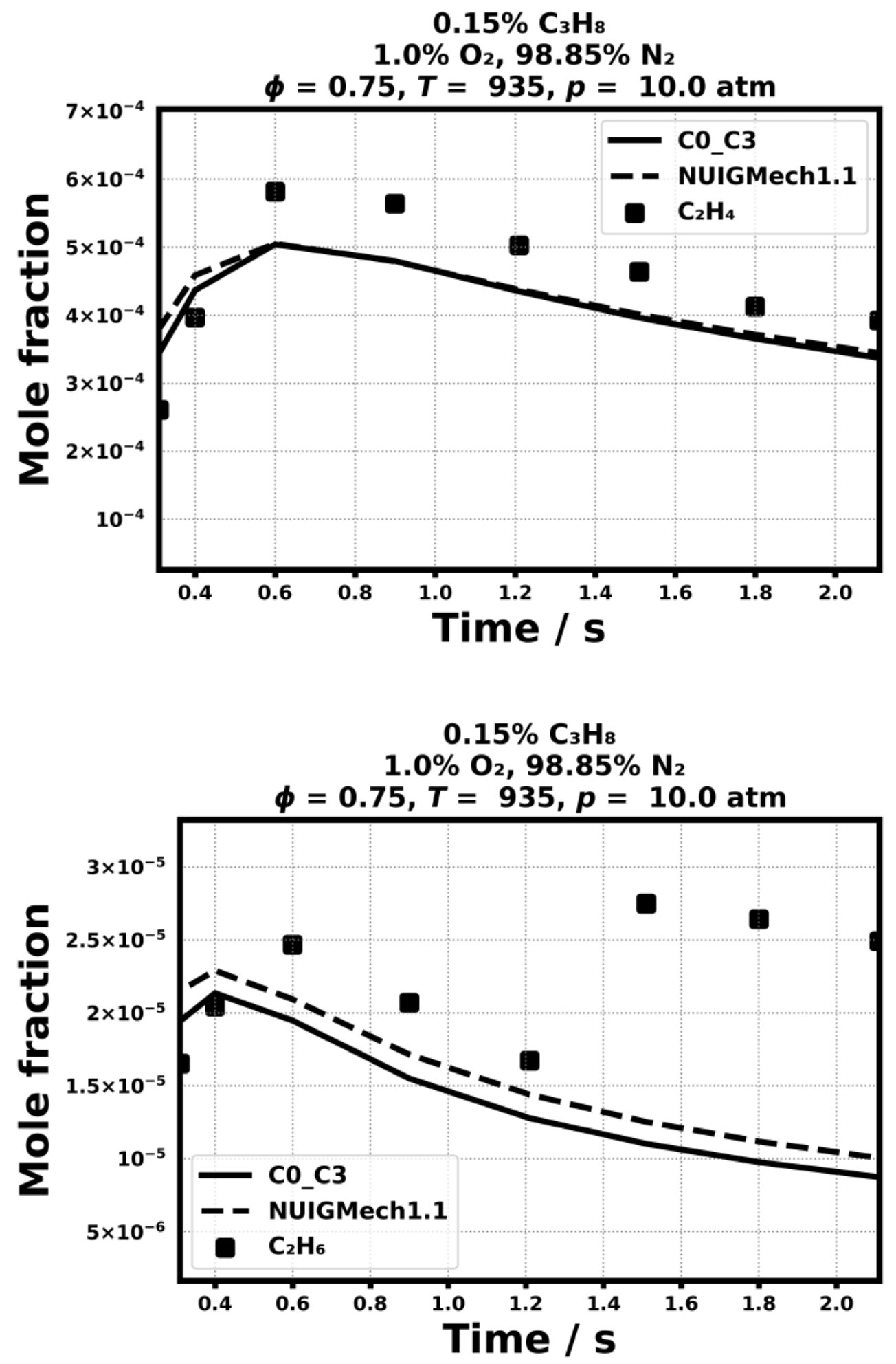

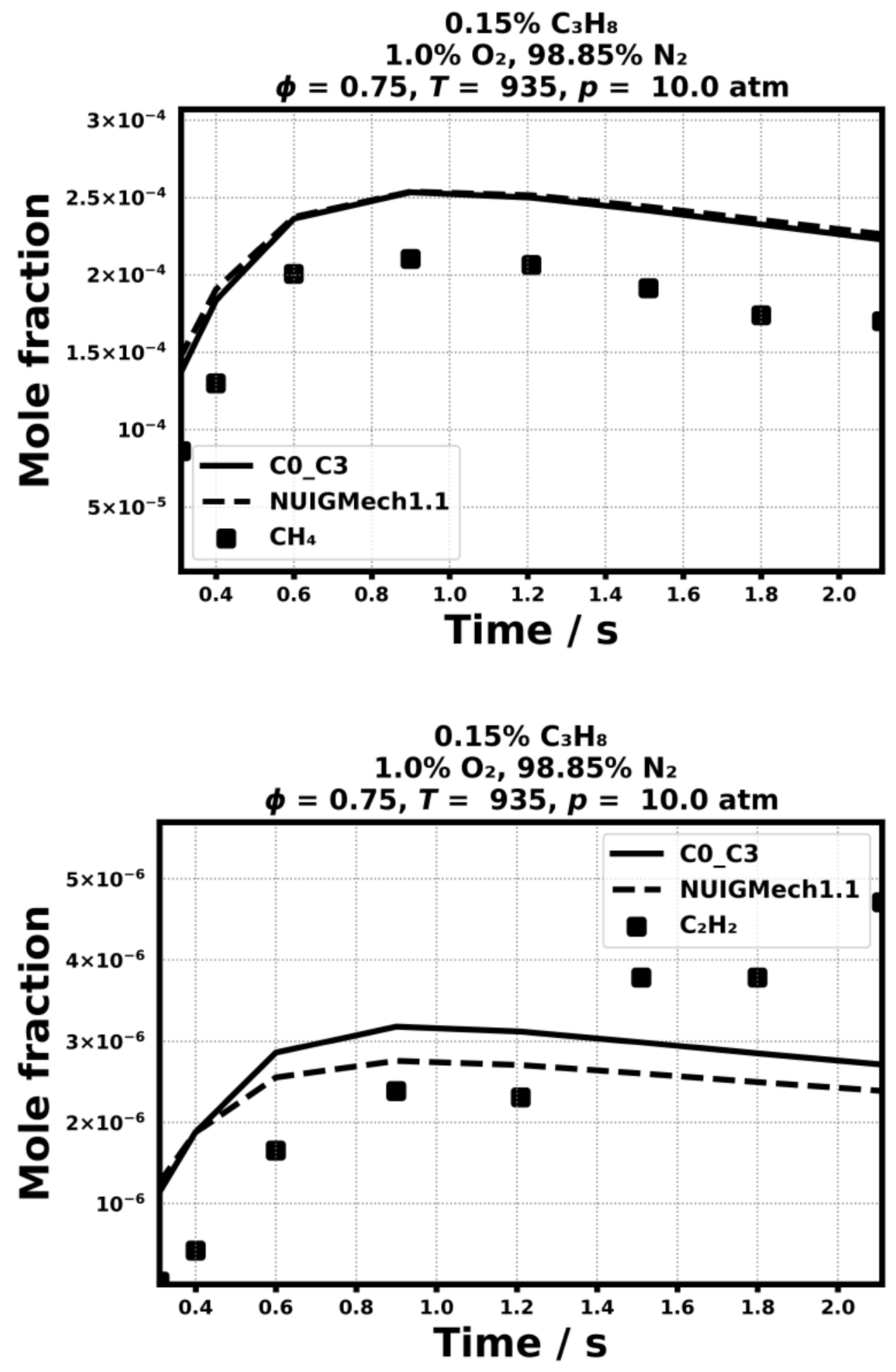

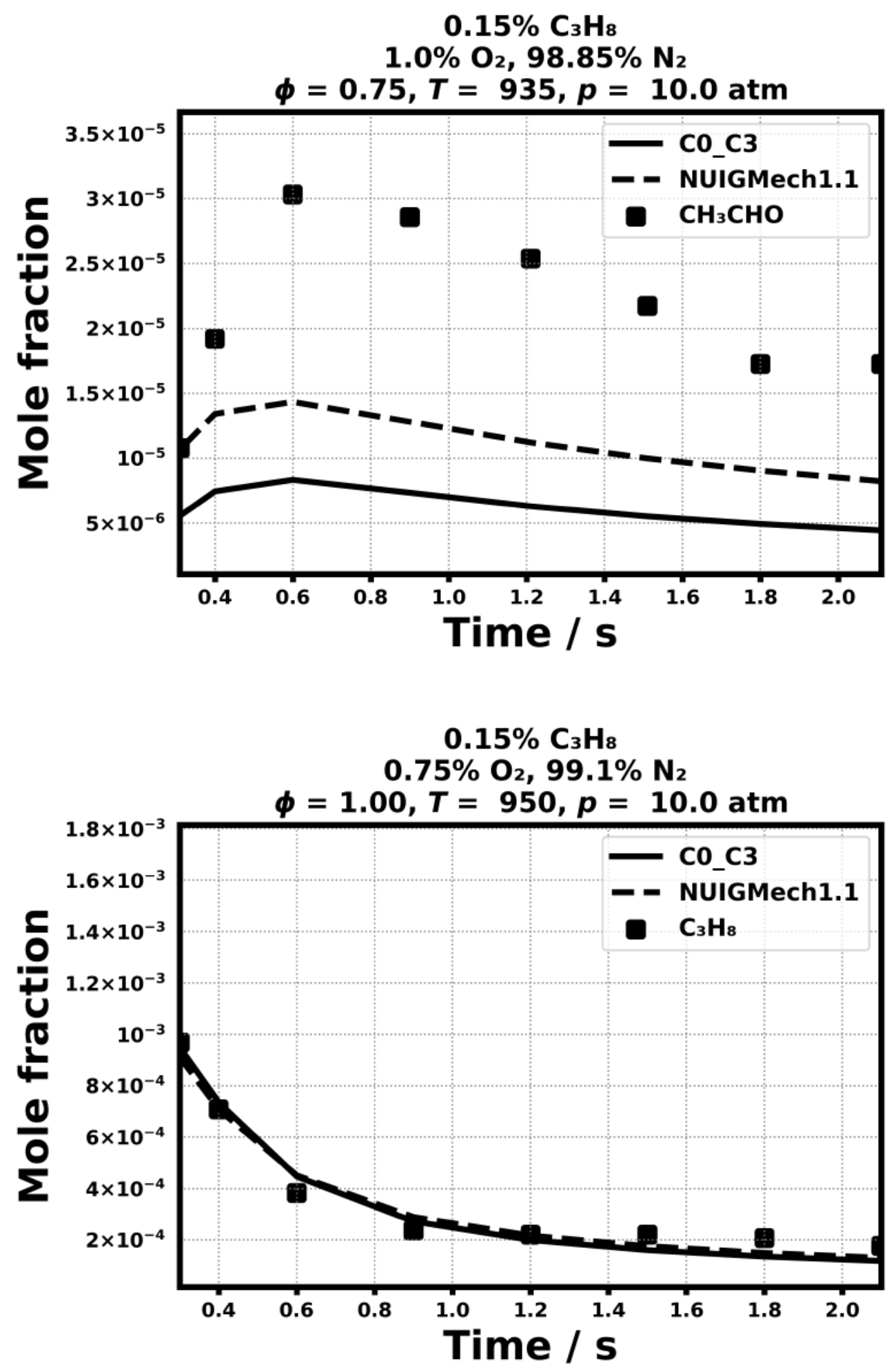

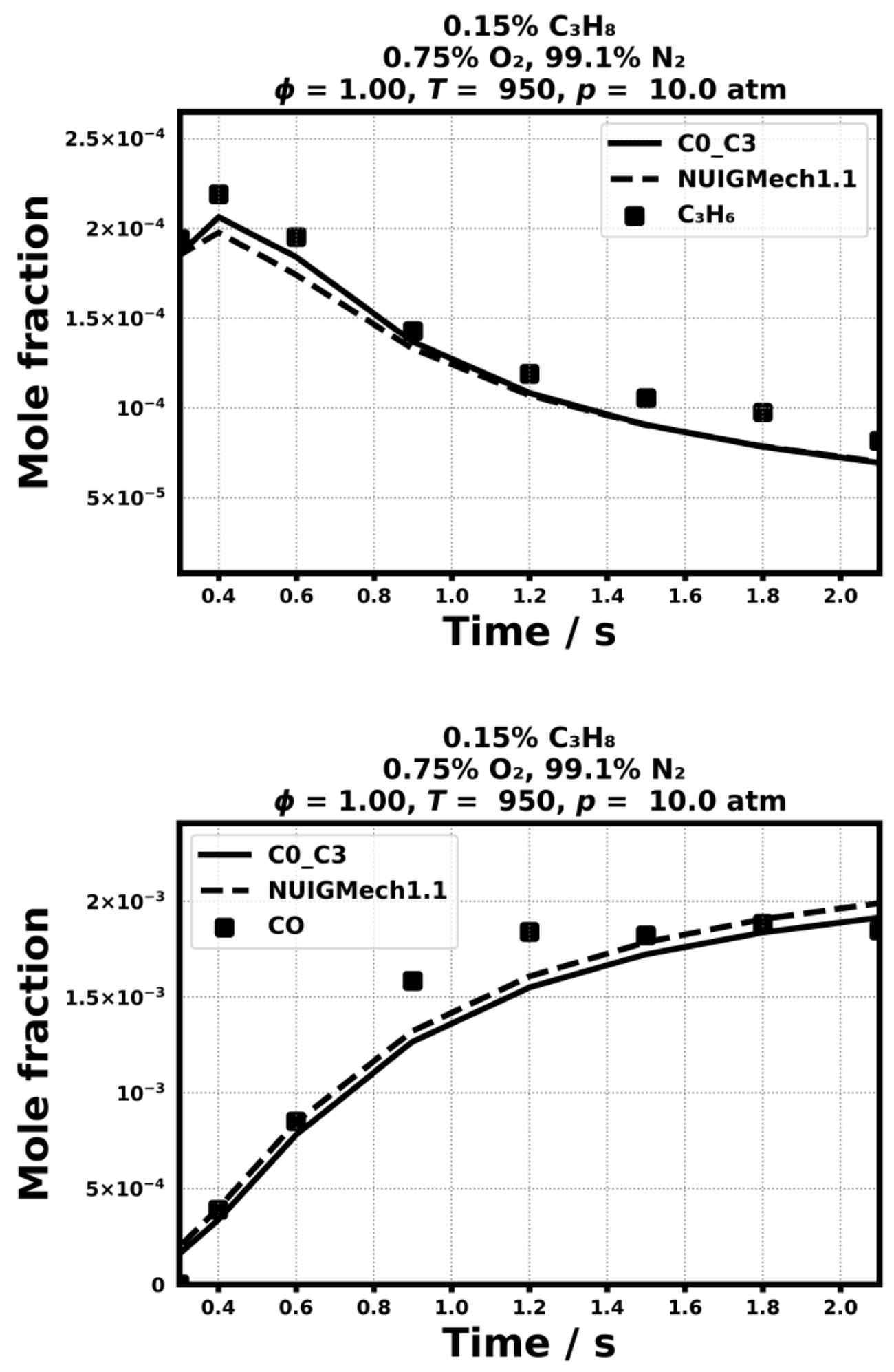

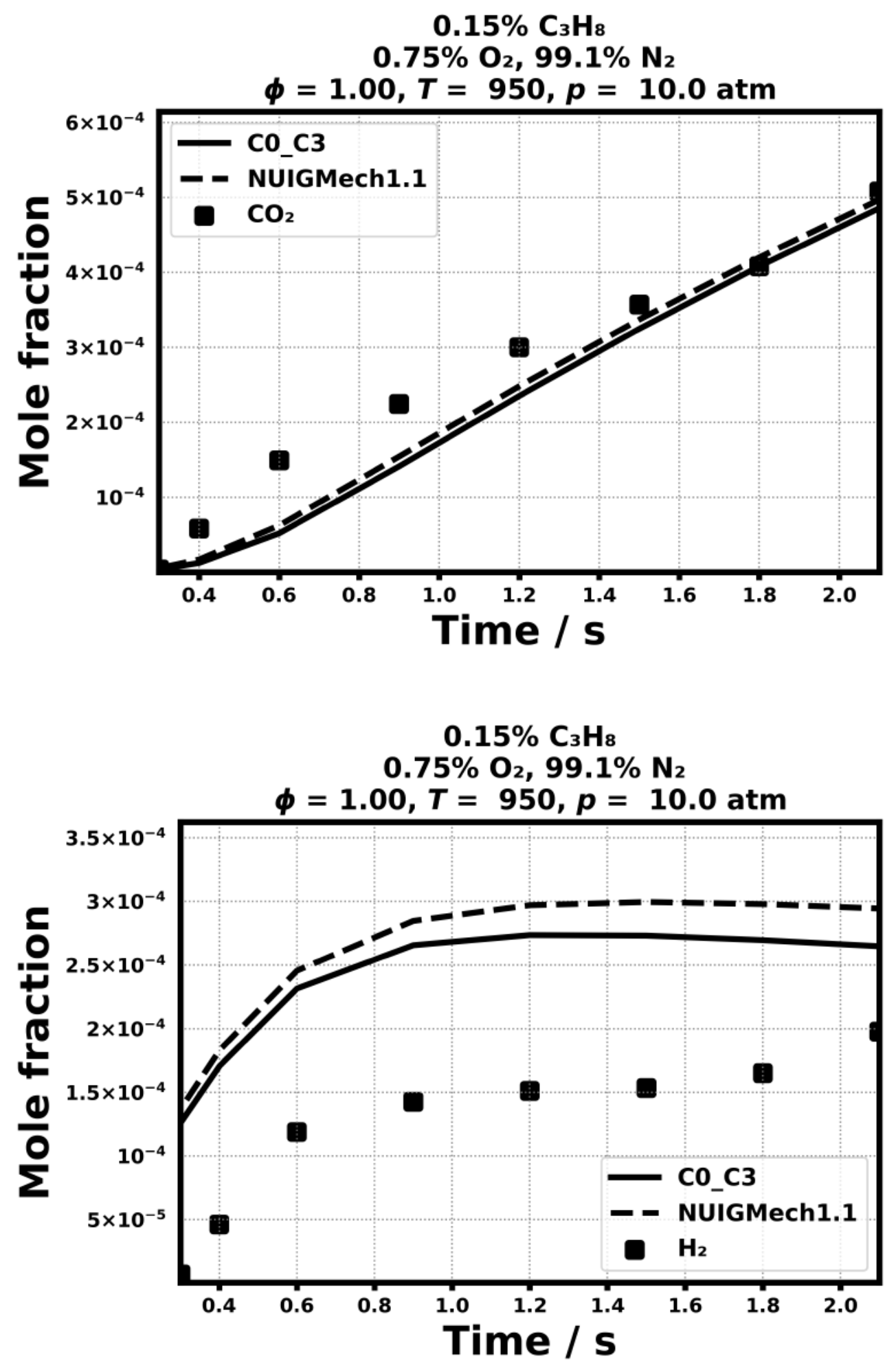

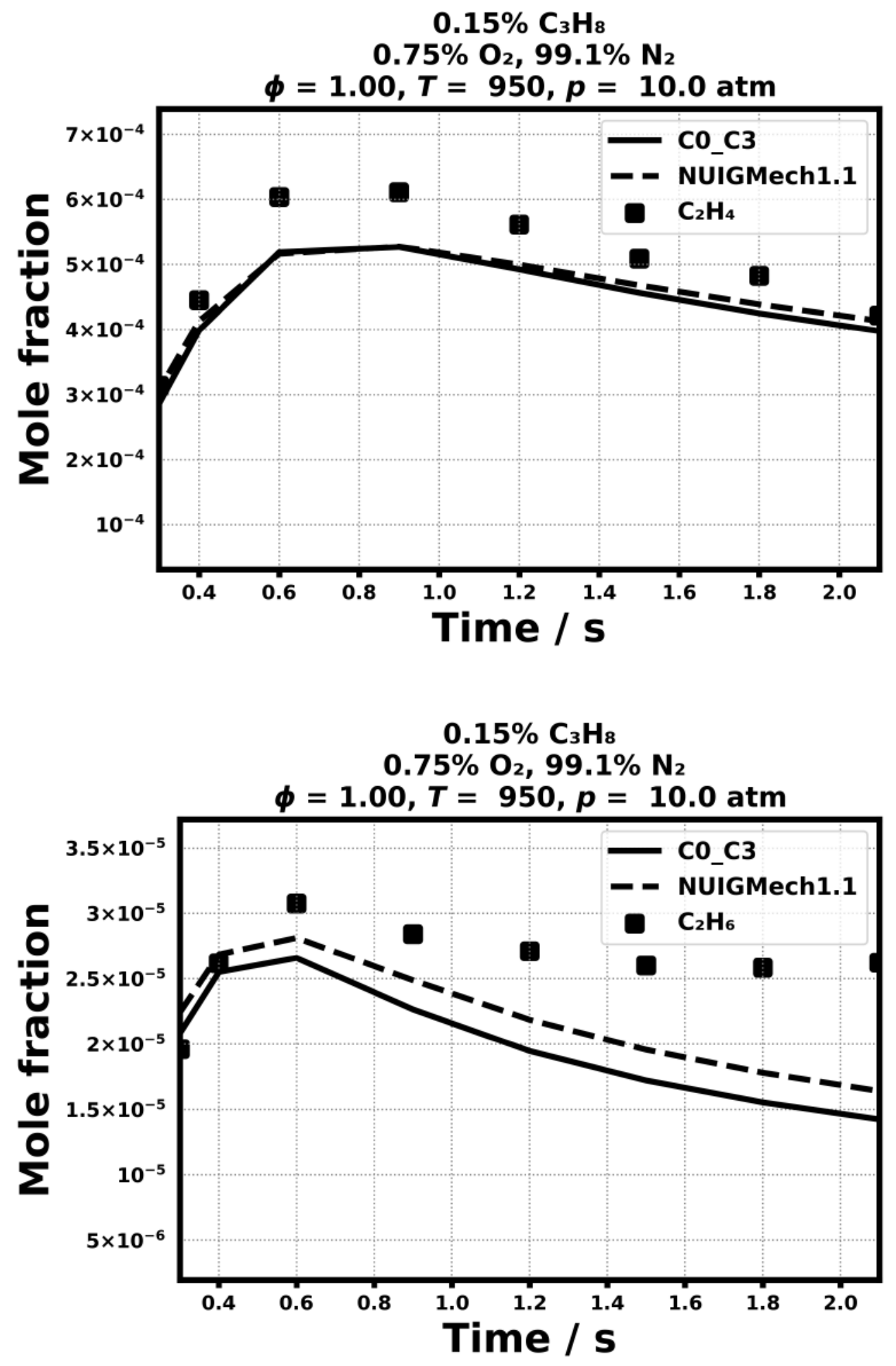

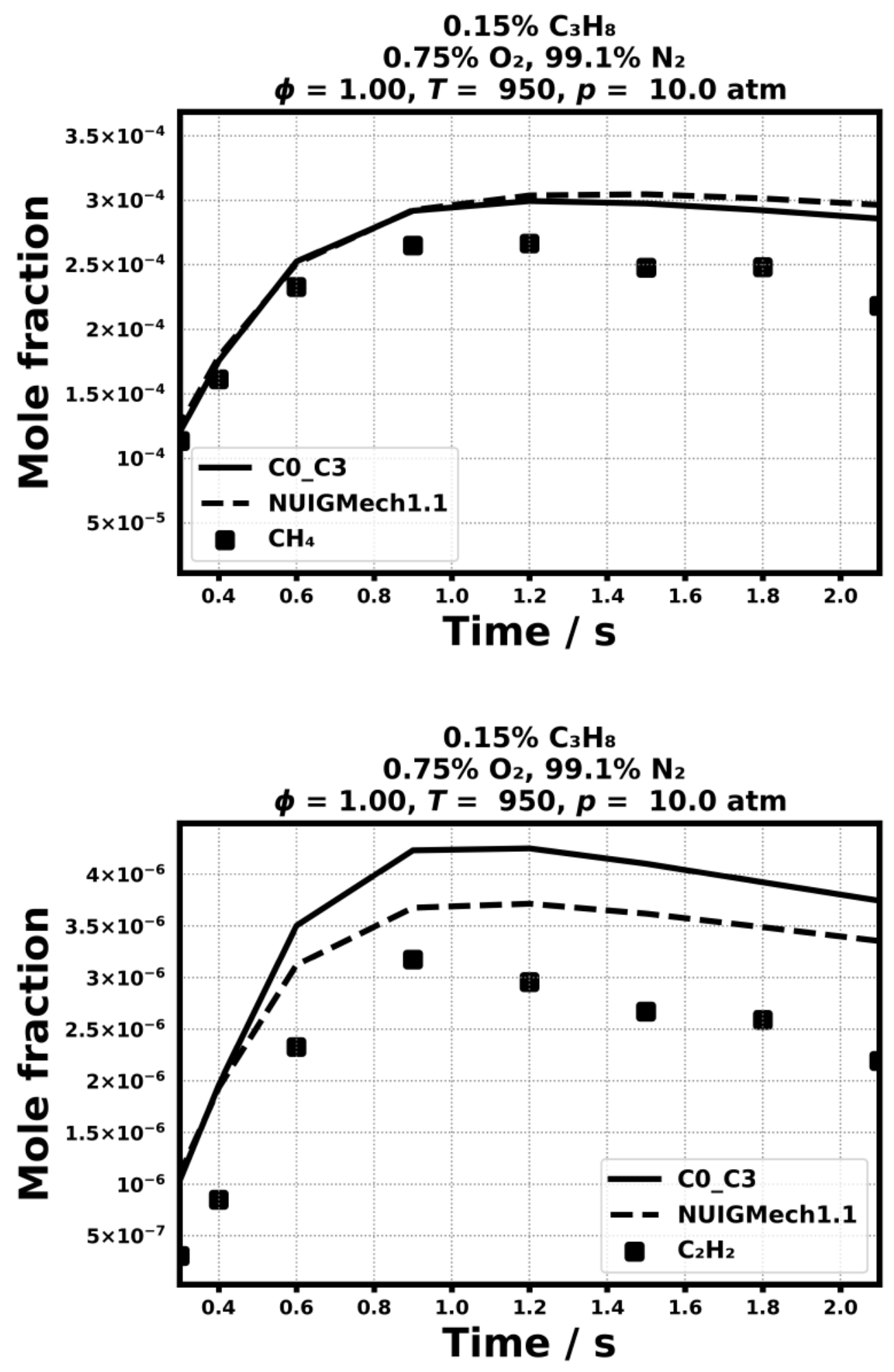

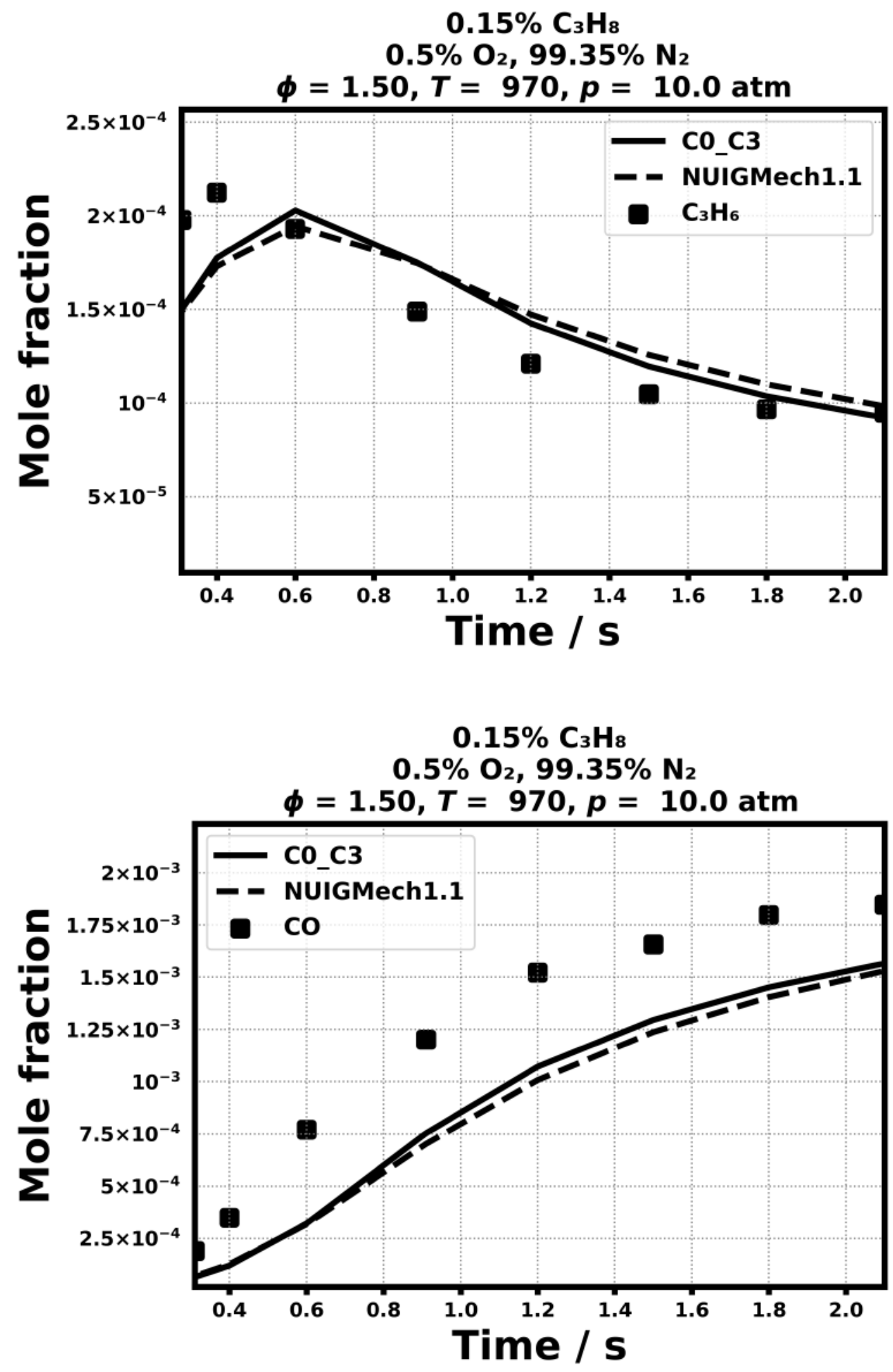

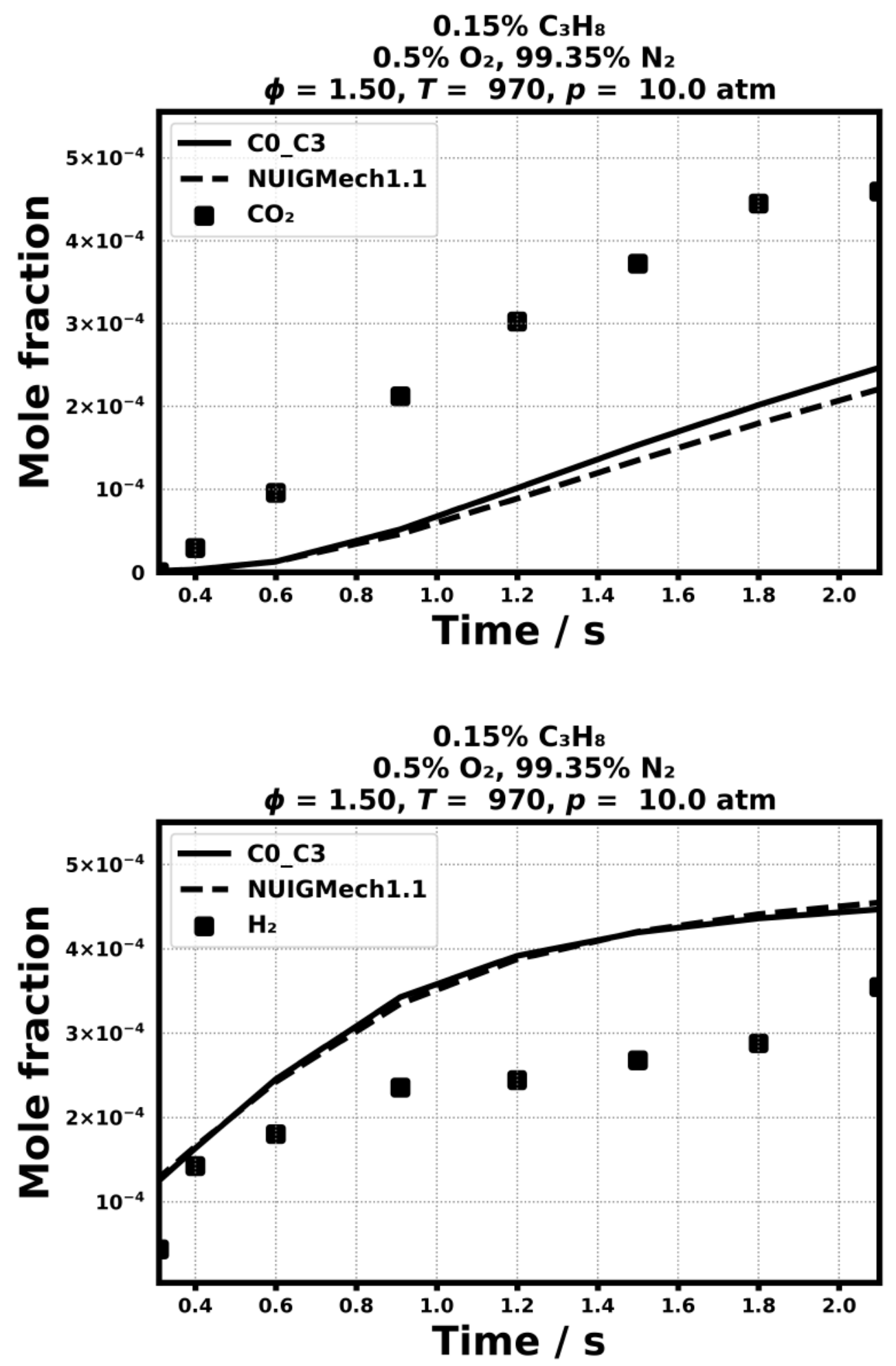

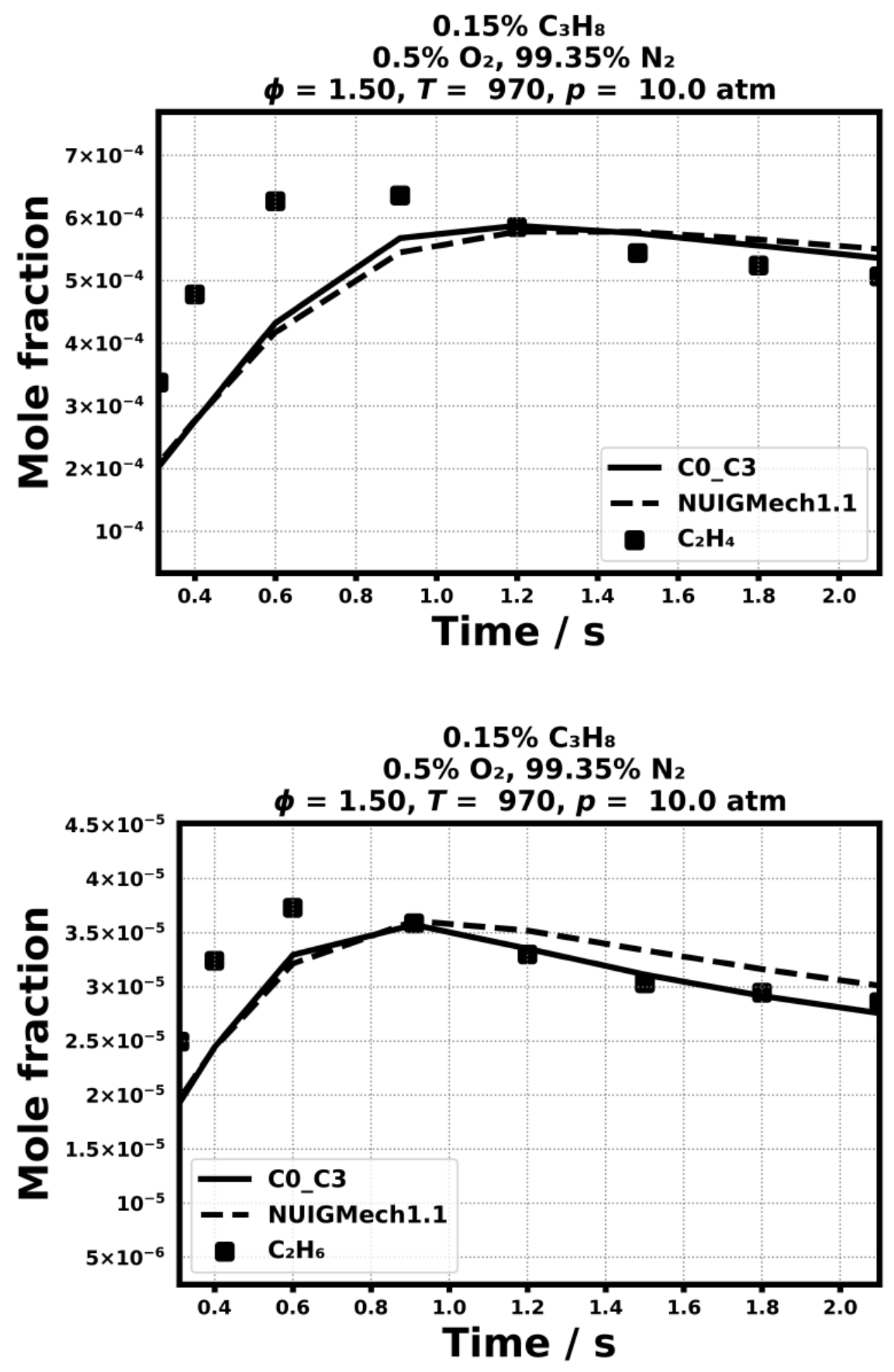

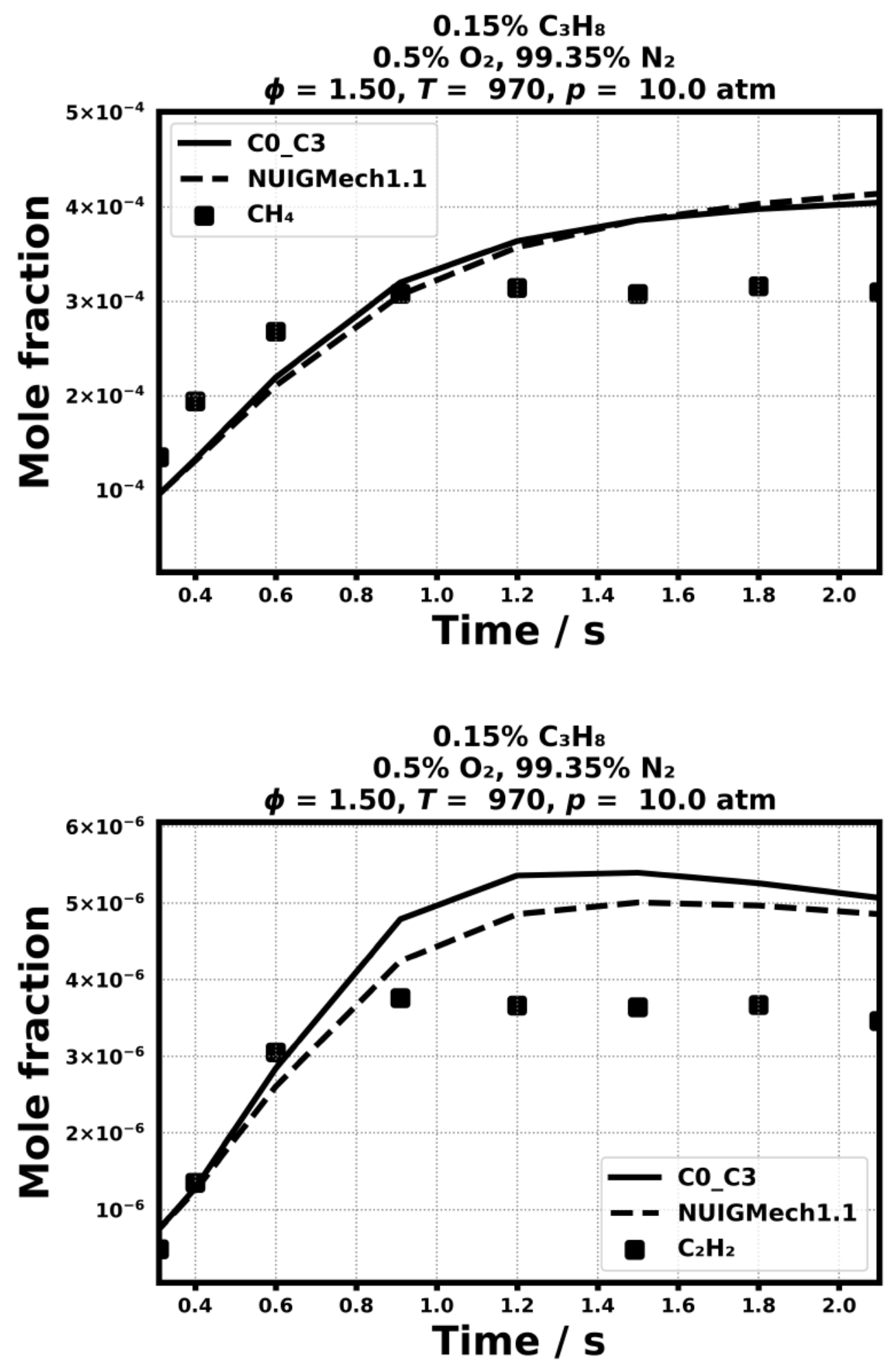

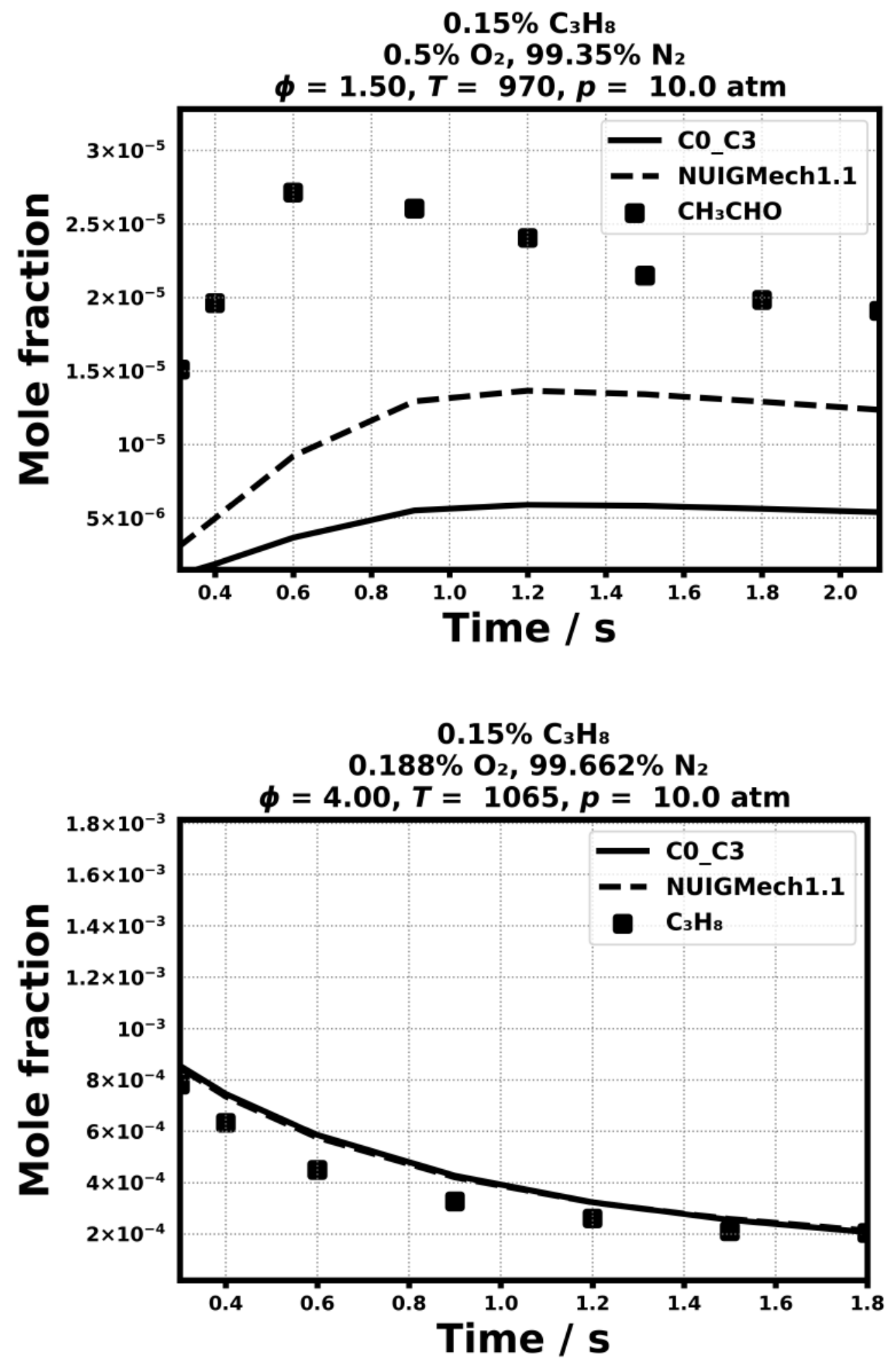

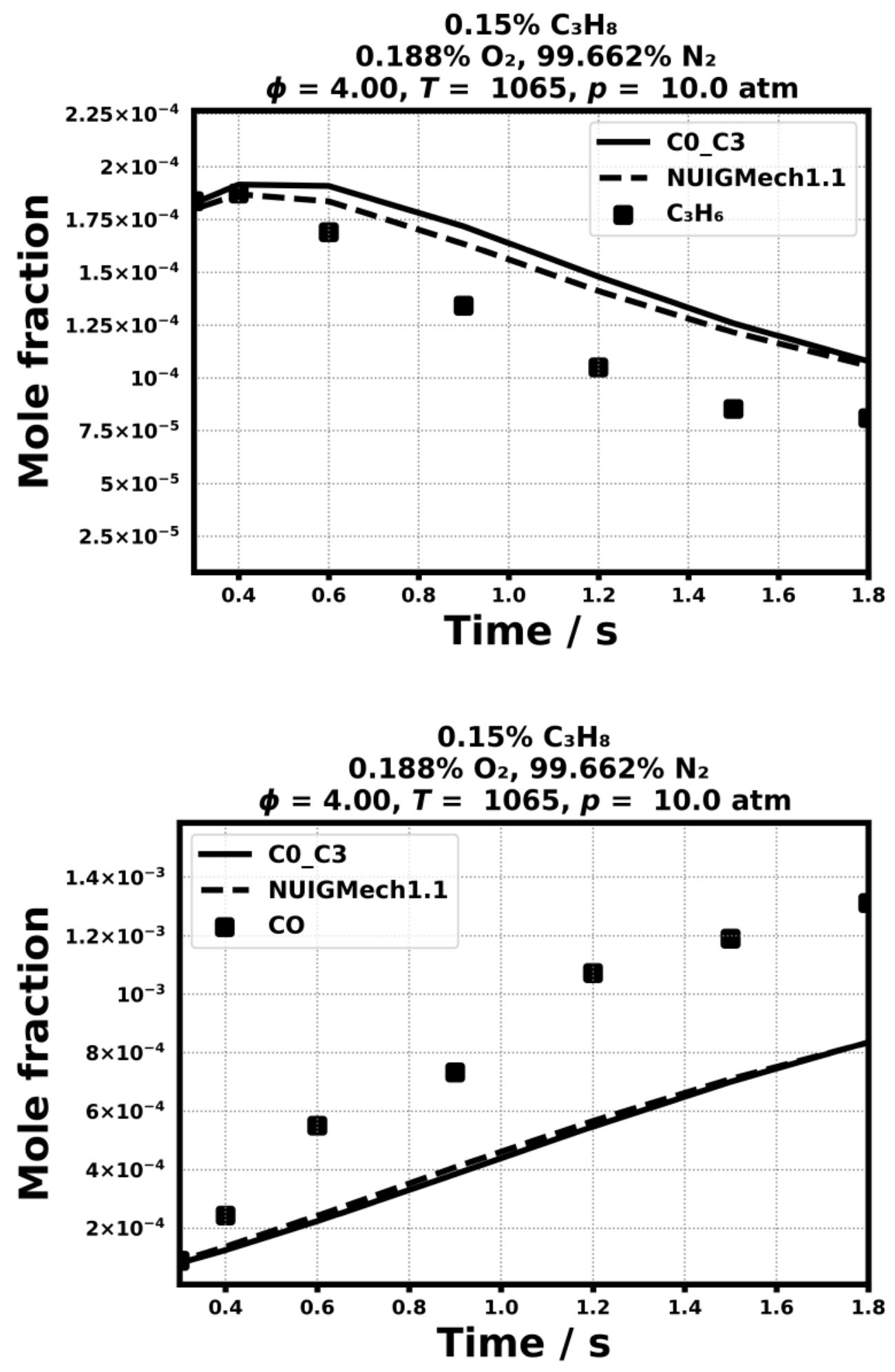

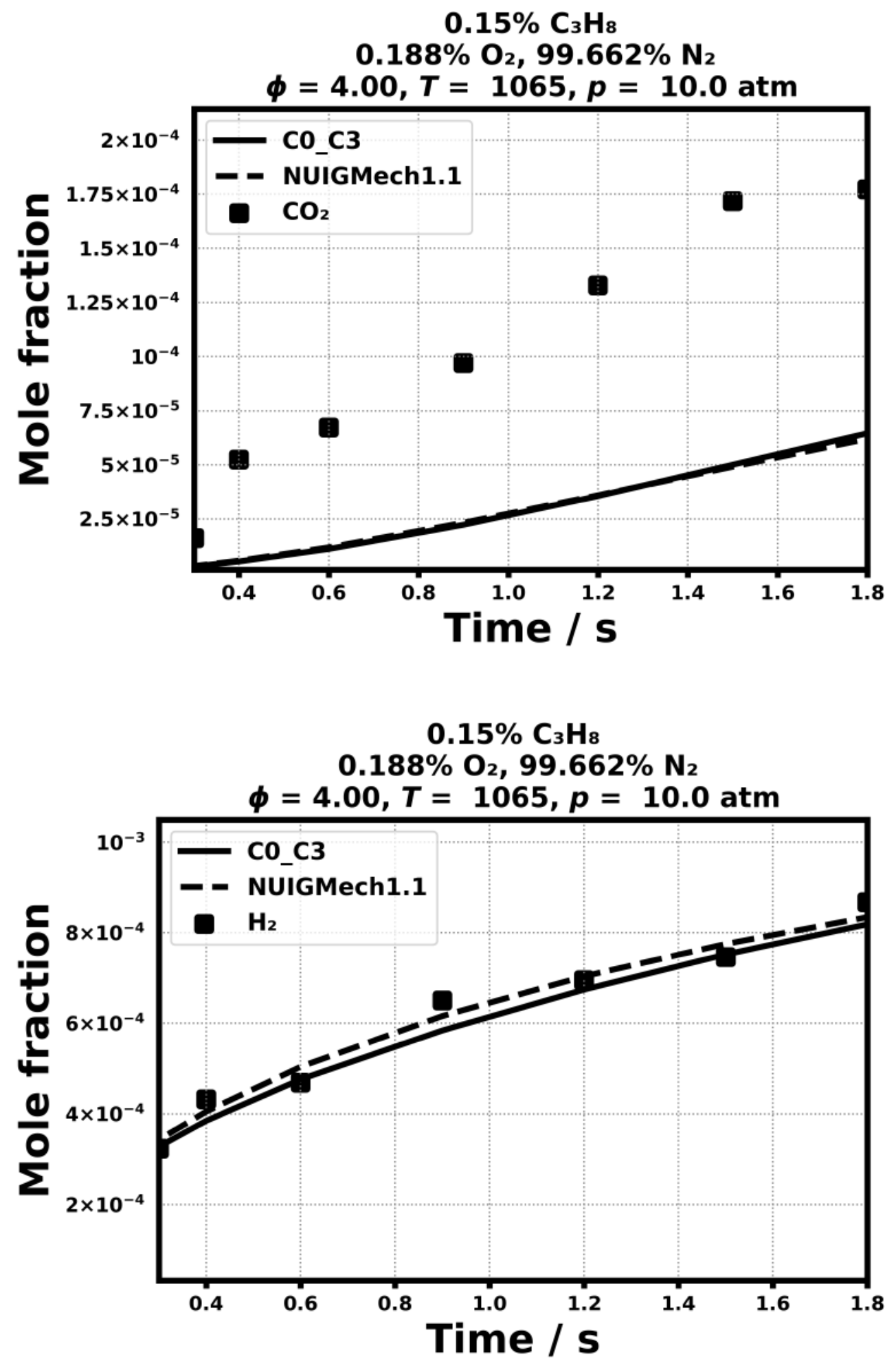

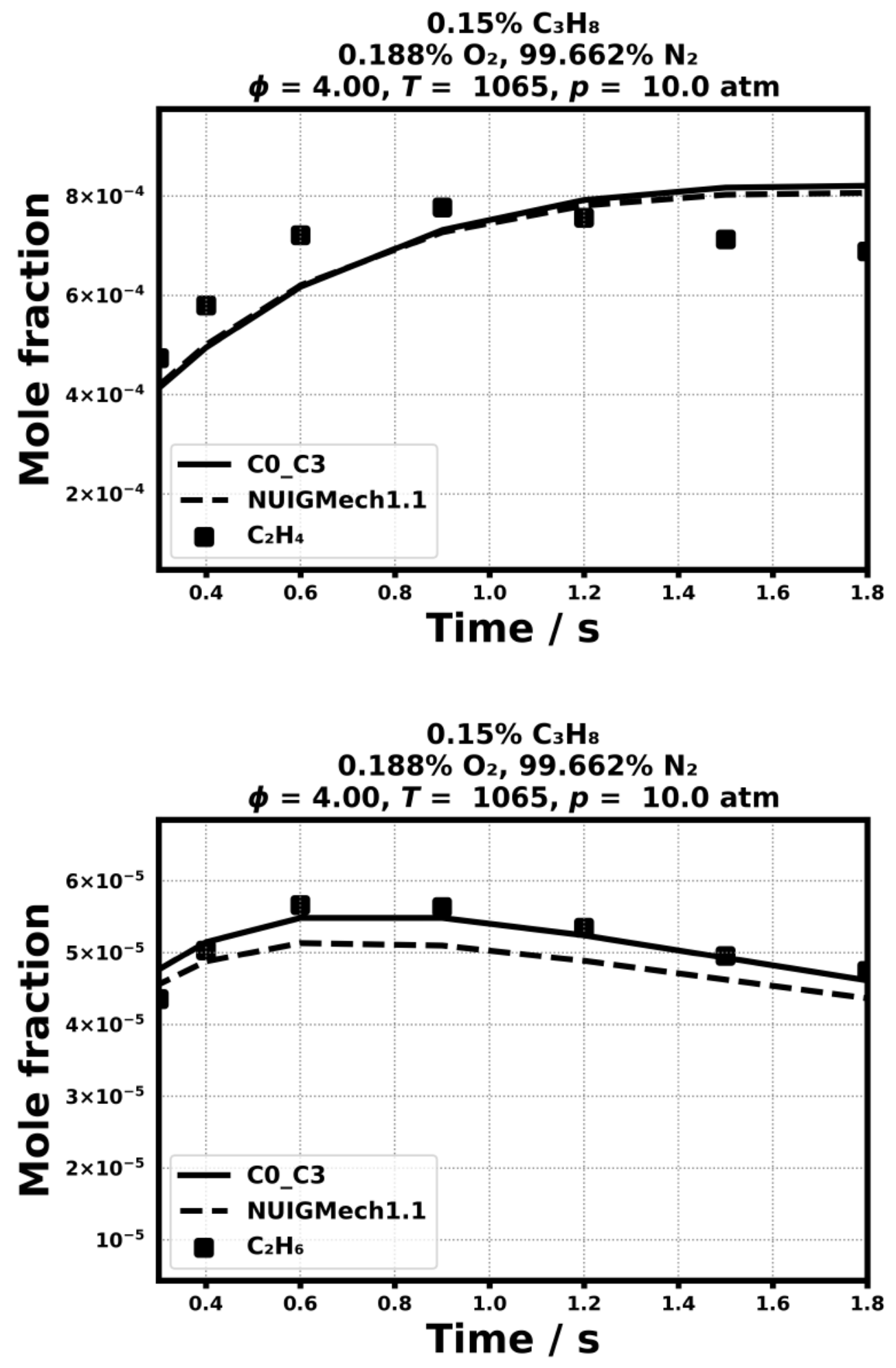

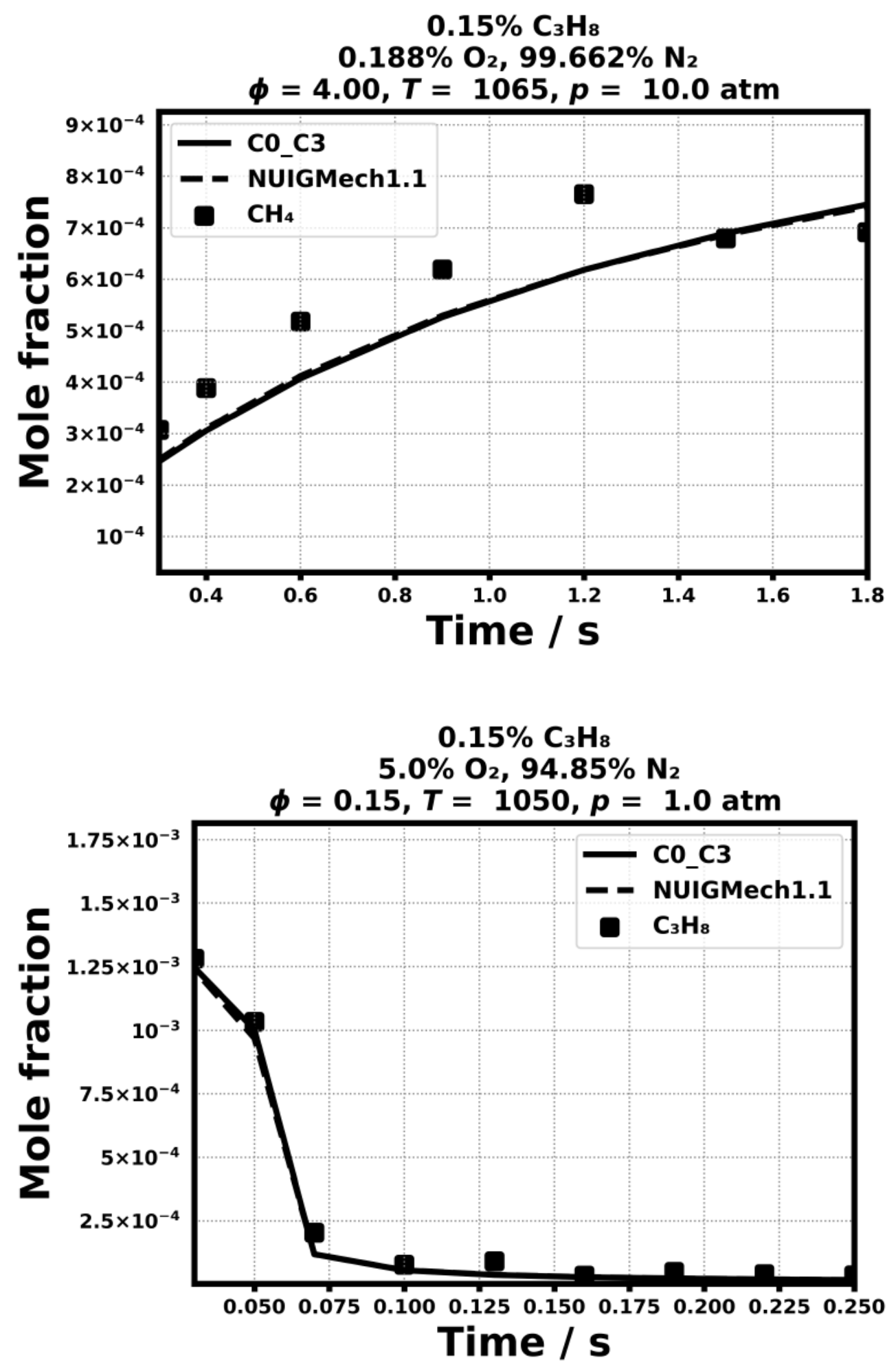

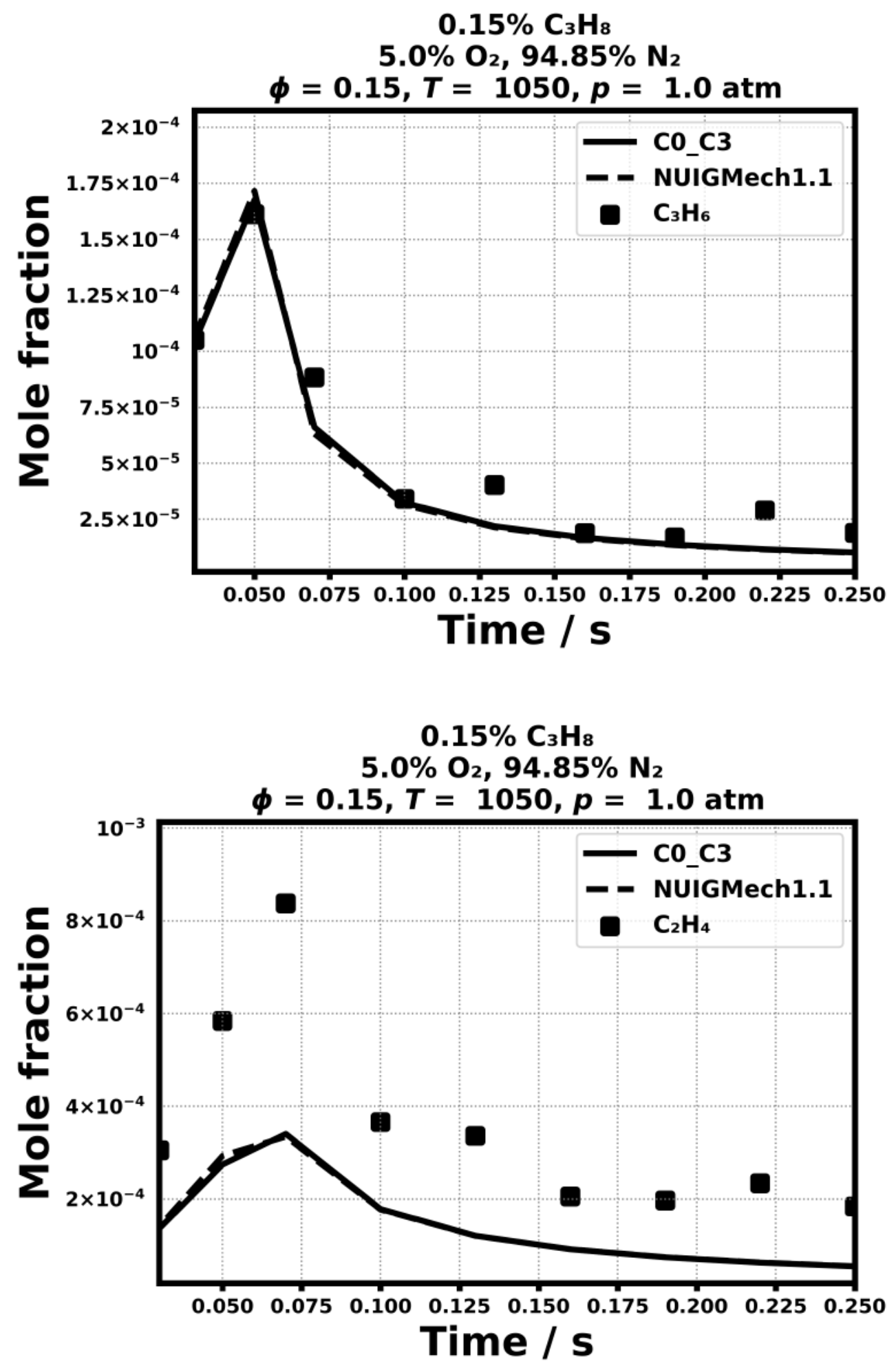

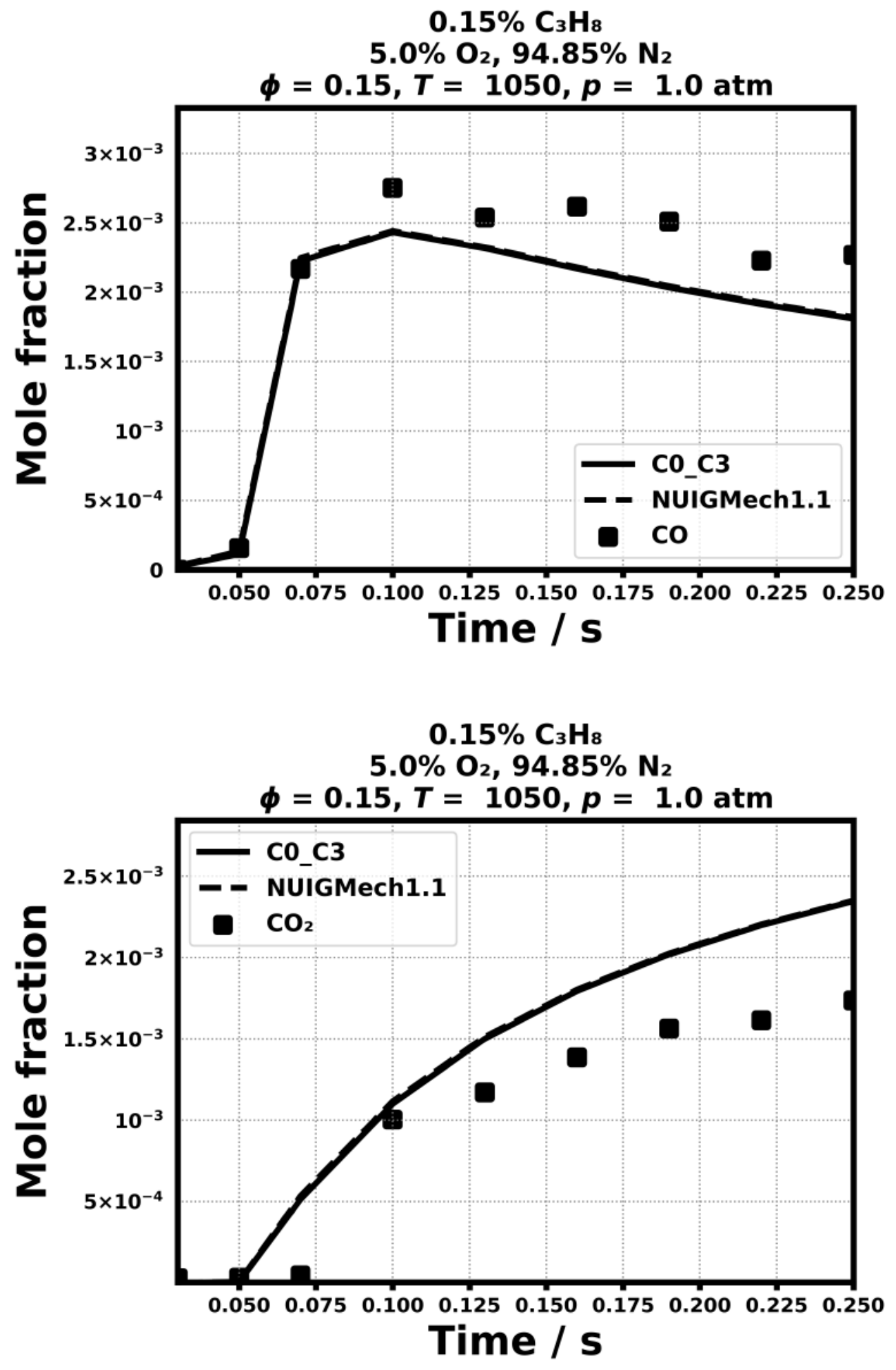

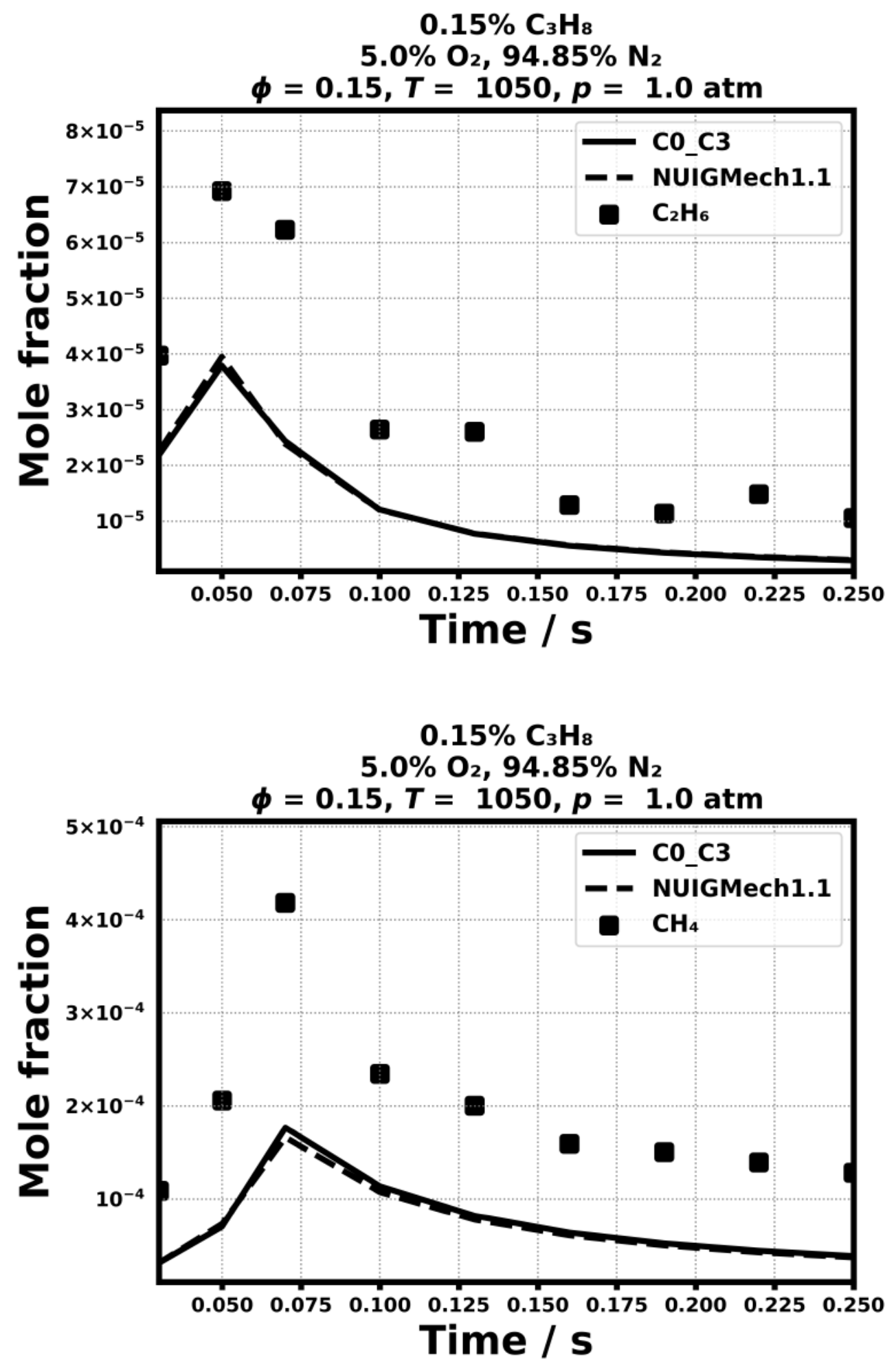

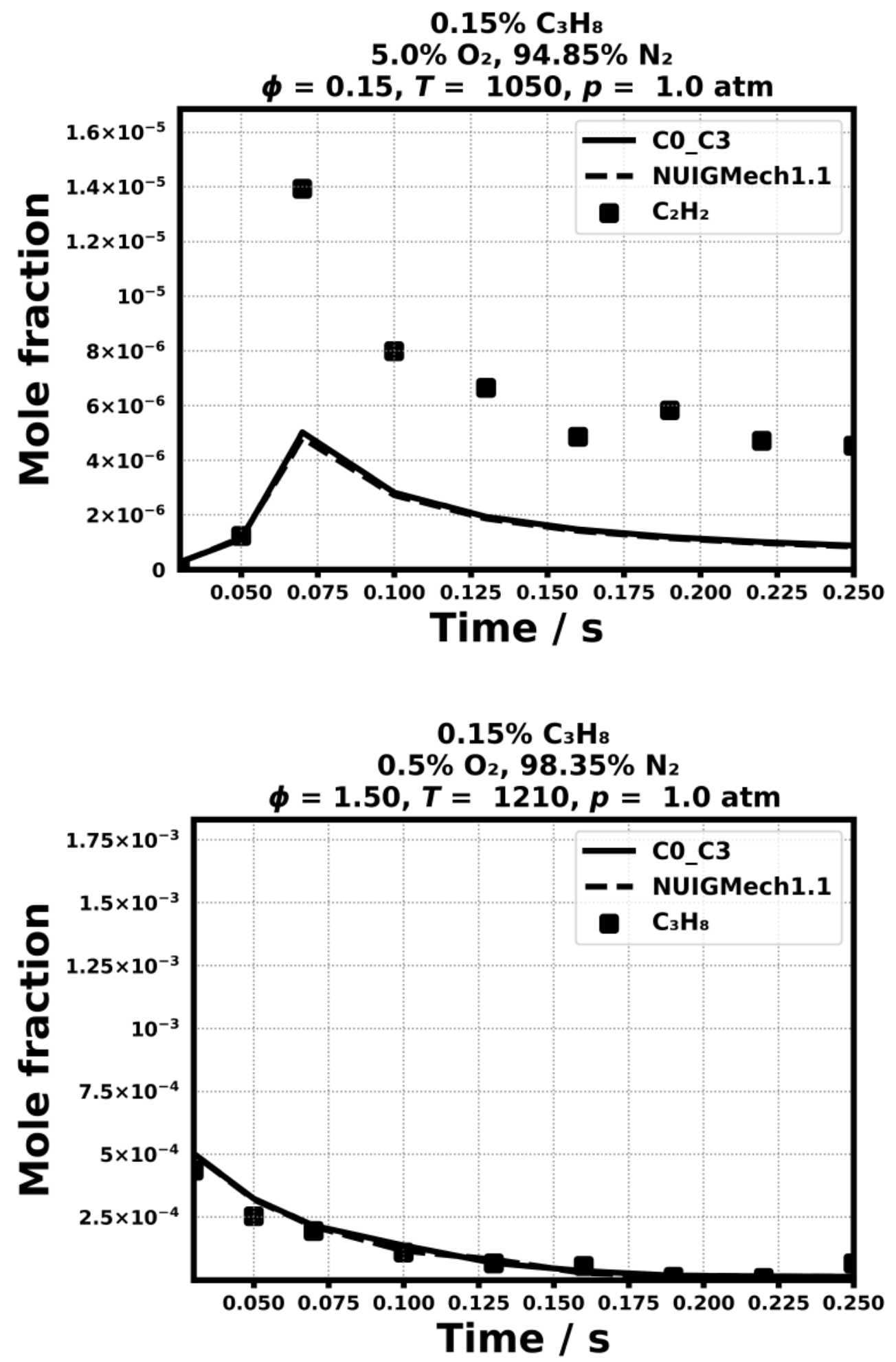

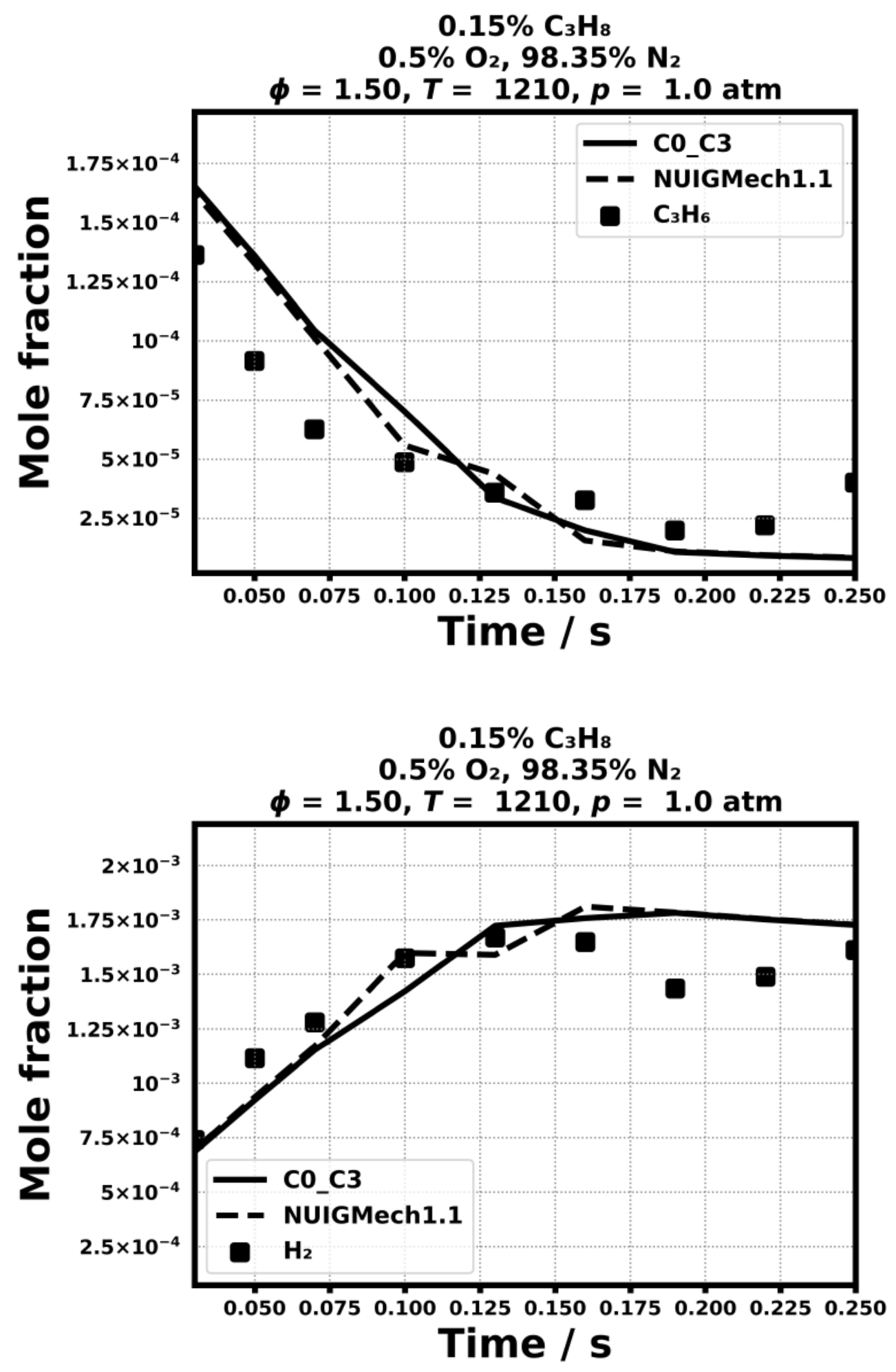

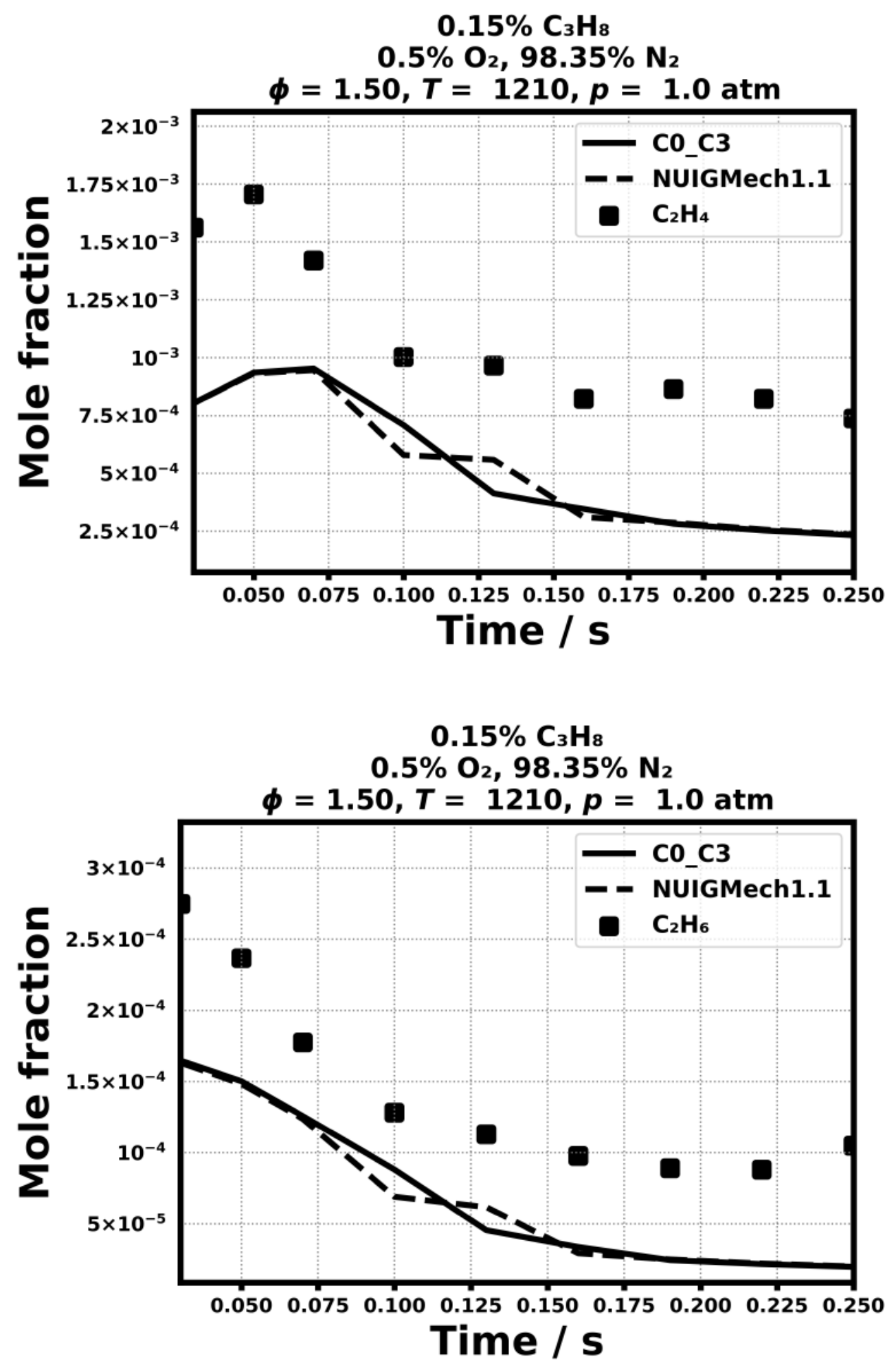

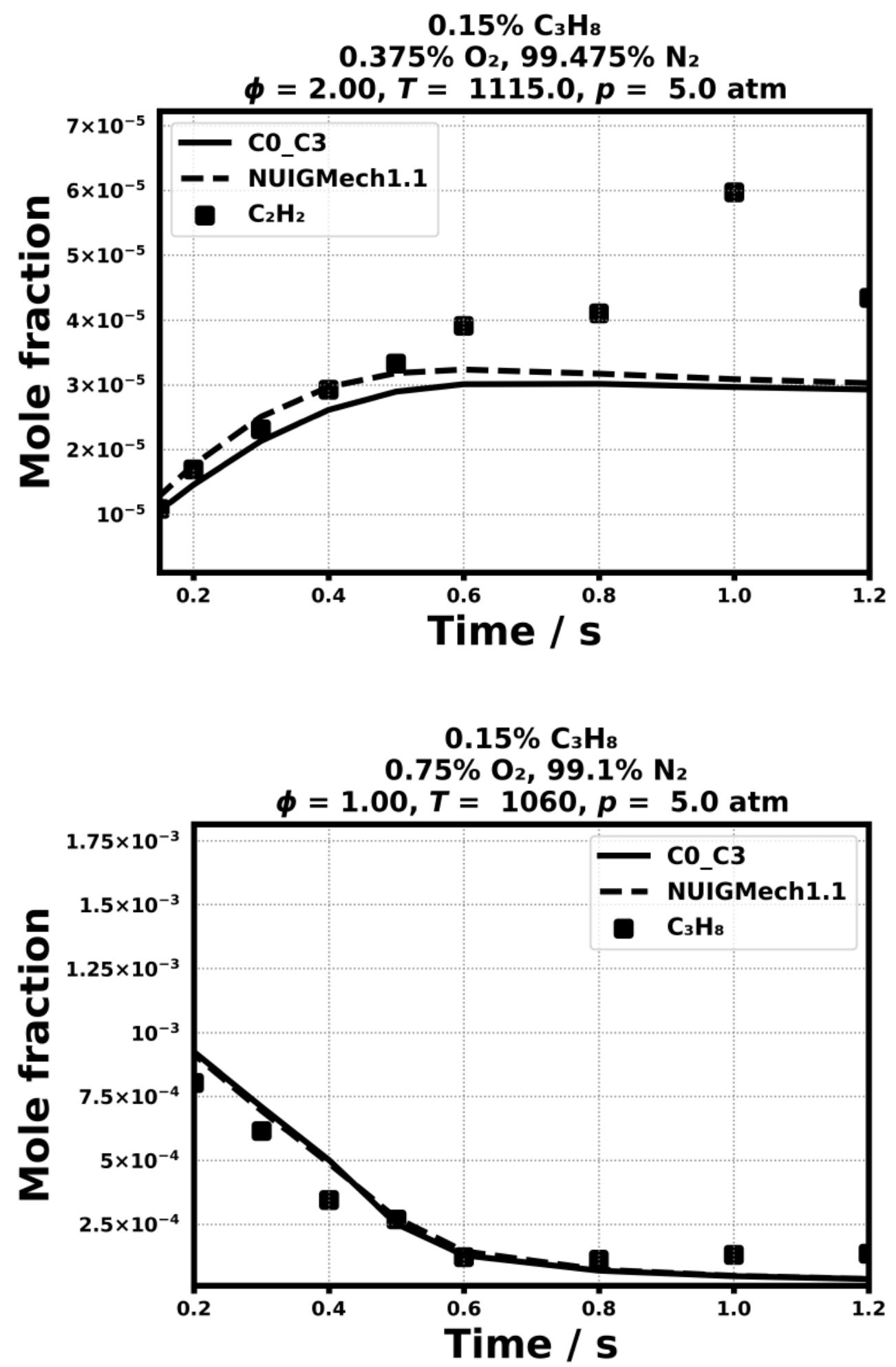

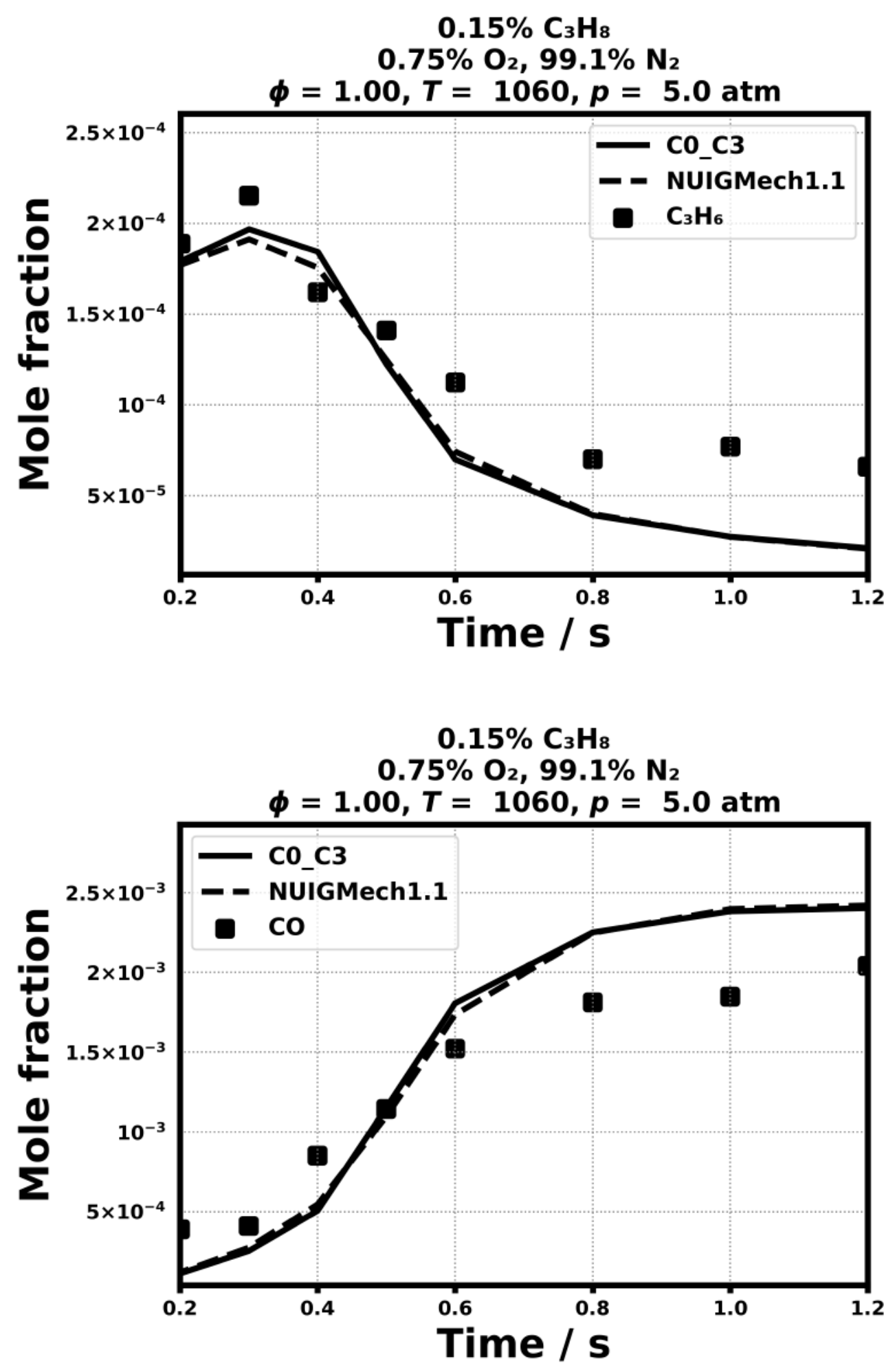

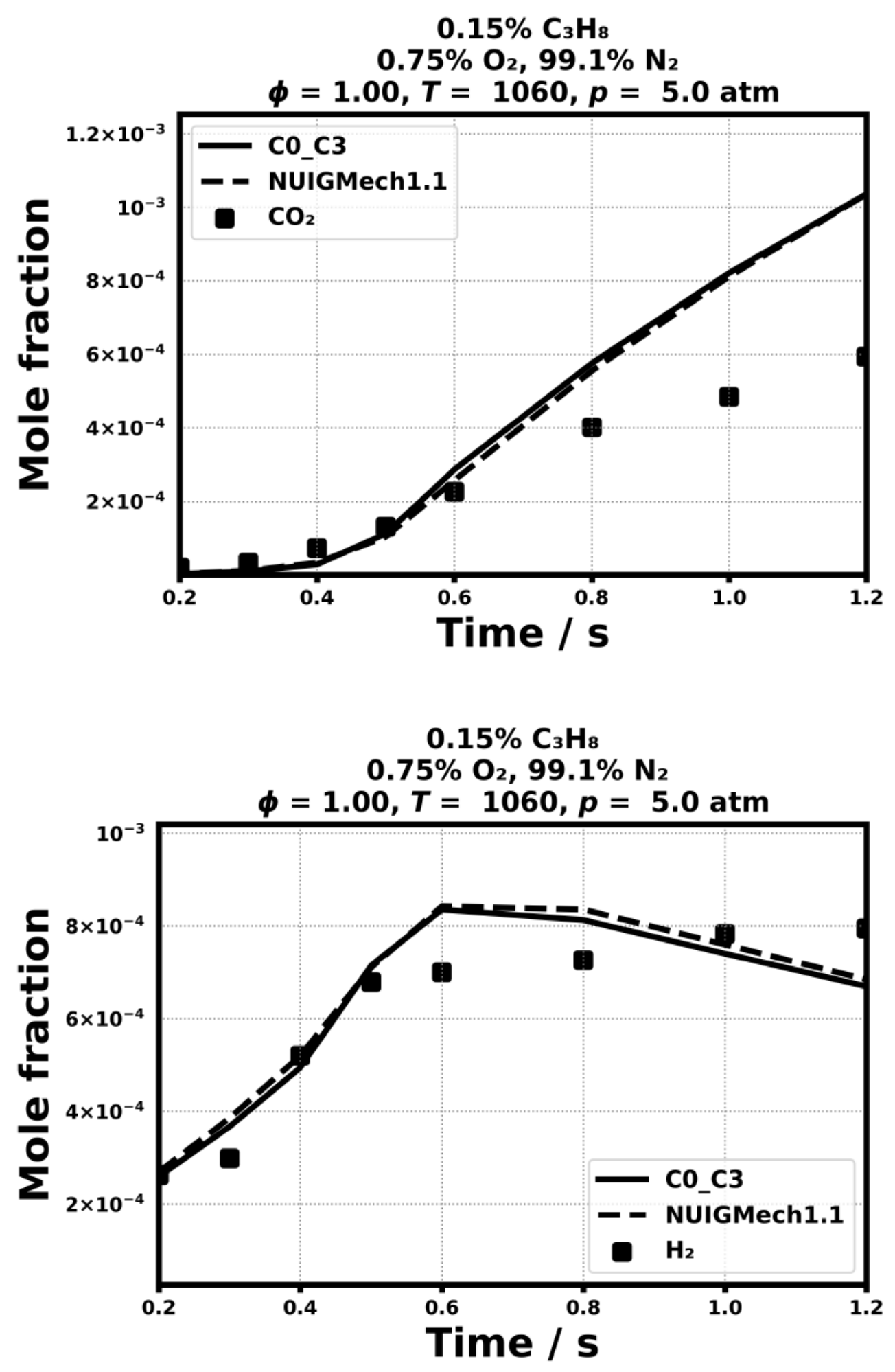

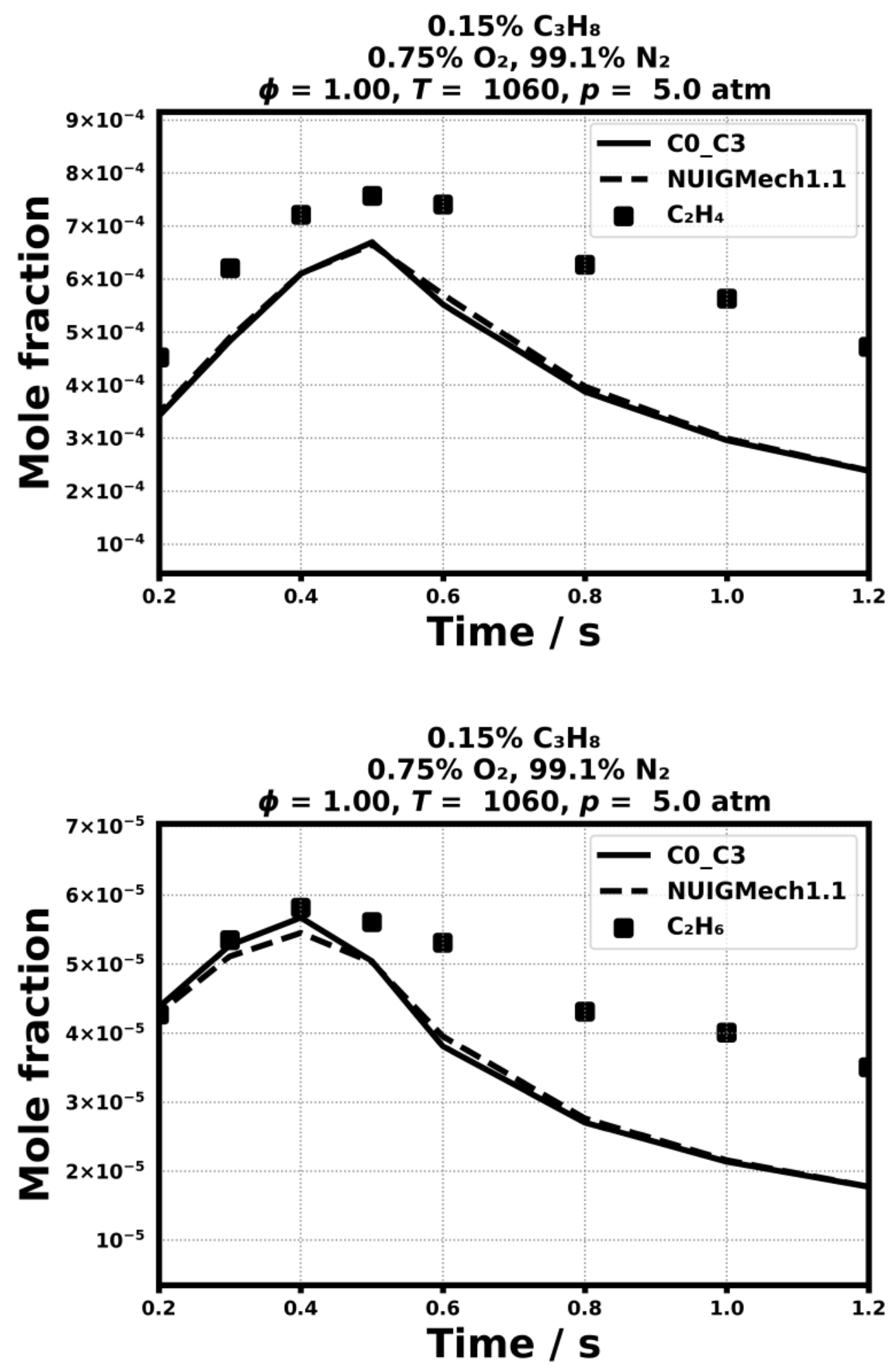

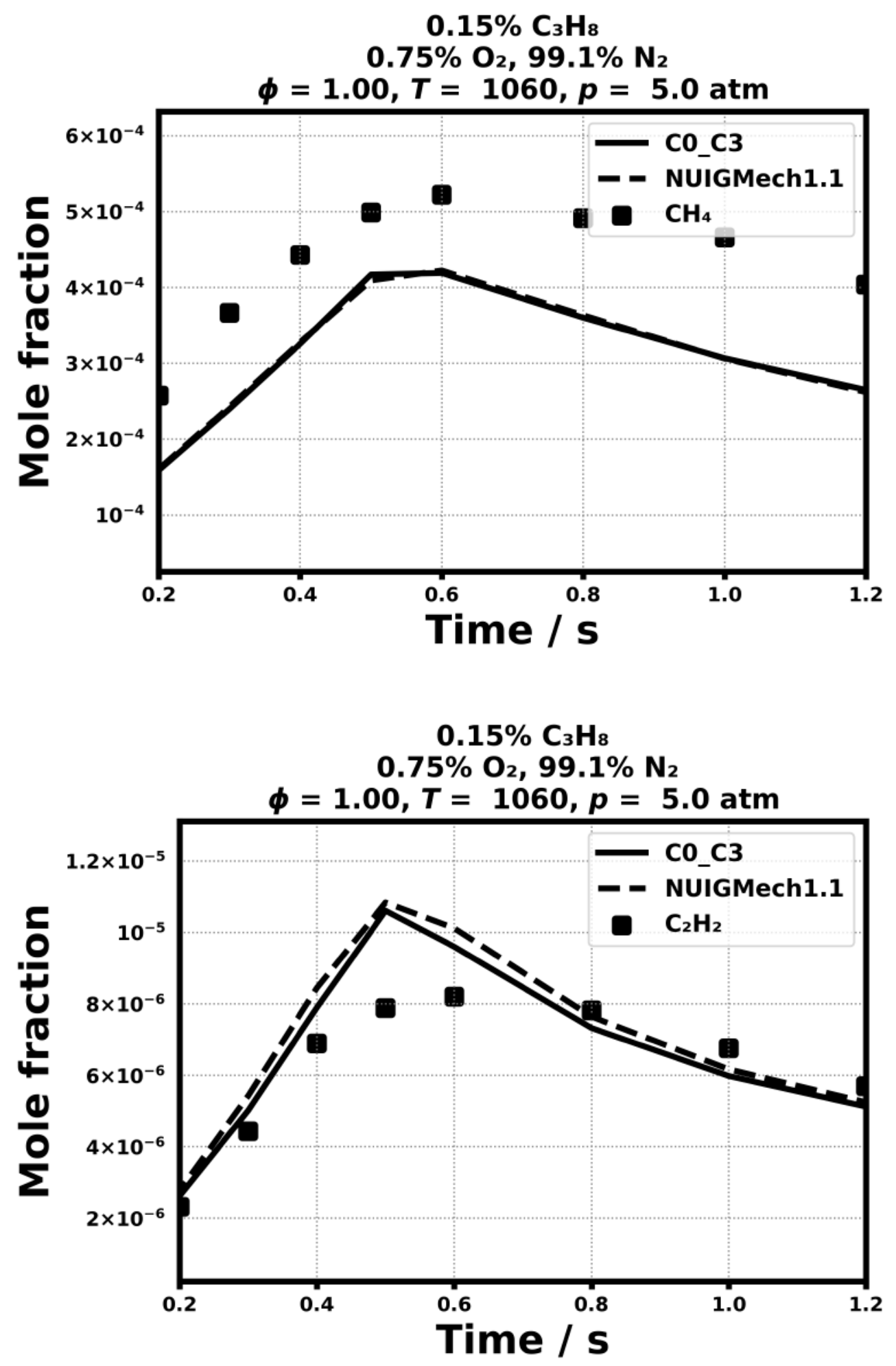

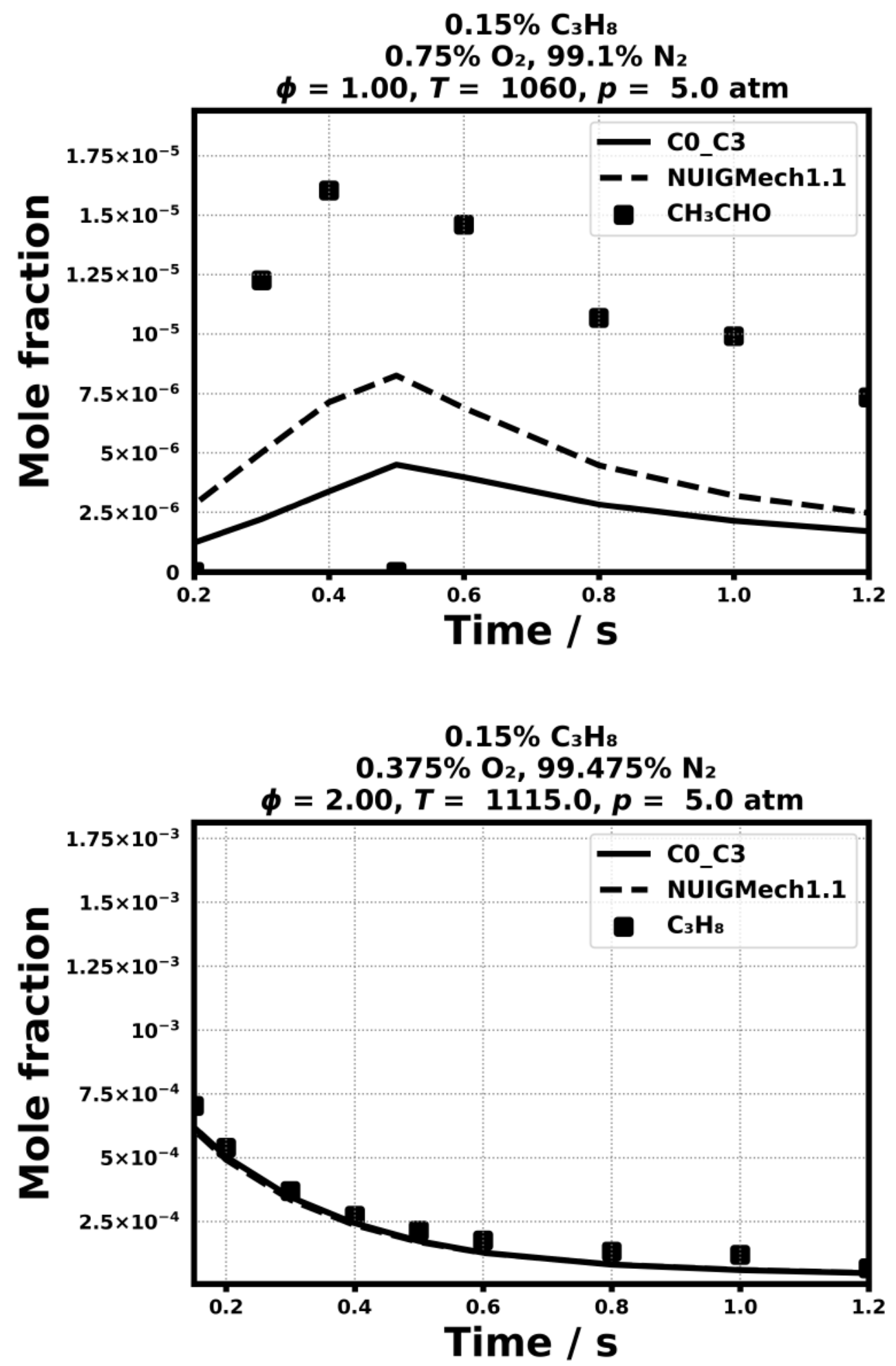

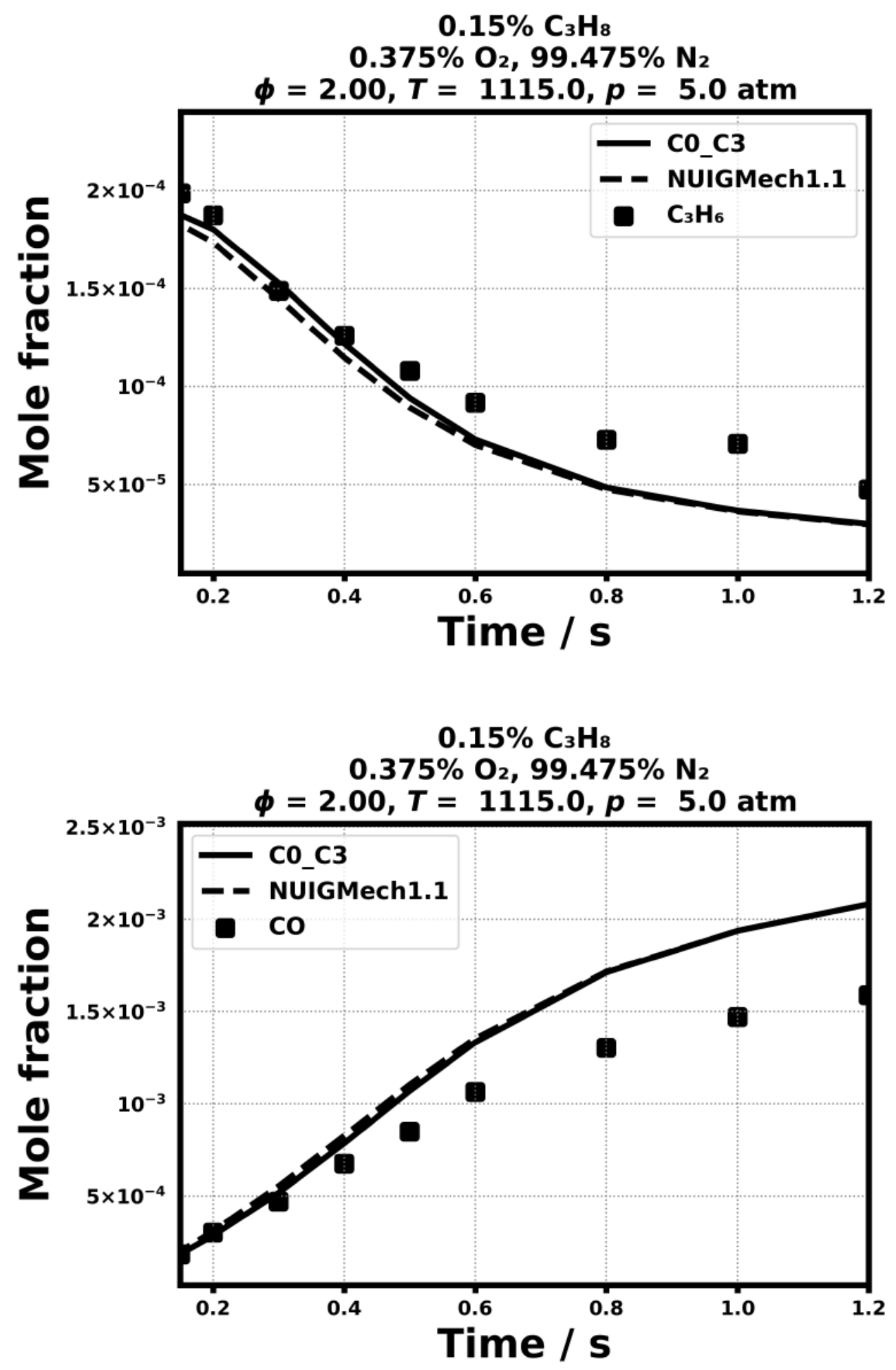


\section{Laminar flame speed}

8.10) Vagelopoulos, C.M., Egolfopoulos, F.N., Proceedings of the Combustion Institute 27 (1998) 513-519.

8.11) Jomaas, G. J., Zheng, X. L., Zhu, D. L., Law, C. K. , Proceedings of the Combustion Institute 30 (2005) 193200.

8.12) Zhao, Z., Kazakov, A., Li, J., \& Dryer, F. L., Combustion science and technology, 176(10) (2004) 1705-1723

8.13) Kuehl, K., Proceeding of Combustion Institute, 8 (1963) 510

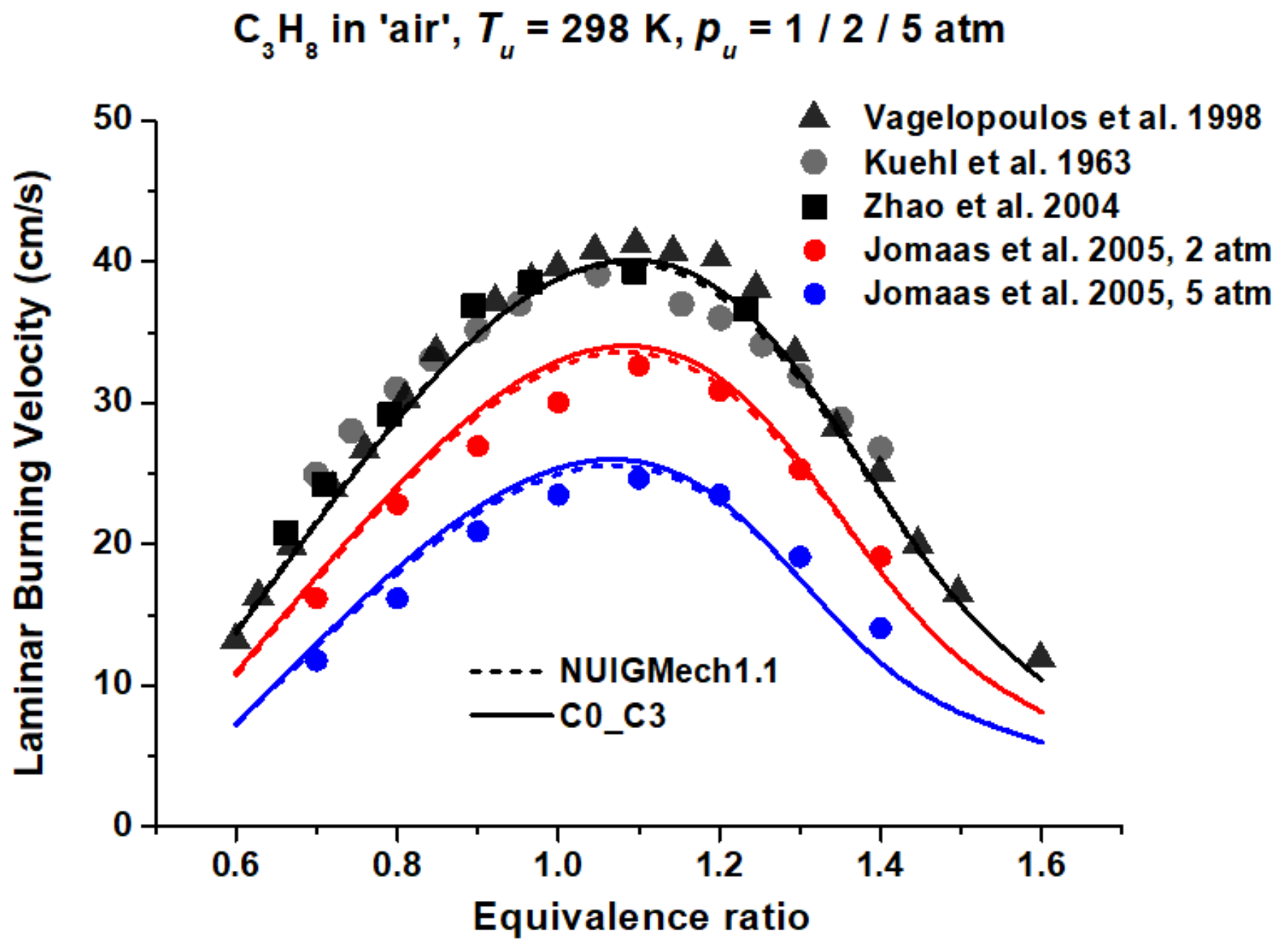




\section{Validation for $\mathrm{C}_{3} \mathrm{H}_{6}$}

\section{Shock tube ignition delay time}

9.1) Burke, S. M., Burke, U., Mc Donagh, R., Mathieu, O., Osorio, I., Keesee, C., ... \& Oehlschlaeger, M. A., Combustion and Flame, 162(2) (2015) 296-314.

\section{$4.46 \% \mathrm{C}_{3} \mathrm{H}_{6}$}

$20.07 \% \mathrm{O}_{2}, 75.47 \% \mathrm{~N}_{2}$

$\phi=1.0,40.73 \mathrm{~atm}$

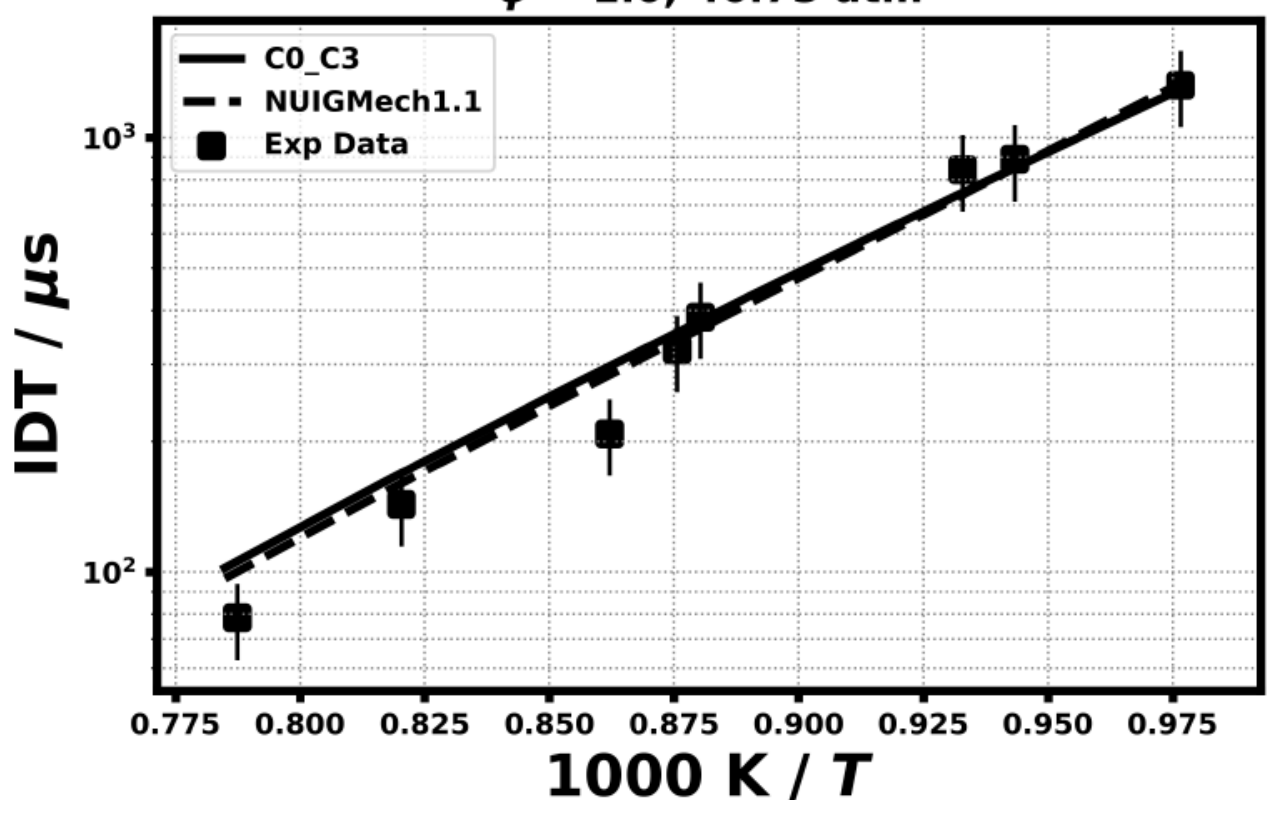

$8.54 \% \mathrm{C}_{3} \mathrm{H}_{6}$

$19.21 \% \mathrm{O}_{2}, 72.25 \% \mathrm{~N}_{2}$

$\phi=2.0,41.74 \mathrm{~atm}$

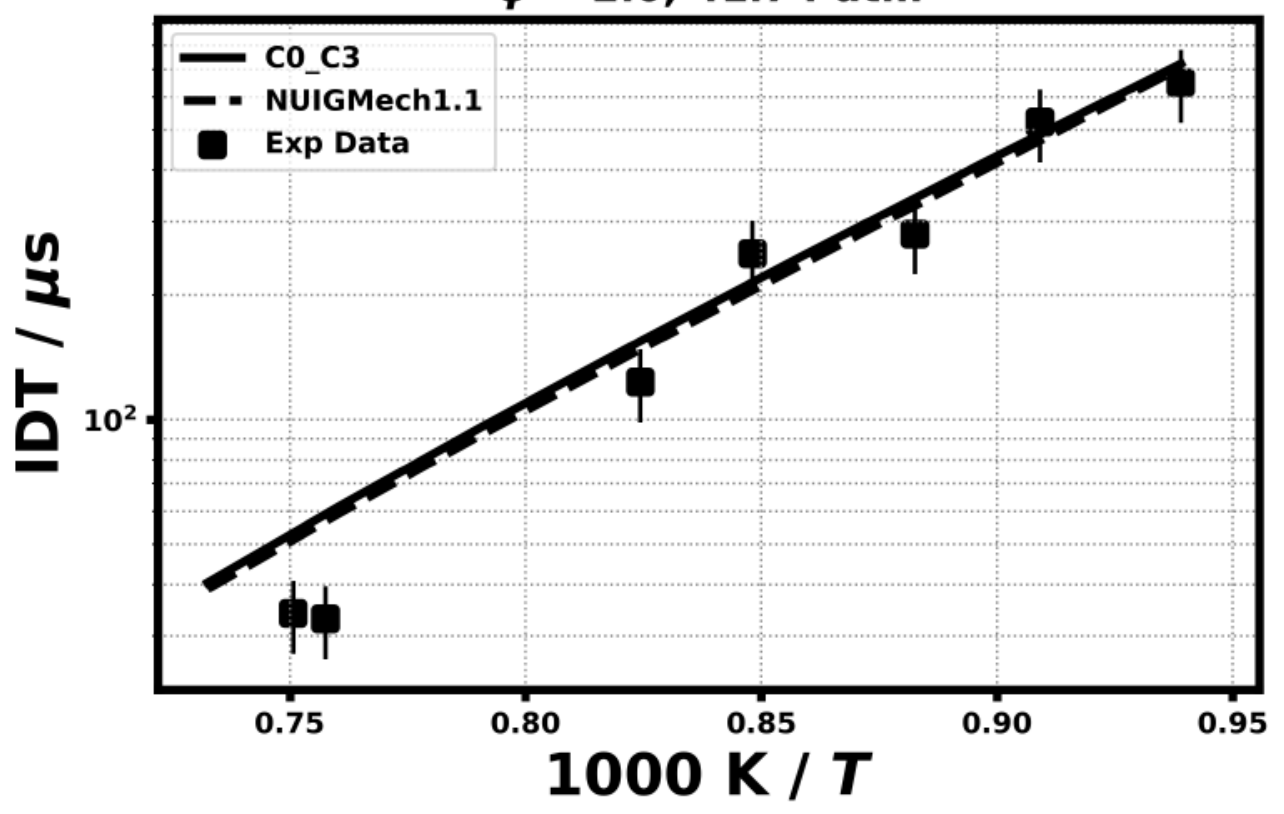



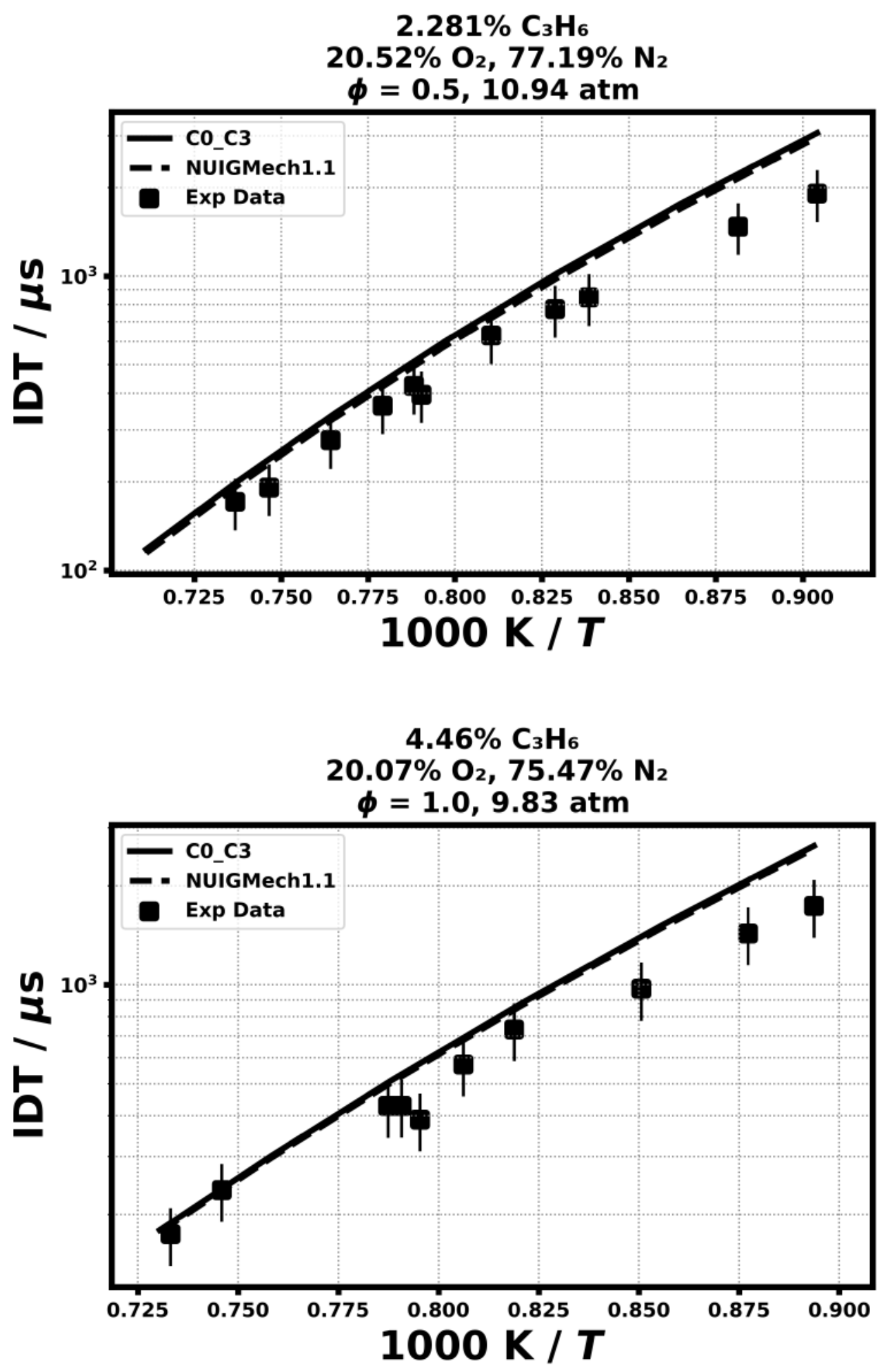

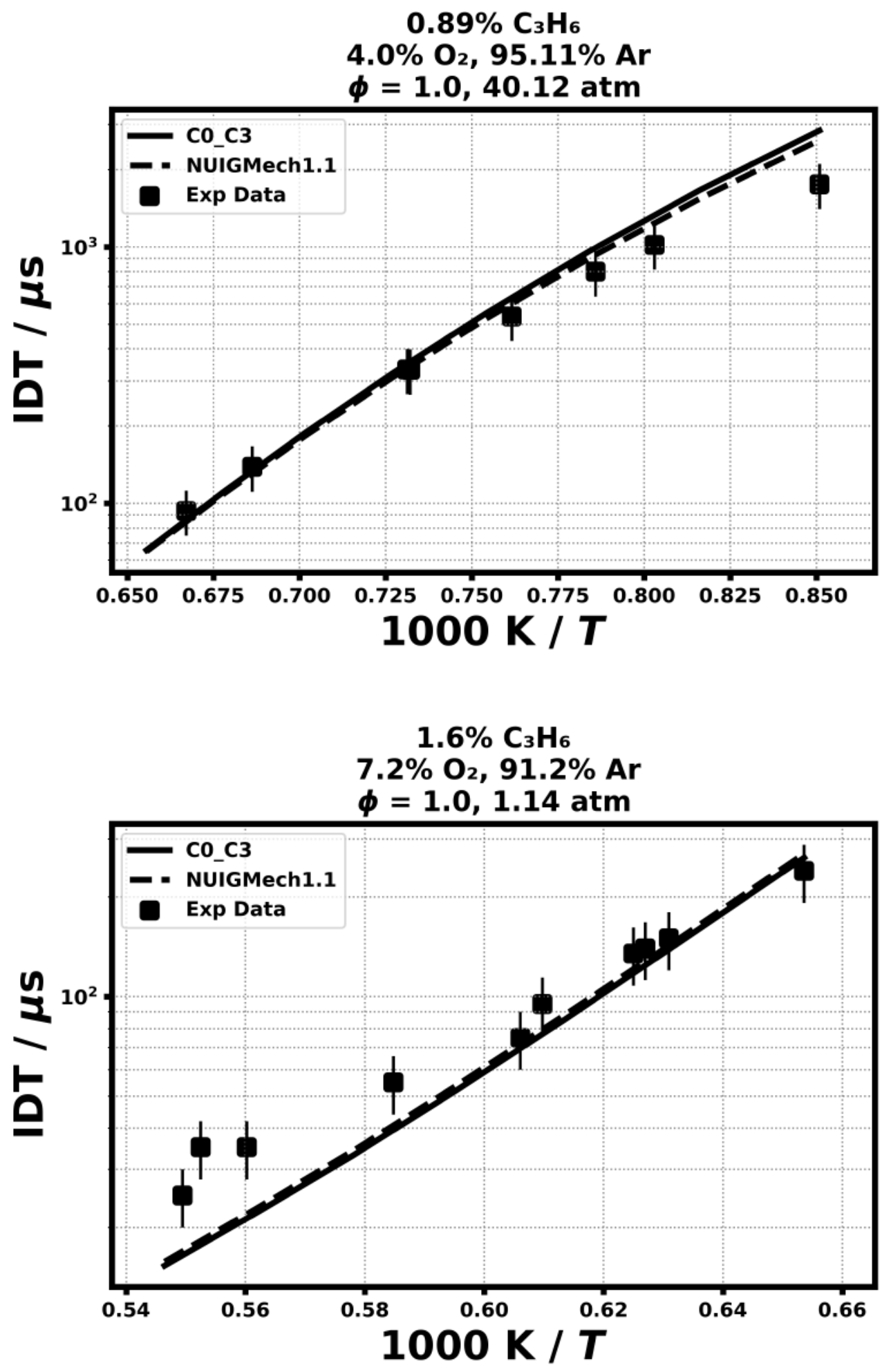

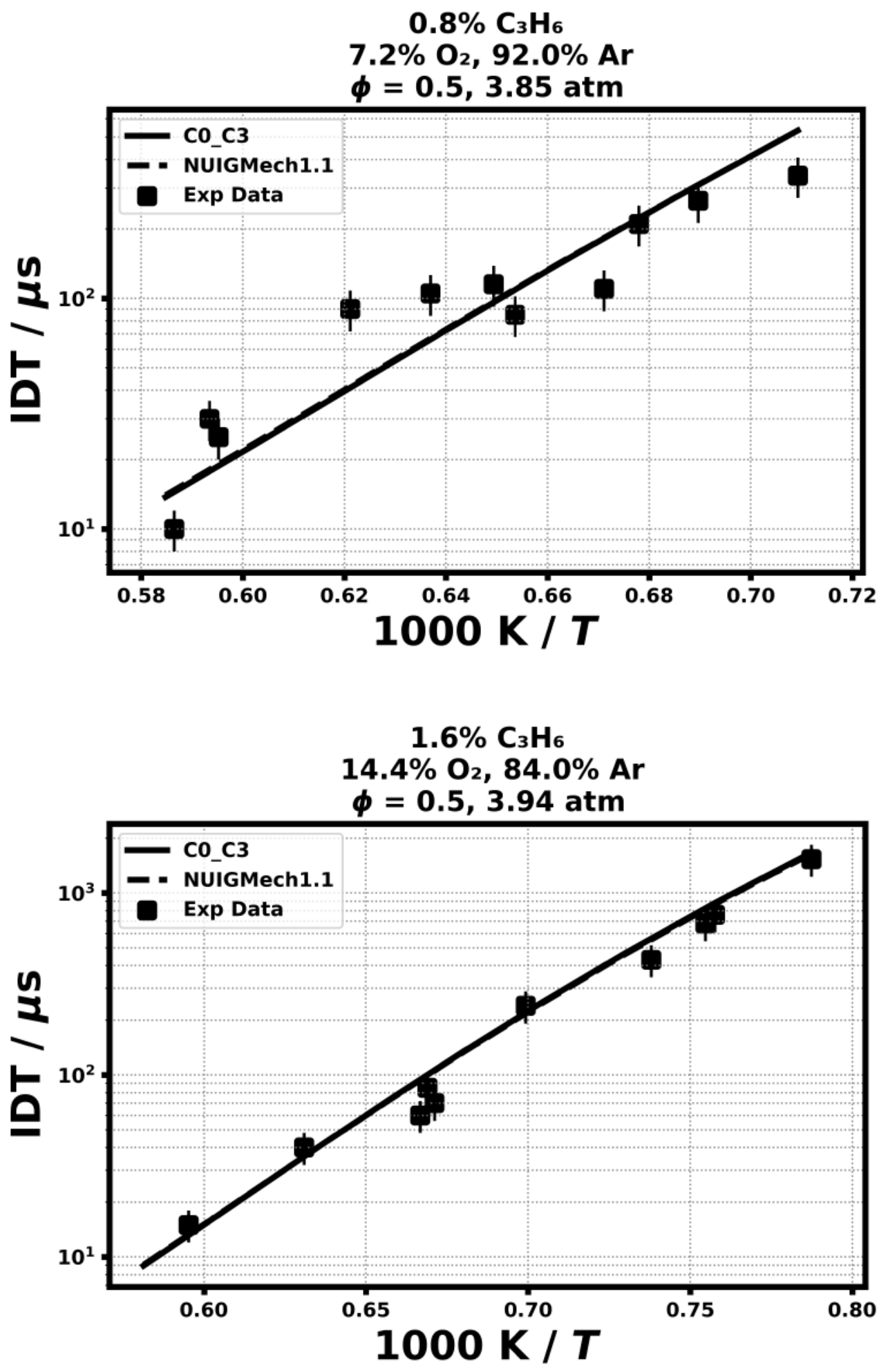

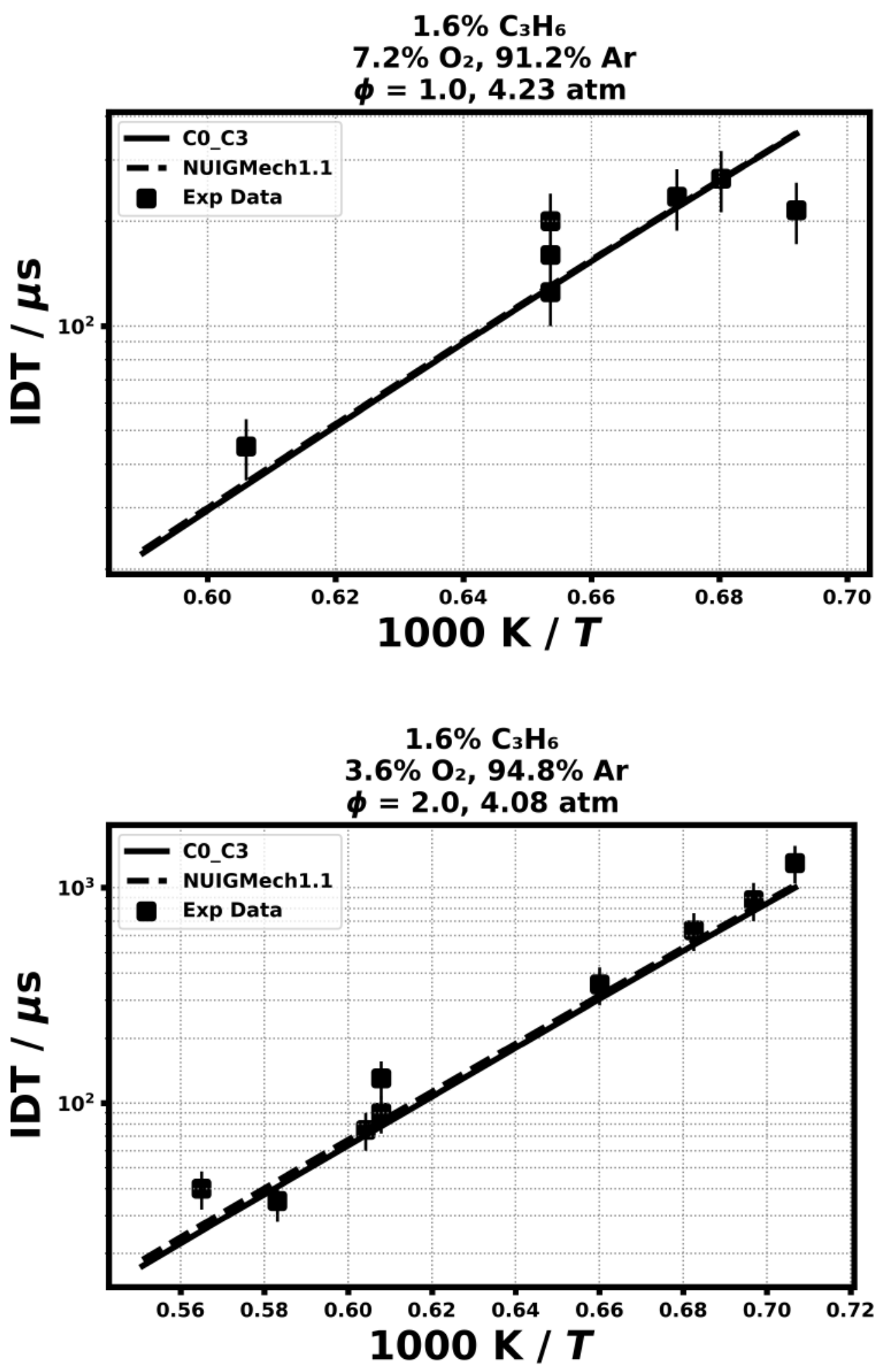

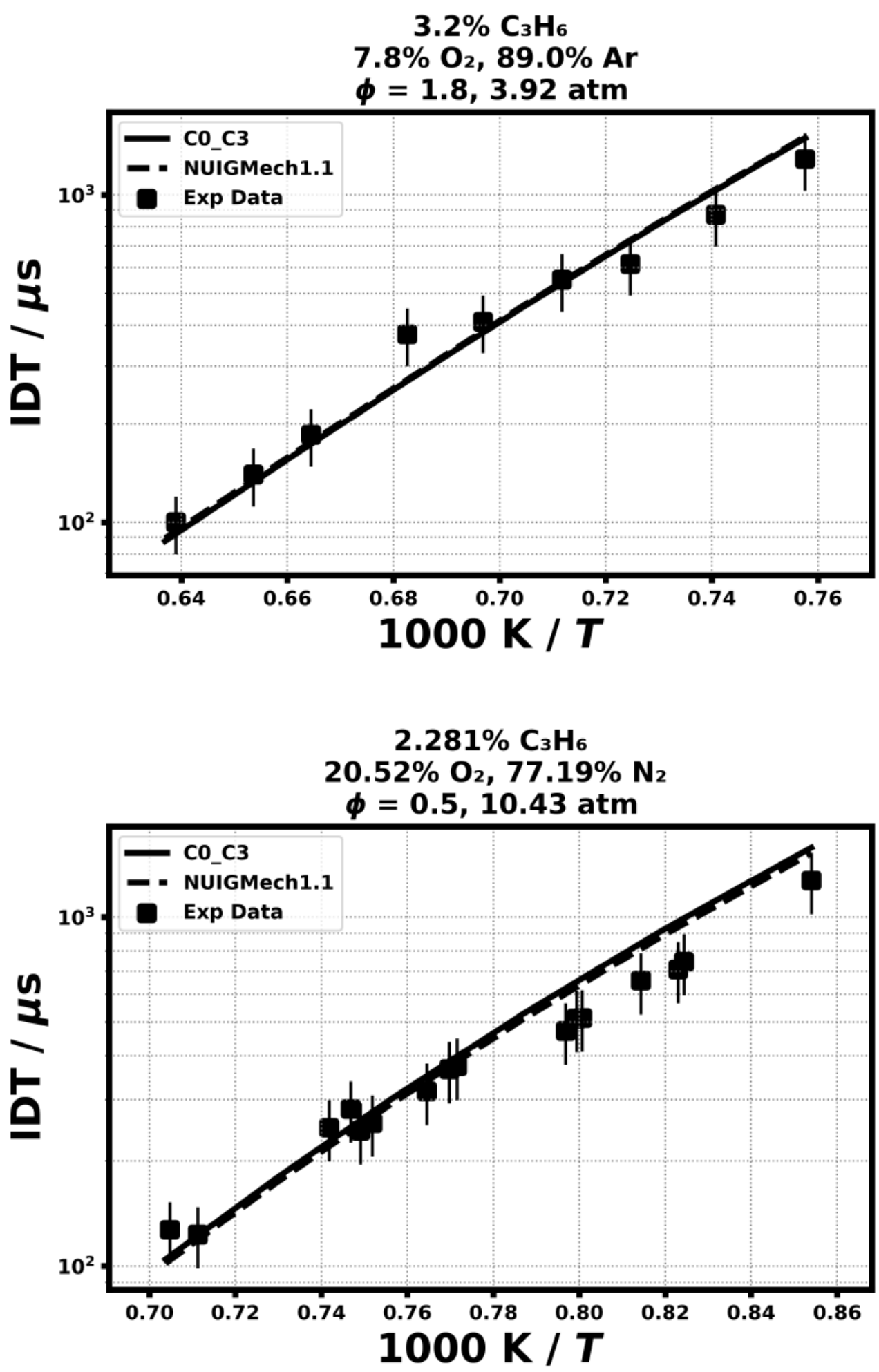

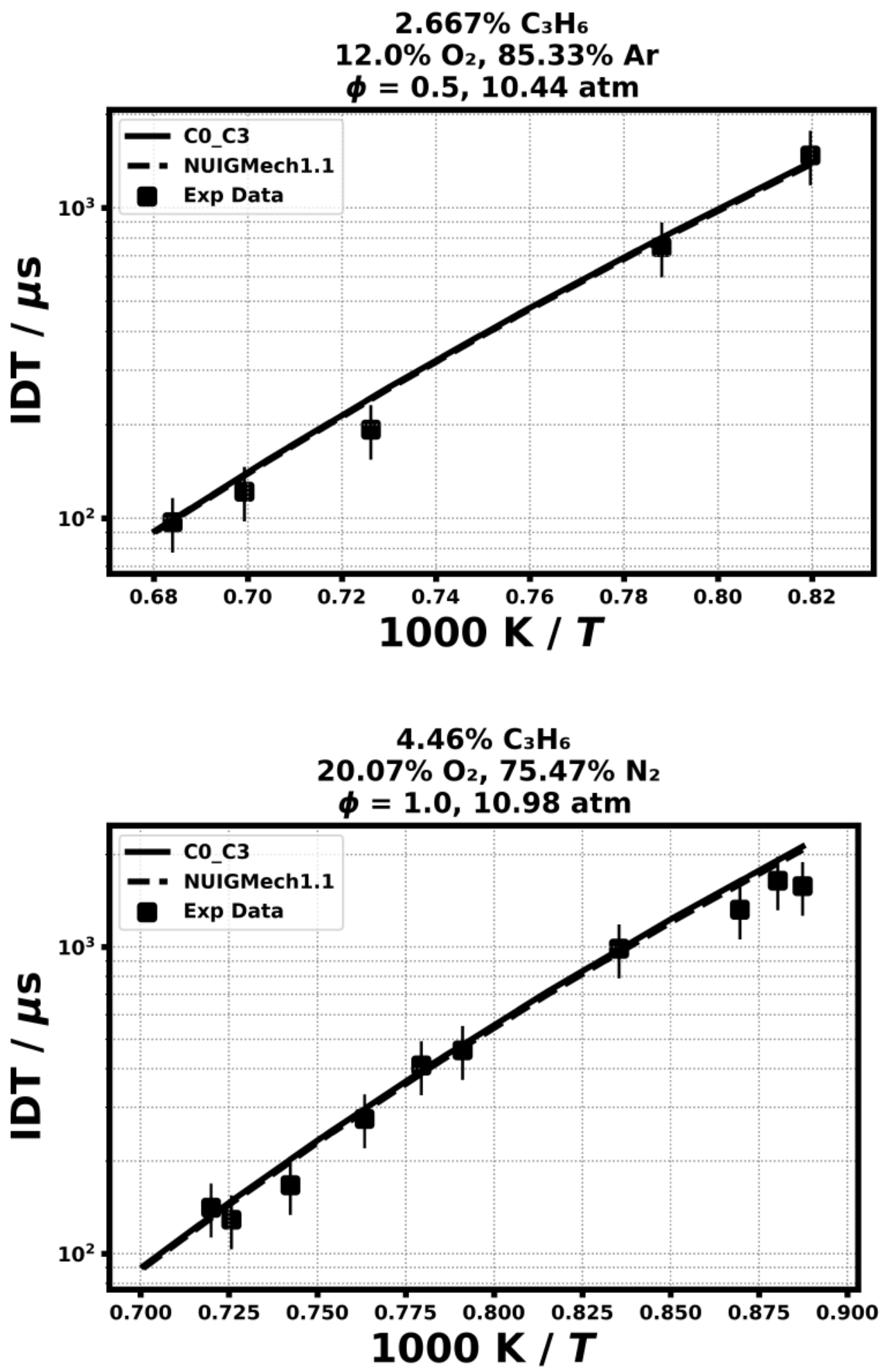

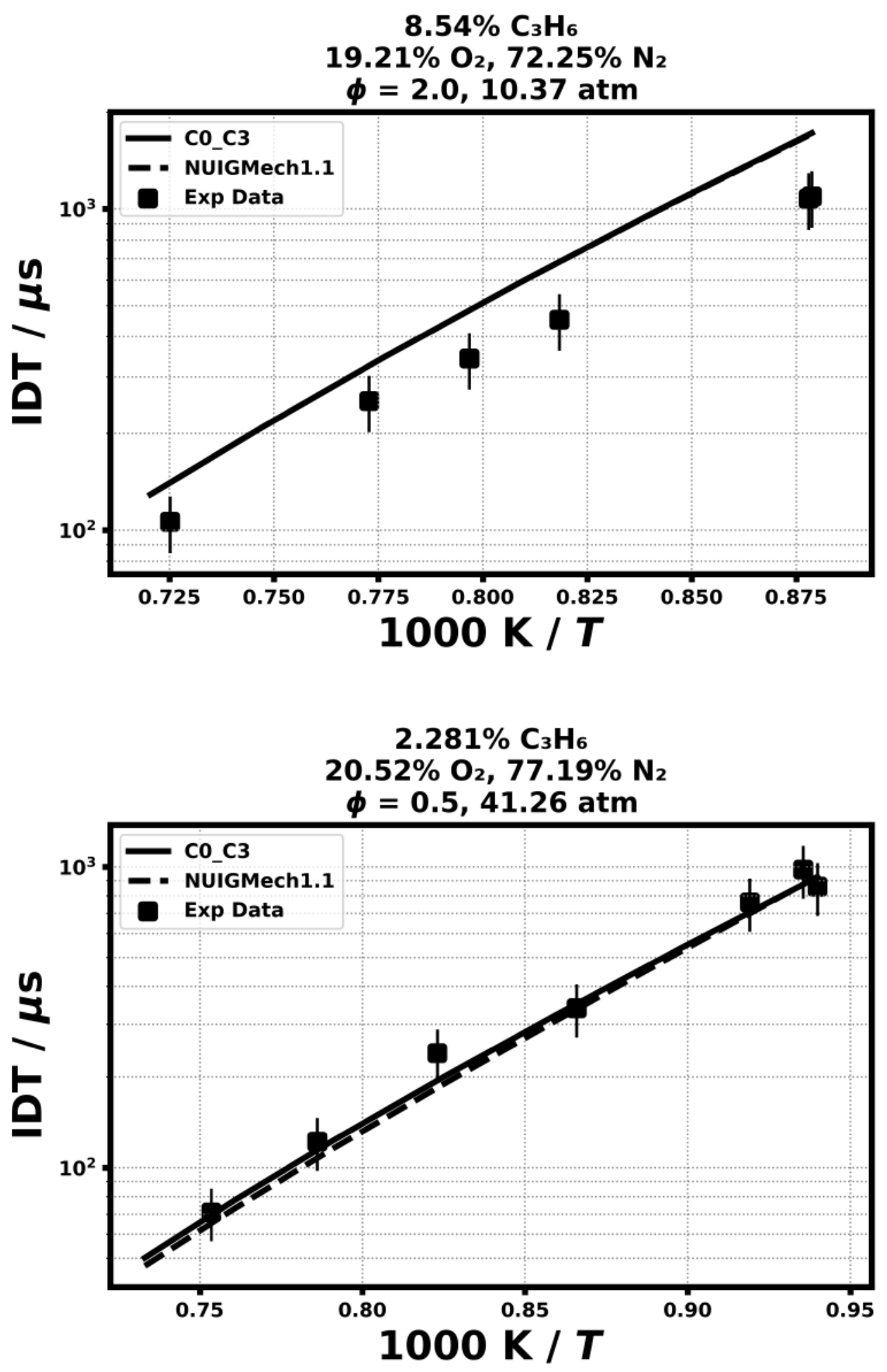

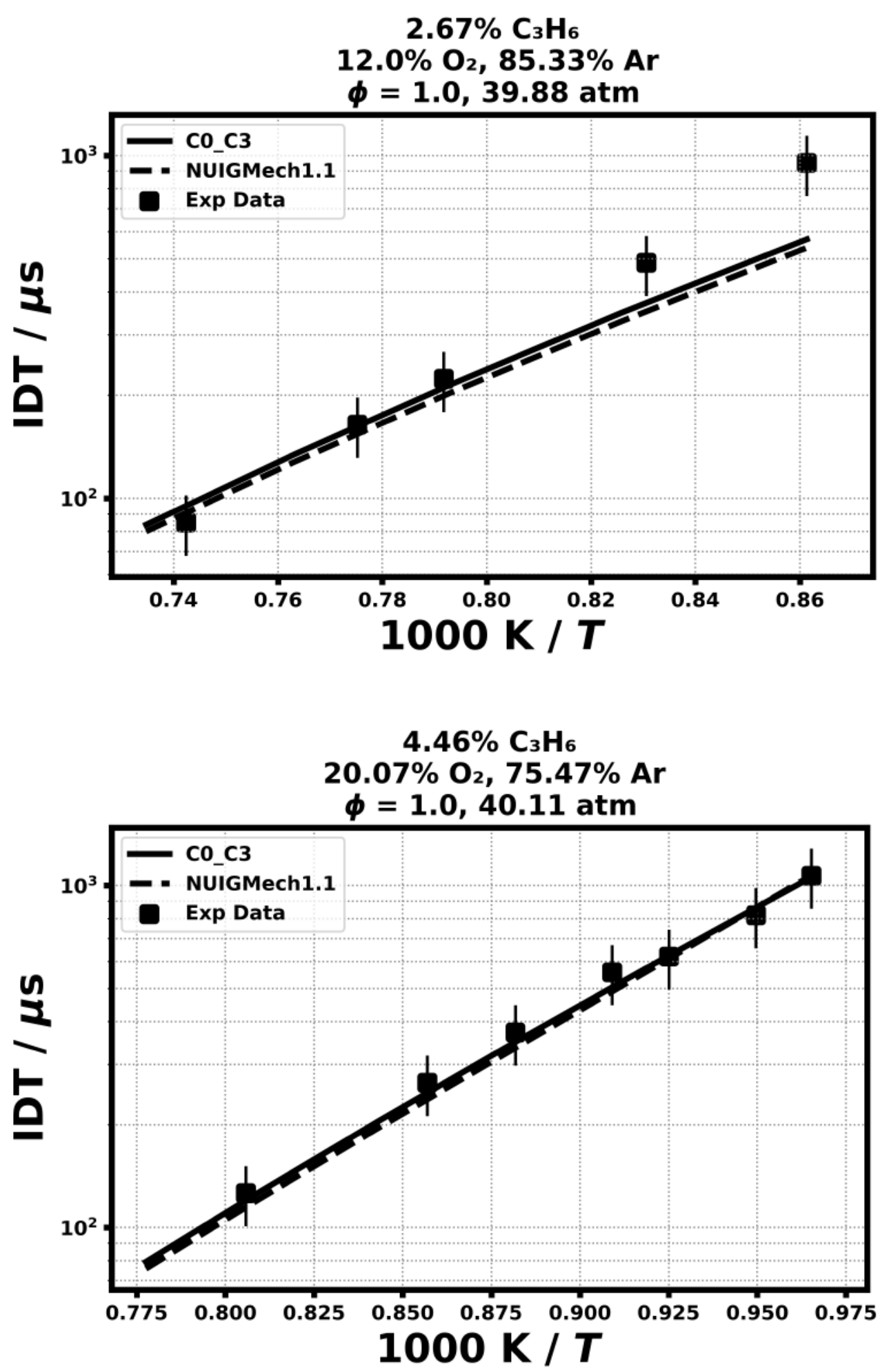

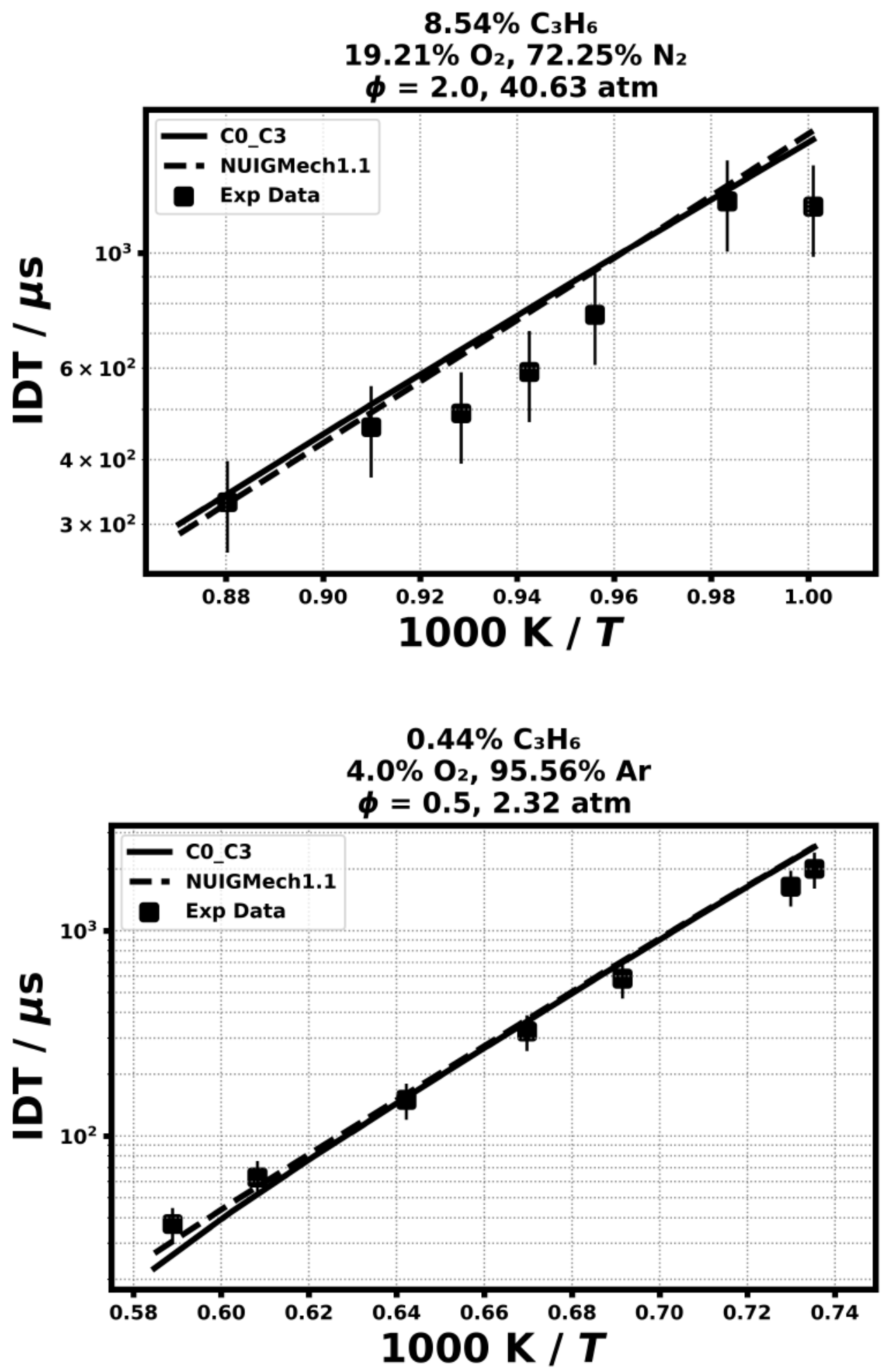

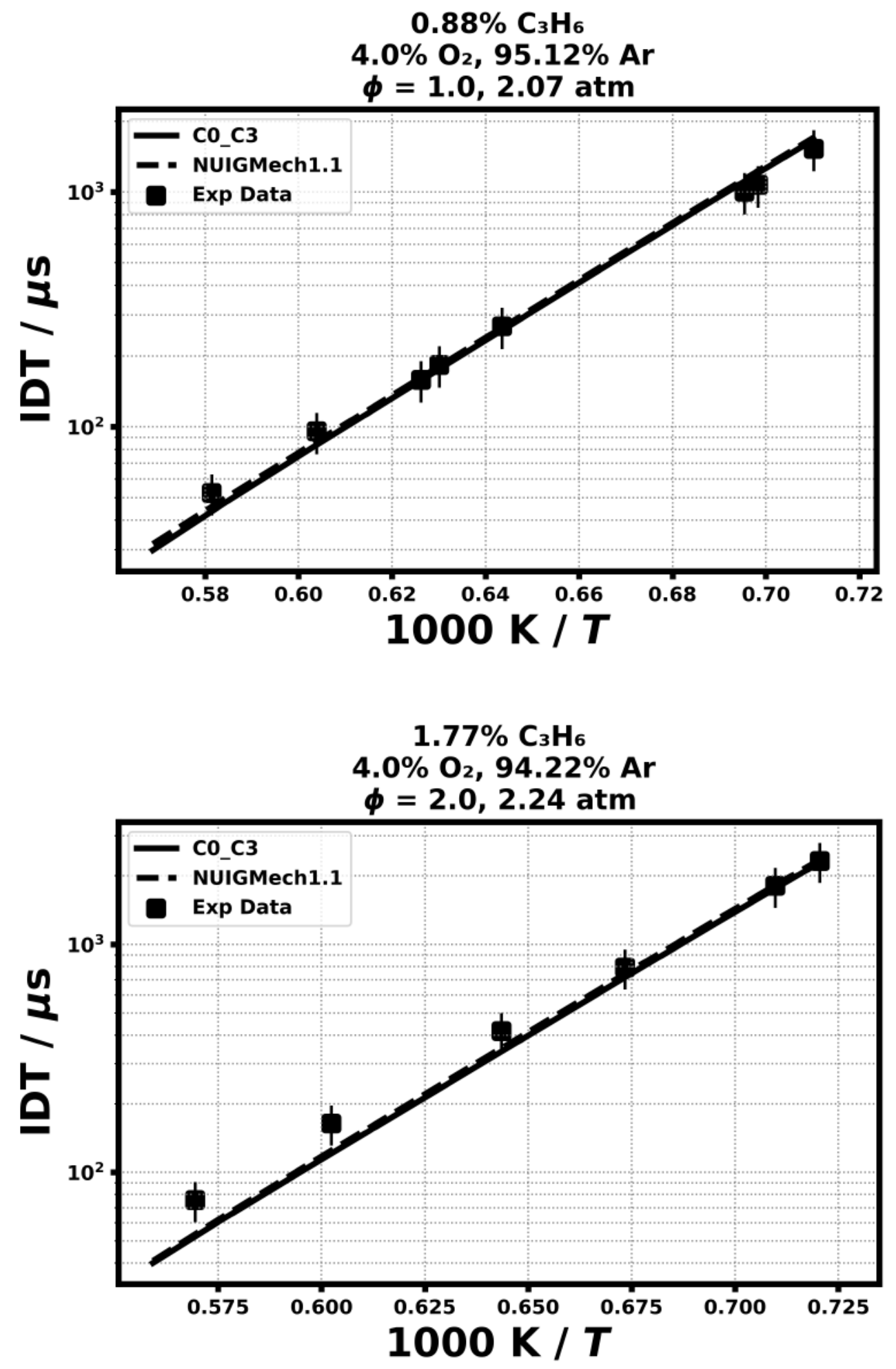

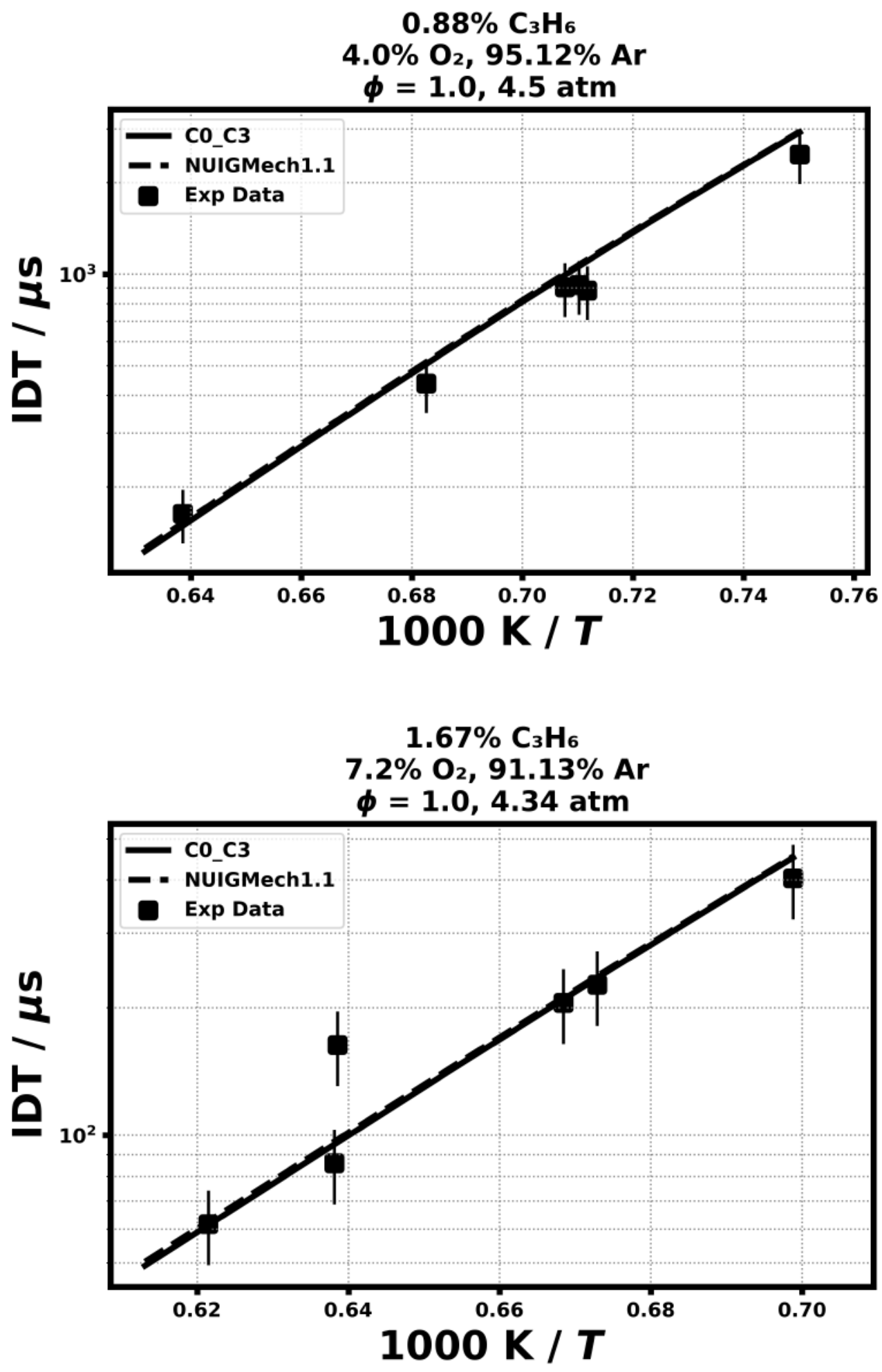

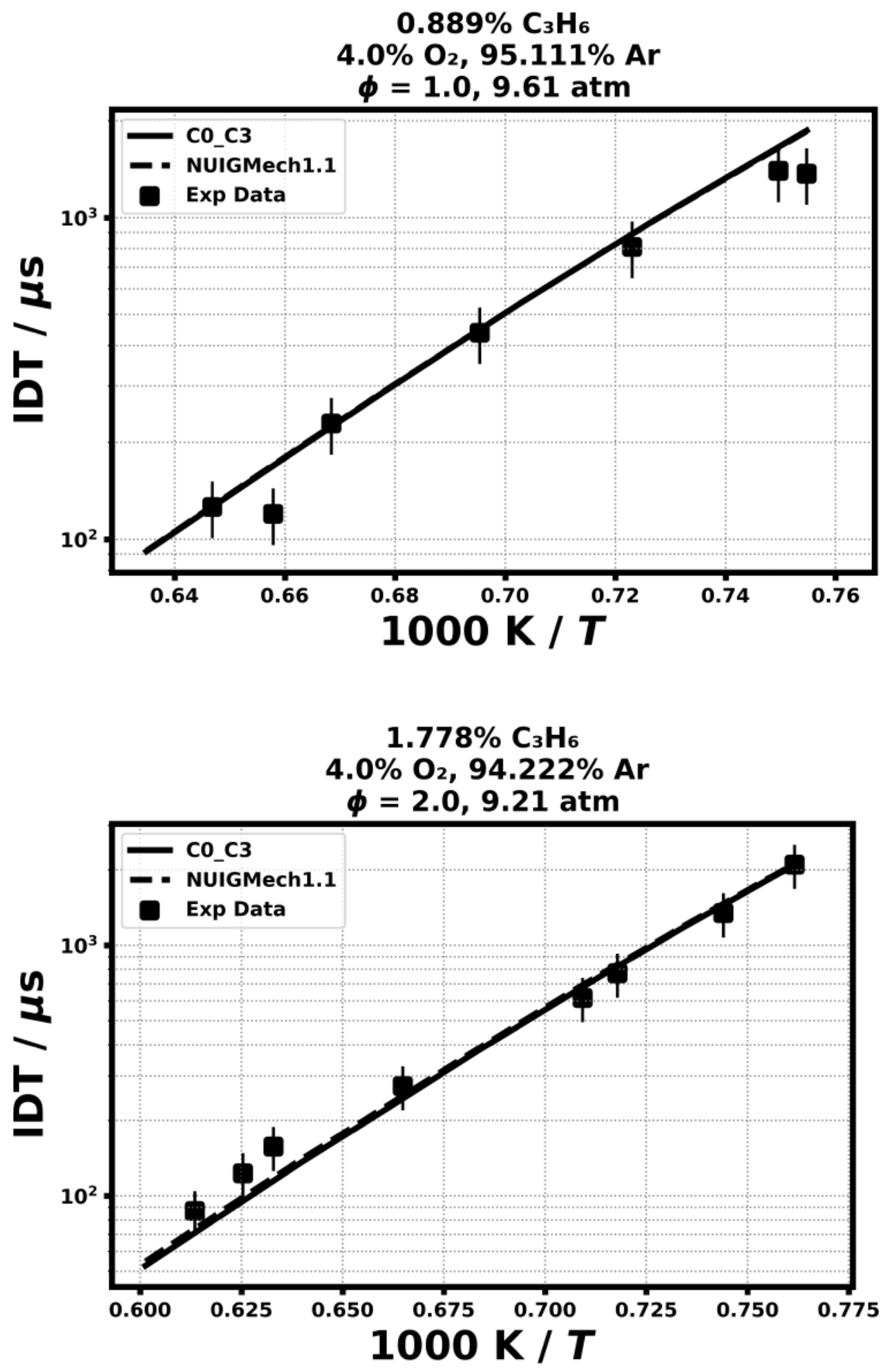

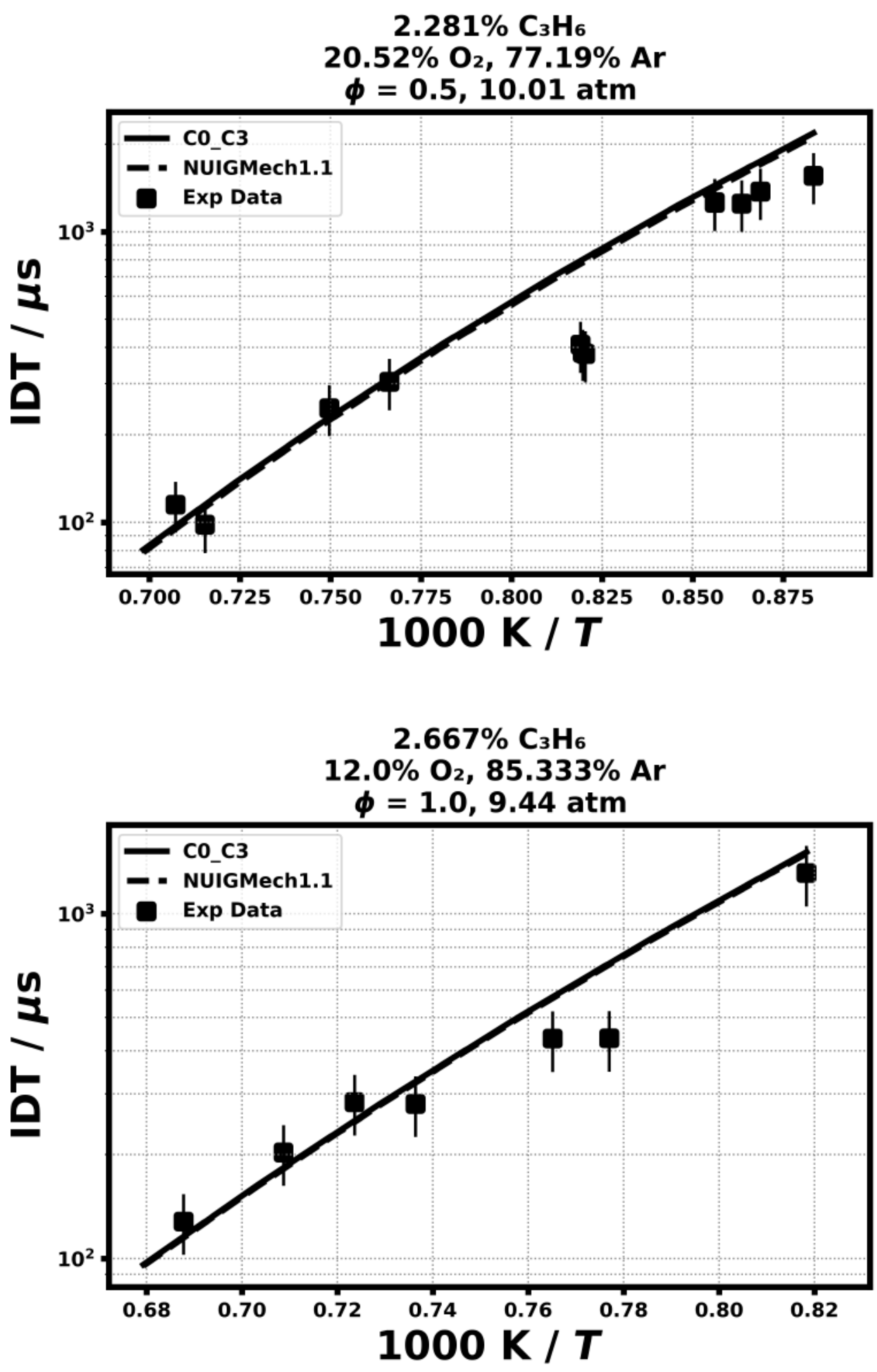

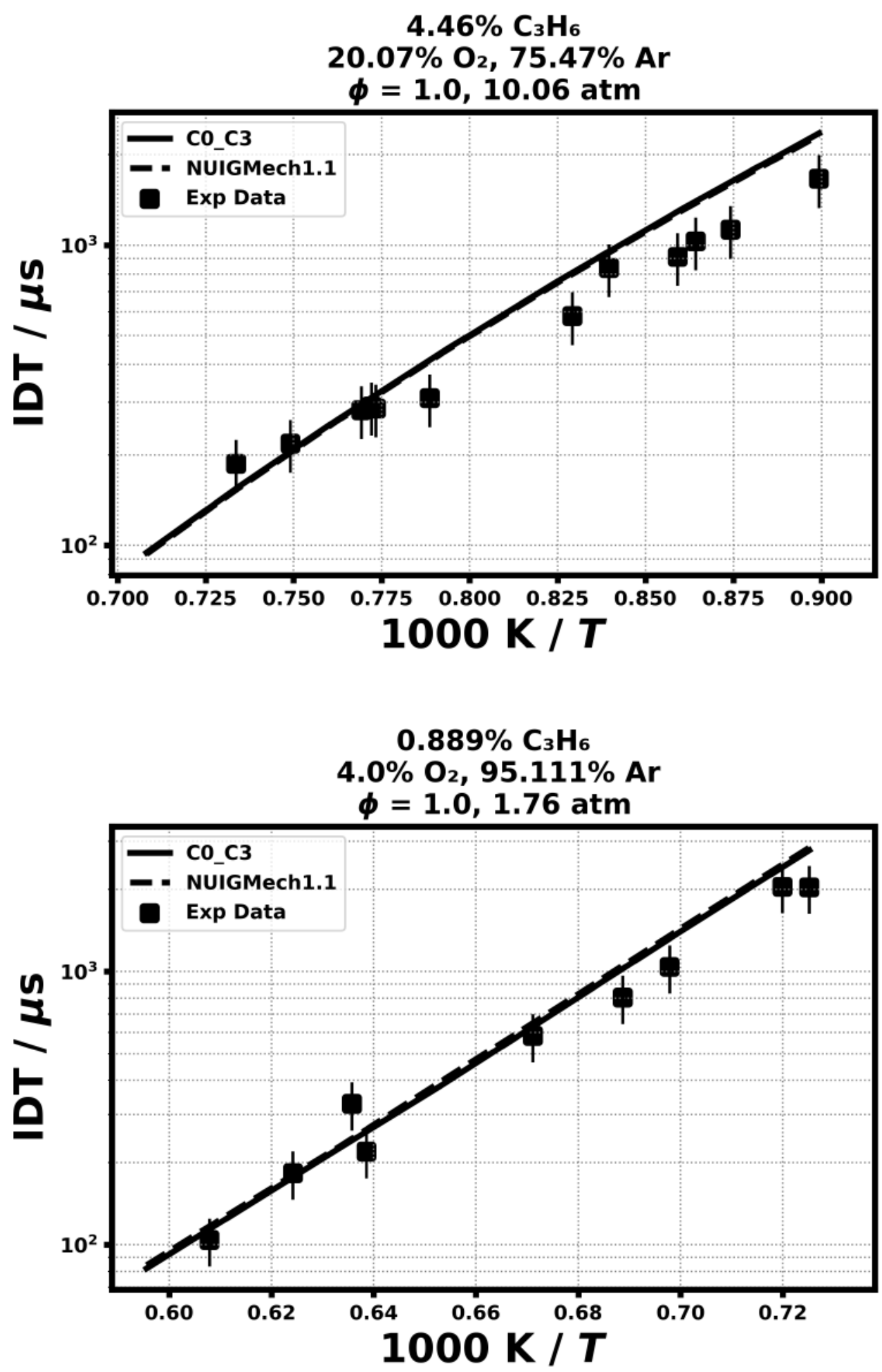

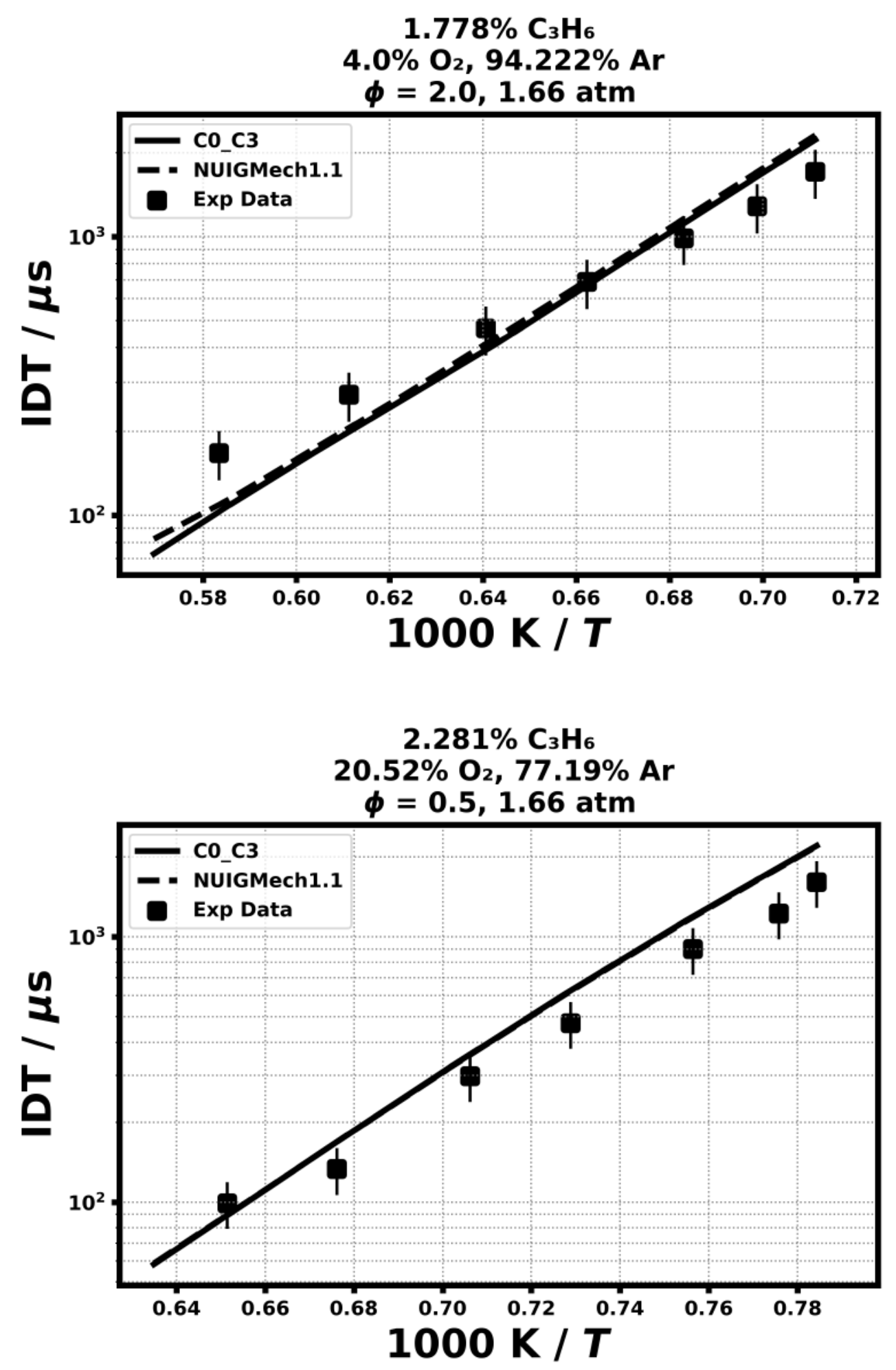


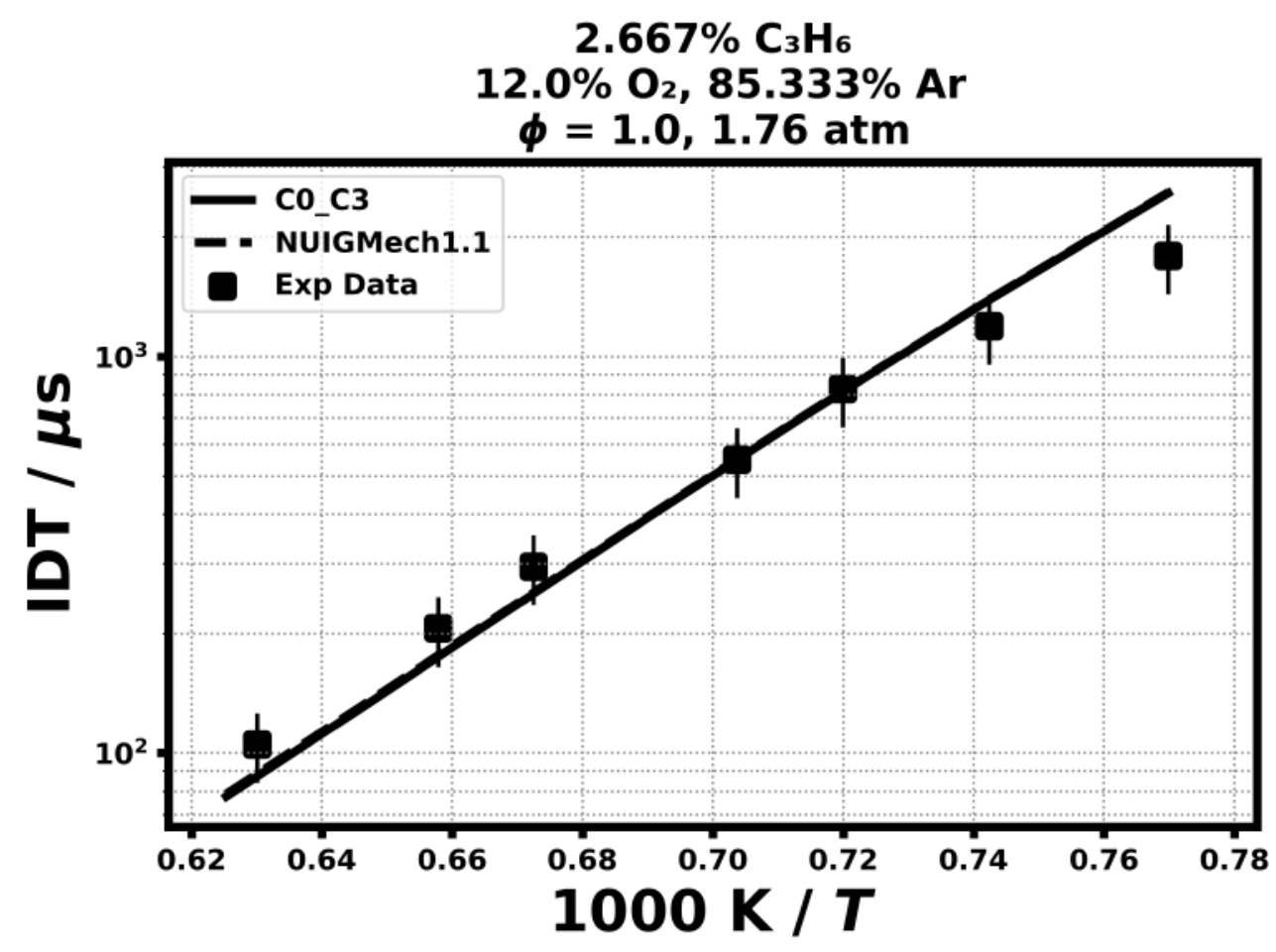

\section{RCM Ignition delay time}

9.2) Burke, S. M., Burke, U., Mc Donagh, R., Mathieu, O., Osorio, I., Keesee, C., ... \& Oehlschlaeger, M. A., Combustion and Flame, 162(2) (2015) 296-314.

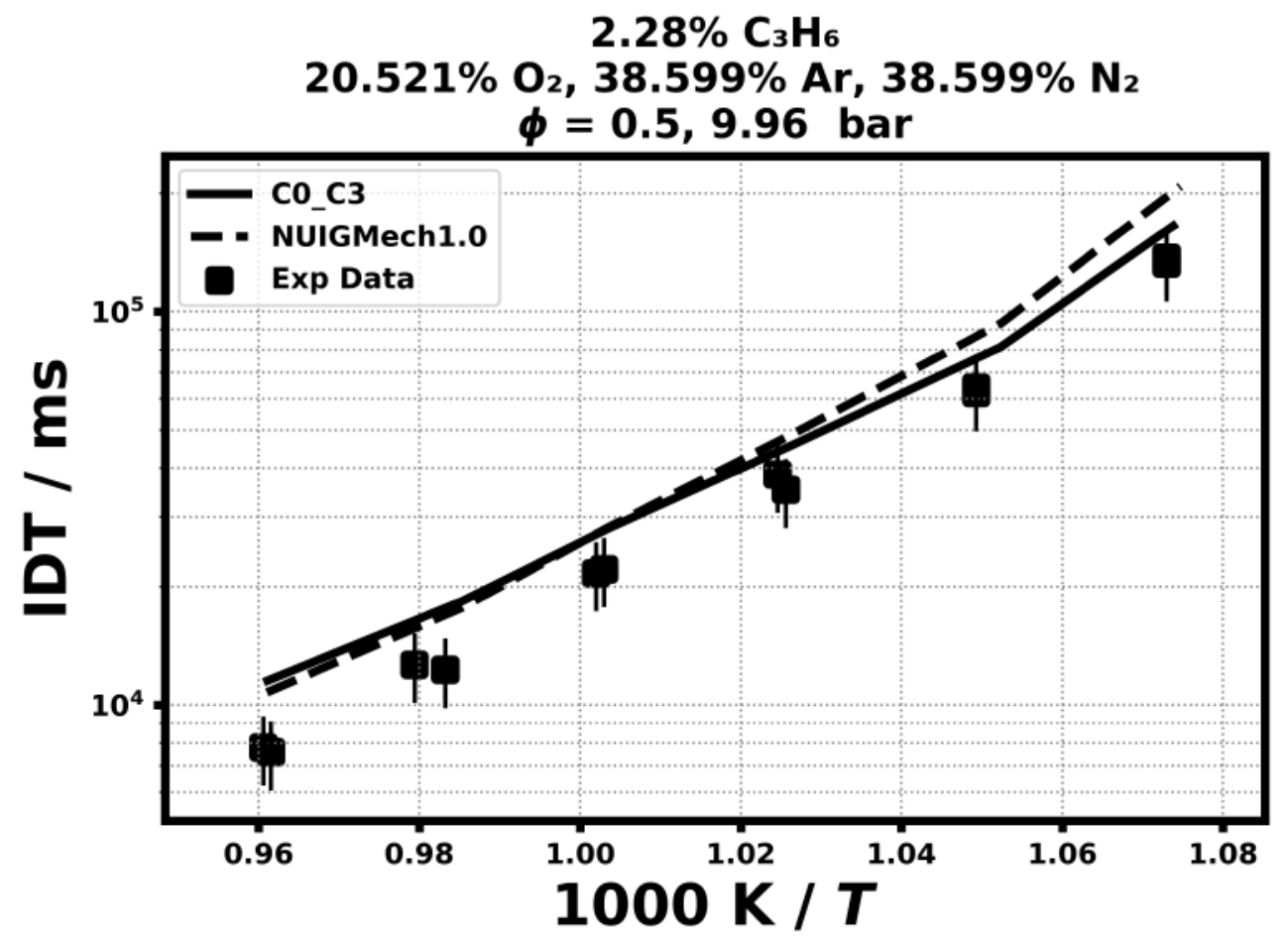



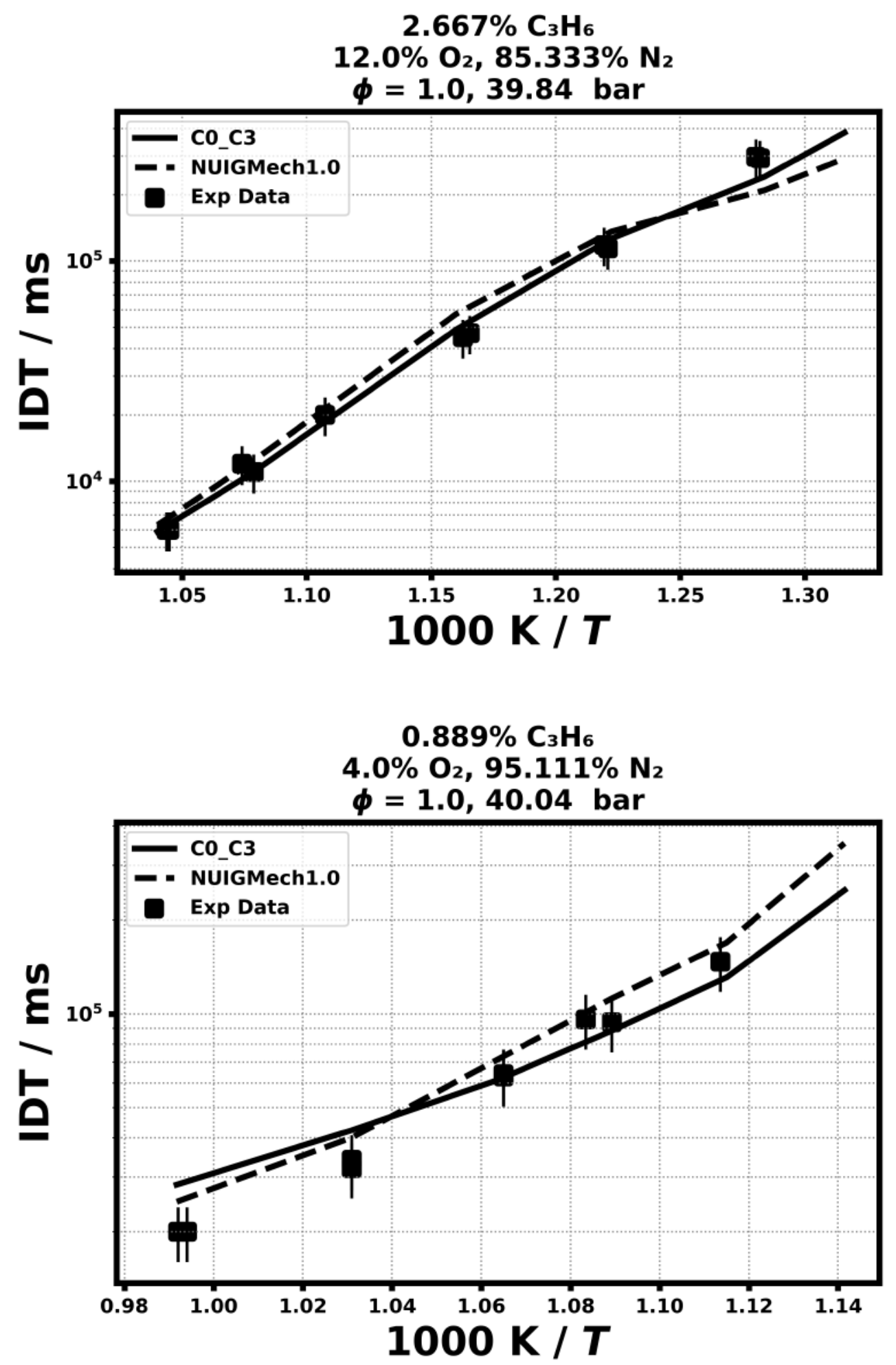

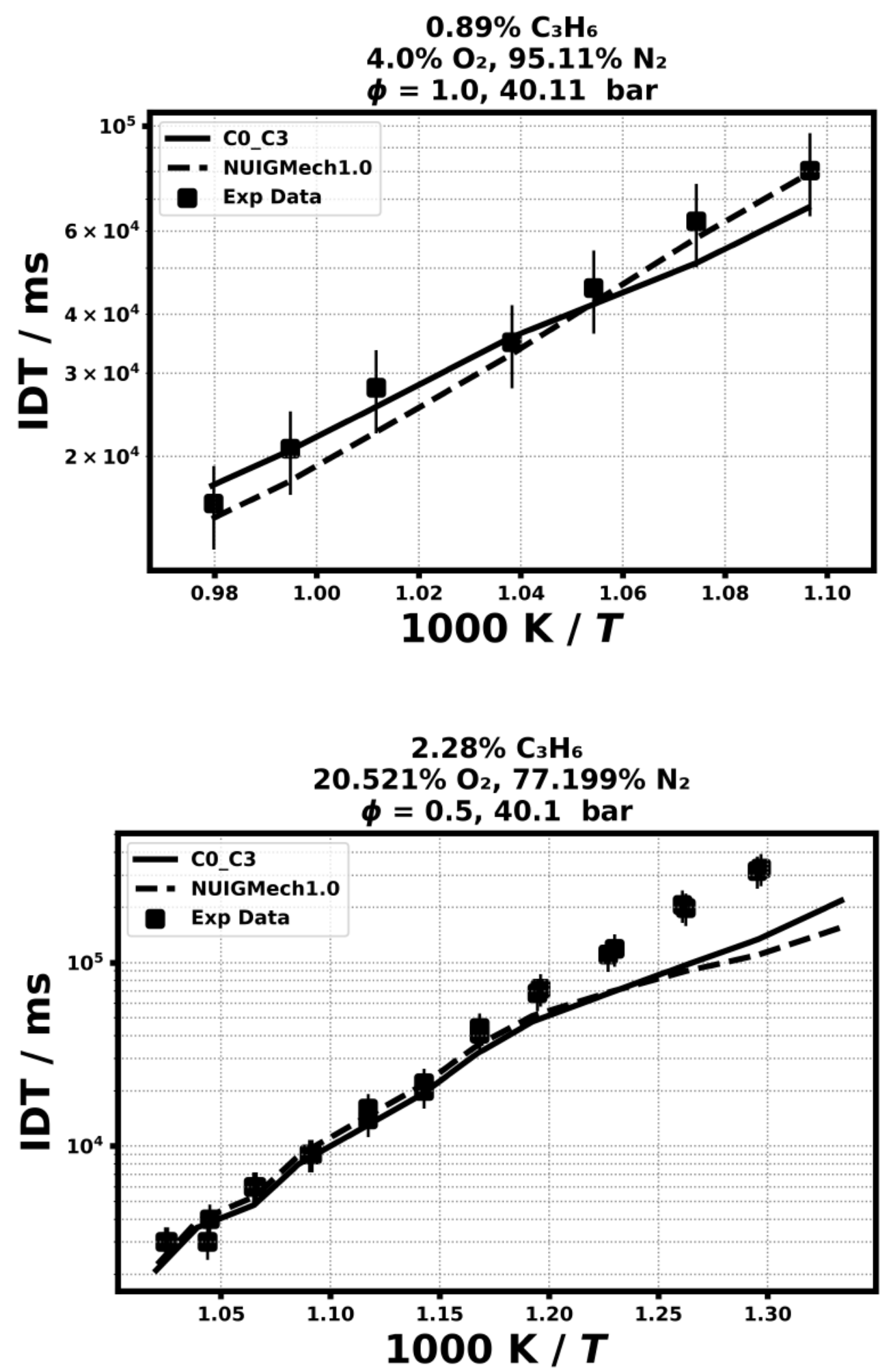

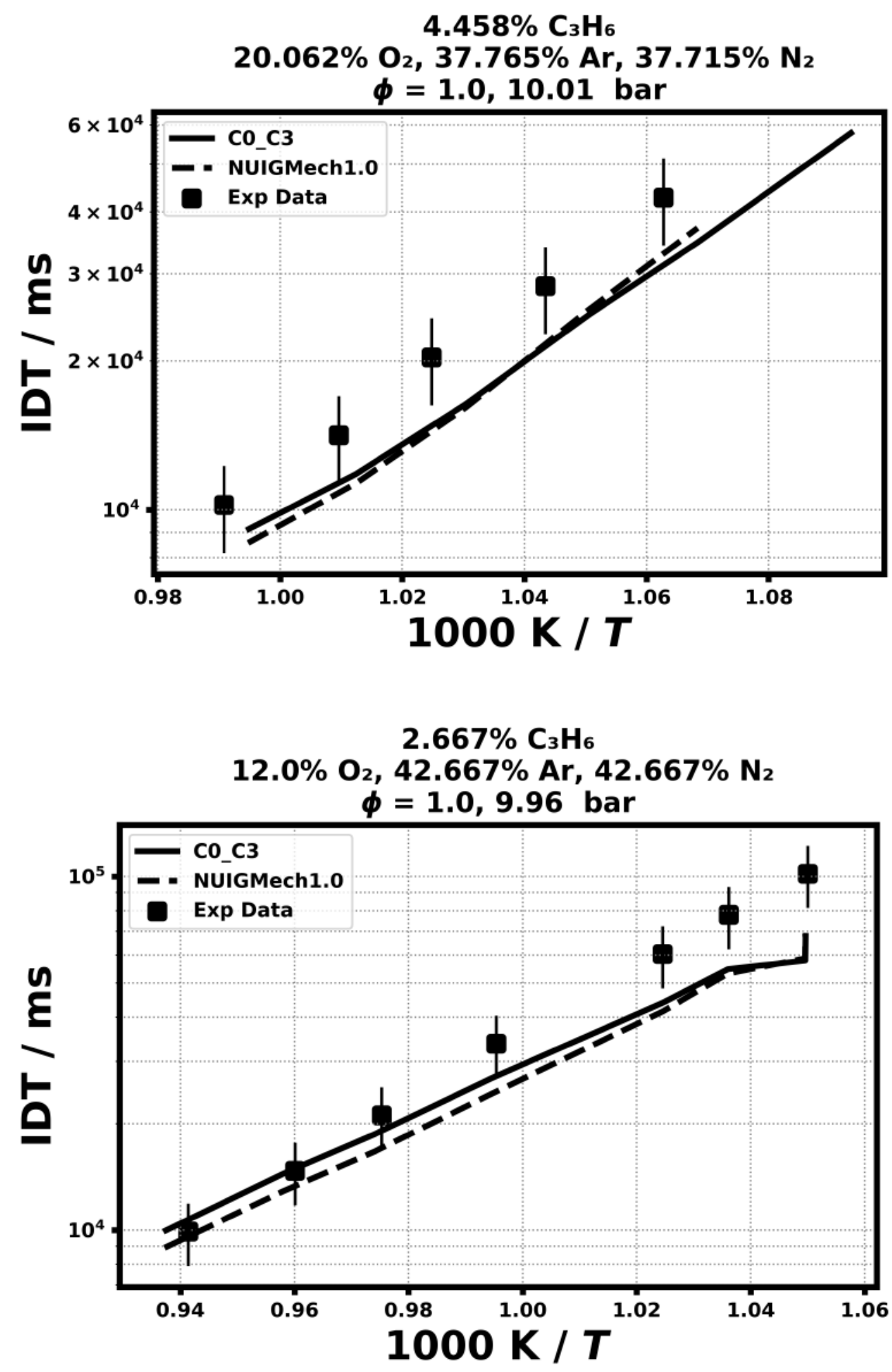


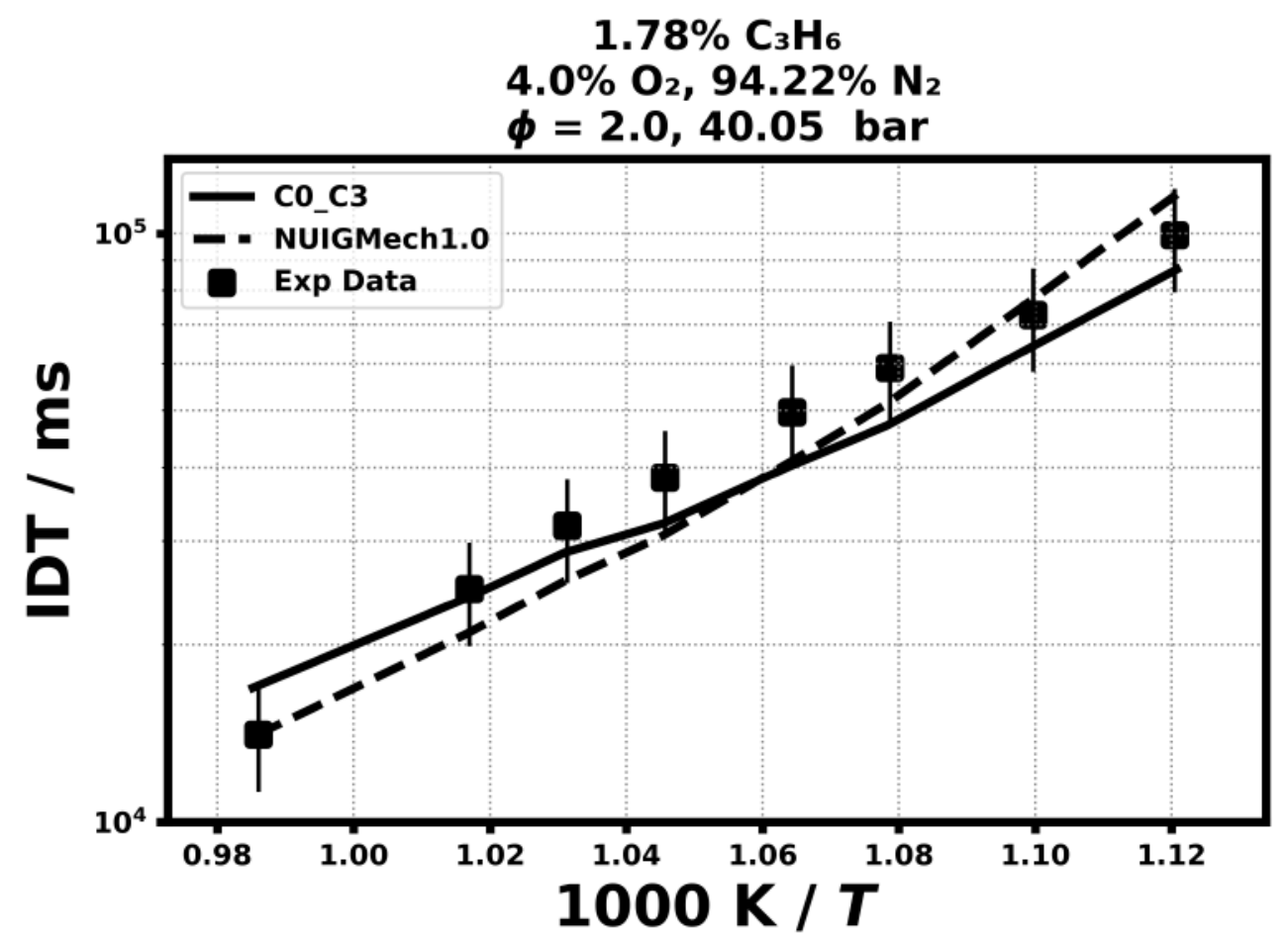

Speciation in Jet-stirred reactor

9.3) Cong, T. L., Bedjanian, E., \& Dagaut, P., Combustion science and technology, 182(4-6) (2010) 333-349.

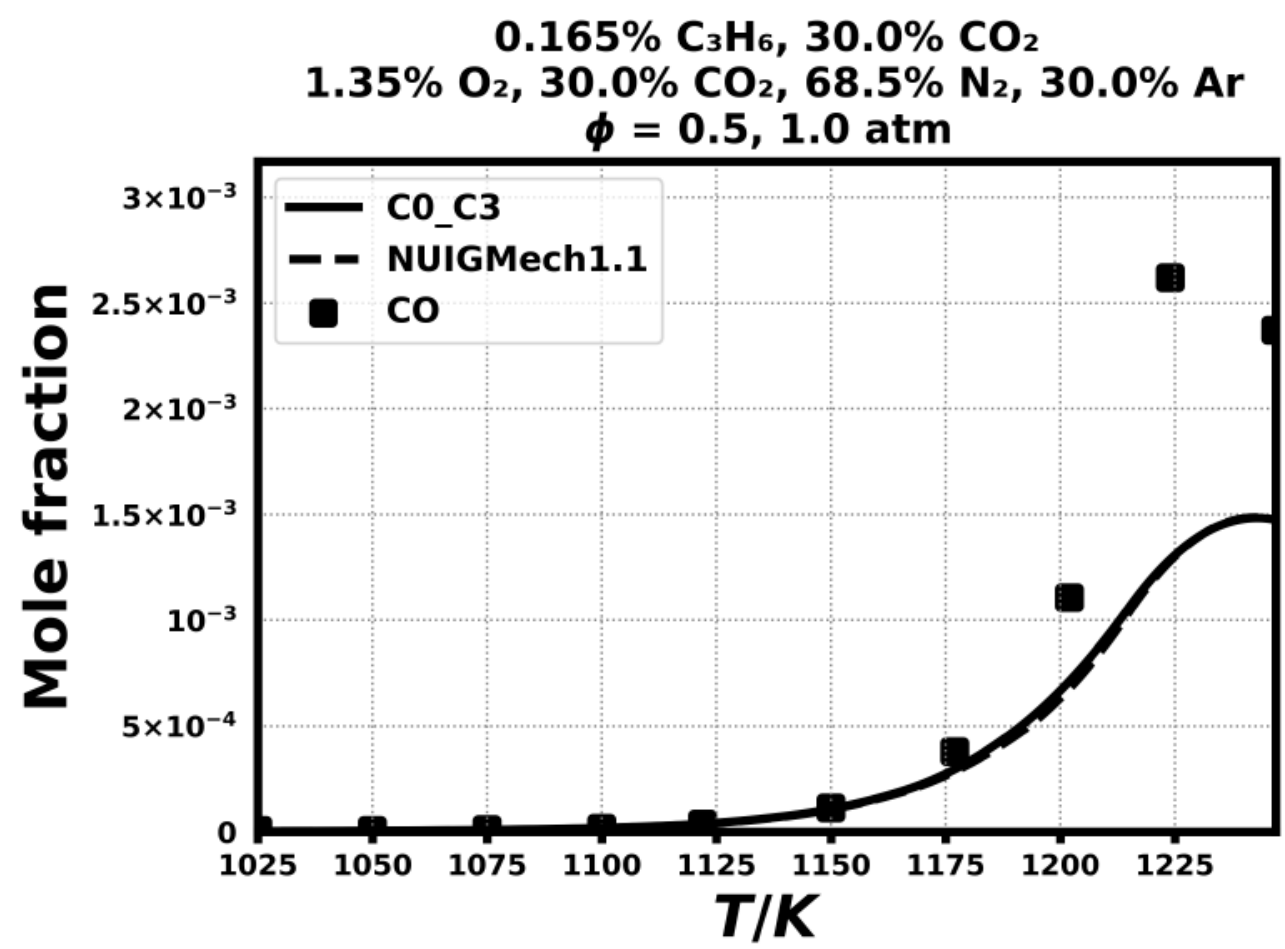


$0.165 \% \mathrm{C}_{3} \mathrm{H}_{6}, 30.0 \% \mathrm{CO}_{2}$

$1.35 \% \mathrm{O}_{2}, 30.0 \% \mathrm{CO}_{2}, 68.5 \% \mathrm{~N}_{2}, 30.0 \% \mathrm{Ar}$ $\phi=0.5,1.0 \mathrm{~atm}$

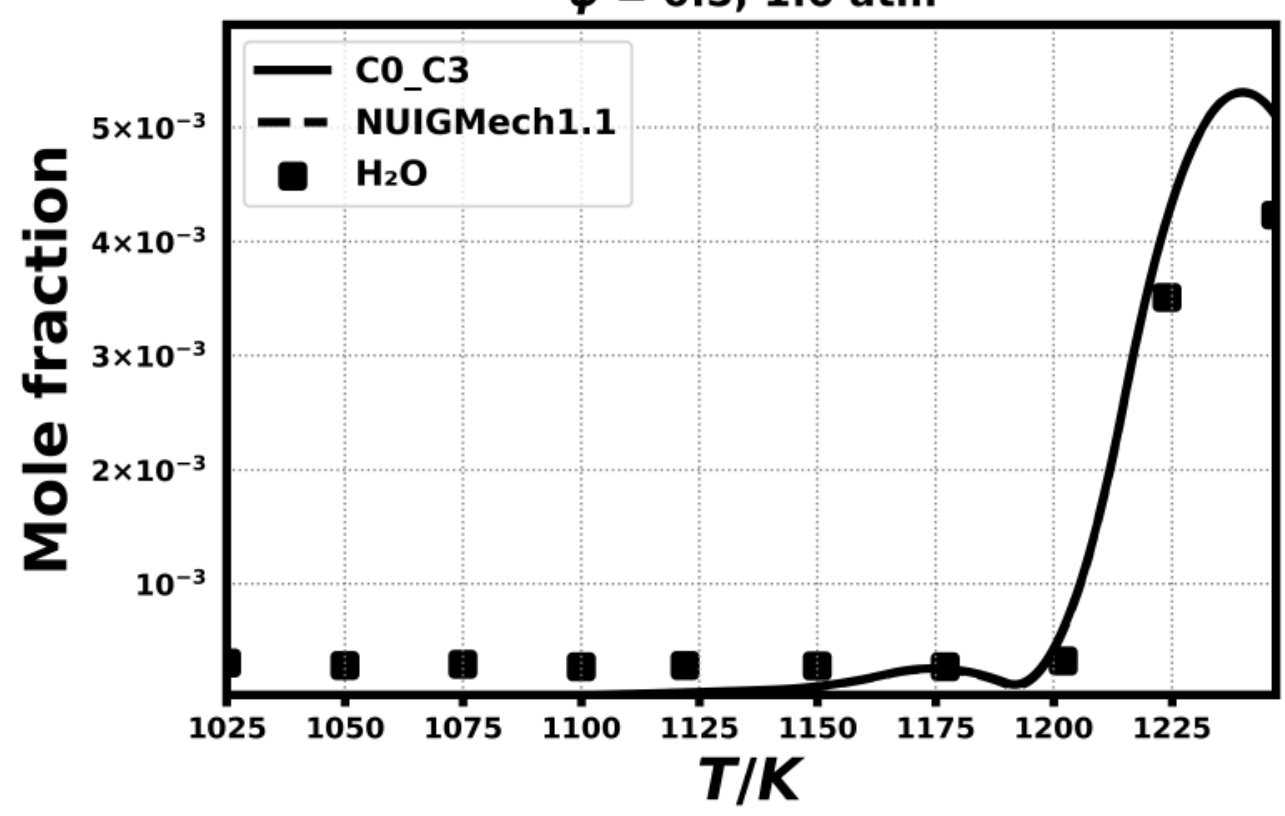

$0.165 \% \mathrm{C}_{3} \mathrm{H}_{6}, 30.0 \% \mathrm{CO}_{2}$

$1.35 \% \mathrm{O}_{2}, 30.0 \% \mathrm{CO}_{2}, 68.5 \% \mathrm{~N}_{2}, 30.0 \% \mathrm{Ar}$ $\phi=0.5,1.0 \mathrm{~atm}$

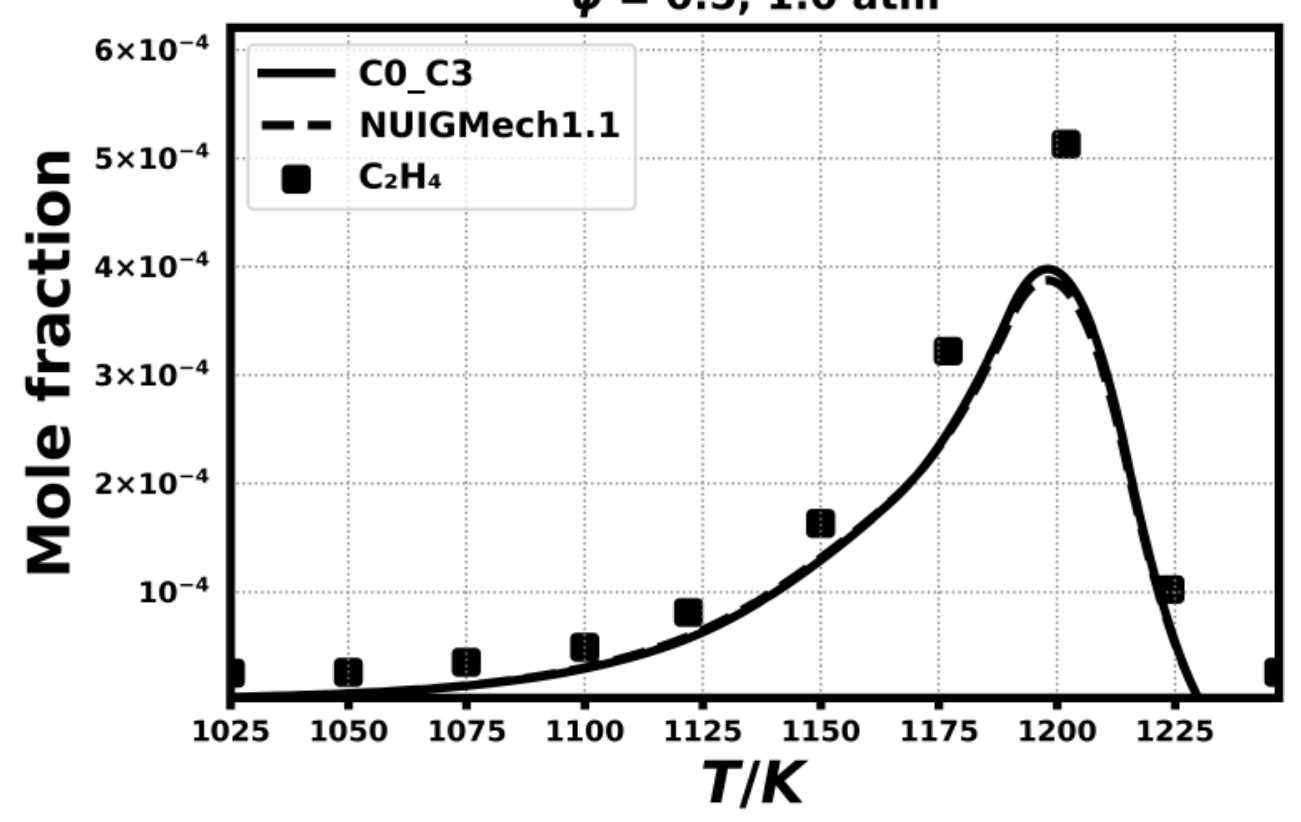


$0.165 \% \mathrm{C}_{3} \mathrm{H}_{6}, 30.0 \% \mathrm{CO}_{2}$

$1.35 \% \mathrm{O}_{2}, 30.0 \% \mathrm{CO}_{2}, 68.5 \% \mathrm{~N}_{2}, 30.0 \% \mathrm{Ar}$ $\phi=0.5,1.0 \mathrm{~atm}$

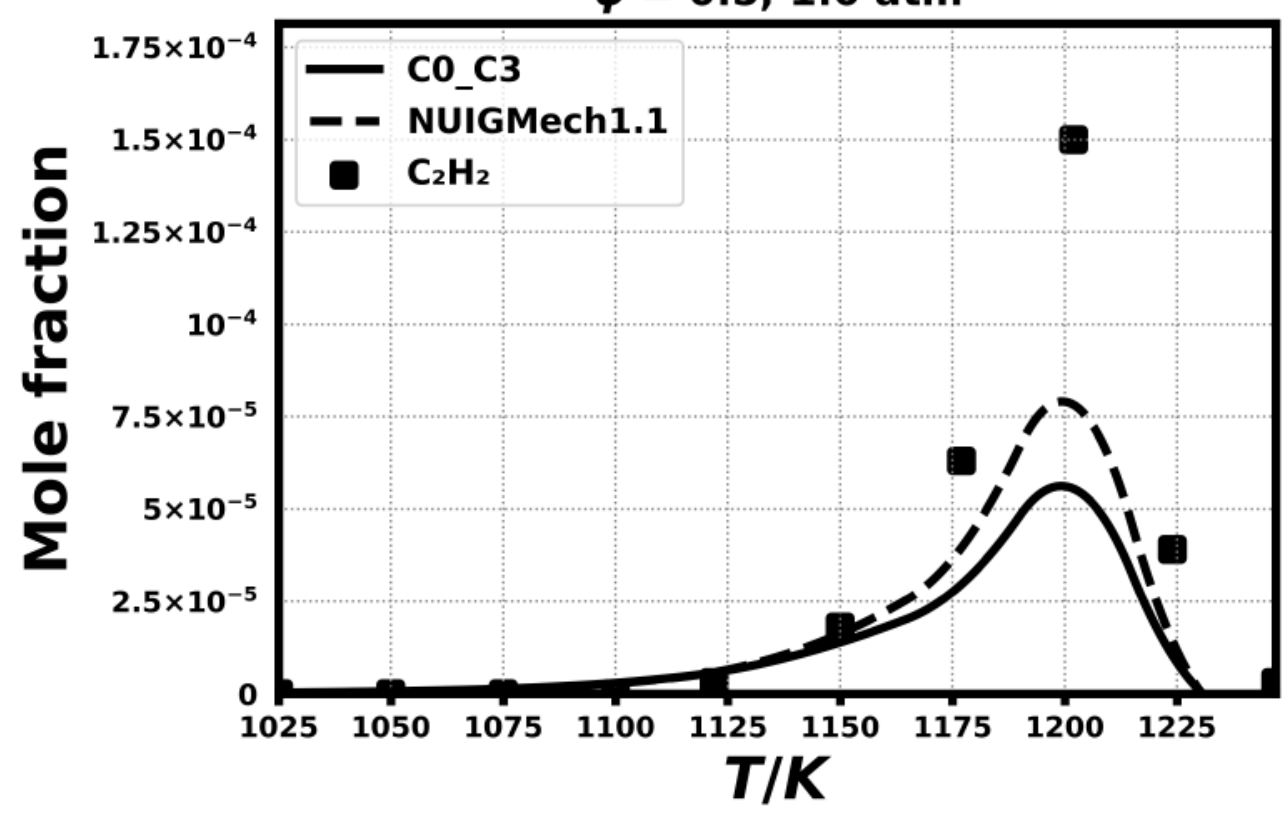

$0.165 \% \mathrm{C}_{3} \mathrm{H}_{6}, 30.0 \% \mathrm{CO}_{2}$

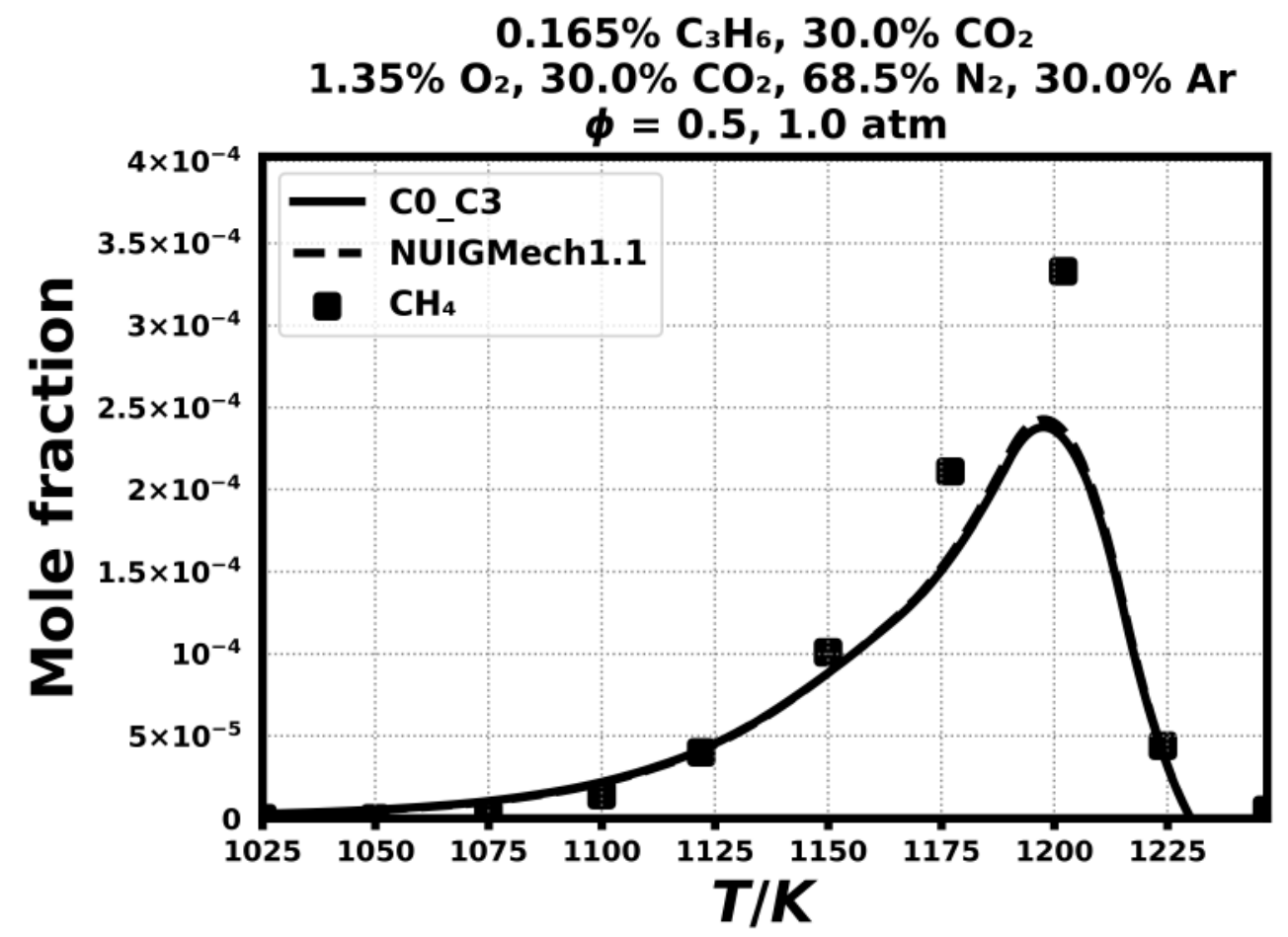


$0.15 \% \mathrm{C}_{3} \mathrm{H}_{6}, 30.0 \% \mathrm{CO}_{2}$

$0.338 \% \mathrm{O}_{2}, 30.0 \% \mathrm{CO}_{2}, 69.513 \% \mathrm{~N}_{2}, 30.0 \% \mathrm{Ar}$

$\phi=2.0,1.0 \mathrm{~atm}$

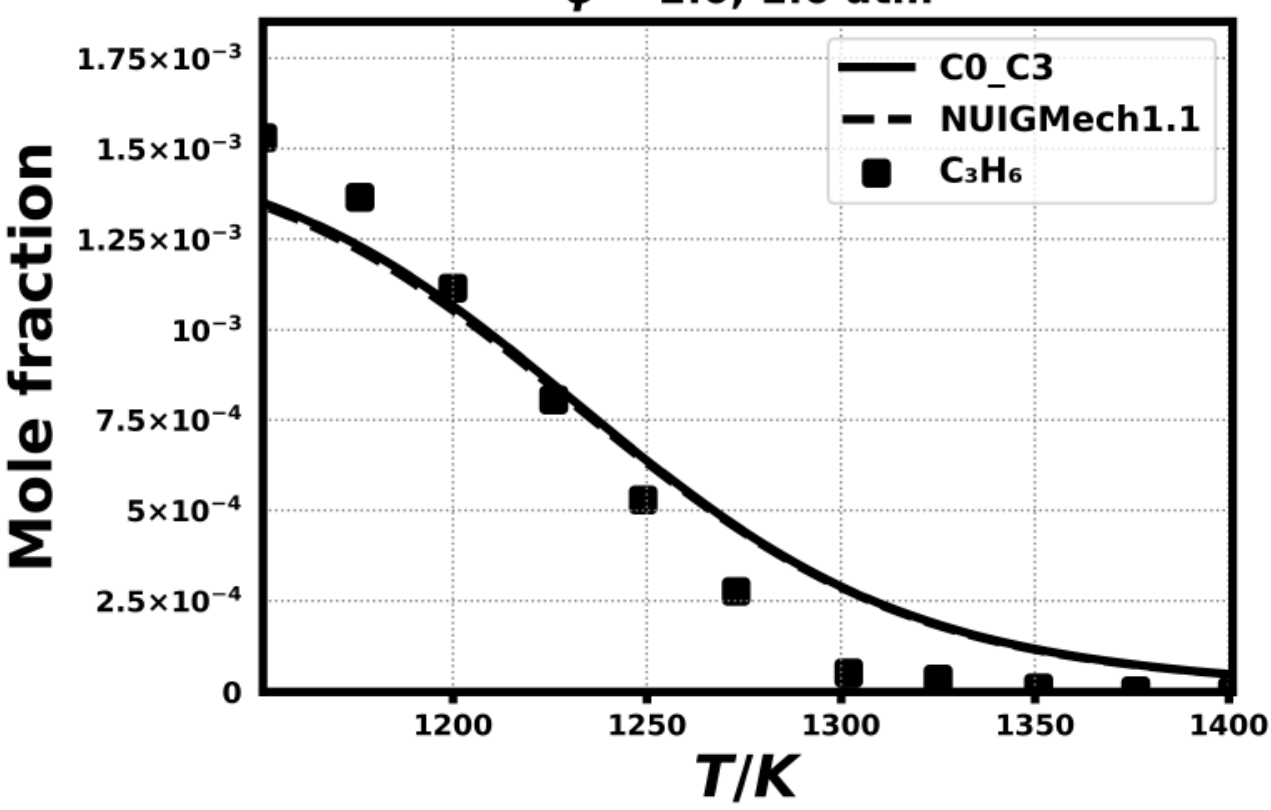

$0.15 \% \mathrm{C}_{3} \mathrm{H}_{6}, 30.0 \% \mathrm{CO}_{2}$

$0.338 \% \mathrm{O}_{2}, 30.0 \% \mathrm{CO}_{2}, 69.513 \% \mathrm{~N}_{2}, 30.0 \% \mathrm{Ar}$ $\phi=2.0,1.0 \mathrm{~atm}$

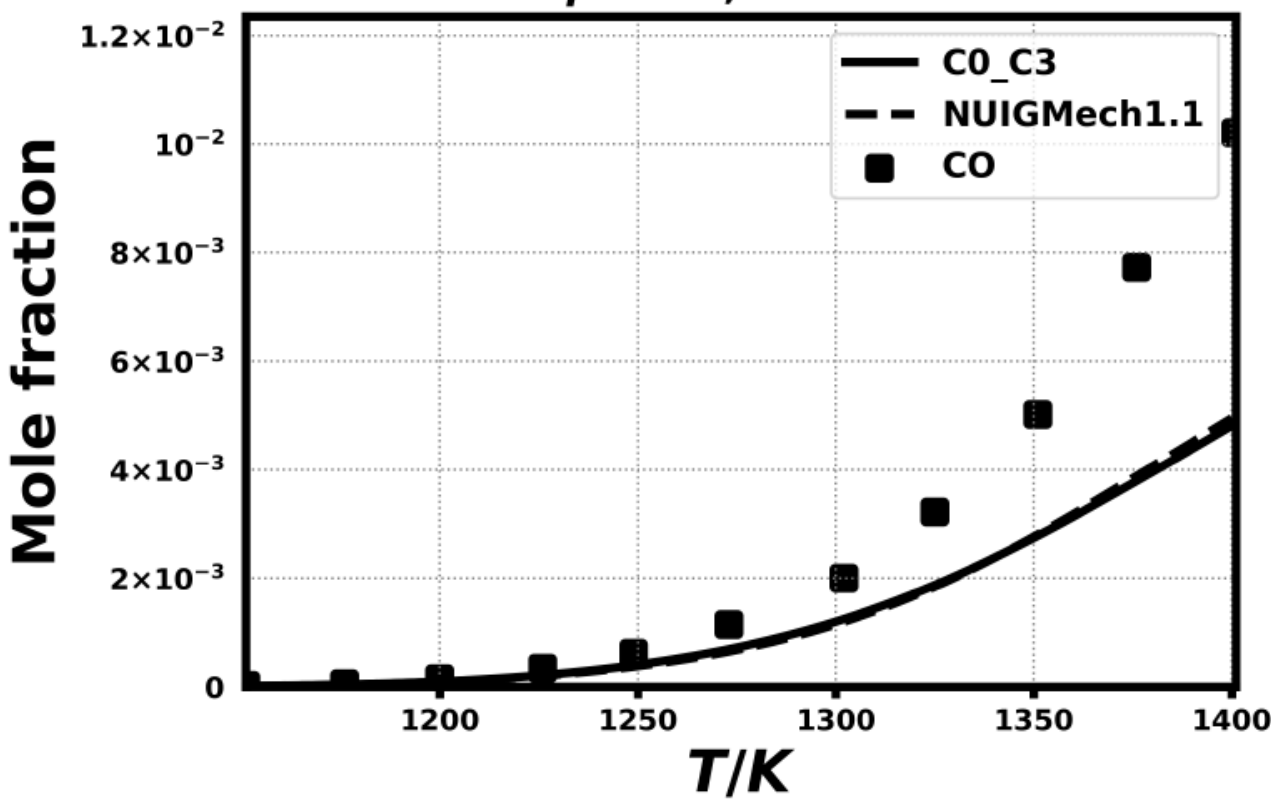


$0.15 \% \mathrm{C}_{3} \mathrm{H}_{6}, 30.0 \% \mathrm{CO}_{2}$

$0.338 \% \mathrm{O}_{2}, 30.0 \% \mathrm{CO}_{2}, 69.513 \% \mathrm{~N}_{2}, 30.0 \% \mathrm{Ar}$ $\phi=2.0,1.0 \mathrm{~atm}$

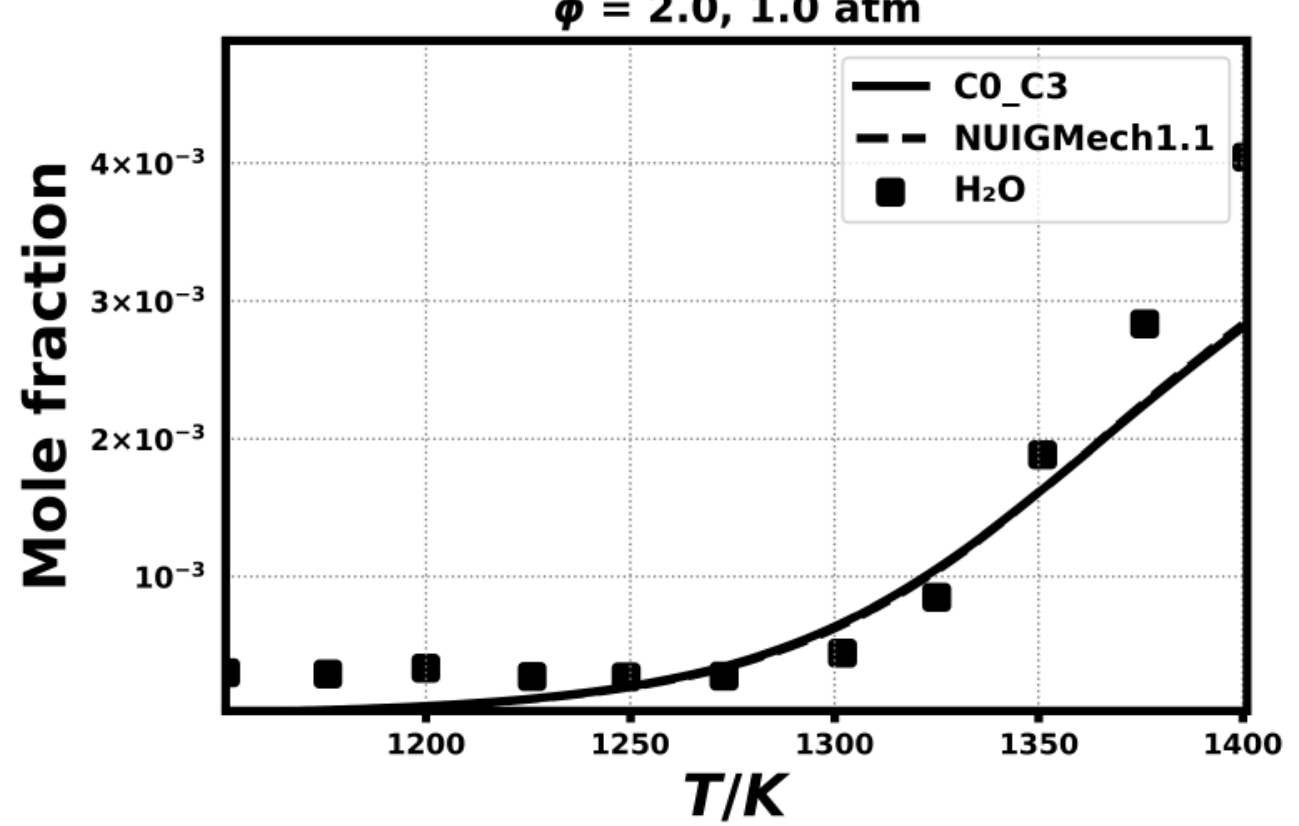

$0.15 \% \mathrm{C}_{3} \mathrm{H}_{6}, 30.0 \% \mathrm{CO}_{2}$

$0.338 \% \mathrm{O}_{2}, 30.0 \% \mathrm{CO}_{2}, 69.513 \% \mathrm{~N}_{2}, 30.0 \% \mathrm{Ar}$ $\phi=2.0,1.0 \mathrm{~atm}$

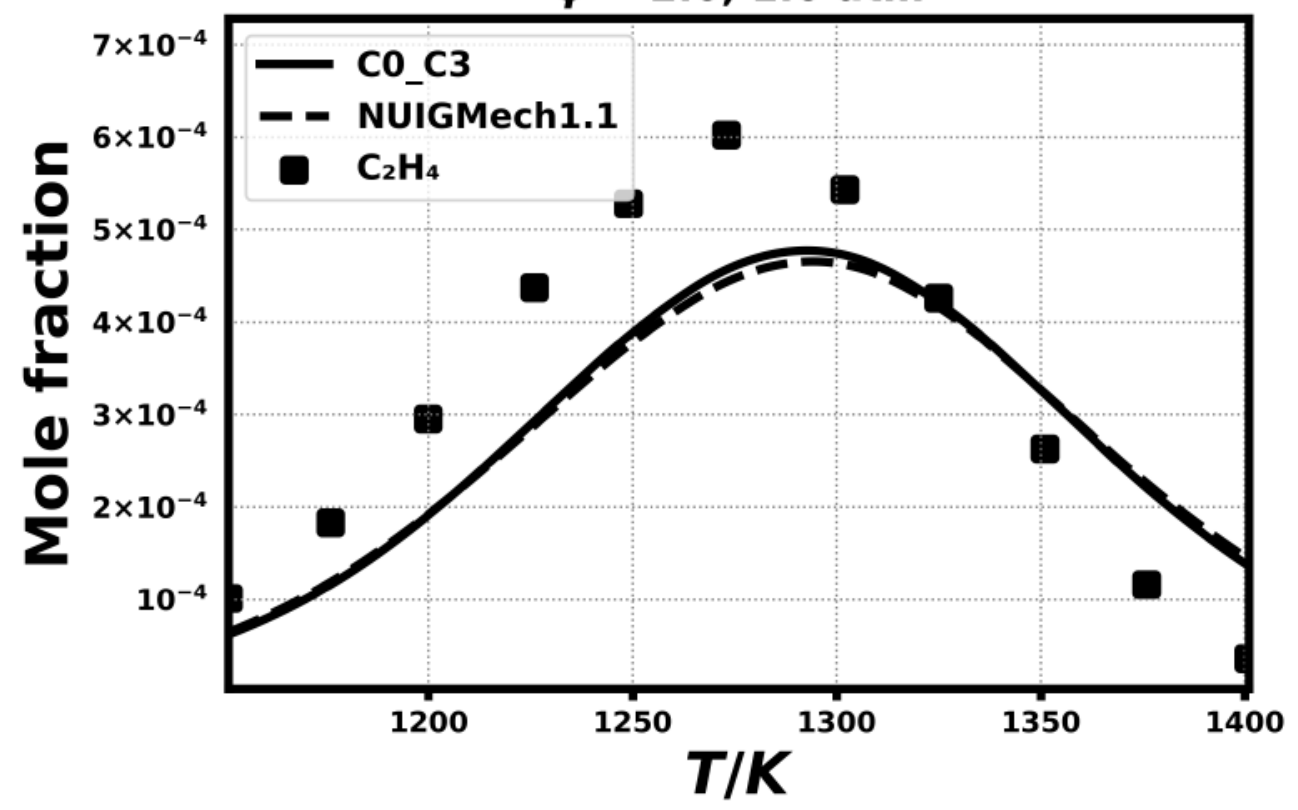


$0.15 \% \mathrm{C}_{3} \mathrm{H}_{6}, 30.0 \% \mathrm{CO}_{2}$

$0.338 \% \mathrm{O}_{2}, 30.0 \% \mathrm{CO}_{2}, 69.513 \% \mathrm{~N}_{2}, 30.0 \% \mathrm{Ar}$

$\phi=2.0,1.0 \mathrm{~atm}$

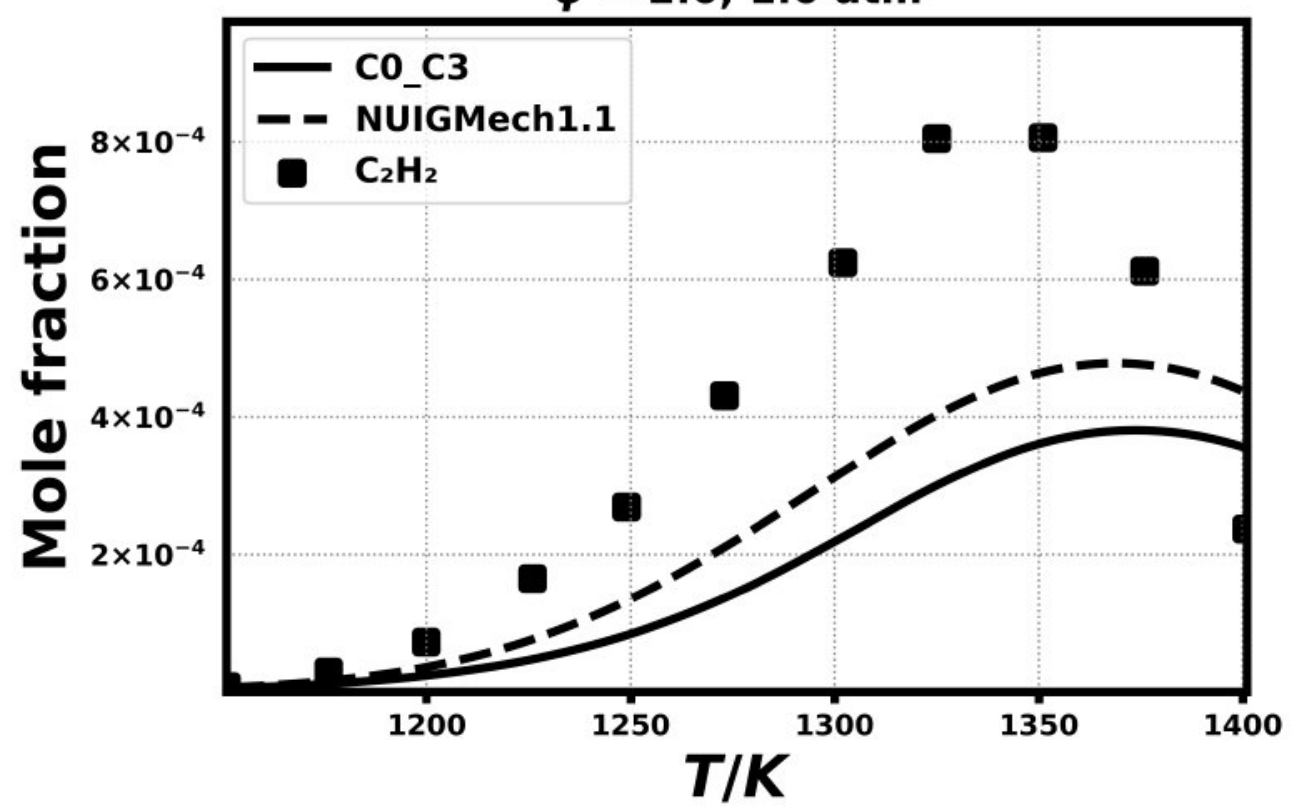

$0.15 \% \mathrm{C}_{3} \mathrm{H}_{6}, 30.0 \% \mathrm{CO}_{2}$

$0.338 \% \mathrm{O}_{2}, 30.0 \% \mathrm{CO}_{2}, 69.513 \% \mathrm{~N}_{2}, 30.0 \% \mathrm{Ar}$ $\phi=2.0,1.0$ atm

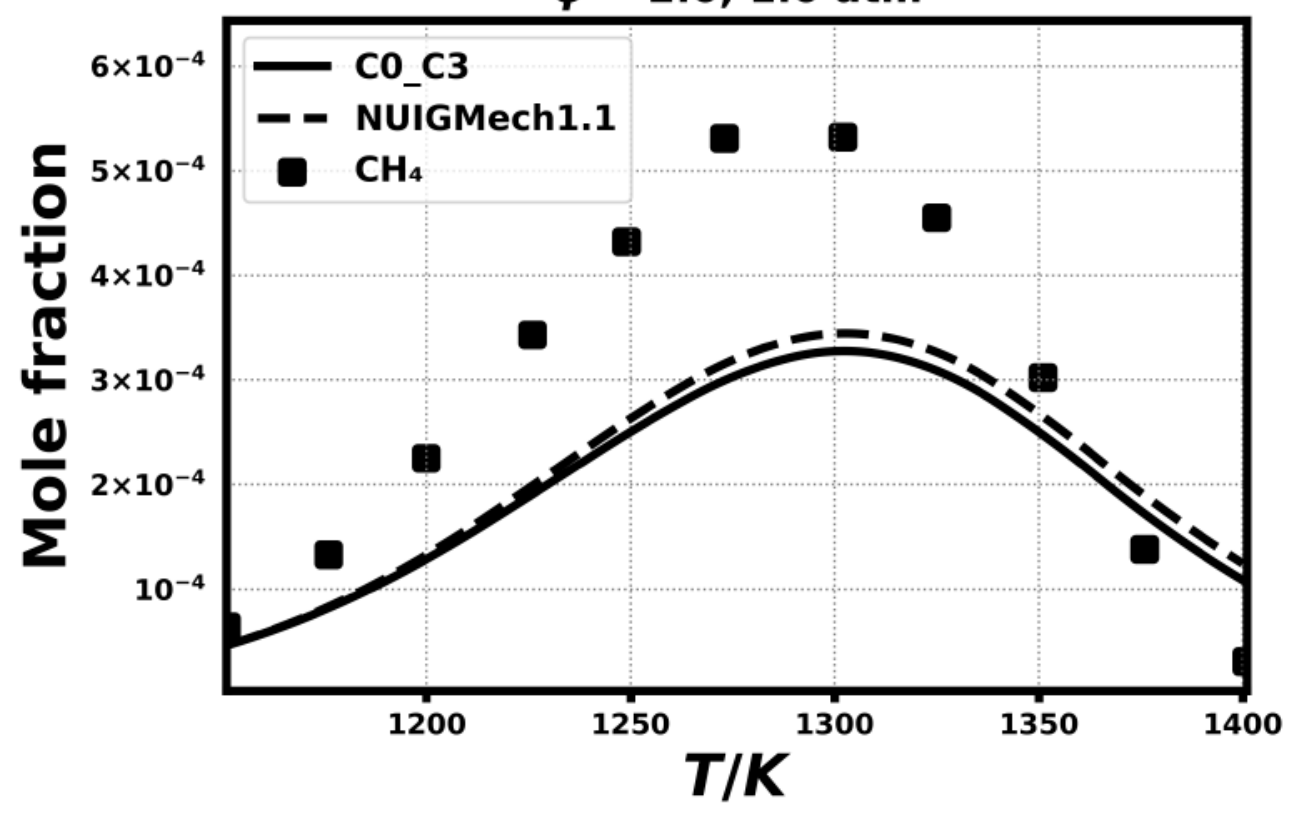



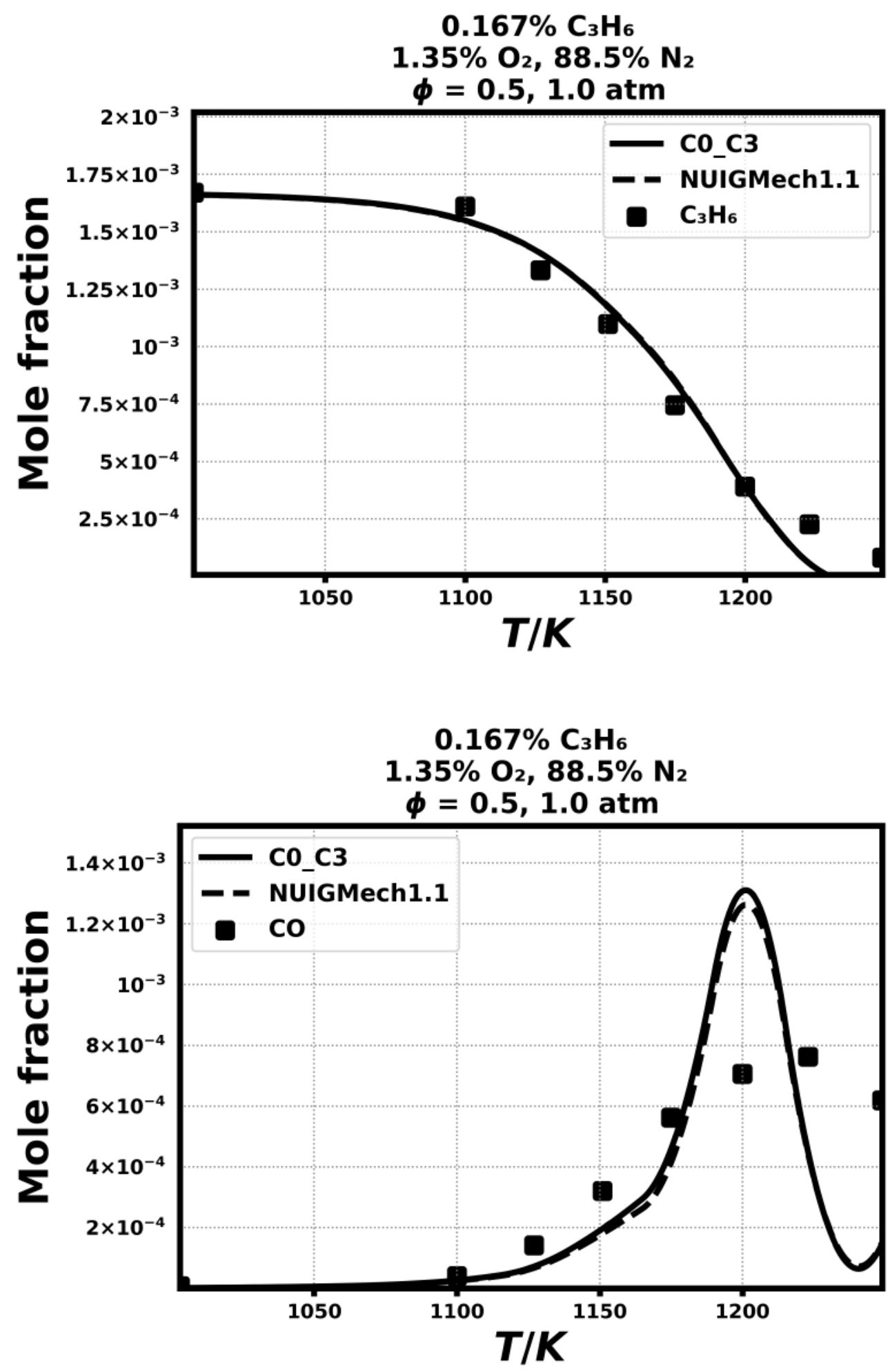

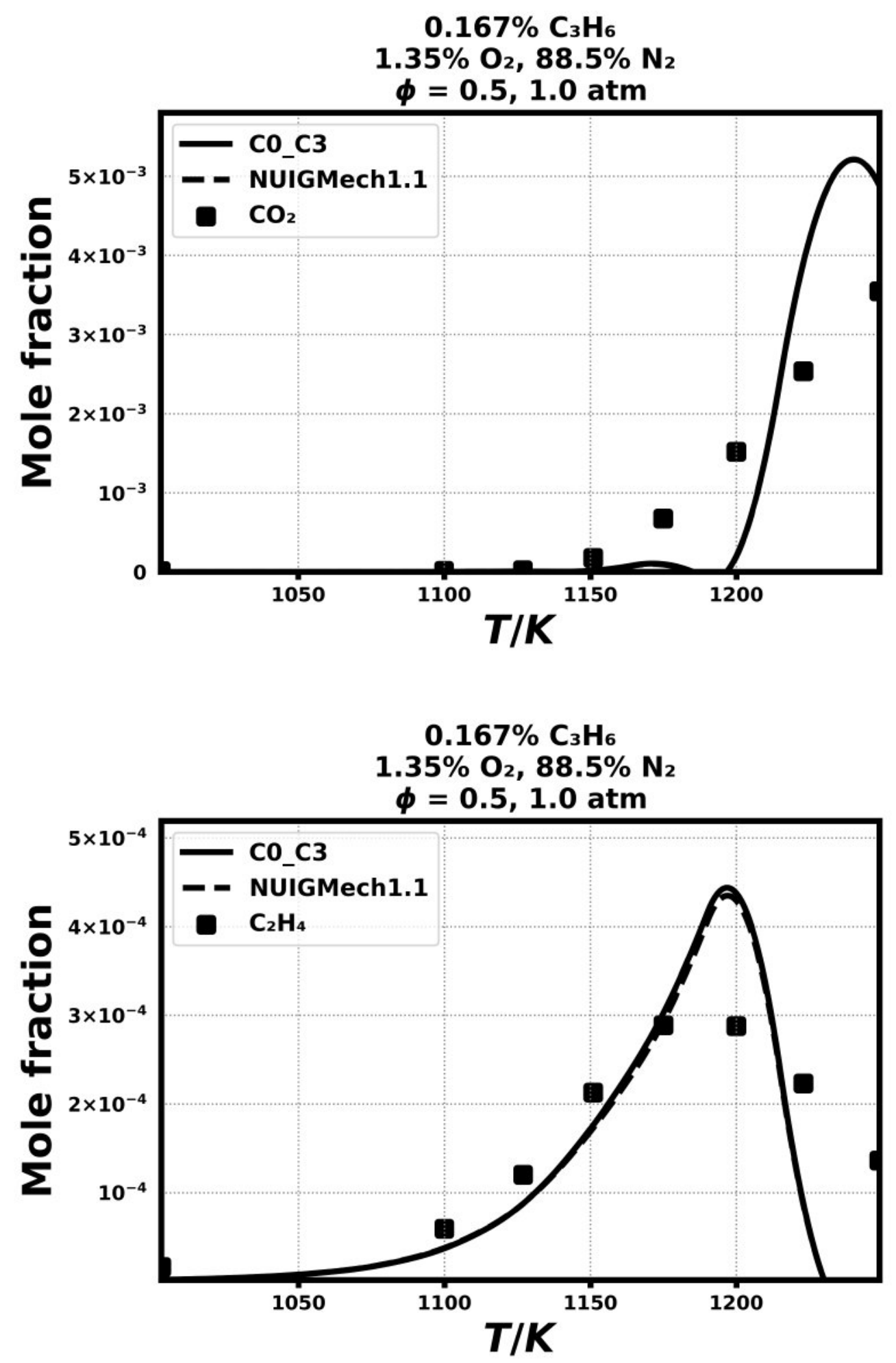

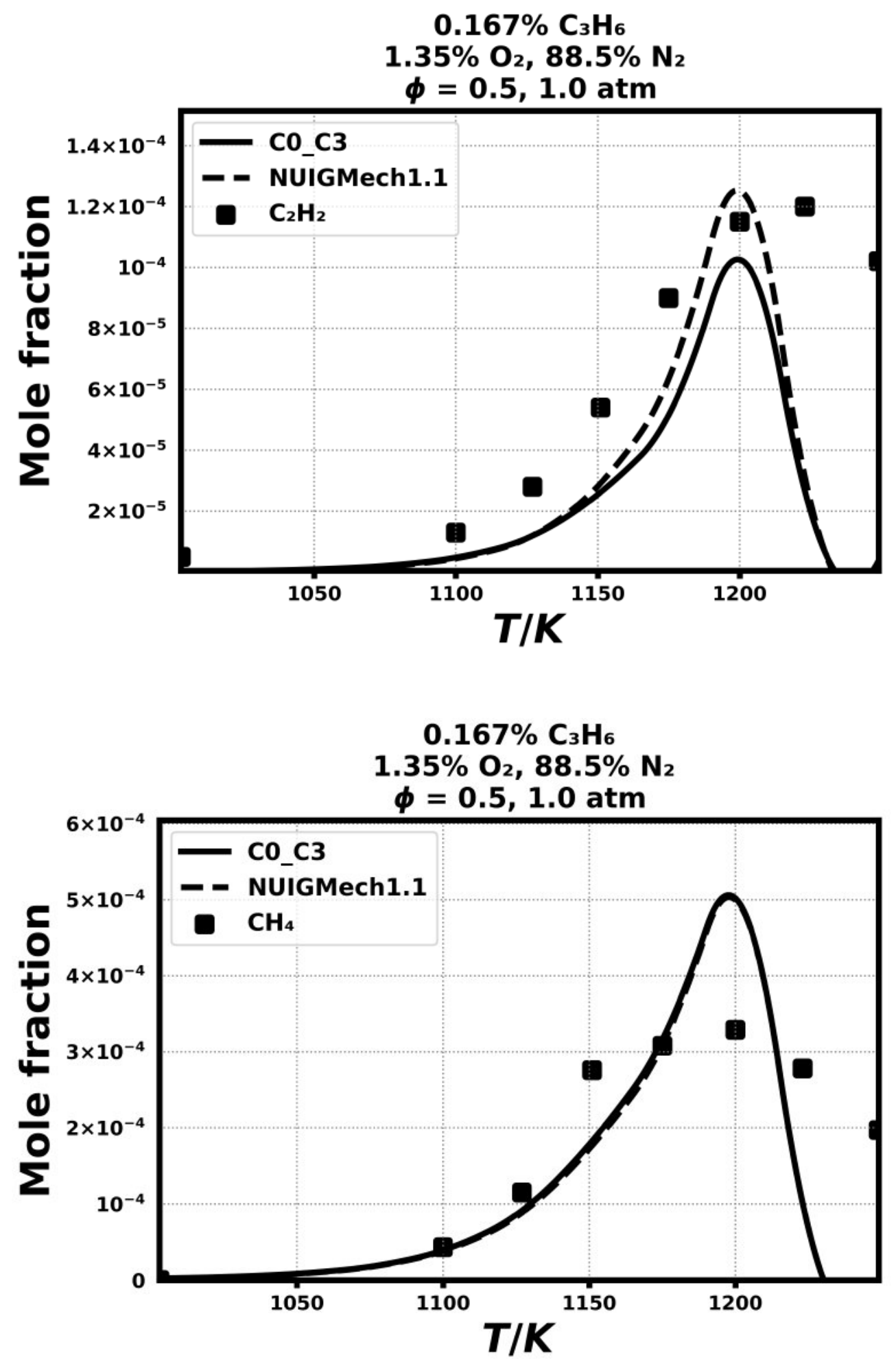

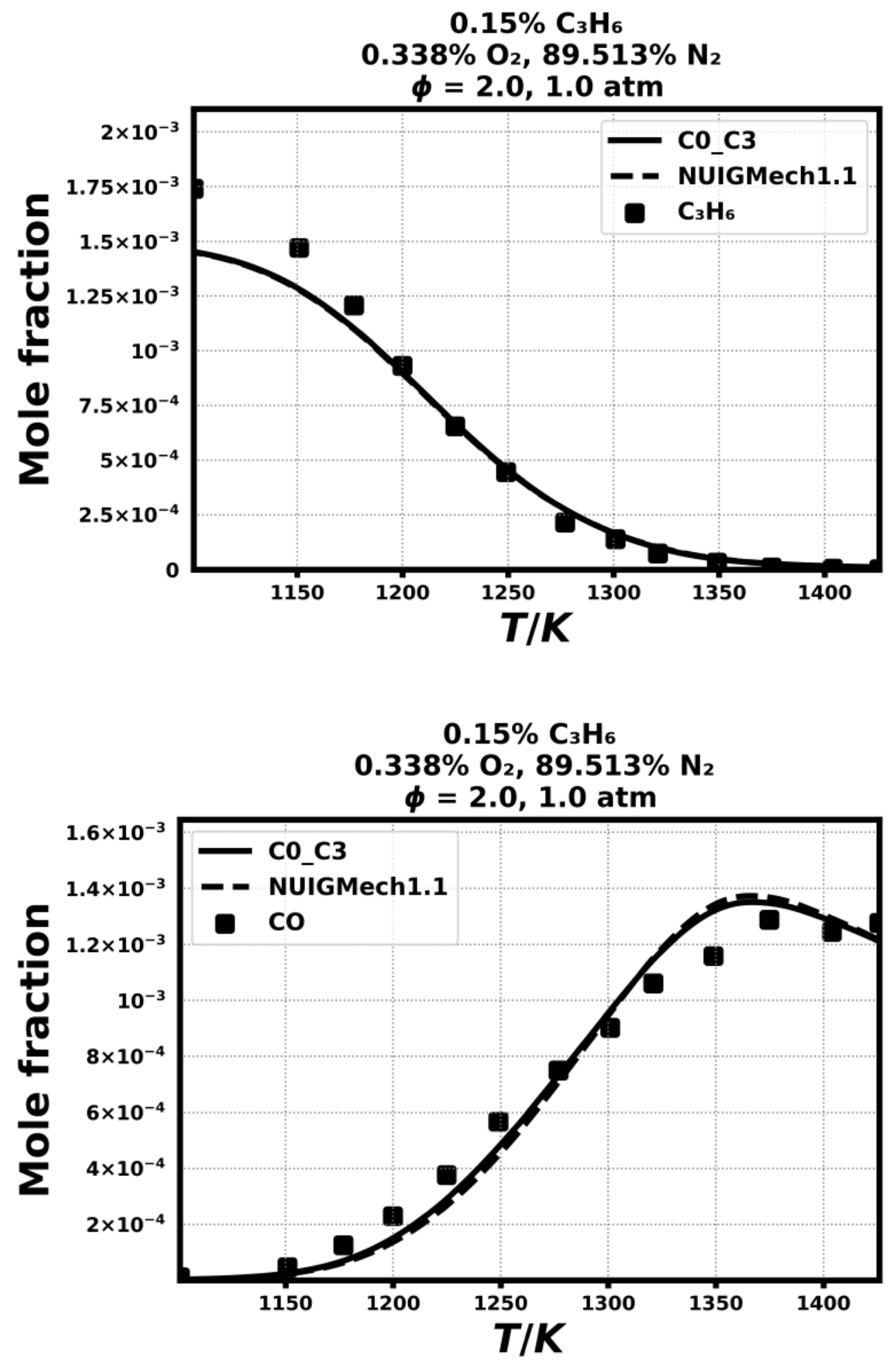

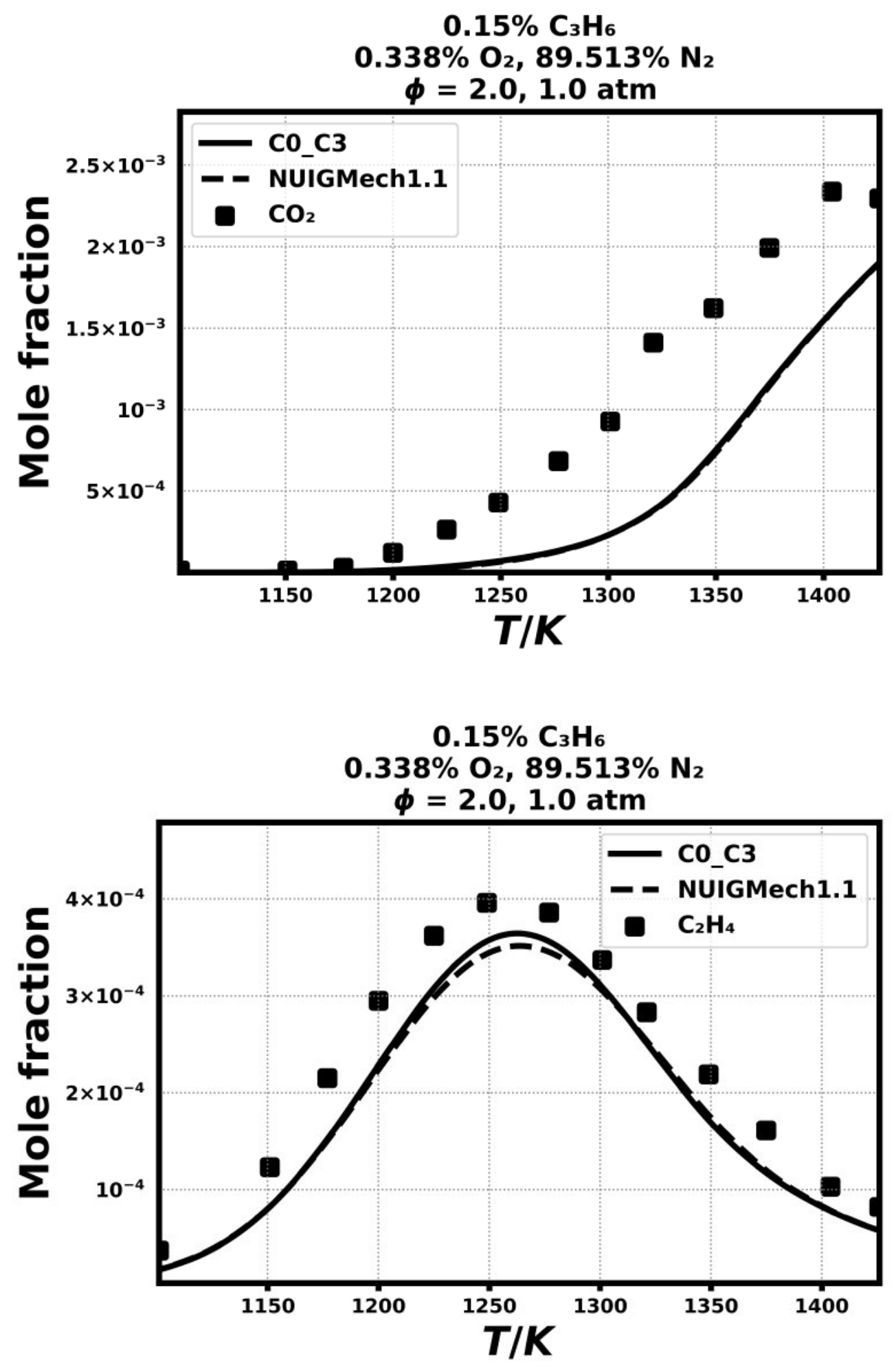

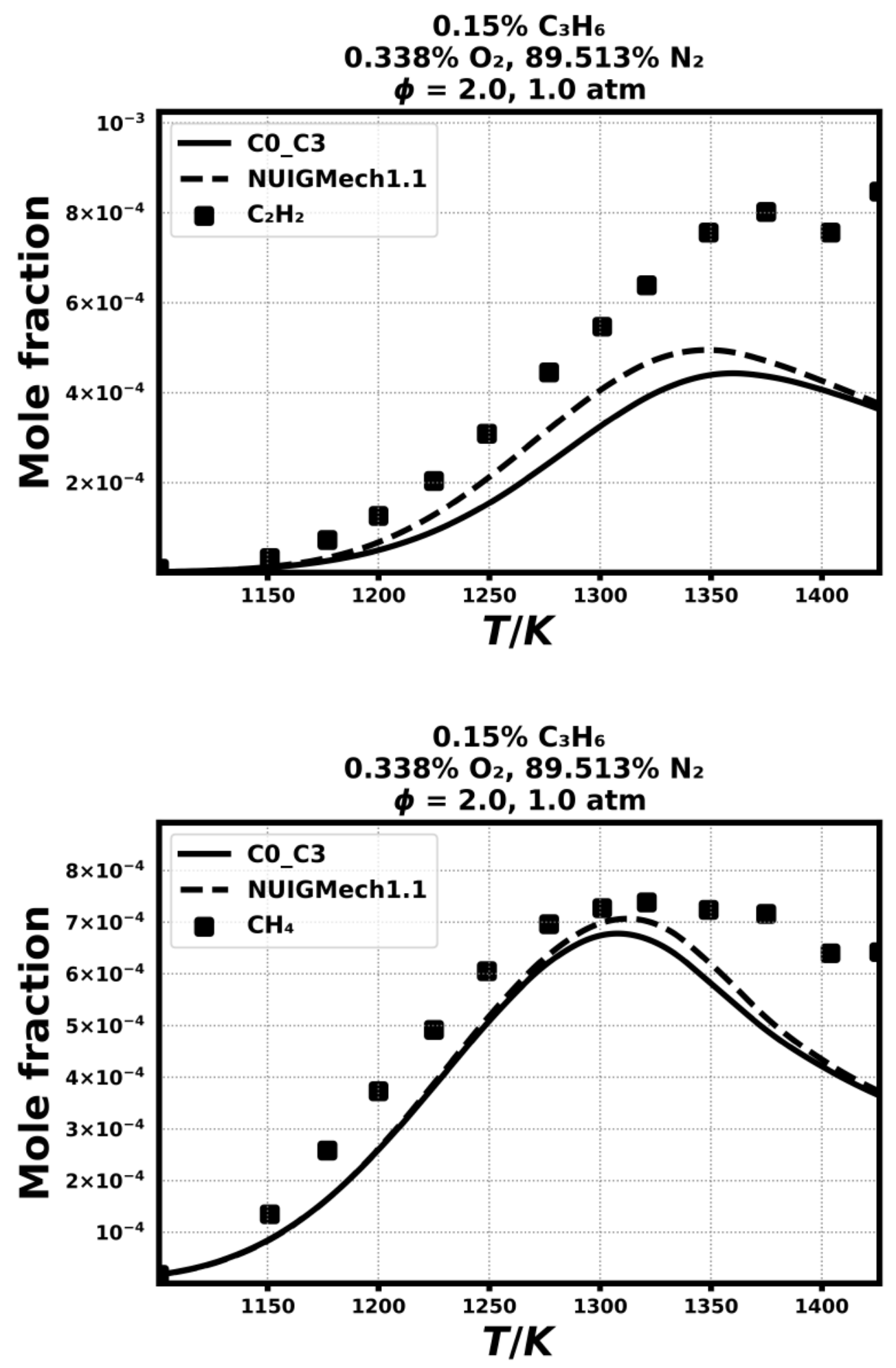

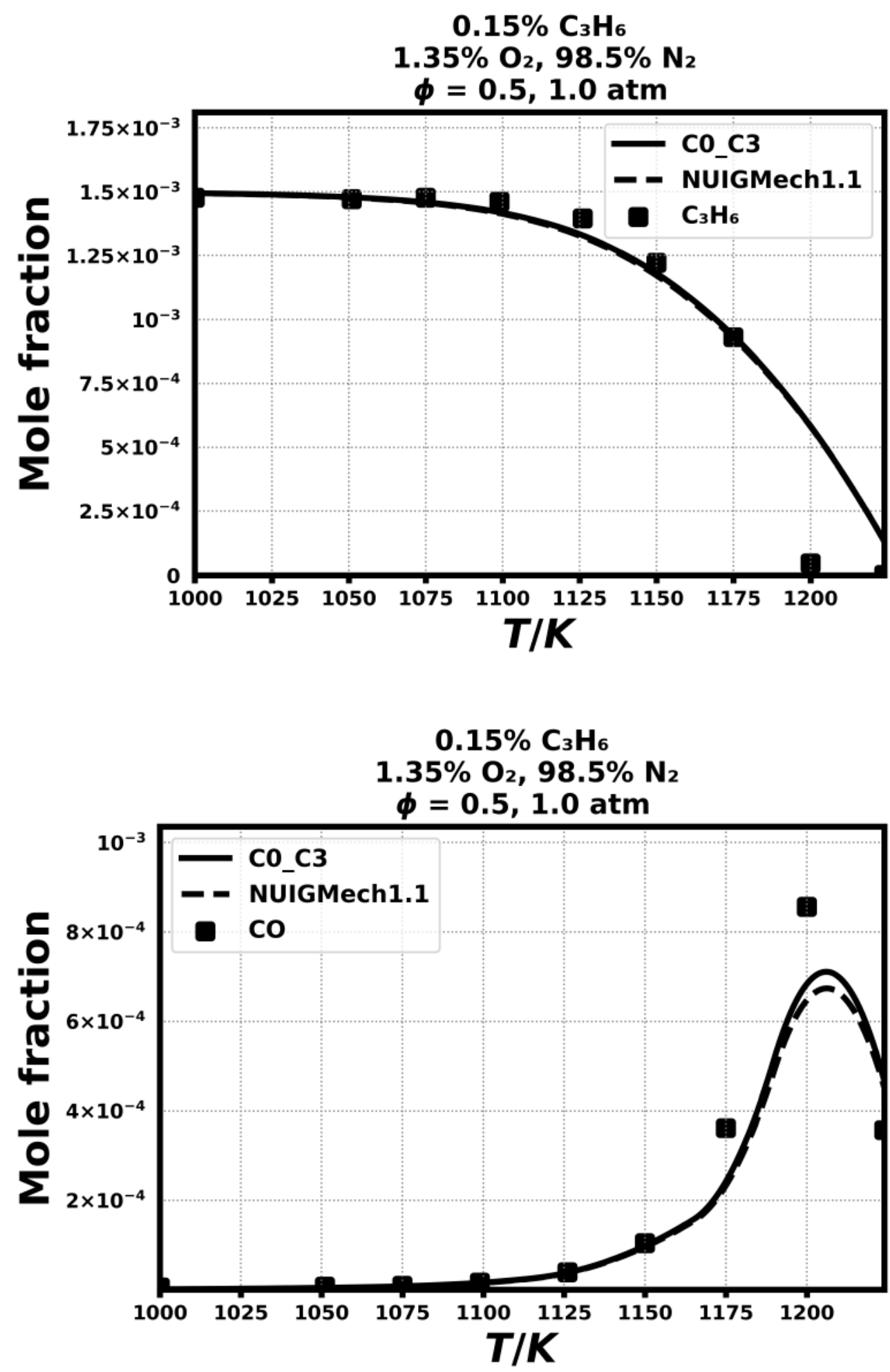

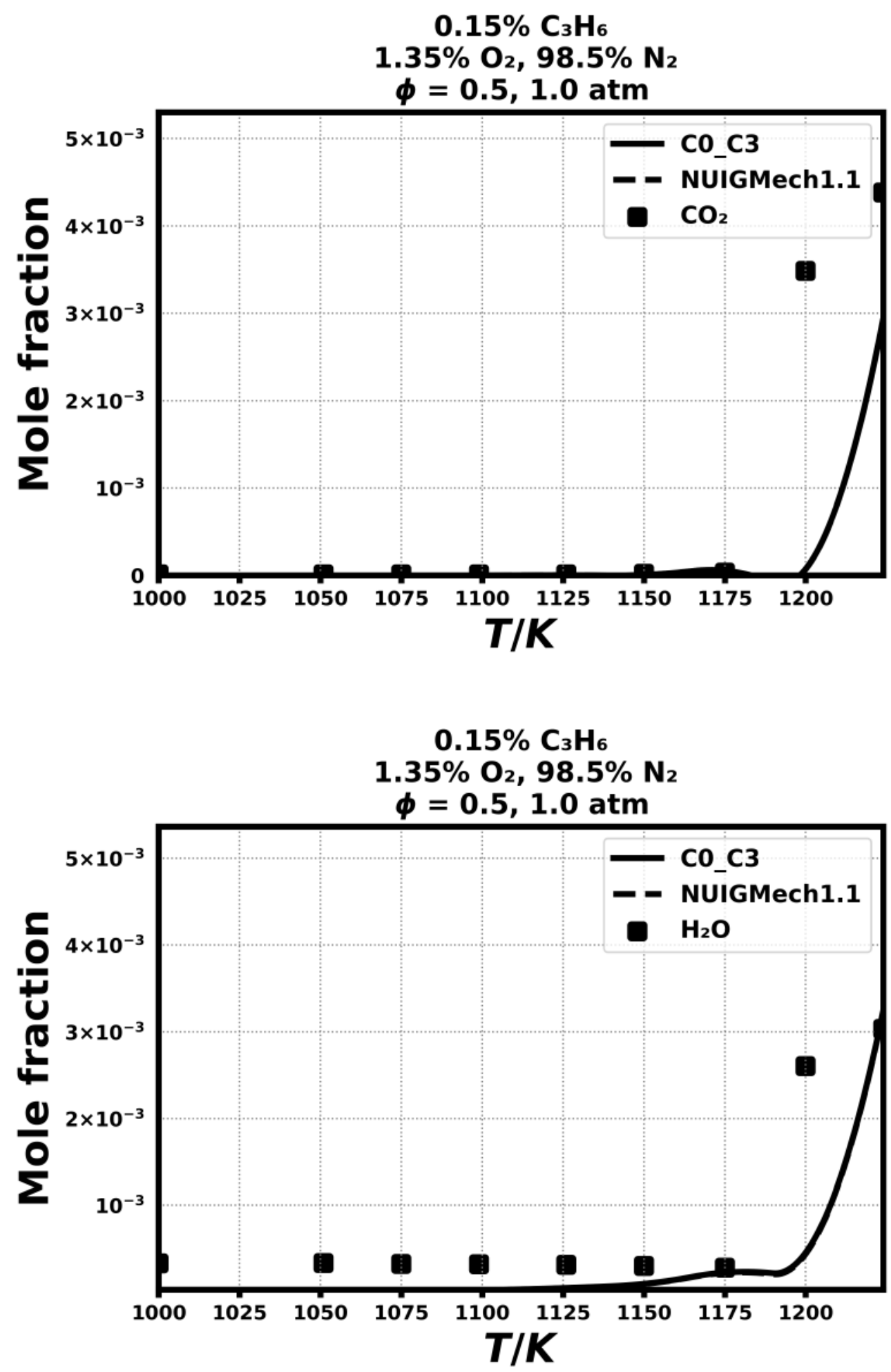

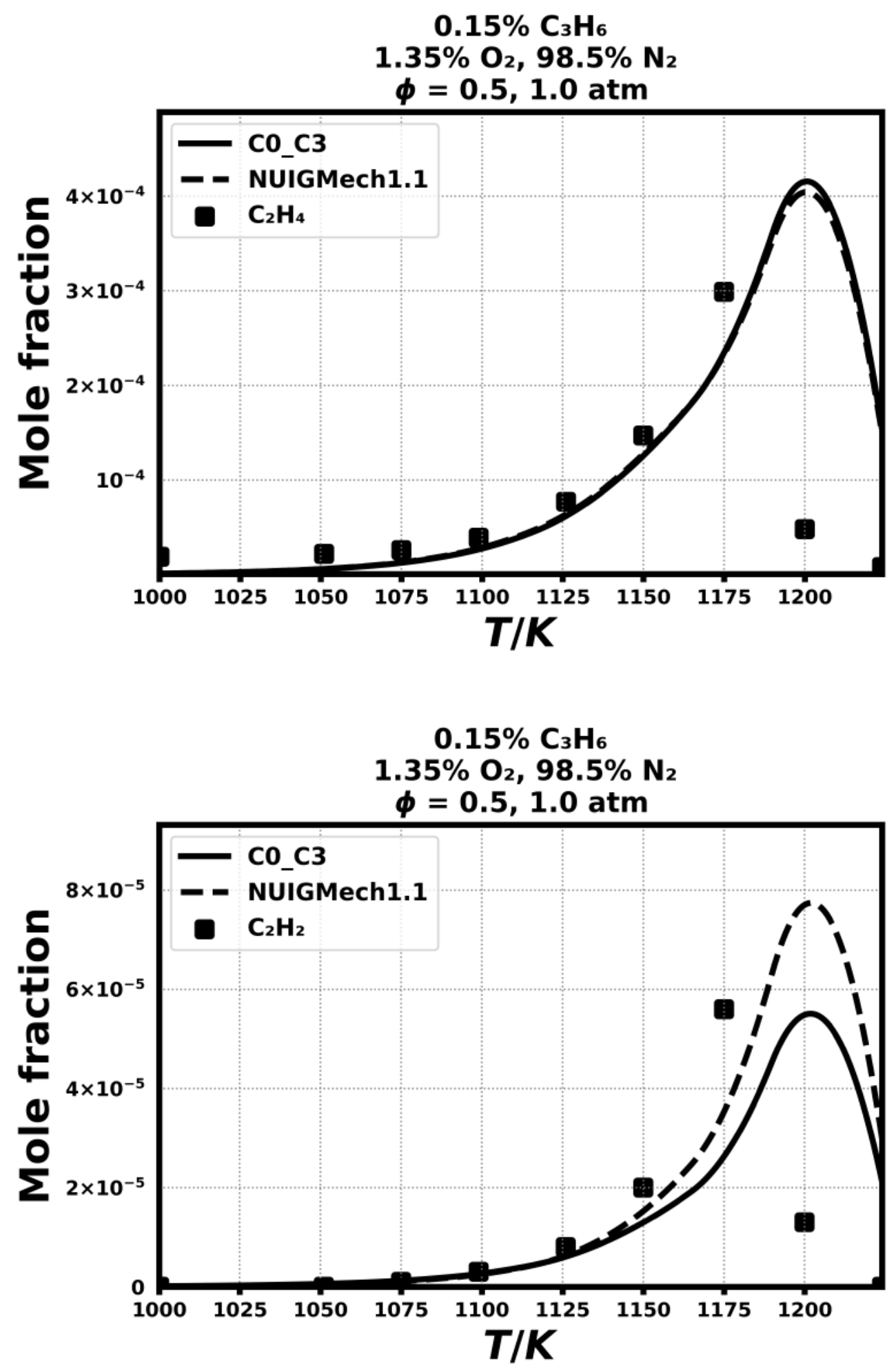


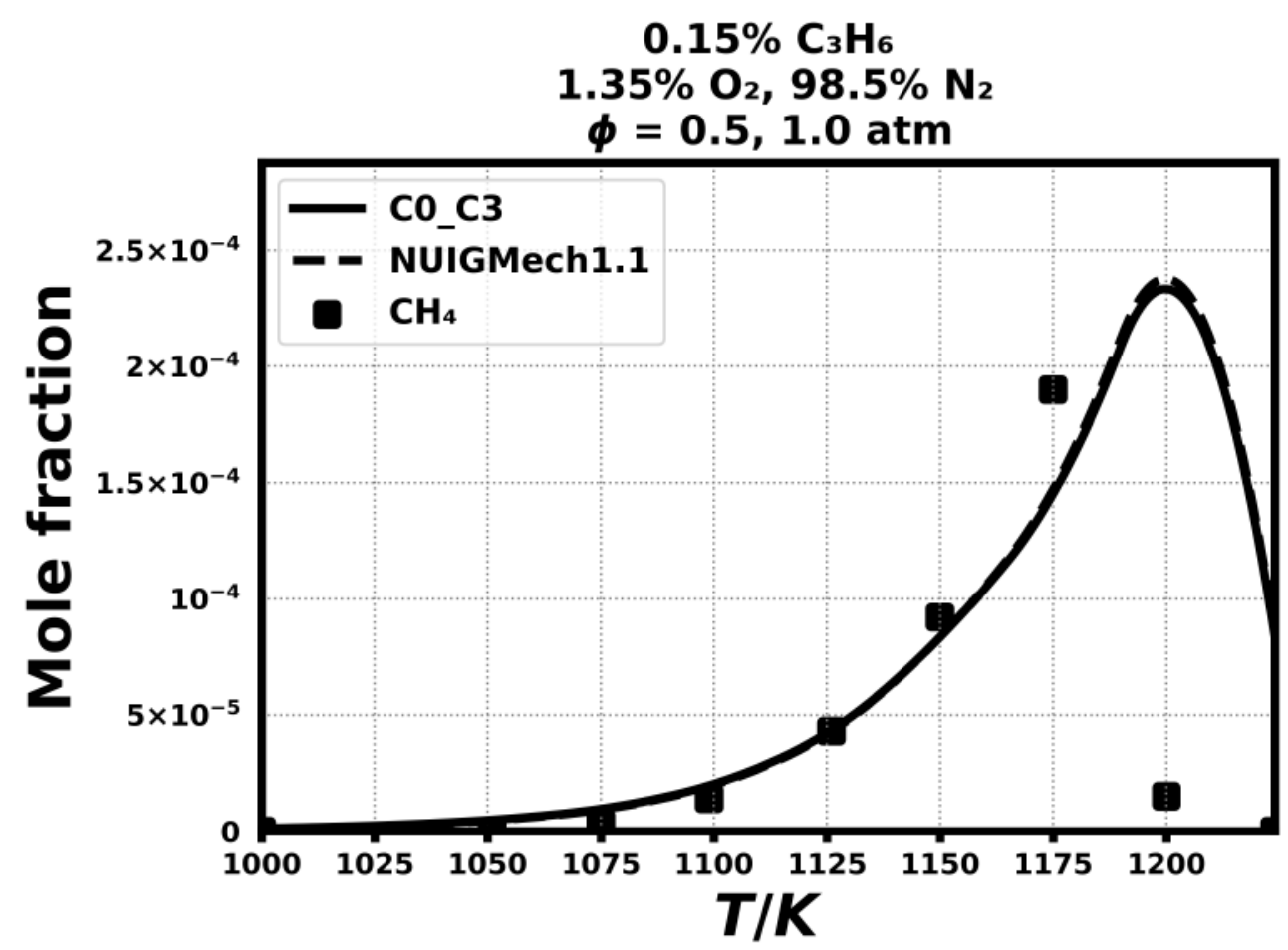

9.4) Burke, S. M., Burke, U., Mc Donagh, R., Mathieu, O., Osorio, I., Keesee, C., ... \& Oehlschlaeger, M. A., Combustion and Flame, 162(2) (2015) 296-314.

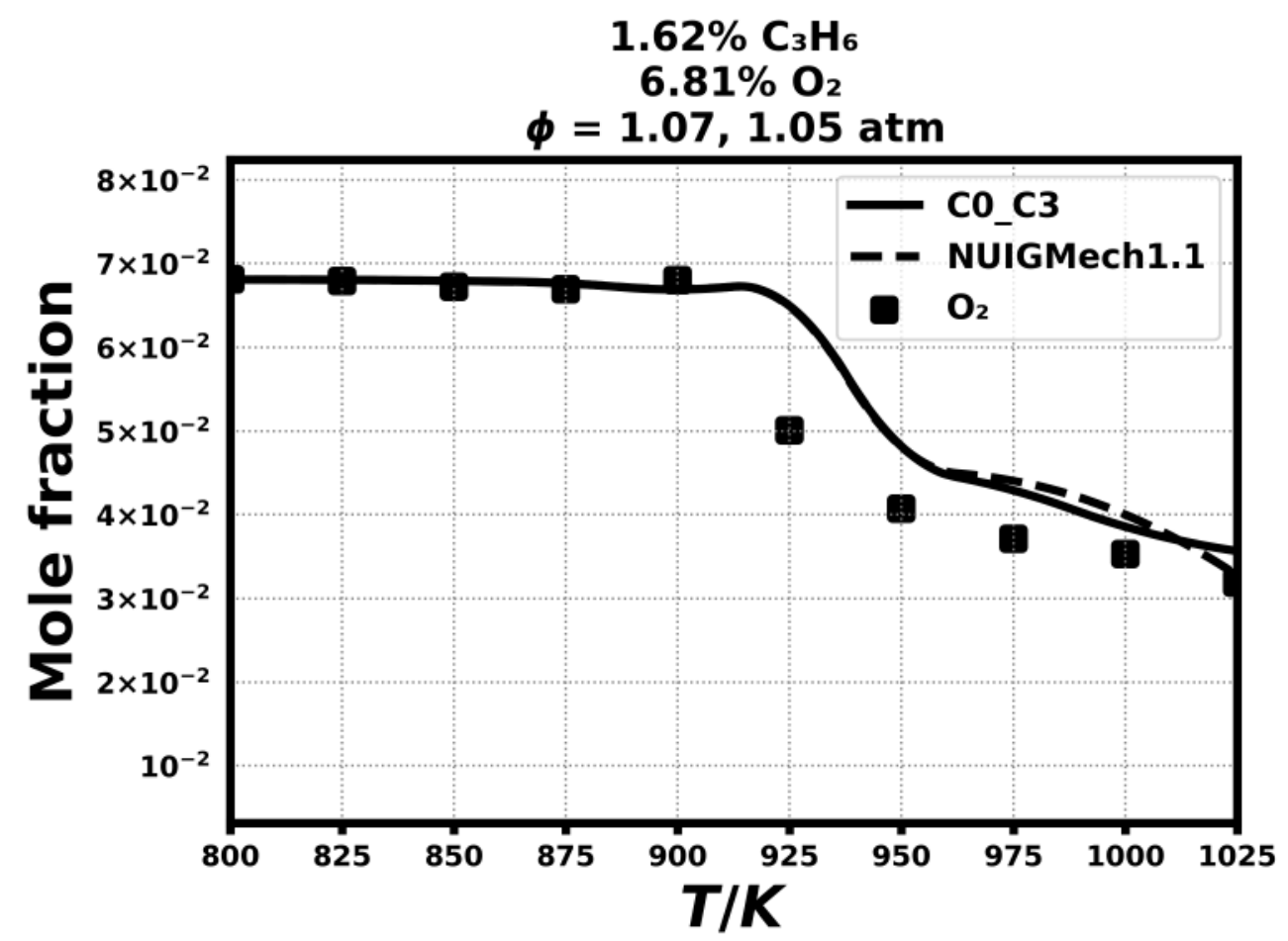



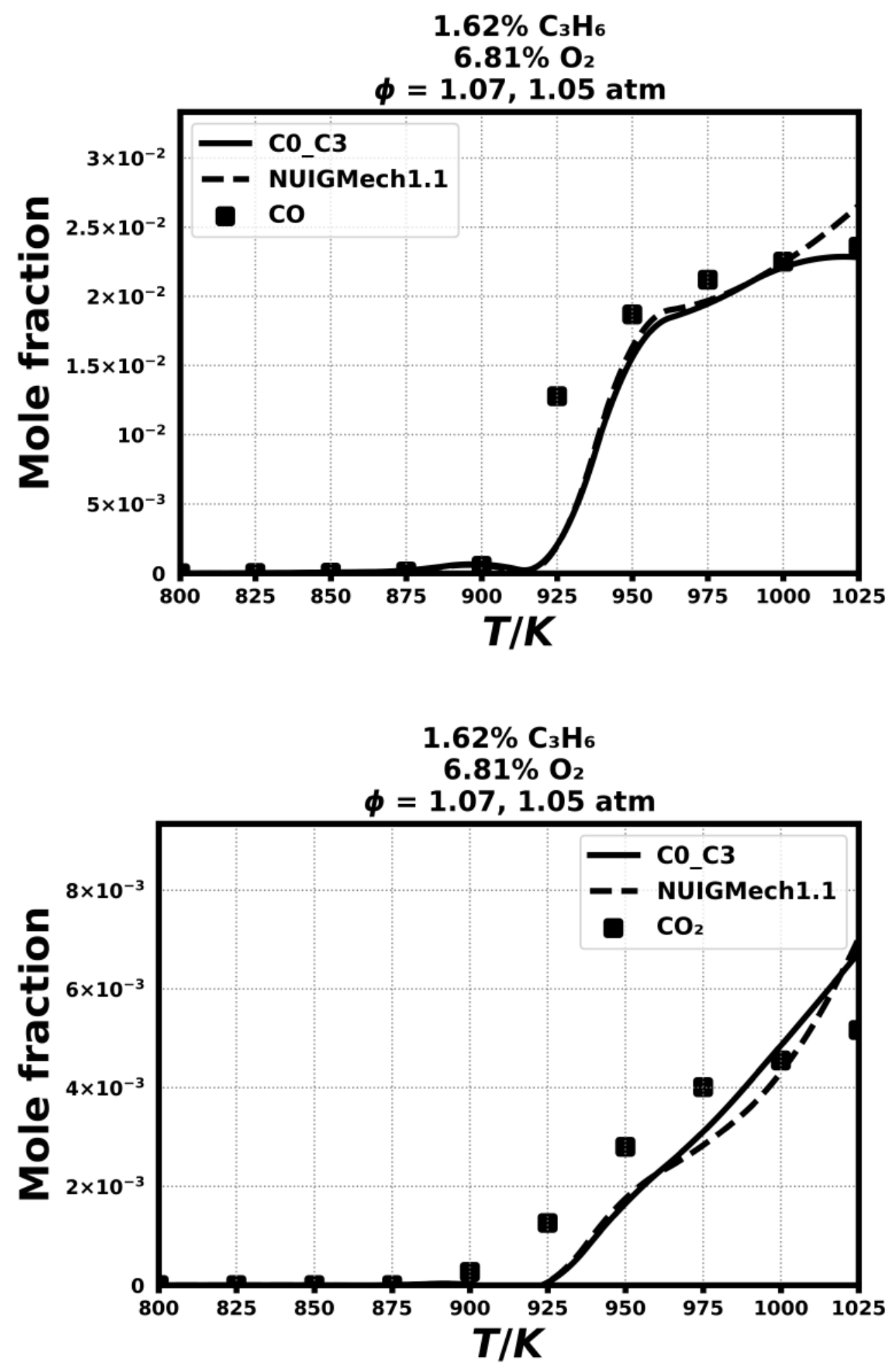

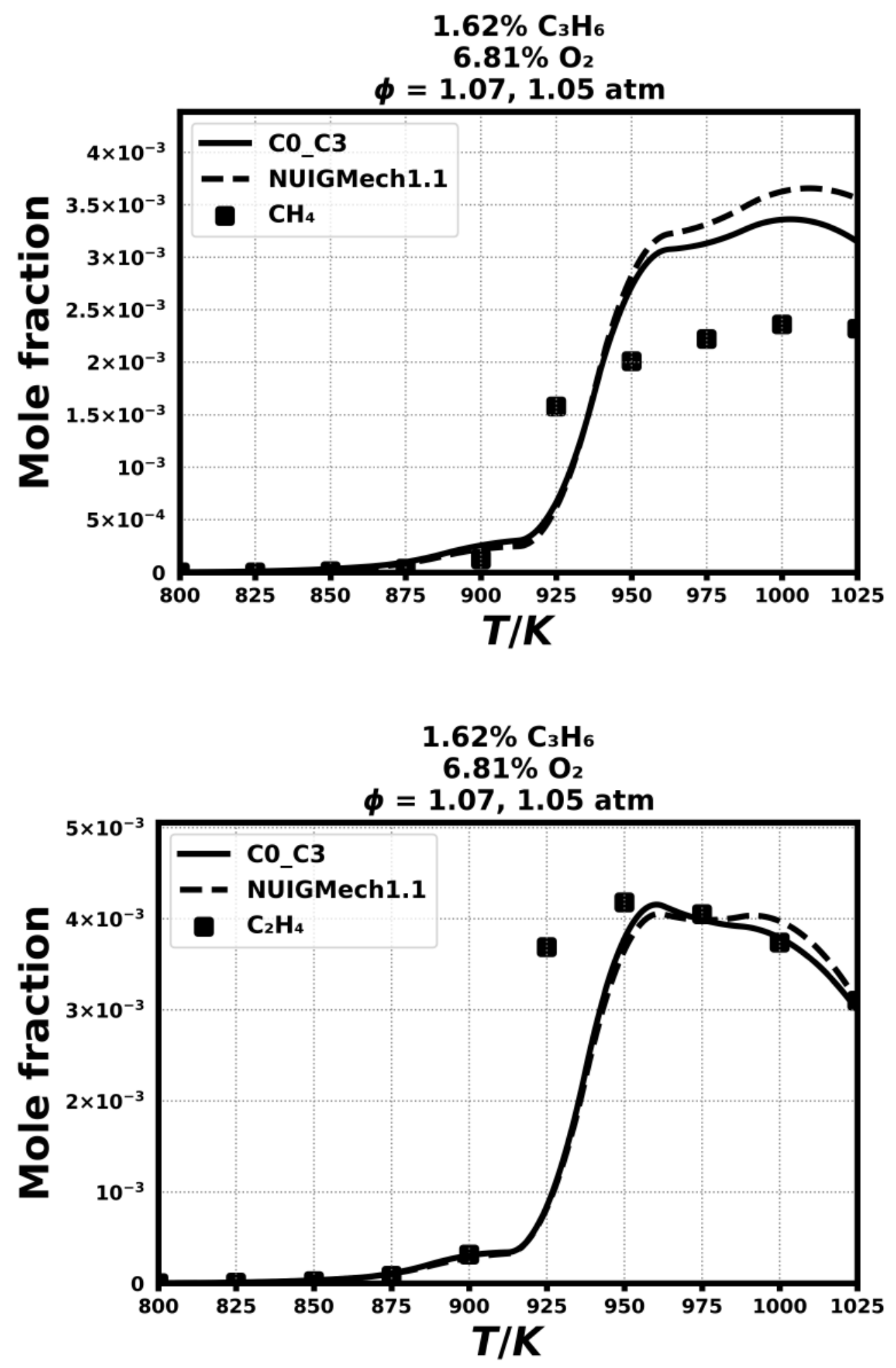

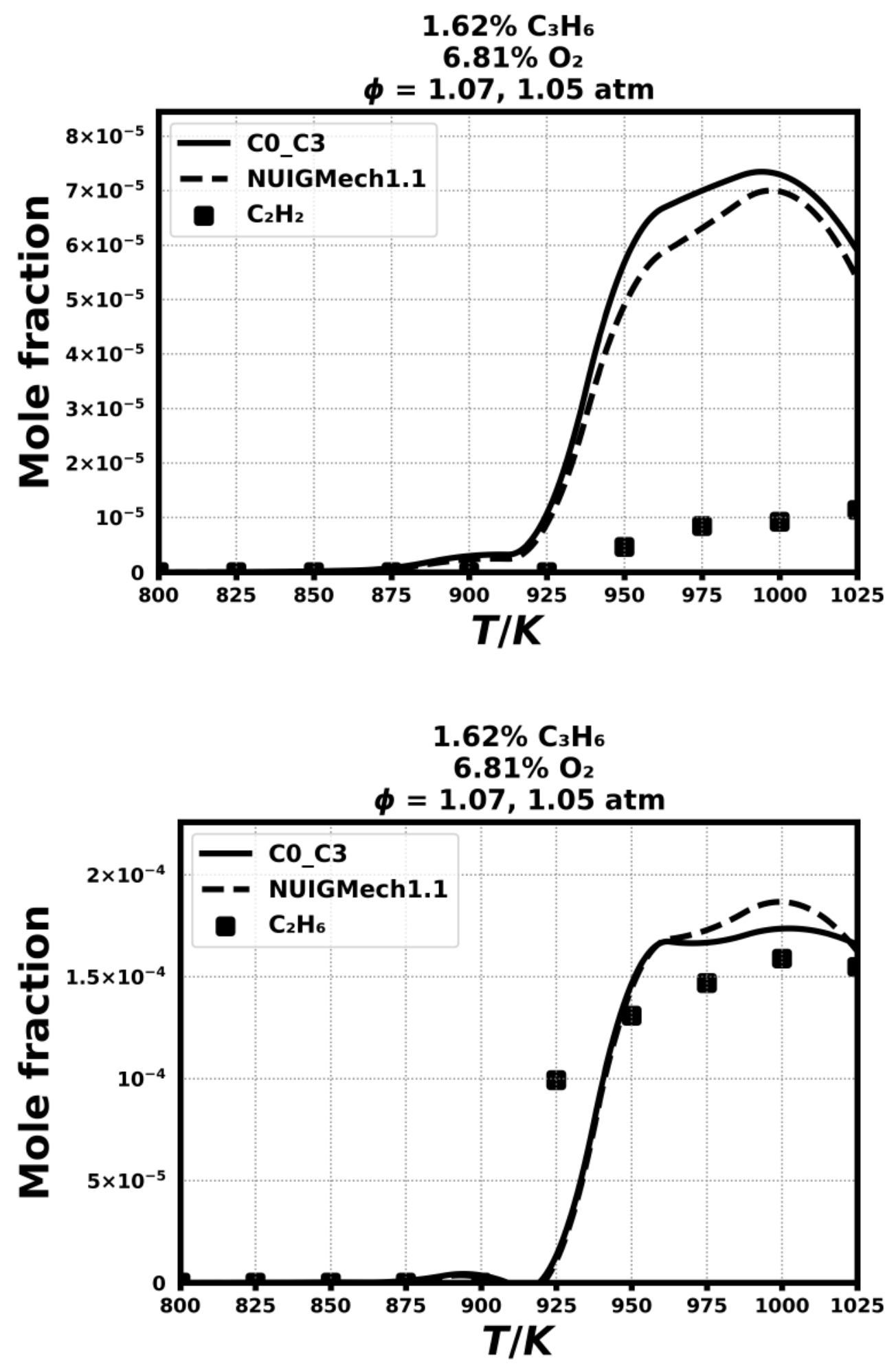

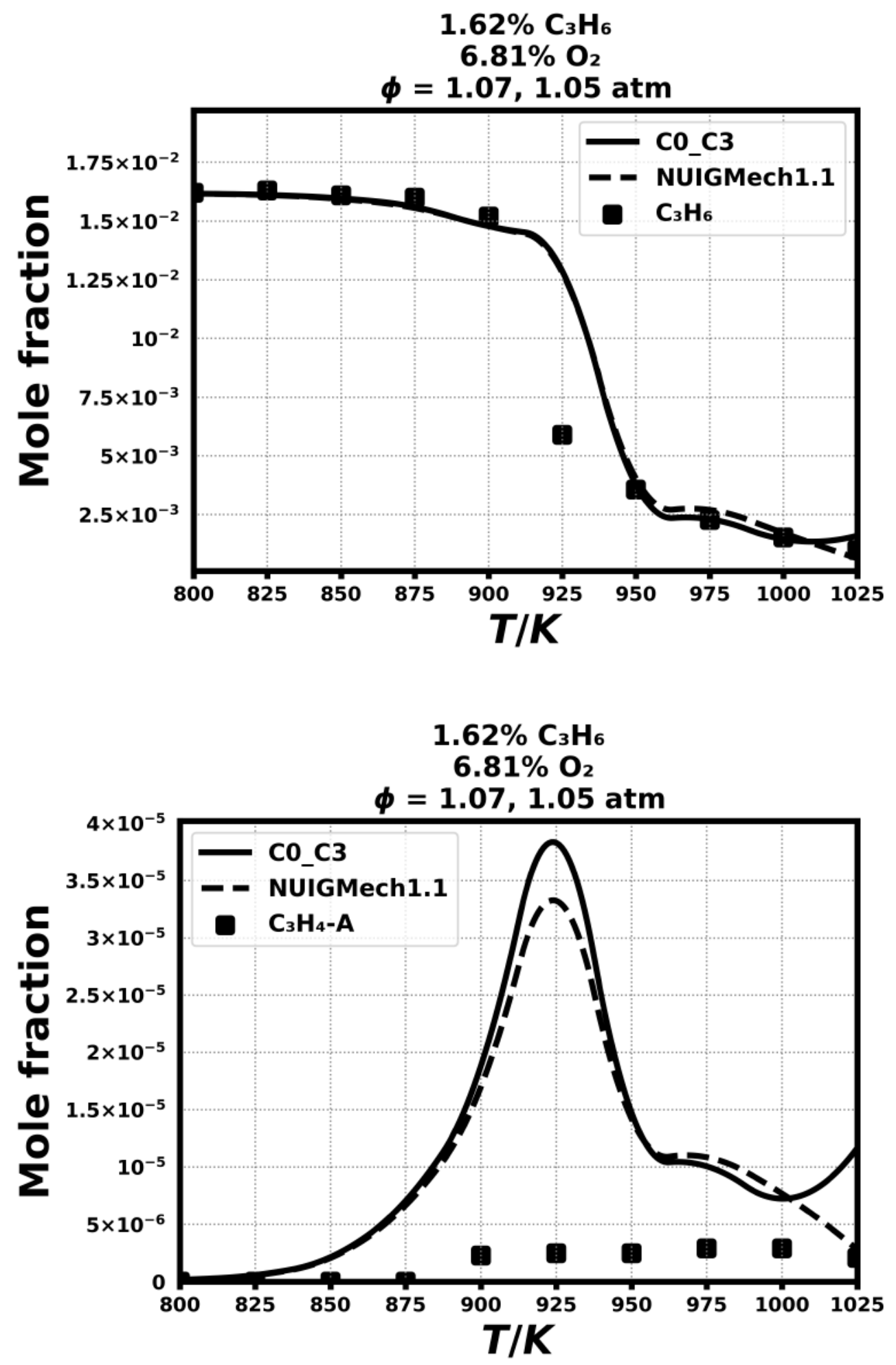

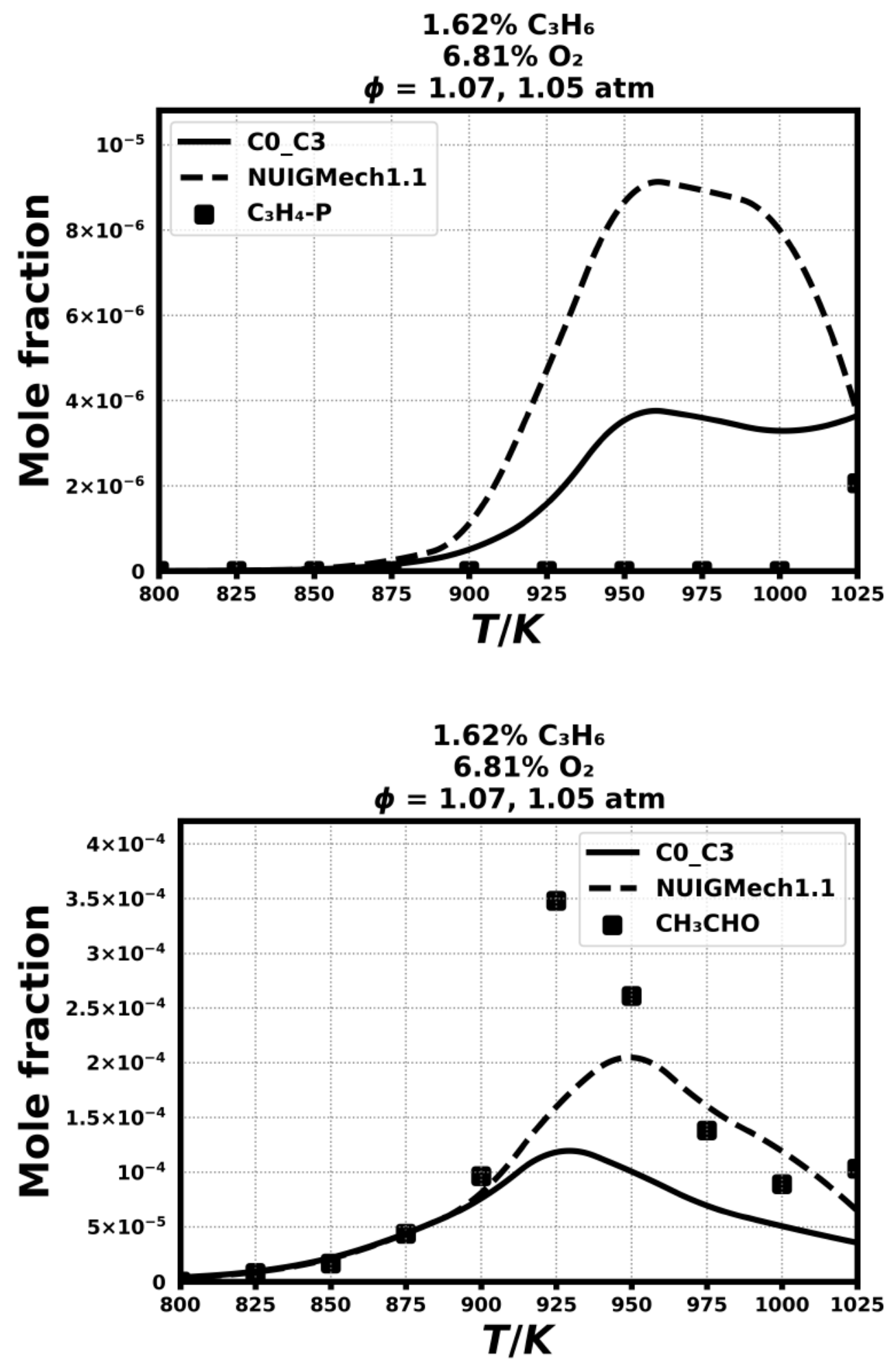

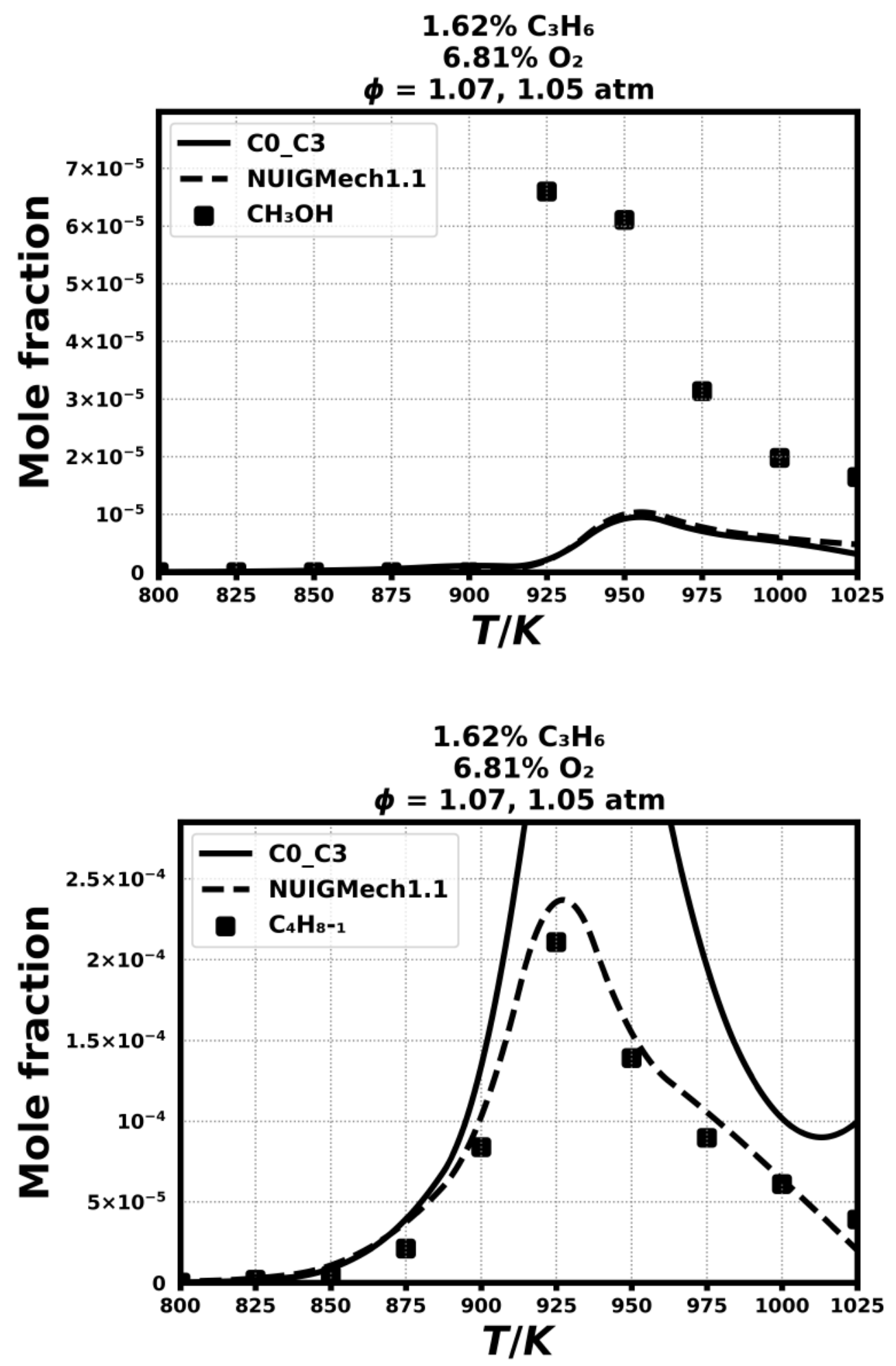

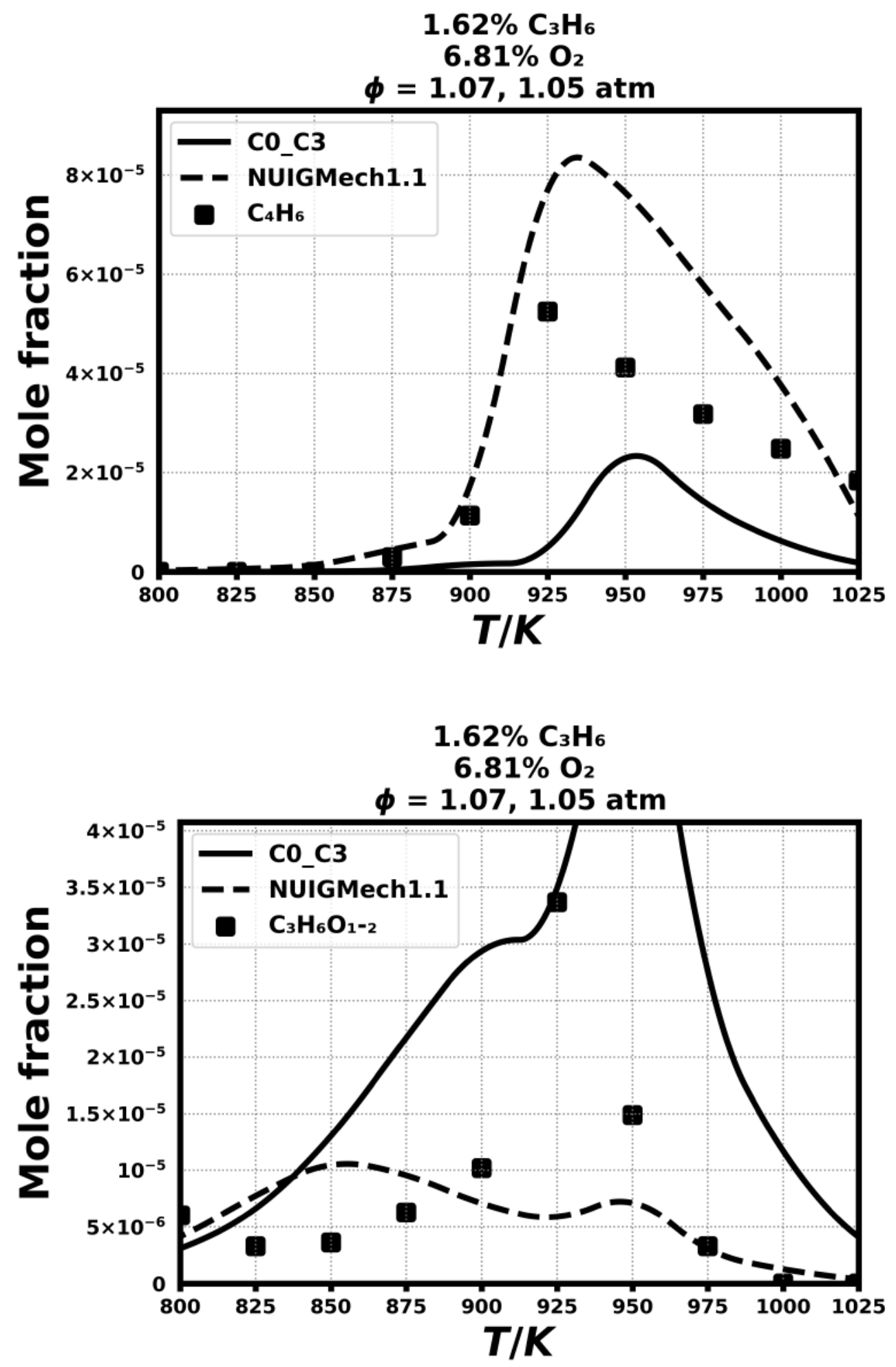

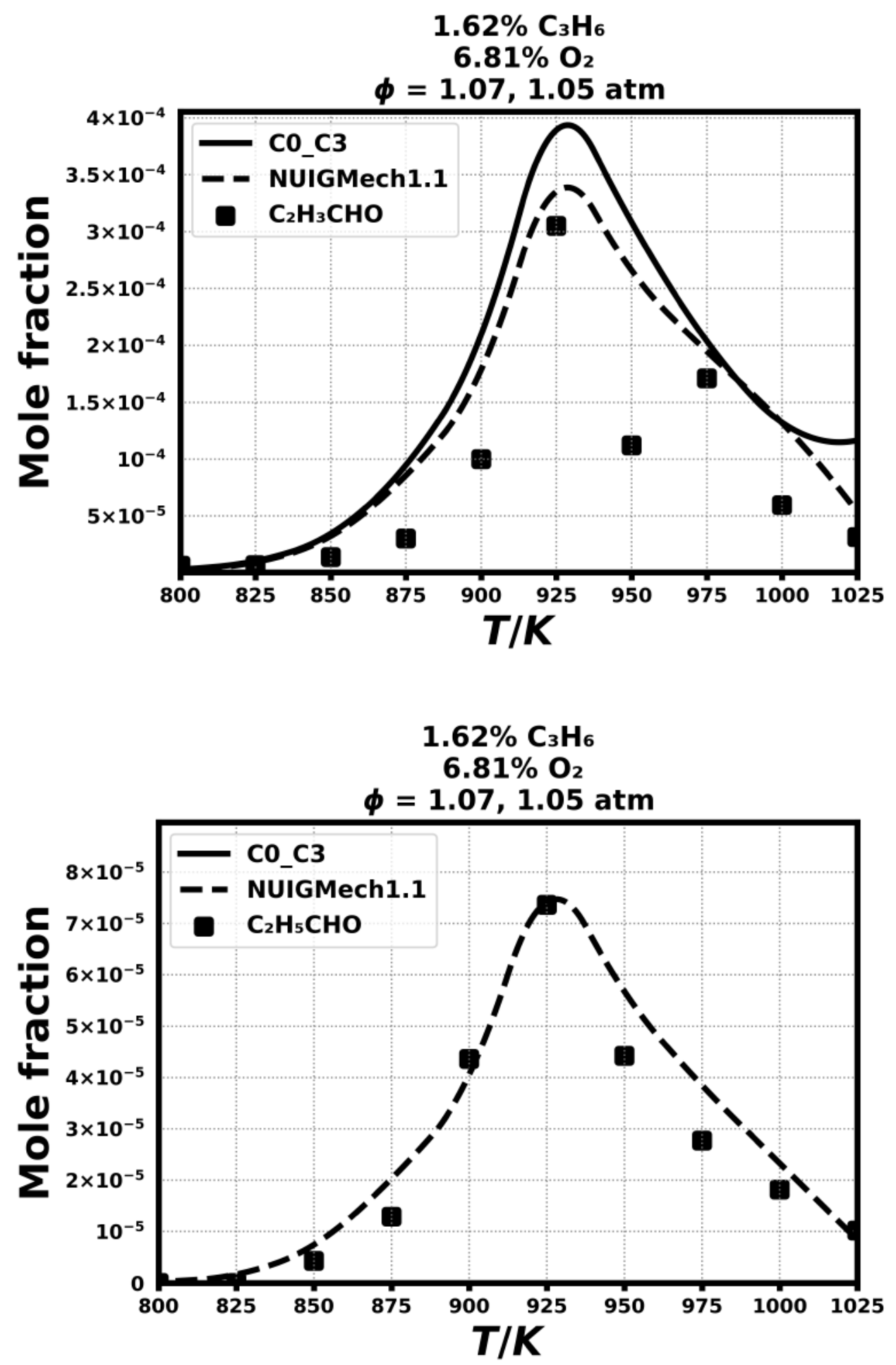

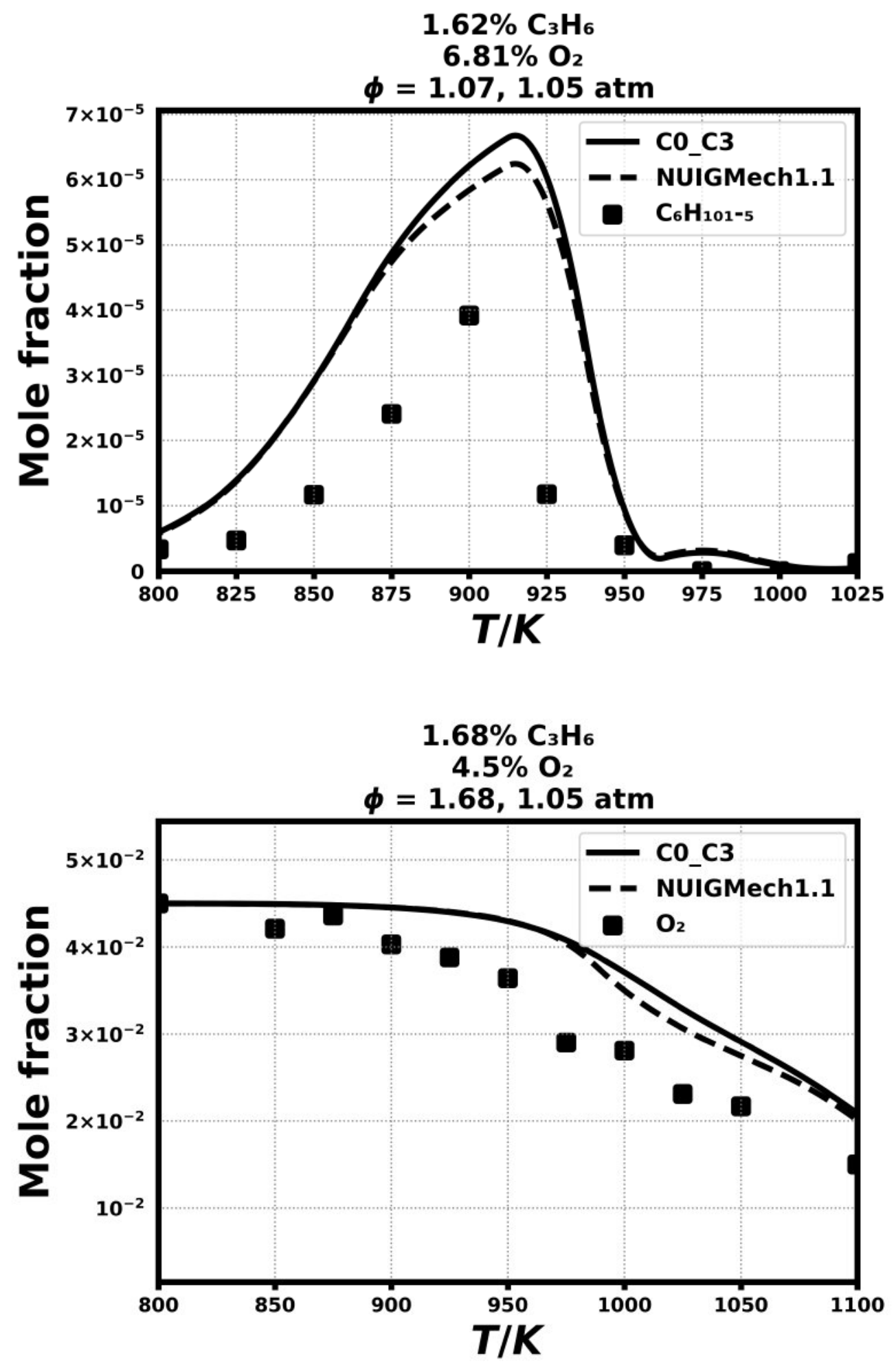

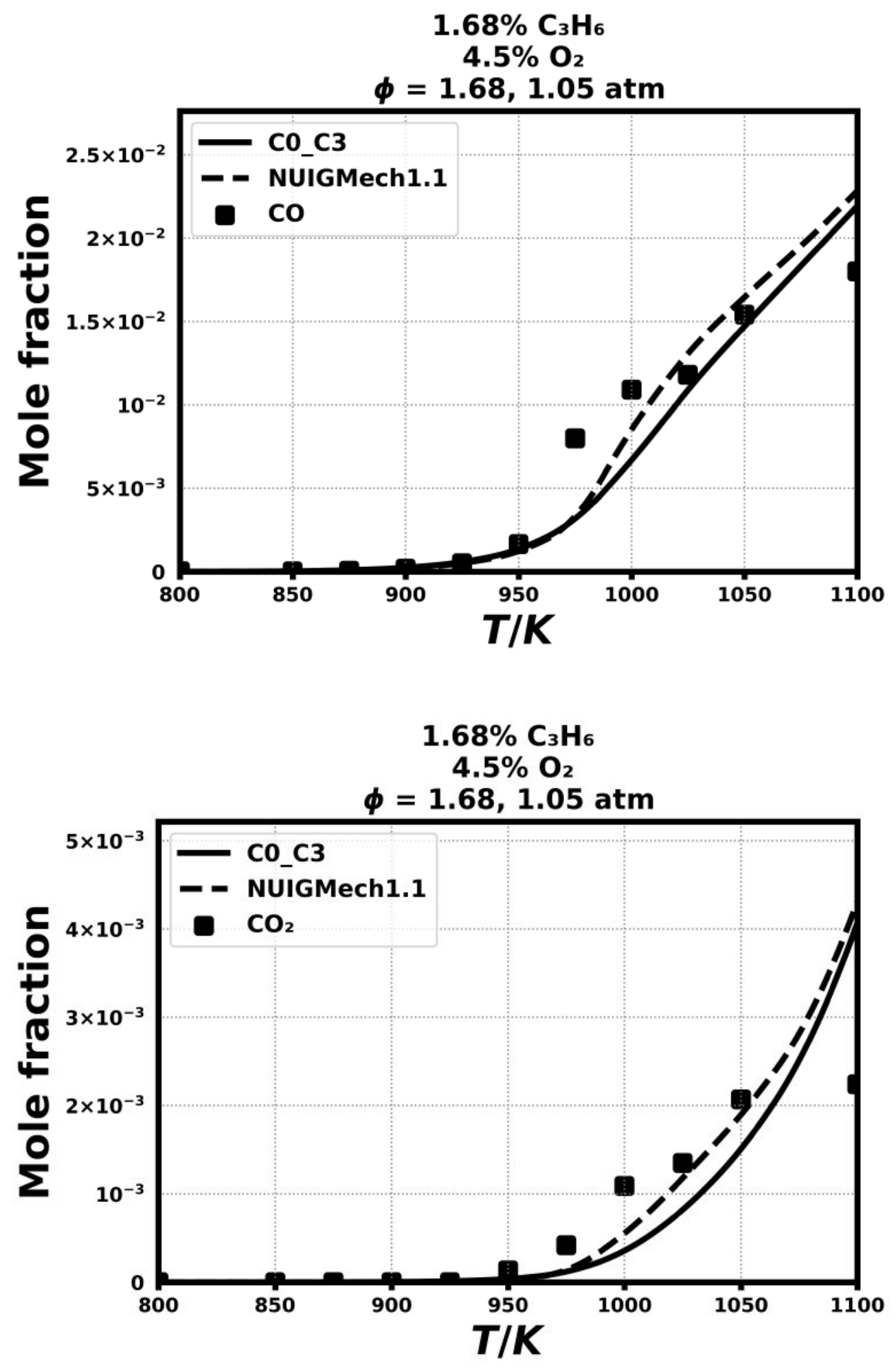

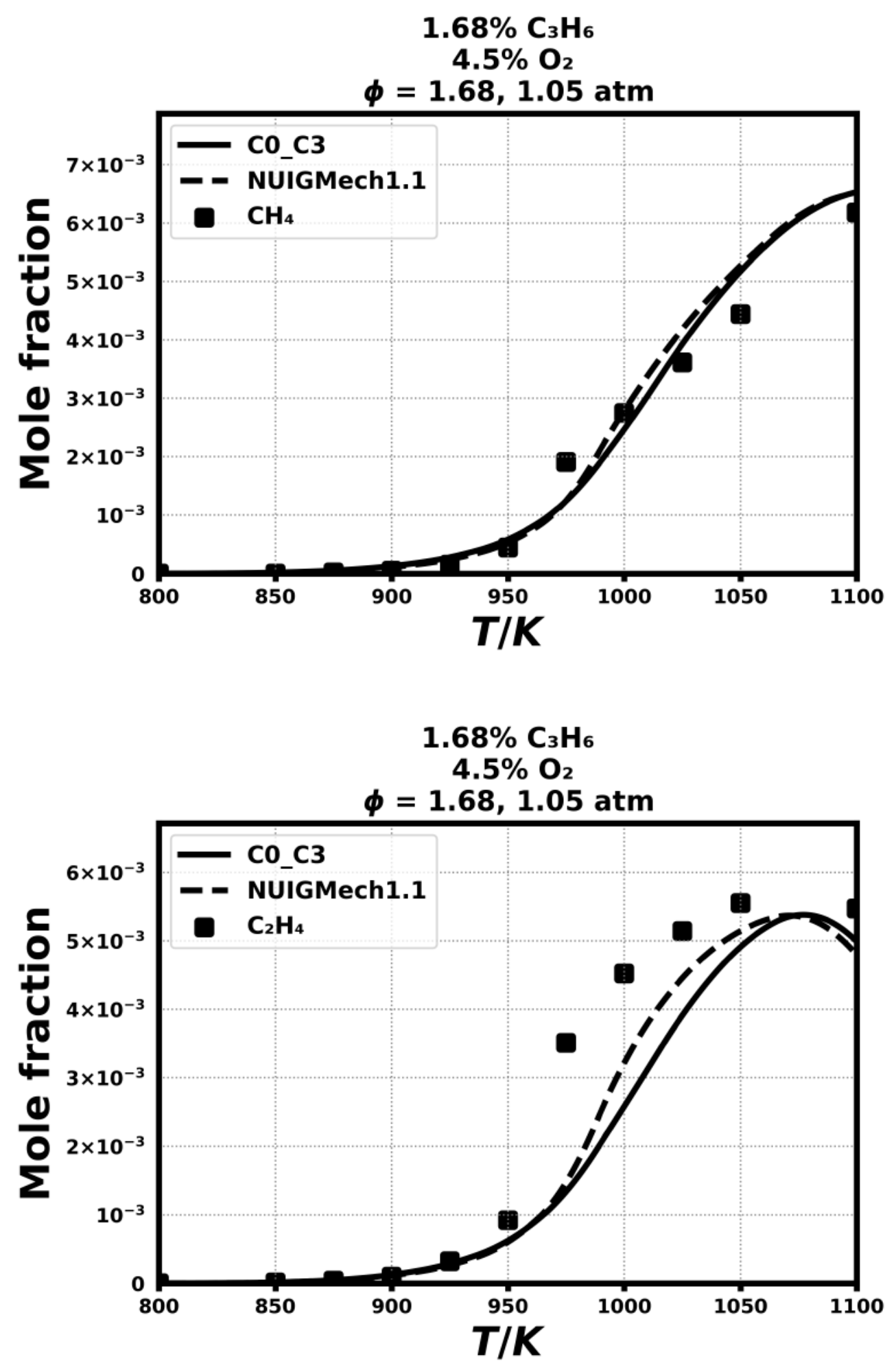

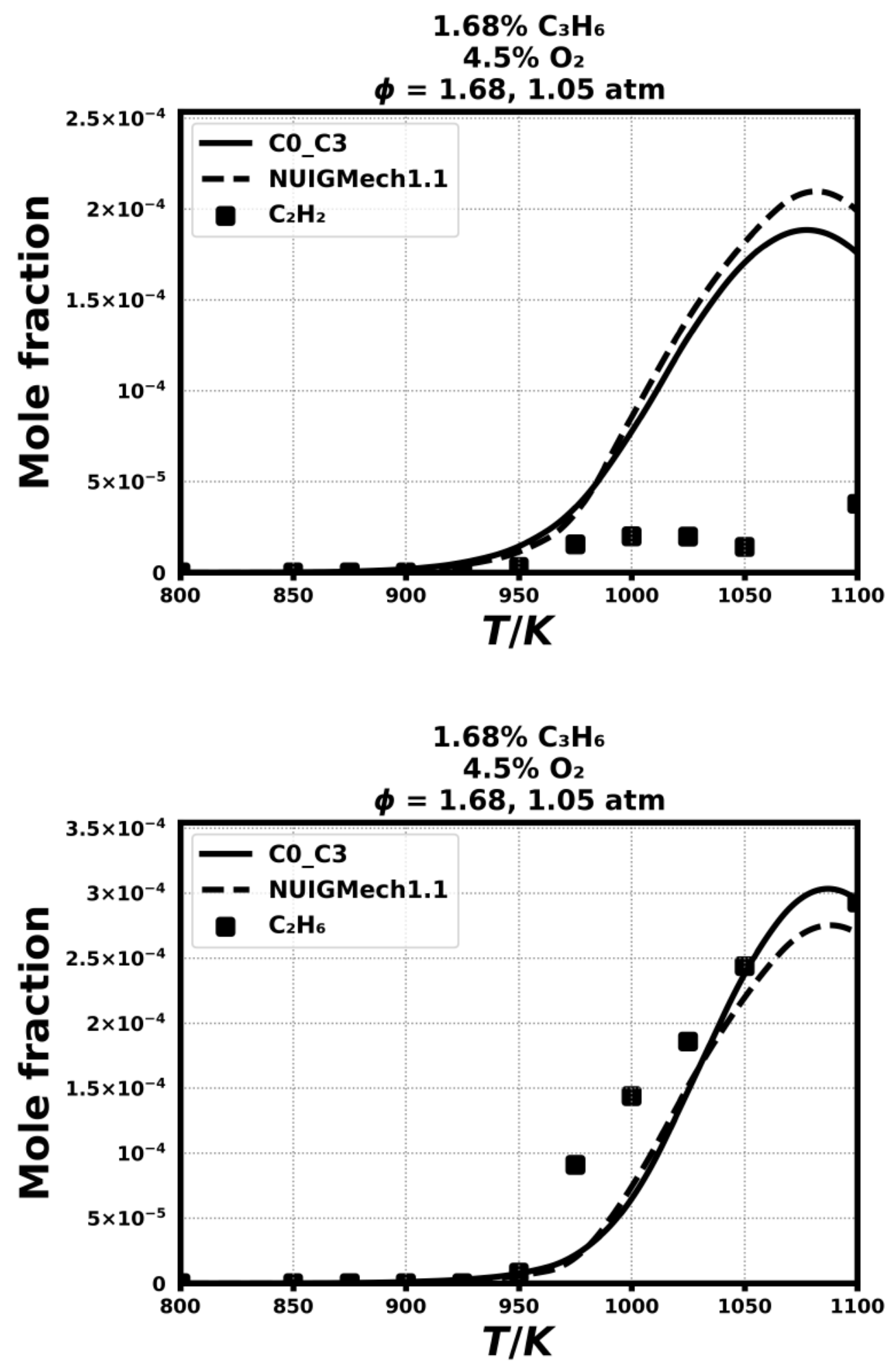

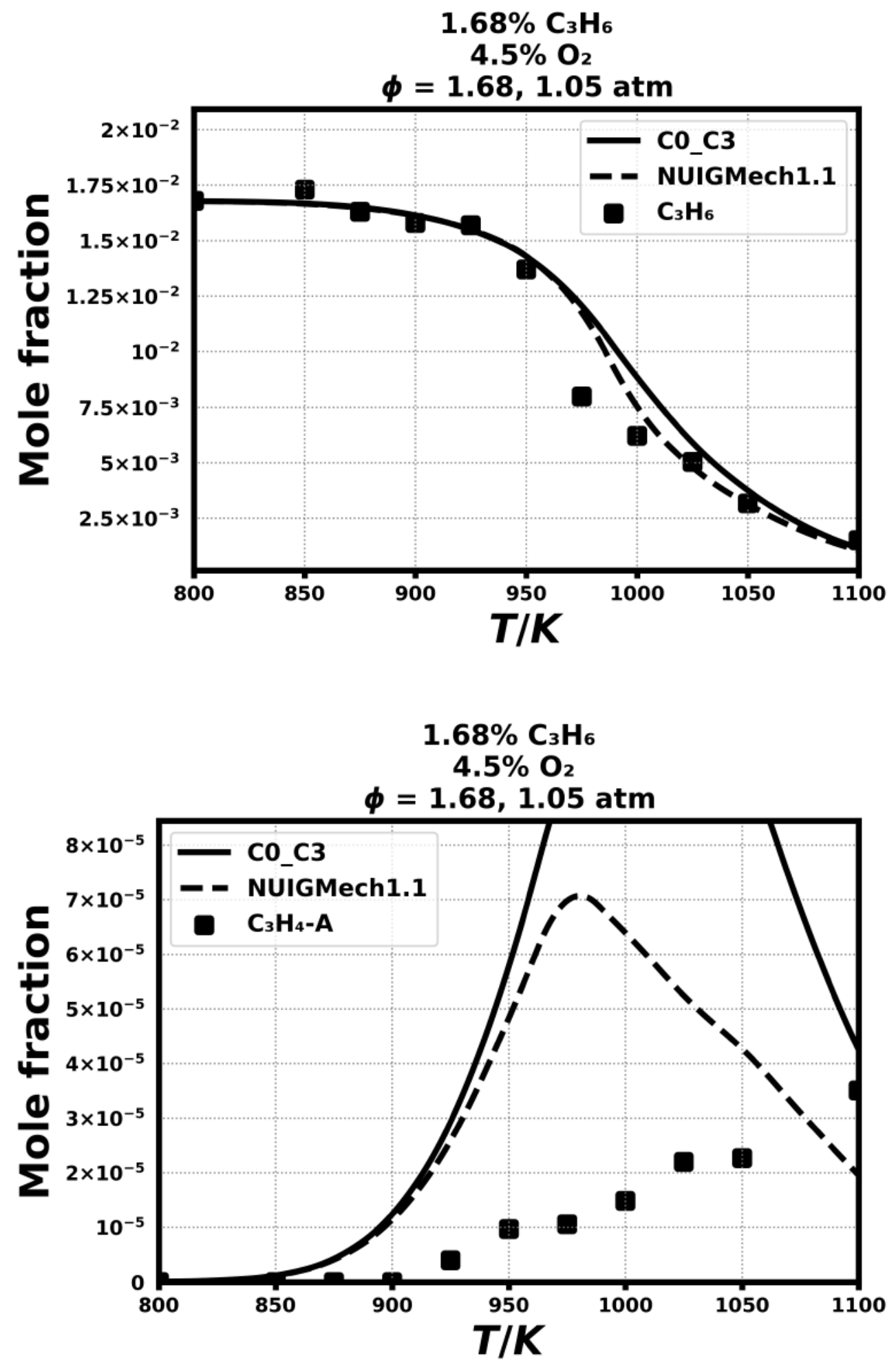

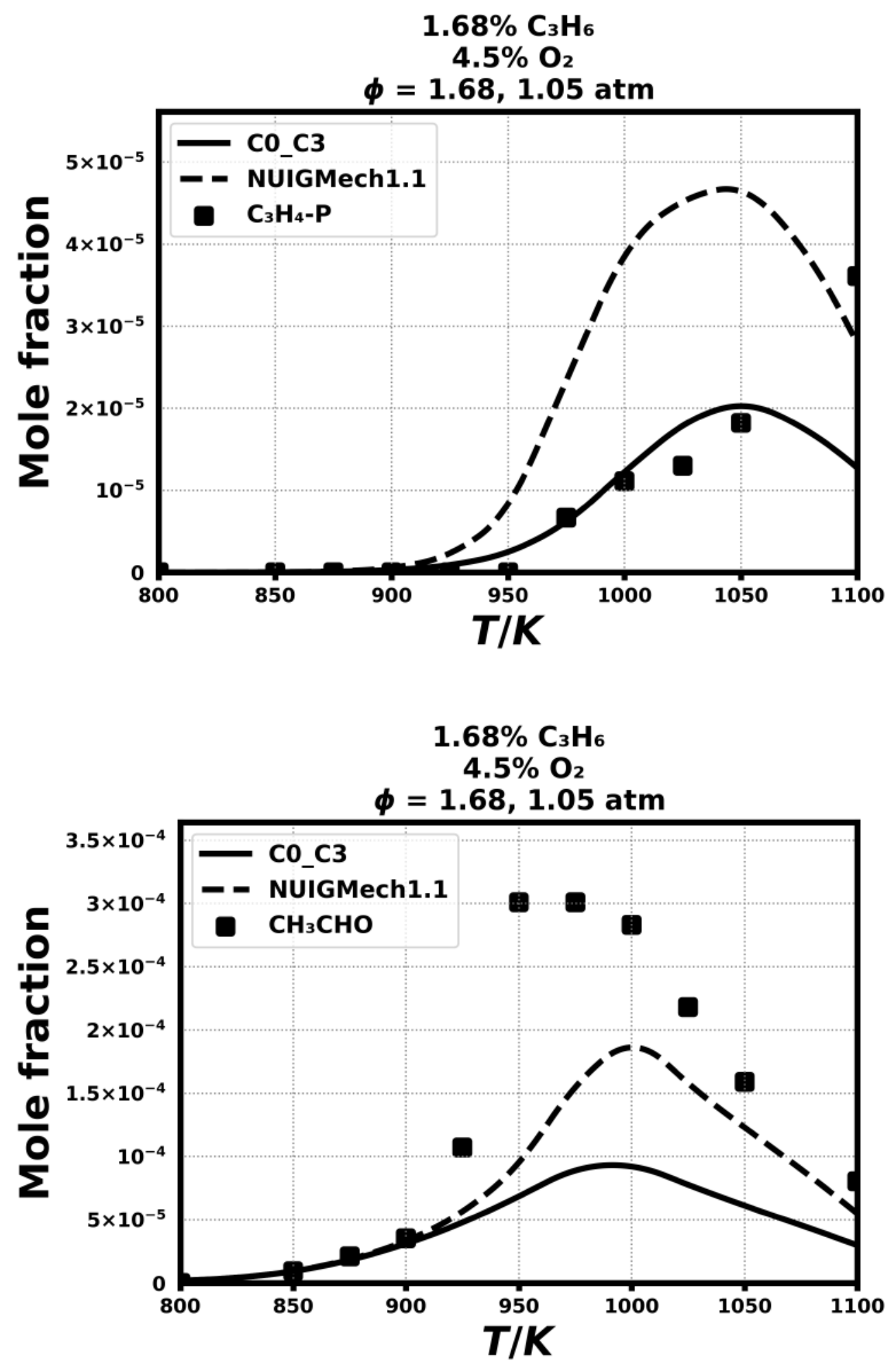

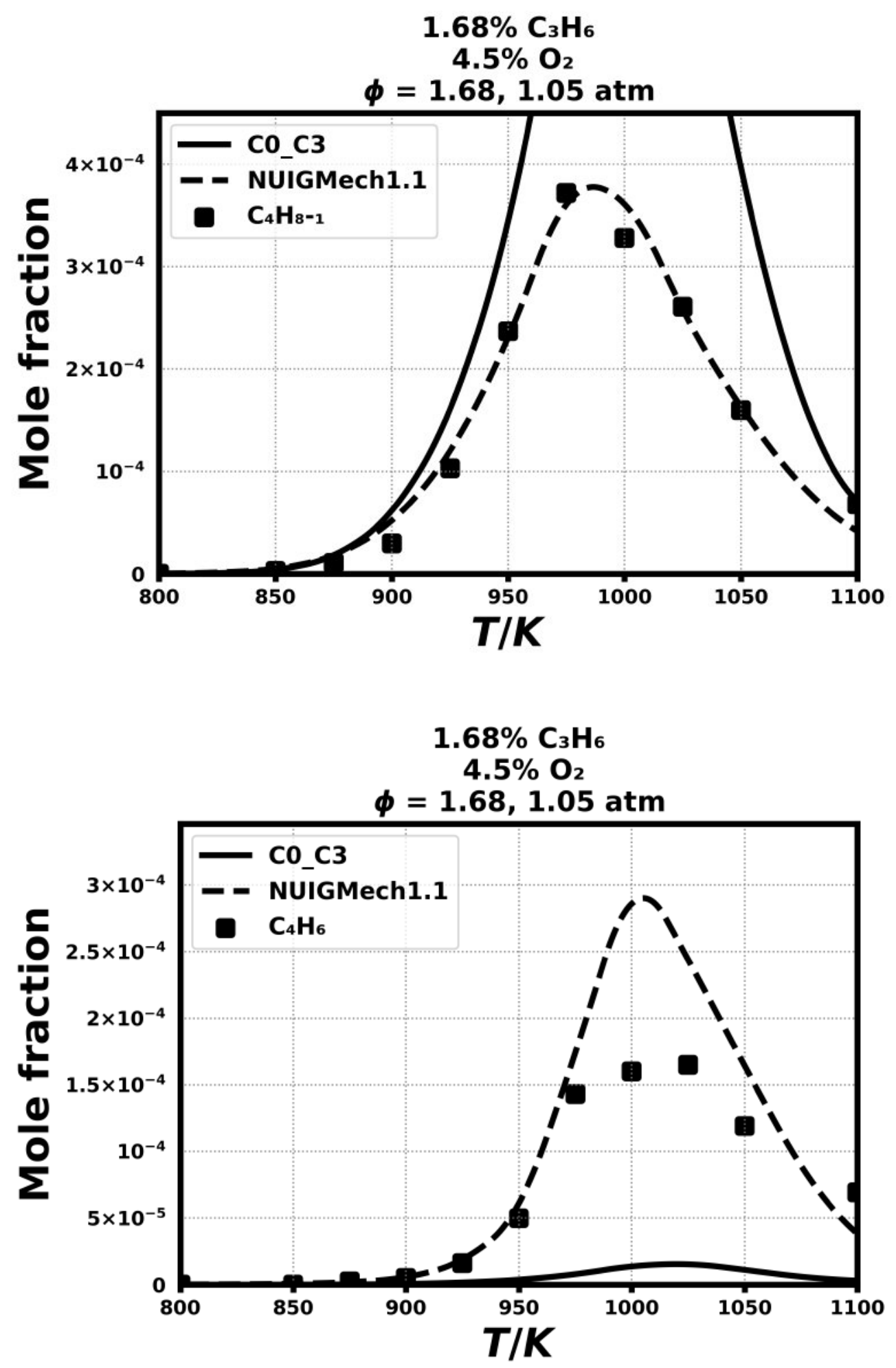

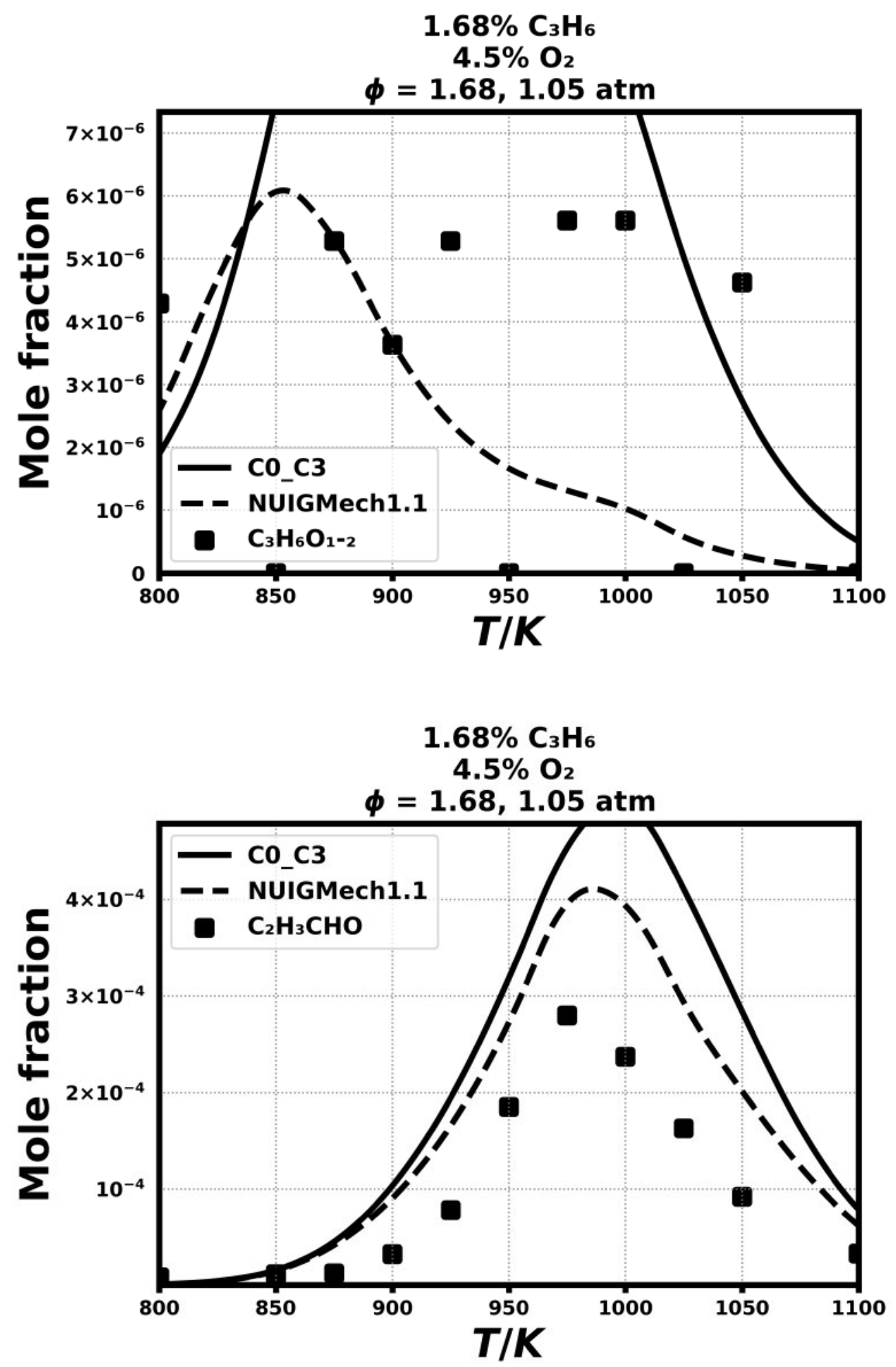

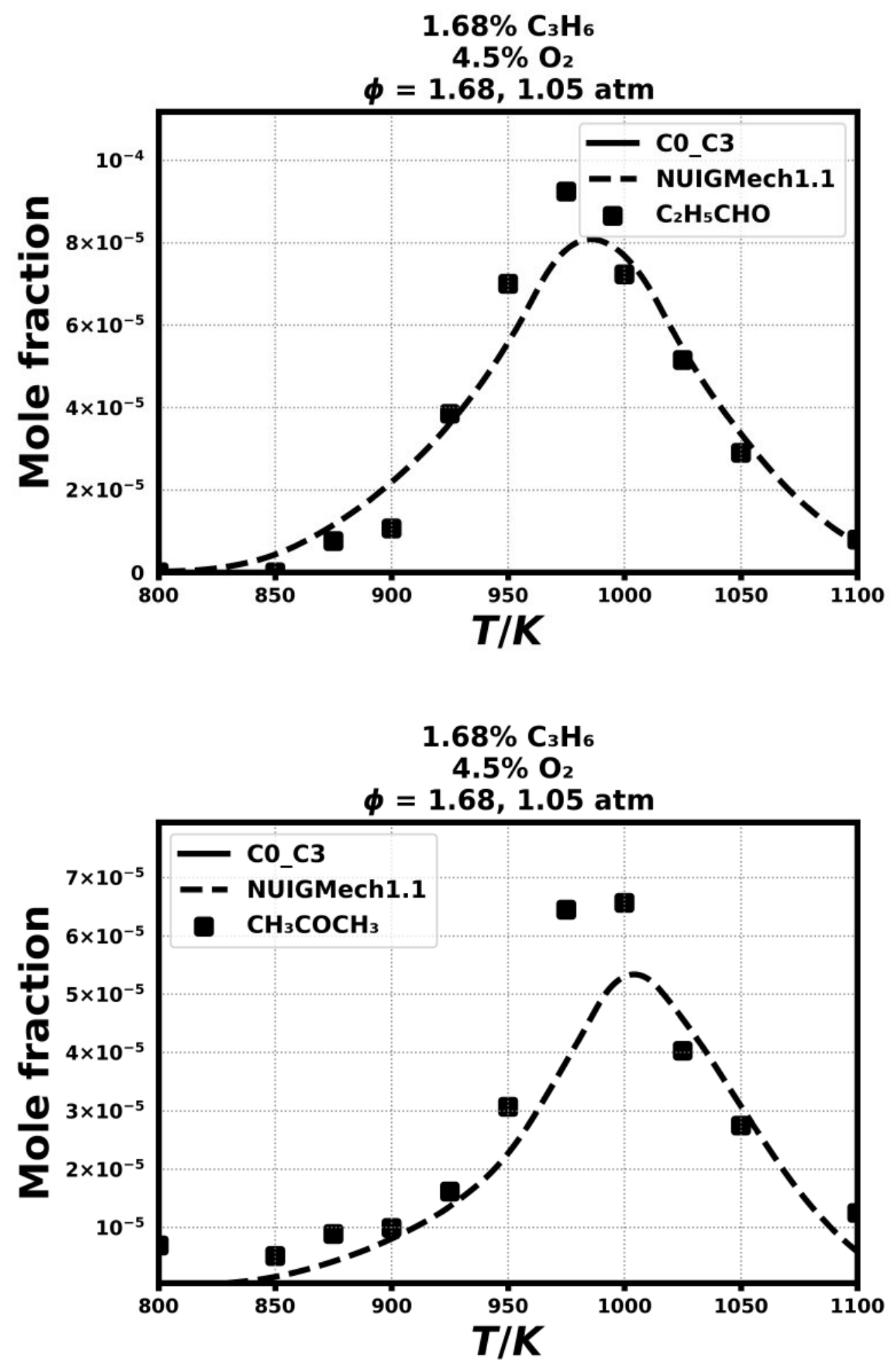

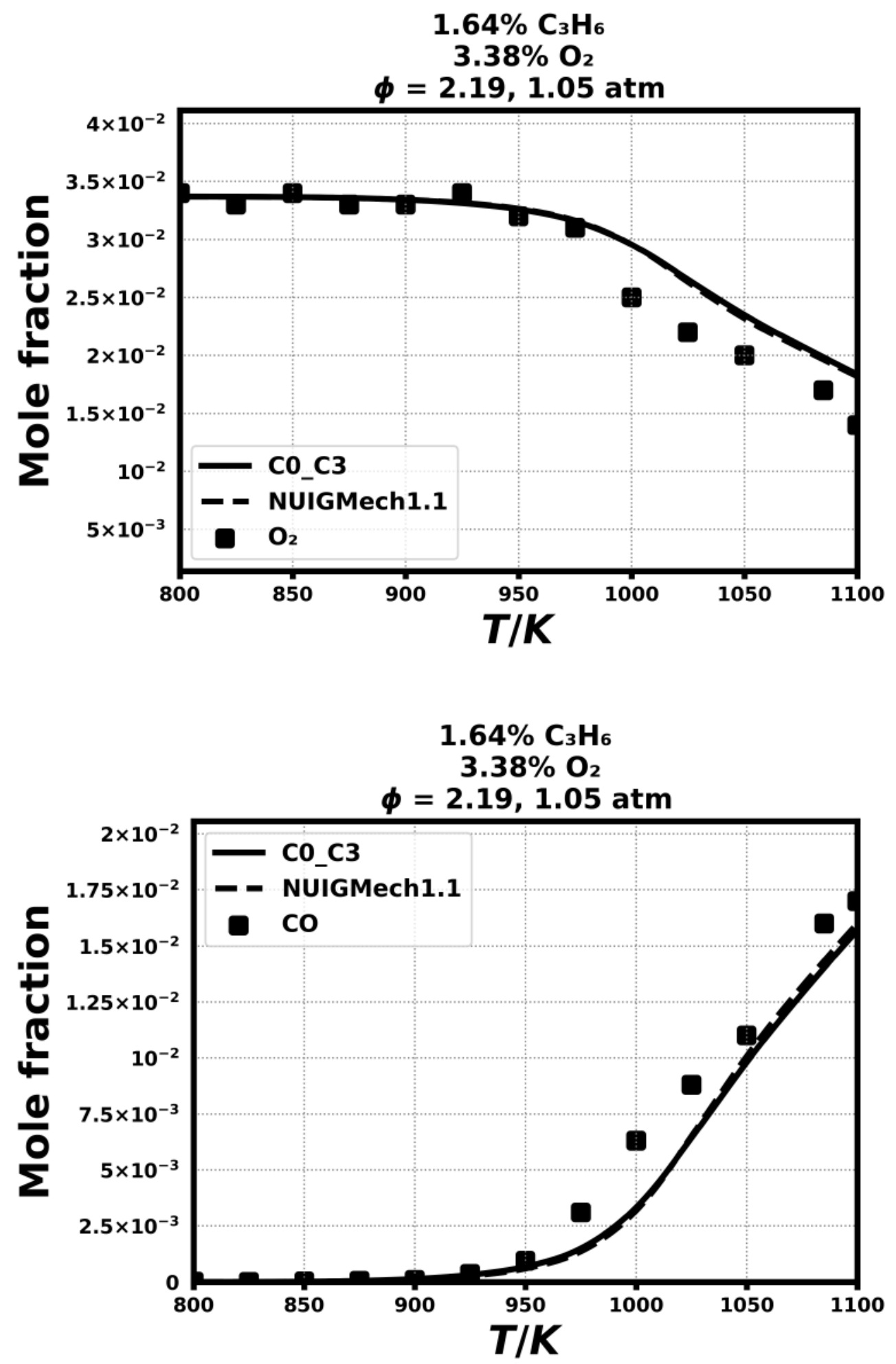

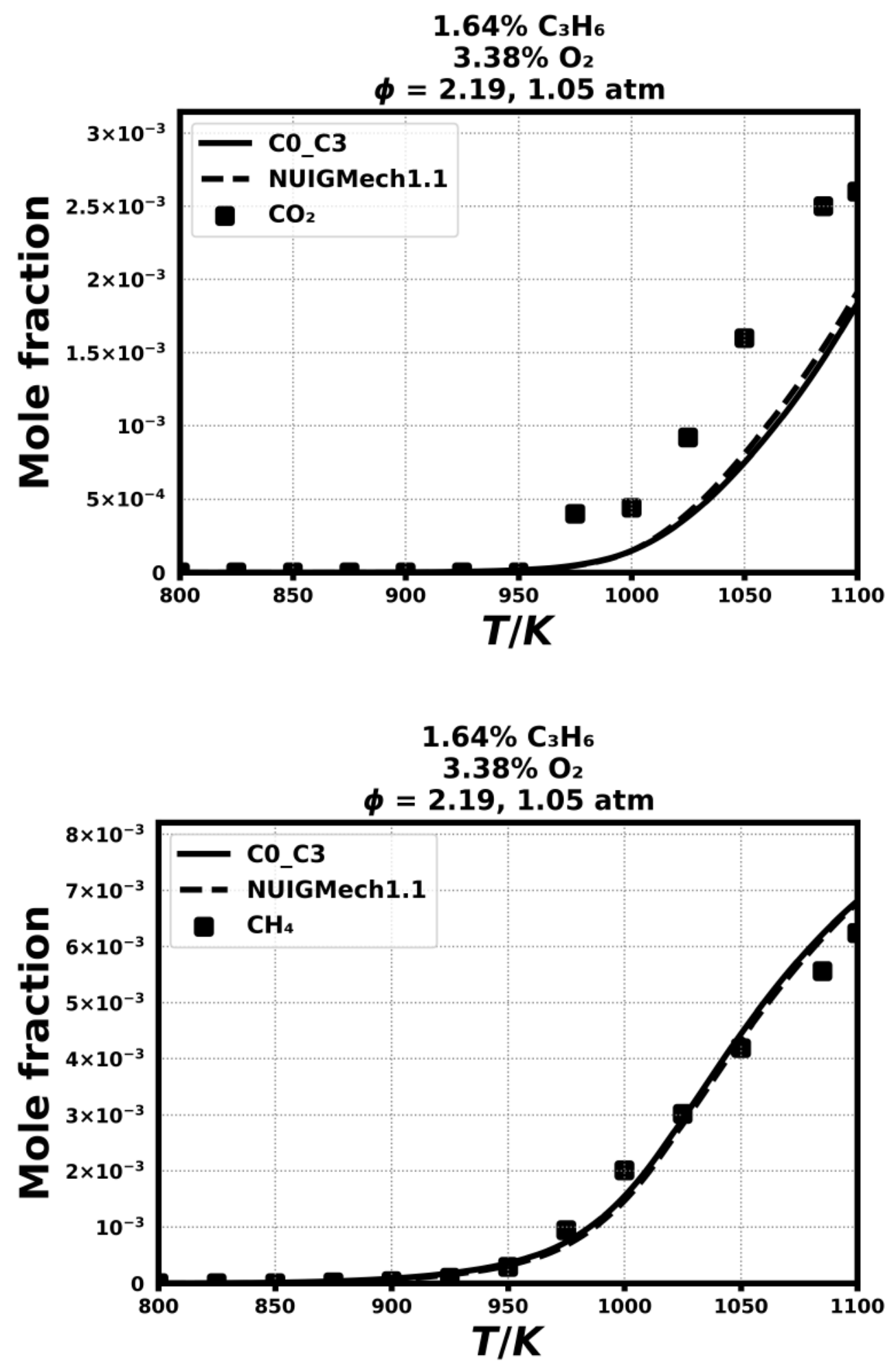

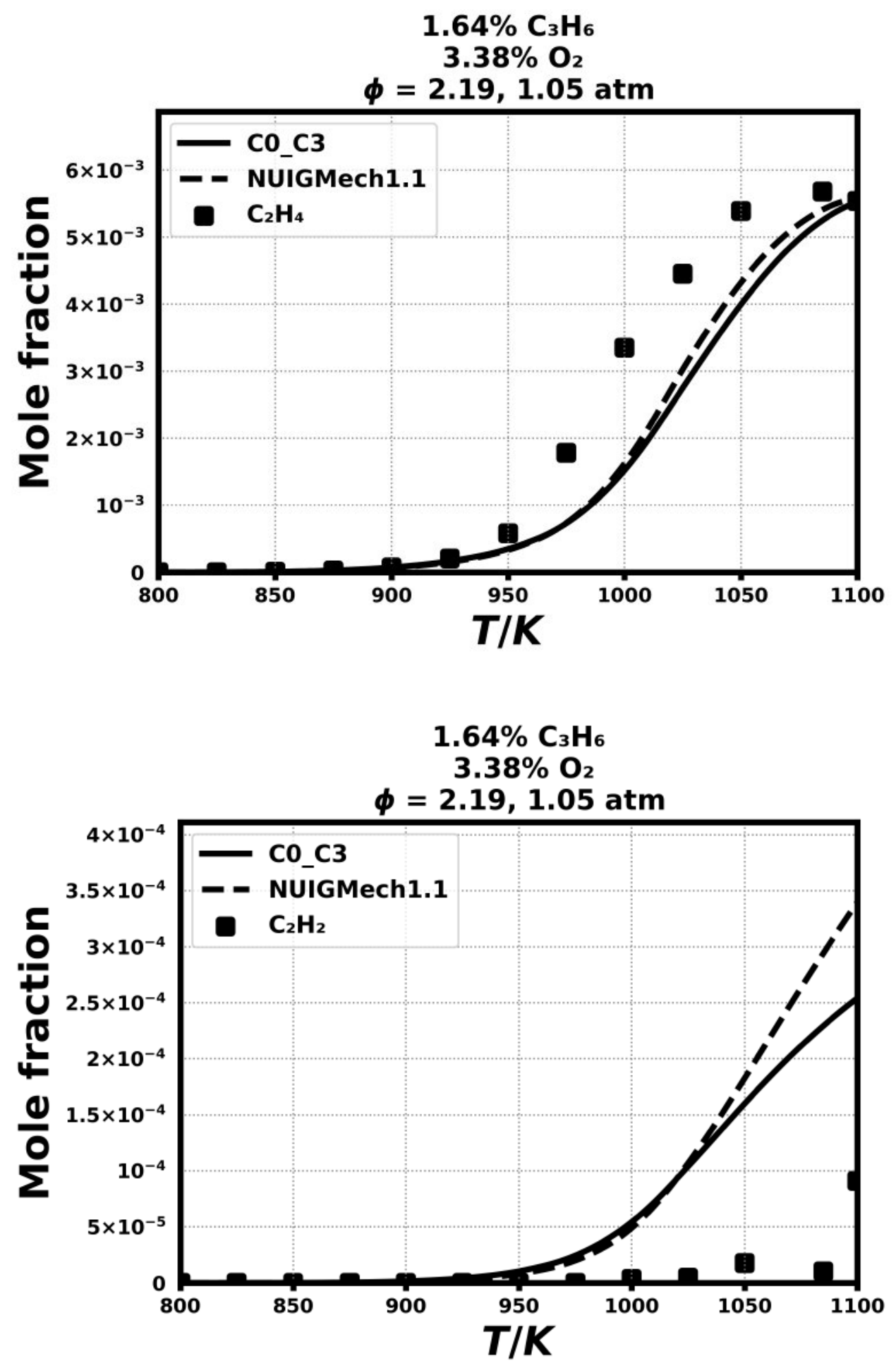

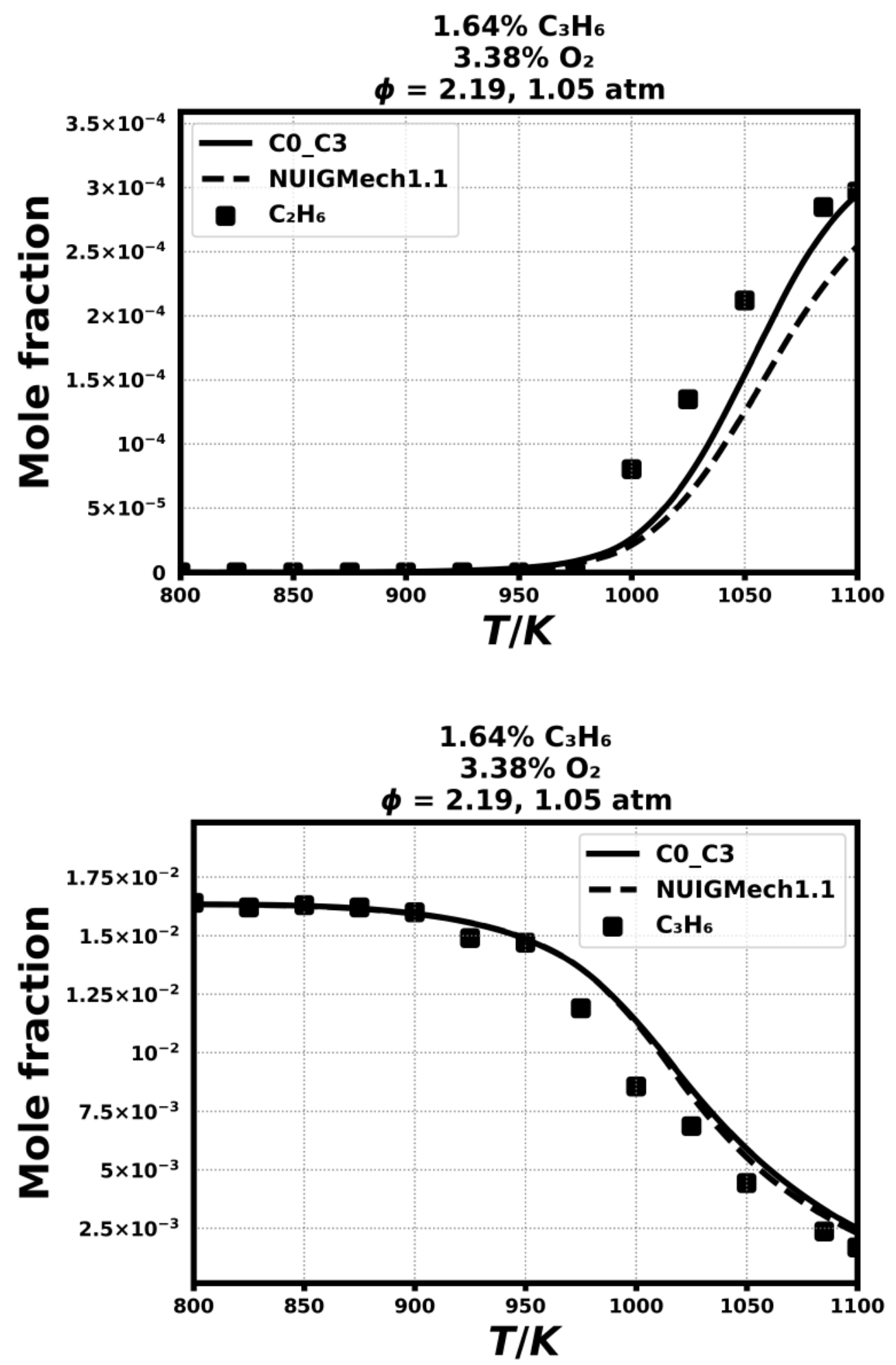

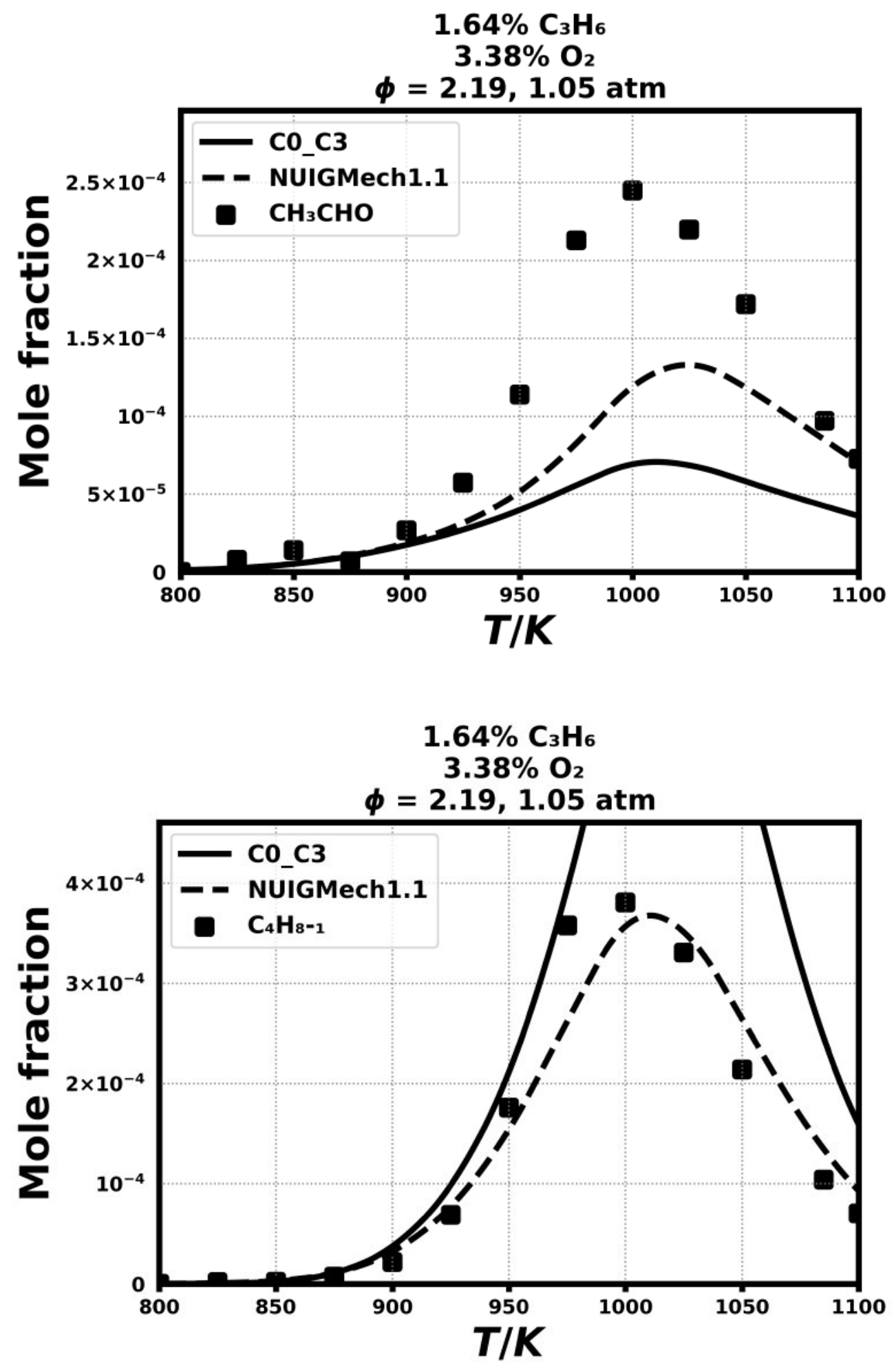

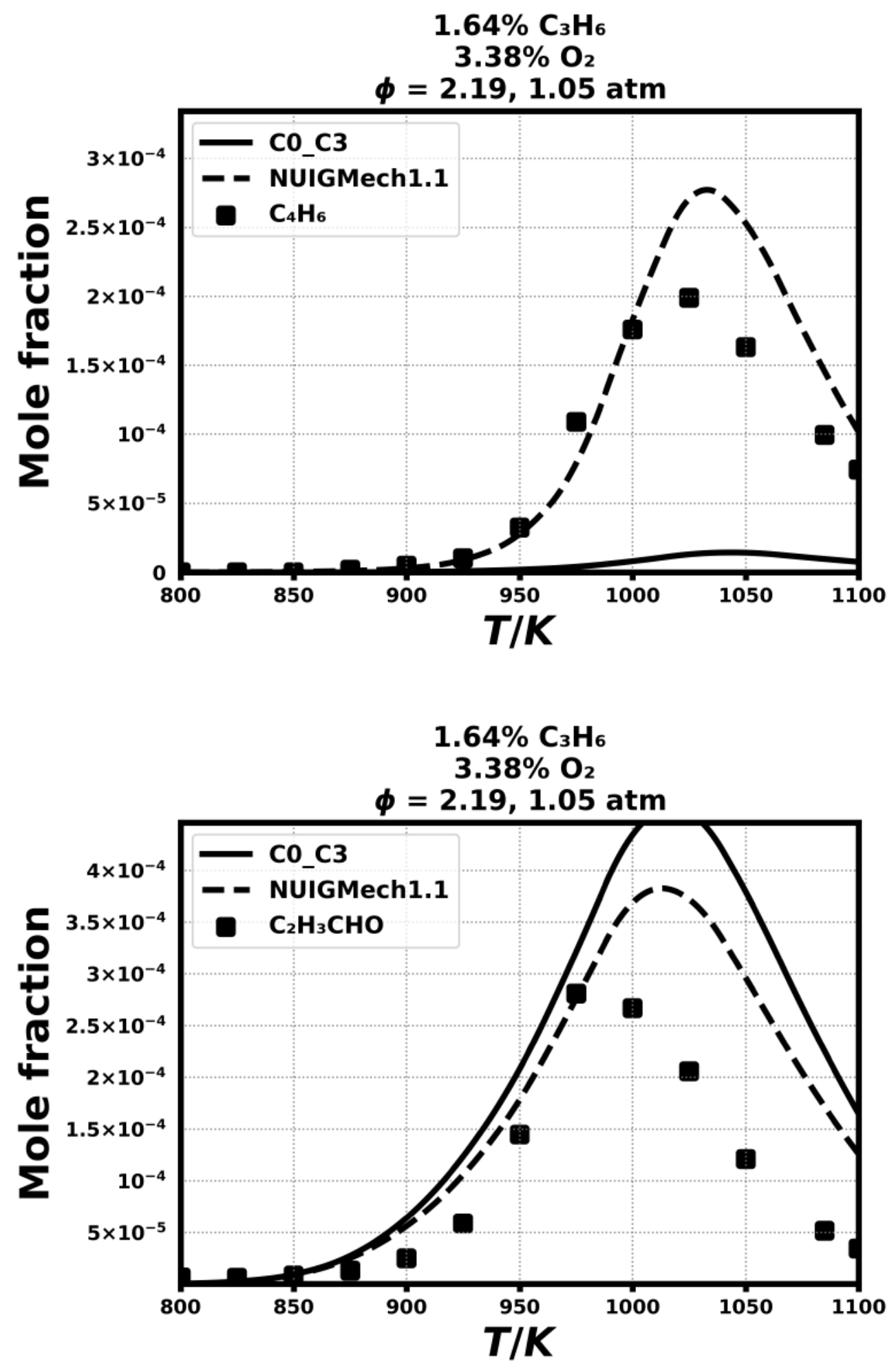


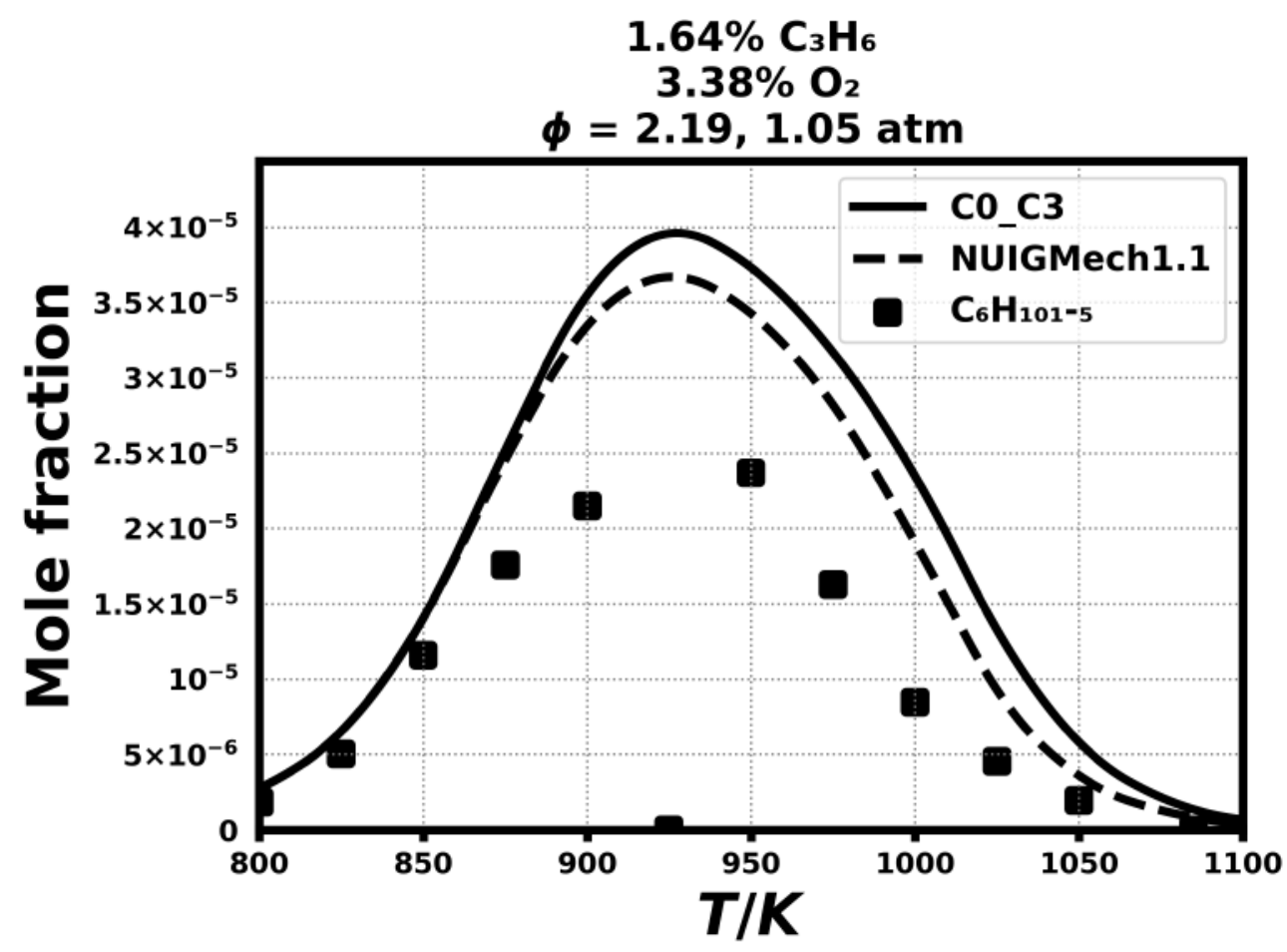

Speciation in Flow reactor

9.4) Burke, S. M., Burke, U., Mc Donagh, R., Mathieu, O., Osorio, I., Keesee, C., ... \& Oehlschlaeger, M. A., Combustion and Flame, 162(2) (2015) 296-314.

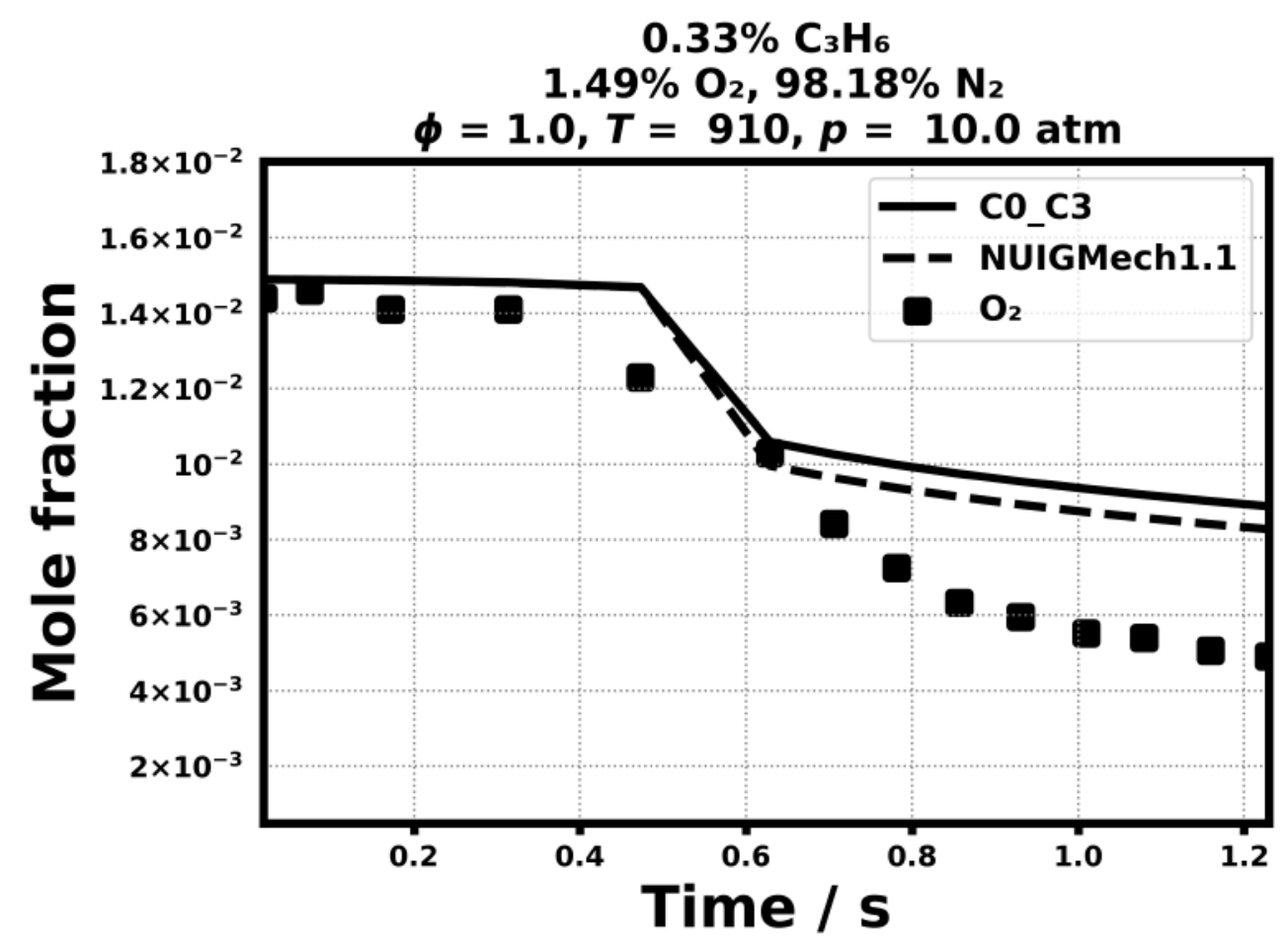



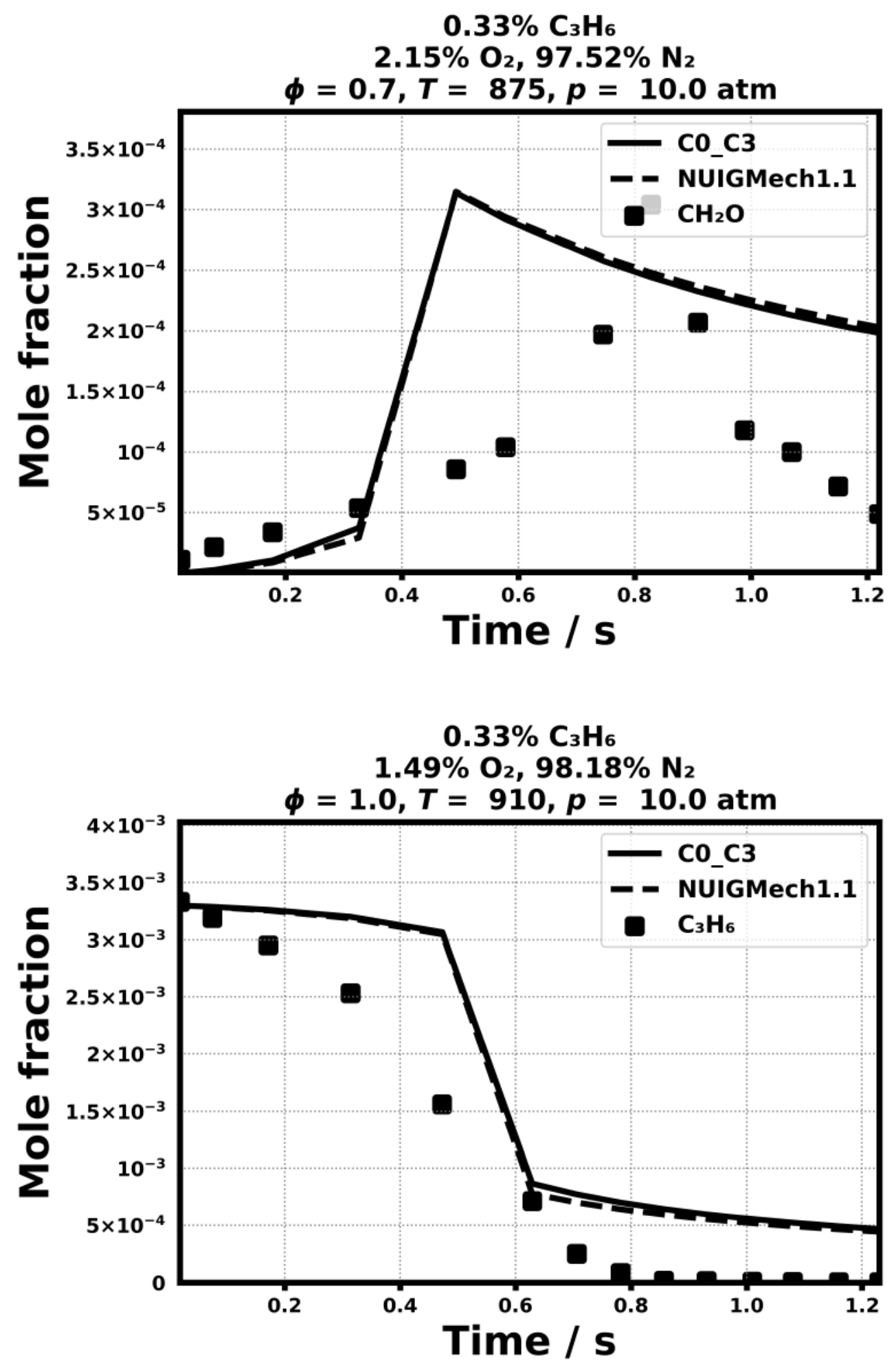

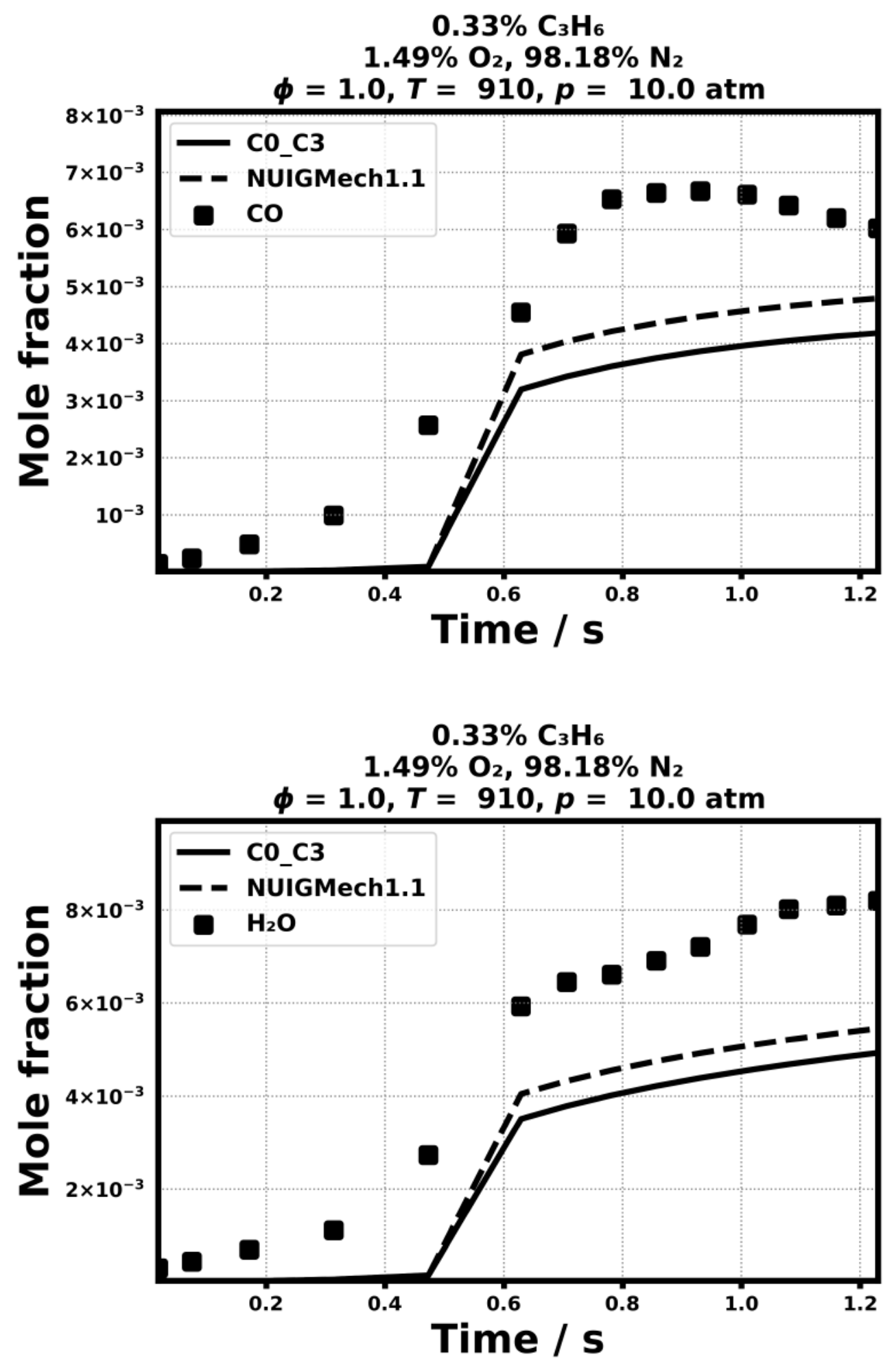

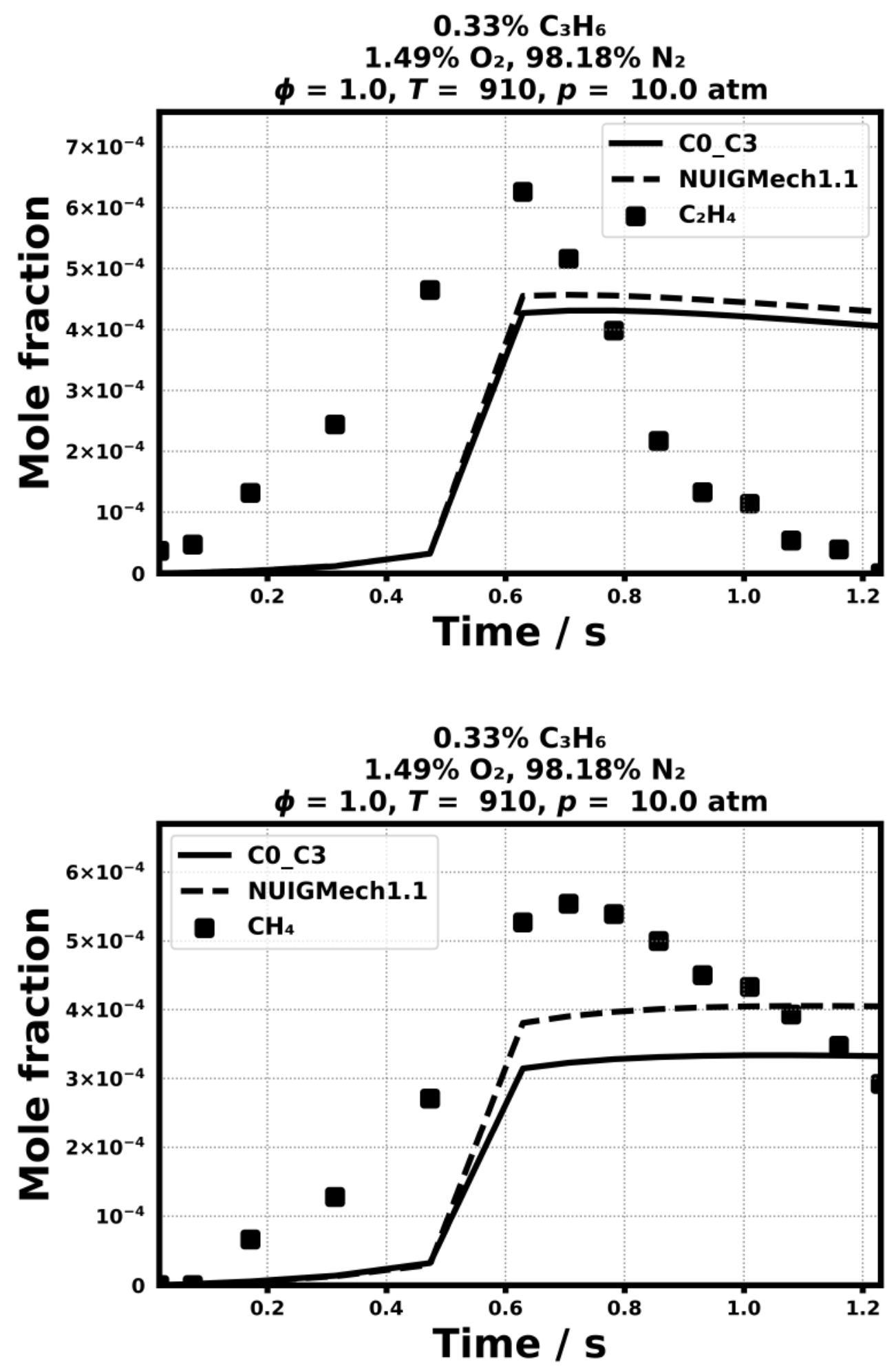

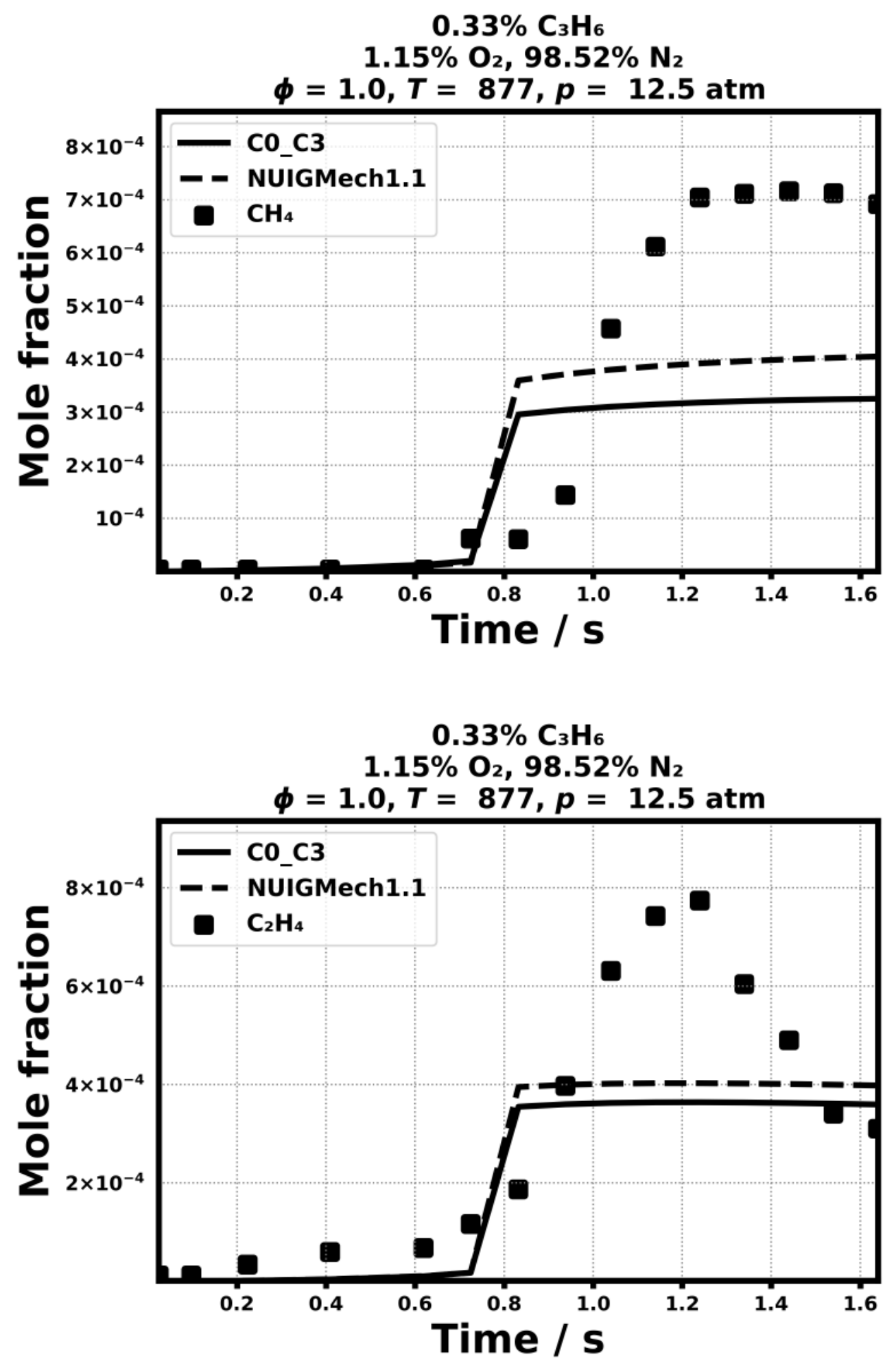

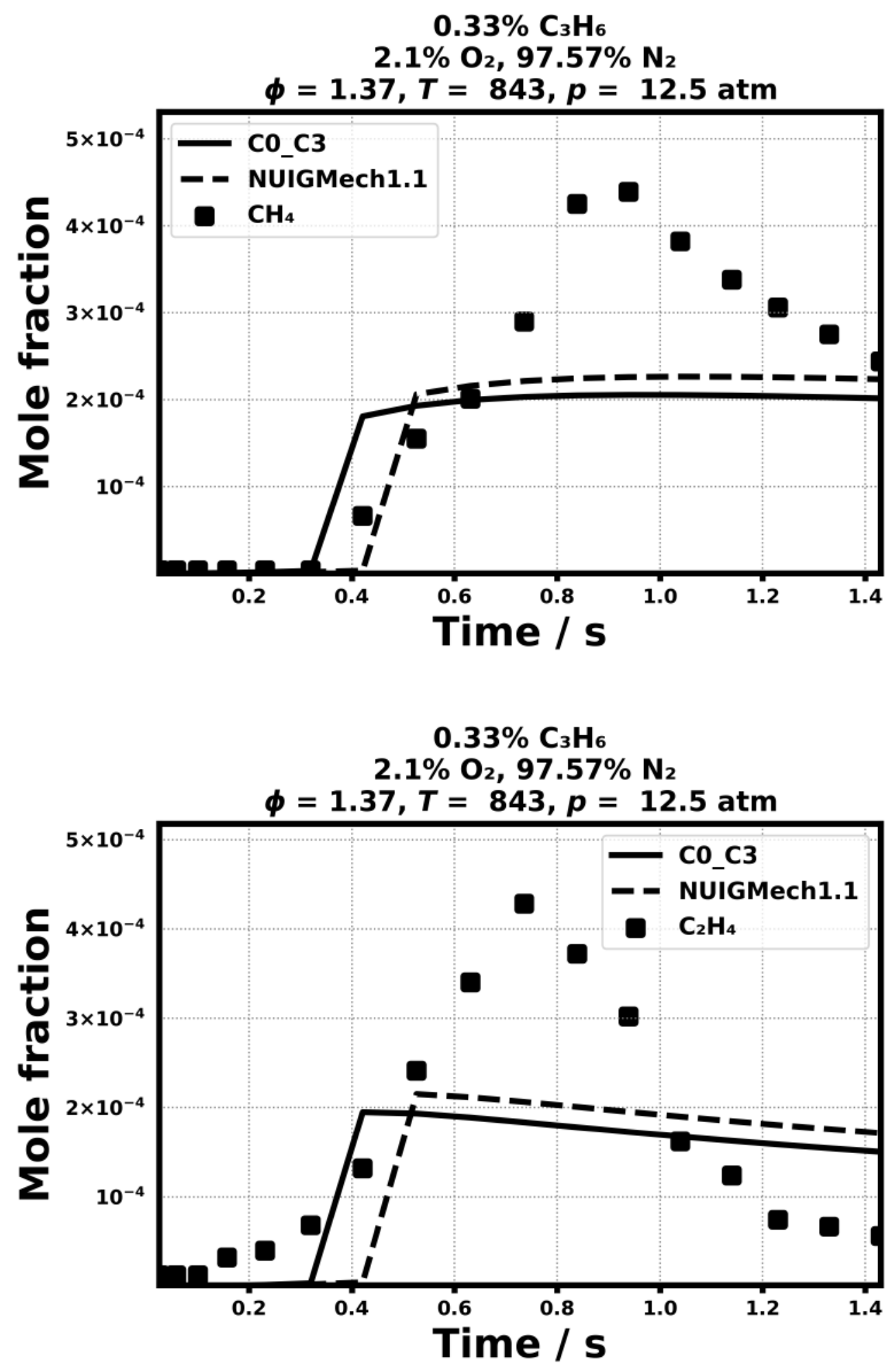

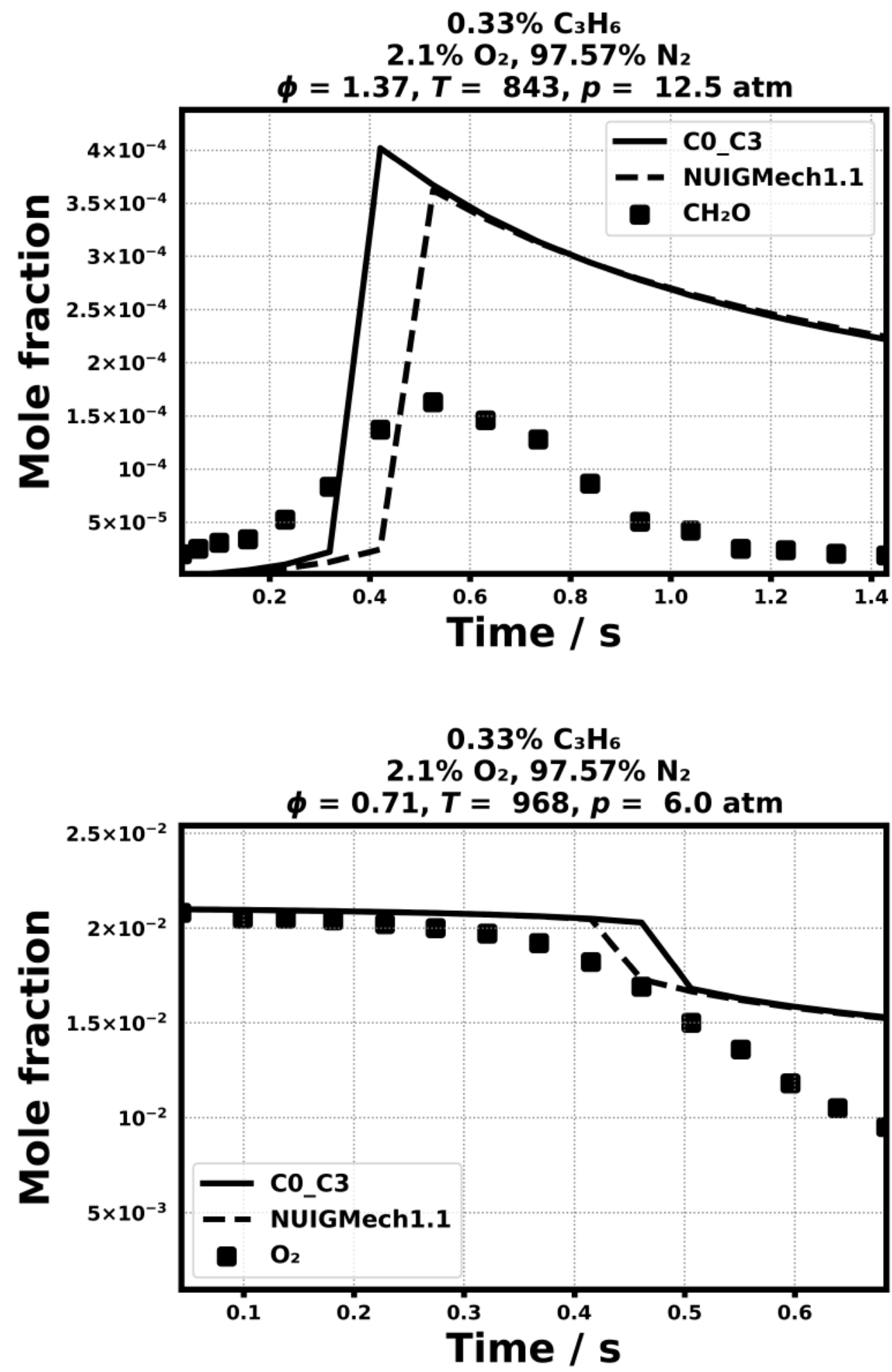

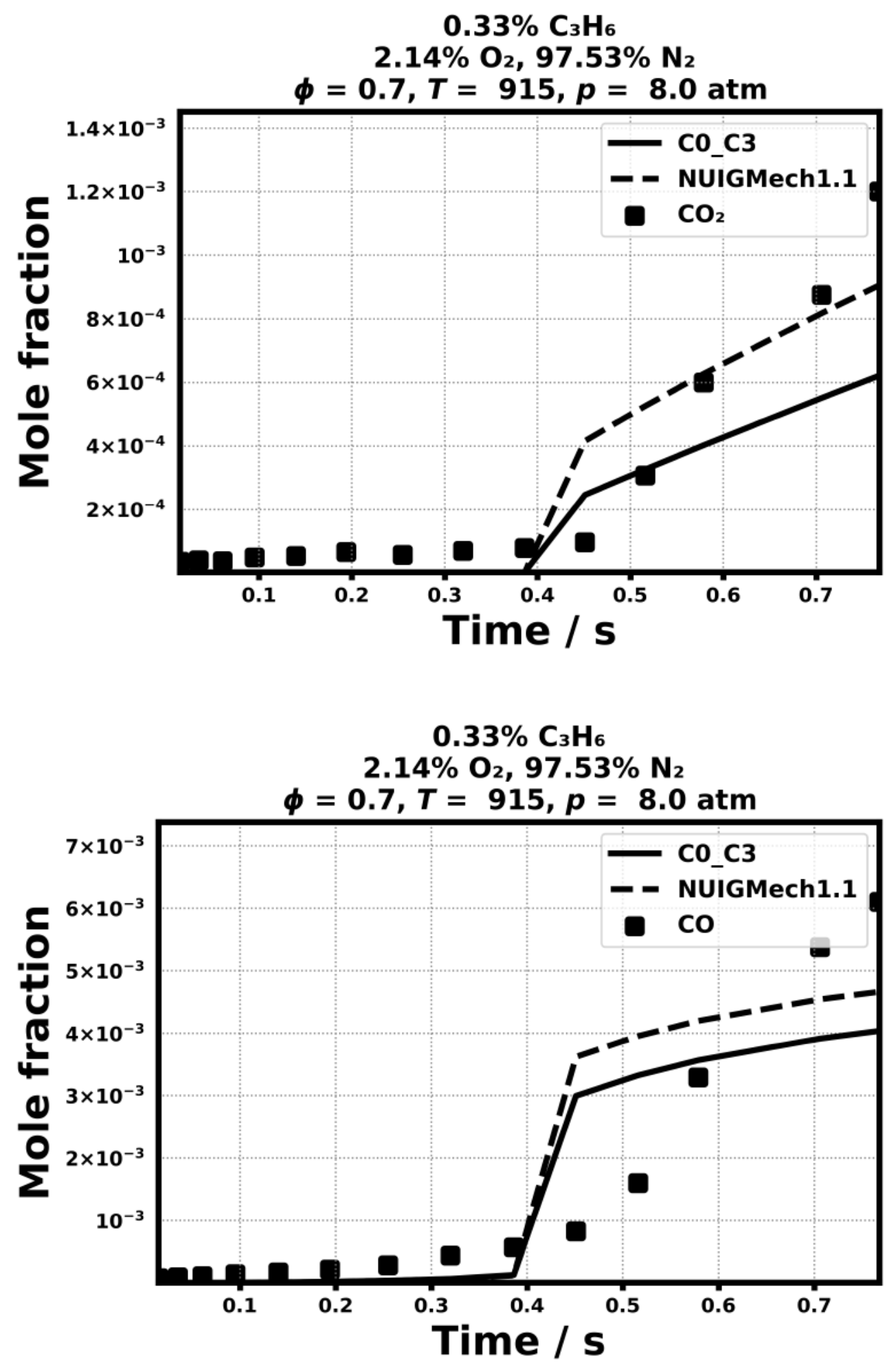

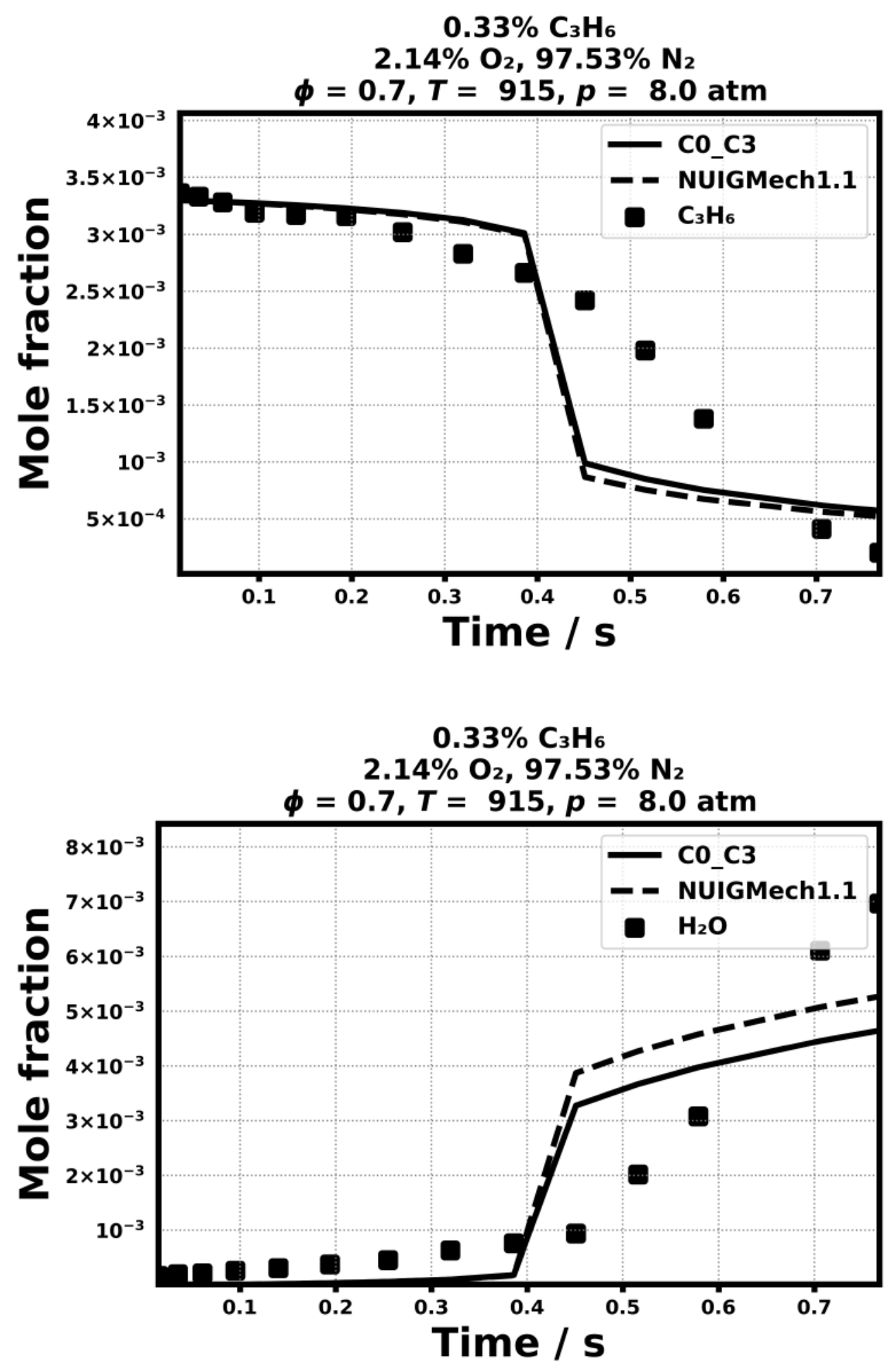

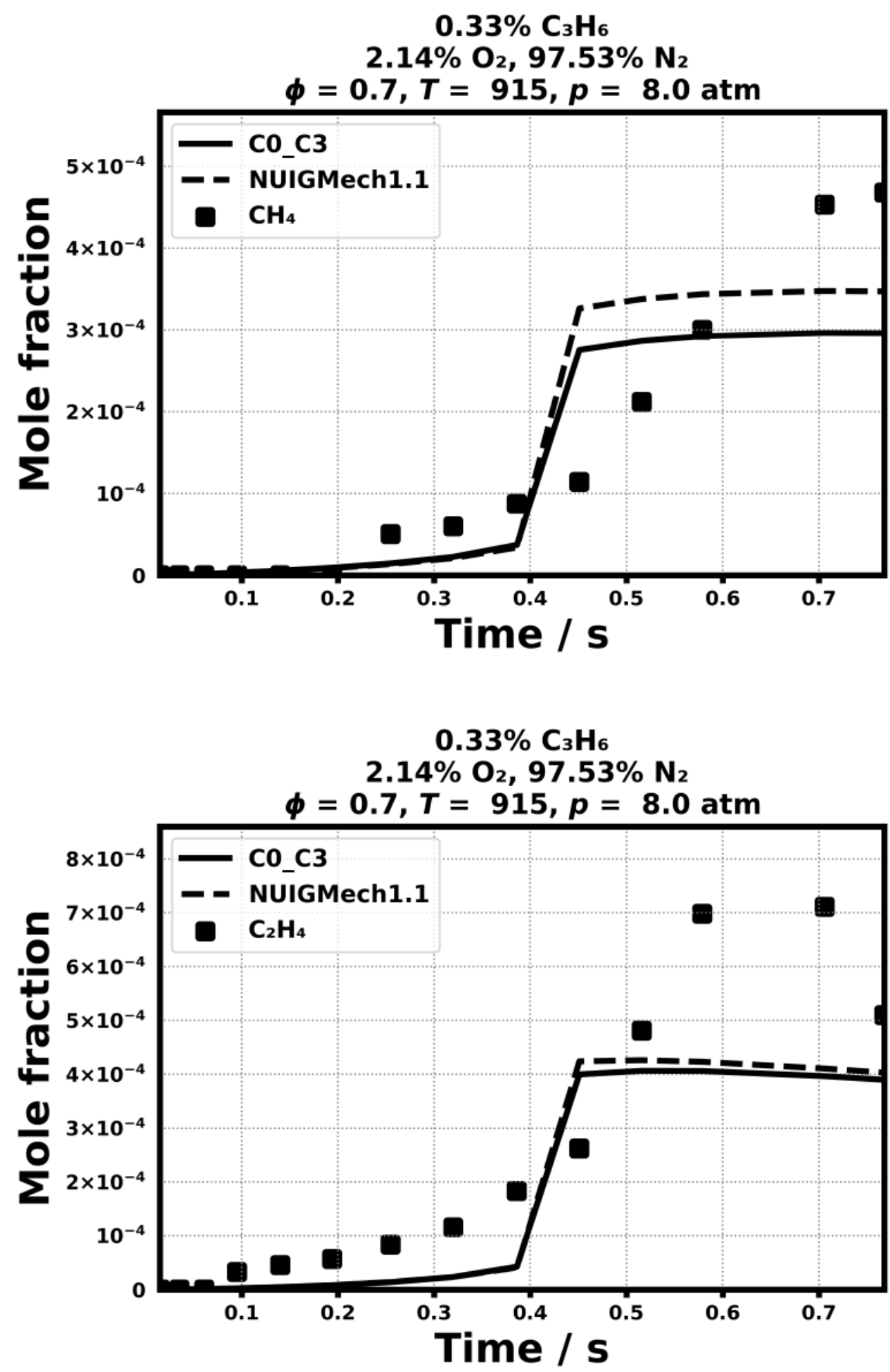

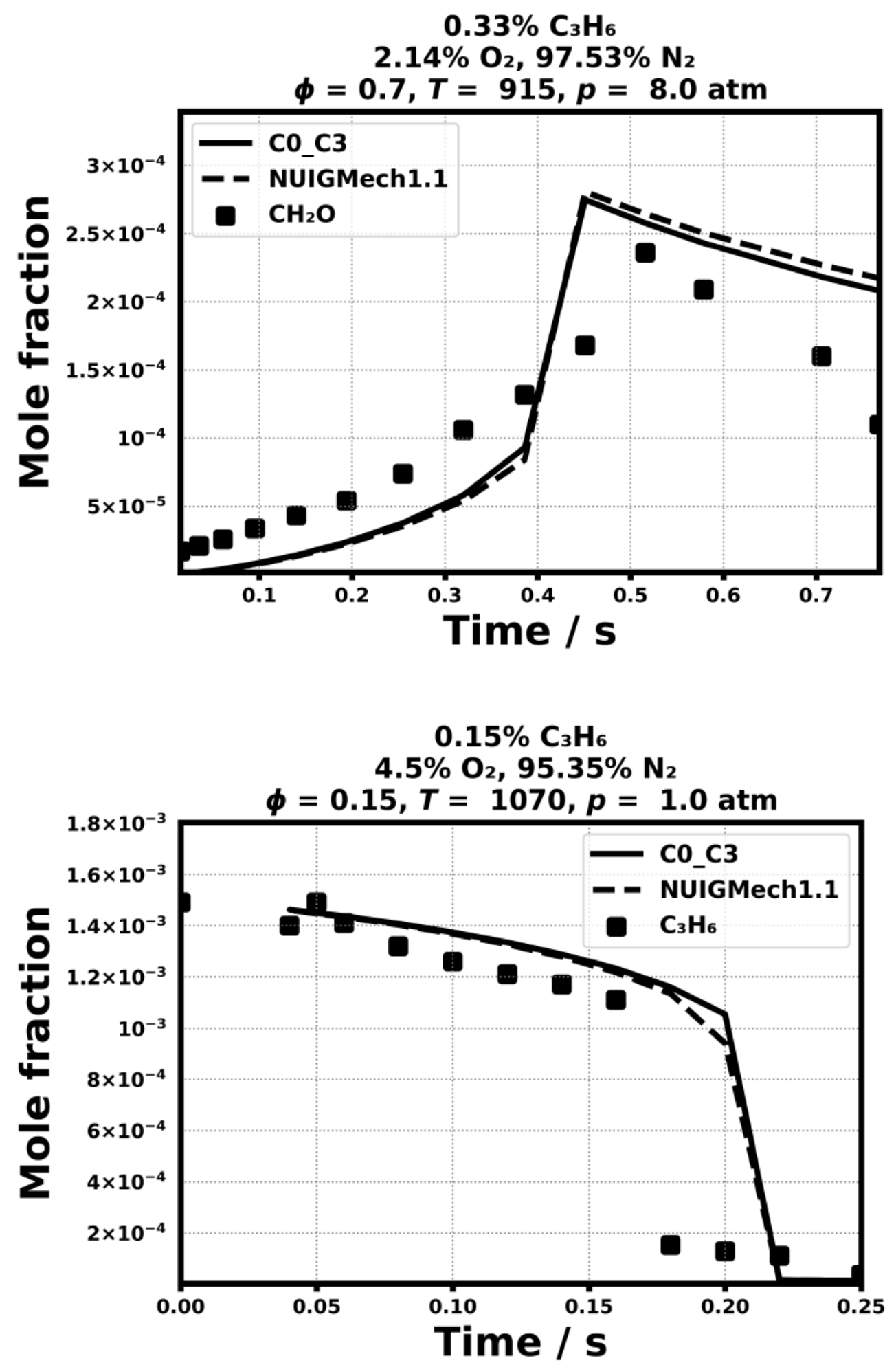

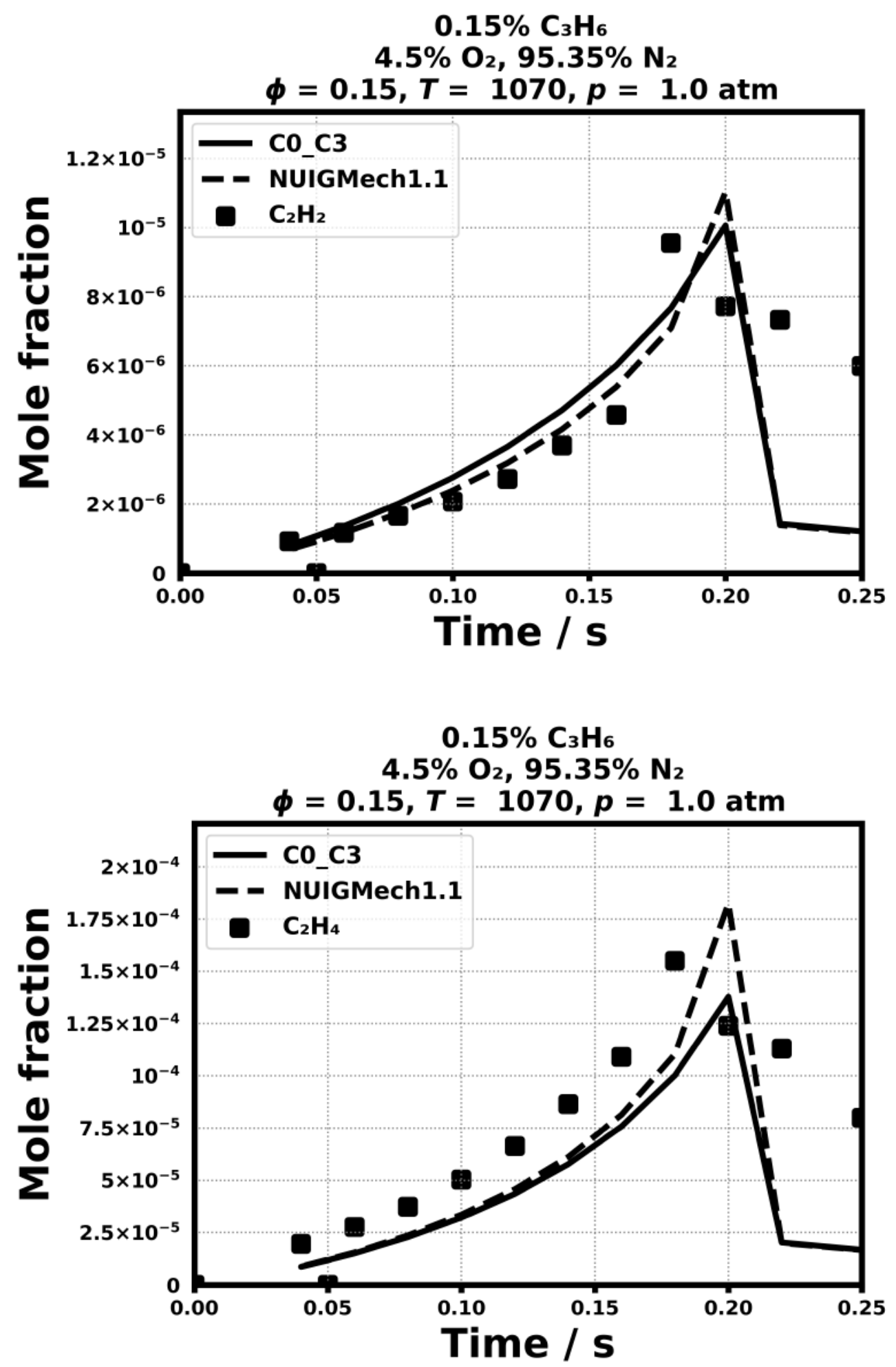

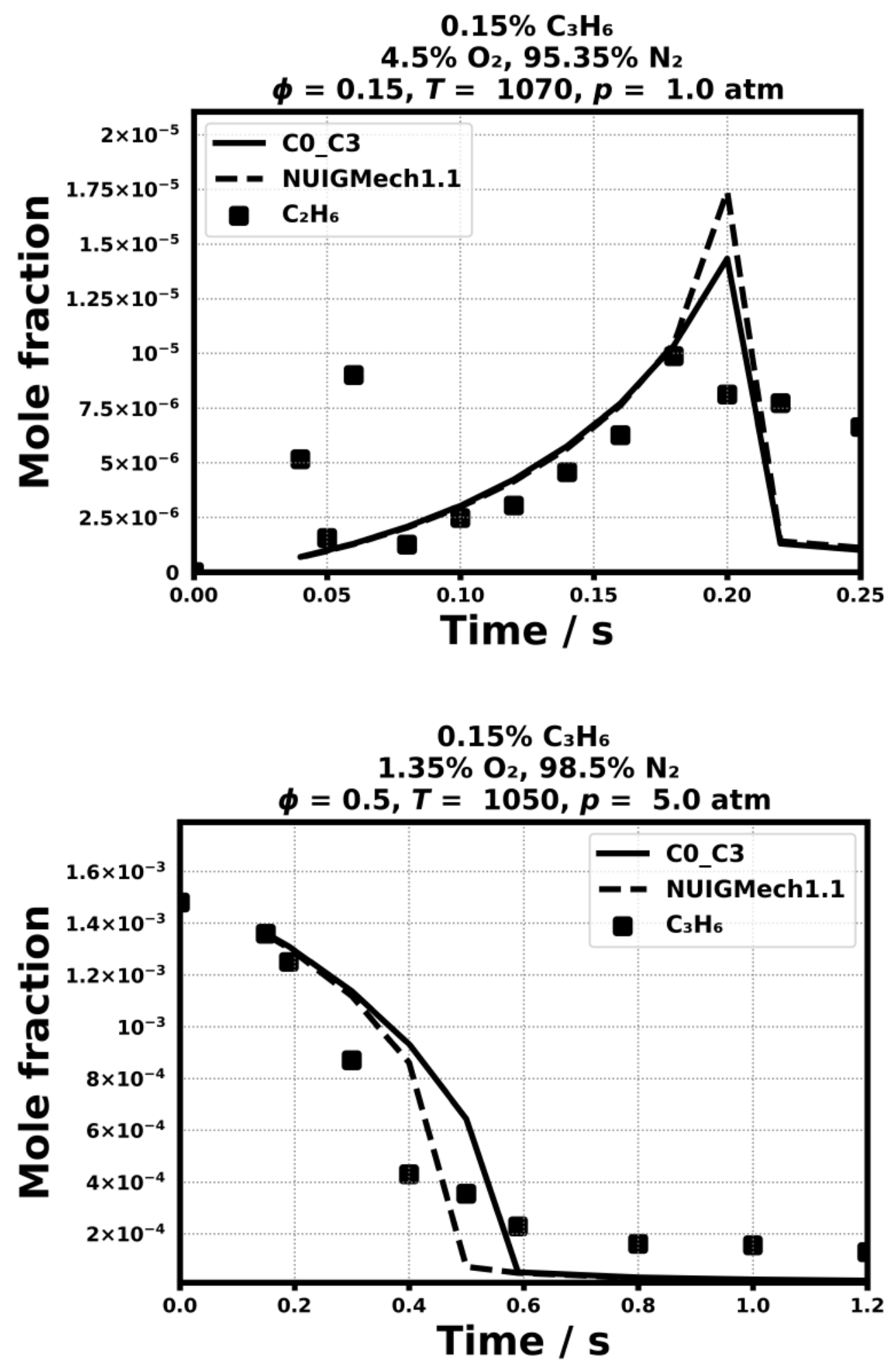

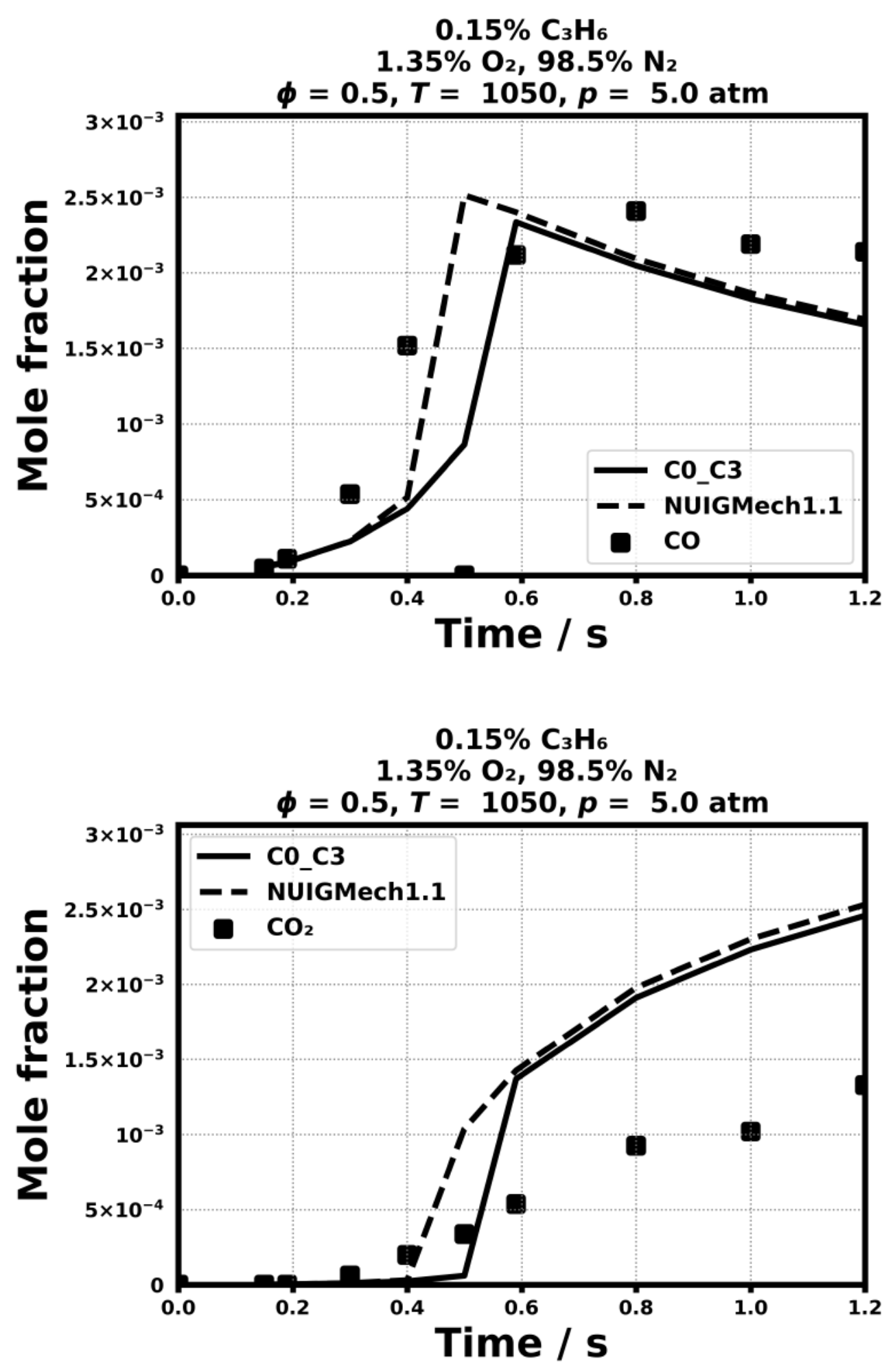

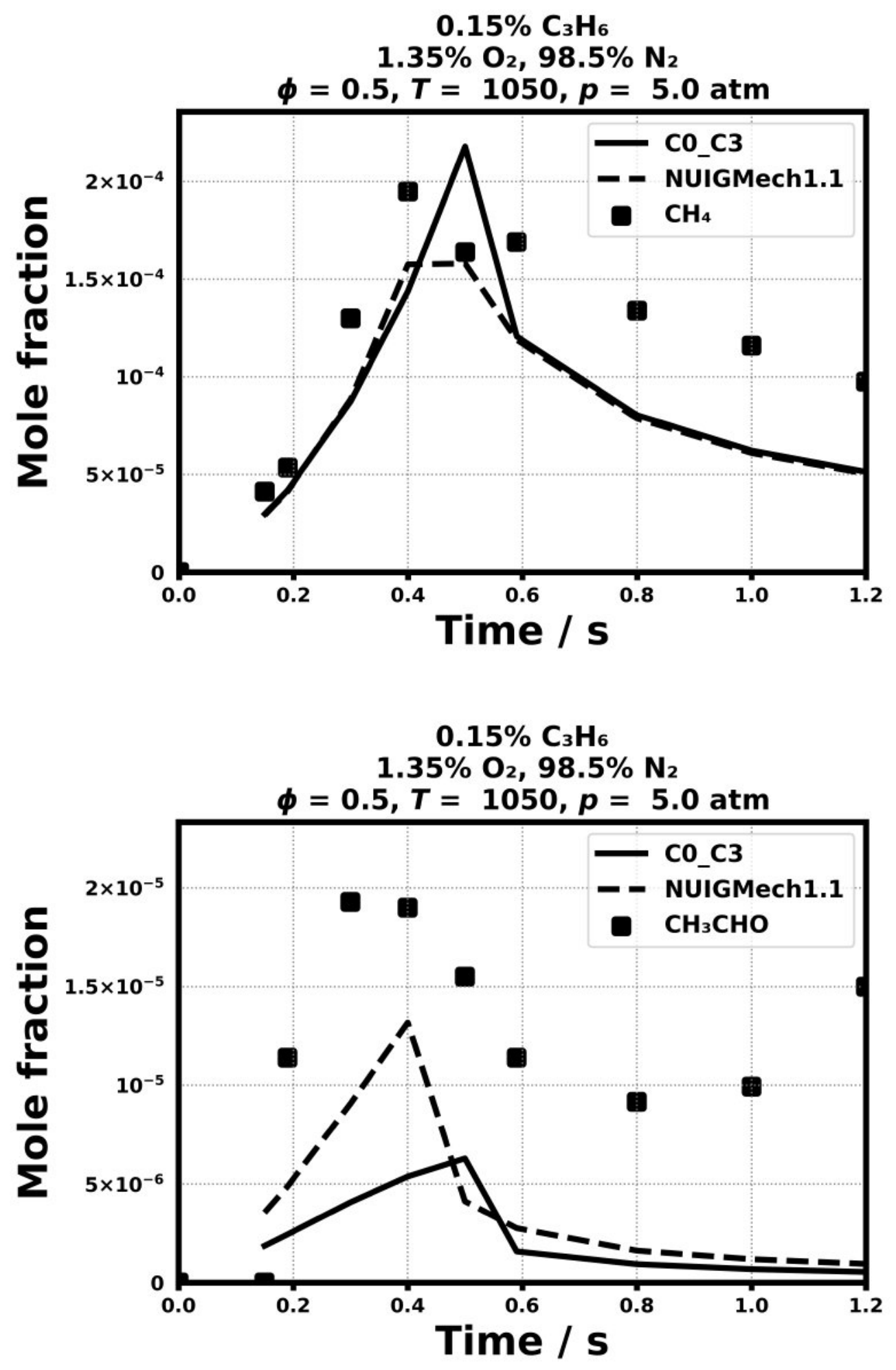

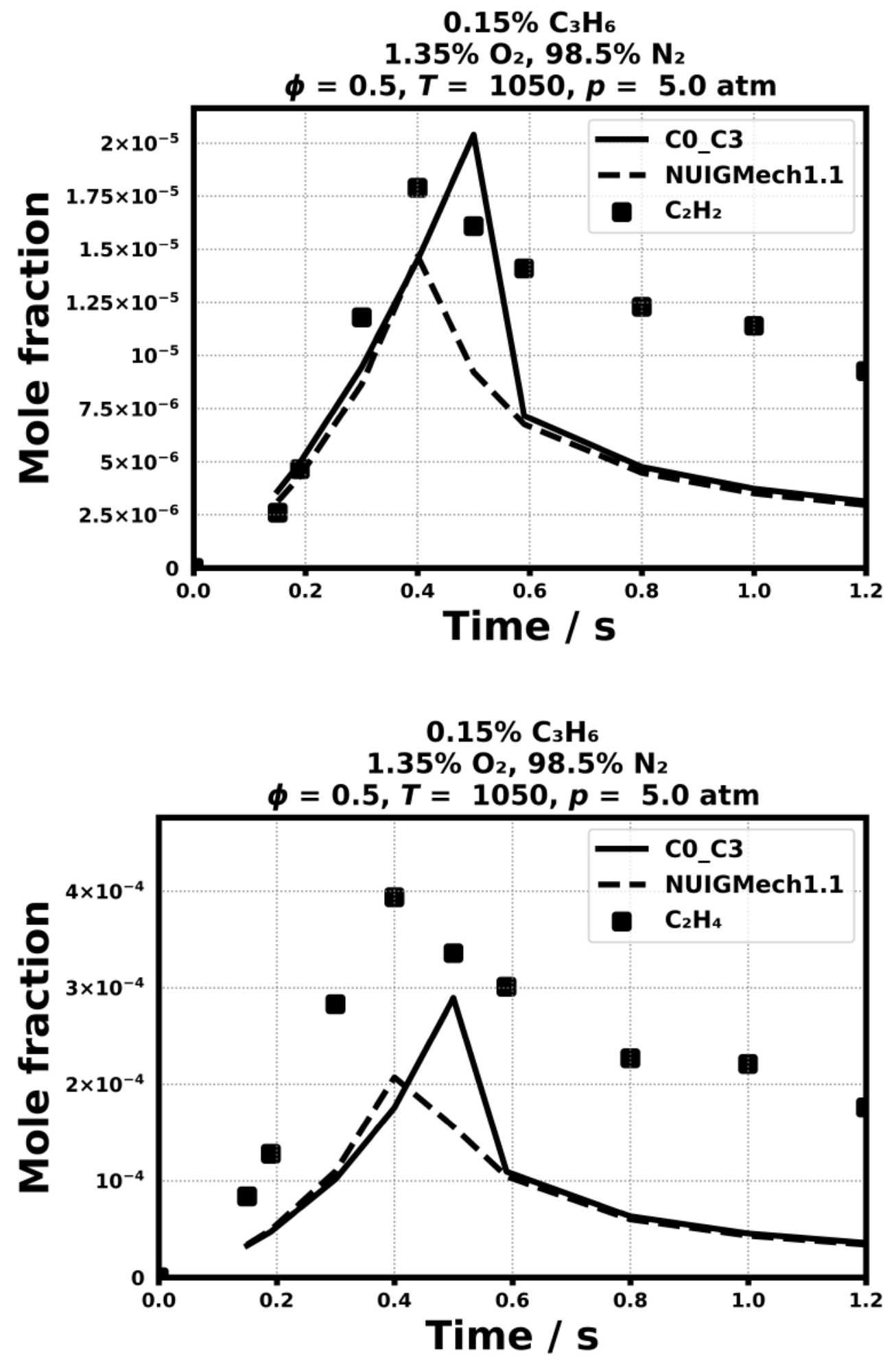


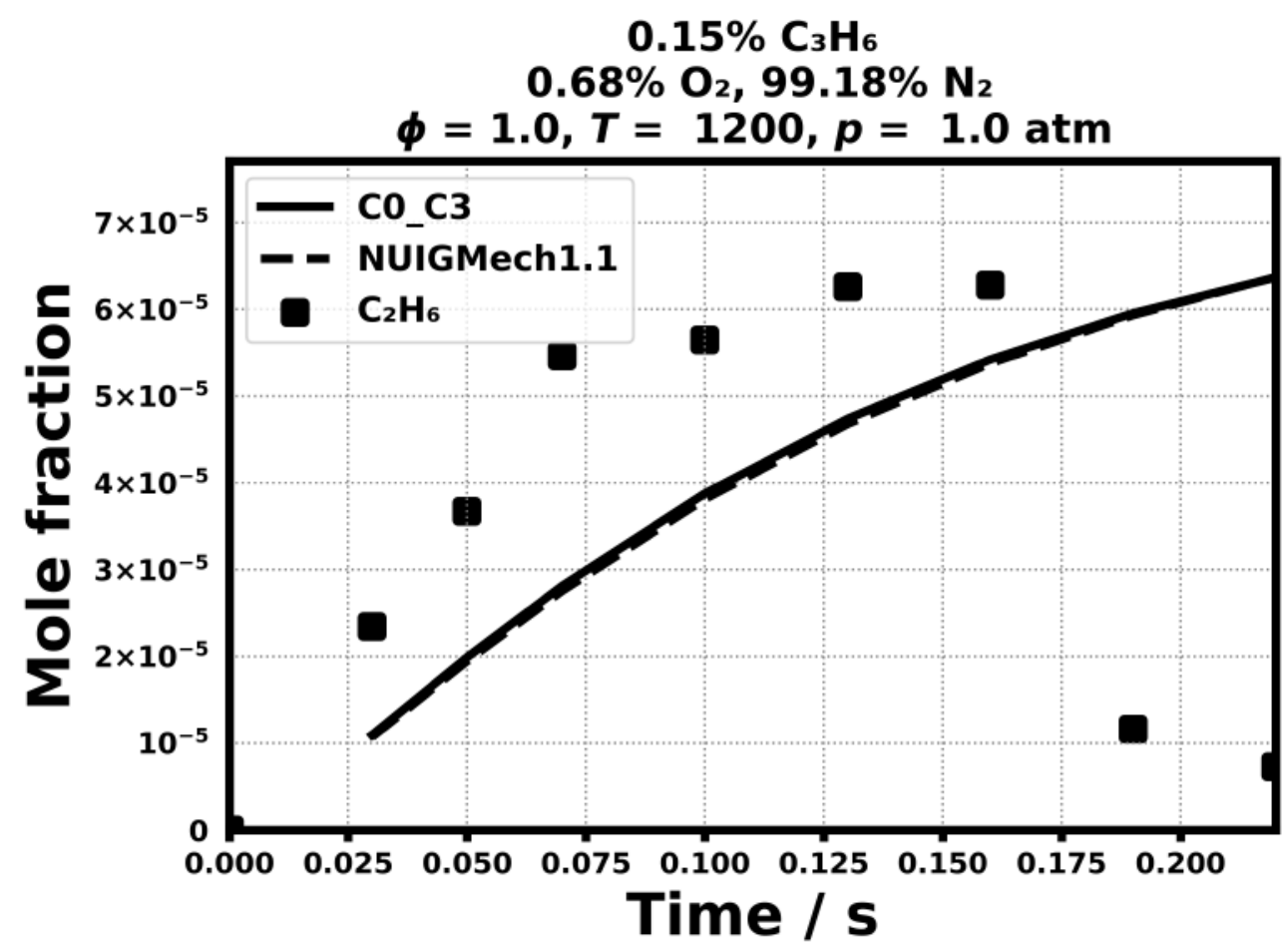




\section{Laminar flame speed}

9.5) Burke, S. M., Burke, U., Mc Donagh, R., Mathieu, O., Osorio, I., Keesee, C., ... \& Oehlschlaeger, M. A., Combustion and Flame, 162(2) (2015) 296-314.

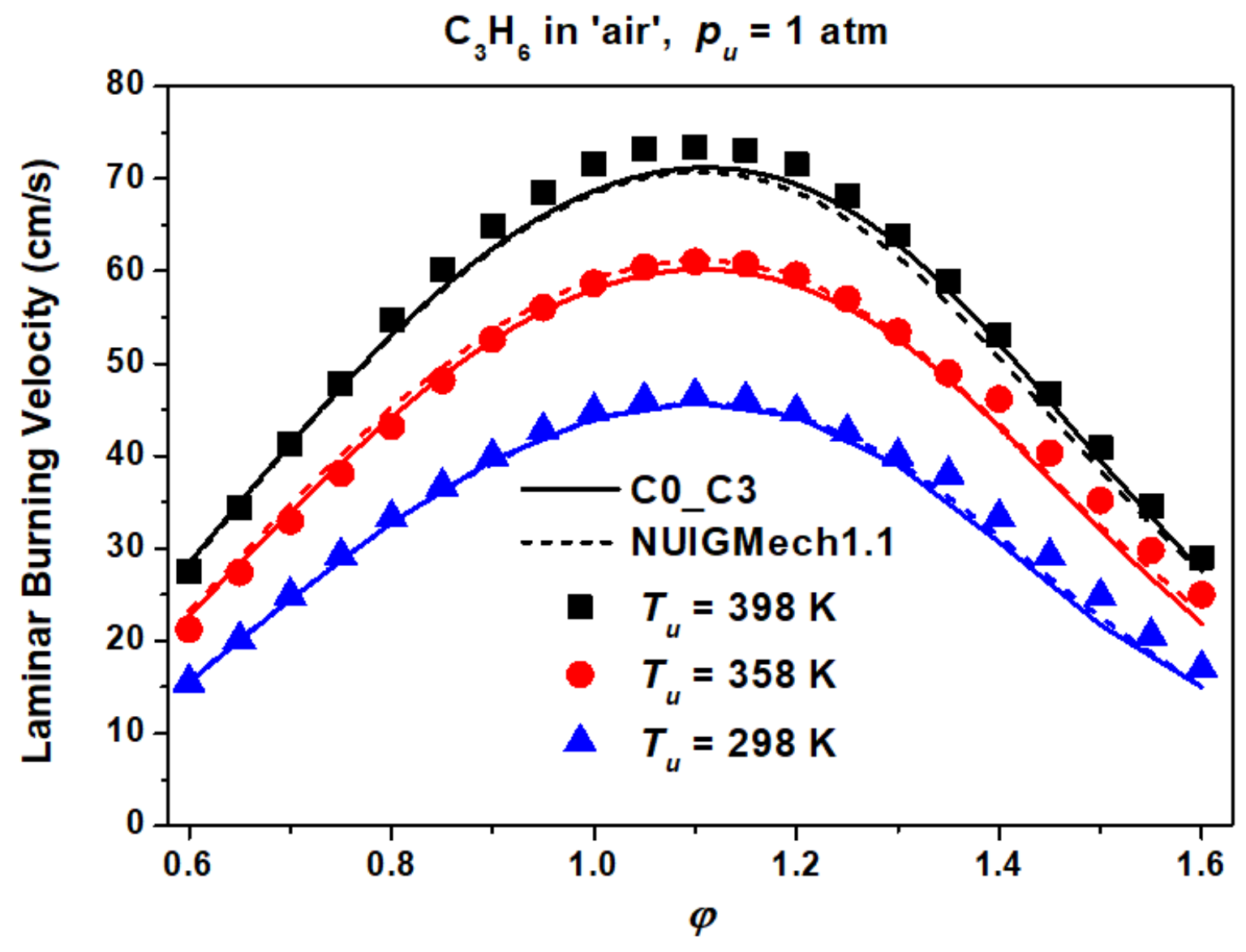




\section{Validation for $\mathrm{C}_{3} \mathrm{H}_{4}-\mathrm{a} / \mathrm{C}_{3} \mathrm{H}_{4}-\mathrm{p}$}

Shock tube ignition delay time

10.1) Curran, H., Simmie, J. M., Dagaut, P., Voisin, D., \& Cathonnet, M., In Symposium (International) on Combustion, 26 (1996, January) 613-620.
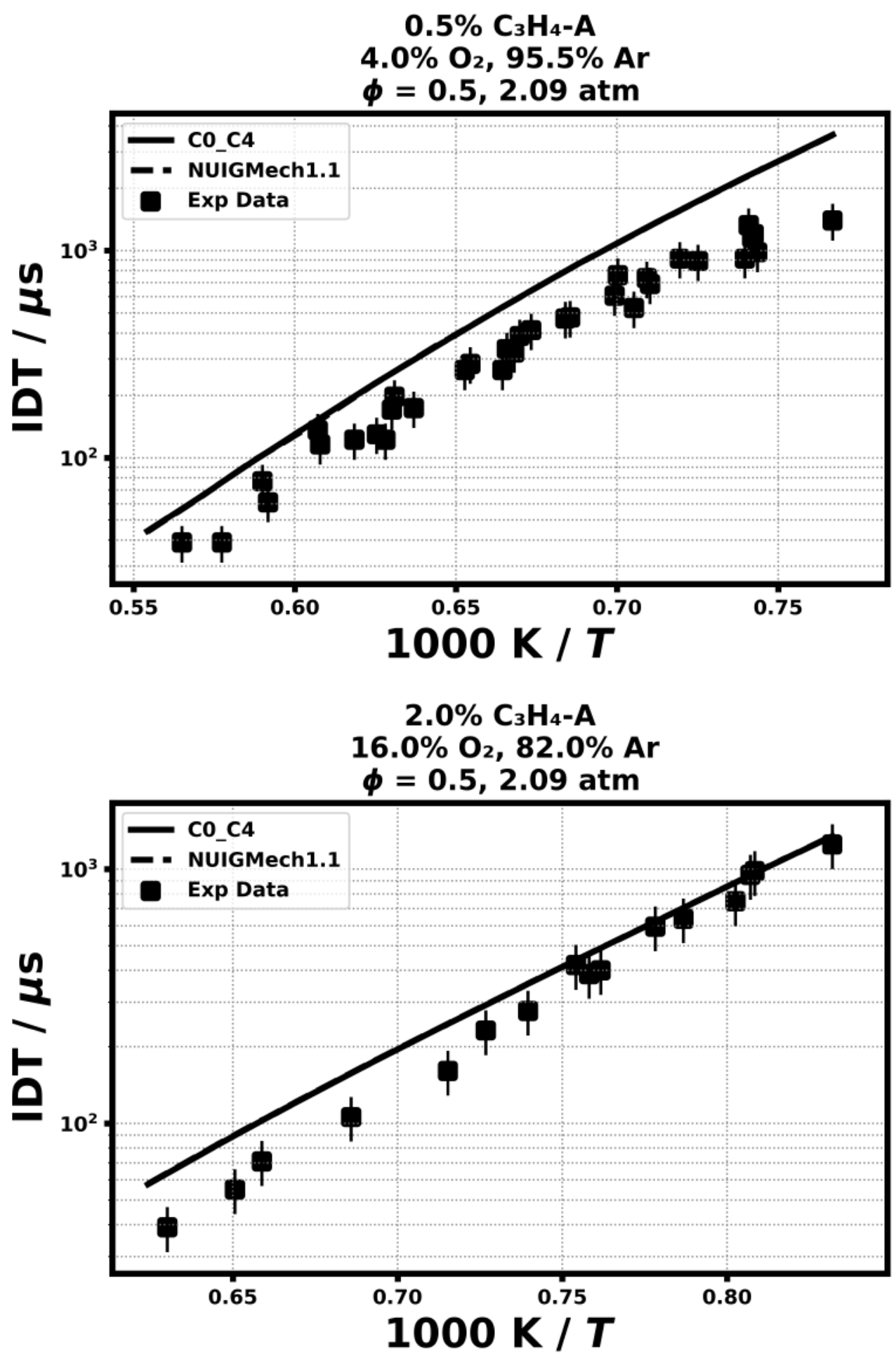

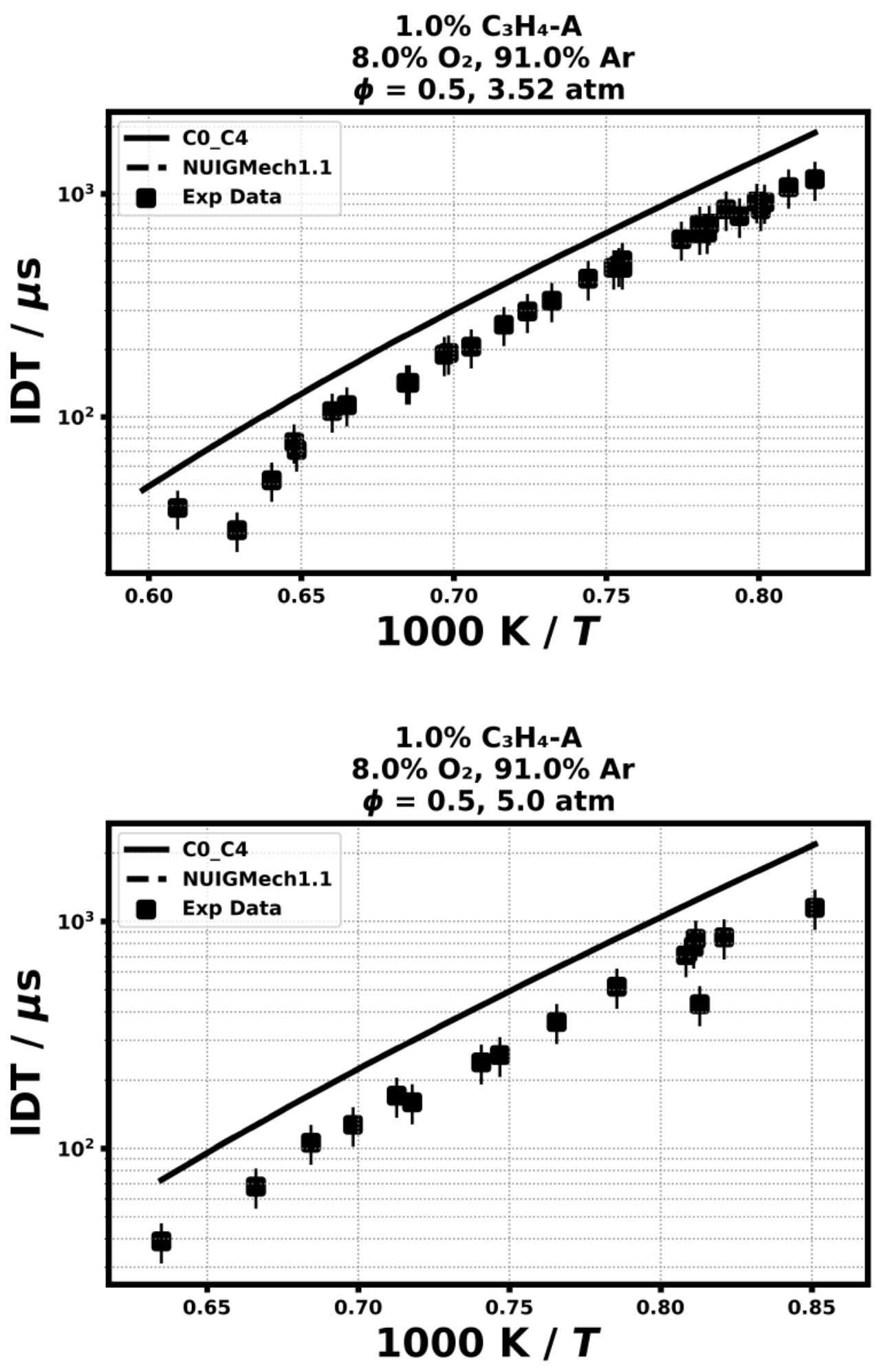

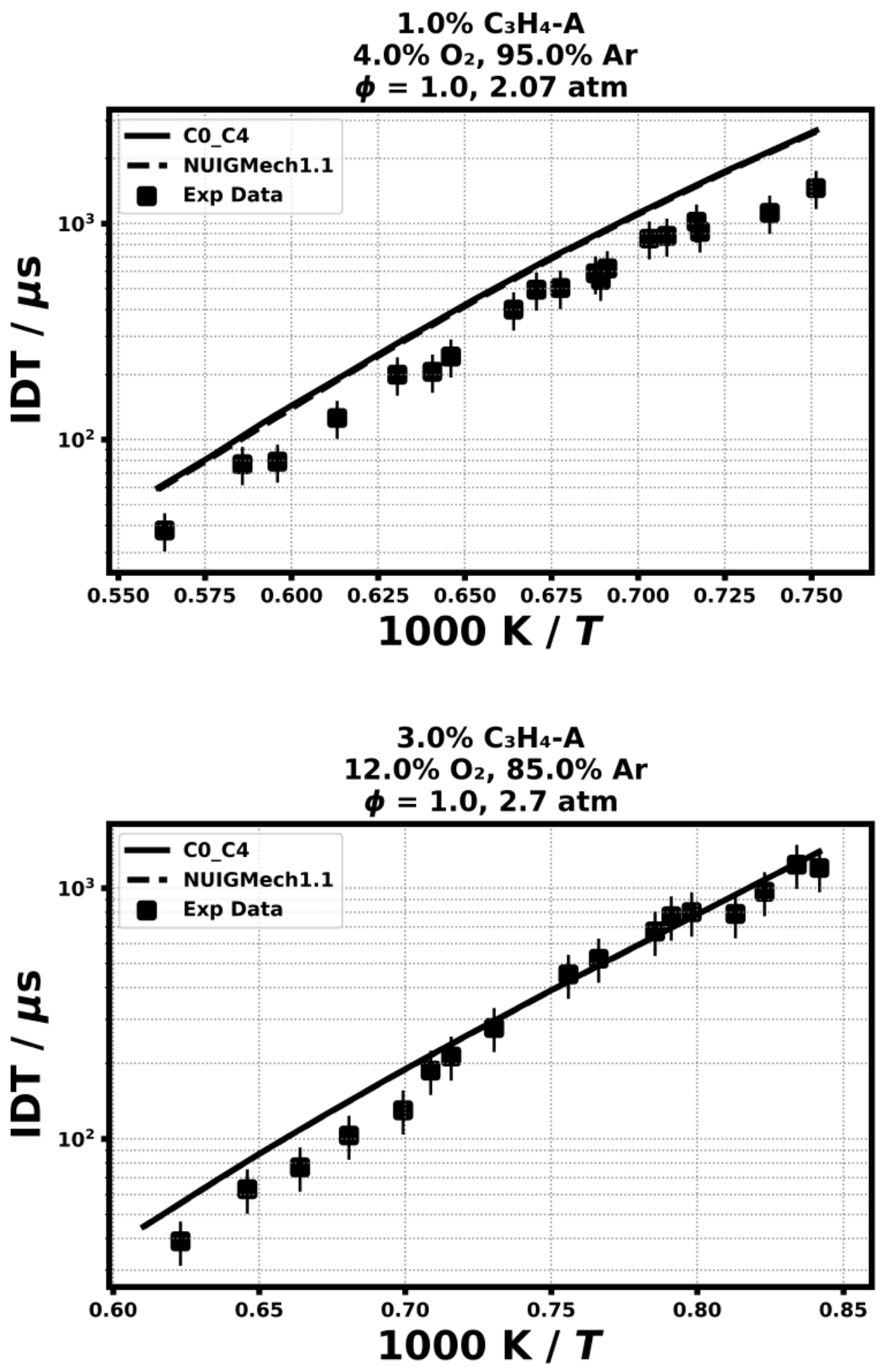

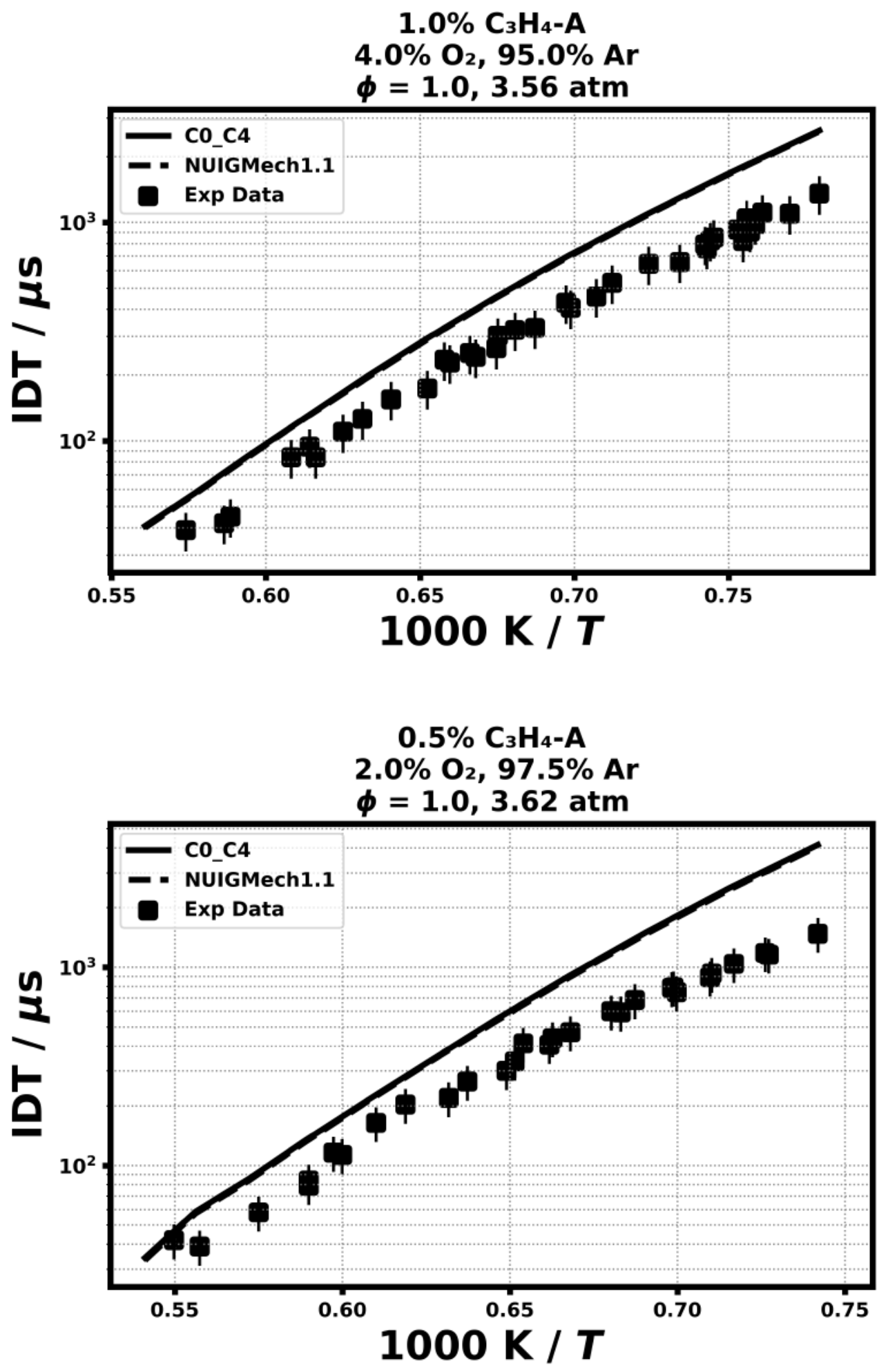

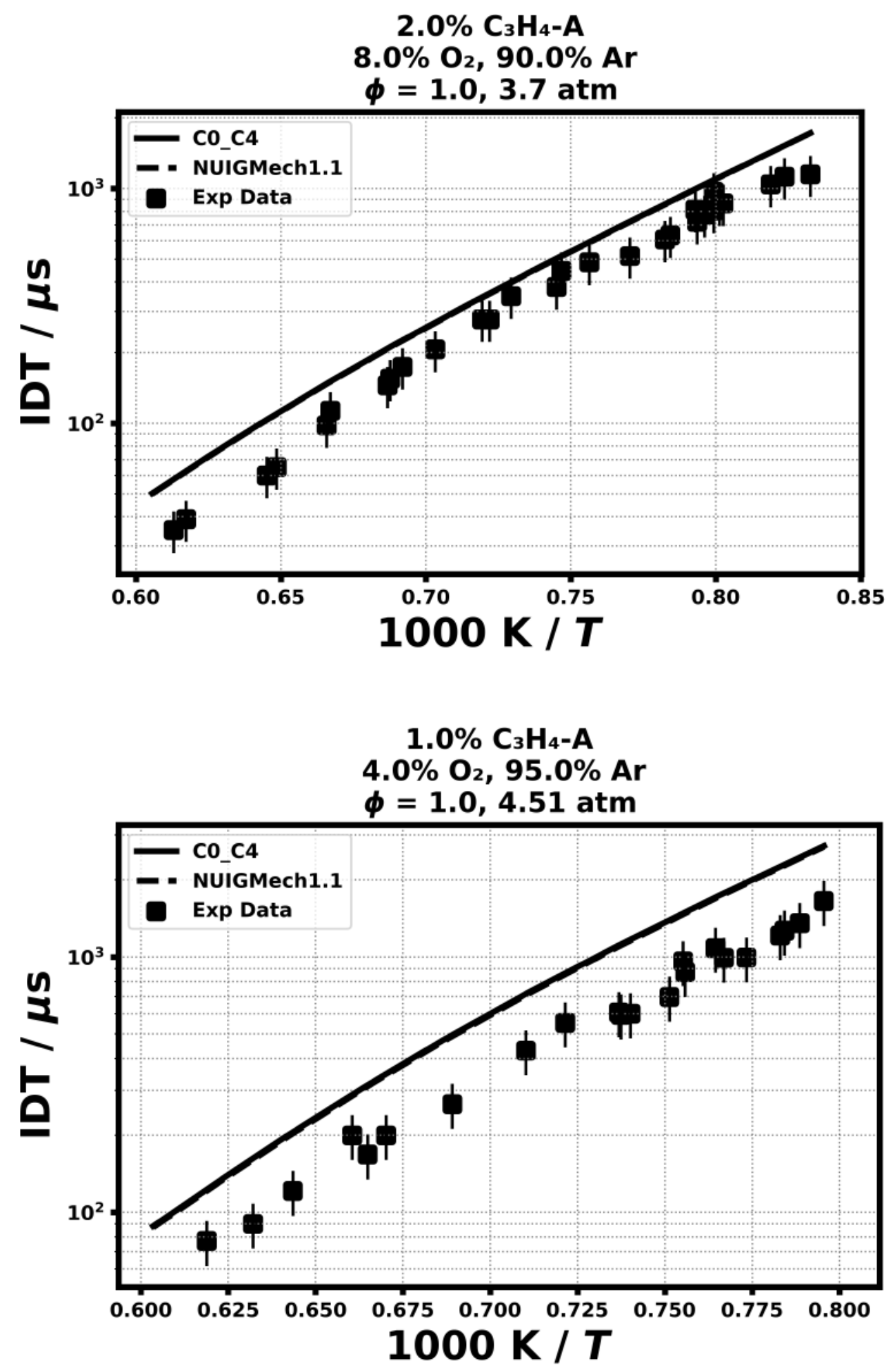

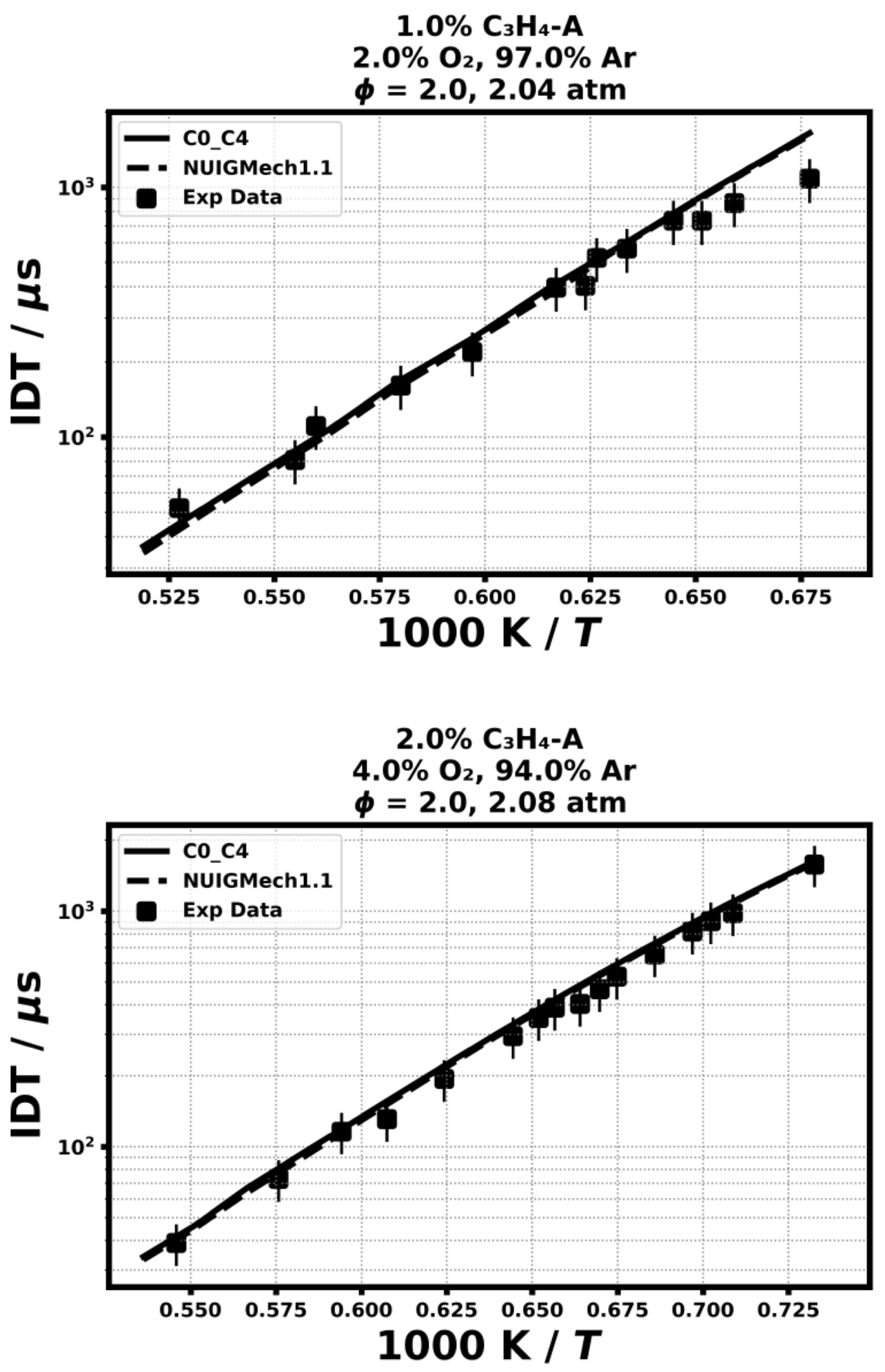

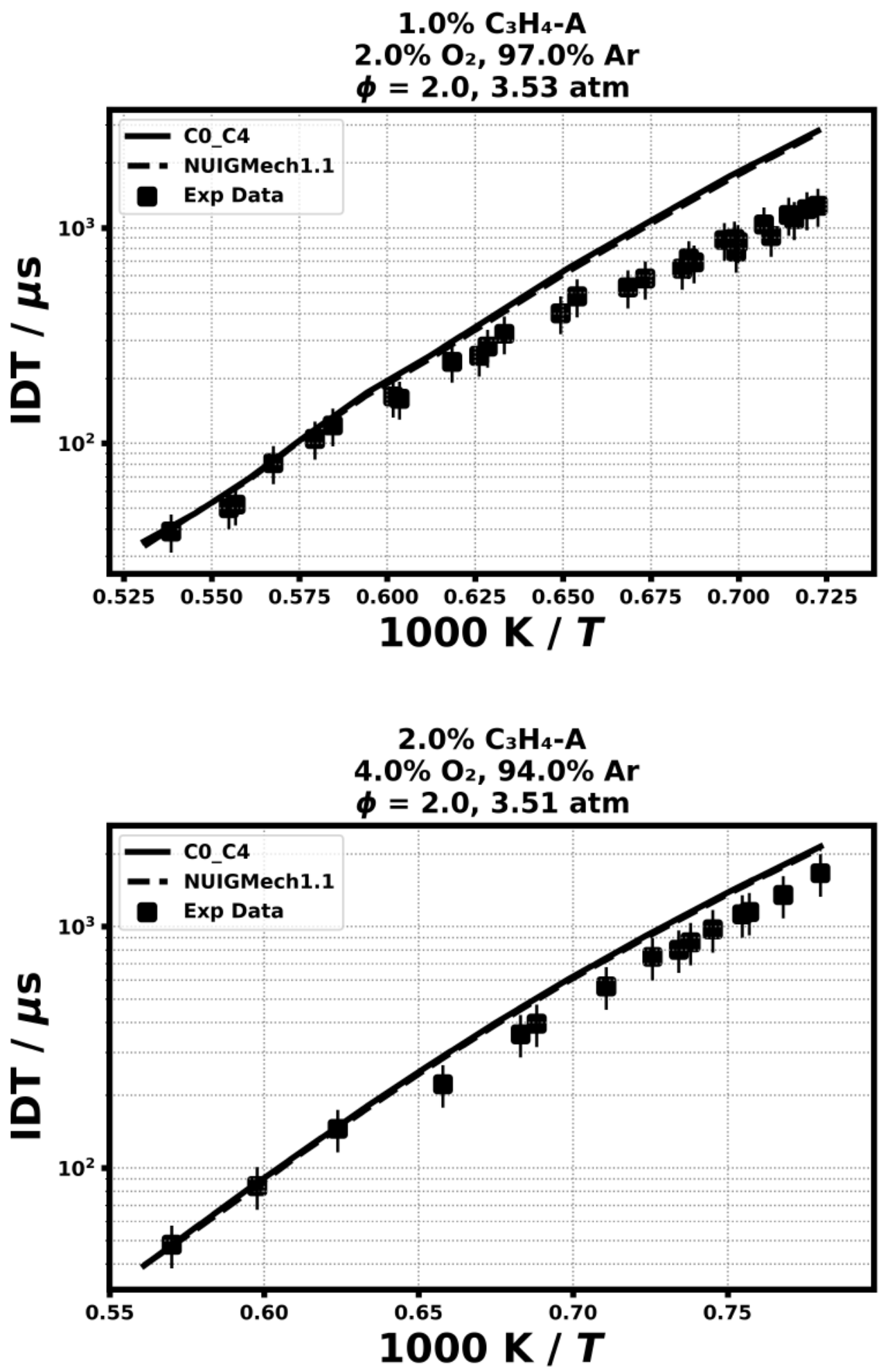

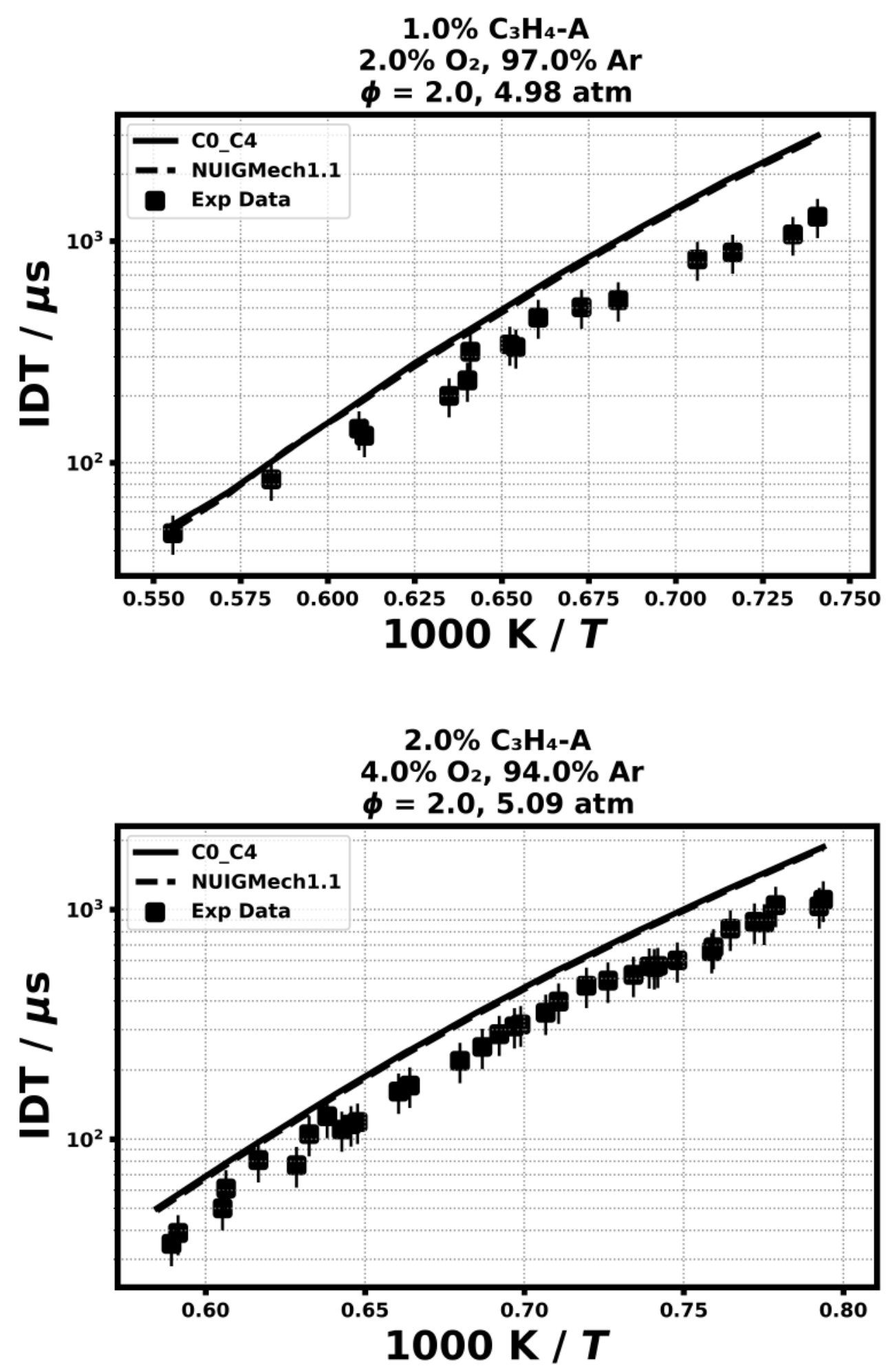

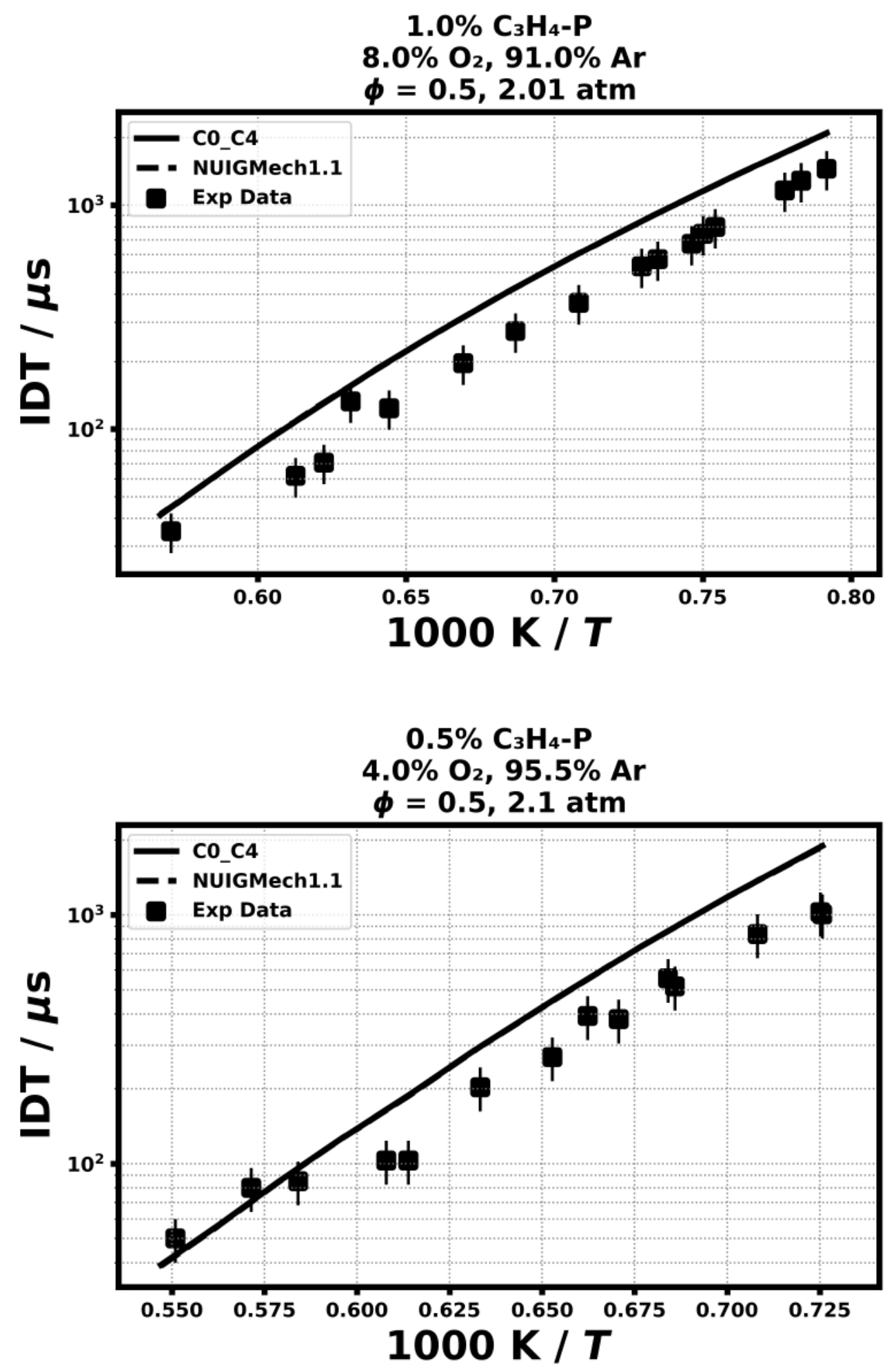

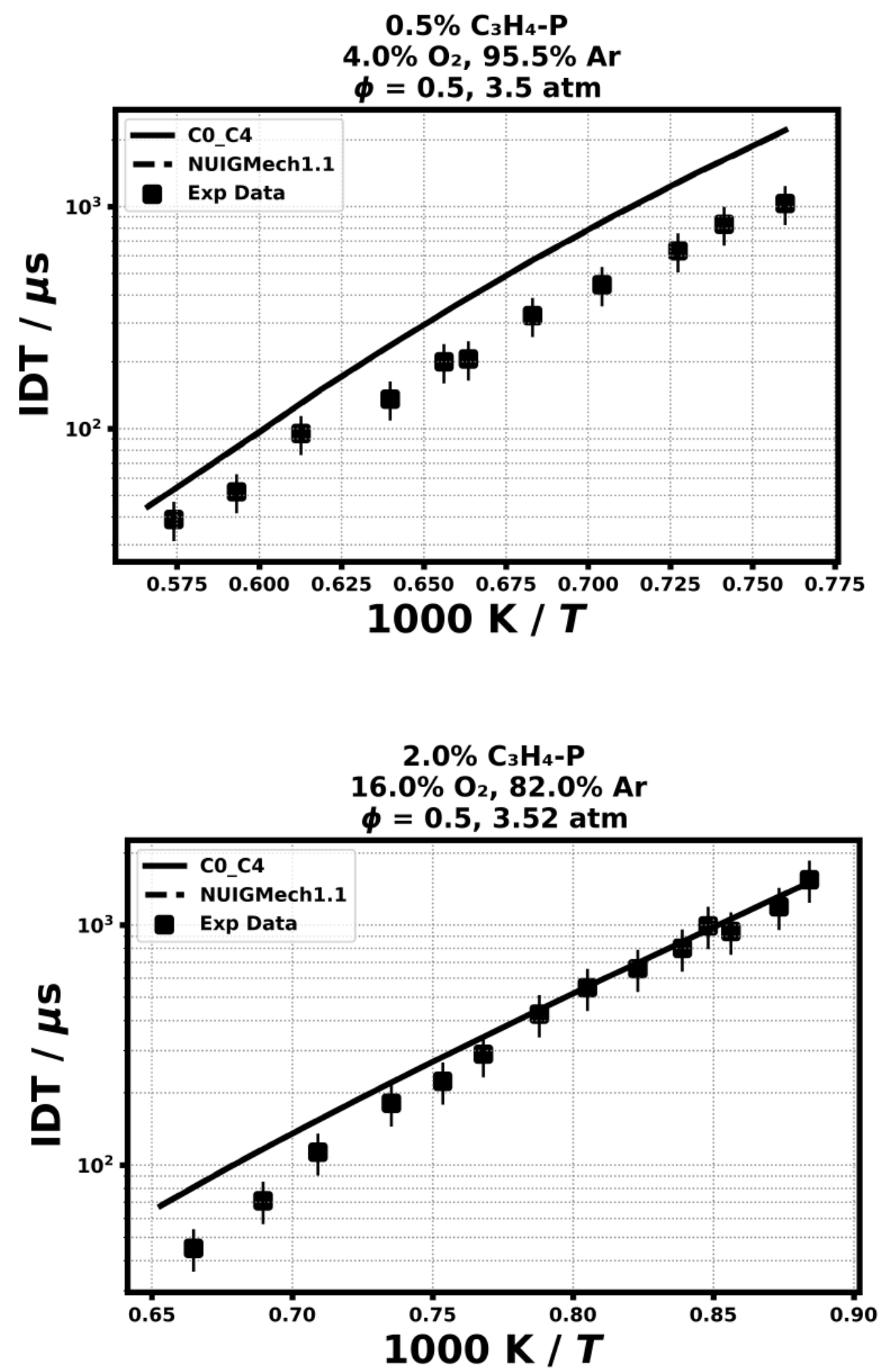

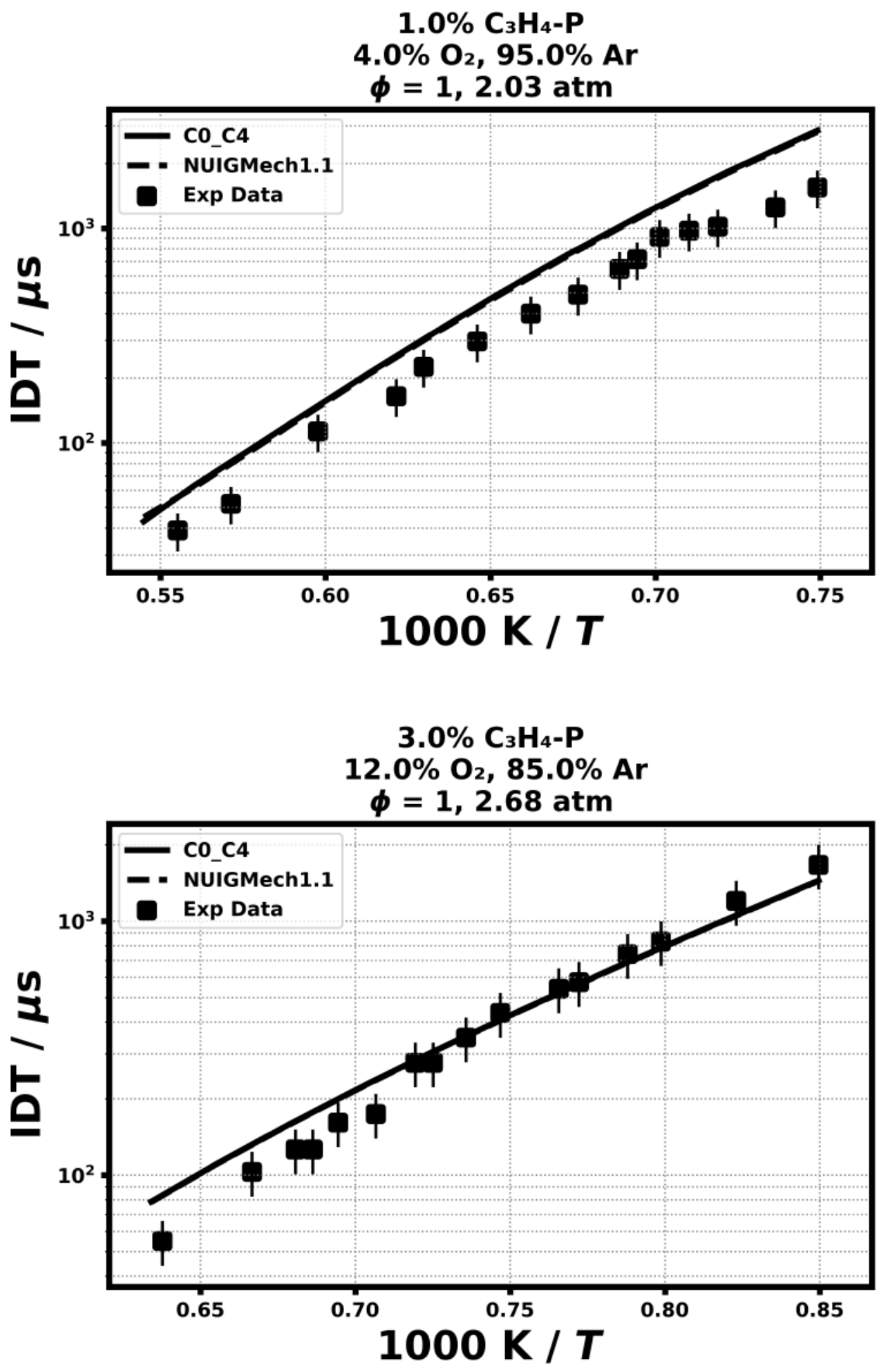

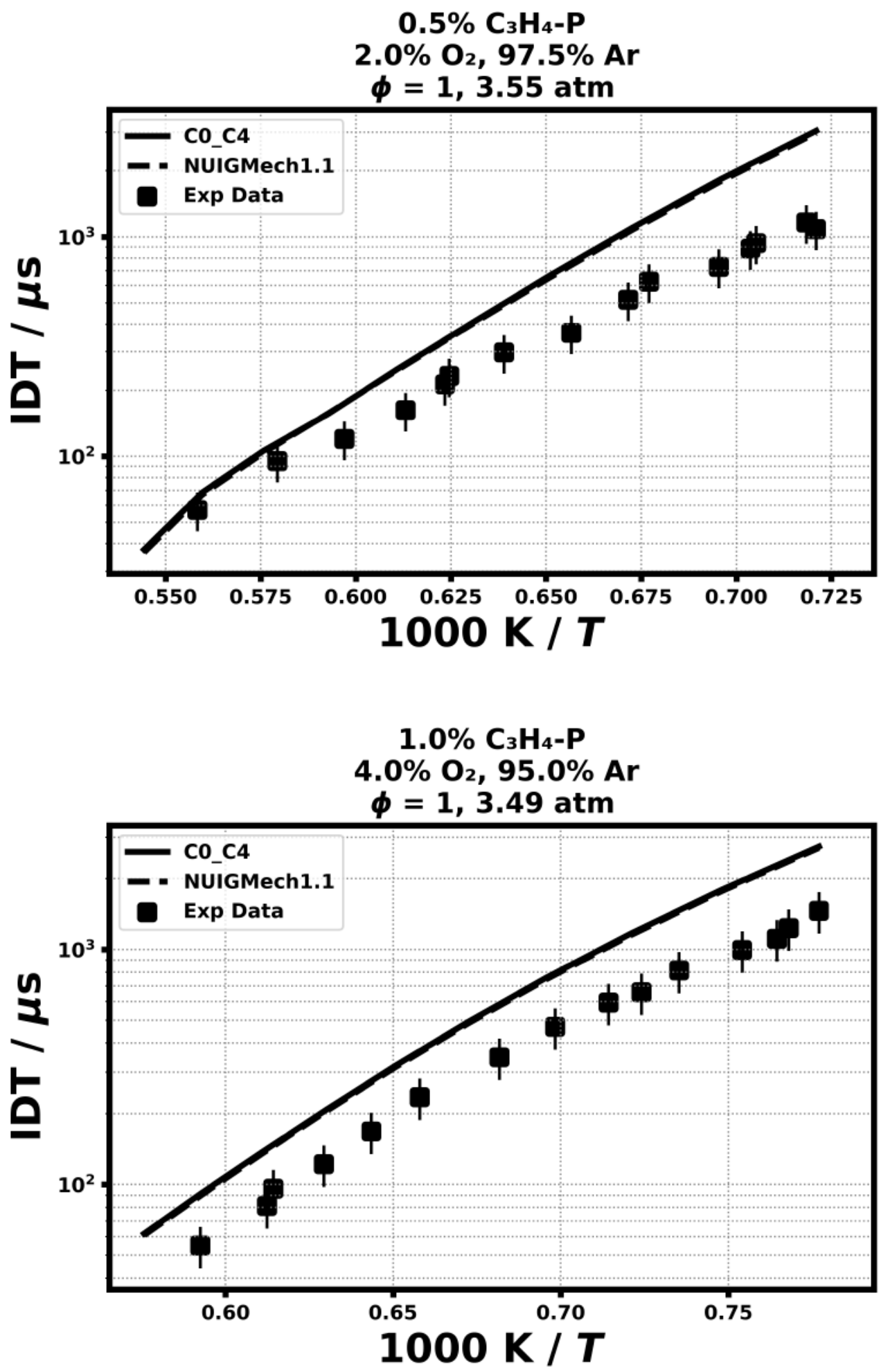

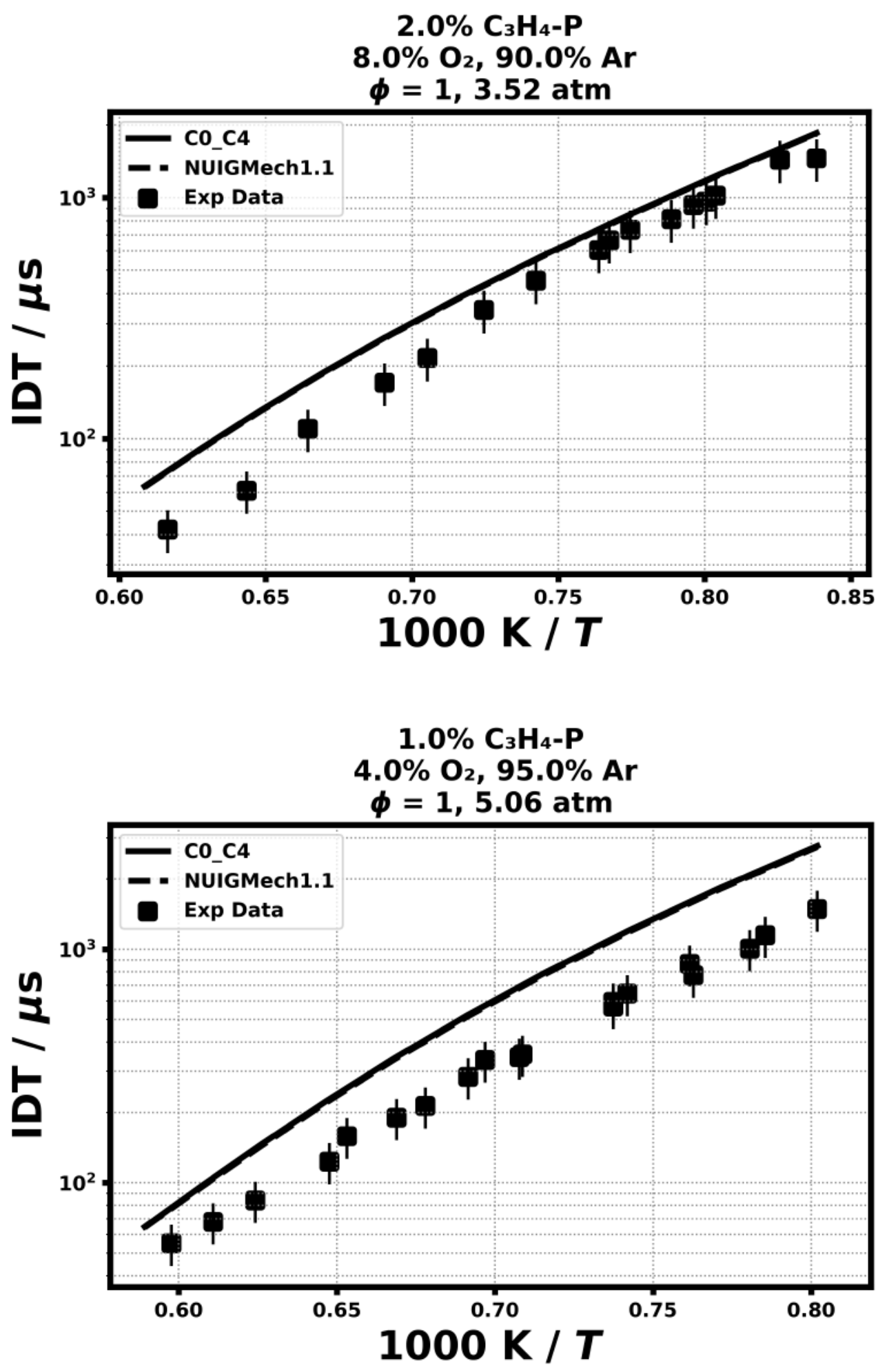

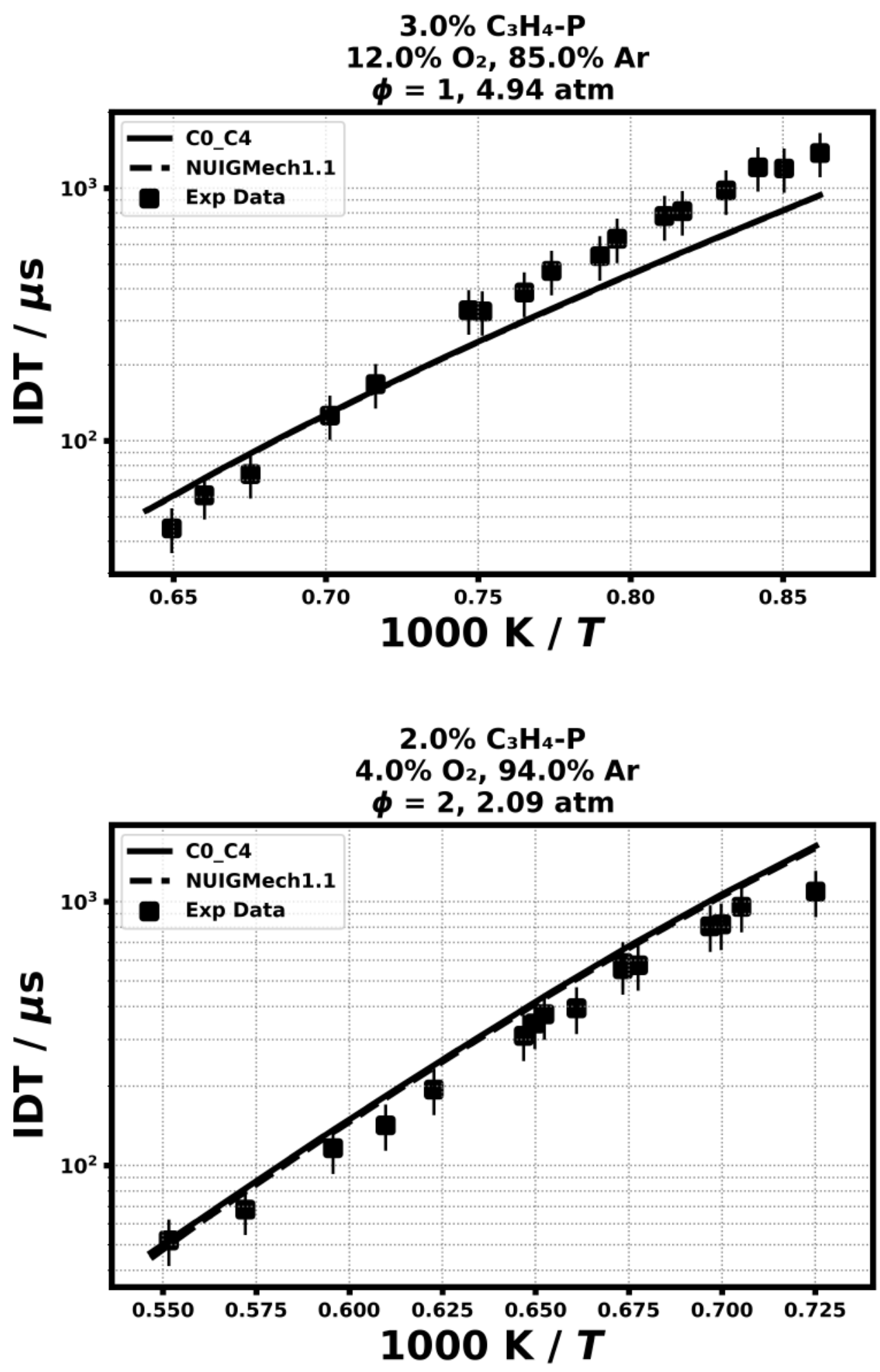

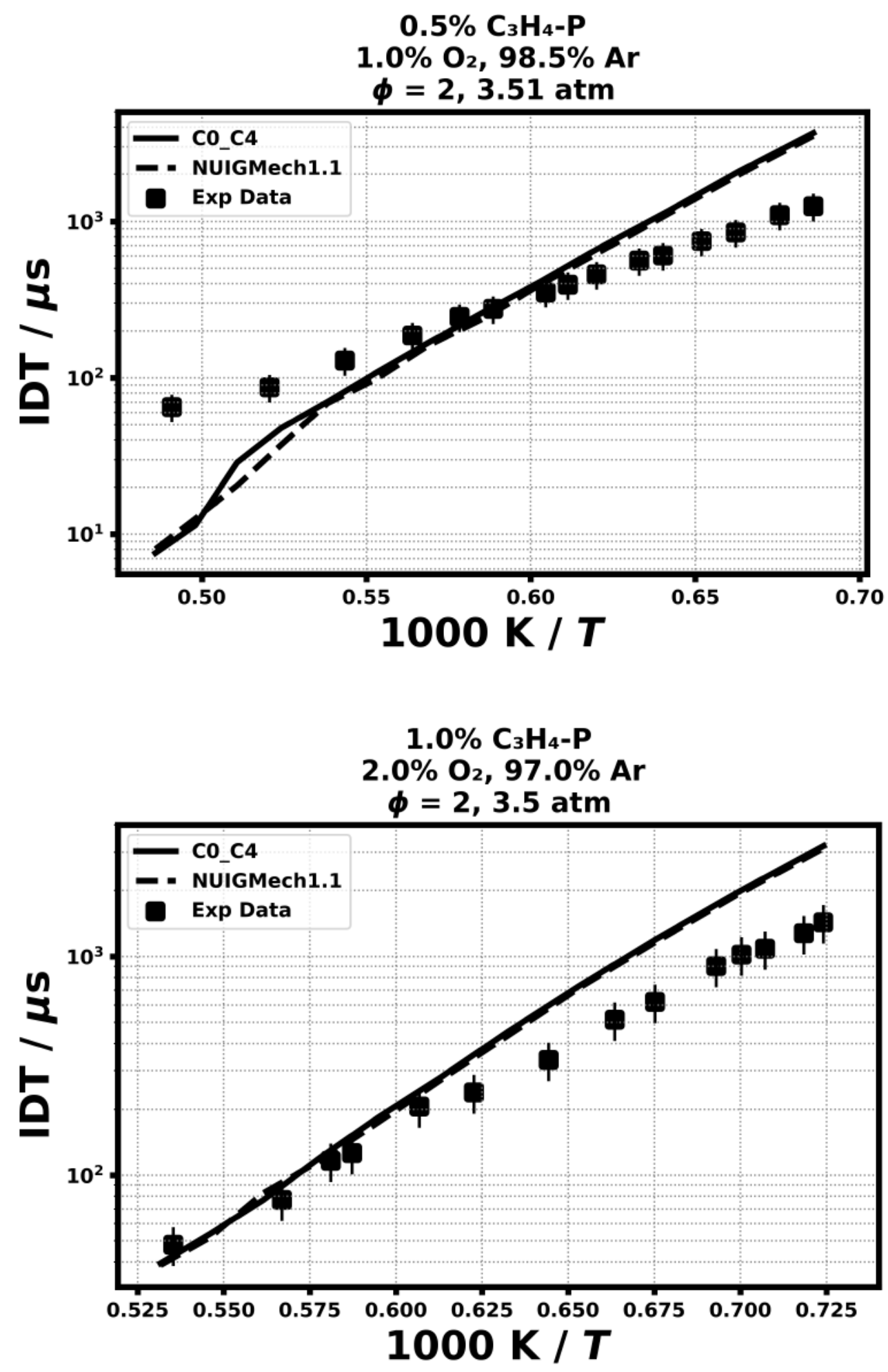

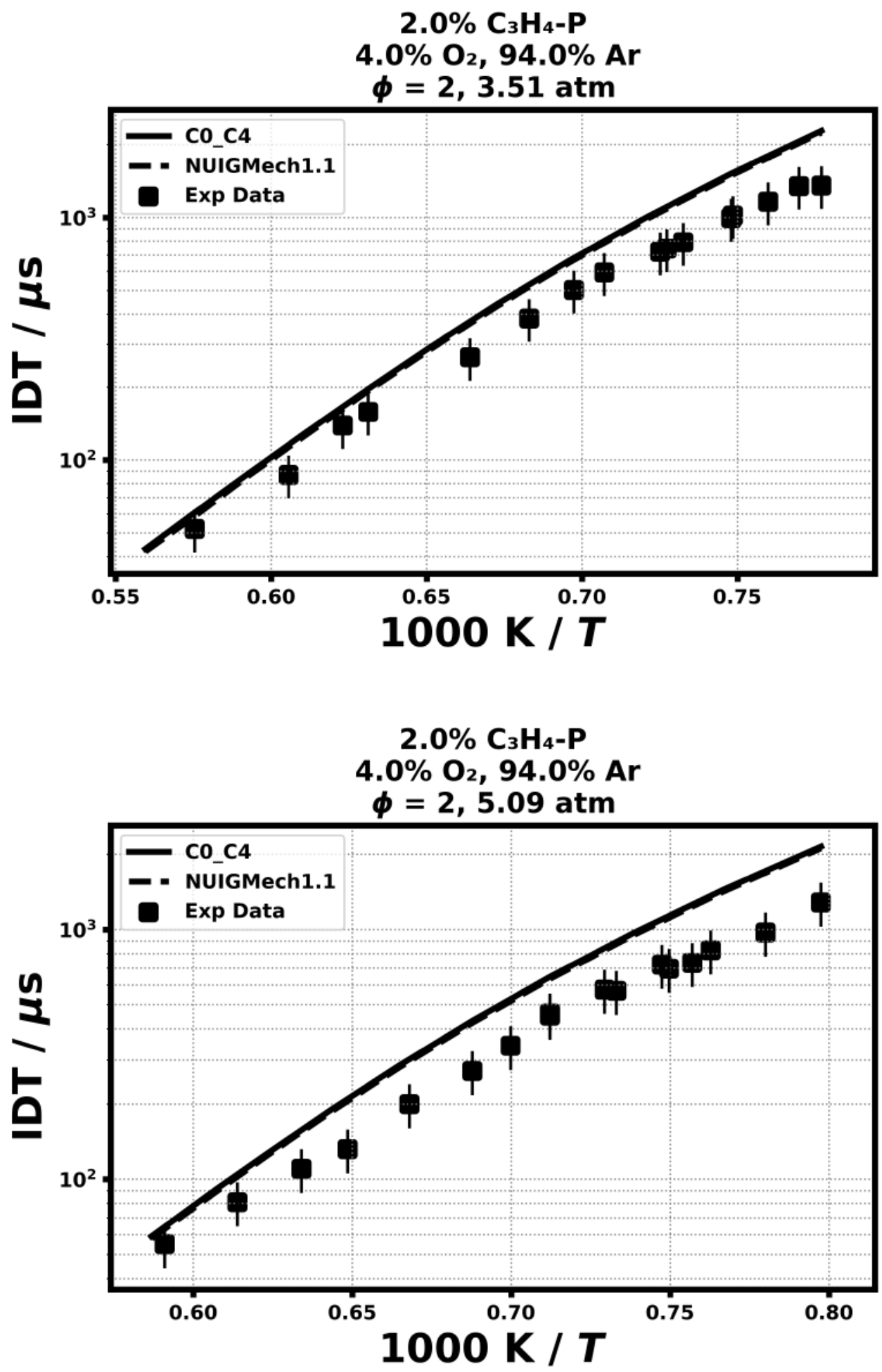


\section{RCM Ignition delay time}

10.2) Panigrahy, S., Liang, J., Nagaraja, S. S., Zuo, Z., Kim, G., Dong, S., ... \& Curran, H. J., Proceedings of the Combustion Institute (2020).

\section{propyne, $p=10.0 \mathrm{~atm}$}
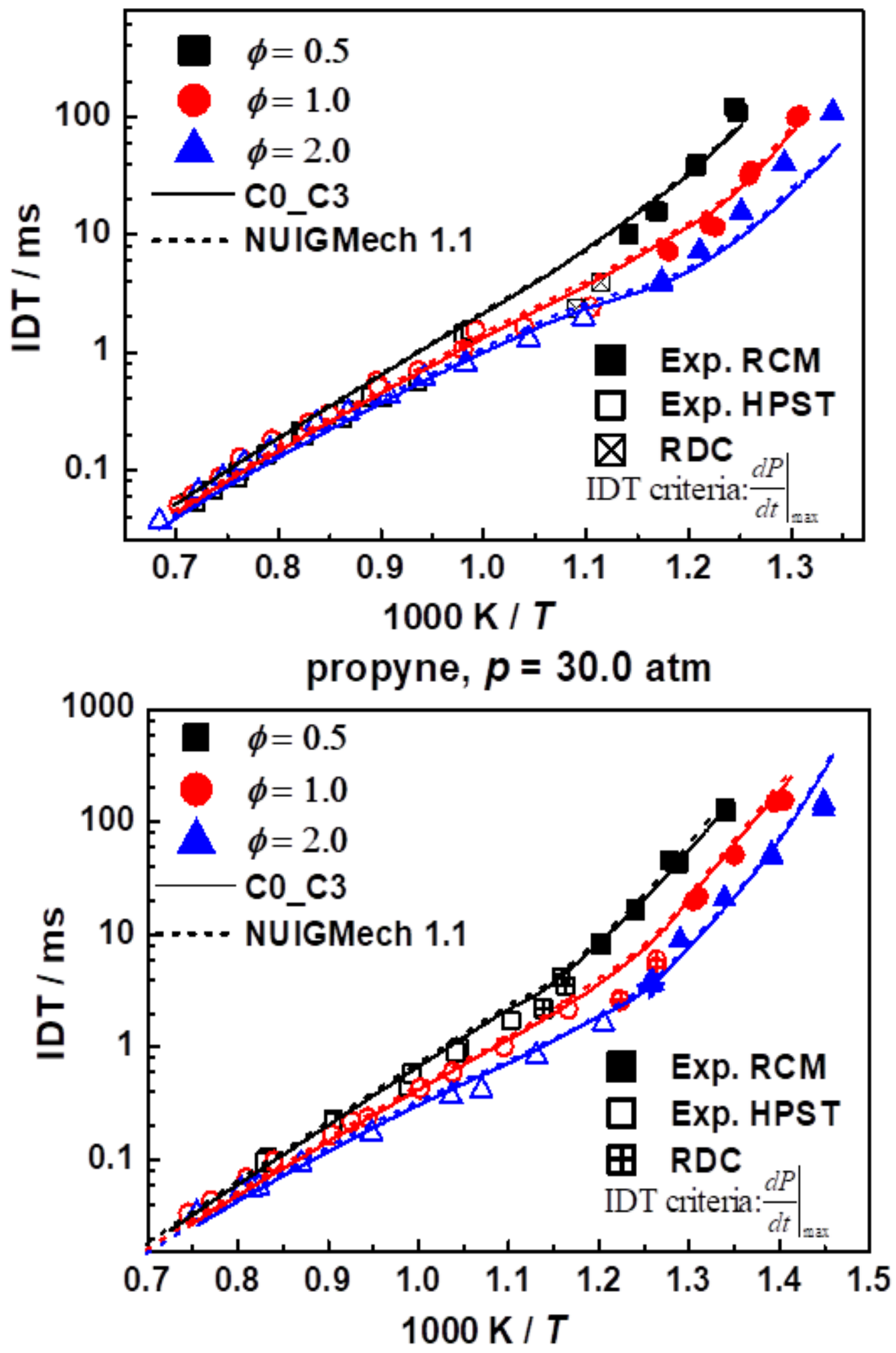


\section{Speciation in Jet-stirred reactor}

10.3) DAGAUT, P., CATHONNET, M., \& BOETTNER, J. C. (1990), Combustion Science and Technology, 71(1-3), 111-128.
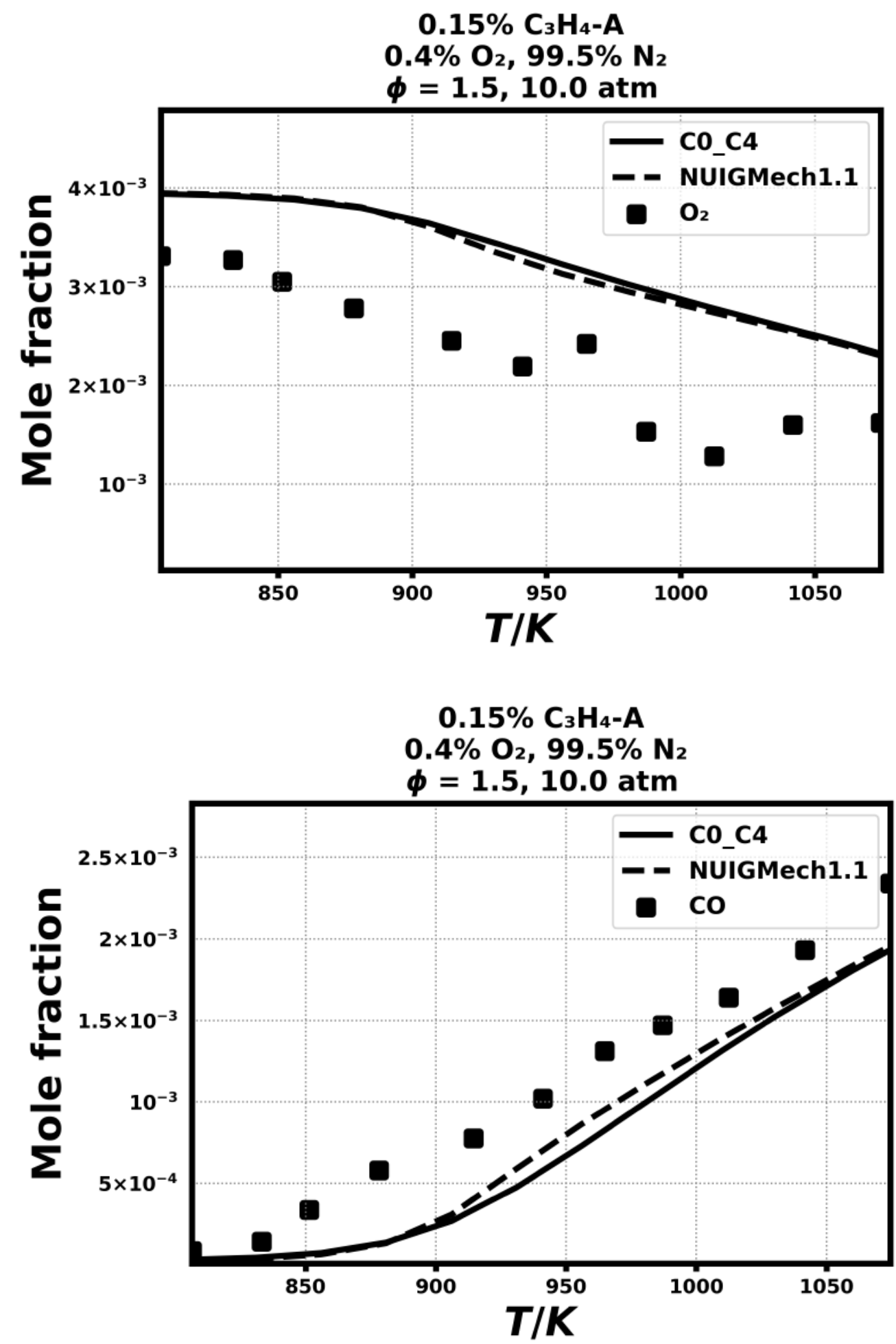

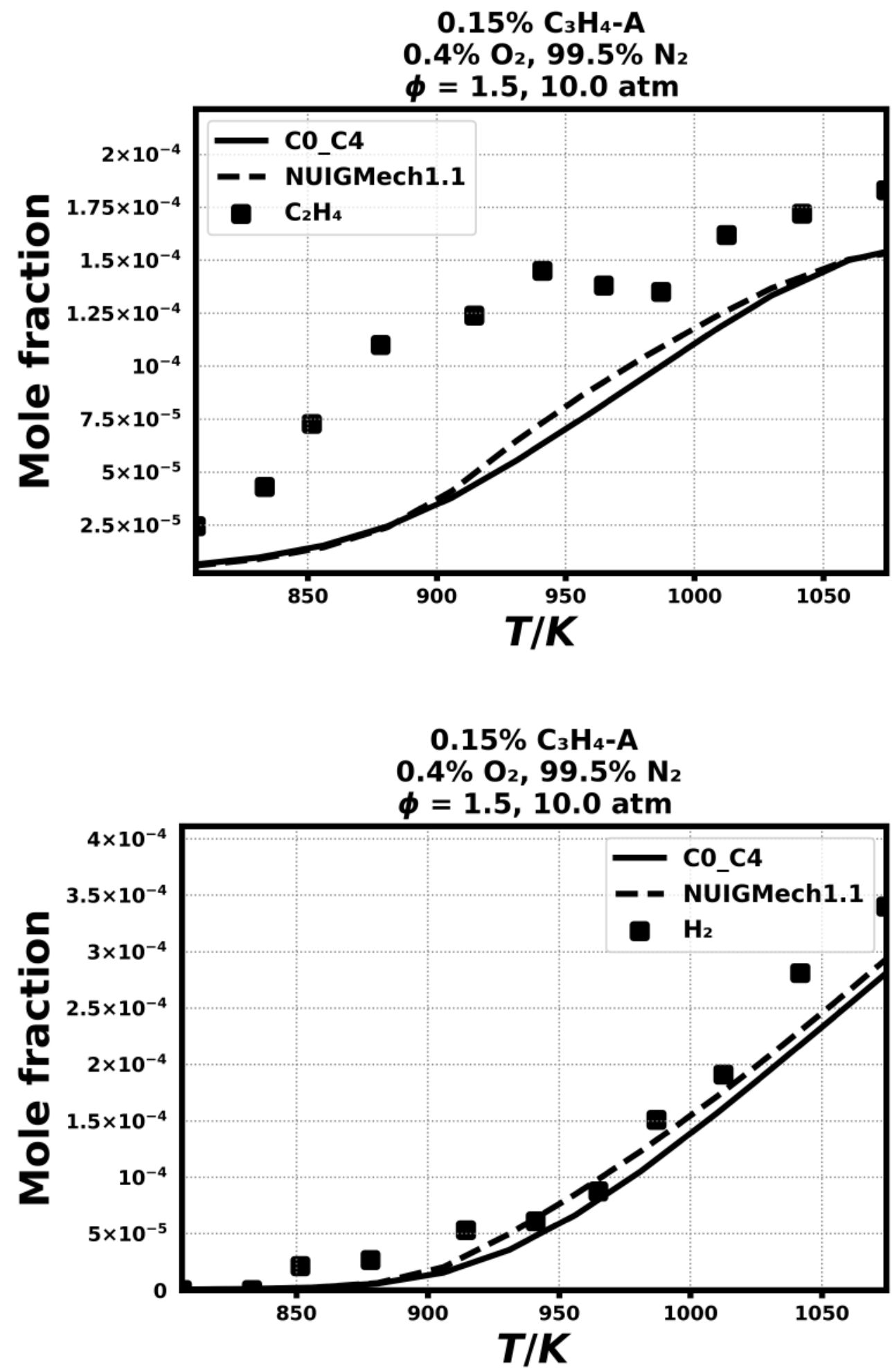

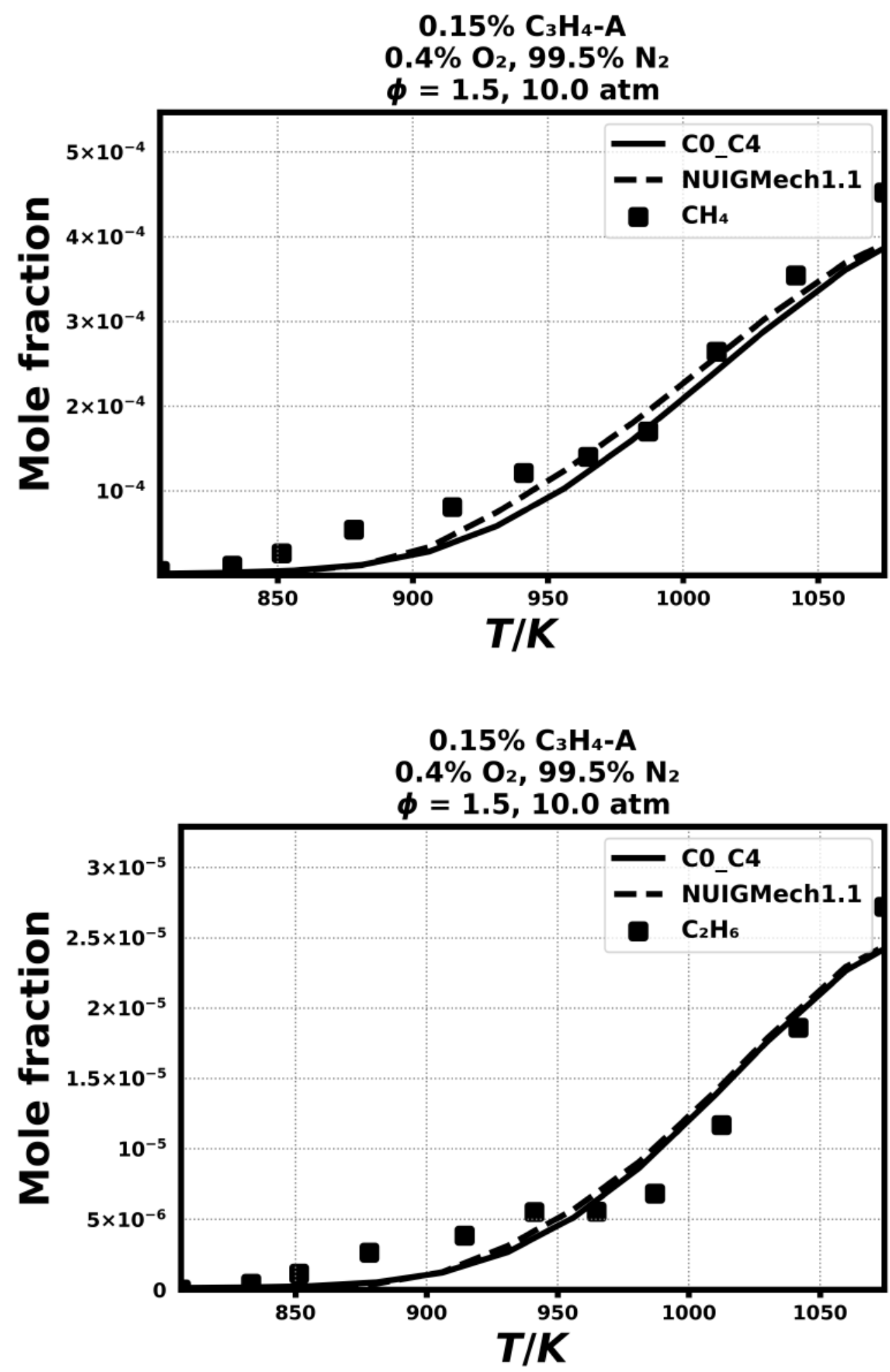

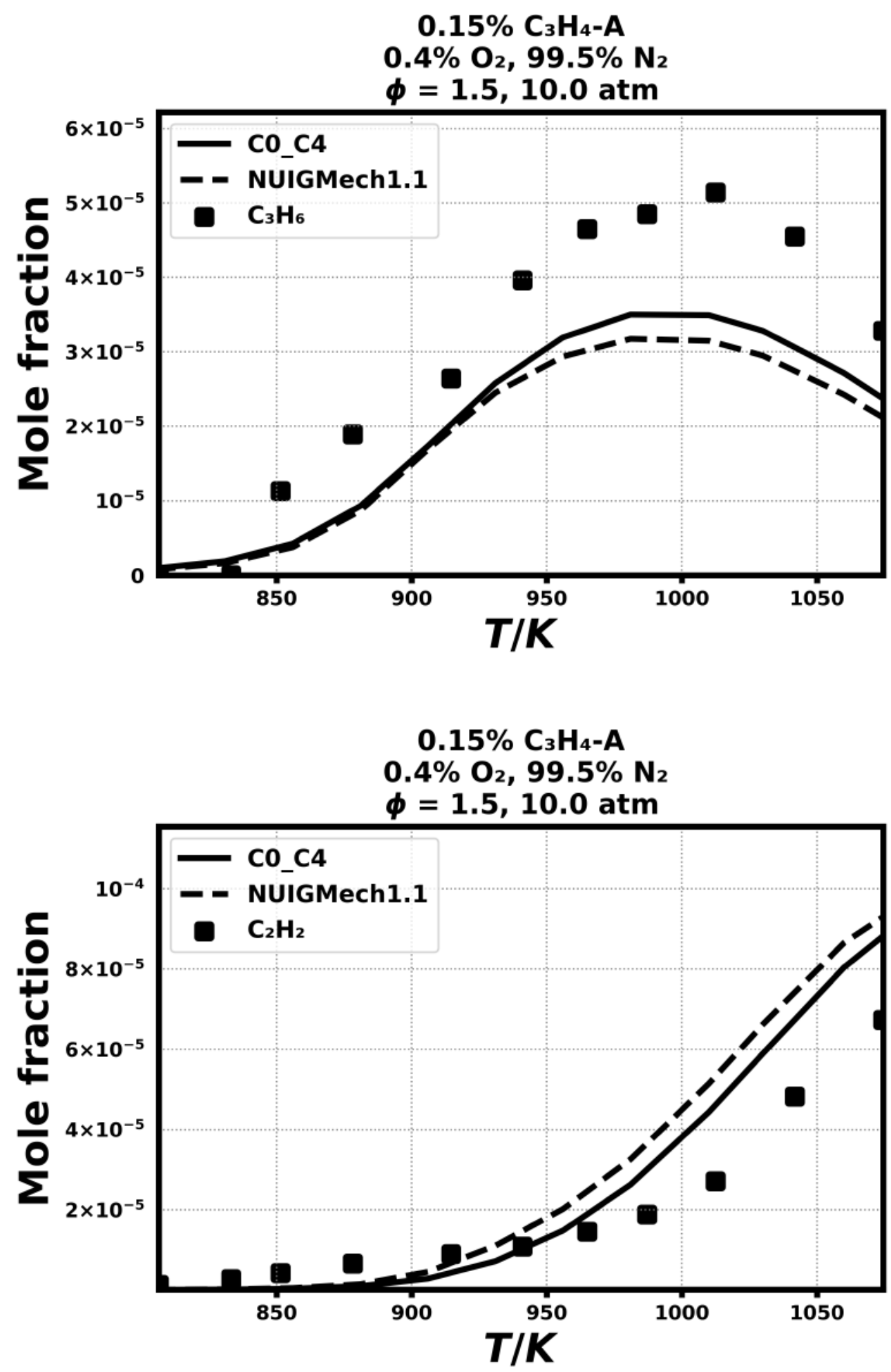

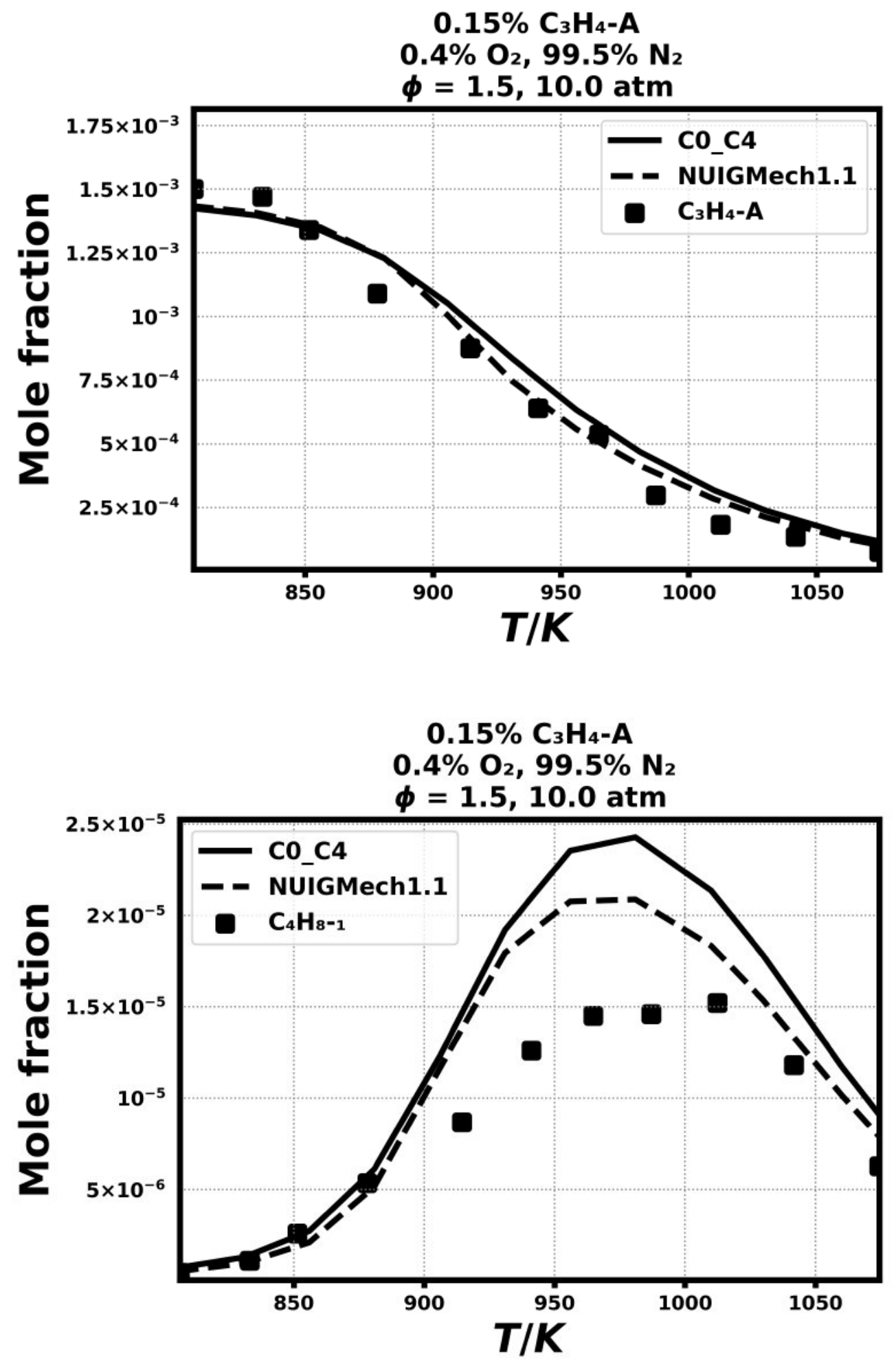

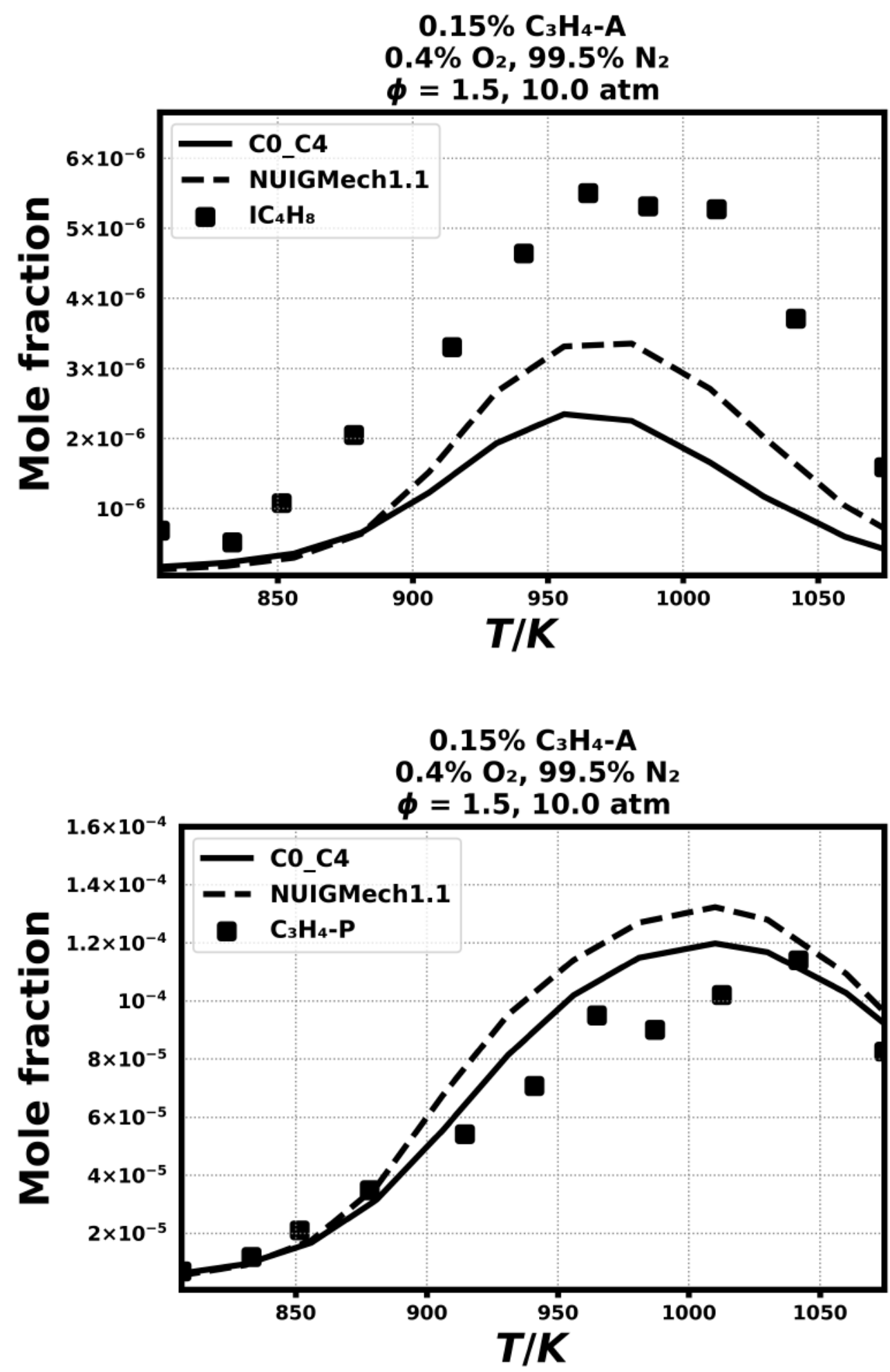

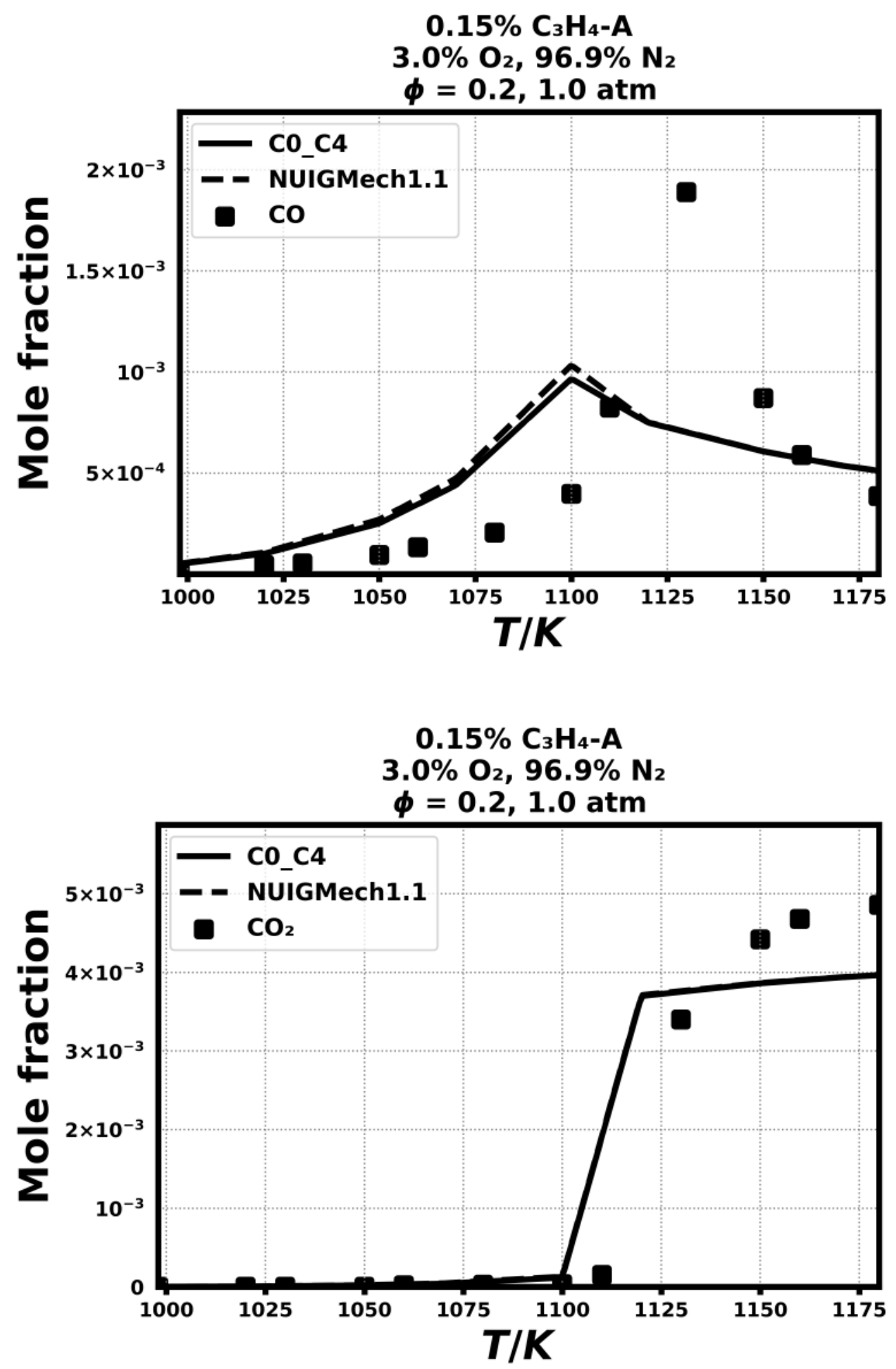

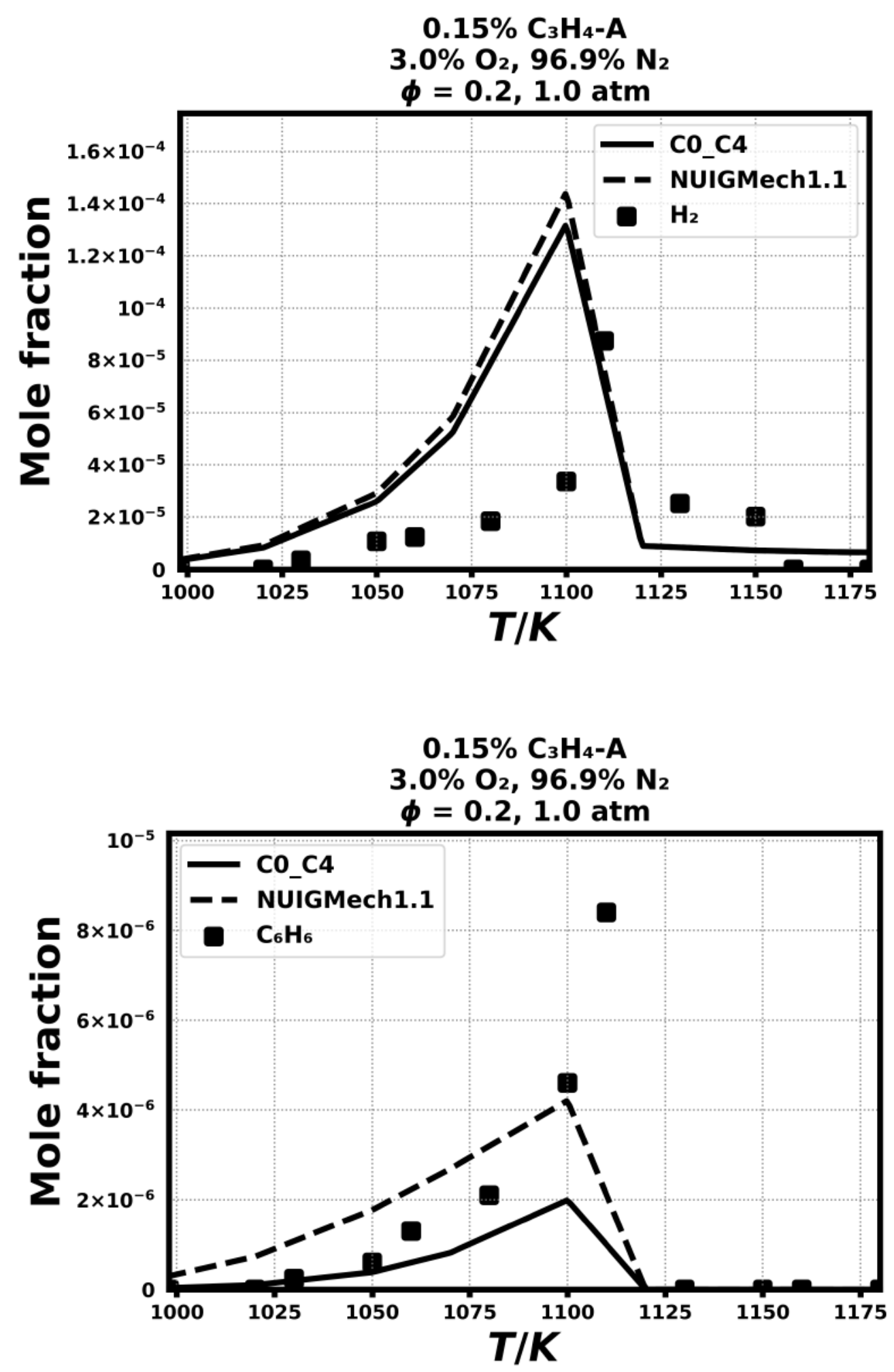

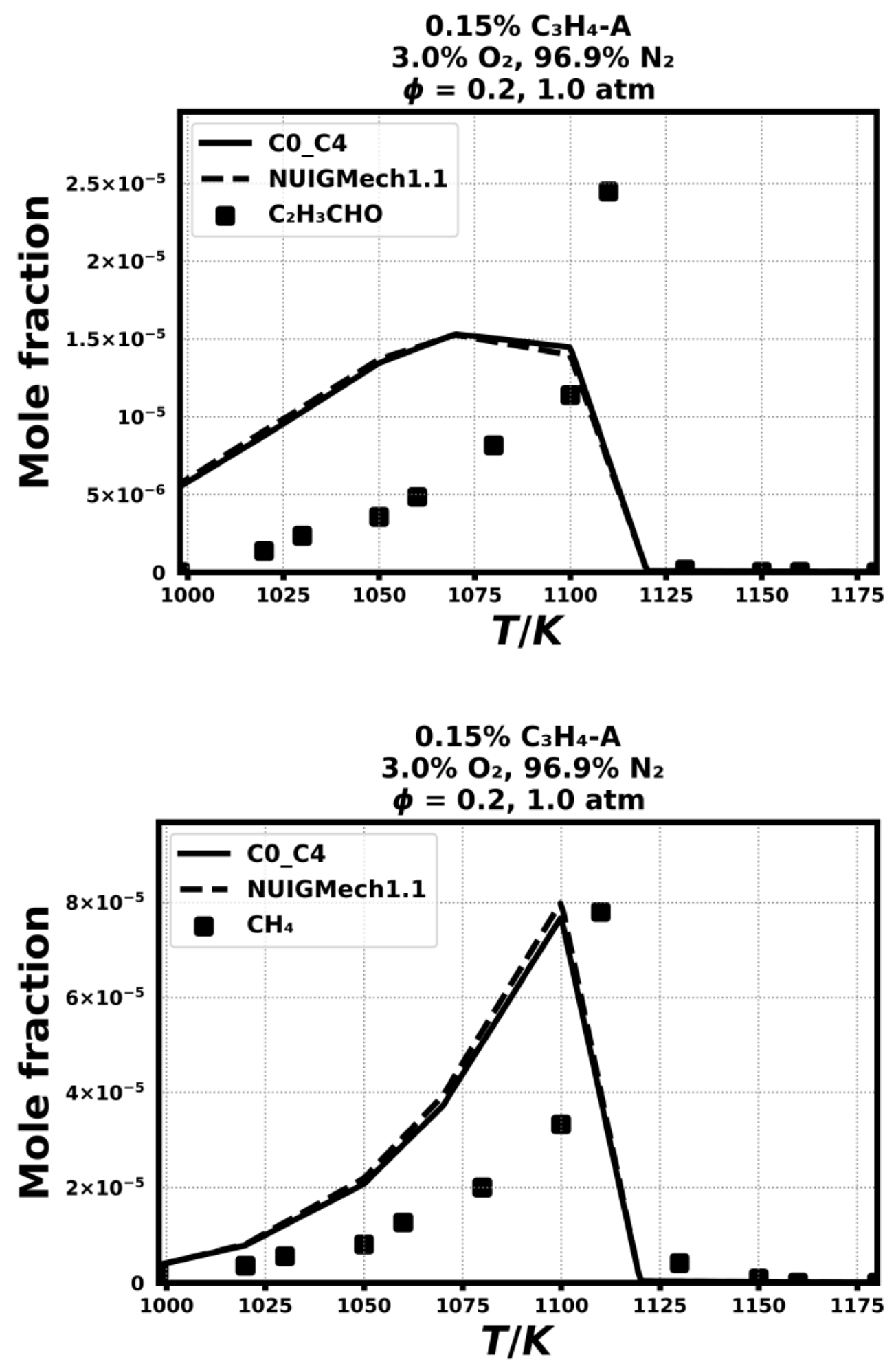

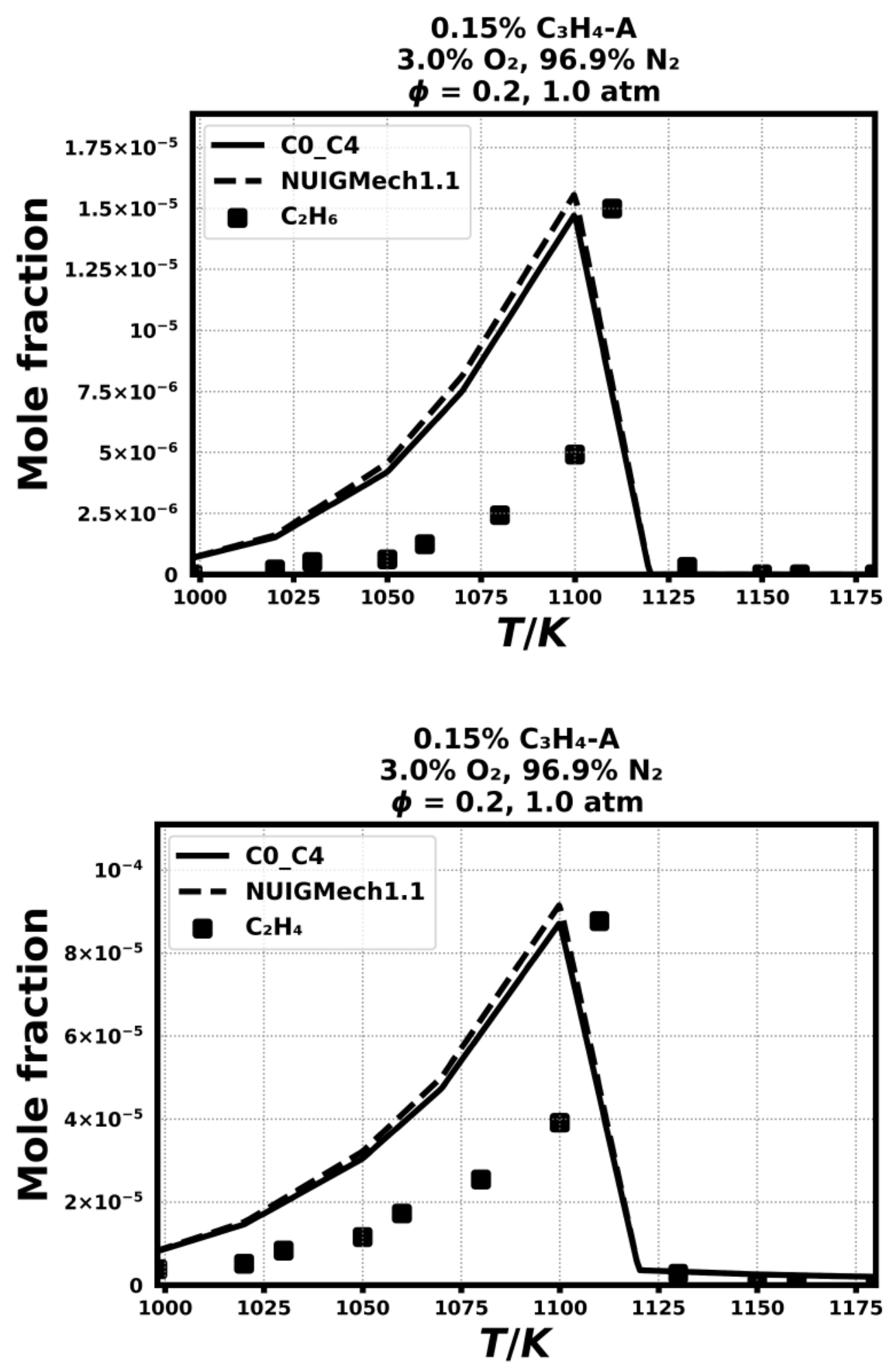

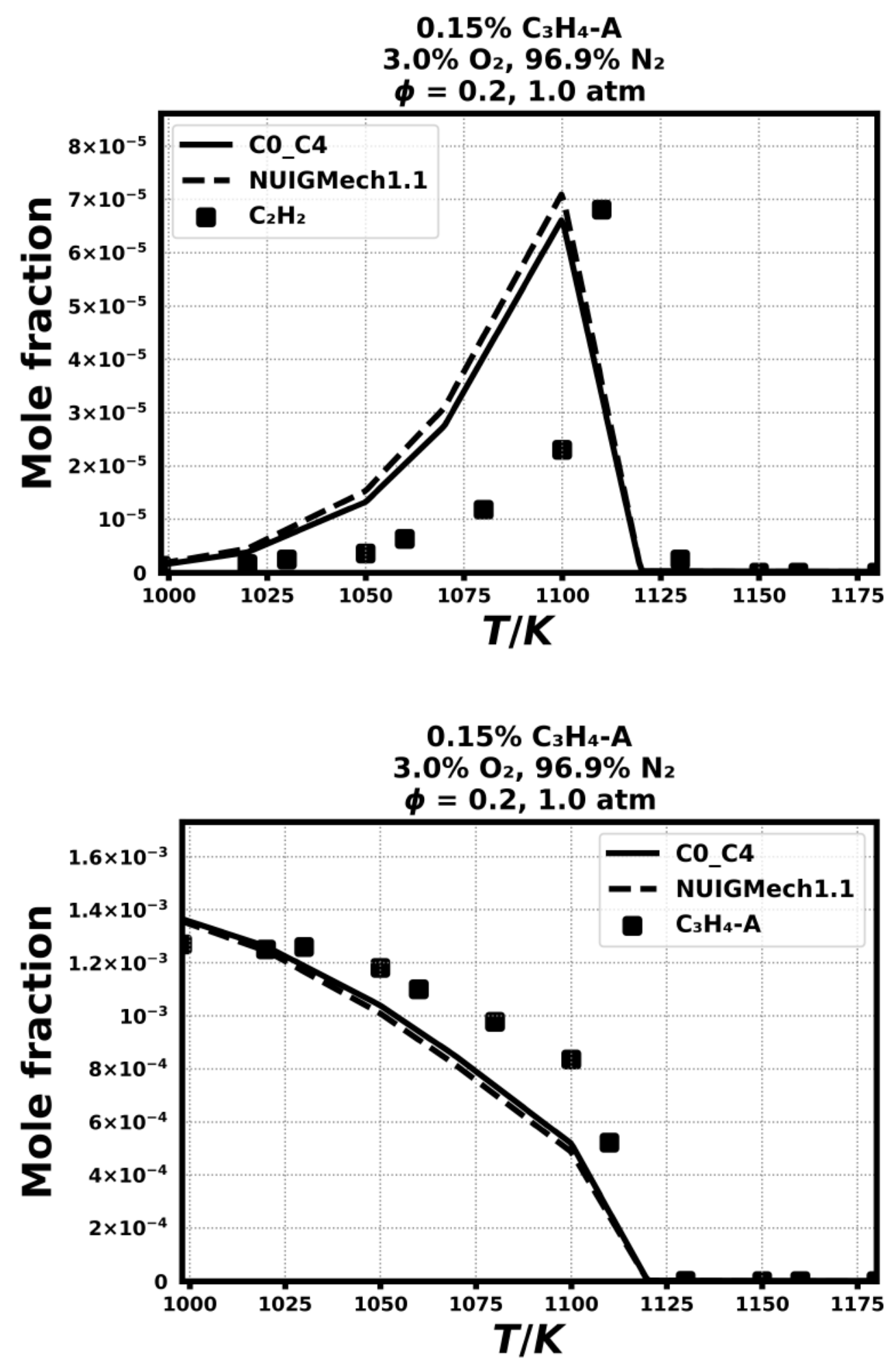

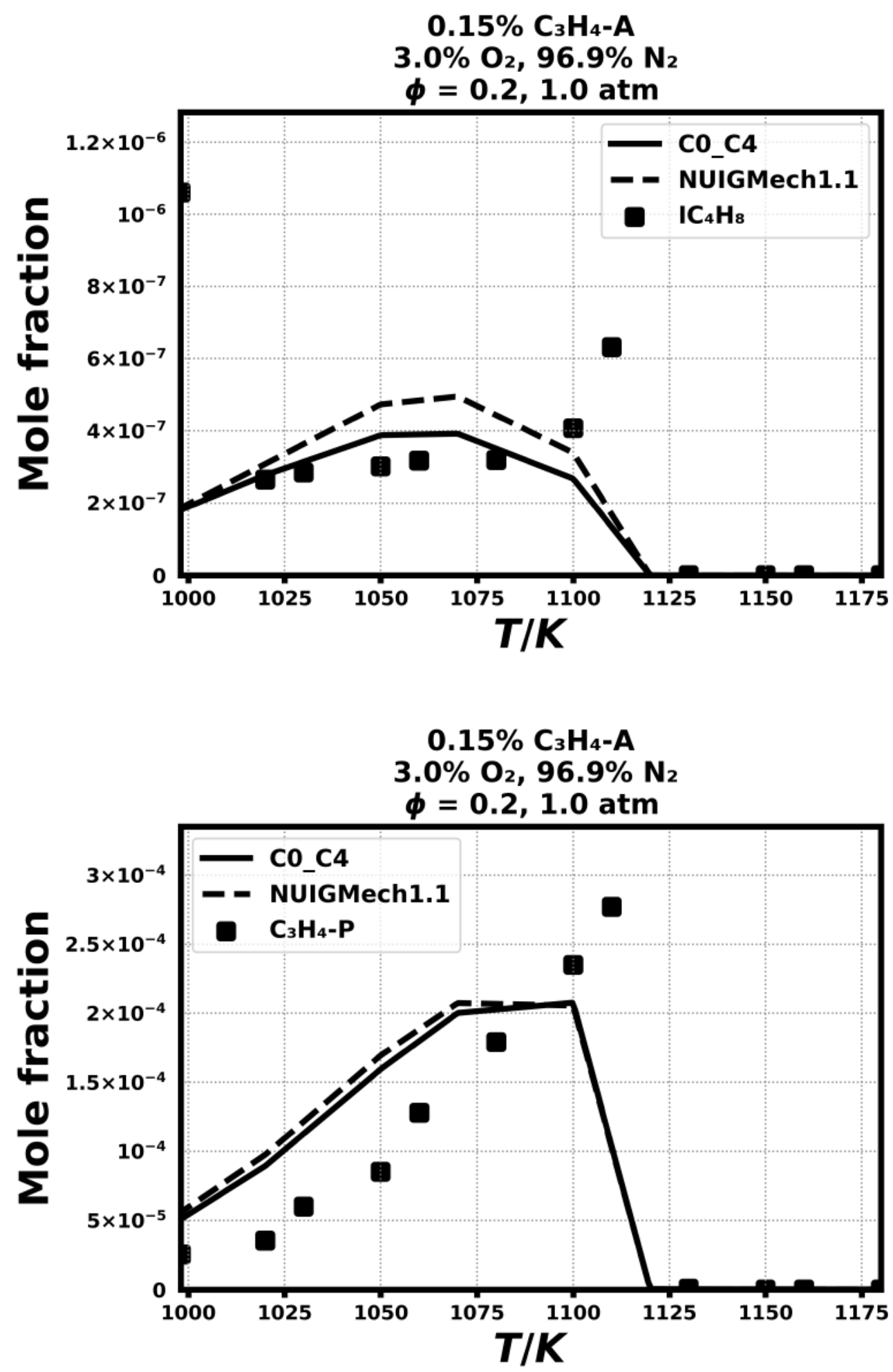

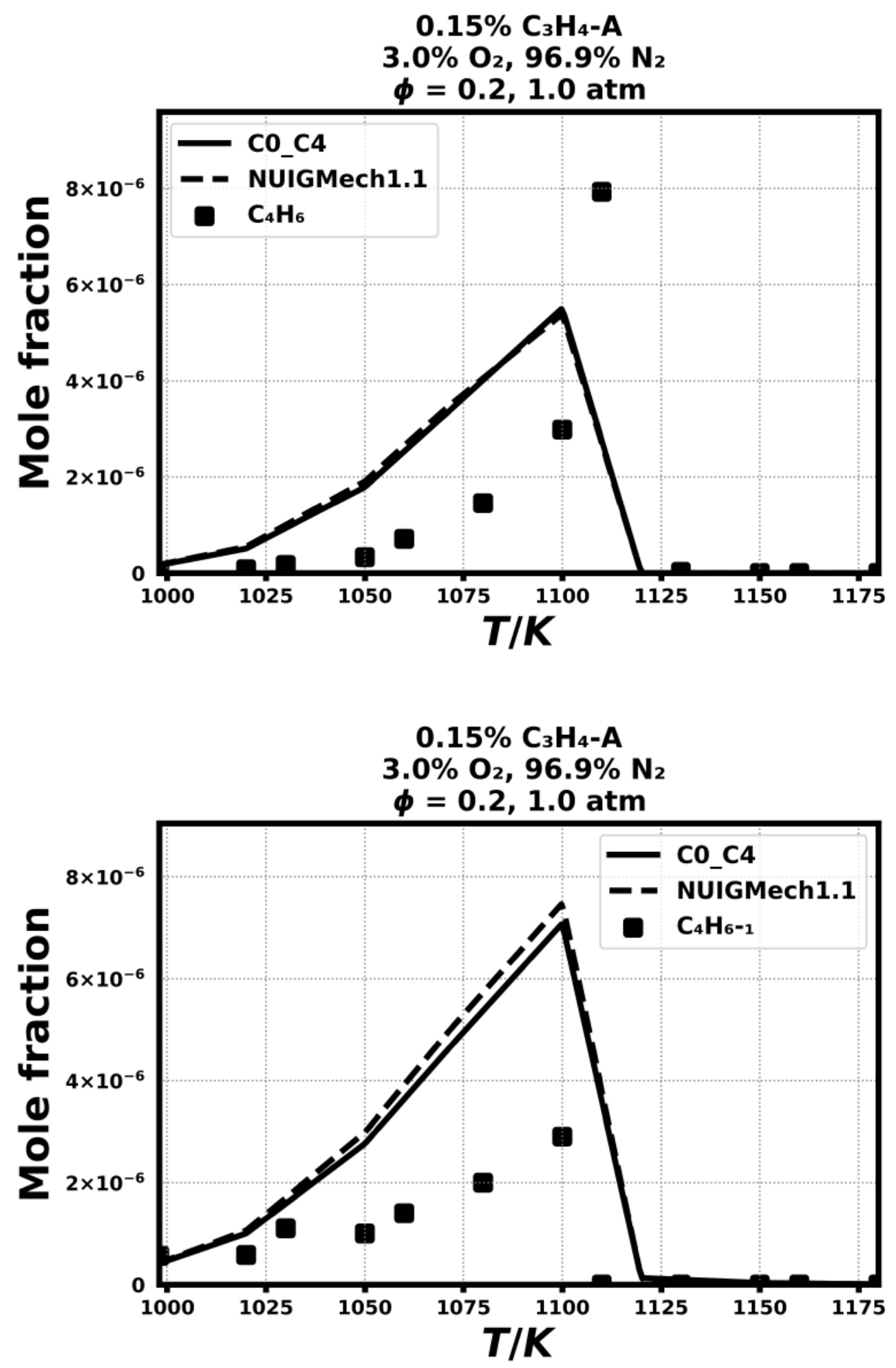

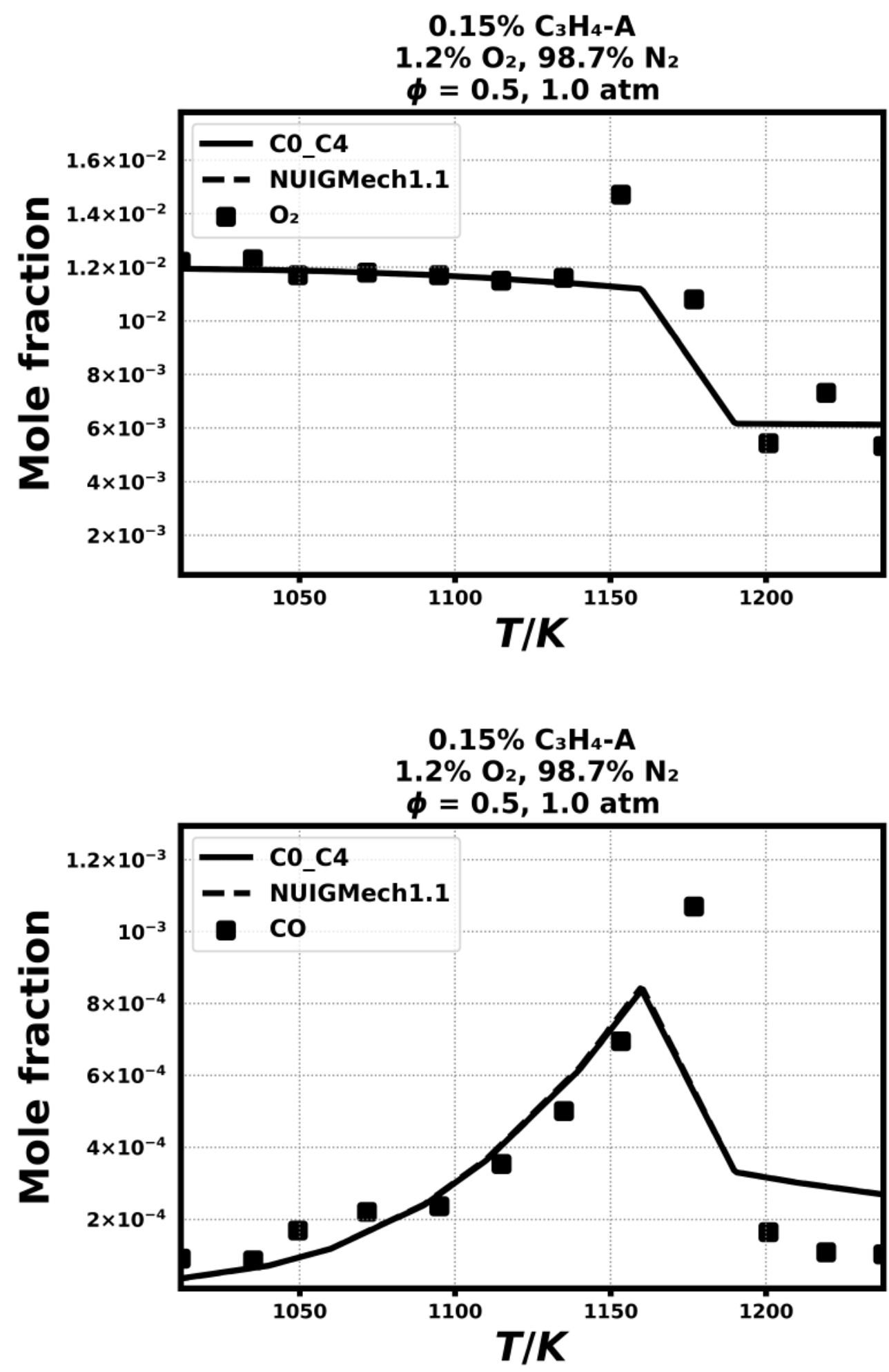

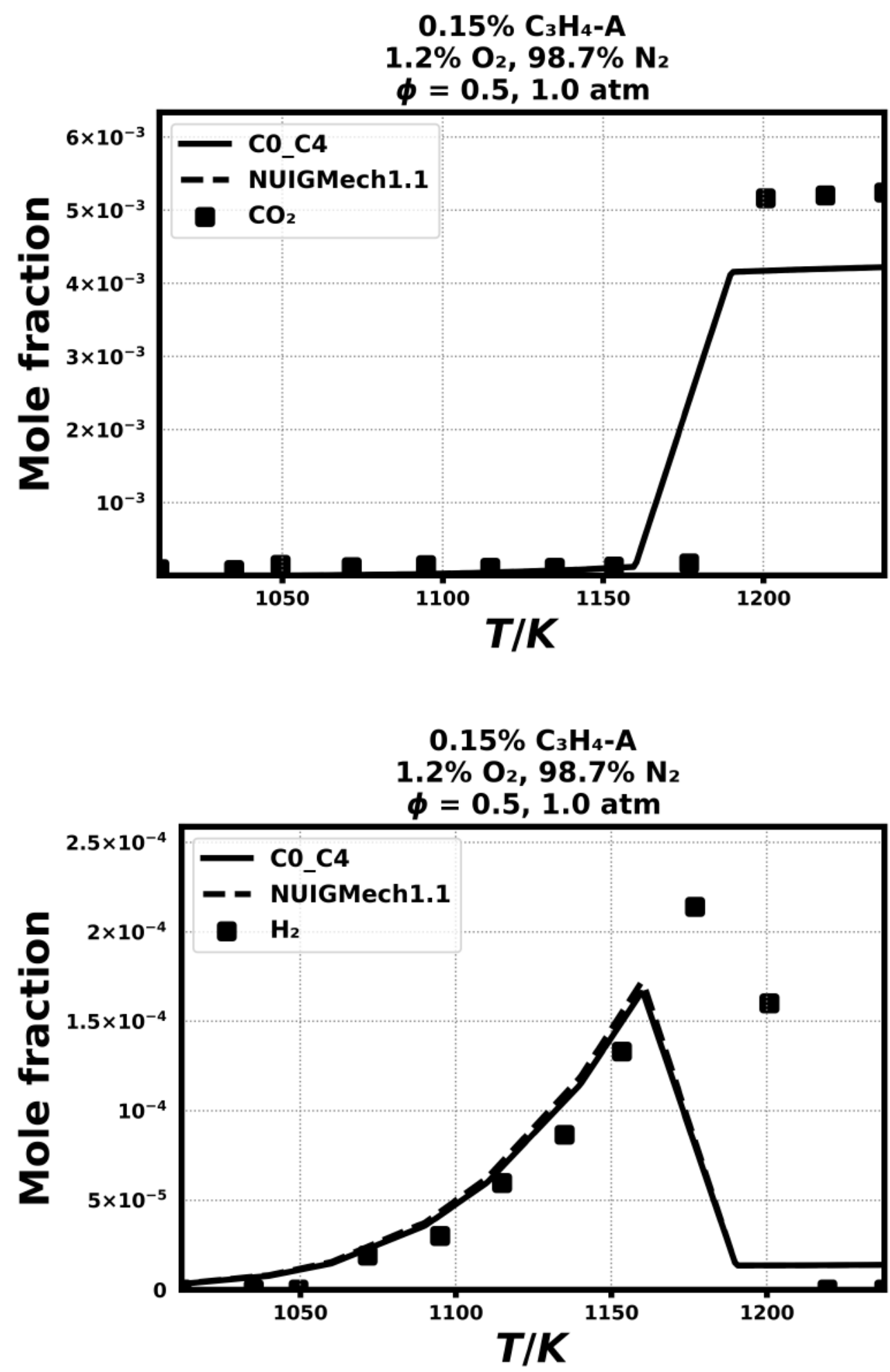

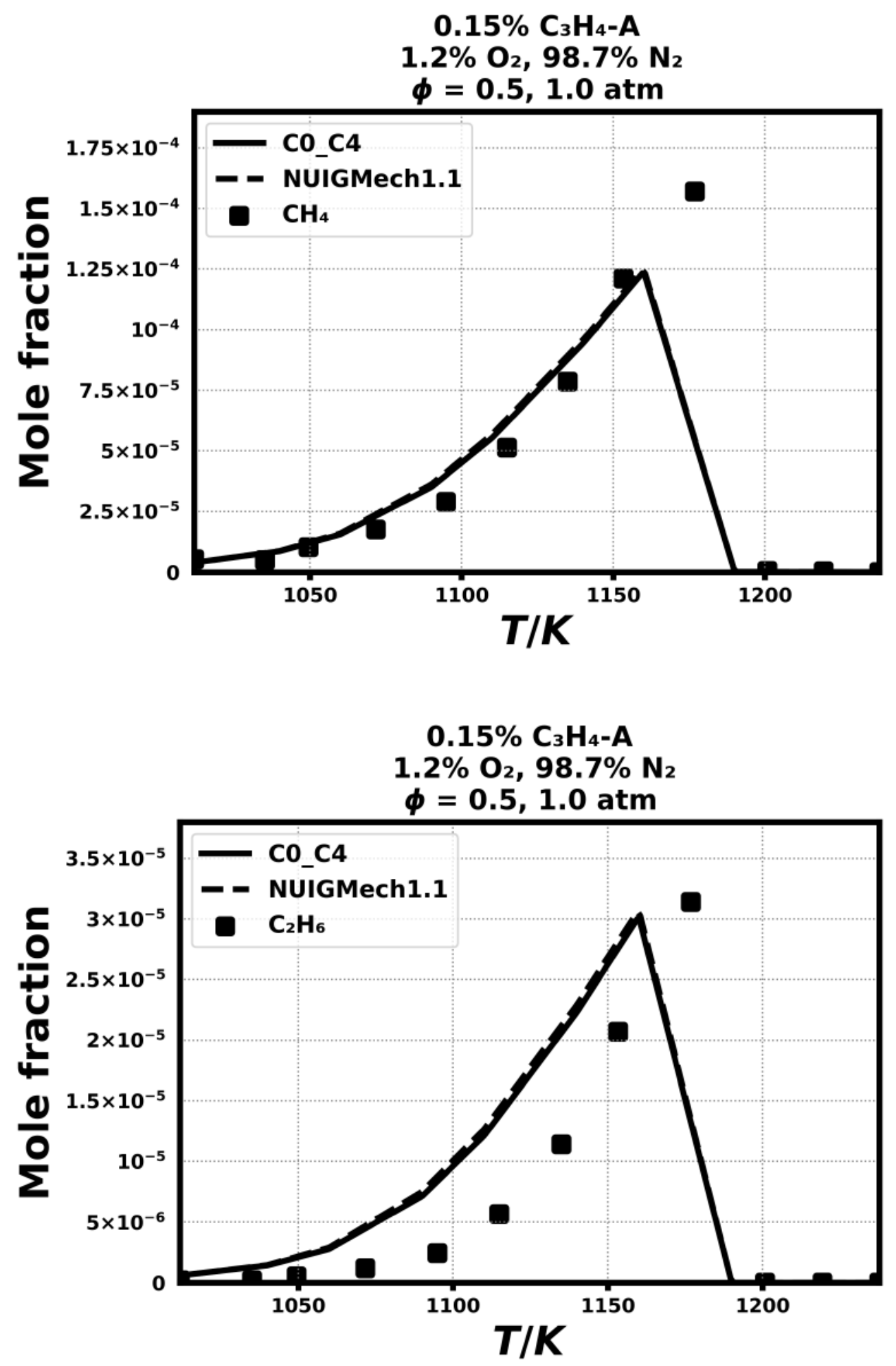

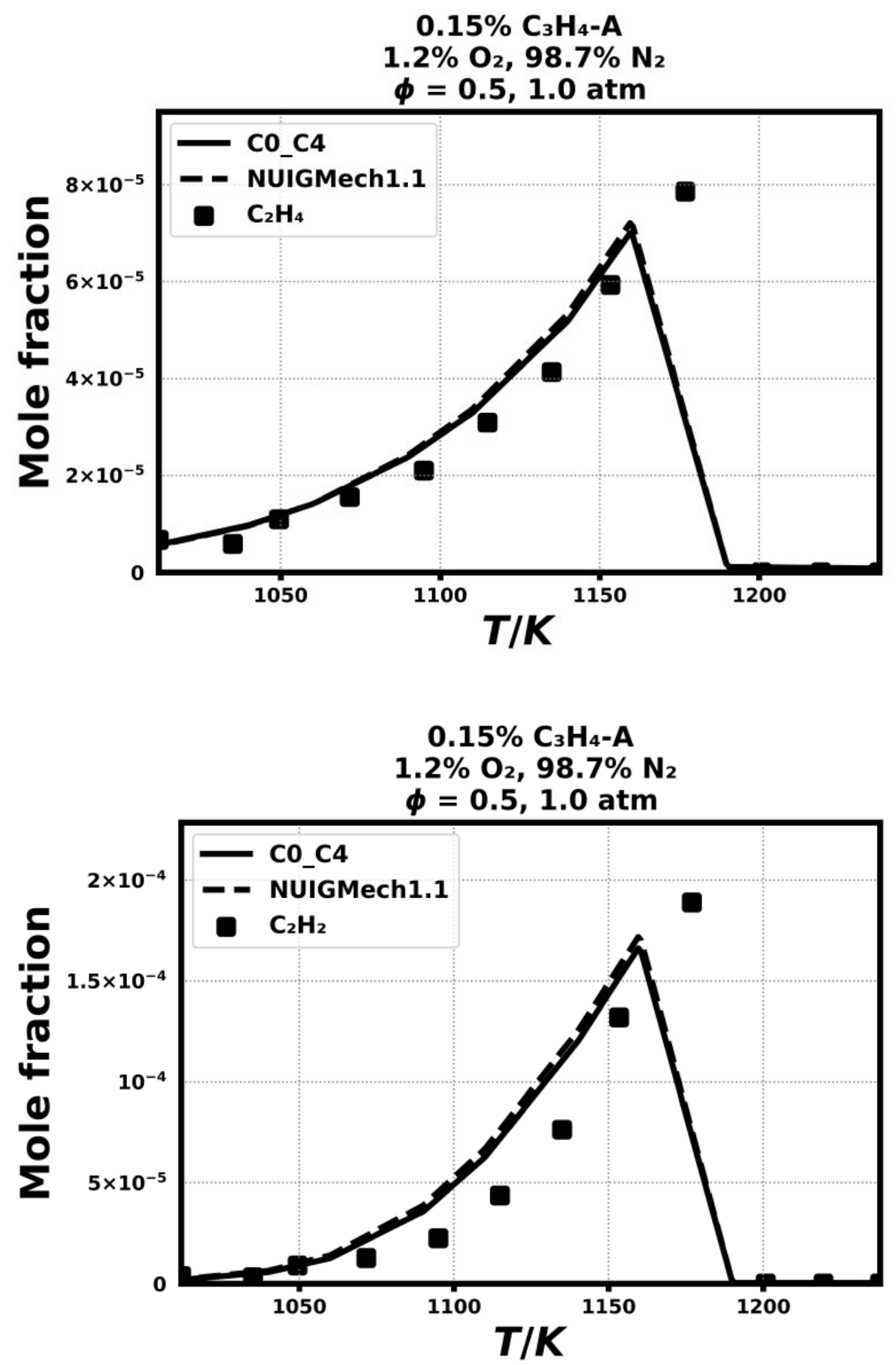

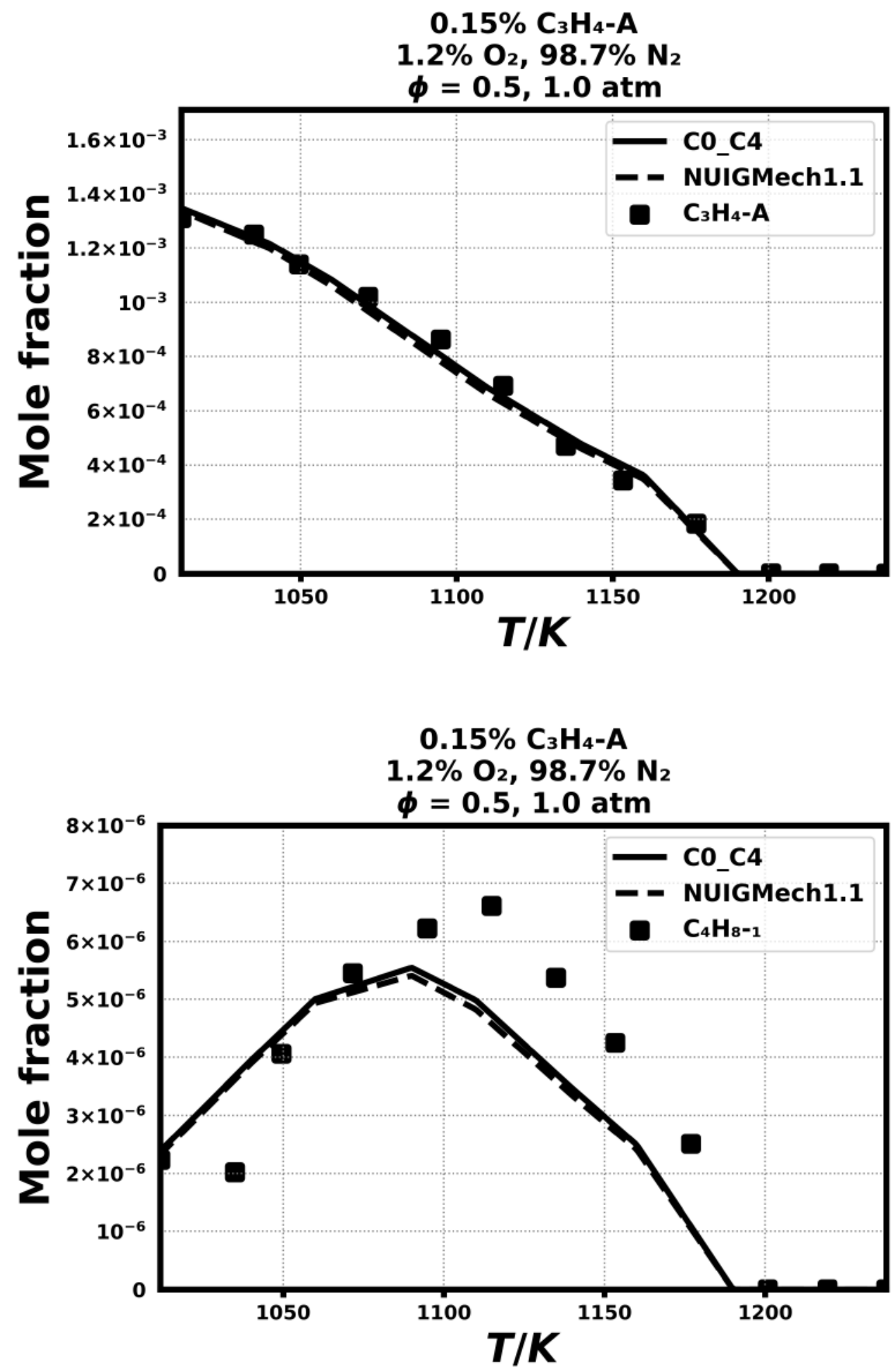

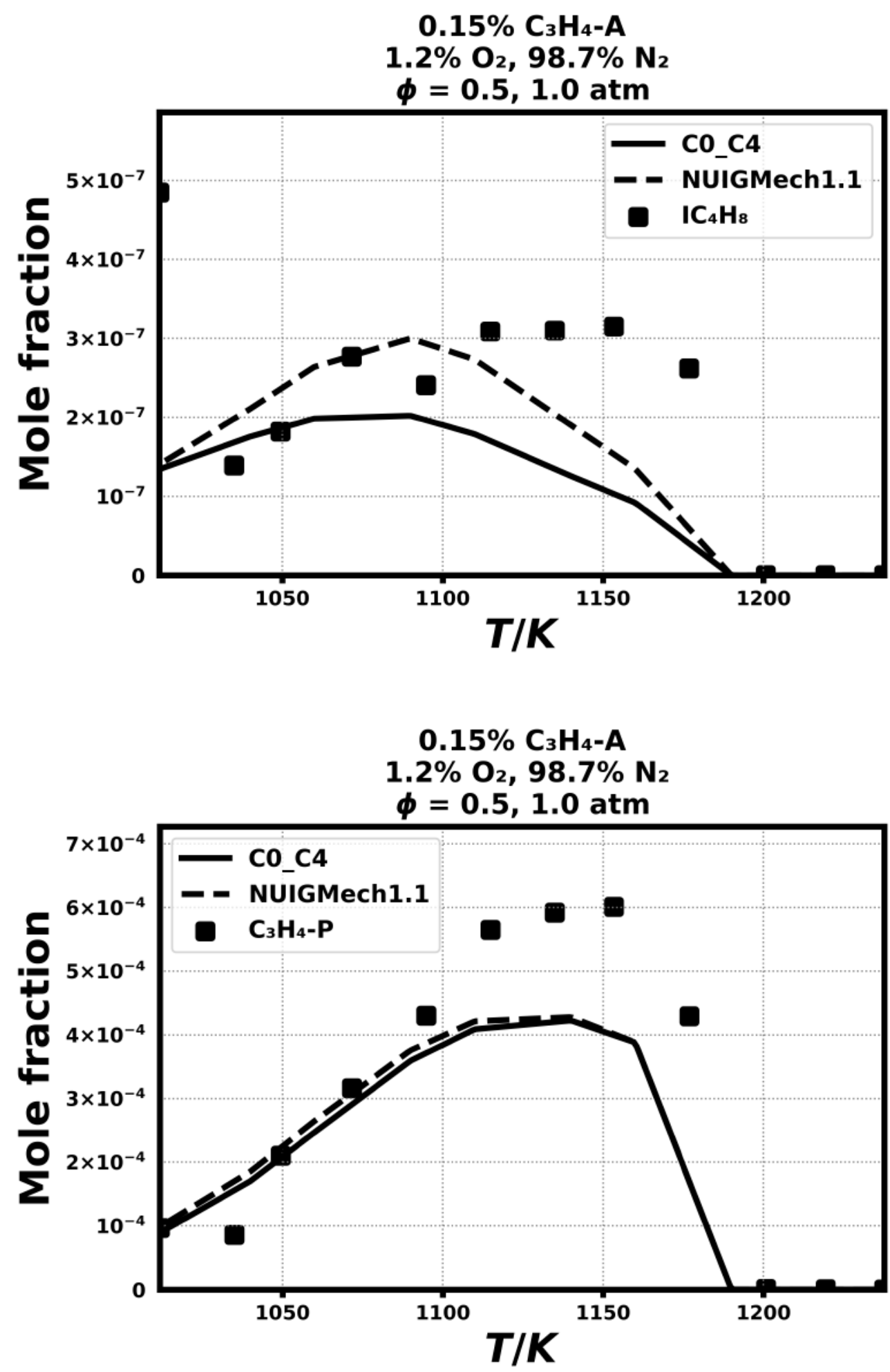

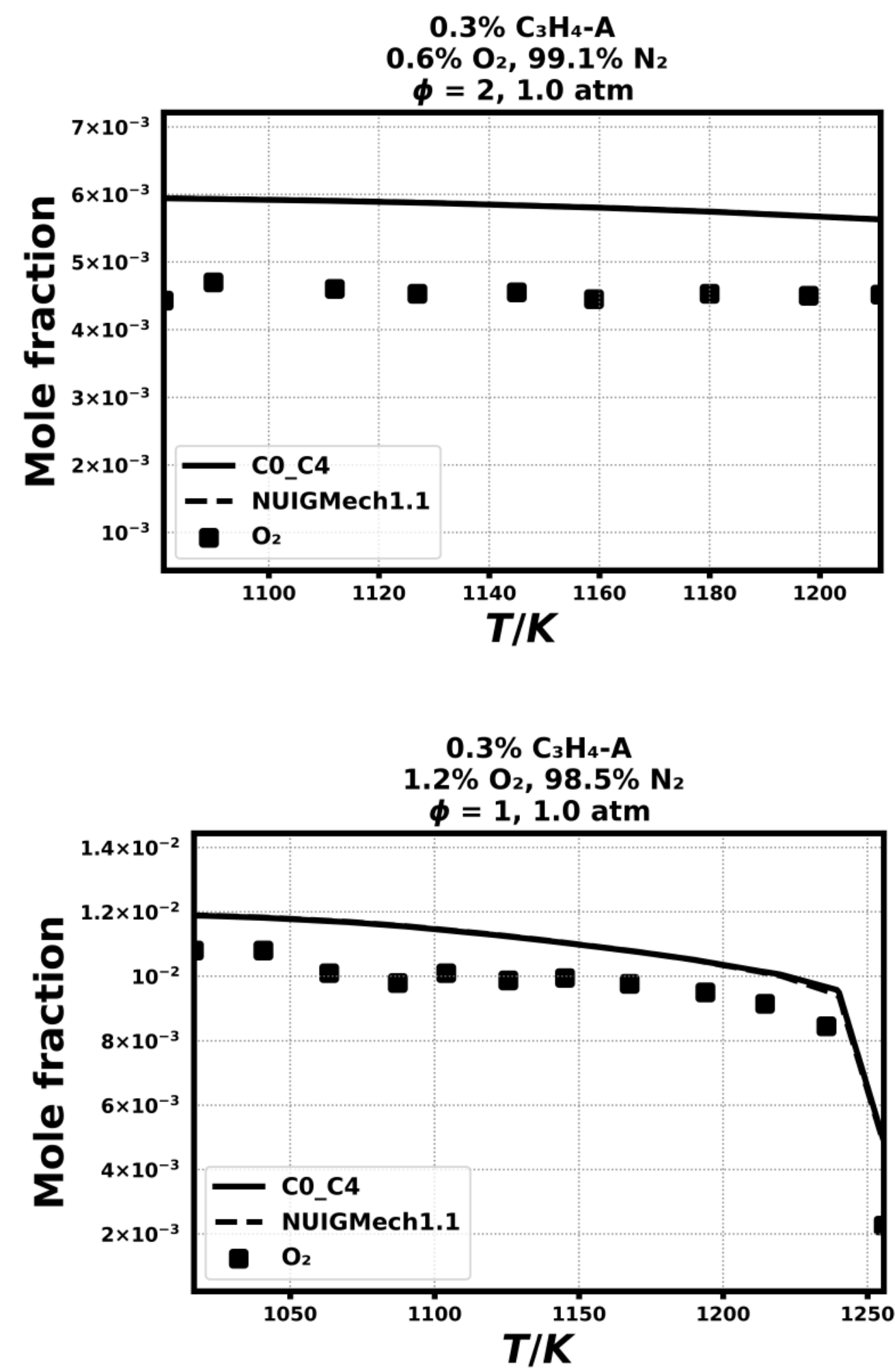

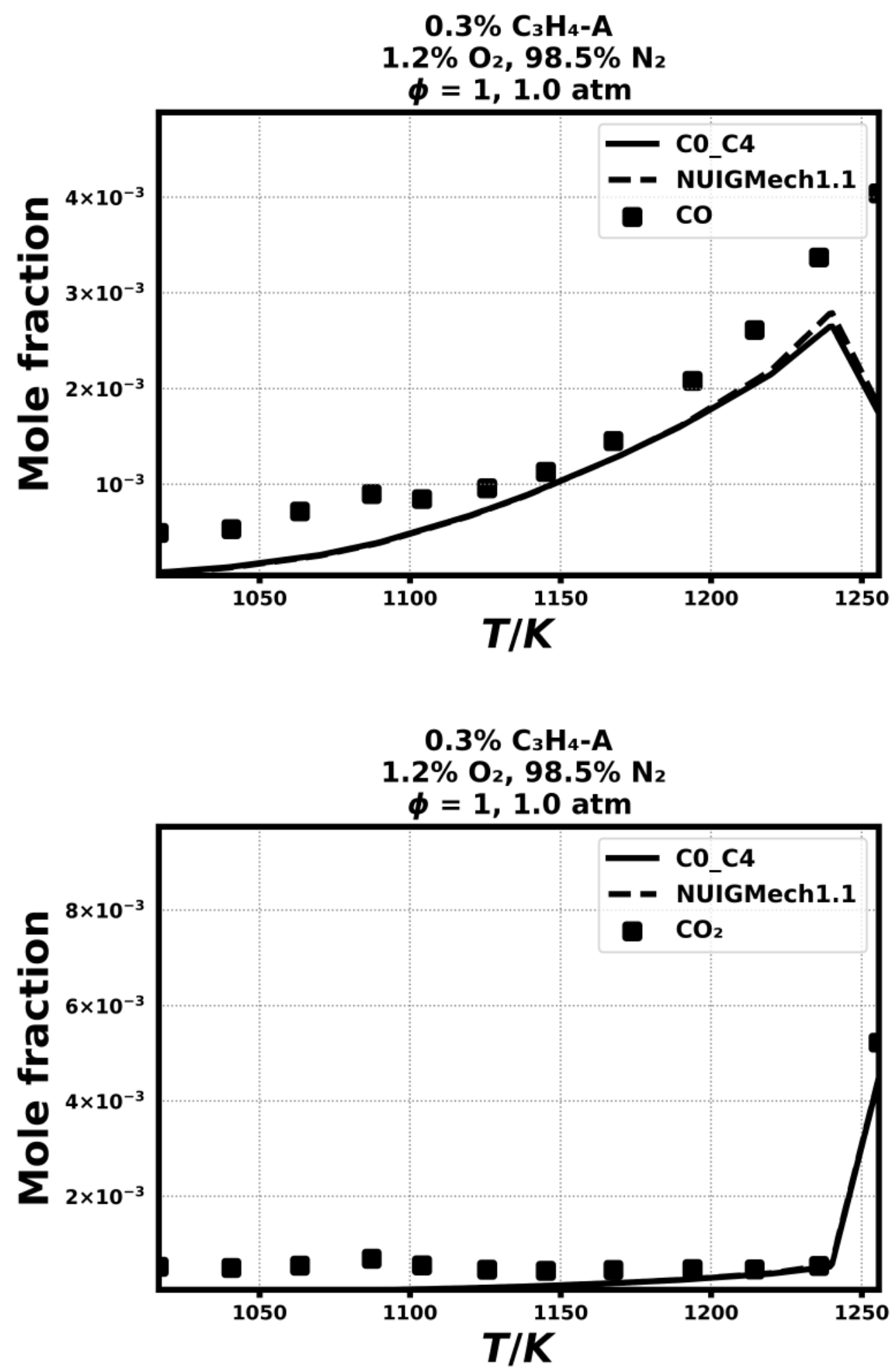

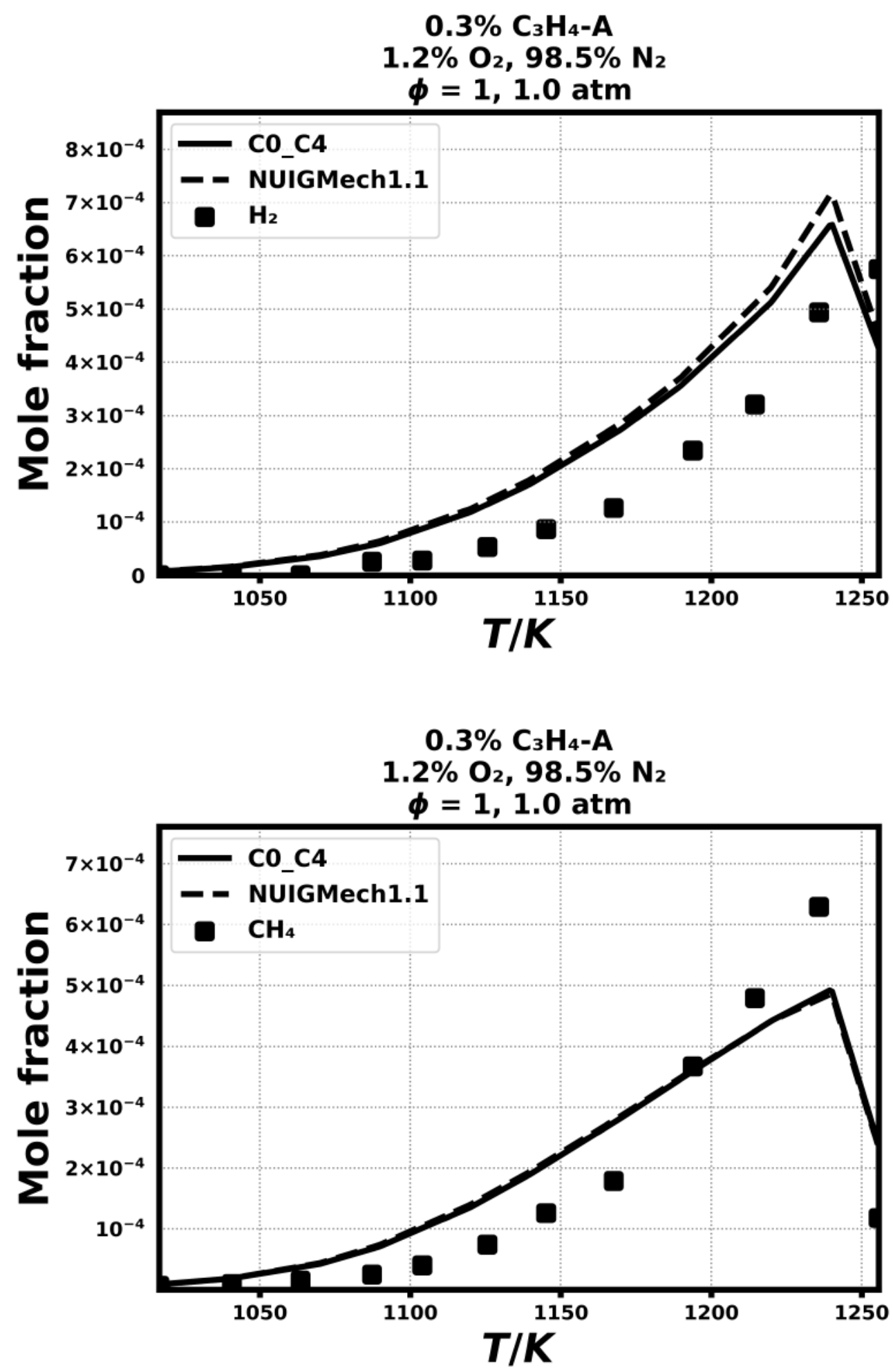

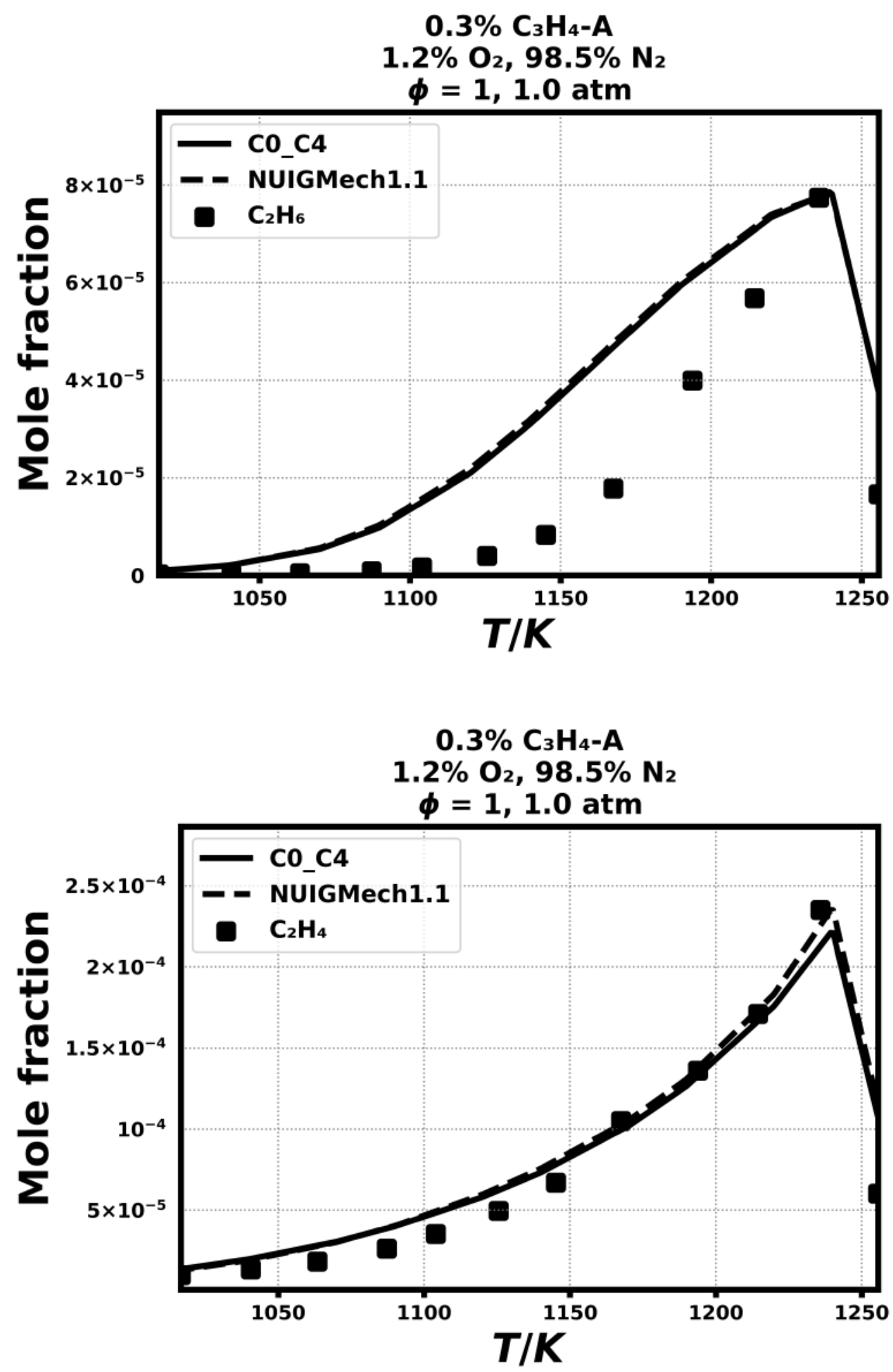

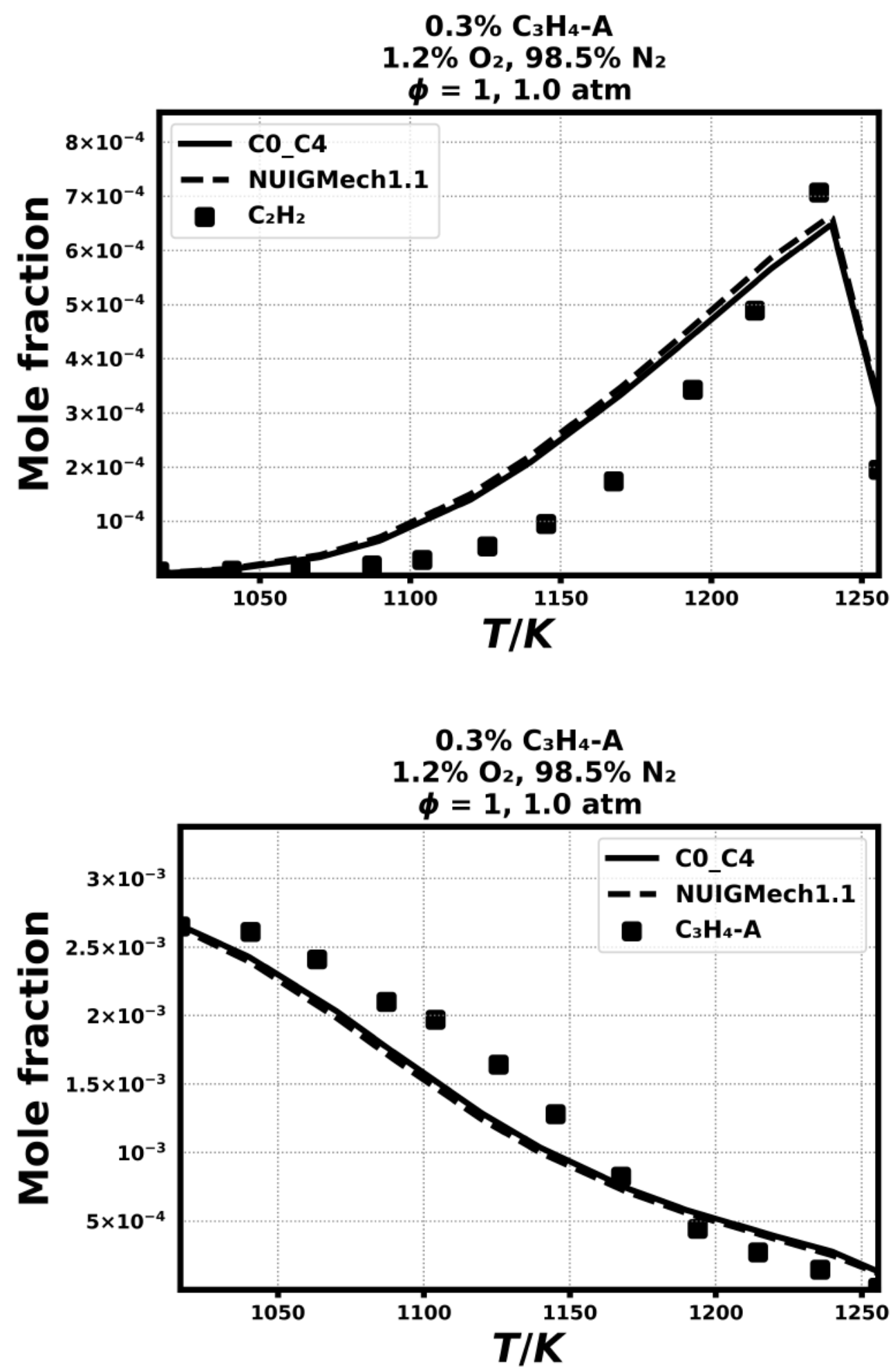

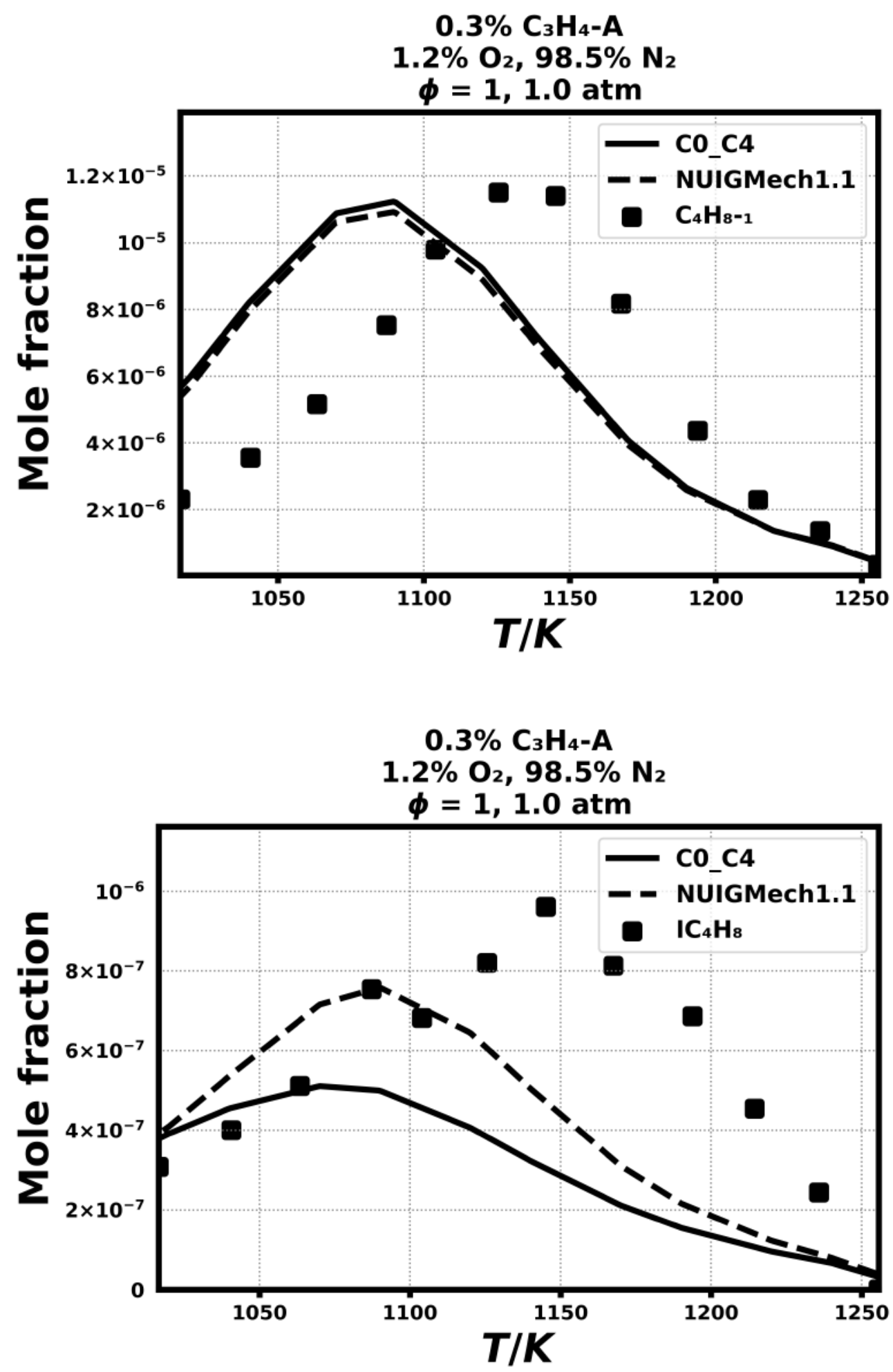

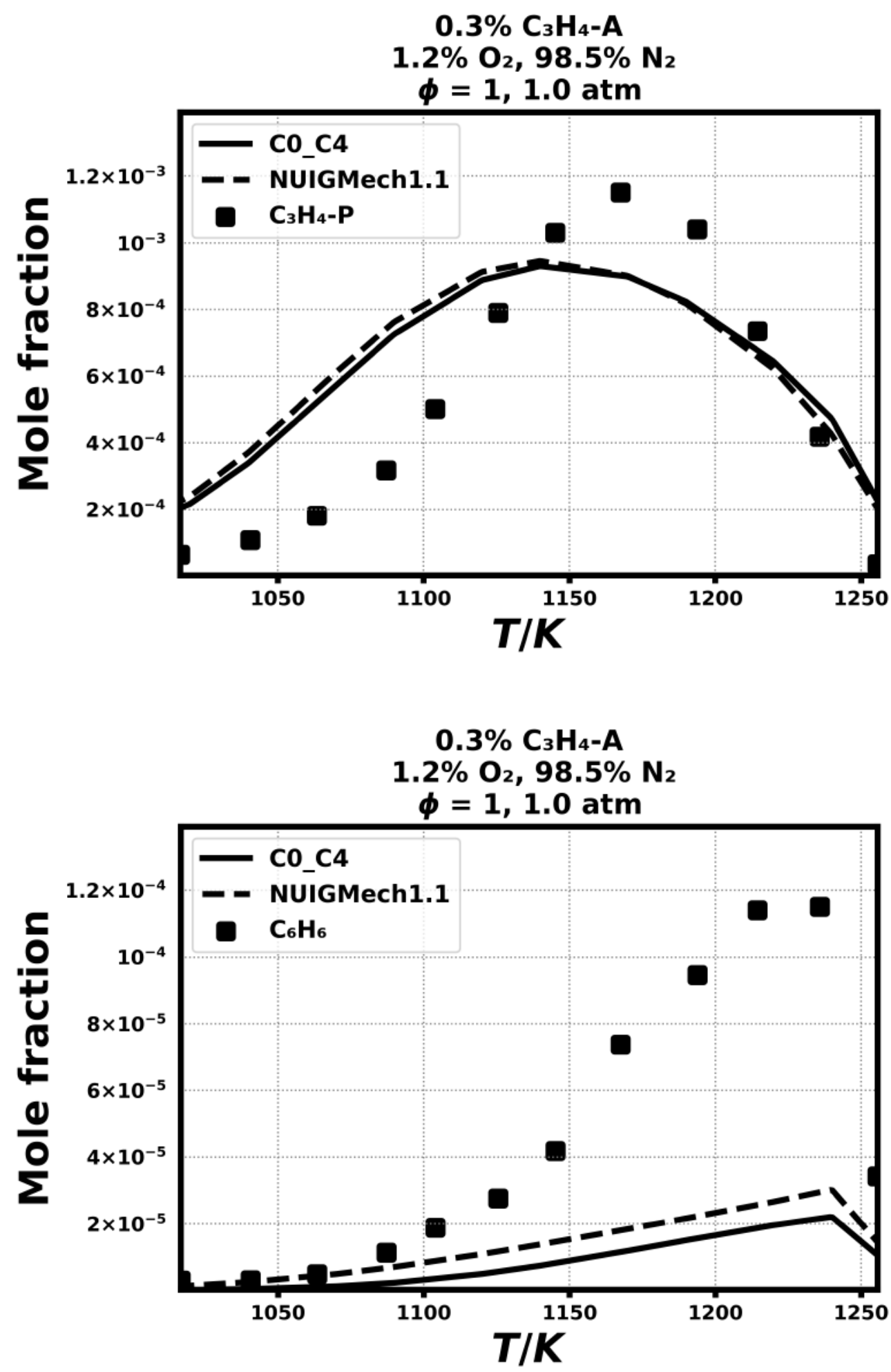

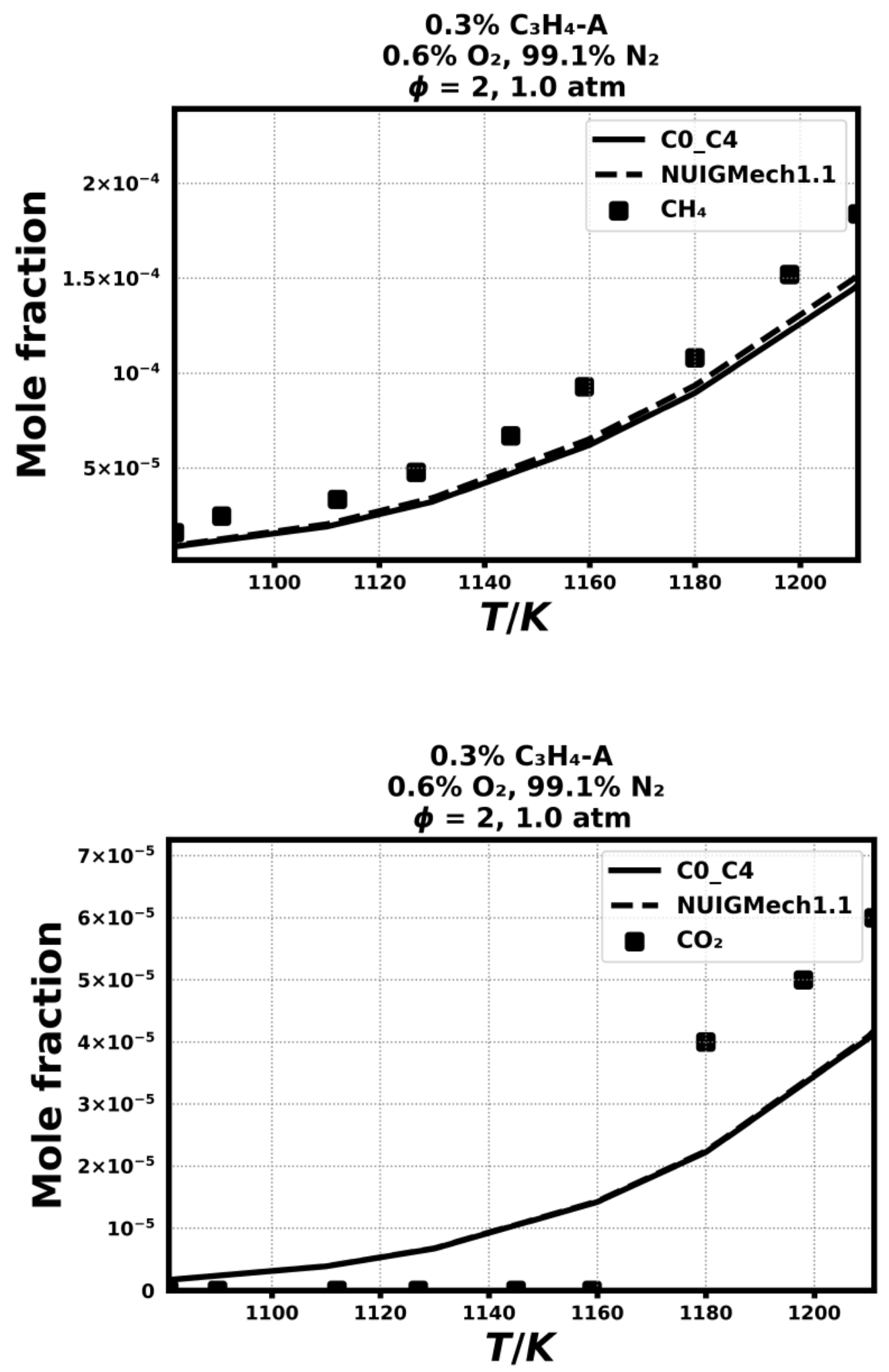

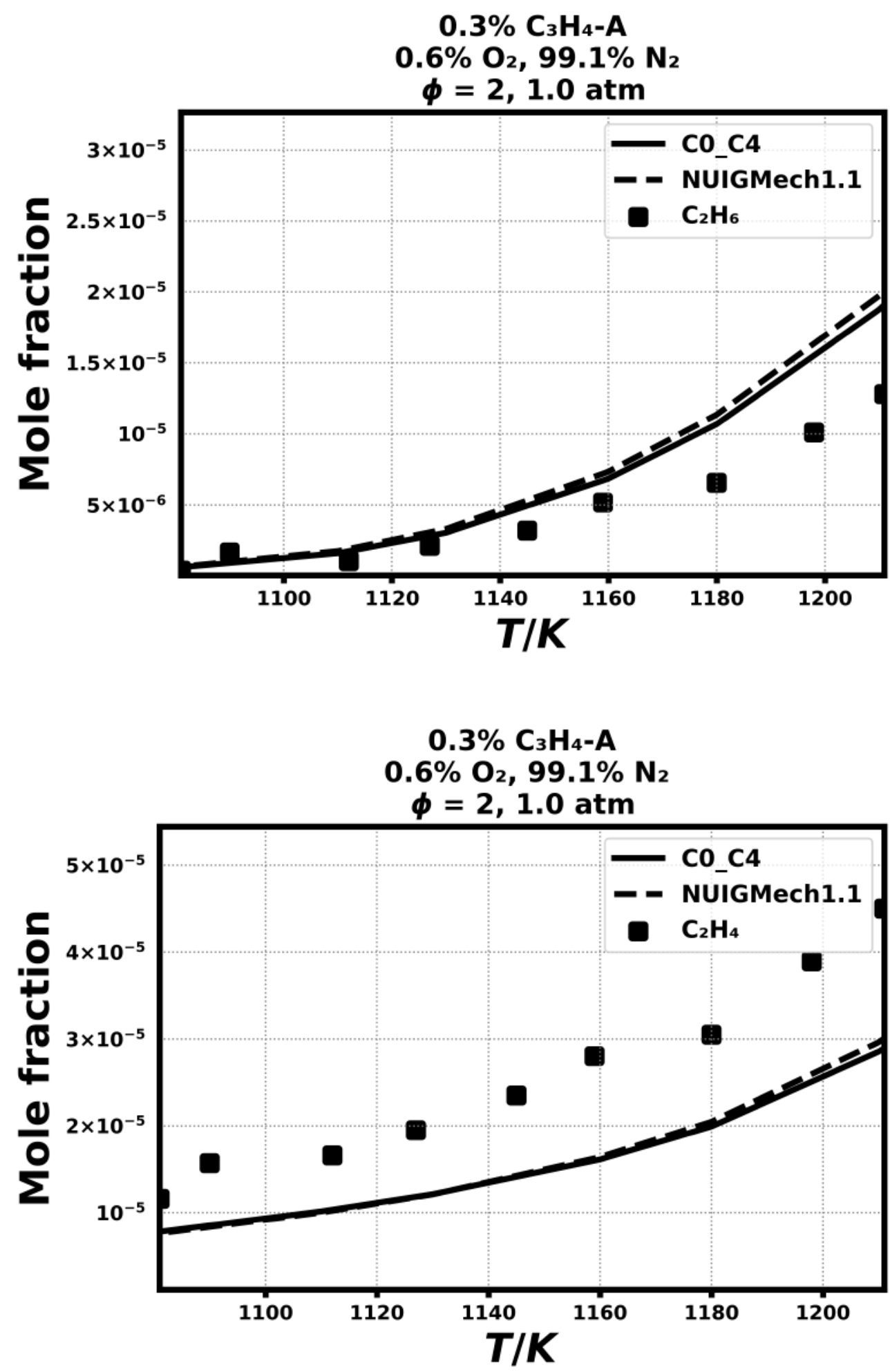

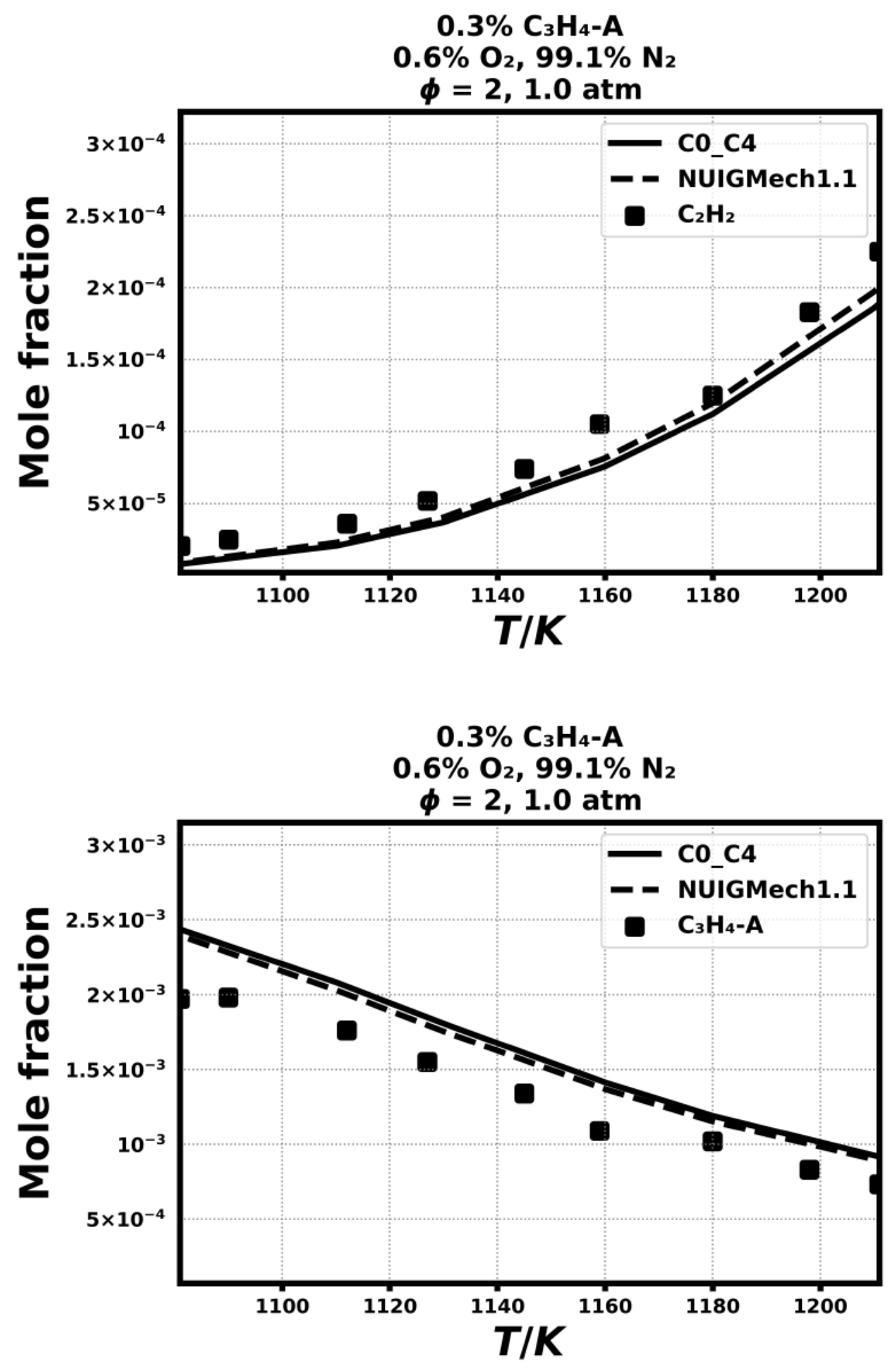

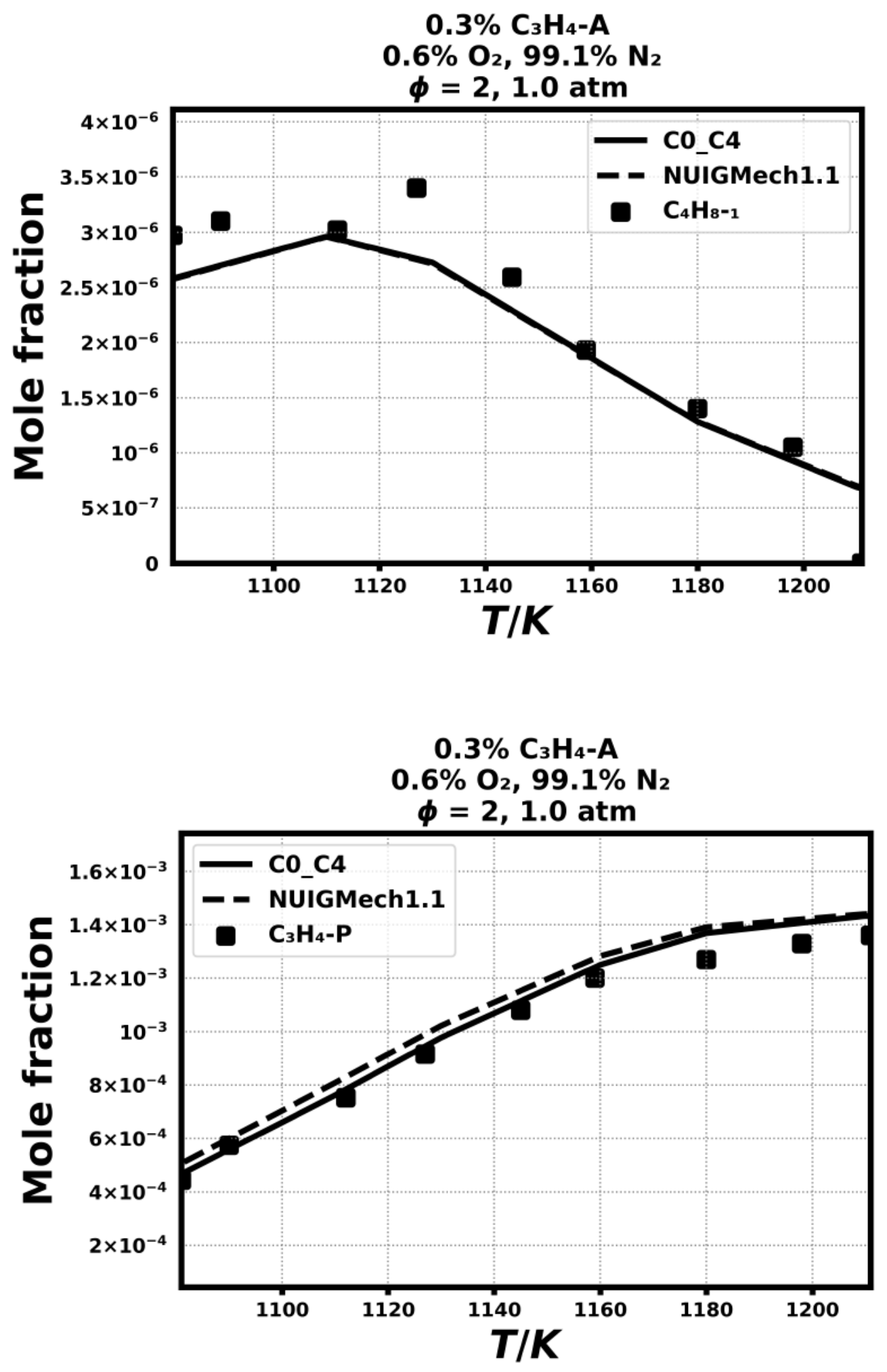

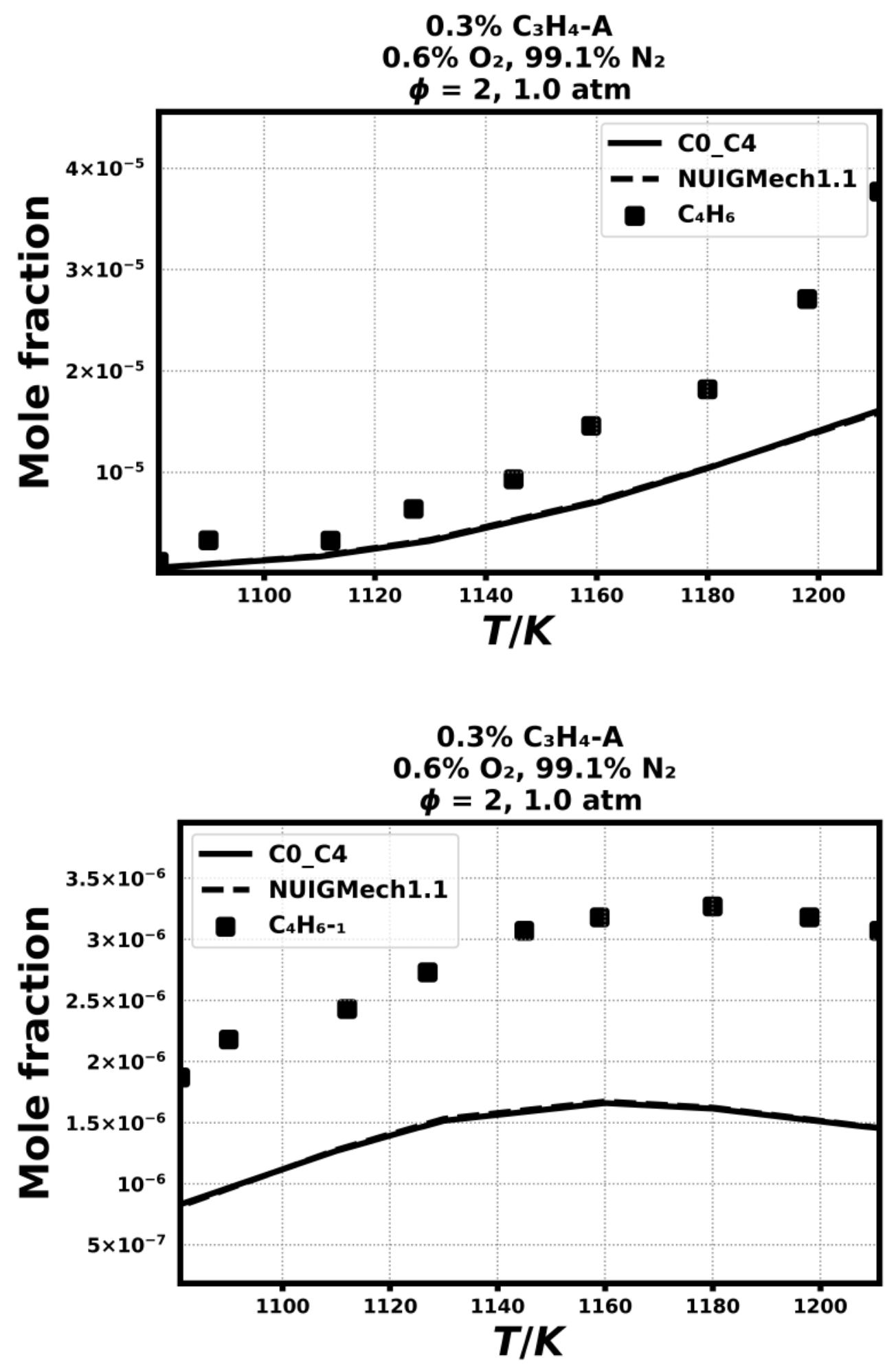
10.4) Curran, H., Simmie, J. M., Dagaut, P., Voisin, D., \& Cathonnet, M., In Symposium (International) on Combustion, 26 (1996, January) 613-620.
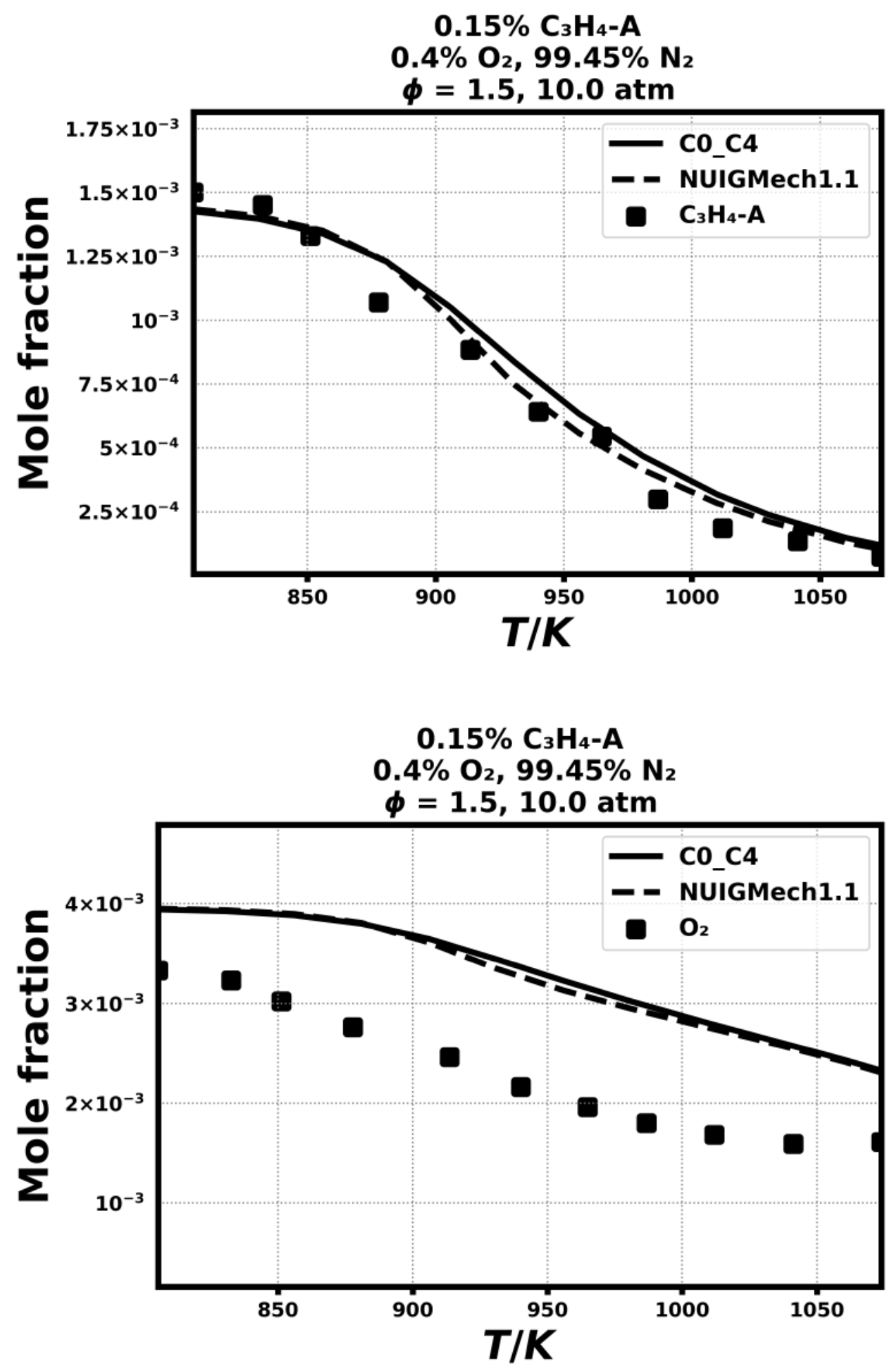

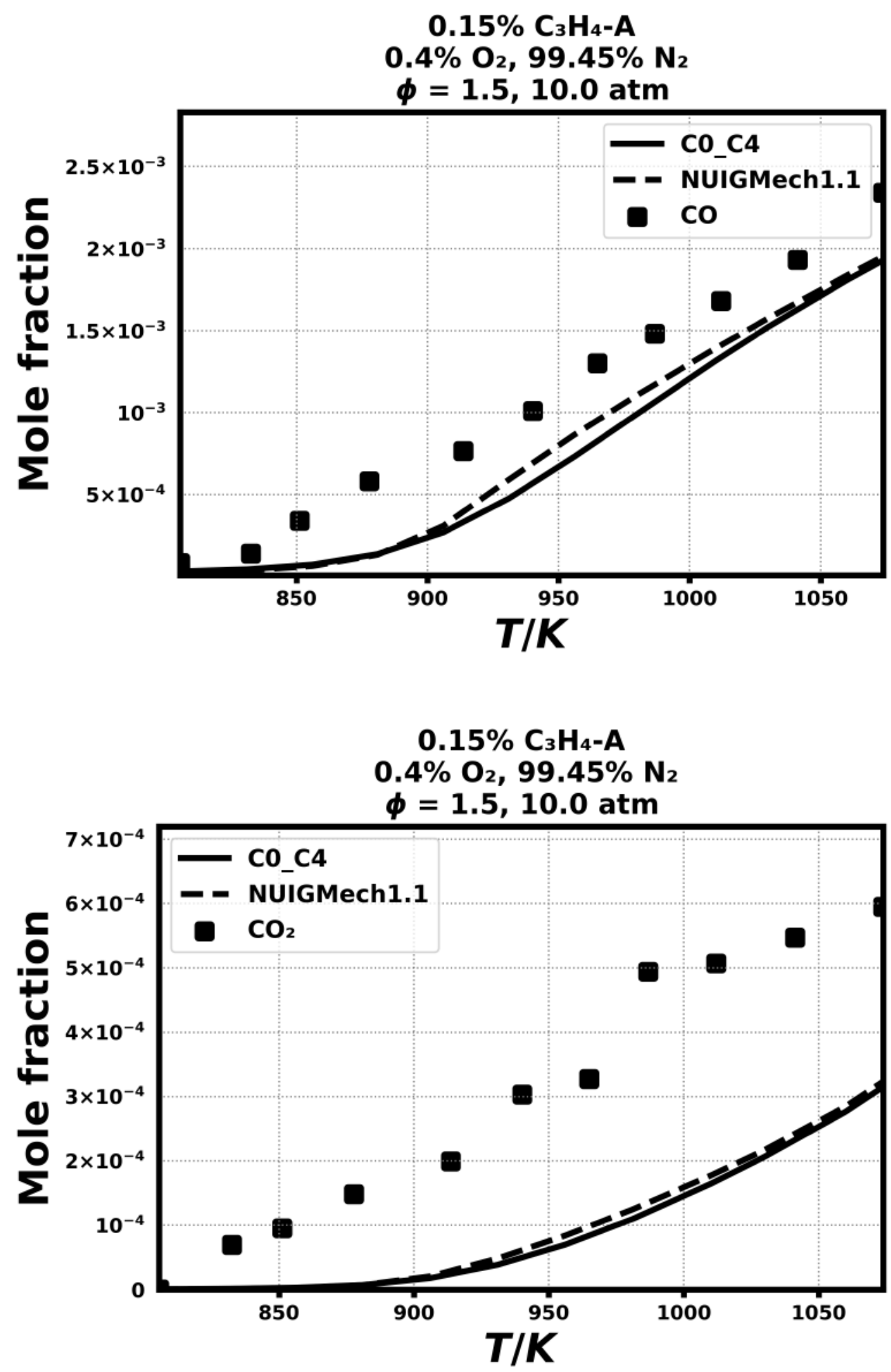

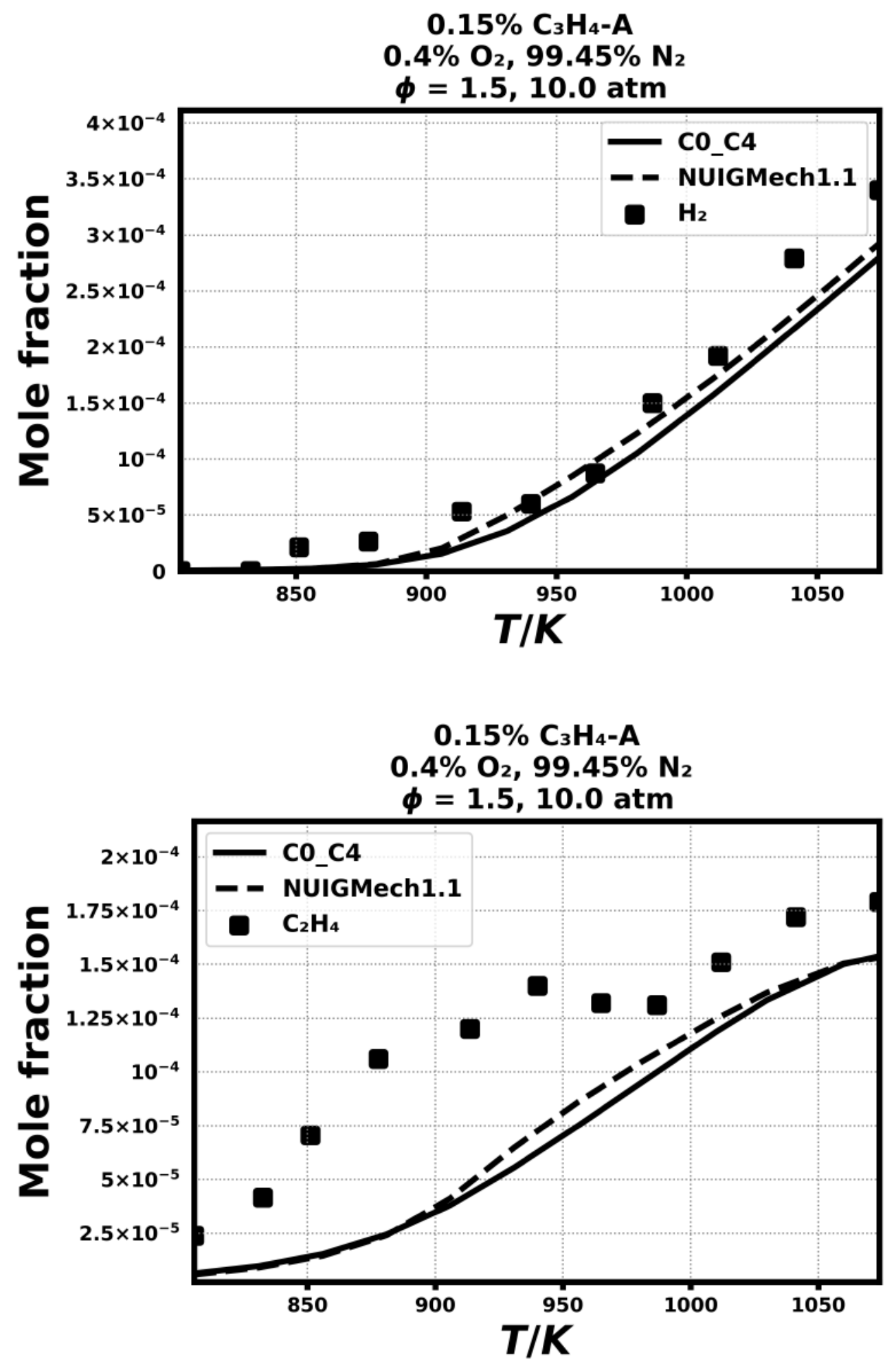

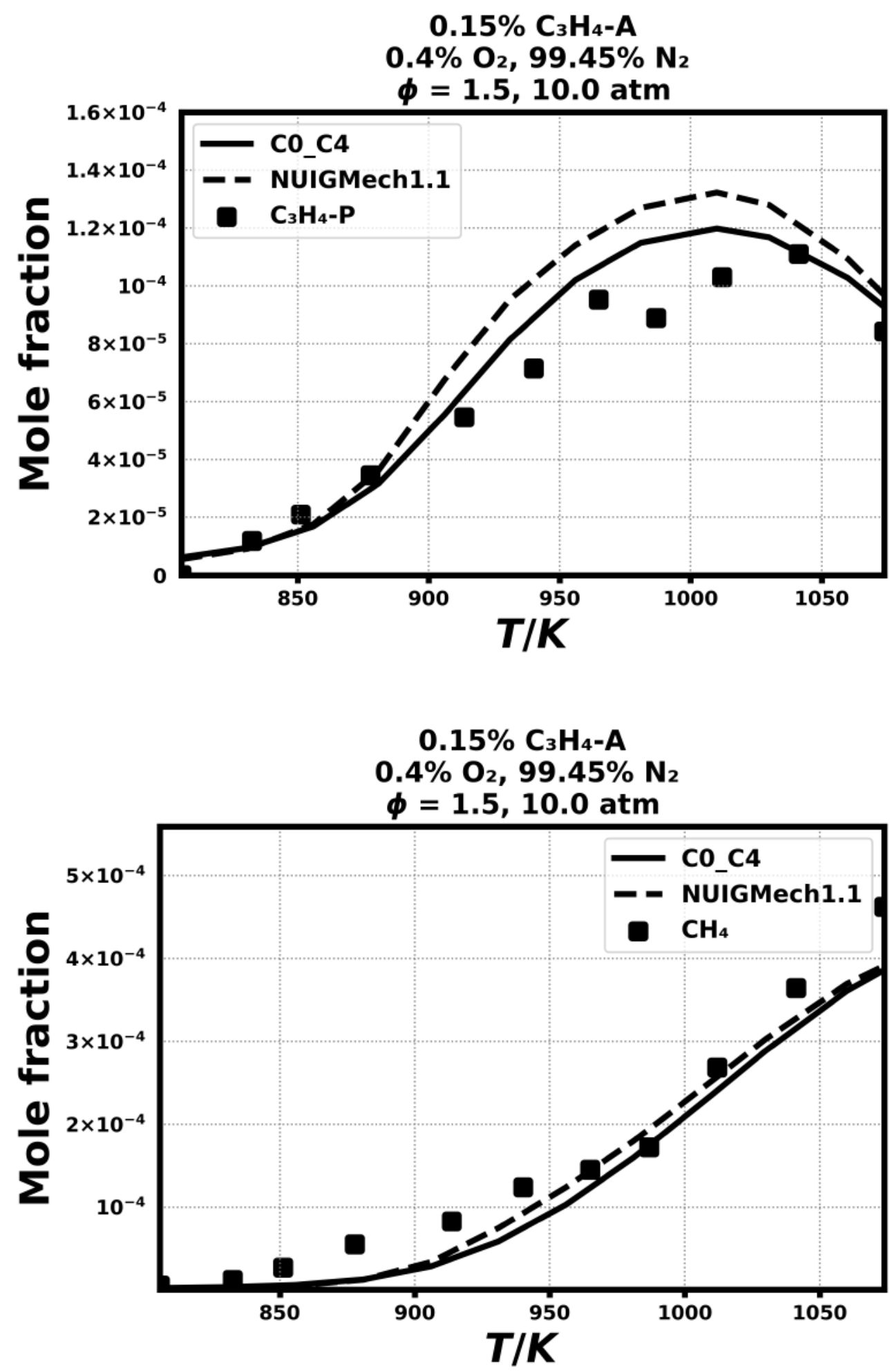

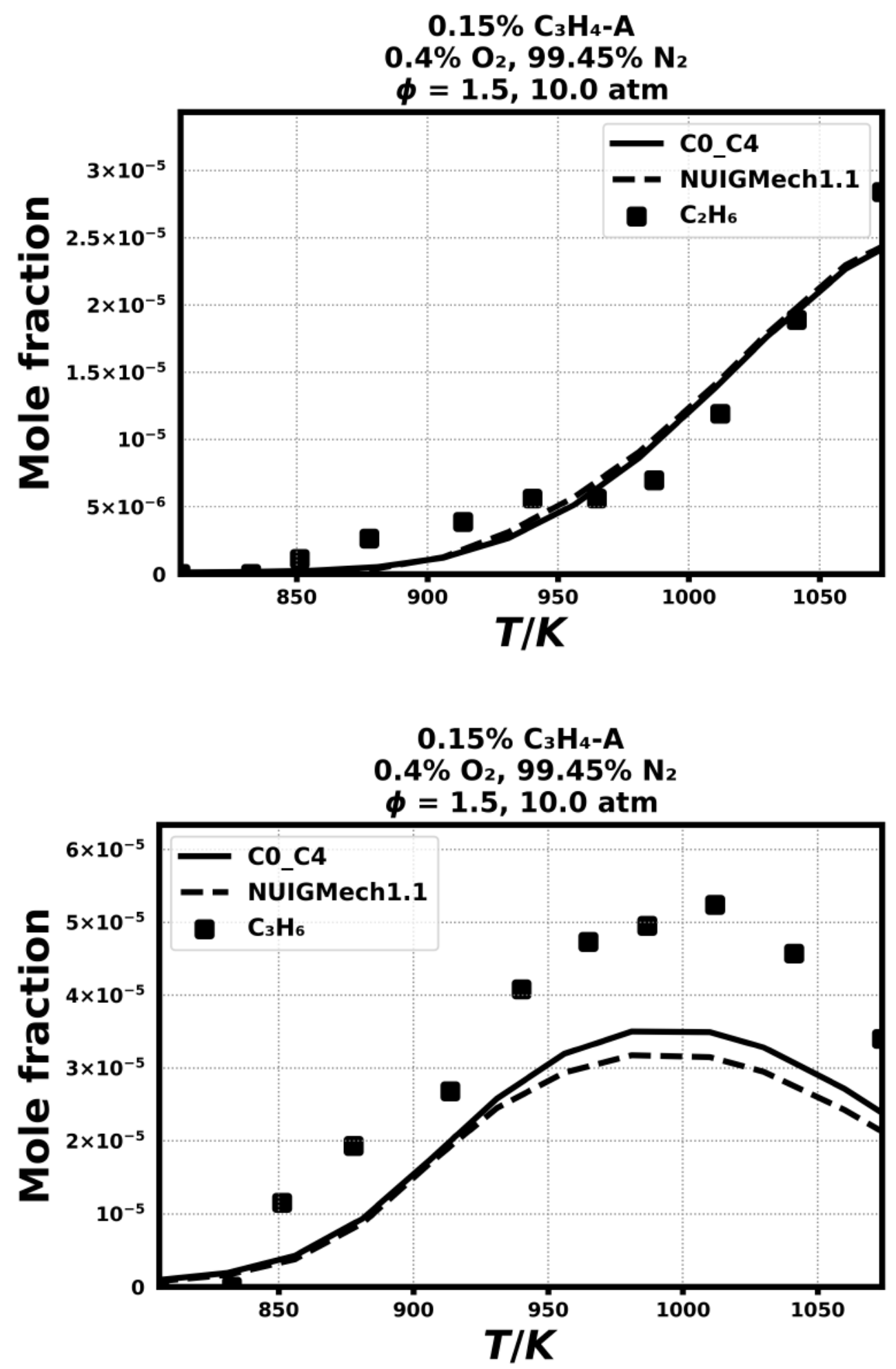


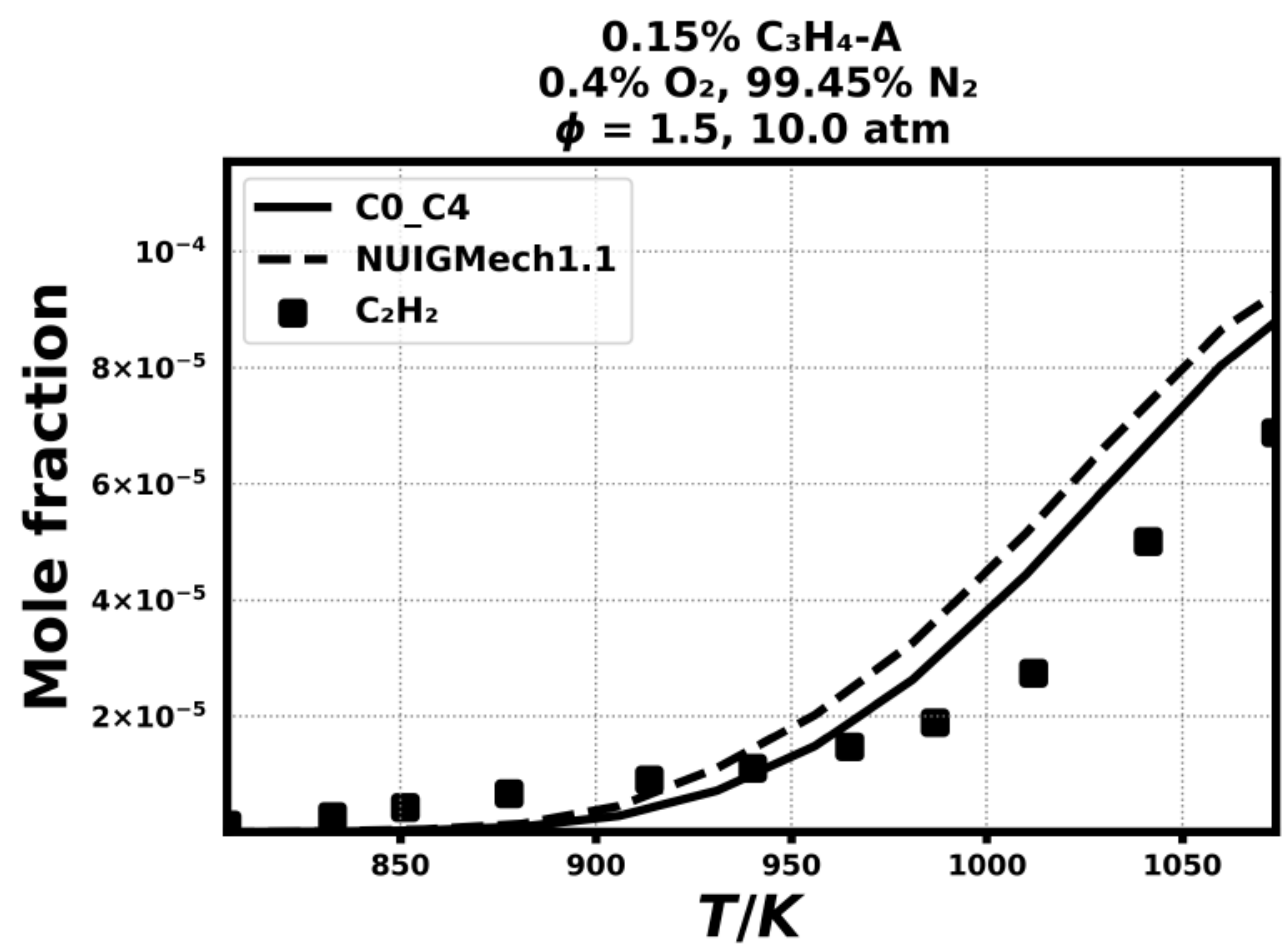

10.5) Faravelli, T., Goldaniga, A., Zappella, L., Ranzi, E., Dagaut, P., \& Cathonnet, M. 28 (2) (2000) 2601-2608.

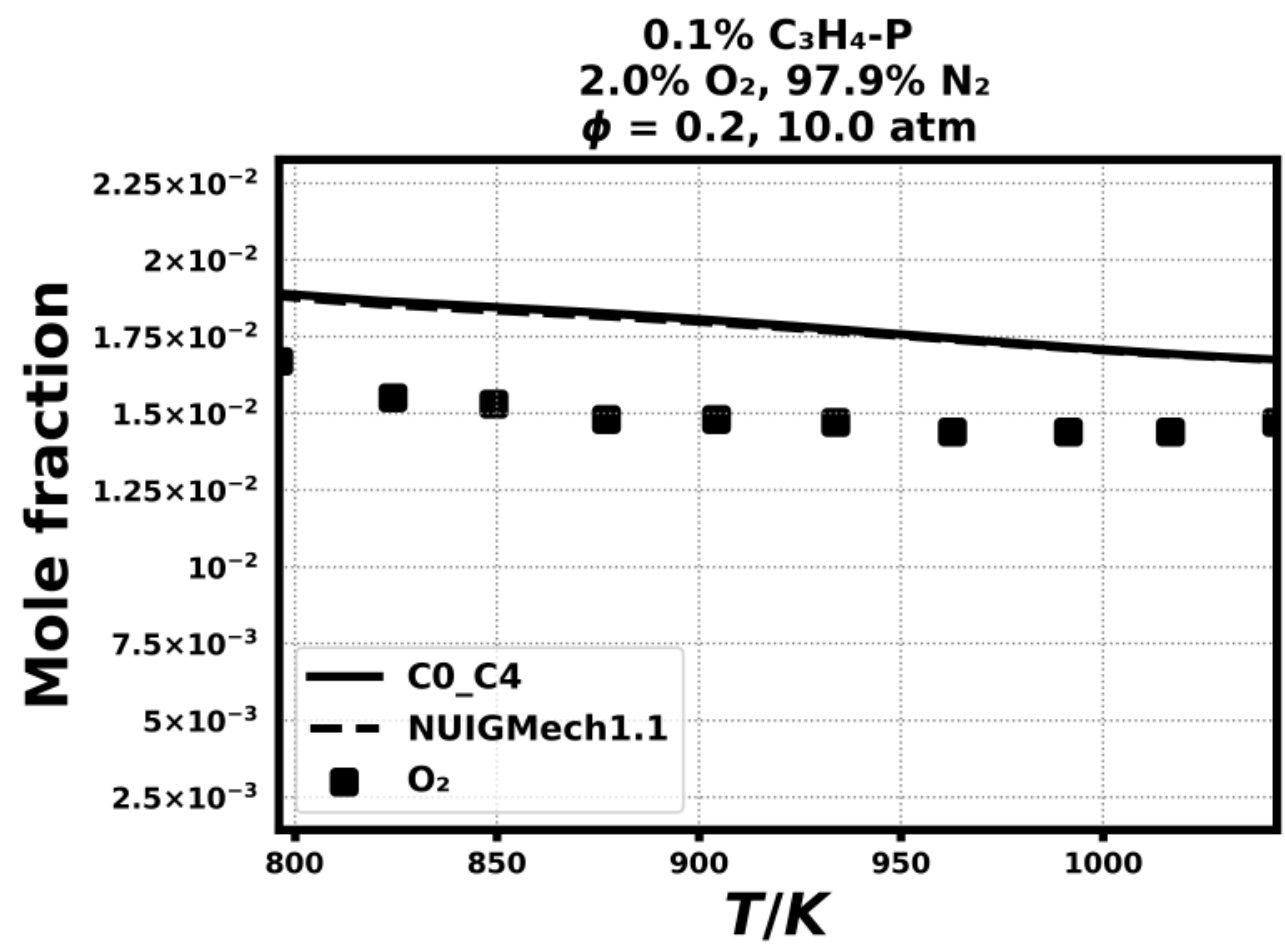



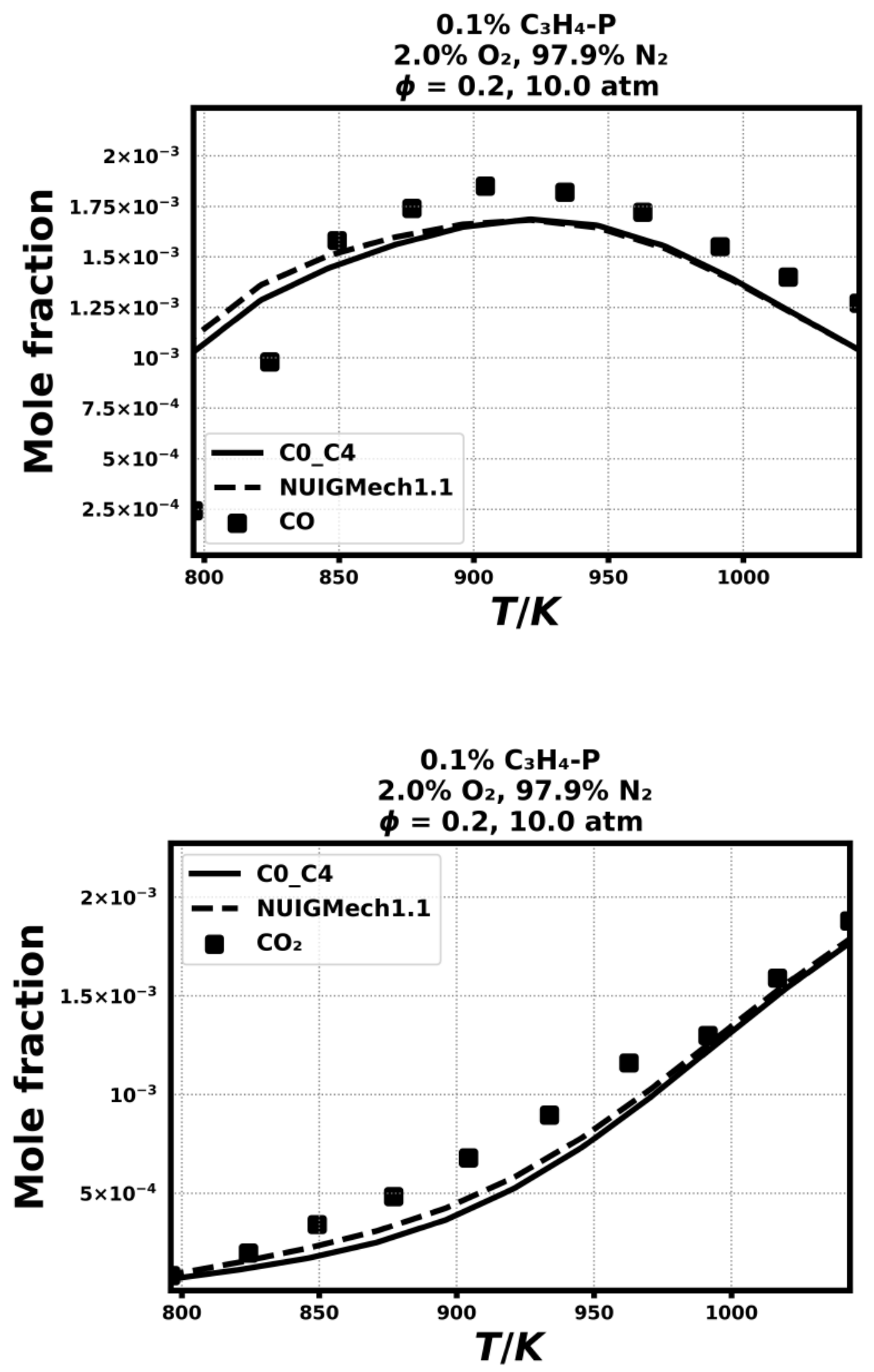

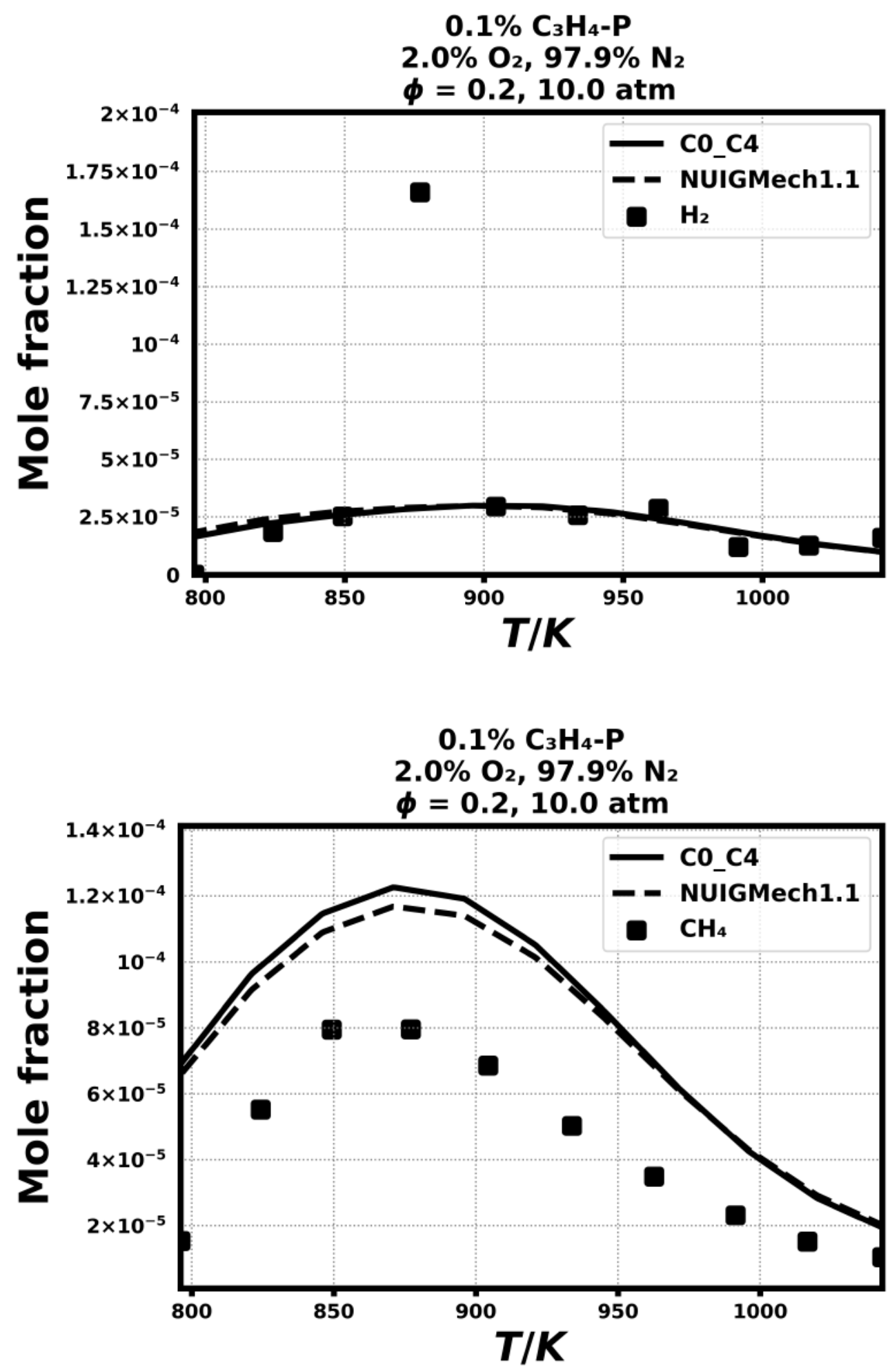

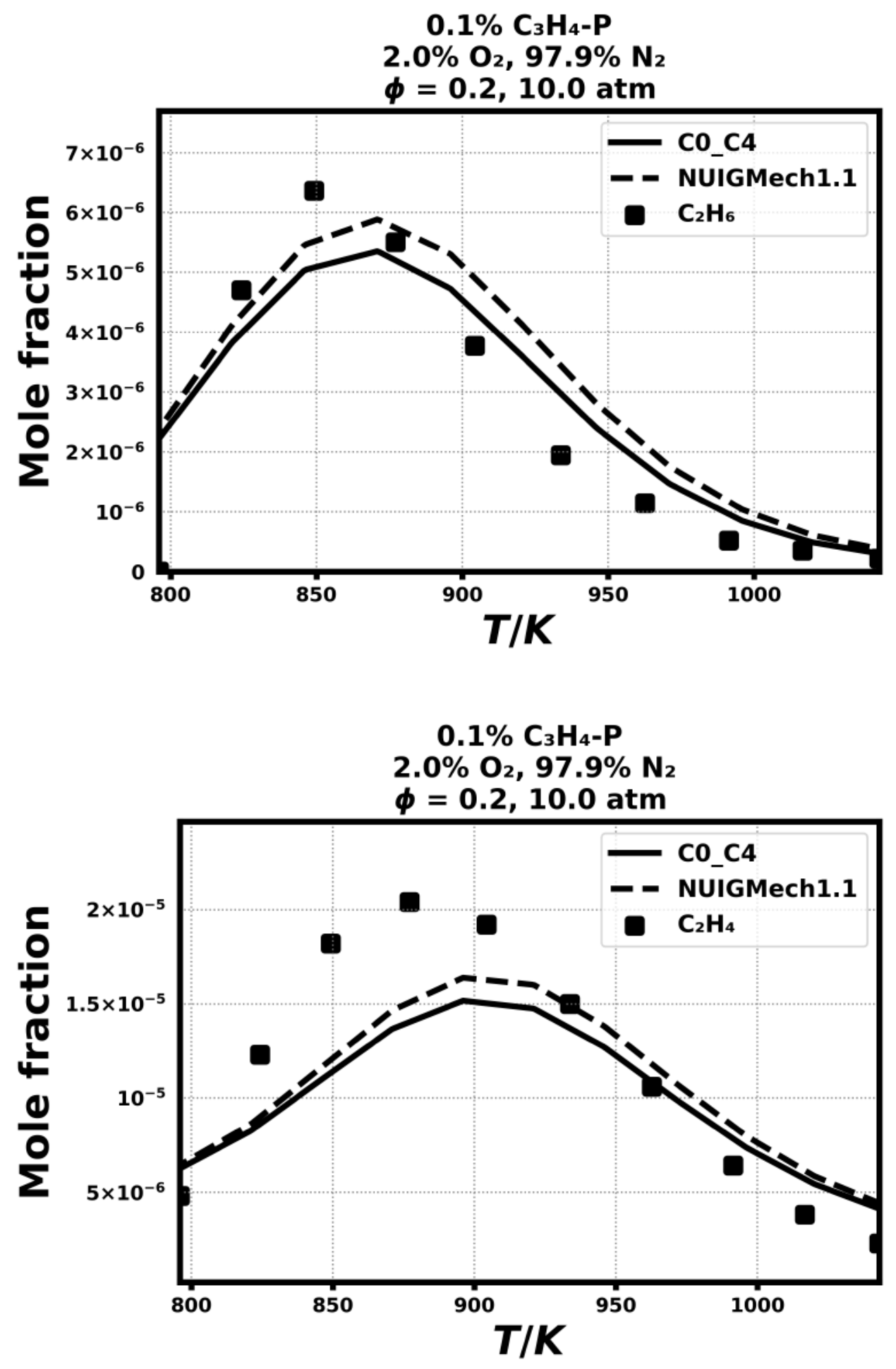

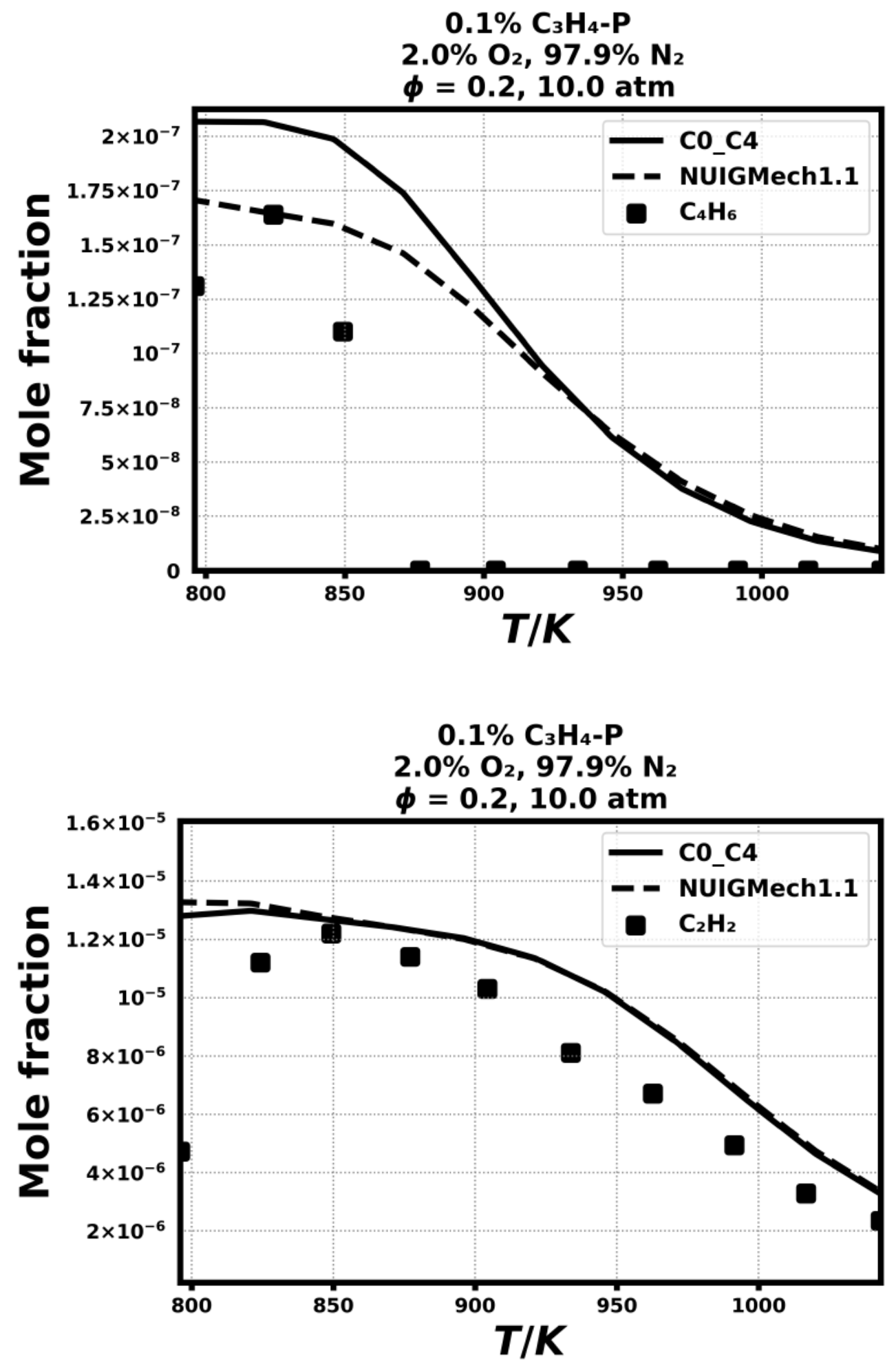

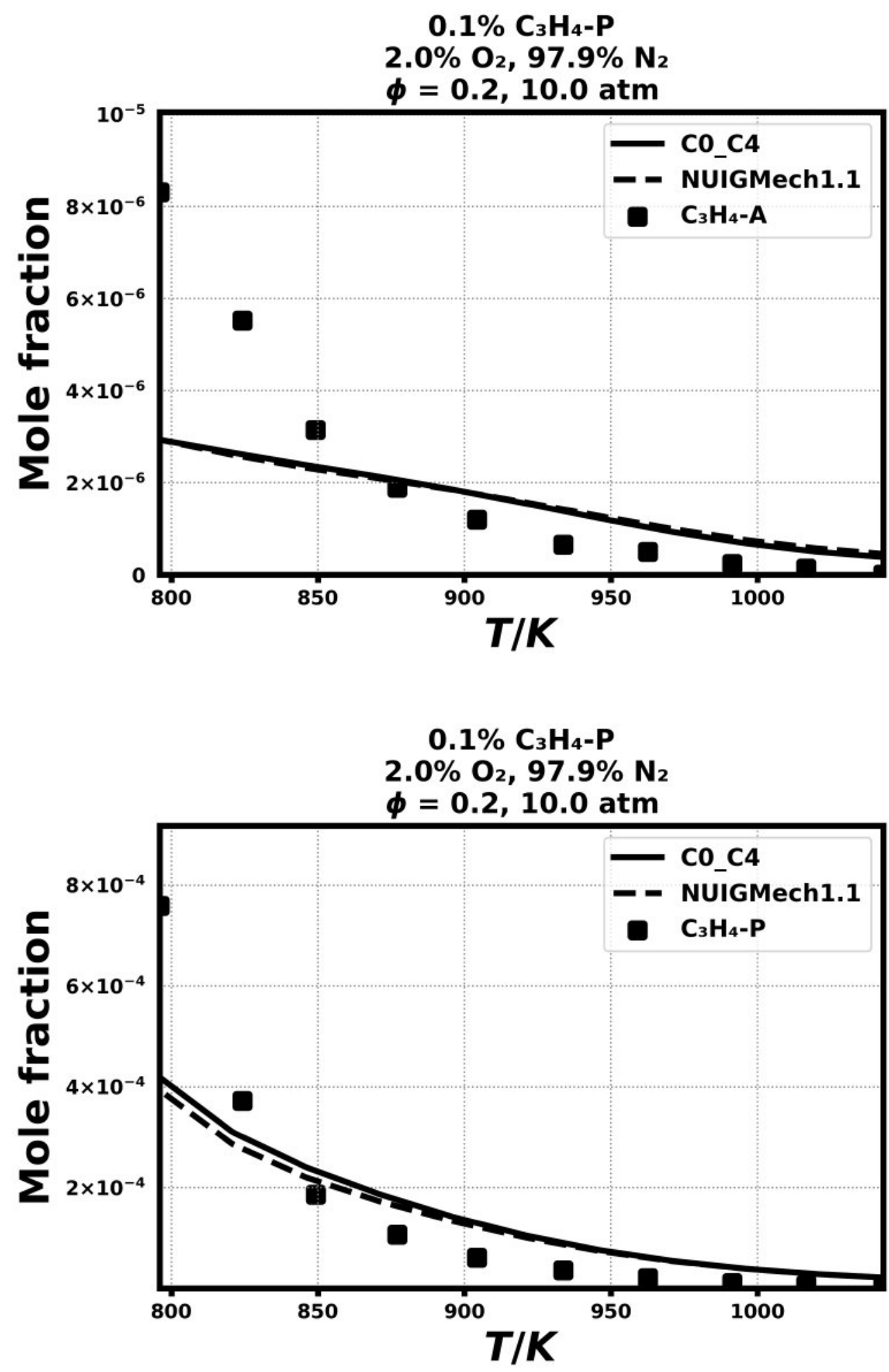

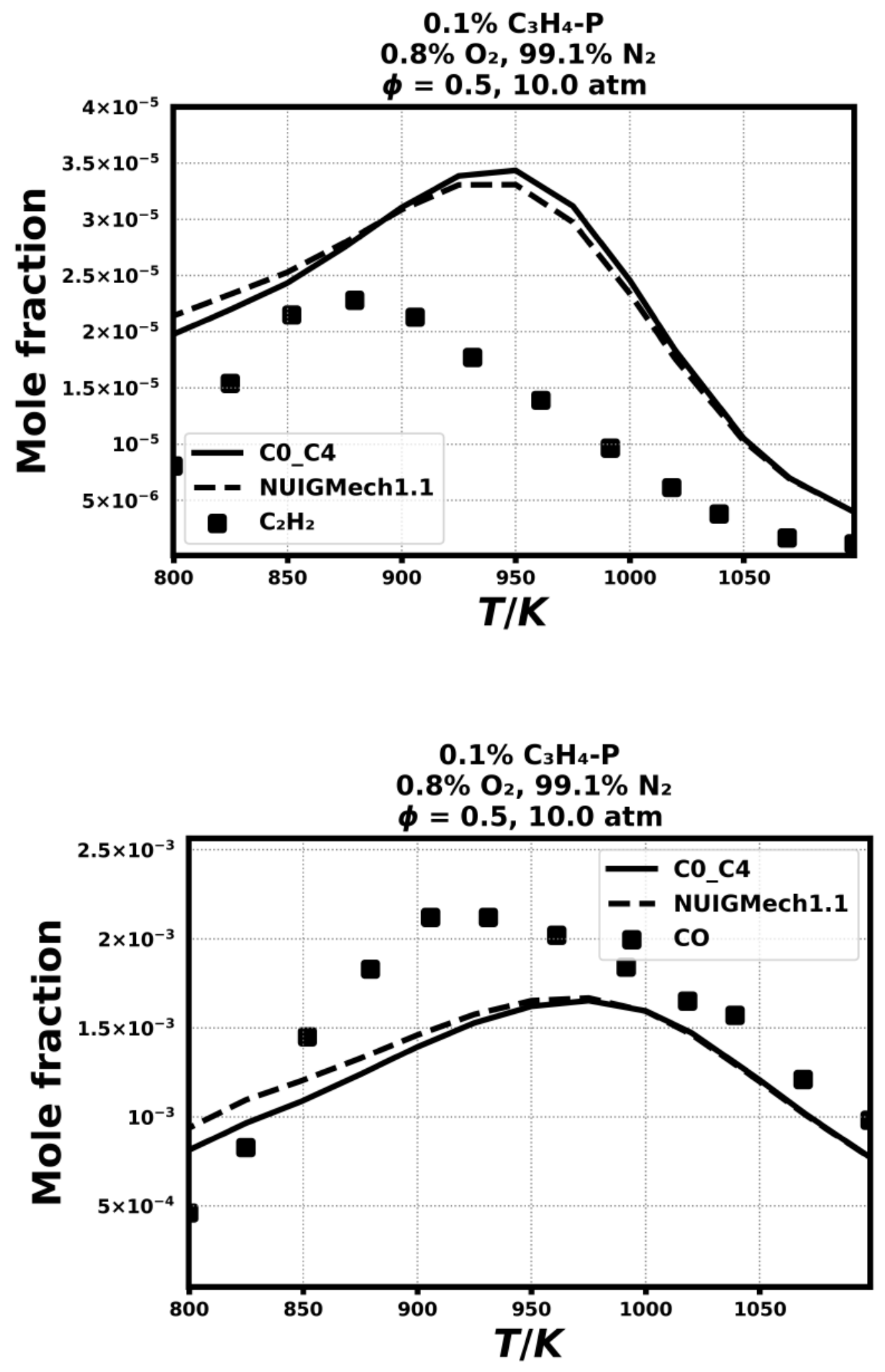

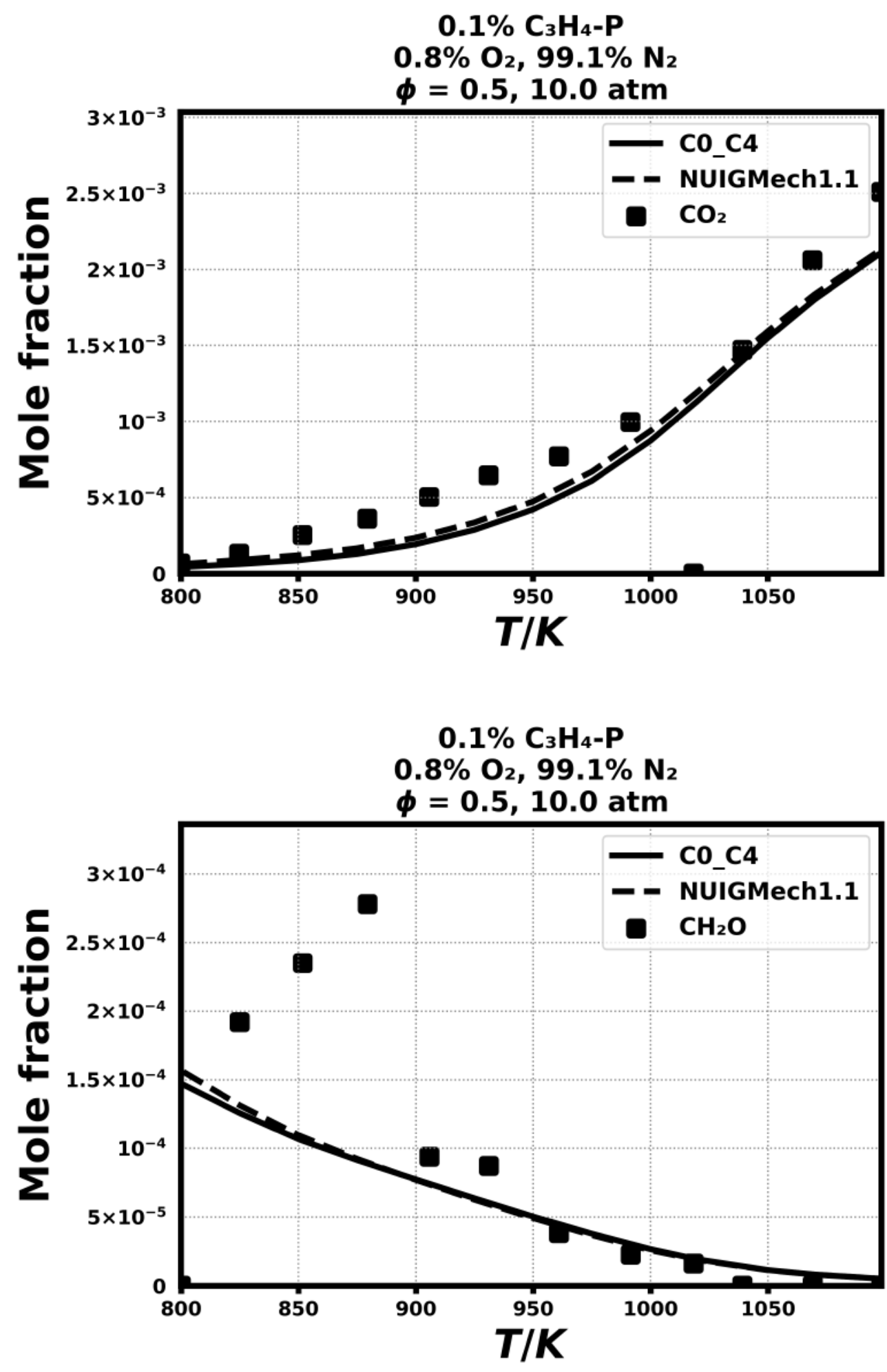

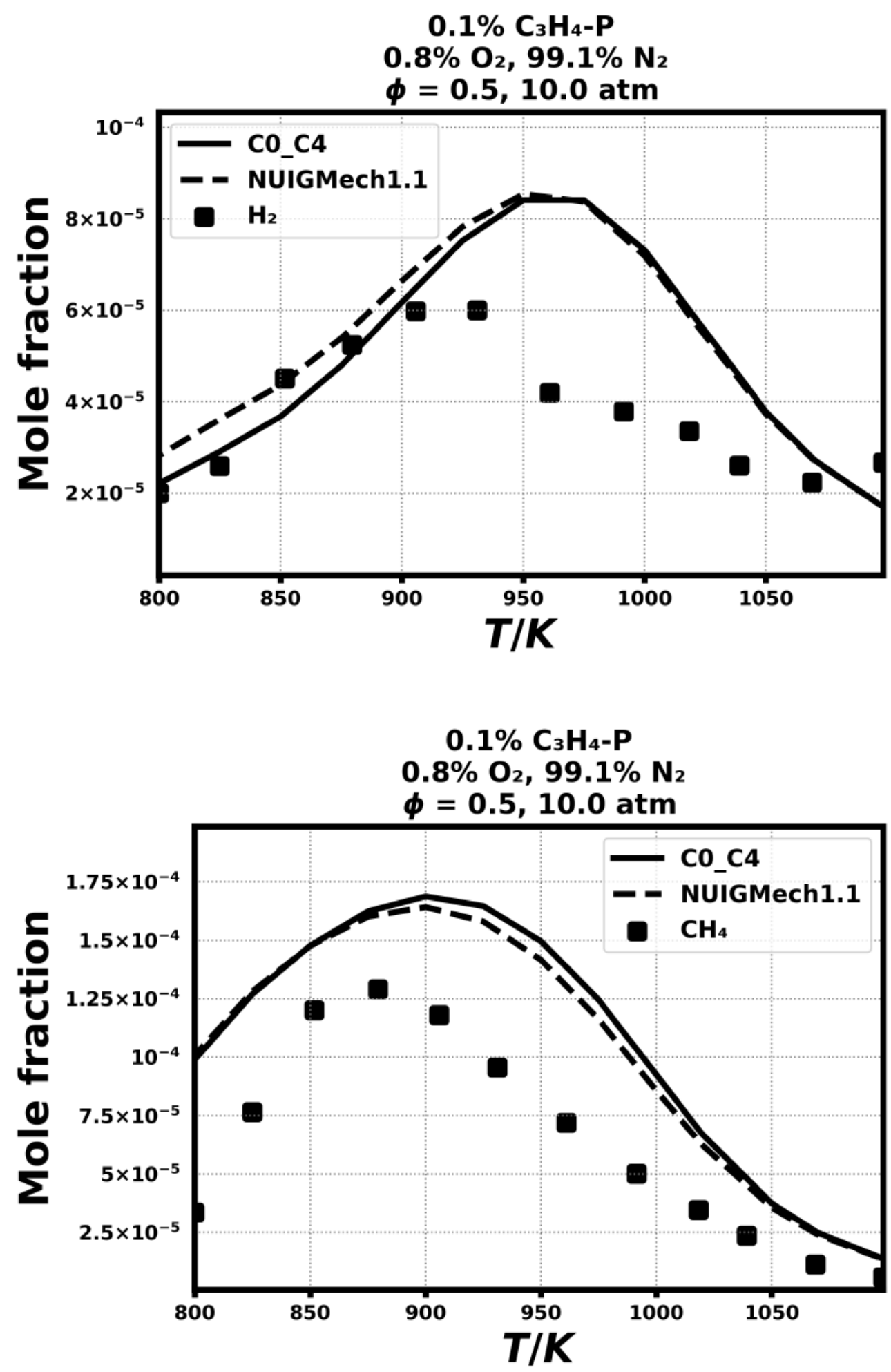

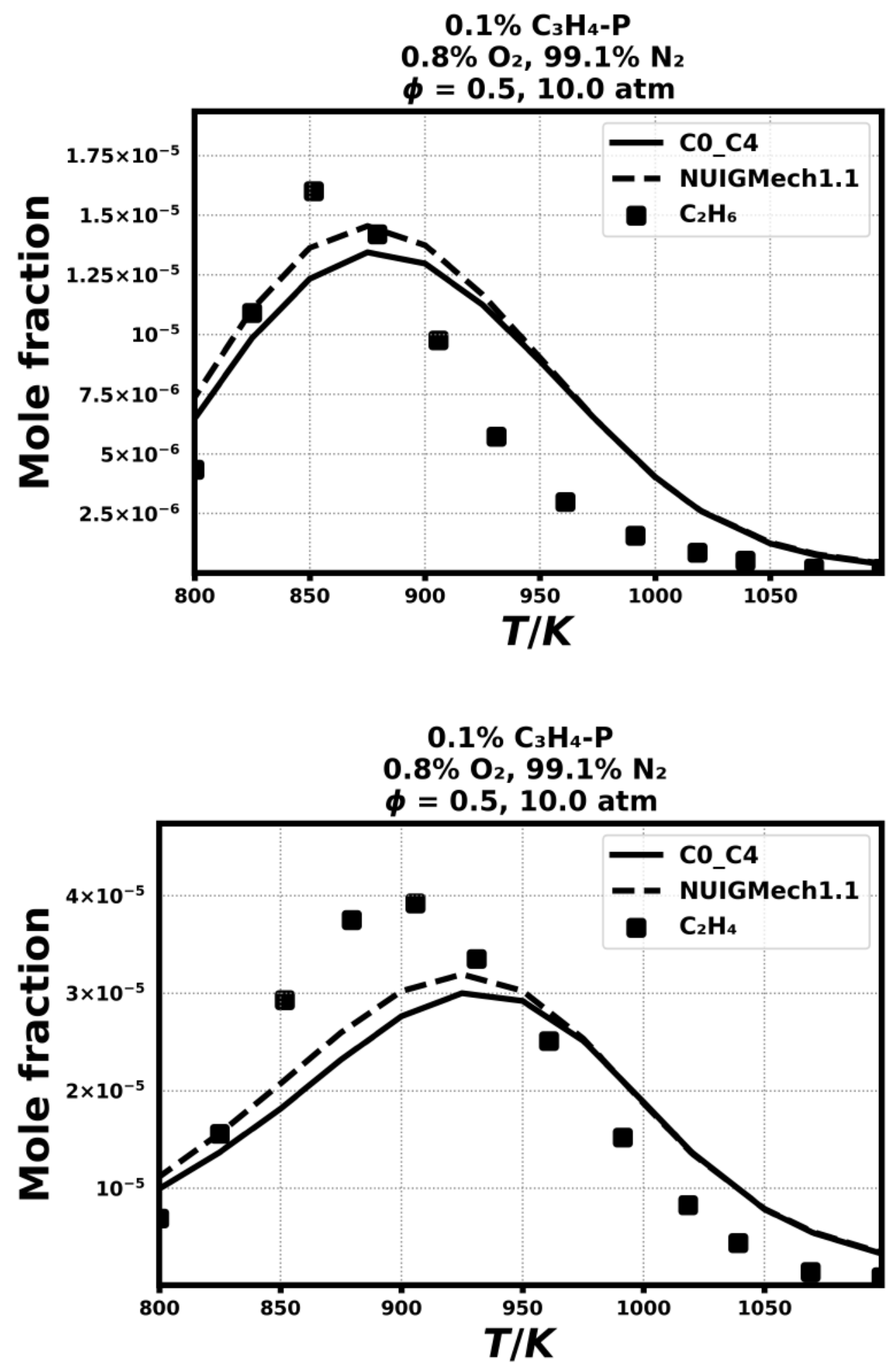

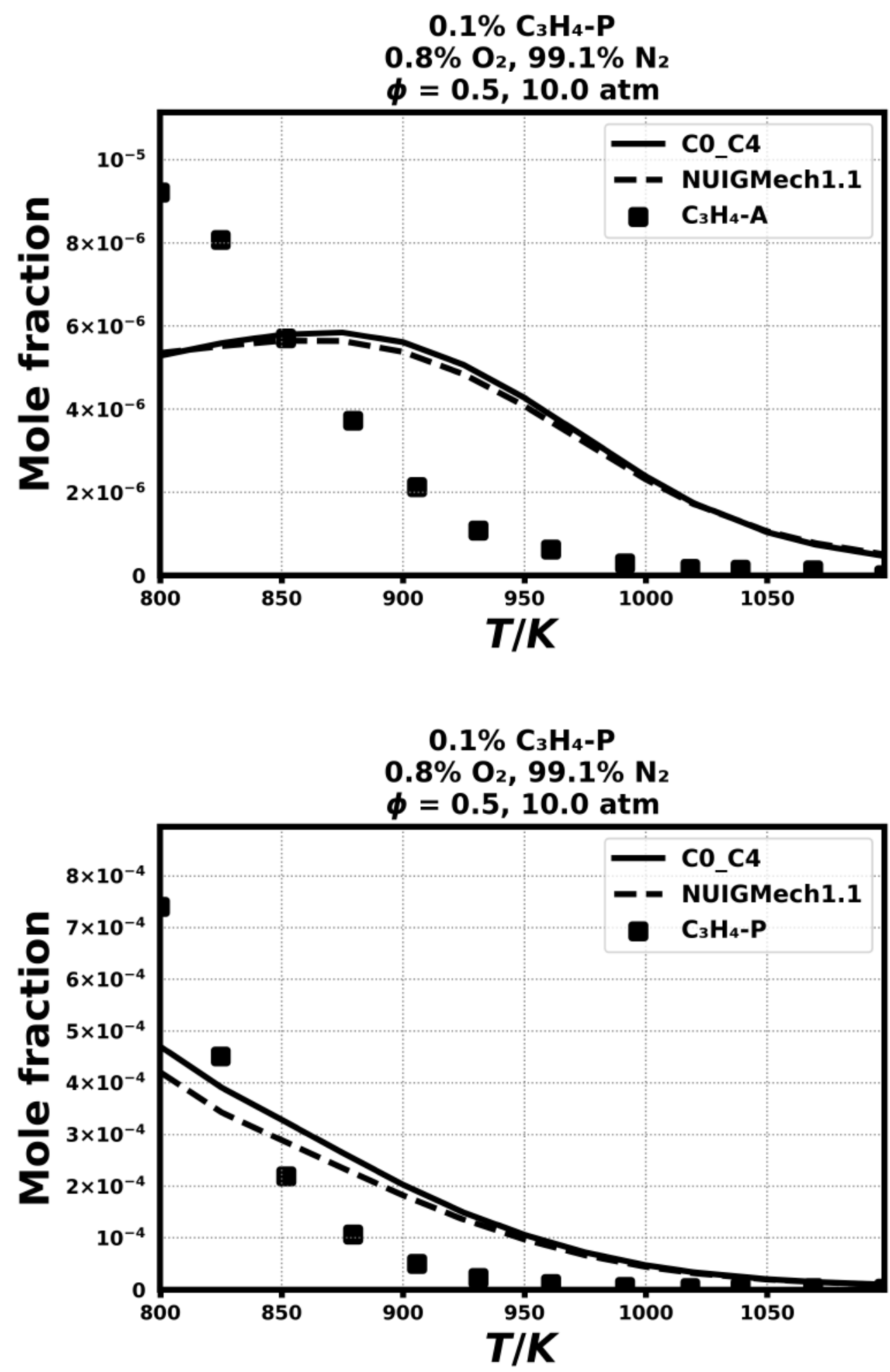

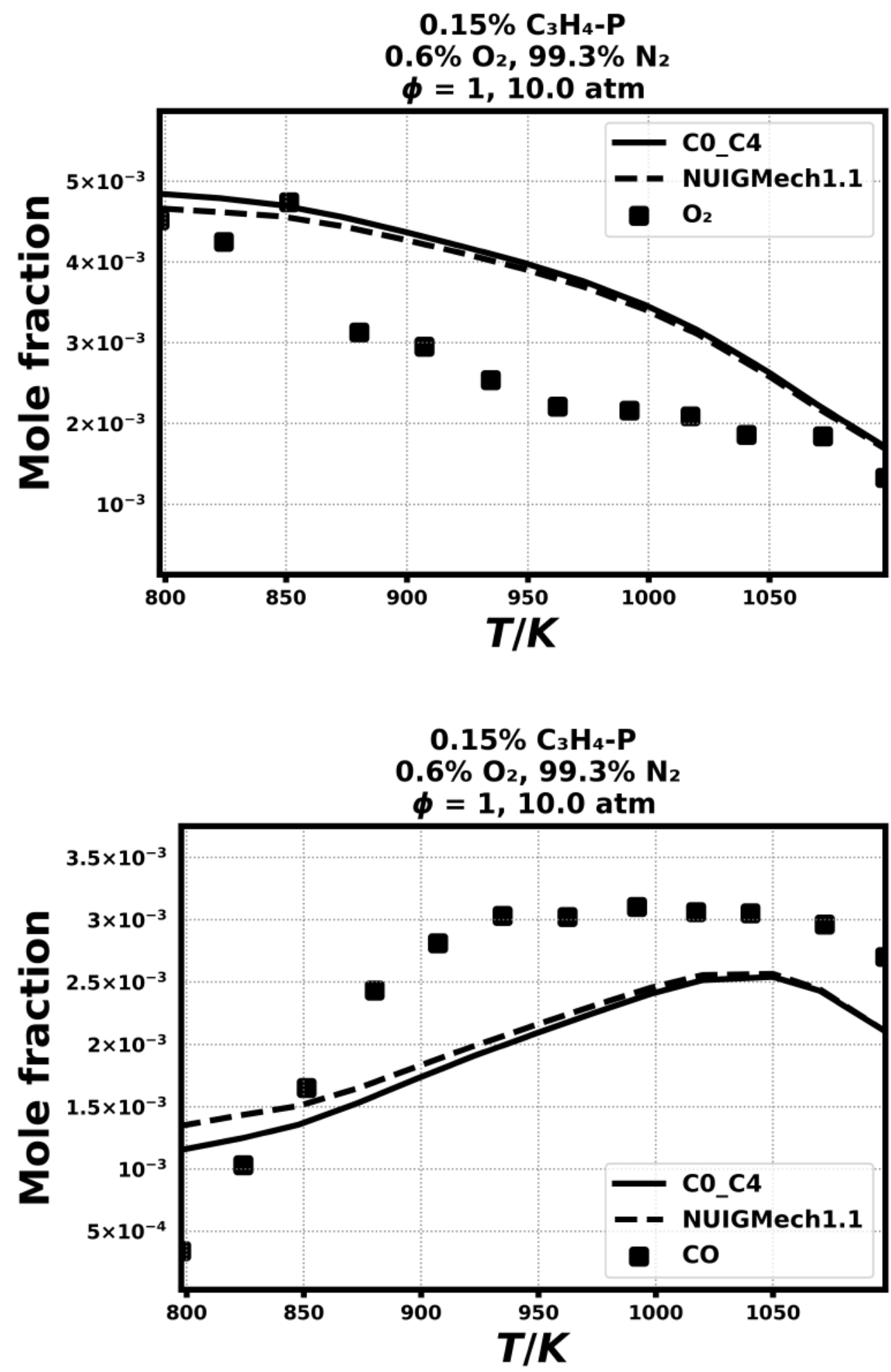

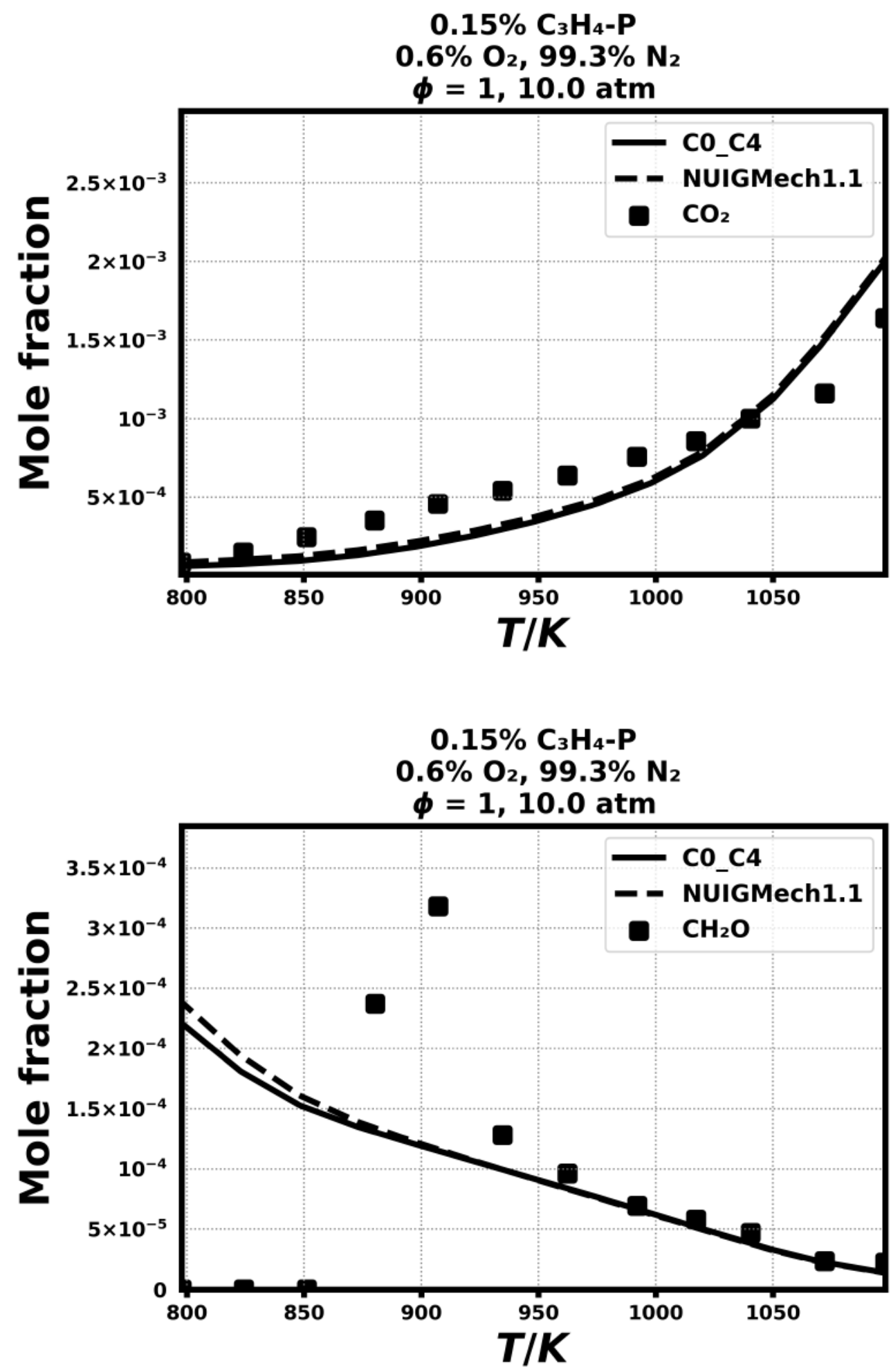

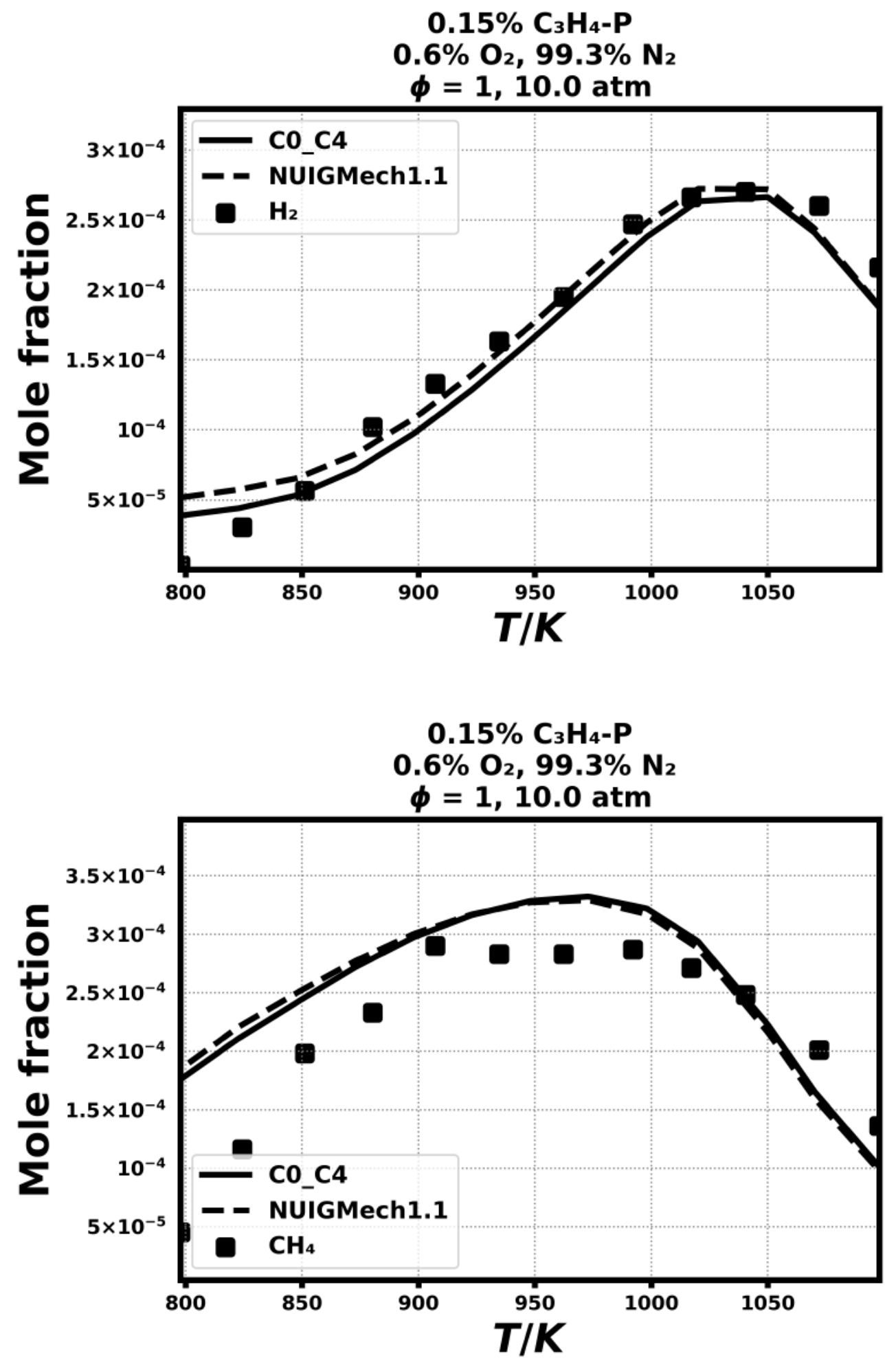

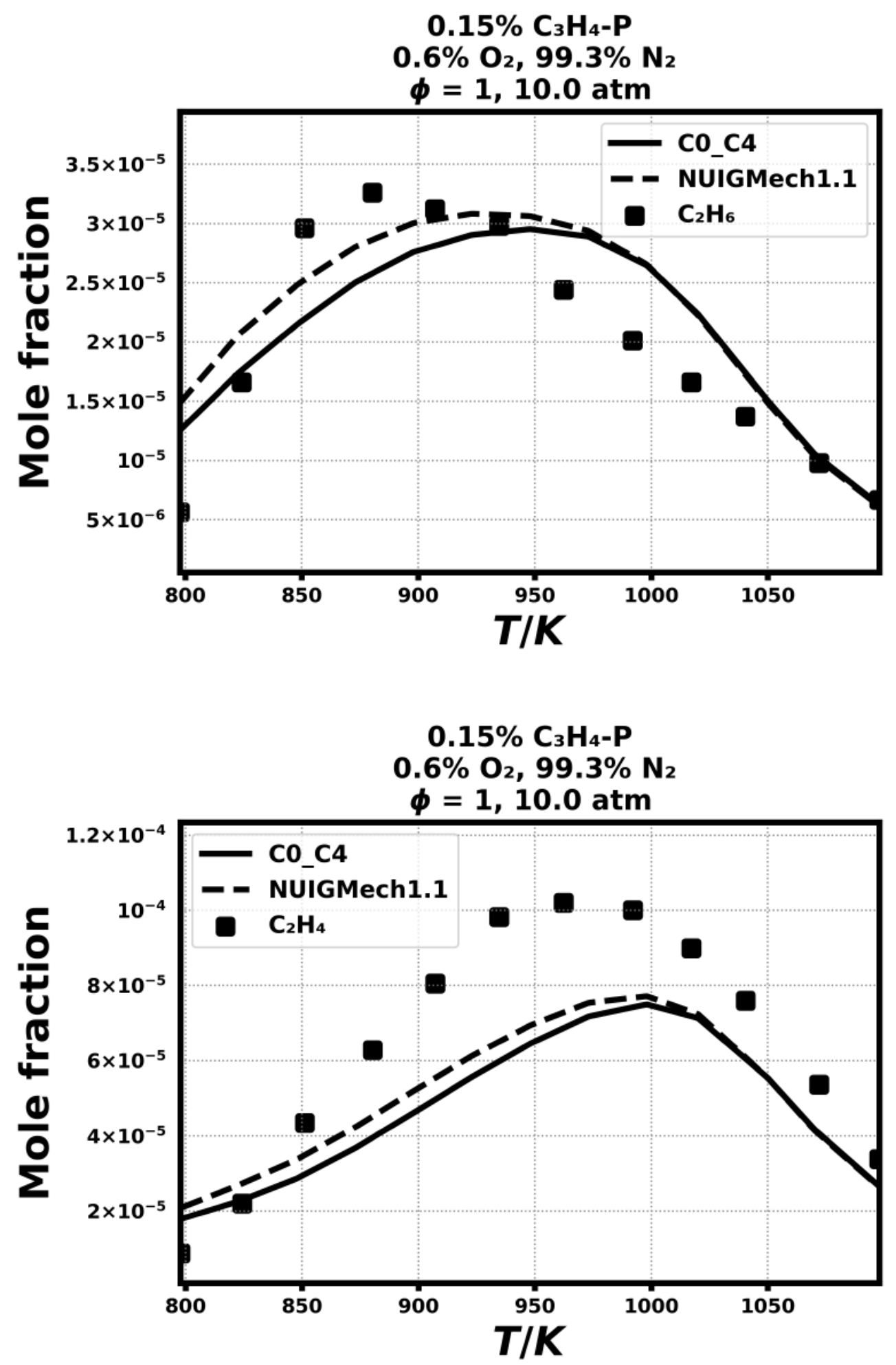

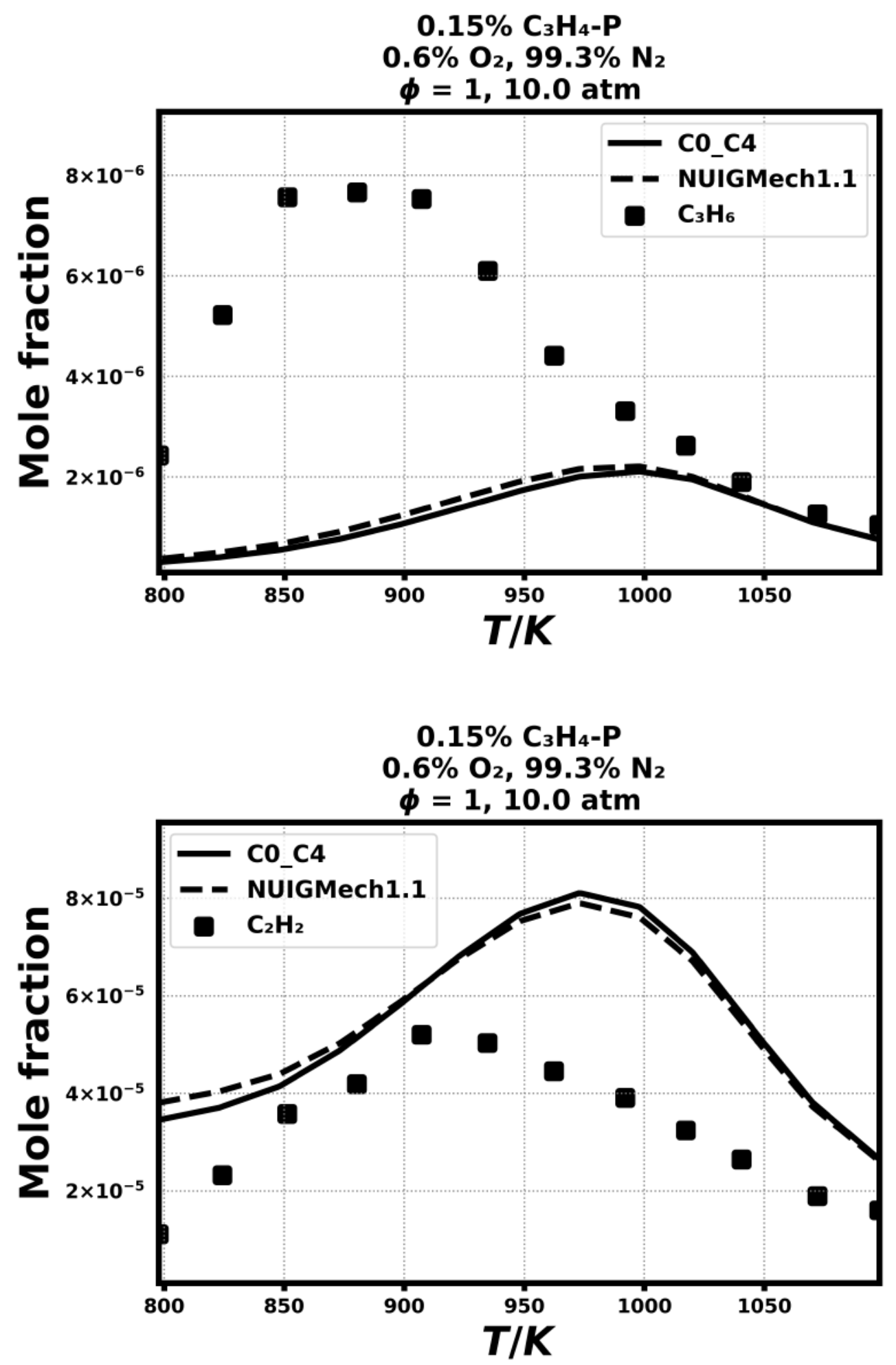

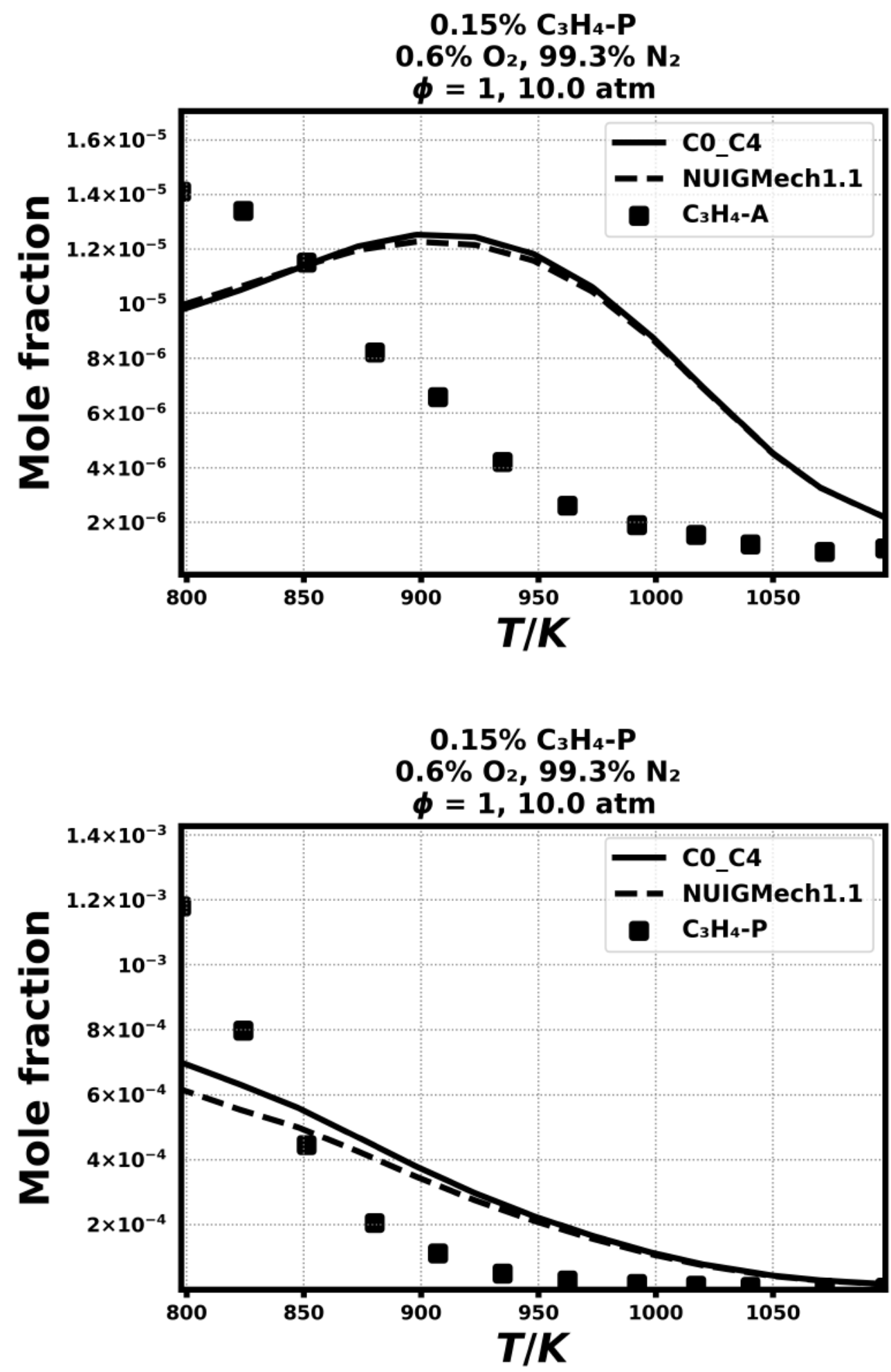

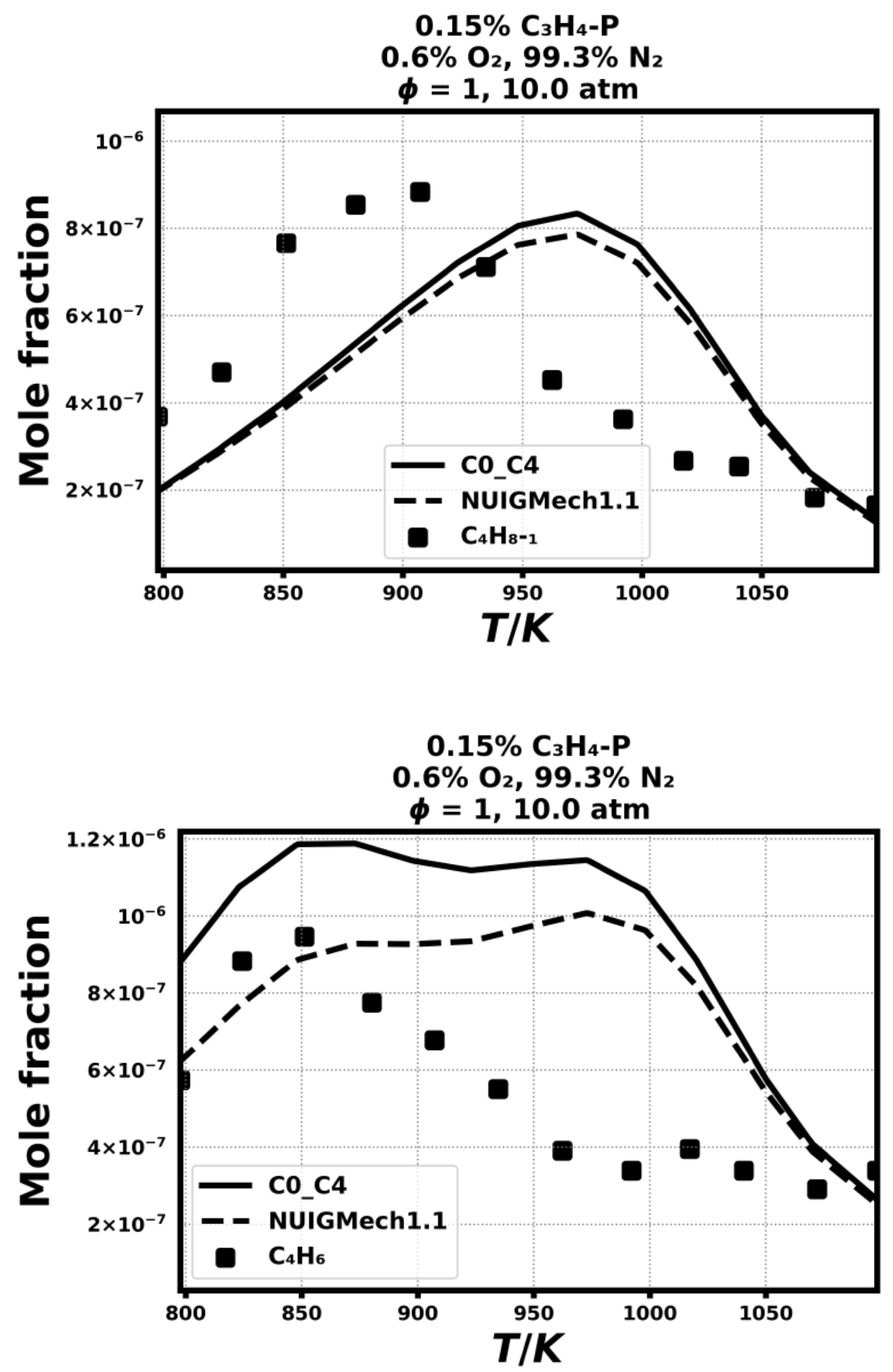

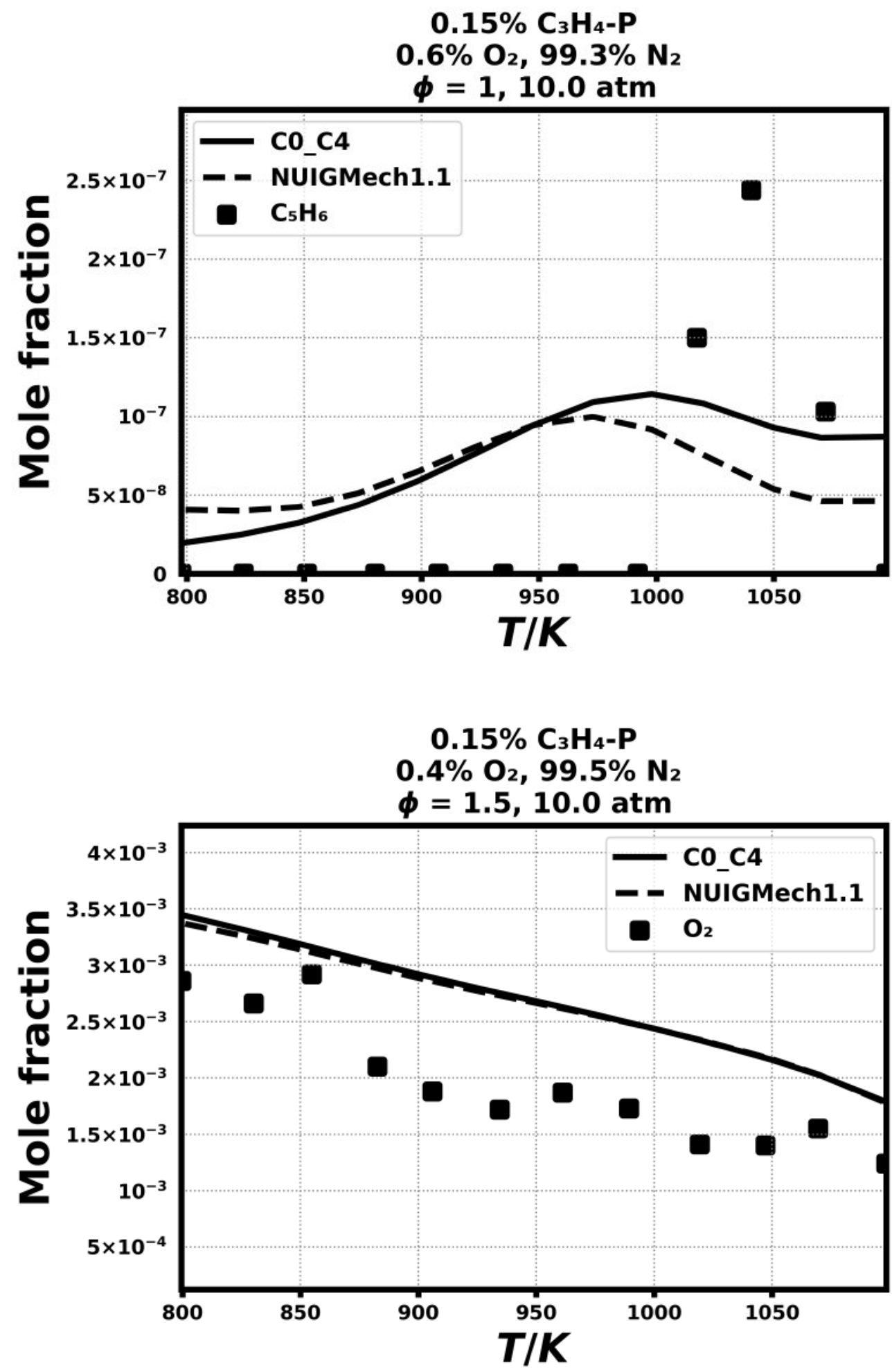

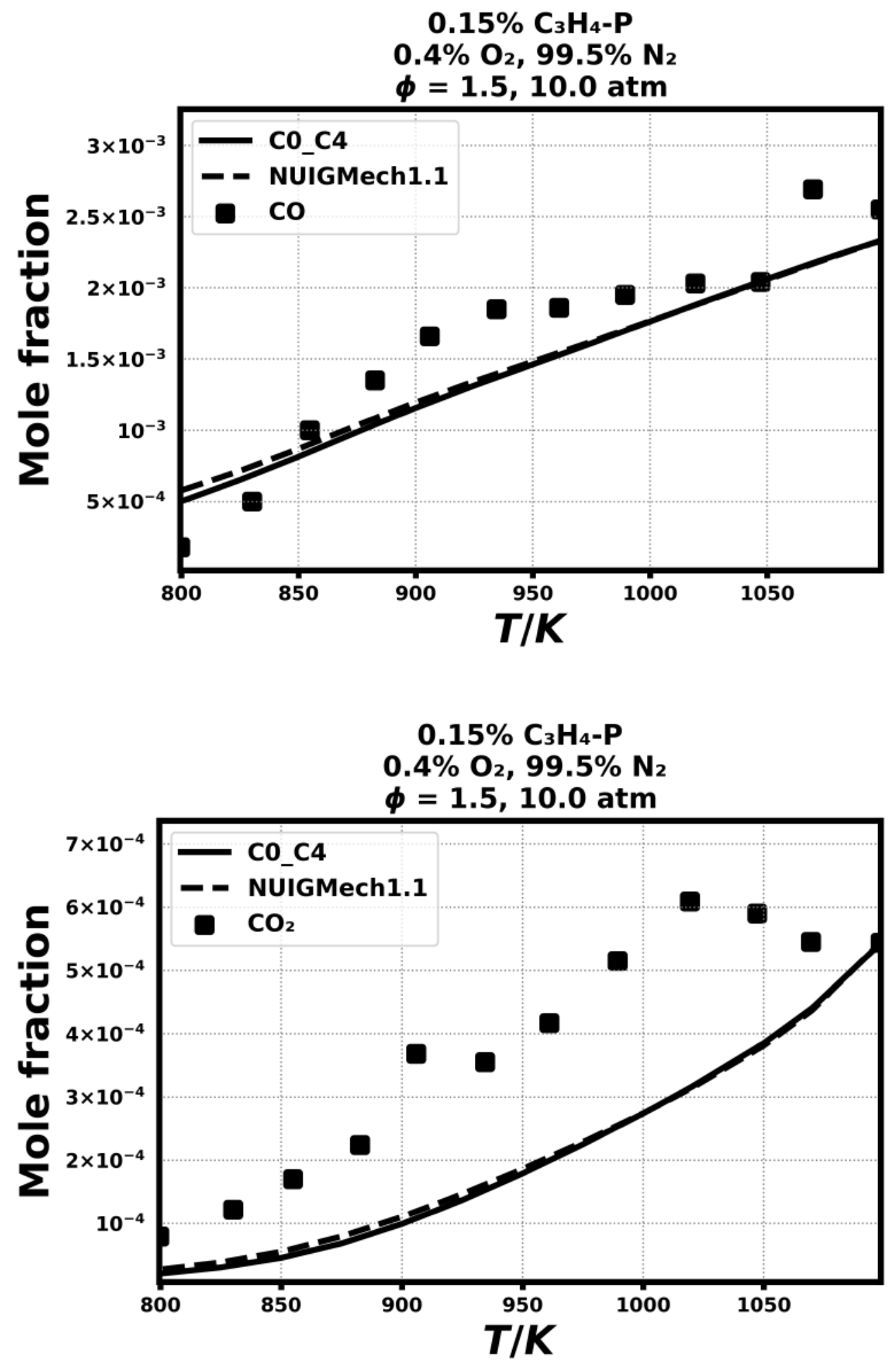

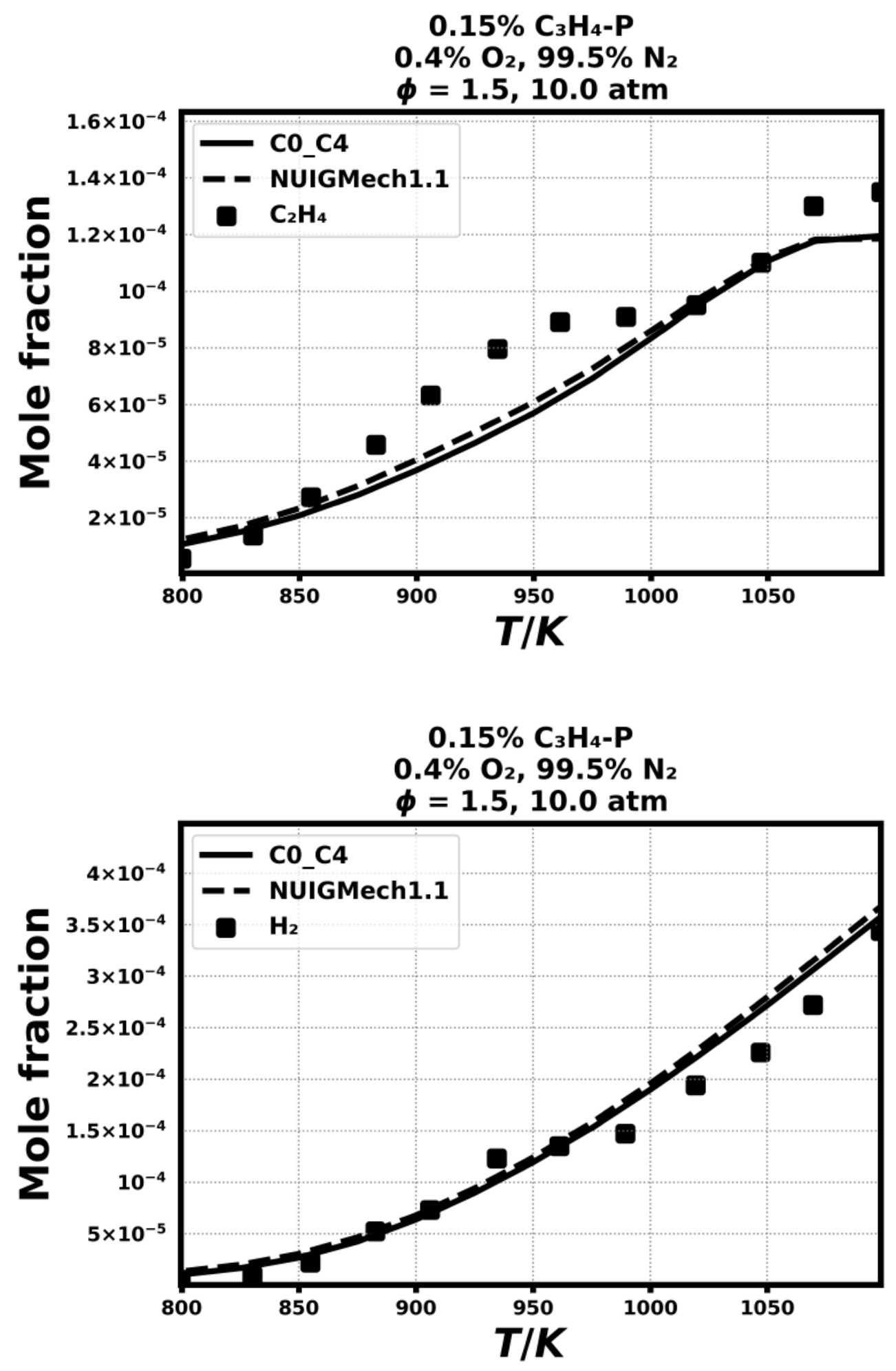

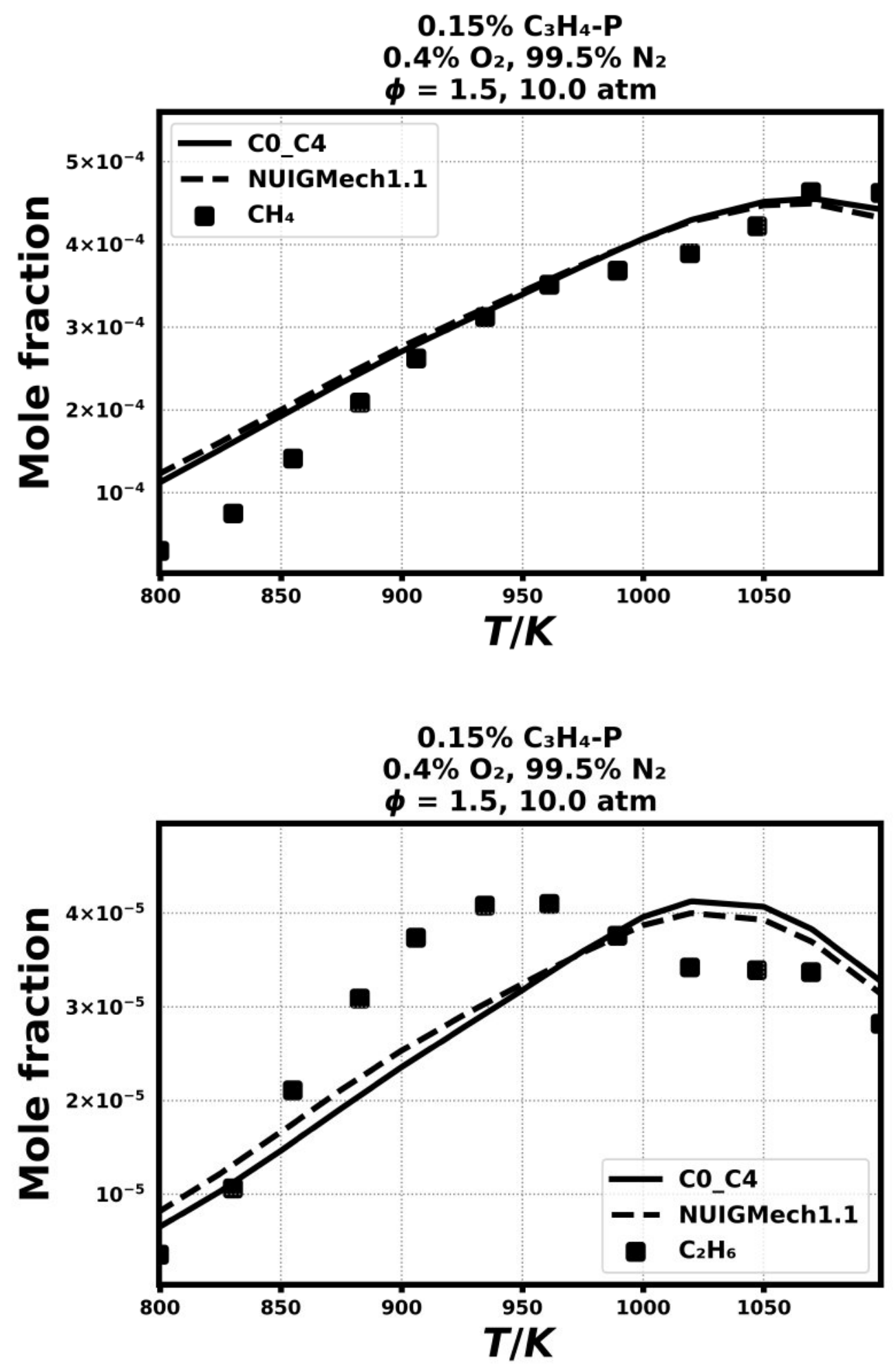

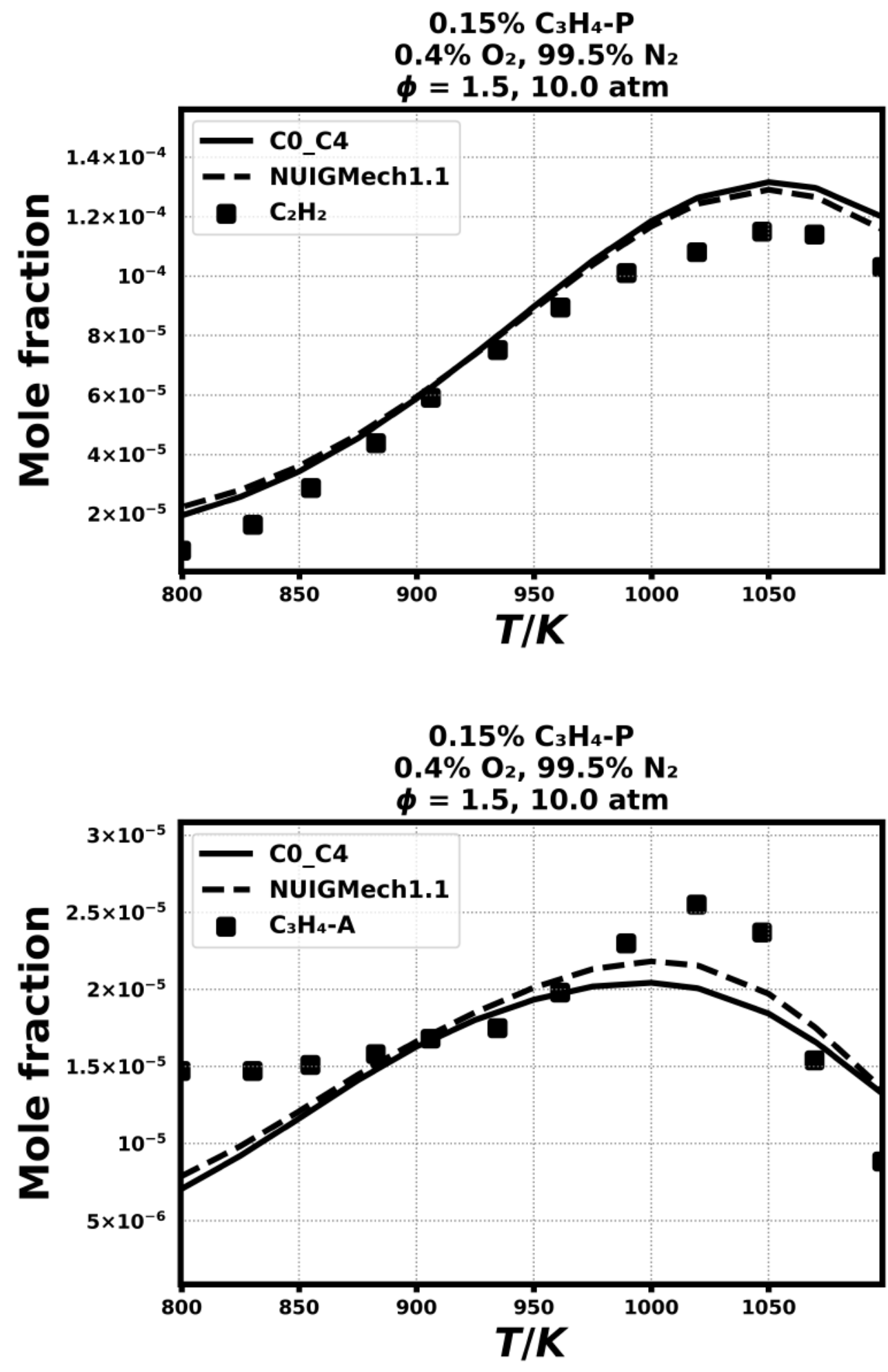

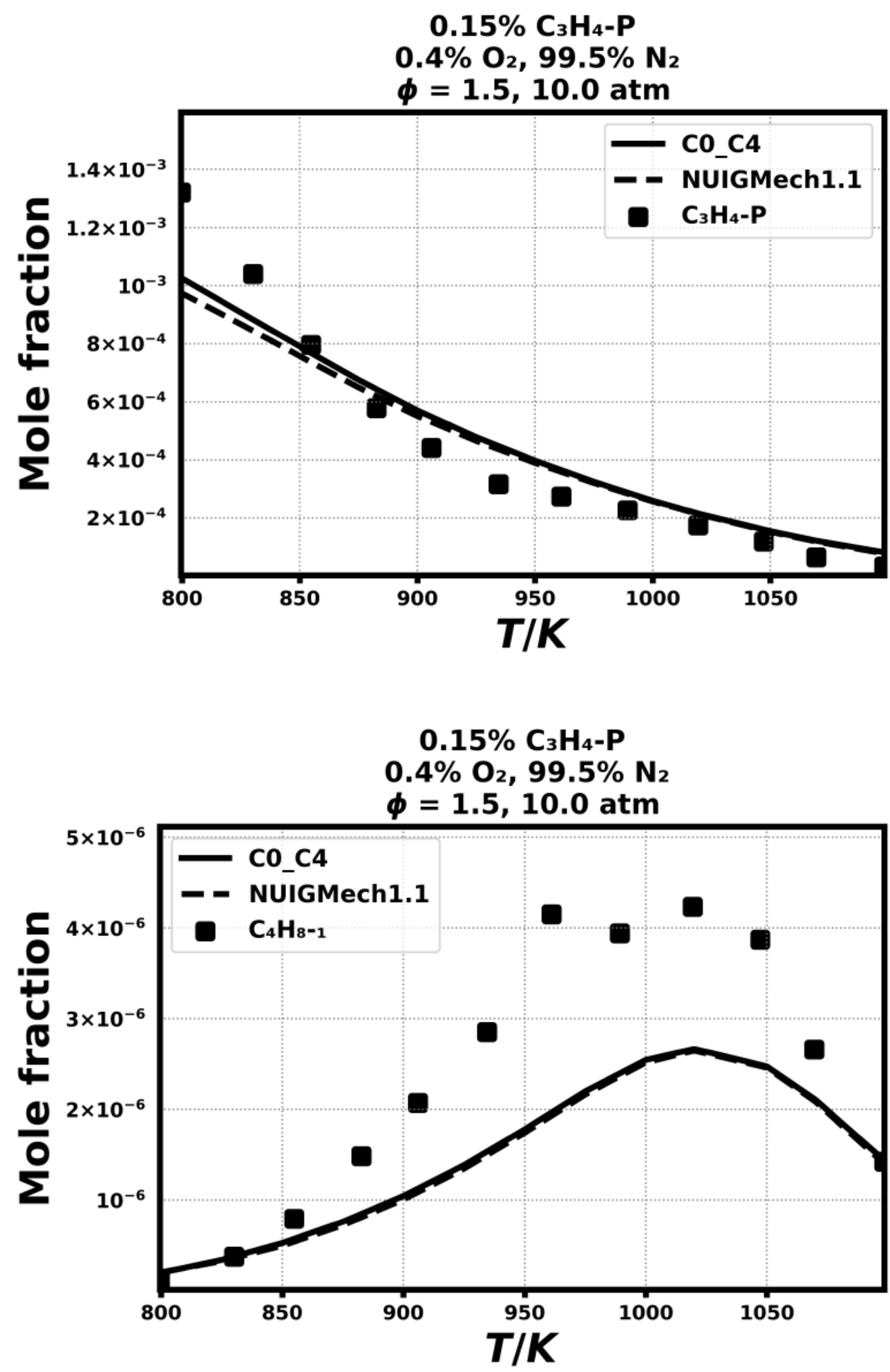

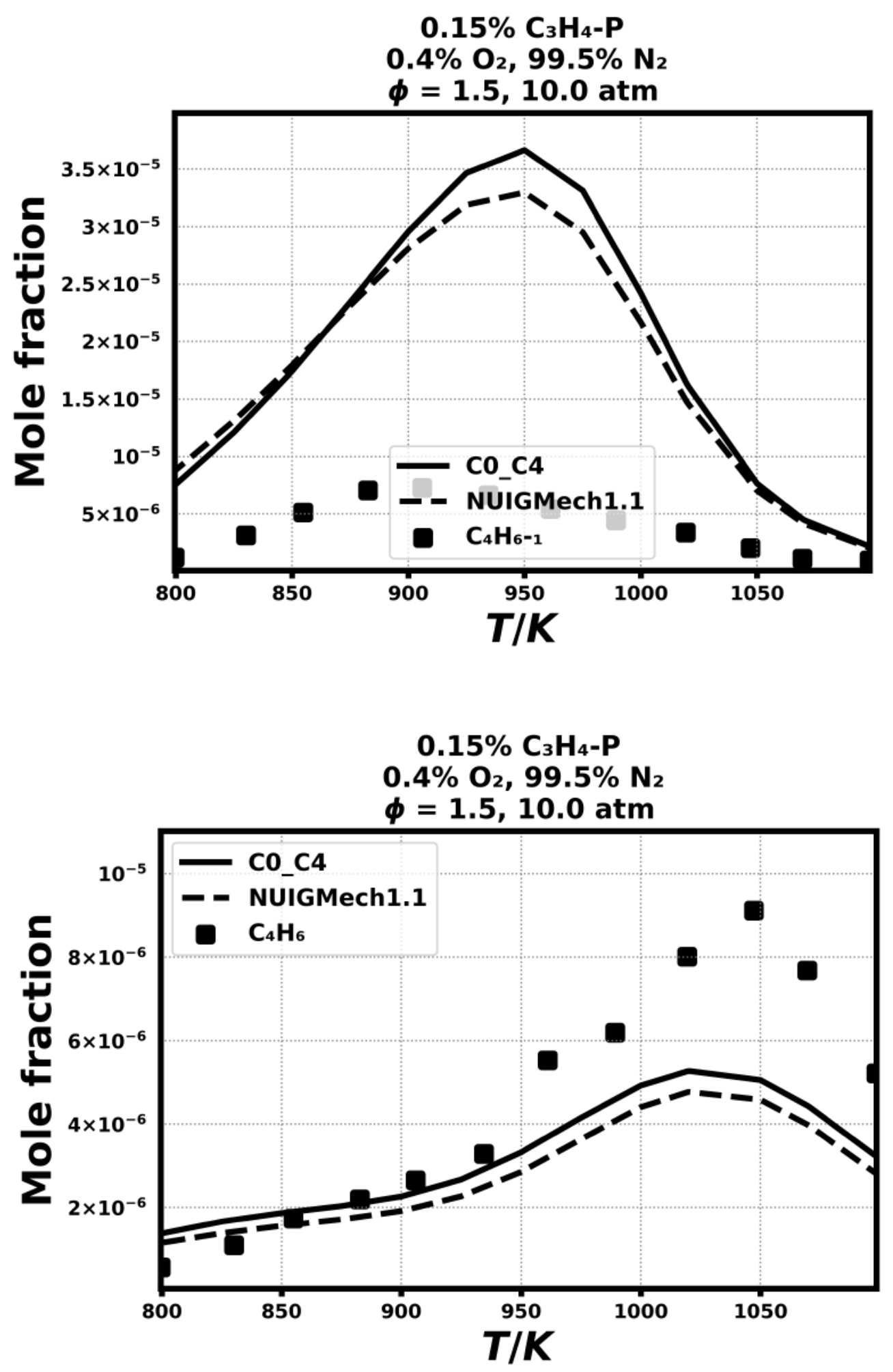

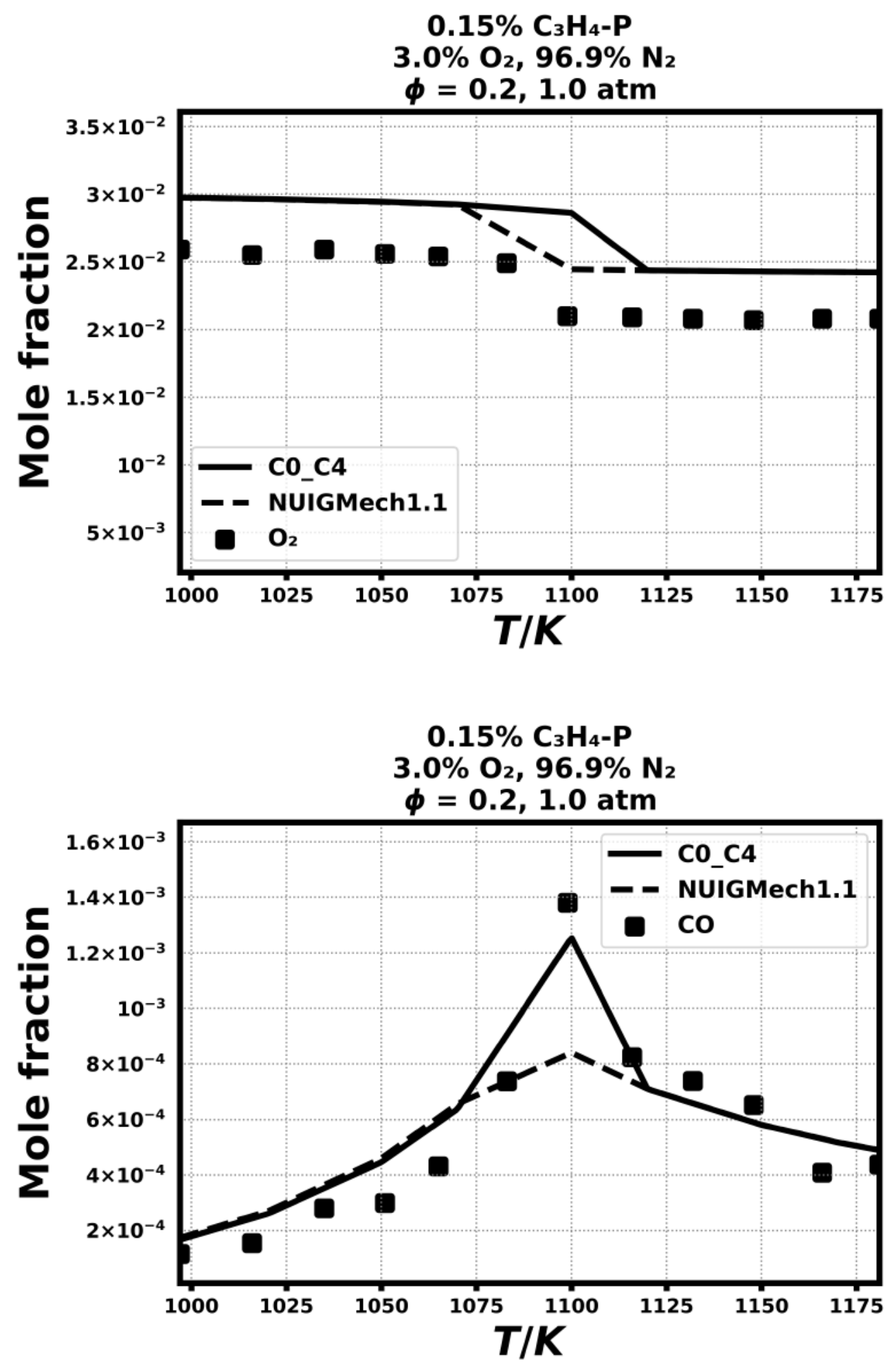

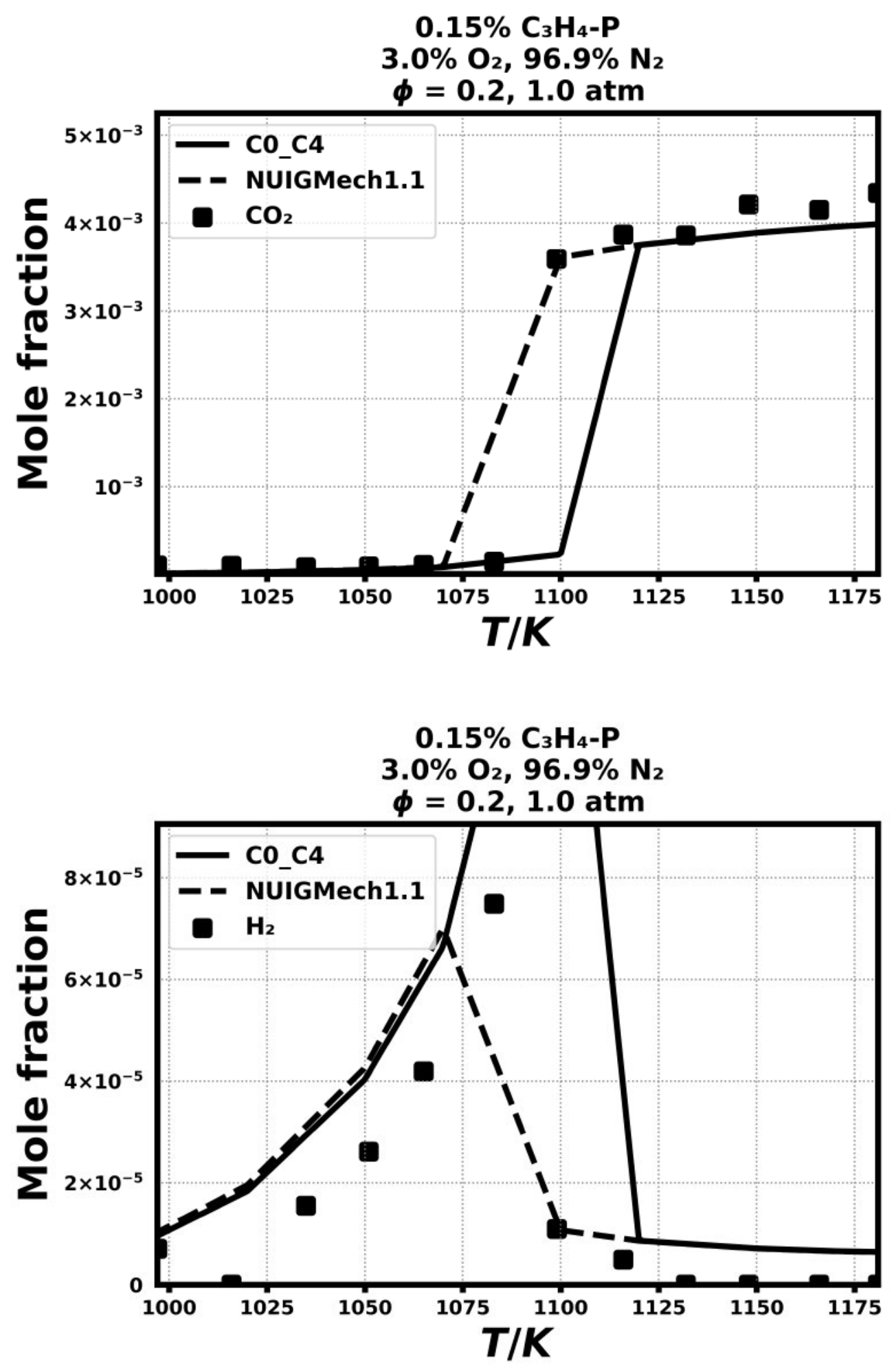

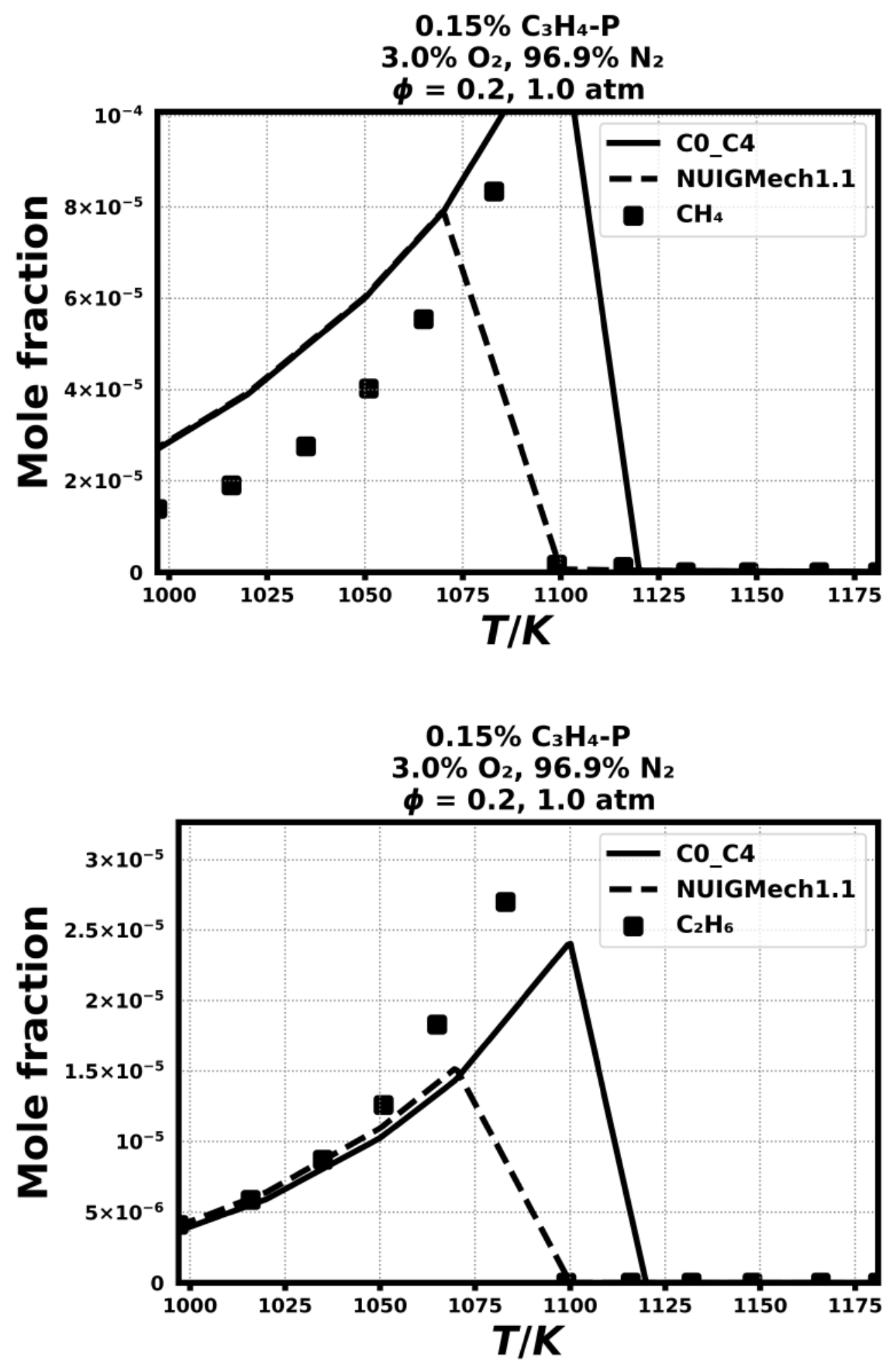

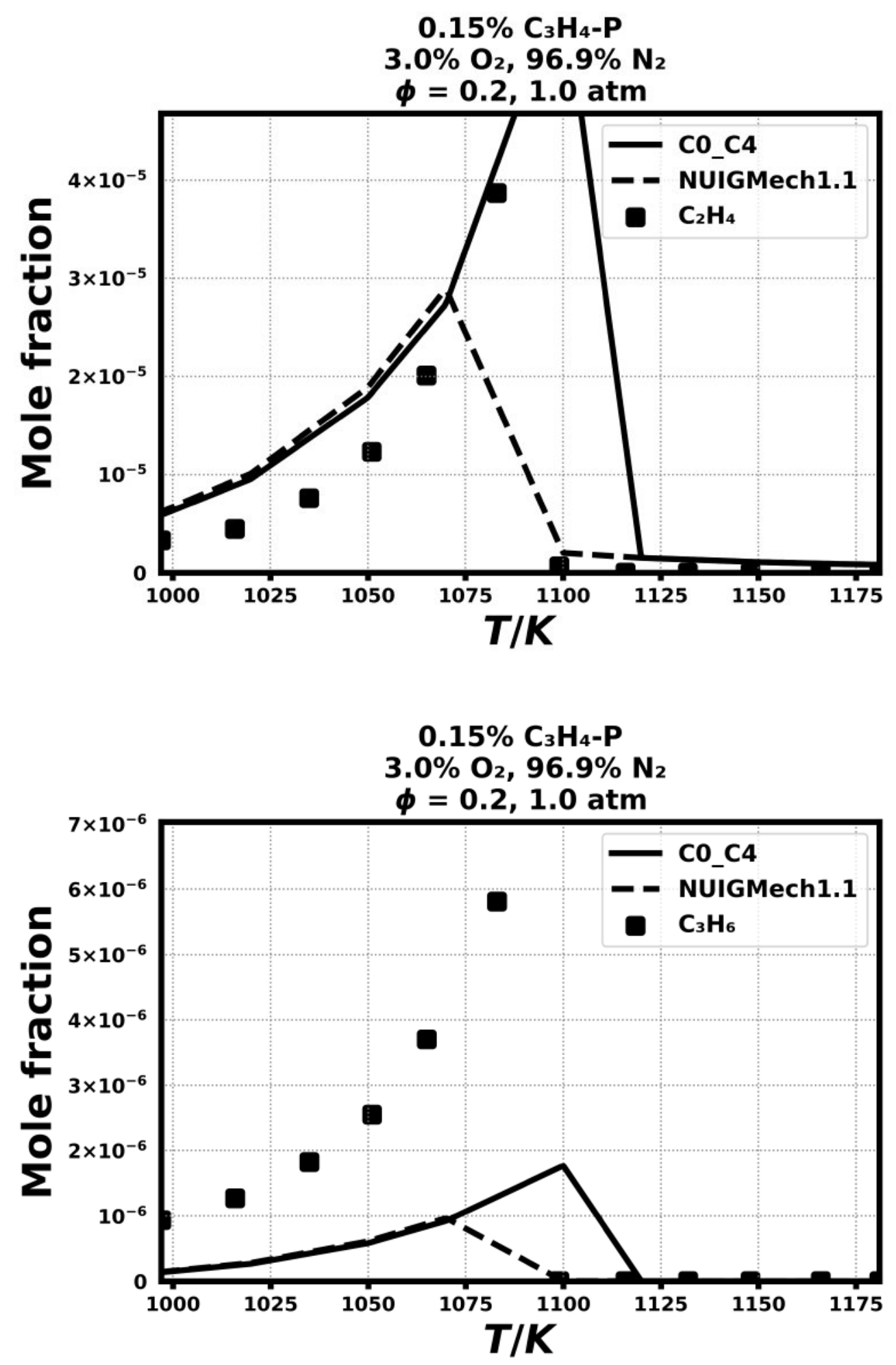

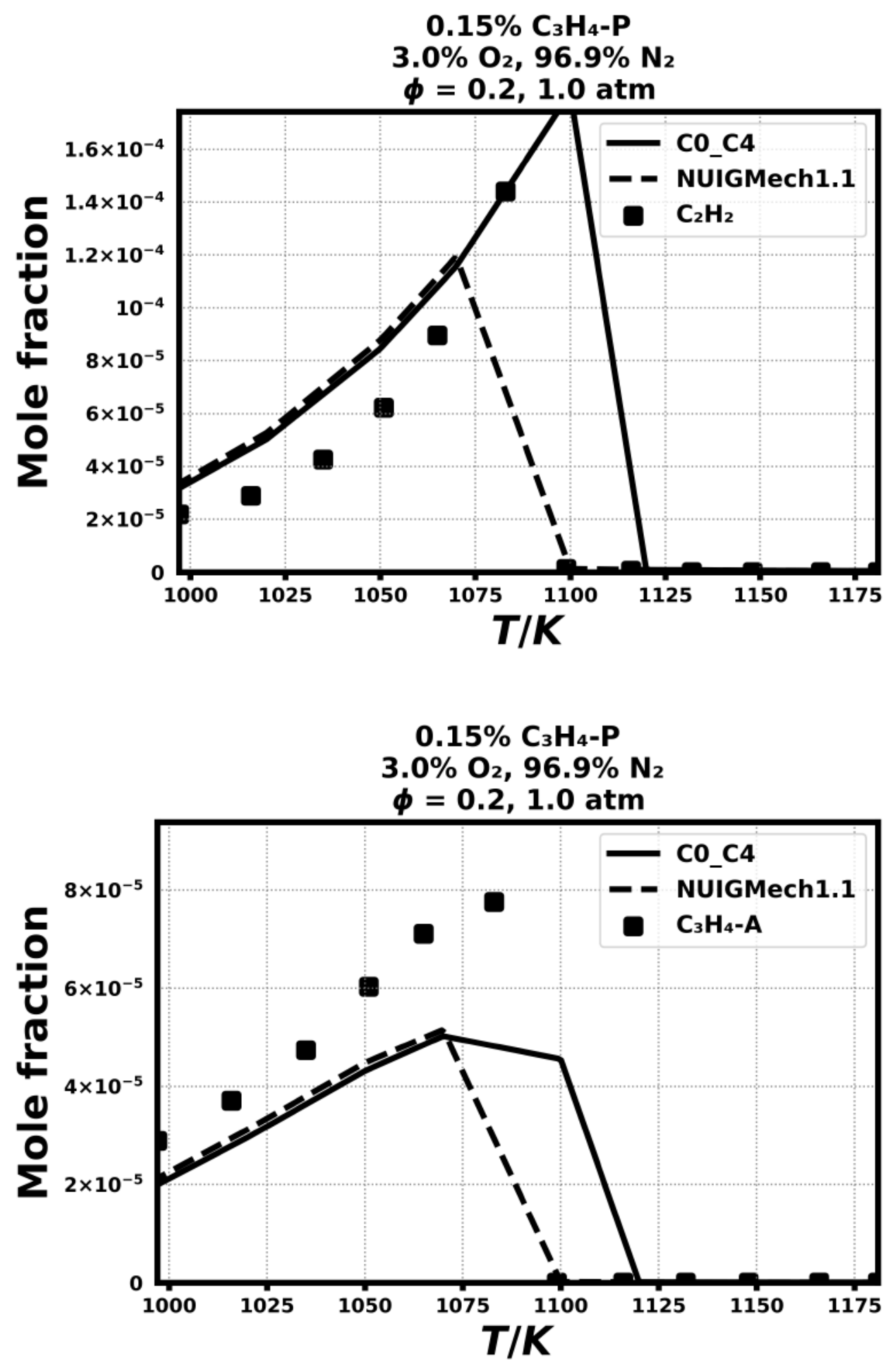

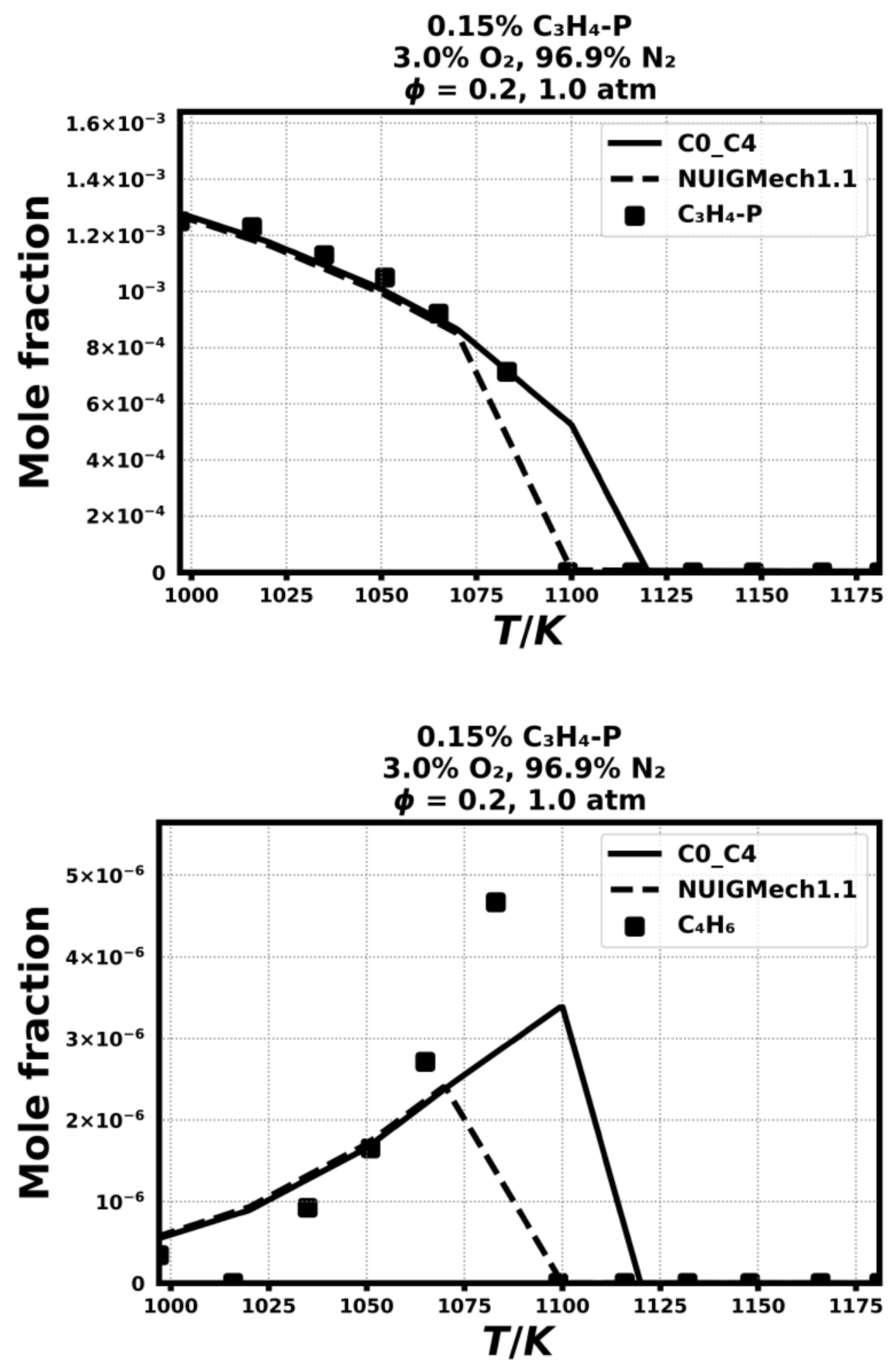

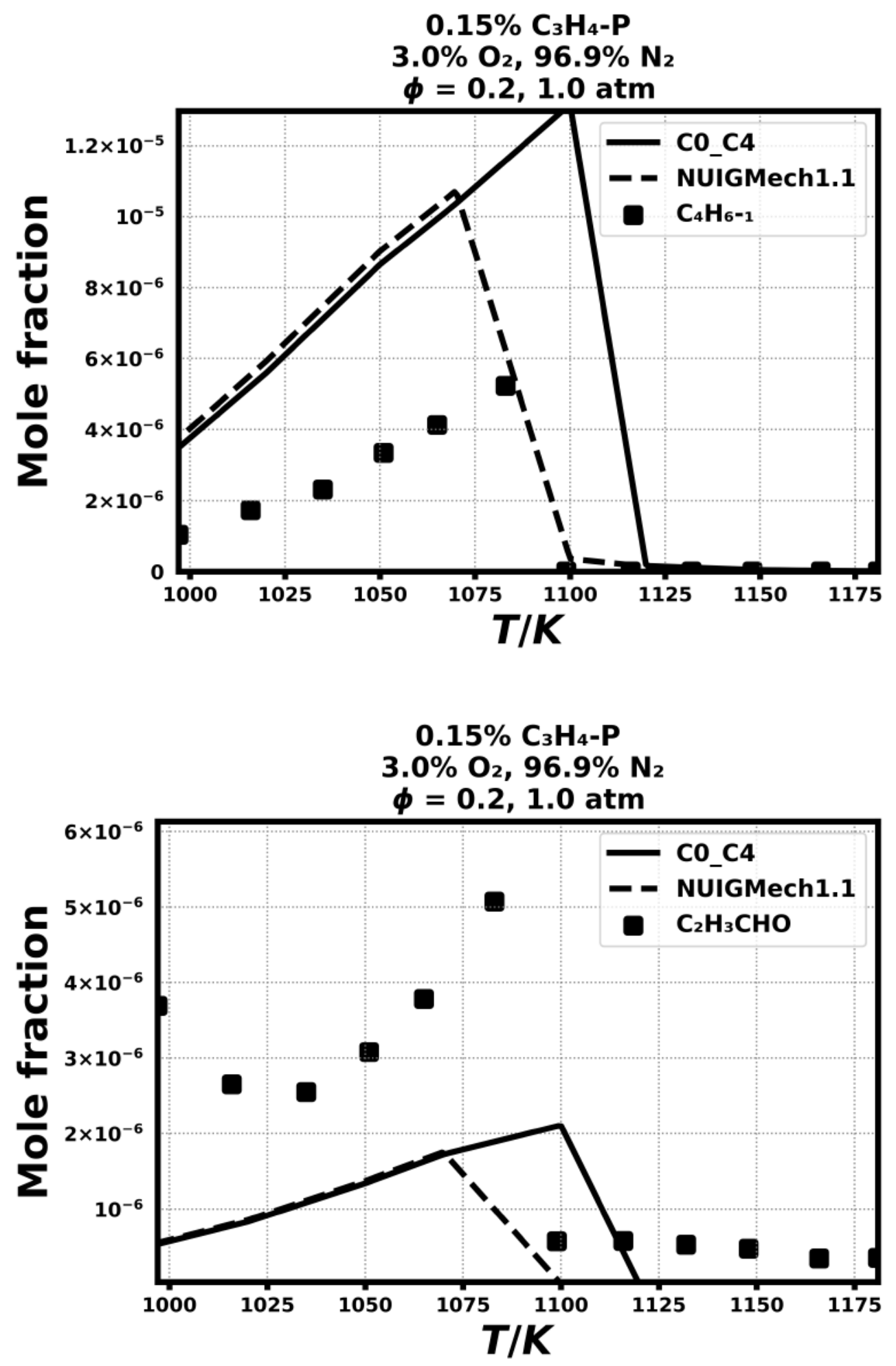

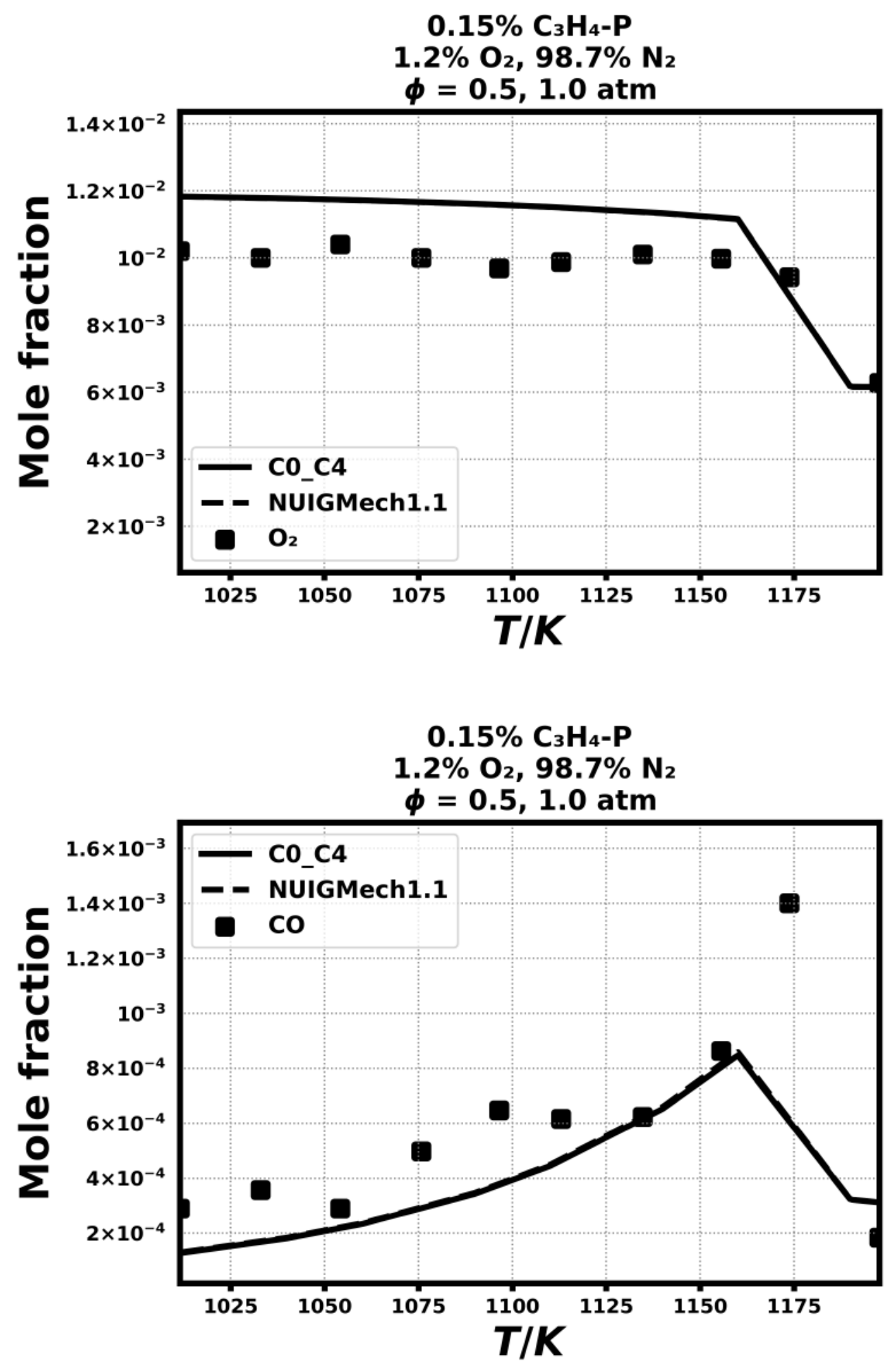

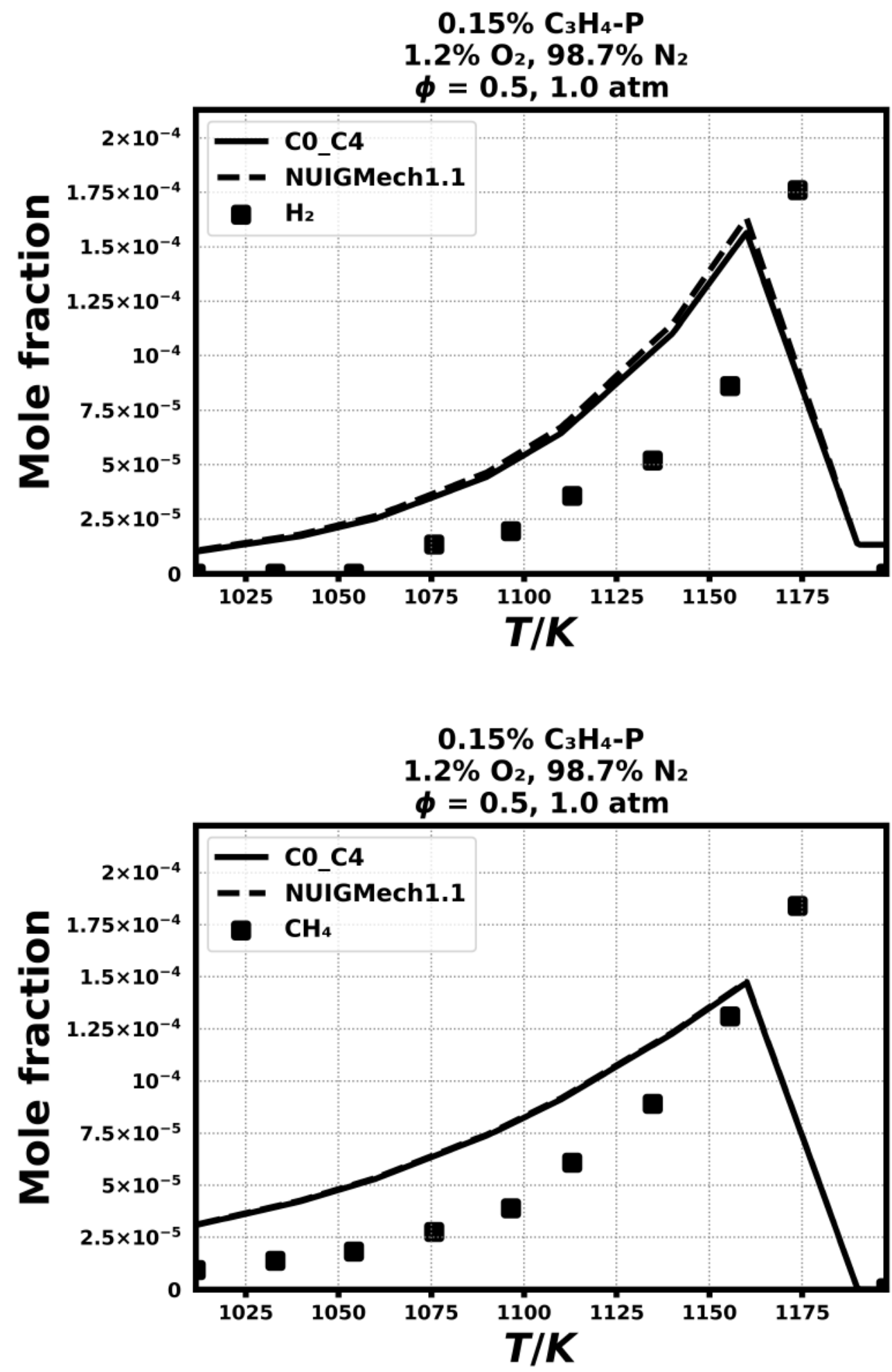

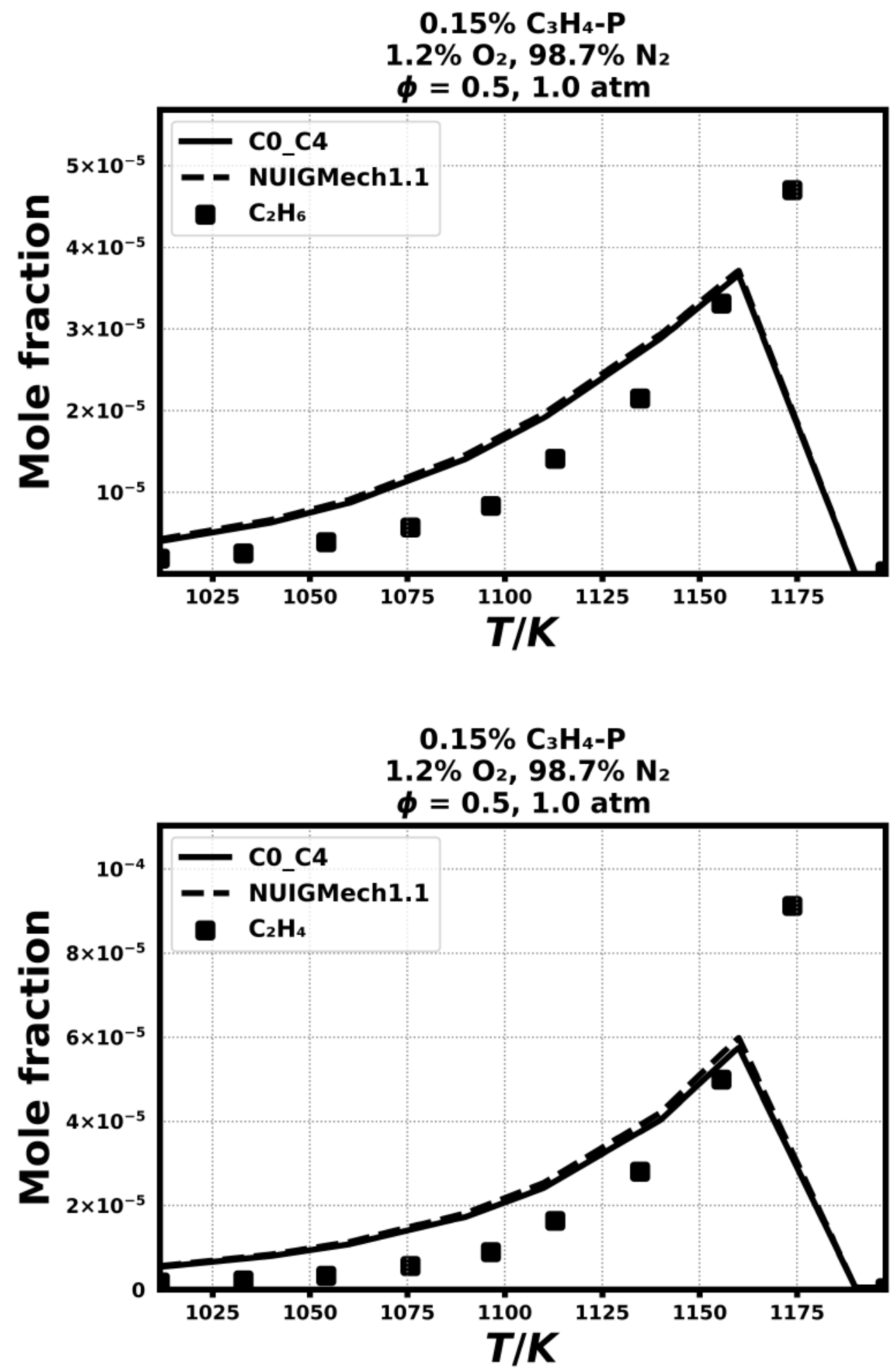

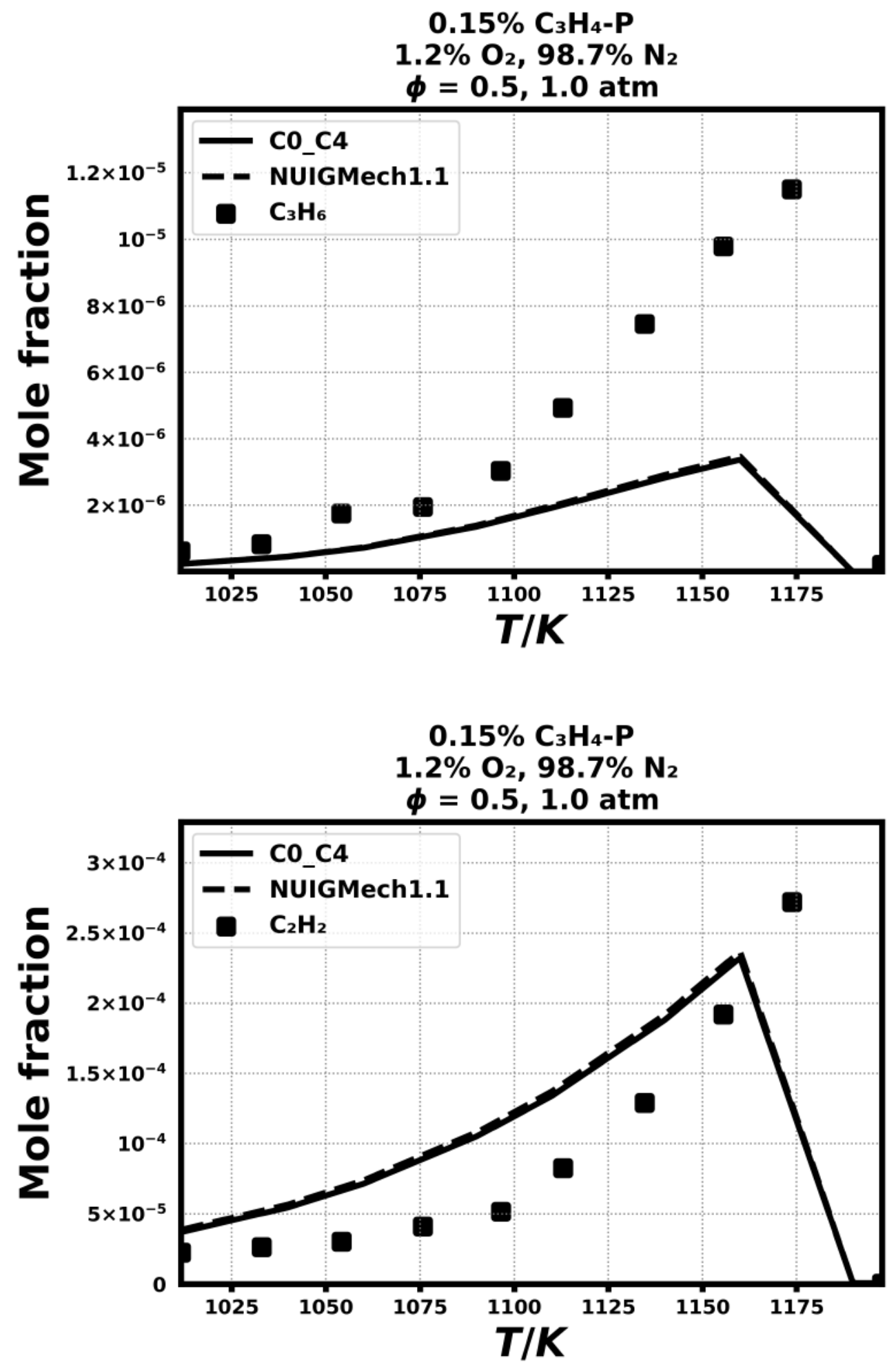

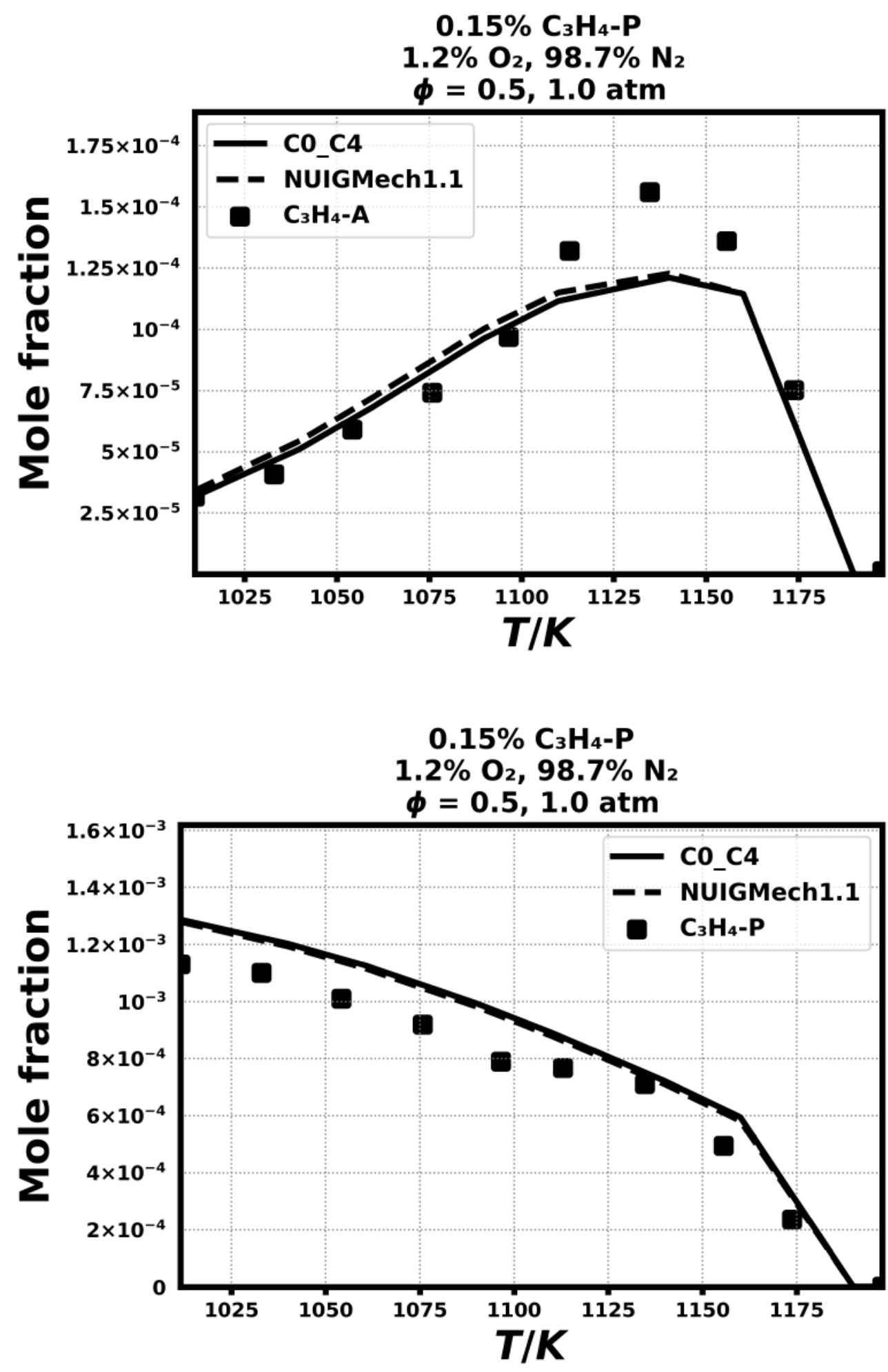

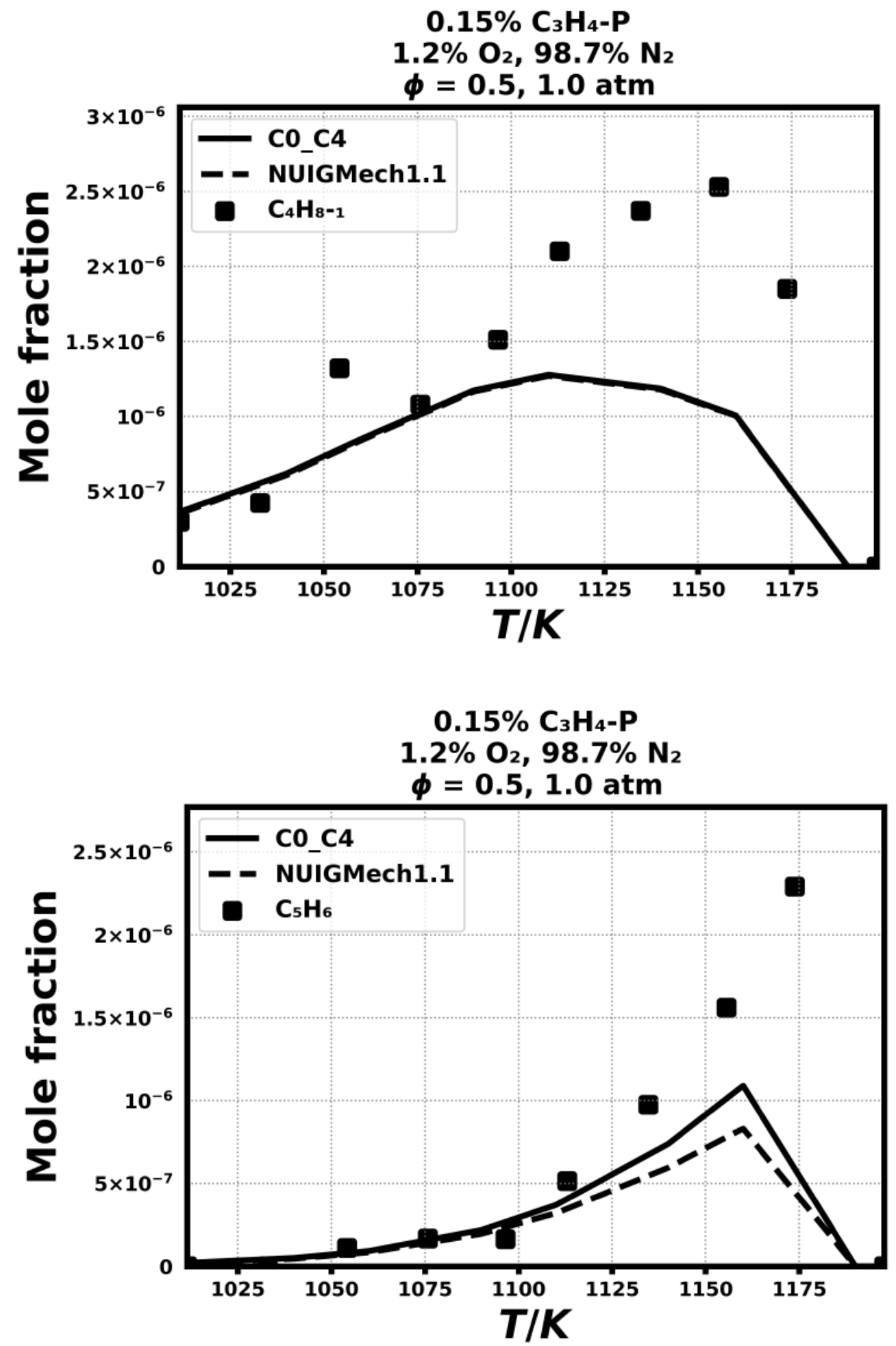

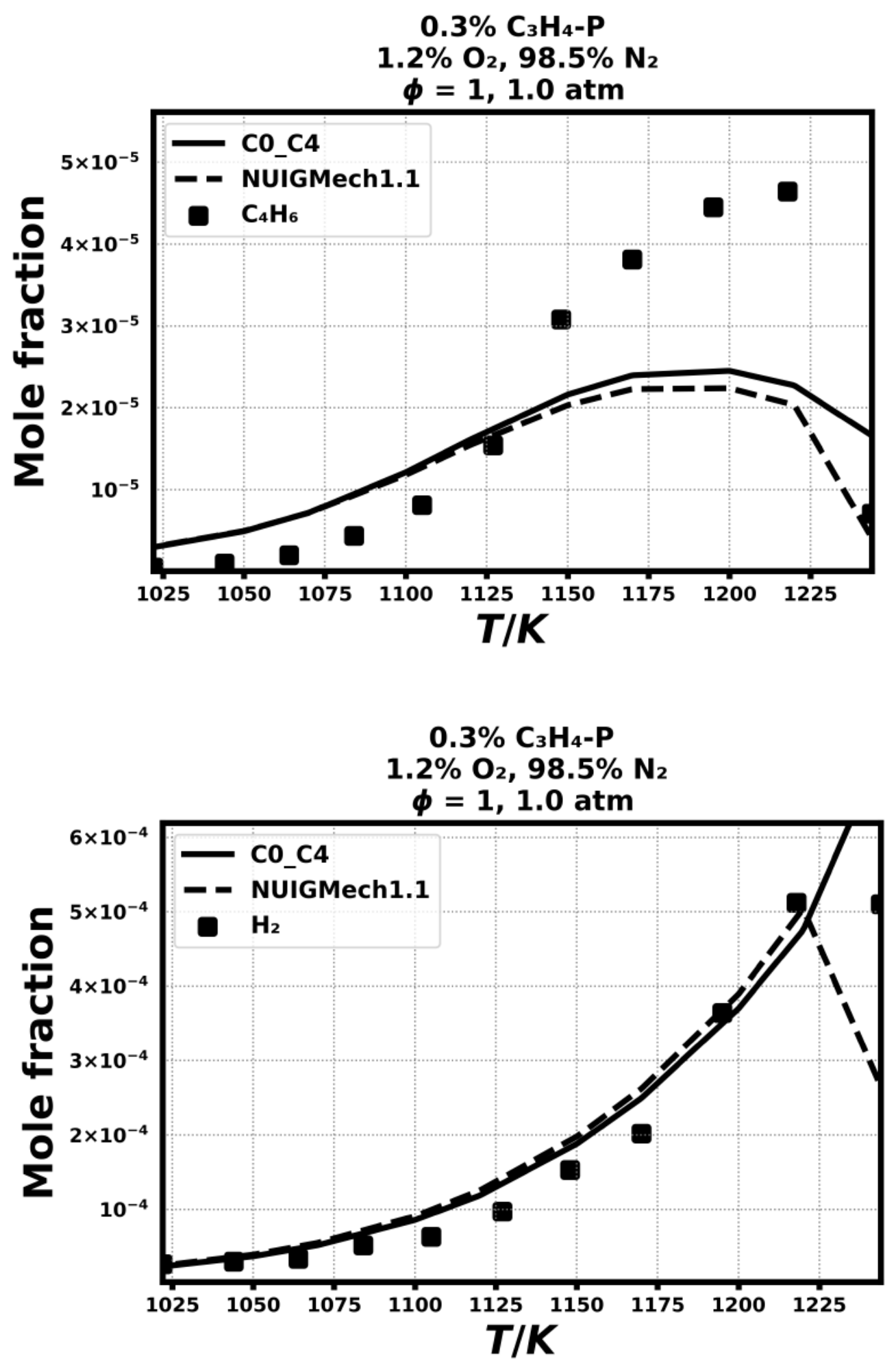

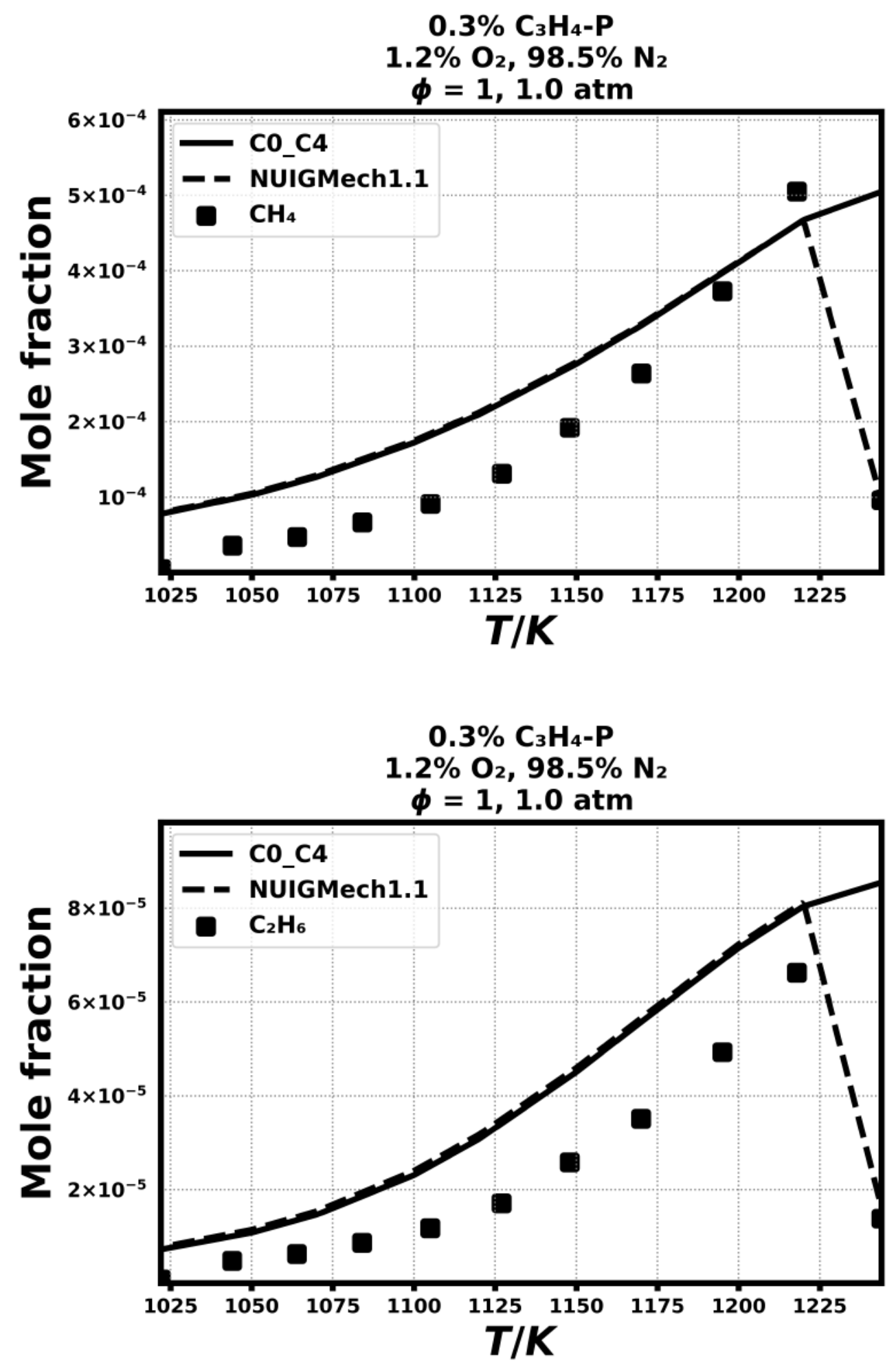

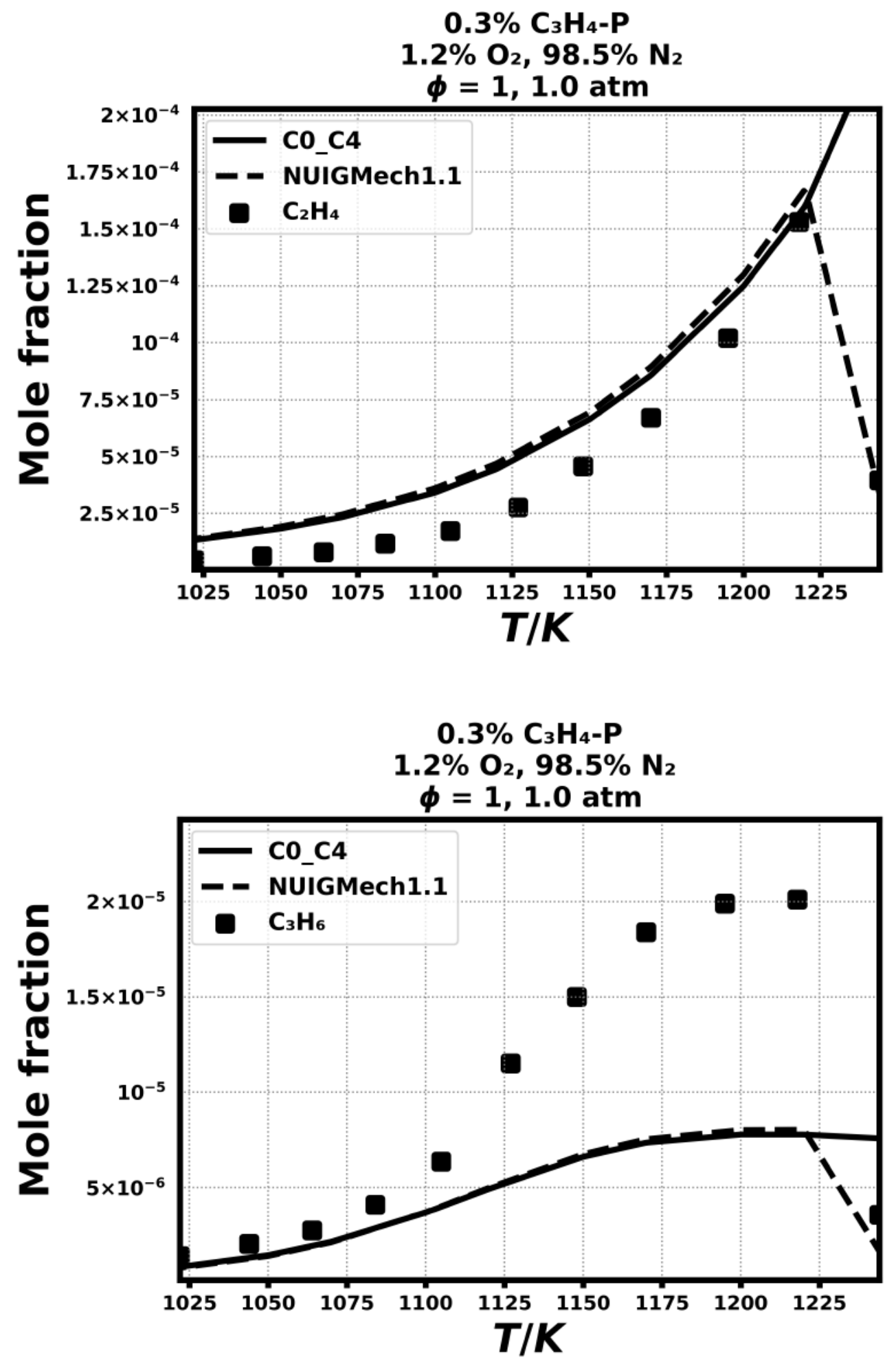

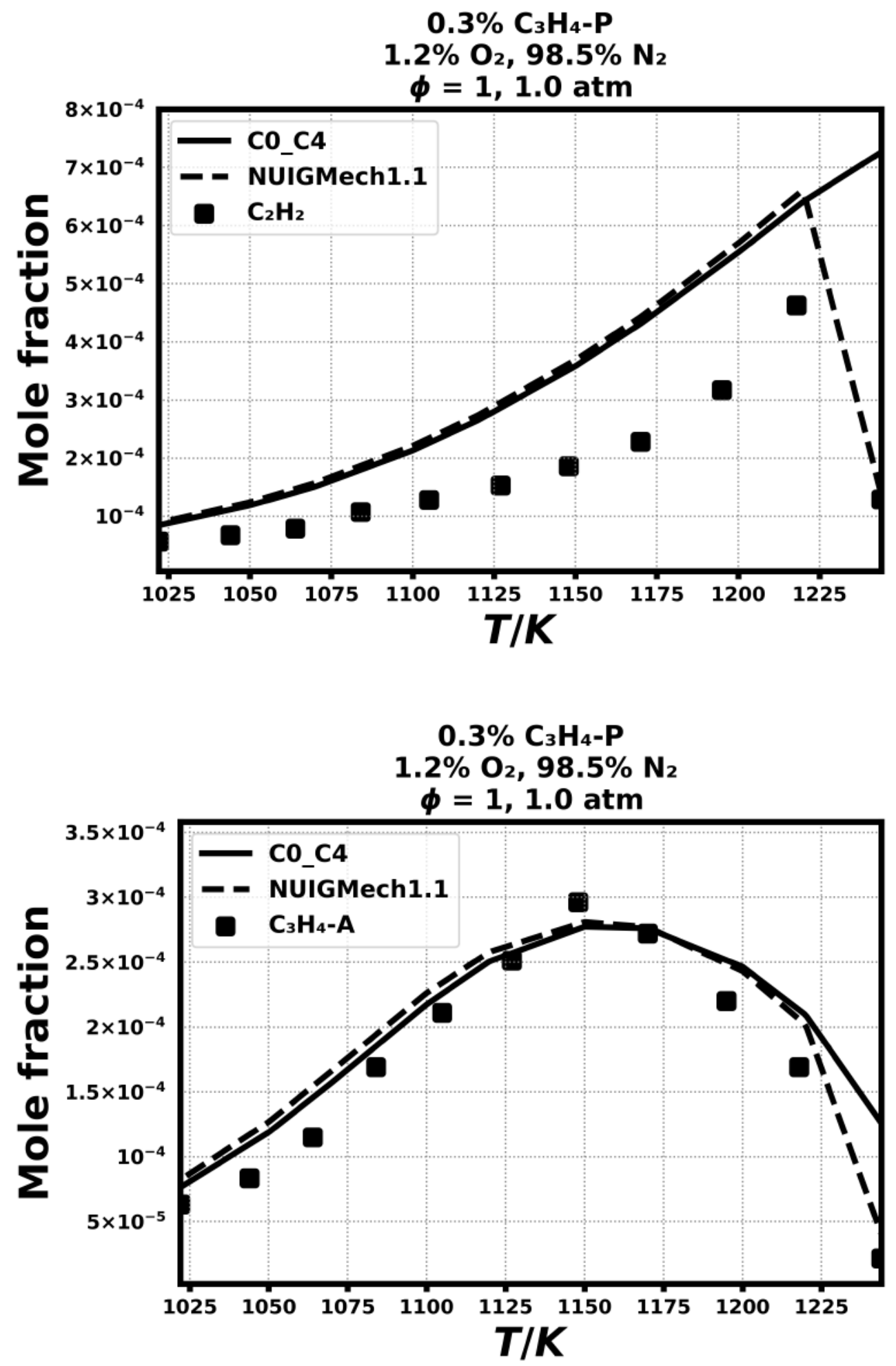

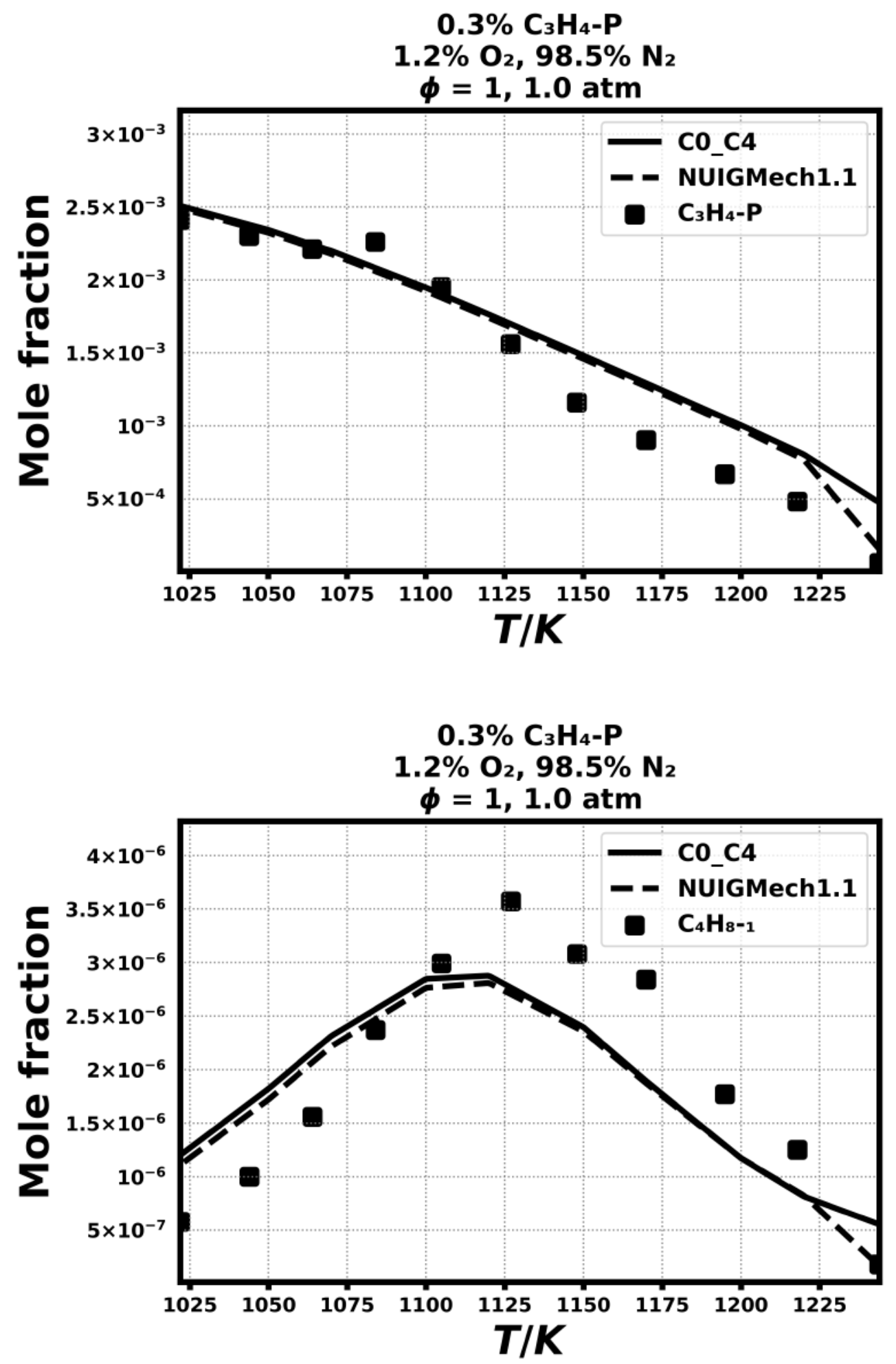


\section{Validation for $\mathrm{C}_{4} \mathrm{H}_{10}$}

\section{Shock tube ignition delay time}

11.1) Healy, D., Donato, N. S., Aul, C. J., Petersen, E. L., Zinner, C. M., Bourque, G., \& Curran, H. J., Combustion and Flame, 157(8) (2010) 1526-1539.
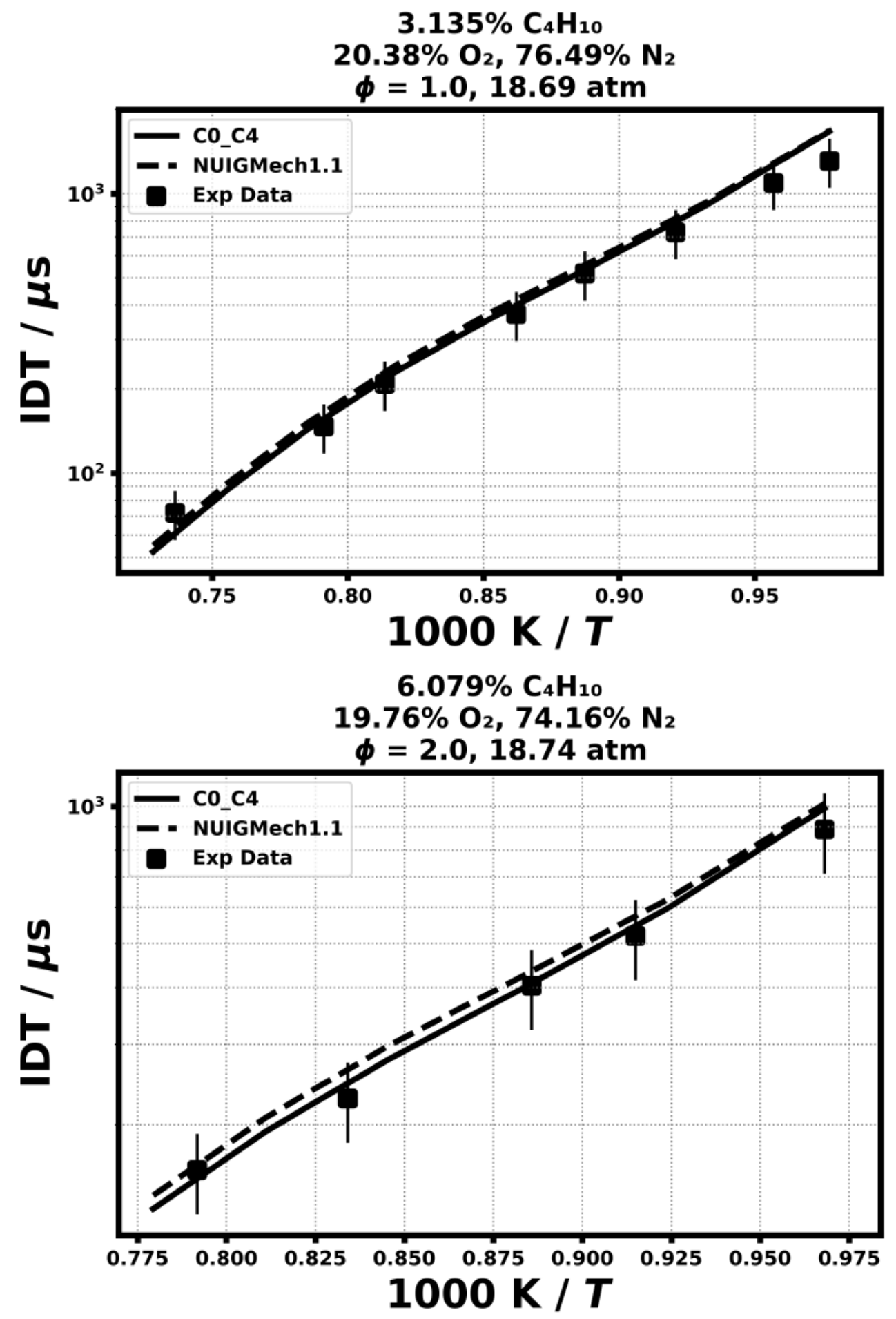

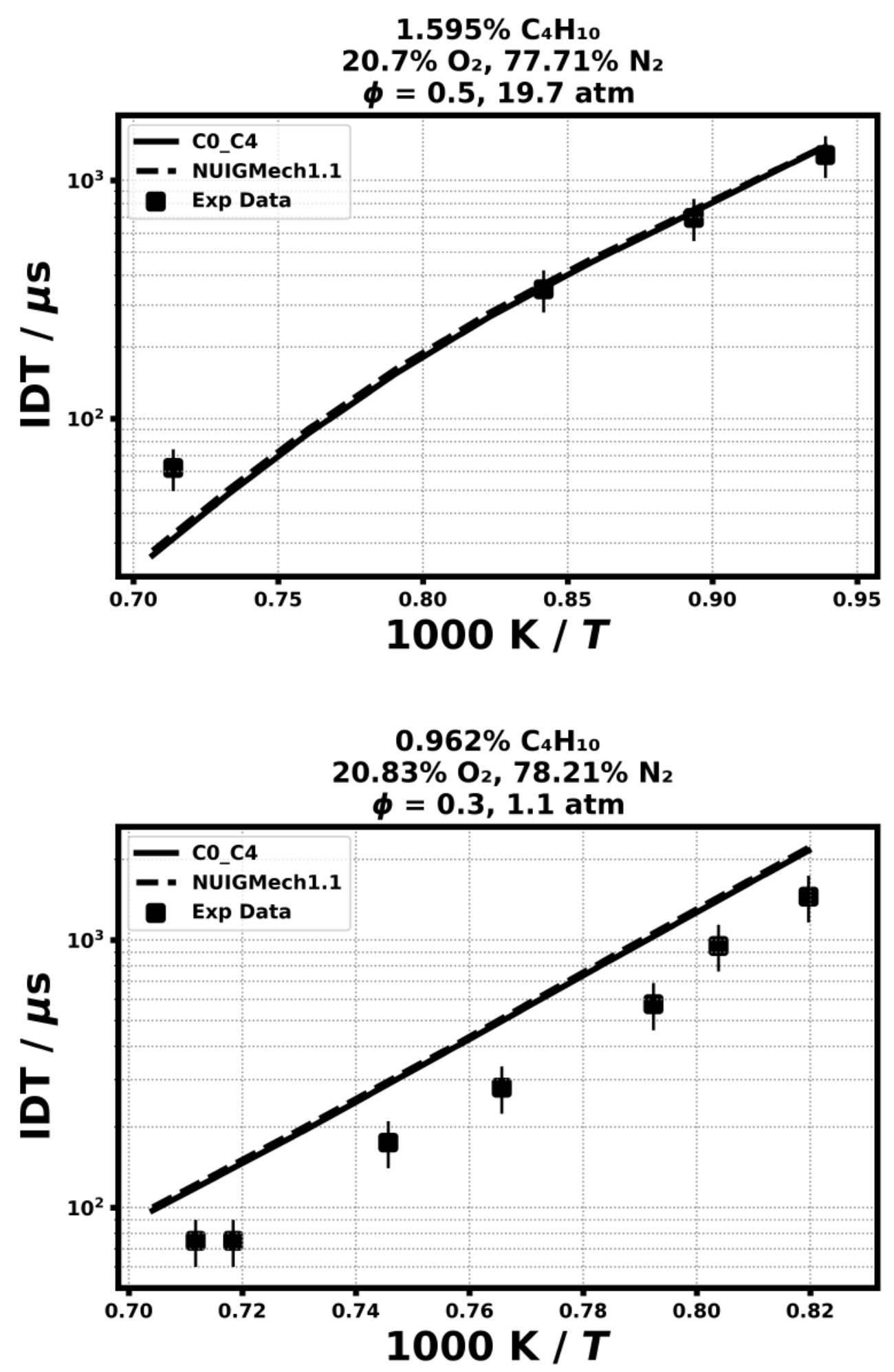

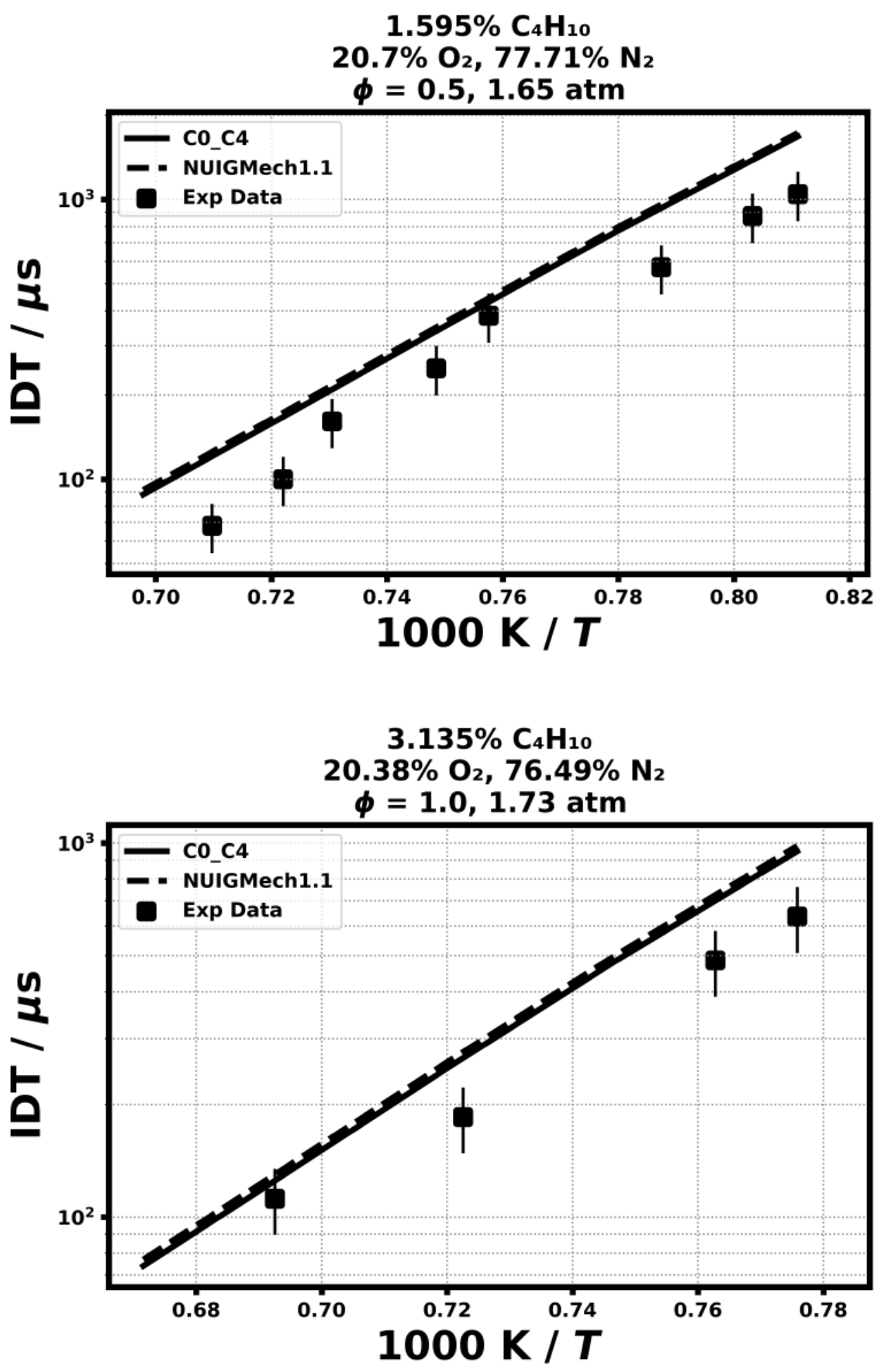

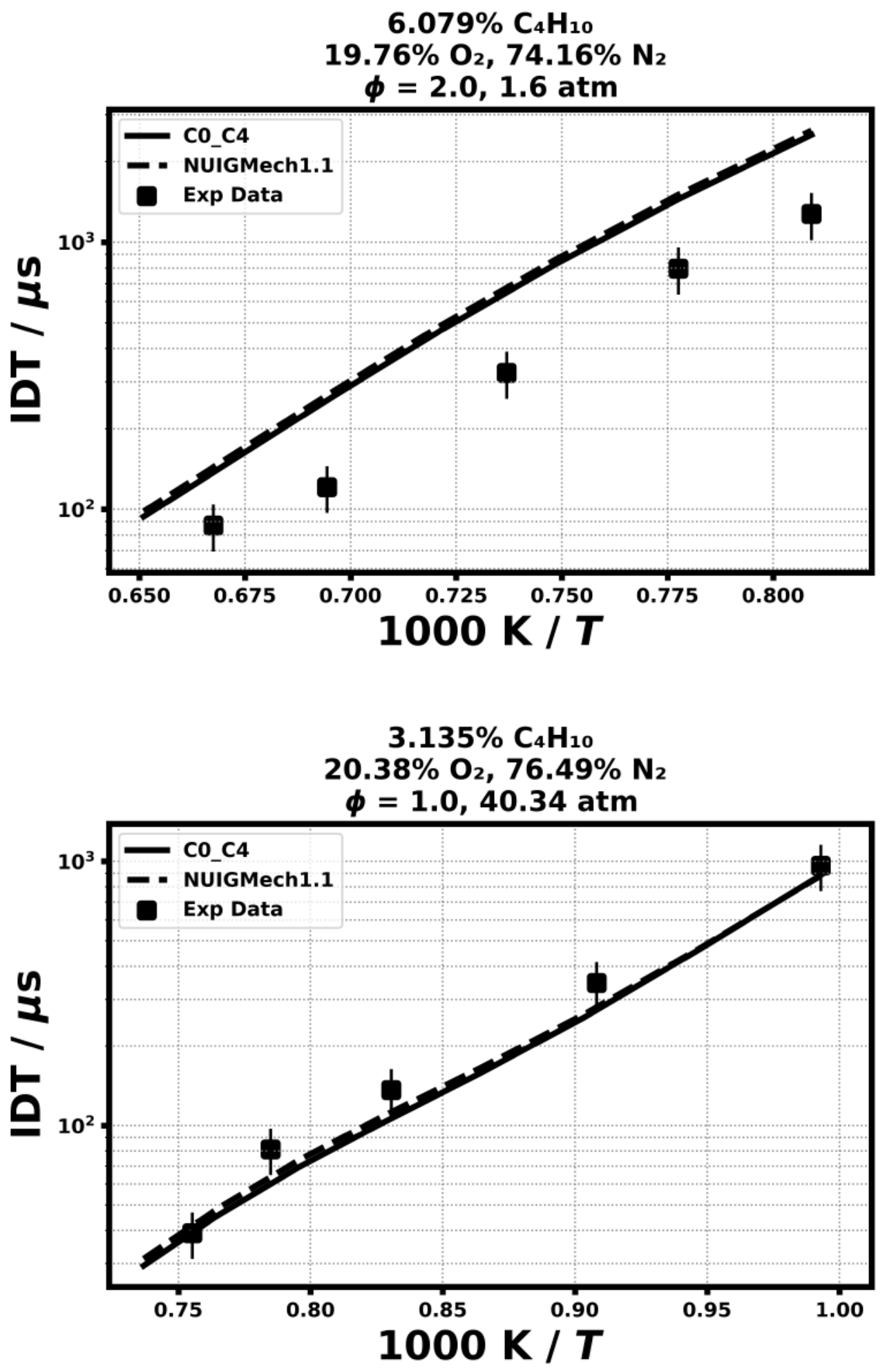

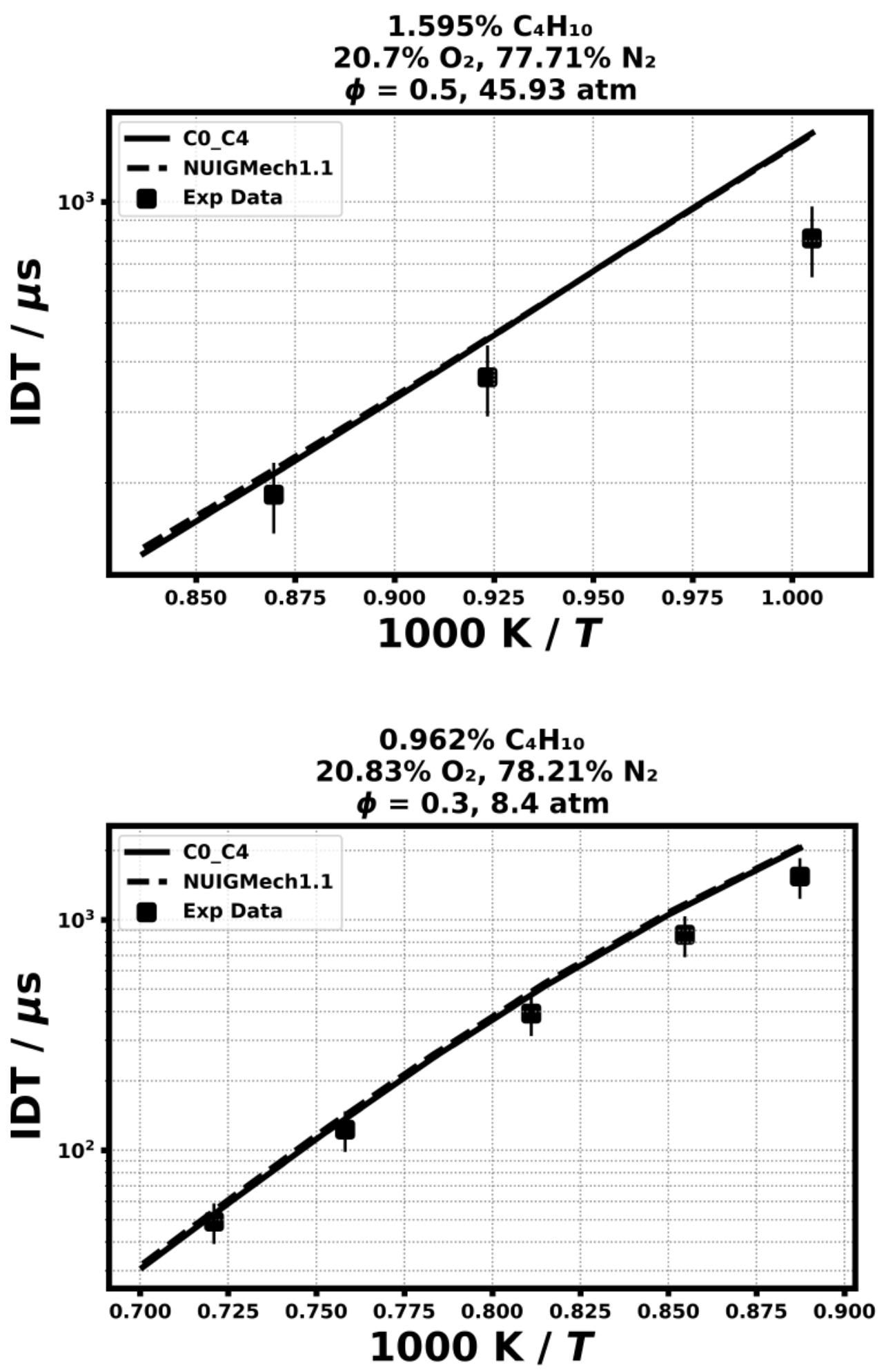

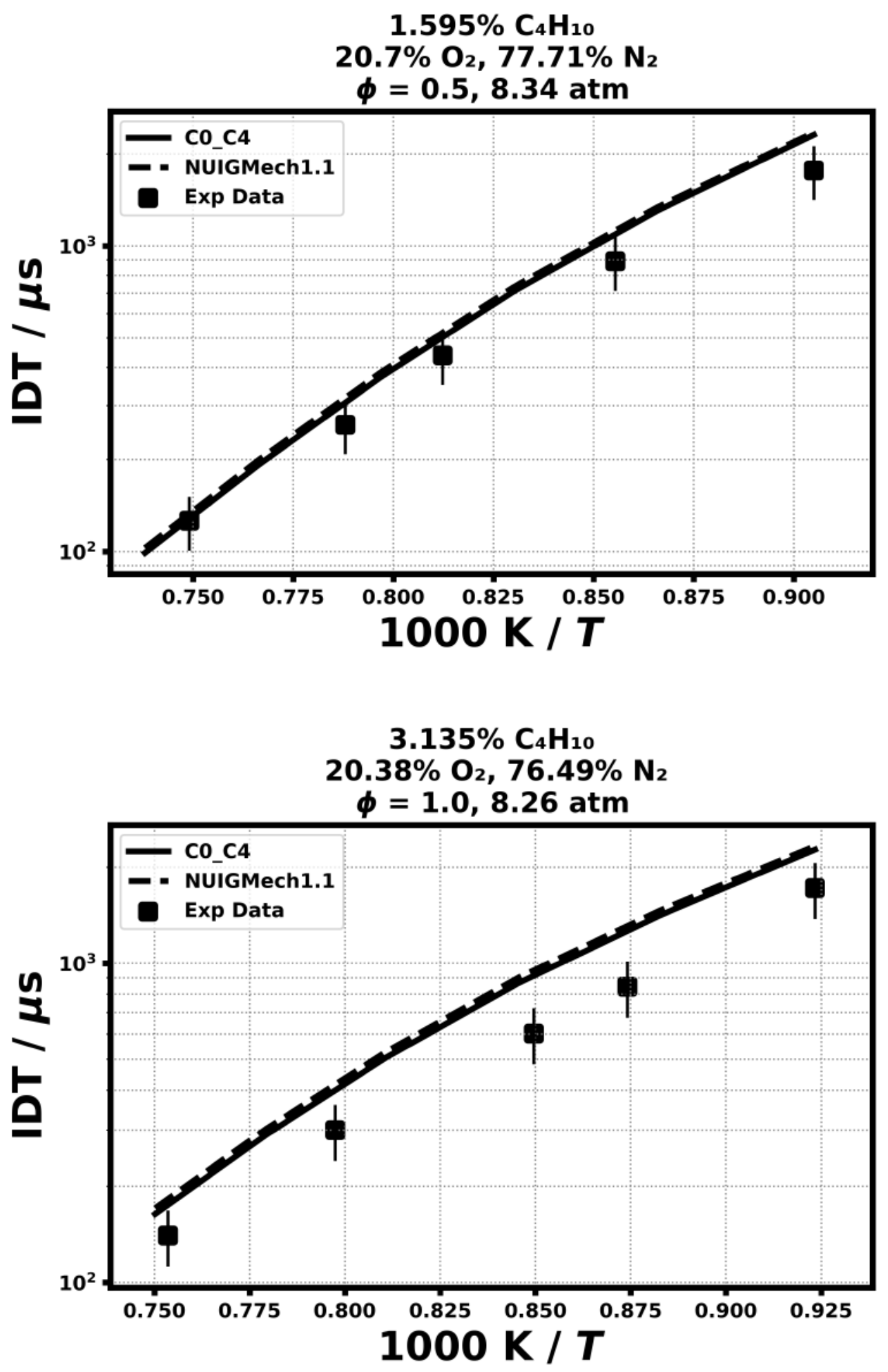


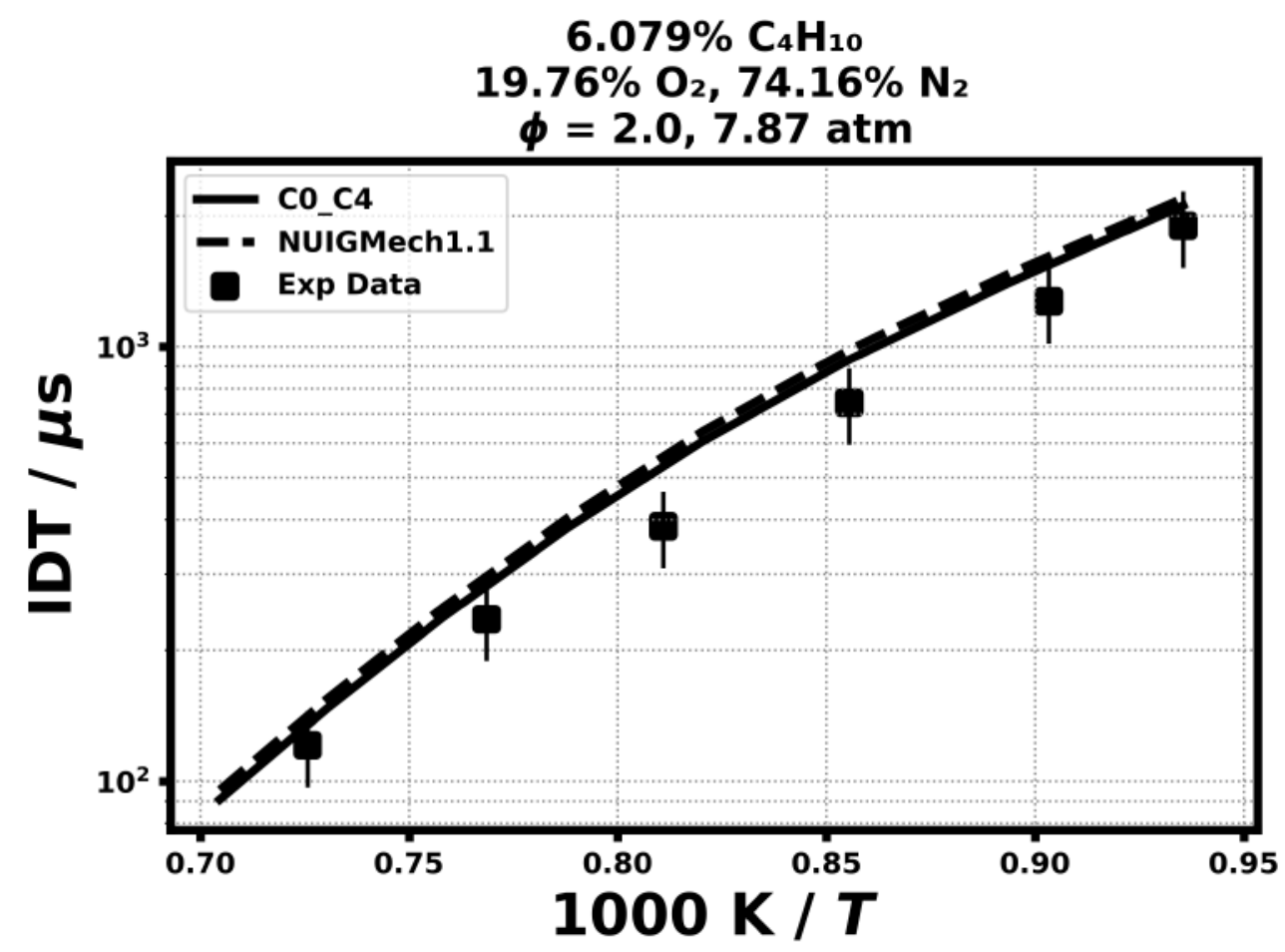




\section{Laminar flame speed}

11.1) Hirasawa, T., Sung, C. J., Joshi, A., Yang, Z., Wang, H., Law, C. K, Proceedings of the Combustion Institute 29 (2002) 1427-1434.

11.2) Davis, S.G., Law, C.K., Combustion Science and Technology 140 (1998) 427-449.

11.3) Bosschaart, K.J., de Goey, L.P.H., Combustion and Flame 136 (2004) 261-269.

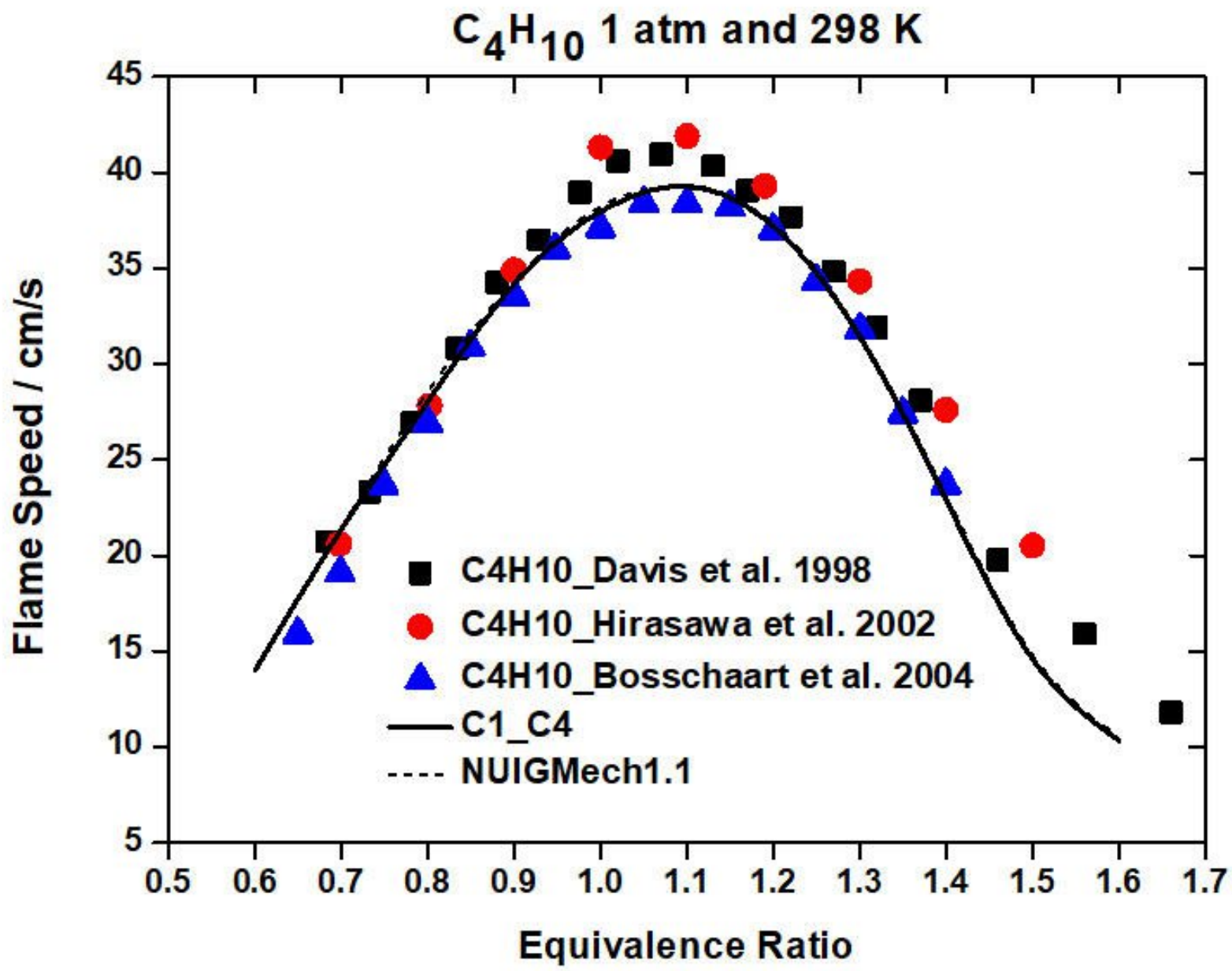




\section{Validation for $\mathrm{C}_{4} \mathrm{H}_{8-1}$}

\section{Shock tube ignition delay time}

12.1) Li, Y., Zhou, C. W., Somers, K. P., Zhang, K., \& Curran, H. J., Proceedings of the Combustion Institute, 36(1) (2017) 403-411.
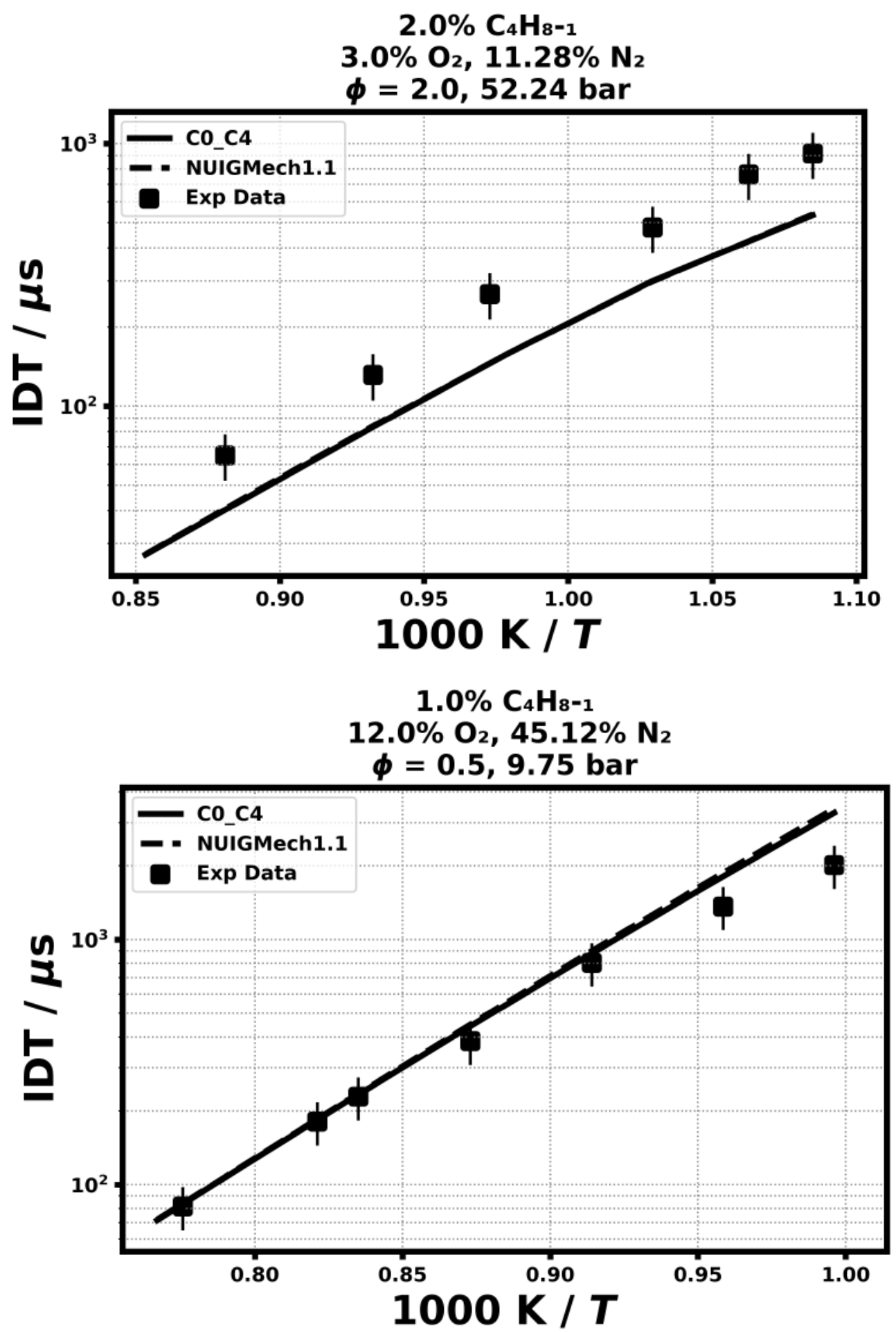

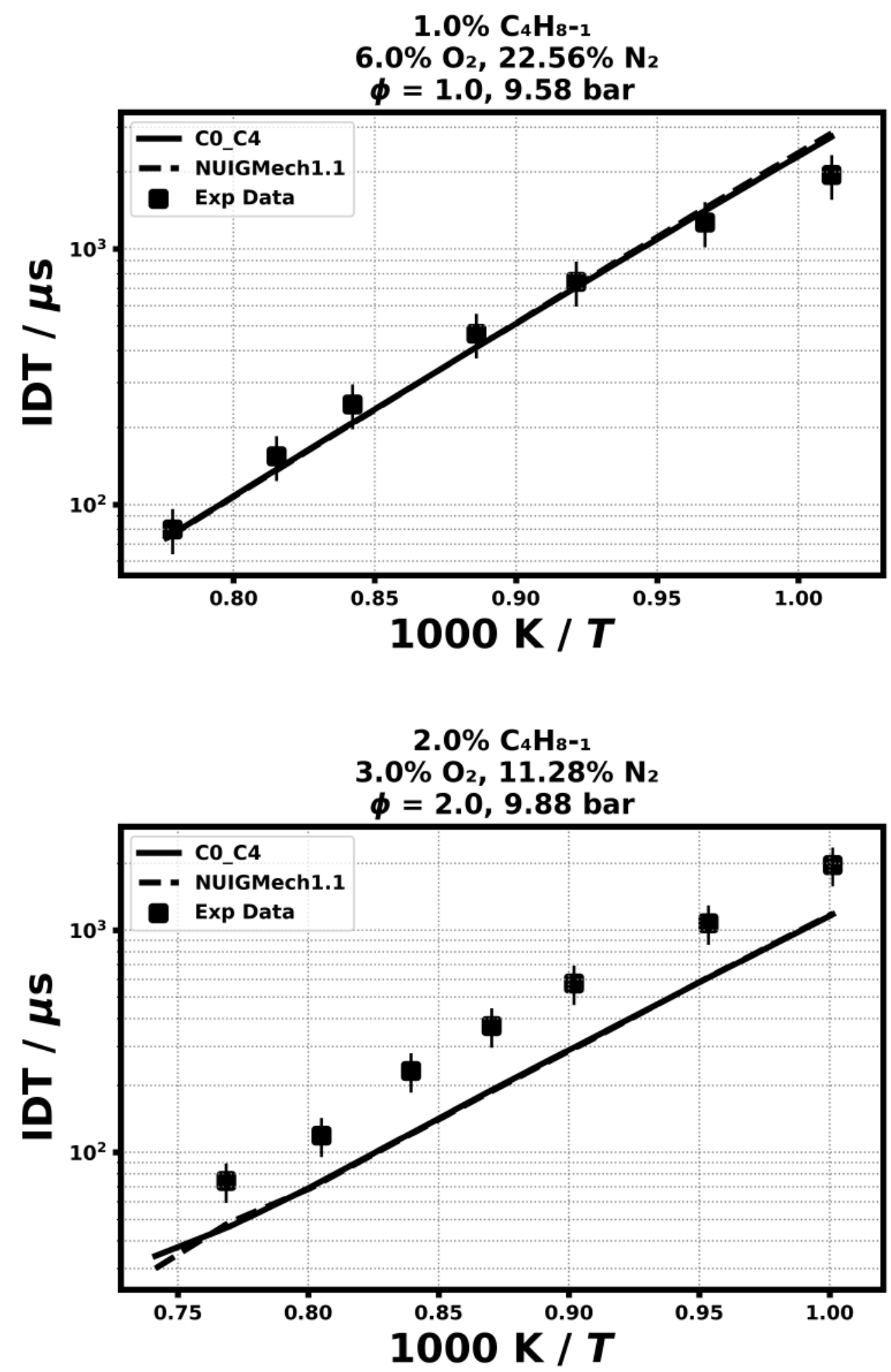

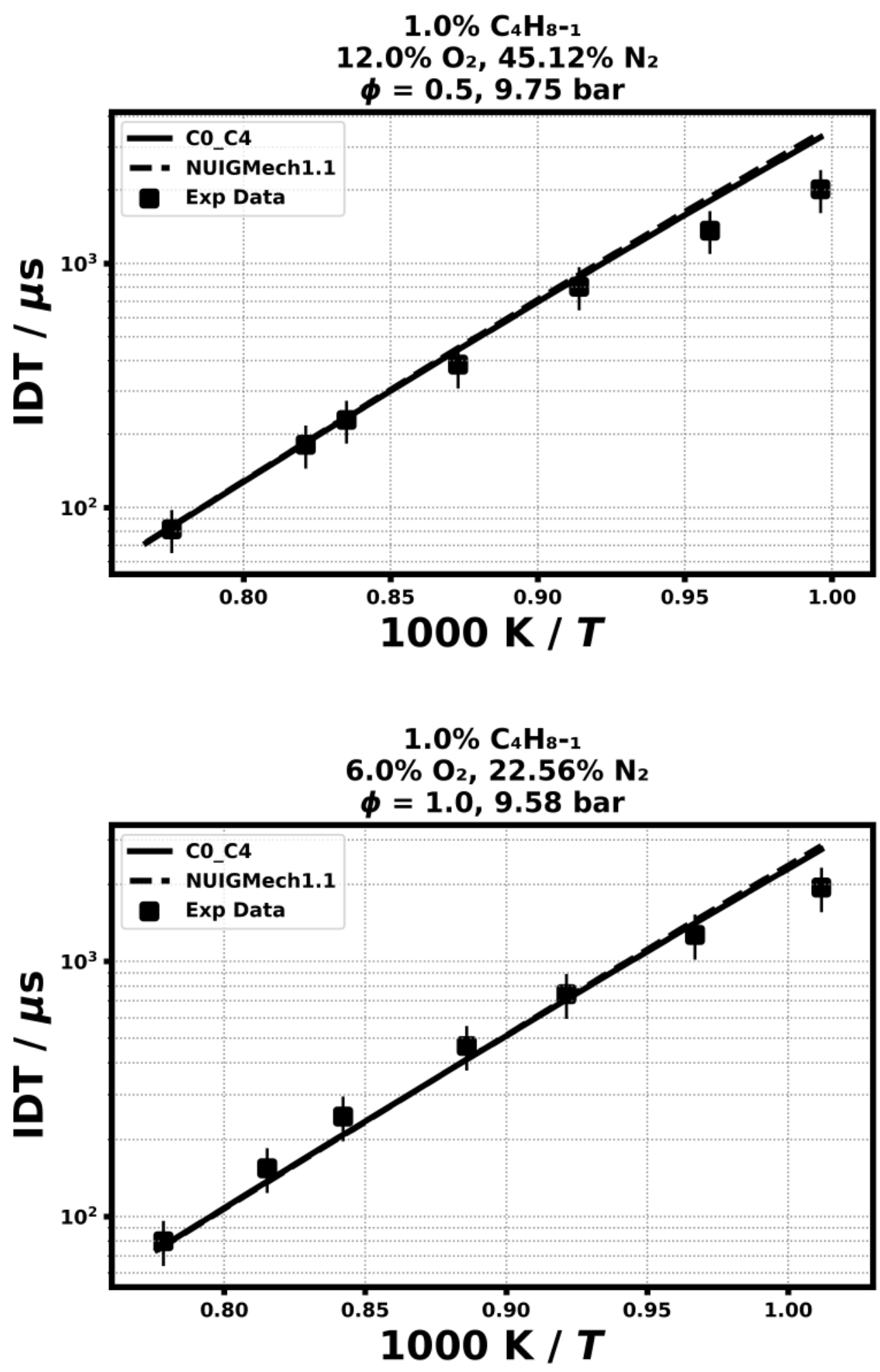

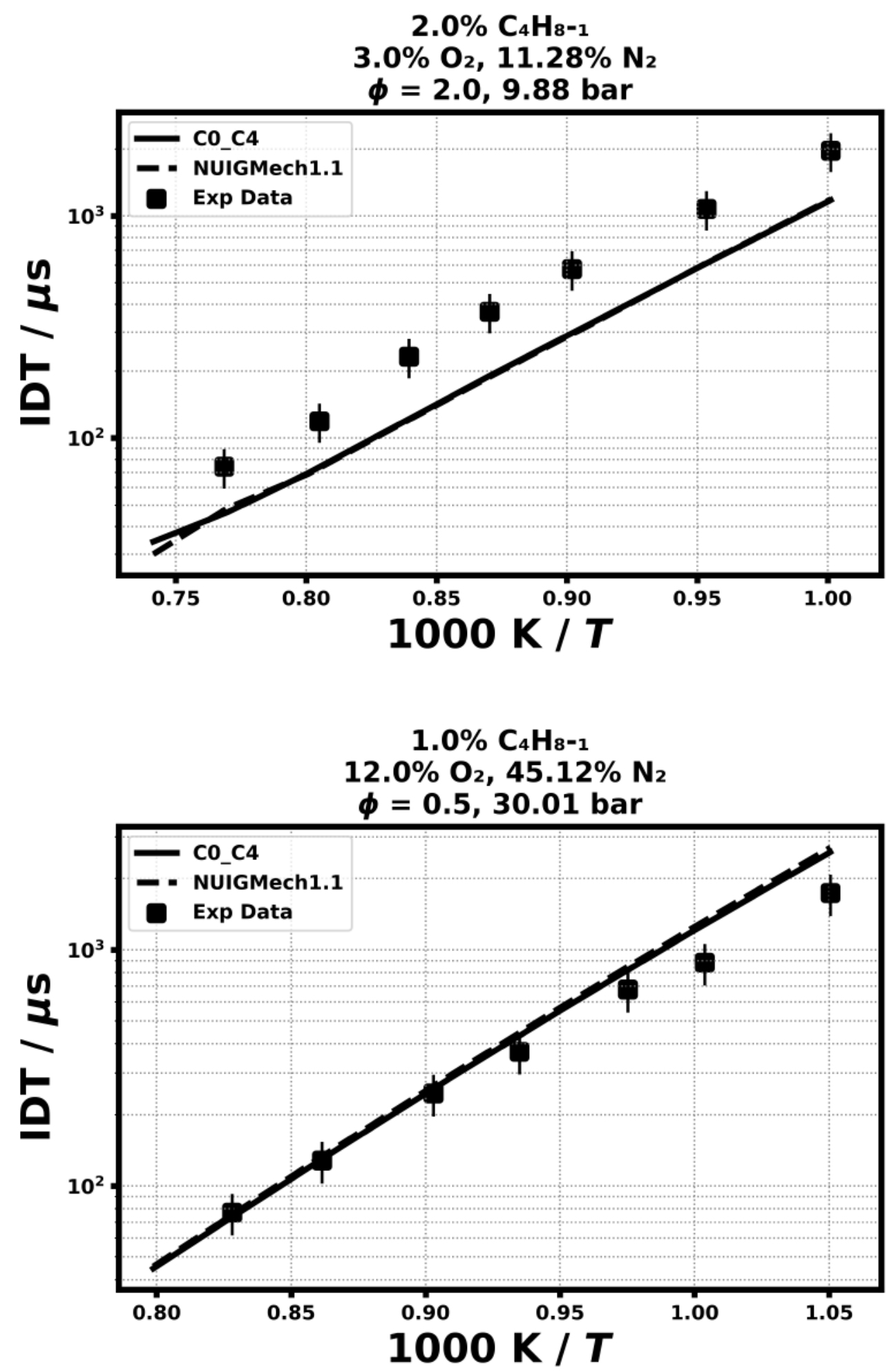

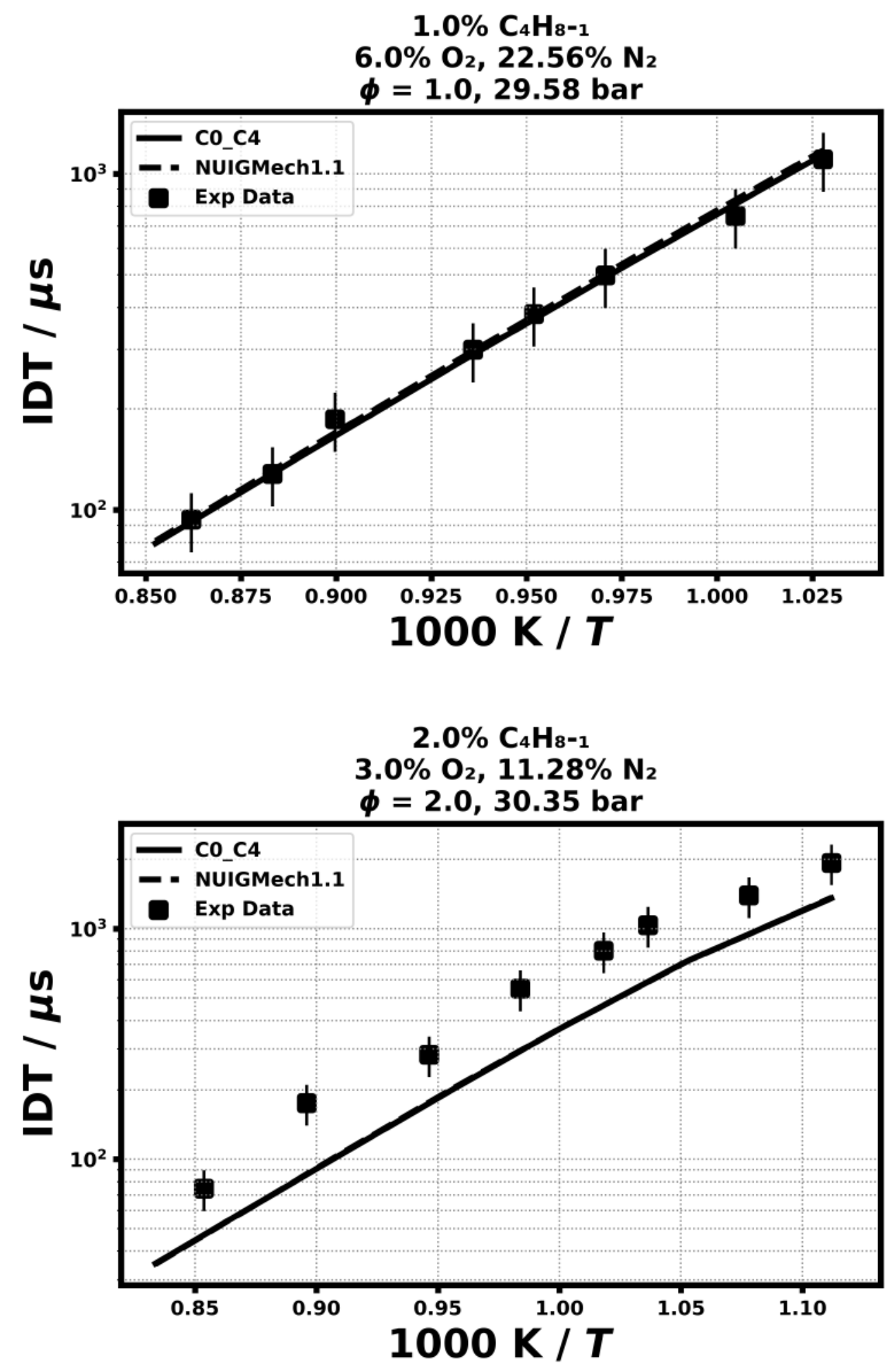

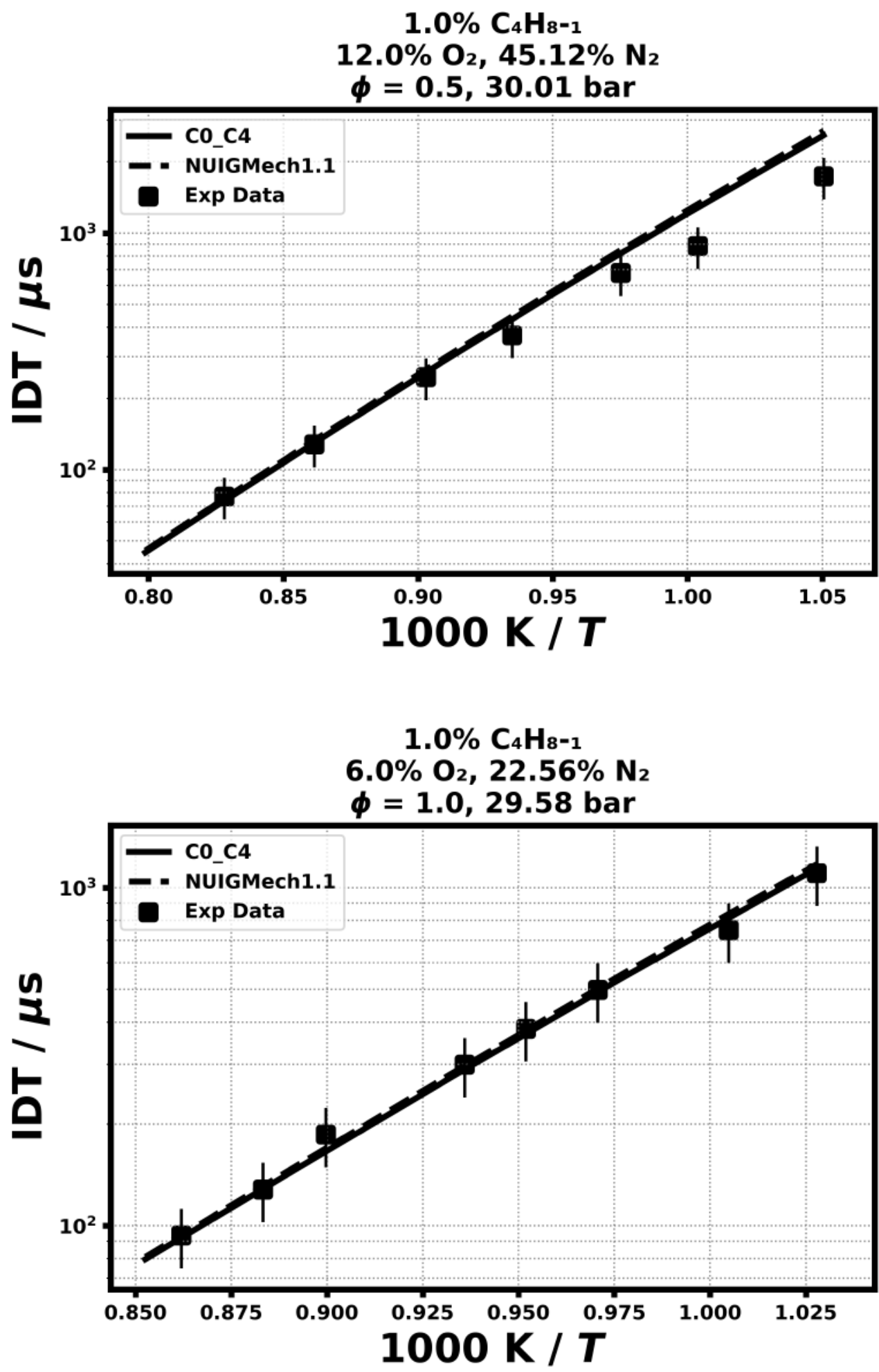

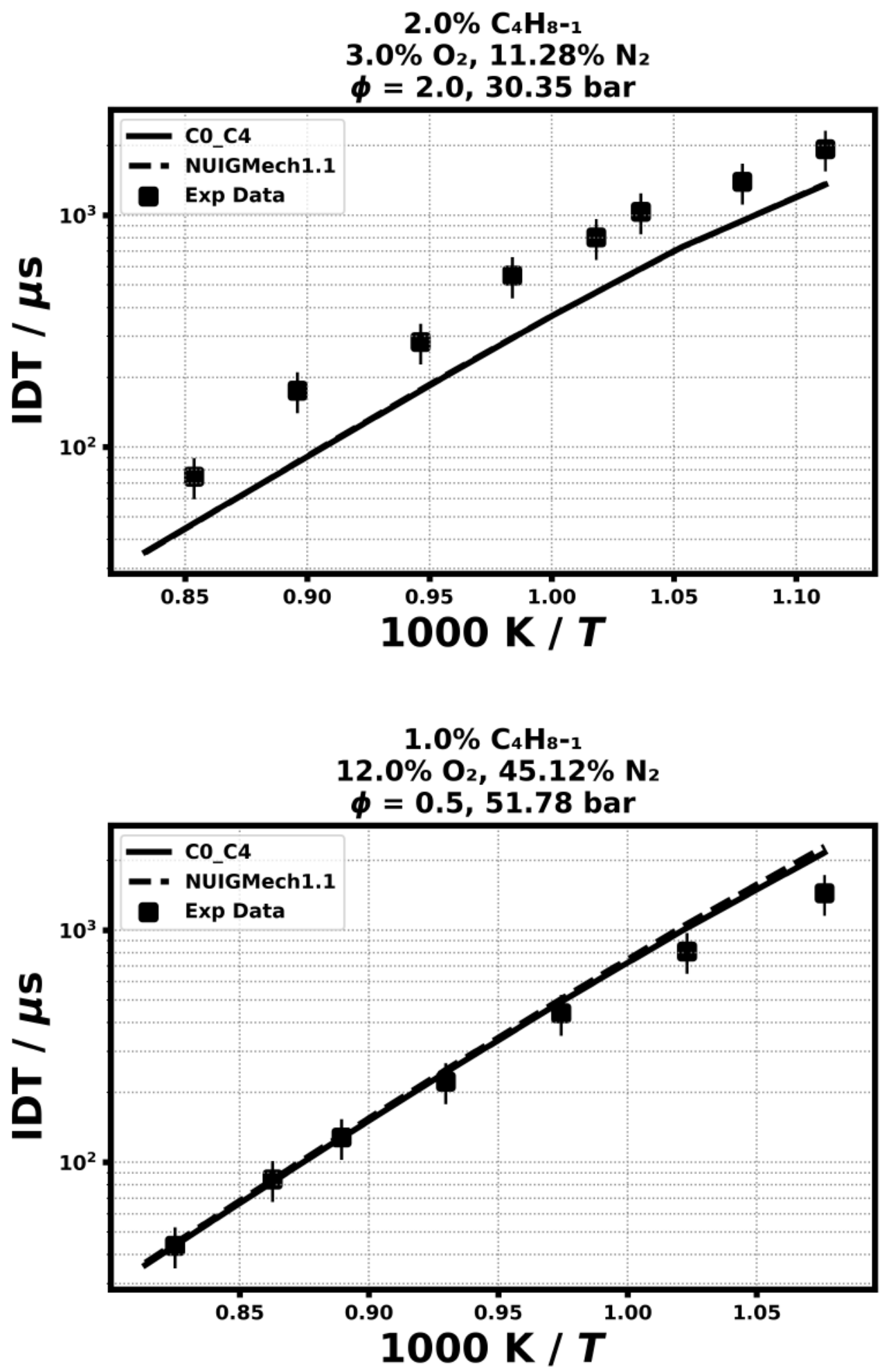

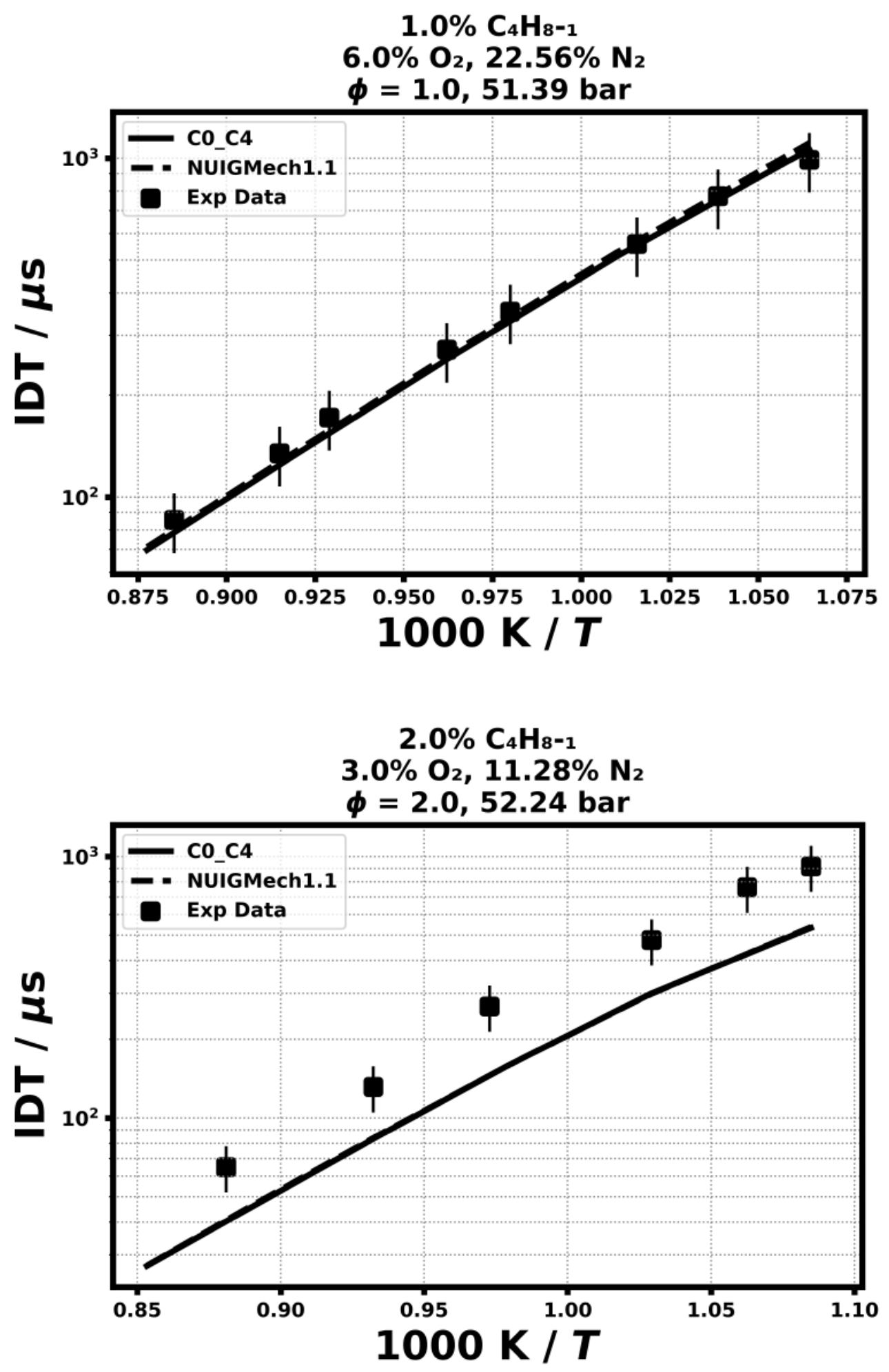

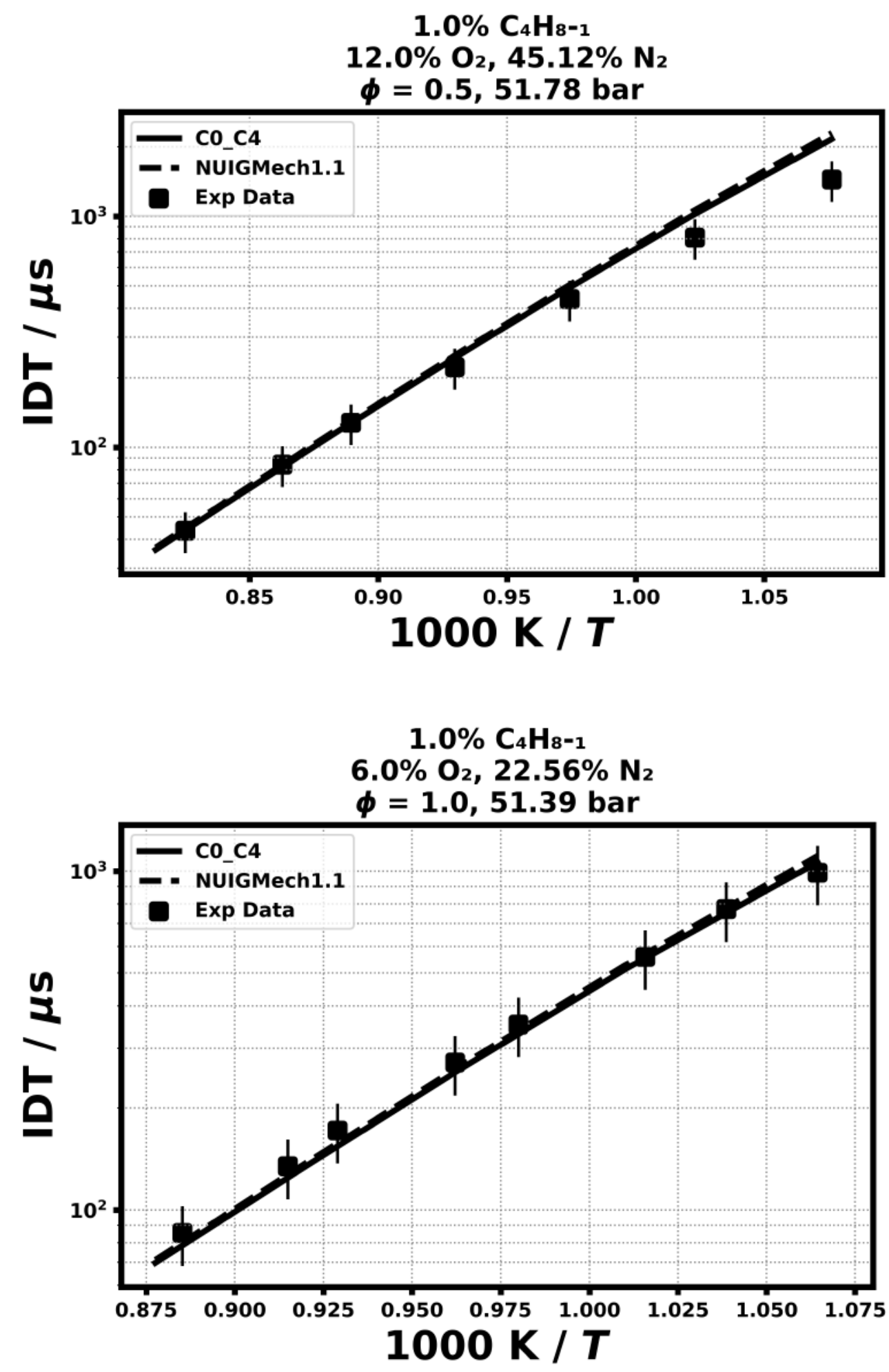
12.2) Pan, L., Hu, E., Zhang, J., Tian, Z., Li, X., \& Huang, Z., Fuel, 157 (2015) 21-27.
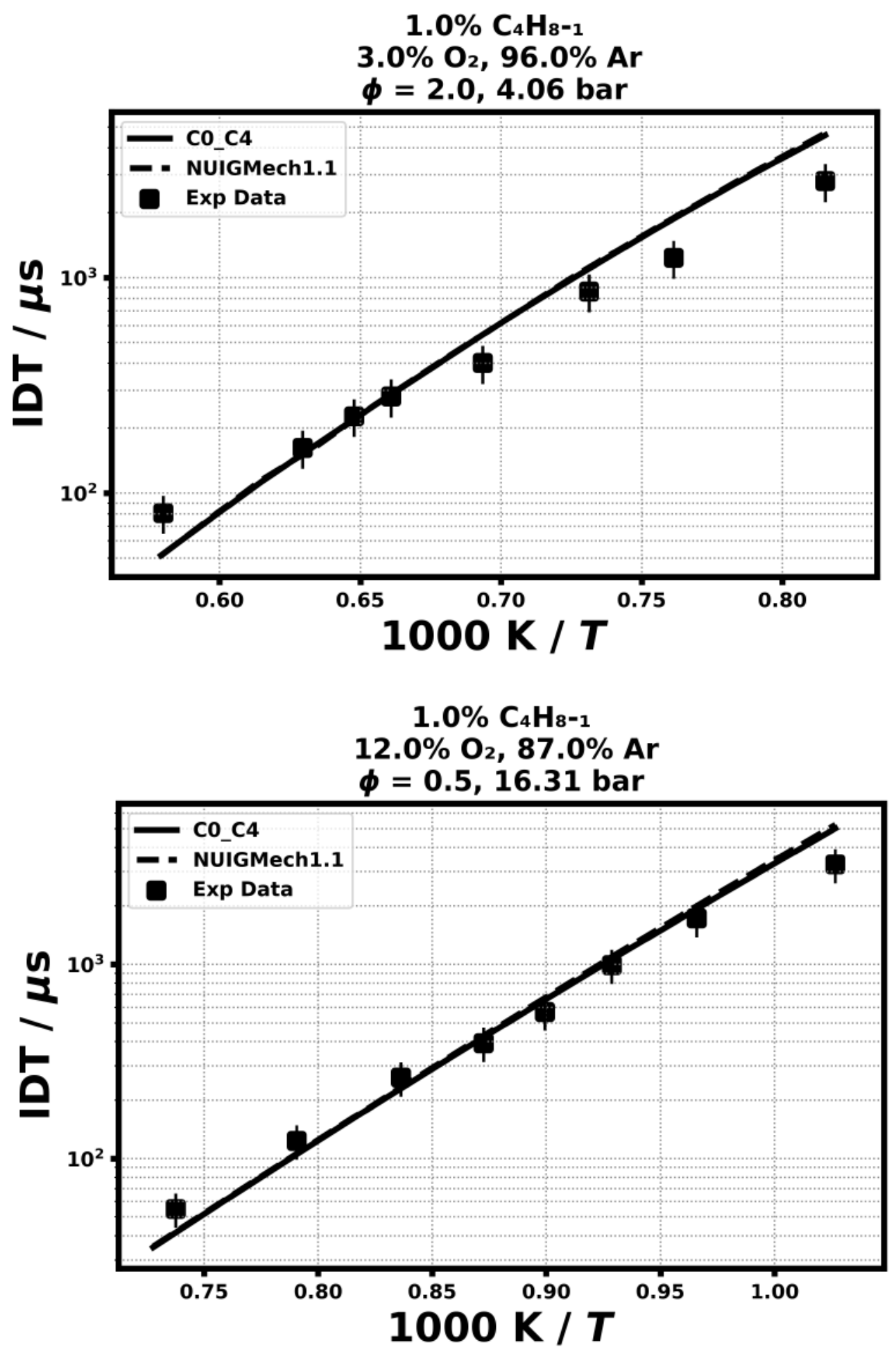

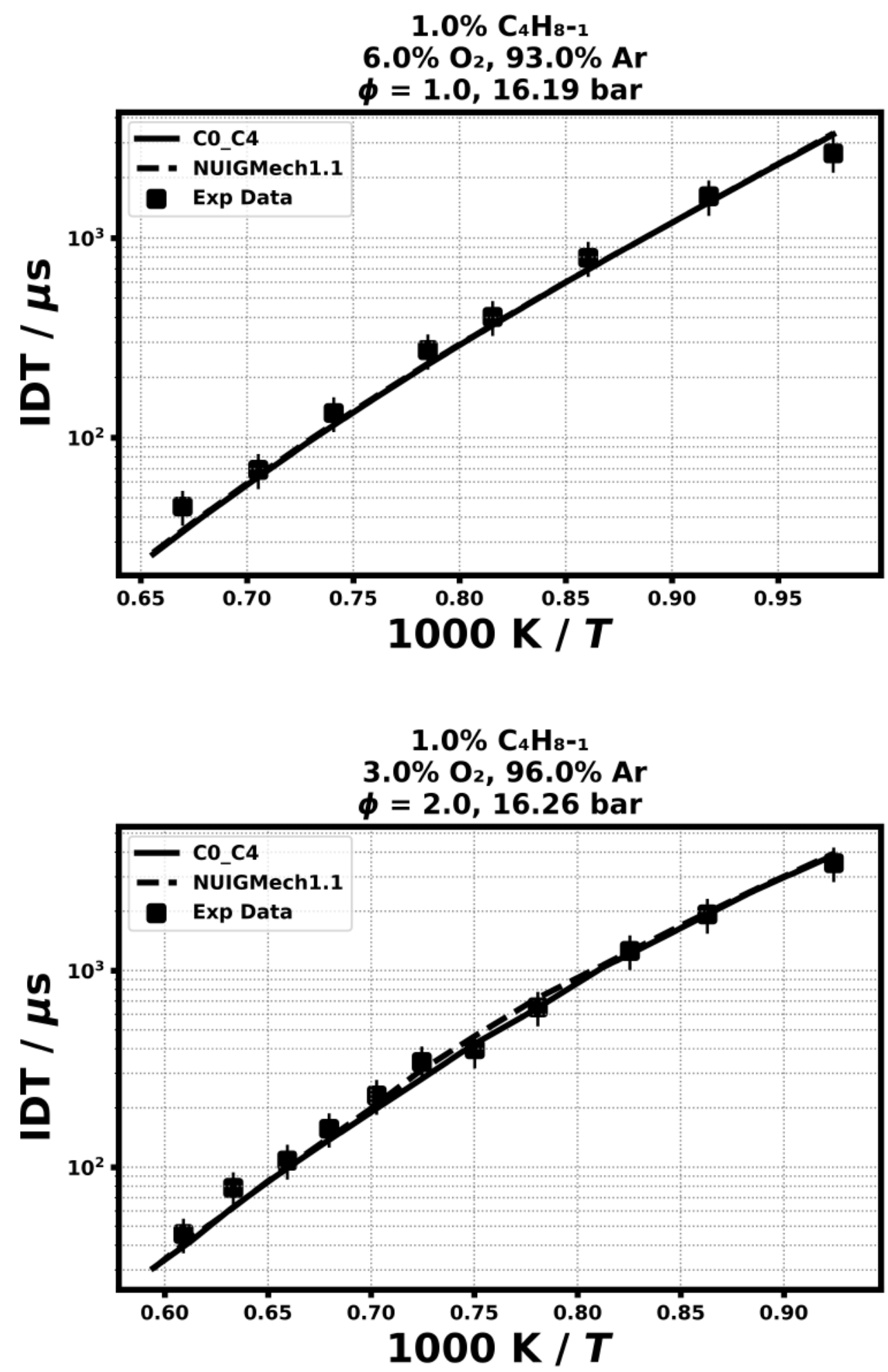

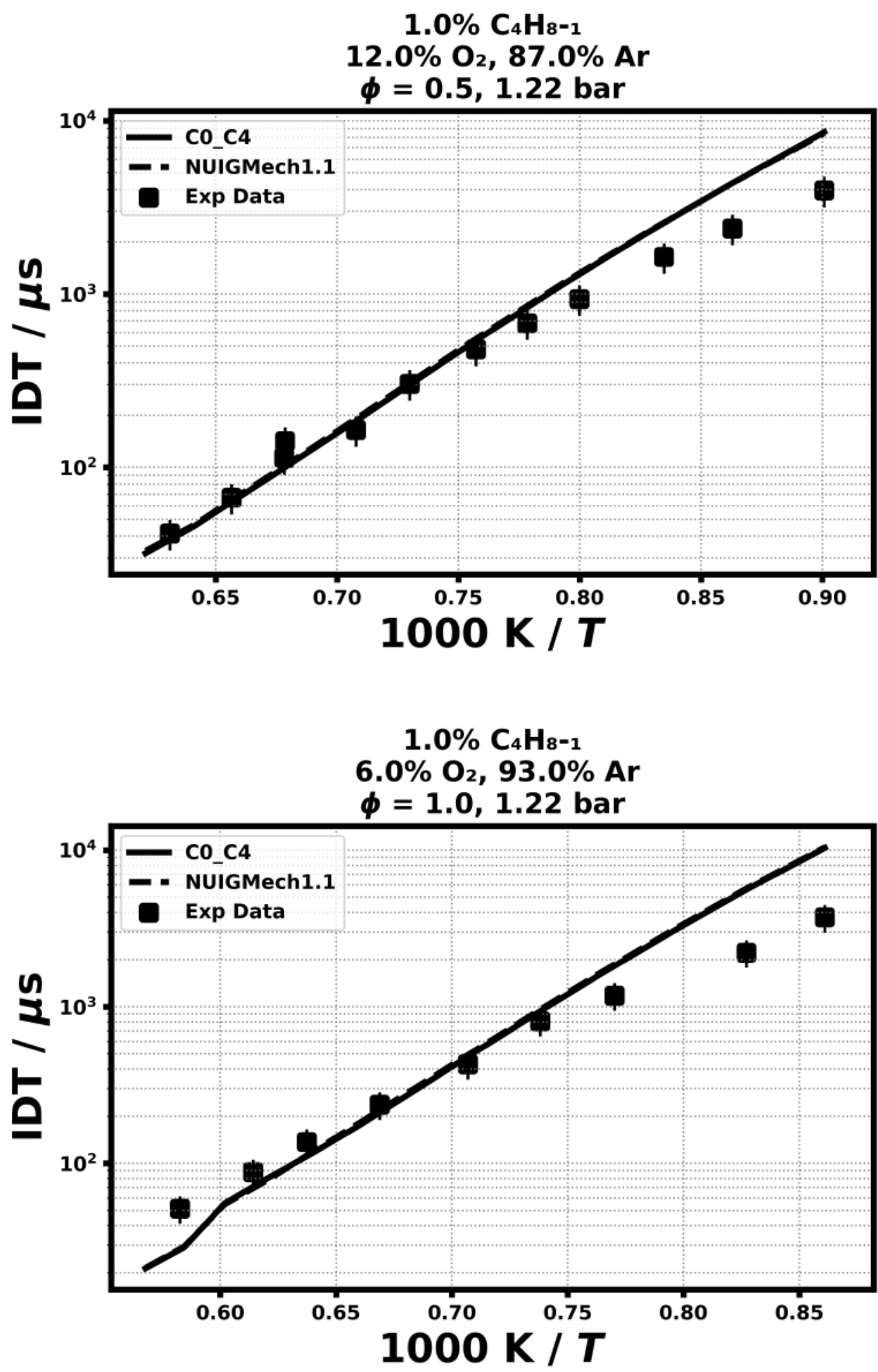

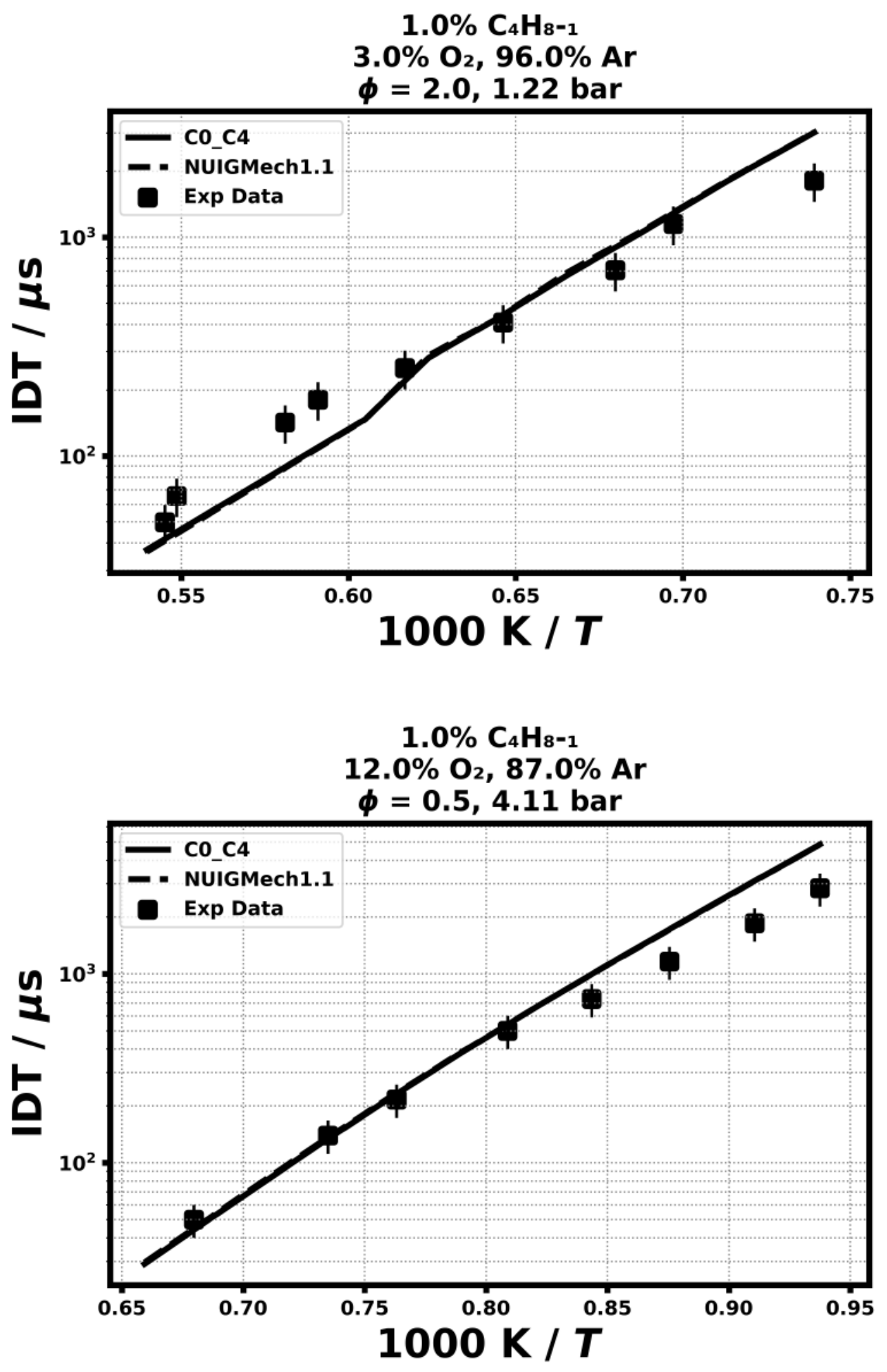


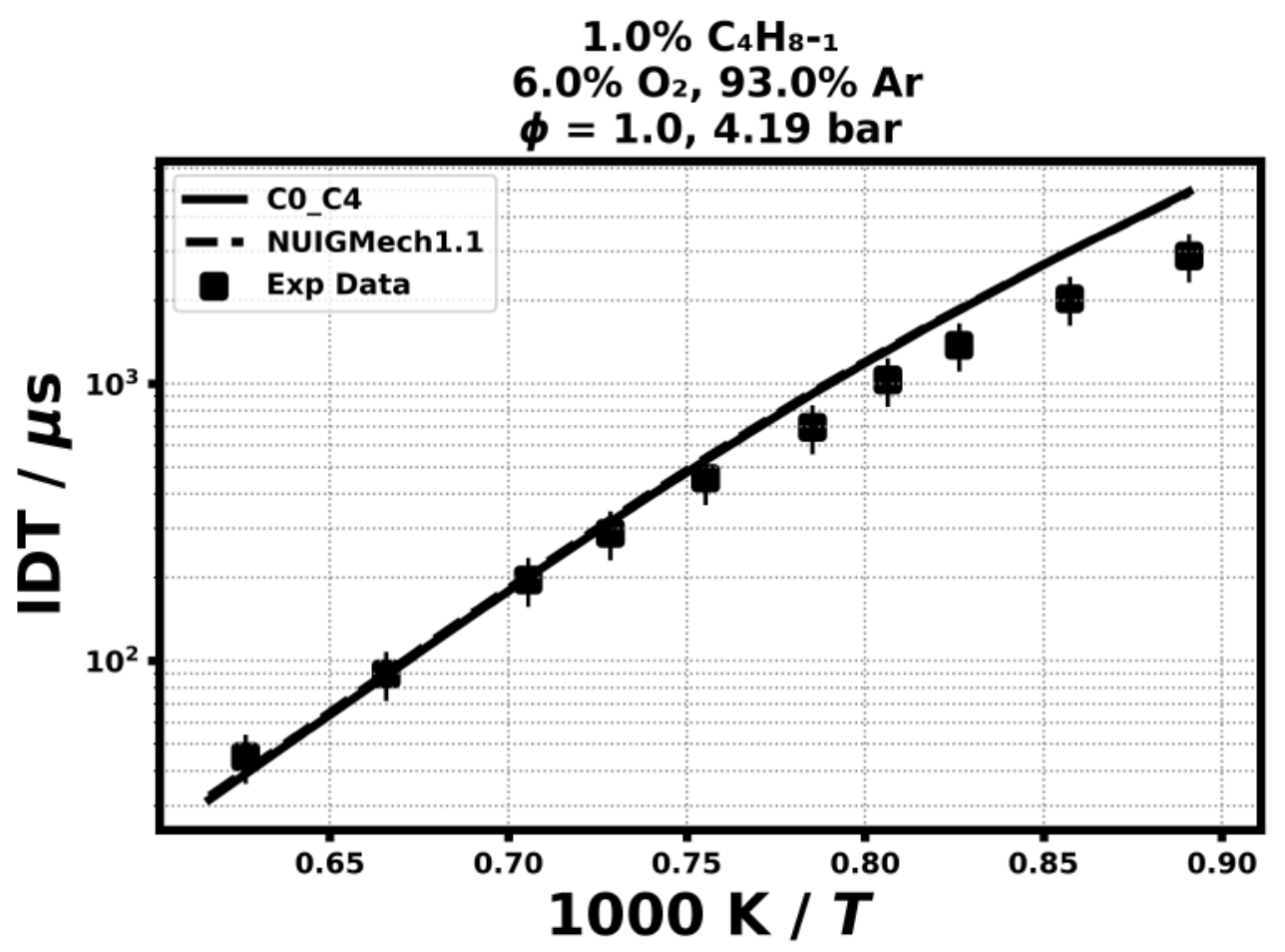




\section{Laminar flame speed}

12.3) Davis, S.G., Law, C.K., Combustion Science and Technology 140 (1998) 427-449.

12.4) Zhao, P., Yuan, W., Sun, H., Li, Y., Kelley, A. P., Zheng, X., \& Law, C. K.

Proceedings of the Combustion Institute, 35(1) (2015) 309-316.

12.5) Fenard, Y., Dayma, G., Halter, F., Foucher, F., Serinyel, Z., \& Dagaut, P. Energy \& Fuels, 29(2) (2015) 1107-1118.

12.6) Li, Y., Zhou, C. W., Somers, K. P., Zhang, K., \& Curran, H. J., Proceedings of the Combustion Institute, 36(1) (2017) 403-411.

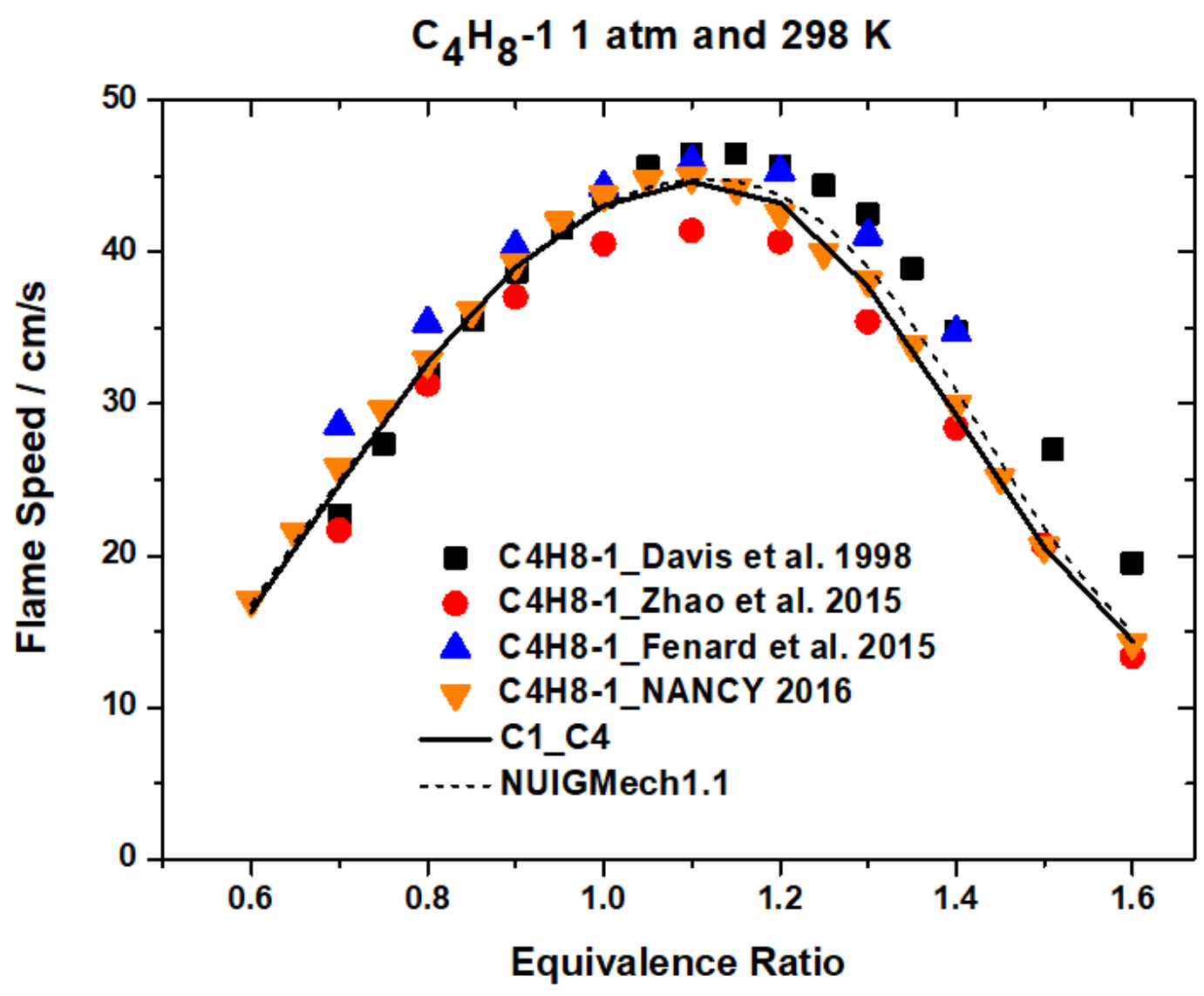




\section{Validation for $\mathrm{iC}_{4} \mathrm{H}_{8}$}

\section{Shock tube ignition delay time}

13.1) Li, Y., Zhou, C. W., Somers, K. P., Zhang, K., \& Curran, H. J., Proceedings of the Combustion Institute, 36(1) (2017) 403-411.
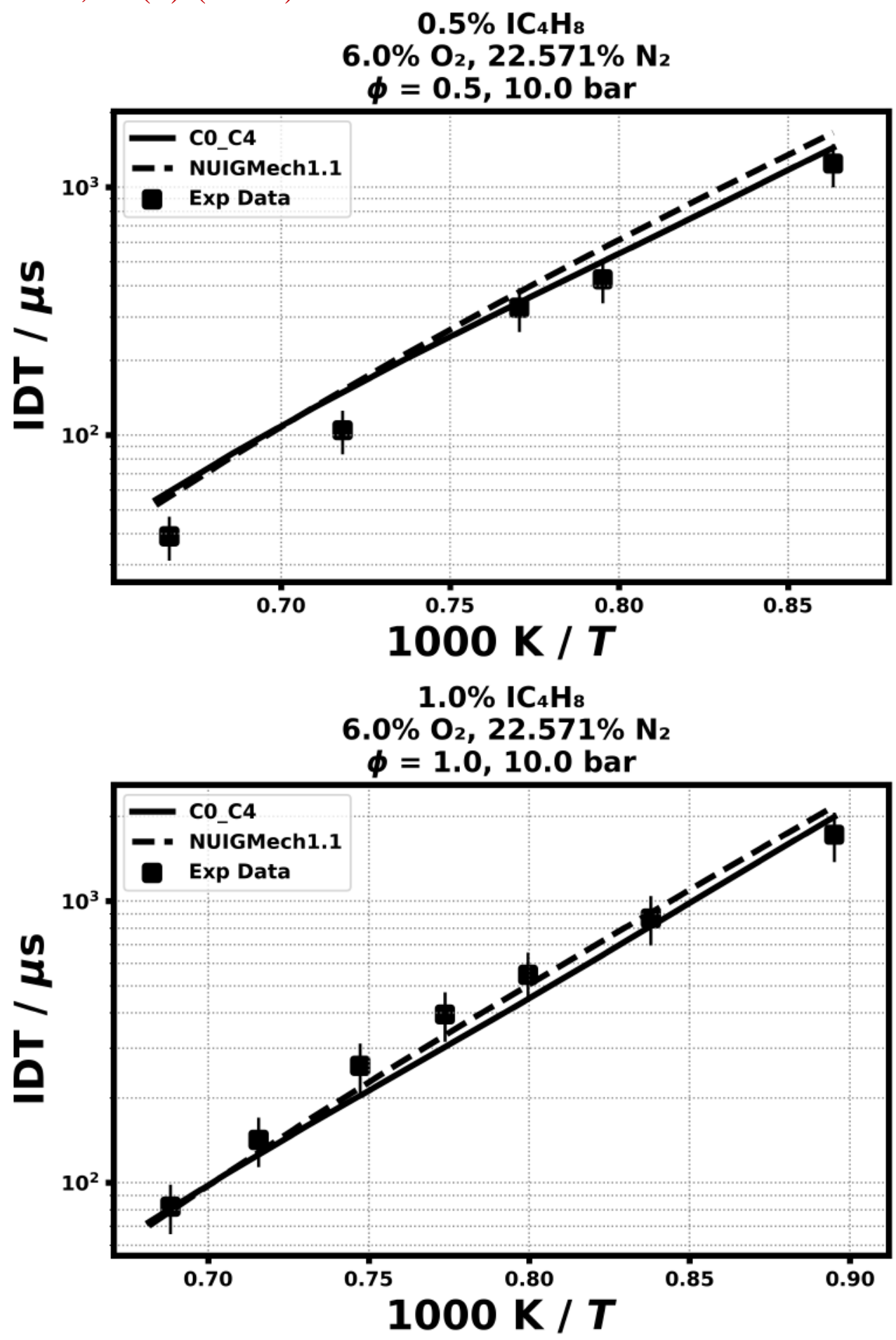

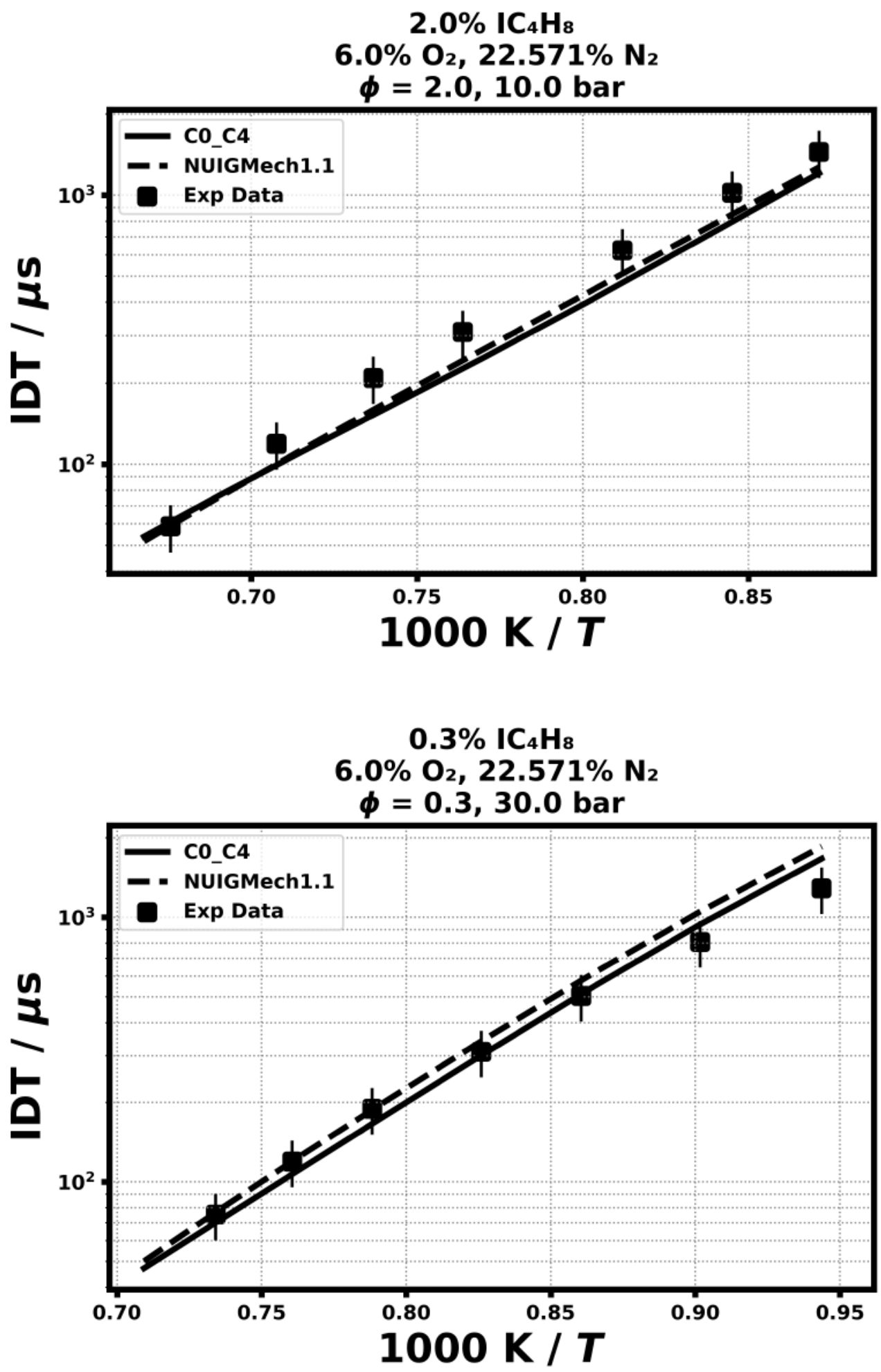

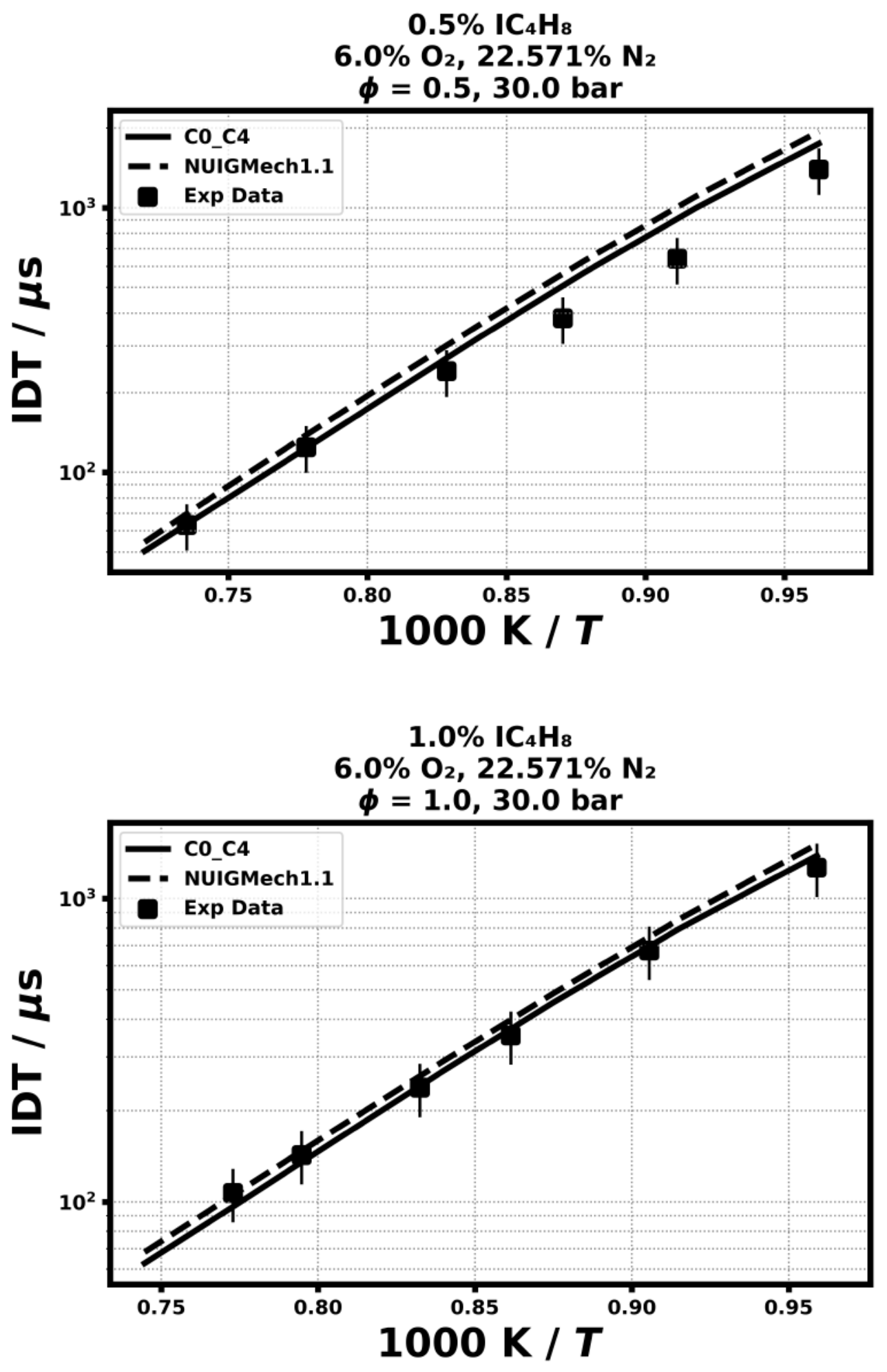

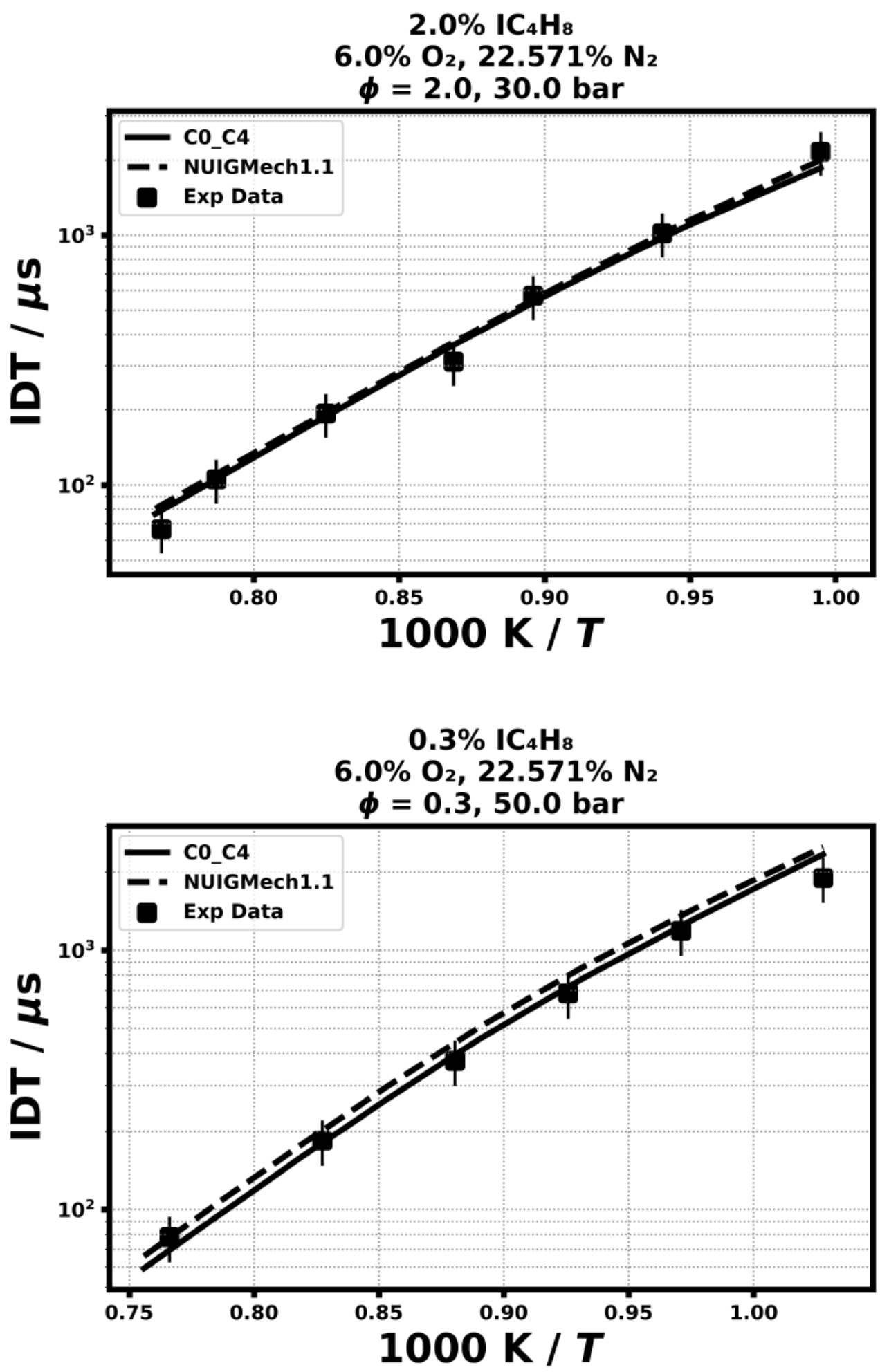

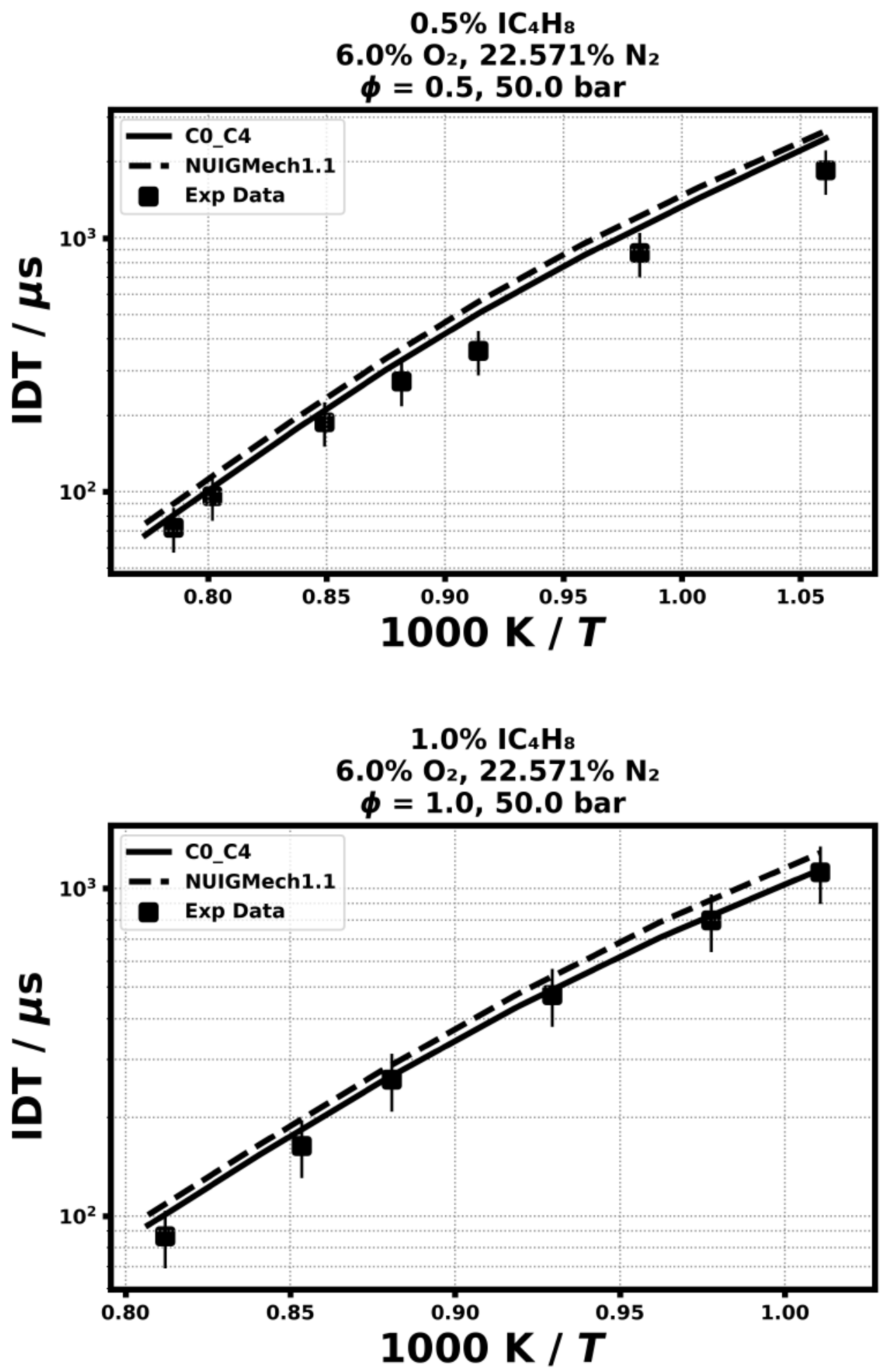


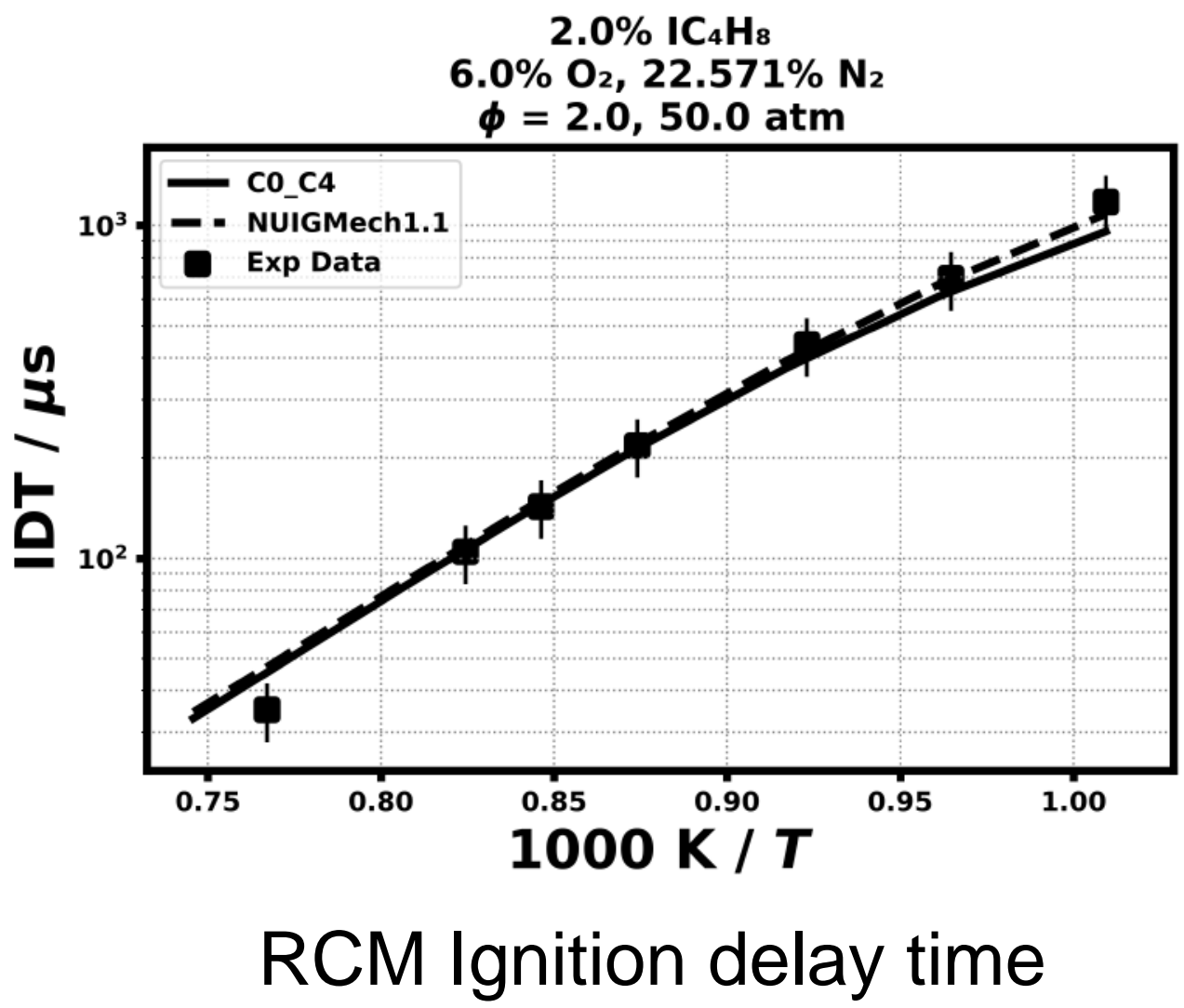

13.2) Li, Y., Zhou, C. W., Somers, K. P., Zhang, K., \& Curran, H. J., Proceedings of the Combustion Institute, 36(1) (2017) 403-411.

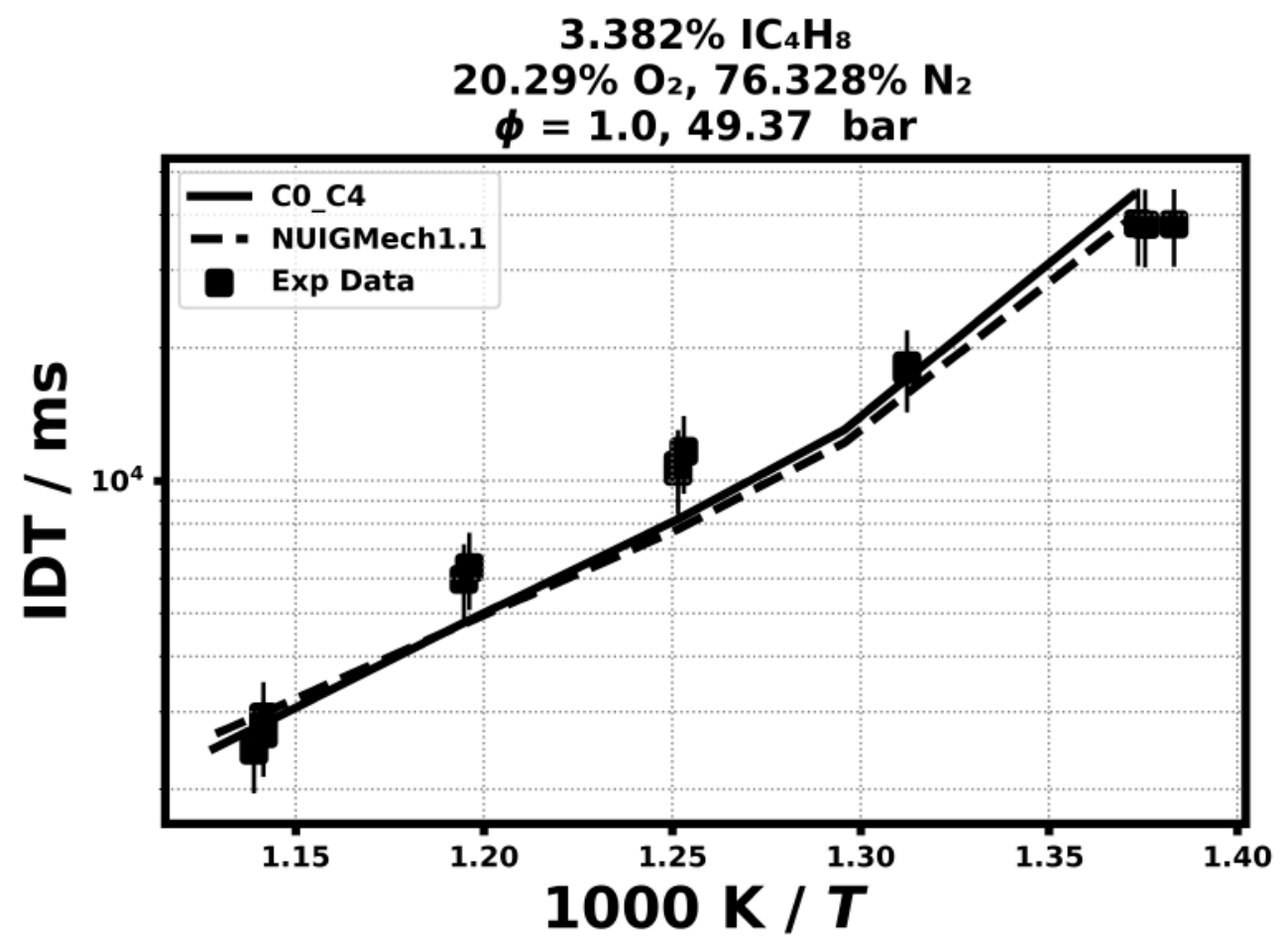



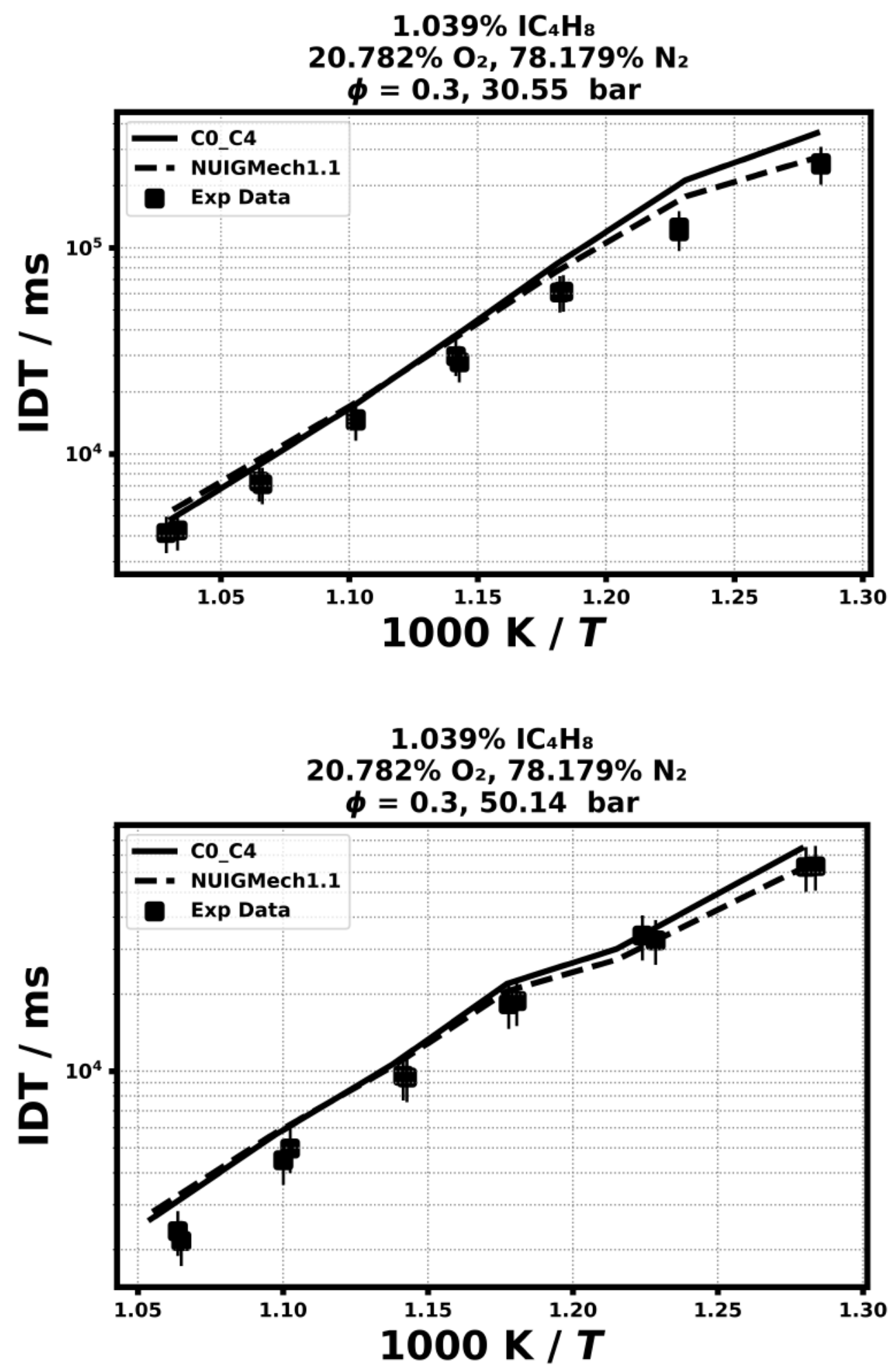

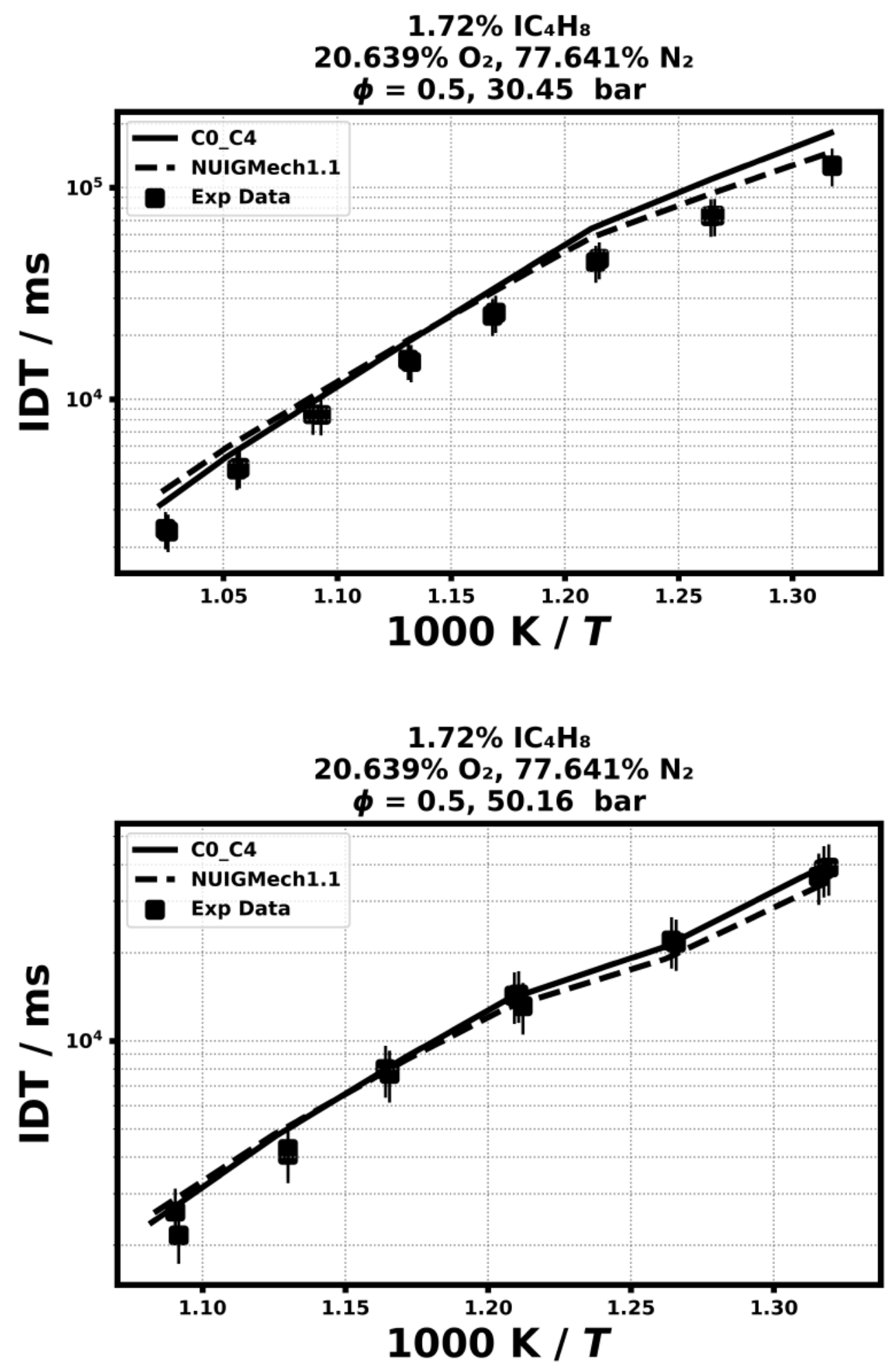

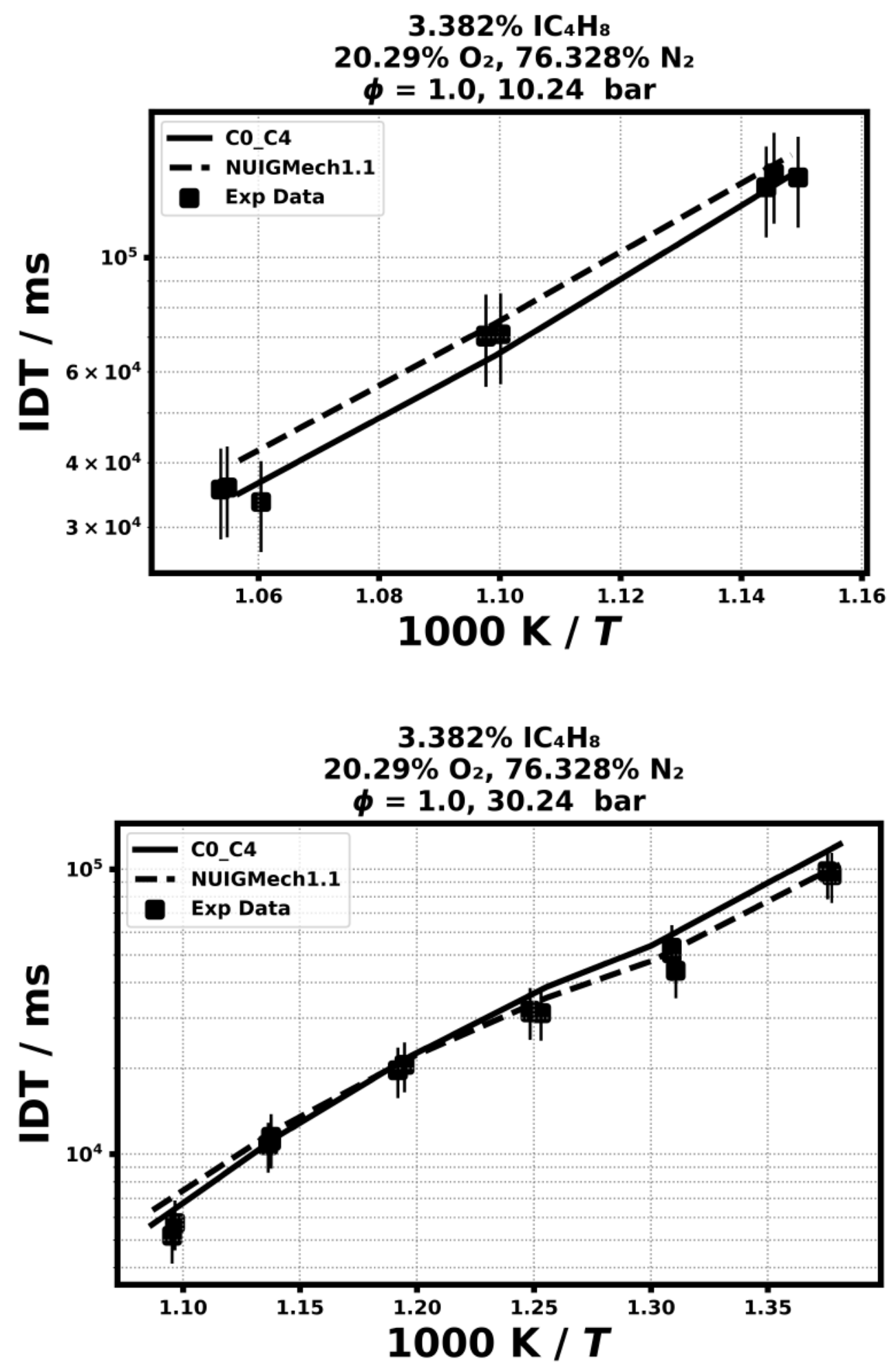


\section{Laminar flame speed}

13.3) Zhou, C. W., Li, Y., O'Connor, E., Somers, K. P., Thion, S., Keesee, C., ... \& Kukkadapu, G., Combustion and Flame, 167 (2016) 353-379.

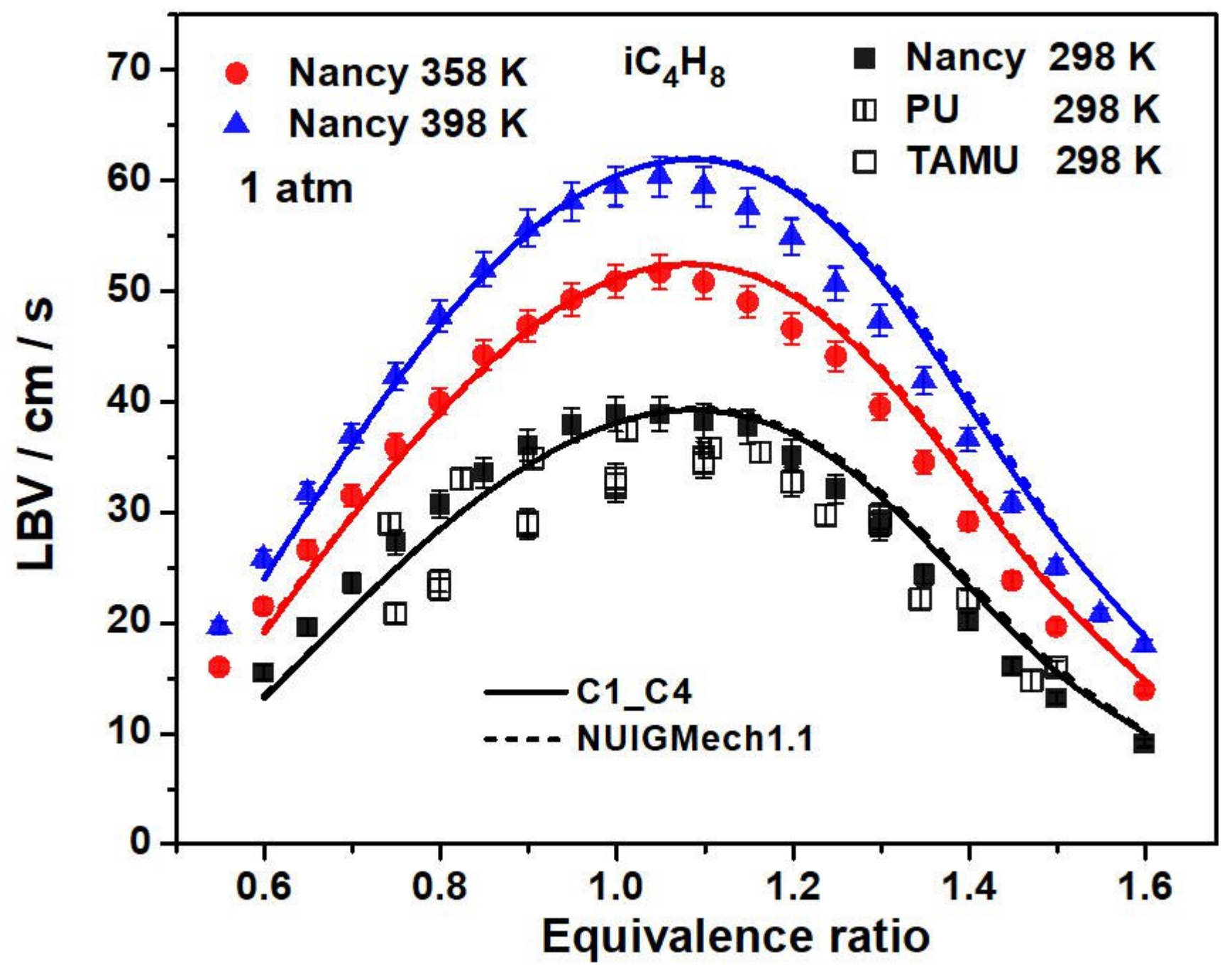




\section{Shock tube ignition delay time}

14.1) Zhou, C. W., Li, Y., Burke, U., Banyon, C., Somers, K. P., Ding, S., ... \& Petersen, E. L., Combustion and Flame, 197 (2018) 423-438.
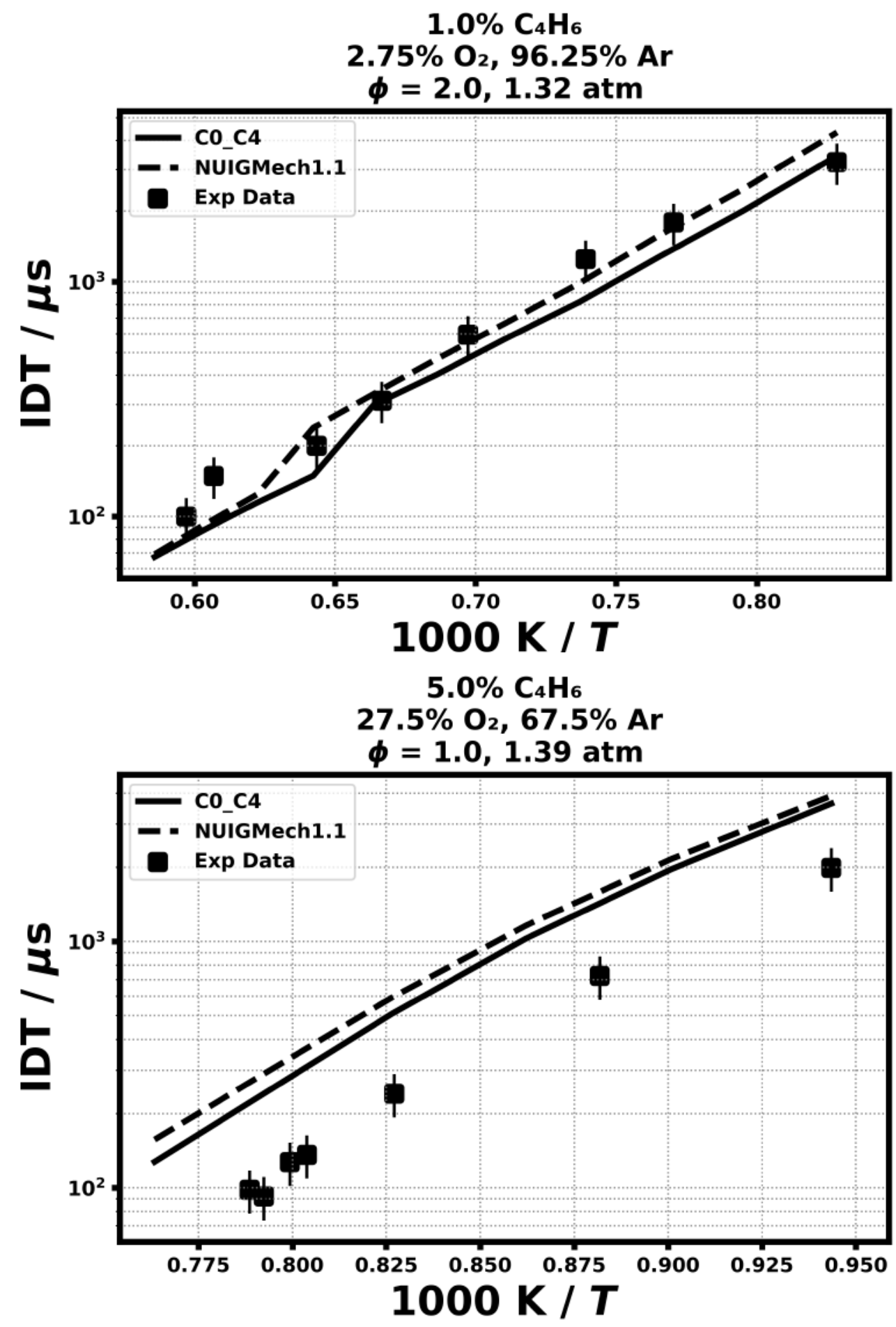

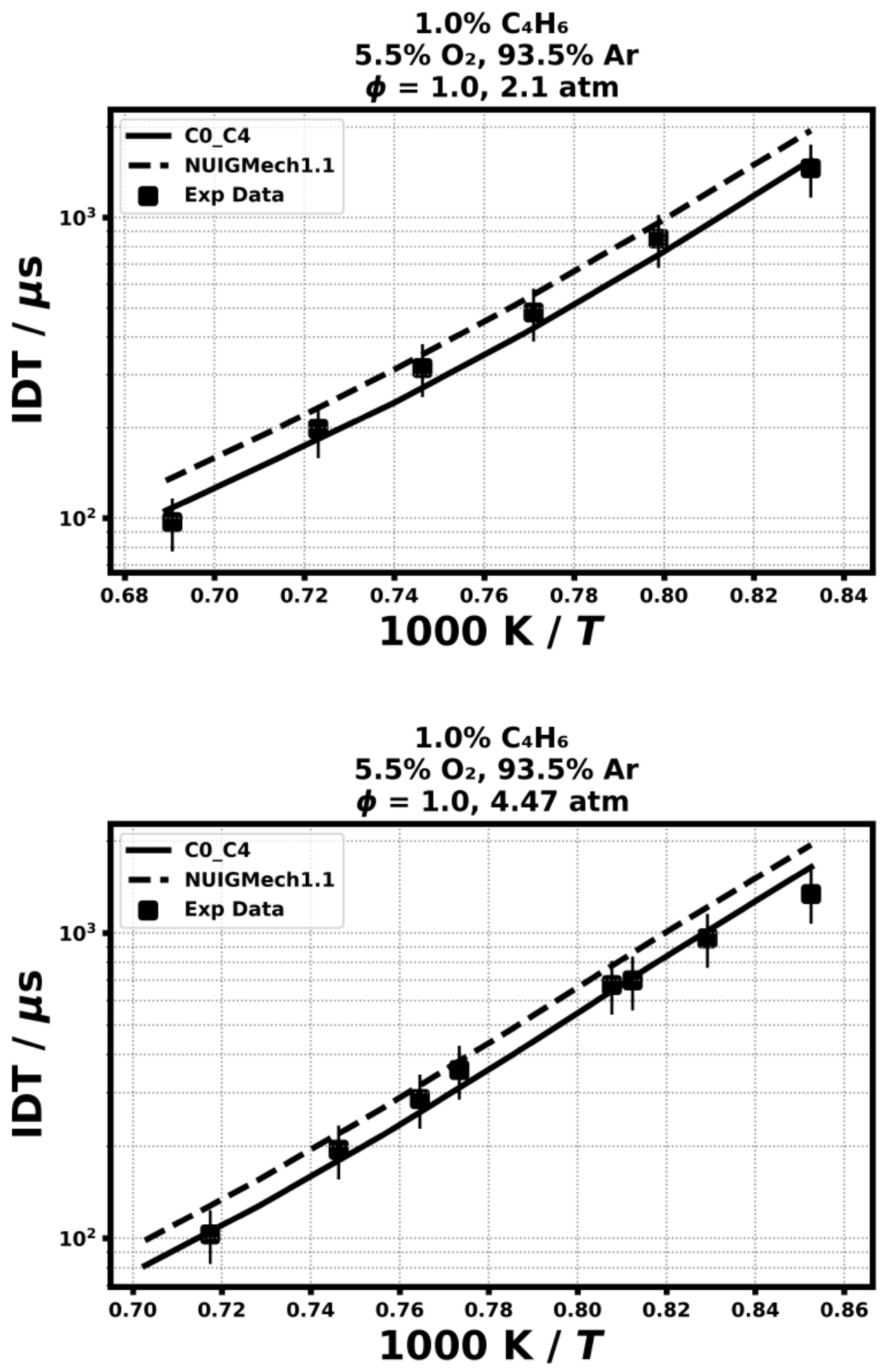

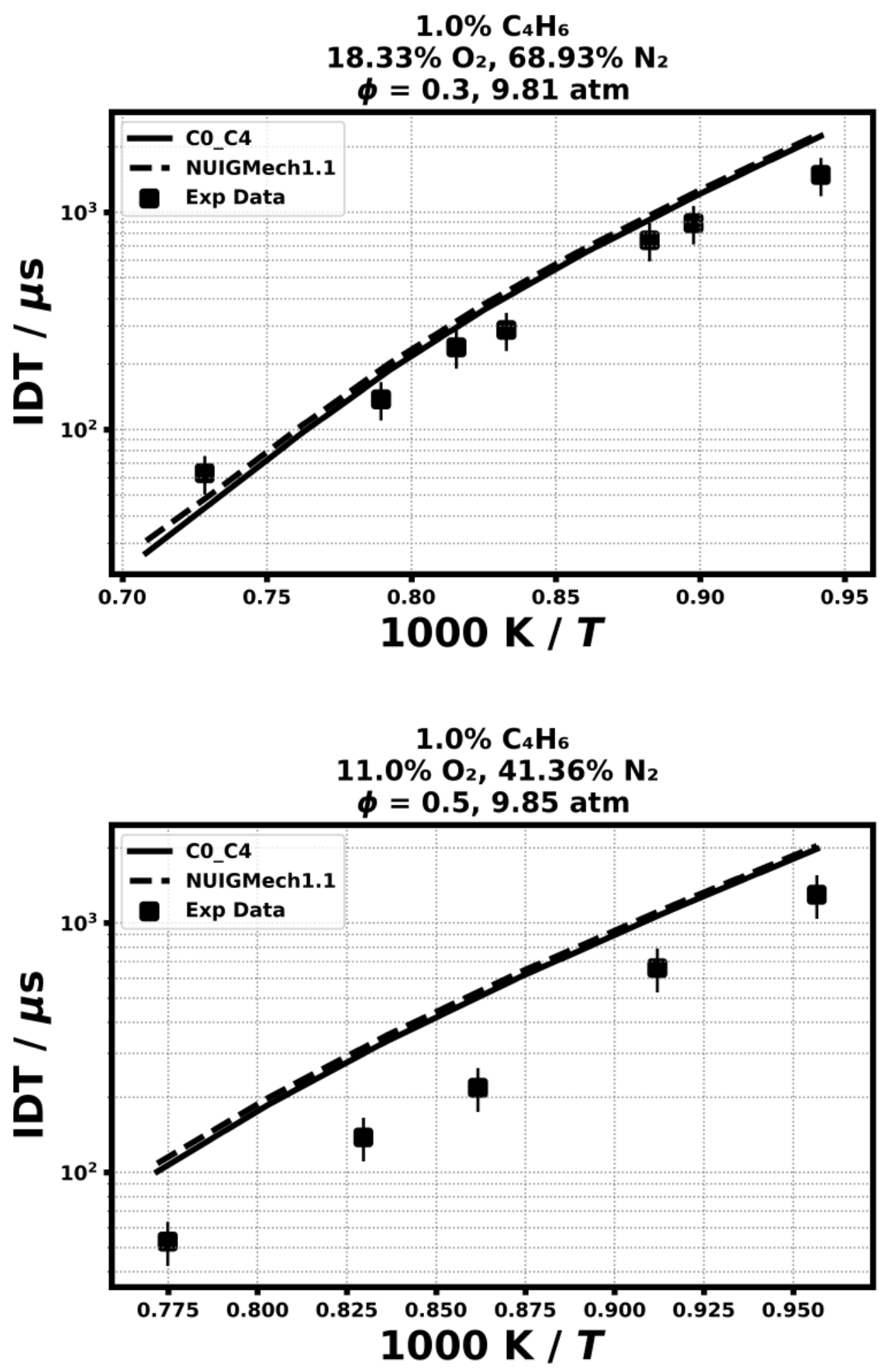

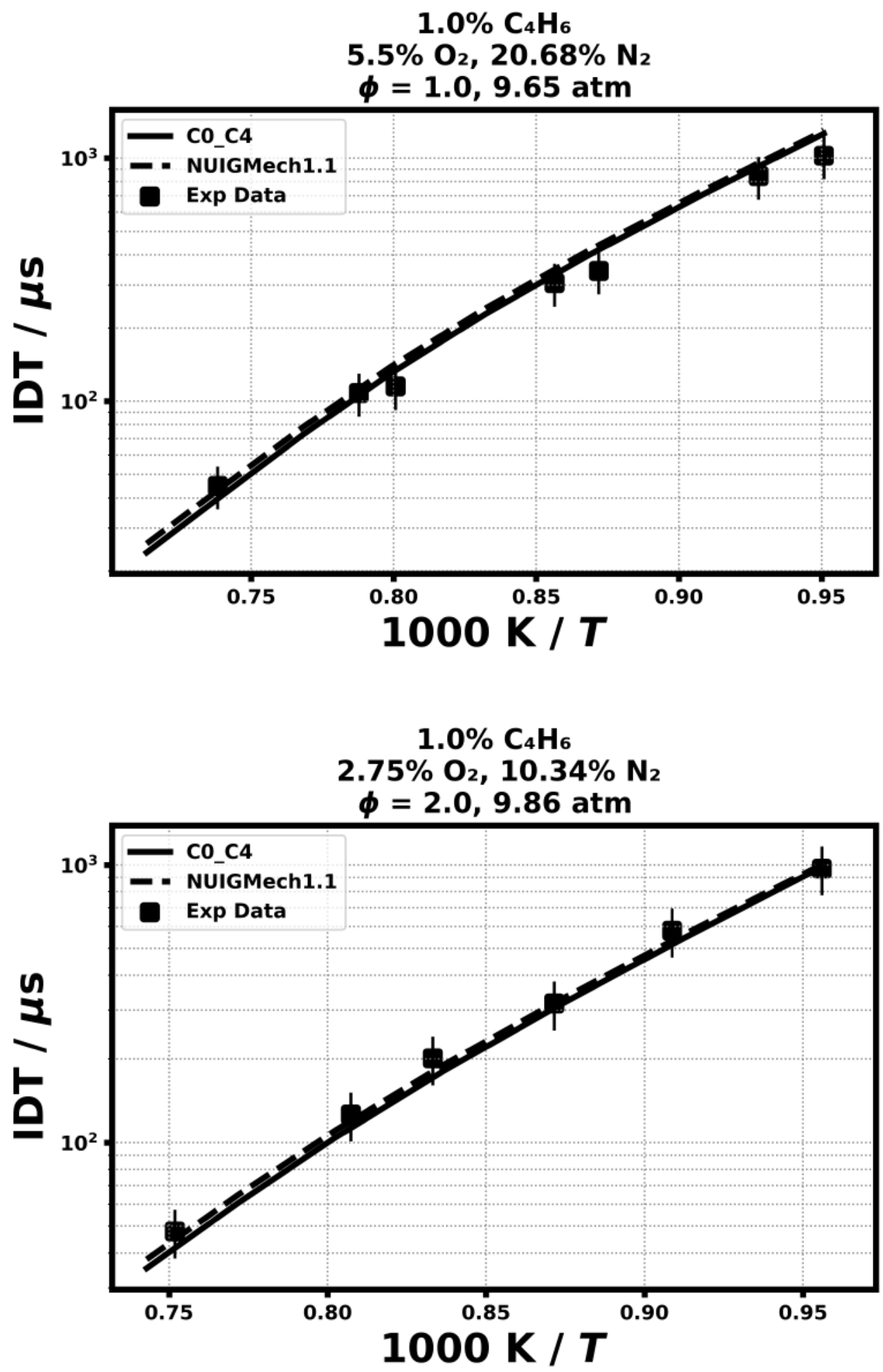

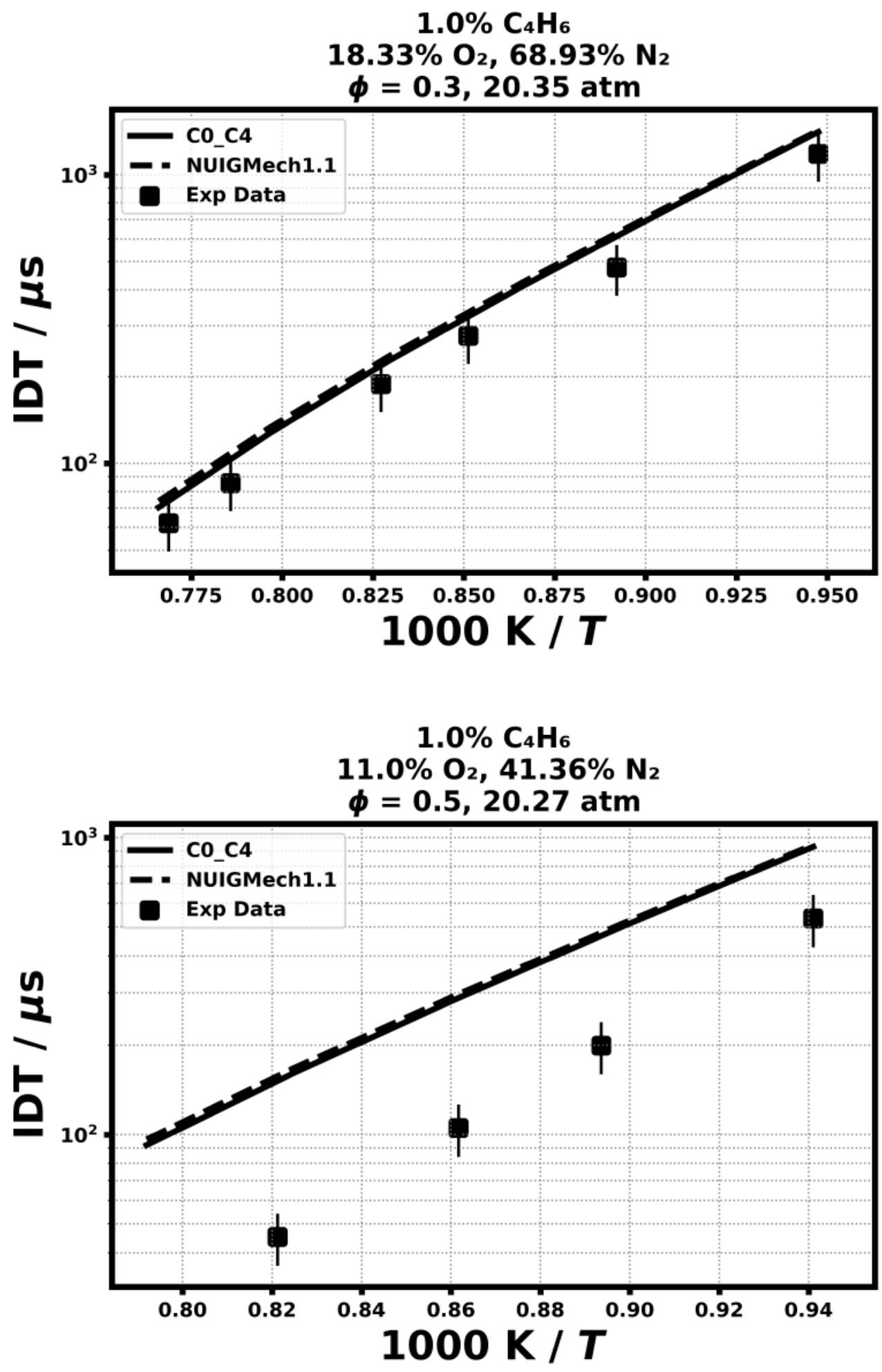

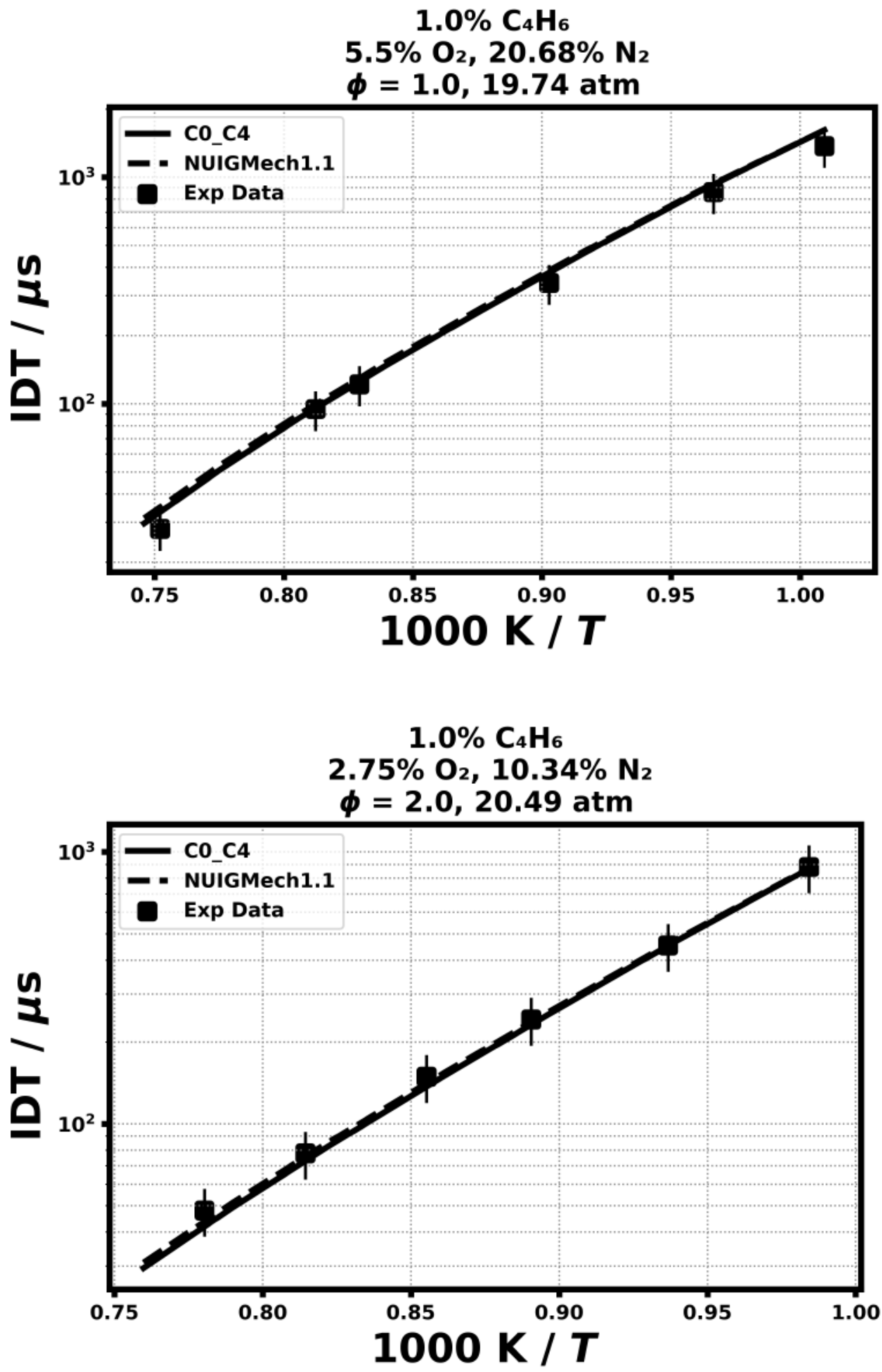

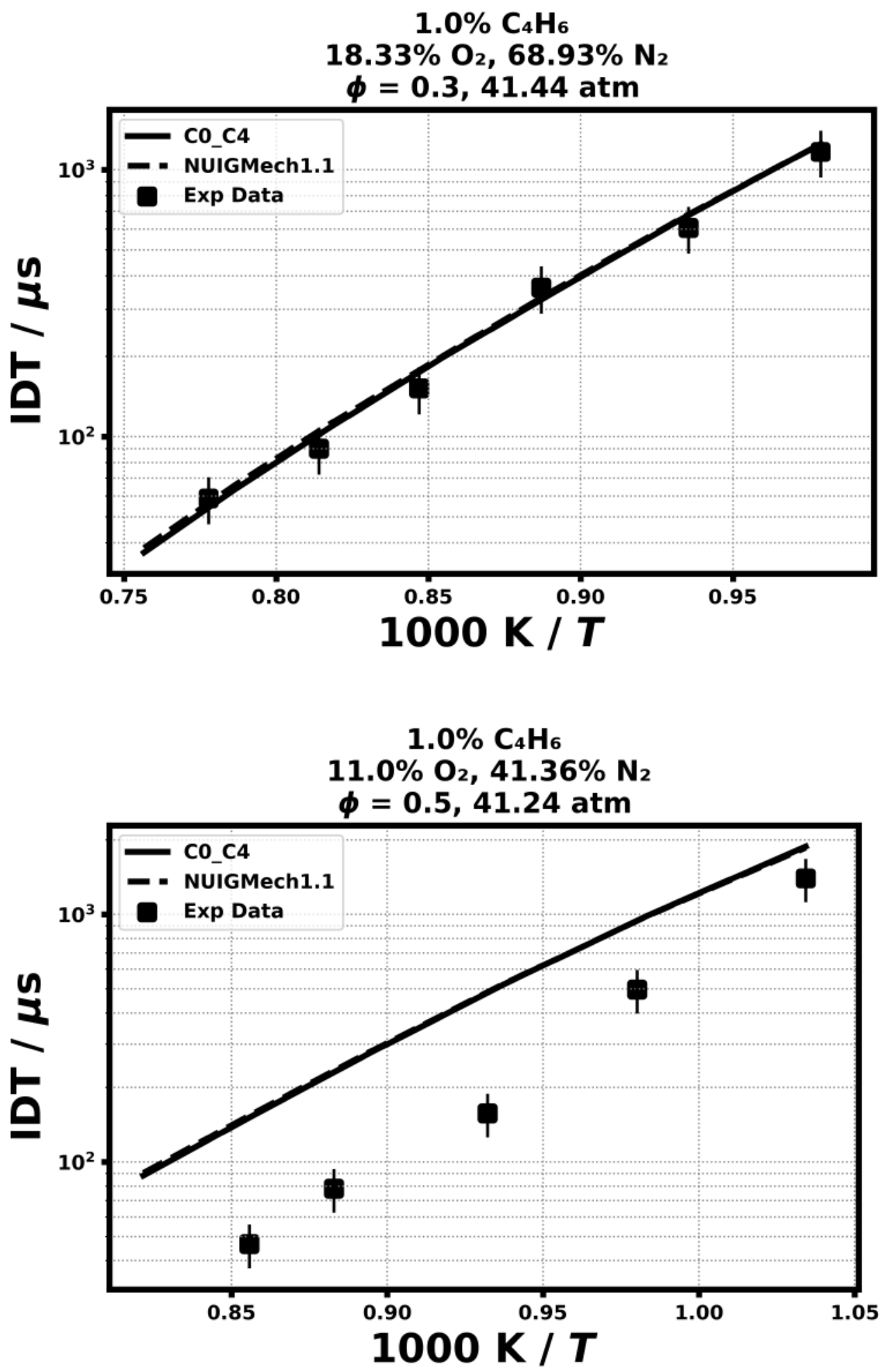

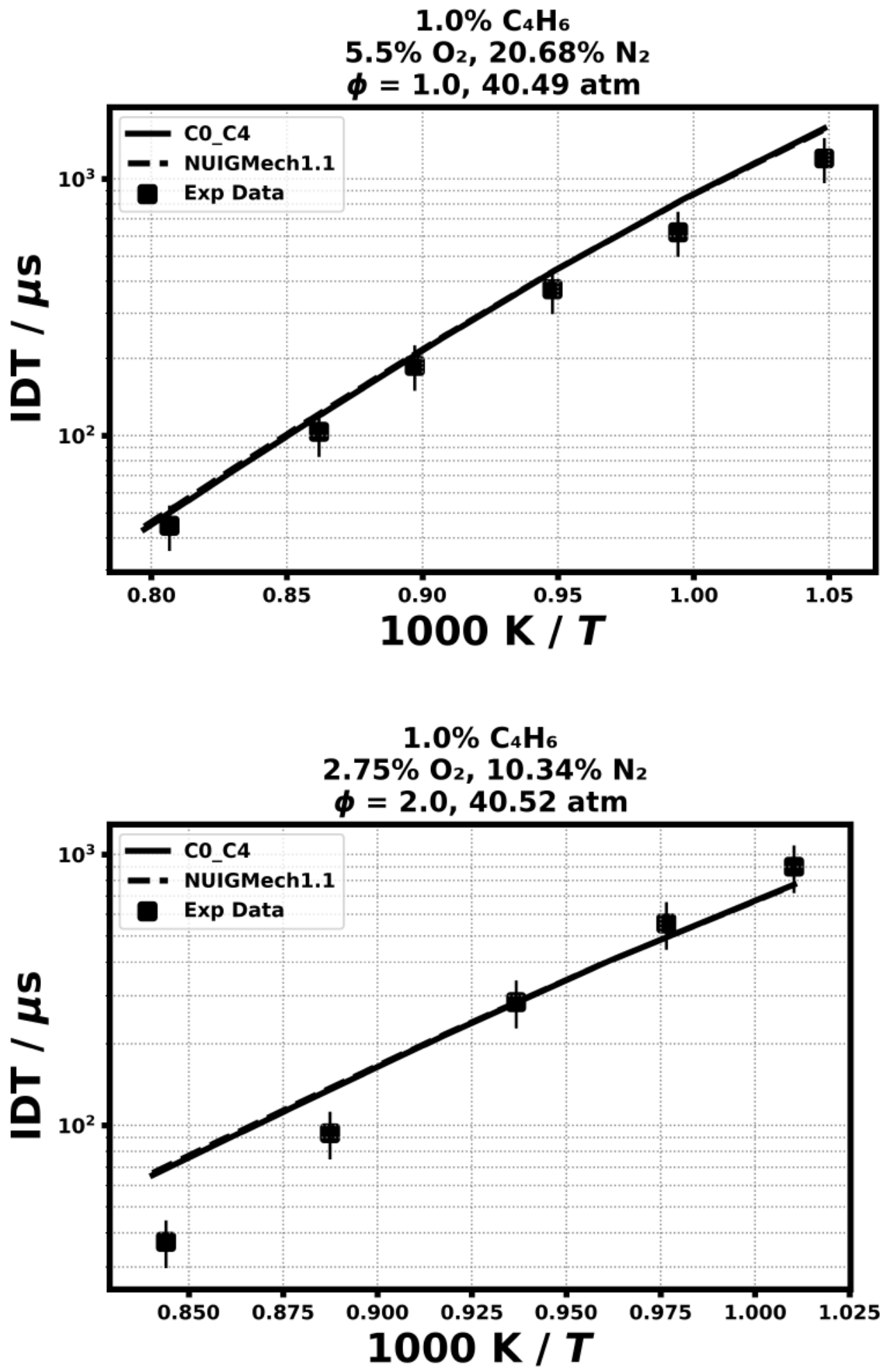

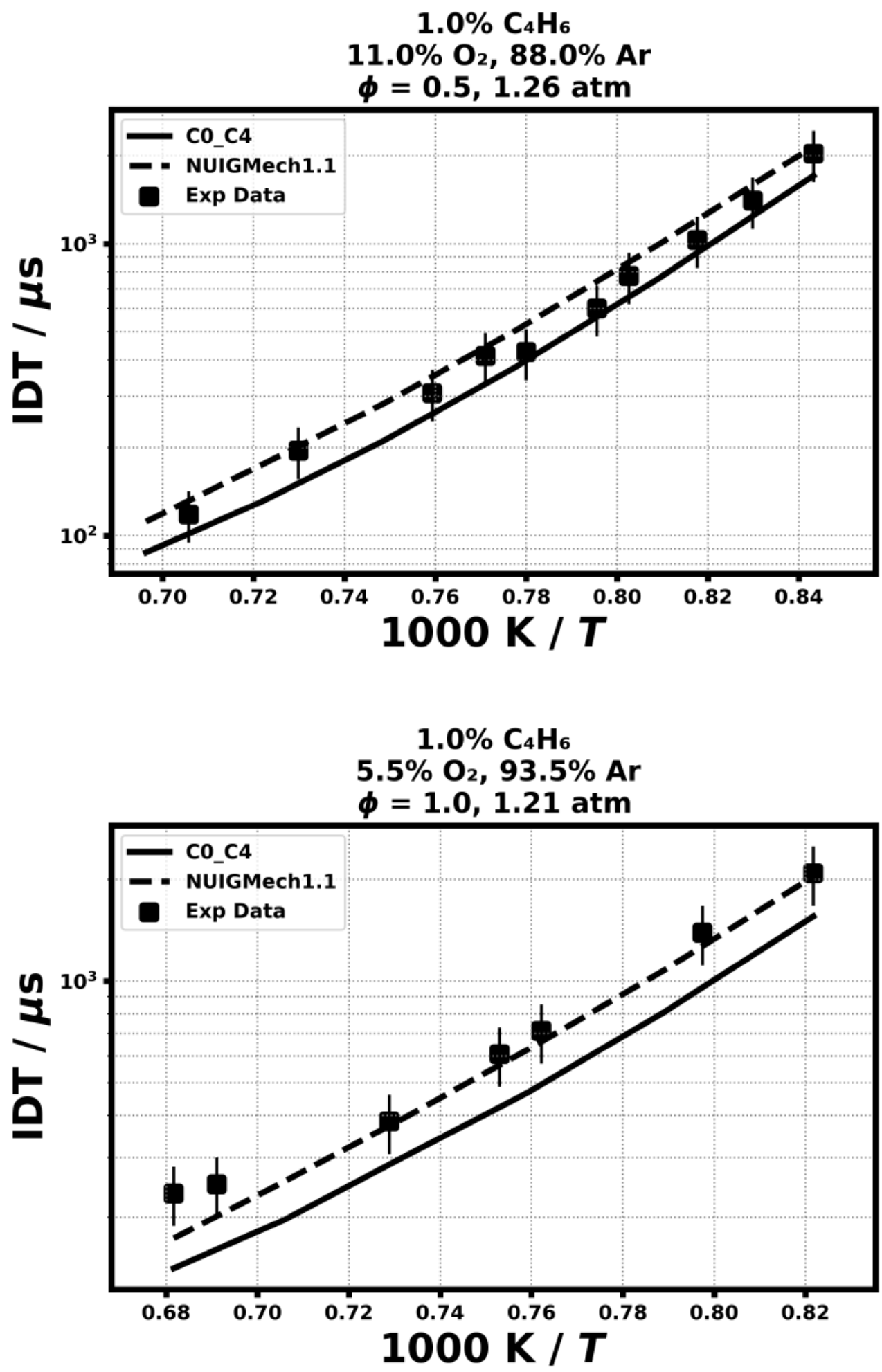

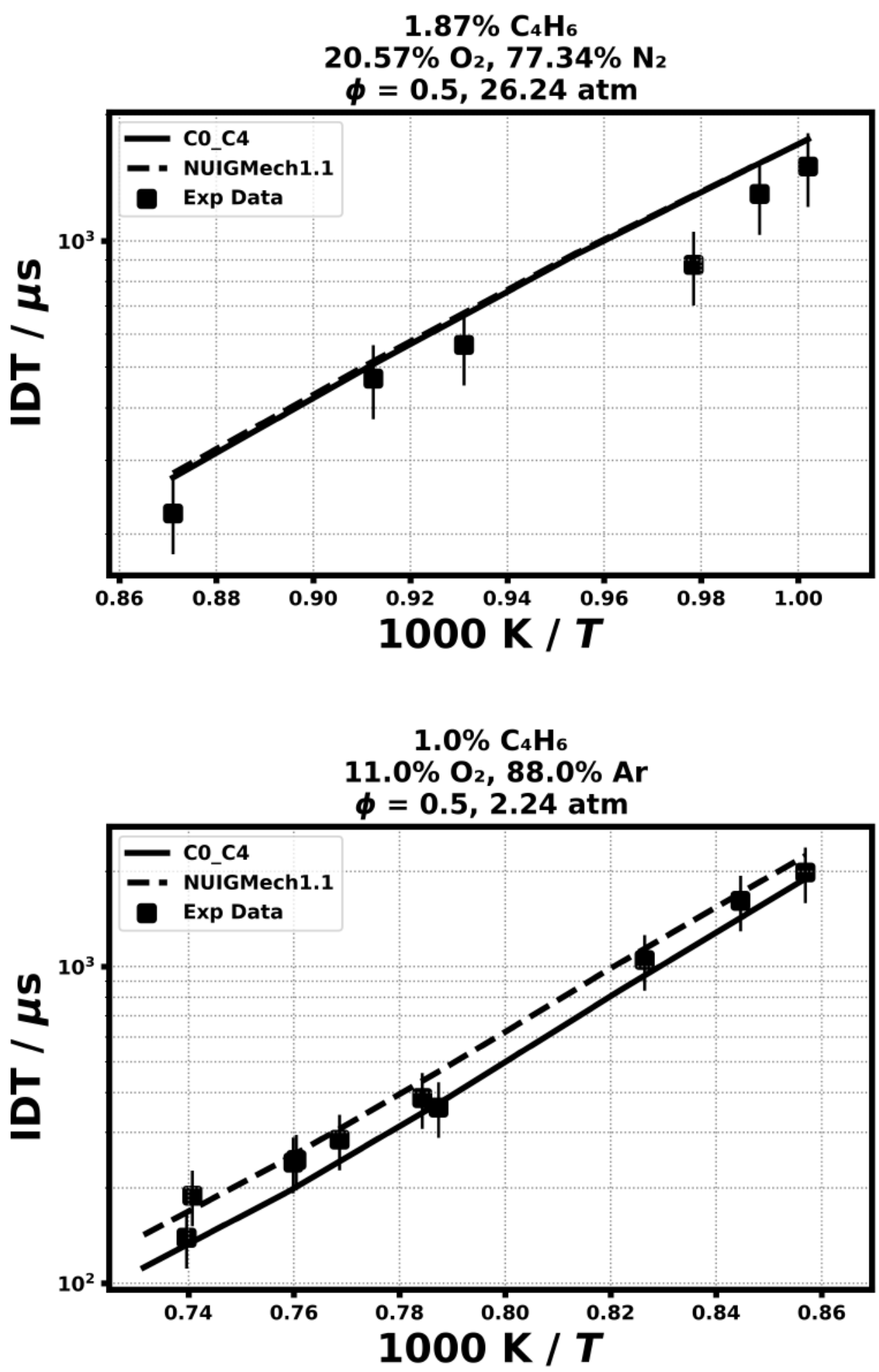

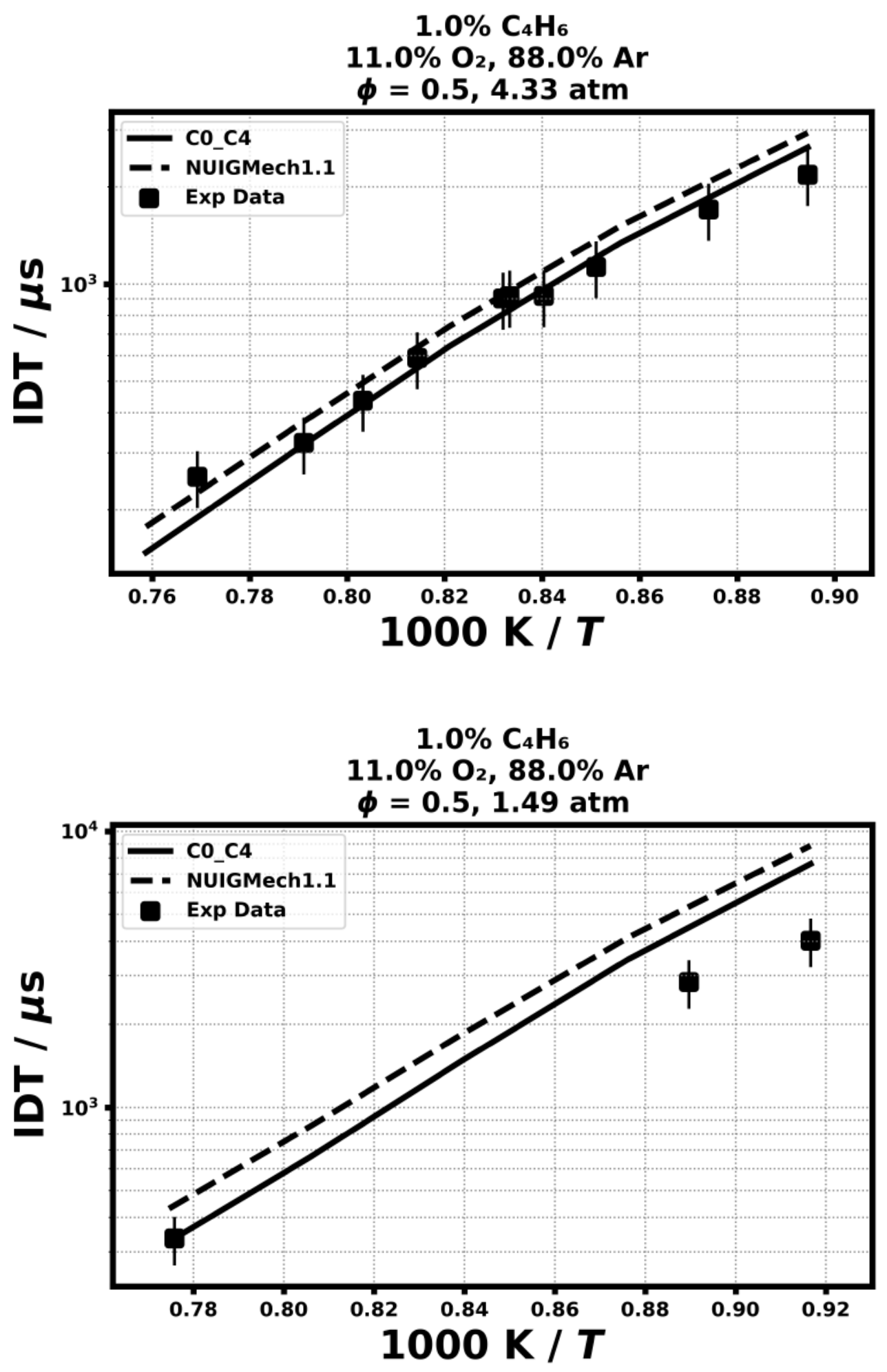

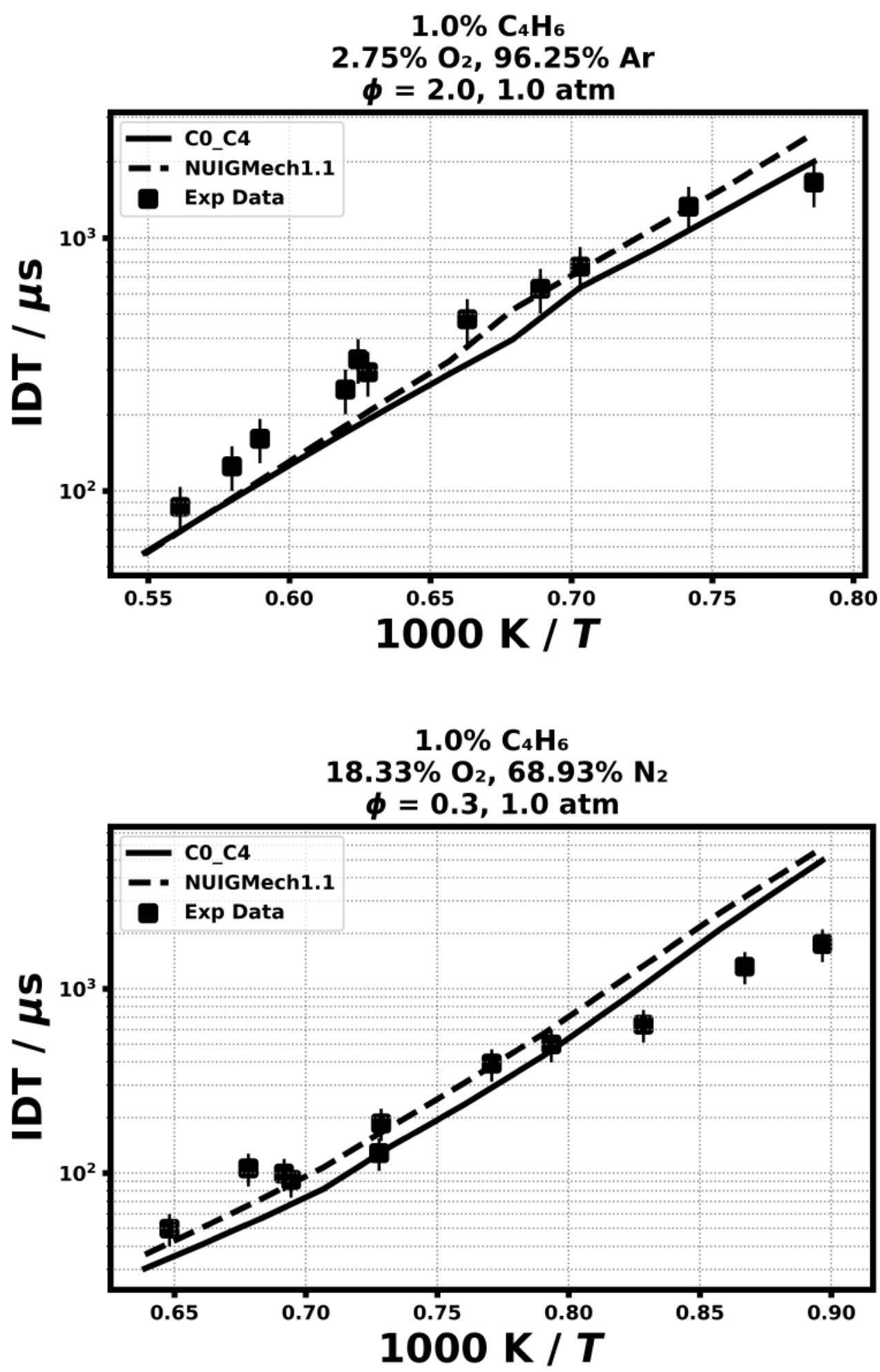

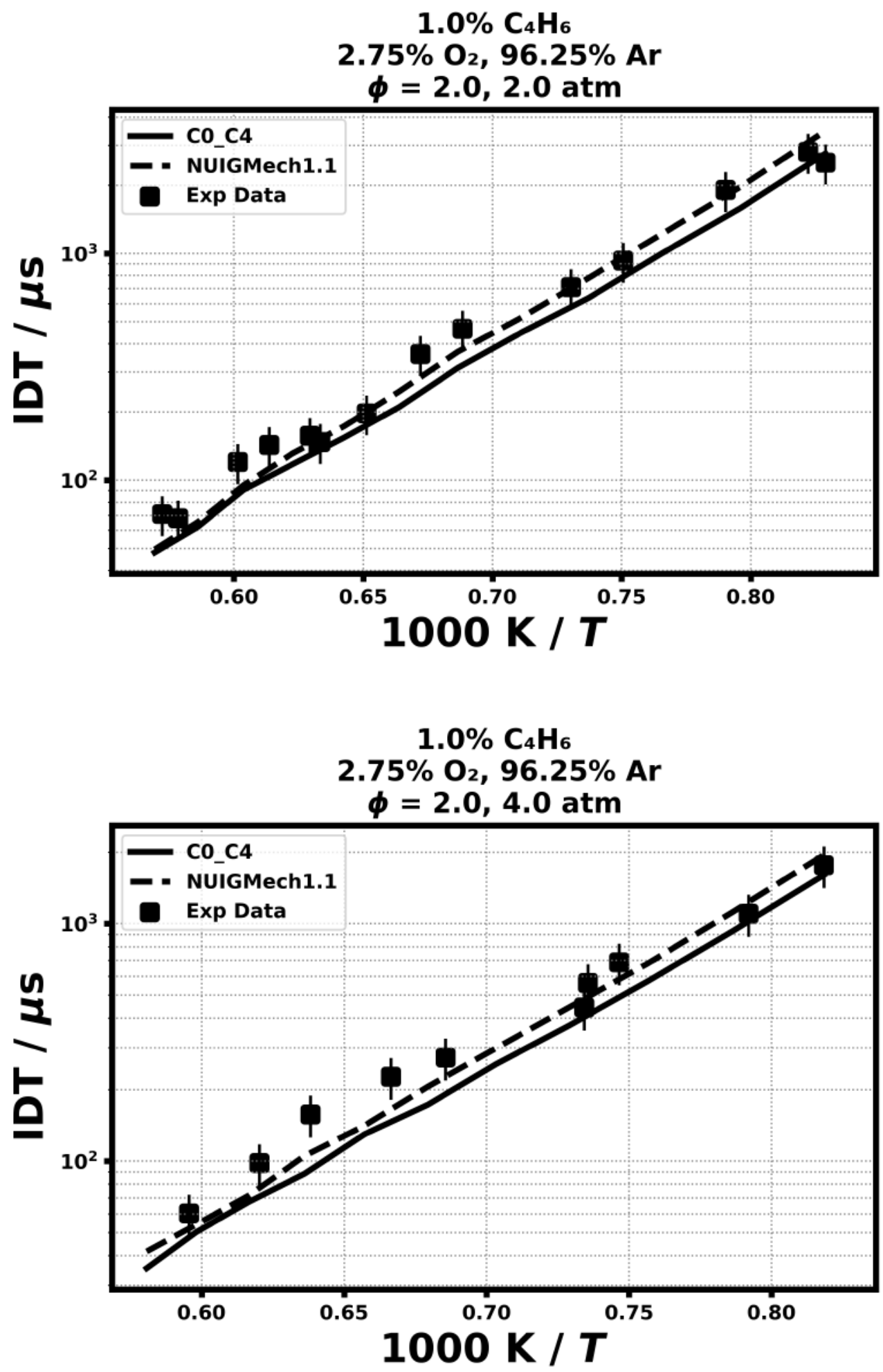


\section{Laminar flame speed}

14.2) Zhou, C. W., Li, Y., Burke, U., Banyon, C., Somers, K. P., Ding, S., ... \& Petersen, E. L., Combustion and Flame, 197 (2018) 423-438.

14.3) Davis, S. G., \& Law, C. K., Combustion science and technology, 140(1-6) (1998) 427-449.

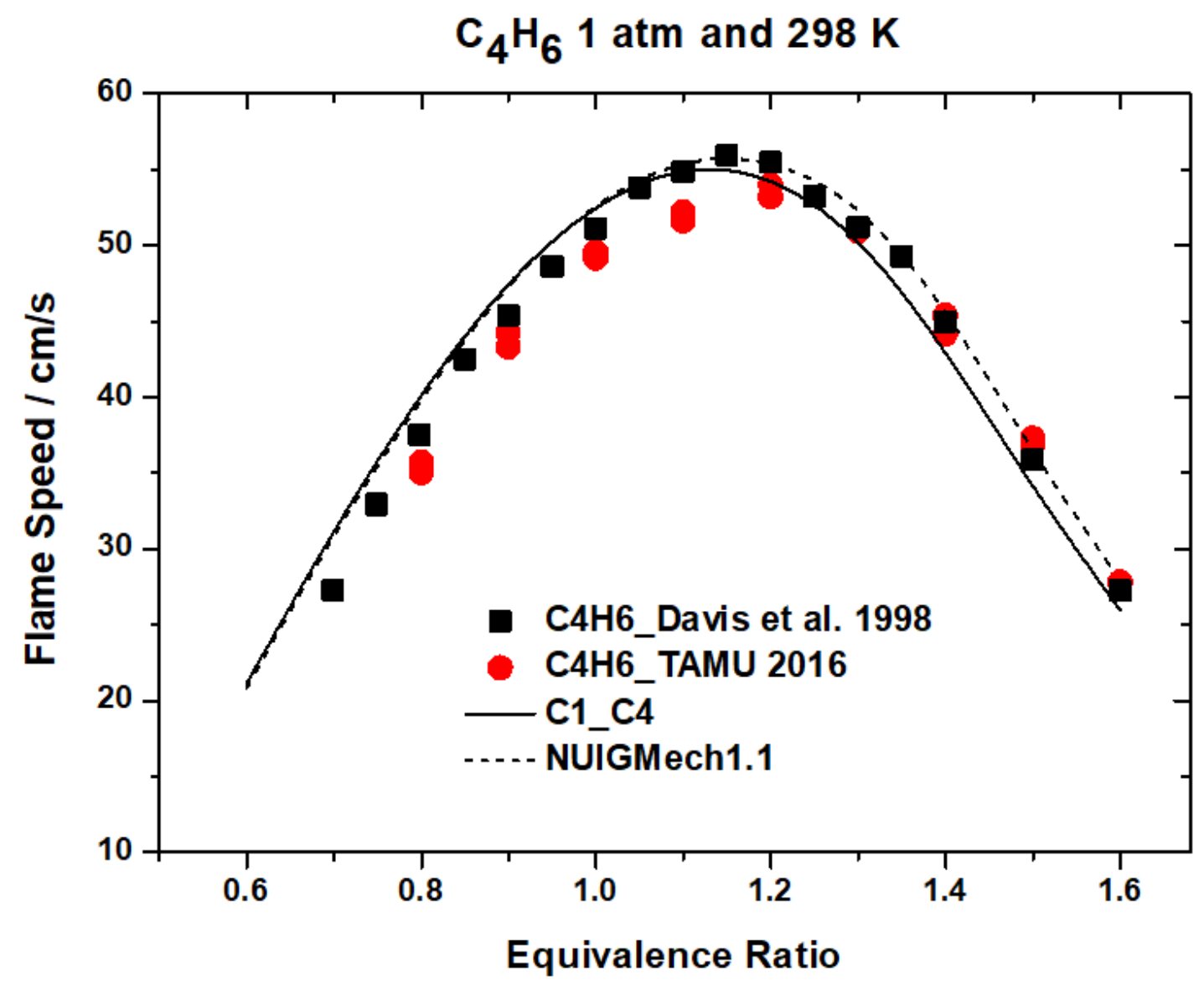

